Bettina Krönung

Gottes Werk und Teufels Wirken 


\section{Millennium-Studien}

zu Kultur und Geschichte des ersten Jahrtausends n. Chr.

\section{Millennium Studies}

in the culture and history of the first millennium C.E.

Herausgegeben von / Edited by

Wolfram Brandes, Alexander Demandt, Helmut Krasser, Hartmut Leppin, Peter von Möllendorff, Karla Pollmann

Band 45 


\title{
Gottes Werk und Teufels Wirken
}

\author{
Traum, Vision, Imagination in der \\ frühbyzantinischen monastischen Literatur
}

\author{
von \\ Bettina Krönung
}

De Gruyter 
Diese Publikation wurde im Rahmen des an der Bayerischen Staatsbibliothek durchgeführten und durch das Bundesministerium für Bildung und Forschung geförderten Vorhabens 16TOA021 - Reihentransformation für die Altertumswissenschaften („Millennium Studien“) mit Mitteln des DFG-geförderten Projekts Fachinformationsdienst Altertumswissenschaften - Propylaeum im Open Access bereitgestellt.

\section{(c) BY-NC-ND}

Dieses Werk ist lizenziert unter der Creative Commons Attribution-NonCommercial-NoDerivatives 4.0 International Lizenz. Weitere Informationen finden Sie unter http://creativecommons.org/licenses/by-nc-nd/4.0/.

Die Bedingungen der Creative-Commons-Lizenz gelten nur für Originalmaterial. Die Wiederverwenung von Material aus anderen Quellen (gekennzeichnet mit Quellenangabe) wie z.B. Schaubilder, Abbildungen, Fotos und Textauszüge erfordert ggf. weitere Nutzungsgenehmigungen durch den jeweiligen Rechteinhaber.

ISBN 978-3-11-033435-7

e-ISBN 978-3-11-033439-5

ISSN 1862-1139

Library of Congress Cataloging-in-Publication Data

A CIP catalog record for this book has been applied for at the Library of Congress.

\section{Bibliografische Information der Deutschen Nationalbibliothek}

Die Deutsche Nationalbibliothek verzeichnet diese Publikation in der Deutschen Nationalbibliografie; detaillierte bibliografische Daten sind im Internet über http://dnb.dnb.de abrufbar.

(C) 2014 Walter de Gruyter GmbH, Berlin/Boston

Druck: Hubert \& Co. GmbH \& Co. KG, Göttingen

@ Gedruckt auf säurefreiem Papier

Printed in Germany

www.degruyter.com 


\section{Vorwort}

Das vorliegende Buch ist eine überarbeitete Fassung der im Januar 2006 von der Philosophischen Fakultät der Friedrich-Schiller-Universität Jena unter dem Titel „Träume, Visionen und andere imaginäre Erfahrungen in der frühbyzantinischen monastischen Literatur" angenommenen Dissertation.

An erster Stelle bin ich allen Professorinnen und Professoren des Graduiertenkollegs „Leitbilder der Spätantike“ am Institut für Altertumswissenschaften in Jena für die Aufnahme als Doktorandin sowie der Deutschen Forschungsgemeinschaft und dem Freistaat Thüringen für die finanzielle Förderung durch ein dreijähriges Promotionsstipendium zu Dank verpflichtet. Mein ganz besonderer Dank gilt meinen Betreuern und Gutachtern, dem inzwischen verstorbenen Herrn Prof. Dr. Jürgen Dummer und Frau Univ. Doz. Dr. Carolina Cupane, die meine Arbeit stets mit großem Interesse, gutem Rat und Offenheit unterstützten und nicht müde wurden, mich in der langen Zeit, die seit dem Abschluss der Dissertation vergangen ist, zu ihrer Publikation zu ermuntern. Bedanken möchte ich mich auch bei allen Dozentinnen und Dozenten, Mitgliedern, Stipendiatinnen und Stipendiaten des Graduiertenkollegs, von deren Fachkenntnis, zahlreichen Anregungen und Kritik ich bei den wöchentlichen Sitzungen unter der Leitung von Herrn Prof. Dr. Meinolf Vielberg, aber auch darüber hinaus, viel profitieren konnte. Stellvertretend für alle Kollegiaten, die meine Arbeit in ihrer Entstehungszeit mit Interesse und Rat unterstützten, sei hier den ehemaligen Assistentinnen und Assistenten der Jenaer Altertumswissenschaften, Frau Prof. Dr. Claudia Sode und Herrn Prof. Dr. Christian Tornau, sowie den ehemaligen Promovendinnen und Promovenden, Dr. Götz Hartmann, Dr. Valentina Toneatto und Dr. Dagmar Hofmann, gedankt. Zu danken habe ich überdies meinen akademischen Lehrern in Wien, allen voran Prof. Dr. Johannes Koder und Prof. Dr. Ewald Kislinger, die mir bei meinen zahlreichen Aufenthalten am Institut für Byzantinistik und Neogräzistik in Wien das Arbeiten in ihrer Institutsbibliothek ermöglichten und das Fortkommen meiner Studien mit Interesse verfolgten und durch diverse Literaturhinweise bereicherten.

In den Jahren, die seit dem Abschluss meiner Dissertation vergangen sind, habe ich mehrere wissenschaftliche Stationen durchlaufen, die mich thematisch zwar eher vom Inhalt dieser Monographie weggeführt haben, die mir aber gleichzeitig einen wissenschaftlichen und finanziellen Rahmen ermöglicht haben, in dem ich die Drucklegung weiterverfolgen konnte. Zu bedanken habe ich mich diesbezüglich ganz besonders bei Prof. Dr. Ralph-Johannes Lilie und 
Prof. Dr. Alexander Beihammer, die mir die Mitarbeit an dem inzwischen abgeschlossenen Projekt Prosopographie der mittelbyzantinischen Zeit an der Berlin Brandenburgischen Akademie ermöglichten, sowie bei allen anderen Mitarbeiterinnen und Mitarbeitern der PmbZ, insbesondere bei Frau Beate Zielke, die mir unter anderem bei der Beschaffung von abgelegener Literatur behilflich war. Den entscheidenden finalen Ansporn zur Fertigstellung der vorliegenden Monographie verdanke ich schließlich Herrn Prof. Dr. Johannes Pahlitzsch, der mir in meiner Zeit als Mitarbeiterin am Arbeitsbereich Byzantinistik der Universität Mainz die Möglichkeit gewährte, trotz der vielfältigen sonstigen Aufgaben an seinem Lehrstuhl, Zeit für die Drucklegung aufzuwenden. Auch Prof. Dr. Günter Prinzing und allen anderen Mitarbeitern und Hilfskräften der Mainzer Byzantinistik danke ich für vielerlei Anregungen und für die kollegiale und herzliche Atmosphäre im Arbeitsbereich. Für die Aufnahme des Buches in die Reihe „Millenium Studies“ bedanke ich mich bei Herrn Prof. Dr. Wolfram Brandes.

Schließlich habe ich all jenen Menschen zu danken, die mich auf dem langen Entstehungsweg dieses Buches begleitet und unterstützt haben und sich während meiner Arbeitszeiten an der Drucklegung auf liebevolle Weise um das Wohlergehen meiner beiden Töchter gekümmert haben. Neben meinen Eltern und Schwiegereltern war dies vor allem mein Mann Thomas, der mich gerade auch in den besonders anstrengenden Phasen auf vielfältigste Weise unterstützt und aufgebaut hat.

Mainz, Januar 2014

Bettina Krönung 


\section{Inhalt}

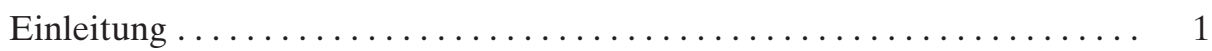

$\S 1$ Imaginäre Erfahrungen in der Spätantike ............... 1

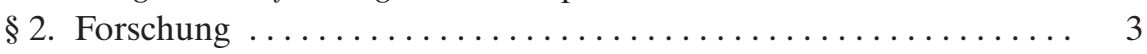

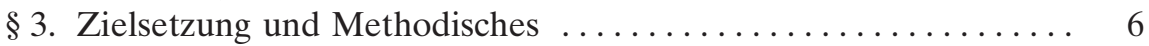

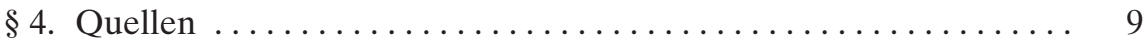

$\S 5$. Abkürzungen der verwendeten Quellen ............... 11

$\S 6$. Aufbau und Inhalt der Arbeit . . . . . . . . . . . . . . . . . . . . . . . 12

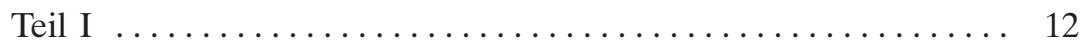

Teil II: Quellen ......................... 16

\section{Teil I}

1. Kapitel - Aspekte von imaginären Erfahrungen in der

frühbyzantinischen monastischen Literatur . . . . . . . . . . . . . . . . . . 19

1.1 Gesuchte und ungesuchte imaginäre Erfahrungen . . . . . . . . . . . 19

1.2 Gesuchte imaginäre Erfahrungen im asketischen Milieu . . . . . . 20

1.2.1 Das charismatische Privileg ............... 20

1.2.2 Schweigen oder Reden über imaginäre Erfahrungen? . . . . 21

1.2.3 Das bewusste Herbeiführen von imaginären Erfahrungen durch asketische Praktiken ................. 24

1.2.4 Irrwege zur imaginären Erfahrung . . . . . . . . . . . 27

1.3 Gesuchte imaginäre Erfahrungen bei „weltlichen Christen“ . . . . 30

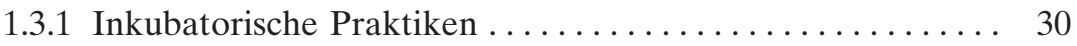

1.3.2 Entwicklung von der ortsgebundenen zur ortsungebundenen

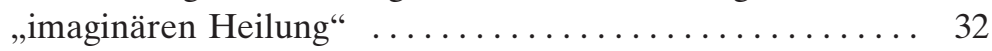

1.3.3 Weitere Typen von gesuchten imaginären Erfahrungen ... 35

1.3.4 Dreigliedrige hierarchische Abstufung im Kontakt mit dem Numinosen durch gesuchte imaginäre Erfahrungen ...... 36

1.4 Ungesuchte imaginäre Erfahrungen .................... . 39

1.5 Imaginäre Erfahrungen als Teil der spirituellen Biographie . . . . 41

2. Kapitel - Bewusstseinszustände und imaginäre Erfahrungen . . . . . . 44

2.1 Im Spannungsfeld zwischen sinnlicher Wahrnehmung und

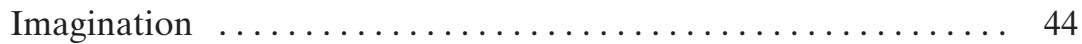

2.2 Bewusstseinszustände als Voraussetzung imaginärer Erfahrungen? 46

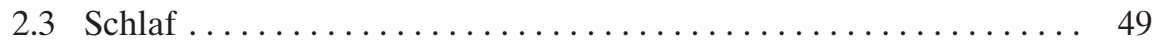

2.3.1 Schlaf und Traum ..................... 49 
A. Traum als Offenbarungsmedium $\ldots \ldots \ldots \ldots \ldots \ldots \ldots$. 49

B. Der nichtige Traum ..................... 51

C. Der gefährliche Traum - dämonische Machenschaft oder psychobiologischer Vorgang? .................. 53

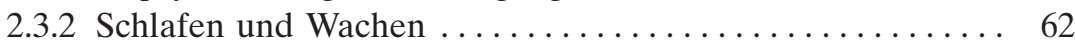

2.4 Religiöse Trance und imaginäre Erfahrungen ............ 70

2.4.1 Die mystische Ekstase ..................... 74

2.4.1.1 Physische und psychische Symptome der mystischen

Ekstase .......................... 78

2.4.2 Heilungsekstasen .......................... 85

2.4.3 Die dämonische Ekstase .................. 87

2.4.3.1 Von der Mondsucht zur Ekstase ............... 91

3. Kapitel - Terminologische und formale Aspekte der imaginären

Erfahrungen ................................... 95

3.1 „Sehen ist zuverlässiger als Hören“ . ................... 95

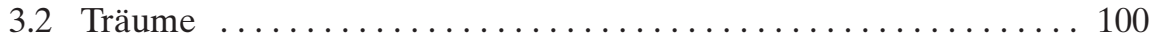

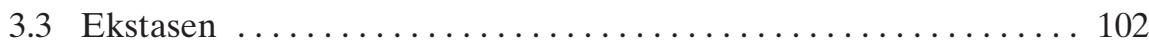

3.4 Gesichte und Stimmen ............................... 104

3.4.1 theoria und phantasia .......................... 105

3.4 .2 phone - Die Audition ............................ 106

3.5 Andere Imaginations-Begriffe . . . . . . . . . . . . . . . . . . . 107

3.6 Terminologische Tabellen ............................ 108

3.6.1 Traumbegriffe ............................. 108

3.6.2 Ekstase .................................... 109

3.6.3 Gesichte und Stimmen ....................... 110

4. Kapitel - Vom heidnischen Mantiker zum christlichen Charismatiker 114

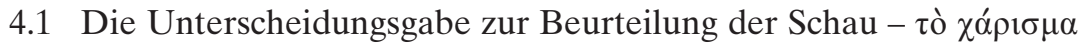

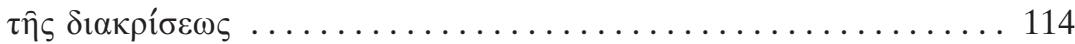

4.1.1 Die Unterscheidung zwischen wahr und trügerisch ...... 114

4.1.2 Von der Traumdeutung (òvıрокрібía) zur Unterscheidung

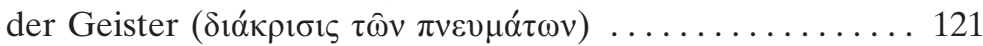

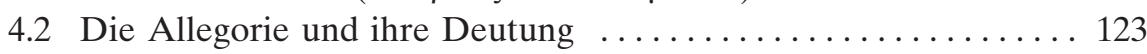

4.2.1 Allegorische Inhalte imaginärer Erfahrungen .......... 123

4.2.2 Literarische Aspekte der Allegorie ................ 127

4.2.3 Das richtige Deuten der Allegorie als Zeichen charismatischer Autorität ................... 130

4.3 Die Schau in die Zukunft durch die Prophetengabe ......... 131

4.3.1 Das Vorgehen des christlichen Charismatikers gegen mantische Praktiken, Zauberer und Magier ........... 131

4.3.2 Die Prophezeiungen des christlichen Charismatikers ...... 140

4.3.3 Der christliche Charismatiker als Traumdeuter .......... 143 
4.4 Das Sichtbarwerden des Unsichtbaren - Die Gabe der Klarsicht 147

5. Schlussbetrachtung

\section{Teil II - Quellen}

A. Allgemeines über imaginäre Erfahrungen ................... 157

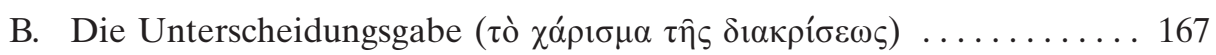

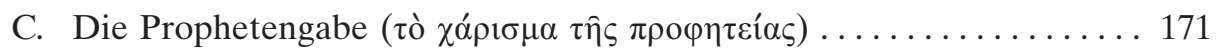

D. Die Gabe der Klarsicht (

E. Inspirations- und Berufungsoffenbarungen sowie Ermutigung zu

Glaube und Askese .............................. 203

F. Mysterienerscheinungen (bei der Eucharistie) ............. 216

G. Gnaden- und Lichterscheinungen ..................... 220

H. Jenseitsoffenbarungen ........................... 223

1. Todesvisionen und Seelenwanderungen ................ 223

2. Weitere Informationen über Himmel, Hölle, Paradies und das göttliche Gericht ............................ 237

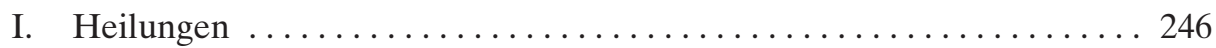

1. Dämonenaustreibungen und Heilung von unreinen Gedanken

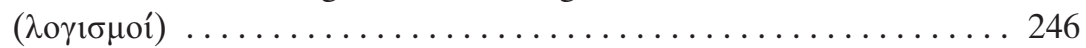

2. Andere Heilungen ............................ 257

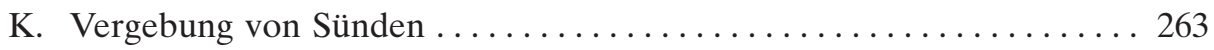

L. Geburtsankündigungen .......................... 267

M. Rettung in Notsituationen .......................... 271

N. Wegweisungen und Reiseanordnungen ................... 277

O. Befehle und Anordnungen ........................... 283

P. Befehle zur Gründung und Errichtung von Kirchen und Klöstern .... 288

Q. Dogmatische, exegetische und ethische Belehrungen ............ 293

R. Zurechtweisungen, Strafandrohungen und Bestrafungen ........ 304

S. Dämonenanschläge ................................... 319

Siglen und allgemeine Abkürzungen ....................... 337 
Quellen und Literaturverzeichnis $\ldots \ldots \ldots \ldots \ldots \ldots \ldots \ldots \ldots \ldots \ldots \ldots \ldots$

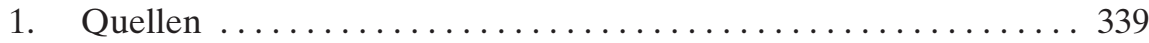

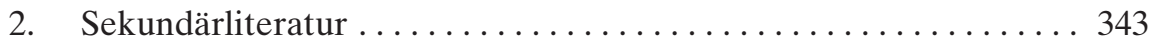

Namens- und Ortsindex .......................... 355

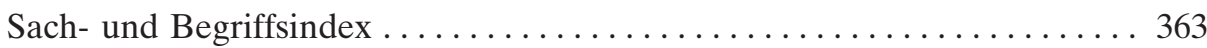

Index der Motive imaginärer Erfahrungen .................. 380

Bibelstellenindex ............................... 389 


\section{Einleitung}

\section{§1. Imaginäre Erfahrungen in der Spätantike}

In einer Epoche wie der Spätantike, die von einem tiefgreifenden religiösen Enthusiasmus bewegt eine Vielzahl alter und neuer Formen von Glaubensausrichtungen aufleben lässt, werden Visionen und Träumen für diverse Bereiche des menschlichen Wirkens eine wichtige und ernst zu nehmende Bedeutung beigemessen. Imaginäre Erfahrungen im weitesten Sinne prägen eine für die Spätantike charakteristische geistige Stimmung, welche von der Überzeugung getragen wird, dass mittels Imagination die Perzeption transzendenter Inhalte möglich ist. Die zugrundeliegende Idee, dass Imagination über die Einbildung und das bloße Abbild des Materiellen hinausgeht, um durch das geistige Sehen physisch wahrnehmbare Welt und numinose Kräfte zu einer Unität im Bild verschmelzen zu lassen, begegnet als weitverbreitete, religionsübergreifende Haltung. Ungeachtet dessen, dass sich die Erklärungen über das Zustandekommen von Imagination, im Folgenden als ,geistige Visualisierung transzendenter Inhalte" verstanden ${ }^{1}$, in ihren philosophischen, theologischen und terminologischen Prämissen keineswegs als einheitlich erweisen ${ }^{2}$, zieht sich die

1 Imagination wird im Folgenden also nicht in der ursprünglichen Bedeutung des lateinischen Begriffes „,imaginatio“ als „(bloße) Einbildung“ oder „Scheinbild“, sondern in einem umfassenderen Sinne für die geistige Visualisierung transzendenter Inhalte verstanden. Die akustische Wahrnehmung transzendenter Inhalte, welche häufig in enger Verbindung mit der Visualisierung auftritt, wird im Folgenden als Teilaspekt der Imagination behandelt (s. S. 95-100, 106 f.). Zur Bedeutungsgeschichte des Begriffes Imagination vgl. MAinberger, Art. Imagination 25-43.

2 Im Griechischen verwenden die spätantiken Autoren für die hier als Imagination bezeichnete Idee häufig den Begriff phantasia, so z.B. Philon, De Abrahamo 15,19-21; $24-25 ; 71,4$, Bd. 4, p. 18,16-19,2; 27,15-30,13, oder Apollonios von Tyana (im Gegensatz zu mimesis) (s.u. A. 3). In anderen Fällen wiederum bezeichnet phantasia bloß die Schaffung bedeutungsloser, nichtiger Bilder; so z. B. Plotin, Enn. I 1, 9,8, Bd.1, p. 57,6-10, wo im Gegensatz zu phantasia („die Wahrnehmung der trügerischen Dinge“) der nous (Verstand) die Wahrnehmung des Numinosen ermöglicht, während in den im Folgenden behandelten monastischen Texten phantasia in der Regel nicht mehr für einen Vorgang der Verbildlichung, sondern als deren (negatives) Wahrnehmungsobjekt, das Trugbild, verwendet wird (s. S. 105 f. u. S. 114-120). Im Folgenden wird der Begriff Imagination jedoch nicht als Äquivalent eines bestimmten griechischen Terminus verwendet, der ja für jeden Kontext eigens erklärt werden müsste, sondern im weiteren Sinne in der oben erläuterten Bedeutung als „,visuelles Wahrnehmen transzendenter Inhalte“. Über die verschiedenen spätantiken Erklärungen bzgl. des Zustandekommens 
genannte Idee als realitätskonstituierende Kraft wie ein Leitfaden durch die verschiedenen geistigen Strömungen der spätantiken Welt. Sie ist gleichzeitig Grundkonstituente und elementarer Bestandteil einer Imaginationsspiritualität, welche für den jüdisch-hellenistischen und den spätantik heidnischen Bereich ebenso charakteristisch ist wie für das sich daraus entwickelnde Christentum in seinen unterschiedlichen Schattierungen und schließlich für ihren „materialisierten" Ausdruck in der Bildwelt der byzantinischen Ikonographie ${ }^{3}$. Auch in den im folgenden behandelten Texten aus dem Bereich der frühbyzantinischen monastischen Literatur wird der Akt der Verbildlichung transzendenter Inhalte unermüdlich thematisiert, zuweilen theoretisch, in den meisten Fällen aber anhand von literarisch ausgeschmückten Exempla über Menschen, die mittels Imagination, gewollt oder auch nicht, in Kontakt mit transzendenten Kräften treten. Da sich die geschilderten Imaginationserlebnisse keineswegs auf bestimmte Formen der Wahrnehmung beschränken, wird im Folgenden der Sammelbegriff imaginäre Erfahrungen für alle Möglichkeiten der geistigen Visualisierung wie Traum, Vision, Ekstase oder Erscheinung im Wachzustand etc. verwendet ${ }^{4}$.

von Imagination vgl. Dronke Imagination, 3-24; Cox Miller, Dreams in Late Antiquity $39-73$.

3 Für den jüdisch-hellenistischen Bereich denke man an Philons Interpretation der Engel als göttliche Wörter, ,welche die menschliche Seele emporheben, um sie vom Sterblichen zu trennen und ihr den Anblick des allein Sehenswerten zu zeigen, wenn sie auf der himmlischen Leiter emporwandeln“, Philon, De somniis I 23,5-7, Bd. 3, p.

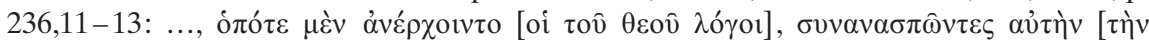

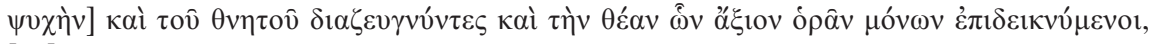
[...]. Dazu Cox Miller, Dreams in Late Antiquity 61. Für den paganen Kontext sei hier das Beispiel des heidnischen Helden Apollonios angeführt, welcher vor dem Ägypter Thespesion die Schaffung von griechischen Götterstatuen mit den Worten erklärt „Imagination ... brachte diese Werke hervor - ein weiserer Schöpfer als Imitation. Imitation schafft, was sie sieht, aber Imagination schafft, was sie nicht sieht, und sie

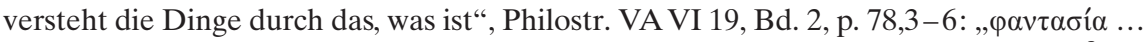

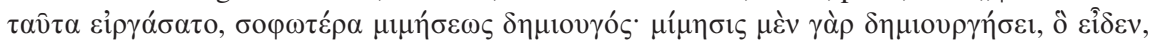

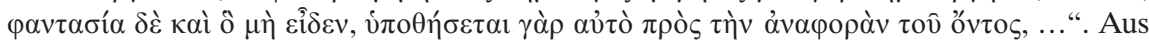
dem christlichen Bereich sei hier exemplarisch Dionysios Aeropagites angeführt, in dessen mystischer Theologie die Imagination den Aufstieg hin zur Schau des Göttlichen erst ermöglicht: „Das menschenfreundliche Prinzip ... hat durch sinnliche Bilder die über die Himmel hinausgehenden Gedanken beschrieben ..., sodass wir durch das Sinnliche zum Geistigen aufsteigen und durch Symbole, die das Heilige schaffen, in die leichten Höhen der himmlischen Hierarchien geführt werden",

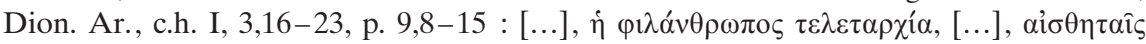

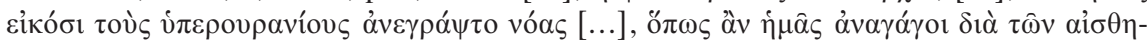

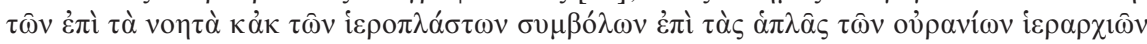

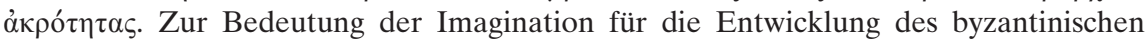
Heiligenbildes s. S. 32-35.

$4 \mathrm{Zu}$ Bedeutung und Terminologie der unterschiedlichen Formen der Imagination s. S. 95-107. 


\section{$\S 2$. Forschung}

Dass trotz der Masse an Schilderungen von imaginären Erfahrungen in den behandelten Texten dem Thema bisher keine umfassende Studie gewidmet wurde, mag zum einen darauf zurückzuführen sein, dass verschiedene Bereiche der Altertumswissenschaften des vergangenen Jahrhunderts von einer dezidiert negativen Haltung gegenüber imaginären Erfahrungen, insbesondere dem Traum und seiner Deutung, als historisch irrelevanten und nicht ernst zu nehmenden Phänomenen geprägt waren. Äußerungen wie „Die antike Traumdeutung ist trotz ihrer wissenschaftlichen Aspirationen nicht viel mehr als ein Gemisch von Fatalismus, Aberglauben und Schmutz" geben den ablehnenden Grundtenor wieder, der einen Teil der wissenschaftlichen Beschäftigung mit der Thematik lange dominierte ${ }^{5}$. Gleichzeitig gab es eine starke Tendenz zur psychopathologischen Deutung, insbesondere im Hinblick auf die Beurteilung von Visionserfahrungen, nicht nur, aber auch in vormodernen Kulturen und Literaturen. So wurden von der ab der Mitte des 19. Jh. aufkommenden Psychopathologie bis etwa in die Mitte des 20. Jh. religiöse Trancezustände als rein psychopathologisches Phänomen betrachtet ${ }^{6}$. Eine solche, jegliche religionsund kulturgeschichtlichen Bedingungen der genannten Phänomene außer Acht lassende Herangehensweise darf aber spätestens seit Arbman, der in seinen wegweisenden Werken erstmals die aus heutiger Sicht evidenten Unterschiede zwischen psychisch bedingten Halluzinationserlebnissen und religiösen Visionserfahrungen formulierte, als überholt bezeichnet werden ${ }^{7}$. Seither beschäftigten sich zahlreiche Arbeiten mit der religiösen Trance in außereuropäischen Traditionen wie dem Schamanismus oder dem Sufismus ${ }^{8}$. Gleichzeitig wurde in

5 OepKe, Art. ővap 228; zur negativen wissenschaftlichen Bewertung des Traumglaubens in der Antike s. Frenschrowski, Traum und Traumdeutung 43, und Krovoza, Die Stellung Freuds zur Vorgeschichte 223. 227, und speziell in der Byzantnistik s. CALOFonos, Dream Interpretation: A Byzantinist Superstition? 215-217, sowie Tiмoтin, Visions 16, A. 11; eine anschauliche Präsentation der Differenzen zwischen Mittelalter und Neuzeit als Ursache für eine negative Bewertung imaginärer Phänomene aus heutiger Sicht bietet Dinzelbacher, Mittelalterliche Visionsliteratur 5.

6 S. dazu Arbman, Ecstasy or religious trance I 148 f.; Benz, Die Vision 208; DinzelBACHER, Körperliche und seelische Vorbedingungen 70.

7 So fehlt etwa der durch psychische Krankheiten wie Schizophrenie oder Paranoia ausgelösten Halluzination jeglicher suggestive oder reflektive Charakter, was für das religiöse Visionserlebnis dagegen charakteristisch ist; eine ausführliche Diskussion über die Differenzen zwischen pathologischen Halluzinationszuständen und religiösen Visionen bei Arbman, Ecstasy or religious trance I 145-215, vgl. auch BenZ, Die Vision 17; Dinzelbacher, Körperliche und seelische Vorbedingungen 71 und Dodds, Pagan and Christian 69.

8 S. Kelsey, Trance 1-189; Frenschkowski, Art. Traum 28-33 (nützliche Zusammenfassung mit weiterführender Literatur); Schimmel, Mystische Dimensionen 1-620; 
einer Vielzahl von Studien die wiederentdeckte religiöse Dimension von Träumen und visionären Phänomenen, v.a. in der Tradition der katholischen, weitgehend Augustinus verpflichteten Mystik des westlichen Mittelalters, untersucht ${ }^{9}$. Aber auch diverse Richtungen der Altertumswissenschaften haben sich seither der Thematik in Antike und Spätantike von kultur-, literatur-, philosophie- und religionsgeschichtlicher Seite angenähert ${ }^{10}$. Was die Thematik in Byzanz angeht, so sind mittlerweile insbesondere die byzantinischen Traumhandbücher sowie die apokalyptische Literatur, sowohl im Hinblick auf ihre Quellenerschließung als auch auf ihre Einordnung in einen weiteren kulturund mentalitätsgeschichtlichen Rahmen, erforscht worden ${ }^{11}$. Zwar sind auch die

Dies., Sufismus 11-35; Goodman, Die andere Wirklichkeit 85-191; Welte, Art. Trance 521-525; SEPpäLÄ, In speechless Ecstasy 1-341.

9 Als Pionierarbeit ist hier v. a. die umfangreiche Monographie von Benz, Vision 7-655, $\mathrm{zu}$ nennen. In der aktuellen Forschung hat sich insbesondere Peter Dinzelbacher in zahlreichen Studien mit der Visionsliteratur im westlichen Mittelalter beschäftigt: Dinzelbacher, Die Jenseitsbrücke im Mittelalter 1-258; Ders., Vision und Visionsliteratur im Mittelalter 1-288; Ders., Körperliche und seelische Vorbedingungen 57-86; DERS., Moderne Sterbeforschung und mittelalterliche Visionsliteratur 9-49; Ders., Mittelalterliche Visionsliteratur 1-227; Ders., Revelationes 1-108; Ders., Nova visionaria et eschatologia 45-84; Ders., Himmel, Hölle, Heilige 1-175. Siehe auch S. 47 A. 192 u. 193.

10 Die Grundlage für eine differenziertere Auseinandersetzung mit der Thematik schuf v.a. DodDs, The Greeks and the Irrational, v.a. 102-134, und DodDs, Pagan and Christian 1-144, welcher auch die neuere Forschung weitgehend prägte (s. auch S. 7 A. 21). Eines der wichtigsten Standardwerke für jede Beschäftigung mit Visionen als religionsgeschichtliches Phänomen ist nach wie vor BENZ, Vision 7-655. Wegweisend für die Auseinandersetzung mit imaginären Erfahrungen, insbes. mit Träumen, in der Spätantike ist Cox Miller, Dreams in Late Antiquity 9-270; DIES., The poetry of thought 1-11. Zum Vorkommen aller Arten von imaginären Erfahrungen in den unterschiedlichen Teilbereichen der narrativen Literatur in der Spätantike s. S. 124 A. 613. $\mathrm{Zu}$ Träumen und Visionen in der hellenistischen, neutestamentlichen und apokryphen Literatur s. in der Bibliographie alle Werke von Klaus Berger, v.a. aber Berger, Visionsberichte 177-233, überdies FrenschKowsKI, Traum und Traumdeutung 5-47; Ders., Art. Traum 28-50. Zur Bedeutung von Vision und Ekstase bei Plotin und im Neuplatonismus allg. s. S. 76 A. 345. Zum Zusammenhang von Traum und Kaisertum in Hellenismus, Prinzipat und Spätantike s. Weber, Herrscher 1-33; Ders., Kaiser, Träume 2-585; Ders., Träume 89-109. Zu Traum und Traumdeutung in der Antike s. Hanson, Dreams and Visions 1395-1427; Walde, Antike Traumdeutung 1-233 (mit weiterführender Bibliographie); Dies., Traumdarstellungen 1-487; Dies., Traum und Traumdeutung 65-90; NÄF, Traum und Traumdeutung 5-236 (mit umfangreicher Literatur und nützlicher Zusammenfassung der Forschungsgeschichte auf den Seiten 12 $14)$.

11 Zu den Traumhandbüchern: Bravo García, Interpretación 63-82; Calofonos, Dream Interpretation 215-220; Oberhelman, Oneirocriticon 1-314; Ders., Dreambooks 1237; Mavroudi, A Byzantine Book on Dream Interpretation 1-119; siehe auch S. 146 A. 714 u. 715 . Zur Apokalyptik: PodKalsky, Byzantinische Reichseschatologie 1103; Abrahamse, Introduction 1-9; Alexander, Apocalyptic Tradition 13-225; 
theoretischen Werke der mystischen Theologen der ersten byzantinischen Jahrhunderte verschiedentlich mit Blick auf die Bedeutung von Vision und Gottesschau behandelt worden ${ }^{12}$, die hier zur Diskussion stehenden Quellen der monastischen Literatur wurden aber bzgl. des Themas als literatur- und kulturgeschichtliches Phänomen noch kaum systematisch untersucht ${ }^{13}$. Gleichwohl ist gerade in den letzten Jahren ein verstärktes Interesse an der Thematik zu beobachten, was u.a. an der Veranstaltung einer internationalen Tagung zu Träumen und Visionen in Byzanz durch das Institute of Byzantine Research of the National Hellenic Research Foundation (NHRF) deutlich wird ${ }^{14}$. Von den neueren und neuesten Publikationen ist insbesondere ein Aufsatz von S. Rubenson zu erwähnen, der sich mit dem Stellenwert von Himmelsreisen in den Briefen des Ammonas und des Antonios beschäftigt und gerade auch für die vorliegende Studie zusätzliche interessante Erkenntnisse liefert ${ }^{15}$. Auch S. Timotins neue Monographie über den Zusammenhang von Visionen, Prophezeiungen und Macht in Byzanz enthält, trotz ihrer Fokussierung auf die mittelbyzantinische Hagiographie, einige Beobachtungen, die für den hier behandelten Gegenstand von Interesse sind ${ }^{16}$.

Magdalino, History of the Future 3-34; Ders., Prophétie inédite 391-402; Ders., The Year 1000 233-270; CAmeron, Oracles and Earthquakes 45-52; Baun, Tales 3-6; Brandes, Apokalyptische Literatur 305-322; Ders., Anastasios 24-63; Ders., Endzeiterwartung 301-320 (die drei zuletzt genannten Titel mit umfangreicher und aktueller Literatur zur Thematik).

12 Die vorhandenen Untersuchungen beschäftigen sich in erster Linie mit den Werken der großen monastischen Theoretiker wie Gregor von Nyssa, Euagrios Pontikos, Pseudo Dionysios Areopagites und Maximos Homologetes, s. die Literatur in Kap. 1.2.3, A. 89; Kap. 2.3.1 C, A. 229, 236 u. 237; Kap. 2.4.1, A. 347; Kap. 3.4.1, A. 531. S. v.a. auch Biedermann, Art. Mystik, Sp.989-991 sowie Uthemann, Art. Mysticism 1431 und BLum, Byzantinische Mystik 3-179 (alle mit weiterführender Literatur).

13 Wenige Detailstudien beschäftigen sich mit einzelnen Aspekten der Thematik. So Consolino, Sogni e visioni nell' agiografia tardoantica, 238-256, der in erster Linie auf die Intention der Hagiographen bei der literarischen Verarbeitung von Träumen und Visionen eingeht, wobei er sich bei den Quellen auf ausgewählte Beispiele aus der Vita Antonii, der Vita Melaniae und der Historia Lausiaca beschränkt. Einen allgemeinen Überblick über die Bedeutung des Traums in der gesamten byzantinischen Literatur bietet DAgron, Rêver 37-55, Guidorizzi, La letteratura dell'irrazionale 608 f.; 613 619; 626 f., sowie Vincent-Bernardi, Didascalie onirique 127-139. Zu Dämonologie und Engelsglauben in Byzanz s. Maltese, Dimensioni bizantine 49-92; Brakke, Demons 3-308. Zu den Höllenreisen in der byzantinischen Literatur s. LAMPAKIs, Oi

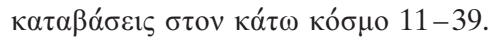

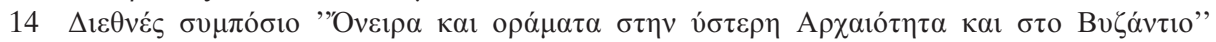

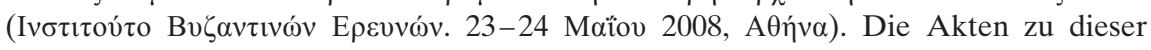
Tagung sind leider noch nicht erschienen.

15 Rubenson, Transformation 271-289. S. S. 24 A. 67, S. 46 A. 186; S. 78 A. 356 u. 358 ; S. 152 A. 735 u. 736.

16 Timotin, Visions, insbes. 1. Kap.: Visions et prophéties dans la tradition chrétienne 164. 


\section{$\S 3$. Zielsetzung und Methodisches}

Ziel der vorliegenden Arbeit ist es, die imaginären Erfahrungen innerhalb der frühbyzantinischen monastischen Literatur nach ihrer literarischen Verarbeitung und den sich darin widerspiegelnden kulturgeschichtlichen Hintergründen zu untersuchen. Dabei ist zu bedenken, dass es sich bei den meisten Beispielen um eine literarische Ausgestaltung des Phänomens handelt, was sich durch Komponenten wie Unterhaltungsanspruch, Lesersteuerungsmechanismen und Funktionalisierung des Phänomens zu bestimmten Zwecken äußert. Eine mehr oder weniger starke „Topisierung“ der imaginären Erfahrungen in den behandelten Texten ist - ungeachtet dessen, ob sie in ihrem Kern authentisch sind oder nicht - offensichtlich ${ }^{17}$. Überdies ist zu bedenken, dass uns jede geschilderte imaginäre Erfahrung lediglich über einen narrativen Diskurs zugänglich ist und seit ihrem möglichen tatsächlichen Stattfinden über eine Reihe von Zwischengliedern, etwa den Akt des Erinnerns, das erstmalige und vielleicht wiederholte Weitererzählen, erst zu ihrer literarischen Fixierung gefunden hat, sodass bei ihrer Rezeption immer von einer multiplen „Verfälschung“ des vielleicht ursprünglich authentischen Erlebnisses ausgegangen werden muss. Der Versuch, die Authentizität der geschilderten imaginären Erfahrungen nachzuweisen, wäre also von vornherein zum Scheitern verurteilt ${ }^{18}$. So wäre es auch wenig zielführend, die behandelten Quellen als Fallbeispiele für Methoden im Sinne der modernen Psychoanalyse heranzuziehen ${ }^{19}$.

Gewisse stereotype Muster sollen aber nicht $\mathrm{zu}$ dem Trugschluss führen, dass imaginäre Erfahrungen als bloßer literarischer Topos zu interpretieren und

17 Zur Definition des Topos-Begriffes speziell in der hagiographischen Literatur vgl. Delierneux, L'exploitation des topoi hagiographiques $57 \mathrm{f}$; Pratsch, Der hagiographische Topos $22 \mathrm{f}$.; zu Prophezeiungen und Träumen als hagiographischer Topos vgl. Ebd. 290-297.

18 So auch Weber, Kaiser, Träume 10; Hanson, Dreams and Visions 1401; Bovon, The Authority of Dreams 148; BraKke, Demons 9.

19 Eine solche Interpretation (im Sinne der modernen Psychoanalyse) ist jetzt bei TAxidIS, Oveıр 20 f., im Hinblick auf Träume, Visionen etc. in der spätbyzantinischen Historiographie anzutreffen. Zu der Problematik solcher Herangehensweisen vgl. auch BEHR, Aelius Aristides 171; Frenschrowski, Traum und Traumdeutung 7; Walde, Antike Traumdeutung und moderne Traumforschung $9 \mathrm{f}$. Nichtsdestotrotz erweisen sich, insbesondere im Hinblick auf die Funktion und Bedeutung von narrativen Bildern bei imaginären Heilungsvorgängen, psychoanalytische Interpretationsansätze dort als weiterführend, wo sie von den Texten selbst vorgegeben werden (s. S. 48 A. 197; S. 69 A. 313, S. 116 A. 565). Die Möglichkeiten eines solchen Ansatzes werden insbesondere in der exzellenten Studie über das ägyptische Mönchtum von BRAKKe, Demons 3-246 deutlich, der die Visualisierungen des Dämonischen innerhalb ihres kulturgeschichtlichen Rahmens als Äußerung von Repression, Projektion und persistenten Ängsten deutet (Ebd. 8). 
die behandelten Beispiele als historische Zeugnisse völlig belanglos wären ${ }^{20}$. So wenig es möglich ist, die Authentizität der beschriebenen imaginären Erfahrungen nachzuweisen, so fruchtlos wäre der Versuch, das Gegenteil zu beweisen. Sieht man einmal von einem strikt positivistischen Ansatz der Quelleninterpretation ab, welcher den im Folgenden behandelten Erzählungen kaum einen historischen Wert abzugewinnen vermag, ist die imaginäre Erfahrung doch in einem engen kulturgeschichtlichen Zusammenhang, nicht nur mit den Autoren, sondern auch mit dem in den Texten thematisierten monastischen Umfeld und dessen weltlichen Wirkungskreis zu interpretieren. Dies wird auf einer theoretischen Grundlage gerade von jenen Quellen bestätigt, deren Entstehung und Rezeption in einem besonders nahen Verhältnis zum monastischen Milieu zu sehen sind wie die Traktate von Euagrios Pontikos und Ioannes Klimakos, aber auch die Korrespondenz des Barsanuphios und Ioannes. In diesen Abhandlungen, häufig aber auch in den auf den ersten Blick rein narrativ anmutenden Beispielen aus den Viten, Vätersprüchen und Exempla-Sammlungen, finden sich theoretische Reflexionen über verschiedene Aspekte der imaginären Erfahrungen, welche von einer intensiven, über die bloße literarische Verwendung hinausgehenden Auseinandersetzung mit der Thematik zeugen. Gleichzeitig lassen sich über den Weg der literarischen und terminologischen Analyse der Erzählungen von imaginären Erfahrungen die entsprechenden geistesgeschichtlichen Konzepte zurückverfolgen. Diese Herangehensweise an die uns in literarischer, häufig motivisch anmutender Ausformung begegnenden imaginären Phänomene ist nicht mehr neu und entspricht der inzwischen in allen Bereichen der Kulturwissenschaften anerkannten und erstmals von DodDs formulierten These der „Cultural Patterns“21, welche von diversen Wissenschaft-

$20 \mathrm{Zu}$ den beiden wissenschaftlichen Extrempositionen ,Historizität versus Fiktionalität speziell in Bezug auf die hagiographische Literatur vgl. Pratsch, Exploring the Jungle 62; zu Topos und Historitzität in der hagiographischen Literatur vgl. Ders., Der hagiographische Topos 364-371; zur Problematik der modernen Historizitätsfrage in Bezug auf Texte anderer Epochen, insbesondere des Mittelalters vgl. JoHANeK, Die Wahrheit der mittelalterlichen Historiographen 23 f.; Vollmann, Erlaubte Fiktionalität 65. 71; Lifshitz, Beyond Positivism and Genre 113. Zur Problematik einer einseitig topischen Bewertung von Visionen in der byzantinischen Hagiographie jetzt auch Timotin, Visions 16.

21 DodDs, The Greeks and the Irrational 112, erklärt den Terminus „cultural pattern“, folgendermaßen: „Experiences of this type reflect a pattern of belief which is accepted not only by the dreamer but usually by everyone in his environment; their form is determined by the belief, and in turn confirm it, hence they become increasingly stylised. As Tylor (E. B. Tylor, Primitive Culture II 49) pointed out long ago, it is a vicious circle: what the dreamer believes he therefore sees, and what he sees he therefore beliefes““. Wie DodDs, Pagan and Christian 39, später weiter spezifiziert, ist damit nicht ,the pattern of the dream as actually dreamt, but simply the pattern to which it conforms in memory" gemeint. 
lern übernommen wurde ${ }^{22}$ und Christine Walde in Bezug auf den Traum folgendermaßen formulierte: „Psychopathologisch ist der Traum ein universales Phänomen der Menschen, inhaltliche und ikonographische Bestimmungen führen aber bereits in die Deutung und das Verständnis des Traums als kulturabhängig hinein" ${ }^{\text {“23. }}$. Für die hier behandelten Texte bedeutet dies also, dass das von den möglicherweise einmal authentisch erlebten imaginären Erfahrungen Weitererzählte und schriftlich Fixierte als verdichteter Sinngehalt einer gesellschaftlichen Realität zu verstehen ist, welche sich in einer kollektiven Bild- und Formsprache literarisch manifestiert. Diese Sprache wiederum darf nur dann Gültigkeit und Wirksamkeit beanspruchen, wenn sie das kulturelle Gedächtnis und das Wertesystem der Gesellschaft, in der und zu der sie spricht, maßgeblich berührt ${ }^{24}$.

Daraus ergibt sich unweigerlich die Frage, was wir uns im Zusammenhang mit Autorschaft und Rezeption der im folgenden behandelten monastischen Literatur unter Gesellschaft eigentlich vorzustellen haben; ein mönchisches, vielleicht auch ein weiterreichendes geistliches Milieu, oder die byzantinische Gesellschaft in einem umfassenderen Sinne? Wie weit der Radius der in der frühbyzantinischen monastischen Literatur verarbeiteten Imaginationswelt innerhalb der gesamten byzantinischen Gesellschaft tatsächlich reichte, kann sicherlich nur ansatzweise beantwortet werden. Dennoch lassen sich einige interessante Beobachtungen über die Wechselwirkung zwischen der literarischen Verarbeitung imaginärer Erfahrungen in der behandelten Literatur und bestimmten kulturgeschichtlichen Entwicklungen in der byzantinischen Gesellschaft in einem weiteren Sinne aufzeigen; allerdings nur unter der Bedingung, dass die monastische Literatur nicht ausschließlich innerhalb der herkömmlichen (künstlichen) Gattungsgrenzen, welche sie als vom „profanen Geschehen“ sowie von der sogenannten „Profanliteratur“ (wie etwa der Geschichtsschreibung) isoliert und unabhängig erscheinen lassen möchten, interpretiert wird ${ }^{25}$.

22 Schon bei Refoulé, Reves et Vie Spirituelle 478, A. 33 ist nachzulesen „C'est une règle générale que les rêves reflètent le milieu social de celui qui les forme“. In diesem Sinne auch Timotin, Visions $11 \mathrm{f}$. sowie Gerok-Reiter, Einleitung $8 \mathrm{f}$.

23 Walde, Art. Traum 530.

24 In diesem Sinne bemerkte auch LatACZ, Lesersteuerung 76, dass „Träume auf den Leser eines Literaturwerks nur wirken können, wenn sie nachvollziehbar die TraumErfahrung und die Traum-Handhabung der vom Autor angezielten Rezipienten widerspiegelt"; dazu auch Dinzelbacher, Revelationes 57 und Gerok-Reiter, Einleitung 9.

25 Zur Problematik der Anwendung von Gattungsbegriffen- und Vorstellungen in der byzantinischen Literatur vgl. MulLet, Dancing with Deconstructionists 264 f.; Dies., The Madness of Genre 234-243; ReInsch, Autor und Leser 404 f.; Kazhdan, A History of Byzantine Literature 140-143. 


\section{§ 4. Quellen}

Um einem Gesamtbild der behandelten Thematik in der Entstehungszeit der Texte näher zu kommen, wurde ein umfangreiches, für die frühe griechische monastische Literatur repräsentatives Quellenkorpus zusammengestellt. Die zeitliche Eingrenzung der Untersuchung bezieht sich auf die ersten, gleichermaßen als spätantik wie frühbyzantinisch bezeichneten Jahrhunderte seit Konstantins „Staatsgründung“ (324/330). Eine mehr oder weniger klare zeitliche Zäsur bildet das „Einsetzen“ des Ikonoklasmus (726), welches sich auch in der monastischen, und vor allem in der hagiographischen Literatur stark bemerkbar macht und deshalb als eigenes Kapitel angesehen werden darf, das hier nicht aufgeschlagen wird ${ }^{26}$. Obwohl es nicht möglich war, sämtliche Textzeugnisse der frühbyzantinischen monastischen Literatur $\mathrm{zu}$ erfassen und manches Beispiel zu ergänzen sein wird, stellt das behandelte Korpus dennoch eine breite und repräsentative Basis für die Thematik in der besprochenen Zeit dar.

Die untersuchten Texte weisen eine Vielzahl von unterschiedlichen literarischen Formen auf, für die die Bezeichnung „Hagiographie“ oder „hagiographische Literatur“" zu eng gefasst wäre ${ }^{27}$, haben aber allesamt das gemeinsame Merkmal, dass sie sich mit dem asketisch-monastischen Milieu in frühbyzantinischer Zeit beschäftigen. Häufig in didaktischer und apologetischer Manier nach antiken literarischen Vorbildern verfasst ${ }^{28}$, thematisieren sie die asketische Lebensweise der frühchristlichen, im Folgenden auch als Charismatiker bezeichneten „heiligen Männer und Frauen“ sowie deren Beziehung zu ihrem engeren und weiteren sozialen Umfeld ${ }^{29}$. Noch zu ihren Lebzeiten, aber auch

26 Zu der im Ikonoklasmus entstandenen Hagiographie vgl. ŠEvčEnKo, Hagiography of the Iconoclast Period 113-131; Dummer, Zum Reflex des Bilderstreites in der byzantinischen Hagiographie 79-92; EFthyMiAdIS, Hagiography 95-108.

27 Vgl. Rapp, ,For next to God, you are my salvation“ 64; Hevelone-Harper, Disciples 7, A. 9; KRÖNUnG, Ekstasen 66, A. 2. Zur Bedeutungsgeschichte des Begriffes „,Hagiographie' [...] als wissenschaftlicher Terminus moderner Prägung“" s. Dummer, Griechische Hagiographie 284; Schiffer, Art. Hagiographie 1277; Van Uytfanghe, Art. Heiligenverehrung 151.

$28 \mathrm{Zu}$ den antiken Vorbildern in den monastischen Quellen sowie ihrem didaktischen Charakter s. Bieler, @EIOE ANHP 1-120; Maraval (Hg.), Grégoire de Nysse, Vie de Sainte Macrince 26-28; Overwien, Quellen 159-184; Rubenson, Anthony 191-208; Ders., Transformation 272, A. 8; jetzt v. a. RAPP, Origins 119-130 und Hägg, Life 18-34 (beide mit ausführlichen Literaturangaben).

29 Die Unterscheidung zwischen „Holy man (= Heiliger Mann)“ und „Saint (= Heiliger)“ geht bekanntlich auf den berühmten Artikel von P. Brown, The Rise and Function of the Holy Man 80-101, zurück. Eine Zusammenfassung der durch Brown ausgelösten wissenschaftlichen Diskussion liefert CAMERon, On defining the holy man 27-43. Zur Entwicklungsgeschichte des Begriffes „Charismatiker“ und zu seiner (soziologischen) 
posthum, wurden die Protagonisten der Texte von ihren Bewunderern, die meist Augenzeugen waren und einen direkten Einblick in das Handlungsumfeld der erzählten Geschichten hatten, in Form von großen Viten des Typs ßíos кà $\pi \mathrm{o} \lambda \imath \varepsilon \varepsilon i ́ \alpha$, von Spruchsammlungen, Exempla und Erotapokriseis gewürdigt, oder sie hinterließen der Nachwelt selbst verfasste theoretische Traktate wie im Falle des Euagrios oder des Ioannes Klimakos ${ }^{30}$. Da sich im Laufe der Untersuchungen gezeigt hat, dass die zuweilen in der Literatur anzutreffenden Einteilungen in unterschiedliche Gattungen der hier behandelten Quellen, insbesondere in hagiographische Literatur auf der einen und asketische Literatur auf der anderen Seite, in vielerlei Hinsicht problematisch ist, wird mit Claudia RaPP anstelle dieser Begriffe die umfassendere Bezeichnung „monastische Literatur“ verwendet ${ }^{31}$.

Aus dem primären Quellenkorpus ausgeklammert wurde die Sonderform der reinen Passiones, die weitgehend eigenen inhaltlichen und generischen Regeln folg $t^{32}$. Ebenfalls als eigener Themenkomplex betrachtet und deshalb als Primärquellen nicht berücksichtigt wurden die Wundersammlungen der Inkubationsheilungen. Als wesentlicher Teilbereich der Thematik imaginäre Erfahrungen wurden sie zwar in die Untersuchungen mit einbezogen ${ }^{33}$, aufgrund ihres großen Umfanges und ihrer thematischen Eigenständigkeit verlangen sie jedoch nach einer eingehenderen separaten Untersuchung. Dasselbe gilt für die byzantinische Apokalyptik und die Höllenreisen, welche zwar in engem Zusammenhang mit der hier behandelten Thematik stehen, wegen ihrer eigenständigen literarischen Entwicklung, die sich überdies zu weiten Teilen außerhalb des festgelegten chronologischen Rahmens abspielt, aus dem Korpus der Primärquellen ausgeschlossen wurden ${ }^{34}$.

Verwendung in Bezug auf die monastische Literatur vgl. Hartmann, Askese und Heiligkeit $1-12$.

30 Literatur $\mathrm{zu}$ allen behandelten Quellen und ihrem jeweiligen Handlungsumfeld s. S. 11 A. 35-38; S. 24 A. 70, sowie Harmless, Introduction, 57-371, Efthymiadis, Déroche, Greek Hagiography 35-94 u. HäGG, The life 18-34.

31 RAPP, ,For next to God, you are my salvation' 64.

32 Vgl. Van Uytfanghe, Art. Biographie $1171 \mathrm{f}$.

33 S. S. 30 A. 110.

34 S. S. 4 f. A. 11 u. 13. 


\section{$\S 5$. Abkürzungen der verwendeten Quellen}

(alphabetisch geordnet, wie in Teil II)

AdMo Euagrios Pontikos, Ad Monachos (4. Jhd.)

ViAn Athanasios von Alexandreia, Vita Antonii (Mitte 4. Jhd.) [BHG 140]

ApAl Apophthegmata Patrum (alphabetische Sammlung) (5./6. Jhd. ${ }^{35}$ ) [BHG 1444]

ApSy Apophthegmata Patrum (systematische Sammlung) (5./6. Jhd.)

Bar Korrespondenz des Barsanuphios und Ioannes (6. Jhd.)

Cap Euagrios Pontikos, Capitula xxxiii (4. Jhd.)

ViDanSt Vita Danielis Stylitae (Vita Antiquor) (5./6. Jhd.) [BHG 489]

DeMa Euagrios Pontikos, De malignis cogitationibus (4. Jhd.)

ViEu Kyrillos von Skythopolis, Vita Euthymii (nach 557) [BHG 647]

HiLa Palladios, Historia Lausiaca (ca. 419) [BHG 1438]

HiMo Historia Monachorum in Ägypto (4. Jhd.) [BHG 1434]

ViHy Kallinikos, Vita Hypatii (nach 446) [BHG 760]

ViIo Kyrillos von Skythopolis, Vita Johannis (nach 557) [BHG 897]

ViIoEl Leontios von Neapolis, Vita Johannis Eleemosynarii (7. Jhd.) [BHG 886]

ViKy Kyrillos Skythopolis, Vita Cyriaci (nach 557) [BHG 463]

ViMa Vita Marthae (6. Jhd.) ${ }^{36}$ [BHG 1174]

ViMac Gregor von Nyssa, Vita Macrinae (4. Jhd.) [BHG 1012]

ViNi Vita Nicolai Sionitae (6. Jhd.) ${ }^{37}$

ViPa Vita Pachomii (390-400) ${ }^{38}$ [BHG 1396]

PaThI De SS Pachomio et Theodoro (Paralipomena [Seu Ascetica], BHG 1399a)

PaThII De Sanctis Pachomio et Theodoro (Epistula Ammonis Episcopi, BHG 1397)

35 Die ab dieser Zeit entstandenen Apophthegmen-Sammlungen vereinen eine Vielzahl von Vätersprüchen, die auf die älteste Tradition des ägyptischen Anachoretentums ab dem 4. Jh. in der sketischen Wüste zurückgehen. Vgl. GuY (ed.), Les apophthegmes des Pères I 23-84.

36 Zu Autorschaft u. Datierung dieser Vita sowie der Vita des Symeon Stylites des Jüngeren vgl. VAN DEN Ven, La vie ancienne 488; Ders. (ed.), La vie ancienne I 101-108. 129; II $251 \mathrm{f}$.

$37 \mathrm{Zu}$ Autorschaft u. Datierung vgl. Blum (ed.), Die Vita Nicolai Sionitae $7 \mathrm{f}$.

38 Berücksichtigt wird nur die „Vita Prima“. Literaturangaben zur jüngeren griechischen Vita (Vita altera) und den nicht griechischen [koptischen, arabischen und lateinischen] Varianten der pachomianischen Schriften, welche in dieser Arbeit nicht berücksichtigt werden, finden sich bei Chadwick, Pachomios, A. 4 u. Harmless, Introduction 148-150. Zur nach wie vor problematischen Prioritätsfrage bezüglich den koptischen und griechischen Versionen s. Ebd. $151 \mathrm{f}$. 
PhHi Theodoret von Kyrrhos, Philotheos Historia (kurz nach 444) [BHG 1440]

ViPo Markos Diakonos, Vita Porphyrii (2. Hälfte 6. Jhd.) [BHG 1570]

Prak Euagrios Pontikos, Praktike (4. Jhd.)

PrSp Ioannes Moschos, Pratum Spirituale (5./6. Jhd.) [BHG 1442]

ViSa Kyrillos von Skythopolis, Vita Sabae (nach 557) [BHG 1608]

ViSc Daniel von Raithu, Vita Johannis Climaci (6./7. Jhd.) [BHG 882]

$\mathrm{ScPa} \quad$ Ioannes Klimakos, Scala Paradisi (6./7. Jhd.)

ViSySal Leontios von Neapolis, Vita Symeonis Stulti (Symeon Salos) (7. Jhd.) [BHG 1677]

ViSyStI Antonios Hagiographikos, Vita Symeonis Stylitae senioris (5. Jhd.) [BHG 1682]

ViSyStII Vita Symeonis Stylitae junioris (6. Jhd.) [BHG 1689]

ViThSy Gregorios, Vita Theodori Syceota (frühes 7. Jhd.) [BHG 1748]

\section{$\S 6$. Aufbau und Inhalt der Arbeit}

Teil I

In Kapitel 1 werden verschiedene grundlegende Aspekte der imaginären Erfahrungen behandelt, die dem Leser einen Überblick über das Vorkommen des Phänomens in der monastischen Literatur verschaffen sollen. Bestimmte Merkmale dienen dabei als Richtlinien für eine Typisierung von imaginären Erfahrungen, so die Unterscheidung zwischen „gesuchten“ und „ungesuchten imaginären Erfahrungen" (Kap. 1.1) sowie zwischen ihrem Vorkommen im monastischen und im weltlichen Umfeld. V.a. in Bezug auf die gesuchten imaginären Erfahrungen lassen sich entsprechend ihrem Handlungsumfeld wesentliche Unterschiede in ihrer Bedeutung und literarischen Verarbeitung aufzeigen: Während die imaginäre Erfahrung im monastischen Bereich eine Schlüsselkomponente asketischer Spiritualität darstellt (Kap. 1.2), dominiert im weltlichen Umfeld der kultische Faktor der imaginären Erfahrung, die hier meist im Zusammenhang mit Heilungen oder anderen Formen von Hilfestellungen durch den heiligen Mann ihren literarischen Ausdruck findet (Kap. 1.3). Weniger scharf sind die Grenzen zwischen „monastisch“ und „weltlich“ bei den ungesuchten imaginären Erfahrungen vorgegeben, bei denen der propagandistisch-propädeutische Zweck der literarischen Darstellung besonders auffällt (Kap. 1.4). Schließlich erweisen sich verschiedene Typen von imaginären Erfahrungen als wiederkehrende literarische Muster in der spirituellen Biographie von heiligen Männern und lassen sich somit in einen breiteren Kontext von biographischen Traditionen in der Spätantike einordnen (Kap. 1.5). 
In Kapitel 2 wird die Frage behandelt, inwieweit die verschiedenen Formen und Typen von imaginären Erfahrungen an bestimmte Bewusstseinszustände gebunden sind. Dabei läßt sich zeigen, dass alle Typen von imaginären Erfahrungen sowohl im Schlaf, im Wachzustand als auch in tranceartigen Zuständen vorkommen können und somit verschiedene in der modernen Literatur zu findende abgrenzende Definitionen von Begriffen wie „Vision“, „Erscheinung“ oder „Traum“ auf die hier behandelten Quellen nicht zutreffen. Wichtiger als die Nennung des Bewusstseinszustandes war den Autoren oft die sensuelle, also visualisierte (und/oder auditive) Vermittlung von transzendenten Inhalten und die dadurch ausgelösten esoterischen Vorgänge (Kap. 2,1 u. Kap. 2.2). Wird der Schlaf als Prädisposition von imaginären Erfahrungen genannt, so ist eine häufige, kaum zufällige Vermeidung von Traumbegriffen zu beobachten, die mit einer tendenziell negativen Bewertung des Traumes in der frühchristlichen Literatur zu erklären ist. Die Möglichkeit einer positiven Beurteilung ist nur im Falle von Offenbarungsträumen gegeben, die in den Texten zumeist durch eine zusätzliche Visionsterminologie gekennzeichnet sind (Kap. 2.3.1 A). Während der Traum in den Texten nur selten als völlig nichtig und bedeutungslos dargestellt wird (Kap. 2.3.1 B), beschäftigen sich die Autoren - sowohl auf exemplarischer als auch auf theoretischer Ebene - besonders ausführlich mit den dämonischen Träumen. Gerade die monastischen Theoretiker wie Euagrios und Ioannes Klimakos sind darum bemüht, das Zustandekommen und die damit zusammenhängende Möglichkeit der Vermeidung von dämonischen Träumen auf philosophischer und humoralpathologischer Grundlage $\mathrm{zu}$ erklären (Kap. 2.3.1C). In enger Verbindung mit der Degradierung des Traumes ist die im frühbyzantinischen Mönchtum verbreitete Ablehnung des Schlafes zu sehen. Wie sich an zahlreichen Beispielen zeigen lässt, stellt das nächtliche Wachen eine Schlüsselkomponente der asketischen Spiritualität dar, die gerade im Zusammenhang mit imaginären Erfahrungen von zentraler Bedeutung ist (Kap. 2.3.2). Nicht nur das nächtliche Wachen, sondern auch zahlreiche weitere in den Texten genannte spirituelle Übungen erweisen sich als Voraussetzung für Zustände der religiösen Trance, in denen die nach innen gerichtete Wahrnehmungsfähigkeit geschärft wird und imaginäre Erfahrungen besonders häufig auftreten. Selbst überraschende imaginäre Erfahrungen in Krankheitszuständen erweisen sich aufgrund ihres häufigen Auftretens als Folge von exzessiv ausgeübten asketischen Praktiken letztlich als Komponente der spirituellen Übungen. Auch bei weltlichen Christen ist das Herbeiführen von Trancezuständen im Zusammenhang mit imaginären Erfahrungen verschiedentlich belegt, hier aber als rituelle Handlung zum Zwecke von Heilungen und anderen Hilfestellungen durch heilige Männer (Kap. 2.4.). Bei der einzigen in den Texten terminologisch festgelegten Form von religiöser Trance handelt es sich um die (mystische) Ekstase, die ihre Legitimation auf der Grundlage der Kirchenväter in Figuren des Alten und Neuen Testaments hat, jetzt aber in einen Aktuali- 
tätsbezug zu der in den Quellen beschriebenen monastischen Spiritualität gesetzt wird und sich damit in eine für die gesamte (christliche und nicht christliche) Spätantike charakteristische Imaginationsspiritualität eingliedert (Kap. 2.4.1). Die in den Texten oft detailliert beschriebene physische und emotionale Symptomatik der mystischen Ekstase sowie ihre bewusste Kontrastierung mit dem Schlaf zeigt deutlich, dass sich die Autoren über die Unterschiede der jeweiligen Bewusstseinszustände im Klaren waren und diese bei den Erzählungen über imaginäre Erfahrungen bewusst einsetzten (Kap. 2.4.1.1). Trancezustände, speziell die Ekstase, werden auch wiederholt im Zusammenhang mit Heilungen oder anderen Heilserfahrungen von weltlichen Christen erwähnt und stellen somit neben dem Traum, der in der Tradition der Inkubation in der christlichen Volksfrömmigkeit seine Bedeutung nicht verloren hatte, eine legitime Möglichkeit der durch induzierende Handlungen evozierten imaginären Erfahrung dar (Kap. 2.4.2). Als Gegenprinzip zur mystischen (und Heilungs-) Ekstase wird in den Texten wiederholt die dämonische Ekstase thematisiert, deren Ursprünge in der antiken (dionysischen) Bedeutung des Begriffes liegen, und die bei den Kirchenvätern erstmals negativ ausgelegt wird. Während die letzteren jedoch die dionysische Ekstase mit den vorgetäuschten Prophezeiungen der Häretiker (z. B. Montanos) in Verbindung bringen, wird sie in den monastischen Texten mit diversen krankhaften Zuständen, deren Ursache zumeist auf dämonische Besessenheit zurückgeführt werden, begründet (Kap. 2.4.3). Wie es im frühen Christentum (zurückgehend auf das Neue Testament) weithin üblich war, beschreiben auch die monastischen Autoren die Symptome der dämonischen Besessenheit mit denjenigen der Epilepsie. Allerdings ist in der Bezeichnung der dämonischen Besessenheit als „Ekstase“ und kaum mehr als „Mondsucht“ (wie noch im Neuen Testament und bei Origenes) eine terminologische (und damit inhaltliche) Veränderung bei der Darstellung des Phänomens festzustellen (Kap. 2.4.3.1).

Ausgangspunkt der formalen und terminologischen Ausführungen in Kapitel 3 ist die in Kapitel 2 eruierte Beobachtung, dass die auffälligste Konstante, die sich inhaltlich und terminologisch durch sämtliche Beispiele von imaginären Erfahrungen hindurch zieht, nicht die zugrundeliegende Form bzw. der Bewusstseinszustand ist, sondern vielmehr der Akt des Sehens (der zuweilen durch den des Hörens ergänzt wird). Die erstrangige Bedeutung des visuellen Aspekts bei imaginären Erfahrungen lässt sich anhand der von den Autoren verwendeten Terminologie zur Einleitung des Imaginationsvorganges, aber auch anhand von verschiedenen weiteren terminologischen und formalen Beobachtungen zeigen. Damit erfährt der visuelle Faktor gegenüber den Offenbarungserzählungen des Neuen Testaments eine deutliche Aufwertung, während die Audition an Bedeutung verliert. Die Begründung für diese Entwicklung ist nicht nur im erbaulichen und propädeutischen Anspruch der monastischen Literatur zu suchen, sondern auch in der für die gesamte Spätantike charakteristische Imagi- 
nationsspiritualität, für die imaginäre Erfahrungen eine real erlebbare Form der Gotteserfahrung darstellten (Kap. 3.1). Die Verwendung aller weiteren im Zusammenhang mit imaginären Erfahrungen vorkommenden Begriffe werden in den Gruppen „Träume“ (Kap. 3.2), „Ekstasen“ (Kap. 3.3), „Gesichte und Stimmen“ (Kap. 3.4), "theoria und phantasia“ (Kap. 3.4.1), „phone“ (Kap. 3.4.2) und „Andere Imaginations-Begriffe“ (Kap. 3.5) abgehandelt und in entsprechenden terminologischen Tabellen präsentiert (Kap. 3.6).

In Kapitel 4 geht es schließlich um die Beurteilung des in den imaginären Erfahrungen Geschauten als wahr oder trügerisch bzw. dämonisch, wofür der paulinischen Gabe der Unterscheidung ( rangige Bedeutung beigemessen wird, wie auf einer breiten Textgrundlage gezeigt werden kann (Kap. 4.1.1). Dabei wird deutlich, dass die Autoren darum bemüht waren, den christlichen Charismatiker in der Funktion des Richters über imaginäre Erahrungen dem im frühen Christentum von kirchlicher und staatlicher Seite bekämpften Traumdeuter entgegenzustellen (Kap. 4.1.2). Die Schlüsselkompetenz, die dem mit der Unterscheidungsgabe ausgezeichneten Charismatiker zugesprochen wurde, war nicht nur die Unterscheidung zwischen wahren und falschen Offenbarungen, sondern auch das Verstehen und Interpretieren von allegorischen Inhalten aller Formen von imaginären Erfahrungen (also nicht nur von Träumen) (Kap.4.2.1 u. Kap. 4.2.3). Gleichzeitig spielt gerade bei den allegorischen Bildinhalten der literarisch-erbauliche Charakter eine entscheidende Rolle, was in besonderem Maße auf die implikativen Inspirations-Allegorien zutrifft, die dem Rezipienten aufgrund ihrer weit verbreiteten literarischen Vorbilder auch ohne Auslegung verständlich gewesen sein dürften (Kap. 4.2.2). Eine ernst zu nehmende Konkurrenz für alle Typen von heidnischen Mantikern wird der christliche Charismatiker aber erst durch die Prophetengabe, die ihm auf der Legitimationsgrundlage des Alten und Neuen Testaments erlaubt, in die Zukunft weisende (imaginäre, aber auch andere) Zeichen zu deuten und damit - ganz im Einklang mit der kirchlichen und kaiserlichen Gesetzgebung - alle Formen von divinatorischen Praktiken auBerhalb eines christlichen Interpretationsrahmens als dämonisches Agieren in die Schranken zu weisen. Von besonderer Brisanz ist im Zusammenhang damit der wachsende Einfluss des Charismatikers auf die oberste Spitze des byzantinischen Reiches, und damit auch auf die kaiserliche Politik (Kap. 4.3.1 u. Kap. 4.3.2). Dass der heilige Mann aber nur in einem Exemplum als Traumdeuter im engeren Sinne fungiert, zeigt die Bemühung darum, die Kompetenzen des christlichen Charismatikers klar von denen des heidnischen Oneirokrites abzugrenzen und somit nicht eine identische, sondern eine neu definierte Form der gesellschaftlich akzeptierten Autorität in Bezug auf die in die Zukunft weisende Zeichendeutung zu finden (Kap. 4.3.3). Neben der Unterscheidungsund der Prophetengabe wird zahlreichen heiligen Männern die unter den pau-

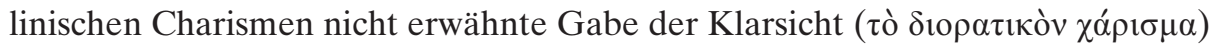


zugesprochen, die sie befähigt, simultan zur physisch wahrnehmbaren Welt die Regungen der Seelen ihrer Mitmenschen wahrzunehmen. Dabei wird deutlich, dass die Autoren daran interessiert waren, die Klarsicht als zusätzliche Gabe neben den biblisch legitimierten Charismen der Unterscheidung und der Prophezeiung zu etablieren (Kap. 4.4).

Teil II: Quellen

Durch die in Teil II der Arbeit präsentierten Textbeispiele soll dem Leser ein umfassender Überblick über das Vorkommen imaginärer Erfahrungen in den Quellen ermöglicht werden. $\mathrm{Zu}$ finden sind in durchnumerierter Abfolge sämtliche Belegstellen aus den behandelten Quellen, die in einem direkten Bezug zu imaginären Erfahrungen stehen, sei es in Form von theoretischen Abhandlungen, sei es in Form von Exempla. Um den Umfang des Anhangs in einem überblickbaren Rahmen zu halten, werden vor allem die längeren Beispiele zusammenfassend in paraphrasierter Übersetzung wiedergegeben, wobei Passagen mit der für die Ausführungen in Teil I und in den Tabellen (Kap. 3.6) relevanten Terminologie im griechischen Original angeführt werden. Um der paraphrasierten Darstellung einen einheitlichen Charakter zu verleihen, werden die Quellen, welche die Protagonisten häufig in direkter Rede sprechen lassen, meist nicht in wörtlicher Übersetzung, sondern narrativ in der dritten Person wiedergegeben. Wörtliche Übersetzungen werden immer mit Anführungszeichen gekennzeichnet. In Teil I wird in den Anmerkungen auf die Nummern der jeweils behandelten Textbeispiele aus Teil II verwiesen.

Die Gründe für die vorliegende Typologie der imaginären Erfahrungen (vgl. Teil II A-R) sind zugleich inhaltlicher wie auch praktischer Natur. Um überhaupt einen Überblick über die unzähligen in den Texten vorkommenden Beispiele von imaginären Erfahrungen zu verschaffen, war es notwendig, ein System zu finden, nach welchem diese sich ordnen und gruppieren lassen. Im Laufe der Quellenlektüre hat sich gezeigt, dass sich die Erzählungen am ehesten nach den Inhalten einteilen lassen, welche die durch die imaginäre Erfahrung ausgelöste Wirkung auf den Menschen (z. B. Berufung, Vergebung von Sünden, Heilung usw.) kennzeichnen. Selbstverständlich handelt es sich dabei um ein im Nachhinein auferlegtes „künstliches Konstrukt“, welches weder Vollständigkeit und Abgeschlossenheit beansprucht noch ausschließt, dass die Grenzen zwischen den einzelnen Typen der imaginären Erfahrungen fließend sind. 
Teil I 



\section{Kapitel - Aspekte von imaginären Erfahrungen in der frühbyzantinischen monastischen Literatur}

\subsection{Gesuchte und ungesuchte imaginäre Erfahrungen}

Bei der Beschäftigung mit imaginären Erfahrungen drängt sich unweigerlich eine gewisse Grundambivalenz der Thematik auf, die kein Spezifikum der hier behandelten Texte ist, sondern in der gesamten Religions-und Kulturgeschichte überall beobachtet werden kann, wo das Verlangen nach visionären Erfahrungen bestimmte Praktiken zum Evozieren derselben hervorgebracht hat: Gemeint ist die dem suggestiven Charakter der Visionserfahrung implizite Ambivalenz zwischen dem induzierten, gesuchten und dem überraschenden, ungesuchten Moment ihres Auftretens ${ }^{39}$. Auch die Texte der frühbyzantinischen monastischen Literatur vermitteln, dass es sich bei imaginären Erfahrungen um ein Phänomen handelt, dessen Auftreten für die Gläubigen, sowohl innerhalb als auch außerhalb des monastischen Umfelds, jederzeit im Bereich des Möglichen lag. Diese grundlegende Bereitschaftshaltung impliziert einerseits das Verlangen danach, Offenbarungen zu suchen, sie selbst zu induzieren. Andererseits aber beinhaltet sie die omnipräsente Möglichkeit der überraschenden Offenbarung als einer plötzlich und unvermittelt hereinbrechenden Gnade (oder auch Strafe) Gottes. Die genannte Spannung zwischen induziertem und überraschendem Moment entspringt also derselben Voraussetzung, nämlich einer suggestiven Erwartungshaltung, und stellt somit eher zwei Seiten einer Medaille als einen wirklichen Gegensatz dar. Aus eben diesem Grund wird auch jede induzierte imaginäre Erfahrung von einem überraschenden, nicht vorhersehbaren Aspekt durchdrungen, und jede überraschende Offenbarung durch die zugrundeliegende Disposition bedingt. Eine Abgrenzung zwischen induziert und überraschend ist letztlich also weniger scharf vorgegeben, als es auf den

39 S. dazu Benz, Die Vision 37; Biedermann, Art. Mystik 989; zum gleichen Phänomen in der klassischen syrischen Literatur und im Sufismus s. SEPPÄLÄ, In speechless Ecstasy 51. Besonders deutlich geht das Spannungsfeld zwischen induzierter und überraschender Visions-Erfahrung aus dem spezifischen Vokabular des Sufismus hervor, wo terminologisch zwischen der „plötzlich als Gnadengabe geschehenden Ekstase“ (arab. wağd) und „dem sich-in-Ekstase-zu-versetzen-Suchen“ (arab. tawağğud bzw. tawāğud) unterschieden wird, vgl. Schimmel, Art. Ekstase 410; Dies., Mystische Dimensionen 254. Dass die Problematik bis heute nicht an Aktualität verloren hat zeigt HofFman, Zur Aktualität der Besessenheit 18 . 
ersten Blick scheint, dient aber im Folgenden dennoch als hilfreiche Einteilung für die Untersuchung des Gegenstanden innerhalb der behandelten Texte.

\subsection{Gesuchte imaginäre Erfahrungen im asketischen Milieu}

\subsubsection{Das charismatische Privileg}

Imaginäre Erfahrungen, in denen das induzierende Element deutlich zutage tritt bzw. explizite Erwähnung findet, kommen häufig in Berichten über charismatische Persönlichkeiten aus dem asketisch monastischen Milieu vor. Hier wird die imaginäre Erfahrung als Weg, mit dem Göttlichen in Kontakt zu treten und zu kommunizieren, propagiert und als zentraler Aspekt monastischer Spiritualität ständig herbeigesehnt und evoziert. Erwartungsgemäß wird wiederholt betont, dass die göttliche Offenbarung nie alleine durch den menschlichen Willen herbeigeführt werden kann, sondern grundsätzlich als ein Gnadenakt Gottes verstanden werden muss, dessen Willen sowohl die Auswahl der Visionäre als auch der Zeitpunkt, an dem sich Visionen zutragen, unterliegen. Antonios etwa verlangt, dass wegen seiner Visionen nicht er, sondern vielmehr der Herr bewundert werde, da dieser die Menschen mit der Gnade ausgestattet habe, Gott gemäß ihren Kräften zu erkennen ${ }^{40}$. Auch von anderen heiligen Männern wird erzählt, dass sie durch die Gnade Gottes Visionen empfangen haben, so von Nikolaos, dem ein Engel in der Gestalt eines Soldaten erschien und sagte: „Da der Herr dir die Gnade erwiesen hat, in Form einer Offenbarung die Werke Gottes zu sehen, werde ich dir nun die Engelsgesichte zeigen “41, und einem Schüler des Symeon Stylites des Jüngeren erschien „durch die in ihm wohnende Kraft der Gnade gleichsam der Morgenstern“, der ein Raubtier, das ihn bedrohte, vertrieb ${ }^{42}$. Insbesondere diejenigen Offenbarungstypen, die sich in der Tradition von I Kor 12,4 als Teil der charismatischen Gaben - des charisma der Prophezeiung und des charisma der Unterscheidung ${ }^{43}$ - erweisen, sind nur Auserwählten zugedacht und daher dem Nicht-Charismatiker unzugänglich. So sagt auch Kyrillos von Skythopolis ,wenn der Herr beschließt, seinen Heiligen etwas zu offenbaren, sind diese Propheten. Wenn er es aber verbergen will, dann sehen sie so wie alle anderen auch “44. Der Privilegierung bestimmter Asketen in Bezug auf göttliche Offenbarungen haftet v.a. für das ägyptische Koinobiten-

4070.

$4190(3)$.

42 148. Zu diesem Bsp. siehe auch S. 69 A. 311. Weitere Belegstellen, in denen die göttliche Gnade ( $\chi \alpha ́ \rho 1 \varsigma)$ Erwähnung findet: 92, 179, 187, 203, 227, 253, 254, 268, 295, 426.

43 S. S. 117 A. 570 u. S. 131.

4429. 
tum, welches sich bereits in der ersten Hälfte des vierten Jahrhunderts zu einer Massenbewegung entwickelt hatte, eine nicht $\mathrm{zu}$ unterschätzende autoritätskonstituierende Konnotation im soziologischen Sinne an, was besonders deutlich aus den Pachomianischen Schriften hervorgeht ${ }^{45}$. Hier werden die Brüder wiederholt belehrt, nicht danach zu verlangen, Visionen und dergleichen zu sehen $^{46}$, gleichzeitig aber auch nicht daran zu zweifeln, wenn jemand erzählt, ein göttliches Gesicht gesehen zu haben ${ }^{47}$. Nur die echten Charismatiker, das heißt Pachomios und sein Schüler Theodoros, sind nämlich in der Lage, Offenbarungen $\mathrm{zu}$ empfangen ${ }^{48}$. Als geschildert wird, dass Pachomios eine heilige Stimme in der Luft hörte und sah, wie die Seele eines sterbenden Bruders in den Himmel emporstieg, „hörten und sahen die anderen Brüder nichts davon“"49.

\subsubsection{Schweigen oder Reden über imaginäre Erfahrungen?}

Die Legitimierung des wiederholt propagierten charismatischen Privilegs in Bezug auf Offenbarungen gründet letztlich auf dem Theologumenon der Unbenennbarkeit und der Unbeschreibbarkeit des Mysterium Gottes, das seinen mystischen Charakter verlieren würde, wenn es für jeden ohne weiteres zugänglich wäre. Dies jedoch gilt nicht nur für das Empfangen, sondern auch für das Erzählen von Offenbarungen. So ist es eigentlich nichts als konsequent, wenn der Autor der Historia Monachorum in Aegypto das Mysterium auch für den Leser Mysterium bleiben lässt und über die Offenbarungen des Apollo und dessen Schüler sagt, ,dass sie vieles sahen, was Worte nicht auszusprechen und Ohren nicht zu hören wagen“"50. Gleichzeitig aber zeigt der zweite Teil des Satzes „und wenn sie aufwachten, erzählten sie den Anwesenden davon“ die Widersprüchlichkeit, in die sich hier der Autor durch die alleinige Erwähnung des Weitererzählens von Schauererlebnissen begibt.

45 Strenge Disziplin und Gehorsam gegenüber der führenden Autorität war im pachomianischen koinobion Voraussetzung für das Funktionieren der klösterlichen Organisation, bei der es sich schon früh (um die Mitte des 4. Jh.) um ein schwer zu überblickendes Massenmönchtum handelte. Dementsprechend wird in den pachomianischen Schriften die charismatische Legitimierung der Autorität, gerade auch durch Visionserfahrungen, besonders stark hervorgehoben; vgl. CHADwICK, Pachomios 22-24. Zum ägyptischen Mönchtum im 4. Jhd., insbesondere zu Pachomios und seinen Regeln vgl. Chitty, The Desert A City 21-28; Bacht, Das Vermächtnis 38-40; Rousseau, Pachomius 87-118; Lorenz, Das vierte Jahrhundert 231-C233. Siehe auch S. 65 A. 285287.

4636 u. 66.

4735 .

$487,23,139,254$.

49230.

5027. 
Auch andere Autoren sind zugunsten des literarischen Reichtums und gleichzeitig zur pädagogisch-propädeutischen Veranschaulichung christlicher, oft bestimmter dogmatischer Lehren inkonsequent und verwenden selbst gerade jene Mittel, die sie eigentlich als unzulässig erklären, nämlich das Erzählen von göttlichen Visionserlebnissen. Dieser vordergründig widersprüchlich anmutende Umgang mit religiösen Inhalten ist ein für die Rhetorik des frühen Christentums typisches Phänomen ${ }^{51}$, welches in den hier behandelten Texten besonders deutlich hervortritt, wenn vom göttlichen Mysterium (wahrgenommen durch imaginäre Erfahrungen), also von der Offenbarung dessen, was ei-

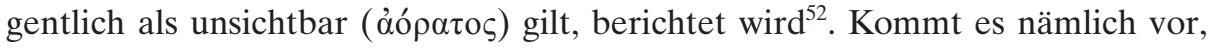
dass einem „Privilegierten“ das Mysterium offenbart wird, so müsste dieses

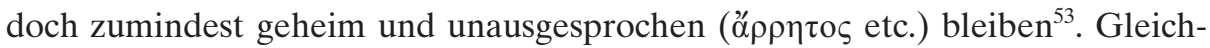
zeitig aber wird der Autor, dessen erklärtes Ziel es ist, die göttliche Auserwähltheit seiner Protagonisten hervorzuheben, schwerlich auf das rezipientenwirksame Heiligungsmittel der Offenbarung verzichten wollen.

Der Unstimmigkeit zwischen dem Inhalt des zentralen christlichen Grundsatzes der Unsichtbarkeit und Unaussprechbarkeit des Göttlichen und dessen Vermittlung an den Rezipienten begegnen die Autoren wiederholt mit rhetorischen Mitteln, die den genannten Widerspruch aber umso deutlicher hervortreten lassen: Als dem Autor der Vita des Symeon Stylites des Älteren kurz vor dessen Tod eine Engelsgestalt in einem furchteinflößenden, aber unbeschreiblichen Gewand erscheint, will er dies eigentlich anderen weitererzählen, wird aber durch eine Geistesentraffung daran gehinder ${ }^{54}$. Zuweilen wird betont, dass der Charismatiker das Geschaute nur teilweise und soweit, wie es für die anderen von Nutzen war, weitererzählte. So heißt es von Pachomios und seinem Schüler Theodoros, dass „sie manchmal Teile von dem, was sie gesehen hatten, entsprechend dem Willen Gottes erzählten, da sie den zukünftigen Nutzen vorhersahen “55 und „,wenn Gott wollte, dass Pachomios etwas von den verborgenen Dingen sah, teilte er ihnen [den Brüdern] nur so viel mit,

51 CAmeron, Christianity and the Rhetoric of Empire 155-188 prägte für dieses Phänomen den Begriff „rhetoric of paradox“; vgl. auch Rousseau, Ascetics as mediators 49, u. Maltese, Dimensione $69 \mathrm{f}$.

52 Das vor allem bei den apostolischen Vätern zum Prädikat Gottes etablierte dóo $\alpha \tau$ ○ wird auch in den behandelten Texten häufig verwendet, so in 31, 66, 33, 233, 259, 267, 278. Über die Entwicklung dieses Begriffs in der biblischen Literatur und bei den

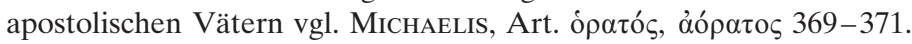

53 Für die Unaussprechlichkeit von göttlichen Visionen werden in den Texten verschie-

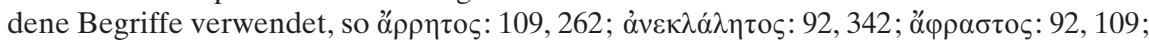

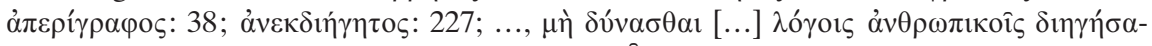

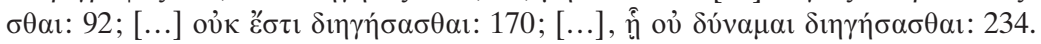

54234.

5533. 
wie ihnen zum Glauben und zur Erbauung gereichte“"56. In anderen Beispielen gehen die Autoren noch weiter, indem sie ihre Visionäre das Geschaute gänzlich verschweigen lassen und somit der Forderung des Abbas Poimen folgen, der sagte: „Wenn du Gesichte siehst und Stimmen hörst, erzähl' es nicht deinem Nächsten “57. So fragte auch der im Sterben liegende Bruder Zacharias, als Abbas Moses von ihm wissen wollte, was er sehe, ob es nicht besser sei, zu schweigen, worauf er die Antwort erhielt: „Ja, schweig!“58. Und Hypatios „wurden, als er sich selber eingeschlossen hatte, viele Geheimnisse offenbart, welche er aber nicht erzählen wollte " ${ }^{“ 59}$. Theodoros von Sykeon wiederum erzählte seine Visionen erst unter vorher eingeholter Schweigepflicht an seine Brüder weiter ${ }^{60}$, Antonios sowie Symeon Stylites der Jüngere nur, nachdem sie dazu gezwungen worden waren ${ }^{61}$, und im Pratum Spirituale ist die Rede vom Mönch Georgios, der seine Vision erst berichtete, als er von Abbas Anastasios nachdrücklich darum gebeten worden war $^{62}$. Besonders deutlich tritt das Paradoxon durch die Schilderung, wie Theodoros von Sykeon nach seiner dreizehntägigen Todesvision wieder erwachte und gefragt wurde, was er gesehen habe, hervor. Theodoros erzählt, dass er in den ganzen dreizehn Tagen, wo er nicht bei ihnen (den anderen Brüdern) war, nicht von der Schau in den Himmeln abgelassen habe. ,Doch als er anfing, von dieser Schau zu erzählen, wurde er von einem demütigen Gedanken ergriffen. Er fing an zu weinen, schlug sich mit den Fingern auf den Mund, wie wenn er sich Vorwürfe machen würde, bekreuzigte sich über den Lippen und flehte um Vergebung für seine Worte“ ${ }^{\text {63 }}$. In einem Beispiel aus der Vita des Symeon Stylites des Jüngeren rechtfertigt der Autor nicht den Visionär, sondern sich selbst für das Erzählen einer Offenbarung. Dies tut er mit der Begründung der Nützlichkeit für den frommen Zuhörer $^{64}$, was das pädagogische Anliegen des Textes offen zutage treten lässt. Bewusst tritt der Autor in einen Diskurs mit dem Rezipienten und lässt diesen mit einer gewissen „Sicherheitsdistanz“ vor dem göttlichen Mysterium an der imaginären Erfahrung des Charismatikers teilhaben, obschon er gerade dies eigentlich als unzulässig erklärt hat ${ }^{65}$.

56 32. S. auch 380 .

5710.

58210.

59 28. Weitere Beispiele: 8, 52, 162, 209, 254.

60 196, 238.

$6171,110,241$.

62 99. Ähnlich auch 246.

63239.

64257.

65 Gould, The Desert Fathers 177-182, interpretiert das Weitererzählen von visionären Erfahrungen hauptsächlich im Hinblick auf die Interaktion innerhalb der Mönchsgemeinschaft der Wüstenväter, vergisst dabei aber, die literarische Ebene, also den Dis- 


\subsubsection{Das bewusste Herbeiführen von imaginären Erfahrungen} durch asketische Praktiken

Trotz der Idee der göttlichen Offenbarung als Gnadenakt, ist, wie bereits angedeutet, dennoch eine starke Tendenz zum Evozieren der imaginären Erfahrung festzustellen. Arsenios’ Ausspruch „,wenn wir nach Gott suchen, wird er uns auch erscheinen" ${ }^{\text {66 }}$ ist kein Einzelfall, und es wird wiederholt von Offenbarungen als Folge eines ausdrücklichen und mitunter ausgedehnten Bittens darum berichtet ${ }^{67}$. Antonios etwa erzählt, dass er ein volles Jahr betete, damit ihm der Ort der Gerechten und der Sünder gezeigt werde ${ }^{68}$. Diese Art von gesuchter Gotteserfahrung wird als Belohnung - gleichsam als Frucht ${ }^{69}$ - der harten asketischen Anstrengung beschrieben und bildet einen wichtigen Bestandteil des in den Quellen propagierten Konzepts des spirituellen Heilswegs. Entsprechend befinden sich die Asketen vor der Schau häufig in spirituellen Übungen, die als wesentliches Element des immer auf Gott und das Jenseits ausgerichteten ,engel-

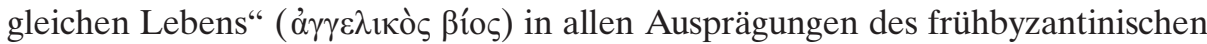
Asketentums üblich waren ${ }^{70}$. Zu den am häufigsten vorkommenden Komponenten der spirituellen Übungen, die den Körper in einen vom Diesseits abgewandten und somit für die göttliche Schau empfänglichen Zustand versetzen sollten $^{71}$, gehören neben der allgemeinen „Weltflucht“ ( $\alpha$ ó $\left.\tau \alpha \xi 1 \varsigma\right)$ und „Fremd-

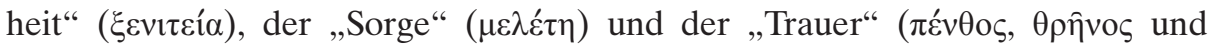

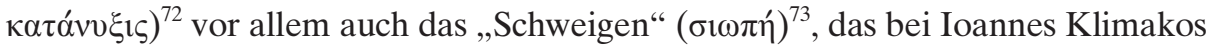

kurs zwischen Autor und Rezipienten, in die Interpretation der Texte mit einzubeziehen.

$66 \quad 13$

$6789,90,125,135,164,189,237,242,252,256,347,348,372,383$, 388. Die gleiche Beobachtung macht Rubenson, Transformation 321, auch für die Briefe des Ammonas.

68249.

69 S. S. 46 A. 186.

70 Zur Spiritualität bei den Wüstenvätern s. Draguet, Les Pères XX-LX; Baus, Die Reichskirche 355-358; Schulze/Ziemer, Mit Wüstenvätern 19-253, speziell bei Euagrios S. 27 A. 89 u. S. 55-59, im pachomianischen Mönchtumg s. RousseAu, Pachomius 119-148, und bei Ioannes Klimakos s. BLum, Byzantinische Mystik 71-158. Zum palästinischen Mönchtum s. Chitty, Desert 82-100; Hevelone-Harper, Disciples 95-142 (speziell zu Barsanuphios und Ioannes). Zur Spiritualität der syrischen Asketen s. CAnivet, Le Monachisme syrien 255-290; Vööвus, History of Asceticism I 69-108. 138-169, II 256-291; speziell zur Spiritualität der Styliten- Heiligen VAN den VeN (Hg.), La vie ancienne I 130-180. Zu den verschiedenen asketischen Strömungen im 3. und 4. Jahrhundert, insbesondere zur begrifflichen und inhaltlichen Beeinflussung der monastischen Spiritualität durch Origenes und Clemens vgl. Strathmann, Art. Askese $765-770$.

$71 \mathrm{Zu}$ allen im Folgenden genannten Begriffen s. Frank, A $\gamma \gamma \varepsilon \lambda$ ıò̀ $\beta$ ßío $18-114$.

72 Zum penthos und threnos: Hausherr, Penthos 1-209; Dodel, Das Sitzen 44; in den Apophthegmata Patrum vgl. B. MüLler, Der Weg des Weinens 83-165; Schulze/ 
unter anderem als „Schöpfer von Gesichten“ bezeichnet wird ${ }^{74}$. Von erstrangiger

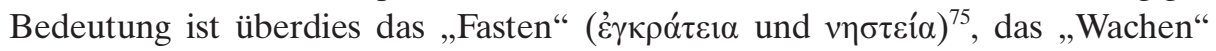
$(\alpha \gamma \rho v \pi v i ́ \alpha)^{76}$ und verschiedene Ausdrücke der spirituellen Versenkung und Me-

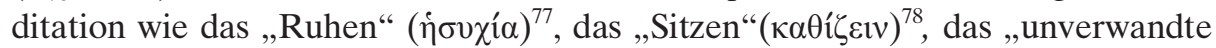

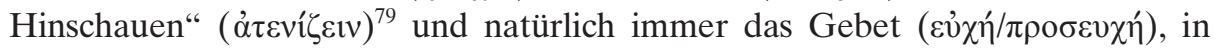

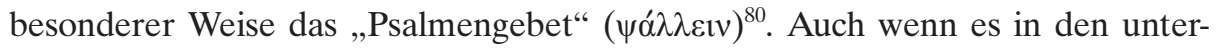
schiedlichen Mönchszentren keine einheitlich reglementierte Form der Askese gab, so tauchen die genannten spirituellen Übungen als Grundpfeiler des Mönchtums doch in allen behandelten Texten immer wieder auf und werden häufig in einem direkten kausalen Zusammenhang mit imaginären Erfahrungen genannt $^{81}$. Dabei unterstützen sie den Asketen in seinem steten Verlangen danach, schon zu Lebzeiten in die Gemeinschaft der Engel aufgenommen zu werden und mit ihnen vor dem Thron im Himmel den Herrn zu schauen (Mt 18,10),

Ziemer, Mit Wüstenvätern 202 f., bei Ioannes Klimakos s. A. Müller, Die Vita des Sinaiten 598 f.; BLum, Byzantinische Mystik 104-106.

73 Zur Schweigepraxis im frühen Mönchtum s. KunZ, Schweigen 401-457; zur siope: Schiffer, Zur Bewertung des Schweigens 1-22, in den Apophthegmata s. Schulze/ ZIEMER, Mit Wüstenvätern 156-168. Zum negativen Gegenbegriff, der „Geschwätzigkeit“ ( $\pi \alpha \rho \rho \eta \sigma i ́ \alpha)$, s. BARTELINK, Quelques observations sur ПAPPH $\Sigma$ IA 7-57.

7449.

75 Zum Fasten (als asket. Praktik): VööBus, History of Asceticism II 261-264; BAus, Die Reichskirche 332; Beatrice, Ascetical Fasting 211-228; Schulze/Ziemer, Mit Wüstenvätern 178-183. Siehe auch S. 71.

76 S. S. $62-69$.

77 Zur Bedeutung der Hesychia, eine im frühen Mönchtum weit verbreitete, im Sitzen vollzogene kontemplative Übung, vgl. HAusherr, L'hésychasme 5-40. 247-285; Dodel, Das Sitzen 149; Schiffer, Schweigen 2, A. 3; Blum, Byzantinische Mystik $130-$ 135; Schulze/Ziemer, Mit Wüstenvätern 51-57.

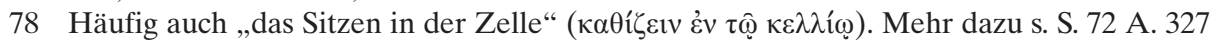
u. 328.

79 S. dazu Gaston, Attention 94.

80 Über Bedeutung, Formen und Entwicklung des Gebets im frühen Christentum s. Severus, Art. Gebet I, speziell B christlich III. - VI 1207-1255; Coyle, What Was „Prayer" 25-41; McGuckIn, The Prayer 69-108; speziell bei den ägyptischen Wüstenvätern s. Gould, The Desert Fathers 166-177; BLum, Byzantinische Mystik 135139; Schulze/Ziemer, Mit Wüstenvätern 35. 169-177, bei den syrischen Asketen s. Vööвus, History of Asceticism II 286-289.

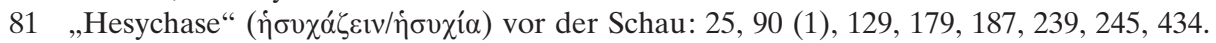
„Fasten“ vor der Schau: 56, 96, 166, 239, 252, 322, 350, 375, 376, 377, 448. „Wachen“

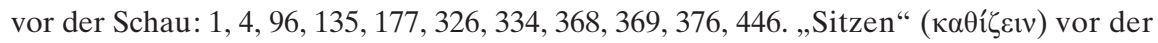
Schau: 11, 52, 61, 68, 71, 156, 179, 207, 210, 211, 217, 241, 244, 308, 332, 347, 360, 373, 383, 437, 466. „Unverwandtes Hinschauen“ ( $\left.\alpha \dot{\tau} \varepsilon v_{i}^{\prime} \varepsilon \varepsilon v\right)$ vor der Schau: 174, 230, 239, 254 , 295. Trauer, Tränen und Weinen vor der Schau: 55, 90, 114, 135, 180, 231, 262, 303, 372 , 382, 388. Psalmen- und Hymnengesang vor der Schau: 25, 93, 145, 205, 415, 435, 450. Gebet vor der Schau: 75, 81, 89, 90, 106, 125, 135, 164, 174, 179, 187, 189, 194, 207, 208, $220,221,231,237,241,242,249,252,256,318,326,332,334,346,347,348,365,371,372$, 376, 381, 405, 406 (2), 431, 433, 475. 
um in der Nachfolge der Jünger Jesu die Geheimnisse des Himmelreiches Gottes zu erkennen (Lk 8,9). In diesem Sinne ermahnt auch Hypatios seine Brüder: „Bedenkt, dass ihr dazu aufgerufen seid, in ein Engelsheer aufgenommen zu werden. Denn so wie die Engel jeden Tag den Herrn preisen, so sollt auch ihr ihn mit Hymnen besingen und danach eifern, ihn durch gute Werke zu loben ... “82. Die Schau ist hier das Ziel der mystischen Kontemplation, in der das innere Auge nicht auf das Sichtbare, sondern auf das Unsichtbare, das Jenseits im Diesseits, hingewendet ist ${ }^{83}$. Symeon Stylites der Jüngere belehrt die Brüder, dass ihnen der kleine Kummer im Diesseits zu einem viel größeren ewigen Ruhm verhelfe, wenn sie nicht zum Sichtbaren, sondern zum Unsichtbaren hinschauen, da das Sichtbare vergänglich, das Unsichtbare aber unvergänglich $\operatorname{sei}^{84}$. Doch trotz allen Anstrengungen, die dem Asketen einen Zugang zu den Mysterien der himmlischen Welt verschaffen, bleibt die höchste, weil unmittelbare Schau Gottes den Menschen im Diesseits versagt. So ist auch die Stelle in der Historia Monachorum zu verstehen: „Derjenige, der würdig ist, Gott teilweise zu erkennen - die vollkommene Erkenntnis Gottes kann nämlich niemand erlangen - besitzt auch die Erkenntnis von allen anderen Dingen. Er erblickt die Geheimnisse, die Gott ihm zeigt, er sieht die Zukunft voraus und schaut Offenbarungen wie die Heiligen ${ }^{485}$. Die Erkenntnis Gottes kann also immer nur eine partielle sein, die das mönchische Streben in einer Vielzahl von ,indirekten“ imaginären Erfahrungen begleitet und sich dem Menschen durch Mittlergestalten wie Engel und Heilige oder durch mystische Zeichen vergegenwärtigt. Die in der imaginären Erfahrung geschauten Bilder werden dabei als Visualisierungen des göttlichen Wirkens verstanden und bedürfen deshalb zuweilen - d.h. entsprechend dem erreichten Grad der spirituellen Vollendung - nicht nur der Unterscheidung durch einen mit der Unterscheidungsgabe ausgezeichneten Charismatiker ${ }^{86}$, sondern auch einer allegorischen Auslegung ${ }^{87}$. Die in der imaginären Erfahrung manifestierte Gottesnähe nimmt also mit dem Voranschreiten auf dem spirituellen Heilsweg zu, weshalb der Asket einem unverschlüsselten, eigentlich erst durch den Tod vollends erfüllbaren direkten Gegenübertreten Gottes in der Regel im Greisenalter am

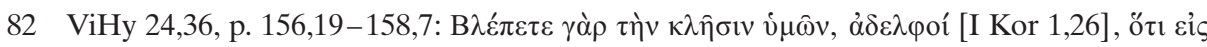

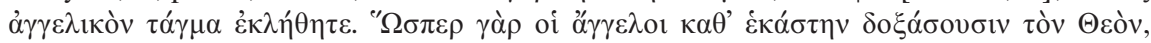

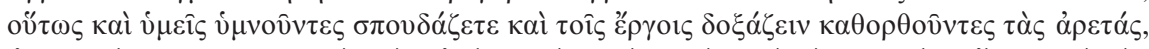

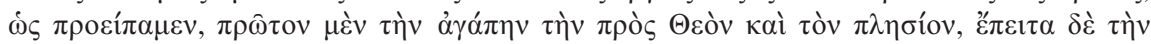

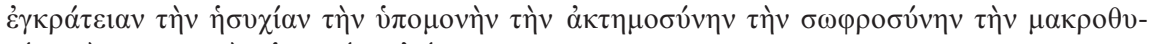

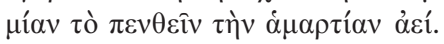

83 Weitere Beispiele und Ausführungen zu diesem Gedanken s. S.71 f. A. 325; S. 82 A. 382.

84259.

8526.

86 S. S. $114-120$.

87 S. S. $123-131$. 
nächsten zu kommen vermag ${ }^{88}$. Die detaillierteste und älteste praktische Anleitung, auf welche Weise das Streben der frühchristlichen Asketen zum ersehnten spirituellen Ziel führen kann, begegnet uns in den Schriften des Euagrios. Hier stellt die im Logos Praktikos abgehandelte praktike die Methode dar, durch welche die erste Etappe des spirituellen Lebens mit dem Ziel der Leidenschaftslosigkeit beschritten werden soll. Diese wiederum ist die Voraussetzung für die in Euagrios' Gnostikos beschriebenen, nur von wenigen zu erreichenden spirituellen Erkenntnis Gottes, der gnose, welche den Asketen auch dazu befähigt und verpflichtet, diejenigen, die sich noch in der praktike befinden, zu unterweisen und zur Leidenschaftslosigkeit hinzuführen ${ }^{89}$. Bezeichnenderweise hebt sich gerade Euagrios von den anderen hier behandelten Autoren dadurch ab, dass er die durch die asketischen Praktiken angestrebte Vision Gottes im neuplatonischen Sinne als intellektuelle Schau versteht. Zwar ist auch Euagrios weit weniger eindeutig als bilderfeindlich zu bewerten, als es in der Forschung aufgrund seiner späteren Verdammung als Origenist häufig geschehen ist ${ }^{90}$. Dennoch werden bei ihm imaginäre Erfahrungen - und zwar nicht nur der Traum - zumeist mit dämonischen Anschlägen in Zusammenhang gebracht, die den Asketen am spirituellen Aufstieg hindern wollen ${ }^{91}$. In allen anderen Texten ist jedoch ein mehr oder weniger ausgeprägter Zusammenhang zwischen spiritueller Übung und dem Streben nach imaginären Erfahrungen festzustellen ${ }^{92}$.

\subsubsection{Irrwege zur imaginären Erfahrung}

Deutlich wird der Zusammenhang zwischen spirituellen Übungen und imaginären Erfahrungen insbesondere auch dann, wenn von der Kehrseite der harten Askese berichtet wird. Exzessives Fasten, Wachen und das raue Leben in der Wüste oder in anderen Extremformen der asketischen Isolation ${ }^{93}$, führen zuweilen über die

88 127, 189, 209, 210, 216, 219, 233, 239, 240, 245, 246.

89 Zu praktikos und gnostikos bei Euagrios und zur Entwicklungsgeschichte der Begriffe in der antiken, spätantiken und byzantinischen Literatur s. Guillaumont (Ed.), Évagre le Pontique, Traité Pratique 38-63; Guillaumont (Ed.), Évagre le Pontique, Le Gnostique 17-33; Guillaumont (Ed.), Sur les pensés 256, A. 2; Brakke, Demons 6. 51-54. 72-74; Konstantinovsky, Evagrius 27-35. Zu Euagrios' Spiritualität siehe auch S. 5559, S. 105 A. 531, S. 114 A 554, S. 118 A. 580-583.

90 S. Konstantinovsky, Evagrius 8 f.; 18-22. Siehe auch S. 49 f. A. 206, S. 57 A. 242 u. 243 , S. 118 A. $582-584$, S. 152 A. 736.

91 S. S. 55-59.

92 Ausführlicher wird darauf noch einmal in Kapitel 2.4 über die religiöse Trance und imaginäre Erfahrungen eingegangen.

93 Man denke an die Styliten, die sich nicht nur den üblichen asketischen Praktiken wie Dauerfasten, Wachen und Gebet hingaben, sondern erschwerend dazu durch das Leben 
Grenzen der bloßen Kontemplation hinaus und evozieren imaginäre Erfahrungen im Zustand der körperlichen Entkräftung und Krankheit, sodass sich dem modernen Leser unwillkürlich der Vergleich mit Fieberträumen und Halluzinationszuständen aufdrängt ${ }^{94}$. So in der Erzählung über den Wüstenvater Zenon, der sich in der Sketis aufhielt, als er eines Nachts die Zelle verließ und sich verirrte. Drei Tage und drei Nächte war er herumgeirrt, als er abgekämpft und kraftlos hinfiel, um zu sterben. Da trat ein Knabe zu ihm, der Brot und einen Becher Wasser bei sich hatte und zu Zenon sagte, er solle aufstehen und essen ${ }^{95}$. Auch vom Wüstenvater Nikolaos wird erzählt, dass er sich mit zwei Brüdern in der Thebais verirrte und sie sich, als sie aufgrund von Durst und Hitze nicht mehr gehen konnten, in den Schatten eines Tamariskenbaums setzten und den Tod erwarteten. Jetzt geriet Nikolaos in Ekstase und sah ein mit Wasser gefülltes Schwimmbecken, an dessen Rand zwei Gestalten Wasser in ein Holzgefäß füllten und Nikolaos und den Brüdern schließlich davon zu trinken gaben ${ }^{96}$. Offensichtlich war man sich über die Gefahren der übertriebenen Askese für das Mönchtum durchaus bewusst. Denn während Fäulnis, Ungepflegtheit und komplette körperliche Entkräftung für die heiligen Männer eine Auszeichnung darstellten ${ }^{97}$, wurde der „normale Mönch“ vor zu viel Askese gewarnt. So sagt Isidor der Große zum Äthiopier Moses, der sich nach seiner Bekehrung zum Christentum durch strenge asketische Übungen selbst kasteit, er solle aufhören, sich mit dem Teufel zu messen, denn auch in der Askese gebe es ein Ma $\beta^{98}$. Der Wüstenvater Helles wurde, nachdem er eine Woche lang gefastet hatte, von einem Engel aufgefordert, aufzustehen und zu essen, was er finde ${ }^{99}$, und auch dem Asketen Ioannes erschien, nachdem er während drei Jahren in ständigem Gebet aufrecht auf einem Felsen gestanden hatte, ohne sich jemals zu setzen oder zu schlafen, und als Nahrung nur das Abendmahl am Sonntag zu sich genommen hatte, ein Engel, der seinen Mund berührte und sagte, dass zwar Christus seine wahre Nahrung und der heilige Geist sein wahrer Trank sein solle, dass es aber

auf der Säule jeder noch so harten Wetterbedingung ausgesetzt waren. S. dazu Vööвus, History of Asceticism 19-35.

94 S. die Beispiele und weitere Ausführungen zum Thema in Kap. 2.4.

95317.

96327.

97 Selbststigmatisierung durch den physischen und sozialen Rückzug aus den gesellschaftlichen Strukturen und das Ausüben harter asketischer Praktiken bis an die Grenze des Todes werden in den Texten immer wieder als Konstituente charismatischer Autorität dargestellt. S. Browning, The ,Low Level' saint's life 124-125. Zur soziologischen Perspektive der Konstituierung charismatischer Autorität durch exzessive Askese s. Hartmann, Askese und Heiligkeit 7-12.

98446.

99350. 
einstweilen genug sei mit der geistigen Nahrung, da er sonst noch anfange, sich aus Übersättigung zu erbrechen ${ }^{100}$.

Auch ein Mangel an Demut ( $\tau \alpha \pi \varepsilon v v o \varphi \rho o \sigma v ́ v \eta)$, der von den Asketen geforderten geistigen Haltung, kann leicht zum Gegenteil dessen führen, was der Mönch durch Askese erreichen möchte ${ }^{101}$. So verkündet ein Wüstenvater: „Mühe, Armut, Fremdheit, das Üben von Tapferkeit und das Schweigen bringen Demut hervor und befreien von vielen Sünden; wenn diese Dinge jedoch nicht beachtet werden, ist der Rückzug umsonst “102. Die Wichtigkeit, die einer demütigen Haltung beim Empfang von Offenbarungen beigemessen wird, verkündet auch ein Väterspruch: „Wenn dir wirklich ein Engel erscheint, dann nimm ihn nicht auf, sondern erniedrige dich selber, indem du sagst ,Ich Sünder bin nicht würdig, einen Engel zu sehen““103. Wenn die spirituellen Übungen nicht in Sündenbewusstsein und in geistiger Selbsterniedrigung ausgeführt werden, bleibt die ersehnte Visionserfahrung aus. So fordert Ioannes Klimakos: „Eile nicht der Schau nach, wenn die Zeit nicht reif ist dafür, damit sie (die Schau) der Schönheit deiner Demut nacheifere, und wenn sie sie erreicht hat, sich für immer mit dir in einer reinen Heirat verbinde“104, und von einem Wüstenvater wird erzählt, dass er Gott bat, er möge ihm die Bedeutung eines Bibelwortes offenbaren. Doch obwohl er schon siebzig Wochen gefastet hatte, wurde es ihm nicht offenbart. Erst als er sich dazu erniedrigte, zu einem anderen Bruder zu gehen, um ihn um Rat zu fragen, erschien ihm ein Engel ${ }^{105}$. Immer wieder werden fehlende Demut, Überheblichkeit oder Nachlässigkeit in der Askese auch als Ursache von dämonischen Erscheinungen und geistiger Verwirrung ins Feld geführt ${ }^{106}$. In dieser Sache wird besondere Vorsicht gefordert, da die Mönche gerade durch die stete Ausrichtung auf die göttliche Offenbarung der permanenten Gefahr der falschen, dämonischen Schau ausgesetzt $\operatorname{sind}^{107}$.

100376.

101 395, 398, 404. Über die zentrale Bedeutung von „Demut“ im frühen Mönchtum s. Dihle, Art. Demut 765-771, bei Ioannes Klimakos s. Blum, Byzantinische Mystik 121123.

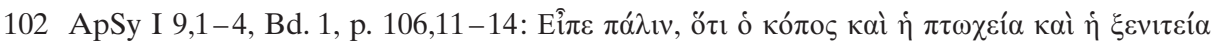

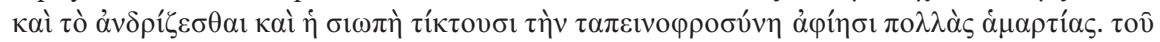

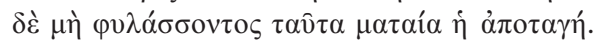

103 15. Weitere Beispiele: 10, 66.

10454.

105375.

106 24, 35, 36, 42, 52, 67, 289, 452, 456.

107 S.u. Kap. 4.1. 


\subsection{Gesuchte imaginäre Erfahrungen bei „weltlichen Christen“}

Das Verlangen nach imaginären Erfahrungen beschränkt sich keineswegs auf das asketische Milieu, sondern nimmt gemäß den behandelten Texten auch eine nicht $\mathrm{zu}$ unterschätzende gesellschaftliche Bedeutung im Alltagsleben der „weltlichen Christen“ ein. Die Antriebskraft, göttliche Offenbarungen zu evozieren, ist hier freilich eine andere als die der spirituellen Schau im asketischen Umfeld. Der weltliche Christ, der bewusst imaginäre Erfahrungen herbeiführt, befindet sich immer in einer Existenzsituation, in der er Gott über seine Mittler, die heiligen Ärzte und Fürsprecher, als Retter in der Not herbeiruft. Neben den unterschiedlichen Typen von „imaginären Heilungen“ [II I] gehören dazu auch Geburtsankündigungen [II L] und „Rettungen in Notsituationen“ [II M $]^{108}$.

\subsubsection{Inkubatorische Praktiken}

Wo die Ärztekunst der weltlichen Mediziner, die Mittel der Magier und Astrologen versagen, hoffen die Gläubigen in der äußersten Not auf die wunderbare Heilkraft der heiligen Männer ${ }^{109}$. Abweichend von den Kulten der frühchristlichen anargyroi ${ }^{110}$, die in direkter Anlehnung an die heidnischen Inkubationspraktiken ${ }^{111}$ stets an die Grabstätte von Heiligen gebunden sind, ist in den behandelten Viten von einer Fülle von unterschiedlichen Möglichkeiten,

108 S. S. 73 f., S. $85-87$.

109 Weitere Ausführungen mit Beispielen von Heilungen durch Charismatiker, nachdem die Mittel von Zauberern und Magiern erfolglos waren s. S. 131-139.

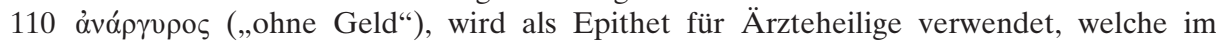
Gegensatz zu den weltlichen Ärzten kein Geld für ihre Heilungen verlangen. Vgl. Kazhdan, Art. Anargyroi 85; Duffy, Byzantine Medicine 23-25; Zu den frühbyzantinischen Inkubationskulten s. Deubner, Kosmas und Damian 3-83; Heinemann, Die Ärzteheiligen Kosmas und Damian 258-317; CsPregi, The miracles of saints Cosmas and Damian 89-121; Dagron (Hg.), Vie et miracles de Sainte Thècle 13-30; Davis, The cult of Saint Thecla 3-80; Johnson, The Life 1-14; Talbot (Hg.), Miracle Tales vii-xxiv; Gascou, Les origines du culte des saints Cyr et Jean 241-284; Pratsch, Inkubationsdarstellungen (im Druck).

111 Zur Inkubation in Antike und Spätantike vgl. Graf, Heiligtum und Ritual 159-199; Edelstein, Asclepius, A Collection II 139-213; Dodds, Die Griechen und das Irrationale 62-64; DERS., Pagan and Christian 46; WACHT, Art. Inkubation 179-265; Miller, Dreams in late antiquity 106-123; Hanson, Dreams and visions 1397; Walde, Antike Traumdeutung 235; Vincent-Bernardi, Didascalie onirique 129; NäF, Traum 228-234. Zu Aelius Aristides und seinen Hieroi Logoi vgl. BeHr, Aelius Aristides 2560. 116-121; SCHRöDER, Heilige Berichte 9-15. Zur Inkubation im antiken Mesopotamien vgl. ZGoLL, Die Welt im Schlaf sehen 74-101; auch aus der jüdischen Tradition ist die Inkubation bezeugt, dazu Frenschkowski, Traum und Traumdeutung 41. Zur Inkubation im Alten Testament s. EHrLICH, Der Traum im Alten Testament 13-57. 
wie ,imaginäre Heilungen“112 stattfinden können ${ }^{113}$, die Rede, während sich inkubatorische Heilungen im engeren Sinne lediglich in zwei Beispielen (beide aus der Vita Euthymii) nachweisen lassen: So wird berichtet, wie der von einem unreinen Geist besessene Paulos ins Koimeterion des Euthymios, direkt neben das Grab des Heiligen gelegt wurde. Dort habe er gefleht und gebetet und sei in der Nacht um die fünfte Stunde unter Wehklagen und Tränen, in eine Ekstase gefallen $^{114}$. Das zweite Beispiel erzählt von einer vom Dämon besessenen Frau, die während drei Tagen und Nächten betend und fastend vor dem Kloster des (bereits verstorbenen) heiligen Euthymios verharrte und gegen Abend geweihtes Öl vom Grab des Heiligen erhielt und von der Flüssigkeit seiner Lampe trank. In der dritten Nacht erschien ihr dann Euthymios und heilte $\operatorname{sie}^{115}$. Im Zusammenhang mit der an eine heilige Stätte gebundenen Inkubation sind auch die sogenannten „Geburtsankündigungen“ [II L] zu nennen. Obwohl sie in der wissenschaftlichen Diskussion relativ einstimmig als „literarischer Topos“ angesehen werden $^{116}$, sind die Beispiele dazu in den Heiligenviten hier deshalb von Interesse, weil die Kinderlosigkeit eines Ehepaars ${ }^{117}$ oder der Wunsch, einen Diener Gottes zur Welt zu bringen ${ }^{118}$, zu inkubationsähnlichen Handlungen der zukünftigen Eltern führt ${ }^{119}$, was durchaus im Zeitkontext der Quellen verstanden werden kann ${ }^{120}$. Auch hier ist das flehentliche Gebet im Vorfeld üblich, und besonders die Erzählungen von der Geburtsankündigung des Euthymios ${ }^{121}$ und des Symeon Stylites des Jüngeren ${ }^{122}$ erinnern stark an inkubatorische Prakti-

112 „Imaginär“ ist hier nicht im Sinn von „eingebildet“ zu verstehen. Auch wenn die Heilung durch die Imagination stattfindet, so ist sie doch real. Zur Bedeutung der Imagination bei den Wunderheilungen s. S. 85-87.

113 S. S. 32-35.

114 262. Zum gleichen Beispiel siehe auch S. 73 A. 330 u. S. 86 A. 411.

115263.

116 So begnügt sich etwa Dinzelbacher, Körperliche und seelische Vorbedingungen 79, mit der simplen Bemerkung, „Prophetische Träume vor der Geburt eines Heiligen sind dagegen ein hagiographischer Topos“, s. auch LanZoNI, Il sogno presago 224-261; Zeller, Geburtsankündigung und Geburtsverkündigung 59 f.; Pratsch, Der hagiographische Topos 72-74. Zur Bedeutung der Geburtsankündigungen als Komponente der spirituellen Biographie s. S. 41-43.

$117311,312,314$.

118315.

119 Eine Ausnahme ist 316. Bei dem Empfängnistraum von Maria, der Mutter des Theodoros von Sykeon, handelt es sich um eine überraschende und von ihr zunächst nicht als solche verstandene Gnade Gottes. Zu diesem Bsp. s. S. 143 f. A. 704.

120 Über inkubatorische Handlungen bei den Geburtsankündigungen in der byzantinischen Hagiographie vgl. auch VAN DEN VEN, La vie ancienne II 6, A. 2, und jetzt v.a. ARIANTZI, Kindheit 51-55.

121312.

122315. 
ken $^{123}$. So wird in der Vita Euthymii geschildert, wie Dionysia, die Mutter des heiligen Euthymios, eines Tages mit ihrem Mann zur Kapelle des Polyeuktos ging. Hier hielten sich die beiden mehrere Tage auf. Als sie sich eines Nachts im Gebet befanden, zeigte sich ihnen ein göttliches Gesicht ... ${ }^{124}$. Noch detaillierter werden die induzierenden Handlungen in der Vita des Symeon Stylites des Jüngeren geschildert. Nachdem Martha, die Mutter des Symeon, gegen ihren Willen verheiratet worden war, ging sie zur Kapelle des heiligen Ioannes am Stadtrand von Antiocheia und betete dort, es möge ihr ein Sohn zum Dienste Christi geschenkt werden. „Lange verharrte sie in der Kapelle und betete unter Tränen, ohne zu essen und zu trinken. Auf diese Weise verbrachte sie einige Zeit an jenem Ort, als sie eines Nachts mit eigenen Augen den heiligen Ioannes Prodromos sah..."125. Ähnliche, an inkubatorische Praktiken erinnernde Handlungen werden auch in je einer Erzählung über imaginäre Erfahrungen unter „Befehle und Anordnungen“ [II O] ${ }^{126}$ und „Sündenvergebung“ [II K] geschildert, wo eine Frau drei Tage lang ohne zu essen und zu trinken am Grab des Ioannes Eleemon verbrachte und mit ihm redete, als ob er noch lebendig wäre ${ }^{127}$.

\subsubsection{Entwicklung von der ortsgebundenen zur ortsungebundenen ,imaginären Heilung“}

Insgesamt gesehen vermitteln die behandelten Texte jedoch deutlich, dass die imaginäre Heilkraft nicht an eine Kultstätte gebunden ist, sondern überall aktiviert werden kann. Dies hängt zunächst damit zusammen, dass die meisten Erzählungen über Heilungen noch zu Lebzeiten der heiligen Männer (und Frauen) handeln. Eine Imagination an der Kultstätte des heiligen Mannes ist nicht notwendig, da dieser in seiner physischen Präsenz direkt aktiv werden kann. So erzählt auch bloß eine Episode von einer imaginären Heilung während der physischen Anwesenheit eines heiligen Mannes: Ein Junge, der sich bei Symeon Stylites dem Jüngeren aufhält, wird durch einen Dämon von einem Felsen herab geworfen, sodass sein Kopf zerschellt und man glaubt, er sei tot. Symeon ordnet an, den Jungen ein wenig schlafen zu lassen, damit der Herr ihn vollständig wiederherstelle. Die Anweisung wird befolgt, und der Junge schläft ein. Da schneidet ihm Symeon in einer unsichtbaren Operation das Ohr auf,

$123 \mathrm{Zu}$ den Praktiken zum Evozieren von Zuständen des Überbewusstseins bei den „,weltlichen Christen“ s. S. 73 f.

124312.

125315.

126357.

127306. 
sodass eine Menge Blut aus seinem Gehirn fließt. Nachdem dies geschehen ist, wacht der Junge auf und ist geheilt ${ }^{128}$. Doch auch wenn die Inkubation im traditionellen, also ortsgebundenen Sinne aufgrund der Möglichkeit der direkten Wunderwirkung der auf der Handlungsebene der Erzählung noch lebenden heiligen Männer selten belegt ist, wird der Imaginationskraft im Zusammenhang mit Heilungen eine wichtige Bedeutung beigemessen. Gegenüber der ortsgebundenen Inkubation wird jetzt aber das Visualisierungsmoment von der Kultstätte an einen anderen Ort verlegt. So wird mehrmals von imaginären Erfahrungen berichtet, in denen den Kranken oder ihren Angehörigen aufgetragen wird, sich an einen bestimmten Ort zu begeben, um dort von einem (noch lebenden) heiligen Mann wieder hergestellt zu werden. Dies ist auch der Fall in einem Beispiel der Philotheos Historia, wo eine adlige Frau aus Antiocheia den heiligen Mann Sabinos aufsucht, um von diesem Heilung für ihre von einem Dämon besessene Tochter zu erhalten. Die Frau kam zu Sabinos, nachdem ihr dieser im Traum erschienen war und befohlen hatte, sich auf den Weg zu seinem Kloster zu machen. Als sie dort Sabinos erblickte, erkannte sie ihn an einem Wangenausschlag, den sie auch im Traum gesehen hatte, und sogleich wurde ihre Tochter geheilt ${ }^{129}$. Auch in anderen, ähnlichen Beispielen geht der realen Heilung ein imaginäres Agieren durch den Wundertäter voraus. So heißt es von einem Blinden, der zu Symeon dem Jüngeren gebracht wurde, dass er noch in der gleichen Nacht einen leuchtenden Jüngling mit einem Fellkleid und nackten Füssen, mit einem Palmzweig in der Hand und engelgleichem Gesicht erblickte. Als der Blinde danach zu Symeon gebracht wurde, sah und erkannte er in ihm die Erscheinung des Heiligen wieder und sagte, dies sei derjenige, den er in der nächtlichen Vision gesehen habe ${ }^{130}$. Manchmal werden die Kranken zu Hause oder an einem unbestimmten Ort von einem (noch lebenden) heiligen Mann durch Bilokation ${ }^{131}$ oder von einem bereits verstorbenen Heiligen ${ }^{132}$, zuweilen $^{2}$

128278.

129 268. Weitere Beispiele: 261 [Erscheinung des Euthymios in Arabien], 269 [Engelserscheinung, Ort unbestimmt], 271 [Engelserscheinung an der Grenze zu Persien], 272 [Engelserscheinung, Ort unbestimmt], 280 [Erscheinung des Symeon Stylites des Jüngeren, Ort unbestimmt].

130 296. Weitere Beispiele: 270 [Erscheinung des Symeon Stylites des Jüngeren, Ort unbestimmt], 274 [Erscheinung des Symeon Stylites des Jüngeren, Ort unbestimmt], 291 [Erscheinung der Martha, Ort unbestimmt], 301 [Erscheinung des Symeon Stylites des Jüngeren, im Krankenhaus]. Weitere Erzählungen von inkubationsähnlichen Wunderheilungen, bei denen die eigentliche Heilung nicht an der Kultstädte stattfindet $s$. PRATSCH, Inkubationsdarstellungen (im Druck).

131273 [Erscheinung des Symeon Stylites des Jüngeren, Ort unbestimmt], 293 [Erscheinung des Symeon Stylites des Jüngeren, zu Hause], 294 [Erscheinung des Symeon Stylites des Jüngeren, Ort unbestimmt], 302 [Erscheinung des Symeon Stylites des Jüngeren, Ort unbestimmt], 427 [Erscheinung des Symeon Stylites des Jüngeren zu Hause]. 
auch von Engeln ${ }^{133}$, imaginär geheilt. Bei einer weiteren Sonderform erscheint der Kranke zunächst beim heiligen Mann, um von ihm Hilfe zu erbitten. Dieser jedoch schickt den Kranken wieder nach Hause, wo er durch eine imaginäre Erfahrung geheilt wird ${ }^{134}$. In mehreren Beispielen wird berichtet, dass der heilige Mann dem Kranken als Zeichen seiner physischen Präsenz auch in Abwesenheit heiligen Staub ${ }^{135}$ oder geweihtes Ö $1^{136}$ mitgibt. Die Symeon Stylites dem Jüngeren in den Mund gelegten Worte, ,die Kraft Gottes wirkt überall“ und „wenn du den Umriss unseres [imaginären] Bildes siehst, dann siehst du uns ${ }^{\text {“137 }}$, fassen die in zahlreichen der behandelten Texten mehr oder weniger deutlich nachvollziehbare Entwicklung von der streng an eine Lokalität gebundenen Inkubation hin zum Glauben an die überall mögliche Wunderwirkung des zunächst imaginären, und später materialisierten Heiligenbildes zusammen. Der heilige Staub schafft hier eine körperliche Anwesenheit des sich in Wirklichkeit anderswo befindenden Wundertäters und erhält somit dieselbe Kraft wie später die wunderwirkende Heiligenikone. In einer Erzählung über den kranken Theodoros von Sykeon, der von den Ärzteheiligen Kosmas und Damian imaginär geheilt wird, nachdem er sie auf einem über sich hängenden Bild gesehen hat ${ }^{138}$, scheint die erwähnte Entwicklung zum Abschluss gekommen zu sein. Ebenso in einem Beispiel aus dem deutlich älteren Pratum Spirituale, wo erzählt wird, dass eine fromme Frau einen Brunnen ausgrub. Da sie aber kein Wasser fand und in große Mutlosigkeit geriet, wurde ihr in einer Erscheinung aufgetragen, sich das Abbild des Theodosios von Skopelos bringen zu lassen. Und tatsächlich, als sie die Ikone des Heiligen in den Brunnen hängte, sprudelte sogleich Wasser hervor ${ }^{139}$. Dass man der Ikone in den monastischen Texten schon lange vor dem Ausbruch des Bilderstreites die Kraft der physischen Präsenz des Heiligen zusprach, wurde schon mehrfach beobachtet ${ }^{140}$ und könnte

132264 [Erscheinung des Euthymios, Ort unbestimmt], 281 [Erscheinung des heiligen Georg, Ort unbestimmt], 290 [Erscheinung des Leichnams der Martha, Ort unbestimmt].

133260 [Engelserscheinung zu Hause], 265 [Engelserscheinung in der Wüste].

134275 [Erscheinung des Symeon Stylites des Jüngeren], 277 [Erscheinung des Symeon Stylites des Jüngeren], 279 [Erscheinung des Symeon Stylites des Jüngeren], 285 [Erscheinung des Theodoros von Sykeon], 298 [Erscheinung des Symeon Stylites des Jüngeren], 300 [Eine Frau sieht im Schlaf, wie Symeon Stylites der Jüngere ihre Tochter heilt].

135279 [von Symeon Stylites dem Jüngeren], 427 [von Symeon Stylites des Jüngeren].

136285 [von Theodoros von Sykeon].

137279.

138 303. Zu diesem Beispiel s. auch Holl, Der Anteil der Styliten 392.

139352.

140 Vgl. Zum Aufkommen der Bilderverehrung in vorikonoklastischer Zeit s. Holl, Der Anteil der Styliten 388-398; Kitzinger, The Cult of the Images in the Age before Iconoclasm 83-150; Dagron, Le cult des images 140 f; SPECK, Weitere Überlegungen 
durch weitere Beispiele belegt werden ${ }^{141}$. Die diesbezüglich älteste und am häufigsten zitierte Episode findet sich in der Vita des Symeon Stylites des Älteren aus dem 5. Jh. Hier berichtet Theodoret, dass die Verehrer des heiligen Mannes in Rom am Eingang ihrer Werkstätten zum Schutz Bilder Symeons aufgestellt hatten ${ }^{142}$. Die genannten Beispiele von imaginären Heilungen zeugen aber nicht nur davon, dass die Bilderverehrung schon in den ersten byzantinischen Jahrhunderten üblich war. Vielmehr zeigen sie auch, dass die hier behandelte Literatur den für die spätere byzantinische Orthodoxie so zentralen Grundsatz des ortsungebundenen Wirkens des Heiligenbildes - nicht nur in seiner materialisierten, sondern auch in seiner imaginierten Form - vorgibt. Das Fundament, das diesen Grundsatz trägt, ist das Theologumenon der Ubiquität des göttlichen Wirkens, wonach die Offenbarung als Gnadenakt Gottes dem Visionär jederzeit und überall zuteilwerden kann ${ }^{143}$.

\subsubsection{Weitere Typen von gesuchten imaginären Erfahrungen}

Gesuchte imaginäre Erfahrungen bei „weltlichen Christen“ kommen aber auch bei anderen Typen, insbesondere bei „Rettungen in Notsituationen“ [II M] vor, obschon hier die induzierende Tendenz weniger eindeutig ist als bei den bisher erläuterten Beispielen. Das dominierende Grundmuster des Handlungsablaufs ist hier, dass der sich in Not befindende Gläubige spontan einen heiligen Mann anruft, welcher ihm sogleich als Helfer erscheint. So wird von einem Sarazenen berichtet, dass er vom Toten Meer her in Richtung Megiste Laura zog, als sein Kamel abstürzte und er den heiligen Sabas um Hilfe anrief. Sogleich sah er einen ehrwürdigen Greis auf dem hingefallenen Kamel sitzen. Er selber lief

256, sowie DERs., Byzantium: Cultural Suicide? 78. Grabar, Martyrium II 343-357 beobachtete bereits den unübersehbaren Trend weg vom Reliquienkult hin zur Bilderverehrung im 6. Jh., jedoch ohne auf die Bedeutung des imaginierten Bildes für diese Entwicklung einzugehen; Cox Miller, Corporal Imagination 7-9, stellt insbesondere die Bedeutung der von den Autoren hagiographischer Texte auf diskursiver Ebene bewusst erzeugten imaginären Bilder (v. a. von heiligen Körpern) zur Etablierung von Heiligenkulten (durch die "Materialisierung des eigentlich nicht Wahrnehbaren“) in den Vordergrund. Die Ebene der imaginären Erfahrungen wird dabei aber kaum berücksichtigt (siehe auch S. 44 f. A. 183).

141 Beispiele aus den Exempel-Sammlungen bei DAGRon, Rêver 42-43. S. auch 134, wo der sechsjährige Symeon Stylites der Jüngere auf einem alten Mauerwerk augenscheinlich Jesus in Begleitung des Volkes der Gerechten sah, .... Vgl. dazu Van den Ven, La vie ancienne II $13-14$, A. 3.

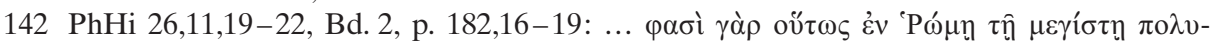

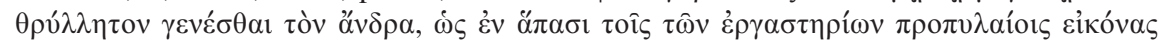

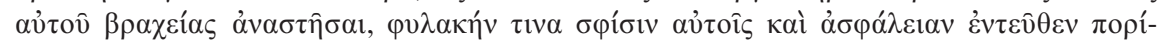

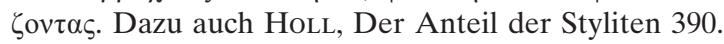

143 S. auch 201 u. Kap. 1.2.1. 
schnell auf einem anderen Weg zum Kamel hinunter, doch als er bei diesem angekommen war, fand er den darauf sitzenden Greis nicht mehr. Das Kamel aber war unversehrt ${ }^{144}$. Ein anderes Beispiel erzählt von Iakobos, der auf einen hohen Baum am Straßenrand stieg, um Früchte zu pflücken, als er sah, wie zwei Dämonen auf ihn sprangen, ihn an den Füssen packten und vom Baum auf den anliegenden Abhang warfen. Mit lauter Stimme rief Iakobos den Heiligen Symeon an und sah ihn, wie er die Hände ausstreckte, ihn festhielt und gesund und unbeschadet wieder aufrichtete [...]. In der Stunde, in der dies geschah, erzählte Symeon den Brüdern das Wunder, welches der Herr durch ihn wirkte ${ }^{145}$.

1.3.4 Dreigliedrige hierarchische Abstufung im Kontakt mit dem Numinosen durch gesuchte imaginäre Erfahrungen

Auffälliges wiederkehrendes Element bei allen Typen von induzierten imaginären Erfahrungen bei weltlichen Christen, aber auch bei einzelnen Beispielen, die von Rettungen in Notsituationen und Heilungen aus dem monastischen bzw. klösterlichen Umfeld berichten ${ }^{146}$, ist das Konzept einer dreigliedrigen hierarchischen Abstufung im Kontakt mit dem Numinosen. Dies bedeutet, dass der heilige Mann eine Fürsprecher-bzw. Mediatorenrolle zwischen dem Notleidenden und Gott einnimmt, so wie es auch im zuletzt genannten Beispiel von Iakobos erwähnt wird (das Wunder wird durch den Herrn gewirkt) ${ }^{147}$. Wenn dies auch nicht in allen Beispielen explizit gesagt wird, so ist das Mittel zur Kontaktaufnahme von einer Stufe zur nächst höheren durch die Imagination doch immer das Gebet, wodurch deutlich wird, dass der heilige Mann die Heilung nicht aus eigener Kraft, sondern durch die Intervention Gottes wirkt. Subjekt der imaginären Erfahrung kann, wie im Beispiel von Iakobos, der den heiligen Mann anflehende Gläubige sein, aber auch der heilige Mann, der beim Beten für einen Gläubigen eine Offenbarung empfängt. Dies ist der Fall in einer Erzählung über Theodoros von Sykeon, der Theodora, die Frau eines von ihm geheilten Silentiarios, empfing, die wissen wollte, ob zuerst sie oder ihr Mann sterbe. Nachdem sie Theodoros mit viel Mühe dazu überredet hatte, betete dieser zu Gott und empfing eine Offenbarung in dieser Sache und teilte Theodora mit, dass ihr Mann kurz vor ihr sterben werde $(\ldots)^{148}$. Die Bedeutung des Gebetes von einer Stufe zur nächst höheren zur Erlangung des göttlichen Beistandes zeigt auch eine Episode aus der Philotheos Historia, wo der in einer

144328.

145 329. S. auch 318.

$146148=330$ (S.u Kap. 2.3.2, A. 311).

147 S.o. A. 145.

148237. 
von den Markioniten heimgesuchten Gegend lebende heilige Mann Iakobos, nachdem er von Theodoret dazu aufgefordert worden war, die ganze Nacht betend verbrachte und schließlich eine Stimme vernahm, die sagte, er solle sich nicht fürchten, da Ioannes der Täufer ständig zum Herrn bete und ein Gemetzel verhindert habe ${ }^{149}$. Bei diesem Beispiel ist mit Ioannes dem Täufer noch eine weitere Zwischenstufe zwischen dem heiligen Mann und Gott eingefügt, was aber nichts am eigentlichen Schema ändert. Genau darum geht es auch, wenn Hypatios äußert, dass ein Besessener nur durch den Herrn geheilt werden kann, der sich wegen der Gebete der Heiligen allen gegenüber menschenfreundlich zeigt $^{150}$. Der christliche heilige Mann erweist sich demnach als Zwischenglied zwischen Mensch und Gott und unterscheidet sich in seiner stets betonten Demutshaltung deutlich von seinem hellenistischen „Vorgängertypus“, dem sogenannten ,göttlichen Mann“, dem die Fähigkeit zugesprochen wurde, aus eigener Kraft Wunder zu wirken ${ }^{151}$. Besonders anschaulich werden die genannten hierarchischen Strukturen in der Vita des Symeon Stylites des Jüngeren wiedergegeben, wo das rettende Eingreifen durch eine imaginäre Erfahrung sowohl aus der Sicht des heiligen Mannes als auch des diesen anflehenden Gläubigen geschildert wird. Hier wird der heilige Mann, der durch die Fähigkeit der Klarsicht ${ }^{152}$ während des Gebets von der Notsituation des Gläubigen erfährt, - noch immer zu Gott betend - bilokatorisch aktiv und rettet den Gläubigen imaginär aus der Notsituation. Dieser hingegen ruft in seiner Not den heiligen Mann um Hilfe an und erblickt ihn sogleich als Helfer in einer imaginären Erfahrung. Neben einem an späterer Stelle ausgeführten Beispiel ${ }^{153}$, begegnet der genannte Ablauf auch in der Erzählung über einen Mann, der von einem Dämon befreit wurde und trotzdem nicht von seiner schlechten Gesinnung abließ, woraufhin ihm der wutentbrannte Symeon in einer nächtlichen Vision die rechte Hand entfernte. Als der Mann erwachte, war seine Hand gelähmt, und nach einigen Tagen löste sich das Fleisch an den Fingern, sodass nur noch die Knochen und die daran befestigten Nerven zurückblieben und von Würmern zerfressen wurden. Als der nunmehr reumütige Mann wieder zu Sy-

149326.

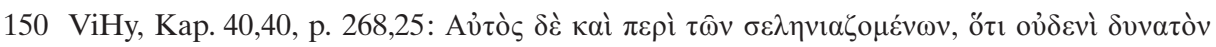

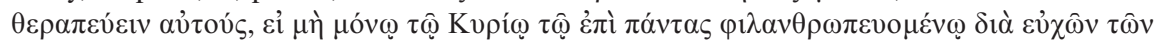

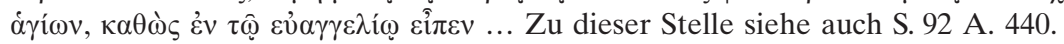

151 Vgl. Bieler, @eiOs anHP 134-140, Stathakopoulos, Rain miracles, hier 82, Van UytFAnghe, La biographie classique 247. Die drei durch das Gebet verbundenen sukzessiven Etappen werden auch bei GraBAR, Martyrium II 355 erwähnt, hier aber mit Betonung auf die Reliquie, die in der Spätantike als Mittler zwischen dem Gläubigen und dem Heiligen galt und in frühbyzantinischer Zeit zunehmend von der Ikone ersetzt wurde.

152 S. S. $147-150$.

$153148=330$ (s. S. 69 A. 311 ). 
meon kam, schickte ihn dieser nach Hause und befahl ihm, vom heiligen Staub, den er ihm mitgab, auf die Wunde zu streuen, um von Gott geheilt zu werden. In der folgenden Nacht sah sich Symeon - gerade als er dabei war, seinen Schülern das Wort Gottes zu verkünden - bei jenem Mann stehen und die schreckliche Wunde heilen, indem er mit der rechten Hand ein wenig Speichel aus seinem Mund nahm und auf der Wunde verteilte und so die Hand des Mannes wieder herstellte, zur Bestrafung seiner schlechten Gesinnung aber den Mittelfinger abfallen ließ. Weiter wird erzählt, dass der Mann in der gleichen Nacht sah, wie Symeon zu ihm kam und durch eine rötliche, aus seinem heiligen Staub bestehenden Salbe, wieder Fleisch um die Knochen seiner Hand bildete. Der Mann sah, wie alle Würmer herunterfielen und sich an den Knochen der Hand wieder Fleisch bildete, so als ob es aus einem flüssigen Zustand in einen festen übergehen würde. Dann bildete sich Haut darüber. Nur der bereits erwähnte Mittelfinger fiel samt dem Nagel $a^{154}$.

Auch bei der Schilderung vom wunderbaren Eingreifen des heiligen Mannes für eine ganze Gruppe von notleidenden Gläubigen, ein in der monastischen Literatur häufig verwendetes Motiv ${ }^{155}$, wird der durch das Gebet ausgelösten imaginären Erfahrung zuweilen eine Schlüsselposition zugewiesen. So wird in der Vita Hypatii erzählt, dass das Wasser des in der Nähe des Klosters des heiligen Mannes gelegenen Stroms verschmutzt war, sodass die Brüder krank wurden und schreckliche Qualen erlitten. Da fing Hypatios an, zu fasten und den Herrn zu bitten, ihnen entweder Wasser zu schenken oder die feindlichen Machenschaften zu beenden. Nach drei Tagen sah er drei Engel, die ihm zeigten, wo er ein Wasserloch graben sollte ${ }^{156}$. Auch vom heiligen Nikolaos wird erzählt, dass er von den Dorfbewohnern gebeten wurde, ihnen eine verborgene Quelle auf dem nahegelegenen Berg, von deren Existenz sie wussten, deren genauen Ort sie aber nicht kannten, zu zeigen. Daraufhin zog Nikolaos mit der gesamten Dorfbevölkerung auf den Berg und flehte zu Gott, er möge ihm den verborgenen Schatz des Wassers zeigen. Danach sagte er zu den Dorfbewohnern, dass ihm Gott an der Stelle, wo er auf die Knie gefallen war, den Segen des Wassers geoffenbart habe. Die Männer begannen an dieser Stelle zu graben, und tatsächlich befand sich dort das verborgene Wasser ${ }^{157}$.

Was in den behandelten Texten zunächst wie ein ziemlich konstruiertes literarisches Muster anmutet, reflektiert eine im Umfeld des frühen Mönchtums offenbar stark verwurzelte soziale Struktur, in der den heiligen Männern die

154427.

155 Die Intervention von Heiligen für eine ganze Gruppe (in der Regel durch das Gebet) kommt v. a. bei gesellschaftsbedrohenden Naturgegebenheiten wie Trockenheit, Hunger etc. vor; vgl. StathaKopoulos, Rain Miracles 81.

156322.

157325 . 
Kompetenz zugesprochen wurde, eine Mediatorenrolle zwischen den weltlichen Christen (bzw. dem sich noch am Anfang der spirituellen Laufbahn befindenden Mönch) $)^{158}$ und dem göttlichen Walten zu übernehmen; wie schon ClAUdiA RAPP anhand der Korrespondenz Barsanuphios und Ioannes plausibel gezeigt hat, war es durchaus üblich, dass sich „normale Gläubige“ mit ihren Sorgen und Wünschen nicht direkt an Gott wandten, sondern in das Gebet eines ausgewiesenen heiligen Mannes einschließen ließen, um in einem bestimmten Anliegen erhört zu werden $^{159}$. Darüber hinaus wird auch hier einmal mehr deutlich, dass für das wunderbare Wirken des heiligen Mannes nicht mehr ein direkter physischer Kontakt mit dem Gläubigen - sei es durch ein unmittelbares Wirken des noch lebenden heiligen Mann oder durch die Vermittlung von Reliquien des bereits verstorbenen Heiligen an einer bestimmten Kultstätte - vorausgesetzt wird. Vielmehr wird jetzt dem (imaginären oder materiellen) Bild des heiligen Mannes dessen reale Präsenz und somit die Kraft zugesprochen, Wunder zu wirken.

\subsection{Ungesuchte imaginäre Erfahrungen}

Die meisten Typen von imaginären Erfahrungen, bei denen der überraschende Aspekt dominiert, beziehen sich sowohl auf das monastische als auch auf das weltliche Umfeld ${ }^{160}$. Es sind dies im Wesentlichen „Befehle und Anordnungen“ [II O $]^{161}$, „Dogmatische, exegetische und ethische Belehrungen“ [II Q] ${ }^{162}$, ,Zurechtweisungen, Strafandrohungen und Bestrafungen“ [II R] ${ }^{163}$, aber auch „Heilungen“ [II I 2] $]^{164}$. Bei den bereits in Kapitel 1.2.4 ausgeführten Beispielen,

158 So A. 146.

159 RApp, For next to God you are my salvation 66-81; s. auch Hevelone-Harper, Disciples 79-105. Zur Mediatorenrolle der heiligen Männer vgl. auch Brown, Autorität und Heiligkeit 108 f. sowie Blum (ed.), Die Vita 21, und Timotin, Visions 44.

$160 \mathrm{Zu}$ den ungesuchten imaginären Erfahrungen siehe auch S. $70 \mathrm{f}$.

161 Befehle und Anordnungen (monast.): 349, 350, 353, 354 355, 356, 360, 362, 365, 367, 376 (weltl.): 352, 358.

162 Dogmatische, exegetische und ethische Belehrungen (monast.): 371, 373, 375, 382, 385 , 390, 392, 393 (weltl.): 377 (1; 2), 378, 379, 384, 386, 387, 391.

163 Zurechtweisungen, Strafandrohungen und Bestrafungen (monast.): 394, 395, 396, 397 , 398, 399, 400, 401, 402, 404, 406, 407, 408, 409, 415, 416, 417, 420, 421, 424, 425, 426; (weltl.): 403, 410, 413, 414, 418, 419, 422, 423, 427, 428, 429.

164 Anders als bei den häufig vorkommenden gesuchten Heilungen von „weltlichen Christen" werden die Charismatiker in der Regel durch ungesuchte imaginäre Erfahrungen geheilt: 266 [Heilung des Bruders Lyakon durch die hlg. Martha], 281 [Heilung des Theodoros von Sykeon durch den hlg. Georg geheilt], 283 [Heilung des Theodoros von Sykeon durch die Jungfrau Maria], 289 [Heilung eines Wüstenbruders durch die Kraft der imaginären Erfahrung], 292 [Heilung des Mönchs Ioannes durch die hlg. Martha], 297 [Heilung eines Bettlers durch den hlg. Symeon Stylites den Jüngeren], 367 
von denen die meisten zu „Rettungen in Notsituationen“ [II M] gehören, ist der überraschende Faktor zwar offensichtlich, da sie aber in der Regel als Folge von exzessiv ausgeübten asketischen Übungen auftreten, fallen sie letztlich doch wieder in den Bereich der bewusst evozierten religiösen Erfahrung ${ }^{165}$. Das dominierende Element, welches sich hier durch alle Typen hindurch zieht, ist der belehrende bzw. korrigierende Aspekt, der immer wieder einen unübersehbaren dogmatischen, manchmal geradezu fundamentalistischen Unterton mitschwingen lässt. In besonderem Maße gilt dies für die drastischen Bilder des Pratum Spirituale, welche die Verdammung von häretischen Strömungen und die Lehren der Orthodoxie veranschaulichen sollen. So berichtet Ioannes Moschos von Bruder Isidoros, der aus der Zeit seines weltlichen Lebens, als er und seine Frau der severianischen Kirche angehört hatten, erzählte, dass er eines Tages feststellte, dass seine Frau im Haus des Nachbarn an einem Gottesdienst der orthodoxen Kirche teilnahm. Als er in das Haus kam und sah, wie seine Frau gerade das heilige Abendmahl zu sich nehmen wollte, packte er sie auf der Stelle am Hals, brachte sie dazu, das heilige Stück auszuspucken und verabreichte ihr Prügel. Doch auf einmal sah er, wie ein Blitz über jenem Ort die heilige Gemeinde ergriff, und nach zwei Tagen sah er einen Äthiopier, der in ein Tuch gehüllt war und zu ihm sagte, dass er und Isidoros gleichermaßen dazu verdammt seien, in dieselbe Hölle zu kommen. Und als Isidoros den Äthiopier fragte, wer er sei, antwortete dieser, er sei derjenige, der Jesus Christus in der Zeit des Leidens auf die Wange geschlagen habe ${ }^{166}$. Ähnlich soll es auch der Severianerin Kosmiane ergangen sein, die sich eines Nachts in die Auferstehungskirche begab und sich dem Altar näherte, als die theotokos zusammen mit anderen Frauen an sie herantrat und zu ihr sagte, dass sie ihr so lange keinen Einlass gewähren werde, bis sie mit ihnen das Abendmahl einnehme. Daraufhin empfing Kosmiane das Abendmahl und wurde in das Allerheiligste der Auferstehungskirche eingelassen ${ }^{167}$. Zweifellos ist gerade bei diesen Typen von imaginären Erfahrungen der Faktor der Instrumentalisierung zu propagandistischen Zwecken des orthodoxen Dogmas besonders offensichtlich. Gleiches gilt aber auch für die von einem stark moralisierenden Duktus geprägten Belehrungen über das richtige christliche Verhalten in einem allgemeineren Sinne. Als Beispiel sei hier die Geschichte über Petros, einen geizigen Zöllner in Alexandrien, erwähnt, der niemals etwas den Armen schenkte. Als eines Tages mehrere Bettler eine Wette abschlossen, ob es gelingen würde, von Petros ein Almosen zu bekommen, setzte sich einer der Bettler vor die Tür des Zöllners. Als Petros

[Heilung eines Asketen durch Ioannes den Täufer]. Aber auch bei „weltlichen Christen“ kommen ungesuchte imaginäre Heilungen vor: 269, 271, 272.

165 S. dazu auch u. Kap. 2.4.

166384.

167 386. Weitere ähnliche Beispiele aus dem Pratum Spirituale: 382, 383, 385, 387, 388, 389, 390, 391, 416, 417, 418, 419. 
nach Hause kam, war er erzürnt über den Anblick des Bettlers, warf ihm aber widerwillig einen Silbertaler zu. Zwei Tage später wurde Petros todkrank und sah im Schlaf, wie er zur Rechenschaft gezogen wurde und wie alle seine Taten auf eine Waage gelegt wurden. Auf der einen Waagschale befanden sich schwarze, hässliche Gestalten, auf der anderen Weißgekleidete von furchteinflößendem Anblick. Da diese nichts Gutes fanden, was sie den von den Schwarzen versammelten Werken hätten entgegensetzen können, waren sie zutiefst betrübt, stöhnten und sagten, dass sie nichts hätten, außer dem Silbertaler, den Petros vor zwei Tagen widerwillig Christus geschenkt habe. Dann warfen sie den Silbertaler auf die Waagschale, und die Waage glich sich aus. Petros trugen sie auf, noch mehr als diesen Silbertaler zu spenden, damit er nicht von den Schwarzen mitgenommen werde. Und als er erwachte, erkannte er, dass das Gesehene wahr war, denn alles, was er seit seiner Jugend getan und selber schon wieder vergessen hatte, sah er nun von diesen Äthiopiern zusammengetragen auf der Waage liegen. Von nun an zeigte sich Petros den Armen gegenüber freigiebig $^{168}$.

Hinzu kommen die „Dämonenanschläge“ [II S], welche als ontologisches Gegenprinzip zu den göttlichen Offenbarungen die Gläubigen fast immer mit trügerischen Bildern täuschen, versuchen und zerrütten wollen ${ }^{169}$.

\subsection{Imaginäre Erfahrungen als Teil der spirituellen Biographie}

Das überraschende Element dominiert überdies bei den meisten imaginären Erfahrungen, die man auch als ,biographisch“ bezeichnen könnte ${ }^{170}$ und die v.a. bei „Inspirations-und Berufungsoffenbarungen“ $[\mathrm{II} \mathrm{E}]^{171}$, aber auch bei „Wegweisungen und Reiseanordnungen“ $[\mathrm{II} N]^{172}$ sowie bei den „Todesvisionen“ [H1] zu finden sind. Biographisch deshalb, weil sie immer an Schlüsselstellen der Asketenleben stattfinden, wo sie durch das gnadenvolle Eingreifen Gottes schicksalhafte Wendungen markieren. Von verschiedenen heiligen Männern wird berichtet, dass sie durch einen Traum oder eine Vision zu einem Leben in Askese hingeführt wurden, unter anderem von Pachomios, von Daniel Stylites oder von Theodoros von Sykeon, der sich als zwölfjähriger Junge in die Kapelle des Märtyrers Gemellos begab und über Nacht dort blieb. Plötzlich sah er sich bei einem König stehen, der von einer großen Leibgarde umgeben war. Eine

168377.

169 Mehr zu den Dämonenanschlägen s. S. 44 A.181 u. S. 114-120.

170 Eine Ausnahme stellen die bereits erwähnten Geburtsankündigungen [II E] dar, bei denen ein starker induzierender Charakter zu beobachten ist. S S. 31 f. u. S. 74.

$171 \quad 165-177$.

$172333,334,335,336,337,338,340,341,342,343,344,345$. 
Purpur tragende Frau stand bei ihm, und der König sagte: „Kämpfe, Theodoros, damit du im himmlischen Heer den vollkommenen Lohn erhältst und ich dich auf der Erde vor den Menschen ehre." Als er diese Stimme hörte, erwachte er und fing an, sich zurückzuziehen ${ }^{173}$. Hoch angesehen waren biographische Träume und Visionen nicht nur in der monastischen Literatur, sondern gerade auch in Biographien historischer Herrscherpersönlichkeiten ${ }^{174}$ und anderer prominenter Repräsentanten der spätantiken und byzantinischen Zeit ${ }^{175}$. Dass sie tatsächlich eine ernst zu nehmende Konstituente für die Legitimierung von Machtpositionen in der Gesellschaft, aber ebenso von persönlicher Heilserlangung darstellten, verdeutlichen insbesondere auch die häufigen Schilderungen von imaginären Erfahrungen in autobiographischen Traditionen ${ }^{176}$, in die sich aus den hier behandelten Quellen die Vita Macrinae mit Gregor von Nyssas berühmter Prophezeiungsvision zur Ankündigung des Todes seiner Schwester Makrina einreihen lässt ${ }^{177}$. Dies zeigt, dass bei einem simplen Verweis der biographischen imaginären Erfahrungen in den Bereich des literarischen oder gar hagiographischen Topos Vorsicht geboten ist. Zwar ist aufgrund ihres mehr oder weniger stereotypen Auftauchens an bestimmten Nahtstellen des biographischen Schemas von einem verhältnismäßig stark literarisierenden Charakter

173177.

174 Beispiele aus der byzantinischen Historiographie: Theophus Continuatus V 8, p. 221,19-222,18) erzählt, dass die Mutter von Basileios I. (867-886) durch mehrere Traumerscheinungen davon überzeugt wurde, ihren Sohn dazu zu bringen, aus der Provinz nach Konstantinopel aufzubrechen. Dieser befolgte ihren Rat, was dazu führte, dass Basileios I. in der Hauptstadt die Kaiserwürde erlangte und als Begründer der makedonischen Dynastie in die Geschichtsbücher einging. Bei Prokop, Anekdota 6,5-9, p. 58,17-60,3, ist nachzulesen, dass der zum Tode verurteilte isaurische Kriegsgefangene Iustinos I. (518-527) bloß deshalb mit dem Leben davon gekommen und später zu großer Macht aufgestiegen sei, da dem Feldherrn des Kaisers Anastasios in einem dreimaligen Traumgesicht von einer unbekannten Gestalt unter fürchterlichen Drohungen befohlen wurde, den Gefangenen freizulassen. Eusebios, Vita Constantini, I $28-$ 30 , p. 30,5-16, berichtet, dass es Konstantin dem Großen nicht möglich gewesen wäre, all seine Siege zu erringen und das Reich am Bosporus zu gründen, wäre ihm nicht im Schlaf ein Lichtkreuz am Himmel erschienen, das ihn mit christlichem Glauben erfüllte. Vgl. auch Timotin, Visions 28. Weitere Beispiele aus Prinzipat und Spätantike in Weber, Kaiser, Träume 174-492; Bovon, The Authority of Dreams 147 f., aus dem westlichen Mittelalter bei HeHL, Politische Träume 197-215, und aus der spätbyzantinischen Geschichtsschreibung s. TAXIDES, óveıpa 51-106. Zum „Privilegierungstraum“ im Alten Testament vgl. LE Goff, Le christianisme et les rêves 172.

175 Eine vorbildhafte Funktion hatten natürlich insbesondere die neutestamentlichen Träume aus dem Leben Jesu, s. S. 50 A. 211. Weitere Beispiele bei Dodds, Pagan and Christian 46; Frenschrowski, Traum und Traumdeutung 9; Cox Miller, Dreams in late antiquity 12; Vincent-Bernardi, Didascalie onirique 128 f.; 130, NäF, Traum und Traumdeutung 151. 159.

176 Dazu vgl. Hinterberger, Autobiographische Traditionen 42. 65, A. 15.

177229 (siehe dazu auch S. 140 f. A. 689). 
auszugehen ${ }^{178}$. Gleichzeitig aber zeugt die topische Verwendung nicht nur von einer ausgeprägten Bereitschaftshaltung hinsichtlich imaginären Erfahrungen in weiten Teilen der Bevölkerung, sondern auch davon, was in der Entstehungszeit und im Rezipientenkreis der Texte eine charismatische Autorität als solche legitimierte, was von ihr gefordert und deshalb auch geglaubt wurde ${ }^{179}$. Gerade die bei der Konstituierung eines charismatischen Idealtypus verwendeten literarischen Mittel stellen ein historisch besonders wertvolles Zeugnis für die gesellschaftliche Realität in der zur Diskussion stehenden Epoche dar ${ }^{180}$.

178 Zur topischen Verwendung der „Inspiration surnaturelle au cours d'une vision de songe“ vgl. Festugière, Lieux communs 126-128; zur Berufung (klesis - vocatio) als hagiographischer Topos vgl. PRATSCH, Der hagiographische Topos 109-116.

179 Mehr dazu in Kap. 4.3 u. Kap. 4.4.

180 Vgl. BJörck, ONAP I $\Delta$ EIN 310 f.; Brown, Autorität und Heiligkeit 95. 


\section{Kapitel - Bewusstseinszustände und imaginäre Erfahrungen}

\subsection{Im Spannungsfeld zwischen sinnlicher Wahrnehmung und Imagination}

Eine der wohl auffälligsten Gemeinsamkeiten der zahlreichen Erzählungen über imaginäre Erfahrungen ist die Verwendung einer Sprache, die darauf abzielt, transzendente Inhalte sensuell, d.h. in einer visualisierten (oder auditiven) Form, zu vermitteln. Gerade aufgrund des in den Quellen postulierten transzendenten Ursprungs werden diese Formen nicht als bedeutungslos bzw. bloß eingebildet, sondern im ontologischen Sinne als reale Anwesenheit des transzendenten Wirkens verstanden, sofern dieses göttlich (und nicht dämonisch) ist $^{181}$. Besonders deutlich wird dies durch eine an Apg 12,9 anlehnende Erzählung aus der Vita Euthymii über den Diakon Phidos, der auf einer Reise von Ioppe nach Konstantinopel Schiffbruch erleidet. Als ihm der bereits verstorbene heilige Euthymios auf dem Wasser wandelnd erscheint, um ihn zu retten und gleichzeitig aufzufordern, seine Reise abzubrechen, „wusste Phidos zunächst nicht, dass das, was geschah, wahr war. Vielmehr glaubte er, ein Gesicht zu sehen “"182. Freilich bietet sich, wie das Beispiel verdeutlicht, die Grenzverwischung zwischen Imagination und faktischer Realität gerade aufgrund der visuellen Komponente der Imagination und umgekehrt aufgrund der Möglichkeit der geistigen Visualisierung des Materiellen auf narrativer Ebene als erbauliches literarisches Stilmittel an: Unter der Voraussetzung, dass auf der Rezipientenebene auch die faktische Realität nicht mehr direkt sinnlich, sondern bloß noch als eine im Geiste stattfindende Visualisierung „geschaut“ werden kann, hebt der Autor die imaginäre Erfahrung auf dieselbe diegetische Wahrnehmungsstufe wie die faktische Realität, sodass in der Vorstellung des Rezipienten

181 Auch dämonischen Erscheinungen wird ein transzendenter Ursprung zugedacht, da die Dämonen verstanden werden als Wesen, die vom Teufel ausgehen, der wiederum ein Teil des göttlichen Heilsplans darstellt (s. S. 133 A. 653 u. 654). Gleichzeitig aber werden die durch Dämonen ausgelösten Bilder nicht als wahr, sondern als vorgetäuscht und somit als falsch im ontologischen Sinne interpretiert, s. S. 114 A. 554. Diejenigen Beispiele, wo Bildinhalten von imaginären Erfahrungen keinen transzendenten Ursprung zugeschrieben wird, beziehen sich auf den als gänzlich nichtig beurteilten Traum sowie auf die rein physiologischen bzw. humoralpathologischen Erklärungen der Entstehung von imaginären Bildern, s. S. 51-52.

182318 . 
beide Ebenen verschmelzen ${ }^{183}$. Besonders deutlich tritt dieses Muster auch bei den Exempla zutage, wo ein Heiliger aufgrund von bestimmten, schon zuvor in einem Traum oder in einer Vision erschienenen Merkmalen erst als solcher erkannt wird ${ }^{184}$. Was aber zunächst als gelungener literarischer Kniff ins Auge fällt, rührt darüber hinaus an den Kern des in sämtlichen Texten vermittelten Realitätsverständnisses in Bezug auf imaginäre Erfahrungen. Typisch dafür ist nicht nur der dem Geschauten zugedachte Wahrheitsgehalt, also dass Phidos Euthymios wirklich (und nicht eingebildet) gesehen haben soll, sondern auch, dass nicht explizit erwähnt wird, in welchem Bewusstseinszustand sich Phidos befand, als er Euthymios erblickte. Bewusst, so scheint es, wird hier die Grenzlinie zur Kennzeichnung des Einsetzens der Imaginären Erfahrung verwischt. Auch in zahlreichen weiteren Beispielen ist der Übergang in die Imagination nicht gekennzeichnet, sodass die sinnliche und die imaginäre Wahrnehmung solcherart ineinanderfließen, dass sich die Ereignisse gleichzeitig auf beiden Ebenen abzuspielen scheinen. Um dies noch einmal zu veranschaulichen, sei ein Beispiel aus der Historia Monachorum angeführt, welches von Makarios, dem Schüler des Antonios berichtet, dass er, nachdem er drei Wochen in der Wüste umhergeirrt war, im Zustand der völligen körperlichen Entkräftung an die Tore des Paradieses gelangte. Er wurde von einem Engel an die von Dämonen bewachten Eingänge des paradiesischen Gartens geführt, wo er zunächst betete, bevor er einzutreten wagte. Drinnen fand er zwei heilige Männer, die selber schon vor langer Zeit auf die gleiche Weise hierhergekommen waren. Sie wuschen Makarios die Füße und reichten ihm Paradiesesfrüchte, die er kostete. Makarios staunte über die Größe der Früchte und die Mannigfaltigkeit ihrer Farben. Inmitten des Paradieses gab es drei große Quellen, die aus der Tiefe hervorsprudelten und den Garten tränkten, sowie riesige Bäume, die jede Sorte von Früchten unter dem Himmel trugen ${ }^{185}$. Die gesamte Darstellung lässt die Vermutung zu, dass Makarios tatsächlich in der Wüste unterwegs war und nach langem Herumirren schließlich zu einer wirklich existierenden Oase gelangte. Umso mehr, wenn es später heißt, dass Makarios seinen Schülern als Beweis für seinen Ausflug ins Jenseits Früchte aus dem paradiesischen Garten mitbrachte. In der Tat ist es leicht nachvollziehbar, dass für die in harter Askese lebenden Wüstenväter ein fruchtbarer, wasserspendender Ort inmitten der Einöde jede Vorstellung vom himmlischen Paradies übertreffen

183 Cox Miller, Corporal Imagination 7 f, , verwendet für alle narrativen Mittel, die die Autoren einsetzten, um die Trennung zwischen Rezipienten und Text durch ein Aktivieren der sensorischen Imagination zu verwischen, den Begriff „Corporal Imagination“. Die Ebene der imaginären Erfahrung, die innerhalb dieses Konzeptes als „Imagination in der Imagination" bezeichnet werden könnte, wird dabei jedoch kaum thematisiert; siehe auch S. 34 f. A. 140.

184 S. S. 33 , A. 129 u. 130.

185252. 
musste. Und dennoch bleibt es für den Rezipienten letztlich im Bereich der Spekulation, inwieweit die Erzählung auf das tatsächliche Eintreten in eine „paradiesisch“ erscheinende, faktisch existierende Wüstenoase verweist oder auf eine imaginäre Reise ins Jenseits, von der Makarios die Früchte seiner asketischen Anstrengungen - die spirituelle Vollendung ${ }^{186}$ - mitbringt. So wenig fassbar wie bei derartigen Erzählungen die Trennlinien zwischen sinnlicher Wahrnehmung und Imagination sind, so verschwommen stellt sich bei den Erzählungen von imaginären Erfahrungen oft auch das Hinübergleiten von einem Bewusstseinszustand in einen anderen dar.

\subsection{Bewusstseinszustände als Voraussetzung imaginärer Erfahrungen?}

In vielen Beispielen wird, wie in den Episoden über Phidos und Makarios' Gang ins Paradies, der Bewusstseinszustand, in dem sich der Seher während der imaginären Erfahrung befindet, gar nicht genannt, und es bleibt unklar, ob sie im Wachzustand, im Schlaf, in Ekstase oder in einem anderen tranceartigen Zustand stattfindet ${ }^{187}$. Manchmal geht auch aus den Kommentaren der Autoren hervor, dass der Bewusstseinszustand, in dem eine Schau stattfindet, für den Offenbarungsgehalt des Geschauten letztendlich irrelevant ist. Von einem ägyptischen Asketen wird erzählt, dass er sich in der inneren Wüste niederließ und während langer Zeit viele gute Werke vollbrachte. Er liebte die Ruhe und verbrachte den Tag mit Gebeten, Hymnen und zahlreichen kontemplativen Erfahrungen „und sah göttliche Visionen, sowohl im Wachzustand als auch im Schlaf ${ }^{\star 188}$. Weitere Beispiele kombinieren die Begriffe, welche für die Schau oder die Audition im Sinne von „göttlicher Offenbarung“ (ỏ $\pi \alpha \alpha \sigma i ́ \alpha$, ő $\alpha \mu \alpha$, ö $\alpha \sigma 1 \varsigma$, ő $\psi 1 \varsigma, \theta \varepsilon \omega \rho i ́ \alpha$,

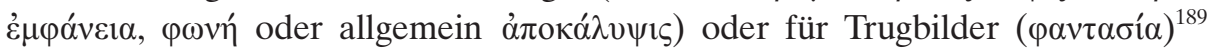
verwendet werden, auf unterschiedliche Weise mit allen Bewusstseinszustän$\operatorname{den}^{190}$. Aussagen darüber, in welchem körperlichen Zustand die genannten Typen

186 Zur Frucht als Metapher für die „spirituelle Nahrung“ des Asketen in der monastischen Literatur s. Rubenson 285-287. Vgl. auch die Bsp. 75, 129, 147, 154, 251, 314, 350, 448.

187 Weitere Beispiele aus denen der Bewusstseinszustand, in dem die imaginäre Erfahrung stattfindet, nicht hervorgeht: $8,10,13,15,23,26,27,28,29,30,31,32,33,35,36,54,60$, $61,67,97,103,106$ (1), 107, 117, 120, 131, 141, 143, 154, 155, 166, 171, 237, 238, 251, 258, $259,270,280,290,294,348,380,392,420$.

18825 .

$189 \mathrm{Zu}$ allen genannten Begriffen s. S. 104-107.

190 Eine Auswahl von Beispielen:

A) Vision (oj $\left.\pi \alpha \alpha \sigma^{\prime} \alpha\right)$ in Ekstase: 157, 397.

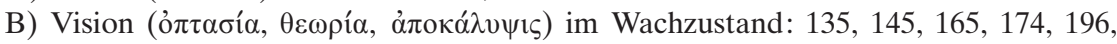
221, 241.

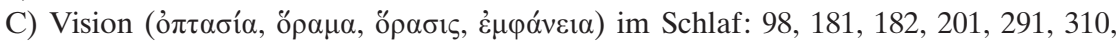
345, 355, 357, 378, 389, 409, 414, 427. 
von imaginären Erfahrungen ausschließlich vorkommen können, sind also in Bezug auf die behandelten Quellen problematisch. Demnach kann die zuweilen anzutreffende Ansicht, dass die Vision im Gegensatz zu dem an den Schlaf gebundenen Traum ausschließlich im Wachzustand stattfinde, für die hier behandelten Texte keinerlei Gültigkeit beanspruchen ${ }^{191}$. Das Gleiche gilt auch für Dinzelbachers Aussage ,Von Vision ist dann zu sprechen, wenn ein Mensch im Zustand der Ekstase oder des Schlafes den Eindruck empfängt, seine Seele werde durch das Walten übernatürlicher Mächte in einen anderen Raum versetzt, der bildhaft beschreibbar ist und wo ihm eine Offenbarung zuteil wird. Im Unterschied dazu gibt es bei der Audition und der Erscheinung keinen Raumwechsel, sondern eine Stimme oder Gestalt manifestiert sich in der gewohnten Lebensumwelt des Charismatikers, der meist im Zustand des normalen Alltagsbewußtseins verbleibt"192. Mit dieser Abgrenzung übernimmt Dinzelbacher letztlich automatisch Augustinus' Kategorien der „visio corporalis“ (bei Dinzelbacher Erscheinung) und der „,visio spiritalis“ (bei Dinzelbacher Vision) ${ }^{193}$. Gegen eine solche Definition wäre nichts einzuwenden, wenn sie nicht - wie es bei Dinzelbacher der Fall ist - pauschal formuliert wäre und somit einem theoretischen Konstrukt der katholischen Mystik Allgemeingültigkeit zuschreiben würde ${ }^{194}$. Für die hier behandelten Texte kann eine solche Abgrenzung alleine deshalb keine Gültigkeit beanspruchen, weil die Erscheinung im Sinne Dinzelbachers öfters auch als Vision (z.B. ó $\pi \tau \alpha \sigma i ́ \alpha)$ spezifiziert wird ${ }^{195}$ und weil zuweilen auch die Rede ist von Erscheinungen, die im Schlaf stattfinden ${ }^{196}$.

191 S. z.B. Hoheisel, Art. Vision/Visionsbericht 1126. S. dazu auch GeroK-Reiter, Einleitung 8. Eine Definition von Vision im hier vertretenen Sinne gibt auch Tiмотіn, Visions

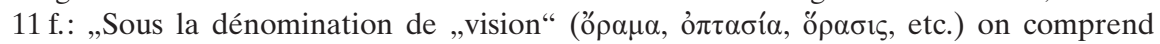
toute représentation, onirique ou en état de veille, qui a été interprétée par les Byzantins comme une révélation divine. Il peut s'agir d'un songe commun ou de l'apparition miraculeuse d'une figure divine ou sainte“.

192 Vgl. Dinzelbacher, Mittelalterliche Visionsliteratur, 19; s. auch Ders., Art. Visio(n) Sp. 1734 f. Diese Definition wurde so von Consolino, Sogni e Visioni 239, A. 5, übernommen.

193 Augustinus' hierarchische Dreiteilung in die „visio corporalis“, „visio spiritalis“ und „visio intellectualis“ (Augustinus, De Genesi ad litteram lib. XII, 12,6-15, p. 386-401) hat die Entwicklung der katholischen Mystik sowie deren Erforschung bis heute grundlegend geprägt; s. Arbman, Ecstasy or religious trance I 3-5.; Kreuzer, Art. Visio 1069; NäF, Traum und Traumdeutung 162; Dinzelbacher, Art. Mystik 982 f. (mit weiterführender Literatur). s. dazu auch Einleitung, A. 9.

$194 \mathrm{Zu}$ der Problematik der verallgemeinernden Anwendung von Augustins' Kategorien äußerte sich bereits ARBMAN, Ecstasy or religious trance I 4: „I need scarcely mention that in other and the great majority of forms of ecstatic religiosity no such theoretical problems have ever existed".

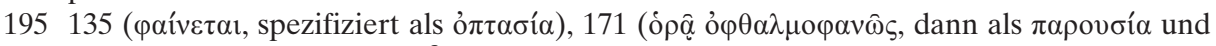
$\theta \varepsilon \omega \rho i ́ \alpha$ spezifiziert), 174 ( $\varepsilon \hat{i} \delta \varepsilon \ldots \kappa \kappa \tau \alpha \beta \varepsilon \beta \eta \kappa o ́ \tau \alpha$, später als ỏ $\pi \tau \alpha \sigma i ́ \alpha$ spezifiziert), 188

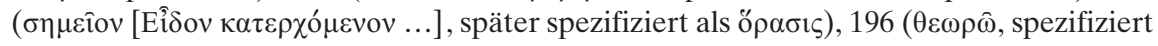


Ob selbstinduziert oder überraschend, ob im Schlaf, im Wachzustand oder in Ekstase, wesentlich ist - so vermitteln es die Texte - immer das Sichtbarwerden (und/oder Hörbarwerden) religiöser Inhalte und oftmals auch der beim Visionär dadurch ausgelösten esoterischen Vorgänge. Dabei spielt die Imagination stets die Rolle eines Motors zur Veränderung, sei es als Heilserfahrung für den kämpfenden Asketen oder als Heilungszenario für den kranken Gläubigen. Besonders anschaulich wird der Moment der Veränderung durch einen imaginären Vorgang in der Erzählung einer Dämonenaustreibung in der Vita des Symeon Stylites des Jüngeren geschildert. Dort ist die Rede von einem kranken Jungen, der erzählt, wie der heilige Symeon mit einem eisernen Stab und einer feurig roten Kette vor ihm stand. Da war auch ein schwarzer und furchterregender Dämon ohne Kopf, den Symeon fesselte und fragte, ob er nicht den Befehl bekommen habe, sich diesem Haus nicht mehr zu nähern. Nachdem der Junge dies erzählt hatte, blieb er lange stumm, und die Augen seines „inneren Menschen“ öffneten sich. Dann sagte er, seine Seele sehe nun, wie der heilige Symeon den Dämon mit hinter dem Rücken gefesselten Händen zu seiner Säule führe. Dort werfe er ihn in einen Feuerofen und lasse ihn heulend verbrennen. Nachdem der Junge dies erzählt hatte, war er wieder gesund ${ }^{197}$. Diese Episode dokumentiert wie viele andere auch, welch zentrale Bedeutung Imaginationsvorgänge im Entstehungs- und Rezeptionsumfeld der behandelten Texte für die Idee von Heilungs- und Heilserlangung gleichermaßen einnahmen. Der Bewusstseinszustand, in dem sich der Imaginationsvorgang abspielt, scheint auch bei diesem Beispiel dem Autor nicht weiter erwähnenswert.

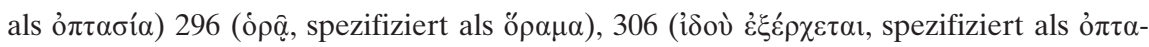

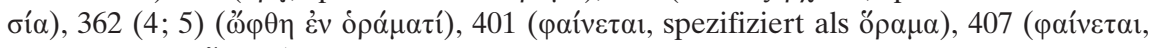
spezifiziert als ő $\rho \mu \alpha)$.

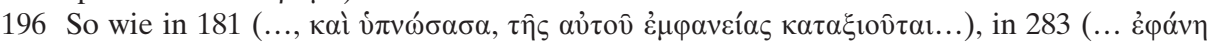

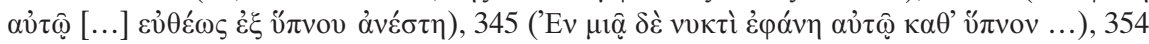

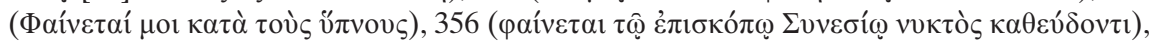

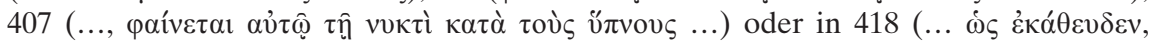

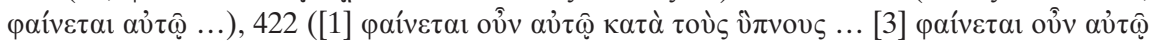

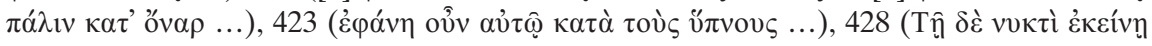

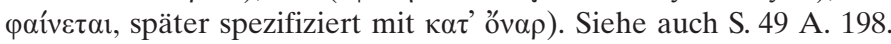

197279. 


\subsection{Schlaf}

\subsubsection{Schlaf und Traum}

\section{A. Traum als Offenbarungsmedium}

Wenn der Schlaf als Ausgangsdisposition der imaginären Erfahrung genannt wird, muss keineswegs notgedrungen von Traum die Rede sein, im Gegenteil, in zahlreichen Beispielen werden auch Formulierungen wie „er sah/es erschien im Schlaf" verwendet ${ }^{198}$. Obschon es möglich ist, dass der Leser bei diesen Schilderungen automatisch von einem Traumgeschehen ausging, spricht die häufige

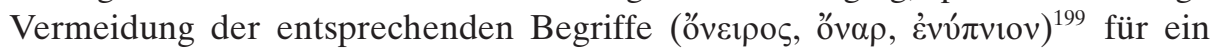
bewusstes Vorgehen der Autoren, welches vom zeitgenössischen Rezipienten mit großer Wahrscheinlichkeit auch als solches verstanden wurde. Diese Vermutung koinzidiert mit einer allgemein negativen Beurteilung des Traums sowohl im Neuen Testament als auch in der gesamten frühchristlichen Literatur ${ }^{200}$, wo der Traum zwar nicht grundsätzlich verleugnet oder abgelehnt wird, die Möglichkeit seiner Instrumentalisierung zu mantischen Zwecken jedoch vollständig entfällt ${ }^{201}$. Positiv wird er nur als Offenbarungsmedium Gottes bewertet, wie wir es schon aus der Septuaginta kennen. Man denke an die Joel-VerheiBung, wo der revelatorische Traum neben die göttliche Visionen gestellt wird ${ }^{202}$ und an die Erfüllung dieser Verheißung in Apg 2,17 ${ }^{203}$. Während Träume ohne Offenbarungsgehalt in der Septuaginta jedoch durchwegs als bedeutungslos beurteilt werden ${ }^{204}$ und im Neuen Testament gänzlich fehlen, begegnen sie in unseren Texten meistens im Zusammenhang mit gefährlichen, häufig als dämonisch bewerteten Trugbildern, wie noch zu zeigen sein wird ${ }^{205}$. Diese Di-

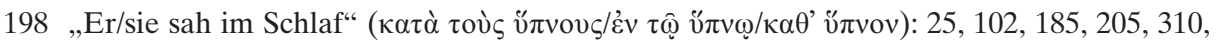

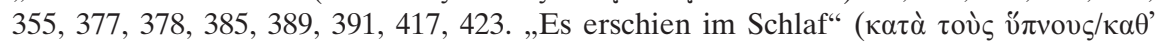

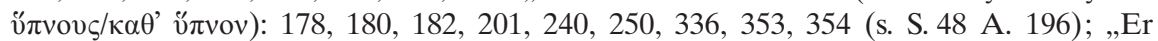

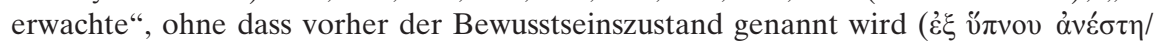

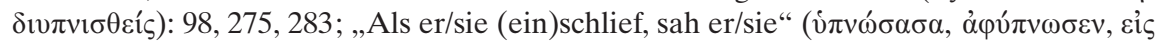

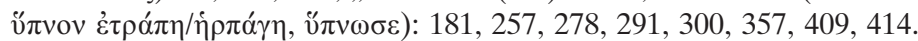

$199 \mathrm{Zu}$ diesen Begriffen s. S. 100-102.

200 Vgl. Berger, Visionsberichte 204; Le Goff, Le christianisme et les rêves 172; FrenSCHKOwSKI, Traum und Traumdeutung 9. S. dazu auch S. 65-69.

201 S. S. 50 A. 211 u. S. 124 A. 612.

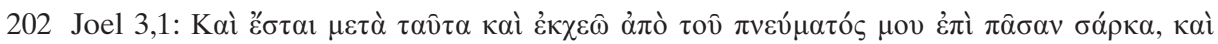

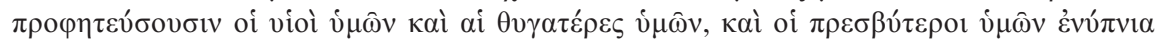

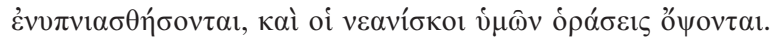

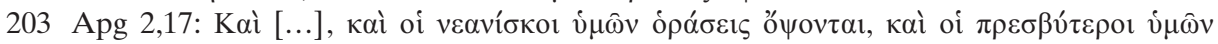

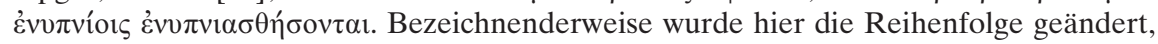
sodass die Träume an zweiter Stelle, nach den Visionen, genannt werden. Vgl. dazu BEnZ, Die Vision, hier „Traumvisionen“ 107-108.

204 Wie bei Sirach, s.u. A. 217.

205 S. S. $53-62$. 
chotomie zwischen göttlich bzw. „engelhaft“ und „dämonisch“, die auch in Euagrios' Formulierung ,ein engelhafter Traum erfreut das Herz, ein dämonischer verwirrt es ${ }^{‘ 206}$ zum Ausdruck kommt, gilt in unseren Texten allerdings nicht nur für den Traum, sondern für alle Formen von imaginären Erfahrun$g \mathrm{n}^{207}$. In den Erzählungen über Träume wird dieser Unterschied häufig dadurch verdeutlicht, dass der Traum, wenn er als Offenbarung gedacht ist, durch einen terminologischen Zusatz (z.B. ỏ $\pi \tau \alpha \sigma i ́ \alpha$ oder ö $\rho \mu \mu \alpha)^{208}$ als Vision spezifiziert wird $^{209}$. Einmal ist von einem Traum des Sergios, Schüler des verstorbenen Symeon Stylites in Syrien die Rede, dessen Offenbarungsgehalt für den Leser erst dadurch deutlich wird, dass er mit einer Vision des heiligen Daniel Stylites übereinstimmt ${ }^{210}$. Bei denjenigen Beispielen, in denen für die Überbringung eines Offenbarungsinhalts die bloße Traumterminologie verwendet wird, handelt es sich meistens um die neutestamentliche, aus dem Matthäusevangelium bekannte Wendung $\kappa \alpha \tau^{\prime}$ öv $\alpha \rho^{211}$. Es ist naheliegend, dass diese direkte Anlehnung an die Traumerzählungen im Neuen Testament in der Entstehungszeit der behandelten Texte bereits als feststehende Terminologie der christlichen Literatur mit implizitem revelatorischem Sinngehalt verwendet wurde, sodass ein entsprechender Zusatz nicht mehr notwendig war. Eine Ausnahme bilden die Traumerzählungen des Theodoret von Kyrrhos, der konsequent eine völlig eigene, an der antiken Dichtung orientierte Traumterminologie verwendet ${ }^{212}$. Auch in der Vita Pachomii kommt zweimal ein Traumbegriff (દ̇vó $\pi v i o v)$ mit der Bedeutung von Offenbarung, jedoch ohne zusätzliche Visionsterminologie, vor. Hier deutet alles auf die bewusste Verwendung des Traumes als inferiores Offenbarungsmedium an den entsprechenden Stellen im Text hin, denn beide Male stellt er in der Funktion eines Initiatinonstraums eine Zäsur dar, die den Übergang vom weltlichen ins monastische, nunmehr durch Visionen im Wachzustand oder in Ekstase gekennzeichnete Leben markiert: Im ersten Fall träumt Pachomios direkt nach seiner Taufe, also am Anfang seiner spirituellen

2066.

207 S. S. 118 A. 583.

$208 \mathrm{Zu}$ diesen Begriffen s. S. 104 f. u. $110 \mathrm{f}$.

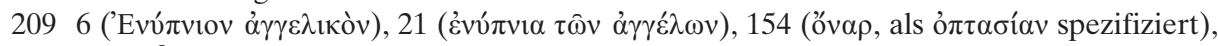

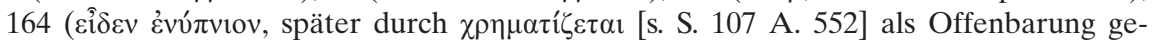

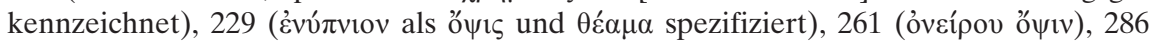

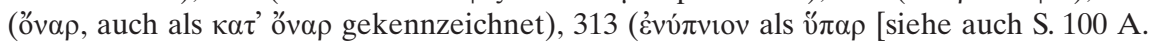

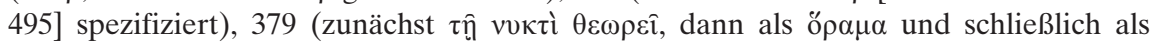

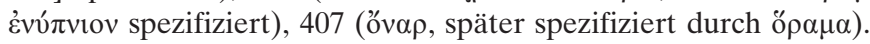

210158.

211 122, 162, 286, 305, 309, 316, 335, 350, 393, 402, 408, 422, 424, 428, 440. Entsprechend Mt 1,$20 ; 2,12.13 .19 ; 27,19$, wobei es sich um die einzigen im Neuen Testament vorkommenden Traumerzählungen handelt, vgl. Frenschkowski, Traum und Traumdeutung 14-30; Bovon, The Authority of Dreams 153 f.; Timotin, Visions 26.

212 37, 39, 93, 94, 268. Zu Theodorets Vokabular s. S. 100 A. 495. 
„Laufbahn“213, während der er zahlreiche weitere Offenbarungen empfängt, jedoch keine mehr im Traum. Auch beim zweiten Beispiel befindet sich der Träumende an der Schwelle vom weltlichen ins monastische Leben ${ }^{214}$. Es ist also anzunehmen, dass der Autor eine gewollte, parallel zum Aufstieg auf dem christlichen Heilsweg verlaufende Abstufung der verschiedenen Offenbarungsformen intendierte ${ }^{215}$, wobei der Traum gegenüber den anderen Revelationsarten eine untergeordnete Stellung einnimmt. Für Offenbarungsträume ohne zusätzliche terminologische Spezifizierung sind lediglich zwei weitere Beispiele, eines aus dem Pratum Spirituale und eines aus der Vita des Daniel, belegt ${ }^{216}$.

\section{B. Der nichtige Traum}

Fungiert der Traum nicht explizit als Träger einer göttlichen Offenbarung, wird er - insbesondere innerhalb des asketischen Lebensideals - dezidiert negativ beurteilt und als trügerische Gefahr der Ablenkung vom monastischen Pfad angesehen. Nur in wenigen Beispielen ist die Rede vom gänzlich nichtigen und bedeutungslosen Traum, vor dessen falschen Beurteilung schon Sir 34,1-6 warnt: „Wie sich der unverständige Mann nichtigen und trügerischen Hoffnungen hingibt, so regen auch die Träume unvernünftige Menschen auf. Wie einer, der nach dem Schatten greift und den Wind hascht, so ist der, der auf Träume achtet. Denn was einem Ding als Spiegelbild gegenübersteht, gleicht einer Traumerscheinung. Sie ist wie ein Abbild des Antlitzes im Verhältnis zu dem Antlitz selbst. ... Weissagungen, Wahrsagungen und Träume sind nichtig

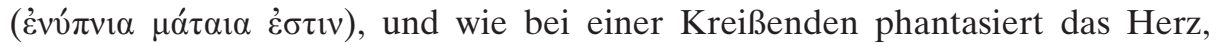
wenn sie nicht vom Höchsten geschickt werden, indem er den Träumenden heimsucht“"217. Die Träume, die „nicht vom Höchsten geschickt werden“, begegnen in den behandelten Texten nunmehr häufig als dezidiert negative, oft dämonische Trugbilder. Nur in vereinzelten, für die monastische Literatur eher untypischen Beispielen, wird der Traum im Sinne von Sirach als gänzlich bedeutungslos dargestellt, so einmal in der Scala Paradisi, wo es heißt „Wer an

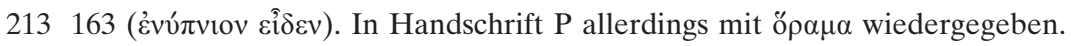

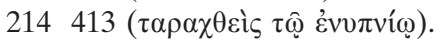

215 Auch für die Träume des Alten Testaments wurde die Beobachtung gemacht, dass ,der Traum als eine Form der Offenbarung erscheint, mit der Gott sich vor allem den ihm ferner Stehenden bekundet", BENZ, Die Vision 106-107.

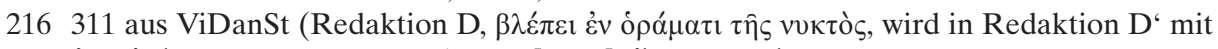

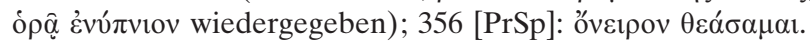

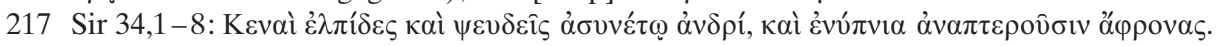

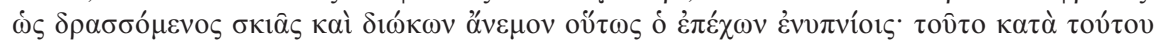

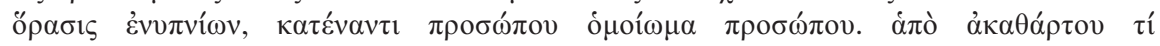

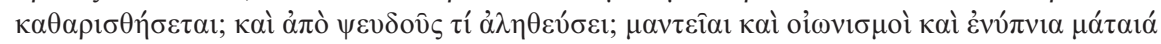

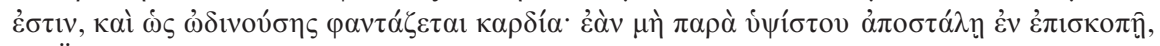
... Übersetzung aus BENZ, Die Vision $104 \mathrm{f}$. 
Träume glaubt, gleicht demjenigen, der seinem eigenen Schatten nachläuft und versucht ihn festzuhalten “218. Ein weiteres Beispiel ist am Anfang der Vita des Symeon Salos zu finden, wo der Traum als Metapher für das schnelle Vergessen von etwas Unbedeutendem verwendet wird, denn „als Symeon und Ioannes beschlossen, Welt und Familie hinter sich zu lassen, vergaßen sie ihren ganzen Besitz und die Eltern wie einen Traum “219. Zuweilen wird der bedeutungslose Traum bewusst mit einer göttlichen Offenbarung kontrastiert, deren Wahrnehmungsform dann nicht genannt wird (sie könnte also ebenfalls in Form eines Traumes stattfinden). So in der Vita Hypatii, wo erzählt wird, dass dem Häretiker Nestorios, nachdem er in Konstantinopel als Bischof eingesetzt worden war, eine Prophezeiung des Hypatios zu Ohren kam, welche besagte, dass Nestorios nicht länger als dreieinhalb Jahre in der Hauptstadt regieren werde. Darauf sandte Nestorios Boten zu Hypatios mit dem Auftrag: „Richtet diesem Träumer aus, dass ich zwanzig Jahre über Konstantinopel regieren werde. Man wird sehen, wo dann deine Träume bleiben werden“. Darauf ließ Hypatios dem Bischof ausrichten: „Wenn das, was ich gesehen habe, eintrifft, war es eine Offenbarung, ansonsten ist es ein Traum, und ich habe es mir wie ein Mensch eingebildet'. Nach dreieinhalb Jahren erfüllte sich die Prophezeiung ${ }^{\text {‘220 }}$. Um ebendiesen Gegensatz zwischen nichtigem Traum und wahrer Offenbarung zu veranschaulichen, bemüht Theodoret von Kyrrhos sogar die homerische Wen-

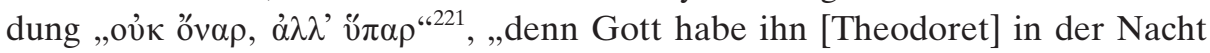
darüber belehrt, nicht in einem schemenhaften Traum, sondern in einem wahren Gesicht“"222. Theodoret macht sich hier eine klassische Wendung zunutze, die verdeutlicht, dass einem Gesicht im Wachzustand schon in der Antike eine höhere revelatorische Glaubwürdigkeit beigemessen wurde als dem Traum. In Verbindung mit dem für das frühe Mönchtum so zentralen Ethos der „Wachsamkeit", von dem weiter unten noch die Rede sein wird, gewinnt der Inhalt der homerischen Wendung noch zusätzlich an Brisanz ${ }^{223}$.

21847.

21951.

22085.

221 Odyssee 19,547, p. 540,21. Der Adler, welcher Penelope erscheint, sagt zu ihr: „ov̉

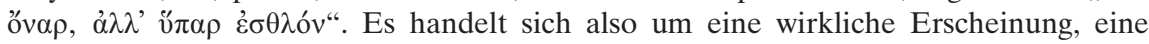
Vision der Realität und nicht um einen Traum. Zur Bedeutung von v̈ $\pi \alpha \rho$ s. S. 100 A. 495.

222 93. S. Gregor von Nyssas abweichende Verwendung von $0 \pi \alpha \rho$ in 313, wo er nicht im Kontrast zum (bedeutungslosen) Traum eingesetzt wird, sondern vielmehr, um den Wahrheitsgehalt des Traumes zu untermauern.

223 S.u. Kap. 2.3.2. 
C. Der gefährliche Traum - dämonische Machenschaft oder psychobiologischer Vorgang?

Nicht nur als bedeutungslos, sondern als entschieden negatives Phänomen wird der Traum vor allem in den Exempla der Heiligenviten im Zusammenhang mit Dämonen dargestellt, die ihn, durch die Hilflosigkeit der Schlafenden angezogen, als Angriffsmedium instrumentalisieren. Wie im oben erwähnten Beispiel aus der Vita Hypatii für einen als bedeutungslos bewerteten Traum wird auch der dämonische Traum in einen bewussten Kontrast zu der nicht durch den Traum vermittelten Offenbarung gestellt. Von Symeon Stylites dem Jüngeren wird berichtet, dass er, bezeichnenderweise noch am Anfang seines asketischen Heilswegs, durch satanische Traumbilder in Versuchung geführt wurde. „Da er jedoch von der Kraft Gottes umgeben war, beugte er sich dem Traum nicht". Vielmehr flehte er, nachdem er aufgewacht war, Gott um Hilfe an und ,sah einen Priester, einen heiligen Diener der himmlischen Altäre, der in den Händen ein Gefäß mit dem Körper und Blut Jesu hielt. Der Ort wurde erfüllt von einem wohlriechenden Räucherwerk, und Symeon musste dem Priester geloben, niemals den Listen des Körpers in den Träumen zu unterliegen ${ }^{224}$. Je weiter ein Mönch auf dem Heilsweg vorangeschritten ist, umso geringer ist die Gefahr, dass er noch von falschen Träumen getäuscht wird. Junge Mönche und Novizen sind also besonders gefährdet, während des Schlafens von trügerischen Bildern heimgesucht $\mathrm{zu}$ werden ${ }^{225}$, aber auch erfahrene Asketen sind nicht vor dämonischen Träumen gefeit, wie aus einem Beispiel aus der Korrespondenz des Barsanuphios und Ioannes hervorgeht, in dem Barsanuphios die wilden Tiere in den Träumen eines geron als dämonische Erscheinungen interpretiert ${ }^{226}$. Auch hier gilt, wie für alle anderen Formen von imaginären Erfahrungen, dass Nachlässigkeit in der Askese und alles, was dem Ideal des engelgleichen Lebens entgegenläuft, die Gefahr der trügerischen Schau, insbesondere des vom rechten Pfad ablenkenden, unerwünschten dämonischen Traums, mit sich bringt. Zum Ausdruck kommt dies auch, wenn von einem Einsiedler in der Thebais erzählt wird, dass er „durch den Stachel der Ruhmsucht von Traumbildern getäuscht wurde“"227.

Bei eingehender Betrachtung der Texte wird jedoch bald deutlich, dass die Gefährlichkeit der Träume für den kämpfenden Asketen keineswegs nur mit dämonischen Machenschaften begründet wird. So ist auf theoretischer Ebene die Vorstellung, dass Dämonen durch nächtliche Täuschungen die Schlafenden angreifen, wiederholt neben Erklärungsmodellen zur Entstehung von Träumen aus unterschiedlichen Richtungen der antiken Philosophie und Physiologie

224473 und 186.

225 S. S. 56 A. 240.

226440 (s. S. 102, A. 507).

22724. 
anzutreffen. In einem Väterspruch des Antonios ist nachzulesen, dass es drei Bewegungen des Körpers gebe: „Die erste ist eine natürliche, die zweite kommt von der Unverträglichkeit der Speisen, die dritte aber von den Dämonen“228. Zwar werden im Väterspruch die drei genannten Bewegungen nicht in einen direkten Zusammenhang mit der Entstehung von Träumen gebracht, dennoch ist die Parallele zu den Ausführungen anderer Autoren, welche die Körperbewegungen als Ursache für Traumbilder nennen, evident, wie aus den folgenden Ausführungen hervorgeht. Während laut der auf Hippokrates und Galen zurückgehenden und bekannterweise auch bei Gregor von Nyssa anzutreffenden physiologischen Erklärung der Entstehung von Träumen meistens der zweite im Väterspruch genannte Aspekt, also die Verdauung, im Vordergrund steht ${ }^{229}$, ist im Väterspruch von zwei weiteren Bewegungen die Rede, nämlich von der

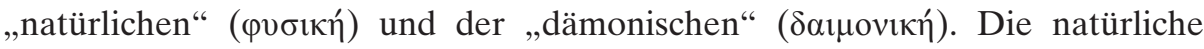
Bewegung sei, so Antonios, direkt mit dem Körper verbunden, funktioniere aber nur mit dem Einverständnis der Seele und bezeichne lediglich eine leidenschaftslose Bewegung im Körper ${ }^{230}$. Die zweite Bewegung werde durch das

228 ApSy V 1,12-14, Bd. 1, p. 240: Nach einer ausführlicheren Abhandlung folgt die Zu-

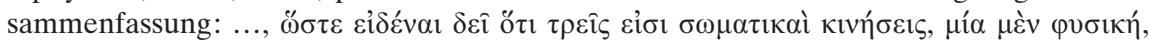

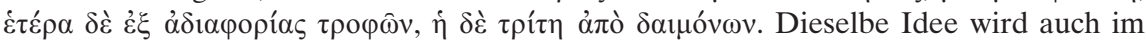
ersten Antonios zugeschriebenen Brief (PG 40, col.979A-B) wiedergegeben, vgl. Guillaumont (ed.), Traité Pratique 628; Guy (ed.), Les apophtègmes des pères I-IX 241, A. 2; Bravo García, Sueño y ensueño 191 f.; Brakke, Demons 16.

229 Zur physiologischen Erklärung der Traumentstehung bei Hippokrates und Galen s. HANson, Dreams and visions 1396-1397 und 1399-1400; LE GoFf, Le christianisme et les rêves 176 f.; Bravo García, Fisiologia y filosofia en Aristoteles 15-65 (dieser Aufsatz war mir leider nicht zugänglich). Greogor von Nyssa, hom. opif. 13 (PG 44, col.165-173), geht von einer weitgehend psychobiologischen Erklärung der Traumentstehung aus und bezeichnet Träume als „phantastischen Nonsens“ ( $\propto \alpha v \tau \alpha \sigma t \omega ́ \delta \eta \varsigma$ $\varphi \lambda v \alpha \rho i ́ \alpha \varsigma)$. Nur in ganz seltenen Fällen, nämlich dann, wenn es dem Geist gelingt, auch während des Schlafens aktiv zu bleiben, erhalten Träumer wie Daniel oder Joseph durch göttliche Kraft das Vorherwissen ( $\pi \rho o ́ \gamma v \omega \sigma i \varsigma)$ über Dinge, die sich in Zukunft ereignen (Zwei Beispiele von solchen Träumen gibt Gregor in der Vita Macrinae, s. 227, 313; während Gregor jedoch in hom. opif. die Traumbezeichnungen der Oneiromantie [s.

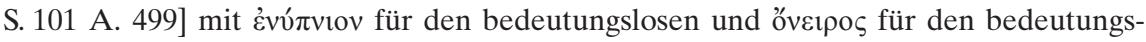
vollen [visionären] Traum verwendet [vgl. Tiмoтin, Visions 32], greift er in beiden Beispielen der Vita Macrinae auf die Terminologie der LXX zurück und bezeichnet die von ihm geschilderten Visionsträume als غ̇vótvvıv; siehe auch S. 101 A. 496). Normalerweise sind jedoch nach Gregors Ansicht während des Schlafens nur jene Teile der Seele aktiv, welche für die Verdauung zuständig sind, wodurch jede Sinneswahrnehmung verunmöglicht wird und wirre Träume aus Tagesresten entstehen. S. Refoulé, Rêves et vie spirituelle 478. 508; Miller, Dreams 47-51 sowie NäF, Traum und Traumdeutung 157-159.

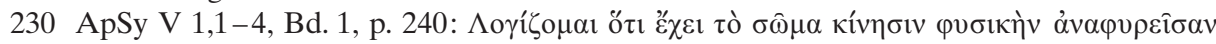

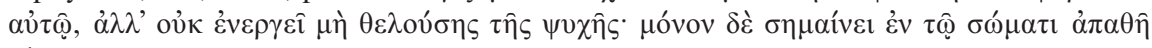

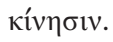


Ernähren und das Erwärmen des Körpers durch Speisen und Getränke ausgelöst, durch welche die Wärme des Blutes den Körper zu Aktivität antreibt ${ }^{231}$. Die dritte Bewegung, die aus den Anschlägen und dem Neid der Dämonen hervorgeht, wird im Väterspruch wohl deshalb nicht weiter erläutert, weil sie, im Gegensatz zu den ersten beiden Bewegungen, in den restlichen Apophthegmen in einer Vielzahl von Erzählungen über Dämonenanschläge veranschaulicht wird und deshalb keiner weiteren Erklärung bedarf ${ }^{232}$. Hervorzuheben ist an dieser Stelle, dass im Väterspruch insbesondere die durch die Ernährung ausgelöste Bewegung als Resultat von menschlichem Fehlverhalten, genauer gesagt von der als „Untugend“ gewerteten Maßlosigkeit, im moralischen Sinne als negativ beurteilt wird, was mit Bibelzitaten untermauert wird, die vor Trunkenheit und Schlemmerei warnen (Eph 5,18; Lk 21,34). Dagegen wird die natürliche Bewegung, von der weiter unten noch die Rede sein wird, als ein rein körperliches und deshalb außerhalb jeder moralischen Wertung stehendes Phänomen beurteilt. Auch in Bezug auf die dämonische Bewegung stellt sich, da die Existenz von Dämonen als Teil des göttlichen Heilsgeschehens angesehen wird, kaum die Frage nach der Schuldhaftigkeit des von ihr Heimgesuchten oder anders ausgedrückt nach der grundsätzlichen Möglichkeit einer Verhinderung des dämonischen Agierens. Vielmehr liegt das Interesse der Autoren diesbezüglich meist in der Frage, wie die Asketen mit dem nicht abwendbaren Wirken der Dämonen umzugehen haben, um nicht vom Voranschreiten auf dem eigenen Heilsweg abgehalten zu werden. Von zentraler Bedeutung erweist sich in

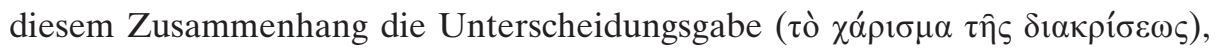
durch die das dämonische Agieren als solches entlarvt und damit wirkungslos gemacht werden $\operatorname{kann}^{233}$.

Weitergehende Ausführungen über die Thematik finden sich bei Euagrios, der v.a. in seiner Schrift De malignis cogitationibus, in der er mehrere Kapitel der Entstehung von dämonischen Trugbildern im Schlaf gewidmet hat, detaillierte Erklärungen über den Zusammenhang der genannten Körperbewegungen und dem Träumen liefert ${ }^{234}$. Euagrios geht von der Annahme aus, dass der Intellekt (vov̧) über die Sinne, d.h. über die Augen und Ohren, oder über die Erinnerung Bilder aufnimmt ${ }^{235}$. Diese Idee, die Euagrios keineswegs nur auf die

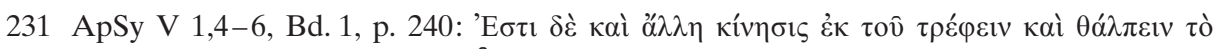

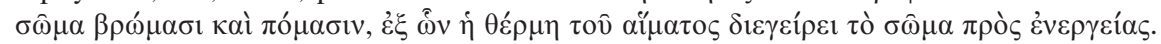

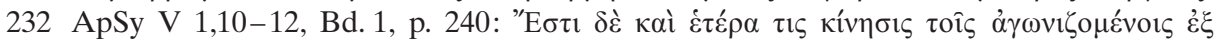

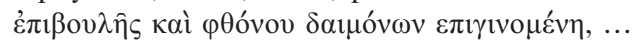

233 S. S. 114-120.

234 DeMa Kap. 4; Kap. 27-29, p. 162-165. 248-257.

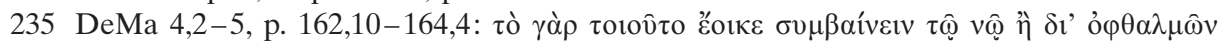

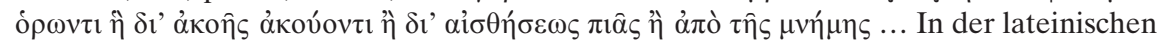
Übersetzung von Euagrios, Capita Cognoscitiva 17, p. 59 (23) wird als zusätzlicher Weg, über den der Intellekt Bilder aufnimmt, auch das Temperament (mit dem griechischen 
Traumbilder beschränkt, sondern auch auf die im Geiste des Wachenden entstehenden Bilder bezieht ${ }^{236}$, verbindet er mit der Intervention der Dämonen, wobei er v.a. die Entstehung der aus der Erinnerung hervorgehenden Bilder näher ausführt und sie mit platonischen und stoischen Begriffen untermauert ${ }^{237}$. Er führt aus, dass die Dämonen, da das Sinneswerkzeug während des Schlafens außer Gefecht gesetzt sei, die Erinnerung bewegen und so den Hauptteil der

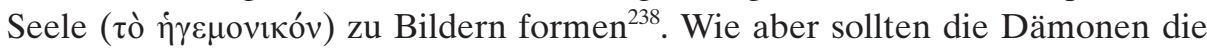
Erinnerung bewegen, wenn nicht durch die Leidenschaften ( $\delta 1 \grave{\alpha} \tau \hat{\omega} v \pi \alpha \theta \hat{\omega} v)$ ? Dies wiederum gehe daraus hervor, dass die Gereinigten und Leidenschaftslosen nichts mehr dergleichen erlitten ${ }^{239}$. So ist es denn auch nicht erstaunlich, dass insbesondere die jungen, am Anfang der asketischen Laufbahn stehenden Mönche, die dem Zustand der vollendeten Leidenschaftslosigkeit noch fern sind, von dämonischen Träumen heimgesucht werden. Als wolle Euagrios jedoch die jungen Mönche durch das allzu idealistische Ziel eines traumlosen Schlafes nicht gänzlich abschrecken, definiert er in der Praktike, einer Lehr-

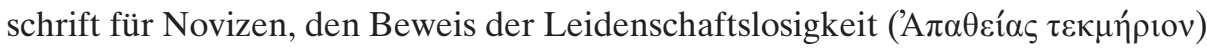
mit deutlich milderen Maßstäben, nämlich wenn „der Geist anfängt, seinen eigenen Glanz zu sehen und im Angesicht der Trugbilder im Schlaf ruhig bleibt und die Dinge gelassen sieht ${ }^{\text {‘240 }}$. Für die große Masse der noch nicht leidenschaftslos gewordenen Mönche stellt sich also nicht die Frage nach der Vermeidung von dämonischen Träumen, sondern vielmehr nach dem Umgang mit ihnen. In Bezug auf die Leidenschaften unterteilt Euagrios wiederum in die aus

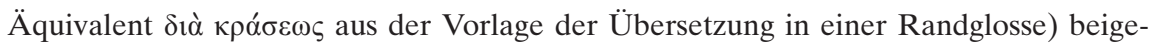
fügt: Quator sunt modi quibus mens accipit notitias, et primus quidem modus, qui per oculos, secundus, qui per auditum, tertius, qui per memoriam, et quartus, qui per temperamentum. S. auch Guillaumont (Ed.), DeMa 163, A. 3, und Bravo García, Sueño y ensueño 186.

236 Insbesondere in Momenten der asketischen Kontemplation und Konzentration, etwa während des Gebets, erzeugen die Dämonen laut Euagrios auf die genannten Arten Bilder im menschlichen Intellekt, was aus diversen Stellen von Euagrios' Schrift De Oratione (PG 79, col. 1165-1200) hervorgeht; s. dazu Refoulé, Rêves et vie spirituelle 477; Bravo García, Sueño y ensueño 185-188.

237 Ergänzend zu Refoulé, Rêves et vie spirituelle 508-512, der insbesondere den stoischen, aber auch den platonischen Hintergrund des Euagrios betont, betont Bravo García, Sueño y ensueño 187. 190, A. 22 u. 23 zusätzlich Euagrios' Anlehnung an Aristoteles.

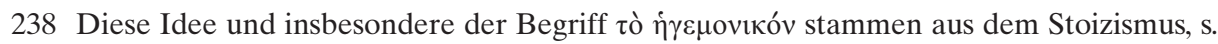

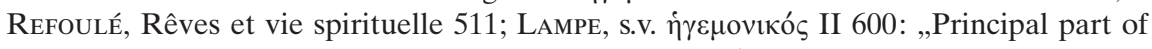

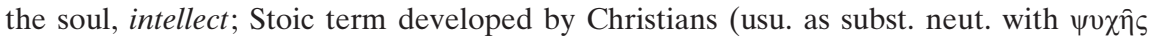
understood and rarely as adj.)“.

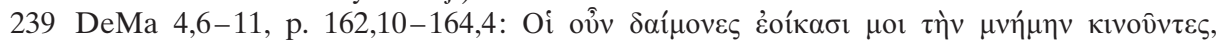

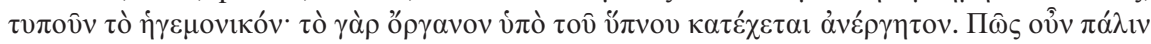

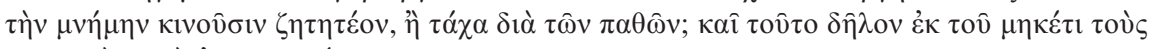

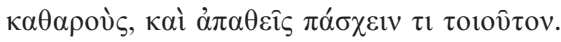

24045. 
Platon bekannten Begriffe des begehrenden ( $\tau$ ò $\varepsilon ં \pi \imath v \mu \iota \kappa o ́ v)$ und des zornigen ( $\tau$ ò $\theta v \mu$ เóv) Teils der Seele, wobei die Dämonen dafür sorgen, dass das Begehren erotische, der Zorn aber furchteinflößende Bilder hervorbringt ${ }^{241}$. Erst wenn die Dämonen weder den zornigen noch den begehrenden Teil der Seele durcheinanderbringen konnten, schaffen sie laut Euagrios Träume der Ruhmsucht und führen die Seele in einen Abgrund von schlechten Gedanken. Als Beispiel führt Euagrios unter anderem an, dass man sich selber irgendwelche Krankheiten heilen oder ein Hirtengewand tragen und eine Herde weiden lassen sieht (S. Bsp. 21). Daneben gibt es laut Euagrios auch eine einfache

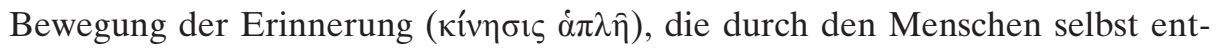
steht oder durch die heiligen Kräfte, mittels derer er [der Mensch] im Schlaf Heiligen begegnet, mit ihnen redet und zusammensteht ${ }^{242}$. Darum geht es Euagrios auch, wenn er an anderer Stelle ausführt, „dass die Beweise der Lei-

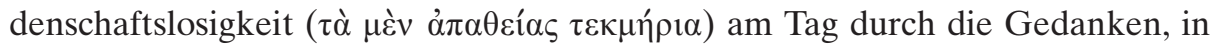
der Nacht durch die Träume zu erkennen seien“"243. Gemeint sind zweifellos jene engelhafte Gesichte, die durch die Unterscheidungsgabe als nicht dämonisch erkannt und als Zeichen der Leidenschaftslosigkeit gedeutet werden können ${ }^{244}$. Euagrios fügt also den drei im Väterspruch erwähnten körperlichen Bewegun-

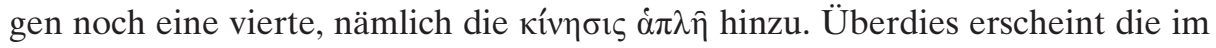
Väterspruch erwähnte Triade der körperlichen Bewegungen bei Euagrios nicht als Gruppe von nebeneinander stehenden Begriffen. Dennoch wird aus der Gesamtheit der euagrianischen Ausführungen deutlich, dass ihm das Konzept zumindest nicht unbekannt gewesen sein kann. Über die erste im Väterspruch erwähnte „natürliche“ Bewegung führt er in der Praktike aus, dass sie, ,wenn sie [die Bewegungen] bildlos sind, die Seele bis zu einem bestimmten Grad gesund ist. Die Schaffung von Bildern ist ein Zeichen von Krankheit. Wenn die Gesichte unbestimmt sind, bedeutet dies ein altes Leiden, wenn sie aber klar umrissen sind, dann ist dies das Zeichen von einer frischen Wunde“245. Wie mit

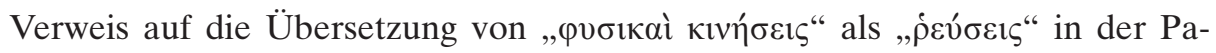
raphrase der Praktike des Parisinus gr. 2748 aus dem 14. Jh. bereits bemerkt wurde, wird mit „natürliche Bewegung“ der körperliche Vorgang angesprochen, der zu nächtlichen Ergüssen während des Schlafens und zu den damit zusam-

241 So in Prak 54, Bd. 2, p. 624-627 und DeMa 27,1-35; 28,1 f., p. 248,1-250,17; zu den genannten Begriffen bei Platon (R. IX 571 f.) s. Refoulé, Rêves et vie spirituelle 510.

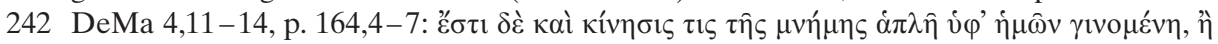

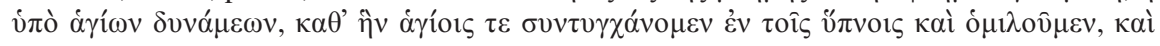

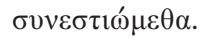

243 44. Siehe auch S. 50 A. 206.

244 21. S. S. 118 A. $579-583$.

24543. 
menhängenden erotischen Bildern führt ${ }^{246}$. Eine dahin gehende Erklärung ist auch in einem Väterspruch des Dioskoros zu finden, der seine Schüler belehrt, dass die von selbst erfolgten Samenausflüsse, die nicht von Bildern begleitet sind, nicht absichtlich, sondern ungewollt zustande kommen, da sie aus der

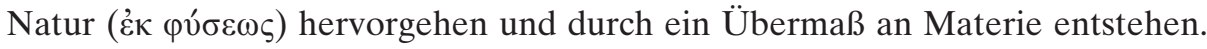
Aus diesem Grunde seien sie auch nicht verantwortlich für die Sünde. Die Trugbilder dagegen entstehen aus einer Absicht und sind Beweise für eine schlechte Gesinnung ${ }^{247}$. Es geht demnach auch bei Euagrios um eine nicht zu kontrollierende Bewegung, die durch den Körper selbst ausgelöst wird, also nicht durch eine dämonische Aktivierung der Erinnerungen mithilfe der Leidenschaften und nicht durch die Erwärmung des Körpers aufgrund von Nahrungsaufnahme. Daraus ergibt sich, dass der von Ergüssen Heimgesuchte zwar nicht als selbst verantwortlich bzw. schuldig für den Vorgang betrachtet werden kann, dass er aber gleichzeitig den Zustand der Leidenschaftslosigkeit ( $\alpha \dot{\pi} \alpha \dot{\theta} \varepsilon 1 \alpha$ ) noch nicht erreicht hat. Sind die Ergüsse von Bildern begleitet, so ist dies entweder auf ein Kranksein der Seele (Euagrios) oder auf eine schlechte Gesinnung (Dioskoros) des Träumenden zurückzuführen ${ }^{248}$. Was nun die dritte, durch die Nahrung ausgelöste Körperbewegung angeht, so kommt sie bei Euagrios ebenfalls vor, wenn auch eher marginal und aufgrund des jetzt postulierten Zusammenhangs von Nahrungseinnahme und der Entstehung von Körpersäften bzw. Ergüssen in einem auffälligen Widerspruch zu den bereits erwähnten Äußerungen über die natürlichen Bewegungen, die als rein körperlich und somit nicht durch äußere Einwirkungen beeinflussbar erklärt werden. Einerseits empfiehlt Euagrios jetzt den Anachoreten, durch Hunger und Durst die Leidenschaften zu hemmen, da diejenigen, die zu viel Brot und Wasser zu sich nehmen, in schändliche Trugbilder fallen ${ }^{249}$. Andererseits warnt er noch einmal speziell vor dem Trinken von Wasser, da dies zu einer Bewegung im Körper führe, die als Gegnerin der Sittsamkeit fungiere. Der eigentliche Grund für diesen Zusammenhang liegt laut Euagrios in der Annahme, dass sich Dämonen besonders gerne an wässrigen Orten aufhalten, weshalb er laut eines Berichtes

246 Guillaumont, (ed.), Évagre, Traité Pratique 628 f. und Bravo García, Sueño y ensueño $190 \mathrm{f}$.

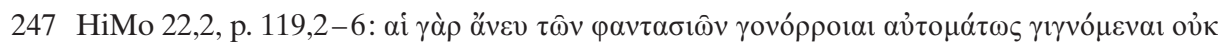

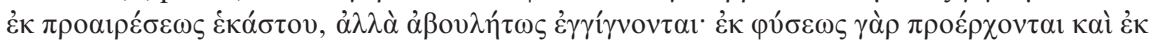

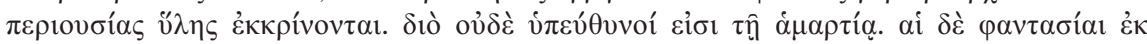

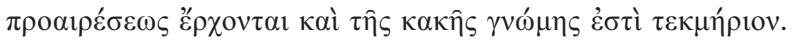

248 Weitere Beispiele von Autoren, welche von der Schuldlosigkeit in Bezug auf die Pollution ausgehen bei Dagron, Rêver 45, A. 32 und Bravo García, Sueño y ensueño 190192.

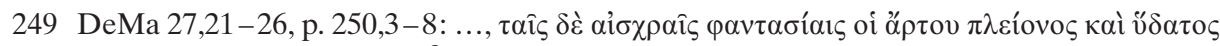

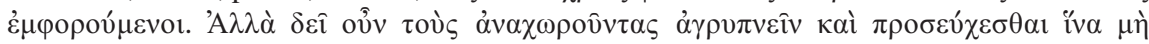

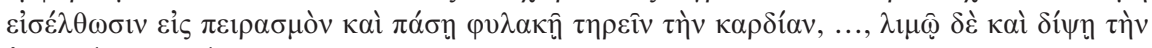

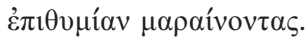


der Historia Monachorum seinen Besuchern empfohlen haben soll, nicht Wasser bis zur Sättigung zu trinken ${ }^{250}$, und in der Praktike ist nachzulesen, dass die Abstinenz von Wasser überaus förderlich sei für die Sittsamkeit ( $\sigma \omega \varphi \rho \circ \sigma u ́ v \eta)$,

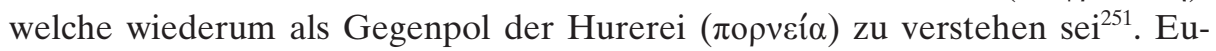
agrios greift hier also die aus der hippokratischen Säftelehre bestens bekannte physiologische Erklärung der Entstehung von Körpersäften bzw. Ergüssen durch das Trinken auf und kombiniert diese mit der im Volksglauben beheimateten Idee der Existenz von Dämonen an wässrigen Orten ${ }^{252}$.

Auch bei Ioannes Klimakos erscheinen die Begriffe der körperlichen Bewegungen wieder, allerdings mit einer anderen Gewichtung der einzelnen Komponenten und mit anderen Begründungen für das Zustandekommen der Bewegungen. Im 14. und 15. Gradus seiner Scala Paradisi über die Völlerei

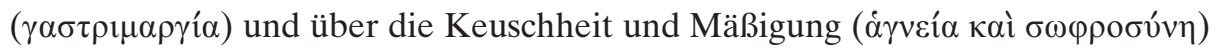
geht es ihm in erster Linie um das Überwinden der Gefräßigkeit ${ }^{253}$ als Voraussetzung für das Erlangen der Keuschheit. Nach der Unzucht und der Hartherzigkeit sei der Schlaf der dritte Abkömmling der Gefräßigkeit ( $\gamma \alpha \sigma \tau \rho \mu \alpha \rho-$ $\gamma^{\prime} \alpha$ ), von dem ein Meer von Gedankenbildern, Fluten, Befleckungen und Abgründen verborgener und unbeschreiblicher Unreinheiten ausgehe ${ }^{254}$. Wie Kli-

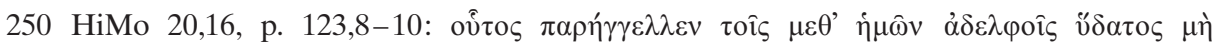

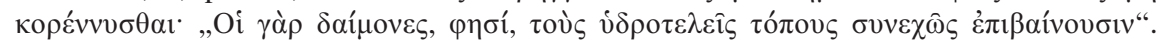
Rufinus (PL 21, col. 449A-B) fügt in seiner lateinischen Rezension der Historia Monachorum hinzu, dass Euagrios den Mönchen, die die dämonischen Trugbilder abhalten wollten, vor dem übermäßigen Wasser Trinken warnte, da das Wasser, wenn es sich im Körper ausbreite, Trugbilder erzeuge und den besten Nährboden für Dämonen schaffe, s. Guillaumont (ed.), Évagre, Traité Pratique 543, A. 17; 544 f. (hier auch weitere Beispiele aus syrischen Quellen) u. 629; Festugière, Les moines d' Orient I $31 \mathrm{f}$.

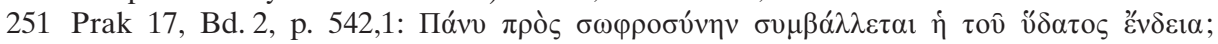
Dieselbe Passage steht auch bei Markos, dem Eremiten (PG 65, col. 1041 A); s. GuILLaumont (ed.), Évagre, Traité Pratique 545.

252 Die Idee, dass die Abstinenz von Wasser zu einer geringeren Produktion von Sperma führt, ist bereits aus Hippocrates, De generat. 1, Bd. VII p. 470,1-2, u.a. bekannt und wird schon bei Philon von Alexandreia, Spec. Leg. 3,10, Bd. V p. 152,16-153,1, im Sinne der Lustbekämpfung als wichtiger Bestandteil der Askese angesehen. S. DAGRon, Rêver 46; auch zu Galen und Oreibasios bzgl. dieser Frage mit weiterführender Bibliographie s. Bravo García, Sueño y ensueño 192 f. mit A. 35 u. 36.

253 Die „Völlerei“ steht schon bei Euagrios an erster Stelle der acht zu überwindenden

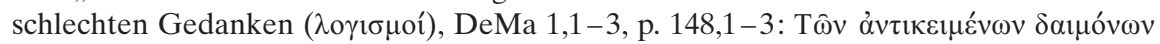

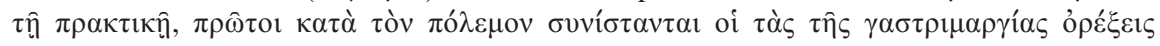

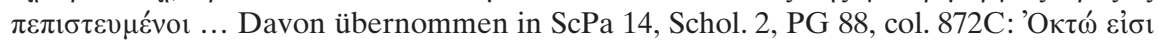

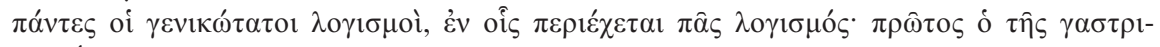

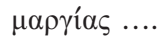

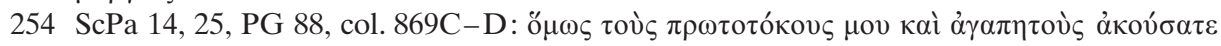

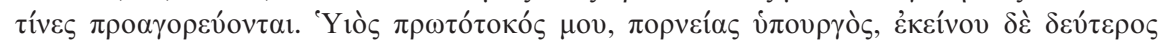

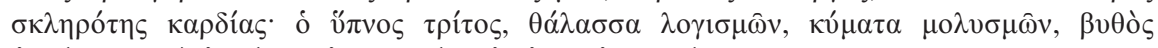

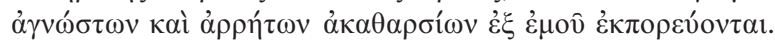


makos ausführt, ist es das sichere Zeichen von Keuschheit, „angesichts der Trugbilder im Schlaf unbewegt zu bleiben “255, wobei der Weg dahin sukzessive zu beschreiten sei, sodass „es der Anfang der Keuschheit ist, ... von Zeit zu Zeit Ergüsse ("̌ккрเбı५) ohne Bilder zu erleiden; das Mittelmaß der Keuschheit sind dann die natürlichen Bewegungen ( Übermaß an Nahrung, jedoch ohne Bilder oder Ergüsse. Das Ziel der Keuschheit ist schließlich die Abtötung des Körpers durch das Abtöten der Gedanken“"256. Es wird also deutlich, dass Ioannes Klimakos als Auslöser der „natürlichen Bewegung“ ein Übermaß an Nahrungseinnahme sieht. Auch andere Textstellen vermitteln den Eindruck, dass hier, anders als im oben erwähnten Väterspruch, keine eindeutige Abgrenzung zwischen der natürlichen Bewegung und der durch die Nahrung ausgelösten Bewegung gemacht wird. Vielmehr werden die beiden Bewegungen als zwei Komponenten eines Vorgangs in einen direkten Kausalbezug zueinander gebracht. In diesem Sinne

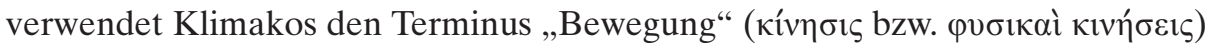
als Sammelbegriff für alle jene Vorgänge, die, durch physiologische Vorgänge ausgelöst, die Keuschheit des menschlichen Körpers schmälern. Deutlich wird diese Zusammenführung der Begriffe auch durch die Ermahnung, leichte Nahrung einzunehmen, ,um durch die schnelle Verdauung von der Erwärmung (des Blutes) befreit zu sein wie von einer Geißel... denn wenn wir uns mit dieser Angelegenheit beschäftigen, dann stellen wir fest, dass der größte Teil der

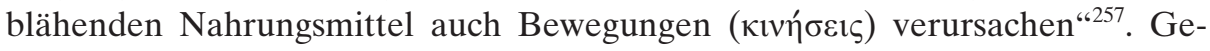
meint sind sicherlich auch hier jene „Bewegungen“ bzw. „natürlichen Bewegungen“, die davon zeugen, dass der Zustand der Keuschheit noch nicht vollständig erreicht ist, und die Ergüsse auslösen können. In einer weiteren Textstelle wird das Zustandekommen des genannten, durch zu viel Nahrung ausgelösten Vorgangs schließlich durch das Agieren des Dämons erklärt, sodass auch hier die dritte im Väterspruch genannte Bewegung, also die dämonische, nicht gänzlich außer Acht gelassen wird. Der Auslöser der Gefräßigkeit sei der Dämon, der den Magen besetzt und dafür sorgt, dass der Mensch nicht satt wird, selbst wenn er ganz Ägypten aufessen und den Nil austrinken würde. Wenn der Bauch dann voll ist, kommt der Dämon der Unzucht und bindet mit dem Schlaf Hände und Füße, um daraufhin alles zu tun, wonach ihm der Sinn steht. Er befleckt Seele und Körper mit Besudelungen, unreinen Phantasien und Er-

25550.

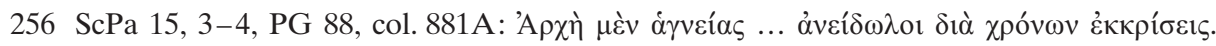

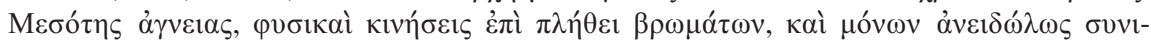

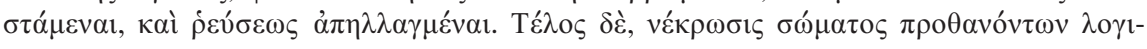
$\sigma \mu \hat{\omega} v$.

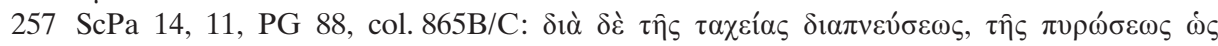

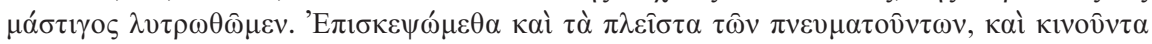

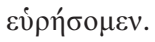


güssen ${ }^{258}$. Offensichtlich präsentiert Ioannes Klimakos hier eine etwas anschaulichere, vielleicht volkstümlichere Begründung oder besser Paraphrase seiner bereits zitierten Erklärungen über das Zustandekommen der Körperbewegungen. Fest steht, dass er in jedem Fall den durch die Ernährung ausgelösten physiologischen Vorgang als Ursache der Körperbewegung im Schlaf erklärt und damit, im Gegensatz zu Euagrios, dem medizinischen Gedankengut seiner Zeit näher steht, als es monastischen Autoren gemeinhin zugetraut wird. Darüber hinaus wird deutlich, dass die Erklärung für das Zustandekommen der Körperbewegungen durch Nahrungsaufnahme in frühbyzantinischer Zeit in einer noch ausschließlicheren Form, als sie ein monastischer Text wie die Scala Paradisi gutheißen konnte, vertreten worden sein musste. So bemerkt Klimakos, „einige definierten, dass die Versuchungen und Ergüsse allein der Nahrung zuzuschreiben sind. Ich sah jedoch Schwerkranke, die übermäßig fasteten und von Ergüssen kräftig befleckt wurden“259. Zweifellos spricht Klimakos hier die rein physiologischen Erklärungsmodelle von Medizinern wie Galen oder Oreibasios an, die sich im Zusammenhang mit Phänomenen wie Ergüssen freilich gar nicht mit der Schuldfrage beschäftigten ${ }^{260}$. Für den in der Askese erfahrenen Klimakos muss es dagegen neben dem übermäßigen Essen noch weitere Gründe für das Zustandekommen von Ergüssen während des Schlafens geben, nämlich der Stolz darüber, seit längerem nicht von Ergüssen heimgesucht worden zu sein und der Urteilsspruch über den Nächsten (der einen Erguss hatte). Wenn aber für jemanden nichts davon zutreffe, dann sei dies das Zeichen für die bereits erreichte Leidenschaftslosigkeit. Erst wenn er auch jetzt noch von einem Erguss heimgesucht werde, sei der Grund im Neid der Dämonen ( $\varphi \theta$ óvo $\delta \alpha \iota \mu o ́ v \omega v)$ zu suchen ${ }^{261}$; für Klimakos stellt dies also der einzige mögliche Fall

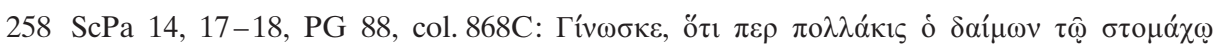

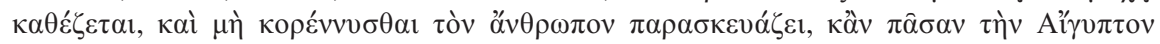

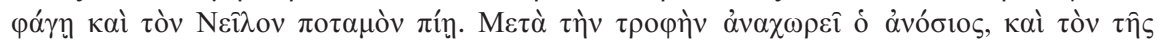

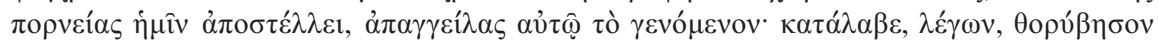

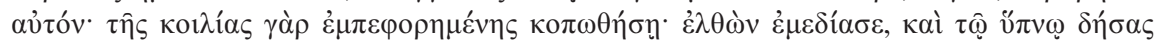

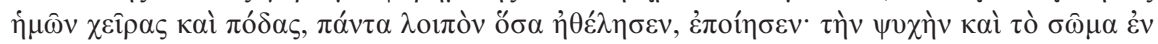

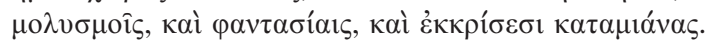

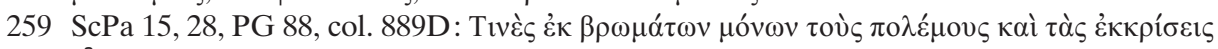

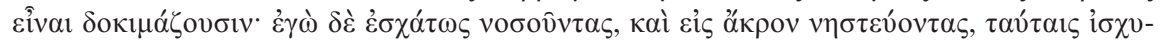

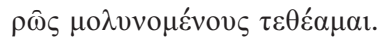

$260 \mathrm{Zu}$ Galen und Oreibasios bzgl. dieser Frage mit weiterführender Literatur Bravo García, Sueño y ensueño 192 f., siehe auch S. 54 A. 229 u. S. 59 A. 252.

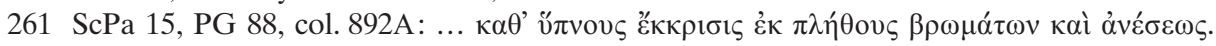

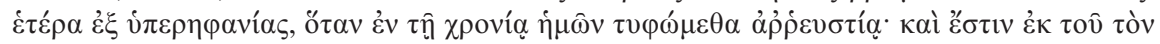

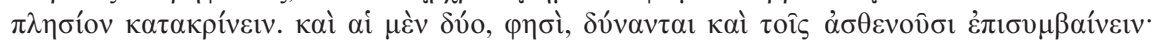

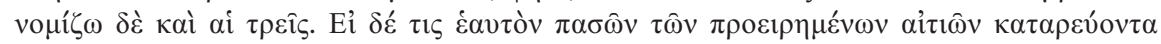

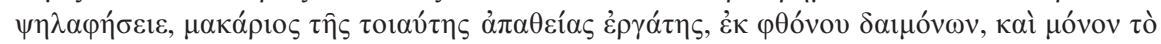

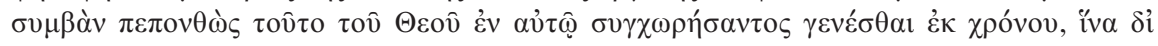

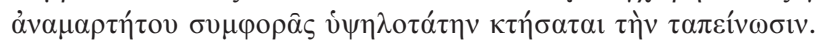


einer schuldfreien Pollution und der damit einhergehenden Bilder dar. Trotz dieser Einschränkung geht mit der an erster Stelle postulierten Kausalverbindung von Nahrung und Körperbewegungen als Zeichen der spirituellen Inferiorität eine weitaus stärkere Verantwortlichkeit des Asketen für das Entstehen von nächtlichen Ergüssen, und somit auch der damit zusammenhängenden Träumen einher, als dies bei Euagrios und in anderen monastischen Texten der Fall ist.

Die unterschiedlichen Interpretationen der nächtlichen Pollution und der damit einhergehenden erotischen Träume zeigt, wie zwingend, gleichzeitig aber auch komplex die Beschäftigung mit dem Thema im monastischen Umfeld war. In der Praxis wird die Schuldfrage sicherlich nicht immer so leicht beantwortbar gewesen sein wie es in Kliamkos' Ausführungen den Anschein macht. Gerade dort, wo Mönche trotz einer untadeligen asketischen Lebensweise betroffen waren, mussten individuelle und verständliche Antworten auf die Frage nach den Gründen für die Heimsuchungen im Schlaf gefunden werden. Eine solche ist überliefert in der Korrespondenz des Barsanuphios und Ioannes, wo ein Bruder fragt, was es zu bedeuten habe, dass er jedes mal, wenn er vor dem Schlafengehen bete und sich bekreuzige, unreine Träume habe, dass er aber, wenn er dies nicht tue, nicht träume. Barsanuphios antwortet, dass dies die List der Dämonen sei, die ihn gerade vom Beten und Bekreuzigen abhalten wollen ${ }^{262}$. Wie genau und durch welche Art von Körperbewegungen die unreinen Träume hervorgerufen werden, scheint den Fragenden nicht weiter zu interessieren; viel wichtiger scheint für ihn Barsanuphios' wegweisende Aufforderung, weiterhin an seinen spirituellen Gewohnheiten festzuhalten, um so die dämonischen Anschläge zu bekämpfen und irgendwann den Sieg über sie davonzutragen.

\subsubsection{Schlafen und Wachen}

Erwartungsgemäß geht die negative Bewertung von Traumbildern, seien sie nun durch Dämonen, durch übermäßiges Essen oder durch andere Untugenden ausgelöst, mit einer dezidierten Ablehnung des Schlafes einher, welche ganz der asketischen Spiritualität des frühen Mönchtums entspricht. Das bereits aus antiken Traditionen, vor allem aber aus dem NT bestens bekannte Gebot des Wachens ${ }^{263}$ entwickelt sich in der christlichen Theologie schon früh zu einer

262 443. S. auch Dagron, Rêver $45 \mathrm{f}$.

263 Zum Wachen in der Antike s. Wöhrle, G., Hypnos 65 f.; Overwien, Die Sprüche des Kynikers Diogenes 295 f.; Strobl, Die Macht des Schlafes 167-173. 193 f. Beispiele aus dem Neuen Testament: Mt 24,42-44 (Ermahnung zur Wachsamkeit); 25,1-13 (Das Gleichnis von den zehn Jungfrauen); 26,40 (Tadelung der drei Jünger, die mit Jesus auf dem Ölberg hätten wachen sollen, jedoch eingeschlafen sind). Weitere Bsp. aus dem NT s. VIRT, Art. Wachsamkeit, Sp. 916. 
„eigentlichen Allegorie vom Sündenschlaf“"264, deren weitreichende Auswirkungen in Byzanz bis in den Kanon der kaiserlichen Tugendattribute zu verfolgen ist, wo dem „Wachen“ ( $\alpha \gamma \rho v \pi v i ́ \alpha)$ ein erstrangiger Stellenwert zukommt $^{265}$. In der Spiritualität des frühen Mönchtums entfaltete sich das nächtliche Wachen auf der Grundlage der neutestamentlichen Aufforderung ,betet ohne Unterlass“ (I Thess 5,17) zu einem Kerngedanken der Askese, was bereits im 4. Jahrhundert durch die Einteilung in Horengottesdienste eine Art Institutionalisierung der Nachtwache zur Folge hatte ${ }^{266}$. Für die sogenannten Akoimeten, einem monastischen Verbund in Konstantinopel, der im frühen 5. Jahrhundert (wahrscheinlich von Alexander dem Akoimeten) gegründet wurde und seine Mönche zu einem ununterbrochenen und kontinuierlichen Stundengebet verpflichtete, wurde die Schlaflosigkeit sogar namensgebend ${ }^{267}$. Erscheint das nächtliche Wachen in unseren Texten zwar in einer weniger rigiden Form als es von den Akoimeten praktiziert wurde, so begegnet es doch auch hier geradezu als Grundpfeiler des asketischen Ideals ${ }^{268}$. Mehr noch, das Durchwachen der Nächte zugunsten von Gebet und Meditation gehört hier mit zu den Übungen, welche die Konzentration der Mönche auf die Gottesschau konditionierten. Immer wieder wird das Wachen als besondere Tugend hervorgehoben, so heißt es im 20. Gradus der Scala Paridisi „Über die körperliche und geistige Nachtwache und wie diese auszuführen ist“"269: „Die Nachtwache zerstreut die Leidenschaft, ist Befreiung von Samenergüssen im Schlaf..." ${ }^{\text {270 }}$, und Euagrios führt an: „Viel Schlaf führt in Versuchungen, der Wachende aber flieht sie““271 oder „Viel Schlaf verdickt den Geist, während ihn ein gutes Wachen schlank macht “272. Offensichtlich wird viel Schlaf als für den Mönch ungesund und gefährlich angesehen, da er verweichlicht und unkontrollierbare dämonische

264 Wittmer-Butsch, Zur Bedeutung von Schlaf 49; vgl. auch Lauer, Art. Schlaf 1470.

265 So hebt Sozomenos, h. e. Ded. 8, Bd. 1, p. 96,15, die Tugend des Kaisers Theodosios II. hervor, in der Nacht zu wachen, um sich mit Literatur zu beschäftigen. Bekannt für seine asketische Lebensführung, zu der insbesondere auch das Durchwachen der Nächte in Gebet und Psalmengesang gehörte, ist überdies Nikephoros II. Phokas, s. Leon Diakonos, Historia V 8, p. 89,21-24. Über ả $\gamma \rho v \pi v i ́ \alpha$ als imperiale Tugend in den Prooimien kaiserlicher Urkunden s. Hunger, Prooimion 94-100.

$266 \mathrm{Zu}$ den unterschiedlichen Formen und Einteilungen der Vigilien vgl. Benz, Die Vision 48-50; TAFT, Art. Vigil 2166 (mit weiterführender Literatur); LutzKa, Die Kleinen Horen 10-14.

267 Bacht, Art. Akoimeten 244 f.; Tацвот, Art. Akoimetoi 46. Zu Alexander dem Akoimeten s. Vööвus, History of Asceticism II 185-196.

268 S. S. 25 A. 76 u. 81.

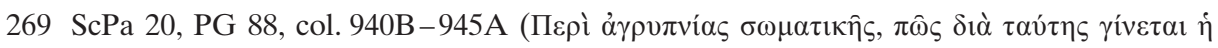

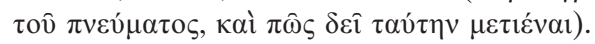

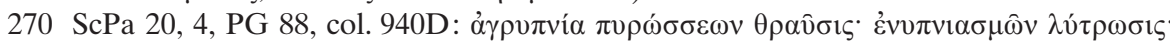

2713.

272 2. Weitere Bsp.: 1, 4, 5. 
Trugbilder hervorruft. So wird auch von Abbas Moses, dessen Seele von Traumbildern zur Unzucht gereizt wurde, berichtet, dass er von einem Bruder die Empfehlung erhielt, in der Nacht zu wachen, zu fasten und zu beten. Darauf gelobte Moses, die ganze Nacht zu wachen, ohne ein Knie zu beugen. Er verbrachte sechs Jahre lang, indem er die ganze Nacht betend in der Mitte seiner Zelle stand, ohne ein Auge zu schließen ${ }^{273}$. Auch die Erzählung von einem Mönchsschüler in der Thebais zeugt davon, dass die erfolgreiche Bekämpfung des Schlafes als besonderes Verdienst angesehen wurde. Als der geistliche Vater während des Unterrichts einschlief, widerstand der Schüler sieben Mal dem schlechten Gedanken, sich schlafen zu legen, obwohl er noch nicht entlassen worden war. Nachdem der geistliche Vater erwacht war, geriet er in Ekstase und sah einen leuchtenden Ort mit einem Thron, auf dem sieben Kränze lagen, welche sein Schüler in eben jener Nacht wegen der Bekämpfung des schlechten Gedankens an den Schlaf von Gott erhalten hatte ${ }^{274}$. Auch von den „großen Charismatikern" wird erzählt, dass sie Meister im Wachen waren. Athanasios berichtet, dass Antonios häufig die ganze Nacht schlaflos verbrachte. Zu bewundern sei er dafür, da er dies nicht nur einmal, sondern immer wieder tat ${ }^{275}$. „Wenn er schlief, begnügte er sich mit einer Binsenmatte. Meistens legte er sich aber ohnehin auf die nackte Erde “276. Ein besonderes Lob für das Wachen geht überdies an Symeon Stylites den Jüngeren ${ }^{277}$. „Er betete von Sonnenuntergang bis Tagesanbruch und schwebte leicht über der Erde, wobei er die linke Hand emporhob und mit der rechten wie mit einem leblosen Stein auf die Brust klopfte. Dabei benetzte er sein härenes Gewand mit Tränen und gönnte seinen

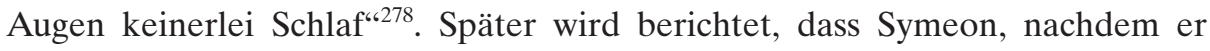
dreißig Tage und Nächte durchwacht hatte, zu Gott betete, er möge ihn von der Trunkenheit des Schlafes befreien. Da wurde ihm durch die Gnade Gottes mitgeteilt, dass es notwendig sei, ein wenig zu schlafen ${ }^{279}$. Während in diesem Beispiel das Überschreiten der Grenzen des für den menschlichen Körper er-

273446.

274156.

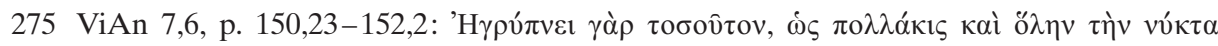

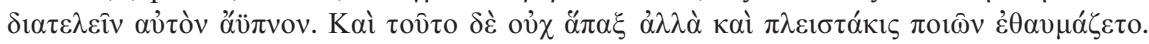

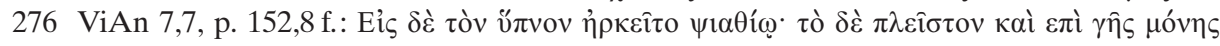

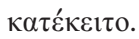

277 Über das Wachen bei den syrischen Asketen vgl. Vööвus, History of Asceticism II 264265, sowie VAN DEN VEN (Hg.), La vie ancienne I 149*-153*, II 46 f., A. 1.

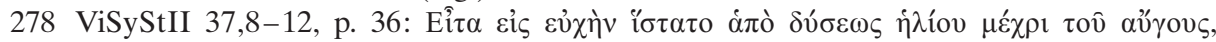

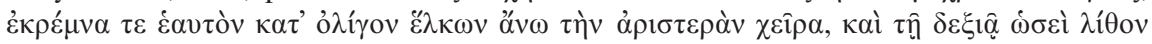

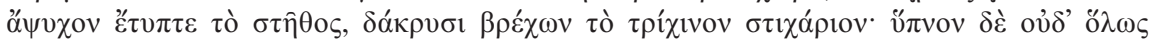

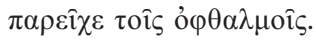

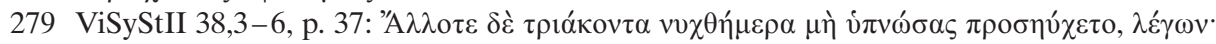

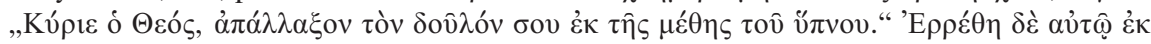

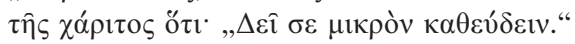


träglichen Maßes an Askese als Zeichen charismatischer Autorität dargestellt wird, dient es anderswo wiederum dem Tadel der Selbstüberhebung ${ }^{280}$. So in der Episode über Abbas Sisoes, welcher den Schlaf bekämpfen wollte und sich deshalb an den Steilhang von Petra hängte. Da kam ein Engel, band ihn los und befahl ihm, dies nie wieder zu tun und diesen Brauch auch keinem anderen zu übergeben ${ }^{281}$. Hier wird allerdings weniger das Wachen als solches, sondern eher die lebensgefährliche Praktik des sich an den Felsen Hängens kritisiert. Als besonders verpönt, und deshalb gerne von Häretikern und Ungläubigen praktiziert, wird überdies das Schlafen am Tag dargestellt, was denn auch unverzüglich mit Bestrafungsvisionen geächtet wird ${ }^{282}$. So wird vom Arianer Artemios erzählt, dass er mit einer blutenden Nase aufwachte, als er am Tag in der Synaxis einschlief $^{283}$, und ein Schauspieler, der über die theotokos lästerte, sei eines Nachmittags eingeschlafen, als ihm die heilige Jungfrau erschien und ihm Hände und Füße entfernte ${ }^{284}$.

Die in den Texten literarisch geäußerte Sorge um Wachsamkeit und die Angst davor, dass zu viel Schlaf zu Disziplinlosigkeit der Mönche führen könnte, findet auch in den Praecepta der pachomianischen Regel ihren Ausdruck, wo Maßnahmen zu einer besseren Kontrolle der Schlafgewohnheiten der Mönche angeführt werden ${ }^{285}$. Von eben diesen Maßnahmen ist auch in der Historia Lausiaca die Rede, wo es heißt, dass auf der Tafel mit den Mönchsregeln, die Pachomios von einem Engel überbracht worden sei, stehe, dass die Mönche nicht liegend schlafen, sondern sich Sitze herstellen sollten, deren Lehnen abgeschrägt seien. Dort sollten sie ihre Decken hinlegen und auf diese Weise sitzend schlafen ${ }^{286}$ - eine Anweisung, die zweifellos das Versinken in den Tiefschlaf verhindern sollte ${ }^{287}$.

Die offensichtliche Ablehnung des Schlafes, bzw. die stete Bemühung um Wachsamkeit, bietet eine mögliche Erklärung dafür, warum bei den Erzählungen über imaginäre Erfahrungen nicht nur, wie bereits besprochen, die Verwendung einer Traumterminologie vermieden wird, sondern auch auffällig häufig unpräzise, selbst den Bewusstseinszustand nicht festlegende Formulie-

280 S. S. $27-29$.

281395.

282 Über die negative Bewertung des „Tagesschlafes“ bereits in der klassischen Literatur vgl. WöHrLe, Hypnos, der Allbezwinger 63-84.

283414.

284418.

285 Praecepta 87; 88, Bd. 2, p. 104,5-23.

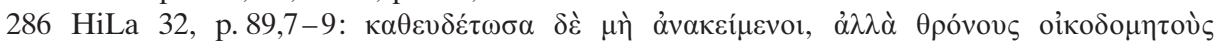

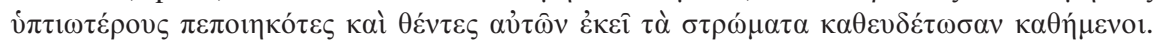
S. auch 360 .

287 Vgl. Dodel, Das Sitzen 97. 
rungen vom Typ der Paulus-Visionen ${ }^{288}$ wie „er sah in einer nächtlichen Vision “289, „es erschien ihm in der Nacht"“290, „es zeigte mir in der Nacht“"291 usw. ${ }^{292}$ anzutreffen $\operatorname{sind}^{293}$. Nächtliche Visionen können auch während des so hochgehaltenen Wachens ${ }^{294}$, beim nächtlichen Psalmengesang und Gebet ${ }^{295}$, aber auch beim Müßiggang ${ }^{296}$ (als Tadel) stattfinden. Noch deutlicher wird die Prävalenz der sich nicht im Schlaf ereignenden imaginären Erfahrungen, wenn, ähnlich wie in Sach 4,1, davon die Rede ist, dass ein Schlafender von einem Heiligen oder

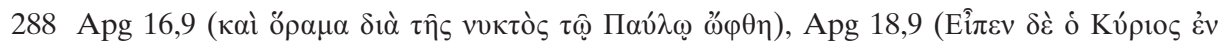

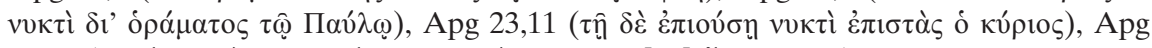

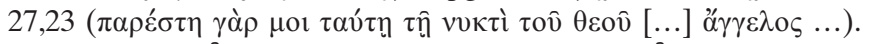

289115 (

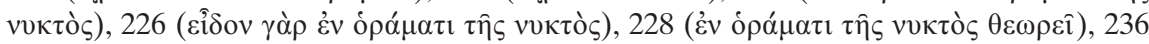

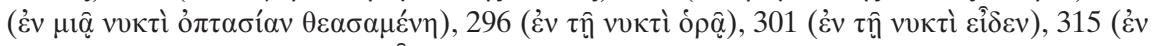

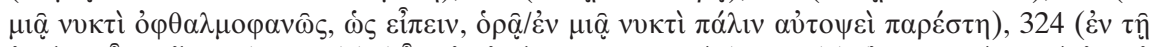

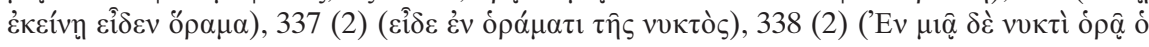

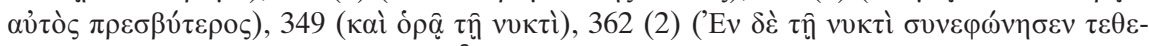

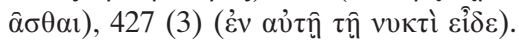

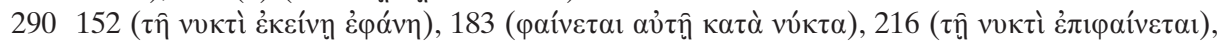
239 (

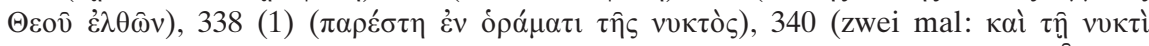

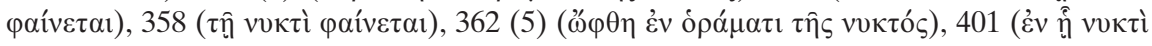

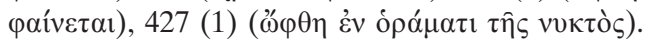

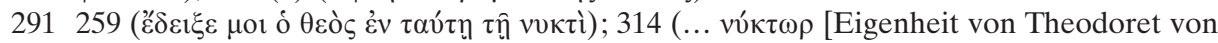

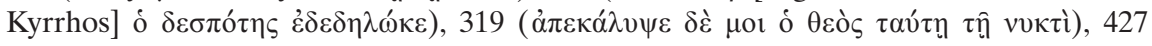

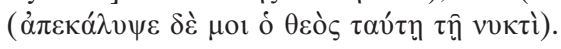

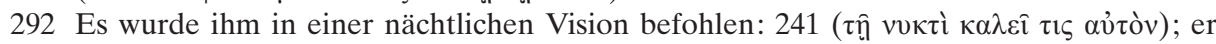

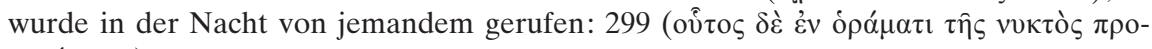

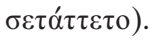

293 Diese Vagheit in den Formulierungen der Apostelgeschichte (s. A. 288) ist auch schon Hanson, Dreams and Visions 1408-1409, aufgefallen. Er begründet dies damit, dass „the ancients themselves could not always distinguish between waking and sleeping in connection with the dream-vision phenomenon" und räumt überdies ein, dass der Traum als Synonym für Vision verwendet wurde (Ebd. 1407). Für die hier behandelten Texte gelten beide Aussagen nicht, da sich die Autoren sehr wohl des Unterschiedes zwischen Schlaf- und Wachzustand bewusst waren und den Traum nicht etwa als Syn-

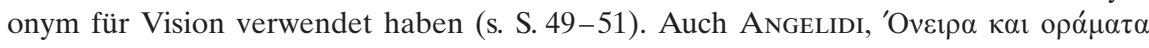
216 beobachtet die Austauschbarkeit von Traum- und Visions-Begriffen in der altkirchlichen Literatur, vermerkt aber gleichzeitig eine bewusste Vermeidung von TraumTermini aus den hier genannten Gründen.

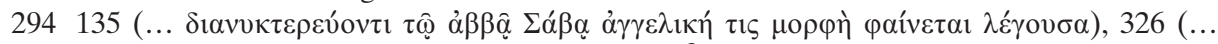

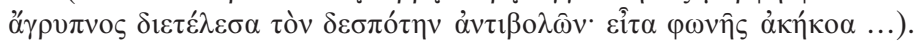

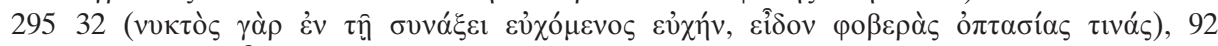

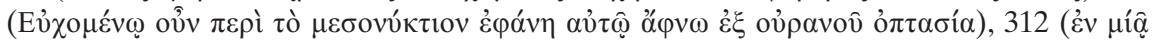

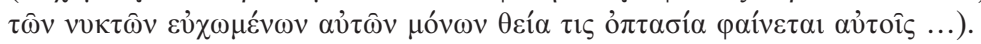

296403. 
Engel geweckt wird ${ }^{297}$, wie z.B. Theodoros von Sykeon, von dem erzählt wird, dass er als Kind immer wieder vom Heiligen Georg geweckt und zu dessen martyrion geführt wurde 298 . Über den jungen Theodoros, Schüler des Pachomios, wird berichtet, dass er sich eines Nachts, als er eigentlich das Gebet verrichten sollte, ein wenig ausruhte. „Er setzte sich an die Tür der Klosterkirche und schlief, bloß um das natürliche Verlangen seines Körpers zu stillen. Da stellte sich ein Engel des Herrn zu ihm, weckte ihn und sagte, er solle ihm folgen ..."299. Auch Ioannes Eleemon erzählt aus seiner Jugend auf Zypern, dass er einmal im Schlaf eine junge Frau sah, welche heller als die Sonne und über das menschliche Verständnis hinaus geschmückt war. „Sie kam, stellte sich vor sein Bett und stieß ihn in die Seite. Da wachte Ioannes auf und sah sie wahrhaftig dastehen..${ }^{300}$. Ab und zu sind auch Wendungen wie „er wachte auf und sah“ anzutreffen, ohne dass ein Heiliger oder Engel an den Schlafenden herantritt ${ }^{301}$. Als weitere Glaubwürdigkeitsmarkierung für den Wahrheitsgehalt imaginärer Erfahrungen setzen die Autoren zuweilen den leichten Schlaf ${ }^{302}$ oder den schlafähnlichen Zustand ${ }^{303}$ ein. So verharrte der todkranke Theodoros von Sykeon dreizehn Tage lang ohne zu essen und zu reden in einem „schlafähnlichen

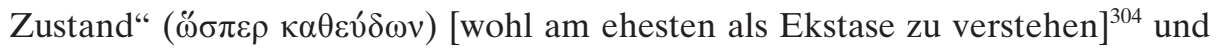
schaute gebannt auf irgendetwas hin. „Nachdem die dreizehn Tage [in denen er

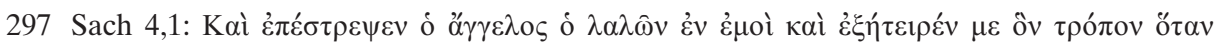

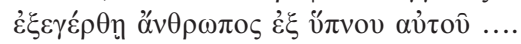

$298344,428$.

299165.

300 161. Zwei weitere Beispiele: 359: Ein Paramonarios der Kapelle des Heiligen Georg erzählte, dass ihm in eben dieser Nacht der heilige Georgios erschienen sei, ihn geweckt habe und gesagt habe, er solle aufstehen, um das Haus mit Kerzen zu beleuchten. 421: Ioannes Klimakos wurde von einem leichten Schlaf ergriffen und sah einen ehrwürdigen Mann, der ihn aufweckte und gleichsam den Schlaf verspottete. Er fragte ihn, wie er so sorglos schlafen könne, wenn sich sein Schüler Moses in Gefahr befinde. Sofort fing Ioannes an, für Moses zu beten.

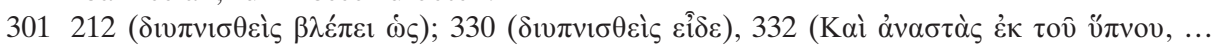

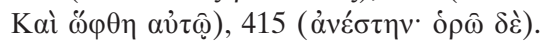

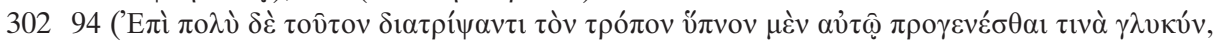

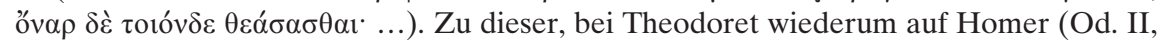
395) anlehnende Formulierung vgl. CANivet, Histoire des moines II 163, A. 163: „La douceur des images oniriques est un signe du bon esprit, car le mauvais esprit suscite des

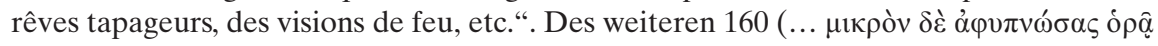

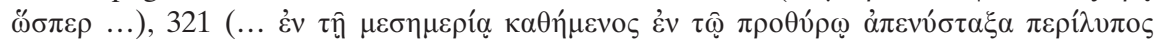

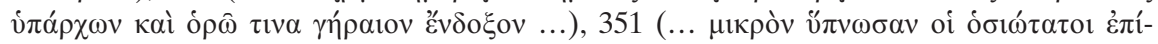

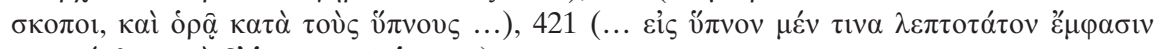

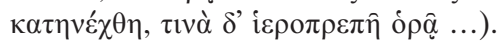

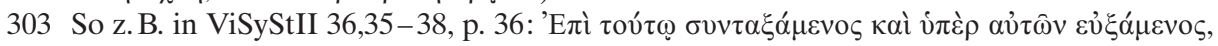

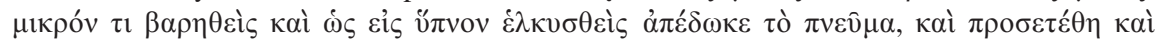

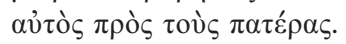

304 S. S. 78 A. 359. 
in den Himmel eingetreten war und sich an dessen Anblick erfreute] vorbei waren, stand er plötzlich von diesem hoffnungslosen Zustand auf ( $\dot{\alpha} v \varepsilon ́ \sigma \tau \eta)$, gerade so wie er die Gewohnheit hatte, vom Schlafen aufzustehen." Die Brüder

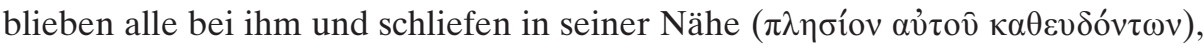
als er auf einmal anfing, sie anzuschreien und aufzuwecken, um sie zu schelten, beim Kanon der Psalmodie unaufmerksam gewesen zu sein und sich der Faulheit und dem Genuss des Schlafes hingegeben zu haben ${ }^{305}$. Der hier beschriebene schlafähnliche Zustand als Ausgangsdisposition der Jenseitsschau beschreibt im Grunde einen gesteigerten „Wachzustand“ des kurz vor dem Tod stehenden Theodoros, welcher auf diese Weise, noch im Diesseits lebend, schon in die Himmel eingeht. Die bevorstehende „Entschlafung“ (коі́ schen Körpers des Heiligen wird somit im übertragenen Sinne zur „Auferste-

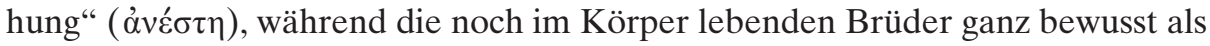

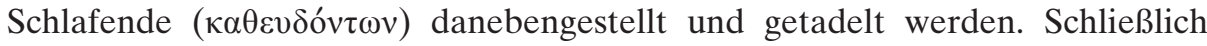
nehmen die Brüder Theodoros nach dessen Rückkehr aus der Ekstase „wie einen, der von den Toten zurückgekehrt war", auf. Die auffallende Nähe von Schlaf und Tod, welche auf ganz ähnliche Weise in der Passio Perpetuae et

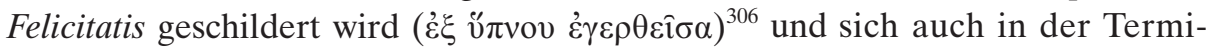
nologie weiterer Beispiele der behandelten Texte findet ${ }^{307}$, ist bereits aus der altgriechischen Mythologie und Philosophie bekannt ${ }^{308}$, erhält aber im $\mathrm{Zu}$ sammenhang mit der christlichen Auferstehungstheologie eine gänzlich neue Bedeutung ${ }^{309}$. Immer wieder wird jetzt klargemacht, dass der körperlich Schlafende ein geistig Toter und der körperlich Tote, also der in der Nachfolge Christi für die Welt gestorbene Asket, der geistig Auferstehende ist. Dieser Dualismus von Leben und Tod ist eine stets wiederkehrende „Leitthematik“ der behandelten Texte, welche in einer Vielzahl von unterschiedlichen Erzähltypen durch die Schlaf- und Wachsamkeitsmetaphorik ausgedrückt wird.

Ein weiteres in diesem Zusammenhang beliebtes Erzählschema berichtet jeweils von einem Charismatiker, welcher, in der Regel während des Betens durch die Fähigkeit der Klarsicht erkennt, dass sich ein schlafender Bruder in

305239.

306 Passio Perpetuae et Felicitatis 20, p. 91,27: Als sich die Märtyrerin in der Arena schon den Qualen des kurz bevorstehenden Todes ausgesetzt hatte, „wurde sie wie aus dem

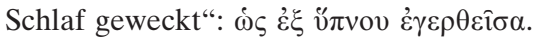

307 кoí $\mu \eta \sigma ı \varsigma$ in der Bedeutung von „Entschlafung“ z.B. in 111, 214, 216, 232. Man denke an die koimesis der Muttergottes und in Anklang daran in 227 auch die koimesis der heiligen Martha, Mutter des Symeon Stylites des Jüngeren.

308 In Hesiods Theogonie (th. 211 f.) ist der Schlaf ( Vgl. Le Goff, Le christianisme et les rêves 176; Manuwald, Traum und Traumdeutung 15; WöHrLe, Hypnos, der Allbezwinger 24-41.165-68; Strobl, Die Macht des Schlafes $14 \mathrm{f}$.

309 S. auch bei Tertullian, De anima 42,3; 43,10-12, p. 845-847; vgl. NäF, Traum und Traumdeutung 139. 
Gefahr befindet. Mit der im Gebet erlangten Hilfe Gottes kommt der heilige Mann dem Notleidenden in einer bilokatorischen Aktion zu Hilfe ${ }^{310}$. So wird zum Beispiel berichtet, dass einige der Brüder nahe dem Kloster des Symeon Stylites dem Jüngeren auf dem Acker schliefen. Da sah der sich im Kloster befindende Symeon, wie eine Leopardin aus dem Gehölz kam, sich neben den Kopf eines der Brüder setzte und anfing zu brüllen, weil sie sein Blut trinken wollte. Symeon aber hinderte das Raubtier daran, den Bruder anzurühren. Als sich dann die anderen Brüder im Kloster zur nächtlichen Psalmodie versammelten, erzählte Symeon vor allen die Geschichte. Er habe den Namen des Herrn angerufen, und das Raubtier habe den Mund zugemacht. Als aber jener Bruder erwachte, sah er die Leopardenfrau neben seinem Kopf sitzen ... ${ }^{311}$. Die durch solche Episoden ${ }^{312}$ vermittelte Botschaft, dass sich der Schlafende durch das Schlafen in Todesgefahr bringt und vom wachenden Heiligen gerettet wird, ist durchaus im übertragenen Sinne zu verstehen. Der auf dem spirituellen Heilsweg „noch nicht Erwachte“ ist in besonderem Maße der Gefahr des Angriffs dämonischer Kräfte ausgesetzt. Für diese steht hier die Bedrohung durch ein Ungeheuer, dessen Auslegung bei Ioannes Klimakos lautet: „Auf die Seele bezogen bedeutet [...] das Ungeheuer dieser schwere und wilde Leib (des kämpfenden Asketen)“313. Der bereits erwachte Charismatiker hingegen besitzt die heilende Kraft, den noch Schlafenden aufzuwecken und das Ungeheuer in ihm zu vertreiben.

Zusammenfassend lässt sich festhalten, dass der Traum, der bereits im Neuen Testament aus mantischen Gründen selten vorkommt ${ }^{314}$, als Offenbarungsmedium aber durchaus positiv bewertet werden kann, in den zur Diskussion stehenden Texten eine zusätzliche Abwertung erfuhr. Dies lässt sich mit der im frühen Mönchtum an Bedeutung gewinnenden Wachsamkeitsspiritualität erklären, welche keineswegs als bloße literarische Spielerei der behandelten Texte, sondern vielmehr als wichtiger Bestandteil der Askesepraxis selbst zu verstehen ist. Demgegenüber erfahren Formen von imaginären Erfahrungen, welche in den Bereich der religiösen Trance fallen, einen deutlichen Aufschwung. Insbesondere gilt dies, neben den zahlreichen Schilderungen, aus denen der Bewusstseinszustand nicht klar hervorgeht, die aber einen tranceähnlichen Zustand des Visionärs vermuten lassen, für die in Kapitel 2.4.1 besprochene mystische Ekstase.

310 S. S. $36-39$.

$311148=330$.

312 Weitere ähnliche Beispiele: 421, 427.

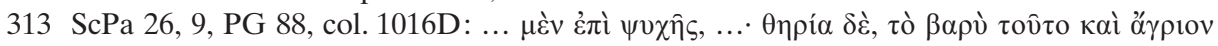
$\sigma \omega \hat{\omega} \mu \cdot \ldots$ vgl. BLuM, Byzantinische Mystik 124. Zu den dämonischen Escheinungen in Form von Tieren siehe auch S. 53 A. 226 u. S. 116 A. 565.

314 S. S. 49. 


\subsection{Religiöse Trance und imaginäre Erfahrungen}

Gerade die Schilderungen von Visionen aus dem monastischen Milieu vermitteln überaus häufig den Eindruck, dass sich ihre Protagonisten während der imaginären Erfahrung in einer körperlichen und geistigen Disposition befinden, für die heute Begriffe wie „religiöse Trance“ oder „Überbewusstsein“ verwendet werden ${ }^{315}$. Zwar findet in den Texten der Begriff "Trance“ als solcher keine griechische Entsprechung ${ }^{316}$, dennoch dient er hier als hilfreicher Sammelterminus für alle jene Dispositionen, die den auf die sinnliche Perzeption bezogenen Bewusstseinszustand des Menschen einengen, um gleichzeitig seine imaginäre, nach innen gerichtete Wahrnehmungsfähigkeit auszuweiten. Die Ekstase ist, wie sich zeigen wird, in Bezug auf die monastischen Texte nur eine, wenn auch die heftigste und die einzige terminologisch festgelegte Form der religiösen Trance.

Hier gilt ganz besonders das bereits im Hinblick auf alle imaginären Erfahrungen konstatierte Spannungsfeld zwischen dem überraschend eintretenden Gnadenerlebnis und der selbstinduzierten Erfahrung ${ }^{317}$. Wiederholt berichten die Texte von ekstatischen Erlebnissen als reiner Gnadengabe, die durch unterschiedliche Faktoren ausgelöst werden, z.B. durch körperliche Schwächung, Krankheiten oder Emotionen, aber auch durch sündhaftes und unorthodoxes Verhalten $^{318}$. Sie überraschen den Visionär entweder als Hilfe in Notsituationen und Heilungen, als Trost, Wegweisungen, Zurechtweisungen oder Belehrungen $^{319}$. Doch gerade bzgl. körperlicher Entkräftung ${ }^{320}$ und Krankheit ${ }^{321}$ ist zu

315 Gemäß der heute allgemein anerkannten psychopathologischen Lehre wird zwischen drei Hauptgruppen von Bewusstseinszuständen unterschieden, dem Unter-Bewusstsein (Schlaf, Krankheit), dem mittleren Tages-Wach-(= Alltags-)Bewusstsein und dem ÜberBewusstsein (Phänomene der religiösen Trance wie meditatives Bewusstsein, mystische Erfahrung, Versenkung), vgl. Scharfetter, Allgemeine Psychopathologie 47-52.

316 Der aus dem Lateinischen trans- (= „hinüber“) gebildete Begriff bezeichnet den Zustand ,jenseits“ des normalen Wachbewusstsein und tauchte erstmals am Ende des 18. Jh. im Zusammenhang mit dem Mesmerismus auf, vgl. Welte, Art. Trance 521. Heute wird der Begriff allg. für diverse Phänomene des Überbewusstseins verwendet.

317 S. S. 19 f.

318 S. S. $27-29,39-41$.

319 S. S. 39 f. A. $161-164$.

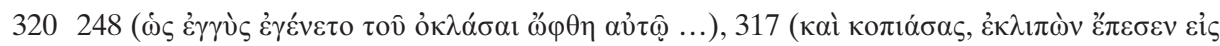

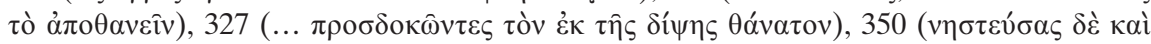

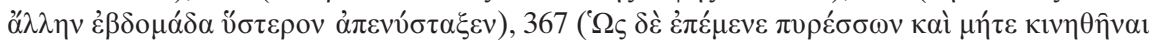

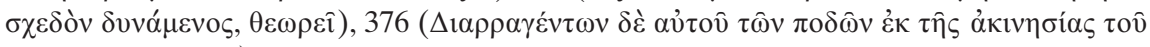

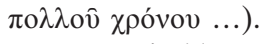

321 Darunter sind körperliche Krankheitszustände zu verstehen, welche in den behandelten Texten als Prädisposition für imaginäre Erfahrungen explizit als solche genannt werden:

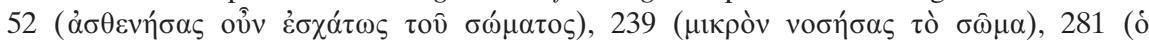

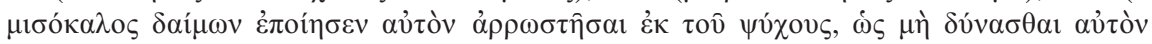


bemerken, dass sie zwar als auslösendes Moment für visionäre Erfahrungen im monastischen Umfeld genannt werden, dass dies aber keinesfalls die Regel ist, so wie es für Texte des lateinischen Mittelalters konstatiert wurde ${ }^{322}$. Überdies muss das Auftreten von Entkräftung und anderen Krankheitszuständen in vielen Fällen als Folge exzessiv ausgeübter asketischer Praktiken (z. B. Fasten und Wachen) und somit letztlich doch wieder als bewusst herbeigeführte Kondition für die Imaginäre Erfahrung interpretiert werden ${ }^{323}$. Überhaupt darf gerade die ausgeprägte Erwartungshaltung der Gläubigen in Bezug auf imaginäre Erfahrungen als Grundvoraussetzung, nicht nur für die bewusst evozierten, sondern eben auch für die zahlreichen überraschend auftretenden Visionen in Trancezuständen gesehen werden. Dies hängt unmittelbar zusammen mit der in den Texten zu beobachtenden starken Tendenz zur selbstinduzierten, durch die oben genannten Askesepraktiken wie Beten, Fasten, Meditieren, Anhören und Rezitieren göttlicher Worte, Psalmen- und Hymnengesang sowie Räucherungen ausgelösten religiösen Trance ${ }^{324}$. Als wesentliches Merkmal für alle geschilderten Formen der Trance erweist sich wiederholt das für die asketischen Übungen so zentrale „Sich-nach-Innen-Kehren“, um sich auf dem Weg der Versenkung „mit den Augen der Seele auf die geistigen Kräfte zu konzentrieren““325. Dies ist

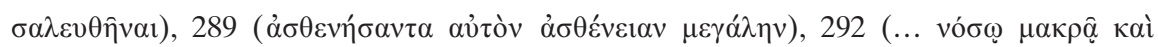

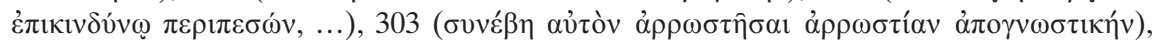

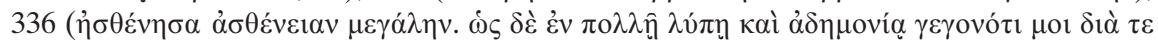

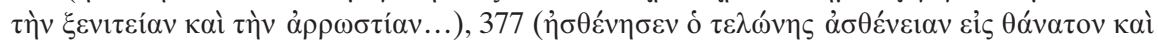

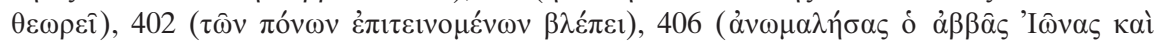

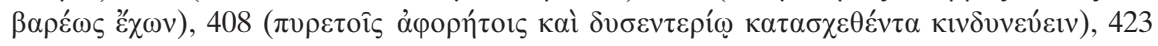

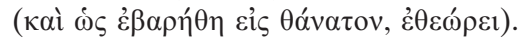

322 Die Aussage „Es lässt sich aufgrund der mittelalterlichen Quellen eindeutig sagen, dass die meisten Visionen und Träume im Zustand der Erkrankung empfangen wurden [...] ein Krankheitszustand also war die üblichste Prädisposition für visionäres Erleben“, Dinzelbacher, Körperliche und seelische Zustände 71, trifft für die hier behandelten Texten nicht zu.

323 S. dazu o. 1.2.4.

324 S. S. 24-26. Beispiele zu den in den Texten genannten asketischen Praktiken, die den (nicht im Schlaf stattfindenden) nächtlichen imaginären Erfahrungen vorausgehen s. S. 66 A. 289-295.

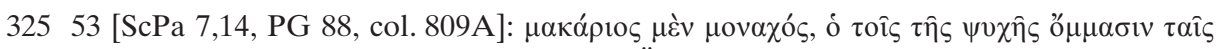

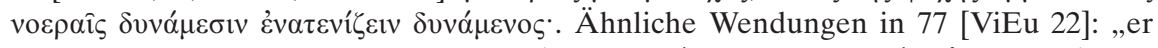

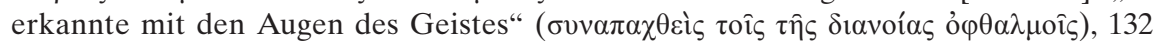

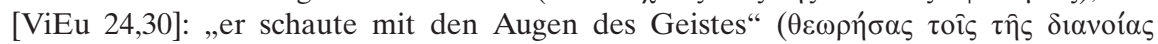
ỏ $\theta \alpha \lambda \mu о i \varsigma), 189$ [ApSy XVIII, 4]; ,Ihre geistigen Augen öffneten sich“ ('Hvoí $\theta \eta \sigma \alpha v \delta \grave{\varepsilon}$

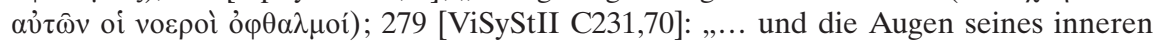

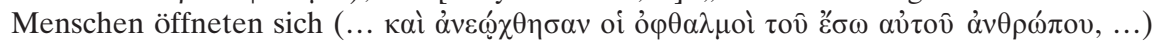
(s. S. 48 A. 197), 442 [Bar 416]: „Der Herr erleuchte die Augen deines Geistes“ ('O Kúpı Beispiele für „das Auge des Herzens“ bzw. „,der Seele“ oder „des Verstandes“ aus der frühen mystischen Literatur bietet CuPANe, Metamorphosen des Eros 37, A. 80. 
ein Kerngedanke jeder mystischen Spiritualität, der sich keineswegs auf die Askesepraktiken der frühbyzantinischen Mönche beschränkt. Die Techniken zur Herbeiführung von tranceartigen Zuständen variieren freilich je nach kultund kulturbedingter Konditionierung der unterschiedlichen religiösen Gruppierungen und Gesellschaften. Werden im Buddhismus Yoga, in schamanischen Kulturen Drogen und Hypnose und in sufischen Kreisen der dikr, das Gottesgedenken durch die wiederholte Nennung des Wortes Allāh (um nur einige wenige Beispiele zu nennen), als Mittel zum Evozieren von TranceZuständen eingesetzt ${ }^{326}$, so beschreiben die frühbyzantinischen monastischen Texte die genannten asketischen Praktiken als Weg zur ekstatischen Schau. Von besonderem Interesse scheint dabei neben den erwähnten Faktoren insbesondere das in den behandelten Texten gerade im Zusammenhang mit

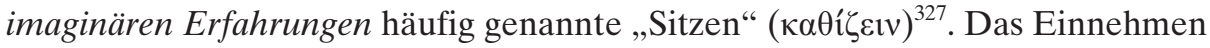
bestimmter Körperhaltungen kann, wie heute auf der Basis religionsethnologischer und medizinischer Untersuchungen belegt ist, ein wesentlicher Aspekt für das Evozieren religiöser Trance und das dadurch ausgelöste visionäre Erlebnis darstellen ${ }^{328}$. Dass es sich bei dem von den frühbyzantinischen Asketen und Mönchen so häufig praktizierten „Sitzen“ ebenfalls um eine Methode zum Herbeiführen von religiösen Trancezuständen und der dadurch ausgelösten imaginären Erfahrungen handelt, ist naheliegend. Einen konkreten Einblick in

326 Vgl. Dodds, Pagan and Christian 86. Zu den Bedingungen für visionäre Erfahrungen im Neuen Testament s. Berger, Historische Psychologie 122, und im frühesten Christentum, s. Ders., Formgeschichte 287. Über Trancetechniken bei den Schamanen s. Kelsey, Trance, Ekstase und Dämonen 43 f., sowie Frenschrowski, Morgenthaler, Traum 29; im Sufismus vgl. Schimmel, Sufismus 18-20; Dies., Mystische Dimensionen 191-265, in der syrischen und sufischen Literatur (im Vergleich) vgl. SEPPÄLÄ, In speechless Ecstasy 291-294; über unterschiedliche Trancetechniken in diversen Kulturen u. allg. zu den Faktoren, die Ekstase-induzierend wirken können s. Pfister, Art. Ekstase 967, Dinzelbacher, Körperliche und seelische Vorbedingungen 81; Welte, Art. Trance 522 f.; Lewis, Art. Ekstase 1186-1188. Mit der religiösen Trance als überkulturelles Phänomen beschäftigen sich v.a. Untersuchungen aus dem Bereich der Religionsethnologie, so z. B. Bourguignon, Religion, Altered State of Consciousness 11, wonach in 437 von 488 kleinen, nicht westlichen Gesellschaften eine oder mehrere kulturspezifische Formen institutionalisierter veränderter Bewusstseinszustände im religiösen Bereich vorkommen, vgl. Goodman, Ekstase 31, u. Dies., Die andere Wirklichkeit 48. Über Gemeinsamkeiten und Differenzen der verschiedenen mystischen Strömungen s. ferner TworuschKa, Sucher, Pilger, Himmelsstürmer, hier „Reisen nach innen, Reisen nach oben" 116-158; Goodman, Die andere Wirklichkeit 43-81.

327 Vgl. dazu die Bemerkung von Dodel, Sitzen 73, dass „das Sitzen die typische Übungshaltung für die asketische Übung im Kellion sei“, mit Verweis auf I Kor 14,30: „Wenn jedoch einem anderen, der noch dasitzt, eine Offenbarung zuteil wird, so soll der erste schweigen“, ebd. 65. Zu den Beispielen s. S. 25 A. 78 u. 81.

328 Auf dieser Erkenntnis gründet die von der Religionsethnologin Felicitas Goodman entwickelte und heute weltweit unterrichtete Trancetechnik der sogenannten „Rituellen Körperhaltungen“, vgl. Goodman, Trance 11-24; s. auch Welte, Trance 524. 
die spirituelle Praxis auf der Grundlage der genannten Übungen gibt die Korrespondenz zwischen Barsanuphios und einem Bruder, der wissen will, ob es gut sei, etwas aus ganzer Kraft im Herzen zu beschauen oder zu beten ( $\mu \varepsilon \lambda \varepsilon \tau \hat{\alpha} v$ ᄁ̀ $\pi \rho \circ \sigma \varepsilon v ́ \chi \varepsilon \sigma \theta \alpha \iota)$, ohne jegliches Mitwirken der Zunge. Wenn ihm dies nämlich widerfahre, dann sei sein Geist versunken, er fühle sich schwer, und es scheine ihm, Dinge und Erscheinungen zu sehen, und er befinde sich wie im Traum. Barsanuphios antwortet, dass dies den Vollendeten vorbehalten sei, die in der Lage seien, ihren Geist zu lenken und ihn in der Furcht Gottes zu halten, damit er nicht abdrifte und in tiefe Zerstreuung oder Trugbilder gerissen werde. Wer aber die Aufmerksamekeit des Geistes nicht gänzlich bei Gott halten könne, der solle die Meditation mit der Zunge begleiten ${ }^{329}$.

Das Herbeiführen von Zuständen des Überbewusstseins im Zusammenhang mit Imaginären Erfahrungen betrifft jedoch nicht nur die asketisch monastische Spiritualität, sondern findet in den Texten auch einen Wiederhall als eine in der Bevölkerung beliebte Möglichkeit der Kontaktaufnahme mit transzendenten Kräften. In den meisten Beispielen geht es dabei um das Evozieren visionärer Erfahrungen, in denen durch imaginäre Vorgänge Heilungen stattfinden oder in denen den Gläubigen in anderen existentiellen Situationen, z. B. bei Kinderlosigkeit, geholfen wird. Wie bereits gezeigt wurde, sind in den behandelten Texten nur zwei Beispiele aus der Vita Euthymii für eine inkubatorische Heilung im engeren Sinne belegt, Heilungen also, die an die Wirkungsstätte eines verstorbenen Charismatikers, nämlich des heiligen Euthymios, gebunden sind ${ }^{330}$. Bezeichnenderweise haben wir es gerade im ersten dieser Beispiele nicht etwa mit einer Traumheilung, sondern mit einer expliziten Ekstaseheilung als Folge von nächtlichem flehentlichem Gebet zu tun (während im zweiten Beispiel der Bewusstseinszustand offen bleibt). Zu erklären ist dies nicht etwa damit, dass es sich bei eben diesem Beispiel um die einzige induzierte imaginäre Heilung handelt, bei der nicht ein weltlicher Christ, sondern ein Mönch von einem Leiden befreit wird. Sind doch auch andere Beispiele von induzierten Heilungsund heilungsähnlichen Ekstasen bei weltlichen Christen belegt, so die ebenfalls bei Kyrillos von Skythopolis zu findende Erzählung über den kranken Romanos, der während des Gebets in eine Ekstase gerät, in der er durch eine imaginäre Intervention des heiligen Euthymios geheilt wird ${ }^{331}$. Zwar kommen in den Texten auch diverse Traumheilungen vor, aber auch diese werden meist als Folge der gleichen vorbereitenden Handlungen (v.a. Gebet, Wachen und Fasten) dargestellt ${ }^{332}$. Es ist also davon auszugehen, dass es nicht nur in den as-

329 18. Über Formen der meditativen Versenkung im ägyptischen Mönchtum s. auch BACHT, Meditatio 244-264.

330 262, 263. S. S. 31.

331 264. Siehe auch S. 86 A. 409 u. S. 135 A. 664.

$332261,275,278,285,286,291,300$. 
ketisch- monastischen Kreisen eine Vorliebe dafür gab, durch Wachen, Beten und andere induzierende Praktiken Zustände des erweiterten Bewusstseins herbeizuführen, um auf diese Weise imaginären Erfahrungen teilhaftig zu werden. Dies bestätigen insbesondere auch die bereits thematisierten Geburtsankündigungen, die häufig als Folge von induzierenden Praktiken in der Kirche eines Heiligen geschildert werden ${ }^{333}$, aber auch zahlreiche weitere Beispiele von imaginären Erfahrungen, die in einen direkten Zusammenhang mit Wachen, Beten und Fasten des Hilfe erflehenden Gläubigen gebracht werden ${ }^{334}$. Wie bereits am Beispiel des von Symeon Stylites geheilten Jungen deutlich wurde, ist auch hier das Eintreten in den Zustand des Überbewusstseins aufs Engste verknüpft mit dem „Öffnen der inneren Augen“, welches den imaginären Heilungsvorgang erst ermöglicht ${ }^{335}$. Weil aber die induzierenden Praktiken hier nicht als Teil einer asketischen Spiritualität, sondern vielmehr als rituelle Handlungen in der Tradition der Inkubation vollzogen werden, ist der Schlaf und damit auch der Traum weit weniger negativ behaftet als dies im Mönchtum der Fall ist ${ }^{336}$.

\subsubsection{Die mystische Ekstase}

„Oft wurde ich [...] in eine solche Ekstase hineingerissen, dass ich nichts mehr wusste von der Last meines Körpers: mein Geist, von seinen äußeren Sinnen wie abgetrennt, war dann allen materiellen Dingen entrückt, so dass ich nichts mehr sah und hörte “337. Cassian beschreibt hier aufgrund persönlicher Erfahrungen jene Symptome, welche charakteristisch sind für den in den behandelten Texten am häufigsten belegten und einzig terminologisch festgelegten Typ von

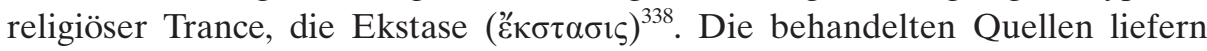
zwar keine theoretischen Abhandlungen über die Ekstase, so wie etwa über den

333311 (Beten), 312 (Wachen und Beten), 315 (Wachen, Beten und Fasten).

334260 (Beten), 263 (Fasten und Beten), 264 (Beten), 273 (Beten), 279 (Beten, Verbrennen von Weihrauch), 290 (Beten), 293 (Beten), 299 (Beten), 301 (Beten), 302 (Beten), 306 (Wachen, Beten und Fasten), 328 (Beten), 329 (Beten), 388 (Beten und Weinen). Bei weiteren Erzählungen über imaginäre Heilungen werden die genannten Praktiken nicht erwähnt, da aber berichtet wird, dass die Kranken wegen ihrem Leiden zu einem Heiligen Mann gingen oder gebracht wurden, ist auch hier eher von imaginären Heilungen als Folge von induzierenden Vorbereitungen als von überraschenden imaginären Erfahrungen auszugehen: 267, 270, 274, 277, 280, 282, 284, 294, 296, 297.

335279 (s. S. 48 A. 197). Siehe auch S. 85 f. A. $408-411$.

336 S. S. $85-87$.

337 Cass., Coll. 19,4, p. 537,5-9: itaque pio domini nostri munere memini me in huiusmodi raptum frequenter excessum, ut obliuiscerer me sarcina corporae fragilitatis indutum, mentemque meam ita omnes exteriores sensus subito respuisse et a cunctis materialibus rebus omnimodis exulasse, ut neque oculi neque aures meae proprio fungerentur officio.

338 Zur expliziten Nennung der mystischen Ekstase in den Texten s. S. 109 f. 
Schlaf. Dennoch wird deutlich, dass die Autoren entsprechend dem christlichen Heilskonzept in zwei Hauptgruppen der Ekstaseerfahrungen, in die positiven, als Medium göttlicher Offenbarungen verstandenen und hier als mystische Ekstasen bezeichneten und in die negativen, die sogenannten dämonischen Ekstasen ${ }^{339}$, polarisieren. Dieser Trennung zwischen der dämonischen Ekstase auf der einen und der mystischen Ekstase auf der anderen Seite begegnen wir auf theoretischer Ebene erstmals in den Werken der Kirchenväter. Bei ihnen wird die dämonische Ekstase, wie noch erläutert werden wird, in Anlehnung an klassische Vorläufer stets als Zustand des dionysischen Bewusstseinsverlusts beschrieben und in Zusammenhang mit den falschen, weil aus ihrer Sicht vorgetäuschten Prophezeiungen der Häretiker gebracht ${ }^{340}$. Daneben ist aber auch wiederholt die Rede von der echten, durch die biblische Tradition legitimierten mystischen Ekstase. So erklärt Ioannes Chrysostomos' die Stelle in Apg 10,10 f., wo Petrus in einer Ekstase die Himmel geöffnet sah ${ }^{341}$, als ,geistige Schau und ein Heraustreten der Seele aus dem Körper“342. Ähnlich beschreibt Prokopios von Gaza die Ekstase als „das Hinausgehen aus der gewöhnlichen Sinneswahrnehmung, gemäß dem Ratschluss Gottes. So versetzte er auch Abraham in Ekstase, damit er die Schau der verborgenen Dinge erlangt “343, und an anderer Stelle postuliert er, dass der vom Geist Gottes erfüllte

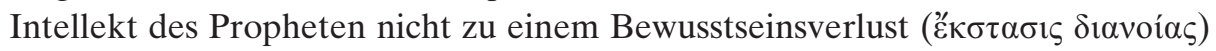
führe, was er damit begründet, dass es nicht möglich sei, dass der Geist der Weisheit den Propheten mit Unwissenheit erfülle ${ }^{344}$. Die monastischen Texte gehen jedoch über die theoretischen Reflexionen der Kirchenväter über die Erfahrungen heiliger Personen aus dem Alten und Neuen Testament hinaus und setzen die biblisch legitimierte Ekstase in einen Aktualitätsbezug zu der von ihren Protagonisten gelebten monastischen Spiritualität. Dies zeigt sich nicht nur durch das häufige Vorkommen von Erzählungen über mystische Ekstasen, sondern vor allem auch durch ihre Kontextualisierung in den breiteren Rahmen der geschilderten asketisch-monastischen Lebenswelt. Damit erweist sich das

339 S. S. $87-94$.

340 S. S. 87 f. A. $419-423$.

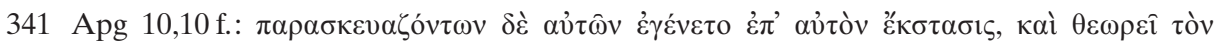

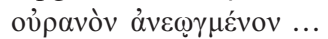

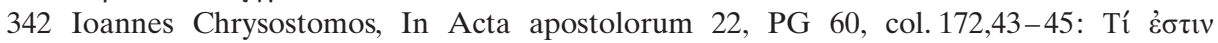

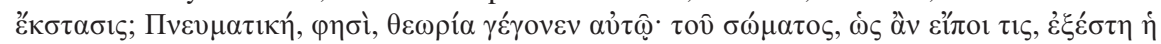
४vхиं.

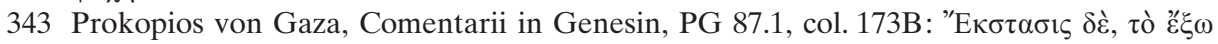

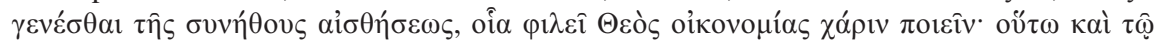

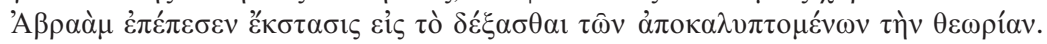

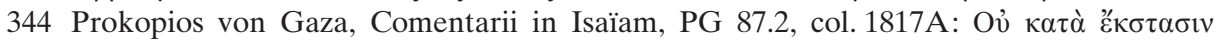

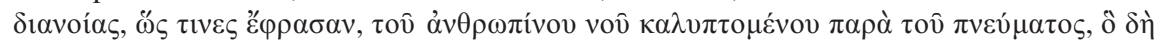

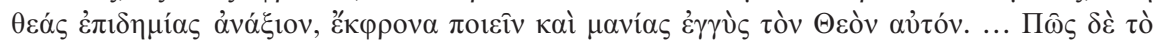

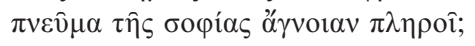


frühbyzantinische Mönchtum und seine weite Ausstrahlung auf die damalige christliche Bevölkerung als Teil einer für die gesamte Spätantike typischen Imaginationsspiritualität, in der das Verlangen nach Entrückungserfahrungen nichts Ungewöhnliches darstellte. Man denke etwa an die durch platonisches, vor allem aber auch durch stoisches Gedankengut beeinflussten spätantiken Philosophen, für welche die Ekstase als Weg, mit dem Göttlichen in Berührung zu kommen, ein zentrales Thema darstellte. So spielt die Ekstase als mystische Praxis im Neuplatonismus eine herausragende Rolle, und Plotin selbst ist bekannt für seine persönlichen Entrückungserfahrungen ${ }^{345}$. Anders als bei Platon, ist es hier aber nicht mehr die dionysische Raserei, die gerade durch den Verlust des Bewusstseins zur Vereinigung mit dem Göttlichen führt ${ }^{346}$, sondern das für die gesamte Spätantike - und eben gerade auch für das frühe Christentum - so typische asketische Lebensideal, das, kombiniert mit einer ausgeprägten Jenseitssehnsucht, in der Ekstase eine Bewusstseinserweiterung und damit die intellektuelle Vereinigung mit dem Göttlichen (Plotin) oder noch häufiger die Schau transzendenter Inhalte (Tertullian, Gregor von Nyssa, Dionysios Areopagites $)^{347}$ anstrebte. Vor allem die Überzeugung, dass Entrückungserfahrungen mittels Imagination die Perzeption transzendenter Inhalte ermöglichen, beschränkt sich keineswegs auf den philosophisch-theologischen Bereich, sondern ist vielmehr wesentlicher Bestandteil einer weitverbreiteten, religionsübergreifenden Imaginationsspiritualität, die gerade auch ein Charakteristikum der ge-

345 Das berühmteste Beispiel bei Plotin, der von seinen ekstatischen Erlebnissen berichtet, Enn. 4,8,1, Bd. 2, p. 224,1-5: „Oft kam ich aus dem Körper heraus zu mir selbst und trat aus den anderen Dingen heraus, und ich sah eine wunderbar strahlende Schönheit ..."

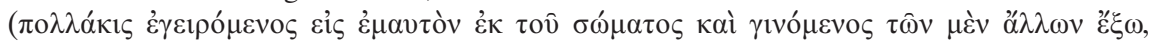

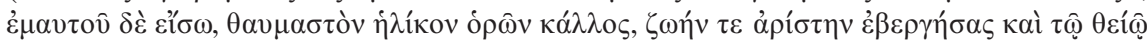

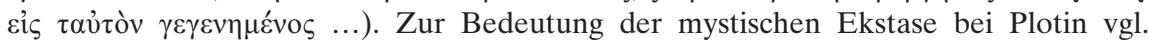
DodDs, Pagan and Christian 72. 84-91; Halfwassen, Plotin 49-58; Alt, Plotin 9 f.; 2931. 118-124.

346 S. S. 87 A. 420.

347 Bei Tertullian, De anima 48.4, p. 854 f., gilt die Ekstase als vierte und höchste Kategorie der Träume. Die Ekstase, so Tertullian, kann nicht beschrieben, noch gedeutet werden, ist aber besonders kostbar, wenn sie durch Enthaltsamkeit ausgelöst, in Gott stattfindet. Die Imagination in Ekstase (bei Tertullian immer als Traum bezeichnet) wird also höher bewertet als die im Schlaf. Diese Ansicht entspricht ganz der Tendenz der hier behandelten Texte. Vgl. MiLler, Dreams 69; NäF, Traum und Traumdeutung 140. Zu der, stark vom Neuplatonismus beeinflussten, mystischen Theologie des Gregor von Nyssa vgl. Daniélou, Platonisme 209-255; Kazhdan, Art. Gregory of Nyssa 822; Miller, ebd. 232 f.; vgl. auch Kap. 3.4.1, A. 531 u. Kap. 4.3.2, A. 690. Zur mystischen Ekstase bei Pseudo-Dionysios Areopagites vgl. VölKer, Kontemplation 25-210; Kazhdan, Art. Dionysios the Areopagite 629; KLITENIC Wear, Dionysius 128 f.; vgl. auch Einleitung A. 3. 
samten spätantiken Erbauungsliteratur darstellt ${ }^{348}$, zu der auch die hier behandelten Quellen gezählt werden dürfen.

Unmissverständlich geht aus diesen hervor, dass die Fähigkeit des bewussten und wiederholten Eintretens in die religiöse Trance nicht etwa als häretische Praktik verpönt war, sondern vielmehr als echte Auszeichnung verstanden wurde, so wie beim Asketen Isidoros, von dem erzählt wird, dass er „so tiefe Kenntnis der heiligen Schrift und der göttlichen Lehren besaß, dass er sogar bei den gemeinsamen Mahlzeiten der Brüder entrückt wurde und in Verzückung geriet. Bat man ihn, über die Ekstase zu erzählen, so sagte er, er sei im Geiste abwesend und von einer Schau entrückt gewesen“349. Die in der Forschung verbreitete, auch im Neuen Pauly nachzulesende Ansicht ,ebenso kennt die christliche Tradition wenigstens offiziell Ekstase nicht. [...] Die dämonische Deutung der Ekstase verhindert die Anerkennung prophetischer Ekstase, die sich nur am Rande halten kann“" 350 , ist also weder durch eine eindeutige Haltung der Kirchenväter zur Thematik, noch durch die hier behandelten Texte zu begründen $^{351}$. Obschon die sogenannten dämonischen Ekstasen eine nicht wegzudenkende Komponente der monastischen Texte darstellen ${ }^{352}$, wird die mystische Ekstase und die damit zusammenhängenden visionären Erfahrungen in fast allen Texten als gewolltes, ständig herbeigesehntes Phänomen beschrieben, das dem Gläubigen einen unmittelbaren Zugang zum Numinosen ermöglicht ${ }^{353}$. So wird die Ekstase in paulinischer Tradition als religiöse Bewusstseinserweiterung dargestellt, die es dem Pneumatiker ${ }^{354}$ ermöglicht, mindestens vorübergehend die schmerzhafte Trennung von Gott im Diesseits zu durchbrechen und an die von ihm schon zu Lebzeiten ersehnten Orte der jenseitigen Welt zu gelangen ${ }^{355}$. Allerdings blieben die Autoren der monastischen

348 S. S. 78 A. 356 u. S. 124 A. 613.

34922.

350 Graf, Art. Ekstase 950; in diesem Sinne auch Brown, Rise and Function 93; van DE Kapelle, Prophets and Mantics 99 f.; Ivanov, Holy Fools 24, und tendenziell auch Timotin, Visions 21.

351 So auch Bovon, The Authority of Dreams 157, der eine allgemeine Tendenz zur ekstatischen Vision im frühen Christentum postuliert.

352 S. S. $87-94$.

$353 \mathrm{Zu}$ den Abweichungen bei Euagrios s. S. 27 A. 89 u. 90.

354 Das heißt gemäß I Kor 2,12, demjenigen, dem der Geist aus Gott und nicht der Geist aus der Welt gegeben wurde, um das von Gott Geschenkte wahrzunehmen ( $\dot{\eta} \mu \varepsilon \hat{i} \zeta \delta \dot{\varepsilon}$ ở

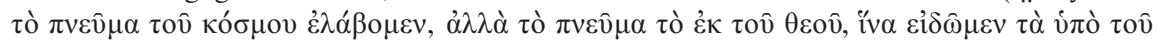
$\left.\theta \varepsilon \circ \hat{v} \chi \alpha \rho \iota \sigma \theta \dot{\varepsilon} v \tau \alpha \dot{\eta} \mu \hat{\imath} v^{*}\right)$.

355 Neben der bereits zitierten Stelle aus den Apostelakten (s. S. 27 A. 288 sowie A. 354) erinnern die Entrückungsschilderungen in den behandelten Texten vor allem an Passagen aus dem 2. Korintherbrief, so an II Kor 5,6, „Wisst aber, solange wir in diesem Körper leben, sind wir vom Herrn getrennt. Wir leben ja noch in der Zeit des Glaubens, noch nicht in der Zeit des Schauens. Lass uns aber voll Zuversicht sein und hoffen, 
Texte, vor allem in phänomenologischer Hinsicht, nicht bei der bloßen Anlehnung an Paulus, sondern bedienten sich am reichen Fundus der in der Spätantike kursierenden, spektakulär ausgeschmückten Entrückungseksta$\operatorname{sen}^{356}$. Damit entsprechen die geschilderten Ekstasen ganz dem Wortsinn von ह̌ $\sigma \tau \alpha \sigma 1 \varsigma^{357}$, „das aus sich Heraustreten“, „das aus dem Körper Herausgerissen werden“ oder „das außerhalb des Körpers Stehen“, um in eine transzendente Realität einzutreten, welche in den Texten oft als topographisch klar umschriebener Ort geschildert wird. Häufig wird der Ekstatiker von einem Heiligen oder von einem engelhaften Boten geführt und an Orte des göttlichen Waltens, in den Himmel oder an andere Orte des Heilsgeschehens entrückt, von dem er früher oder später wieder zurückkehrt ${ }^{358}$.

\subsubsection{Physische und psychische Symptome der mystischen Ekstase}

Bestimmte, in den Texten im Zusammenhang mit imaginären Erfahrungen erwähnte physische und psychische Merkmale erweisen sich als derart typisch für die mystische Ekstase, dass auch bei einer ganzen Reihe von Berichten ohne explizite terminologische Kennzeichnung alleine aufgrund der geschilderten Begleitsymptome mit Sicherheit von ekstatischen Bewusstseinszuständen ausgegangen werden kann ${ }^{359}$. Typisch ist bei diesen Symptomen, dass sie meist nicht nur auf eine bloße Einengung der materiellen Wahrnehmung wie z.B. bei

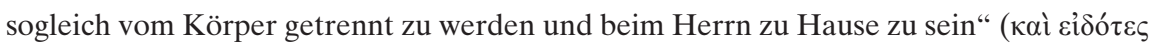

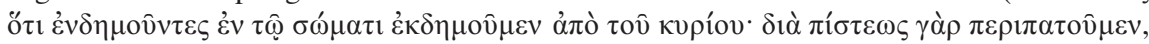

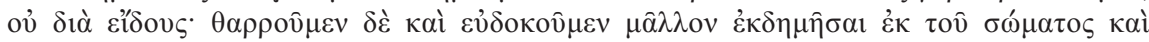

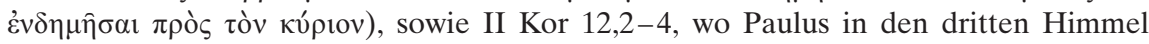

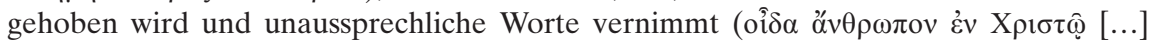

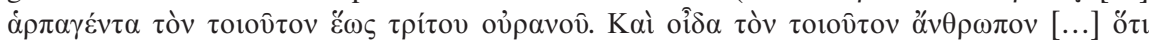

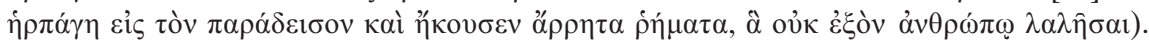

$356 \mathrm{Zu}$ nennen sind v.a. diverse apokryphe Erzählungen aus der jüdisch hellenistischen Literatur, so die Himmelsreise des Jesaja, s. Bovon, The Authority of Dreams 155; Rubenson, Transformation $278 \mathrm{f}$, , oder die Bücher Henoch und Baruch, s. DeanOtting, Heavenly Journeys 46-70. 98-119. 262-290; ColPe, HabermeHL, Jenseitsreise 491-495; ColPe, Himmelfahrt 214-215. Weitere Literatur s. S. 124 A. 613.

$357 \mathrm{Zu}$ der in den Texten verwendeten Terminologie s. S. 102-104 u. $109 \mathrm{f}$.

358 Entrückung zum oder in den Himmel: 109 (2), 156, 170, 224, 227, 239, 245, 250, 251, 252, 257, 258, 259, 262, 273, 292, 295, 297, 388; Entrückung an heilige Stätten: 96, 136, 220, 243; Entrückung in eine Kampfarena: 168; Entrückung zum himmlischen Gericht: 159, 171, 208, 233, 244, 249, 289; Entrückungen in die Hölle: 246, 256, 383, 464; Entrückungen mit Unheilsprophezeiungen: 71, 91, s. S. 109 f. Eine Himmelsreise in Anlehnung an die Himmelsfahrt des Jesaja kommt auch in den Briefen des Ammonas vor, vgl. Rubenson, Transformation 278. Siehe auch S. 152 A. 736.

359 Ekstasen ohne explizite Nennung s. Terminologische Tabelle 3.6.2. 
leichten meditativen Trancezuständen, sondern vielmehr auf den ,völligen Verlust der sensorischen Perzeption der Umwelt und Katalepsie“ hindeuten ${ }^{360}$.

Zuweilen wird berichtet, dass die Ekstase durch ihre Symptome von den umstehenden Zeugen als solche erkannt und richtig eingeschätzt wird. Die Scala Paradisi erzählt von einem Bruder, dass er „oft vom Gedanken an den Tod in Ekstase versetzt wurde und wie bewusstlos oder nach einem epileptischen Anfall von den Brüdern, die ihn fanden, fast leblos aufgehoben wurde ${ }^{\text {‘361 }}$. Es kann aber auch vorkommen, dass der Entrückte von den Anwesenden aufgrund seiner Körperstarre bereits für tot gehalten wird, so Theodoros von Sykeon, der sich, wie bereits erwähnt, über dreizehn Tage hinweg in einem ,schlafähnlichen Zustand befand, sodass alle im Kloster wehklagten, da sie glaubten, er verweile nicht mehr in diesem Körper“"362. Dasselbe gilt für eine Entrückungsvision des Daniel Stylites, der durch die heftige Kälte in einen ,schlafähnlichen“ Zustand gerissen wurde, sodass die Brüder glaubten, er sei erfroren. Erst als sie zu ihm auf die Säule stiegen und ihn mit warmem Wasser auftauten, kam er wieder zu sich und ,antwortete ihnen, wie wenn er aus dem Schlaf erwachte“"363.

Aus der Beschreibung des Zustandes der Ekstatiker als „schlafähnlich“ geht die symptomatische Nähe von Schlaf und Ekstase hervor, was aber umso deutlicher zutage treten lässt, dass sich die Autoren über den Unterschied der beiden Bewusstseinszustände im Klaren waren und dass sie Wert darauf legten, diesen Unterschied terminologisch zu kennzeichnen ${ }^{364}$. Damit halten sich die Autoren an Prokopios von Gazas Deutung der bzgl. Abgrenzung von Ekstase und Schlaf schwer zu interpretierenden Septuagintastelle „Da ließ Gott eine Ekstase auf den Menschen fallen, sodass er einschlief“ (Gen 2,21) ${ }^{365}$ : „Das ,er schlief‘ bedeutet nicht Schlaf [...], sondern zeigt die Beschaffenheit der Ekstase an. Wenn nämlich die Propheten solche Offenbarungen erhielten, haben sie oft gewacht, und gemäß der göttlichen Kraft erhielten sie wie im Traum die Schau von dem, was er ihnen offenbaren wollte ${ }^{6366}$. Wie bei Prokopios von Gaza wird in der monastischen Literatur die Ekstase in den meisten Fällen zwar als äuBerlich schlafähnlich, aber dennoch in deutlicher Abgrenzung vom Schlaf be-

360 Diese Definition von Ekstase gibt DinZelbacher, Revelationes 17; vgl. auch KAZHDan, Art. Ecstasy 675; Kelsey, Trance, Ekstase und Dämonen 43; Welte, Art. Trance 522.

361 48. Zum Zusammenhang von Ekstase und Epilepsie s. S. 91-94.

362 239. Zu diesem Beispiel siehe auch S. 23 A. 63, S. 67 f. A. 305, S. 140 A. 686.

36375 .

364 Über die physiologischen Unterschiede zwischen Ekstase und Schlaf s. Goodman, Ekstase 34.

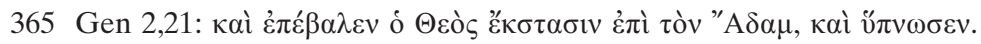

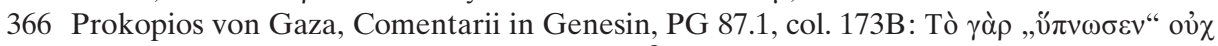

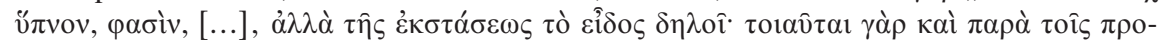

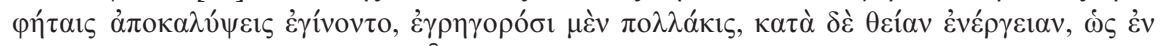

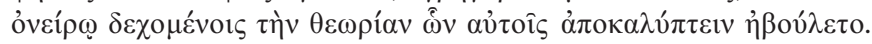


schrieben und, da sie den Menschen beim Wachen befällt, gegenüber dem negativ konnotierten Schlaf als erstrebenswerte Prädisposition für göttliche Offenbarungen hervorgehoben.

Eine Ausnahme stellt Palladios dar, der als einziger Autor die Ekstase mit dem Schlaf vermischt und die Formulierung „er wurde vom Schlaf überwältigt und sah eine Ekstase ${ }^{\star 367}$ verwendet. Anders als in den übrigen Texten, in denen die Ekstase immer als Bewusstseinszustand, in dem etwas gesehen wird, vorkommt, gebraucht hier die Historia Lausiaca den Begriff in der Bedeutung eines Gesichts, das gesehen wird, also in der Funktion des wahrgenommenen Objektes, das sonst entweder bildlich beschrieben oder durch andere allgemeine Termini für „Schau“ wie ỏ $\pi \tau \alpha \sigma i ́ \alpha$, ő $\alpha \mu \alpha$ etc. gekennzeichnet wird ${ }^{368}$. Dass eine solche Verwendung des Begriffes ह̌ $\sigma \tau \tau \alpha \sigma ı \varsigma$ im Entstehungsumfeld der Texte unüblich war, wird auch durch die Übernahme der Palladios-Stelle bei Sozomenos bestätigt, der die unscharfe Ausdrucksweise der Historia Lausiaca folgendermaßen „korrigiert“: ,... er wurde vom Schlaf überwältigt. Dann geriet er in eine Art Ekstase und schien zu sehen ... ${ }^{\text {(369. }}$. Auch ein weiteres Beispiel aus der Historia Lausiaca könnte vermuten lassen, dass sich Palladios über den Unterschied zwischen Schlaf und Ekstase nicht im Klaren war, zumal als Prädisposition für ein und dieselbe imaginäre Erfahrung einmal der Schlaf, einmal die Ekstase angegeben wird: Von Abbas Elias wird erzählt, dass er eines Abends einschlief und von drei Engeln besucht wurde. Diese schnitten ihm in einer imaginären Operation zur Bekämpfung seiner unreinen Begierden die Hoden ab. Dann heißt es ,in der Ekstase, denn so darf man es wohl nennen, schien es ihm, als heile die Wunde zu $^{\text {‘370 }}$. Eine solche Vermischung der Begriffe entspricht in keiner Weise der Grundtendenz der Texte, welche in der Regel die Ekstase klar vom Schlaf differenzieren. Die abweichende Verwendung in der Historia Lausiaca könnte mit einer Unsicherheit bezüglich der entsprechenden Definitionen zu erklären sein, was aber nicht mit der Tatsache übereinstimmen würde, dass sich Palladios anderswo offensichtlich sehr wohl über Inhalt und Bedeutung des Begriffes Ekstase für die monastische Spiritualität bewusst war. Dieser Eindruck entsteht, wenn er etwa über die bereits erwähnten regelmäBigen mystischen Ekstasen des Asketen Isidoros berichtet ${ }^{371}$. Auch die Erzählung über eine in Ekstase stattfindende Engelsvision des Euagrios Pontikos zeigt, dass Palladios bestens über die Askesepraktiken seiner Zeit Bescheid wusste $^{372}$. Noch deutlicher geht die bewusste Wortwahl der Autoren bzgl. Ek-

367217.

368 S. S. $104 \mathrm{f}$.

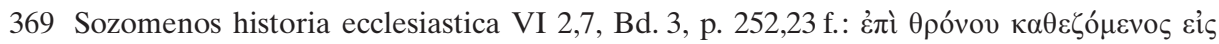

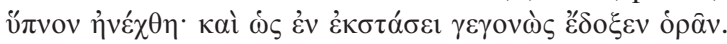

370265.

371 22. $\mathrm{Zu}$ diesem Bsp. siehe auch S. 77 A. 349.

372405. 
stase bzw. Schlaf aus der Umarbeitung derselben Stelle durch Sozomenos hervor, wo Euagrios das Engelsgesicht nicht mehr in Ekstase, sondern in einem Traum erblickt ${ }^{373}$. Eine solche Umarbeitung scheint keineswegs zufällig, wie ein weiterer Visionsbericht, den Sozomenos aus der Vita Antonii übernommen hat, zeigt. Es handelt sich um die berühmte Prophezeiungsvision des heiligen Antonios, der - als Metapher für die Arianer - Maultiere sieht, die gegen einen Altar treten und ihn umstoßen. Während Antonios bei Athanasios von einer drastisch geschilderten Ekstase mit den typischen körperlichen Symptomen wie Seufzen und Stöhnen ergriffen wird ${ }^{374}$, ist bei Sozomenos „nur noch“ von einem simplen Traumgesicht die Rede ${ }^{375}$. Die genannten Veränderungen entsprechen Sozomenos' offensichtlicher Vorliebe für Traumerzählungen, die in der Historia Ecclesiastica im Gegensatz zu der meines Wissens nur ein einziges Mal vorkommenden Ekstase ${ }^{376}$ wiederholt anzutreffen sind ${ }^{377}$. Das Erblicken eines Gesichts im Traum scheint für den Rechtsanwalt Sozomenos und wohl auch für das von ihm intendierte Lesepublikum naheliegender gewesen $\mathrm{zu}$ sein als die v.a. im asketischen Milieu, aber auch im christlichen Volksglauben beliebten Ekstase-Gesichte. Was die Uneindeutigkeit in den erwähnten Formulierungen der Historia Lausiaca angeht, so lässt sie am ehesten die Bemühung des geistlichen Autors Palladios erkennen, Erzählungen über im Schlaf stattfindende imaginäre Erfahrungen durch die zusätzliche Erwähnung, dass es sich ja eigentlich um Ekstase-Gesichte handelte, im Sinne von Prokopios' SeptuagintaKommentar aufzuwerten ${ }^{378}$.

Trotz der wiederholt zu beobachtenden symptomatischen Nähe von Ekstase und Schlaf wird in seltenen Fällen ein Merkmal der Ekstase geschildert, welches die beiden Bewusstseinszustände auch von außen betrachtet deutlich voneinander unterscheidet. Es handelt sich dabei um die geöffneten Augen während der Entrückung, ein Symptom, welches zweimal im Zusammenhang mit Todesvisionen, geschildert wird: In einem Väterspruch ist die Rede vom sterbenden Agathon, der ,während drei Tagen bewegungslos mit geöffneten Augen verharrte“377. Die Scala Paradisi berichtet vom Bruder Stephanos, dass er einen Tag vor dem Hinscheiden ,im Geist entrückt wurde und mit offenen Augen mal rechts und mal links vom Bett schaute ${ }^{* 380}$. Tatsächlich sind offene, genauer

373 Sozomenos, historia ecclesiastica VI 30,9-11, Bd. 3, p. 412,8-10 (s. Bsp. 405).

374 71. Siehe auch S. 85 A. 402.

375 Sozomenos, historia ecclesiastica VI 5,6, Bd.3, p. 270,11-13 (s. Bsp. 71).

376 S. S. 80 A. 369.

377 Sozomenos, historia ecclesiastica I 3,1; V 1,8; 9,6; VI 2,3; 5,6; 30,9-11; VII 29,2; VIII 24,2 ; Bd. 1, p. 122,18 ; Bd. 3, p. 84,5 ; p. 132,4 ; p. 252,3 ; p. 270,13 ; p. $412,9-17$; Bd. 4 , p. 218,$3 ;$ p. 338,3 .

378 S. S. 75 A. 343.

379209.

380233. 
gesagt „starre, nach oben verdrehte Augen“ sowie das „Hin- und Herwiegen des Kopfes" typische, wenn auch nicht zwingende Merkmale der ekstatischen Tieftrance $^{381}$. Dass sie in den genannten Beispielen besonders hervorgehoben werden, mag daran liegen, dass die Autoren damit die bereits erwähnte Metapher des „Öffnens des Inneren Auges““382, welches in Bezug auf das Sterben der heiligen Männer als endgültiges Eingehen in die göttliche Herrlichkeit verstanden werden kann, bewusst durch das gleichzeitig reale und metaphorische Bild der während der Ekstase physisch geöffneten, aber nicht sehenden, jedoch imaginär ins Jenseits schauenden Augen verstärken wollen.

Als weiteres äußeres Begleitsymptom kommt auch das „Auf das Gesicht/auf den Boden Fallen “3833 vor, obschon dieses Merkmal häufiger mit dämonischen Ekstasen in Verbindung gebracht wird ${ }^{384}$.

In vielen Beispielen ist die Rede von Ekstasen, die sich nicht als kurzzeitiger „Anfall“ äußern, sondern während einer längeren Zeitspanne andauern ${ }^{385}$. Der Entrückte befindet sich dabei in der Regel in einer Art meditativer Kontemplation, welche häufig mit einer besonderen emotionalen Ergriffenheit wie im oben genannten Beispiel aus der Vita Antonii einhergeht. Die durch das Geschaute ausgelösten Affekte wie Furcht, Schrecken, Freude oder Trauer können sich durch unterschiedliche körperliche Symptome wie Stöhnen, Weinen, Zittern oder durch das Ausstoßen einzelner Sätze durch den Ekstatiker äußern $^{386}$. Überdies wird in einigen Beispielen von bestimmten Handlungen der heiligen Männer während der Ekstase berichtet: Hypatios empfing, so heißt es, kurz vor seinem Tod bei der Eucharistie „in Ekstase von einem, der neben ihm stand, den Segen und gab ihn jemandem weiter, obwohl niemand da war, um den Segen zu empfangen, sodass ihn abermals der neben

381 Welte, Art. Trance 524.

382 S. S. 26 A. 83 u. 84 ; S. 48 A. 197; S. 71 A. 325.

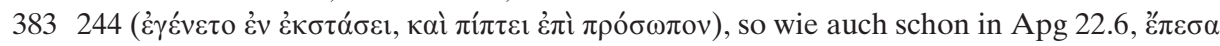

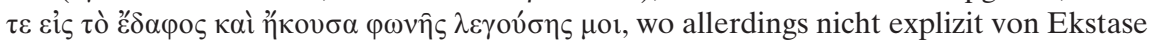
die Rede ist.

384 S. S. 91 A. 436.

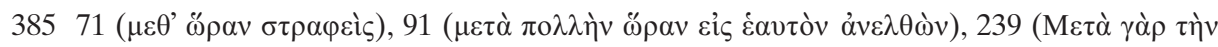

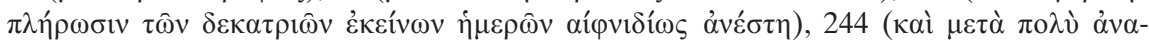

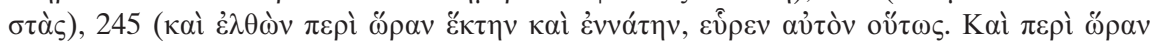

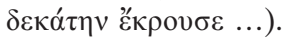

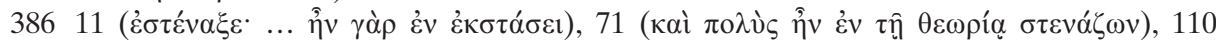

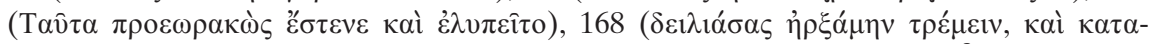

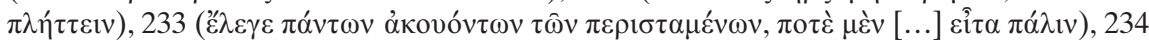

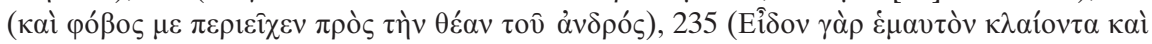

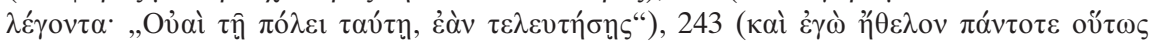

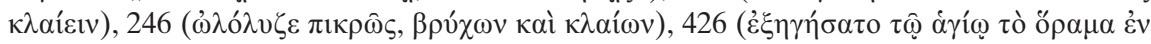

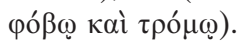


ihm Stehende empfing،387. Vom Wüstenvater Siluanos wird erzählt, dass er einmal von seinem Schüler Zacharias besucht wurde, als er sich gerade ,in Ekstase befand und die Hände im Gebet erhoben hatte“. Siluanos verharrte mehrere Stunden in dieser Position, und erst als Zacharias das dritte Mal bei ihm vorbeischaute, war er wieder zu sich gekommen und befand sich in Hesychase $^{388}$. Zuweilen berichten die Autoren das während der Entrückung Erlebte bzw. Geschaute aus der Perspektive der heiligen Männer. In diesen Fällen wird dem Leser meist vermittelt, dass der Ekstatiker sich in einer Art Selbstbeobachtung als Akteur eines imaginären Geschehens agieren sieht. Interessanterweise handelt es sich auch hierbei um ein für Trancezustände typisches Phänomen, welches in der Religionsethnologie aus der Sicht des Entrückten als „Gefühl der Dissoziation“ beschrieben wird ${ }^{389}$. In den hier zur Diskussion stehenden Texten kommt diese Art von Ekstasebericht besonders häufig im Zusammenhang mit den Prophezeiungsvisionen des Symeon Stylites des Jüngeren vor, wo wiederholt Formulierungen anzutreffen sind wie ,er/ich wurde im Geist entrückt und sah sich/mich selbst ...“390 oder „er sah sich in der Kraft des Geistes ...“391. Die Rede ist also vom Heraustreten des Geistes aus dem Körper, welches es dem Ekstatiker ermöglicht, sich selbst an einem anderen Ort, nämlich da, wo er sich im Geist gerade befindet, imaginär stehen, herumgehen oder andere Handlungen vollziehen zu sehen. Auf eindrückliche Weise beschreibt auch Athanasios, wie Antonios einmal ,fühlte, dass er entrückt wurde ... Das Sonderbare war, dass er dastand und sich selber wie aus sich herausgehen sah und von einigen in die Luft geführt wurde ...". Am Ende der Entrückung heißt es dann ,und auf einmal sah er sich selbst, wie wenn er zurückkommen und wieder bei sich stehen würde, und er war wieder gänzlich Antonios“6392. Ähnlich wird auch bei einer Visionserzählung des heiligen Sabas berichtet „Er sah sich selbst beim Gottesdienst in der heiligen Anastasis $^{\text {“393. }}$ Zu erwähnen ist diesbezüglich überdies die Schilderung der Rückkehr

387219.

388245.

389 Welte, Art. Trance $521 \mathrm{f}$.

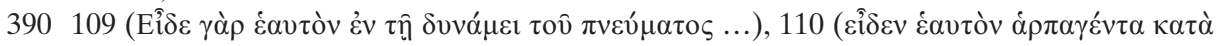

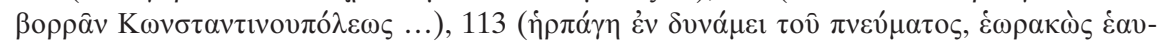

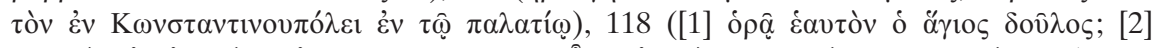

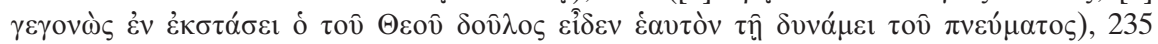

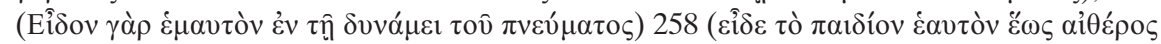

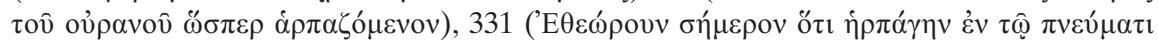

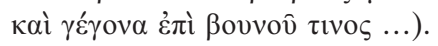

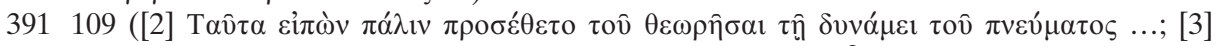

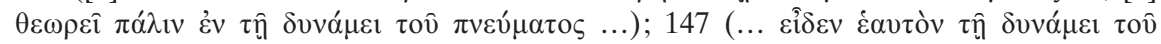
$\pi v \varepsilon \hat{\mu} \mu \alpha \tau \circ \varsigma$...).

392208.

393392. 
aus einer Ekstase aus der Sicht der Martha, welche berichtet, wie sie von den Flanken einer „Maschine“ ( $\mu \eta \chi \alpha v \eta ́)$, deren Kopf bis in den Himmel reichte, aus den himmlischen Lüften auf die Erde zurückbefördert wurde, wo sie dann wieder zu sich $\mathrm{kam}^{394}$. In den monastischen Texte sind zwar keine theoretischen Abhandlungen über die Trennung von Seele und Körper während der Ekstase anzutreffen, die erwähnten Beispiele legen aber die Vermutung nahe, dass die Autoren von einer solchen Trennung, wie wir es auch bei Ioannes Chrysostomos gesehen haben ${ }^{395}$, ausgingen. Recht gibt einer solchen Annahme auch Kyrillos von Skythopolis, bei dem es heißt: „Der heilige Ioannes hatte das Verlangen zu sehen, wie sich die Seele vom Körper trennt. Als er dabei war, Gott darum zu bitten, wurde er im Geist nach Bethlehem entrückt und sah [...] ${ }^{\text {‘396. }}$.

In den meisten Fällen wird das Ende der Ekstase weniger detailliert als in den oben genannten Beispielen geschildert, wobei v.a. Wendungen wie „er kam wieder zu sich“, selten auch ,er erwachte aus der Ekstase“ anzutreffen sind ${ }^{397}$. Allerdings ist auch hier häufig von den bereits erwähnten Symptomen emotionaler Bewegtheit wie Weinen, Stöhnen, Zittern ${ }^{398}$, aber auch von beharrlichem Schweigen oder Appetitlosigkeit die Rede, von denen der Ekstatiker auch nach der Entrückung noch begleitet wird und die zuweilen auch auf die anwesenden Zeugen des Geschehens übergreifen ${ }^{399}$. Als Pachomios nach einer Ekstase die Brüder versammelte und ,ihnen das von ihm Geschaute berichtete, weinten alle in großer Furcht ${ }^{\star 400}$. Bei Symeon Stylites wird erzählt, dass die Brüder durch die von ihm berichtete Schau in Furcht gerieten und dass sich Symeons Gesicht noch während des Erzählens plötzlich veränderte. „Er fing an zu schweigen, antwortete nicht mehr und war äußerst betrübt, sodass wir (die anwesenden Brüder) in Trauer gerieten“"401. Von Antonios wird berichtet, dass er, nachdem er aus einer

394227 (2).

395 S. S. 75 A. 342.

396 220. S. auch das Beispiel 318 aus der ViEu, wo der von Euthymios von hoher See entraffte Diakon Phidos sich in Jerusalem „in einem Zustand der völligen Bewusst-

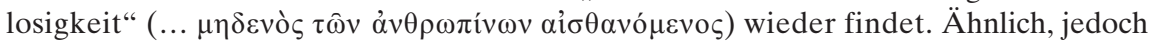
im Hinblick auf Träume, äußert sich Athanasios von Alexandreia in Contra Gentes 31,38-44, wo er „die träumende Seele als einen rationalen und unsterblichen Reisenden“ beschreibt; vgl. Miller, Dreams 66. Zur Diskussion über das Verhältnis von Seele und Körper während des Träumens in der Spätantike vgl. Miller, ebd. 39-73.

397 Siehe auch S. 103 A. 514.

398 S. S. 82 A. 386.

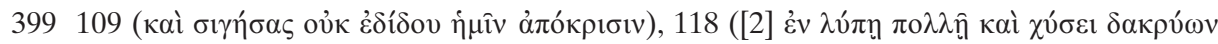

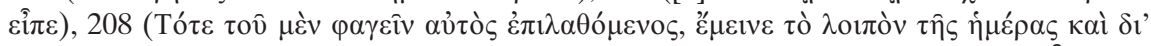

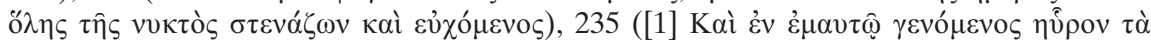

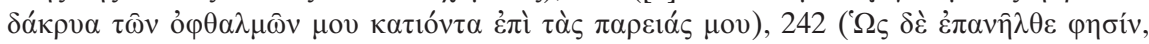

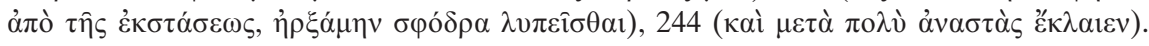

40091.

401109 (1). 
einstündigen Ekstase zurückgekehrt war, aus Schrecken über das Geschaute stöhnte, zitterte und weinte, sodass auch die Anwesenden in Schrecken gerie$\operatorname{ten}^{402}$. Bei Symeon Stylites dem Jüngeren heißt es nach einer Todesprophezeiung, „als ich wieder zu mir kam, sah ich, wie Tränen über meine Wangen liefen. Und als ich noch einmal in Ekstase geriet, weinte ich ..." ${ }^{403}$. Es kommt auch vor, dass die durch die Entrückung ausgelöste Ergriffenheit so weit geht, dass sie weitreichende Folgen für das Leben des Ekstatikers hat. So ist von einem Einsiedler die Rede, der nach einer durch Krankheit ausgelösten Ekstase, die ihn an die Grenze des Todes brachte, alle bat, ihn alleine zu lassen. „Dann verbrachte er zwölf Jahre, ohne mit irgendjemandem zu sprechen, saß nur da und staunte über das, was er in der Ekstase gesehen hatte. Er war so nachdenklich, dass er niemals seinen Gesichtsausdruck änderte, sondern immer gedanklich außer sich war und ständig lautlos heiße Tränen vergoss“"404.

\subsubsection{Heilungsekstasen}

Wie bereits erwähnt, finden sich in den behandelten Texten neben den zahlreichen Beispielen für mystische Ekstasen als integraler Bestandteil der monastischen Spiritualität auch verschiedene Erzählungen über ekstatische Visionserfahrungen als Äußerung christlicher Volksfrömmigkeit. Diese werden zuweilen (aber nicht notgedrungen) terminologisch als Ekstase ('̌ $\sigma \tau \alpha \sigma ı)$ ) gekennzeichnet $^{405}$ und in Zusammenhang mit Heilungen oder anderen Heilserfahrungen von weltlichen Christen geschildert ${ }^{406}$. Werden hier auch in vielen Fällen die gleichen induzierenden Praktiken wie bei der mystischen Ekstase erwähnt ${ }^{407}$, so unterscheiden sie sich von dieser vor allem durch die Art ihres visuellen Gehalts und dessen Wirkung auf den Hilfe Suchenden. Hier geht es immer um eine gleichermaßen körperliche wie spirituelle Heilung mittels imaginärer Vorgänge, für die der Kranke aufgrund eines Zustandes des erweiterten Bewusstseins empfänglich wird, so wie wir es schon am Beispiel über den von Symeon Stylites geheilten Jungen gesehen haben ${ }^{408}$. Auch andere Erzählungen verdeutlichen, dass die Heilung gerade dann stattfinden kann, wenn dem Kranken das Leiden bildlich, z.B. in der Form eines Gestalt annehmenden Dämons, vor (die inneren)

40271.

403235.

40452.

405 Explizite Nennung von Ekstase: 262, 264, 280, 388. Ohne terminologische Kennzeichnung: 263, 267, 270, 271, 274, 277, 279, 282, 306, 312, 329.

406 Nur in 262 kommt eine induzierte Heilungsekstase im monastischen Umfeld vor, s. S. 31 A. 114, S. 73 A. 330 , S. 86 A. 411.

407 S. S. 74 A. 333 u. 334.

408 279. S. S. 48 A. 197 , S. 71 f. A. 325 , S. 74 A. 335. 
Augen und dann von ihnen weg geführt wird. Deutlich wird dieser Vorgang v. a. auch anhand der Heilungsekstasen in der Vita Euthymii. So wird über den angeblich durch einen Zauber erkrankten Romanos erzählt, dass ihm in Ekstase der heilige Euthymios erschien und mit den Fingern wie mit einem Schwert den Bauch aufschnitt, um ihm ein mit Einritzungen versehenes Zinnplättchen zu entnehmen ${ }^{409}$. Vom bereits erwähnten kranken Paulos ${ }^{410}$ berichtet Kyrillos von Skythopolis, dass er in einer Ekstase einen lichterfüllten Ort erblickte und selbst auf dem Kopf eine schwarze Kapuze mit spitzigen Rosshaaren trug, die ihn fürchterlich stachen und quälten. Er flehte den Herrn um Rettung an, woraufhin er plötzlich den heiligen Euthymios in gleißendem Glanz, mit weißem Haar, vom Alter untersetzt, mit großem Bart, kugelrundem Gesicht und freudestrahlendem Ausdruck erblickte. Euthymios trug einen schwarzen Umhang, hielt einen Stab in der Hand und fragte Paulos, warum er ihn störe und was er von ihm wolle, worauf dieser furchterfüllt erwiderte, dass er um sein Mitleid flehe. Erst als Paulos versprach, sich von nun an richtig zu verhalten, riss ihm Euthymios die schwarze Kapuze vom Kopf, die sich in seinen Händen zu einem kleinen Äthiopier verwandelte, aus dessen Augen Feuer schoss. Und am Boden erblickte er eine tiefe Grube, in die Euthymios den Äthiopier warf. Daraufhin war Paulos geheilt ${ }^{411}$. Besonders deutlich geht aus dieser Erzählung die für alle imaginären Heilungen (also auch für Traumheilungen ${ }^{412}$ ) charakteristische enge Verknüpfung von körperlicher und spiritueller Heilung hervor, so wie wir es schon aus den neutestamentlichen Wundererzählungen kennen ${ }^{413}$. Zu dieser Verknüpfung, die an den Kern der Wunderheilungen durch Jesus rührt, kommt aber in den monastischen Texten noch das Schlüsselelement der Imagination hinzu. Denn hier stellen die Autoren die Heilung eines körperlichen Leidens als Folge eines durch den Charismatiker in einer imaginären Erfahrung herbeigeführten spirituellen Wandels dar. Dieser geht sowohl mit dem (visuellen) Erkennen eines wie auch immer gearteten unkörperlichen Krankheitszustandes in Form eines Dämons als auch mit dem Erblicken des heilenden Charismatikers einher. So auch in der Erzählung über die von einem wilden Dämon besessenen Jungfrau Theosebeia, die in der Gegenwart von Symeon Stylites dem Jüngeren in Ekstase geriet und sah, wie der mit einem Gewand aus Licht bekleidete heilige Mann, der auf dem Kopf eine Krone trug, über welcher ein Kreuz leuchtete, und auf dessen Stirne Sterne prangten, den Dämon in ihr fesselte, der daraufhin als dunkler Inder durch ihre Schulter ausfuhr. Nachdem Theosebeia dies gesehen hatte, wurde sie Nonne

409 264. Zu diesem Bsp. siehe auch S. 73 A. 331, S. 135 A. 664.

410 262. S. S. 85 A. 406.

411262.

412 S. S. 73 A. 332.

413 Vgl. Berger, Wunder 18-22; Ders., Der Wundertäter 14-16. 
und blieb es bis zu ihrem Lebensende ${ }^{414}$. Angesichts der in den Texten zahlreich vorkommenden Traumheilungen, die nach exakt dem gleichen Schema wie die hier vorgestellten Ekstaseheilungen ablaufen ${ }^{415}$, ist davon auszugehen, dass das Träumen in der Bevölkerung weit weniger negativ besetzt war als in den asketisch monastischen Kreisen und nach wie vor eine mögliche Form der inkubationsähnlichen Heilung darstellte ${ }^{416}$. Gleichzeitig wird aber deutlich, dass auch hier die Ekstase als legitime und praktikable Möglichkeit der durch induzierende Handlungen evozierten visionären Erfahrung angesehen wurde. An anderer Stelle wurde bereits gezeigt, dass alle diese Formen der imaginären Heilung nicht mehr an ein bestimmtes Heiligtum gebunden waren, wie es noch bei der klassischen Inkubation der Fall war ${ }^{417}$, sondern gemäß dem Prinzip der Ubiquität des göttlichen Gnadenwirkens überall und jederzeit zuteil werden konnten $^{418}$.

\subsubsection{Die dämonische Ekstase}

Anders als bei all den Beispielen für die Ekstase als Weg zum Göttlichen hin, liegen die Ursprünge der zweiten Gruppe in der antiken Bedeutung des Wortes, die letztlich auf die dionysische Ekstase des Euripides ('̌́ $\sigma \tau \alpha \sigma ı \varsigma \varphi \rho \varepsilon v \hat{\omega} v)^{419}$ und auf die Philosophie Platons zurückgeht. Die Ekstase kann hier neben dem

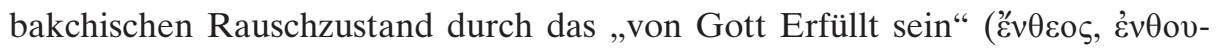
$\sigma \iota \alpha \sigma \mu o ́ \varsigma)$ alle Phänomene des Irrsinnes und der Verrücktheit beschreiben ${ }^{420}$. Auch hier geht es um ein „Aus sich Heraustreten“, allerdings nicht als Be-

414280.

415 S. S. 73 A. 332.

416 S.o. Kap. 1.3.1.

417 S.o. Kap. 1.3.2.

418 S. S. 35 A. 143.

419 Euripides, Ba. 359. 850, p. 42,9; 94,13. Zu dieser Wendung in der klassischen Antike vgl. Pfister, Art. Ekstase $945 \mathrm{f}$.

420 Als Vorbild diente in erster Linie Platons Phaidros. Hier ist es der enthousiasmos, der den vom Eros besessenen und von der Menge für wahnsinnig gehaltenen Philosophen zur ekstatischen Schau der Ideen und somit hin zum Göttlichen führt (Platon,

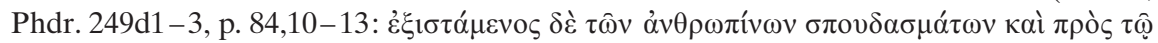

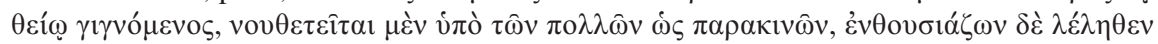

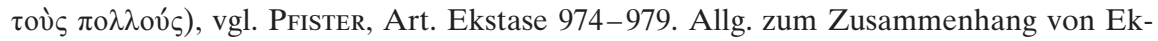
stase und Enthusiasmos in der Antike s. Wissmann, Art. Ekstase 490. Über den Zusammenhang von ekstatischen Erlebnissen und Wahnsinn ( $\left.\mu \alpha v^{\prime} \alpha\right)$ in der mythischen Überlieferung und in der Ausgestaltung bei Dichtern der Antike s. Pfister, Art. Ekstase 949. Eine Unterscheidung zwischen verschiedenen Arten des Wahnsinnes wie bei

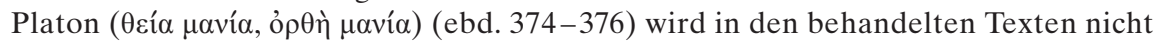
mehr gemacht. Der göttliche Wahnsinn, also die $\theta \varepsilon^{\prime} \alpha \mu \alpha v^{\prime} \alpha$, verliert im Christentum seine Bedeutung gänzlich. 
wusstseinserweiterung, wie wir es bei der mystischen Ekstase gesehen haben, sondern vielmehr in der Bedeutung von außer sich, verrückt oder von Sinnen sein. Was jedoch in der klassischen Antike als „religiöse Raserei“ seine Berechtigung hatte, nimmt im frühen Christentum eine negative Bedeutung an und wird zunächst in einen Zusammenhang mit den vorgetäuschten Prophezeiungen der Häretiker gebracht. So heißt es schon bei Origenes, „im Zustand der Ekstase und Raserei zu prophezeien, ohne bei sich selbst zu sein - dies ist nicht das Werk des göttlichen Geistes“421 und laut Basileios von Kaisarea „, behaupten manche, dass sie in Ekstase prophezeien, wenn ihr menschlicher Intellekt vom Heiligen Geist umhüllt ist. Dies ist jedoch entgegen der Verheißung der göttlichen Herabkunft, nämlich wie von Sinnen vorzutäuschen, göttlich inspiriert zu sein und, einmal von den göttlichen Lehren erfüllt, den eigenen Verstand zu

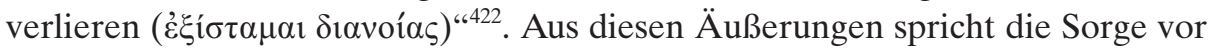
einem Missbrauch der Ekstase durch falsche Propheten, die durch ekstatisches Gehabe listig vorgeben, vom Geist Gottes erfüllt zu sein. Eusebios spezifiziert diese falsche Ekstase terminologisch, wenn er von dem aufgrund eines übermäßigen Verlangens nach Ansehen von einem dämonischen Geist besessenen Häretiker Montanos berichtet, dass er in „Pseudoekstase“ ( $\pi \alpha \rho \varepsilon ́ \kappa \sigma \tau \alpha \sigma ı \varsigma)$ anfing $\mathrm{zu}$ lallen und in Zungen $\mathrm{zu}$ reden. Auf diese Weise $\mathrm{zu}$ prophezeien sei, so Eusebios, gegen die Tradition und das althergebrachte Erbe der Kirche ${ }^{423}$.

Auch in den monastischen Texten ist die von den Kirchenvätern vorgegebene Trennung zwischen mystischer und dämonischer Ekstase durch zahlreiche Beispiele belegt. Allerdings wird hier die dämonische Ekstase häufig durch die

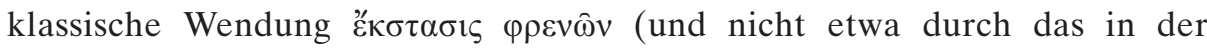
Septuaginta [Dtn 28,28] im Sinne von „Sinnesverwirrung“ verwendete und auch

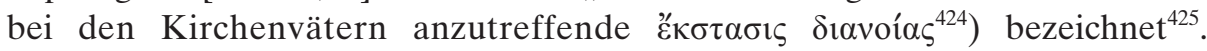

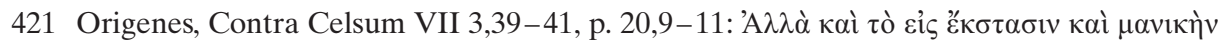

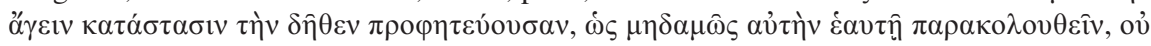

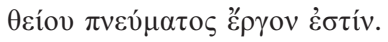

422 Basileios von Kaisarea, Commentarius in Isaiam prophetam, Praef. 5,1-6, PG 30,

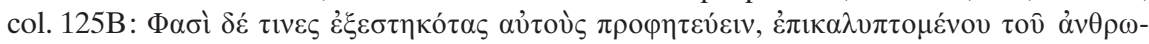

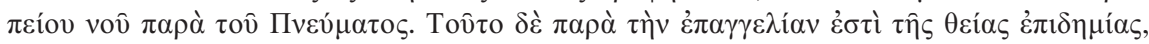

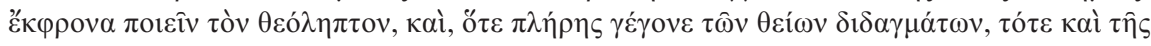

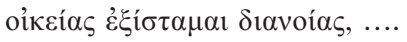

423 Eusebios von Kaisarea, Historia Ecclesiastica V 16, 7.2-9, p. 47,24-48,6: हैv $\theta \alpha$

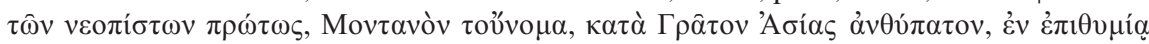

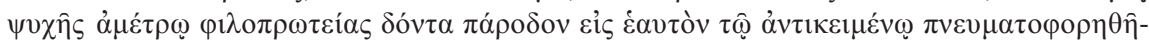

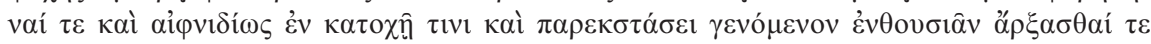

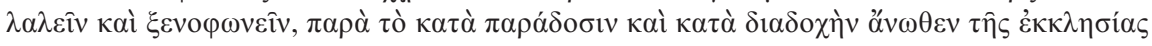

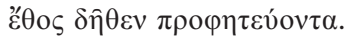

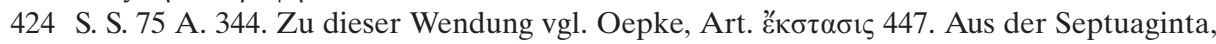

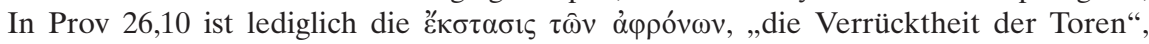
bekannt. 
Überdies verbinden die monastischen Autoren die Kennzeichen der dionysischen Ekstase nicht mit der Pseudoekstase der falschen Propheten, sondern vielmehr mit diversen krankhaften Zuständen, die fast immer mit dämonischer Besessenheit in Verbindung gebracht werden und meist dann auftreten, wenn Menschen aufgrund von dämonischen Attacken krank und von schmutzigen, unlauteren Gedanken verfolgt werden. Im Gegensatz zu der mystischen Ekstase, bei der sich der Ekstatiker in einem durch die göttliche Gnade ausgelösten Zustand des religiösen Überbewusstseins befindet, scheint der durch dämonische Besessenheit Entrückte einen Bewusstseinsverlust durch das Einwirken dämonischer Kräfte zu erleiden. Er befindet sich in einem Zustand, in dem sich das Unterbewusste auf unkontrollierbare Weise nach außen kehrt und zu körperlichen Regungen der Raserei und des Wahnsinns führt. Dies äußert sich darin, dass die hier geschilderten Symptome die der mystischen Ekstase häufig an physischer Intensität übertreffen. Oftmals wird geschildert, wie der Ekstatiker in einen Zustand der Raserei versetzt wird, aus dem er nicht wieder zu sich selber zurückfindet, sofern ihm nicht die heilende Kraft eines heiligen Mannes zu Hilfe kommt. Besonders gefährdet für dämonische Ekstasen sind laut der Vita Pachomii die „normalen“ Mönche des koinobitischen Klosterlebens, „denn glauben sie etwas zu sein, was sie nicht sind, werden sie vom Feind dazu verführt sehen zu wollen,

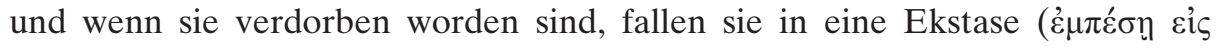

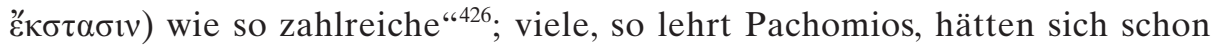
umgebracht, weil sie den dämonischen Anschlag der Gotteslästerung nicht bekämpfen konnten, , der eine, indem er sich wie ein Rasender ( $\dot{\omega} \varsigma \dot{\varepsilon} \kappa \sigma \tau \alpha \tau 1-$ кós) von oben in die Tiefe stürzte, der andere, indem er sich mit einem Messer den Bauch aufschlitzte und wieder andere auf andere Weise“"427. Euagrios, der die Ekstase auch umschreibt als „erneute Neigung des verständigen Teils der Seele zum Schlechten hin, nachdem er sich bereits der Tugend und der Kenntnis Gottes zugewandt hat “428, warnt folgendermaßen: „Der Überheblichkeit folgt Zorn und Kummer und schließlich das äußerste

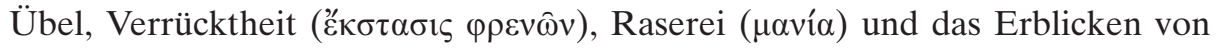
einer Masse von Dämonen“ “429 und „keiner soll in Zorn, Überheblichkeit oder Kummer als Anachoret leben und die Brüder fliehen, wenn er von solchen Gedanken geplagt wird, denn aus derartigen Leidenschaften geht Verrücktheit (๕̌ $\sigma \tau \alpha \sigma \iota \varsigma)$ hervor“4330. Antonios berichtet in einem Väterspruch, dass er

$425 \mathrm{Zu}$ allen in den Texten vorkommenden Ekstase- Termini s. Kap. 3.6.2.

42635 .

42734.

42819.

42942.

43020. 
„Mönche kannte, die trotz harter Mühen gefallen und verrückt geworden sind

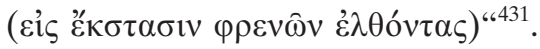

Zur Veranschaulichung der genannten Warnungen sind in den Texten auch konkrete Beispiele über Mönche und andere Gläubige nachzulesen, die angeblich von dämonischen Ekstasen heimgesucht wurden. In der Vita des Theodoros von Sykeon ist die Rede von einem gewissen Theodoros, der ,von

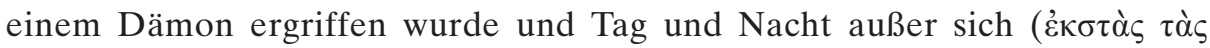

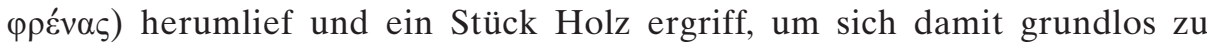
verletzen. Was auch immer er fand, zerstörte er, und er tat unschickliche und strafbare Dinge, schrie mit lauter Stimme und stieß ungehörige Worte hervor “432. Eine besonders drastische Erzählung aus der Vita Pachomii berichtet von einem Bruder, „der vom Dämon der Unzucht in eine Ekstase gerissen

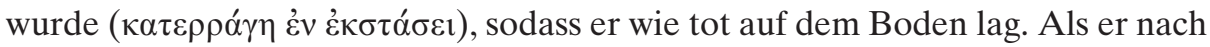
Tagen wieder ein wenig zu sich kam, ging er zu den Brüdern und sagte unter Weinen und Zittern, er selbst sei der Grund für seinen eigenen Untergang. [...] Und noch während er dies sagte, wurde er so vom Dämon ergriffen, wie wenn er außer sich geraten würde. Er rannte eine lange Strecke auf den Berg und kam in

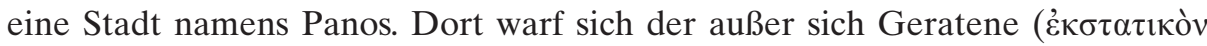
őv $\tau \alpha)$ nach einiger Zeit in den Ofen des Bades und verbrannte “433. Ein weiteres Beispiel ist in der Historia Monachorum in Aegypto nachzulesen: „Ein Hir-

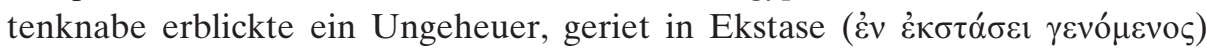
und fiel in Ohnmacht. Der Junge blieb den ganzen Tag bewusstlos in der Wüste liegen. Erst am Abend wurde er von seinen Eltern gefunden. Er atmete kaum mehr und war völlig aufgeblasen von der Ekstase ..." ${ }^{\text {“434 }}$. Der Hirtenknabe wird in der Folge, im Gegensatz zu dem Beispiel aus der Vita Pachomii, wo die Ekstase einen tödlichen Ausgang nimmt, von seinen Eltern zu einem heiligen Mann gebracht und von seiner Krankheit erlöst. Neben den genannten Beispielen von durch Dämonen verführten und deshalb außer sich geratenen „Rechtgläubigen“" ist die dämonische Ekstase auch im Zusammenhang mit Irrglauben und Heidentum anzutreffen. So in der Vita Porphyrii, wo berichtet wird, dass die Manichäerin Iulia in der Gegenwart des Porphyrios anfing zu zittern, dass sich ihr Gesicht veränderte und dass sie während

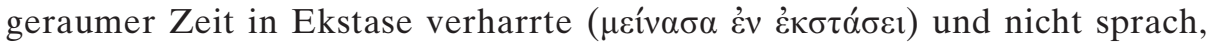

431 9. Ähnlich lautet die Antwort auf eine Frage im Dialogus de contemplatione 4,1-5,2, p.

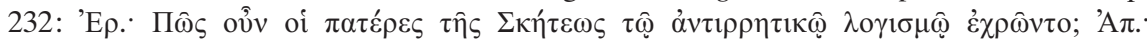

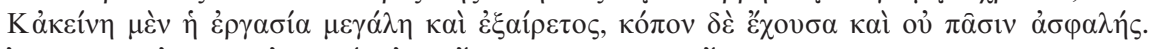

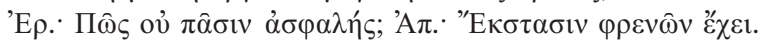

432481.

433456.

434449. 
sondern stumm und regungslos mit geöffneten Augen auf den heiligen Bischof starrte ${ }^{435}$. Auch hier nimmt die Ekstase einen tödlichen Ausgang.

In mehreren Beispielen wird die dämonische Besessenheit nicht termi-

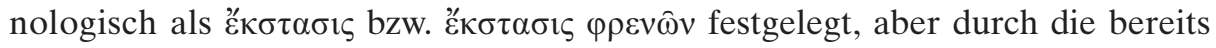
aufgezählten Symptome wie „Brüllen“, „zu Boden bzw. ins Wasser fallen“, „Körperstarre“, „Schäumen“ etc. beschrieben ${ }^{436}$. So z. B. in einer Erzählung aus der Vita des Symeon Stylites dem Jüngeren, wo der Neid eines Dämons auf die Schönheit eines Mädchens dazu führte, dass dieses plötzlich anfing zu stöhnen und am ganzen Körper zu zittern, sodass es den Verstand verlor ( $\mu \eta ́ \tau \varepsilon$ $\varphi \rho \varepsilon ́ v \alpha \varsigma$ ¿̌ $\chi \varepsilon \imath v)$ und keinen Augenblick Ruhe hatte, um sich zu erholen. Erst das Eingreifen des Styliten führte dazu, dass sich die Glieder des Mädchens plötzlich wieder beruhigten ${ }^{437}$.

\subsubsection{Von der Mondsucht zur Ekstase}

Unverkennbar ist bei vielen der genannten Beispiele die mehr oder weniger direkte Anlehnung an die aus den Evangelien bekannte Geschichte über den mondsüchtigen Knaben, der gemäß Mk 9,14-29 von seinem Vater zu Jesus gebracht wurde, da er seit seiner Kindheit immer wieder von einem unreinen Geist gepackt und geschüttelt wurde und dabei Schaum vor dem Mund hatte und mit den Zähnen knirschte, bis er schließlich in Starrheit fiel ${ }^{438}$. In verkürzter Form erscheint die gleiche Erzählung in Mt 17,15, wo die Worte des Vaters folgendermaßen lauten: „Herr erbarme dich meines Sohnes, denn er ist mondsüchtig ( $\sigma \varepsilon \lambda \eta v i \alpha ́ \zeta \varepsilon \tau \alpha \imath)$ und hat schwer zu leiden; er fällt nämlich oft ins Feuer und oft ins Wasser “439. Die offenkundigen Parallelen zwischen den Erzählungen des Neuen Testament und den oben genannten aus der monastischen Literatur wären nicht weiter erwähnenswert, würde nicht die auffällige Verän-

435463.

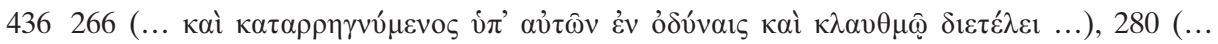

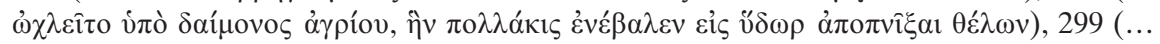

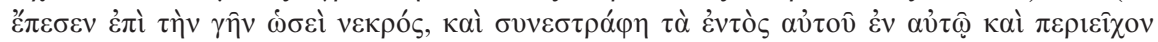

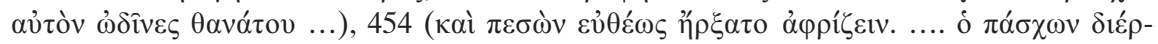

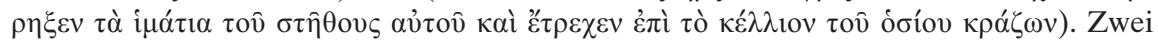
weitere Beispiele in MAKrIs, Zur Epilepsie 377, A. 54; 378, A. 56.

437276.

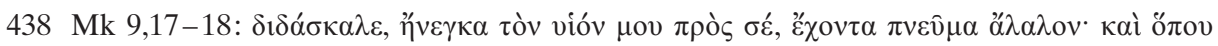

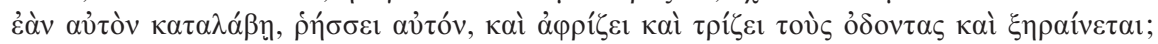
Übersetzung der Stelle nach MaKRIs, Zur Epilepsie 365.

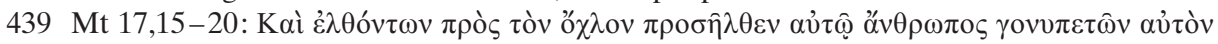

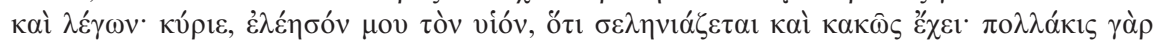

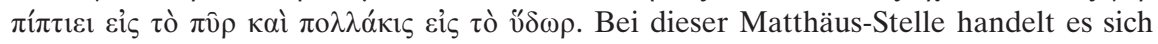
wahrscheinlich um eine Redigierung von Mk 9,17-18, wo (wie auch in Lk 9,37-43) der Begriff „mondsüchtig sein“ nicht verwendet wird, die Symptome der Epilepsie aber ausführlicher als bei Mt geschildert werden; s. MAKRIs, Zur Epilepsie 365. 
derung in der Bezeichnung der Besessenheit ins Auge fallen. Zwar taucht der neutestamentliche Begriff „mondsüchtig“ weiterhin als Bezeichnung für Epilepsie bzw. dämonische Besessenheit auf, so einmal in der Vita Hypatii ${ }^{440}$ und zweimal in den Viten des Kyrillos von Skythopolis ${ }^{441}$. Weit häufiger aber haben die Autoren, wie oben gezeigt wurde, das bei Matthäus verwendete Wort $\sigma \varepsilon \lambda \eta v i \alpha ́ \zeta \varepsilon \tau \alpha \iota$ mit dem im Neuen Testament in dieser Bedeutung ungebräuchli-

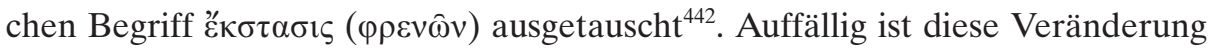
insbesondere deshalb, weil beide Begriffe gleichermaßen mit den körperlichen Symptomen der Epilepsie umschrieben werden und, jedenfalls was die Symptomatik und die Dämonisierung der geschilderten Krankheit angeht, als Synonyme verstanden werden können. „Krämpfe“, „Brüllen“, „Schaum vor dem

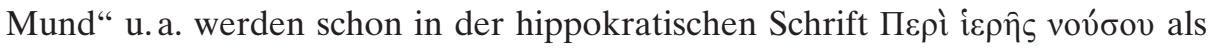
typische Symptome der in der klassischen Antike als hiera nosos bezeichneten Epilepsie aufgezählt ${ }^{443}$. Diese wiederum wurde in der Antike in einen physiologischen Zusammenhang mit den Mondphasen gebracht und deshalb auch als Mondsucht bezeichnet ${ }^{444}$. In Verbindung mit dämonischer Besessenheit taucht die Mondsucht dann zum ersten Mal in der zitierten Stelle in Mt 17,15 auf und geht von hier aus, v. a. durch die Exegese des Origenes, in die Welt des frühen Christentums ein ${ }^{445}$. Bereits von Origenes wurde die Erklärung des Mondeinflusses als Auslöser für die Epilepsie durch die Ansicht eingeschränkt, dass der eigentliche Verursacher der Krankheit der Dämon und nicht, wie von der Masse der abergläubischen Bevölkerung geglaubt, der Mond sei $^{446}$. Vor dem Hintergrund der kritischen Haltung, welche die offizielle Kirche gegenüber der Astrologie hegte, verwundert eine solche Erklärung nicht. Die terminologische Entwicklung in den monastischen Texten verdeutlicht jedoch nicht nur die Verlagerung von einer astrologischen hin zu einer dämonologischen Interpre-

440 ViHy, Kap. 40,40,1, p. 268,25 (gr. Text s. S. 37 A. 150).

441 263; ViKy, Kap. 9,16, p. 228,11.

442 Die einzige negative Verwendung, allerdings mit der allgemeinen Bedeutung von „von Sinnen sein“ findet sich bei Mk 3,21, wo Jesus von seinen Verwandten für verrückt

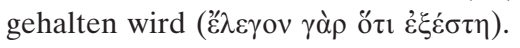

443 Hippokrates, Morb.Sacr. 7,3-12, p. 64,29-66,30. Vgl. Lesky, WaszinK, Art. Epilepsie 819. Die Bezeichnung hiera nosos wird in byzantinischer Zeit dann v. a. für Lepra u.a. und nicht mehr für Epilepsie verwendet; vgl. Philipsborn, IEPA NOsOs 224; Scarborough, Art. Insanity 998; Makris, Zur Epilepsie 399-401.

444 MaKrIs, Zur Epilepsie 365. Über die verschiedenen diesbezüglichen medizinischen und philosophischen Erklärungsmodelle s. TEMKIN, The falling sickness 95.

445 Vgl. Dölger, Der Einfluss des Origenes 95-98; Festugière, Les moines d' Orient I 25; MaKris, Zur Epilepsie 365 f.; 394, A. 142; Temkin, The falling sickness 91 f. mit A. 32 u. 96.

446 Diese Meinung taucht auch in späteren Kommentaren von Ioannes Chrysostomos und Athanasios auf. S. DöLgER, Der Einfluss des Origenes 88 f.; 101; MAKRIS, Zur Epilepsie 366; Temkin, The falling sickness 96. 
tation des Begriffes „Mondsucht“, sondern auch dessen zunehmende Meidung durch christliche Autoren ${ }^{447}$. Allerdings scheint die Gleichsetzung der Epilepsie mit dämonischer Besessenheit im frühen Christentum nicht ganz so zwingend gewesen $\mathrm{zu}$ sein, wie es gerne postuliert wird ${ }^{448}$. Ioannes Klimakos kennt und benennt, wenn auch als einziger Autor der behandelten Texte, die Epilepsie ( $\dot{\pi} \imath \lambda \eta \psi i ́ \alpha)$, bringt sie aber nicht mit Dämonen in Zusammenhang, sondern sieht sie offenbar als physiologische Krankheit, deren Symptome er wiederum in einen Zusammenhang mit der mystischen Ekstase bringt ${ }^{449}$. Für die dämonische Ekstase dagegen findet sich meines Wissens bei Ioannes Klimakos kein Beispiel. Erstaunlicherweise ist die dämonische Ekstase auch in der Vita Antonii, deren Vorbildfunktion für die restliche monastische Literatur der frühbyzantinischen Zeit in der Forschung gerne hervorgehoben wird, nicht belegt, weder als

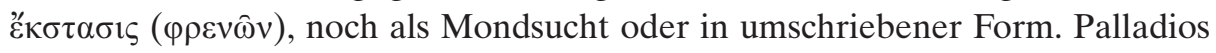

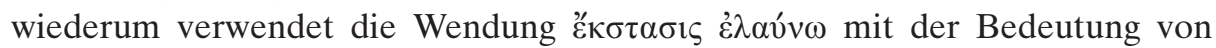
„verrückt werden“, ohne diese jedoch in einen Zusammenhang mit Dämonen zu bringen ${ }^{450}$, und lediglich Theodoret von Kyrrhos verwendet in seiner Philotheos Historia den klassischen Begriff $\lambda v \sigma \sigma \eta, \lambda v \sigma \sigma \alpha \omega^{451}$, obschon aus anderen Werken hervorgeht, dass ihm die dämonische Ekstase sehr wohl bekannt war ${ }^{452}$.

Dass ein großer Teil der Autoren auf der Suche nach einer Alternative für

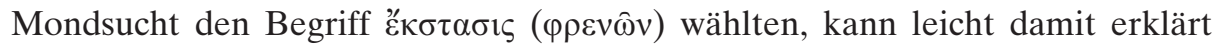
werden, dass die dionysische Ekstase aus christlicher Sicht als abzulehnende und dämonische Heiden-Praktik verstanden wurde und deshalb als Bezeichnung für

447 Was freilich nichts über die tatsächliche Verbreitung und Verwendung des Begriffes in der Volkssprache aussagt, wo das Wort $\sigma \varepsilon \lambda \eta v i \alpha \sigma \mu$ óv gemäß byzantinischen Medizinbüchern nach wie vor gebräuchlich gewesen sein dürfte, vgl. Temkin, The falling sickness 86, A. 9.

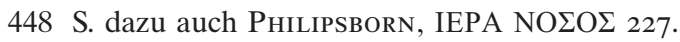

44948 (s. S. 79 A. 361). In ScPa IV 28 f., PG 88, col. 689B, ist überdies die Rede vom jungen Isidoros, der vor einer Aufnahme ins Sinai-Kloster seinen Gehorsam beweist, indem er sieben Jahre an der Pforte eines Klosters weilt und die Mönche um Fürbitten anfleht,

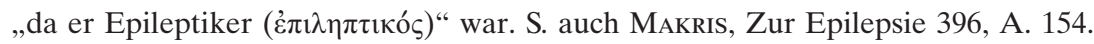

450 So ist in HiLa Kap. 39, p. 123,6-9 nachzulesen, dass die Schwester des Ägypters Pior im Alter erfuhr, dass ihr Bruder, der fünfzig Jahre zuvor das Mönchsgewand genommen hatte, noch lebte, und dass sie verrückt geworden wäre, wenn sie ihn nicht wieder

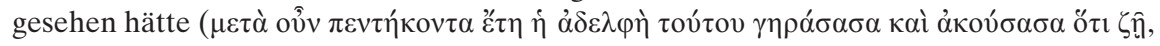

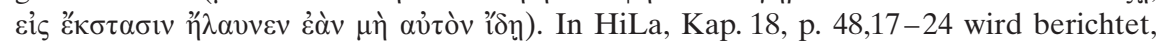
dass Makarios von Alexandreia beschloss, den Schlaf zu überwinden und deshalb während zwanzig Tagen nicht unter ein Dach ging, obschon er sich in der Hitze verbrannte und es ihm in der Nacht vor Kälte die Glieder zusammenzog. Und so sagte er sich, dass er sich schnellstens unter ein Dach begeben müsse, damit sein Gehirn nicht

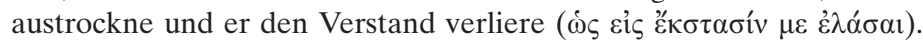

$451 \mathrm{Zu}$ den Beispielen s. Kap. 3.6.2.

452 So bezeichnet Theodoret in seiner Historia Ecclesiastica (Theodoret, Historia Eccle-

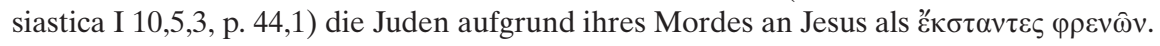


Verrücktheit, aber auch für eine Krankheit mit Symptomen, die der bacchischen Raserei glichen (also die Epilepsie) und deshalb in weiten Kreisen als dämonisch galten, verwendet wurde. Das Problem, dass der Terminus Ekstase bereits mit der positiven Bedeutung der mystischen Ekstase ${ }^{453}$ besetzt war, wurde von einigen Autoren gelöst, indem sie die dämonische Besessenheit gar nicht benannten, sondern bloß mit den oben erwähnten Symptomen umschrieben und auf diese Weise sowohl eine Vermischung mit der mystischen Ekstase, als auch eine Wahl zwischen den Begriffen „Mondsucht“" und „Ekstase“ umgingen ${ }^{454}$.

453 S.o. Kap. 2.4.1.

454 Z.B. bei Leontios von Neapolis: 454. In der positiven Bedeutung der mystischen Ekstase kommt bei Leontios der Begriff Ekstase nur einmal (222) vor. Siehe auch S. 110. 


\section{Kapitel - Terminologische und formale Aspekte der imaginären Erfahrungen}

\section{1 „Sehen ist zuverlässiger als Hören“}

Wie aus den vorangehenden Kapiteln deutlich wird, beschränken sich die in den behandelten Texten vorkommenden Formen der imaginären Erfahrungen keineswegs bloß auf das Träumen. Vielmehr bleibt bei vielen Beispielen die präzise Form der Wahrnehmung unklar, oder es handelt sich explizit nicht um Träume, sondern um ein Sehen in Ekstase bzw. im Wachzustand. Die auffälligste Konstante, welche sich terminologisch und somit auch inhaltlich gesehen durch den allergrößten Teil der Beispiele hindurch zieht, ist also nicht die Form des Sehens, oder anders gesagt der Bewusstseinszustand, in dem sich das Sehen abspielt, sondern vielmehr der Akt des Sehens an sich, welcher zuweilen durch den des Hörens ergänzt wird. Die meisten Erzählungen werden durch Wendungen wie „er sah“ oder „es erschien“ eingeleitet, unabhängig davon, ob sie sich im Traum, im Schlaf, in der Ekstase, in der Nacht, in einer Vision usw. abspielen. Die griechischen Begriffe, die dafür verwendet werden, sind zahlreich ${ }^{455}$ und variieren zwischen ópá $\omega$ in seinen aktiven und passiven (v. a. $̋ ̋ \varphi \theta \eta)$ Formen $^{456}$,

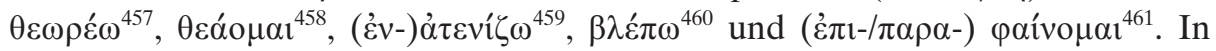

$455 \mathrm{Zu}$ den verschiedenen griechischen Begriffen für „Sehen“, „Schauen“ usw. und ihre Verwendung vgl. MichaELis, Art. ópó teilung visionaler Gattungen wird das Einleiten der Visionserzählungen durch Verben des Sehens als „Semantisches Signal“ der Gruppe b) bezeichnet, vgl. Berger, Visionsberichte 202 (zu den semantischen Signalen der Gruppe a, c und e s.u A. 463 u. 469).

456 Aktiv: 52, 85, 90 (1;2), 108, 110, 113 (1;2;3), 115, 117, 118 (1), 122, 125, 129, 145, 154, 155, 172, 173, 174, 176, 186, 187, 188, 192, 194, 204, 207, 218 (3), 219, 223, 224, 226, 227, 230 (2), 231, 232, 235 (1), 242, 243, 245, 246, 247, 250, 253, 257, 258, 259, 270, 273, 279 (1;3), 280 (2), 284, 285, 286, 290, 291, 292, 293, 296, 297, 301, 303, 304, 306, 310 (1;3), 311, 321, $322,324,329,330,331,337,338$ (2), 342, 346, 349, 351, 355 (1), 361, 362 (3), 365, 371, 372, 374, 380, 384, 392, 397, 398, 406, 409, 413, 415, 421, 422, 425, 427 (2;3), 430, 431, 433. Passiv: 95, 172, 184, 202, 215, 218 (1), 240, 248, 254, 262 (1), 277, 303, 307, 330, 341, 362 $(4,5), 390,427(1), 460$.

$45725,89,90(3), 109(2 ; 3), 120,132,133,143,161,169,177,190,196,197,205,206,213,221$, 222, 225, 227, 228, 234, 241, 242, 256, 261, 262 (2, 3), 264, 267, 272 (2), 274, 280 (1;3), 294, 300, 302, 327, 328, 329, 331, 334, 347, 352, 355, 357, 362 (2), 363 (3), 367, 368, 370, 377 (1;2), 378, 379, 383, 384, 385, 387, 388, 389, 391, 403, 417, 419, 423, 424, 435, 450, 477.

45838,113 (2), 143, 205, 230, 236, 249, 255, 261, 268, 354, 356, 384, 389, 449.

459 Vgl. dazu mit den Beispielen Kapitel 1.2.3, A. 79 u. 81. 
der Regel wird durch ein Objekt im Akkusativ ausgedrückt, was gesehen wird, oder es handelt sich um „Erscheinungen“, welche dem Wahrnehmenden als Subjekt erscheinen oder an ihn herantreten. In diesen Fällen werden die Erzählungen mit Wendungen wie ,es stellte sich daneben/trat heran/es wurde

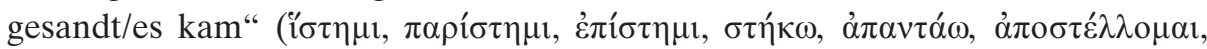
$\left.\varepsilon^{\prime} \rho \chi 0 \mu \alpha \imath\right)^{462}$ eingeleitet $^{463}$, welche ebenfalls meist als Einleitungstermini für eine imaginäre Erfahrung stehen. Öfters wird der Akt des Sehens zusätzlich durch die Adverbien „augenscheinlich“ (o’ $\varphi \theta \alpha \lambda \mu \circ \varphi \alpha v \hat{\omega} \varsigma)^{464}$, „mit eigenen Augen“

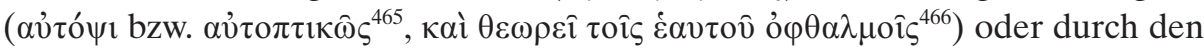

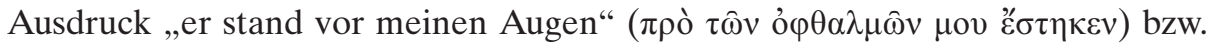

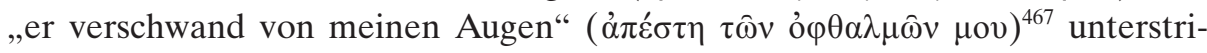
chen, welche die Augenzeugenschaft des Empfängers der imaginären Erfahrung und somit des ersten Gewährsmanns der Geschichte, betonen und dem Leser als Glaubwürdigkeitsmarkierung dienen $\operatorname{sollen}^{468}$.

Verhältnismäßig selten ist die für Traum- und Visionserzählungen der antiken und spätantiken Literatur als überaus typisch konstatierte Einleitungs-

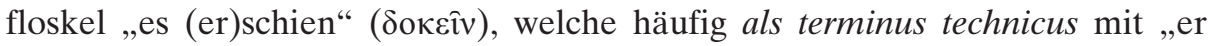

$4608,18,60,66,70,75,137,138,157,163,164,165,208,212,271,279,309,311,316,318,342$, $402,437,440$.

461 15, 90 (3), 92, 100, 135, 152, 162, 178, 180, 189, 201, 203, 206, 211, 216, 229, 239, 263, 283, $287,308,312,318,335,336,340,354,356,358,359,363$ (2), 364, 368, 369, 382 (2), 393,

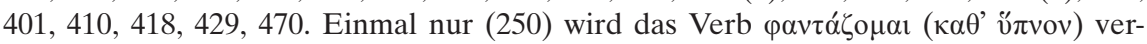
wendet.

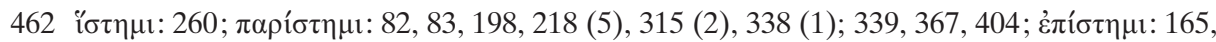

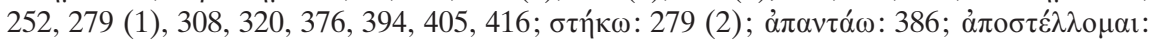

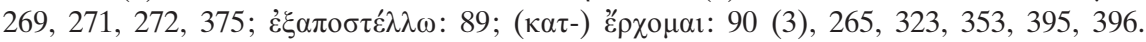

463 Alle diese Begriffe gehören bei Berger, Visionsberichte 202, zu den Gruppen c) und e) der „Semantischen Signale“ visionaler Gattungen.

464 171, 195, 215, 306, 315, 343, 386, 438, 465, 467, 471. Zu diesem Ausdruck vgl. FestUgière (ed.), Vie de Théodore de Sykéon II 175, A. 3. Vgl. die Ähnlichkeit zu der in Apg 10,1

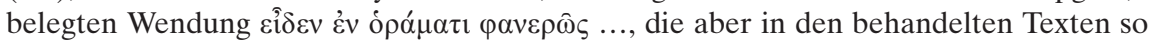
nirgends belegt ist.

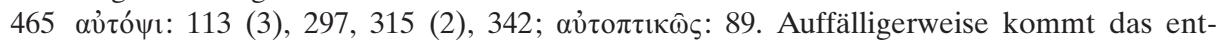

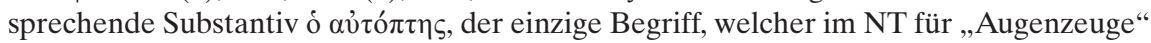

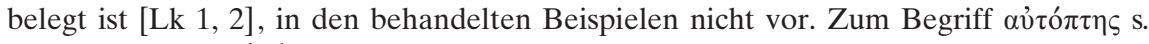

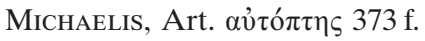

$466272(2)$.

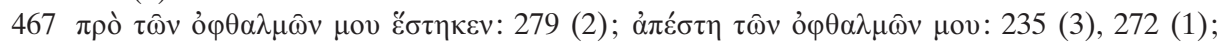
$\mu \varepsilon \tau \alpha \sigma \tau \eta ิ v \alpha \imath \tau \hat{\imath} v$ ö $\psi \varepsilon \omega v: 313$.

468 Häufig werden in den Texten zugunsten der Glaubwürdigkeit der erzählten Geschichten ganze Überlieferungsketten genannt, welche über mehrere Gewährsleute zur Quelle des Erzählten zurückführen. Zu den Glaubwürdigkeitsmarkierungen in der hagiographischen Literatur vgl. ReINSCH, Autor und Leser 407 f. Siehe auch S. 114-116. 
träumte“ übersetzt werden $\mathrm{kann}^{469}$, anzutreffen ${ }^{470}$. Dies entspricht tendenziell

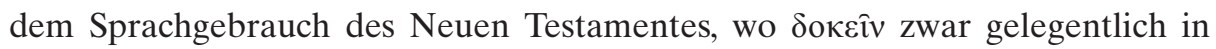
Visionsberichten vorkommt, aber nur im Zusammenhang mit scheinbaren Offenbarungen, also wenn jemand meint, eine Offenbarung zu sehen, die keine solche ist [Mk 6,49; Lk 24,37; Joh 20,15; Apg 12,9] ${ }^{471}$. Durch die Vermeidung von ठокєiv umgingen die monastischen Autoren offenbar die Zweideutigkeit des Begriffes, der zwar, wie die angeführten Beispiele zeigen, nach wie vor im antiken Sinne verstanden werden konnte, dem aber spätestens seit dem Neuen Testament auch die Konnotation des „Scheins“, also des „nicht wirklich Seienden“, anhaftete. Insgesamt gesehen steht aber die starke Betonung der Augenzeugenschaft durch das ,mit eigenen Augen“ und deshalb nicht eingebildet Wahrgenommenen in einem auffälligen Kontrast zu den Offenbarungen des Neuen Testaments, bei welchen es sich, von wenigen Ausnahmen abgesehen, fast ausschließlich um Wortoffenbarungen mit klaren Weisungen handelt ${ }^{472}$. Besonders deutlich wird dies in den behandelten Texten bei den Angelophanien, welche zwar teilweise wie im Lukasevangelium als reine Wortoffenbarungen vorkommen ${ }^{473}$, häufig aber bewusst durch optische Ausschmückungen ergänzt werden, deren Herkunft meist in der reichen Bildwelt der alttestamentlichen und spätjüdischen Apokalyptik zu suchen sind ${ }^{474}$. Manchmal geschieht dies bloß in Form weniger Begriffe, welche in knapper Weise beschreiben, wie der erschienene Engel aussah. So heißt es etwa „er erschien in der Gestalt eines Bruders“ “475, „,es erschien ihm ein wunderschöner Jüngling “476, „es kamen zwei Engel mit Laternen“"477, „,es erschien ihm eine Engelsgestalt in strahlendem Kleid“478 oder „,da kam ein Engel mit einem Schwert“"479 etc. Häufig werden die Erzählungen aber auch durch detaillierte Bildbeschreibungen ausgeschmückt, was in besonderem Maße für die apokalyptischen Visionen des Symeon Stylites des Jüngeren und seiner Mutter, der heiligen Martha, gilt ${ }^{480}$.

469 Häufiges Vorkommen in dieser Bedeutung z.B. bei Artemidor und Aelius Aristides. Dazu Kessels, Studies on the Dream 202 f.; Hanson, Dreams and Visions 1409. Bei Berger, Visionsberichte 201-202, als „Semantisches Signal“ der Gruppe a) bezeichnet.

470 75, 217 (Soz.), 229. 265, 283, 313, 366.

471 Vgl. Berger, Visionsberichte 202.

472 Ausnahmen, d.h. eindeutig bildhafte Visionen, nur in Apg 10,11 und in der Offb. Bei den Angelophanien wie in Lk 1,11 ff. handelt es sich dagegen stets um das Überbringen von Botschaften ohne visuellen Gehalt, vgl. dazu MichaELis, Art. óó́ 350-352.

473 Wie in 68, 82, 211, 269, 307, 308, 323, 335, 375, 382, 390, 396, 404.

474 S. S. 124 A. 613.

475320.

476340 (1).

477199.

478369.

479200.

480 Wie in 172, 173, 174, 176, 195, 224, 227. 
Die offensichtliche Vorliebe für die visuelle imaginäre Erfahrung bedeutet allerdings nicht, dass die auditive Offenbarung völlig an Bedeutung verliert. Vielmehr sind Auditionen im Sinne eines Vernehmens der Stimme Gottes

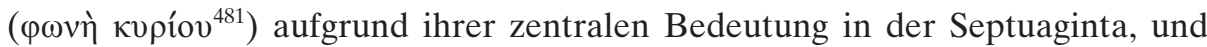
davon ausgehend im Neuen Testament ${ }^{482}$, auch in den monastischen Texten nach wie vor hoch angesehen. Während bei den visuellen imaginären Erfahrungen aufgrund des Theologumenons von der Unsichtbarkeit Gottes ${ }^{483}$ meist Mittlergestalten wie Engel, Heilige oder auch Christus visualisiert werden, bietet die Audition die Möglichkeit eines direkten, unmittelbaren Empfangs der Botschaft Gottes. So erstaunt es auch nicht, dass vorzüglich die „großen Charismatiker“ von der göttlichen Stimme erreicht werden. Meistens geschieht dies in Form von sogenannten ,audiovisuellen Erfahrungen“, bei denen eine Stimme erklingt, um den visuellen Teil einer imaginären Erfahrung zu kommentieren oder zu ergänzen $^{484}$. Hin und wieder überrascht aber die Stimme Gottes den Gläubigen ganz im alttestamentlichen Offenbarungsstil, ohne dabei von einer bildhaften Erscheinung begleitet zu werden ${ }^{485}$.

Insgesamt gesehen aber verliert das auditive Element zugunsten des visuellen an Gewicht, was weiterhin deutlich wird, wenn die Audition als eine Art „Vorstufe“ zu der visuellen Gotteserfahrung dargestellt wird. So, wenn vom jungen Pachomios erzählt wird, dass er eines Tages in die Wüste ging und zu einem verlassenen Kloster gelangte, ,als eine Stimme zu ihm kam - bis jetzt hatte er nämlich noch kein Gesicht gesehen -, die ihm auftrug, dort zu bleiben und ein Kloster zu gründen“"486. Auch das in der monastischen Literatur wieder aktuell gewordene antike Schlagwort „Sehen ist zuverlässiger als Hören“487 zeugt von einer klaren Aufwertung der Visualität und davon, dass die Funktion des (inneren) Auges als Triebkraft der Nachahmung für die erzieherische Aufgabe exemplarischer Erzählungen in den monastischen Texten gegenüber dem

481 Zur Terminologie s. S. $106 \mathrm{f}$.

482 V.a. Ex 3,4 ff.; 19; 20. Davon beeinflusst Apg 7,31; Lk 9,35; Mt 3,17 Par; 17,5; 2 Petr

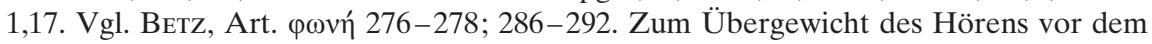
Sehen im Alten und im Neuen Testament s. auch Michaelis, Art. ópó 330.351.

483 S. S. $21-23$, S. 26 f. A. $85-88$.

484 85, 90 (1), 92 (2), 132, 159, 177, 188, 192, 207, 212, 218 (2;4), 235 (3), 295, 334, 348, 371, $372,374,397$.

$485175,326,365,399,400,406(2)$.

486365.

487 Das bereits aus Heraklit, Fragmenta 101 a, p. 254, und Herodot I 8,10 f., p. 34,21 f.

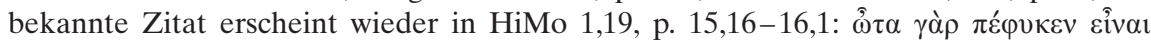

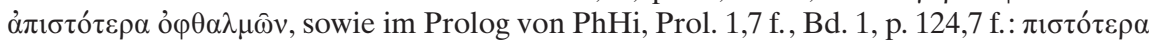

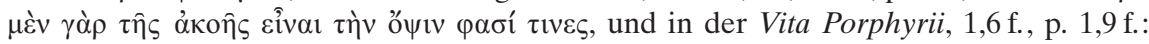

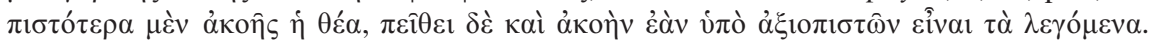
Vgl. dazu Rydèn, Bemerkungen 22; Festugière, Les moines d'Orient IV 1, 14, A. 121 mit Verweis auf „Lieux communs“. 
Neuen Testament an Bedeutung gewinnt. Die Begründung dafür lautet, dass über den Sehsinn Rezipiertes besser im Gedächtnis haften bleibt als bloß Gehörtes ${ }^{488}$ und dass dem Auge eine erstrangige beglaubigende Bedeutung bei der Zeugenschaft von vorbildlichem Verhalten zukommt. So betont Theodoret von Kyrrhos, dass er einiges von dem, was er erzählt, mit eigenen Augen gesehen hat, alles aber, was er nicht gesehen hat, von solchen gehört hat, die es gesehen haben $^{489}$. Die Begründungen für die Prävalenz des Sehens vor dem Hören sind im doppelten Sinne zu verstehen: sie beziehen sich einerseits auf den Autor einer Geschichte, der in der Regel Anspruch auf eine direkte oder indirekte Augenzeugenschaft erhebt. Andererseits beziehen sie sich auf den Rezipienten, der durch bildhafte Erzählungen belehrt werden soll, indem er also im Geiste sieht, was er durch die Vermittlung des Textes lesend oder hörend, jedoch nicht mit dem physischen Auge, wahrzunehmen vermag. Im Falle von imaginären Erfahrungen haben wir es demnach mit einer doppelten oder mehrfachen Imagination zu tun ${ }^{490}$, die als narratives Mittel deshalb von erstrangiger Bedeutung ist, weil sie dem Rezipienten die teilweise allzu abstrakten theologischen Inhalte der christlichen Heilslehre und des orthodoxen Dogmas in eingängigen Bildern vermittelt und ihm zugleich die Möglichkeit der direkten Erlebbarkeit der Kraft Gottes vor Augen führt. Zweifellos findet die pädagogische Verwendung von Bildern zur religiösen „Erziehung“ nicht nur in den Darstellungen der bildenden Kunst wie Wandmalereien und Ikonen, sondern vor allem auch in den bildhaften Erzählungen der monastischen Literatur ihren Ausdruck $^{491}$. Aus der Bibel und v. a. auch aus der apokryphen Literatur geläufig gewordene Bilder und Gleichnisse, die überdies beim Gang in die Kirche in ikonographischer Form geschaut und mündlich tradiert wurden, mussten zum selbstverständlichen, weit in die unterbewusste Lebenswelt hineingreifenden Vorstellungshorizont des spätantiken Christen gehören. Es erstaunt nicht, dass eben diese verinnerlichten Symbole, Bild- und Handlungsabläufe auch in den Berichten von imaginären Erfahrungen wieder auftauchen, und von dort ausgehend sicherlich auf die Vorstellungswelt der Rezipienten zurückwirkten. Eine adäquate Beurteilung über die Tragweite, welche die oft etwas steif und statisch anmutenden Symbole für die Lebenswelt eines Gläubigen der frühbyzantinischen Zeit hatte, erscheint aus der Sicht des von einer schier grenzenlosen Vielfalt von Bildkomplexen beeinflussten modernen Geistes schlicht unmöglich.

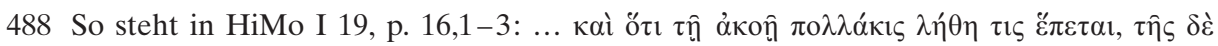

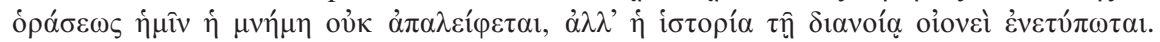

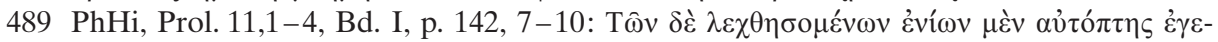

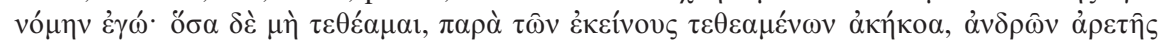

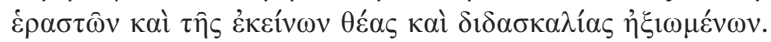

490 S. S. 45 A. 183.

491 S. auch Delehaye, Cinq Leçons 117-146; Kazhdan, Maguire, Byzantine Hagiographical Texts 11-18; Dronke, Imagination $21 \mathrm{f}$. 
Zwar können über die Authentizität und Fiktionalität der berichteten imaginären Erfahrungen und deren Bildinhalte kaum gesicherte Aussagen gemacht werden, dennoch aber scheint es keinen Zweifel darüber zu geben, dass die Vermittlung von bestimmten Inhalten durch imaginäre Erfahrungen für den Autor nur dann erfolgsversprechend sein konnte, wenn er davon ausgehen konnte, dass der Rezipient seiner Erzählungen die imaginäre Erfahrung eben nicht als ausschließlich topisch verwendbares literarisches Mittel aufnahm, sondern als Form der Gotteserfahrung im Bereich des real Erlebbaren verstand, sei es als tranceartige Gotteserfahrung der Mönche und Asketen oder als Weg zur Heilung und Heilserlangung für den weltlichen Christen.

\subsection{Träume $e^{492}$}

Außer der neutestamentlichen Wendung к $\alpha \tau^{\prime}$ őv $\alpha \rho$ (siebzehn Belege) ${ }^{493}$ und dem nur bei Theodoret von Kyrrhos verwendeten antiquierenden Verb ỏveıoo $\pi \omega \lambda \varepsilon \omega^{494}$,

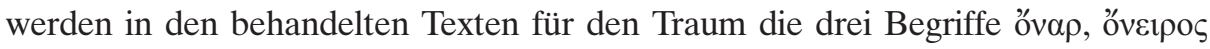

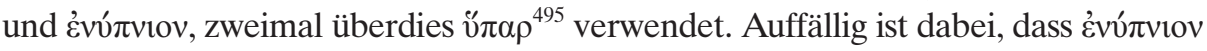
mit zweiundzwanzig Belegen deutlich häufiger vorkommt als őva $\rho$ (acht Belege)

492 Zum Vorkommen aller Traumbegriffe in den Texten s. S. 108.

493 S. S. 50 A. 211. Die ältesten Zeugnisse für $\kappa \alpha \tau$ 'őv $\alpha \rho$ sind von Weihinschriften bekannt, in der Regel mit einer kausalen Konnotation im Sinne von ,aufgrund einer Weisung im Traum“. Diese Bedeutung fällt aber bei den Erzählungen des Matthäusevangeliums, die erwartungsgemäß für die Verwendung in den hagiographischen Texten Pate gestanden haben, weg. Vgl. Frenschrowski, Traum und Traumdeutung

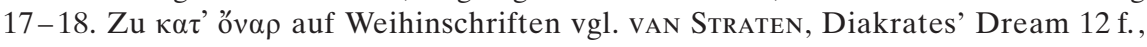
$22 \mathrm{f}$.

494 37, 39. In der Korrespondenz des Barsanuphios und Ioannes ist überdies einmal das

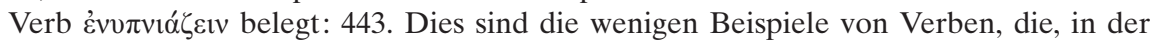
klassischen Antike schon seit dem 5. Jh. v. Chr. in Verwendung, in den behandelten Texten noch als Bezeichnung für den Vorgang des Träumens belegt sind. Über die

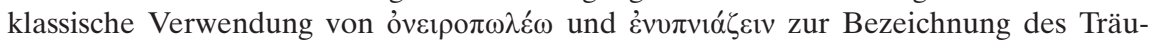
mens vgl. Vinagre, Die griechische Terminologie der Traumdeutung 259 f., A. 6.

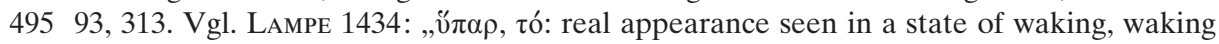
vision“. Wie bereits erwähnt (vgl. Kap. 2.3.1, A. 221 u. 222) wird das Wort bei dem gerne auf antike Vorbilder zurückgreifenden Theodoret von Kyrrhos in direkter Anlehnung an Homer verwendet. Zum Gebrauch bei Theodoret s. CANIVET, Le Monachisme syrien $122 \mathrm{f}$; f ferner mit Verweis auf das Vorkommen derselben Wendung bei Heliodor von Emessa Canivet, Histoire des moines de Syrie II 17, A. 1; über die Wendung in der klassischen Literatur vgl. Kessels, Studies on the dream 186 ff.; Manuwald, Traum und Traumdeutung 17-18; DodDs, Die Griechen und das Irrationale 55. Über die im Gegensatz zu den restlichen hier behandelten Quellen stärker an klassische Autoren anlehnende Sprache des Theodoret s. CAnivet, Histoire des moines de Syrie I 43; DERS., le Monachisme syrien 36-37. Zur Verwendung des Begriffes bei Gregor von Nyssa s. A. 222. 
und óveıpos (acht Belege), zumal alle drei Termini im Neuen Testament keine entsprechenden Vorbilder haben. Der Grund für die relative Beliebtheit des évv́$\pi v i o v$ ist wohl am ehesten darin zu suchen, dass der Begriff die übliche Traumbezeichnung in der Septuaginta darstellt ${ }^{496}$. Der für sich stehende, also nicht wie im Matthäusevangelium adverbiell gebrauchte Terminus őv $\rho$ und seine Nebenform ǒveıpo s sind dagegen vor allem in der klassischen Antike bei Homer, den Tragikern und Plato verwendet worden ${ }^{497}$. Freilich haben die Begriffe schon längst nicht mehr die in der Antike gebräuchlichen Bedeutungen. Vielmehr sind sie über den Weg hellenistischer Prosa- und Erzählliteratur inzwischen zu austauschbar verwendeten Begriffen etabliert worden. Auch die in der Traumdeutung, vor allem in den Oneirokritika des Artemidor ${ }^{498}$ (2. Jh. n. Chr.) belegte Gebundenheit der Traumbegriffe an die mantische Wertigkeit der Träume ${ }^{499}$ findet nachweislich bereits ab dem 1. Jh. v. Chr. keine Parallele mehr in Umgangs- und Prosasprache ${ }^{500}$, was sich auch in den frühen monastischen Texten widerspiegelt. Während bei Artemidor ǒveıpor immer bedeutungsvoll, d.h. in die Zukunft deutend, \&́vó $\pi v 1 \alpha$ dagegen immer bedeutungslos sind ${ }^{501}$, werden in den behandelten Texten die unterschiedlichen

496 Vgl. Frenschkowski, Traum und Traumdeutung 14, Timotin, Visions 22.

497 Während in der klassischen Literatur öva $\rho$ die gesamte nächtliche Erfahrung im Schlaf

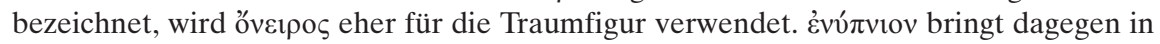
erster Linie den Bewusstseinszustand, in dem sich das Träumen abspielt, zum Ausdruck; vgl. BJörck, ONAP I $\Delta$ EIN 311-314; Kessels, Studies on the Dream 174-189; Dodds, Die Griechen und das Irrationale $57 \mathrm{f}$; VInagre, Die griechische Terminologie 274; Manuwald, Traum und Traumdeutung 16; Frenschkowski, Traum und Traumdeutung 14; Weber, Kaiser, Träume 32.

498 Zur antiken Traumdeutung vor Artemidor vgl. Del CoRno, Graecorum de re onirocritica VII-XV. 99-198; DodDs, Die Griechen und das Irrationale 69. Eine nützliche Zusammenfassung über Leben, Werk und Methode der Traumdeutung bei Artemidor bietet Walde, Antike Traumdeutung 127-196. Über den sozialgeschichtlichen Hintergrund der Oneirokrititka vgl. HaHn, Traumdeutung $7 \mathrm{f}$; NäF, Traum und Traumdeutung 124-141.

499 Artemidor (I Proöm 1-2, p. 3-5) trennt zwischen غ̇vv́đvıvo, dem bedeutungslosen und

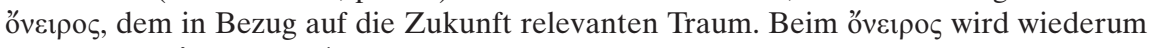

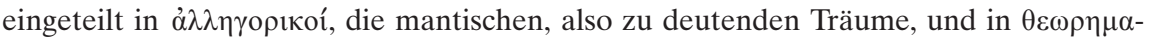

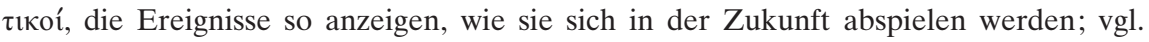
Kessels, Ancient Systems of dream-classification 392; Walde, Antike Traumdeutung $151 \mathrm{f}$; N N̈̈F, Traum und Traumdeutung $126 \mathrm{f}$. Ein möglicher Einfluss dieser ,wissenschaftlichen" Traumklassifikation zeigt sich in der terminologischen Entwicklung der Votivinschriften, bei denen in der früheren Zeit (4. v.-1. Jh. n. Chr.) غ̇vv́ $\pi v ı v$ überwiegt, während später meistens óvetpo und őva verwendet wird. Zu der genannten terminologischen Entwicklung bei den Votivinschriften vgl. van Straten, Diakrates' Dream 13.

500 Austauschbar werden die Begriffe etwa bei Philon und Josephus verwendet; vgl. dazu Frenschrowski, Traum und Traumdeutung 14; VinAgre, Die griechische Terminologie der Traumdeutung 275, A. 59; WeBER, Kaiser, Träume 33.

501 S.o. A. 499. 
Begriffe austauschbar für alle Arten von Träumen verwendet und können demnach „göttlichen“, „dämonischen“ oder auch „physiologischen“Ursprungs sein ${ }^{502}$. So-

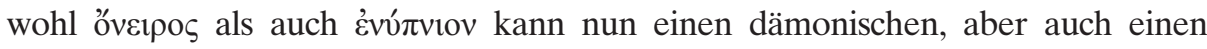
Offenbarungstraum bezeichnen. So wird von einem Einsiedler aus der Thebais gesagt, dass er durch den Stachel der Ruhmsucht von Traumbildern getäuscht

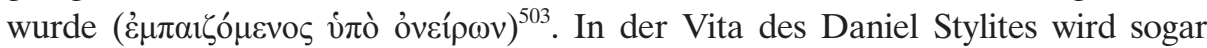

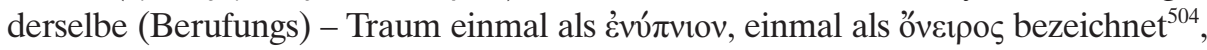
und in der Korrespondenz des Barsanuphios und Ioannes wird in zwei Beispielen

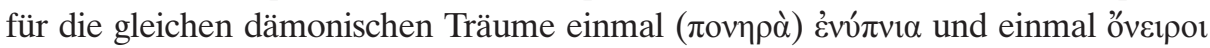
( $\alpha i \sigma \chi \rho o i ́)$ verwendet ${ }^{505}$. Es ist also erst die Bewertung des Trauminhalts als „wahr“

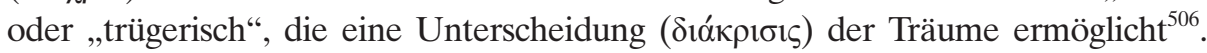
Terminologisch kann diese Unterscheidung allenfalls dort zum Ausdruck kommen, wo ein Traum vor seiner Interpretation anders bezeichnet wird als danach, wie es in einem Beispiel aus der Korrespondenz des Barsanuphios und Ioannes der Fall ist. Hier will ein geron von Barsanuphios wissen, was es zu bedeuten habe, wenn er im

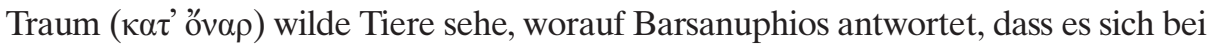
den Träumen ('́vv́rvıı ) von wilden Tieren um Täuschungen der Dämonen handle

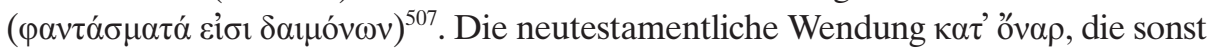
durchweg in der Bedeutung von Offenbarungstraum verwendet wird ${ }^{508}$, kann hier nur deshalb als Bezeichnung für einen dämonischen Traum verwendet werden, weil er vom geron nicht als solcher erkannt wird.

\subsection{Ekstasen $^{509}$}

Wenn die Quellen die mystische Ekstase terminologisch kennzeichnen, sind besonders häufig Wendungen wie ,und dann geriet ich/er in Ekstase und sah“, aber auch das Verb „außer sich/in Ekstase geraten“ ( $\dot{\xi} \xi \hat{\imath} \sigma \tau \eta \mu$ ) anzutreffen. Bezeichnenderweise wird bei fast allen erwähnten Beispielen der Ekstatiker als handelndes Subjekt genannt, nur zweimal begegnet das neutrale ,in Ekstase

502 S.o. Kap. 2.3.1 A-C.

50324.

504 158. Siehe auch S. 50 A. 210.

$505439,441$.

506 Die Beobachtung, dass die Traumbegriffe austauschbar sind, machte für Euagrios auch Guillaumont (ed.), Évagre le Pontique, Traité Pratique 624, A. 54. Die Aussage bei Dagron, Rêver 42, A. 21, dass sich die Hagiographen über den klassischen Unterschied

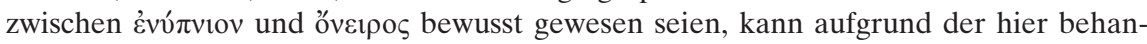
delten Texte nicht bestätigt werden. Vgl. Dagron, Rêver 42, A. 21. Zu der Unterscheidung der Träume s.u. Kap. 4.1.

507440 .

508 S. S. 100 A. 493.

$509 \mathrm{Zu}$ allen in den Texten vorkommenden Ekstase-Begriffen s. S. $109 \mathrm{f}$. 
sehen/herantreten“ “510, und in der Bedeutung von „Verzückung“ bzw. „Erstaunen“ ist "̌́ $\sigma \tau \alpha \sigma ı \varsigma$ nur in der Vita des Symeon Stylites belegt ${ }^{511}$, dort allerdings neben einer Reihe von expliziten Trance-Ekstasen ${ }^{512}$. Dieser durchwegs auf die aktive Rolle des Ekstatikers hindeutende Wortgebrauch weicht deutlich von demjenigen des NT $\mathrm{ab}^{513}$ und stützt zusätzlich die Annahme, dass das bewusste Evozieren von Trancezuständen im frühen Byzanz zu einem zentralen Bestandteil sowohl der spirituellen Praxis im monastischen Umfeld als auch der christlichen Volksfrömmigkeit geworden war. Das gleiche betrifft auch die Formulierungen, die das Ende einer Ekstase kennzeichnen wie „,er kam wieder zu sich“514, ,er erwachte aus der Ekstase“"515 oder andere Wendungen ${ }^{516}$. Daneben finden sich im Zusammenhang mit Entrückungserfahrungen auch häufig andere Formulierungen wie ,,ich wurde (im Geist) entrafft/heruntergeführt/hochgehoben/hingeführt“"517 oder „,er sah (sich) durch die Kraft des Geistes/der Gnade“"518.

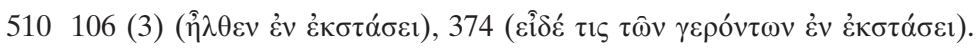

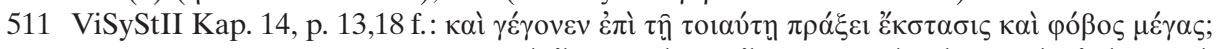

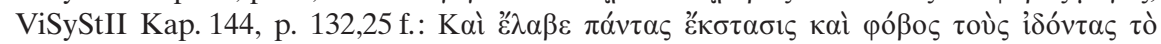

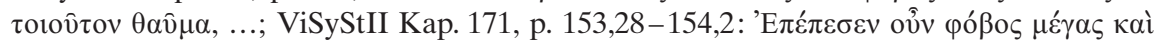

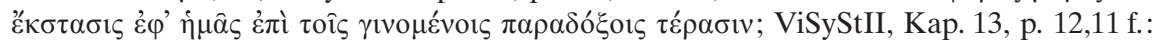

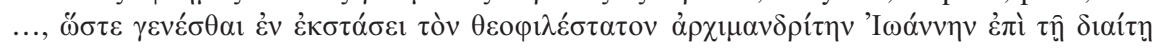

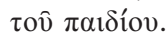

512 So in 106, 108, 112, 118 (2), 235 (2), 425, 426.

513 Neben der bereits erwähnten Stelle bei Paulus, wo es heißt, dass die Ekstase über Petrus

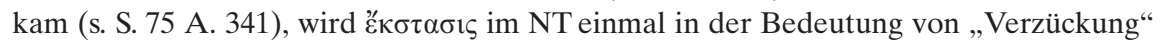

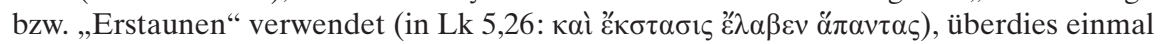

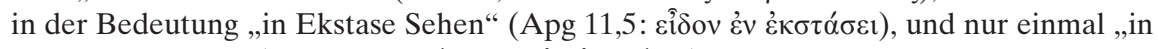

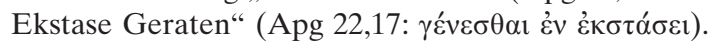

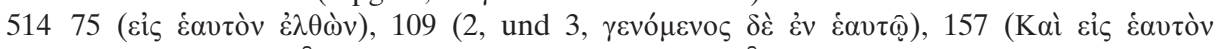

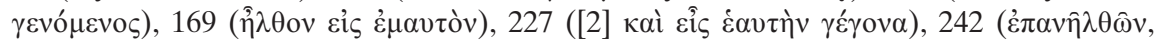

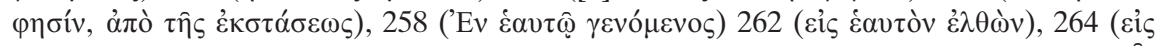

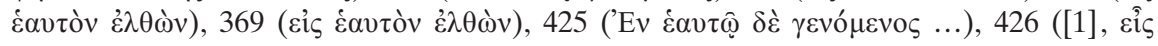

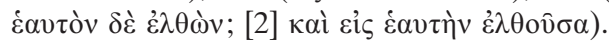

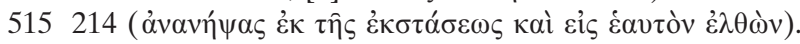

516 S. S. 83 f. A. $392-397$.

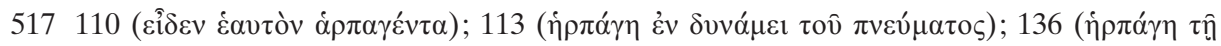

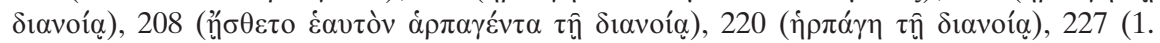

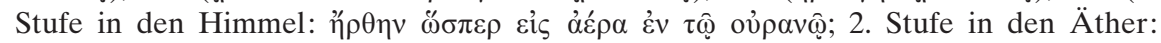

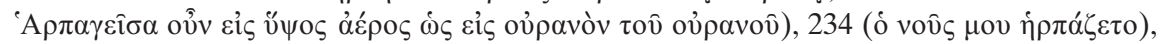

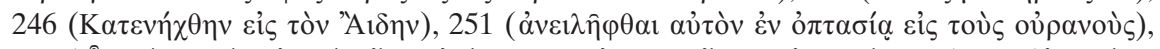

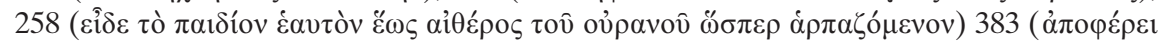

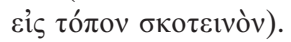

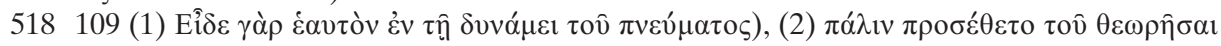

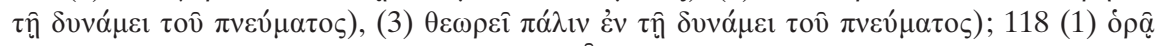

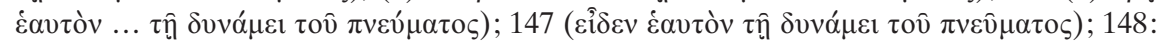

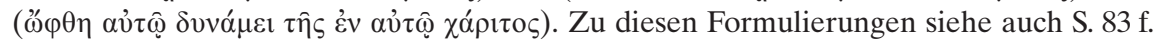
A. 389-396. 
Auf die Begriffsgeschichte und die Terminologie der dämonischen Ekstase wurde bereits in Kap. 2.3.3 ausführlich eingegangen ${ }^{519}$.

\subsection{Gesichte und Stimmen}

Die am häufigsten verwendeten Begriffe zur Bezeichnung von imaginären Erfahrungen sind diejenigen, die den Inhalt dessen, was gesehen bzw. gehört wird, abstrakt zusammenfassen, also Termini für „Gesicht“, „Schau“, „Stimme“ usw. In den allermeisten Fällen sind es Begriffe, die den visuellen Gehalt des Wahrgenommenen bezeichnen, also „Visionen“ im Wortsinn, die in ihrer ursprünglichen Bedeutung keine Wertung des Geschauten implizieren. Nach der Häufigkeit ihres Vorkommens geordnet, sind die dafür verwendeten griechi-

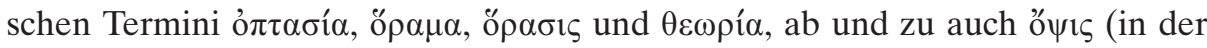

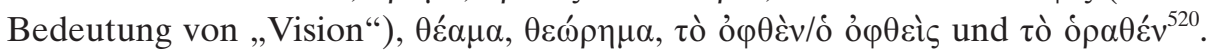
Diese Begriffe werden auch adverbiell verwendet, so v.a. die Ausdrücke $\varepsilon \dot{v} v$

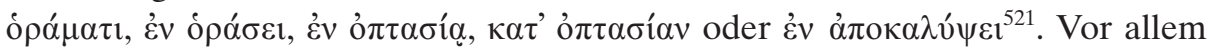

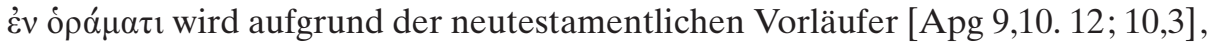
ähnlich wie $\kappa \alpha \tau$ ' ǒv $\alpha \rho$, inzwischen als feststehendes Idiom für die visionäre Art des Vorgangs bei imaginären Erfahrungen verwendet ${ }^{522}$. Trotz der ursprünglich neutralen Bedeutung implizieren die Begriffe aufgrund ihrer biblischen Vorbilder $^{523}$ auch in den behandelten Texten fast immer eine positive Wertung ${ }^{524}$ und werden stets eingesetzt, um dem Leser zu vermitteln, dass es sich um eine göttliche „Offenbarungsvision“ handelt, welche zuweilen auch durch den all-

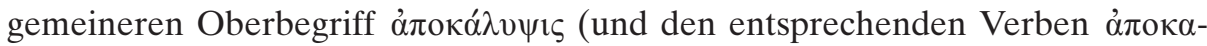
$\lambda v ́ \pi \tau \omega$ und $\dot{\alpha} \pi \circ \kappa \alpha \lambda v ́ \pi \tau о \mu \alpha \imath)$ zusammengefasst wird. Mehrmals wird der Offenbarungsgehalt mit entsprechenden Attributen unterstrichen, so heißt es dann

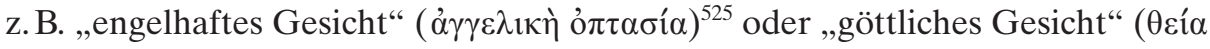

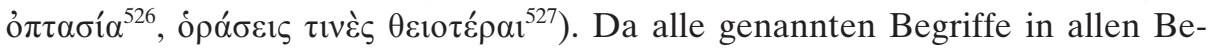

519 S. S. $87-94$, siehe auch S. 109 f.

520 Zum Vorkommen aller dieser Begriffe in den Texten s. die Tabelle S. 110-113.

521 Zum Vorkommen dieser Phrasen in den Texten s. die Tabelle S. 110-113.

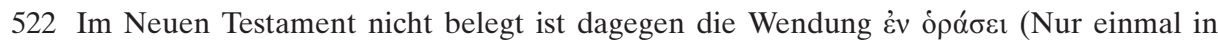

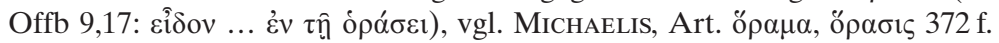

523 Auffälligerweise wird der im NT verglichen mit ö $\alpha \mu \alpha$ (Apg 9,10.12; 10,3.17.19; 11,5; $12,9 ; 16,9 \mathrm{f} ; 18,9)$ nur selten und nicht spezifisch für visuelle Erlebnisse eingesetzte Begriff ỏ $\pi \alpha \sigma i ́ \alpha$ (Lk 1,22; 24,23; Apg 26,19) in den behandelten Texten, gerade auch im Zusammenhang mit Visionen, besonders häufig verwendet. Zu den Begriffen im NT s. Michaelis, Art ö $\alpha \mu \alpha$, ỏ $\pi \alpha \sigma i ́ \alpha$ 372-3. Siehe auch S. 50 A. 208 u. 209.

524 Ausnahmen: 101, 442, 459 (hier werden Dämonenerscheinungen als ỏ $\tau \tau \alpha \sigma i ́ \alpha$ bzw. als ö $\alpha \mu \alpha$ bezeichnet).

525 23, 135, 201, 405. Siehe auch S. 50 A. 209.

$526106(3), 312,420$. 
wusstseinszuständen vorkommen können, sind sie in keinem Fall als Synonyme für den Traum zu verstehen ${ }^{528}$. Eine ỏ $\pi \tau \alpha \sigma i ́ \alpha$ ist nicht notgedrungen ein Traum, kann aber sehr wohl im Traum wahrgenommen werden.

\subsection{1 theoria und phantasia ${ }^{529}$}

Eine spezielle, sich von den restlichen Begriffen etwas abhebende Bedeutung wohnt dem Terminus $\theta \varepsilon \omega \rho i ́ \alpha$ inne, der in zahlreichen Exempla explizit in der Bedeutung von „Gottesschau“ bzw. „Gotteskontemplation“ verwendet wird ${ }^{530}$. Dabei schwingt immer auch die neuplatonische Deutung des Begriffes durch die mystisch asketischen Autoren wie Gregor von Nyssa und Euagrios Pontikos mit, welche die $\theta \varepsilon \omega \rho i ́ \alpha$ als höchste Stufe auf dem sukzessive aufsteigenden spirituellen Heilsweg hin zur intellektuellen Schau Gottes verstehen ${ }^{531}$. Während aber in den Schriften der letzteren die $\theta \varepsilon \omega \rho i ́ \alpha$ als abstrakter Begriff innerhalb eines komplexen mystisch-theologischen Systems abgehandelt wird, verwenden die paradigmatischen Erzählungen den Begriff häufig in einem allgemeineren Sinn der „von Gott kommenden Schau“ in bewusster Opposition zum Terminus $\varphi \alpha v \tau \alpha \sigma i ́ \alpha$ (oder $\varphi \alpha ́ \sigma \mu \alpha$ und $\varphi \alpha ́ v \tau \alpha \sigma \mu \alpha$ ), dem dämonischen Trugbild. Hier ist es gerade das Vorkommen des einen $(\theta \varepsilon \omega \rho i ́ \alpha)$ oder des anderen ( $\varphi \alpha v \tau \alpha \sigma i ́ \alpha)$ Begriffes, das dem Leser die Wertung einer Schau deutlich macht. Besonders evident ist dies bei Erzählungen, wo dem Empfänger einer imaginären Erfahrung zunächst unklar ist, ob er eine göttliche oder eine dämonische Schau gesehen hat. Erst ein mit der Unterscheidungsgabe ausgezeichneter Charismatiker kann zur Klärung des Wahrheitsgehalts der Schau verhelfen ${ }^{532}$. Der Leser hingegen Weiß aufgrund der Verwendung des Begriffes $\theta \varepsilon \omega \rho i ́ \alpha$ oder $\varphi \alpha v \tau \alpha \sigma i ́ \alpha$ schon von Anfang an, ob es sich um eine göttliche oder eine dämonische Schau handelt. So in einem Väterspruch über Bruder Zacharias, welcher eines Tages eine Schau ( $\theta \varepsilon \omega \rho i ́ \alpha)$ hatte, die er Bruder Karion berichtete. Da dieser jedoch ein praktikos $^{533}$ war und sich ,in diesen Dingen nicht so genau auskannte“, glaubte er, dass die Schau dämonisch sei und verpasste Zacharias Schläge. Dieser aber

$527 \quad 25$.

528 Eine solche Gleichsetzung ist bei Benz, Die Vision 104 und bei Hanson, Dreams and Visions 1407 anzutreffen (siehe auch S. 66 A. 293).

529 Zum Vorkommen dieser Begriffe in den Texten s. S. $112 \mathrm{f}$.

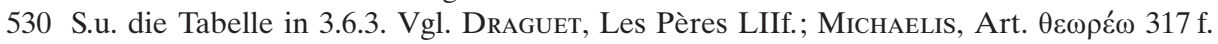

531 Zur theoria bei Gregor v. Nyssa vgl. Miller, Dreams 233, A. 7, mit weiterführender Literatur; bei Euagrios s. GullLaumont, La vision de l'intellect 255-262; KonSTANTINovsKy, Evagrius 77-107. Siehe auch S. 76 A. 347.

532 Zur Unterscheidungsgabe s.u. Kap. 4.1.

$533 \mathrm{Zu}$ dem Begriff praktikos, der deutlich von der Nähe der in diesem Väterspruch vermittelten Lehre zu der mystischen Spiritualität des Euagrios zeugt, s. S. 27 A. 89. 
ging zu Abbas Poimen, welcher verstand, dass die Schau ( $\theta \varepsilon \omega p i ́ \alpha)$ von Gott kam und ihn zu einem anderen geron schickte. Von eben diesem erfährt Zacharias endlich, was der Leser schon längst weiß, nämlich dass die Schau von Gott $\operatorname{war}^{534}$. Das pädagogische Gegenstück über dämonische Trugbilder findet sich ebenfalls in einem Väterspruch. Hier wird erzählt, dass einige Brüder den heiligen Antonios aufsuchten, um von ihm zu erfahren, ob die Erscheinungen (

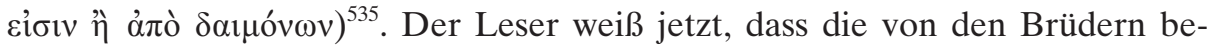
richteten $\varphi \alpha v \tau \alpha \sigma i ́ \alpha$ dämonisch sind. Ähnlich wie im bereits erwähnten Beispiel aus der Korrespondenz des Barsanuphios und Ioannes ${ }^{536}$, wird auch hier das Unwissen der Brüder bewusst dafür eingesetzt, durch die klärenden Worte des Antonios auch den Leser an der Belehrung über den Inhalt dämonischer Erscheinungen teilhaben zu lassen.

Auffälligerweise findet sich das einzige Beispiel für eine Verwendung von

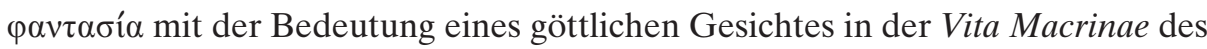
Gregor von Nyssa, dem kaum eine zufällige Wortwahl zuzutrauen ist ${ }^{537}$. Eine mögliche Erklärung für diesen von den restlichen Quellen abweichenden Wortgebrauch ist die oben erwähnte dezidiert mystisch philosophische Bedeutung, mit der Gregor den Begriff $\theta \varepsilon \omega$ pí $^{2}$ auch in der Vita Macrinae ausschließlich verwendet, um die „Kontemplation der erhabenen Dinge“ zu bezeichnen $^{538}$. Für die Benennung des in einer Offenbarung geschauten Bildes musste sich Gregor demnach eines anderen Begriffes bedienen. Allem Anschein nach lehnt er sich dabei bei der Verwendung des Begriffes $\varphi \alpha v \tau \alpha \sigma i ́ \alpha$ an den bei Philon und Apollonios von Tyana belegten Gebrauch des Wortes in der Bedeutung von Imagination, „die schafft, was sie nicht sieht und die die Dinge durch das versteht, was ist“, ganz im Gegensatz zur mimesis, „die schafft, was sie sieht ${ }^{4539}$.

\subsection{2 phone - Die Audition}

Als akustisches Pendant zu den genannten visuellen Begriffen wird der Terminus

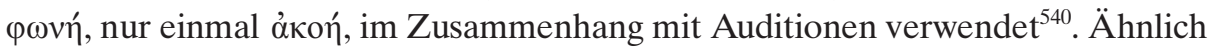

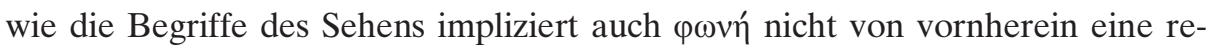

53461

53560.

536 S. S. 102 A. 507.

537 229. Zu diesem Bsp. siehe auch S. 141 A. 689.

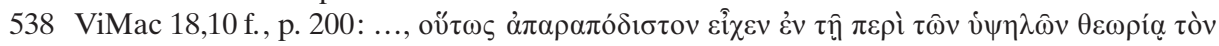
vov̂v, ...

539 S. S. 1 f. A. 2 u. A. 3.

540 Zum Vorkommen dieser Begriffe s. Tabelle s. S. $112 \mathrm{f}$. 
ligiöse Wertung ${ }^{541}$, wird aber in den hier behandelten Texten meistens in der oben genannten Bedeutung von ,göttlicher Stimme“, manchmal auch von „Engelsoder Heiligenstimmen “542 verwendet. Gleichzeitig können aber auch die Dämonen Stimmen erzeugen ${ }^{543}$, sodass bei der Audition wie bei allen anderen Arten von imaginären Erfahrungen die permanente Gefahr besteht, einer dämonischen Täuschung anheimzufallen. Auch hier wird also die Notwendigkeit eines sorgfältigen Abwägens des Gehörten vermittelt. Von Pachomios wird erzählt, dass er, nachdem er eine Stimme gehört hatte, ,,in der Reinheit seines Geistes gemäß den heiligen Schriften abwägte, dass die Stimme heilig war $[\ldots]^{\text {“544 }}$.

\subsection{Andere Imaginations-Begriffe}

Schließlich seien hier noch einige Begriffe genannt, die im Zusammenhang mit imaginären Erfahrungen wiederholt verwendet werden, so Termini für Er-

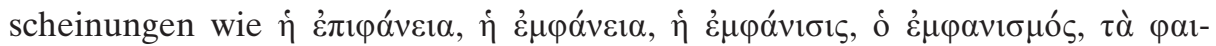
vó $\mu \varepsilon v \alpha, \dot{\eta} \pi \alpha \rho o v \sigma i \alpha^{545}$, des weiteren Begriffe für „der Anblick/Aussehen“ wie $\dot{\eta}$

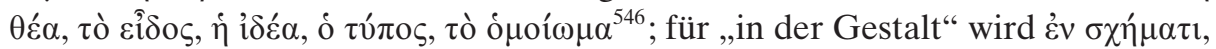

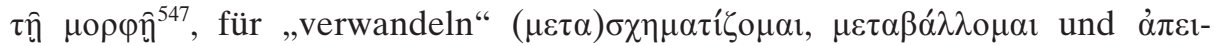
$\kappa \alpha ́ \zeta o \mu \alpha \imath^{548}$ verwendet. Von Bedeutung für die Thematik ist überdies „das Zeichen“ (

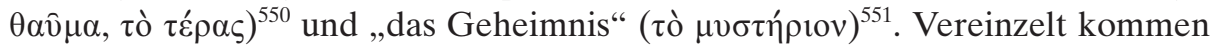

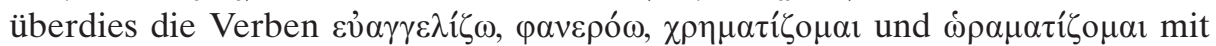
den Bedeutungen „offenbaren“ und „Visionen empfangen“ vor ${ }^{552}$. Nur einmal

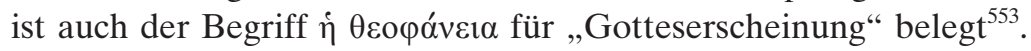

$541 \mathrm{Zu}$ den unterschiedlichen Bedeutungen des Begriffes s. Betz, Art. $\varphi \omega v \eta ́$.

542 174, 230, 354, 355.

543 Wie in 430.

544365.

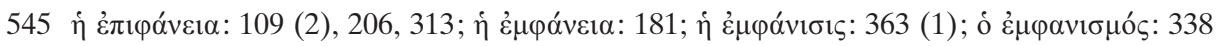

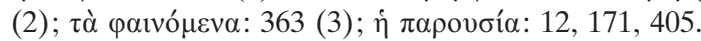

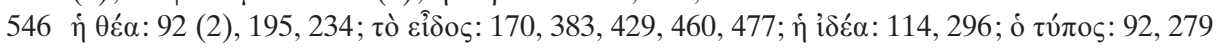
(1), 334, 457; тò ó $\mu$ oí $\mu \alpha:$ 352, 469, 470.

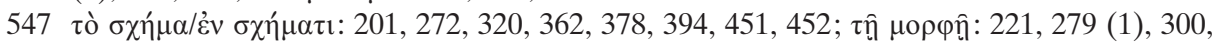
369.

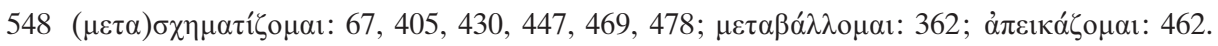

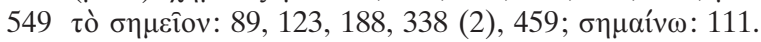

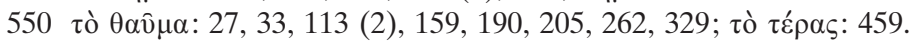

551 16, 17, 26, 28, 174, 189, 195.

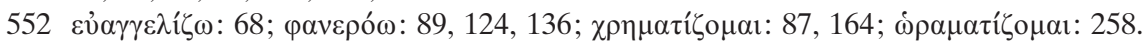

553135. 


\subsection{Terminologische Tabellen}

\subsubsection{Traumbegriffe}

\begin{tabular}{|c|c|c|c|c|c|c|}
\hline \multirow{2}{*}{$\begin{array}{l}\text { Autoren und Werke/ } \\
\text { Terminologie }\end{array}$} & \multicolumn{6}{|c|}{ Traumbegriffe } \\
\hline & 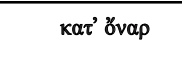 & 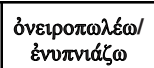 & ŏvap & övelpos & દ̇vórviov & uั $\pi \alpha \rho$ \\
\hline ViPa, PaThI, PaThII & & & & & $\begin{array}{l}3(163,164, \\
413)\end{array}$ & \\
\hline \multicolumn{7}{|l|}{ Athanasios, ViAn } \\
\hline Historia Monachorum & $2(305,350)$ & & & & & \\
\hline Gregor v. Nyssa, ViMac & & & & & $2(229,313)$ & $1(313)$ \\
\hline Apophthegmata Patrum & & & $1(154)$ & & & \\
\hline Evagrios Pontikos & & & & & $\begin{array}{l}3\left(6^{[*]}, 21^{[*]},\right. \\
44)\end{array}$ & \\
\hline Kallinikos, ViHy & & & & & $\mathbf{1}\left(85^{*}\right)$ & \\
\hline Palladios, HiLa & & & & $\mathbf{1}(24 *)$ & $\mathbf{1}\left(446^{*}\right)$ & \\
\hline $\begin{array}{l}\text { Theodoret von Kyrrhos, } \\
\text { PhHi }\end{array}$ & & $2(37,39)$ & $\begin{array}{l}3(93 *, 94, \\
268)\end{array}$ & & & $1(93)$ \\
\hline Ioannes Moschos, PrSp & $1(309)$ & & & $1(356)$ & & \\
\hline Bar & $1\left(440^{*}\right)$ & $1(443 *)$ & & $\begin{array}{l}3\left(18^{*}, 439^{*},\right. \\
\left.441^{*}\right)\end{array}$ & $\begin{array}{l}4\left(62^{[*]}, 439 *\right. \\
\left.441^{*}\right)\end{array}$ & \\
\hline Ioannes Klimakos, ScPa & & & & $\mathbf{1}(47 *)$ & $\begin{array}{l}3\left(55^{*}, 56^{*},\right. \\
\left.101^{*}\right)\end{array}$ & \\
\hline ViNi & $1(162)$ & & & & & \\
\hline $\begin{array}{l}\text { Kyrillos v. Skythopolis, } \\
\text { ViEu ... }\end{array}$ & $2(335,402)$ & & & $1(261)$ & & \\
\hline $\begin{array}{l}\text { Antonios } \\
\text { Hagiographikos, ViSyStI }\end{array}$ & $1(424)$ & & & & & \\
\hline ViSyStII, ViMa & $1(408)$ & & & & $2\left(186^{*}, 473^{*}\right)$ & \\
\hline Vita d. Daniel Stylites & & & $1(158)$ & & $2(158,311)$ & \\
\hline $\begin{array}{l}\text { Markos Diakonos, } \\
\text { ViPo }\end{array}$ & $1(41 *)$ & & & & & \\
\hline Gregorios, ViThSy & $\begin{array}{l}\mathbf{5}(122,285,286 \\
316,428)\end{array}$ & & $1(286)$ & & & \\
\hline Leontios, ViSySa, ViIoEl & $2(393,422)$ & & $2(51 *, 407)$ & & $1(379)$ & \\
\hline
\end{tabular}

Bei den mit * versehenen Nummern handelt es sich um dämonische (oder nichtige) Träume, bei allen anderen um Visionsträume. 


\subsubsection{Ekstase}

\begin{tabular}{|c|c|c|c|c|c|c|c|}
\hline \multirow{2}{*}{$\begin{array}{l}\text { Autoren und } \\
\text { Werke/ } \\
\text { Termino- } \\
\text { logie }\end{array}$} & \multicolumn{4}{|c|}{ Dämonische Ekstase } & \multicolumn{3}{|c|}{ Mystische Ekstase } \\
\hline & 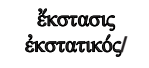 & 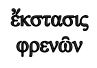 & 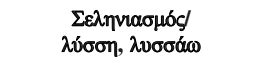 & - & 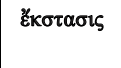 & 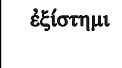 & - \\
\hline $\begin{array}{l}\text { ViPa, PaThI, } \\
\text { PaThII }\end{array}$ & $3(34,35,456)$ & & & & $2(91,372)$ & & \\
\hline $\begin{array}{l}\text { Athanasios, } \\
\text { ViAn }\end{array}$ & & & & & $1(71)$ & & $\mathbf{1}(208)$ \\
\hline $\begin{array}{l}\text { Historia } \\
\text { Monachorum }\end{array}$ & $1(449)$ & & & & & & $\begin{array}{l}2(251, \\
252)\end{array}$ \\
\hline \multicolumn{8}{|l|}{$\begin{array}{l}\text { Gregor v. } \\
\text { Nyssa, } \\
\text { ViMac }\end{array}$} \\
\hline $\begin{array}{l}\text { Apophtheg- } \\
\text { mata Patrum }\end{array}$ & $1(12)$ & $\mathbf{1}(9)$ & & & $\begin{array}{l}7(11,156, \\
242,243, \\
244,245, \\
289,374, \\
397)\end{array}$ & & $\begin{array}{l}\mathbf{3}(209, \\
246,373)\end{array}$ \\
\hline $\begin{array}{l}\text { Evagrios } \\
\text { Pontikos }\end{array}$ & $2(19,20)$ & $1(42)$ & & & & & \\
\hline $\begin{array}{l}\text { Kallinikos, } \\
\text { ViHy }\end{array}$ & & & 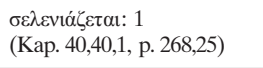 & & $\mathbf{1}(219)$ & & \\
\hline $\begin{array}{l}\text { Palladios, } \\
\text { HiLa }\end{array}$ & & & & & $\begin{array}{l}3(217, \\
265,405)\end{array}$ & $1(59)$ & $1(249)$ \\
\hline $\begin{array}{l}\text { Theodoret } \\
\text { von } \\
\text { Kyrrhos, } \\
\text { PhHi }\end{array}$ & & & $\begin{array}{l}\lambda \dot{\sigma \sigma} \eta, \lambda v \sigma \sigma \alpha ́ \omega: 8 \\
\text { (Kap. } 3,9,14 ; 6,6,4 ; 8,12,12 ; \\
9,10,21 ; 21,23,14 ; 21,24,1 ; \\
\text { 22,4,6; 28,1,17; Bd I. p. 260, } \\
\text { 10; 354,9; 398,14; 426,15; } \\
\text { Bd. II, p. 106,16; 106,18; } \\
\text { 128,13; 226,1) }\end{array}$ & & & & \\
\hline $\begin{array}{l}\text { Ioannes } \\
\text { Moschos, } \\
\text { PrSp }\end{array}$ & & & & & $\begin{array}{l}8(168, \\
169,170, \\
256,327, \\
388,419, \\
464)\end{array}$ & & $1(383)$ \\
\hline \multicolumn{8}{|l|}{ Bar } \\
\hline $\begin{array}{l}\text { Ioannes } \\
\text { Klimakos, } \\
\text { ScPa }\end{array}$ & & & & & $1(52)$ & $2(48,233)$ & \\
\hline \multicolumn{8}{|l|}{$\mathrm{ViNi}$} \\
\hline $\begin{array}{l}\text { Kyrillos v. } \\
\text { Skythopolis, } \\
\text { ViEu ... }\end{array}$ & & & 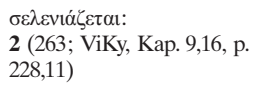 & & $\begin{array}{l}2(262 \\
264)\end{array}$ & & $\mathbf{1}(136 / 220)$ \\
\hline $\begin{array}{l}\text { Antonios } \\
\text { Hagio- } \\
\text { graphikos, } \\
\text { ViSyStI }\end{array}$ & & & & & & & $1(234)$ \\
\hline
\end{tabular}




\begin{tabular}{|c|c|c|c|c|c|c|c|}
\hline \multirow{2}{*}{$\begin{array}{l}\text { Autoren und } \\
\text { Werke/ } \\
\text { Termino- } \\
\text { logie }\end{array}$} & \multicolumn{4}{|c|}{ Dämonische Ekstase } & \multicolumn{3}{|c|}{ Mystische Ekstase } \\
\hline & 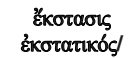 & 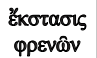 & 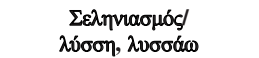 & - & 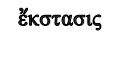 & 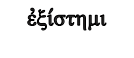 & - \\
\hline $\begin{array}{l}\text { ViSyStII, } \\
\text { ViMa }\end{array}$ & & & & $\begin{array}{l}\mathbf{4}(266,274 \\
278,299)\end{array}$ & $\begin{array}{l}\mathbf{1 0}(106, \\
108,112, \\
118,224, \\
235,280, \\
331,425, \\
426)\end{array}$ & $\mathbf{1}(195,338)$ & $\begin{array}{l}\mathbf{1 1}(109 \\
{[1-3], 110,} \\
113,118, \\
147,148, \\
227,257, \\
258)\end{array}$ \\
\hline $\begin{array}{l}\text { Palladios, } \\
\text { HiLa }\end{array}$ & & & & & $\begin{array}{l}\mathbf{3}(217, \\
265,405)\end{array}$ & $\mathbf{1}(22)$ & $1(249)$ \\
\hline $\begin{array}{l}\text { Theodoret } \\
\text { von } \\
\text { Kyrrhos, } \\
\text { PhHi }\end{array}$ & & & $\begin{array}{l}\lambda v ́ \sigma \sigma \eta, \lambda v \sigma \sigma \alpha ́ \omega: 8 \\
\text { (Kap. 3,9,14; 6,6,4; 8,12,12; } \\
9,10,21 ; 21,23,14 ; 21,24,1 ; \\
\text { 22,4,6; 28,1,17; Bd I. p. 260, } \\
\text { 10; 354,9; 398,14; 426,15; } \\
\text { Bd. II, p. 106,16; 106,18; } \\
\text { 128,13; 226,1) }\end{array}$ & & & & \\
\hline $\begin{array}{l}\text { Vita d. } \\
\text { Daniel } \\
\text { Stylites }\end{array}$ & & & & & $\begin{array}{l}2(157, \\
214)\end{array}$ & & \\
\hline $\begin{array}{l}\text { Markos } \\
\text { Diakonos, } \\
\text { ViPo }\end{array}$ & $1(463)$ & & & & $1(96)$ & & \\
\hline $\begin{array}{l}\text { Gregroios, } \\
\text { ViThSy }\end{array}$ & & $1(481)$ & & & & & $\mathbf{1}(239)$ \\
\hline $\begin{array}{l}\text { Leontios, } \\
\text { ViSySa, } \\
\text { ViIoEl }\end{array}$ & & & & $1(454)$ & $1(222)$ & & \\
\hline
\end{tabular}

\subsubsection{Gesichte und Stimmen}

\begin{tabular}{|c|c|c|c|c|c|c|c|c|}
\hline \multirow{2}{*}{$\begin{array}{l}\text { Autoren und } \\
\text { Werke/ } \\
\text { Termi- } \\
\text { nologie }\end{array}$} & \multicolumn{8}{|c|}{ Gesichte und Stimmen I } \\
\hline & ó $\pi \tau \alpha \sigma \alpha \alpha$ & $\begin{array}{c}\varepsilon^{2} v \\
\text { ontaơợ }\end{array}$ & 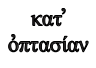 & 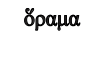 & 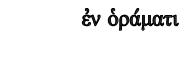 & "̈parrs & $\begin{array}{c}\text { Év } \\
\text { ód́ąt }\end{array}$ & ö४rs \\
\hline $\begin{array}{l}\text { ViPa, PaThI, } \\
\text { PaThII }\end{array}$ & $\begin{array}{l}\mathbf{6}(32,36,92 \\
137,458,459)\end{array}$ & & & $\begin{array}{l}7(35,66, \\
91,138, \\
365,380, \\
414)\end{array}$ & & & & \\
\hline $\begin{array}{l}\text { Athanasios, } \\
\text { ViAn }\end{array}$ & $2(57[5], 241)$ & & & & & & & \\
\hline $\begin{array}{l}\text { Historia } \\
\text { Mona- } \\
\text { chorum }\end{array}$ & & $\mathbf{1}(251)$ & & $\mathbf{1}(159)$ & & $1(25)$ & & \\
\hline $\begin{array}{l}\text { Gregor v. } \\
\text { Nyssa, } \\
\text { ViMac }\end{array}$ & & & & & & & & $\begin{array}{l}1(229) \\
\text { ('̇vorvíov } \\
\text { ő } \psi 1 \varsigma)\end{array}$ \\
\hline $\begin{array}{l}\text { Apophtheg- } \\
\text { mata Patrum }\end{array}$ & $2(154,397)$ & & & & $1(155)$ & $\mathbf{1}(188)$ & & \\
\hline \multicolumn{9}{|l|}{$\begin{array}{l}\text { Evagrios } \\
\text { Pontikos }\end{array}$} \\
\hline $\begin{array}{l}\text { Kallinikos, } \\
\text { ViHy }\end{array}$ & & & & & & & & \\
\hline
\end{tabular}




\begin{tabular}{|c|c|c|c|c|c|c|c|c|}
\hline \multirow{2}{*}{\begin{tabular}{l|} 
Autoren und \\
Werke/ \\
Termi- \\
nologie
\end{tabular}} & \multicolumn{8}{|c|}{ Gesichte und Stimmen I } \\
\hline & ò $\pi \tau \alpha \sigma^{\prime} \alpha$ & 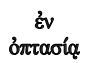 & $\begin{array}{c}\kappa \alpha \tau^{\prime} \\
\text { ó } \pi \tau \alpha \sigma i \alpha v\end{array}$ & о̆ $\alpha \mu \alpha$ & 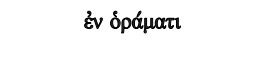 & 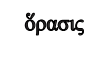 & 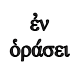 & öwrs \\
\hline \multicolumn{9}{|l|}{$\begin{array}{l}\text { Palladios, } \\
\text { HiLa }\end{array}$} \\
\hline $\begin{array}{l}\text { Theodoret } \\
\text { von Kyrrhos, } \\
\text { PhHi }\end{array}$ & $1(405)$ & & & & & & & \\
\hline $\begin{array}{l}\text { Ioannes } \\
\text { Moschos, } \\
\text { PrSp }\end{array}$ & & & & $\mathbf{1}(101)$ & & $\begin{array}{l}2(355 \\
389)\end{array}$ & & \\
\hline Bar & $2(63,64)$ & & $1(442)$ & & & & & \\
\hline $\begin{array}{l}\text { Ioannes } \\
\text { Klimakos, } \\
\mathrm{ScPa}\end{array}$ & & & & $1(310)$ & & & & \\
\hline $\mathrm{ViNi}$ & $1(364)$ & & & & $\mathbf{1}(89)$ & & & \\
\hline $\begin{array}{l}\text { Kyrillos v. } \\
\text { Skythopolis, } \\
\text { ViEu ... }\end{array}$ & $\begin{array}{l}\mathbf{1 0}(135,182 \\
201,216,231 \\
264,312,335 \\
357,369)\end{array}$ & $1(369)$ & & $\begin{array}{l}\mathbf{3}(318, \\
392,401)\end{array}$ & & & & 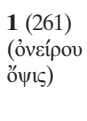 \\
\hline \multicolumn{9}{|l|}{$\begin{array}{l}\text { Antonios } \\
\text { Hagio- } \\
\text { graphikos, } \\
\text { ViSyStI }\end{array}$} \\
\hline $\begin{array}{l}\text { ViSyStII, } \\
\text { ViMa }\end{array}$ & $\begin{array}{l}\mathbf{8}(110,174,227 \\
{[2], 253,277,} \\
291,301,426)\end{array}$ & & & $\begin{array}{l}2(324, \\
426[2])\end{array}$ & $\begin{array}{l}\mathbf{1 5}(115,225,226,228,270, \\
280[3], 290,294,296,299, \\
302,337,338,362[4 ; 5], \\
427[2])\end{array}$ & $\begin{array}{l}\mathbf{5}(106 \\
{[2], 107,} \\
258,338 \\
[1], 409)\end{array}$ & $\begin{array}{l}\mathbf{2} \\
(117, \\
475)\end{array}$ & $1(290)$ \\
\hline $\begin{array}{l}\text { Vita d. } \\
\text { Daniel } \\
\text { Stylites }\end{array}$ & $3(75,157,158)$ & & & & $2(311,333)$ & & & \\
\hline $\begin{array}{l}\text { Markos } \\
\text { Diakonos, } \\
\text { ViPo }\end{array}$ & & & & $1(98)$ & & & & \\
\hline $\begin{array}{l}\text { Gregorios, } \\
\text { ViThSy }\end{array}$ & $\begin{array}{l}\mathbf{5}(196,236, \\
240,345,359)\end{array}$ & $1(120)$ & & & & $\begin{array}{l}2(344, \\
358)\end{array}$ & & \\
\hline $\begin{array}{l}\text { Leontios, } \\
\text { ViSySa, } \\
\text { ViIoEl }\end{array}$ & $\begin{array}{l}4(161,221, \\
222,306)\end{array}$ & & & $\begin{array}{l}\mathbf{4}(161, \\
378,379 \\
407)\end{array}$ & & & & \\
\hline
\end{tabular}




\begin{tabular}{|c|c|c|c|c|c|c|c|}
\hline \multirow{2}{*}{$\begin{array}{l}\text { Autoren und } \\
\text { Werke/ } \\
\text { Termi- } \\
\text { nologie }\end{array}$} & \multicolumn{7}{|c|}{ Gesichte und Stimmen II } \\
\hline & $\theta \varepsilon \omega p^{\prime} \alpha$ & $\theta \varepsilon ́ \alpha \mu \alpha$ & $\theta \varepsilon \omega ́ \rho \eta \mu \alpha$ & 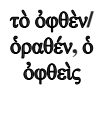 & 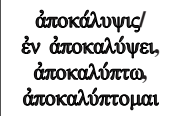 & 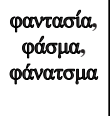 & 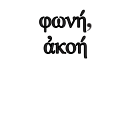 \\
\hline $\begin{array}{l}\text { ViPa, PaThI, } \\
\text { PaThII }\end{array}$ & & & & & $3(66,139,165)$ & $1(459)$ & $\begin{array}{l}\mathbf{5}(92,230 \\
{[1], 365,} \\
371,372)\end{array}$ \\
\hline $\begin{array}{l}\text { Athanasios, } \\
\text { ViAn }\end{array}$ & $2(8,71)$ & & $\mathbf{1}(430)$ & & $2(241)$ & $\begin{array}{l}\mathbf{2}(57[2], \\
57[5], \\
430)\end{array}$ & $2(207,430)$ \\
\hline $\begin{array}{l}\text { Historia } \\
\text { Mona- } \\
\text { chorum }\end{array}$ & $1(25)$ & & & & $2(26,250)$ & $1(448)$ & $\begin{array}{l}\mathbf{4}(159,218 \\
[2 ; 4], 305])\end{array}$ \\
\hline $\begin{array}{l}\text { Gregor v. } \\
\text { Nyssa, } \\
\text { ViMac }\end{array}$ & $\begin{array}{l}1 \text { (ViMac } 18,10 \text { f., p. } 200 ; \text { [s. auch } \\
\text { Kap. 3.4.1, A. 84]) }\end{array}$ & $\begin{array}{l}\mathbf{1} \\
(229)\end{array}$ & & & & $1(229)$ & \\
\hline $\begin{array}{l}\text { Apophtheg- } \\
\text { mata Patrum }\end{array}$ & $2(61,346)$ & $1(10)$ & & $\mathbf{1}(432)$ & $1(375)$ & $\begin{array}{l}2(60, \\
317)\end{array}$ & $\begin{array}{l}7(10,188 \\
212,348 \\
373,399 \\
400)\end{array}$ \\
\hline $\begin{array}{l}\text { Evagrios } \\
\text { Pontikos }\end{array}$ & $1(46)$ & & & & & $2(45,46)$ & \\
\hline $\begin{array}{l}\text { Kallinikos, } \\
\text { ViHy }\end{array}$ & & & & & $\begin{array}{l}\mathbf{5}(28,85,406 \\
452,453)\end{array}$ & $\mathbf{1}(452)$ & $\begin{array}{l}\mathbf{2}(85,406 \\
[2])\end{array}$ \\
\hline $\begin{array}{l}\text { Palladios, } \\
\text { HiLa }\end{array}$ & $1(22)$ & & & & $3(82,247,249)$ & $\begin{array}{l}2(446, \\
447)\end{array}$ & \\
\hline $\begin{array}{l}\text { Theodoret } \\
\text { von Kyrrhos, } \\
\text { PhHi }\end{array}$ & $\mathbf{3}(38,39,40)$ & & & & & $1(461)$ & $1(326)$ \\
\hline $\begin{array}{l}\text { Ioannes } \\
\text { Moschos, } \\
\text { PrSp }\end{array}$ & & & & $1(368)$ & $2(256,383)$ & & $2(192,355)$ \\
\hline Bar & & & & & $3(16,17,74)$ & $\begin{array}{l}\mathbf{3}(18 \\
440,442)\end{array}$ & \\
\hline $\begin{array}{l}\text { Ioannes } \\
\text { Klimakos, } \\
\text { ScPa }\end{array}$ & $2(54,67)$ & & $1(49)$ & $\begin{array}{l}2(310 . \\
421)\end{array}$ & & $\mathbf{1}(50)$ & \\
\hline $\mathrm{ViNi}$ & & & & & $1(325)$ & & \\
\hline $\begin{array}{l}\text { Kyrillos v. } \\
\text { Skythopolis, } \\
\text { ViEu ... }\end{array}$ & & & & & $\begin{array}{l}\mathbf{6}(129,131,141 \\
231,232,420)\end{array}$ & $1(470)$ & $2(132,334)$ \\
\hline \multicolumn{8}{|l|}{$\begin{array}{l}\text { Antonios } \\
\text { Hagio- } \\
\text { graphikos, } \\
\text { ViSyStI }\end{array}$} \\
\hline $\begin{array}{l}\text { ViSyStII, } \\
\text { ViMa }\end{array}$ & $\begin{array}{l}\mathbf{1 8}(106[2], 107,109[1 ; 3], 113[1, \\
2], 118[1], 145,148,171,224,259, \\
277,330,331,427[2], 475)\end{array}$ & & & $\begin{array}{l}\mathbf{1}(362 \\
[1])\end{array}$ & $\begin{array}{l}9(103,106[1] \\
117,118,171 \\
176,257,337 \\
362)\end{array}$ & & $\begin{array}{l}4(174,175 \\
235,295)\end{array}$ \\
\hline $\begin{array}{l}\text { Vita d. } \\
\text { Daniel } \\
\text { Stylites }\end{array}$ & & & & & & $1(444)$ & \\
\hline
\end{tabular}




\begin{tabular}{|c|c|c|c|c|c|c|c|}
\hline \multirow{2}{*}{$\begin{array}{l}\text { Autoren und } \\
\text { Werke/ } \\
\text { Termi- } \\
\text { nologie }\end{array}$} & \multicolumn{7}{|c|}{ Gesichte und Stimmen II } \\
\hline & $\theta \varepsilon \omega \rho^{\prime} \alpha$ & $\theta \varepsilon ́ \alpha \mu \alpha$ & $\theta \varepsilon \omega ́ p \eta \mu \alpha$ & 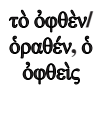 & 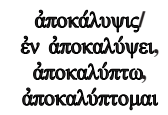 & 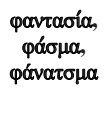 & 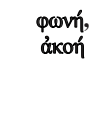 \\
\hline $\begin{array}{l}\text { Markos } \\
\text { Diakonos, } \\
\text { ViPo }\end{array}$ & & & & & $3(97,98,166)$ & & \\
\hline $\begin{array}{l}\text { Gregorios, } \\
\text { ViThSy }\end{array}$ & $1(196)$ & & & $\begin{array}{l}2(120, \\
316)\end{array}$ & $\begin{array}{l}4(119,153,237, \\
238)\end{array}$ & $1(480)$ & $1(177)$ \\
\hline $\begin{array}{l}\text { Leontios, } \\
\text { ViSySa, } \\
\text { ViIoEl }\end{array}$ & & & & $\begin{array}{l}2(377, \\
407)\end{array}$ & & $1(161)$ & \\
\hline
\end{tabular}




\section{Kapitel - Vom heidnischen Mantiker zum christlichen Charismatiker}

\subsection{Die Unterscheidungsgabe zur Beurteilung der Schau -

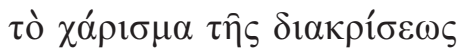

\subsubsection{Die Unterscheidung zwischen wahr und trügerisch}

Aus einer Vielzahl von Beispielen geht hervor, dass die Inhalte der geschilderten imaginären Erfahrungen ihre eigentliche Bedeutung erst durch eine

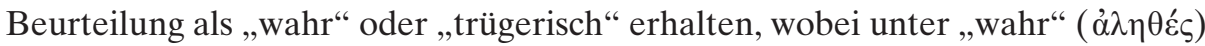
im heilsgeschichtlichen Sinne die in Gott gründende Offenbarung verstanden wird, unter „trügerisch“ ( $\psi \varepsilon v \delta \emptyset\rceil \delta \alpha \iota \mu o v i \omega ́ \delta \eta \varsigma)$ hingegen die durch dämonische Mächte ausgelöste Erscheinung ${ }^{554}$. Das wiederholte Vorkommen der gegensätzlichen Begriffe „wahr“ und „trügerisch“ bzw. „dämonisch“555, zeugt vom hohen Stellenwert, welcher einer richtigen Beurteilung des Geschauten bzw. Gehörten beigemessen wurde. Leontios von Neapolis erzählt, dass Ioannes Eleemon die Nächstenliebe und Barmherzigkeit in der Gestalt einer jungen, strahlenden Frau mit einem Kranz von Ölzweigen auf dem Kopf erblickte. Als er sich nach dieser Erscheinung zur Kirche begab, traf er einen frierenden Mann, schenkte ihm sein Ziegenfell und sagte bei sich: „Dadurch werde ich

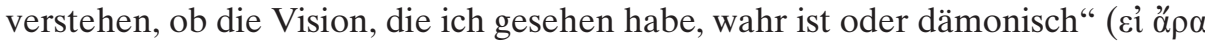

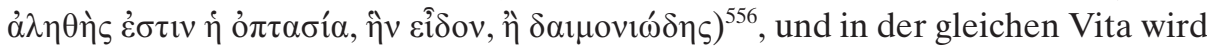

554 Die Dämonen wurden in der Spätantike zwar als zwischen Himmel und Erde lebende, gasförmige und somit unsichtbare, aber „substantielle“ Geisteswesen betrachtet (so auch die Engel). Gleichzeitig wurde der Wahrheitsgehalt der von den Dämonen ausgelösten Bilder $(\varphi \alpha v \alpha \tau \alpha \sigma i ́ \alpha)$ im „heilsgeschichtlichen Sinn“ in Zweifel gezogen. Über die erstmalige Nutzbarmachung der heidnischen Dämonologie im Sinne des Christentums s. Michl, Engel 110-132; speziell bei Origenes, der die Dämonologie der monastischen Autoren (v. a. des Euagrios) stark beeinflusste, s. BraKKE, Demons 10-12. 15-17, und bei Tertullian s. Hammerstaedt, Die früheste lateinische Dämonologie in Tertullians Apologeticum 25-27; NäF, Traum und Traumdeutung 138-141. Zum Dämonenglauben in der frühbyzantinischen Hagiographie u. monastischen Literatur s. Guillaumont, Art. Démon 189-212; Festugière, Les moines d'Orient I 23-39; Coyle, Early Monks 229-249; BrakKe, Demons 3-246, u. allg. im frühen Byzanz, s. Maltese, Dimensione 49-68. Zu den in den behandelten Quellen vorkommenden Erklärungen für das Zustandekommen von dämonischen Bildern siehe auch S. 44 A. 181, S. 53-62 A. 648 u. 650.

555 Vgl. S. 44-46, S. 102 A. 502-506, S. 106 A. 535.

556161. 
vom geizigen Zöllner Petros berichtet, dass er einen Belehrungstraum hatte und

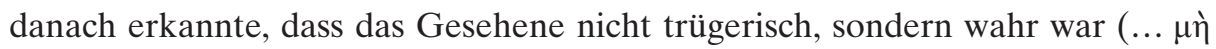

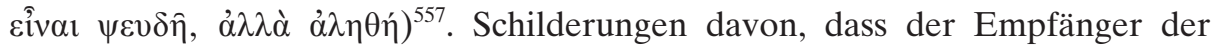
imaginären Erfahrung bei der Rückkehr ,ins normale Tagesbewusstsein“"558 als Zeugnis für die Wahrheit des Geschauten „Striemen am Rücken“, „Weihrauchkugeln in der Hand“, „Früchte aus dem Paradies“, „Nasenbluten von einer imaginären Bestrafung“ oder „einen Ring der theotokos" mit sich bringt ${ }^{559}$, sollen die imaginär konstituierte heilsgeschichtliche Wahrheit bekräftigen ${ }^{560}$. Ebenfalls als Glaubwürdigkeitssignal für den Wahrheitsgehalt des Geschauten setzen die Autoren kollektive und serielle imaginäre Erfahrungen ein $^{561}$. In diesem Zusammenhang wurde bereits festgestellt, dass die Anwendung solcher literarischer Formen nichts über einen Mangel an Authentizität der jeweiligen Erzählungen bzw. über ihr tatsächliches Vorkommen in Entstehungs- und Rezipientenumfeld der Texte aussagt. Ist es doch leicht nachvollziehbar, dass etwa Wiederholungsträumen in der Tat größere Zuverlässigkeit beigemessen wurde als einmaligen Traumgesichten, was wiederum zu einem gehäuften Vorkommen von Wiederholungsträumen, sowohl innerhalb als auch außerhalb der literarischen Dimension, führte ${ }^{562}$. Gerade die negative Antwort des Barsanuphios auf die Frage eines gläubigen (weltlichen) Christen, ob es stimme, dass etwas wahr sei, wenn man es dreimal im Traum sehe ${ }^{563}$, zeigt, wie verbreitet diese Ansicht in der Bevölkerung gewesen sein muss. Barsanuphios' begründet seinen Ratschlag, einem solchen Traum keinen Glauben zu schenken, damit, dass etwas, was einmal falsch erschienen sei, dies auch dreimal oder mehrfach tun könne. Damit unterstreicht er letztlich nur die Antwort, die er dem gleichen Fragenden schon

557377.

558 S. S. 70 A. 315.

559 Striemen auf dem Rücken: 403, 407; Weihrauchkugel in der Hand: 315; Paradiesesfrüchte: 251, 252 (siehe auch S. 45 f. A. 185 u. 186); Fingerring: 239; Nasenbluten: 414; die Schau stellt sich durch die folgenden Ereignisse als „wahr" heraus: 222.

560 Über die sogenannte „Materialisation“ (das Hinterlassen eines materiellen Zeichens) in der klassischen Literatur vgl. DoDDs, Die Griechen und das Irrationale 58.

561 Doppelte, dreifache und mehrfache imaginäre Erfahrungen: 62, 205, 313, 355, 362, 367 , 387, 389, 390, 391, 415, 416, 418. Kollektive imaginäre Erfahrungen: 159, 215, 406, 428. Serielle Visionen kommen besonders in den apokalyptischen Entrückungen des Symeon Stylites des Jüngeren vor, u.a. in 106, 109, 113, 118, aber auch in anderen Beispielen, z. B. in 218. Weitere Beispiele in DAGRon, Rêver 41, A. 19.

562 Alle diese Formen der sogenannten „Doppelträume“ sind schon aus der antiken und biblischen Literatur [z.B. Gen 41,32; 1 Sam 3,1-8; Mt 28,16-20; Apg 9,10 ff.] bekannt und wurden v.a. bezüglich Traumerzählungen schon mehrmals zum Gegenstand der Forschung. Mit zahlreichen Beispielen zur Thematik vgl. WikenhausER, Doppelträume $100 \mathrm{f}$.; Hanson, Dreams and Visions, hier „The elaboration of Dream-Vision Report“ 1414-1420; Berger, Formgeschichte 288; Ders., Visionsberichte 218-219 sowie FrenschKowsKi, Traum und Traumdeutung 34-39.

56362. 
an anderer Stelle gegeben hat, nämlich dass dieser sich nicht auf die eigenen Gedanken verlassen, sondern die Unterscheidung der heiligen Väter befragen solle ${ }^{564}$. Hier geht es also in erster Linie darum, die Kompetenz der richtigen Deutung eines Traumes ausschließlich dem christlichen Charismater zuzusprechen. Nur diesem wird die Fähigkeit zugestanden, den Wahrheitsgehalt eines Traumes - ist er nun einmalig oder mehrfach aufgetreten - festzustellen. Fällt die Beurteilung positiv aus, so darf ein mehrfaches Auftreten des Traumes am Ende allemal als Zeichen für seinen Wahrheitsgehalt stehen; ebenso, wie es in zahlreichen Exempla in den behandelten Texten der Fall ist.

Die Schwierigkeit bei der Unterscheidung zwischen „wahr“ und „trügerisch" liegt darin, dass die dämonischen Bilder jenen der göttlichen Offenbarung oft zum Verwechseln ähnlich sehen und alleine aufgrund ihres Bildinhaltes nicht als solche erkennbar werden. So verwandeln sich die Dämonen nicht nur in unterschiedliche Tiere ${ }^{565}$, verführerische Frauen ${ }^{566}$ und Äthiopier, Inder, Sarazenen bzw. schwarze Knaben oder Hunde ${ }^{567}$, sondern auch in Gestalten des christlichen Heilsgeschehens wie Engel, Heilige oder sogar Christus selbst ${ }^{568}$. Alleine das Kreuz Christi vermag der Teufel nicht vorzutäuschen, da er - so ist es in der Korrespondenz des Barsanuphios und Ioannes zu lesen - nicht imstande sei, es in einer anderen Form abzubilden. Somit sei das Erscheinen des Kreuzeszeichen ein Beweis für den göttlichen Ursprung eines Traumes ${ }^{569}$. Die

564 442. Zum gleichen Bsp. s. A. 569 u. S. 120 A. 595.

565 Dämonen in Gestalt von wilden und lärmenden Tieren: 430, 451, 457, 469, 470, 477; Dämon in Gestalt eines dreiköpfigen Wildschweins bzw. einer Katze: 286; als Maus: 287; als Drachen: 288.

566 Dämonen in Gestalt von verführerischen Frauen: 430, 456, 457, 464; verführerischer Jüngling: 462.

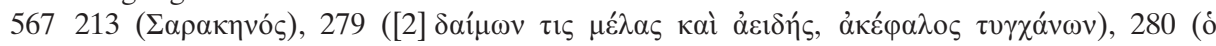

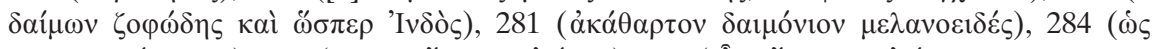

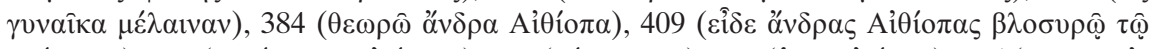

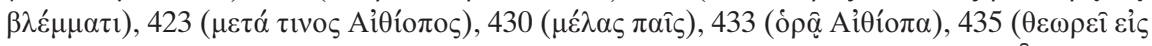

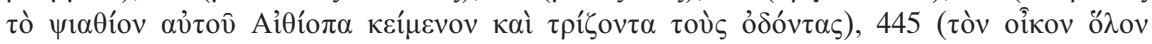

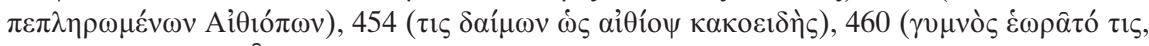

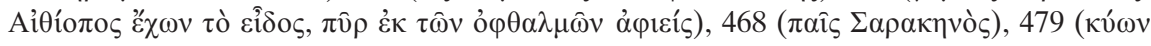

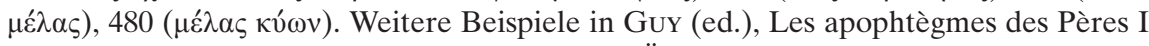
244, A. 1. Zum Motiv des Teufels in Gestalt des Äthiopiers vgl. DöLger, Die Sonne der Gerechtigkeit 49-64; Consolino, Sogni e visioni 250; Müller, Von Teufel 92-95; BrakKe, Demons 157-181. Das gleiche Motiv kommt auch im hellenistischen Liebesroman vor, so bei Eustathios Makrembolites, wo Hysminias von äthiopischen Seeräubern gequält wird, EustMak 8, 1 ff. (Marcovich 94, 3 f.), vgl. Plepelitz, Eustathios Makrembolites 65.

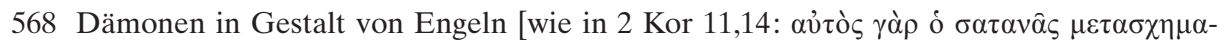

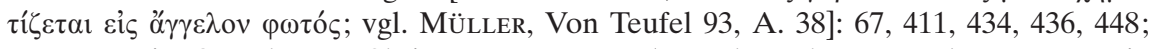
Dämonen in Gestalt von Christus: 437, 447, 452. Vgl. auch Refoulé, Rêves et vie

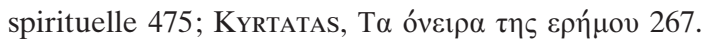

569442. 
omnipräsente Gefahr eines dämonischen Ursprungs von Bildern gilt nicht nur für Träume, sondern für alle genannten Formen von imaginären Erfahrungen,

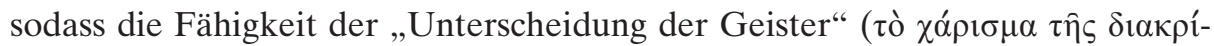
$\sigma \varepsilon \omega \varsigma \tau \hat{\omega} \nu \pi v \varepsilon v \mu \alpha ́ \tau \omega v)$, eine der neun paulinischen Gaben des Heiligen Geistes ${ }^{570}$, für die Beurteilung jeder imaginären Erfahrung eine zentrale Bedeutung einnimmt. Da die Unterscheidungsgabe immer als charisma, also als eine von Gott geschenkte Gnade verstanden wird, verwundert es auch nicht, dass in erster Linie von den „großen Charismatikern“ wie Antonios ${ }^{571}$, Sabas ${ }^{572}$, aber auch von anderen angesehenen heiligen Männern ${ }^{573}$ berichtet wird, dass sie mit der Unterscheidungsgabe ausgezeichnet waren. Über Pachomios heißt es, dass ihm eines Tages, als er gerade dabei war, eine Binsenmatte zu flechten, ein Dämon erschien, der von sich behauptete, er sei Christus. „Da der Heilige aber die Unterscheidungsgabe des Geistes besaß, sodass er die schlechten von den heiligen Gedanken unterscheiden konnte“, dachte er sofort daran, dass in der Vision der heiligen Dinge die schlechten Gedanken die Schau des Sehenden gänzlich verlassen, und dass sie (die Sehenden) sich auf nichts, außer auf die Heiligkeit der Erscheinung konzentrieren ${ }^{574}$. Er aber sah dies und fing an, nachzusinnen und abzuwägen und kam zum Schluss, dass es offensichtlich sei, dass es eine Lüge ( $\delta \hat{\eta} \lambda o v$ ö $\imath$ $\psi \varepsilon v ́ \delta \varepsilon \tau \alpha \iota)$ und nichts von den heiligen Dingen war

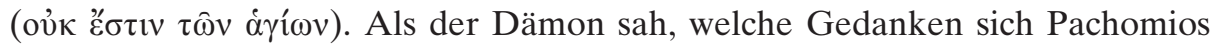
machte, fing er an, seine schlechten Geister zurückzuziehen ${ }^{575}$.

Obschon Gottes Gnade als Voraussetzung für das Erlangen der Unterscheidungsfähigkeit betrachtet wird, kann das charisma nur über den Weg der harten asketischen Übung, „durch viel Gebet und Askese erlangt werden“"576. Wer auf dem spirituellen Heilsweg der Vollendung entgegen schreiten will,

570 Diese neun Gaben werden aufgezählt in I Kor 12,8-10:

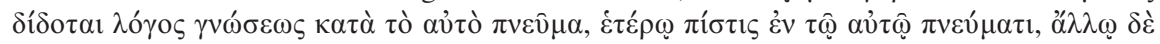

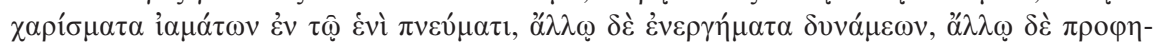

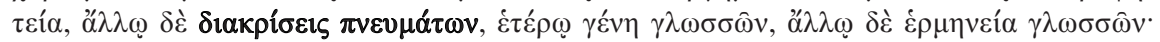

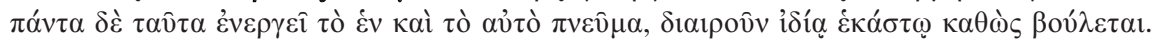

57158.

572 In 231 wird von Sabas berichtet, wie er nach einer Offenbarung das von ihm Geschaute richtig beurteilte und entsprechend handelte.

573 So etwa über den Lybier Stephanos: 65. S. auch die Bsp. 146 und 335 (über den Bischof Aitherios wird berichtet, dass er nach einer Offenbarung das von ihm Geschaute richtig beurteilte und entsprechend handelte). Weitere Beispiele in BARTELInK (ed.), Vita Antonii 251, A. 2; Vinagre, Die griechische Terminologie 266, A. 29; Dagron, Rêver $43-47$.

574 Über die montanistische Tendenz des hier geäußerten Gedankens, dass in göttlichen Gesichten die persönlichen Gedanken des Schauenden gänzlich verschwinden, während sich der Empfänger bei der dämonischen Vision über sein Schauen bewusst ist und die Kontrolle über seine Gedanken zu behalten vermag, vgl. Снadwick, Pachomios 23.

575458.

$57657(1 ; 4)$. 
kommt nicht umhin, der Fähigkeit nachzustreben, die eigenen Gesichte als „wahr" oder „dämonisch“ zu beurteilen. Anleitungen, wie die göttlichen von den trügerischen Bildern zu unterscheiden sind, finden sich in je einem ganzen Kapitel der Apophthegmata Patrum und der Scala Paradisi ${ }^{577}$, aber auch in Passagen der euagiranischen Schriften und in den großen Heiligenviten. Als deutliches Signal, anhand dessen eine Schau beurteilt werden kann, wird immer wieder die Wirkung, die sie auf den Asketen hat bzw. die Befindlichkeit, die sie bei ihm zurücklässt, angeführt. So zeigt laut Antonios bei Erscheinungen „die Freude und der Zustand der Seele die Heiligkeit des Anwesenden an “578. Und bei Ioannes Klimakos heißt es, dass der friedlich vom Schlaf Erwachende, vor allem, wenn er nach viel Gebet und Fasten eingeschlafen ist, im Verborgenen von Engeln getröstet worden sei; der verdrießlich Erwachende aber habe schlechte Träume erlitten ${ }^{579}$. Auch Euagrios, der die Entstehung der dämonischen bzw. engelhaften Gesichte anhand von unterschiedlichen Bewegungen des Körpers erklärt ${ }^{580}$, führt aus, dass die Zeichen der Leidenschaftslosigkeit in der Nacht an der Art der Träume zu erkennen sind ${ }^{581}$, dass die „engelhaften Träume eine große Seelenruhe und unbeschreibliche Freude mit sich bringen “582 und dass „ein engelhafter Traum das Herz erfreut, während ein dämonischer es verwirrt “" ${ }^{483}$. In der Vita Antonii heißt es, dass bei der guten Erscheinung Freude, Hoffnung und Mut entsteht ${ }^{584}$. Dagegen bringt „der Angriff und die Erscheinung der bösen Geister Verwirrung mit sich, er kommt mit Schlagen, Lärm und Geschrei wie die Geräusche, die von ungezogenen Jugendlichen und Dieben hervorgerufen werden. Daraus entsteht sogleich Furcht der Seele, Verwirrung und Unordnung der Gedanken, Niedergeschlagenheit, Hass gegen die Asketen, Nachlässigkeit, Kummer, Erinnerung an die Verwandten, Todesfurcht und schließlich Verlangen nach dem Bösen, Gleichgültigkeit gegenüber den Tugenden und ein Durcheinander der Sitten “585. Als sicherster Weg, diesen Übeln zu entkommen, wird immer wieder Furchtlosigkeit, Gebet und das

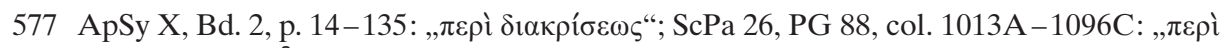

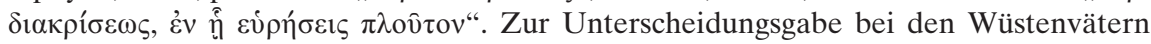
vgl. Draguet, Les Pères LIV-LVI, speziell bei Ioannes Klimakos s. Blum, Byzantinische Mystik 121-130.

57857 (3).

57956.

580 S. S. $55-59$.

58144.

58221.

583 6. S. S. 50 A. 206 u. mit weiteren Beispielen Refoulé, Rêves et vie spirituelle 476.

58457 (3). Die Beseitigung der Furcht, welche aufgrund des Wissens um eine numinose Präsenz ausgelöst wird, ist ein in der monastischen Literatur beliebtes Motiv. Die Vorläufer dafür sind die Engel des Neuen Testaments (Bsp. Lk 2,10), welche ihre Offenbarungsrede häufig mit Phrasen wie „fürchtet euch nicht“ ( $\mu$ ๆ $\varphi \circ \beta \varepsilon i ̂ \sigma \theta \varepsilon)$ einleiten.

58557 (2). 
Schlagen des Kreuzeszeichen genannt. Denn ,wenn ein Trugbild kommt, darf man sich nicht fürchten, sondern muss Mut fassen und fragen: ,Wer bist du? Wenn es eine Vision der Heiligen ist, informieren sie dich sofort und verwandeln die Angst in Freude. Wenn es aber der Dämon ist, dann geht ihm die Kraft aus, sobald er den Geist [des Asketen] gestärkt sieht. Ein Beweis der Leidenschaftslosigkeit ist das bloße Fragen: ,Wer bist du und woher kommst du? “586. Angst dagegen zieht die Dämonen an. Darüber berichtet Theodoret von Kyrrhos in einer Erzählung über Bruder Iakobos, der sich in der Zeit, als isaurische Räuberbanden den Orient verwüsteten, davor fürchtete, gefangen genommen zu werden. „Da der Teufel diese Angst spürte, weil er häufig hörte, wie Iakobos seinen Bekannten davon erzählte“, ahmte er eines Nachts wehklagende Frauen nach. Iakobos schien es, dass Feinde ankommen und die Dörfer niederbrennen würden. So wartete er die ganze Nacht darauf, von den Räubern ergriffen zu werden. Erst als am nächsten Tag Leute vorbeikamen und erzählten, dass sie nichts von wütenden Isauriern gehört hätten, verstand Ia-

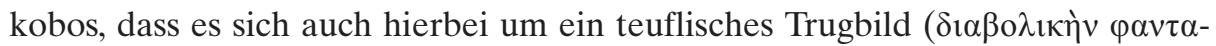
бíav) handelte ${ }^{587}$.

Dass sich beim Beten zeigt, ob die Erscheinung „wahr“ oder „trügerisch“ ist, kommt nicht nur in den Erzählungen vor, wo ein Heiliger die dämonischen Trugbilder durch das Gebet in die Flucht schlägt ${ }^{588}$, sondern auch da, wo ein vermeintliches Trugbild trotz Gebet nicht verschwindet und sich deshalb als „wahr“ erweist ${ }^{589}$. So in einer Episode aus den Apophthegmensammlungen, wo ein Knabe mit Brot und Wasser an Bruder Zenon herantritt, der sich in der Wüste verirrt hatte und kurz davor war zu sterben. Zenon stand auf und betete,

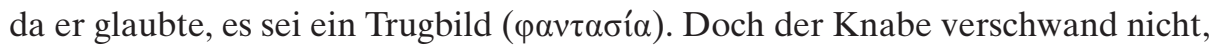
sondern lobte Zenon für sein vorbildliches Handeln, gab ihm $\mathrm{zu}$ essen und führte ihn nach Hause ${ }^{590}$.

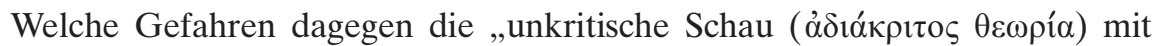
sich bringt ${ }^{\star 591}$, berichtet eine Episode über Makarios, einen Schüler des heiligen Hypatios, „der sich aus fehlender Unterscheidungsfähigkeit“ ( durch Trugbilder in der Gestalt Christi täuschen ließ und so den Verstand verlor $^{592}$. In der Vita Pachomii wird von einem Bruder erzählt, bei dem der Dämon in der Gestalt einer schönen Frau an die Tür klopfte und um Beherbergung bat. In der Blindheit seines Verstandes „konnte der Bruder nicht unterscheiden, was dies

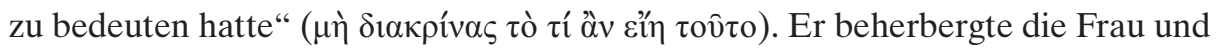

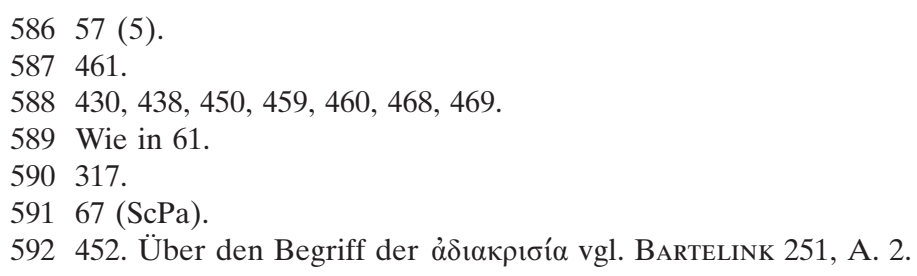


wurde von einem heftigen Verlangen ergriffen, welches ihn in eine dämonische Ekstase, in Raserei und schließlich in den Tod führte ${ }^{593}$.

Wer aber einmal den spirituellen Grad eines diakritikos erreicht hat, unterliegt nicht mehr der Gefahr, von dämonischen Bildern getäuscht zu werden. Vielmehr wird ihm nun auch von seiner Umwelt die Stärke und Autorität zugetraut, nicht nur die eigenen Gesichte, sondern auch diejenigen einer breiteren Masse von „nicht Charismatikern“ zu beurteilen, wie bereits aus den beiden oben zitierten Beispielen aus den Apophthegmensammlungen hervorgegangen ist ${ }^{594}$. Dass dem Charismatiker im monastischen Milieu, ja wahrscheinlich sogar in einem weiteren Radius der frühchristlichen Gesellschaft, eine herausragende Stellung gleichsam als „Richter der menschlichen Seele" zugesprochen wurde, verdeutlicht auch die bereits erwähnte Antwort des Barsanuphios an einen weltlichen Christen, der wissen wollte, wie es möglich sei, dass der Teufel es wage, Christus oder die heilige Eucharistie zu zeigen, sei es durch eine Vision oder durch eine Traumerscheinung. Nach einer Erklärung über die Beschaffenheit von dämonischen Erscheinungen ermahnt Barsanuphios den Fragenden, nach Visionen oder Träumen immer danach zu streben, von den heiligen Vätern die Unterscheidung des Geschauten zu er-

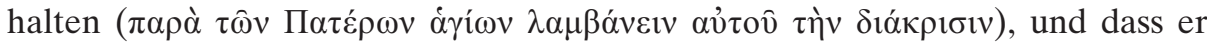
sich diesbezüglich nicht auf die eigene Vernunft verlassen solle ( $\mu \grave{\eta} \pi i ́ \sigma \tau \varepsilon v \varepsilon \tau \emptyset$

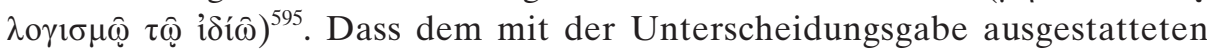
Charismatiker nicht nur die Fähigkeit der Unterscheidung von imaginären Erfahrungen, sondern auch von den für die monastische Spiritualität so

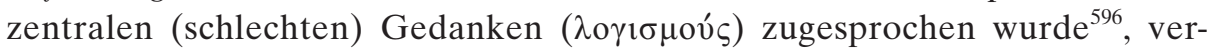
deutlicht ein Beispiel aus den Apophthegmata Patrum, in dem Abbas Moses verkündet „es ist gut, die Gedanken nicht zu verbergen, sondern sie geistlichen und mit der Unterscheidungsgabe begabten Vätern zu erzählen; nicht denen, die nur durch das Alter weiß geworden sind, denn viele schauen nur auf das Alter und erzählen dann ihre Gedanken. Anstatt geheilt zu werden, fallen sie noch mehr in die Hoffnungslosigkeit wegen der Unerfahrenheit derer, die sie anhören “597.

593456.

594 S. S. 106 A. 534 u. 535.

595 442. S. S. 116 A. 564 u. 569.

$596 \mathrm{Zu}$ den schlechten Gedanken siehe auch S. 56 A. 236, S. 57 A. 243, S. 59 A. 254, S. 60 A. 256, S. 64 A. 274 , S. 89 A. 430.

59759. 


\subsubsection{Von der Traumdeutung (o’veıрокрıбía)

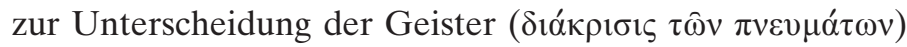

Die behandelten Texte vermitteln also unmissverständlich, dass die Kompetenz zur Beurteilung der imaginären Erfahrung stets einer heiligen, mit dem paulinischen charisma ausgestatteten Autorität zuzusprechen ist. Dabei wird deutlich,

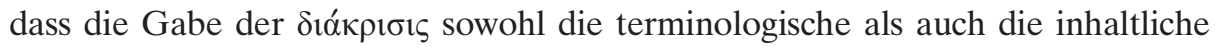
Grundlage bereithält, den christlichen Heiligen mit einer Fähigkeit auszustatten, die eine gesellschaftliche Autoritätsperson im gegebenen Zeitkontext erst als solche etablieren konnte. So wurde der christliche Charismatiker in der Funktion des diakritikos - eines Richters über imaginäre Erfahrungen - der staatlich verbotenen $^{598}$ und von kirchlicher Seite aus dem Bereich der Orthodoxie verbann$\operatorname{ten}^{599}$, aber nach wie vor populären Profession des Traumdeuters (ỏveıрокрí $\left.\eta \varsigma\right)^{600}$ als ernst zu nehmende Alternative entgegengestellt. Sicherlich wäre ein direkter Vergleich zwischen den monastischen Texten und den in den Oneirokritika des Artemidor kulminierenden Traumhandbücher der Antike zu weit gegriffen, handelt es sich doch um zwei literarische Bereiche mit weitgehend unterschiedlichen Zwecken. Während die Traumhandbücher vom Typ der

598 Diokletians Verbot der ars mathematica, die seit der frühen Kaiserzeit immer häufiger als Synonym für Astrologie erscheint, wird später erweitert und spezifiziert. Unter Konstantios II. wurden im Jahre 357 explizit solche Divinatoren belangt, „die unter dem Deckmantel der Traumdeutung eine gewisse Kunst der Divination oder irgendetwas Ähnliches am Hof ausüben“ (Cod. Theod. 9,1,16 = Cod. Just. 9,18, 7, Bd. 2, p. 380, col1.). Einer Reihe von seit Diokletian erlassenen Verboten bzgl. Traumdeutung folgt die justinianische Gesetzgebung. Vgl. Calofonos, Dream Interpretation 217; Dagron, Rêver 39; s. auch Fögen, Die Enteignung der Wahrsager 11-53. S. auch Weber, Kaiser, Träume 112; Dickie, Magic and Magicians 262-272; Vincent-Bernardi, Didascalie onirique 130, A. 13.

599 So hält die Traditio Apostolica (Trad. Ap.16, p. 74,1-5) im 3. Jhd. fest, dass ein Traumdeuter nicht als Kandidat zur Taufe zugelassen werden sollte, vgl. FrenschKowski, Traum und Traumdeutung 13. Ein Kanon des ersten Konzils von Ankyra im Jahre 314 n. Chr. verlangte fünf Jahre Buße für diejenigen, welche nach altgläubiger Sitte die Träume auslegten oder Spezialisten der Traumdeutung in ihren Häusern Magie betreiben ließen (Ankyra I, kan. 24, Ralles, Potles, Bd.3, p. 66). Die Synode von Laodikeia untersagt im späten 4. Jhd. Klerikern und Priestern Nebentätigkeiten als Mathematiker und Astrologen (Laodikeia, kan. 36, Ralles, Potles, Bd. 3, p. 203). Das Konzil von Karthago spricht sich gegen die Vermehrung der Heiligenstätten aus, welche irgendwo und ohne Reliquien konstruiert werden durch Gläubige, die Erscheinungen der Heiligen oder Märtyrer im Traum induzieren (Karthago, kan. 14, MANsi, Bd. 3, p. 971); vgl. Dagron, Rêver 39 f., A. 12 u. A. 13; Fögen, Die Enteignung der Wahrsager 21; WeBer, Kaiser, Träume 54. 62.

600 Gerade die Tatsache, dass die Traumdeutung in den Gesetzestexten über Jahrhunderte hinweg wiederholt verboten wurde, spricht für ihre ungebrochene Popularität in der Gesellschaft; dazu Calofonos, Dream Interpretation 217; Bovon, The Authority of Dreams 158. Mehr darüber s. S. 145 f. A. 709-712. 
Oneirokritika einen ganz konkreten, alltagsbezogenen und profanen Zweck zu erfüllen hatten ${ }^{601}$, nämlich die zukunftsweisende Deutung einer ganzen Palette von Traumbildern in allen Gesellschaftsschichten, könnte die monastische Literatur am ehesten als narrative Erbauungs- und religiöse Bildungsliteratur bezeichnet werden, die neben vielen anderen Inhalten auch die Belehrung über das christliche Heilsgeschehen durch exemplarische Schilderungen von imaginären Erfahrungen zu bieten hatte. Dennoch ist nicht zu übersehen, dass die Autoren darum bemüht waren, die heiligen Männer mit bestimmten Zügen auszustatten, die eine auffällige Ähnlichkeit mit dem heidnischen Traumdeuter aufweisen.

Darauf verweist zunächst die häufige Verwendung des neutestamentlichen

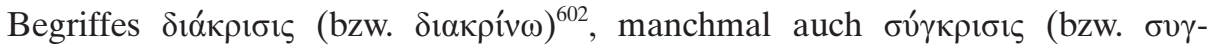

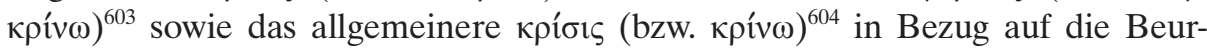
teilung aller Formen von imaginären Erfahrungen, also auch auf Träume. Bezeichnenderweise wird in den Texten bei der Beurteilung von Träumen nie das heidnisch besetzte Wort „Traumdeutung" bzw. „Traumdeuter“ (ỏveıрокрıбía,

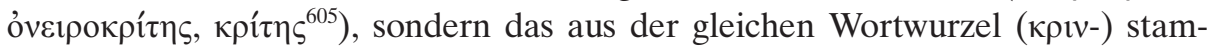
mende und den zeitgenössischen Rezipienten höchstwahrscheinlich an „Traum-

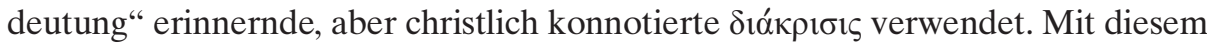
Begriff bleibt eine Deutung entsprechend der Paulusstelle nicht mehr nur auf Träume beschränkt, sondern wird auf alle Formen von imaginären Erfahrungen ausgedehnt. Dem System der Traumauslegung des Artemidor, welches auf der

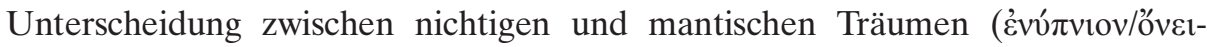
$\rho \circ \varsigma)^{606}$ basiert, wird jetzt eine umfassendere, auf alle Formen der imaginären Erfahrungen bezogene Unterscheidung in „wahr“ und „trügerisch" entgegengestellt.

$601 \mathrm{Zu}$ den Oneirokritika s. S. 101 A. 498 u. 499.

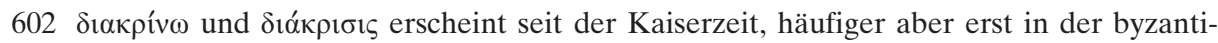
nischen Zeit. Vgl. VinAGRE, Die griechische Terminologie 266.

603 Hier in 316 und 380. Die Verwendung des Wortes in Zusammenhang mit Traumdeutung ist vereinzelt aus der Septuaginta (Gen 40,1.12) bekannt, vgl. VinaGRE, Die griechische Terminologie 266.

604310 [1], 311. Dieser Begriff wird für das Deuten von Träumen schon seit altersher

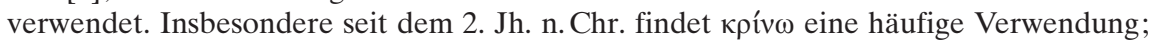
vgl. Vinagre, ebd. $267 \mathrm{f}$.

605 Kpítn deuter" verwendet; vgl. VinaGRe, ebd. 268.

606 S. S. 101 A. 499. 


\subsection{Die Allegorie und ihre Deutung}

\subsubsection{Allegorische Inhalte imaginärer Erfahrungen}

Da aber die geschilderten Bilder der imaginären Erfahrungen nie als ein direktes Schauen, sondern vielmehr als Zeichen des göttlichen Wirkens verstanden werden müssen, kann die neue Art von „,christlicher Imaginationsdeutung“ nicht bei der bloßen Unterscheidung zwischen „wahr“ und „trügerisch“ stehenbleiben. Die Zeichen, die sich in den mannigfaltigen Bildinhalten der „wahren“ Gesichte, der Offenbarungen also, manifestieren, erfordern eine Auslegung, die eine explizit christliche, oft auch einem bestimmten „orthodoxen" Dogma verpflichtete sein soll und in diesem Sinne weitgehend der Tradition der frühen Bibelallegorese folgt ${ }^{607}$. Dabei stellt sich jedoch die Problematik, dass imaginäre Erfahrungen, sofern ihnen eine über die bloße literarische Verwendung hinausgehende Bedeutung beigemessen wird, als reelle Erfahrungen jedes menschlichen Lebens nur sehr bedingt einem bereits bestehenden und mehr oder weniger abgeschlossenen Kanon schriftlich fixierter Allegorien folgen, wie schon Philon von Alexandreia wusste ${ }^{608}$. Die sich daraus ergebende Notwendigkeit von laufend neuen Auslegungen birgt die Gefahr der unorthodoxen oder schlimmer noch, der mantischen Deutung in sich. In den hier behandelten Texten äußert sich dieses Dilemma in dem offensichtlichen Bestreben, einen klar umrissenen Typus von spiritueller Autorität zu entwerfen, der durch die charismatische Auszeichnung legitimiert, alle Arten von imaginären Erfahrungen, also allegorische Visionsinhalte sowohl in Form von ekstatischen Gesichten als auch von Träumen, richtig zu deuten vermag ${ }^{609}$. Auf diese Weise versuchen die Autoren nicht, das unkontrollierbare Moment der imaginären Erfahrungen zu leugnen, sondern vielmehr, dieses in ein kontrollierbares Interpretationsmodell einzubinden. Sie gehen damit einen Schritt weiter als die Evangelien, die den genannten Unsicherheitsfaktor zu weiten Teilen umgehen,

607 Ein Ansatz der allegorischen Auslegung biblischer Motive findet sich bereits in Gal 4,24, wo Paulus über das Bild der beiden Söhne des Abraham sagt, dass es allegorisch zu

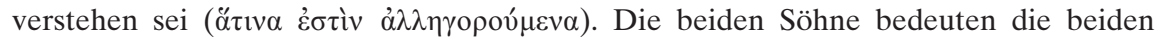
Bücher der Schrift. Vgl. Kablitz, Art. Allegorische Interpretation 9. Besonders beliebt für allegorische Auslegungen war der Traum des Jakob von der Himmelsleiter (Gen 28,10 ff.). Über die Bibelallegorese, insbesondere bei Philon, Augustinus, Josephus und Origenes, aber auch bei weiteren frühchristlichen Autoren s. CAmeron, Christianity 65, A. 65; Miller, Dreams in Late Antiquity 91-105; Clark, ,Spiritual Reading '255-274; NäF, Traum 130 f.; Harmless, Introduction 13.

608 Vgl. Bovon, The Authority of Dreams 152.

609 Von der Art und Weise, wie dies in den Texten geschieht, wird weiter unten noch die Rede sein; s.u. Kap. 4.2.3 u. Kap. 4.3.3. 
indem sie nur Träume mit klaren Weisungen ohne allegorische Bildinhalte ${ }^{610}$ und kaum Offenbarungen mit ekphrastischen Allegorien ${ }^{611}$ wiedergeben ${ }^{612}$. Entgegen dieser Zurückhaltung in den Evangelien setzt sich im frühen Christentum immer mehr der schon in der Johannesapokalypse zum Ausdruck kommende, aber auch für die gesamte spätantike Literatur ausgeprägte und religionsübergreifende Trend zur Allegorese in Bezug auf imaginäre Erfahrungen durch. Vor allem die spätantike Erbauungsliteratur zeichnet sich durch ein ausgesprochenes Flair für die bildhafte Verschlüsselung transzendenter Inhalte und damit auch für die allegorische, nach einer Auslegung verlangenden Imagination, aus ${ }^{613}$. So darf es nicht verwundern, dass die allegorische Erzählung auch den Duktus der hier besprochenen Texte kennzeichnet, wobei sie

610 Vgl. Benz, Die Vision 108-109, sowie Frenschkowski, Traum und Traumdeutung 11. Siehe auch S. 97 A. 472.

611 Ausnahmen: Mt 28,3, wo Maria aus Magdala und Maria am offenen Grab des Herrn ein Engel erscheint, „dessen Aussehen wie der Blitz und dessen Kleid weiß wie Schnee“ war, sowie die Verklärung Jesu in Mk 9,2 ff., bei der Petrus und Jakobus Elia und Mose erscheint. S. Berger, Formengeschichte 221; Historische Psychologie 121, A. 2. Anders als bei den ekphrastisch ausgeschmückten Visionsallegorien der hier behandelten Texten handelt es sich bei den neutestamentlichen Beispielen aber um eher allgemein formulierte Visionsinhalte ohne weitere deskriptive Ausführungen des Geschauten.

612 Der für die Sprache der Evangelien sonst so typische Bilder- und Metaphernreichtum, der vor allem bei den Gleichnissen zum Ausdruck kommt, ist in den Offenbarungserzählungen nur wenig ausgeprägt. In diesem Punkt bewegen sich die Evangelien weitgehend in der Tradition der alttestamentlichen Idee der Inferiorität von Visionen und göttlichen Träumen gegenüber der direkten Offenbarung Gottes; vgl. Timotin, Visions $25 \mathrm{f}$.

613 Diesbezüglich sind neben Erzählungen aus dem Alten Testament, der Johannesoffenbarung, den apokryphen Evangelien und den Petrus- und Paulus- Apokalypsen auch die gnostischen Apostelakten des 2. Jh. sowie die Henochilteratur, der Hirt des Hermas und die frühen Märtyrerakten, insbesondere die Passio Perpetuae von Bedeutung. Leider kann im Rahmen der vorliegenden Arbeit der Herkunft des für die imaginären Erfahrungen in der monast. Literatur verwendeten Bildmaterials nicht im Einzelnen nachgegangen werden. (Als Grundlage für weitere Untersuchungen s. Motivindex). Weiterführende Literatur zur Thematik: Dean-Otting, Heavenly Journeys. S. auch Michaelis, Art. óó́ 352, Kyrtatas,

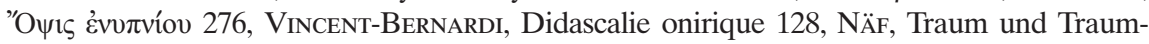
deutung 134-136 (mit aktueller Bibliographie), und TıмотıN, Visions 25 (mit weiterführender Literatur zur frühchristl. Apokalyptik). Zu den Bildinhalten in der Johannesoffenbarung s. Berger, Formengeschichte 221. Speziell über den Hirten des Hermas und die Passio

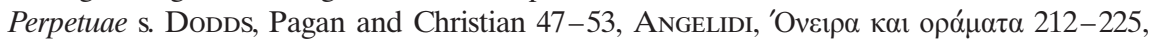
Miller, Dreams 131-183; Bovon, The Authority of Dreams 155-157. Zu den paganen und hellenistischen Einflüssen auf die allegorischen Visionsinhalte in dieser Literatur vgl. BERGER, Visionsberichte 207-209; über Träume in den hellenistischen Romanen vgl. WeIN-

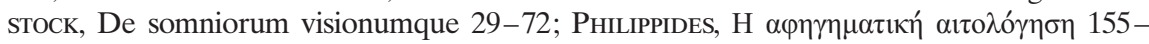
176; Mac Alister, Dreams and Suicides 1-18. Zum Traum in den apokryphen Apostelakten vgl. SöDER, Die apokryphen Apostelgeschichten 171-180. Zur Allegorie als Charakteristikum der spätantiken Rhetorik s. CAMERON, Christianity 64-68. Siehe auch S. 78 A. 356. 
gerade im Zusammenhang mit imaginären Erfahrungen, in einem mehr oder weniger klar umrissenen System christlicher Motivik und Auslegung eingesetzt wird. Allegorien mit profanem Inhalt etwa aus den Traumbüchern des Artemidor sind also kaum zu erwarten, während Motive aus dem Bilderreichtum des christlichen Heilsgeschehens zahlreich sind. Dennoch werden die bekannten Motive zuweilen mit überraschender schöpferischer Freiheit zu neuen Bildkompositionen verarbeitet, und nicht selten kommen auch Bilder allgemein ethischen Charakters zum Einsatz, die zwar nicht aus einem spezifisch christlichen Motivfundus stammen, jedoch problemlos christlich gedeutet werden können.

Bezeichnenderweise haben ausgerechnet die Vätersprüche, welchen anderswo im Vergleich zur „Hagiographie“ eine dezidiert „bilderfeindliche Haltung“" nachgesagt wurde ${ }^{614}$, besonders bunte Allegorien zu bieten. Als Beispiel sei hier der Spruch über Arsenios angeführt, der in der Zelle saß und eine Stimme vernahm, die ihn aufforderte mitzukommen, um sich die Werke der Menschen zeigen zu lassen. „Er stand auf und ging hinaus. Der andere [unklar wer] führte ihn zu einem Ort und zeigte ihm einen Äthiopier, der Holz hackte und eine große Trage herstellte. Dann versuchte er sie hochzuheben, was ihm aber nicht gelang. Anstatt Holz von der Bahre herunterzunehmen, hackte er neue Stücke und legte sie auf die Trage. Dies tat er während langer Zeit. Dann wurde ihm ein Mensch gezeigt, der bei einer Grube stand und Wasser daraus schöpfte. Er schüttete es in ein Wassergefäß um, welches durchlöchert war und das Wasser zurück in die Grube fließen ließ. Die Stimme sagte jetzt: ,Komm, ich werde dir etwas anderes zeigen'. Jetzt sah er einen Tempel und zwei Männer, die auf Pferden saßen und seitlich Holz schleppten, einer neben dem anderen. Sie wollten durch das Tor in den Tempel eintreten, was ihnen aber nicht gelang, da das Holz auf der Seite herausragte. Keiner von den beiden erniedrigte sich, das Holz hinter dem anderen hineinzutragen. Deshalb blieben sie außerhalb des Tores stehen. ,So sind die', sagte die Stimme, ,die das Joch der Gerechtigkeit mit Überheblichkeit tragen und sich nicht dazu erniedrigen, sich selber zu korrigieren und den demütigen Weg Christi zu gehen. Deshalb bleiben sie außerhalb des Königreiches Gottes. Der Mann aber, der Holz hackt, befindet sich in vielen Sünden. Anstatt zu bereuen, fügt er noch weitere Gesetzlosigkeiten auf seinen Sündenberg. Und der Wasser schöpfende Mann tut gute Werke. Weil er aber Übel in sie hineingemischt hat, zerstört er dabei auch seine guten Werke. Es ist notwendig, dass jeder Mensch nüchtern bleibt bei dem, was er wirkt, damit er sich nicht umsonst anstrengt" sagte die Stimme“"615.

614 Vgl. Dagron, Rêver 47. Ähnlich werden die Vätersprüche auch bei Vincent-Bernardi, Didascalie onirique 130, beurteilt.

615 373. Ähnlich auch Bsp. 397. 
Zweifellos erinnert der narrative Aufbau, vor allem aber die Deutung des Gesichts, an die neutestamentlichen Parabeln, speziell an das Sämannsgleichnis (Mt 13,1-20) ${ }^{616}$. Auch wenn die Herkunft der hier verwendeten Allegorien nicht geklärt werden konnte, ist anzunehmen, dass sie zu einem größeren Fundus von Gleichnissen und Metaphern gehören, welche zur Entstehungszeit der Texte im gesamten östlichen Mittelmeerraum kursierten. Zu diesem Fundus gehören neben den neutestamentlichen Gleichnissen unter anderem auch jene Parabeln, die später (ca. 10./11. Jh.) durch erbauliche Geschichten wie die erbauliche Geschichte Barlaam und Ioasaph oder der Liber Syntipas in die westliche mittelalterliche Literatur gewandert $\operatorname{sind}^{617}$. Das Eigentümliche am oben zitierten Gleichnis aus den Apophthegmata Patrum ist seine narrative Einbettung in den Rahmen einer Vision. Dies bringt den Effekt mit sich, dass die Aufgabe der Belehrung, welche sonst einer spirituellen Lehrperson, z.B. Jesus oder Barlaam zufällt, hier eine numinose Stimme übernimmt. Die Auslegung findet also noch während der imaginären Erfahrung statt, und vom Akt der Deutung durch einen Charismatiker, etwa durch einen anderen Wüstenvater, ist nicht die Rede. Wie aus dem Kontext der Apophthgemensammlung hervorgeht, wird Arsenios, der Empfänger der Offenbarung, selbst als Charismatiker „höchsten Grades“ dargestellt ${ }^{618}$, was unter anderem durch sein würdevolles Äußeres zum Ausdruck kommt ${ }^{619}$. Sein Ansehen ist so groß, dass ihm Kaiser Theodosios sogar die Erziehung seiner Söhne Arkadios und Honorios anvertraut ${ }^{620}$. Aufgrund seiner fortgeschrittenen spirituellen Autorität wird ihm auch zugesprochen, die Deutung seiner Schau direkt von Gott zu empfangen, eine Lehrperson zur Auslegung benötigt er nicht.

Ob die Bildinhalte nun wie bei Arsenios noch während der imaginären Erfahrung von einer Stimme ${ }^{621}$, einem angelus interpres ${ }^{622}$, vom Heiligen Geist ${ }^{623}$

616 Auf die Ähnlichkeit von Gleichnissen und Visionserzählungen als gleichermaßen auszulegende bildhafte Rede verweist auch BERGER, Historische Psychologie 121.

$617 \mathrm{Zu}$ den wissenschaftlichen Positionen bzgl. Provenienz und Datierung sowie zur überaus komplexen handschriftlichen Überlieferung des griechischen Barlaam, mit einer umfassenden Bibliographie zu allen Teilbereichen des Werkes, s. VolK, Die Schriften XVIII-XLI. 1-140. 240-581. Zu den Parabeln des Barlaam vgl. Bolton, Parable 6477. Lienhard, Textumformungen 499-507. Zum Liber Syntipas: Jernstedt (Ed.); zur Überlieferungsgeschichte des Liber Syntipas vgl. Maltese, Il Libro di Sindbad 7-26.

618 S. auch 13, 130, 197. Über Arsenios vgl. Guy (ed.), Les apophthegmes I 74-7.

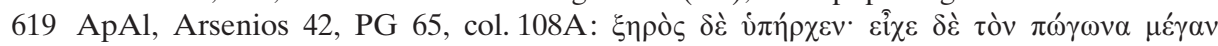

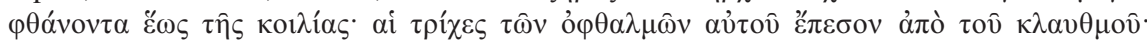

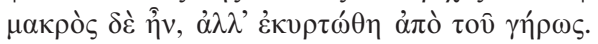

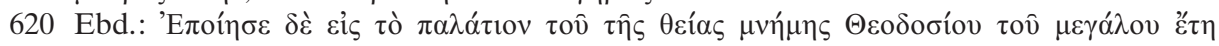

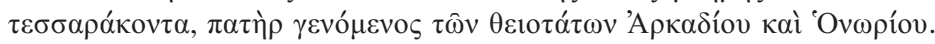

$621207,241,258,372,373$.

622 156, 169. „Der Erscheinende erhält einen „Führer“ oder Interpreten (angelus interpres), der ihm erklärt, was er sieht. ... entscheidend ist, dass ... die Offenbarung nicht 
oder von einem Heiligen ${ }^{624}$ ausgelegt werden, oder ob dem Charismatiker, wie in den Beispielen von Pachomios, die Bedeutung der Offenbarung erst nach einem Abwägen des Geschauten klar wird ${ }^{625}$, so steht auf jeden Fall fest, dass das Verstehen der Bilder als von Gott gesandtes charisma direkt auf den Visionär kommt. Im berühmten Gesicht des Antonios mit dem bis zu den Wolken reichenden Riesen, welcher nach den in die Höhe schwebenden geflügelten Wesen greift, um sie in die Tiefe zu stürzen, wird der Moment, in dem Gott die Gnade des Verstehens auf Antonios herabsendet, folgendermaßen formuliert: „und auf einmal kam eine Stimme zu Antonios, die sagte, er solle verstehen, was er sehe (Dan 9,25). Dann wurde sein Geist geöffnet (Lk 24,31), und er verstand, dass dies der Übergang der Seelen war und dass der Riese der Feind war, der die Frommen beneidet und seine Günstlinge am Vorbeigehen hindert, der aber jene, welche sich von ihm nicht haben überzeugen lassen, nicht zurückhalten kann“626. Ähnliches gilt für die Berufungsoffenbarung des Pachomios, der in der Nacht nach seiner Taufe sich selbst sah, wie er durch Tau aus dem Himmel befeuchtet wurde. Die Tropfen sammelten sich auf seiner rechten Hand und verwandelten sich gleichsam in festen Honig. Dann fiel der Honig zu Boden, und Pachomios hörte jemanden, der zu ihm sagte: „Das, was geschehen ist, sollst du verstehen, danach ist es deines“627.

\subsubsection{Literarische Aspekte der Allegorie}

Zweifellos sollte bei den zitierten Beispielen der literarische, teilweise topische Charakter, überhaupt der hohe Unterhaltungswert allegorischer Erzählungen, im Auge behalten werden. Insbesondere bei den allegorischen Berufungsoffenbarungen (wie in der Vita Pachomii) ${ }^{628}$ und bei den Inspirationsvisionen zur Legitimierung des Verfassens eines Werkes tritt dieser Aspekt deutlicher als bei anderen Typen imaginärer Erfahrungen zutage, da es sich zumeist um impli-

auf zwei Schultern ruht, dem Träumer und dem Ausleger, dem Visionär und dem irdischen Interpreten, sondern dass der eine Visionär die Deutung seiner Vision gleich selbst mitgeliefert bekommt. Er allein ist damit die zugleich die Offenbarung empfangende wie sie auslegende Autorität": BERGER, Visionsberichte 220.

623171.

624415.

625 Wie in 458 (zu diesem Bsp. siehe auch S. 117 A. 575) auch in 365 [ViPa 12]: Kaì $\tau \alpha \hat{\tau} \tau \alpha$

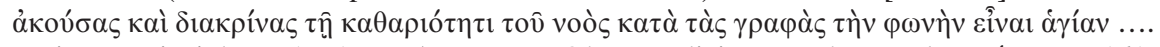

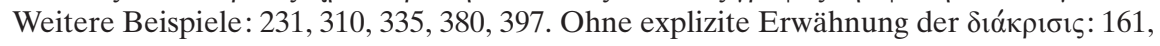
$164,184,425$.

626241.

627163.

628163 (s.o. A. 627). S. auch die anderen Beispiele in II E. 
kative Allegorien handelt ${ }^{629}$, d.h., die Bedeutung der geschauten Allegorie wird nicht weiter erklärt, weil sie sich dem Rezipienten von selbst erschlossen haben muss. So soll der wegen seinem schriftstellerischen Unvermögen verzweifelte Kyrillos von Skythopolis vom heiligen Vater Euthymios „die Gnade des angemessenen Ausdrucks" empfangen haben, als ihm dieser erschien, aus seiner Brust ein Alabastergefäß aus Silber und eine Sonde zog, die er in das Gefäß eintauchte, und Kyrillos damit dreimal den Mund befeuchtete. „Die Flüssigkeit sah aus wie Öl, und ihr Geschmack war süßer als Honig und wahrlich eine Offenbarung der göttlichen Worte,Wie süß ist deine Rede meinem Gaumen, süßer als Honig meinem Munde' (Ps 118, 103), sodass er, nachdem er durch diese unaussprechliche Süßigkeit aufgewacht war, noch immer jenen Wohlgeschmack auf Lippen und Mund fühlte“630. Auch über Ephraim den Syrer sind Inspirationsvisionen überliefert. So heißt es in einem Väterspruch, dass Ephraim, ,als er noch ein Kind war, im Traum oder in einer Vision aus seiner Zunge einen Weinstock empor sprießen sah, der wuchs und alles erfüllte, was unter dem Himmel existierte. Da kamen alle Vögel des Himmels und aßen von den Beeren des Weinstocks, wobei sich die Frucht, die sie wegpickten, vervielfachte “631. In einem anderen Väterspruch ist die Rede von einem Heiligen, der eine Truppe von Engeln vom Himmel herunterkommen sah, die auf den Befehl Gottes in den Händen eine Schriftrolle hielten und sich gegenseitig fragten, welchen Sinn es habe, dies zu überliefern. „Und die einen sagten dies und die anderen jenes, und auf die Frage antworteten sie: ,Wahrlich sind alle heilig und gerecht. Und trotzdem kann diese Aufgabe niemand übernehmen außer Ephraim'. Und der Heilige sah, dass sie die Rolle Ephraim übergaben. Und als der Heilige am Morgen aufstand, hörte er, wie Ephraim sein Werk verfasste, indem aus seinem Mund gleichsam eine Quelle hervorsprudelte, und er erkannte, dass die Worte, die durch die Lippen des Ephraim flossen, vom heiligen Geist kamen “632. Allem Anschein nach konnten hier die Autoren davon ausgehen, dass der Rezipient die verwendeten Bilder auch ohne Erklärung richtig zu deuten wusste. Die verwendeten Allegorien mussten nicht nur aufgrund der damals bereits bestehenden Berühmtheit des Ephraim ${ }^{633}$ verstanden worden sein, sondern auch deshalb, weil die schon in der paganen Literatur verbreiteten allegorischen Inspirationsoffenbarungen auch in verschiedenen Gattungen der zeitgenössischen Literatur nach wie vor überaus geläufig und

629 Vgl. PeIL, Art. Allegorie 8.

630179.

631154.

632155.

633 Vgl. Baldwin, Art. Ephrem the Syrian $708 \mathrm{f}$. 
beliebt waren ${ }^{634}$. Gerade die „Weinstock-Allegorie“ ist in der antiken und in der byzantinischen Literatur mehrfach belegt ${ }^{635}$.

Manchmal wendet sich der Autor mit der Deutung einer Allegorie auch direkt an den Leser, ohne weiter darauf einzugehen, ob und wann der Empfänger der imaginären Erfahrung das von ihm Geschaute verstanden hat. So wird in den Apophthegmata Patrum von einem Greis berichtet, dass er in einer Ekstase sah, wie drei Mönche am Meeresufer standen. Von der anderen Seite des Ufers kam eine Stimme, die ihnen zurief: „Nehmt Flügel aus Feuer und macht euch auf zu mir“. Zwei der Mönche taten dies und machten sich daran, auf die andere Seite zu gelangen. Der dritte aber blieb, weinte heftig und schrie. Später gab man auch ihm Flügel, jedoch nicht aus Feuer, sondern schwache und kraftlose. Unter großen Schmerzen wurde er niedergeworfen und stand wieder auf, und nur mit großem Kummer kam er auf der anderen Seite an. Die abschließende Bemerkung des Autors lautet schlicht „,so ist es mit diesem Geschlecht. Wenn es auch Flügel zu Hilfe nimmt, so nicht aus Feuer, sondern kranke und schwache“"636. Ähnliches gilt für ein Beispiel aus der Vita des Symeon Salos, wo ein Vornehmer aus Emessa im Schlaf sich selbst mit einem Äthiopier Tavli spielen sieht, was mit dem einfachen Satz kommentiert wird „Dieser war aber der Tod“637. Ebenso knapp fällt die Kommentierung eines Bildes in der Schau des Mönchs Sabinos aus, welcher sah, wie Ioannes Eleemon

634 Weitere Beispiele aus der hagiographischen Literatur vgl. Festugière, Lieux communs 126-129 und Pratsch, Der hagiographische Topos 53-55. Zum paganen Bereich mit Beispielen und weiterführender Bibliographie vgl. DodDs, The Greeks and the Irrational 71; Beispiele aus der Historiographie vgl. Weber, Kaiser, Träume $30 \mathrm{f}$.

635 In Gregor von Nyssas Schrift In Ephraim (PG 46, col. 824A) sowie in einer darauf zurückgehenden anonymen Vita des Ephraim (BHG, $\mathrm{n}^{\circ}$ 584) kommt die gleiche Allegorie in leicht abgeänderter Form vor; hier sind es die Eltern, die das Bild des aus dem Mund des Ephraim wachsenden Weinstocks in einem Traum erblicken, vgl. LANZONI, Il sogno presago 243; Maraval (Hg.), Grégoire de Nysse, Vie de Sainte Macrince 146, A. 1. Das gleiche Motiv kommt später bei Theophanes Continuatus V 8, p. 222,2-9, hier als Anspielung auf Herodot I 108,1-10, p. 132,9-18, vor, wo der Mutter des Basileios „,scheint, als sähe sie im Traum einen großen Baum aus ihr emporwachsen - wie die Mutter des Kyros einst einen Weinstock sah - und auf ihrem Haus in Blütenpracht und schwer von Früchten behangen stehen. Golden war sein großer Stamm vom Boden weg, auch Zweige und Blätter schienen aus Gold. Als sie dies einem Verwandten, der in solchen Dingen das Richtige zu treffen scheint, erzählte, musste sie hören, dies bedeute, dass ihrem Sohn ein herrliches und großes Schicksal bestimmt sei“.

636374.

637 423. Diese Deutung des Äthiopiers als Tod ist in den behandelten Texten einmalig. An allen anderen Stellen wird er als Bild für den Teufel oder für Dämonen verwendet; s. S. 116 A. 567; Die Ähnlichkeit der personifizierten Vorstellung von Teufel und Tod ist jedoch naheliegend und tritt besonders deutlich in der ikonographischen Tradition zutage, wo der Tod zuweilen als schwarzer Dämon dargestellt wird; vgl. Stichel, Studien zum Verhältnis von Text und Bild 31-33. 
das Bischofsgebäude verließ, „,was das Hinscheiden aus seinem eigenen Körper bedeutete“638.

\subsubsection{Das richtige Deuten der Allegorie als Zeichen charismatischer Autorität}

Trotz der mehr oder weniger starken literarischen Stilisierung der geschilderten Allegorien, zeigen die behandelten Texte, dass es den Autoren ein Anliegen war, ein ganz bestimmtes Bild von charismatischer Autorität zu vermitteln. Diese Autorität sollte nicht nur als literarische Heldengestalt faszinieren, sondern auch Funktionen einer gesellschaftlich geforderten Idealfigur übernehmen. $\mathrm{Zu}$ den unabdingbaren Kompetenzen, die der Charismatiker zu erfüllen hatte, gehören neben der Unterscheidung imaginärer Erfahrungen in „wahre“ und „trügerische“ auch das Verstehen allegorischer Äußerungen des göttlichen Waltens. Während dem „normal Sterblichen“ der Zugang zum Numinosen verwehrt bleibt, ist dem Charismatiker der Schlüssel zum Verständnis der Zeichen Gottes durch seine pneumatische Begnadung gegeben. Besonders anschaulich kommt dies in einem Beispiel aus der Vita der heiligen Martha zum Ausdruck, wo der Empfänger der imaginären Erfahrung das von ihm Geschaute zunächst falsch versteht. Erst die Deutung des Symeon Stylites des Jüngeren kann das Missverständnis klären. So wird erzählt, dass „der Mönch Antonios von einem Engel des Herrn aufgefordert wurde, schnell loszugehen, einen Weinstock aus dem Garten der heiligen Anastasis zu holen und damit zu Symeon Stylites zu gehen. ... Da Antonios glaubte, dass die Worte über die Rebe wirklich so gemeint waren, zögerte er nicht länger, sondern machte sich unverzüglich mit einem Weinstock aus dem Garten der heiligen Anastasis auf den Weg zu Symeon. ... Antonios aber zeigte Symeon seinen Weinstock und erzählte, was ihm in der Vision erschienen war. ... In einer der darauffolgenden Nächte erschien ihm Martha und forderte ihn auf, sofort loszureisen, um den Segen zu vollbringen. ... Als Antonios dies Symeon erzählte und die Zeichen der Erscheinung schilderte, wurde er vom heiligen Mann auf der Stelle mit einem Brief nach Jerusalem zum Staurophylax geschickt. ... Antonios kam zur heiligen Anastasis in Jerusalem und übergab dem Staurophylax den Brief des Symeon mit dem Auftrag zur Herstellung einer Kreuzesreliquie. Sofort wurde ein goldenes Kreuz hergestellt, in das ein Stück des echten Kreuzes eingefügt wurde. Dann wurde es in einen Behälter gelegt und von Antonios zusammen mit einem Schreiben zum heiligen Symeon gebracht ${ }^{\star 639}$. Obwohl in diesem

638 222. Hier wird die Allegorie nur für den Leser schon während des Erzählens der Schau gedeutet. Sabinos hingegen versteht den Sinn erst, als er erfährt, dass zum Zeitpunkt seiner Schau Ioannes gestorben ist.

639338. 
Beispiel die Deutung der Allegorie von Symeon nicht direkt ausgesprochen wird, geht aus dem Verlauf der Erzählung unmissverständlich hervor, dass mit dem Weinstock, wohl in Anspielung auf Joh 15, $1^{640}$, Jesus gemeint ist, welcher in der zitierten Passage durch das Kreuz symbolisiert wird. Die Fähigkeit und die Kompetenz, Antonios' Gesicht zu deuten, wird alleine dem Charismatiker Symeon zugesprochen.

Wie bei den meisten Beispielen von allegorischen imaginären Erfahrungen der Typen Befehle, Reiseanordnungen usw. [Teil II, N-P], handelt es sich auch hier um eine „Weisungsallegorie“. Der Bildinhalt übernimmt dabei die Funktion, dem Empfänger der imaginären Erfahrung einen göttlichen Auftrag ,vor Augen zu führen“, der in seinem Leben eine schicksalhafte Wende, zum Beispiel die Umkehr hin zu einem christlichen Leben, bewirkt. Beliebt ist auch das narrative Schema, dass der Empfänger der Offenbarung das von ihm Geschaute zunächst nicht versteht und sich ihm erst durch die darauf folgenden Ereignisse erschließt, dass die Allegorie eine Art Gleichnis für ein Geschehen ist, das sich gleichzeitig mit der Schau an einem anderen Ort abgespielt hat. So verstand auch Ioulianos, ein Schüler des Theodoros von Sykeon, ein allegorisches Traumgesicht erst, als er von der Heilung eines durch dämonische Kräfte an den inneren Organen erkrankten Silentiarios durch Theodoros erfuhr: In der Nacht der Heilung hatte er gesehen, wie Theodoros am Meeresufer stand, als der Silentiarios an diesen herantrat und in seinen Armen ein großes, dreiköpfiges, fürchterlich brüllendes Wildschwein hielt. Als der Heilige das Tier ergriff, verwandelte es sich zu einer kleinen Katze, die er in die Meeresbrandung warf ${ }^{641}$.

\subsection{Die Schau in die Zukunft durch die Prophetengabe}

4.3.1 Das Vorgehen des christlichen Charismatikers gegen mantische Praktiken, Zauberer und Magier

In allen bisher besprochenen Beispielen ist der für die heidnische Traumdeutung wesentliche, nämlich der in die Zukunft deutende Aspekt der allegorischen Auslegung noch nicht gegeben. Zu einer echten Konkurrenz zum Mantiker wird der christliche Charismatiker jedoch erst dadurch, dass ihm neben der Fähigkeit der Unterscheidung und der allegorischen Deutung auch die Prophetie, eben-

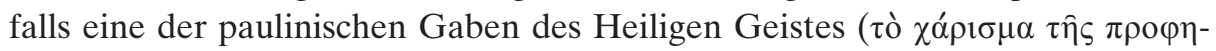
$\left.\tau \varepsilon^{\prime} \alpha \varsigma\right)^{642}$, zugesprochen wird. Erwartungsgemäß sind es wiederum die ,großen heiligen Männer“, z.B. Antonios, Hypatios, Euthymios, Symeon Stylites der

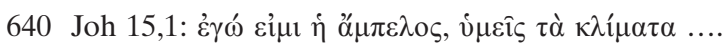

641 286. Weitere ähnliche Beispiele: 379, 385, 391, 389.

642 S. S. 117 A. 570. 
Jüngere, Daniel Stylites, aber auch andere, etwa die Jungfrau Piamun, der Wüstenvater Zenon oder Ioannes von Lykopolis, die sich aufgrund herausragender asketischer Verdienste durch die Gabe der Prophezeiung auszeichnen ${ }^{643}$. Als Erben der alttestamentlichen Propheten besitzen auch sie die Fähigkeit, in die Zukunft weisende Zeichen zu deuten, von denen in den behandelten Texten die Inhalte imaginärer Erfahrungen nur eine, wenn auch die weitaus üblichste Form ist ${ }^{644}$.

In Anlehnung an die alttestamentliche Opposition zwischen dem „vom Geist Gottes erfüllten" und deshalb einzig kompetenten Traumdeuter Joseph und den ägyptischen Magiern des Pharaos (Gen 41,38) lassen sich die christlichen Prophetenheiligen bestens für das Vorgehen gegen die heidnischen Divinationspraktiken instrumentalisieren ${ }^{645}$. Dabei maßregeln die heiligen Männer nicht nur konkret fassbare Berufsgruppen wie Magier, Zauberer und dergleichen, sondern auch einen breiteren, gesichtslosen Rezipientenkreis, eine Art „Volksseele“, die wohl der eigentliche „Träger“ divinatorischer Praktiken gewesen ist. So belehrt die Vita Antonii den Leser darüber, dass das Voraussehen zukünftiger Ereignisse nicht in seinen Kompetenzbereich fällt, durch die rhetorische Frage „Was für einen Nutzen bringt es denen, die im Voraus hören, was sich Tage später ereignen wird? Warum danach trachten, solche Dinge zu wissen, auch wenn die Kenntnis [dieser Dinge] richtig ist? Weder führt dies zu Tugend, noch ist es das Kennzeichen eines guten Charakters. Denn keiner von uns wird verurteilt, etwas nicht gewusst zu haben, und keiner wird als selig erklärt, dass er es erfahren hat und wusste. Vielmehr wird jeder darin beurteilt, ob er den Glauben bewahrt (II Tim 4,7) und die Gebote treu gehütet hat (I Tim 6,14)“646.

Dass alles darauf hindeutet, dass die sich bewahrheitende Zukunftsschau im Wirkungskreis der Texte als ernst zu nehmendes Phänomen betrachtet wurde, zeigt neben der zitierten Stelle und einem bereits erwähnten Apophthegma ${ }^{647}$ auch ein weiteres Beispiel der Vita Antonii, wo der Blick in die Zukunft mit dem Eingreifen von Dämonen erklärt wird. Diese haben durch ihre ätherische Be-

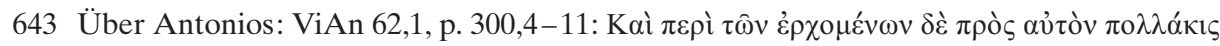

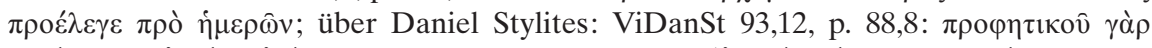

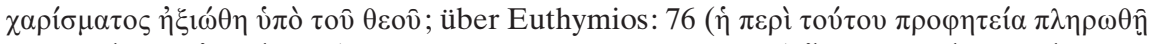

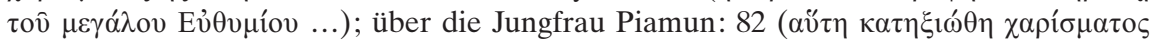

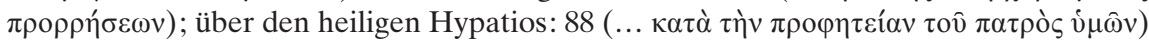

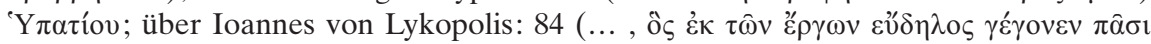

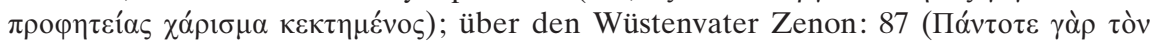

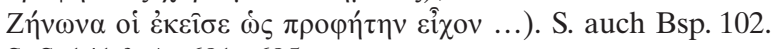

644 S. S. 141 f. A. 691-695.

645 Weitere Vorläufer aus dem Alten Testament: Deut 3,1-6; 2. Chron 33,6; Jer 14,14; $23,25-32 ; 29,8-9$.

64669 (2).

64760 (S. S. 106 A. 535). 
schaffenheit ${ }^{648}$ die Fähigkeit, bereits stattgefundenen Ereignissen ,vorauszueilen“, so wie der Reiter dem Fußgänger vorauseilt, um sie Menschen mitzuteilen, die vorher noch nichts davon wussten. Wenn sich das Ereignis kurz darauf als tatsächlich geschehen herausstellt, so hält der Getäuschte die dämonische Ankündigung für einen Blick in die Zukunft ${ }^{649}$. Vor der listigen Art der Dämonen, den normalen Menschen vorzutäuschen, sie besäßen die Prophetengabe, warnt auch die Scala Paradisi: „Die Dämonen der Eitelkeit werden uns im Schlaf zu Propheten. Mit ihrer Verschlagenheit schlussfolgern sie zukünftige Geschehnisse und verkünden sie uns daraufhin. Trifft das Geschaute ein, so werden wir von Erstaunen erfüllt und unsere Gedanken erheben sich, als ob die Gabe der Vorhersehung sich in unserer Reichweite befände. Denen, die sich von diesem Dämon überzeugen lassen, wurde er oft zum Propheten, allen aber, die ihn verachten, stellte er sich als Lügner heraus. Weil er ein pneumatisches Wesen ist, sieht er, was sich ringsum im Luftraum ereignet. Begreift er zum Beispiel, dass jemand im Sterben liegt, sagt er es den Leichtgläubigen im Traum voraus “650. Eine abweichende, aber letztendlich das gleiche Ziel verfolgende Erklärung für das Zustandekommen der dämonischen „Scheinprophezeiungen“ ist in den Paralipomena Pachomio et Theodoro zu finden. Nachdem Pachomios „die Tochter des Teufels und Anführerin der ganzen dämonischen Phalanx “651 der Lüge überführt hat, „da nur Gott in die Zukunft blicken kann“652, gibt die Dämonin selber zu, dass sie ,über die Vorhersage nichts weiß, da nur Gott fähig sei, zukünftige Dinge vorauszusagen. Sie kenne sich besser mit Spekulationen aus, indem sie aus den bereits vorhergesagten Dingen das noch nicht Geschehene errate.“653 Mit den „bereits vorhergesagten Dingen“ sind hier die im göttlichen Heilsplan festgesetzten Ereignisse gemeint, über die der Teufel Bescheid weiß, da er ,von Gott selber vor langer Zeit die Kraft erhalten hat, wen auch immer er will, zu versuchen"654 und selbst seit jeher ein Teil des göttlichen Heilsplans ist (Gen 3,14).

Ob sich der Rezipient monastischer Texte durch derartige Ermahnungen auch tatsächlich vom allzu menschlichen Bedürfnis nach dem Blick in die Zu-

648 S. S. 114 A. 554.

64969 (1).

650101.

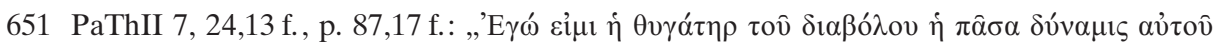

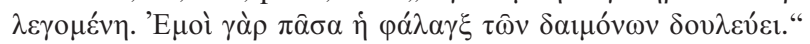

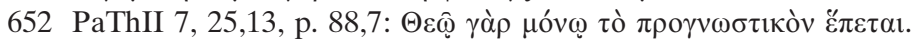

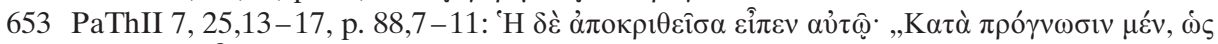

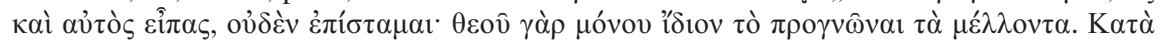

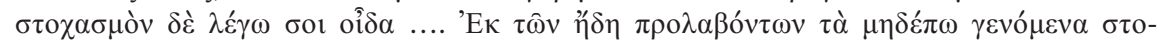

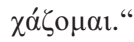

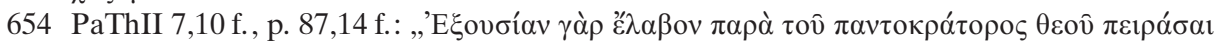

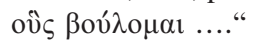


kunft abhalten ließ, wird gerade durch jene Stellen in Zweifel gezogen, wo die Autoren ganz konkret berichten, welche Arten von mantischen Praktiken in der Bevölkerung beliebt waren. In der Vita Porphyrii heißt es, dass die Bevölkerung von Gaza der Statue der Aphrodite opferte, da man glaubte, dass die Göttin den Heiratswilligen im Traum günstige Dinge voraussage ${ }^{655}$. Vom heiligen Hypatios wird erzählt, dass er eines Tages einen Mann zu sich kommen ließ, von dem er gehört hatte, dass er divinatorisch tätig war, und sagte zu ihm: „Ich habe von dir gehört, dass du die Zukunft voraussagst, und wenn jemand etwas verloren hat, sagst du ihm, wer es gestohlen hat. Ich bitte dich, sag auch mir, wie du das machst, damit auch ich erfahre, ob ich dich zu recht ehren soll“. Da fing der andere mit Begeisterung an zu erzählen: „Wenn mir jemand über irgend eine Angelegenheit berichtet, wird es mir sogleich in der Nacht offenbart, und ich erzähle es ihnen, damit sie in den Tempel opfern gehen. Und so sage ich es jedes Mal, wenn der Engel mir etwas offenbart". Als Hypatios erfahren hatte, auf welche Weise durch den Mann Dämonen in die Menschen kommen, ließ er ihn fesseln und einsperren ${ }^{656}$.

Wie auch immer das Verhältnis der „Volksseele“ zur Wahrsagerei in Wirklichkeit ausgesehen hat, so steht zumindest fest, dass in der monastischen Literatur einzig und alleine der heiligen Autorität die Kompetenz zugebilligt wird, die Zukunft vorauszusehen. Wer es dennoch wagt, Träume nach eigenem Wissen und Gewissen im Hinblick auf die Zukunft zu interpretieren oder sich durch irgendwelche anderen divinatorischen Praktiken in den alleine vom göttlichen Walten abhängigen Bereich des menschlichen Schicksals einzumischen, macht sich schnell als Magier oder Zauberer verdächtig. In den Fußstapfen des biblischen Prototypen Simon Magus (Apg 8,9-24) und bald auch des „Heidenhelden“ Apollonios von Tyana ${ }^{657}$ übernimmt er die Funktion des Antichristen, welcher den dunklen Mächten dient und damit das Christentum bekämpft.

Dass das Auftreten von Magiern und Zauberern keineswegs als rein literarisches Phänomen zu verstehen ist, geht neben den einschlägigen Gesetzestexten, die alle Arten der Zukunftsschau als magische Praktiken verbieten und im Laufe der frühbyzantinischen Zeit kontinuierlich erneuert und verschärft werden $^{658}$, auch aus historiographischen Quellen ${ }^{659}$ und aus den monastischen Texten selbst hervor. Wiederholt ist davon die Rede, dass sich Kranke zunächst für teures Geld vergeblich von Zauberern und Magiern behandeln lassen, bevor

65541.

656453.

657 Vgl. Speyer, Zum Bild des Apollonios von Tyana; Anderson, Sage, Saint and Sophist 6; FöGEN, Die Enteignung der Wahrsager 185-187; Pratsch, Der hagiographische Topos 171.

658 S. S. 121 A. $598-600$.

659 Dazu ReInsch, Autor und Leser 405. 
sie sich an die einzig kompetenten Heiligen wenden ${ }^{660}$. So begab sich der gelähmte Terebon, der Sohn des heidnischen Aspebetos, Verbündeter des persischen Herrschers Isdigerd, nachdem er durch ein Traumgesicht dazu aufgefordert worden war, zum Kloster des Euthymios. Bevor dieser ihn heilte, berichtete Terebon: „Vor einiger Zeit kam in Persien dieses Leid über mich, und ich habe jedes ärztliche Wissen und jede magische List durchschritten. Doch nichts hat mir geholfen, vielmehr ist mein Leid noch grösser geworden. Eines Nachts habe ich mich gefragt, wo die ganze ärztliche Kunst bleibe, wo die Phantasien der Magier und die Anrufungen und Märchenerzählungen der Astronomen und Astrologen, wo die Sänger und die geschwätzigen Zauberer. Denn nichts von all diesen Dingen besitzt Macht, wenn es nicht von Gott gutgeheißen wird“661. In der syrischen Vita des Symeon Stylites wird über einen heidnischen Verwalter in Palästina berichtet: „Sein Kopf war gebeugt, und sein Nacken lag an seiner Brust, und er konnte seinen Kopf nicht heben. Er kam aber zu dem Manne Gottes, indem ihn zwei Leute auf einem Stuhl transportierten, trug ihm die Bitte vor, er möchte für ihn Gott um Barmherzigkeit bitten, und teilte ihm mit, zahlreiche Ärzte hätten ihn behandelt und viele Kosten hätte er gehabt wegen seiner Krankheit bei den Zauberern und Magiern, aber er hätte keinen Nutzen gehabt in seinem Missgeschick“662. Anderswo wird berichtet, dass Zauberer von missgünstigen Menschen dafür bezahlt werden, andere unter Anwendung magischer Praktiken mit Krankheiten oder gar mit dem Tod zu schlagen. Kyrillos von Skythopolis erzählt, dass ein Mann von einer teuflischen Eifersucht auf einen gewissen Romanos besessen war, welcher in einem Dorf in der Nähe von Gaza lebte. Da er aber in seinem Verlangen, Romanos die Güter wegzunehmen, erfolglos war, machte er sich, rasend vor Zorn, nach Eleutheropolis auf, ,wo er sich mit der Bitte an einen Zauberer wandte, Romanos in den Tod zu treiben. Der Zauberer setzte, nachdem er sich eine beträchtliche Summe hat bezahlen lassen, seine satanischen Zaubersprüche ein“. Tatsächlich wurde Romanos von einer Krankheit ergriffen, die ihn an den Rand des Todes brachte. Erst als er im Gebet Euthymios anflehte, er möge Gott für ihn bitten, ihn von seiner schrecklichen Krankheit zu befreien, geriet er in Ekstase und sah Euthymios, der in einer imaginären Operation ein Zinnplättchen mit eingeritzten Zeichen $^{663}$ aus seinem Bauch herausholte ${ }^{664}$.

660 S. S. 30 A. 110.

661261.

662 Übers. Lietzmann, Syrische Lebensbeschreibung des Heiligen Symeon 112, 64.

663 Wahrscheinlich handelt es sich um ein defixio, ein sogenanntes „Fluchtäfelchen“; vgl. Luck, Magie 4. 65-67. Festugière, Les moines d‘ orient III/1, 134, A. 182, bemerkt, dass man Romanos zweifellos, während er sich in einem künstlichen Schlaf befand, dazu gebracht hatte, ein defixio zu schlucken, welches in ein mit magischen Buchstaben ('̌ $\chi 0 v$

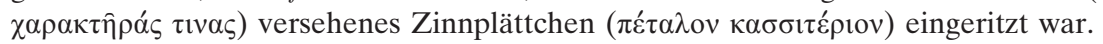

664264. 
Immer wieder wird das imaginäre oder direkte Eingreifen und Vorgehen gegen Magier und Zauberer als zentrale Aufgabe des christlichen Charismatikers geschildert. Auch Symeon Stylites überführt Divinatoren der falschen Prophetie. Nach einem Erdbeben in Antiochien ,sagten einige von den Heiden und von den mit der Astrologie Vertrauten“, dass die ganze Stadt zerstört werde. Symeon hingegen sagte zu den Frommen, die bei ihm Zuflucht gesucht hatten, sie sollen mutig sein und sich nicht fürchten. „Der Irrtum jener Berechnenden, welche durch die Divination der Ereignisse vorgeben, den Willen Gottes zu kennen, wird ein Ende haben, da Gott seinem Volk gnädig geworden ist“"665.

Zuweilen ist auch davon die Rede, dass der christliche Charismatiker die Fähigkeit besitzt, „negative imaginäre Erfahrungen“, also dämonische Trugbilder, bewusst zu evozieren oder loszuschicken. Wie der heidnische Magier vermag er pneumatische Kräfte zu aktivieren, tut dies aber zu einem anderen Zweck und im Dienste einer anderen Macht ${ }^{666}$. Während der Magier kraft satanischer Mächte agiert, um Besessenheit und Irrsinn über die Leute zu bringen, ist dem heiligen Mann von Gott die Fähigkeit ( $\dot{\xi} \xi o v \sigma i ́ \alpha)$ verliehen, gegen das Dämonische in der Schöpfung, also auch gegen den Magier, anzukämpfen ${ }^{667}$. Anschaulich wird das Aktivieren dämonischer Kräfte, im positiven wie im negativen Sinne, in einer Episode aus der Vita des Theodoros von Sykeon geschildert. Hier ist die Rede von einem Zauberer, der Zauberbücher mit Sprüchen und Mitteln besitzt, durch welche er Dämonen in die Menschen senden kann. Auch gegen Theodoros schickt er böse Geister los. Dieser lässt jedoch im entscheidenden Augenblick eine Flamme aus seinem Mund schießen, sodass die Dämonen an ihm abprallen. Jetzt schickt Theodoros die Dämonen zurück zum Zauberer, sodass dieser besessen wird und sich schließlich vom heiligen Mann heilen lassen muss. Theodoros tut dies allerdings nur unter der Bedingung, dass der andere seine Zauberbücher verbrenne und nie mehr gegen jemanden Übel wirke $^{668}$. In einer ähnlichen Episode wird geschildert, wie Hypatios in einem Kloster vergeblich einen Magier zurechtwies, der die anderen Brüder und den Abt dauernd schikanierte. Als sich Hypatios wieder in seinem eigenen Kloster befand, sah er vier Dämonen in der Gestalt von Kamelen mit Hälsen und Köpfen wie Drachen. Der Engel Gottes aber, welcher Hypatios beschützte, hob ihn in die Höhe, so dass die Dämonen die Hälse reckten, um ihn zu erreichen. Dies gelang aber nicht, weil Hypatios immer höher hinaufstieg. Schließlich zeigte der Engel ihm den Magier, der die Dämonen losgeschickt hatte, wie er in der Gestalt eines Sklaven auf dem Bett saß. Daraufhin befahl Hypatios den

665107.

666 S. auch Kazhdan, Holy and Unholy Miracle Workers 76-79.

667 Zum Begriff $\grave{\varepsilon} \xi o v \sigma i ́ \alpha$ im Zusammenhang mit christlichen Wundertätern s. BieLeR,

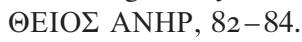

668 ViTh 37-38. 
Dämonen, dem Magier das, was jener ihm Übles habe antun wollen, zurückzubringen. So geschah es, und der Magier wurde selbst von den Dämonen be$\operatorname{sessen}^{669}$.

Die Kompetenz des heiligen Mannes, in Sachen Magie nach dem Rechten zu sehen, beschränkt sich allerdings nicht auf Agitationen im weltlichen und klösterlichen Umfeld, sondern dringt zuweilen bis an die oberste Spitze der staatlichen Hierarchie vor. Und hier wird die durch das göttliche charisma legitimierte Autorität des Heiligen erst richtig sichtbar: wer nicht auf die prophetischen Warnungen des Heiligen hört und Hilfe bei Magiern sucht, wird mit Wahnsinn und Tod bestraft. Dass diese Regel auch für den Kaiser gilt, erzählt eine Episode aus der Vita des Symeon Stylites des Jüngeren. Als Kaiser Iustinos krank wurde, bat der Patriarch Ioannes den heiligen Symeon, er möge für den Kaiser beten. Symeon antwortete, dass Iustinos bald wieder gesund werde, sofern man ihm keine Behandlung verschreiben werde, die Gott nicht gefällig sei. Iustinos wurde aber nicht gesund, „da er die Worte des Heiligen überging“. Vielmehr lieferte er sich „seelentötenden Männern“ aus. Diese ließen nämlich einen gewissen Timotheos kommen, der Jude war und sich in der Ärztekunst auskannte. In Wirklichkeit war er aber ein Feind des Sohnes Gottes, denn er war ein „Dämonendiener und beschäftigte sich dauernd mit Zauberkünsten“. Der Patriarch Ioannes versuchte zwar zu verhindern, dass dieser Scharlatan zum Kaiser vorgelassen wurde, doch man hörte nicht auf ihn. Als sich dies ereignete, sah sich Symeon in der Mittagsstunde durch die Kraft des heiligen Geistes in der kaiserlichen Stadt. Er betrat den Palast und sah, was durch den Juden angerichtet wurde. Darüber geriet er in heftigen Zorn. Diese Vision ließ er dem Patriarchen Ioannes mitteilen. Überdies forderte er offen und ohne Umschweife, Ioannes solle dafür einstehen, ,dass eine derartige Praktik, welche den Herrn in großen Zorn versetze“, vom Kaiser ferngehalten werden solle. Denn wenn er darin verharre, werde eine göttliche Entscheidung über ihn kommen. Er, Symeon, habe nämlich gesehen, dass die Seele des Kaisers auf Irrwege geraten sei. Doch man hörte nicht auf den Heiligen. Vielmehr wurde auch noch

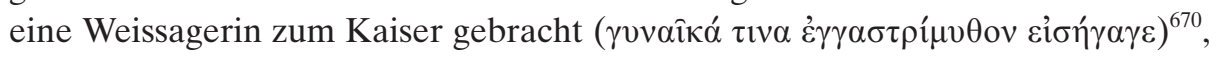
damit sie den Verlauf der Krankheit bekannt gebe. Als dies geschah, geriet Symeon in Ekstase und fand sich wieder im Palast. Der Kaiser empfing am

669 451. Ähnliche Beispiele: 269, 433, 471.

670 Bei der sogenannten „Gastromantie“ kann es sich um eine Nebenart der „Hydromantie“ handeln. Ein Medium starrt auf die Wasseroberfläche in einem bauchigen Gefäß $(\gamma \alpha \dot{\sigma} \sigma \rho \alpha)$, wo ihm die vom Magier heraufbeschworenen Wesen erscheinen, und beantwortet dabei die ihm gestellten Fragen. „Gastromantie“ kann sich aber auch auf die Stimme eines Bauchredners beziehen, die Aussagen über die Zukunft macht; vgl. LucK, Magie 322, A. 66; im geschilderten Beispiel handelt es sich wohl eher um die zweite Form von „Gastromantie“; vgl. auch VAN DEN VEN, La vie ancienne II 206, A. 1; s. auch Dodds, Christian and Pagan $53 \mathrm{f}$. 
gewohnten Ort seine Besucher, als sich die Himmel öffneten und eine göttliche Kraft herunterkam, dem Kaiser das kaiserliche Gewand auszog, das Diadem vom Kopf nahm und sagte: „Von nun an sollst du zum Gerede aller Menschen werden, da du dich selber der dämonischen Verirrung hingegeben hast, anstatt auf die göttliche Hilfe zu hoffen“. Voll Kummer und unter Tränen erzählte Symeon diese göttliche Offenbarung den Brüdern. Dem Patriarchen Ioannes teilte er in einem Brief mit, er solle ihn nicht mehr wegen des Kaisers belästigen. Nach wenigen Tagen wurde überall verkündet, dass der Kaiser verrückt geworden war und dass man bemüht war, ihn im Palast einzusperren. Nach einiger Zeit starb Iustinos ${ }^{671}$.

Hier wird durch das bewusste Nebeneinanderstellen des jüdischen Magiers $^{672}$ und des christlichen Propheten Symeon vermittelt, dass der heilige Mann jetzt eine gesellschaftliche Funktion zu übernehmen hat, welche am Kaiserhof über Jahrhunderte hinweg Wahrsagern, Traumdeutern und anderen „Scharlatanen“ zukam. Suchten die römischen, teilweise noch die byzantinischen Kaiser die Legitimierung für bestimmte politische Entwicklungen in den Auslegungen von Magiern, Zauberern und anderen Divinatoren ${ }^{673}$, so wurde man sich doch immer mehr der Gefahren bewusst, welche die Mantik aufgrund ihres unkontrollierbaren Charakters für das Staatsoberhaupt und seinen Machtapparat in sich barg ${ }^{674}$. So konnten gerade allegorische Träume durch die Offenheit ihrer Deutung als Mittel der Manipulation des Träumenden eingesetzt und so der Herrschaft zum Verhängnis werden ${ }^{675}$.

Überdies führte das Aufkommen einer Vielfalt von unterschiedlichen christlichen und gnostischen Strömungen, deren Aufschwung nicht zuletzt mit einer ausgeprägten Endzeiterwartung in der Spätantike zu erklären ist, dazu, dass imaginäre Erfahrungen - und insbesondere Prophezeiungen -

671 118. Zu diesem Beispiel s. auch Pratsch, Gegenspieler 80-82; Ders., Der hagiographische Topos $173 \mathrm{f}$.

672 Nicht nur Heiden, sondern auch Juden waren seit altersher für ihre magischen Fertigkeiten bekannt. Noch mehr als ein heidnischer Magier musste ein jüdischer Divinator als Inbegriff des Feindes Christi und als „Beschmutzung des rechten Glaubens“ gegolten haben. S. Kazhdan, Holy and Unholy Miracle Workers 78; DickiE, Magic and Magicians 287-293; Pratsch, Gegenspieler 80, A. 32.

673 Als Beispiel sei hier Ammianus Marcellinus angeführt, wo (Amm. 21,14,1-2) Konstantios als Kaiser beschrieben wird, der falschen Traumdeutungen Glauben schenkt. Als sein Tod angekündigt wird, verlässt er sich lieber auf Traumdeuter, die ihm eine günstige Antwort geben; vgl. Weber, Kaiser, Träume 472; NäF, Traum und Traumdeutung 142.

$674 \mathrm{Zu}$ der zunehmend kritischen Beurteilung der kaiserlichen Abhängigkeit von Divinatoren, die bei den Geschichtsschreibern zum ersten Mal bei Ammianus Marcellinus deutlich zum Ausdruck kommt, s. FöGEN, Die Enteignung der Wahrsager 89-182.

675 So sollen z.B. laut Cassius Dio verschiedene Personen aus dem unmittelbaren Umfeld des Septimus Severus aufgrund von Träumen, die zu ihren Ungunsten gedeutet wurden, zu Tode gekommen sein, Weber, Kaiser, Träume 344-348. 
beliebig zur Legitimierung charismatischer „Führerpersönlichkeiten“ der jeweiligen Gruppierungen instrumentalisiert werden konnten ${ }^{676}$ und somit der Monopolanspruch des Kaisers auf Privilegierungsträume- und Visionen in Frage gestellt wurde ${ }^{677}$.

Mit der staatlichen Etablierung und der voranschreitenden kirchlichen Institutionalisierung des Christentums im frühbyzantinischen Kaiserreich versuchte man allmählich, die geschilderten Unsicherheiten durch Gesetze zu regulieren $^{678}$. Eine ideologische Grundlage für diese Maßnahmen hält das christliche Gesellschaftskonzept bereit, begründet in der Voraussetzung, dass vor Gott alle Menschen gleich sind. Damit verliert jedermann, einschließlich des Kaisers, die Freiheit, sich nach eigenem Willen Eingang in den Bereich des Transzendenten zu verschaffen (Mt 22.21), zumal als Christen alle gleichermaBen dem göttlichen Willen untergeordnet sind. Dass, wie aus den Beispielen der hier behandelten Texten immer wieder ersichtlich wird, trotzdem am Glauben an die Mantik festgehalten wurde, verlangte nach wiederholten Gesetzeserlassen, vor allem aber nach neuen Leitbildern in der Gesellschaft, die als moralische und religiöse Vorbilder eine ernst zu nehmende Alternative zum gefährlichen Mantiker darstellten. Diese Rolle fällt dem christlichen Charismatiker, insbesondere dem Prophetenheiligen $\mathrm{zu}^{679}$. Dass sich ein großer Teil der geschilderten Prophezeiungen auf die Entwicklung des politischen Lebens bezieht, gehört dabei zum gleichen Konzept, das sich im Verlaufe der byzantinischen Zeit noch verstärkte und $\mathrm{zu}$ einem zunehmenden wechselseitigen Abhängigkeitsverhältnis von Machthabern und Heiligen führte ${ }^{680}$.

676 S. S. $41-43,88$ A. 423.

677 Zur Bedeutung von Träumen und Visionen bei verschiedenen gnostischen Strömungen, Manichäern und Montanisten vgl. VööBus, History of Asceticism I $111 \mathrm{f}$; WeBER, Kaiser, Träume 53; Harmless, Introduction 436; zur Bedeutung von Prophezeiungen bei den Montanisten und ihrer Beurteilung durch die Kirchenväter vgl. DodDs, Pagan and Christian 63-68; Timotin, Visions 36 f.; siehe auch S. 88 A. 423; zur Verbreitung unterschiedlicher charismatischer Strömungen seit dem 2. Jh. n. Chr. vgl. Anderson, Sage, Saint, Sophist 4-7. Zu den Privilegierungsträumen prominenter Persönlichkeiten in der Spätantike s. S. 42 A. 174 u. 175. Zu den Endzeiterwartungen in Byzanz, v.a. um das Jahr 500 n. Chr., aber auch danach, s. PodKalsky, Byzantinische Reichseschatologie 79-83; Magdalino, History of the Future 3-34; Brandes, Anastasios 28-41. 53-63; DERS., Endzeiterwartung 315.

678 S. S. 121 A. $598-600$.

679 Vgl. auch Speyer, Der christliche Heilige der Spätantike 77-84.

680 Vgl. Patlagean, Sainteté et pouvoir 182-185; Timotin, Visions 15, A. 10 (mit ausführlichen Literaturangaben). 
4.3.2 Die Prophezeiungen des christlichen Charismatikers

Die Prophezeiungen der heiligen Männer und Frauen beziehen sich auf eine ganze Palette von unterschiedlichen Ereignissen, sowohl aus dem Bereich des eigenen spirituellen Lebenswandels als auch aus Gesellschaft und Politik. Einer der am häufigsten vorkommenden Typen von Vorhersagen ist die Todesankündigung. Wiederholt wird geschildert, dass der heilige Mann den nahenden Tod voraussieht, sei es den eigenen ${ }^{681}$, den von anderen heiligen Männern und Frauen $^{682}$, Klerikern ${ }^{683}$ oder von berühmten Persönlichkeiten, z.B. von Kaisern und deren Gattinnen ${ }^{684}$. Auffällig in ihrer Ausführlichkeit sind die allegorischen Jenseitsreisen der „Apokalyptiker“ Symeon Stylites des Jüngeren und seiner Mutter Martha, die kurz vor ihrem Hinscheiden in die Himmel entrückt werden und noch einmal zurückkehren, um von ihrer Reise zu berichten ${ }^{685}$. Ebenso wie die schon mehrfach erwähnte Todesvision des Theodoros von Sykeon $^{686}$, erinnern diese Berichte an die Schilderungen der prämortalen Jenseitsreisen in den Märtyrerakten ${ }^{687}$. Sicherlich handelt es sich hierbei nicht zuletzt um ein dankbares literarisches Mittel, um dem Leser den Lohn eines frommen christlichen Lebens vor Augen zu führen. Doch auch an dieser Stelle ist einmal mehr zu bedenken, dass die behandelten Texte in einem Umfeld entstanden sind, in dem imaginären Erfahrungen als Teil einer spirituellen Lebenshaltung eine gänzlich realitätsbezogene, über die literarische Darstellung hinausgehende Bedeutung beigemessen wurde. Deutlich wird dies gerade dort, wo von Todes- und Jenseitsvisionen außerhalb des monastischen Milieus die Rede ist, so in der Korrespondenz des Barsanouphios und Ioannes, wo der Sohn eines Philosophielehrers kurz vor seinem Tod berichtet, dass er sah, wie ihn die heiligen Väter von einem Sarazenen befreiten und an einen leuchtenden Ort führten ${ }^{688}$. Keiner der Autoren jedoch vermittelt die Relevanz von Todesprophezeiungen für eine umfassendere mystische Lebenshaltung deutlicher als Gregor von Nyssa, der in seiner autobiographisch angelegten Vita Macrinae von einer Traumvision berichtet, deren Rätsel er zunächst nicht entschlüsseln konnte, durch die er aber in der Seele ein trauriges Ereignis voraussah. Erst als er Makrina sterbenskrank vorfand, verstand er die Bedeutung des zuvor Geschauten richtig als Ankündigung des bevorstehenden Todes

$68180,83,214,216,218,219,221,232,240$.

$682104,105,111,199,207,220,222,224,226$.

$683117,235$.

$68479,217,238$.

$685224,227$.

686239 (s. S. 23 A. 63, S. 68 A. 305, S. 79 A. 362).

687 Die bekanntesten Beipsiele sind die Todesvisionen des Polykarp und der Perpetua; vgl. Bovon, The Authoroty of Dreams 156 f. Zu Perpetua siehe auch S. 68 A. 306. 688213. 
seiner Schwester. Das im Traum Geschaute - Gregor sah sich die in gleißendem Licht erstrahlenden Reliquien von Märtyrern in den Händen halten - erweist sich schließlich als enigmatische Bildsprache, die ihm den gleichermaßen körperlichen wie geistigen Zustand seiner Schwester erst erklärbar macht, denn was er sah (nämlich die kranke Makrina), „war in der Tat die Reliquie eines heiligen Märtyrers, die tot war durch die Sünde, jedoch durch die ihr innewohnende Gnade des Geistes hell leuchtete“689. Ähnlich interpretiert Gregor auch einen Traum, dessen Prophezeiung sich allerdings nicht auf den nahenden Tod, sondern vielmehr auf das neu entstehende Leben durch die Geburt seiner Schwester Makrina bezieht. In diesem Traum sah sich Gregors Mutter unmittelbar vor der Geburt der Makrina das Kind, das sie noch in sich trug, in den Armen halten. Auch hier deutet Gregors Interpretation der Erscheinung einer über die menschlichen Maße leuchtenden Gestalt, die das Kind in den Armen seiner Mutter mit dem Namen Thekla anspricht, auf eine tiefere, mystische Realität in Makrinas Existenz: „Es scheint mir aber, dass der Erschienene dies nicht verkündete, um die Mutter bei der Namenswahl zu leiten, sondern vielmehr, um die Lebensweise des Kindes vorherzusagen und durch den gleichen Namen die Ähnlichkeit der Gesinnung anzuzeigen“"690.

Auffällig ist bei den Prophezeiungsvisionen die ausgeprägte Beliebtheit für allegorische Inhalte, wodurch deutlich wird, dass der heilige Mann neben der Gnade der bloßen Prophezeiung auch die Fähigkeit besitzt, die in die Zukunft weisenden Zeichen Gottes richtig zu deuten. Die in einer Imagination gesehenen Zeichen sind dabei eine Möglichkeit neben anderen. Wie die heidnischen Zeichendeuter nicht nur Träume interpretierten, sondern auch Astrologie, Geomantie, Pyromantie und viele andere mantische Praktiken betrieben ${ }^{691}$, kann auch der heilige Mann verschiedene Arten von Zeichen deuten. Es ist zwar auffällig, dass sich in den behandelten Texten die Zukunftsschau auf die imaginäre Erfahrung konzentriert, dennoch deutet auch der christliche Heilige hin und wieder Zeichen physischer Natur, gerade wenn es um endzeitliche Ankündigungen geht. So wurde Theodoros von Sykeon, als er sich in Konstantinopel aufhielt, vom Patriarchen Thomas gebeten, ihm zu sagen, ob sich bei den Prozessionen tatsächlich auf wunderbare Weise die Kreuze bewegten. Als der Heilige dies bestätigte, wollte Thomas von ihm wissen, ,was dieses Zeichen

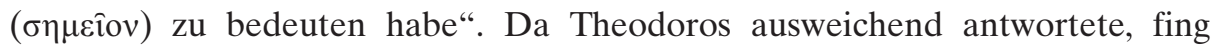
Thomas an, ihn noch hartnäckiger zu bitten, denn ,ich bin davon überzeugt, dass du nicht nur dieses Zeichen, sondern auch viele andere kennst. Wenn es dir aber bis jetzt verborgen geblieben ist, und du nicht danach verlangt hast, es zu

689 229. $\mathrm{Zu}$ dieser Todesvision s. auch Cox Miller, Dreams in late antiquity 232-253; NäF, Traum $158 \mathrm{f}$.

690313.

691 Vgl. Luck, Magie 1-11. 
erfahren, dann wird es Gott dir nun offenbaren, wenn du ihn darum bittest“". Darauf eröffnete ihm Theodoros unter Tränen, dass er ihn nicht betrüben wollte, da es nicht zu seinem Nutzen sei, die zukünftigen Ereignisse zu erfahren. Da der Patriarch aber nicht nachgab, erzählte ihm Theodoros, dass das Beben der Kreuze viel Schlimmes bedeute, so z. B. Zweifel und Apostasie im Glauben, den Einfall barbarischer Völker, Blutvergießen, Zerstörung, Gefangenschaft und Verwüstung der Kirchen ${ }^{692}$. Zweifellos haben wir es hier mit einer typischen endzeitlichen Prophezeiung zu tun, in der das Beben der Kreuze als Vorzeichen des Weltendes interpretiert und mit dem Einfall der mythischen Völker Gog und Magog (Hes 38) - hier in der Gestalt von barbarischen Völkern (gemeint sind die Awaren) - und der Zerstörung des letzten Weltreiches (Dan 2 und 7) hier durch die Verwüstung der Kirchen Konstantinopels angezeigt - in $\mathrm{Zu}-$ sammenhang gebracht wird $^{693}$.

Bezüglich Zeichendeutung hält auch die Philotheos Historia eine nennenswerte Passage bereit. So berichtet Symeon Stylites der Ältere, dass er einmal

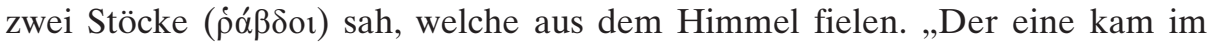
Osten, der andere im Westen auf die Erde. ... Er erklärte es als Zeichen für einen Aufstand der Perser und der Skythen gegen die Macht der Byzantiner“694. Es ist naheliegend, die zwei vom Himmel fallenden Stöcke im Zusammenhang mit der divinatorischen Praktik der „Rhabdomantie“, dem Wahrsagen mittels Ruten, zu interpretieren. In einer Stelle bei Herodot (4.67) heißt es, „dass Meder, Perser und Skythen einen Stock oder eine Rute verwendeten, um gewisse Dinge zu erfahren “695. Wer Theodorets Anspielung auf Herodot versteht, weiß auch, dass die Stöcke als Symbol für die „Rhabdomantie“ betreibenden Perser und Skythen stehen. Die Stöcke werden hier also zum Zeichen für das Zeichen, welches in seiner neuen Bedeutung nur der christliche Charismatiker zu verstehen imstande ist.

Hier ist der heilige Mann endlich am Gipfel dessen angelangt, was ihn als echte Alternative zum heidnischen Mantiker, als Zeichendeuter also, erscheinen lässt. Doch im Gegensatz zu jenem ist er immer ein anargyros, der sich für seine Vorhersagen von niemandem bezahlen lässt ${ }^{696}$. Lieber hält er sich, wie Theodors im oben zitierten Beispiel, in christlicher Demutshaltung zurück und behält die bevorstehenden Ereignisse für sich. Gerade diese „heilige Zurückhaltung“, die unter anderem durch den Rückzug aus der Welt symbolisiert wird, verleiht dem

692123.

693 Vgl. Magdalino, History of the Future 18, A. 58 u. 59; Brandes, Anastasios 24 f.; 38 f. 69495.

695 Luck, Magie 323.

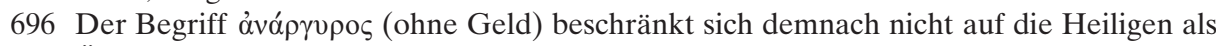
Ärzte (s o. Kap. 1.3.1, A. 110), sondern kann durchaus in Bezug auf alle Betätigungsfelder der heiligen Männer verwendet werden; vgl. Dodds, Pagan and Christian 58, SPEYER, Der christliche Heilige in der Spätantike 86. 
Heiligen die notwendige Autorität, vor der sich sogar die Machtträger von Staat und Kirche in Ehrfurcht beugen ${ }^{697}$. Er wird jetzt immer mehr zu einer gesellschaftlichen Autoritätsperson höchsten Ansehens, in deren visionären Gesichten das Schicksal der gesamten überblickbaren Welt zusammenfließt und sich zu prägnanten, allegorischen Bildern verdichtet. Das Einsetzen von Klerikern in ihre ranghohen $\ddot{\text { Amter }}{ }^{698}$, Machtwechsel am Kaiserhof ${ }^{699}$, bevorstehende Kriege $^{700}$, Erdbeben ${ }^{701}$ und vieles mehr ${ }^{702}$, wird durch allegorische Bilder in imaginären Erfahrungen visualisiert.

\subsubsection{Der christliche Charismatiker als Traumdeuter}

Weitaus seltener ist davon die Rede, dass sich Leute aus dem Volk an christliche Heilige wenden, um sich von ihnen Traumgesichte deuten zu lassen. Dies kann nicht wirklich erstaunen, zumal eine offizielle oder regelmäßige Tätigkeit als Traumdeuter dem vom heiligen Mann gewählten und von der Gesellschaft idealisierten Lebensstil der asketischen Zurückgezogenheit widersprechen würde und gleichzeitig dem Agieren des heidnischen Traumdeuters viel zu nahe käme. In einem Beispiel nur wird von einem allegorischen Traum mit anschließender Deutung erzählt. Maria, die Mutter des Theodoros von Sykeon, sieht nach ihrer Empfängnis im Traum einen großen Stern vom Himmel auf ihren Bauch herunter strahlen. Danach geht sie zu einem ,vorausschauenden“ $(\pi \rho \circ о \rho \alpha \tau \iota \kappa o ́ \varsigma){ }^{703}$ Geistlichen in der Gegend und erzählt ihm, was sie im Traum gesehen hat. Er aber antwortet ihr: „Dein Sohn wird ein großer Mann werden, aber nicht im Ansehen bei den Menschen, sondern in der Gunst Gottes. Ein leuchtender Stern wird von den Weisen, die sich darin verstehen, Gesichte zu deuten, als königliche Würde gedeutet. Über deine Angelegenheit soll aber nicht auf diese Weise gesprochen werden. In der Gestalt des leuchtenden Sterns wurde dir vielmehr der Glanz der guten Werke und der Ausstattung mit den

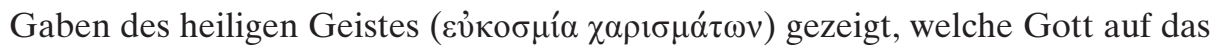

697 Die Gegenüberstellung des christlichen Charismatikers, der die Kompetenz hat, Zeichen zu deuten, und des Patriarchen, welcher in dieser Sache auf die Fähigkeit des Heiligen angewiesen ist, ruft in Erinnerung, dass christliche Bischöfe, welche sich als Divinatoren versuchten, gesetzlich belangt wurden. Vgl. Dickie, Magic and Magicians 274-281.

$69876,96,116,117$.

$699116,119$.

700 S. S. 142 A. 692 ; ferner 93, 106.

701 99, 107, 109, 110. S. dazu auch Dagron, Quand la terre tremble 17.

702 90, 91, 92, 108, 113.

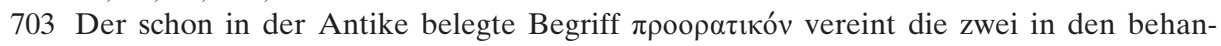

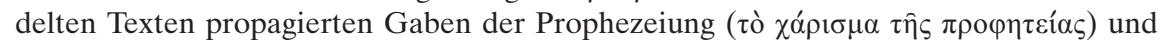

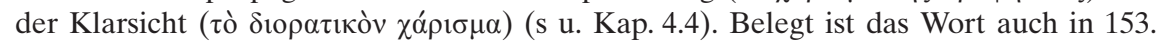


Kind in dir herabgesandt hat. So pflegt nämlich der Herr seine würdigen Diener

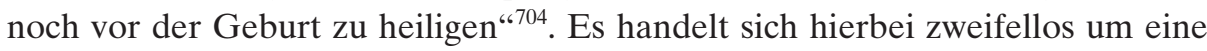
Anspielung auf Mt 2,1-2, und die Weisen bedeuten die Magier aus dem Morgenland, welche dem Stern nach Bethlehem gefolgt sind, um den neugeborenen König anzubeten. Die Gegenüberstellung der beiden unterschiedlichen Deutungen desselben Bildes durch den Geistlichen zielt demnach nicht darauf ab, die ursprüngliche, neutestamentliche Auslegung durch die Weisen aus dem Morgenland in Frage zu stellen ${ }^{705}$. Vielmehr muss die Allegorie in Bezug auf Theodoros anders ausgelegt werden, da die Geburt des Königs ( $\beta \alpha \sigma i \lambda \varepsilon v ́ \varsigma)$ Jesus in der christlichen Weltsicht ein einmaliges, unwiederbringliches Ereignis darstellt. Für seine Nachfolger, die christlichen Heiligen, muss demnach notgedrungen eine neue Auslegung gefunden werden ${ }^{706}$.

Ein ähnliches Bild, allerdings ohne Deutung durch einen Charismatiker, begegnet in der Geburtsankündigung des heiligen Daniel. Martha „sah in einer nächtlichen Vision zwei große, diskusförmige Leuchten, die vom Himmel herunterkamen und direkt bei ihr stehen blieben. Dann stand sie auf und erzählte es ihrem Mann und ihren Verwandten, und jeder beurteilte ihre Worte unterschiedlich. Sie aber sagte bei sich, dass Gott am Besten wisse, was das Richtige für sie sei. Und es vergingen nur wenige Tage, bis sie schwanger wurde. “"707 Der Autor macht hier deutlich, dass ein Auslegen des Geschauten in Anbetracht des unabwendbaren göttlichen Fatums sinnlos wäre, und die Bedeutung der Allegorie wird für den Leser aus der Handlung klar - so würde man jedenfalls glauben. Oder hätte jemand die diskusförmigen Leuchten nicht als ein Zeichen für die Geburt des in Zukunft die Welt erstrahlenden Prophetenheiligen Daniel interpretiert? Jedenfalls werden die beiden Leuchten erst an viel späterer Stelle der Vita mit dem Erscheinen des Kaisers Leon und seiner Frau zur Proskynese

704316.

705 Festugières Versuch, die „Weisen“ als heidnische „Traumdeuter“ im Sinne Artemidors zu interpretieren und den Stern, der in einer entsprechenden Deutung bei Artemidor und im byzantinischen Traumbuch des Achmet nicht vorkommt, als Sonne umzudeuten, muss deshalb fehlschlagen (Festugière, Vie de Théodore de Sykéôn II 172, 4,6-8). Hätte der Autor der Vita die Intention verfolgt, eine für ein christliches Verständnis falsche heidnische Deutung des Bildes anzugeben, so hätte er das ohne weiteres tun können. In diesem Fall hätte er aber mit großer Wahrscheinlichkeit anstelle von „die

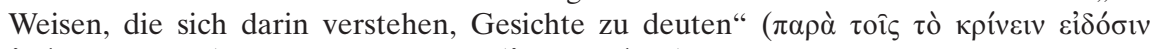

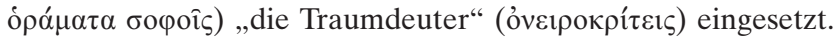

706 Die Deutung des am Himmel aufgehenden Sterns als Symbol für eine ,aufgehende spirituelle Autorität" kommt auch in Kap. 18 des Testaments des Levi vor, hier aber im Zusammenhang mit der Ankunft eines neuen Priesters: „Then in the priesthood the Lord shall raise up a new priest .... And his star shall arise in heaven, as (of) a king, lighting up the light of knowledge in the sun of day ..." (Übers. aus DeAn-OtTING, Heavenly Journeys 85 ).

707311. 
vor Daniels Säule erklärt ${ }^{708}$. Auf den ersten Blick mag es erstaunen, dass hier durch die Leuchten nicht Daniel selber, sondern die auf ihn erstrahlende weltliche Kaisermacht ausgedrückt werden soll. Angesichts der vielschichtigen Bedeutungsmöglichkeiten der monastischen Texte ist jedoch anzunehmen, dass es sich hier wiederum um ein Zeichen für das Zeichen handelt und die ,weltliche Macht“, mit der Daniel geehrt wird, als Bild für die himmlische Königswürde eingesetzt wird. Damit hätte der Autor mehrere Bedürfnisse mit einem Symbol befriedigt: die Ehrung der Kaiser und des heiligen Daniel gleichermaßen. Eine Würdigung des weltlichen wie des himmlischen Königreichs, welche das eine im Glanz des anderen erstrahlen lässt. Das unterschiedliche Interpretieren von Marthas Gesicht durch ihren Mann und die Verwandten macht klar, dass ihnen allen die Kompetenz für eine richtige Deutung fehlt, und dass deshalb ihre Auslegungen bedeutungslos sind.

Sicherlich sagt die Erzählung über die Geburtsankündigung des Theodoros von Sykeon als Einzelbeispiel für die Traumdeutung durch einen heiligen Mann wenig über eine tatsächliche Tätigkeit der christlichen Charismatiker als Traumdeuter aus. Schließlich handelt es sich um eine „Schlüsseloffenbarung“, welche in der Heiligenbiographie einen mehr oder weniger festen Platz einzunehmen hat, also weitgehend als literarische Stilisierung interpretiert werden kann. Dennoch ist anzunehmen, dass trotz des topischen Charakters der Erzählung der Gang der frommen Maria zu einem geistlichen Vater, dem die Gabe der Vorhersage nachgesagt wird, dem Leser durchaus plausibel erschien und ihn möglicherweise darin bestärkte, dasselbe auch zu tun.

Wie das Verhältnis des kleinen Mannes zu divinatorischen Praktiken, speziell zur Traumdeutung und zum christlichen Heiligen als Traumdeuter tatsächlich ausgesehen hat, ist alleine aufgrund der behandelten Texte schwerlich nachzuvollziehen. Fest steht, dass die Traumdeutung und die mantische Zeichendeutung in all ihren Formen, trotz den gesetzlichen Restriktionen nicht aus dem Begehren der „Volksseele“ gelöscht werden konnte. Entscheidend dürfte dafür nicht zuletzt die Tatsache gewesen sein, dass diese „Volksseele“ zuweilen selbst im Kaiserherzen aufflackerte. Von Konstans II. (641-668) wird beispielsweise berichtet, dass er einen persönlichen Traumdeuter hatte ${ }^{709}$. Unter dem an okkulten Wissenschaften interessierten Kaiser Leon VI. (886-912) ${ }^{710}$ wurde Oneiromantie schließlich offiziell von der Liste der teuflischen Praktiken gelöscht ${ }^{711}$. Dass der Versuch, die Traumdeutung durch Gesetze zu unterbinden,

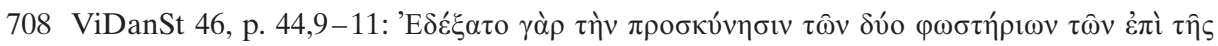

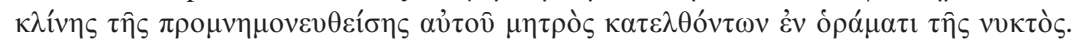

709 Theophanes Confessor, Chronographia, p. 164,6 f.; vgl. Calofonos, Dream Interpretation 219; mit weiteren Beispielen vgl. Weber, Kaiser, Träume $113 \mathrm{f}$.

710 Dazu Mavroudi, A Byzantine Book on Dream Interpretation 61.

711 Basilika Lib. LX, 39, 28, p. 3009,17-3010,4. Im Nomokanon des Photios wird das Gesetz wieder aufgenommen, Nomocanon 9, 25, Ralles, Potles I, p. 191 f; vgl. Dagron, Rêver 
von Anfang an zum Scheitern verurteilt sein musste, wusste Synesios von Kyrene schon im Jahre 404, als er sich in seiner Abhandlung über Träume ( $\pi \varepsilon \rho \grave{~}$

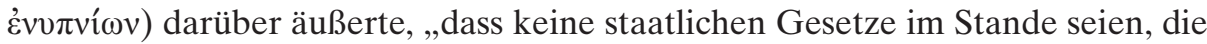

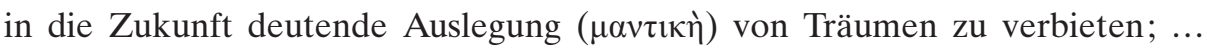

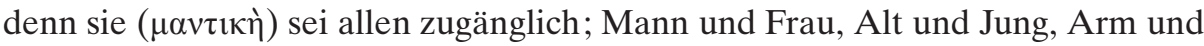
Reich, Privatperson und Beamten, Handwerker und Redner. Unabhängig von Geschlecht, Alter, Reichtum und Beruf, lässt sie sich niemandem verbieten. Jedem ist sie überall zugänglich, als bereitwilliger Prophet, als guter und verschwiegener Berater"“712.

Die in den behandelten Texten sichtbare Suche nach einer für das Christentum akzeptablen Form der Mantik mündet in einem Kompromiss. Dieser äußert sich nicht nur in der Verbreitung der sogenannten ,byzantinischen Prophetenbücher" ${ }^{6713}$, sondern auch im erneuten Aufkommen von Traumhandbüchern seit dem 7. Jh., welche jetzt meist Autorennamen christlicher Autoritätspersonen wie Patriarchen tragen ${ }^{714}$, oder im Fall des Oneirokritikon des Achmet, trotz exotischem Kolorit, in christianisierter Form auftreten ${ }^{715}$. Schließlich äußert sich der Kompromiss auch in neuen Formen der „,christlichen Zeichendeutung“, z. B. der Bibliomantie ${ }^{716}$, welche letztlich nichts anderes ist als eine mantische Praktik im christlichen Gewand.

39; Calofonos, Dream Interpretation 219; Mavroudi, A Byzantine Book on Dream Interpretation 61; VINCENT-BERNARDI, Didascalie onirique 131.

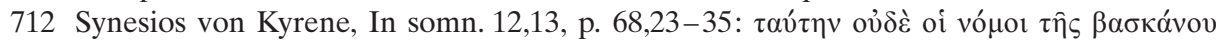

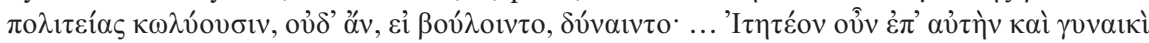

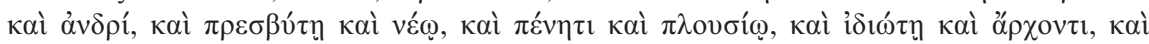

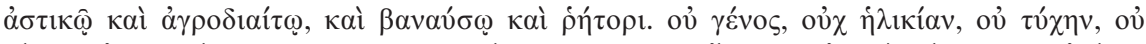

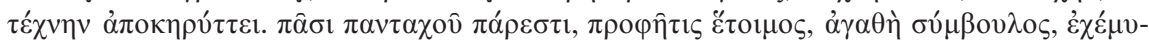
өoc. Zu Synesios vgl. Dodds, Pagan and Christian 38-39; Le Goff, Das Christentum und die Träume $282 \mathrm{f}$; Cox Miller Dreams in Late Antiquity 70-73; Vincent-BerNARDI, Didascalie onirique 129; NäF, Traum und Traumdeutung 170-172.

713 Darunter werden Sammelhandschriften der biblischen Bücher der 16 Propheten verstanden, die insbesondere seit dem 10. Jh. in Byzanz Verbreitung fanden; vgl. BrowN TKacz, Art. Prophet book $1736 \mathrm{f}$.

714 So das „Traumbuch des Propheten Daniel“ aus dem 7. Jh. (ed. DrexL), das „Traumbuch des Patriarchen Nikephoros“ (ed. Guidorizzi) und das „Traumbuch des Patriarchen Germanos“ (ed. DreXl), welche zwischen dem 9. und 12. Jh. entstanden sind (Engl. Übers. dieser Texte: Oberhelman, Dreambooks 59-148. 153-166); s. dazu Ebd. 1-58; Calofonos, Dream Interpretation 219 f.; Vincent-Bernardi, Didascalie onirique 131. 137.

715 Achmet, Oneirocriticon (ed. Drexl); vgl. Oberhelman, The Oneirocriticon of Achmet 11-22; Guidorizzi, La letteratura dell'irrazionale 616-618; zur Herkunft des Traumbuches s. Mavroudi, A Byzantine Book on Dream Interpretation 1-62; VincentBERNARDI, Didascalie onirique 137-139.

$716 \mathrm{Im}$ christlichen Kontext ist damit die Vorhersage durch das zufällige Aufschlagen einer Bibelstelle gemeint. Vgl. Calofonos, Dream Interpretation, 218; Luck, Magie 325; TAXIDIS, 'Oveipa 186-189. 


\subsection{Das Sichtbarwerden des Unsichtbaren - Die Gabe der Klarsicht}

Schließlich sei noch das letzte im Zusammenhang mit imaginären Erfahrungen wiederholt in den Texten belegte charisma, die sogenannte „Klarsicht“ ( $\tau$ ò $\delta 10-$

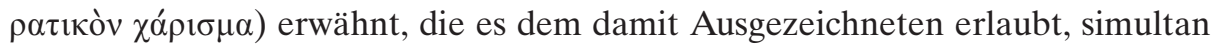
zur physisch wahrnehmbaren Umwelt das Innenleben der anderen - sowohl anals auch abwesenden - Menschen zu erblicken. So belehrt Pachomios einen Schüler darüber, „dass die Klarsicht zu den heiligen Dingen gehört und befähigt, die Regungen der Seelen wahrzunehmen, so wie Elisa bei Gehasi [2 Kön $5,27]$. Wenn Gott in ihnen, der alles erforscht, ihnen offenbart, dann sind sie klarsichtig. Und wenn er es nicht offenbart, dann sind sie wie jedermann“"717. Zur Gabe der Klarsicht, die neben Pachomios auch zahlreichen anderen heiligen Männern, so Arsenios ${ }^{718}$, Euthymios ${ }^{719}$, dem Wüstenvater Aphrodisios, Prokopios von Rhodos ${ }^{720}$, Theodoros von Sykeon ${ }^{721}$, aber auch verschiedenen anonymen Vätern in der ägyptischen und palästinischen Wüste ${ }^{722}$ zugesprochen wird, gehört insbesondere, dass der damit Ausgezeichnete direkt in die anderen Menschen hineinsehen und wahrnehmen kann, was sich dort abspielt. Von Euthymios wird gesagt, ,er hatte auch jenes charisma von Gott erhalten, dass er durch die Erscheinung des sichtbaren Körpers die seelischen Bewegungen sah und erkannte, mit welchen Gedanken ein jeder kämpfte, welche er überwinden konnte, und von welchen er besiegt wurde“"723. Häufig zeigen sich dem Klarsichtigen die Regungen und Bewegungen des menschlichen Innenlebens in Bildern, die er richtig zu deuten weiß. So erzählt Euthymios seinen Schülern die Geschichte eines Klarsichtigen, der durch die Gabe der Klarsicht einen im Sterben liegenden „Pseudoheiligen“ als solchen entlarvt. Dieser wird von allen Stadtbewohnern für heilig gehalten, erzürnt aber im Verborgenen seines Herzens Gott durch unreine Gedanken. Als der Klarsichtige die Stadt des vermeintlichen Heiligen betritt, findet er alle Bürger unter Tränen. Sie fürchten um das Leben des von ihnen für heilig gehaltenen Mannes und damit um ihre eigene Rettung. Sofort geht der Klarsichtige zum vermeintlichen Heiligen, um von ihm den Segen zu empfangen. Als er zu ihm kommt, trifft er auf eine große Menschenmenge von Weltlichen und Klerikern bis hin zum Bischof, die kurz davor sind, den Heiligen zu bestatten. „Der Klarsichtige aber tritt an diesen heran und findet ihn noch lebend. Mit den Augen des Geistes sieht er jetzt, wie der Tartaros des Hades einen feurigen Dreizack hält, wel-

71766.

718130.

719 S.u. A. 723 . S. auch 129, 131.

$720140,142$.

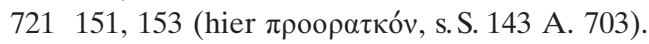

$722126,127,128,141,153$ (s. o. A. 721), 197.

723133. 
chen er in das Herz des falschen Heiligen hineinrammt, und unter großen Qualen seine Seele aufspießt. Und er hört eine Stimme aus dem Himmel, die sagt: ,So wie die Seele dieses Mannes nicht einen Tag aufgehört hat mich zu quälen, so lass du nicht davon, seine Seele zu plagen und aufzuspießen““724.

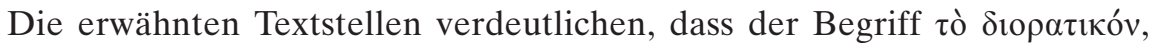
der seine Ursprünge in der alexandrinischen Theologie hat und erstmals bei Clemens von Alexandreia und dann auch bei Origenes und Gregor von Nyssa zu finden ist ${ }^{725}$, als fester Terminus in das Vokabular der monastischen Literatur eingegangen ist. Anders als bei den genannten Theologen wird der Begriff hier aber weniger im neuplatonischen Sinne als Bezeichnung für die Fähigkeit der geläuterten Seele der rein intellektuellen Gottesschau durch die mystische Kontemplation verwendet, sondern vielmehr für eine bestimmte Gabe, ein charisma, im oben beschriebenen Sinne. Und obschon die Klarsicht nicht unter den paulinischen Gaben des heiligen Geistes in I Kor 12,10 auftaucht ${ }^{726}$, wird sie in der monastischen Literatur neben den anderen charismatischen Gaben, ins-

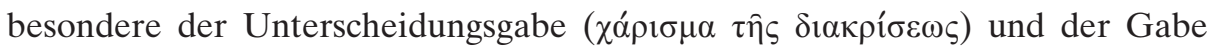

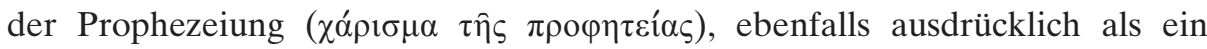
charisma beschrieben, mit dem ein großer Teil der heiligen Männer ausgezeichnet ist ${ }^{727}$. Es scheint, dass die monastische Literatur damit bewusst ein zusätzliches, durch die Bibel nicht als solches legitimiertes charisma einführte und sogar zu sanktionieren versuchte, wie aus den zum Thema relevanten Passagen aus der Vita Pachomii hervorgeht. Denn über die Angelegenheit, dass Pachomios von vielen für klarsichtig gehalten wurde, war ein Streit ausgebrochen, weswegen er sich auf der Synode von Latopolis ${ }^{728}$ seinen Gegnern stellen musste. Die Bischöfe anerkannten Pachomios zwar als Mann Gottes, da sie wussten, dass er Dämonen gesehen, gegen sie angekämpft und sie aus den Seelen von Menschen vertrieben hatte. Da es sich aber bei der Klarsicht um eine bedeutungsvolle Angelegenheit handelte, sollte er sich noch einmal ihretwegen verteidigen, um damit die Gegner zu überzeugen ${ }^{729}$. Der im Text nicht direkt genannte Grund, warum Pachomios' Gabe der Klarsicht als suspekt angesehen

724132.

725 Vgl. Tiмотіn, Visions $40 \mathrm{f}$.

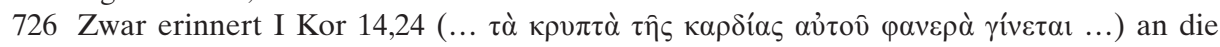
Eigenschaft der Klarsicht. Weder ist hier aber die Rede von einem $\chi \alpha ́ \rho ı \sigma \mu \alpha$, noch von

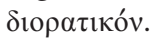

727 S.u. II D, S. $194-202$.

728 In der Nähe von Latopolis (arab. Esnē), seiner Heimatstadt in Oberägypten, $45 \mathrm{~km}$ südlich von Luxor auf dem westl. Nilufer, gründete Pachomios nach 345 sein Kloster. Latopolis war seit dem 4. Jh. Bischofssitz; die Synode von Latopolis ist allerdings nur aus den pachomianischen Schriften belegt; vgl. Horn, Art. Esnē 883 f.; ChitTy, The Desert A City 24, A. 57; Bacht, Das Vermächtnis 18. 31.

729137. 
wurde, liegt am ehesten darin, dass eine direkt auf die Bibel zurückgehende Legitimation des charismas nicht nachzuweisen ist. Denn damit fehlt auch die Gewissheit, dass die in Frage gestellte Gabe durch den heiligen Geist ihren Ursprung in Gott und nicht etwa in dämonischen Kräften hat und in Zusammenhang mit Magie gebracht werden kann. Bestärkt wird diese Annahme, wenn Pachomios in seiner Verteidigungsrede unter anderem sagt, "lass doch das charisma Gottes“, denn würde Jesus, „wenn er jemanden sähe, der aus ganzem Herzen den Untergang seines Nächsten oder sogar vieler fürchtet, ihn nicht mit der Gabe versehen zu erkennen, wie sie zu retten sind, sei es durch die Unterscheidung des heiligen Geistes, sei es durch ein Gesicht?“730. Pachomios nennt hier die paulinische Unterscheidungsgabe und die ó $\tau \alpha \sigma i ́ \alpha$, ganz allge-

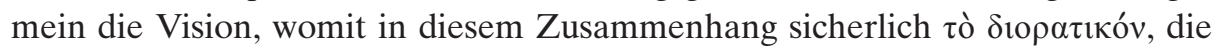
Klarsicht, gemeint ist ${ }^{731}$, in einem Atemzug. Damit stellt er sie gleichwertig nebeneinander und spricht sich an offizieller Stelle, nämlich vor der kirchlichen Synode, für eine durch die Worte von Jesus selbst legitimierte Akzeptanz der Klarsicht durch die Kirche aus. Dass es sich hierbei nicht um eine beiläufige Erwähnung des Phänomens oder um eine zufällige Wortwahl handelt, zeigt eine spätere Textstelle, wo erzählt wird, dass Theodoros, der Lieblingsschüler des nun bereits verstorbenen Pachomios, ,als er vom Gerede über die Klarsichtigkeit des Pachomios gehört hatte, anfing zu verbergen, wenn er durch den Willen Gottes etwas in einem Gesicht sah“732. Und auch er erklärt seinen Brüdern noch einmal, „dass keiner an einem Mann Gottes zweifeln würde, wenn er hören würde, dass dieser ein Gesicht gesehen hat, da derjenige, der die Gesichte zeigt, in ihm wohnt. Es ist aber wichtig, in dieser Sache vorsichtig zu sein, damit nicht derjenige, der von sich glaubt, es zu sein (klarsichtig), obwohl er es gar nicht ist, im Verlangen nach dem Sehen vom Feind überlistet wird und in der Schlinge gefangen in eine Ekstase fällt, so wie es bei vielen der Fall ist. “733 Deutlich wird hier, dass es bei der Klarsicht um die nur dem christlichen Charismatiker zugesprochene Fähigkeit geht, durch die göttliche Offenbarung denjenigen Teil im Menschen zu sehen, der dem gemein Sterblichen verborgen bleibt. Der Klarsichtige soll als „Herzensrichter“ in direkter Nachfolge Petri verstanden werden, der „das Übel Simons des Magiers nicht im körperlichen Gesicht, sondern im Herzen sah, als er ihm sagte: ,Denn ich sehe, dass du bittere Galle und eine Fessel voll Ungerechtigkeit bist““6734. Die immer wieder zur Rechtfertigung des charismas angeführten Belegstellen aus dem Alten und Neuen Testament sowie die erwähnte Sanktionierung durch die Synode sind für das Textverständnis

730137.

731 Da es sich um die Verteidigung desselben Begriffes handelt.

732138.

73335.

734139. 
deshalb von zentraler Bedeutung, da sie dem heiligen Mann in der Konsequenz die Kompetenz zusprechen, die Grenzlinie zwischen Orthodoxie im Wortsinn und der von Kirche und Staat bekämpften Magie zu ziehen. Ihm wird die Macht anvertraut, zwischen guten und bösen Menschen, zwischen weißer und schwarzer Magie und zwischen wahren und trügerischen Gesichten zu unterscheiden. 


\section{Schlussbetrachtung}

Die auffälligste Konstante, die sich im Zusammenhang mit imaginären Erfahrungen durch den allergrößten Teil der behandelten Texte der frühbyzantinischen monastischen Literatur hindurchzieht, ist die geistige Verbildlichung transzendenter Inhalte, das vor dem inneren Auge Sichtbarwerden der göttlichen Wirkkraft und häufig auch der dadurch ausgelösten esoterischen Vorgänge. Pauschale Aussagen über Formen, Typen und terminologische Spezifika von imaginären Erfahrungen erweisen sich deshalb als problematisch, weil die Texte eine starke Tendenz zur bewussten Vermeidung von klaren Definitionen im Hinblick auf die Thematik aufweisen. Oft bleibt der Bewusstseinszustand, in dem imaginäre Erfahrungen stattfinden (also Schlaf, Wachzustand, Trancezustände) unklar. Gleichzeitig kombinieren die Autoren alle Begriffe zur Bezeichnung der göttlichen Schau und Audition, aber auch von dämonischen Trugbildern auf unterschiedliche Weise mit allen Bewusstseinszuständen. Verschiedene moderne, weitgehend auf der augustinischen Tradition basierende Definitionen von Begriffen wie „Vision“, „Erscheinung“ oder „Traum“ sind aus diesem Grund für die hier behandelten Quellen und die von ihnen vermittelte Idee von imaginären Erfahrungen unzutreffend.

Im Einklang mit dem für die monastische Spiritualität zentralen asketischen Ideal des nächtlichen Wachens und der damit zusammenhängenden Abwertung des Schlafes wird in den Texten auch der Traum tendenziell negativ bewertet. Doch auch hier ist bei verallgemeinernden Aussagen Vorsicht geboten. Denn der positive, als göttliche Offenbarung bewertete Traum ist nicht nur für das weltliche, sondern auch für das asketisch monastische Umfeld verschiedentlich belegt, was gerade dort erstaunen mag, wo eine positive Deutung der nächtlichen Imagination am wenigsten zu vermuten wäre, nämlich bei dem sonst für seine Bilderfeindlichkeit bekannten Euagrios Pontikos. Überdies wird gerade bei der Bewertung von Träumen, aber auch von allen anderen Formen der Imagination, eine simplifizierende Einteilung in „göttlich“ und „dämonisch“ den Quellen nicht gerecht. Finden sich doch in den monastisch-asketischen Traktaten des Euagrios und des Ioannes Klimakos, aber auch in den Vätersprüchen, Ausführungen über die Entstehung von geistigen Bildern, und damit auch von Träumen, die von einem breiten philosophisch-medizinischen Wissen der Autoren zeugen und den dämonischen Ursprung der Träume nur als einen Aspekt der negativen Imagination thematisieren, der in den Ausführungen manchmal stärker, manchmal schwächer oder gar nicht Beachtung findet. Vor allem Ioannes Klimakos überrascht in dieser Hinsicht mit einer besonders 
„weltlichen Anschauung“, indem er mit einer weitgehend humoralpathologischen Erklärung des negativen Traumes die Verantwortlichkeit für den unerwünschten Traum zu weiten Teilen bei dem sich nicht an die Ideale des asketischen Lebenswandels haltenden Mönches sucht (durch zu viel Nahrung etc.) und nur am Rande mit dem Agieren von Dämonen in Zusammenhang bringt. Ähnlich beschreibt Klimakos auch die von vielen anderen Autoren mit dämonischer Besessenheit in Zusammenhang gebrachten Symptome der Epilepsie, die jetzt oft als Ekstase (und nicht mehr wie im Neuen Testament als Mondsucht) bezeichnet wird, ganz neutral als körperliche Krankheit im bloßen medizinischen (und nicht im dämonischen) Sinne. Eine relative Offenheit im Umgang mit Träumen zeigt sich des Weiteren in der Traumterminologie, die in den behandelten Texten nicht an die mantische bzw. göttlich/damönische Wertigkeit gebunden ist, wie es in der antiken, vor allem in den Oneirokritika des Artemidor dokumentierten Traumdeutung noch der Fall war.

Im Hinblick auf imaginäre Erfahrungen lässt sich, wie schon RubENSON anhand der Briefe des Ammonas einleuchtend gezeigt hat ${ }^{735}$, auch die oft vorgenommene Polarisierung in den in der jüdischen Tradition wurzelnden mystischen Asketismus auf der einen und den philosophischen (neuplatonischen) Asketismus des Origenismus auf der anderen Seite nur sehr bedingt auf die gesamte monastische Literatur übertragen. Es ist zwar richtig, dass der in vielerlei Hinsicht philosophischen Konzepten folgende Euagrios, abgesehen von den erwähnten Beispielen für den engelhaften Traum, jede Art von Imagination, und damit auch die in Form von ekstatischen Entrückungszuständen erlebte bildliche Vision, ablehnt. Zahlreiche Beispiele von visuellen Imaginationen aus dem Bereich des ägyptischen Wüstenasketentums, v. a. aus den Vätersprüchen, aber auch aus der Vita Antonii oder der Historia Monachorum zeigen jedoch in aller Deutlichkeit, dass die Grenzen zwischen „mystisch“ und „philosophisch“ in der frühbyzantinischen asketischen Lebenswelt weit weniger scharf gezogen wurden, als es in der Forschung gerne dargestellt wird ${ }^{736}$. Vielmehr ist in nahezu allen behandelten Werken der monastischen Literatur eine starke Tendenz hin zur Visualisierung transzendenter Inhalte durch imaginäre Erfahrungen festzustellen. Die wichtige, im Vergleich zum neuen Testament zunehmende Bedeutung des visuellen Aspekts der imaginären Erfahrung geht einher mit einer Aufwertung der religiösen Trance, die oftmals terminologisch als (mystische) Ekstase (ekstasis) gekennzeichnet wird und in enger Verbindung mit verschiedenen asketischen Praktiken zu beurteilen ist, die zu den Grundpfeilern der in den Texten thematisierten monastischen Spiritualität gehören. Demnach führt das ständige Verlangen nach imaginären Erfahrungen in weiten Kreisen des

735 Rubenson, Transformation 279.

736 Sogar bei Origenes ist die Bedeutung der Himmelsreise und die Offenbarung von himmlischen Mysterien belegt, wie RuBENSON, Transformation 279 gezeigt hat. 
frühbyzantinischen Mönchtums zu einem bewussten Evozieren derselben. Die damit einhergehende Gefahr der Überreizung des asketischen Strebens nach Offenbarungen äußert sich in jenen Textbeispielen, die vor den negativen Folgen des übertriebenen Verlangens nach imaginären Erfahrungen warnen. Gleichzeitig wird die Sorge vor einer Profanierung der göttlichen Offenbarung durch das weit verbreitete Streben nach imaginären Erfahrungen gerade dort sichtbar, wo auf die Privilegierung bestimmter Charismatiker im Hinblick auf Revelationen wert gelegt wird (z. B. in der Vita Pachomii).

Dass sich dieselbe Sorge auch auf die Vermittlung von Visionsinhalten auf literarischer Ebene bezieht, zeigt sich besonders deutlich am Einsatz von rhetorischen Mitteln zur Rechtfertigung des Weitererzählens des eigentlich nicht aussprechbaren göttlichen Mysteriums. Das Gleiche gilt auch für die Gefahr der Missachtung des Theologumenon der Unsichtbarkeit Gottes, die schon die imaginäre Erfahrung als solches in sich birgt, die aber erst recht bei der Vermittlung des Geschauten an den Rezipienten zum Ausdruck kommt. Dass die Autoren dennoch nicht davor zurückschrecken, die Bildinhalte von imaginären Erfahrungen in einer Vielzahl von anschaulich geschilderten Exempla in Worte zu fassen, liegt nicht nur am hohen Unterhaltungswert von Visionserzählungen und der propädeutischen Funktion, die diese zur Vermittlung von allgemein christlichen und von spezifisch dogmatischen Lehrsätzen einnehmen konnten, sondern vor allem auch daran, dass die Visualisierung des Numinosen durch die Offenbarung nie als ein direktes Schauen Gottes verstanden wird. Vielmehr begleiten die imaginären Erfahrungen das asketische Streben durch ein indirektes Schauen des göttlichen Wirkens in Form von Mittlergestalten wie Engel, Heilige und einer Vielzahl von mystischen Zeichen.

Die daraus resultierende Gefahr einer Missinterpretation der geschauten Zeichen bringt die Notwendigkeit einer allegorischen Auslegung mit sich, welche die Texte nur den auf dem asketischen Weg besonders weit fortgeschrittenen heiligen Männern zubilligen. Ihnen wird die Fähigkeit zugesprochen, nicht nur die eigenen Offenbarungen, sondern auch diejenigen der anderen, noch am Anfang des spirituellen Heilsweges stehenden Asketen, aber auch die von weltlichen Christen, richtig zu deuten. Darüber hinaus werden die gleichen heiligen Männer mit den paulinischen Gaben der Unterscheidung (to charisma tes diakriseos) und der Prophezeiung (to charisma tes profeteias) ausgestattet. Während der heilige Mann durch die erste Gabe mit der Fähigkeit versehen wird, die göttliche Schau von der trügerischen, häufig als dämonisch dargestellten Erscheinung zu unterscheiden, spricht ihm die Gabe der Prophezeiung überdies die Kompetenz zu, die göttlichen Zeichen auch im Hinblick auf ihre Bedeutung für die Zukunft richtig zu deuten. Damit erschaffen die Autoren mit dem christlichen Charismatiker in der Funktion eines Richters und Deuters von imaginären Erfahrungen ein Gegenmodell zu den im frühen Christentum von kirchlicher und staatlicher Seite bekämpften Traumdeuter, aber auch zu allen 
anderen Formen von zukunftsdeutenden Divinatoren. Mit der in den Texten überdies häufig belegten Gabe der Klarsicht (to charisma tes diakriseos), konstituieren die Autoren ein weiteres (nicht paulinisches) charisma, durch das der heilige Mann befähigt wird, mit den Augen des Geistes in Form von Bildern zu sehen, was sich in den Seelen der anderen Menschen abspielt.

Dort, wo imaginäre Erfahrungen bei weltlichen Christen zur Sprache kommen, äußert sich die Relevanz der Visualisierung transzendenter Inhalte zum großen Teil im Zusammenhang mit Heilungswundern, die die göttliche Wirkkraft am Menschen direkt sichtbar machen und deshalb keiner weiteren Unterscheidung in wahr oder trügerisch bedürfen. In der Tradition der antiken Inkubationskulten ist in diesem Bereich nach wie vor die Traumheilung mehrfach belegt, aber auch hier ist wiederholt die Rede von induzierten mystischen Trancezuständen, die dem Kranken und Notleidenden eine gleichermaßen spirituelle wie körperliche Heilung durch imaginäre Vorgänge ermöglichen. Bezeichnenderweise zeigen die Beispiele in den behandelten Texten, dass sich der Akt der imaginären Heilung im Gegensatz zu der klassischen Inkubation weg von der Kultstätte bewegt und sich entsprechend dem Theologumenon der Ubiquität des göttlichen Gnadenwirkens zu einem ortsungebundenen Vorgang entwickelt. Das Wirken des imaginären Bildes des Heiligen nimmt dabei die gleiche Funktion ein wie dessen materialisiertes Bild, die gerade in frühbyzantinischer Zeit an Bedeutung gewinnende Ikone, der die physische Präsenz des Heiligen und damit die überall wirksame Heilkraft zugesprochen wird. Charakteristisch für den Ablauf von Wunderheilungen, aber auch von allen anderen Typen von gesuchten imaginären Erfahrungen bei weltlichen Christen (z.B. bei Rettungen aus Notsituationen), ist eine drei (oder mehr) -gliedrige hierarchische Abstufung beim Erflehen des göttlichen Beistandes. Der heilige Mann nimmt dabei stets eine Mittlerfunktion zwischen dem heilssuchenden Gläubigen und Gott ein, wobei das Gebet das Medium der Kontaktaufnahme von einer Stufe zur nächst höheren darstellt und Gottes Wirken durch das Agieren des heiligen Mannes in Form einer imaginären Erfahrung sichtbar wird. Dieser Vorgang verdeutlicht einmal mehr eine im weiteren Umfeld des frühen Mönchtums verwurzelte soziale Struktur, in der den heiligen Männern eine zentrale Mediatorenrolle zwischen den weltlichen Christen und dem göttlichen Wirken eingeräumt wurde. 
Teil II - Quellen 



\section{A. Allgemeines über imaginäre Erfahrungen}

1. AdMo 11, p. 47: „Gib deinem Körper nicht viel Nahrung, damit du während des Schlafs nicht böse Trugbilder siehst. So wie nämlich die Flamme Wachs schmilzt, so löscht der Hunger schlimme Trugbilder“ ([1] Mì $\delta \omega َ \varsigma \beta \rho \omega ́ \mu \alpha \tau \alpha$

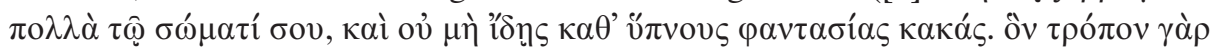

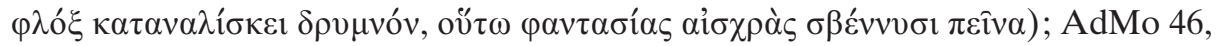
p. 53: „Der schläfrige Mönch gerät in Übel, der wachende aber wird sein wie ein

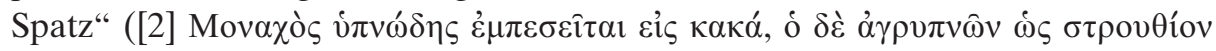
है $\sigma \tau \alpha \imath)$.

2. AdMo 48, p. 53: „Viel Schlaf verdickt den Geist, während ihn ein gutes

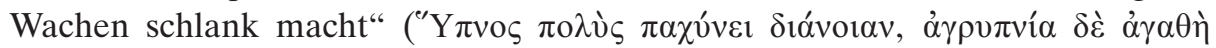
$\lambda \varepsilon \pi \tau u ́ v \varepsilon 1 \alpha u ̛ \tau \eta ́ v)$.

3. AdMo 49, p. 54: „Viel Schlaf führt in Versuchungen, der Wachende aber

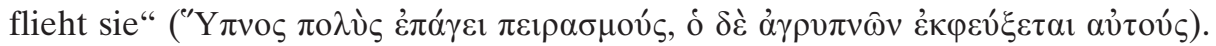
4. AdMo 50, p. 54: „So wie das Feuer Wachs schmilzt, so vertreibt das gute

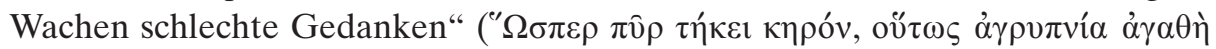

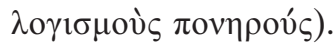

5. AdMo 51, p. 54: „Besser ein schlafender Mann als ein wachender Mönch in

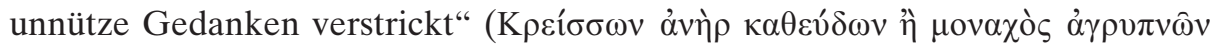

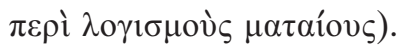

6. AdMo 52, p. 54: „Ein engelhafter Traum erfreut das Herz, ein dämonischer

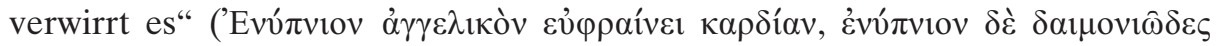

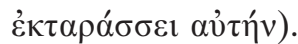

7. PaThII 9, p. 101,12-25: Pachomios, ein späterer Vorsteher der Klöster in Tabenissi, erzählte über Theodoros (den Schüler des älteren Pachomios): „Gott teilte ihm vieles durch Offenbarungen, noch mehr aber durch sein Herz mit. Anderes erfuhr er wiederum durch Engel, und er ehrte ihn mit unterschiedli-

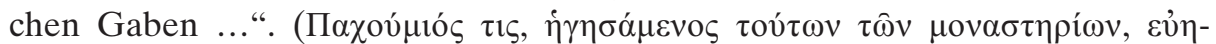

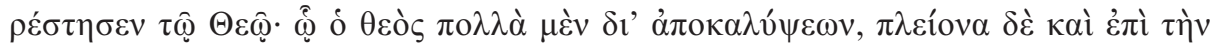

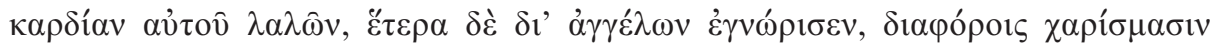

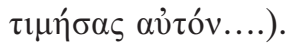

8. ViAn 82,2, p. 344,7-16: Wenn sich Antonios mit seinen Besuchern aufhielt, schwieg er oft, so wie es bei Daniel geschrieben steht (Dan 4,19). „Einige Stunden später fing er dann wieder an, die Brüder, die ihn umgaben, zu unterrichten. Doch diese verstanden, dass er ein Gesicht gesehen hatte" (oi $\delta \grave{\varepsilon}$

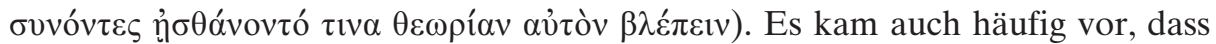
er sich auf dem Berg aufhielt und sah, was in Ägypten geschah, dann erzählte er 
es dem Bischof Serapion, der sich bei ihm drinnen aufhielt und Antonios in der

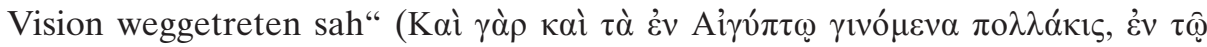

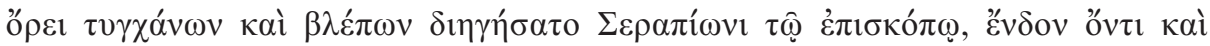

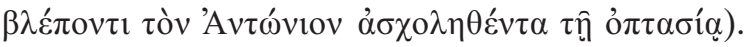

9. ApAl, Antonios 37, PG 65, col. 88B: Antonios sagte: „Ich kannte Mönche,

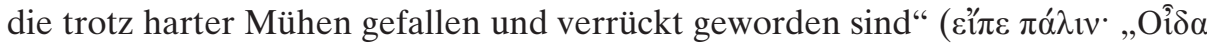

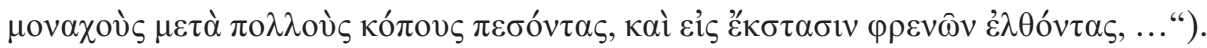
10. ApAl, Poimen 139, PG 65, col. 356D-357A: „Abbas Poimen sagte: ,Wenn du Gesichte siehst und Stimmen hörst, erzähl es nicht deinem Nächsten. Dies

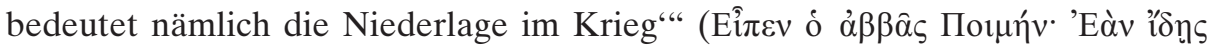

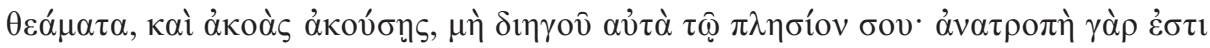
$\pi \mathrm{o} \lambda \varepsilon \dot{\mu o v})$.

11. ApAl, Tithoes 6, PG 65, col. 428D: „Als Abbas Tithoes einmal saß, befand

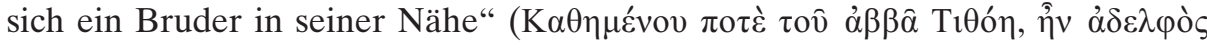

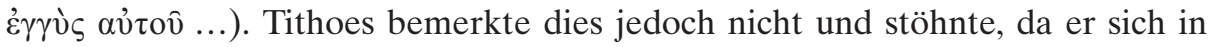

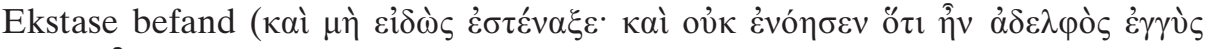

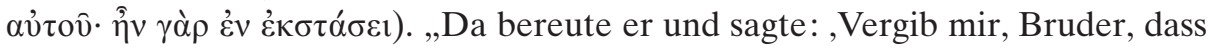
ich noch nicht Mönch geworden bin, weil ich vor dir gestöhnt habe“" (Kaì

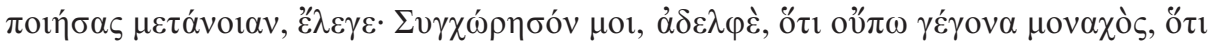

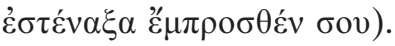

12. ApSy III 39, Bd. I, p. 172: „Ein geron sagte:, Wenn es möglich wäre, dass bei der Wiederkunft Gottes nach der Auferstehung die Seelen der Menschen aus Furcht sterben würden, dann würde die ganze Welt vor Schrecken und Zerrütung sterben. Welch ein Anblick ist es nämlich, die Himmel aufgerissen und Gott in Zorn und Unwillen offenbart zu sehen, und unzählige Armeen von

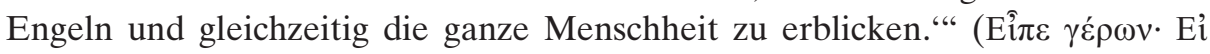

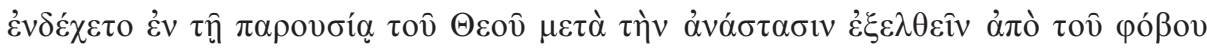

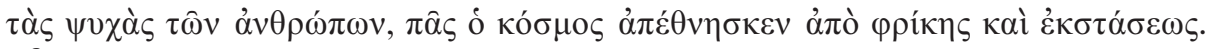

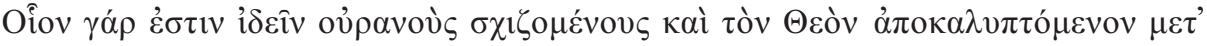

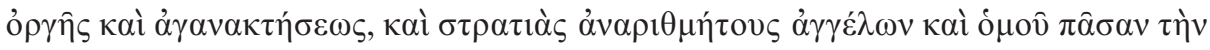

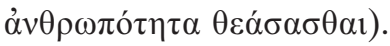

13. ApSy XI 5, Bd. 2, p. 138: „Und er [Arsenios] sagte wiederum: ,Wenn wir nach Gott suchen, wird er uns erscheinen, und wenn wir ihn bewahren, wird er

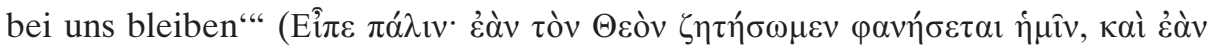

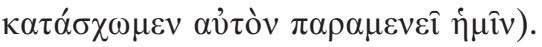

14. ApSy XI 15, Bd. 2, p. 142: „Als Abbas Bissarion im Sterben lag, sagte er: ,Es ist notwendig, dass der Mönch wie die Cherubim und Seraphim ganz Auge

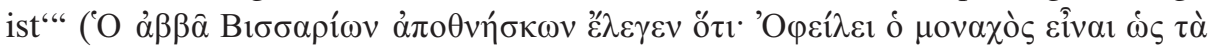

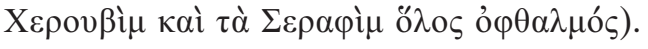

15. ApSy XV 88, Bd.2, p. 342: „Die gerontes sagten: ,Wenn dir wirklich ein Engel erscheint, dann nimm ihn nicht auf, sondern erniedrige dich selber, indem du sagst: «Ich Sünder bin nicht würdig, einen Engel zu sehen»"“ ("E $\lambda \varepsilon \gamma o v$ oi 


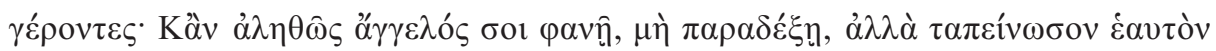

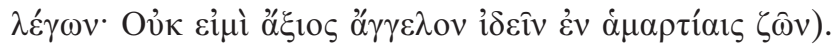

16. Bar 196, 12-14, Bd. 1,2, p. 622: Barsanuphios antwortet einem gläubigen Christen [...], dass er Gott bitten solle, ihnen den Heiligen Geist zu schicken. Denn wenn er komme, dann werde er sie über alles belehren und ihnen alle

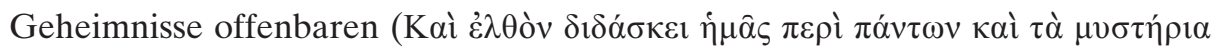

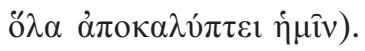

17. Bar $644,44-47$, Bd. 3, p. 74: „,...] lass uns demütig werden, dann wird uns

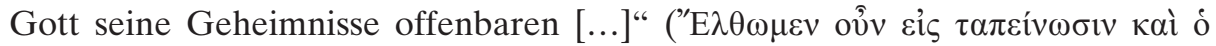

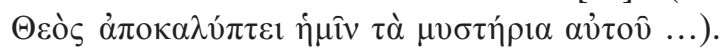

18. Bar 431, Bd. 2,2, p. 508: Ein Bruder fragte, ob es gut sei, etwas aus ganzer Kraft im Herzen zu beschauen oder zu beten, ohne jede Mitwirkung der Zunge. Wenn ihm dies nämlich widerfahre, dann sei sein Geist versunken, er fühle sich schwer, und es scheine ihm, Dinge und Erscheinungen zu sehen, und er befinde

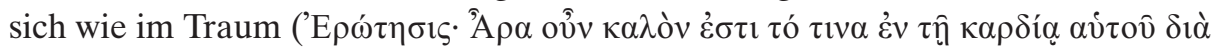

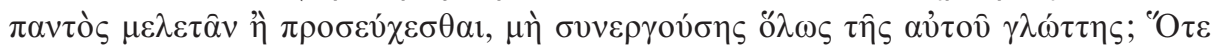

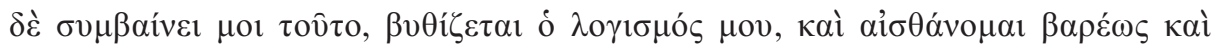

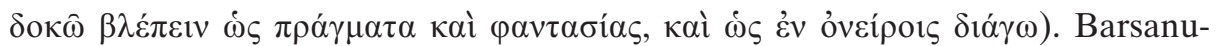
phios antwortete, dass dies den Vollendeten vorbehalten sei, die in der Lage seien, ihren Geist zu lenken und ihn in der Furcht Gottes zu halten, damit er nicht abdrifte und in tiefe Zerstreuung oder in Trugbilder gerissen werde. Wer aber die Aufmerksamkeit des Geistes nicht gänzlich bei Gott halten könne, der

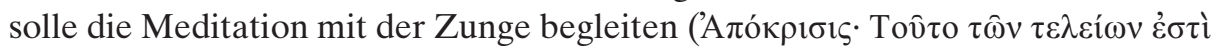

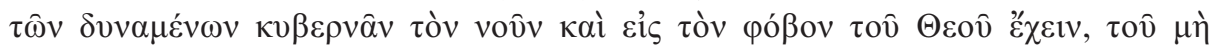

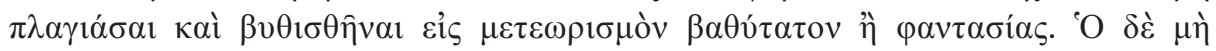

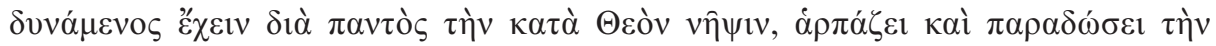

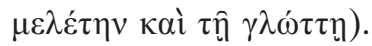

19. Cap xxxiii, PG 40, col. 1265B: „Die Ekstase ist die erneute Neigung des verständigen Teils der Seele zum Schlechten hin, nachdem sie sich bereits der

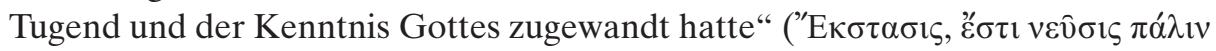

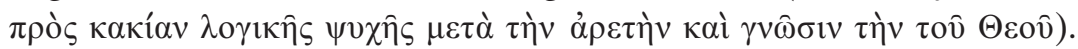

20. DeMa 23,1-4, p. 232,4-7: „Keiner soll in Zorn, Überheblichkeit oder Kummer als Anachoret leben oder die Brüder fliehen, wenn er von solchen Gedanken geplagt wird; aus derartigen Leidenschaften geht nämlich auch

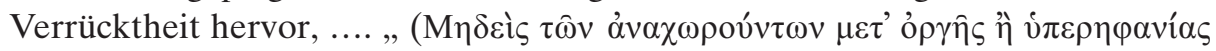

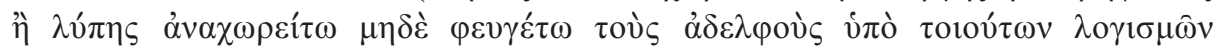

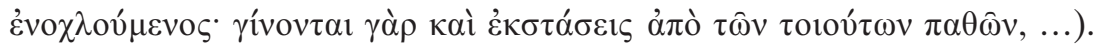

21. DeMa 28, p. 252,1-254,12: ,Wenn die Dämonen in der Nacht weder den zornigen noch den begehrenden Teil der Seele durcheinanderbringen konnten [s. S. 57 A. 241], dann schaffen sie Träume der Ruhmsucht und führen die Seele in einen Abgrund von schlechten Gedanken herab. Die von ihnen erzeugten Träume sind, um ein Beispiel davon zu geben, so beschaffen: Häufig sieht sich 
einer selbst die Dämonen tadeln und irgendwelche Krankheiten heilen oder ein Hirtengewand tragen und eine Herde weiden lassen. Und wenn er aufwacht, empfängt er auf einmal das Trugbild der Priesterschaft und macht sich den ganzen Tag Gedanken über die damit zusammenhängenden Dinge. [...] Häufig werfen sie die Anachoreten in eine untröstliche Trauer, indem sie ihnen Angehörige zeigen, die krank und auf dem Land oder auf dem Meer Gefahren ausgesetzt sind. Es geschieht aber auch, dass sie in den Träumen den Brüdern selbst den Schiffbruch des monastischen Lebens vorhersagen, indem sie sie von hohen Leitern, die sie erklommen haben, herunterstürzen und sie erblinden und

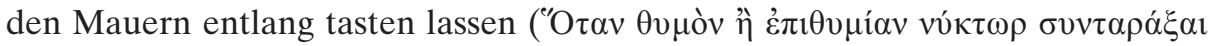

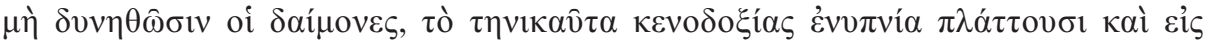

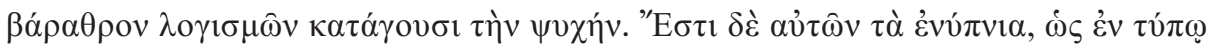

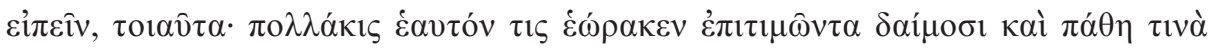

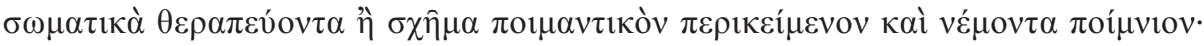

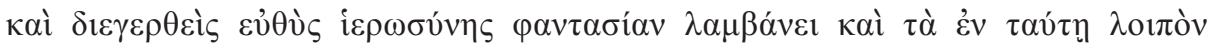

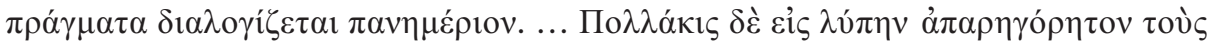

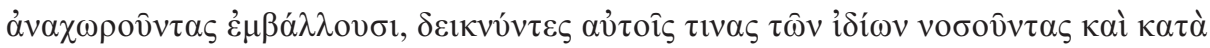

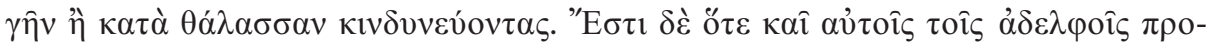

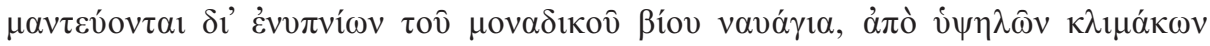

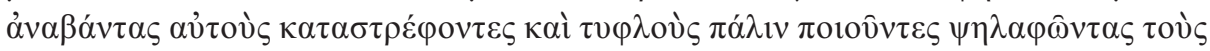

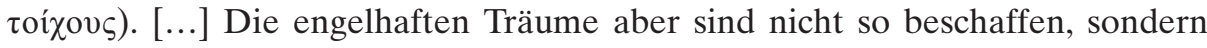
bringen eine große Seelenruhe und unbeschreibliche Freude mit sich und die Tilgung der leidenschaftlichen Gedanken während des Tages sowie reines Gebet und sogar Reden über die Geschehnisse, die leise aus Gott hervorgehen und die

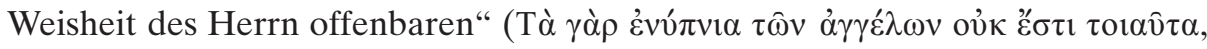

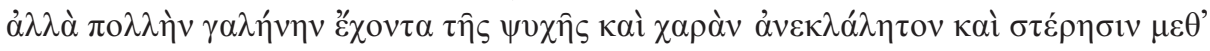

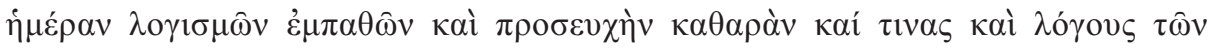

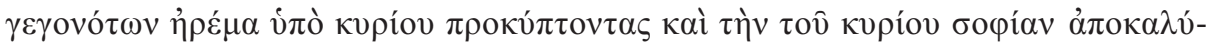
$\pi \tau \mathrm{ov} \tau \alpha \varsigma)$.

22. HiLa 1,18, p. 15,22-16,1: Vom Asketen Isidoros wird berichtet, „dass er so tiefe Kenntnis der heiligen Schrift und der göttlichen Lehren besaß, dass er sogar bei den gemeinsamen Mahlzeiten der Brüder entrückt wurde und in Verzückung geriet. Bat man ihn, über die Ekstase zu erzählen, so sagte er: ,Ich war im Geiste abwesend und von einer Schau entrückt" (

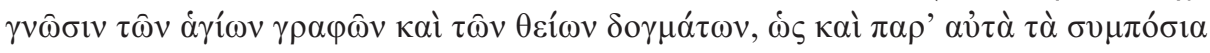

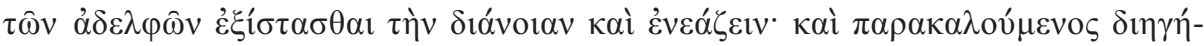

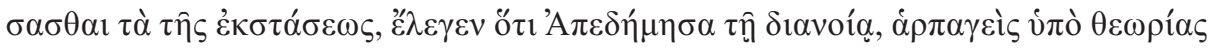
$\tau \imath v o ́ \varsigma)$.

23. HiLa 32,3 f., p. 88,2 f.: Von Pachomios, wird gesagt, dass er „einer von den Männern war, die den geraden Weg eingeschlagen haben, sodass ihm die Gabe

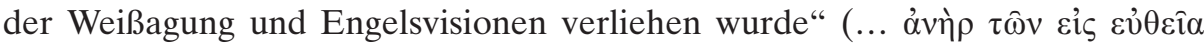

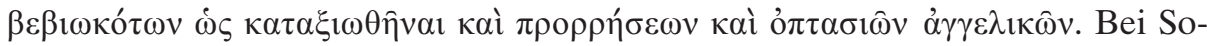




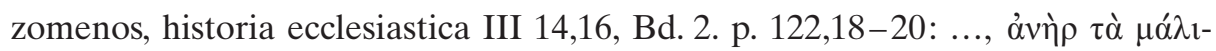

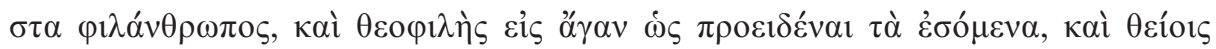

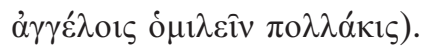

24. HiLa 58,37, p. 153,2 f.: Ein Einsiedler lebte in einer Höhle in der Thebais. „Er wurde durch den Stachel der Ruhmsucht von Traumbildern getäuscht, ...“

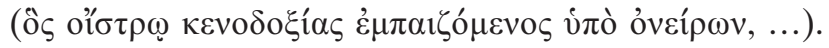

25. HiMo 1,45, p. 26,11-27,5: Ein Mönch ließ sich in der inneren Wüste nieder und vollbrachte während langer Zeit viele gute Werke. „Er liebte die Ruhe und verbrachte den Tag mit Gebeten, Hymnen und zahlreichen kontemplativen Erfahrungen und sah göttliche Visionen, sowohl im Wachzustand als auch im

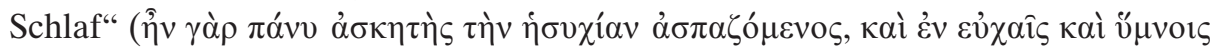

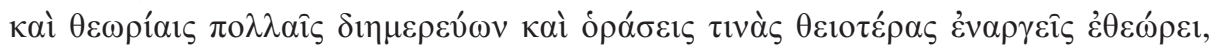

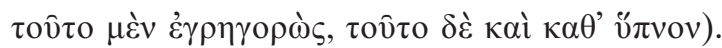

26. HiMo 1,28, p. 19,1-6: „Derjenige, der würdig ist, Gott teilweise zu erkennen - die vollkommene Erkenntnis Gottes kann nämlich niemand erlangen besitzt auch die Erkenntnis von allen anderen Dingen. Er erblickt die Geheimnisse, die Gott ihm zeigt, er sieht die Zukunft voraus und schaut Offen-

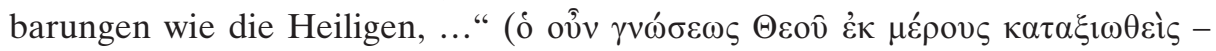

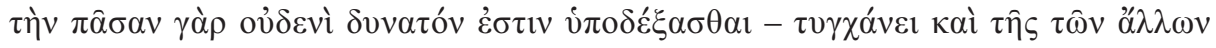

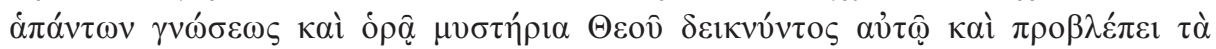

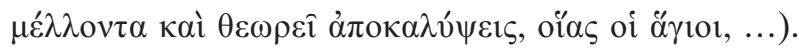

27. HiMo 8,34, p. 56,14-18: Sie (Apollo und der von ihm bekehrte Mörder, s. 159) ,sahen und hörten viele Wunder, welche Worte nicht auszusprechen und Ohren nicht zu hören wagen, und wenn sie aufwachten, erzählten sie den Anwesenden davon. Alle aber waren überaus verwundert, wenn beide von der

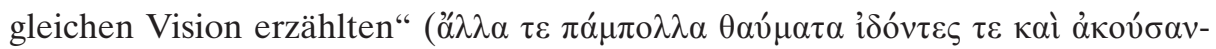

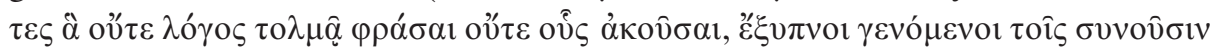

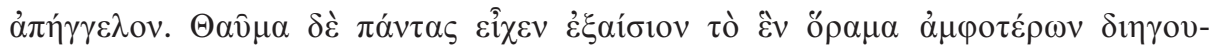
$\mu \varepsilon ́ v(\omega v)$.

28. ViHy 14,1, p. 122,12 f.: „Oft wurden ihm [Hypatios], der sich selber eingesperrt hatte, viele Geheimnisse offenbart, die er nicht erzählen wollte" (По $\lambda$ -

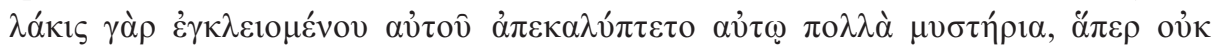

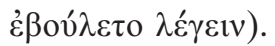

29. ViIo 5, p. 205,5-12: Als Ioannes in die Laura des Sabas kam, übergab dieser ihn wie einen Anfänger dem Haushälter. Sabas erkannte nämlich nicht den

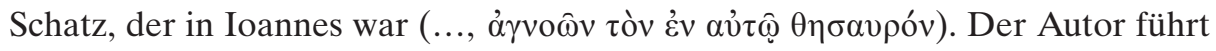
aus, dass es nicht erstaunlich sei, dass Sabas der Schatz der guten Taten des Ioannes verborgen blieb. Denn wenn der Herr beschließe, seinen Heiligen etwas zu offenbaren, seien diese Propheten. Wenn er es aber verbergen wolle, dann

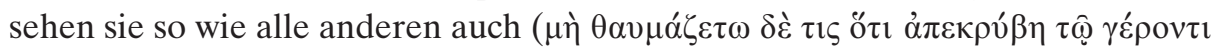

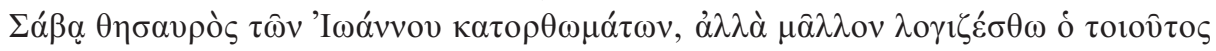




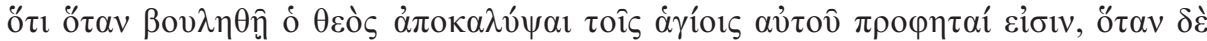

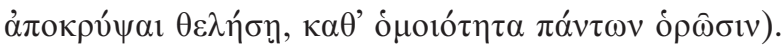

30. ViIoEl 38,72-101, Bd. 2, p. 389,4-28: Der heilige Bitalios verbrachte seinen Lebensabend damit, die Prostituierten Alexandreias von ihrer Lebensweise abzubringen. In den Nächten besuchte er die Prostituierten und stand, während sie schliefen, betend in einer Ecke ihres Zimmers. Da er seine guten Taten verbergen wollte, ertrug er es, von verschiedenen Seiten wegen seines lasterhaften Lebens angeklagt und verleumdet zu werden. Trotzdem hörte er nicht auf, seine Werke zu vollbringen. Vielmehr bat er Gott, manchen nach seinem Tod in einer Vision erscheinen zu dürfen, damit er für diejenigen, die ihn ver-

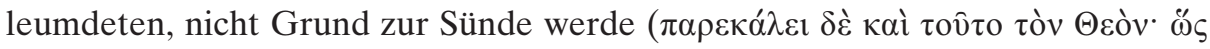

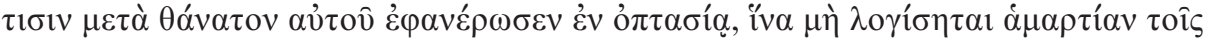

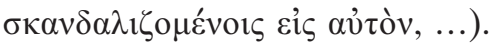

31. ViPa 22, Halkin 1982, p. 17,17 f.: Nachdem Pachomios erfolgreich die Dämonen bekämpft hatte, ,sah er gleichsam den unsichtbaren Gott in der

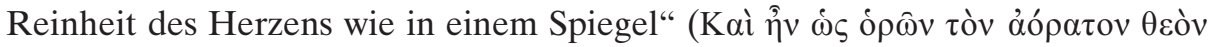

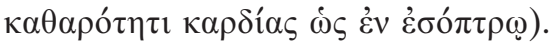

32. ViPa 88, Halkin 1982, p. 43,25-44,16: Theodoros, der Schüler des Pachomios, hatte während langer Zeit die Angewohnheit, nach seiner Arbeit jeden Abend von Pabaus nach Tabennese zu gehen, um von Pachomios die Worte der Heiligen Schrift zu vernehmen. Eines Tages geschah es, dass er Pachomios nicht fand. Deshalb ging er in das Zimmer über dem Versammlungsraum, um Passagen aus den göttlichen Schriften zu lernen. Und als er beim Lernen war, fing der Ort, an dem er sich befand, an zu beben. Theodoros fragte sich, was das sein könnte, und ging hinunter in den Versammlungraum, um zu beten. Doch als er eintrat, konnte er aus Furcht vor dem, was sich an jenem Ort abspielte, nicht stehen bleiben. Sein Körper fing an zu beben, und als die Angst noch zunahm, sprang er aus der Tür, ohne zu verstehen, wie ihm geschah. Nach der morgendlichen Versammlung fand er Pachomios, wie er gerade dabei war zu er-

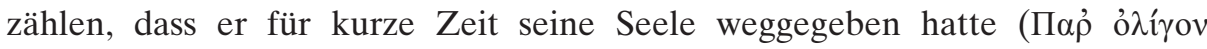

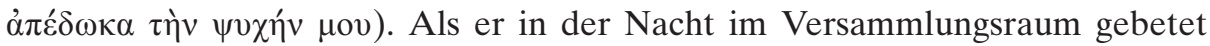

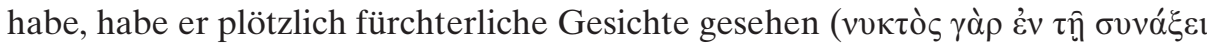

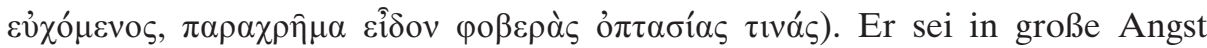
geraten und habe Gott darum gebeten, dass diese Furcht für immer in ihm und in den Brüdern bleibe. Und während er sich noch in dieser Not befand, sei irgendein Dreister eingetreten. Sofort sagte Theodoros, dass er dies gewesen sei. Die Anwesenden aber staunten über diese Worte. „Denn wenn Gott wollte, dass Pachomios etwas von den verborgenen Dingen sah, pflegte er ihnen sonst nur so viel mitzuteilen, wie ihnen zum Glauben und zur Erbauung gereichte" (..., દ̇àv

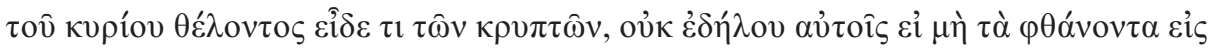

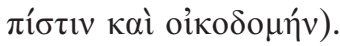


33. ViPa 93,28, Halkin 1982, p. 46,8 f.: „Manchmal erzählten sie [Pachomios und Theodoros] Teile von dem, was sie gesehen hatten, entsprechend dem Willen Gottes, da sie den zukünftigen Nutzen vorhersahen. Pachomios lehrte nämlich, den Gedanken an den Wunsch, etwas von den unsichtbaren Dingen zu sehen, auf keinen Fall zuzulassen, da sie voll Wunder und Schrecken sind für den, der

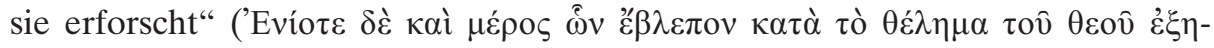

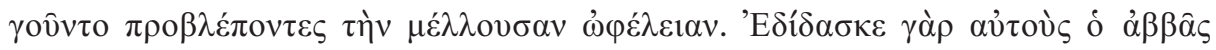

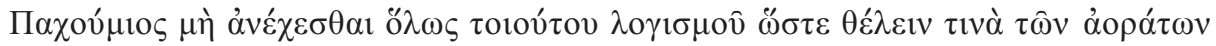

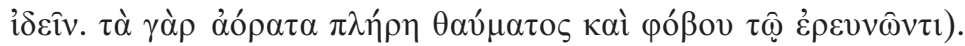

34. ViPa 96,8-11, Halkin 1982, p. 47,22-25: Laut Pachomios haben sich viele schon umgebracht, weil sie den dämonischen Anschlag der Gotteslästerung nicht bekämpfen konnten, ,der eine, indem er sich wie ein Rasender von oben herunterwarf, der andere, indem er sich mit einem Messer den Bauch auf-

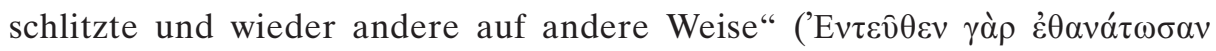

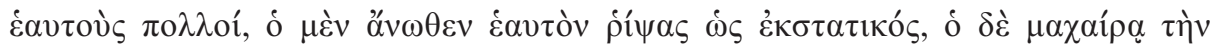

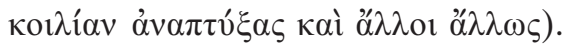

35. ViPa 135,8-11, Halkin 1982, p. 64,20-23: „Niemand soll über einen Menschen Gottes Zweifel hegen, wenn er hört, dass dieser eine Vision sieht, denn derjenige, der die Visionen zeigt, wohnt in ihm. Aber auch hier müssen wir uns absichern, damit niemand zu sein glaubt, was er nicht ist, und vom Feind in das Verlangen geführt wird zu sehen. Wenn er einmal in der Schlinge gefangen

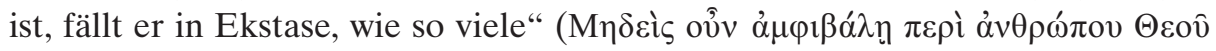

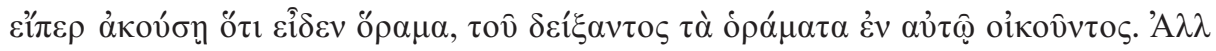

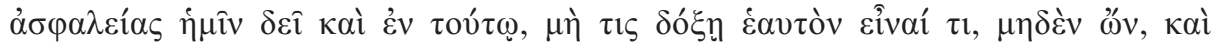

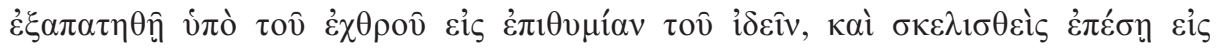

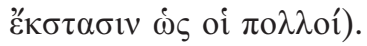

36. PaThI 11,33,20-24, p. 91,30-34: Pachomios „ermahnte die Brüder, sie sollten nicht stolz auf ihre guten Werke sein und auch nicht danach verlangen, Visionen zu sehen oder Dämonen zu schauen, sich mit derartigen Dingen zu beschäftigen oder durch ein solches Verlangen das Göttliche versuchen, das durch die Heilige Schrift verkündet ,du sollst nicht deinen Herrn versuchen“

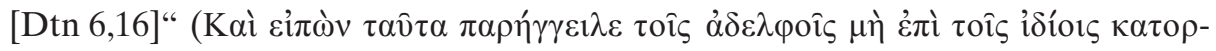

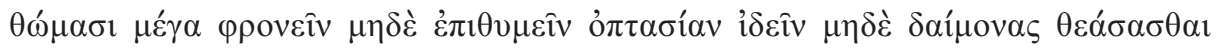

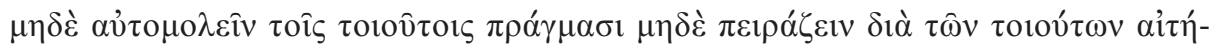

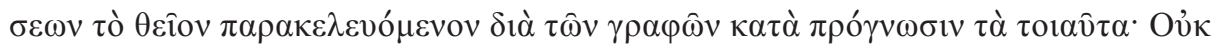

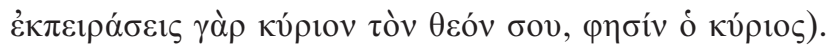

37. PhHi 2,2, Bd. 1, p. 198,17-20: Vom Eremiten Iulianos von Osrhoene wird gesagt, „dass er die Glut der Liebe [zu Gott] so sehr in sich aufgenommen hatte, dass er vor Verlangen betrunken war und nichts mehr von den irdischen Dingen wahrnahm, sondern in der Nacht bloß noch vom Geliebten träumte und sich ihn

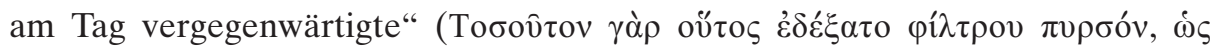




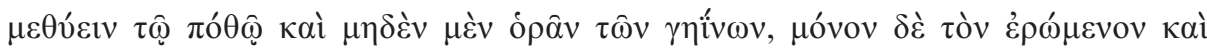

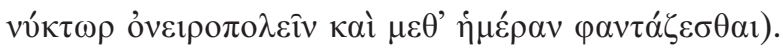

38. PhHi 9,2, Bd. 1, p. 408,13-21: Petros, der Galater, ging nach Palästina, „um die Orte zu sehen, wo sich das Leid des Erlösers abgespielt hatte, und um dort vor Gott, dem Retter, niederzuknien. Nicht, dass er geglaubt hätte, er [Gott] sei durch einen Ort umrissen, denn er wusste um die Unbeschreibbarkeit seiner Natur. Vielmehr ging er hin, um die Augen durch die Schau des von ihm Begehrten zu nähren, und damit sich nicht allein der sehende Teil der Seele ohne das physische Auge durch den Glauben am geistlichen Genuss erfreue " (.. iv $\alpha$

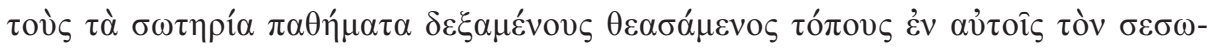

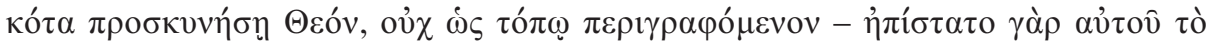

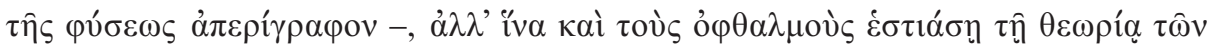

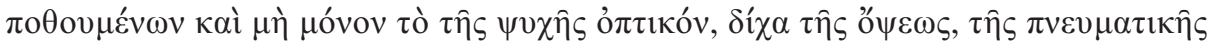

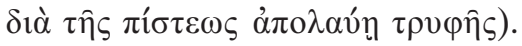

39. PhHi 21,34, Bd. 2, p. 122,3-10: Als Erklärung dafür, warum sich Iakobos in die Einsamkeit zurückzog und keine Leute empfing, führt Theodoret an, dass es den Liebenden eigen sei, alles andere zu verachten, um sich mit der geliebten Person zu vereinigen, in der Nacht von ihr zu träumen und sie sich am Tag zu

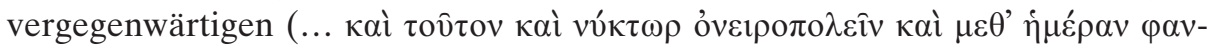
$\tau \alpha \dot{\zeta} \zeta \varepsilon \sigma \theta \alpha \imath)$. Aus diesem Grund schien sich Iakobos zu ärgern, wenn er in die ersehnte Schau gelangt war, aber daran gehindert wurde, sich von der geliebten

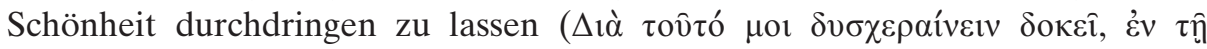

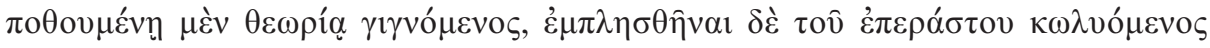

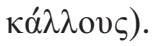

40. PhHi 26,20, Bd. 2, p. 200,20-22: Nach der Erzählung von Symeons Vision (vgl. 95) führt Theodoret aus, dass er noch anderes von dieser Art zu erzählen hätte, dass er dies aber weglasse, um die Ausdehnung des Werkes zu vermeiden. Das Gesagte sei ausreichend, um die Fähigkeit der spirituellen Schau seines

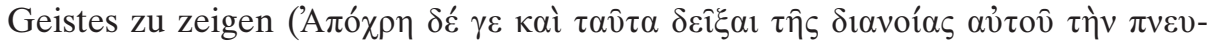

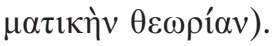

41. ViPo 59, p. 47,23-48,10: Die Bevölkerung von Gaza opferte der Statue der Aphrodite, da sie glaubte, dass die Göttin den Heiratswilligen im Traum

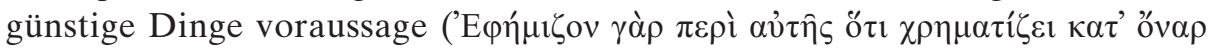

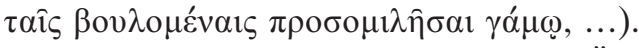

42. Prak 14,5, Bd. 2, p. 534,1-3: „Der Überheblichkeit folgt Zorn und Kummer und schließlich das äußerste Übel, Verrücktheit, Raserei und das Erblicken von

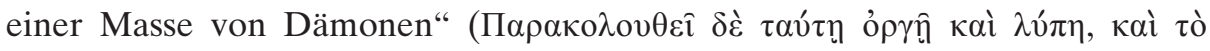

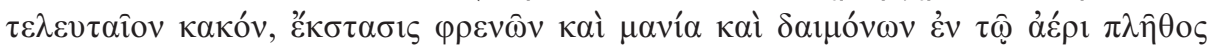

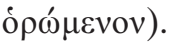

43. Prak 55, Bd. 2, p. 628,1-5: „Wenn sie bildlos sind, bedeuten die natürlichen Bewegungen des Körpers im Schlaf, dass die Seele bis zu einem bestimmten Grad gesund ist. Die Schaffung von Bildern ist ein Zeichen von Krankheit. 
Wenn die Gesichte unbestimmt sind, bedeutet dies ein altes Leiden, wenn sie aber klar umrissen sind, dann ist dies das Zeichen von einer frischen Wunde“"

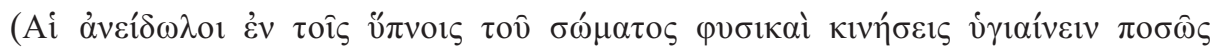

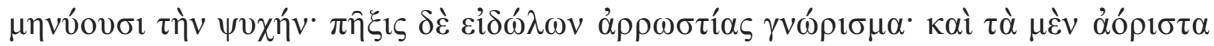

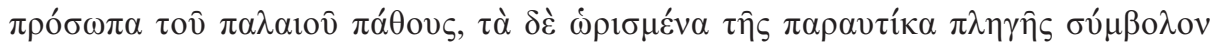
vó $\mu 1 \zeta \varepsilon)$.

44. Prak 56, Bd. 2, p. 630,1 f.: „Die Beweise der Leidenschaftslosigkeit erkennen wir am Tag durch die Gedanken, in der Nacht durch die Träume“ (T⿳亠㐅冋 $\mu \grave{\varepsilon} v$

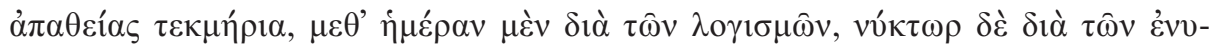

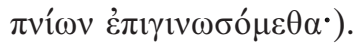

45. Prak 64, Bd. 2, p. 648,1-3: „Es ist ein Zeichen der Leidenschaftslosigkeit, wenn der Geist anfängt, seinen eigenen Glanz zu sehen und im Angesicht der Trugbilder im Schlaf ruhig bleibt und die Dinge gelassen sieht" ('A $\pi \alpha \theta$ cí $\alpha \varsigma$

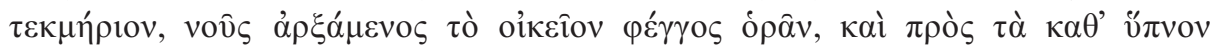

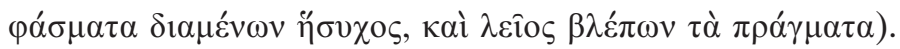

46. Prak 76, Bd.2, p. 664,1-5: „Die Engel freuen sich, wenn das Schlechte abnimmt, die Dämonen, wenn die Tugend kleiner wird. Die einen sind nämlich die Schöpfer von Barmherzigkeit und Liebe, die anderen gehorchen dem Zorn und dem Hass. Wenn sich uns die ersten nähern, erfüllen sie uns mit spiritueller Kontemplation. Wenn aber die anderen herankommen, werfen sie die Seele in

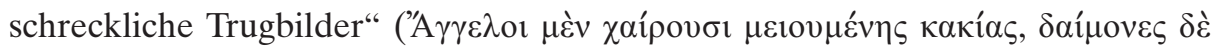

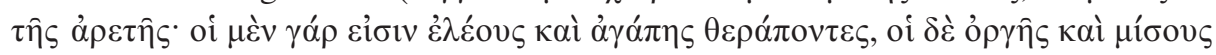
نं

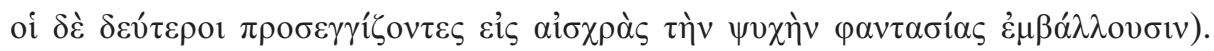
47. ScPa 3, PG, 88, col. 669C: „Wer an Träume glaubt, gleicht demjenigen, der seinem eigenen Schatten nachläuft und versucht ihn festzuhalten" ('O toóvvv

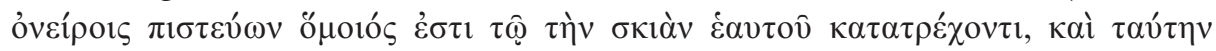

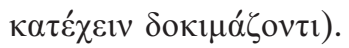

48. $\mathrm{ScPa} 4$, PG 88, col. 796C: Ein anderer aus Thola wurde oft von diesem Gedanken (an den Tod) in Ekstase versetzt. „Und wie bewusstlos oder nach einem epileptischen Anfall wurde er von den Brüdern, die ihn fanden, beinahe

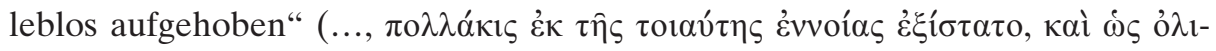

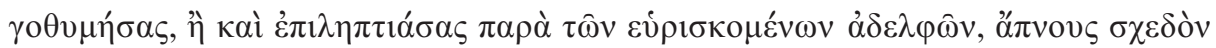

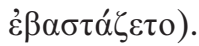

49. $\mathrm{ScPa}$ 11, PG 88, col. 852B: „Schweigen in Erkenntnis ist [...] ein Schöpfer

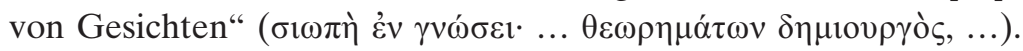

50. $\mathrm{ScPa} 15$, PG 88, col. 881B: „Der wahrhaftige Beweis für Keuschheit ist es, wenn man angesichts der Trugbilder im Schlaf unbewegt bleibt" (

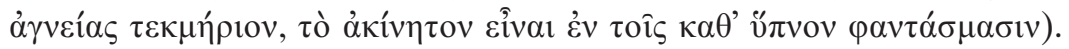

51. ViSySa 1676C,4, p. 59,12-14: Als Symeon und Ioannes beschlossen, Welt und Familie hinter sich zu lassen, ,vergaßen sie ihren ganzen Besitz und die 


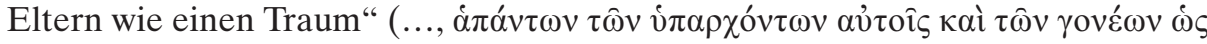
öv $\alpha \rho \dot{\varepsilon} \pi \imath \lambda \alpha \theta$ ó $\mu \varepsilon v o 1, \ldots)$.

52. ScPa 6, PG 88, col. 796D: Ein Einsiedler namens Chorebitos lebte ständig in Unbekümmertheit vor sich hin und sorgte sich nicht um seine Seele. „Dann kam eine schwere Krankheit über ihn, und er war für genau eine Stunde [schein]tot"

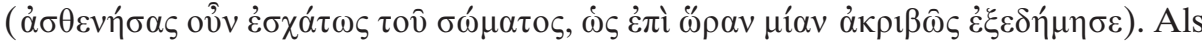

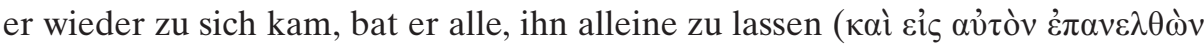

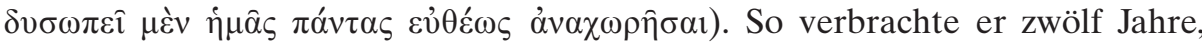
ohne mit irgendjemandem zu sprechen. „Er saß nur da und staunte über das, was er in der Ekstase gesehen hatte. Er war so nachdenklich, dass er niemals seinen Gesichtsausdruck änderte, sondern immer gedanklich außer sich war und

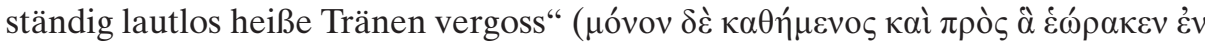

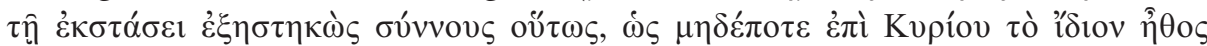

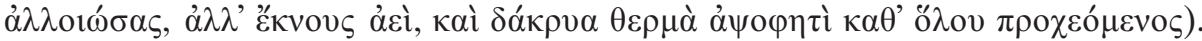
53. ScPa 7, 14, PG 88, col. 809A: „Selig ist der Mönch, der fähig ist, mit den

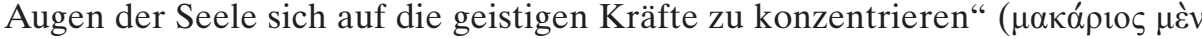

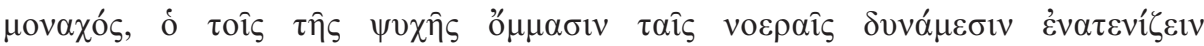
$\left.\delta v v \alpha ́ \mu \varepsilon v \circ \varsigma^{\circ}\right)$.

54. ScPa 7, PG 88, col. 813C: „Eile nicht der Schau nach, wenn die Zeit nicht reif ist dafür, damit sie [die Schau] der Schönheit deiner Demut nacheifere, und wenn sie sie erreicht hat, sich für immer mit dir in einer reinen Heirat verbinde“

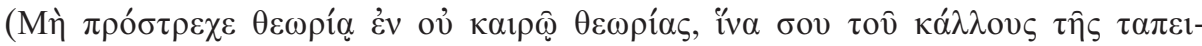

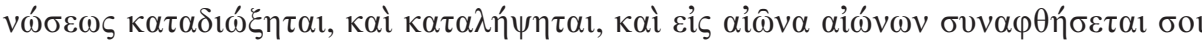
$\grave{\varepsilon} v \pi \alpha v \alpha ́ \gamma v(\gamma \alpha \dot{\mu} \mu \omega)$.

55. ScPa 14, PG 88, col. 865D: „Im Herzen des Gefräßigen sind Träume von Essen und Speisen, im Herzen der Trauernden aber Träume von Strafen und

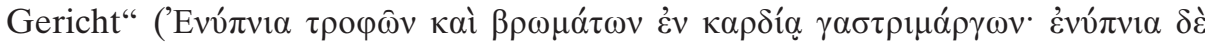

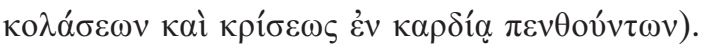

56. ScPa 15, PG 88, col. 896B: „Wenn wir friedlich vom Schlaf erwachen, sind wir im Verborgenen von Engeln getröstet worden, vor allem, wenn wir nach viel Gebet und Fasten eingeschlafen sind. Wenn wir aber verdrießlich erwachen,

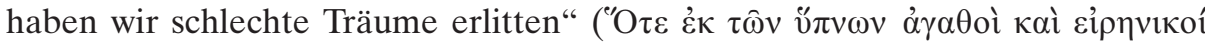

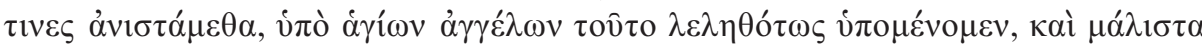

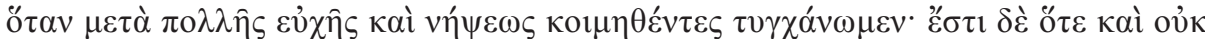

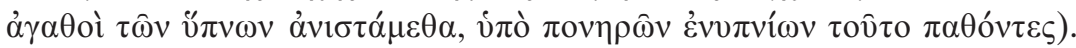




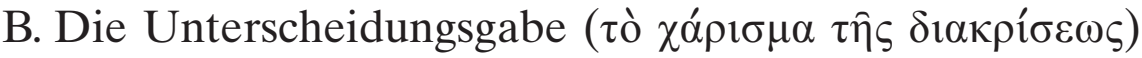

57. ViAn 22,3 p. 196,6-8: (1) „Viel Gebet und Askese ist erforderlich, damit jemand, der durch den Heiligen Geist die Gabe der Unterscheidung der Geister

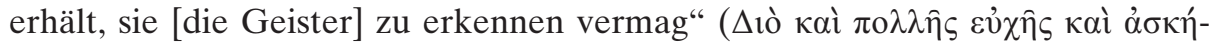

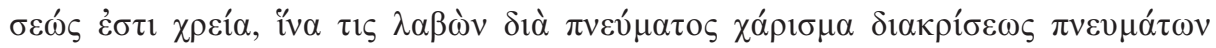

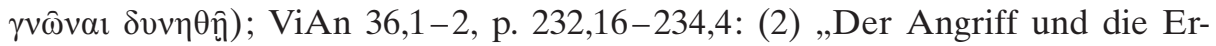
scheinung der bösen Geister bringt Verwirrung mit sich, kommt mit Schlagen, Lärm und Geschrei wie die Unruhe, die von ungezogenen Jugendlichen und Dieben hervorgerufen wird. Daraus entsteht sofort Furcht der Seele, Verwirrung und Unordnung der Gedanken, Niedergeschlagenheit, Hass gegen die Asketen, Nachlässigkeit, Kummer, Erinnerung an die Verwandten, Todesfurcht und schließlich Verlangen nach dem Bösen, Gleichgültigkeit gegenüber den

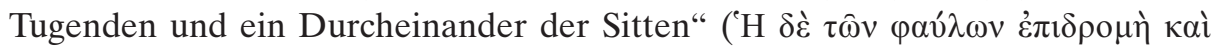

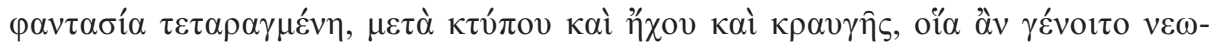

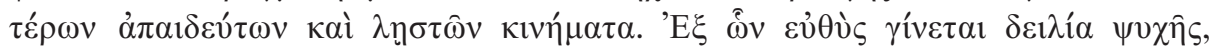

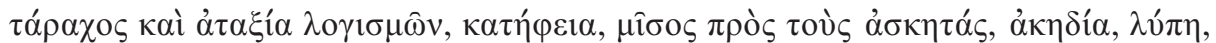

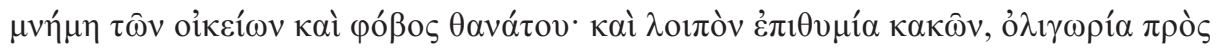

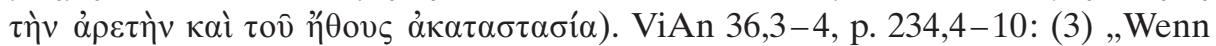
ihr etwas seht und euch fürchtet und die Furcht plötzlich verschwindet, und anstelle der Furcht unaussprechliche Freude, Hoffnung und Mut sowie Besinnung, Sammlung der Gedanken und ähnliche bereits erwähnte Dinge wie Tapferkeit und Liebe zu Gott entsteht, dann fasst Mut und betet. Denn die Freude und der Zustand der Seele zeigen die Heiligkeit des Anwesenden an“

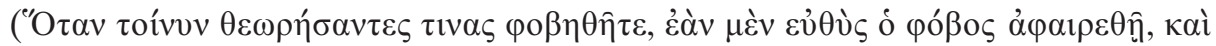

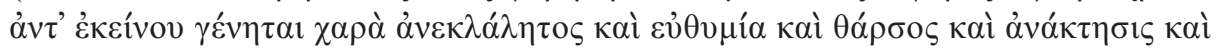

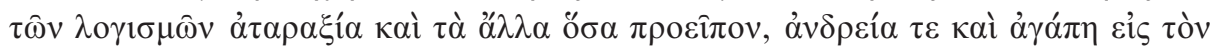

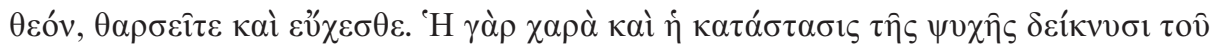

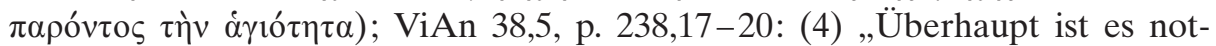
wendig $\mathrm{zu}$ beten [...], sodass wir die Gabe der Unterscheidung der Geister

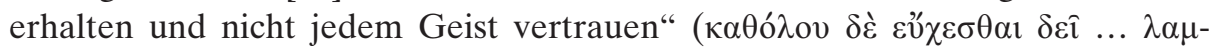

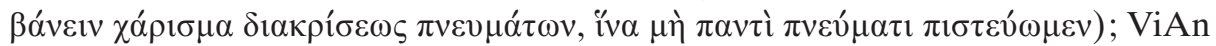
43,1-3, p. 252,3-9: (5) „Wenn ein Trugbild kommt, soll man sich nicht fürchten, sondern - welcher Art es auch immer sei - Mut fassen und als erstes fragen: ,Wer bist du und woher kommst du?' Wenn es eine Vision der Heiligen ist, informieren sie dich sofort und verwandeln die Angst in Freude. Wenn es aber der Dämon ist, dann geht ihm sofort die Kraft aus, sobald er den Geist [des Asketen] gestärkt sieht. Ein Beweis der Leidenschaftslosigkeit ist das bloße 


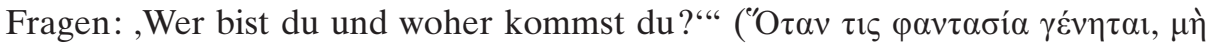

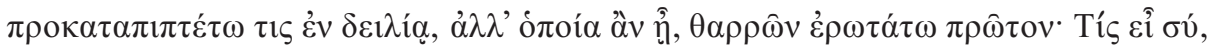

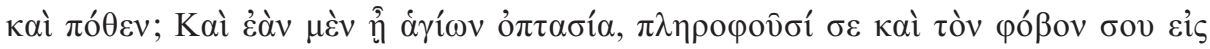

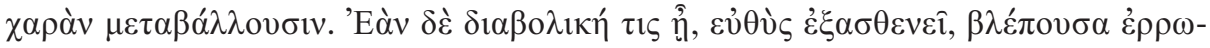

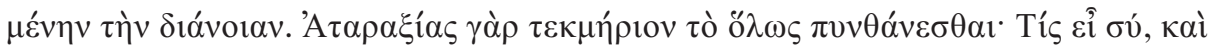
$\pi$ ó $\theta \varepsilon v ;)$.

58. ViAn 88,1 p. 360,6-10: Antonios „besaß die Gabe der Unterscheidung der Geister, weshalb er erkannte, was die anderen bewegte und was wer auch immer

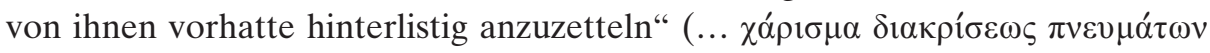

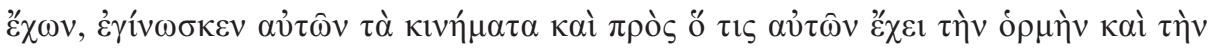
$\sigma \pi \mathrm{ov \delta \eta ̀े} \mathrm{\tau ovิ} \mathrm{\varepsilon ̇ \pi ıßov \lambda \varepsilon v́ \varepsilon iv).}$

59. ApSy V 4,1-8, Bd I, p. 242: „Es ist gut, die Gedanken nicht zu verbergen, sondern geistlichen und mit der Unterscheidungsgabe begabten Vätern zu erzählen; nicht denen, die nur durch das Alter weiß geworden sind, denn viele schauen nur auf das Alter und erzählen dann ihre Gedanken. Zahlreiche sind nämlich wegen der Unerfahrenheit dessen, der sie anhörte, an-

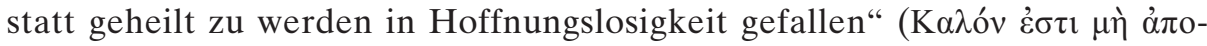

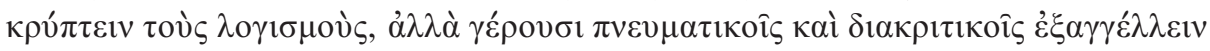

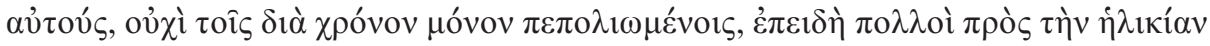

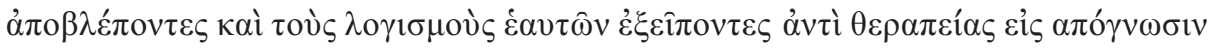

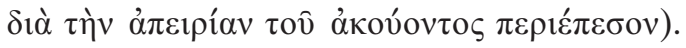

60. ApSy X 2, Bd.2, p. 14 [vgl. ApAl, PG 65, col. 77C]: Einige Brüder besuchten den Heiligen Antonios, ,um ihm von Erscheinungen zu berichten, die sie sahen. Sie wollten von ihm erfahren, ob diese wahr oder von den Dämonen

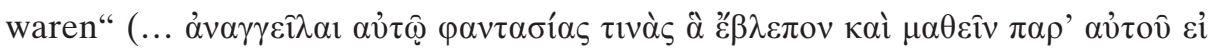

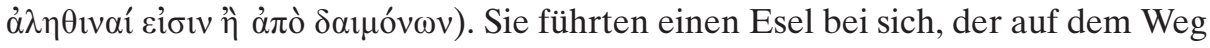
starb. Als sie zu Antonios kamen, empfing sie dieser und fragte, warum der Esel gestorben sei. Die Besucher waren erstaunt darüber, dass Antonios vom Schicksal des Esels wusste. Er aber sagte, die Dämonen hätten ihn darüber

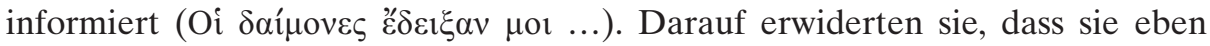
deshalb zu ihm gekommen seien, um ihn zu befragen, weil sie zuweilen Erscheinungen sahen, die sich häufig bewahrheiteten, und sie sich womöglich

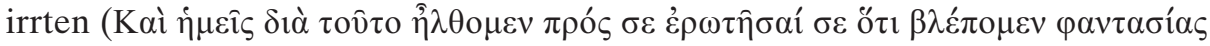

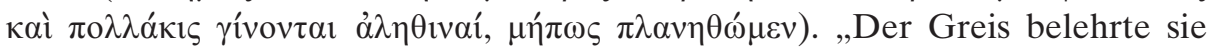
anhand des Beispiels mit dem Esel, dass sie [die Erscheinungen] dämonisch

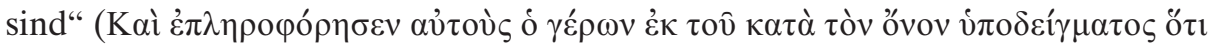

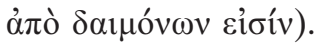

61. ApSy XV 18, Bd.2, p. 300 [vgl. ApAl, PG 65, col. 180B]: „Als Bruder Zacharias eines Tages in der Sketis saß, hatte er eine Schau, die er Abbas

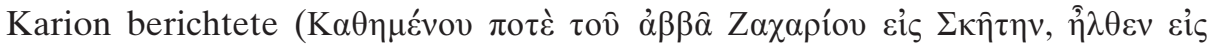




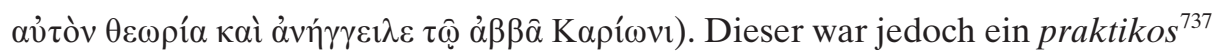

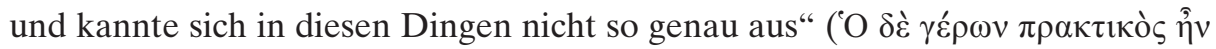

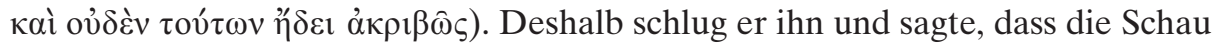

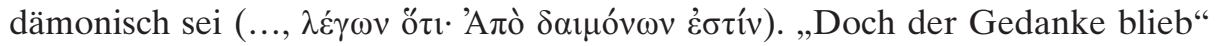

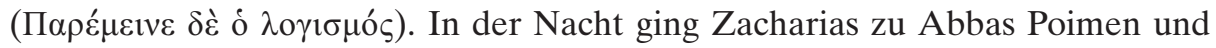
erzählte ihm alles und wie sehr es in ihm brenne. Dieser verstand, dass die Schau

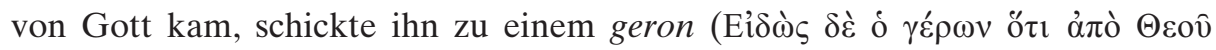

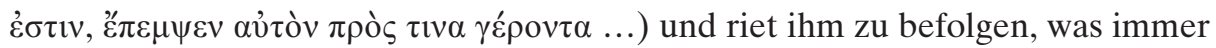
jener ihm sagen werde. Zacharias ging zum Mönch, und ,noch bevor er ihn etwas fragen konnte, nahm dieser alles vorweg und sagte, dass die Schau von

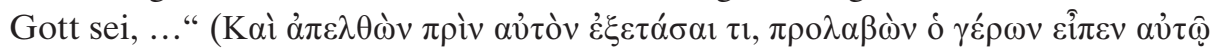

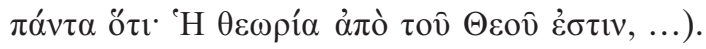

62. Bar 418, Bd. 2,2, p. 490: Ein gläubiger (weltlicher) Christ fragte Barsanuphios, ob es stimme, dass etwas wahr sei, wenn man es dreimal im Traum sehe

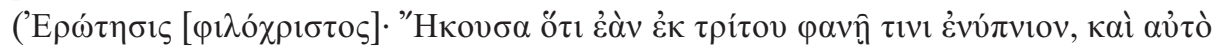

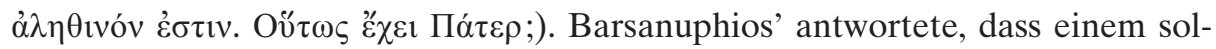
chen Traum keinen Glauben zu schenken sei, da etwas, was einmal falsch erschienen sei, dies auch dreimal oder mehrfach tun könne ('A

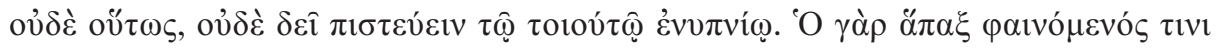

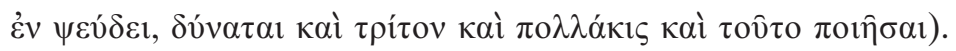

63. Bar 414, Bd. 2,2, p. 486: Ein gläubiger (weltlicher) Christ fragte Barsanuphios, ob ein Sünder, wenn er Visionen habe, nicht glauben solle, dass sie von

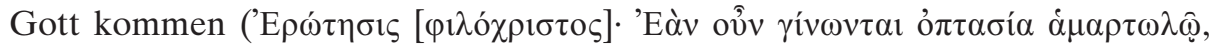

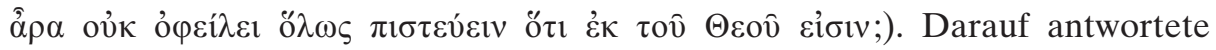
Barsanuphios, wenn dies einem Sünder passiere, sei es offensichtlich, dass es eine List der Dämonen sei, um die unglückliche Seele ins Verderben zu stürzen

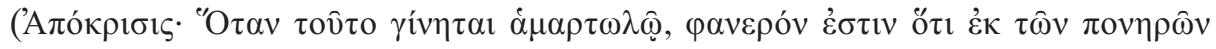

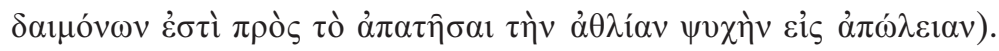

64. Bar 415, Bd. 2,2, p. 486-488: Der gleiche (weltliche) Christ fragte Barsanuphios, ob man sich abwenden solle, wenn sie (die Dämonen) in der Gestalt

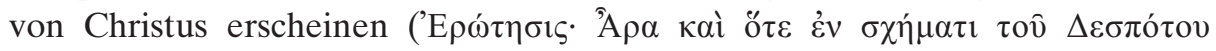

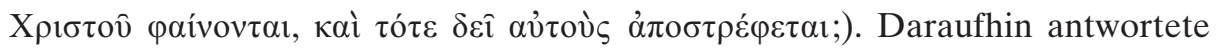
Barsanuphios, dass man sich vor allem von ihrer List und ihrer Täuschung abwenden solle, indem man sie verfluche, und er solle sich niemals irreführen lassen von dieser dämonischen Überredungskunst. Die Heiligen nämlich haben göttliche Offenbarungen, denen aber immer Ruhe und Friede und Hoffnung in

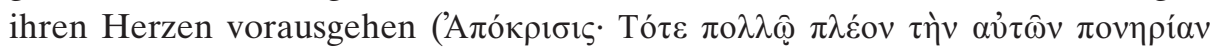

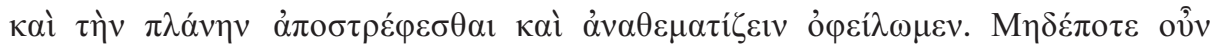

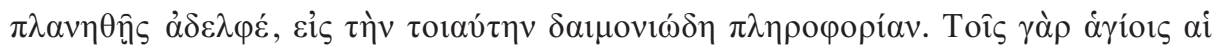

737 S. dazu Kap. 1.2.3, A. 89. 


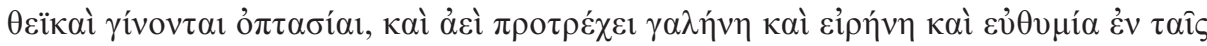
$\alpha \hat{\tau} \tau \hat{\omega} v \kappa \alpha \rho \delta i ́ \alpha \varsigma)$.

65. HiLa 24,3-5, p. 77,14-16: Über den Lyber Stephanos heißt es, dass er in der Askese bis zur obersten Stufe gelangt und mit der Unterscheidungsgabe gewürdigt worden sei, so dass jeder Not Leidende, der ihn aufsuchte, unbetrübt

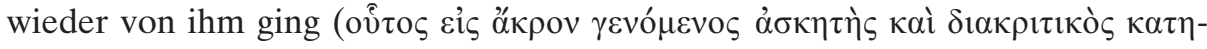

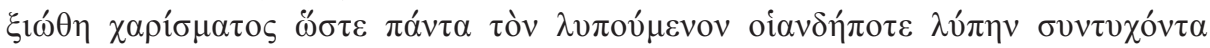

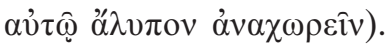

66. ViPa 48, HaLkin 1982, p. 28,19-30: Als einer von den Mönchen von Pachomios verlangte, er möge von seinen Visionen erzählen (Ei $\pi \grave{\varepsilon} \eta \dot{\eta} \mu i ̂$ ö $\rho \alpha \mu \alpha$ ஸ்v $\beta \lambda \dot{\varepsilon} \pi \varepsilon 1 \varsigma$...), antwortete dieser, dass ein Sünder wie er Gott nicht darum bitte, Visionen zu sehen, denn dies sei gegen den Willen Gottes (Tò $\mu \grave{\varepsilon} v$ ópá $\mu \alpha \tau \alpha$

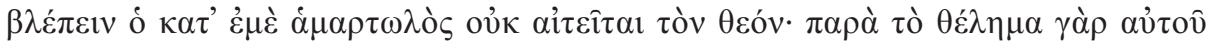
$\dot{\varepsilon} \sigma \tau \imath v)$. Trotzdem aber wolle er ihm etwas über eine Vision erzählen ('Aкоvбov $\delta \grave{\varepsilon}$ ő $\mu \omega \varsigma \pi \varepsilon \rho \grave{~ o ̀ ~} \rho \alpha ́ \mu \alpha \tau о \varsigma)$. Wenn er einen reinen und demütigen Menschen treffe, dann sei dies eine große Vision ('E⿳亠े '̌̉n

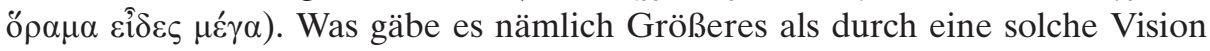
gewürdigt zu werden, den unsichtbaren Gott wie in einem Tempel im sichtbaren

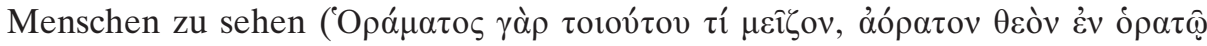

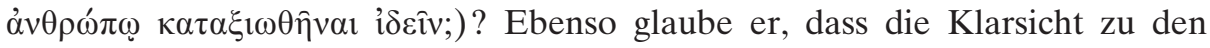
heiligen Dingen gehöre und befähige, die Regungen der Seelen wahrzunehmen,

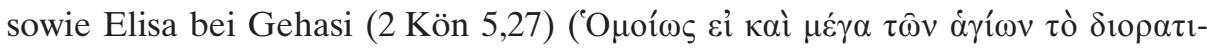

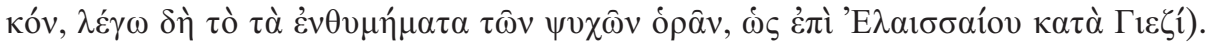
Wenn Gott, der in ihnen ist und alles erforscht, ihnen Offenbarungen zuteil werden lasse, dann seien sie klarsichtig. Und wenn er es nicht offenbare, dann

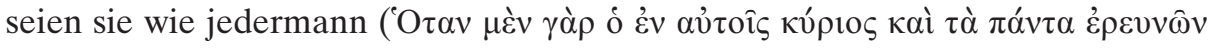

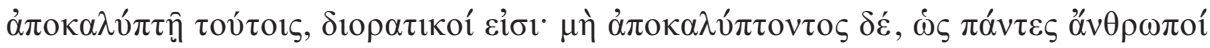

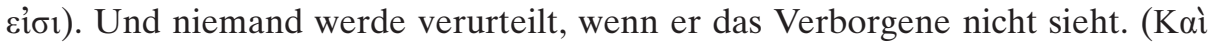

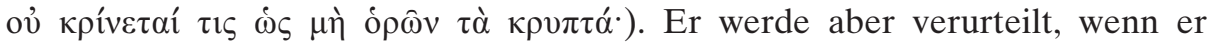
denjenigen in den Psalmen gleiche, die vom Geist verdammt werden, da sie sich Gott nicht zum Vorbild gemacht haben (Ps 53,5).

67. ScPa 7, PG 88, col. 825A: „Die unkritische Schau bringt viele Gefahren mit sich. Denn der Teufel verwandelt sich oft in einen Engel des Lichts und täuscht jene, die ihre eigenen Grenzen nicht kennen. Deshalb sagte einmal ein Greis:

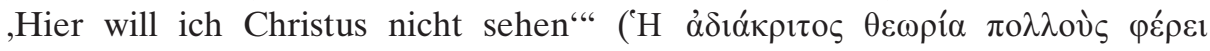

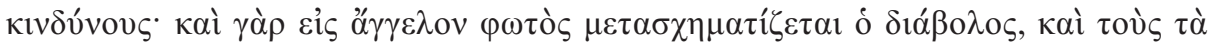

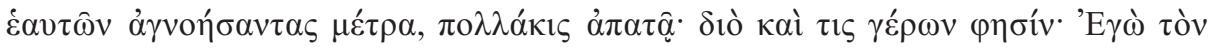

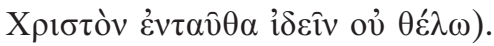




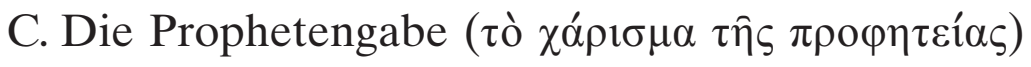

68. PaThII 9, p. 102,19-29: Pachomios (ein Nachfolger des großen Pachomios) sagte einmal zu den anderen Mönchen, dass man Pekyssios nach Latopolis ${ }^{738}$ geschickt habe, um dort den Bedürftigen beizustehen. Da habe ihm (Pachomios), als er im Sitzen meditierte, ein Engel des Herrn mitgeteilt, dass derjenige, der heute kommen werde, als Gefäß der Auswahl Gottes herbeigeführt werde

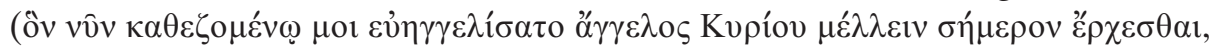

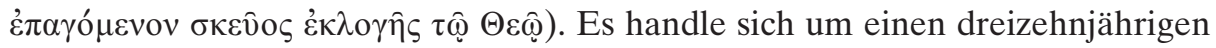
Jungen namens Theodoros, der vom heiligen Geist durchdrungen sei. Am Abend kam Pekyssios zurück und brachte den jungen Theodoros mit sich.

69. ViAn 31,2, p. 220,12-15: (1) „Was ist daran zu bewundern, wenn sie [die Dämonen] aufgrund ihrer dünneren Körperbeschaffenheit als die der Menschen denen, die sie am Anfang eines Weges erblickt haben, vorauseilen, um von ihnen zu berichten? Dies könnte auch ein Reiter vor der Ankunft von denjenigen, die zu Fuß unterwegs sind, berichten. Aus diesem Grund sollte man sie [die Dämonen] deswegen nicht bewundern. Von den Ereignissen, die noch nicht eingetroffen sind, sehen sie nämlich nichts voraus, denn Gott alleine ist derjenige, der alle Dinge kennt, bevor sie geschehen sind [Dan 13,42]. Die Dämonen aber verkünden, was sie gesehen haben, wie Diebe, indem sie vorauseilen“ (Tí

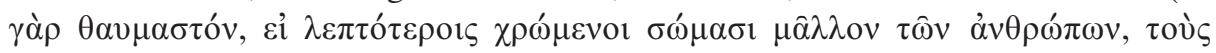

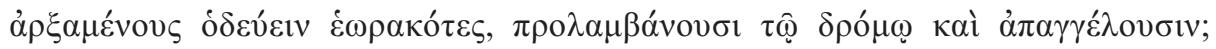

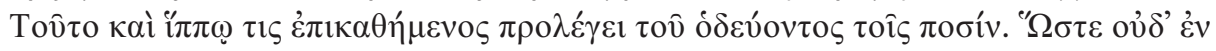

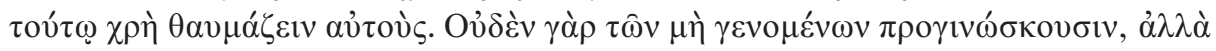

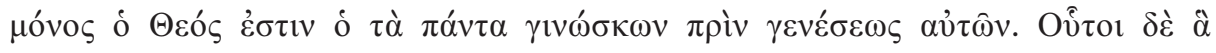

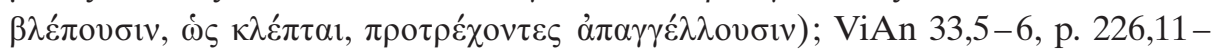
228,2: (2) „Was für einen Nutzen bringt es denen, die im Voraus hören, was sich Tage später ereignen wird? Warum danach trachten, solche Dinge zu wissen, auch wenn die Kenntnis [dieser Dinge] richtig ist? Weder führt dies zur Tugend, noch ist es das Kennzeichen eines guten Charakters. Denn keiner von uns wird verurteilt, etwas nicht gewusst zu haben, und keiner wird als selig erklärt, weil er es erfahren hat und wusste. Vielmehr wird jeder danach beurteilt, ob er den Glauben bewahrt [2 Tim 4,7] und die Gebote treu

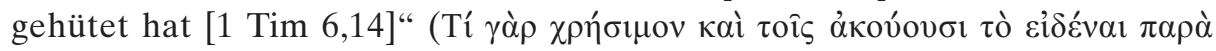

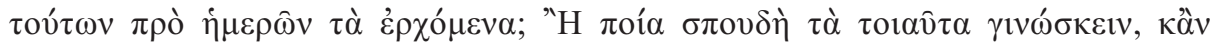

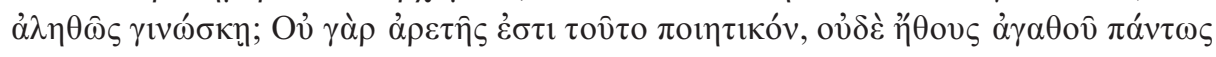

738 S. S. 148 A. 728. 


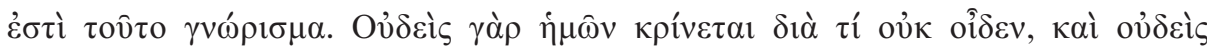

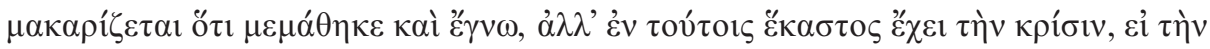

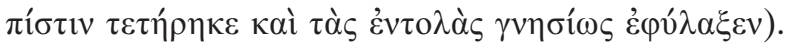

70. ViAn $62,1-2$, p. 300,4-14: Antonios sagte oft voraus, wer ihn wann besuchen kam, häufig schon einen Monat im Voraus. Manche kamen bloß, um ihn zu sehen, andere, weil sie krank waren. Wieder andere, weil sie von Dämonen in die Irre geführt wurden. „Obwohl er solche Visionen hatte und auch davon sprach, verlangte er, dass ihn niemand deshalb bewundere, sondern vielmehr der Herr bewundert werde, da er uns Menschen mit der Gnade ausgestattet hat,

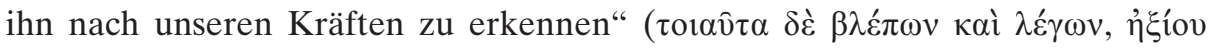

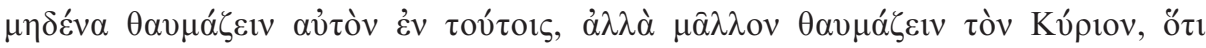

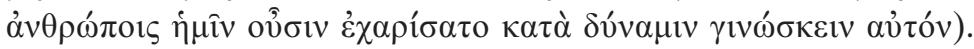

71. ViAn 82,4-9, p. 344,16-348,2: Als Antonios „eines Tages dasaß und arbeitete, geriet er in eine Ekstase, und während der Schau stieß er tiefe Seufzer

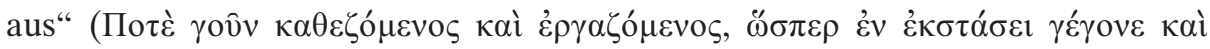

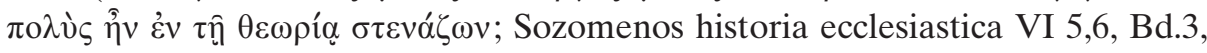

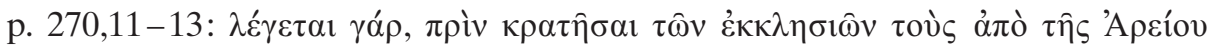

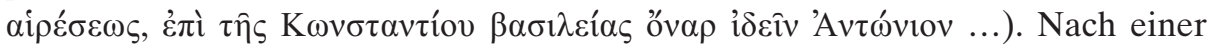
Stunde wandte er sich unter Stöhnen und Zittern an die Anwesenden, stand auf und fing an zu beten. Dann beugte er die Knie und blieb lange so. Als er wieder aufstand, weinte er. Nun zitterten auch die Anwesenden, ..." (Eî̀ $\alpha \mu \varepsilon \theta^{\prime}$ ஸ̆ $\rho \alpha$

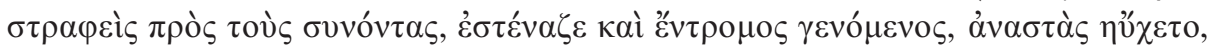

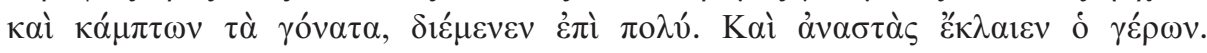

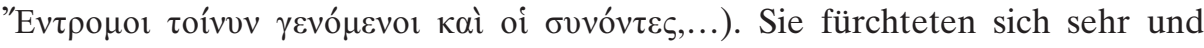
wollten von ihm erfahren, was los sei. So lange belästigten sie ihn, bis er sich gezwungen sah zu erzählen. Unter starkem Stöhnen sagte er, es wäre besser zu

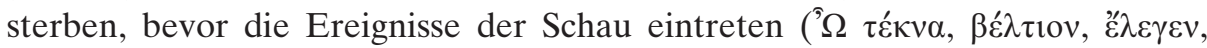

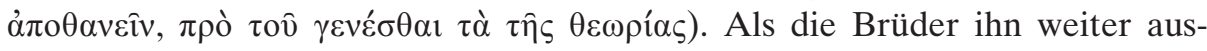
fragten, antwortete er ihnen, dass die Kirche von Zorn erfasst werde und dass sie Menschen übergeben werde, die gleich unvernünftigem Vieh seien (Mt 17,22). Er habe den Altar des Hauses des Herrn gesehen, umgeben von Maultieren, die den sich darin Befindenden Fußtritte gaben. Sicherlich hätten die Brüder gehört, wie er stöhnte, als ihm eine Stimme gesagt habe „mein Altar

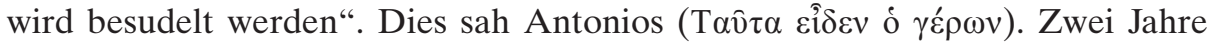
später fand der große Anschlag der Arianer statt.

72. ViAn 89,2, p. 362,11 f.: Antonios „erfuhr durch die Vorsehung Gottes im

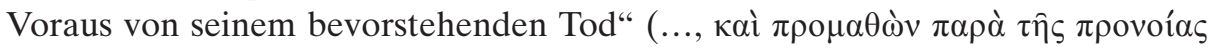

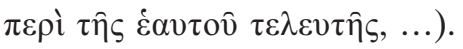

73. ApAl, Ioannes Kolobos 38, PG 65, col. 216D-217A: Ioannes erzählte von einem pneumatikos ${ }^{739}$, der den Tod eines sterbenden Asketen voraussah und

739 S. S. 77 A. 354. 
sich zu diesem begeben wollte, um sich von ihm zu verabschieden (Fortsetzung in 199).

74. Bar 1,19-22, Bd. 1,1, p. 426: Barsanuphios schreibt an Ioannes, dass er Bruder Seridon (dem Abt des Klosters) gesagt habe, er solle Ioannes mit großer Barmherzigkeit aufnehmen, da ihm Gott vor zwei Jahren offenbart habe, dass er (Ioannes) hierher kommen werde und dass sich viele Brüder um sie herum versammeln werden. Er habe diese Offenbarung so lange für sich behalten, bis er erfuhr, was Gott tun werde. Nun, wo die Zeit gekommen sei, eröffne er es

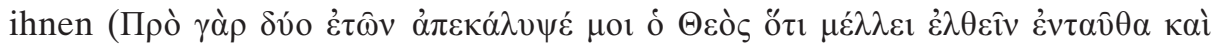

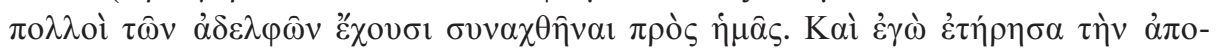

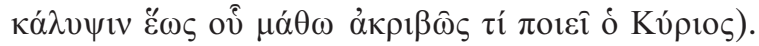

75. ViDanSt 53, p. 51,4-53,2: Eines Winters wurde es derart kalt, dass der auf der Säule stehende Daniel einfror und sich nicht mehr bewegen konnte. Sein Gesicht war vor lauter Eis nicht mehr zu sehen. Als es wieder ein wenig wärmer wurde, stiegen seine Schüler zu Daniel auf die Säule, um ihn mit einem Schwamm und lauwarmem Wasser aufzutauen, bis sein Gesicht wieder zum Vorschein kam. Sie sagten zu ihm, dass er sich in Lebensgefahr befunden habe. Plötzlich erwiderte Daniel, als ob er aus dem Schlaf erwacht wäre, dass er sich in einer großen Ruhe befunden habe, bis er von ihnen geweckt wurde (D: 'A $\pi$ o-

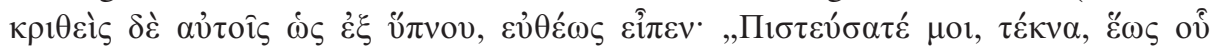

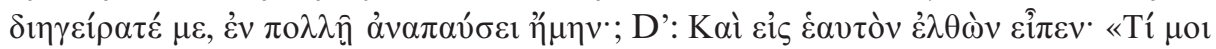

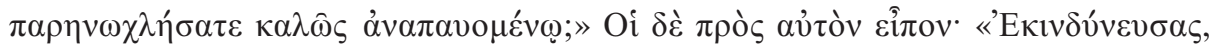

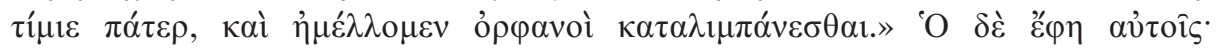

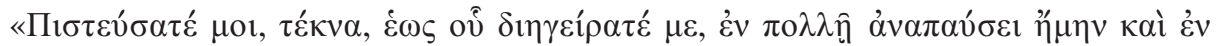
$\theta \varepsilon \dot{\rho} \rho \mu \eta \underline{\eta} \mu \gamma \alpha \dot{\lambda} \eta \rrbracket »)$. Da er von der unerträglichen Kälte ergriffen und sein Kleid vom Wind zerfetzt worden sei, habe er sich während einer Stunde in großer Not befunden. Dann habe er Gott um Hilfe gerufen und sei gleichsam vom Schlaf weggerafft worden. (Die folgende Vision ist nur in D vorhanden) Er habe sich auf einem leuchtenden Bett ausgeruht und sei von prächtigen Umhängen gewärmt worden. Dann sah er einen alten Mann, der auf einem Thron vor ihm saß

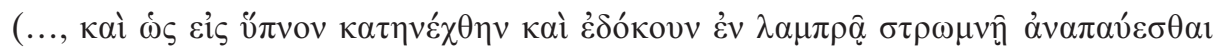

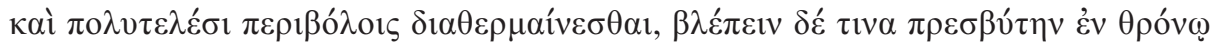

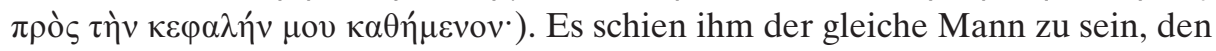
er auf dem Weg traf, als er vom heiligen Symeon kam (vgl. 333). Und er schien mit viel Wärme und Aufrichtigkeit zu sprechen und ihm einen großen Falken zu zeigen, der aus dem Osten kam und nach Konstantinopel flog, wo er auf der Säule auf dem Forum des Kaisers Leon ein Adlernest fand. In diesem Nest ließ er sich zusammen mit den Kücken des Adlers nieder und nahm jetzt selbst das Aussehen eines Adlers an. Als er den alten Mann fragte, was dies zu bedeuten habe, antwortete dieser, dass es für ihn keinen Nutzen hätte, es jetzt zu erfahren. Er werde es aber später verstehen. Und während er ihn umarmte und wärmte, sagte er mit Freude, wie innig er Daniel liebe und dass er in seiner Nähe sein 
wollte, da aus seinen Wurzeln in Zukunft viele Früchte hervorgehen sollten. Und da sie, so Daniel, gerade dabei waren, sich aneinander zu erfreuen, haben

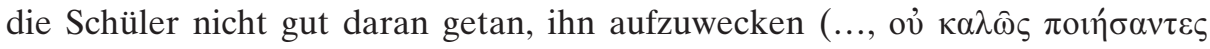
$\grave{\varepsilon} \xi v \pi v \eta ́ \sigma \alpha \tau \dot{\varepsilon} \mu \varepsilon)$. Jene aber erwiderten, sie hätten sich in großer Mutlosigkeit befunden, da sie glaubten, Daniel sei tot. Dann fragten sie ihn, was die Vision

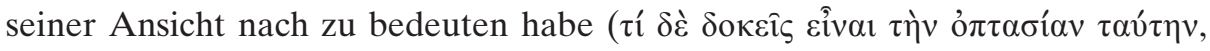
$\pi \alpha ́ \tau \varepsilon \rho ;)$. Daniel antwortete, er verstehe es nicht genau, Gott werde aber tun, was

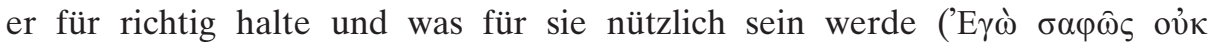

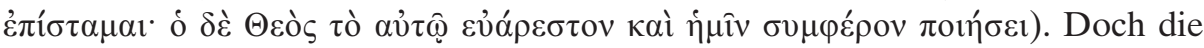
Schüler versuchten, die Vision zu deuten und sagten, Daniel müsse mit der Hilfe des Kaisers den Leichnam des heiligen Symeon aus dem Osten nach Konstantinopel bringen. Aus der Vision gehe nämlich hervor, dass dies der Wille des

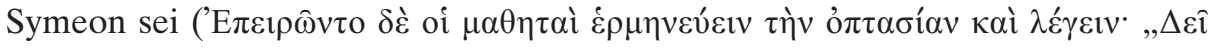

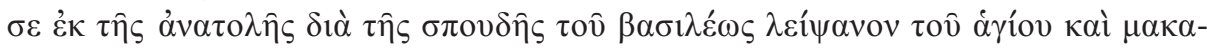

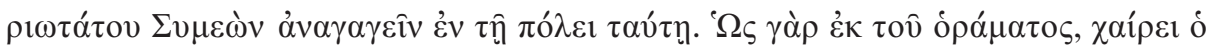

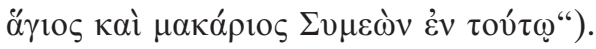

76. ViEu 16, p. 26,4 f.: Euthymios sagte Chrysippos voraus, dass er Führer der

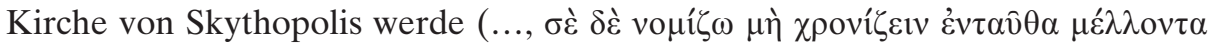

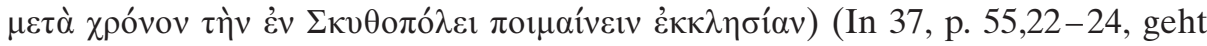

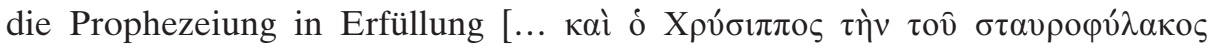

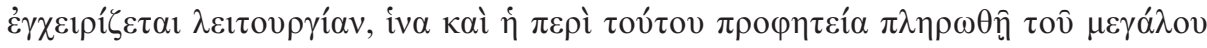

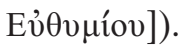

77. ViEu 22,14-22, p. 35,14-22: Euthymios sah mit den Augen des Geistes Anastasios, den Hüter der Heiligen Stätte, bereits als Patriarchen von Jerusa-

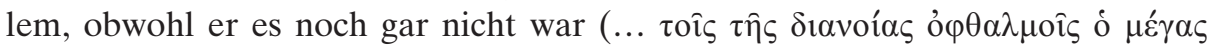

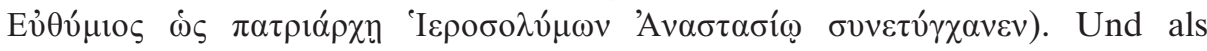
Chrysippos Euthymios darauf aufmerksam machte, dass Anastasios alleine deshalb nicht Patriarch sein könne, weil er farbige Kleider trage, behauptete der

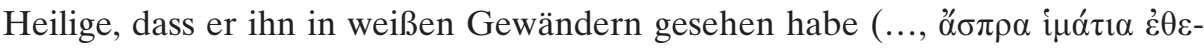

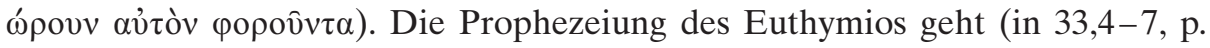
52,2-5) in Erfüllung, und Anastasios wird Patriarch.

78. ViEu 31, p. 50,8-10: Euthymios übergab den jungen Sabas dem Theoktistos, damit dieser auf ihn aufpasse. Er sah nämlich schon damals, dass Sabas in der monastischen Lebensweise hervorragen würde. Diese Prophezeiung ging

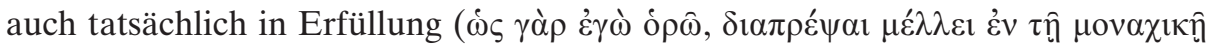

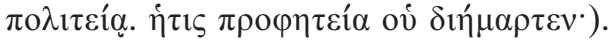

79. ViEu 35, p. 53,19-21: Euthymios sagte den Tod der Herrscherin Eudokia voraus. Denn als sie ihn bat, an seinem Gebet teilnehmen zu dürfen, antwortete

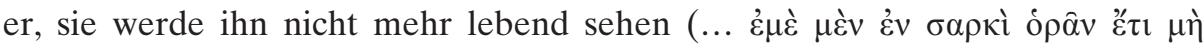

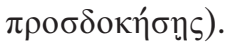

80. ViEu 39, p. 57,12-15: „Zusätzlich zu den anderen Gaben, die Euthymios besaß, wurde er auch mit derjenigen ausgezeichnet, im Vornherein den Tag 
seiner Entschlafung und die zukünftigen Ereignisse an seinem Sterbeort zu

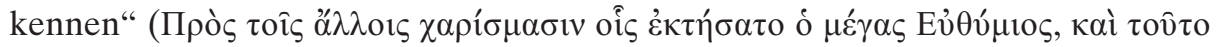

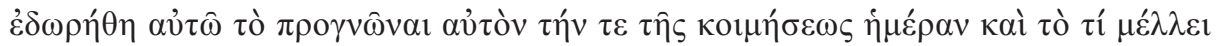

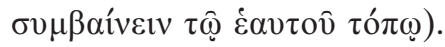

81. HiLa 18, p. 52,1-53,13: Abbas Makarios wanderte durch die Wüste Thebais zum Kloster der Tabennesioten, wo er auf den mit der Prophetengabe ausgezeichneten Archimandriten Pachomios traf. Doch über Makarios war Pacho-

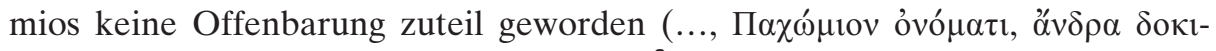

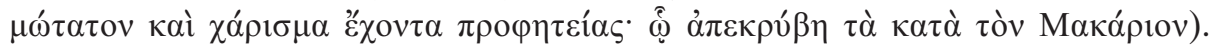
Nachdem Pachomios aber seine Lebensweise beobachtet hatte, wurde er allmählich neugierig und betete zu Gott, er möge ihm offenbaren, wer Makarios sei. So geschah es (vgl. auch 134).

82. HiLa 31, p. 86,10-87,17: Die Jungfrau Piamun war mit der Vorhersage

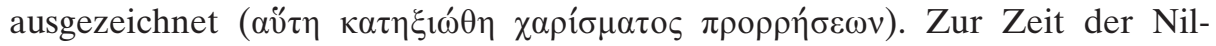
schwelle geschah es, dass ein Dorf ein anderes überfiel. (In Ägypten streite man sich zuweilen derart um die Verteilung des Wassers, dass man sich blutig schlage oder sogar töte). So kam es, dass ein anderes Dorf das von Piamun angreifen wollte. „Da trat ein Engel zu ihr und offenbarte ihr den Anschlag der Feinde“"

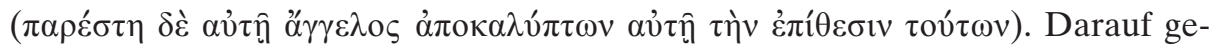
lang es ihr, das Unglück vom Dorf abzuwenden. Durch ihr Gebet wurden die Angreifer drei Meilen vom Dorf entfernt gleichsam festgenagelt, sodass sie sich nicht mehr bewegen konnten.

83. HiLa 60, p. 154,8-11: Eine Eremitin lebte sechzig Jahre in Askese, als sie diese Welt verlassen sollte. Da erschien ihr Kolluthos, der Märtyrer des Ortes

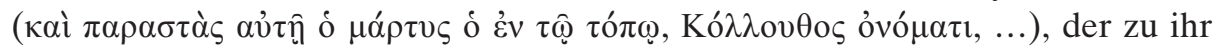
sagte: „Heute sollst du zum Herrn gehen und alle Heiligen erblicken; komm also mit uns ins martyrion zum Abendmahl!“. Sogleich stand sie auf, zog sich an und ging ins martyrion des Kolluthos, um dort zu beten. Noch in der gleichen Nacht starb sie.

84 HiMo 1,1, p. 9,7 f.: Über Ioannes Lykopolis wird gesagt, dass er die Gabe der

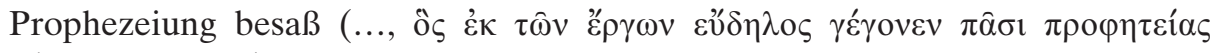
$\chi \alpha \dot{\rho i \sigma \mu \alpha \kappa \varepsilon \kappa \tau \eta \mu \varepsilon ́ v o \varsigma, ~ . . .) . ~}$

85. ViHy 32,1-9, p. 208,6-212,6: Nestorios von Antiocheia kam nach Konstantinopel, um dort Bischof zu werden. Im selben Augenblick, als Nestorios die kaiserliche Stadt betrat, sah der heilige Hypatios ( $\dot{\varsigma} \delta \delta \dot{\varepsilon} \pi \lambda \eta \sigma i ́ o v ~ \tau \hat{\jmath} \varsigma \pi$ ó $\lambda \varepsilon \omega \varsigma$

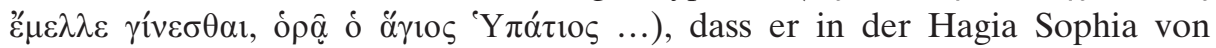
irgendwelchen Weltlichen eingesetzt wurde. Und auf einmal sagte eine Stimme

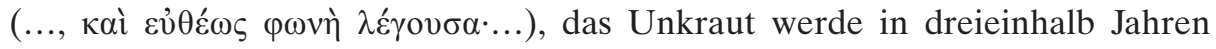
ausgerissen. Als Nestorios dann bereits als Bischof von Konstantinopel eingesetzt worden war, erfuhr er von der Prophezeiung des Hypatios und schickte eine Gesandtschaft zu ihm. Man solle diesem Träumer ausrichten lassen, dass er, Nestorios, zwanzig Jahre über diese Stadt regieren werde, und man werde schon 


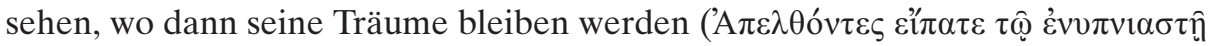

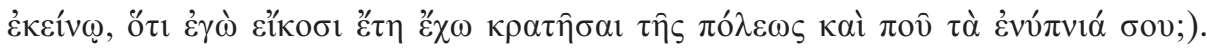
„Darauf ließ Hypatios dem Bischof ausrichten: ,Wenn das, was ich gesehen habe, eintrifft, war es eine Offenbarung, ansonsten ist es ein Traum, und ich

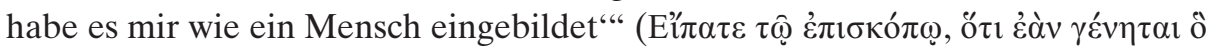

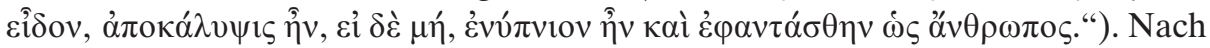
dreieinhalb Jahren erfüllte sich die Prophezeiung des Hypatios.

86. ViHy 50,2, p. 286,4-6: Drei Monate vor seinem Tod sagte Hypatios seinen Schülern voraus, dass ein furchtbarer Zorn über die Erde kommen werde und es für ihn besser sei, noch vorher zu gehen; ViHy 52,1-9, p. 292,4-294,10: Die Prophezeiung erfüllte sich. Dreißig Tage nach dem Tod des Hypatios zerstörte ein fürchterlicher Hagel die Reben. Darauf folgten schwere Erdbeben und schließlich verwüsteten die Hunnen die Umgebung. Da erinnerten sich die Brüder an die Prophezeiung des Hypatios und verstanden, dass ihm dies nur

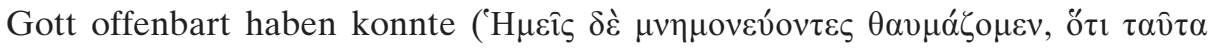

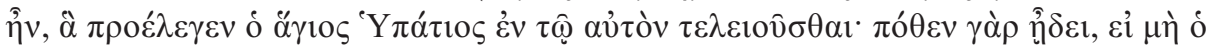

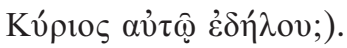

87. ViHy 54,1-4, p. 296,1-13: Nach dem Tod des Hypatios kam ein Priester ins Kloster des Heiligen. Er erkundigte sich nach Abbas Zenon, dessen Kloster in der Gegend des roten Meeres lag, wo man ihn für einen Propheten hielt (Пóv-

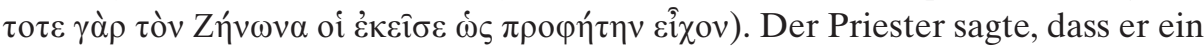
alter Wüstenfreund von Zenon sei. Dieser habe ihm, als er noch lebte, gesagt, der Herr habe ihm (Zenon) den Auftrag gegeben, zu Hypatios zu gehen, um bei

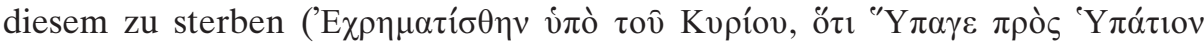
$\kappa \dot{\alpha} \kappa \varepsilon i ̂ ~ \tau \varepsilon \lambda \varepsilon\llcorner 0 \hat{\sigma \alpha}$ l). Überdies habe Zenon ihm gesagt, der Herr werde kurz nach

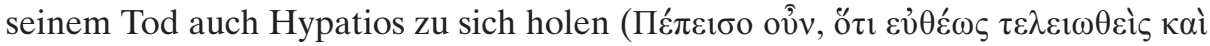

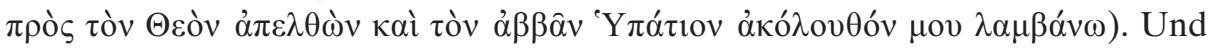
tatsächlich starb Hypatios drei Monate nach Zenon, so wie es diesem von Gott

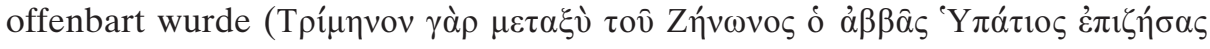

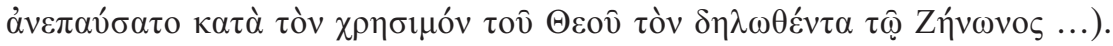

88. ViHy 55,1 f., p. 296,21-25: Der Bruder Polychronios wurde gemäß der

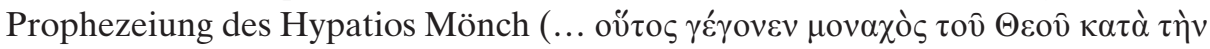

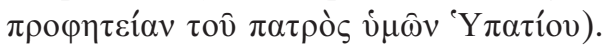

89. ViNi 12,1-7, p. 34,1-7: „Die Diener Gottes Sabbatios und Nikolaos [Nikolaos von Akalissos, der Onkel des Nikolaos Sionites] sahen noch viele andere Zeichen durch Visionen, und es erschien ihnen augenscheinlich die heilige Sion"

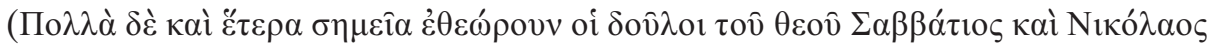

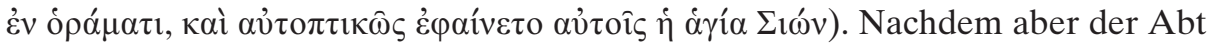
Sabbatios gestorben war, „, betete sein Stellvertreter Nikolaos täglich zu Gott, er möge auch ihm das Zeichen, das Sabbatios erschienen war, offenbaren $(\dot{o} \delta \dot{\varepsilon}$

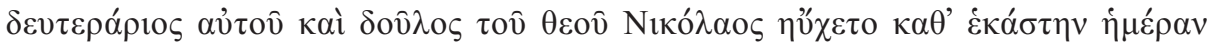

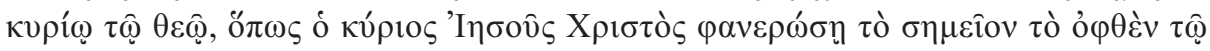


óđí $\Sigma \alpha \beta \beta \alpha \tau i ́(\omega)$. In ihm brannte das Feuer des heiligen Geistes, und er betete und flehte zu Gott, er möge ihm die ersehnten Offenbarungen über die heilige

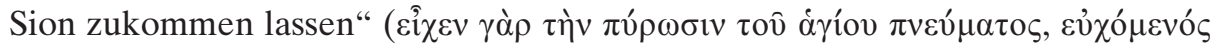

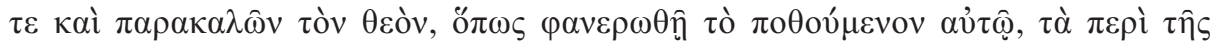

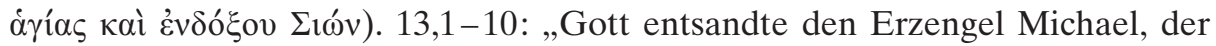
leibhaftig vor Nikolaos trat und zu ihm sprach: ,Willst du das liebliche Haus der

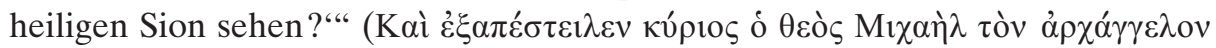

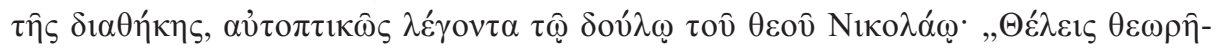

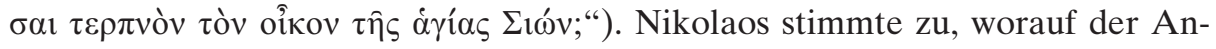
führer der himmlischen Heerscharen sagte: „Folge mir, und du wirst das Haus erblicken, welches von Gott errichtet wird“. Darauf führte er ihn zu einem Berg. Als Nikolaos emporblickte, sah er, wie das Haus Gottes errichtet wurde, und es erstrahlte ein helles Licht auf dem Berg. Und der Engel, der ihn führte, sagte zu ihm: „Es gibt hier ein Kind namens Nikolaos, ein Sohn des Epiphanios und der Nonna. Er wird an diesem Ort wohnen und unseren himmlischen Vater preisen. Er ist nämlich schon im Mutterleib von Gott auserwählt worden." Nachdem er

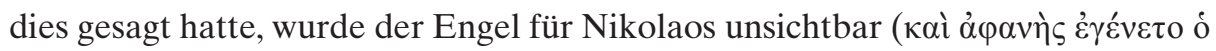

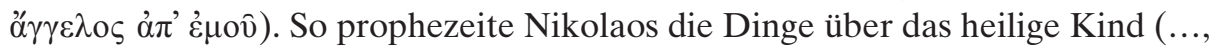

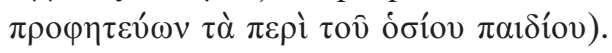

90. ViNi 47,1-48,8, p. 64,12-66,16: Eines Tages, als Nikolaos in der Zelle ruhte,

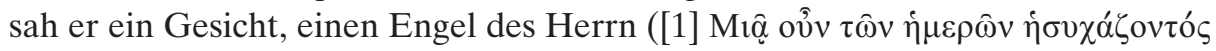

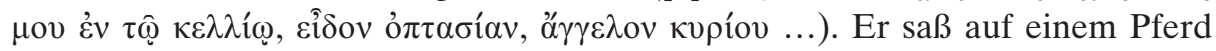
und sagte zu Nikolaos, er solle sehen, was in der ganzen Welt geschehen werde. Die Zeit der Ernte sei gekommen, und der Herr habe ihn ausgesandt, um ihm die Erntewerkzeuge zu überbringen. Nikolaos erzitterte am ganzen Körper, als

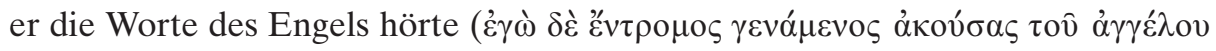
ovं $\omega \varsigma$, ,...). Als er den Engel fragte, wer er sei, antwortete dieser, er sei der Engel, der die Erntesicheln hüte. Nikolaos trat an den Engel heran und erblickte drei Sicheln von jeweils fünf Ellen Breite und fünfzehn Ellen Länge ${ }^{740}$. Nikolaos betastete die Sicheln und gab dem Engel drei Brote und zwei Tauben. „Dann

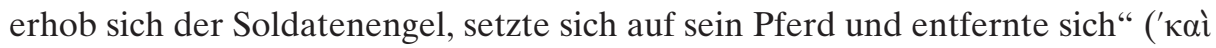

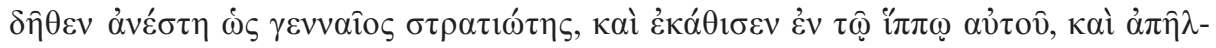

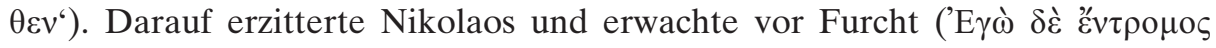

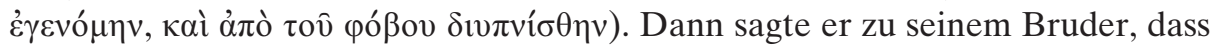
sie an diesem Tag mehr Psalmen als sonst singen sollten, da er in der Nacht

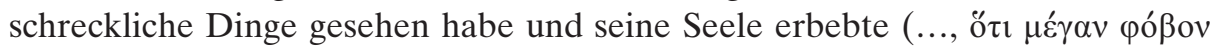

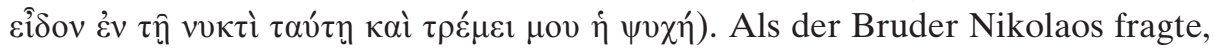
was er gesehen habe, antwortete dieser, er habe gesehen, dass das Ende der Welt bevorstehe und Gott verlange, dass dies durch ihre Hand besiegelt werde.

740 Zw. 2,35 und 3,10 m breit u. zw. 7,05 u. 9,30 m lang, vgl. Blum (ed.), Die Vita 112, Kap. 47 , A. 3. 
„Nikolaos ging unter Tränen zum Morgengebet und flehte zu Gott, er möge ihm mitteilen, was sein Gesicht zu bedeuten habe" (o $\delta \dot{\varepsilon} \alpha \dot{\beta} \beta \beta \hat{\alpha} \varsigma$ Nıкód $\alpha \circ \varsigma \mu \varepsilon \tau \grave{\alpha}$

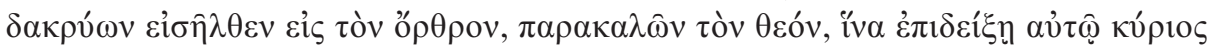

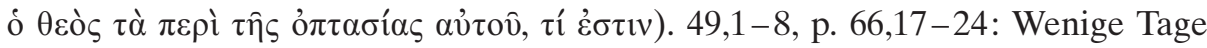
später sah Nikolaos den großen Altar, der verstümmelt war und sich auf die

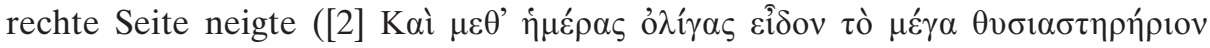

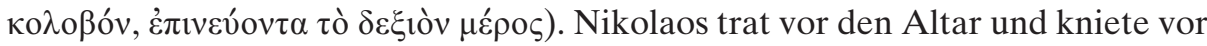
ihm nieder. Und als er zur Apsis emporblickte, war sie nach oben hin offen. Und als er sich zum Kirchenschiff umdrehte, tropfte es im ganzen Gebäude. Das Wasser sammelte sich beim Haupteingang und floss durch das Tor hinaus. Aus Furcht und Anstrengung wurde Nikolaos gleichsam aus dem Schlaf gerissen, und er sagte zu seinem Diener: „Große Zeichen und Gesichte hat mir der Herr gezeigt, ich weiß aber nicht, was sie bedeuten. Lasst uns deshalb Gott ehren und

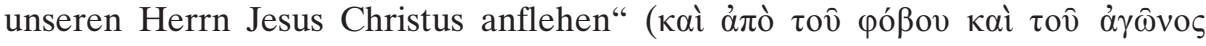

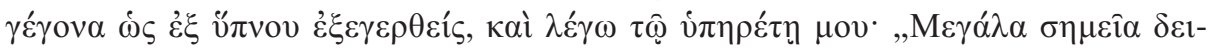

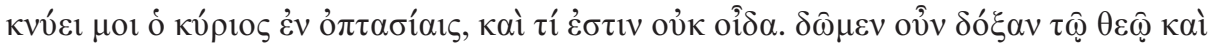

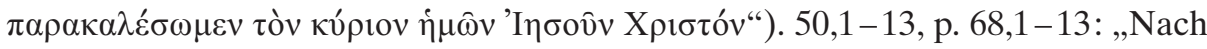
sieben Tagen kam ein Engel des Herrn herab und erschien Nikolaos in der

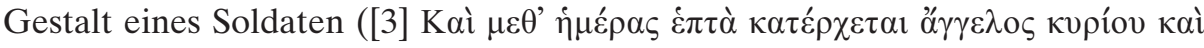

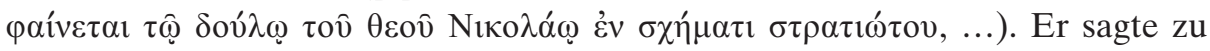
Nikolaos: ,Da dir der Herr die Gnade erwiesen hat, in Form von Offenbarungen die Werke Gottes zu erblicken, werde ich dir nun Engelserscheinungen über-

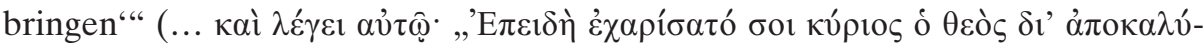

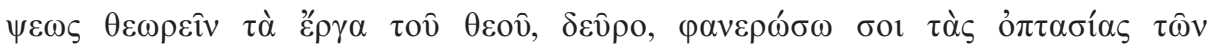
$\grave{\alpha} \gamma \gamma \hat{\varepsilon} \lambda \omega v^{\prime \prime)}$. Als Nikolaos ihn fragte, wer er sei, antwortete er, er sei der Erzengel Michael. Der Herr habe ihm befohlen, für Nikolaos sichtbar werden zu lassen, was in der ganzen Welt geschehen wird. Er sei gesandt worden, um ihm den bevorstehenden göttlichen Schrecken zu offenbaren. Bei demjenigen, den Nikolaos auf dem Pferd gesehen habe und der die Sicheln trug, handle es sich um einen Engel des Herrn, der geschickt wurde, um für ihn die zukünftigen Heimsuchungen der Welt und die Übergabe der Menschenseelen durch die Heiligen an Gott sichtbar werden zu lassen. Nikolaos solle für die Seelen derer beten, die aus Lykien kommen werden. 51,1-7, p. 68,14-19: Als Nikolaos den Engel fragte, wie er dies als sündiger Mensch vollbringen könne, antwortete dieser: „Die Sicheln, die du gesehen hast, bedeuten die Kraft und das Zeichen des Herrn. Dir ist es zugedacht, ihnen (den Sicheln) durch deine Hände die Seelen der Menschen zu übergeben, denn die Pest steht gleichsam als Ernte bevor. Die Ernte bedeutet nämlich die Pest vor dem Ende des Menschengeschlechts". Nachdem der Engel dies gesagt hatte, ging er weg von Nikolaos. 52,1-10, p. 68,21-30: Die Prophezeiung erfüllte sich, und innerhalb von vierzig Tagen wurden die Menschen von der Pest heimgesucht. 
91. ViPa 71, Halkin 1982, p. 37,11-23: Als die Brüder einmal Binsen schnitten und gerade dabei waren, sie aufs Schiff zu verladen, geriet Pachomios plötzlich

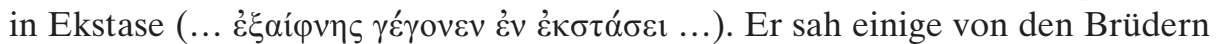
von einem feuerlodernden Kreis umgeben, den sie nicht überschreiten konnten. Andere sah er barfuß auf dornigen Hölzern herumgehen. Sie wurden von Splittern durchbohrt, konnten aber nirgends heruntersteigen. Andere wiederum standen auf einer steilen Uferböschung und konnten weder emporsteigen, noch konnten sie sich in den Fluss werfen, da sie von einer Menge von Krokodilen beobachtet wurden, die von unten her in die Höhe sprangen, um sie zu verschlingen. Und als er noch immer stillstand und dies betrachtete, sahen ihn die

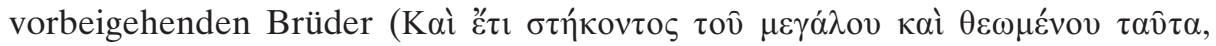

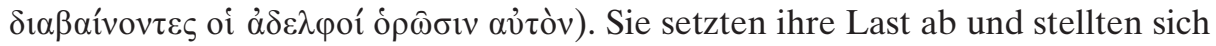

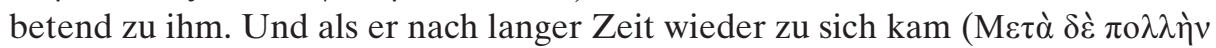

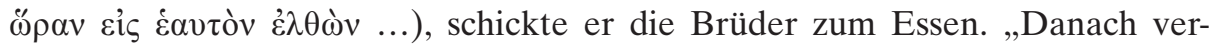
sammelte er sie und erzählte ihnen von der Vision, und alle weinten in großer

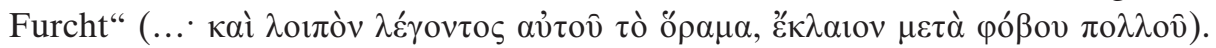
Als sie ihn fragten, was dies zu bedeuten habe, antwortete er, dass er fühle, dass

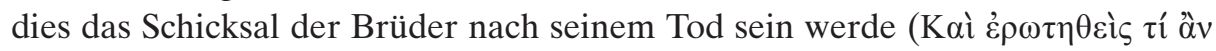

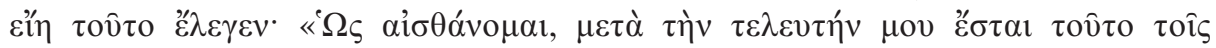

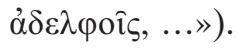

92. PaThI 3,17,7-23, p. 80,23-81,7: „Als er [Pachomios] beim Beten war, erschien ihm gegen Mitternacht plötzlich eine Vision aus dem Himmel, die den

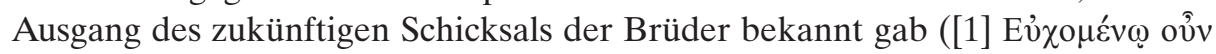

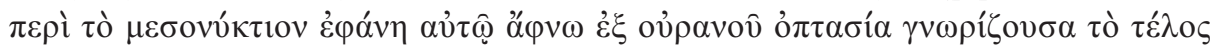

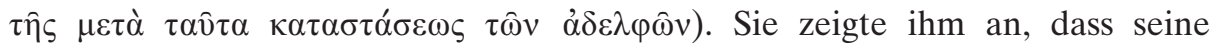
Nachfolger fromm leben werden und dass es in Zukunft ein Wachstum seiner Klöster geben werde. Er sah aber auch eine Ansammlung von unzähligen Brüdern, die in einer überaus tiefen und dreckigen Grube umherwandelten

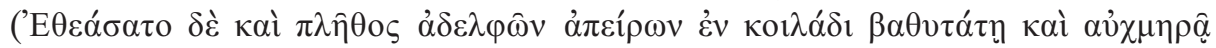

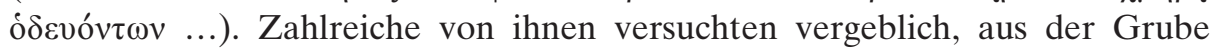
herauszusteigen. Viele begegneten einander, erkannten sich aber wegen der großen Dunkelheit nicht. Andere wiederum heulten mit mitleiderregender Stimme auf, und nur wenige konnten durch große Anstrengung aus jener Grube herausklettern; doch einmal oben angekommen, traten sie ins Licht und dankten Gott dafür." Da erkannte Pachomios, was mit den Brüdern in Zukunft geschehen würde, und dass dies ein Bild für die schlimmen Zustände im Kloster in der Zukunft war, deren Anfänge derjenige, der dies aufschrieb, noch miter-

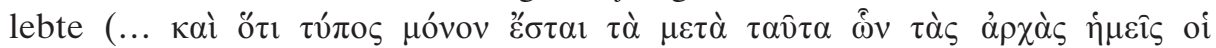

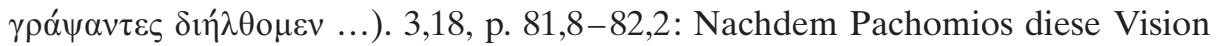

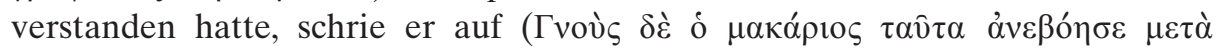
$\kappa \lambda \alpha v \theta \mu о \hat{v} . .$.$) und warf Gott vor, dass die ganze Mühe doch nicht umsonst$

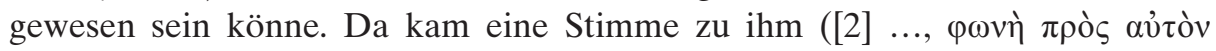




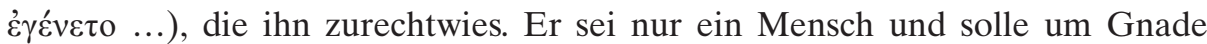
bitten. Als Pachomios dies hörte, warf er sich sogleich zu Boden und flehte um Barmherzigkeit, worauf ,sich plötzlich zwei Engel Gottes zu ihm stellten. Bei ihnen befand sich ein Jüngling von unbeschreiblichem Angesicht und Aussehen,

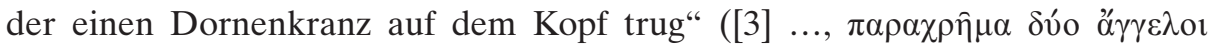

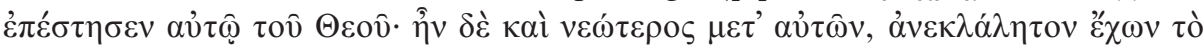

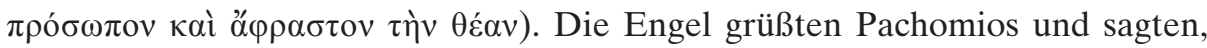
dies sei die Verkörperung von Gottes Erbarmen, Jesus Christus, den der Herr auf die Erde geschickt habe, wo er gekreuzigt und mit einer Dornenkrone bekränzt wurde. Pachomios fing an, sich zu verteidigen und sagte, nicht er habe Jesus gekreuzigt, worauf der Junge lächelte, sagte, dass er dies wisse, und ihn mit den Worten ermutigte, dass die Wurzel des von Pachomios gesäten Samens nie verdorren werde. Und nachdem er noch mehr über die zukünftigen Ereignisse gesagt hatte, stieg er in den Himmel auf. Da öffneten sich ihm die Himmel, und die Luft wurde von einem Licht erfüllt, dessen Leuchten menschliche Worte

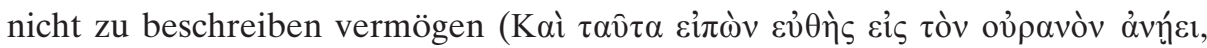

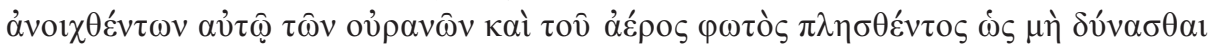

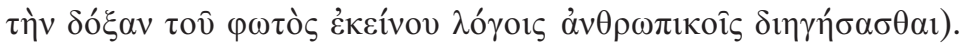

93. PhHi 21,17-18, Bd.2, p. 96,12-98,23: Als die Markioniten versuchten, Theodoret vom richtigen Weg abzubringen und ihn bekämpften, bat er den Asketen Iakobos um göttliche Erbauung. Dieser ermutigte ihn, denn sie (die Markioniten) werden sich wie ein Spinnennetz auflösen. Gott habe ihn nämlich in der Nacht darüber belehrt, nicht schemenhaft in einem Traum, sondern in

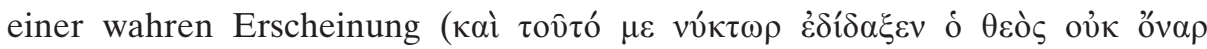

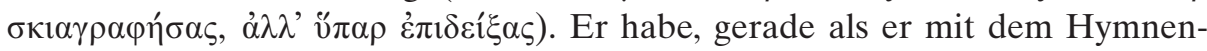
gesang anfing, in der Gegend, wo dieser Ort liegt, eine feurige Schlange gesehen. Sie kroch vom Westen in den Osten und schwebte inmitten der Luft. Nachdem er drei Gebete verrichtet hatte, sah er, wie sich die Schlange zu einem Kreis zusammenrollte und mit dem Kopf den Schwanz berührte. Als er acht weitere Gebete verrichtet hatte, sah er sie in zwei Teile gespalten und zu Rauch aufgelöst. Dies hatte Iakobos vorhergesehen, und Theodoret beobachtete, wie

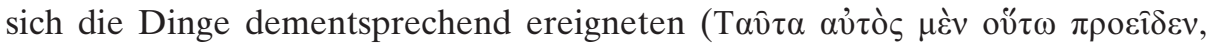

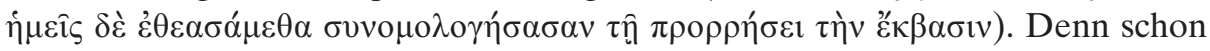
am Morgen stürmte das Heer der Markioniten mit gezückten Schwertern aus dem Westen heran. In der dritten Stunde drängten sie sich zusammen, um sich selber zu schützen, so wie die Schlange mit dem Schwanz den Kopf bedeckte

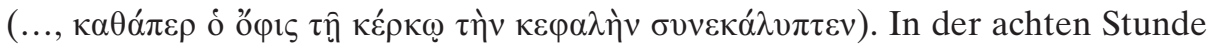
zerstreuten sie sich und gaben den Zugang zur Burg frei, wo sie (Theodoret und Iakobos) eine Schlangenstatue (Symbol der Markioniten) fanden [s. auch 326]. 94. PhHi 26,3, Bd.2, p. 162,8-164,6: Symeon (Stylites der Ältere) ging zu einem Märtyrerheiligtum, um dort zu beten. Er warf sich auf den Boden und flehte zu Gott, er möge ihn auf den Weg des richtigen Glaubens bringen. 
„Nachdem er lange Zeit in dieser Position geblieben war, wurde er von einem

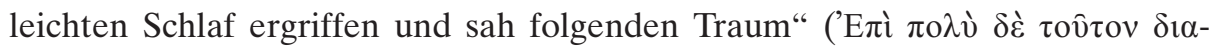

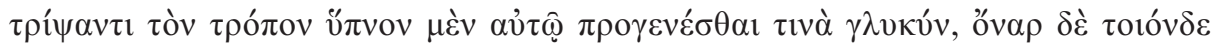
$\left.\theta \varepsilon \alpha ́ \sigma \alpha \sigma \theta \alpha \iota^{\circ}\right)$ : Er schien Fundamente auszugraben, als er die Stimme von jemandem hörte, der ihn aufforderte, noch tiefer zu graben. Symeon befolgte die Anweisung. Dann wollte er sich ausruhen. Doch auch jetzt befahl ihm der andere weiterzugraben, ohne in seinen Kräften nachzulassen. Nachdem er diese Anweisung drei, vier mal wiederholt hatte, sagte er, die Grube sei jetzt tief genug und er könne von nun an mühelos anfangen zu bauen. Denn wenn die Schwierigkeiten einmal nachgelassen hätten, ließe sich der Bau leicht vollenden. „Diese Vorhersage wurde durch die Ereignisse bezeugt, denn das, was [durch

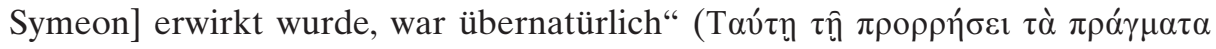

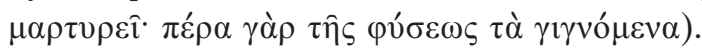

95. PhHi 26,19B, Bd. 2, p. 200,11-4: Einmal sah Symeon Stylites der Ältere

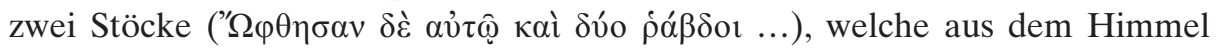
kamen. Der eine fiel im Osten, der andere im Westen auf die Erde. Er erklärte es als Zeichen für einen Aufstand der Perser und der Skythen gegen die Macht

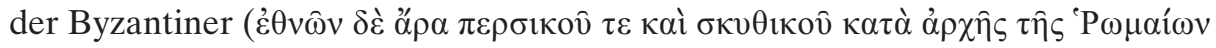

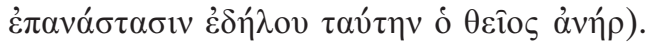

96. ViPo 7,8-27, p. 7,8-27: Porphyrios erzählt dem Autor (Markos), wie er einmal während des vierzigtägigen Fastens an einem Sonntag wachte (Прò

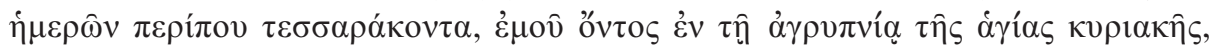
...), als er von einem unbeschreiblichen Schmerz am Herzen ergriffen wurde. Da er den Schmerz nicht ertrug, legte er sich an der heiligen Schädelstätte nieder, und wegen der starken Schmerzen geriet er gleichsam in Ekstase und sah

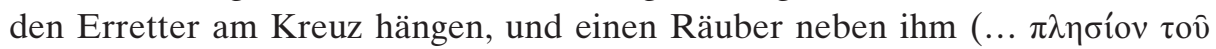

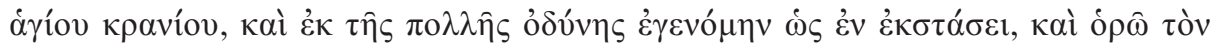

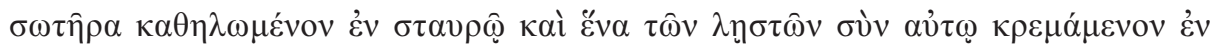
$\alpha \prime \lambda \lambda \omega \sigma \tau \alpha v \rho \hat{\omega})$. Porphyrios fing an zu schreien, worauf die Stimme des Räubers sagte: „Herr, erinnere mich, wenn du in dein Königreich eingehst“. Darauf antwortete der Heiland: „Steig von deinem Kreuz herunter und rette den, der daliegt, so wie auch du gerettet wurdest“. Da stieg der Räuber vom Kreuz herunter, umarmte und küsste Porphyrios, streckte seine rechte Hand aus, um ihn zu stützen, und sagte: „Komm zum Herrn“. Porphyrios erhob sich sogleich und ging zu ihm hin. Der Herr aber stieg von seinem Kreuz herunter und sagte zu Poryphyrios: „Nimm dieses Holz und hüte es“. Porphyrios nahm das Holz und trug es davon, als er auf einmal wieder aus der Ekstase erwachte und zu sich

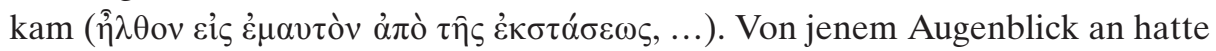
er keine Schmerzen mehr. 10,6, p. 10,6: Als Porphyrios mit 45 Jahren Hüter des heiligen Kreuzes ( $\sigma \tau \alpha v \rho \circ \varphi v ́ \lambda \alpha \xi)$ in Jerusalem wurde, ging das, was er in Ekstase

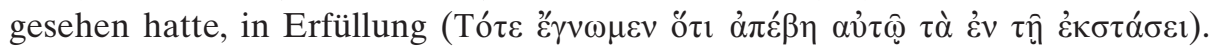


97. ViPo 36, p. 30,17-31,16: Als Porphyrios, der Bischof von Gaza, und Ioannes, der Erzbischof von Kaisarea, auf Rhodos den Mönch Prokopios trafen (vgl. 140), erzählte dieser, was ihm Gott über sie offenbart hatte ( $\Delta \varepsilon \hat{v} \tau \varepsilon$ ov̉v

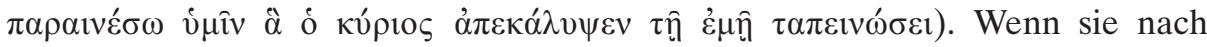
Konstantinopel kommen werden, sollten sie als erstes den Bischof Ioannes besuchen und diesem ihr Anliegen mitteilen. Auch er werde ihnen raten, was

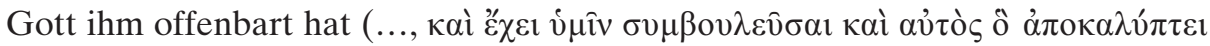

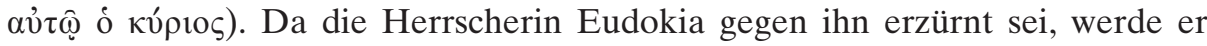
zwar nicht selbst im Palast vorsprechen können. Er werde sie aber Amantios, dem kubikularios der Kaiserin, empfehlen, der sie zu Eudokia bringen werde, um ihr Anliegen (die Zerstörung der heidnischen Tempel in Gaza) vorzutragen. Dann sollten sie ein zweites mal zu ihr gehen und ihr mitteilen, dass Gott ihr einen Sohn schenken werde (Kaiser Theodosios II.), vorausgesetzt sie kümmere sich um ihre Pflichten. Darüber werde sich die schwangere Kaiserin derart freuen, dass sie fortan alles zu Gunsten von Porphyrios und Ioannes veranlassen werde. (Diese Prohphezeiung erfüllt sich an späterer Stelle; vgl. die Kap. 37, 38, $39,40,41,42$, p. $31,17-36,12)$.

98. ViPo 45,11-25, p. 38,6-20: Nachdem die Prophezeiung des Prokopios (Geburt eines männlichen Thronfolgers, s.o. 97) in Erfüllung gegangen war, kündigte die Augusta Eudokia an, in der Angelegenheit des Porphyrios etwas zu unternehmen. Darauf erwiderte Porphyrios, dass alles, was sie beschlossen habe, dem Ratschluss Gottes entspreche. Ihm sei nämlich in der letzten Nacht durch

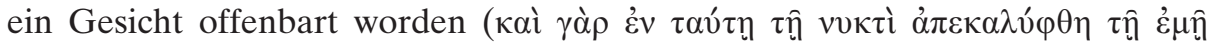

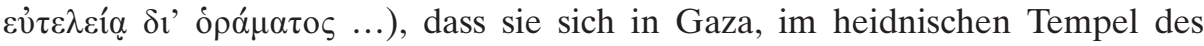
Marneion, befanden. Die Augusta habe ihm das Evangelium gegeben und gesagt, er solle es nehmen und lesen. Porphyrios rollte es auf und fand die Passage, wo der Herr zu Petrus sagt: „Du bist Petrus, und auf diesem Felsen baue ich meine Kirche [Mt 16,18]“. Daraufhin habe die Augusta gesagt: „Friede mit dir,

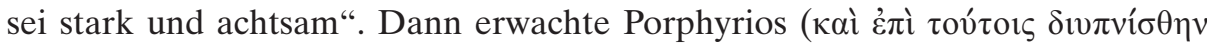
...). Deshalb sei er überzeugt, dass Eudokia gemäß dem Sohn Gottes handle. (Später geht die Offenbarung in Erfüllung, und am Ort wo vormals der Tempel des Marneion stand, wurde auf kaiserlichen Befehl eine Kirche mit dem Namen

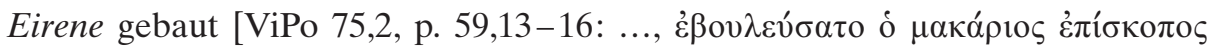

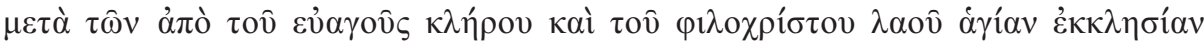

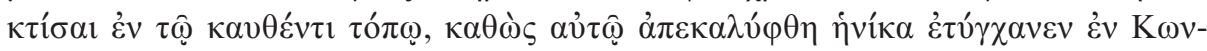

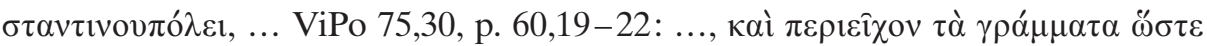

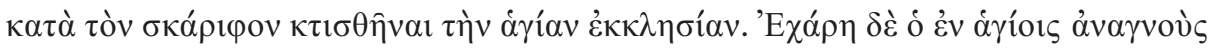

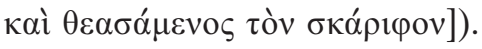

99. PrSp 50, PG 87.3, col. 2905B: Abbas Anastasios von Skythopolis erzählte, dass er eines Nachts aufgewacht sei, um das semantron zu schlagen, da er $\mathrm{ka}$ nonarchos (Vorsänger) war. Da hörte er den Mönch Georgios weinen. Als er zu ihm ging und ihn fragte, warum er so weine, antwortete dieser zunächst nicht. 
Erst als er ihn erneut fragte, was los sei, seufzte er aus tiefstem Herzen und sagte: „Wie soll ich nicht weinen, wenn unser Herr nicht von uns angefleht werden will?" Er habe sich nämlich vor jemandem gewähnt, der auf einem

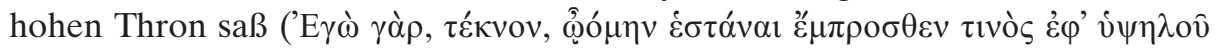
$\kappa \alpha \theta \eta \mu \varepsilon ́$ vov $\theta \rho o ́ v o v)$. Viele tausend Flehende seien um ihn herumgestanden und hätten um etwas gebeten. Der Herr aber habe sich ihre Bitten nicht angehört. Dann sei eine in Purpur gehüllte Frau hervorgetreten und habe ihn angefleht, er möge ihre Bitten erhören. Doch auch darauf sei der Herr nicht eingegangen. Deshalb weine und klage er aus Angst vor den zukünftigen Ereignissen. Am nächsten Tag gab es ein Erdbeben, und am Strand von Phoinikien wurden Städte zerstört.

100. PrSp 123, PG 87.3, col. 2985A-B: Als Abbas Zosimos jung war, ging er vom Berg Sinai hinunter in die Wüste und traf auf einen Mönch. Dieser sah ihn und fragte, noch bevor der andere ihn begrüßen konnte, was ihn, Zosimos, hierhergeführt habe. Er solle weggehen, denn er könne nicht hier bleiben. Als Zosimos darüber staunte, dass der Mönch ihn mit Namen kannte, erzählte

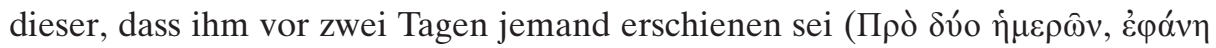
$\mu$ oí $\tau ı \varsigma . .$.$) , der sagte, es werde ein Mönch namens Zosimos zu ihm kommen. Er$ solle ihm aber nicht erlauben, bei ihm zu bleiben, da er wolle, dass die Kirche Babylons in Ägypten ihm folge. Dann sei der Erschienene so schnell wie ein

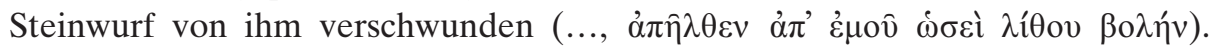
Nachdem der Mönch dies zu Zosimos gesagt hatte, betete er zwei Stunden lang. Dann ging er zu Zosimos und hieß ihn willkommen, da Gott ihn hierher geführt habe, um seinen Körper zu bestatten. Kurz darauf starb der Mönch, und Zosimos bestattete ihn.

101. ScPa 35, PG 88, col. 669C-672A: „Die Dämonen der Eitelkeit werden uns im Schlaf zu Propheten. Mit ihrer Verschlagenheit schlussfolgern sie zukünftige Geschehnisse und verkünden sie uns daraufhin. Trifft das Geschaute ein, so werden wir von Erstaunen erfüllt und unsere Gedanken erheben sich, als ob die Gabe der Vorhersehung sich in unserer Reichweite befände. Denen, die sich von diesem Dämon überzeugen lassen, wurde er oft zum Propheten, allen aber, die ihn verachten, stellte er sich als Lügner heraus. Weil er ein pneumatisches Wesen ist, sieht er, was sich ringsum im Luftraum ereignet. Begreift er zum Beispiel, dass jemand im Sterben liegt, sagt er es den Leichtgläubigen im Traum voraus“ ( $\Delta \alpha i ́ \mu o v \varepsilon \varsigma \kappa \varepsilon v o \delta o \xi i ́ \alpha \varsigma \kappa \alpha \theta$ ”

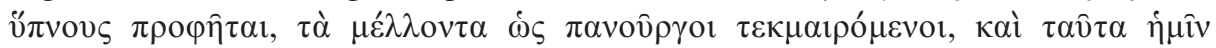

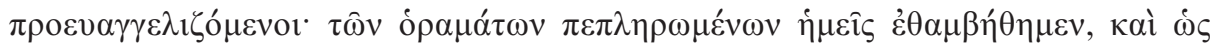

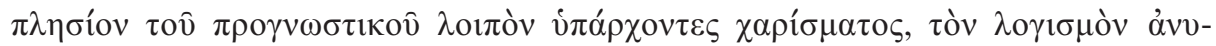

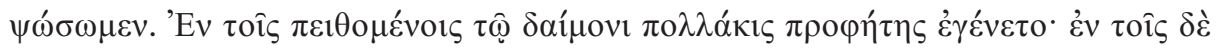

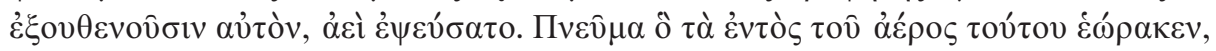

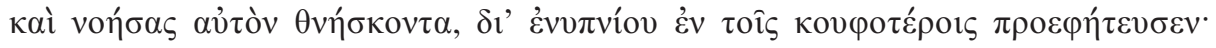

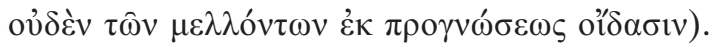


102. ViSySa 1677C-D, p. 60,20-27: Nikon, der Abt des Klosters des Gerasimos, „wurde von Gott mit der Würde der Prohpezeiung ausgezeichnet“ (... каì

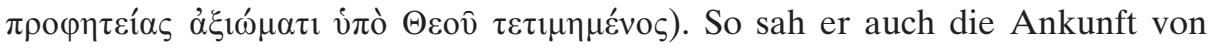

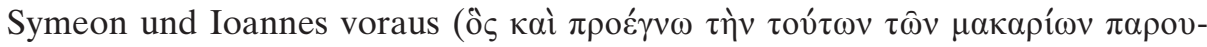
oíav). Er sagte nämlich, dass er am Tag ihrer Ankunft im Schlaf jemanden gesehen habe, der ihm auftrug, die Pforte des Klosters zu öffnen, damit seine

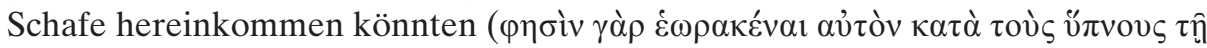

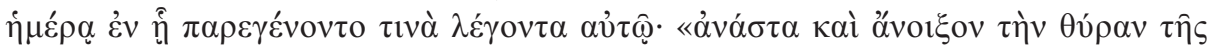

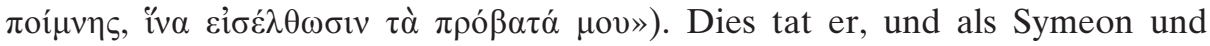
Ioannes zum Kloster kamen, fanden sie die Tür geöffnet.

103. ViSyStII 11, Bd. 1, p. 11,6-18: Symeon kam nach seiner Berufung in ein Kloster in den Bergen. Ioannes, der Vorsteher dieses Klosters, nahm ihn auf, weil er davor schon mehrere Offenbarungen über Symeon empfangen hatte.

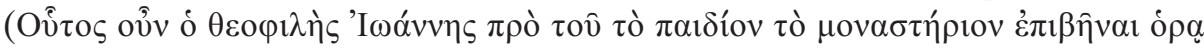

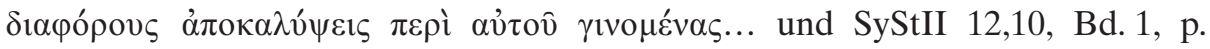

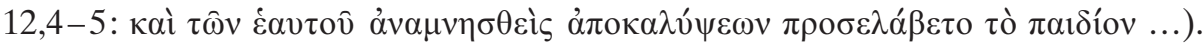
Einmal sah er Symeon als weißgekleideten Jungen, der auf einem Wagen sitzend zum Kloster befördert wurde, dann wieder, wie er um das Kloster herumflog und darauf landete oder wie er mit einer feurigen Säule in der Luft umherschritt und sich dem Kloster näherte. Ein anderes Mal wurde ihm der Junge von einem Engel gezeigt, der sagte, er werde durch diesen gerettet werden.

104. ViSyStII 15, Bd. 1, p. 13,22-14,2: Symeon Stylites sieht den Tod des

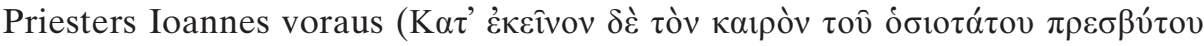

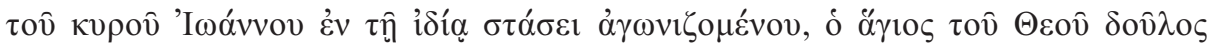

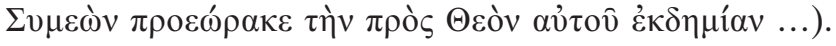

105. ViSyStII 36, Bd. 1, p. 34,25-35,1: „Der heilige Symeon sah den Tod des Presbyters Ioannes voraus, als dieser noch gesund und robust war" (... o ö $\gamma 10 \varsigma$

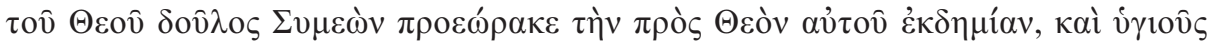

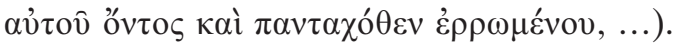

106. ViSyStII 57, Bd. 1, p. 50,12-52,11: Der Herr offenbarte Symeon, was er

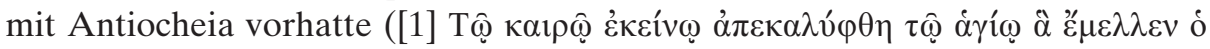

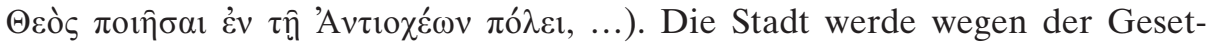
zeslosigkeit und Götzenanbetung ihrer Bewohner von den Persern niedergebrannt und verwüstet werden. Dann sah Symeon, wie ein Geist gesandt wurde, der ein Messer in die Stadt brachte (Eph 6,17). Diese Schau erzählte er den Brüdern und einigen frommen Antiochenern, die zu ihm gekommen waren ([2]

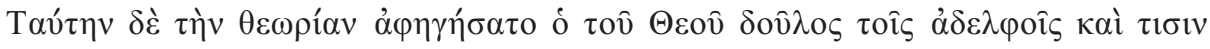

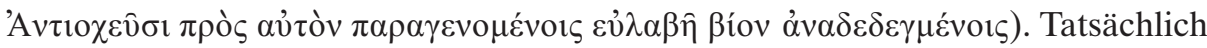
wurde die Stadt kurz danach von den Truppen des Chosroes angegriffen und belagert. Da wollte Symeon vom Herrn erfahren, ob er die Meinung ändern werde in dem, was er ihm angezeigt hatte, oder ob er vorhatte, die Stadt den 
Persern zu übergeben. Da aber der Zorn Gottes an seinem Gipfel angelangt war, wurde ihm nichts angezeigt. Als Symeon wiederholt betete, verkündete ihm der Herr, dass er die Stadt ausliefern und mit Feinden füllen werde. Die meisten Bewohner werden umkommen, und viele werden als Kriegsgefangene weggeführt. Symeon werde aber bald sehen, was es mit dieser Vision auf sich habe (...,

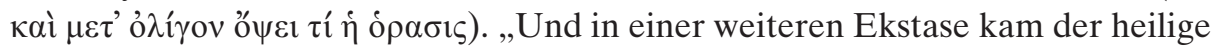
Geist zu Symeon und überbrachte ihm das lebensspendene Kreuz" ([3] Kaì

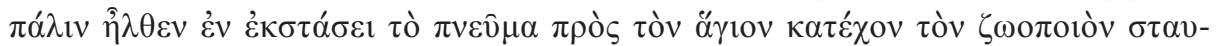
$\rho o ̀ v)$. Er sah zwei in Leinen gekleidete Engel, die gespannte Bögen und Pfeile in ihren Händen hielten. Als Symeon sie fragte, was dies zu bedeuten habe, antworteten sie, das Kreuz sei die Rettung und die Bewahrung vor jedem Feind. Die Pfeile aber seien für das Herz all jener gedacht, die ihn mit dem Messer

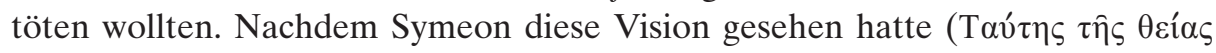

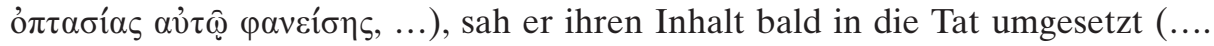

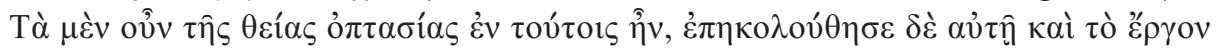

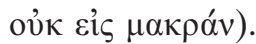

107. ViSyStII 78, Bd. 1, p. 66,20-68,5: Die folgende Schau verschwieg Symeon

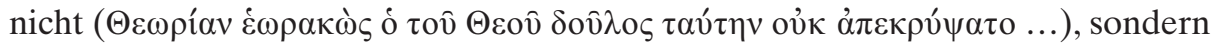
sagte voraus, dass ein Erdbeben Antiocheia in große Furcht versetzen werde. Nur Reue und Fürbitten könnten die Stadt vom Zorn, der auf ihr liege, befreien.

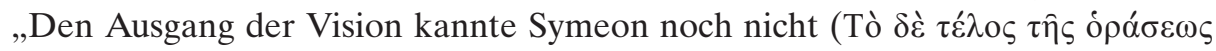

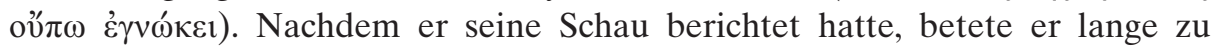
Gott." Am gleichen Abend fing die Erde an zu beben und die Stadt geriet in großen Aufruhr. „Als dies geschah, sagten einige von den Heiden und von den mit der Astrologie vertrauten voraus, dass die ganze Stadt zerstört werde“ ('Ev

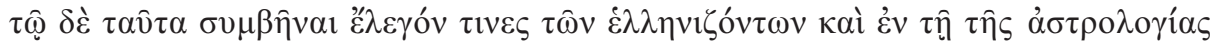

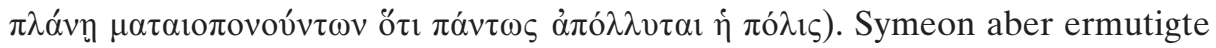
diejenigen, die bei ihm Zuflucht gesucht hatten. Denn der Irrtum jener Berechnenden, die durch die Divination der Ereignisse vorgeben, den Willen Gottes zu kennen, werde ein Ende haben, da Gott seinem Volk gnädig ge-

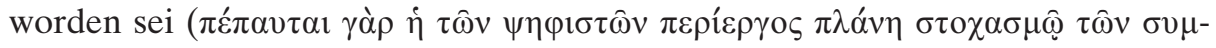

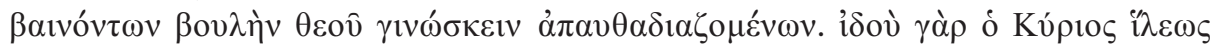

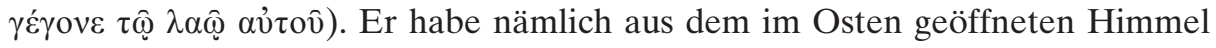
das große und unaussprechliche Licht des Sohnes Gottes gesehen. Tatsächlich gelang es Symeon, das Erdbeben aufzuhalten.

108. ViSyStII 103, Bd. 1, p. 80,25-81,23: „Eines Tages geriet Symeon in eine Ekstase. Er sah eine große Schar von Männern, Frauen und Kindern ('Ev $\mu 1 \hat{\alpha}$

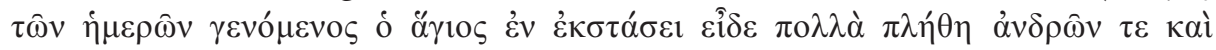

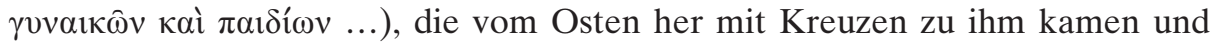
Litaneien und Doxologien zu Gott sandten. Der heilige Geist spendete der Menschenschar Schatten und zog mit ihr mit." Als die Schar zum wunderbaren Berg kam, fragte der heilige Geist Symeon, ob er wisse, dass dies das Volk der 
Iberer ${ }^{741}$ sei, das ihn um des heiligen Geistes willen liebe und zu ihm kommen werde. Weil es die Gabe der Heilung an sich erfahren werde, werde es im ganzen Land von ihm predigen und allen Gläubigen von ihm erzählen. Überdies werde es sich bei Symeon niederlassen. Nach dieser Schau vergingen nur wenige

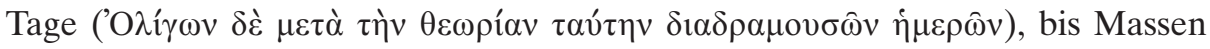
von Iberern zu Symeon kamen.

109. ViSyStII 104, Bd. 1, p. 81,24-84,8: Nach der Zerstörung Antiocheias „,sah

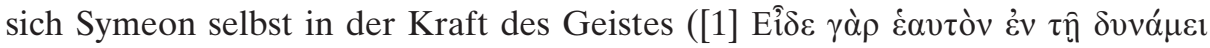

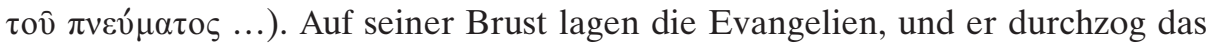
Land von Tyros bis nach Jerusalem und zu den Behausungen der Wüstensiedler. Von dort eilte er weiter nach Laodikeia und Antiocheia, wo er auf eine Truppe von Engeln traf", die ihn fragten, was ihn so umtreibe und warum er sich für die Antiochener einsetze, obwohl diese feindlich über ihn redeten. Nach der Vision sagte Symeon zu seinen Brüdern, ein großer Zorn bedrohe die Welt und er wisse nicht, was er zu dieser Schau sagen solle, dass sie aber beten sollen (... ở oî $\delta \alpha$

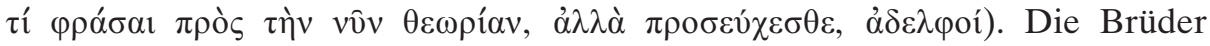
fürchteten sich, und als Symeon ihnen dies erzählte, veränderte sich plötzlich sein Gesicht. Er fing an zu schweigen, antwortete nicht mehr und war äußerst

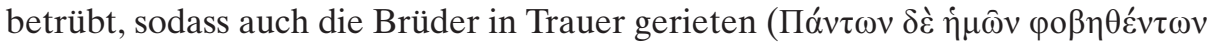

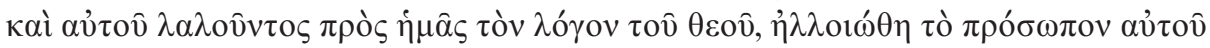

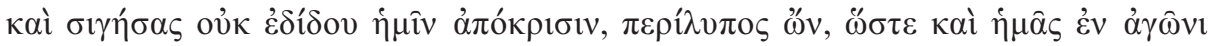

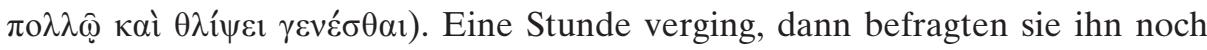
einmal über die Vision, worauf Symeon erwiderte, sie sollen zu Gott beten. Denn ohne Gottes Mitleid und Vergebung werde kein Stein auf dem anderen bleiben, er habe nämlich die Kraft Gottes auf unbeschreibliche Weise an jedem Ort im Himmel und auf Erden gesehen ( $\theta \varepsilon 0 \hat{~} \dot{\varepsilon} v \pi \alpha v \tau i ̀ . .$.$) , sodass keine einzige Stelle der fürchterlichen Kraft Gottes$ entgehe. Und diese Kraft habe beinahe jedes Geschöpf heimgesucht, bis ihm der Rest der Schau entrissen wurde, da er nicht ertragen habe, was ihm alles gezeigt

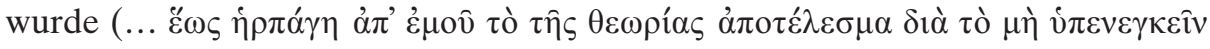

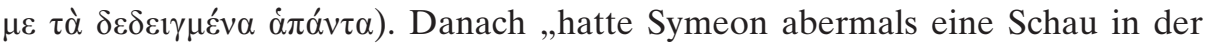

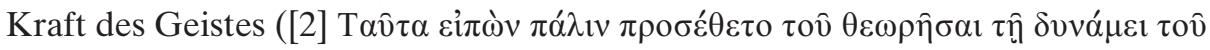
$\pi v \varepsilon v ́ \mu \alpha \tau o \zeta . .$.$) . Er sah die Himmel geöffnet, und über den Himmeln eine andere,$

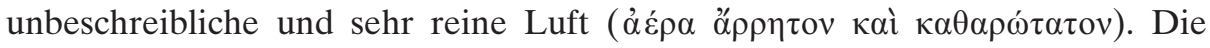
himmlischen Kräfte in dieser Luft formierten sich zu zwei Truppen, die gleichsam miteinander verbunden waren, indem die eine vor die andere gestellt war. Die Köpfe hielten alle gebeugt. Und über ihnen schwebte ein Thron, auf dem der Sohn Gottes saß, der sich unmittelbar vor einem heftigen Zornesausbruch befand, und niemand stand zum Gebet vor ihm. Doch Symeon fand sich durch die Kraft des Geistes in der Luft vor dem heiligen Thron wieder." Als er

741 Gemeint sind hier Georgier, s. dazu VAN DEN Ven, La vie ancienne, Bd. 2, 102, A. 103. 
anfing, den Herrn anzuflehen, schauderten die beiden Truppen. Der Herr möge sich erbarmen und von seinem Zorn ablassen. Auf diese Weise setzte sich Symeon für die Bewohner Antiocheias und seiner Umgebung ein. Und tatsächlich erhörte der Herr seine Worte und zeigte durch den Ausdruck seines Gesichts,

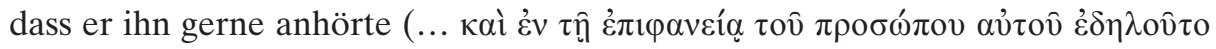

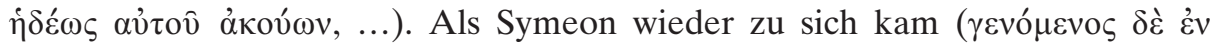
$\dot{\varepsilon} \alpha \nu \tau \hat{\omega}$...), forderte er die Brüder auf, zu beten als Dank dafür, dass die Umgebung von Antiocheia (der Landstrich, den er in der Vision abgewandert hatte) gerettet werde. Und wiederum ,sah er durch die Kraft des Geistes ([3] ...

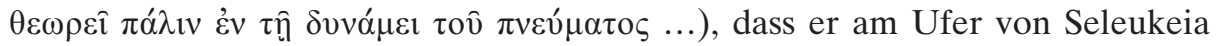
stand. Er sah direkt vor sich über dem Meer in der Atmosphäre ein Luftschiff schweben. Darin standen wutentbrannte Engel, die auf die Kraft des Geistes warteten. Der Geist stand an jenem Ort still und er lenkte das Boot in Richtung des Meeres. Er wiegte dreimal die Hände in der Luft, brach in lautes Geschrei aus und rief: „Schneide ab und entwurzle!“ Als die Engel im Schiff dies hörten, ertönte ihre Stimme so laut, dass die ganze Hölle ( $\alpha \beta \beta \sigma \sigma o \varsigma)$ erbebte. Das Schiff steuerte in der Luft in Richtung Strand, und im selben Augenblick fielen ganze Städte und Dörfer." Als Symeon wieder zu sich kam ( $\Gamma \varepsilon v o ́ \mu \varepsilon v o \varsigma \delta \grave{\varepsilon} \varepsilon \dot{\varepsilon} v \dot{\varepsilon} \alpha v \tau \hat{\omega} \ldots$...), forderte er die Brüder auf, weiter zu beten, da ein großer Zorn über der Welt

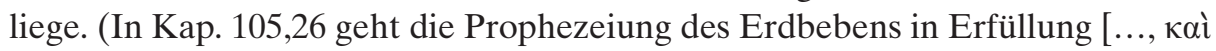

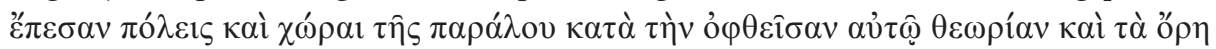

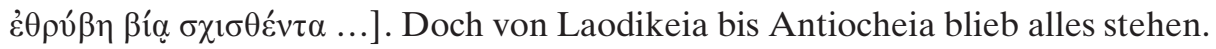
Wie Symeon vorhergesagt hatte, fiel nichts zusammen. Vielmehr blieb alles

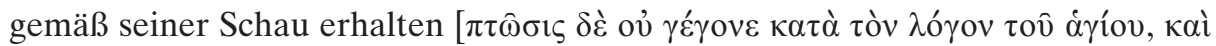

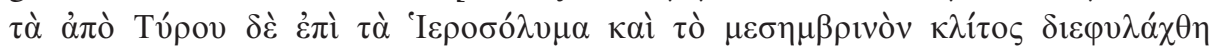

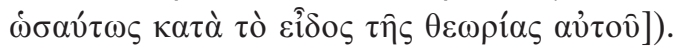

110. ViSyStII 106, Bd. 1, p. 86,6-26: Neun Tage nach dem Beben (s.o. 109) sah

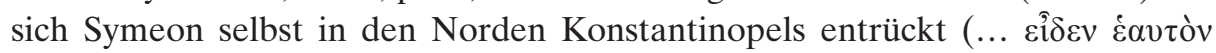

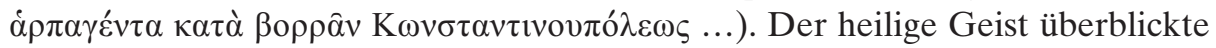
die Stadt, wiegte dreimal die Hände über ihr und beklagte sie, denn auch Konstantinopel werde heimgesucht. Als Symeon dies vorhersah, seufzte er und

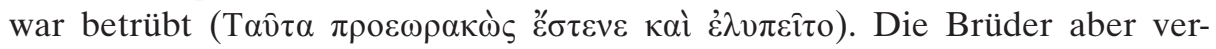
standen, dass er eine Vision gesehen hatte und zwangen ihn, sie zu erzählen

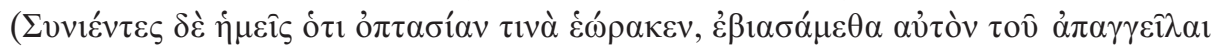
$\dot{\eta} \mu \mathrm{i} v)$. Sechs Tage später fand in Konstantinopel ein Erdbeben statt.

111. ViSyStII 109, Bd. 1, p. 88,22 f.: Der Herr zeigte Symeon den Tod seines

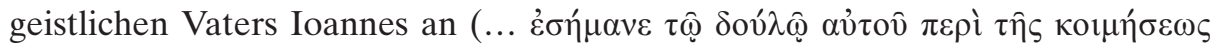

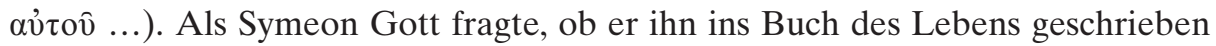
habe, antwortete dieser, dass er nicht nur diesen, sondern auch alle seine Brüder ins Buch des Lebens geschrieben habe. Zwei Tage später starb Ioannes.

112. ViSyStII 134, Bd. 1, p. 126,12-24: Symeon geriet in eine Ekstase (... \&ُv

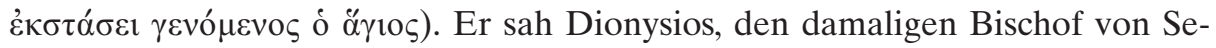


leukeia, zu sich kommen und in die äußere Abschrankung seiner Säule eintreten. Am nächsten Tag bewahrheitete sich die Schau.

113. ViSyStII 160, Bd. 1, p. 141,22-143,16: Symeon „,wurde durch die Kraft des heiligen Geistes entrückt und sah sich selbst im Kaiserpalast von Konstantinopel“" ([1] ... iे

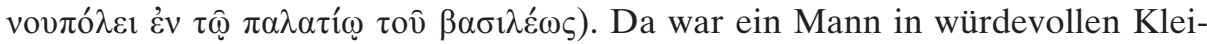
dern, dem durch den heiligen Geist große Macht über den Osten zugesprochen wurde. „Dann befand sich dieser Herrscher auf dem Marktplatz von Antiocheia. Der Jordan folgte ihm, und das Paradies Gottes offenbarte sich, indem es alles bedeckte. Ein Raubtier, das sich in einer Höhle versteckt hatte und gefangen genommen worden war, wurde in einem Triumphzug durch die Stadt geführt und verspottet. Der Herrscher schlug auf die Rücken der Menschen und fügte ihnen tödliche Wunden zu, um alle Wesen zu erschrecken. Dann sah Symeon einen ihm Bekannten, der vor dem Herrscher stand, welcher ihn aber unbe-

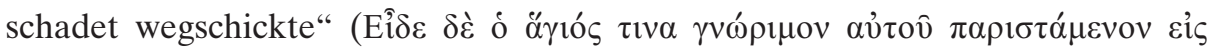

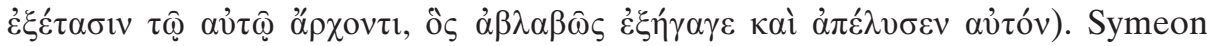
erzählte diese Vision seinen Brüdern und fügte hinzu, dass ein unfehlbarer Herrscher kommen und richten werde. Das Leuchten des Jordan, das diesem folgte, bedeute aber, dass all die Ungläubigen sichtbar werden. Das Paradies bedeute, dass die guten Taten im Andenken an die Heiligen erkannt werden. Das wilde Tier aber bedeute, dass die Verirrung des Teufels als Beispiel herangezogen werde und dass die Bilder der Heiden verlacht werden. (Diese Prophezeiung wird in 161, Bd. 1, p. 143,17-144,24, erfüllt): Der Befehlshaber Amantios kam nach Antiocheia und führte eine gerechte Herrschaft ein. Dann hatte Symeon wieder eine Vision ( . . ז

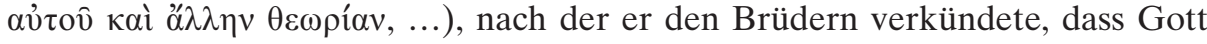
eine Entscheidung gegen die Heiden und Häretiker getroffen habe, um ihren Irrtum bezüglich Götzenanbetung aufzudecken und alle ihre Bücher einzusammeln und dem Feuer zu übergeben. Nachdem er dies vorausgesehen und

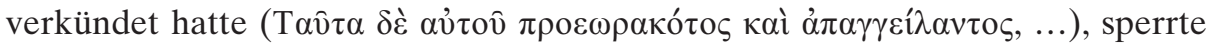
Amantios alle Heiden, Astrologen und Häretiker ein, beschlagnahmte ihre Bücher und verbrannte sie. Danach hatte Symeon (in 162, Bd. 1, p. 144,25-31)

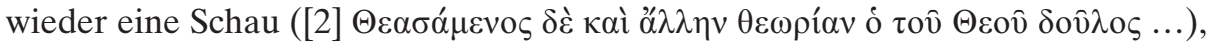
nach der er die Brüder darüber informierte, dass Gott weiterhin die Heiden verurteile. Er habe sich nämlich selber auf einer Straße in Antiocheia gesehen. Dort sei er auf einen am ganzen Körper gelähmten Armen getroffen, den er aufrichtete und heilte. Als dies geschah, seien Massen herbeigeeilt, um dieses Wunder $(\theta \alpha v \hat{\mu} \alpha)$ zu sehen. (Diese Schau bewahrheitet sich in 163, Bd. 1, p. 145,10-20): Hier wird ein Bettler in der Stadt geheilt (vgl. auch 297, unter

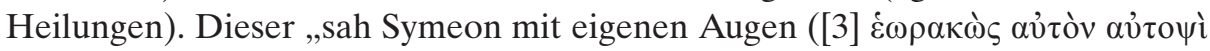
...) als langhaarigen Mönch, der seine Hand ausstreckte und ihn aufrichtete. Er wurde begleitet von der Mutter Gottes und einer Menge von Heiligen, die sich 
über die Verurteilung der Heiden freuten. Dies war nämlich das Paradies Gottes, welches alles überdeckte und von dem Symeon vorher gesagt hatte, es in der ersten Schau der Ankunft des Herrschers gesehen zu haben“ (... ôv $\pi \rho \circ \varepsilon$ ś

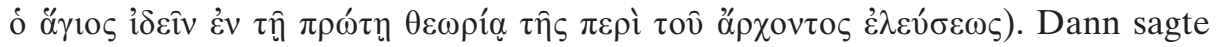
Symeon (in 164, Bd. 1, p. 145,22-146,15) zu den Brüdern, er habe gesehen, wie der Herrscher beim Verhör der im Gefängnis Eingesperrten im Gericht den Vorsitz hatte. Über dem Herrscher sah Symeon gleichsam ein Firmament, worin die Sonne, der Mond und die Sterne befestigt waren, die aber von der sich ausbreitenden Dunkelheit verdeckt wurden. Auf einige zeigte der heilige Geist mit dem Finger und befreite sie so von der Dunkelheit. Und sie erstrahlten, während andere verdeckt blieben. Symeon ,verstand durch diese Vision

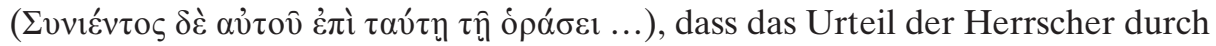
den Herrn und seine Gnade aus dem Himmel kommt, für die einen zum Leben, für die anderen zum Tod (dies war nämlich die Dunkelheit, welche die einen verdeckte, von den anderen aber überstrahlt wurde) [...]. Dann saß der Richter auf seinem Thron und verhängte Strafen über diejenigen, die ihre Übeltaten zugaben. Anderen befahl er, in Hospitälern zu dienen, und wieder anderen befahl er, in Klöster zu gehen. Einige wiederum schickte er in die Verbannung oder verurteilte sie zum Tode. Die meisten von ihnen aber begründeten ihr Verhalten mit Unwissenheit, und da sie bereuten, wurden sie auf kaiserlichen Befehl unverhört entlassen." Nur ein einziger, der viele Volksaufstände angezettelt hatte, wurde gefangen gehalten.

114. ViSyStII 173, Bd. 1, p. 154,18-155,3: Als im Kloster Kohle fehlte und die Brüder welche besorgen wollten, hielt Symeon sie zurück. Denn am nächsten Tag werde ein Bauer mit einem weißen und einem schwarzen Maultier kommen und die Kohle bringen. So geschah es. Die Brüder aber staunten, als sie die Gestalt der Pferde und die Erfüllung der Prophezeiung erblickten (..., \&̇ $\theta \alpha$ -

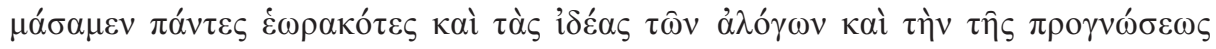
$\pi \rho \circ \eta \tau \varepsilon i ́ \alpha v, \ldots)$.

115. ViSyStII 182, Bd. 1, p. 161,13-162,4: Eines Tages zerstörte ein Wildschwein den Garten des Klosters. Deshalb gingen die Brüder zu Symeon und baten ihn, er möge dafür sorgen, dass das Tier umgebracht werde. In derselben Nacht sah einer der Brüder in einer Vision einen Löwen, der von Symeon

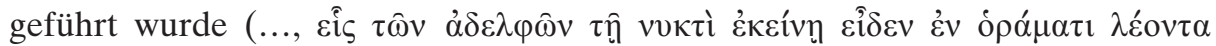

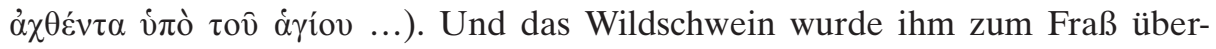
geben. Nachdem der Bruder aufgewacht war, fand er den Löwen, der das Wildschwein zerrissen und verschlungen hatte und sich auf dem Weg ausruhte. 116. ViSyStII 202, Bd. 1, p. 176,17-177,6: Ioannes, ein ein frommer Gelehrter aus Antiocheia, besuchte einmal den Heiligen Symeon. Da er zum Priester geweiht und als apokrisiarios in die heilige Stadt geschickt werden sollte, wollte er von Symeon erfahren, ob dies der Wille Gottes sei. Dieser riet ihm, seinem Vorgesetzten zu gehorchen, denn Gott habe ihn für den apostolischen Sitz in der 
heiligen Stadt vorgesehen. Er möge dies aber so lange geheim halten, bis es sich erfülle. Dadurch hatte Ioannes Vertrauen zu Symeon gefasst und verlangte, von ihm zu erfahren, wer der Nachfolger des Kaisers Iustinianos werde. 203, Bd. 1, p. 177,7-18: Erst nachdem Ioannes versprochen hatte, die Worte des Symeon nicht weiterzuerzählen, prophezeite dieser, dass Iustinos der Nachfolger Iustinianos werde (Erfüllung der hier erwähnten Prophezeiung in 205, Bd.1, p. 178,14-15: „Der Geist Gottes beseitigte den Kaiser Iustinianos und setzte den erwähnten Ioannes als Patriarchen ein, gemäß der Vorhersage des Heiligen“

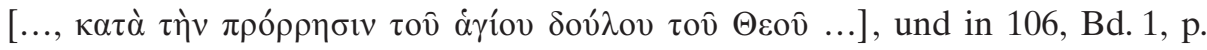
178,18-23: „Nachdem Iustinianos gestorben war, ging die kaiserliche Macht an

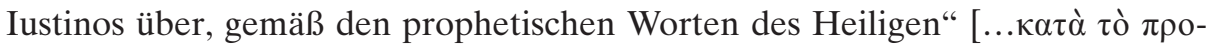

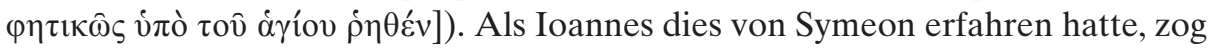
er los und ging nach Konstantinopel. Die Schüler des Symeon aber hielten es für notwendig, die Worte der Prophezeiung zur Erinnerung zu notieren ('H $\mu \varepsilon i \bar{\zeta} \delta \grave{\varepsilon}$

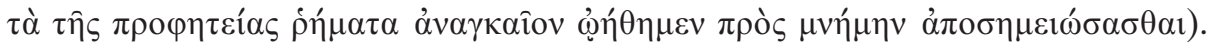
117. ViSyStII 204, Bd. 1, p. 177,19-178,8: Symeon forderte die Brüder auf, für die Kirche Antiocheias zu beten. Er habe nämlich in einer Vision gesehen ( $\hat{\imath}_{\hat{i} \delta o v}$

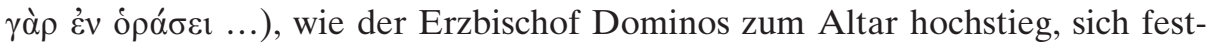
klammerte und anfing zu röcheln. Dann stieg er wieder hinunter und stellte sich auf die rechte Seite des Altars. Der Klerus und das Volk warteten, da sie glaubten, er verrichte das Gebet. Während langer Zeit verharrte er dort, dann ging er in seine Zelle. Gleichzeitig sah Symeon Mönche aus Palästina, die in der Kirche die Liturgie feierten. Und Symeon selbst verrichtete das Gebet. Nachdem er diese Vision erzählt hatte, sagte Symeon, dass in diesen Tagen der Patriarch sterben werde. An seine Stelle werde ein Mann aus Palästina treten. Und so geschah es. Dominos starb und an seine Stelle trat Anastasios aus Palästina. Die Brüder priesen Gott, der die Zeiten veränderte und Symeon das

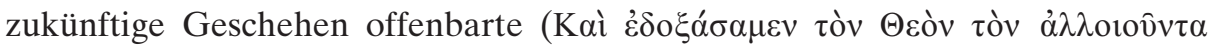

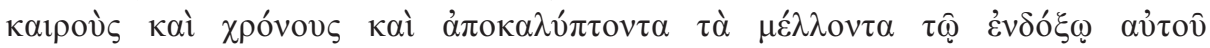

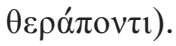

118. ViSyStII 208-211, Bd. 1, p. 179,6-181,9: Als Kaiser Iustinos krank wurde, bat der Patriarch Ioannes Symeon, er möge für den Kaiser beten. Symeon antwortete, dass Iustinos bald wieder gesund werde, sofern man ihm keine Behandlung verschreiben werde, die Gott nicht gefällig sei. Iustinos wurde aber nicht gesund, da er die Worte des Heiligen überging. „Vielmehr lieferte er sich

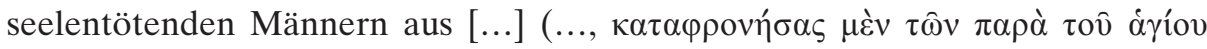

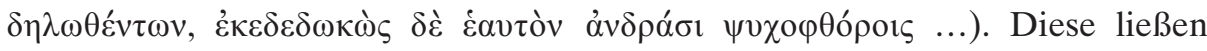
nämlich einen gewissen Timotheos kommen, der Jude war und sich in der Ärztekunst auskannte. In Wirklichkeit war er aber ein Feind des Sohnes Gottes

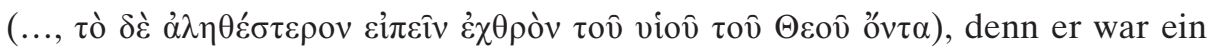

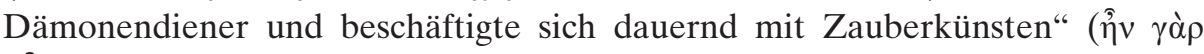

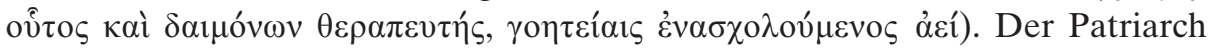


Ioannes versuchte zwar zu verhindern, dass dieser Scharlatan zum Kaiser vorgelassen wurde, doch man hörte nicht auf ihn. 209, Bd. 1, p. 180,1-18: „Als sich dies ereignete, sah sich Symeon in der Mittagsstunde durch die Kraft des hei-

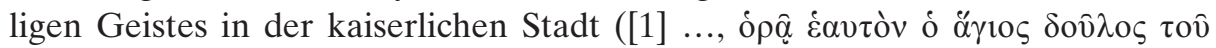

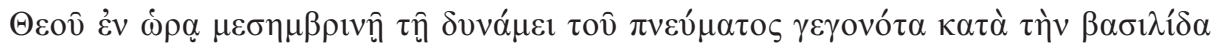
$\pi$ ó $\lambda_{\imath} v$...). Er betrat den Palast und sah, was durch den Juden angerichtet wurde. Darüber geriet er in heftigen Zorn [...]. Diese Vision ließ er dem Patriarchen

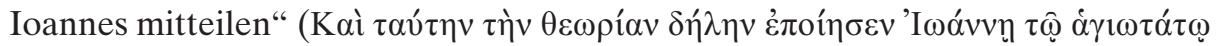
$\pi \alpha \tau \rho ı \alpha ́ p \chi \eta, . .$.$) . Überdies forderte er von Ioannes dafür einzustehen, dass eine$ derartige Praktik, welche den Herrn in großen Zorn versetze, vom Kaiser ferngehalten werden solle. Ansonsten werde eine göttliche Entscheidung über ihn kommen. Er habe nämlich durch den heiligen Geist gesehen, dass die Seele

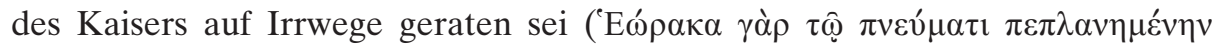

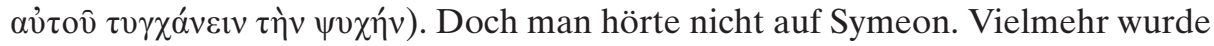

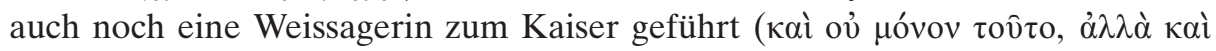

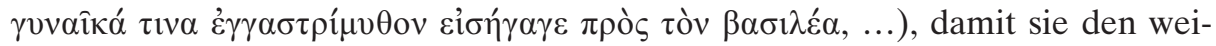
teren Verlauf der Krankheit bekanntgebe. 210, Bd. 1, p. 180,19-181,2: „Als dies geschah, geriet Symeon in Ekstase und fand sich wieder im Palast ([2] ...,

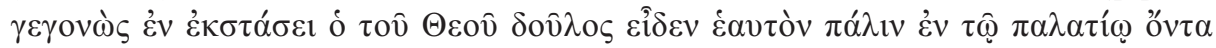
...). Der Kaiser empfing am gewohnten Ort seine Besucher, als sich die Himmel öffneten und eine göttliche Kraft herunterkam, dem Kaiser das kaiserliche Gewand auszog, das Diadem vom Kopf nahm und sagte: ,Von nun an sollst du zum Gerede aller Menschen werden, da du dich selber der dämonischen Verirrung hingegeben hast, anstatt auf die göttliche Hilfe zu hoffen' ('E $\sigma 0 \tau \varepsilon \dot{\varepsilon} \omega \varsigma \hat{\omega} \delta \varepsilon$

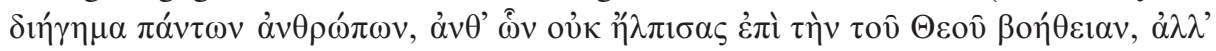

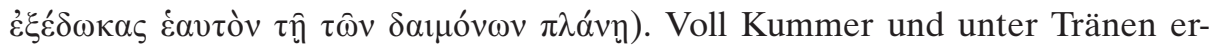

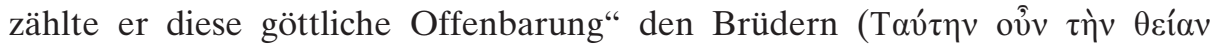

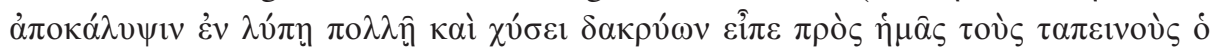

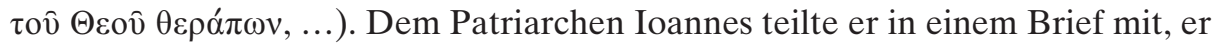
solle ihn nicht mehr wegen des Kaisers belästigen. 211, Bd. 1, p. 181,3-9: „Nach wenigen Tagen wurde überall bekannt, dass der Kaiser verrückt geworden war

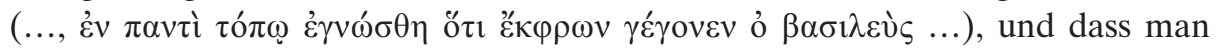
bemüht war, ihn im Palast einzusperren." Nach einiger Zeit starb Iustinos.

119. ViThSy 54, Bd. 1, p. 46,10-36: Maurikios, der komes des Kaisers Tiberios, befand sich nach seinem Sieg gegen die Perser auf dem Rückweg nach Konstantinopel und zog durch Galatien. Hier besuchte er den Heiligen Theodoros und bat ihn, er möge für ihn und seine Soldaten beten, dass sie heil nach Konstantinopel zurückkehrten. Theodoros betete für Maurikios und sagte ihm

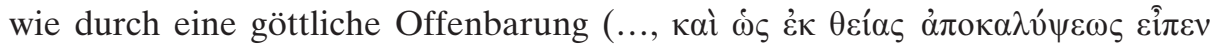
$\left.\alpha \jmath ̛ \hat{\omega}^{\cdot}\right)$, dass er später Kaiser werde. Als Maurikios zurück in Konstantinopel

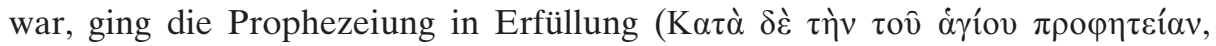

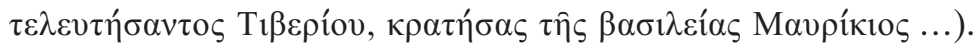


120. ViThSy 58, Bd. 1, p. 49,9-50,19: Nachdem Timotheos, der Bischof von Anastasiupolis, gestorben war, wollte man den Heiligen Theodoros als Nachfolger einsetzen. Da dieser sich aber weigerte, wurde er zwangsweise auf einer Liege davongetragen und in die Metropole Ankyra gebracht, wo er vom Erzbischof Paulos empfangen und zum Bischof geweiht wurde. Paulos erzählte, dass

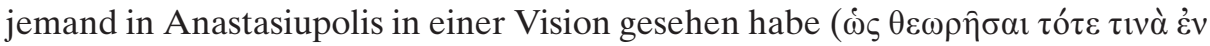

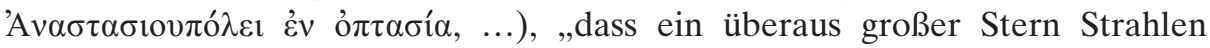
aussandte und vom Himmel auf ihre Kirche herunterstrahlte, dort stillstand und die Stadt und ihre ganze Umgebung erleuchtete“. Daraufhin verließ Theodoros Ankyra und ging nach Anastasiupolis, wo er gemäß der Erscheinung anfing, durch seine göttlichen Gaben der Heilungen wie ein Stern zu leuchten (...

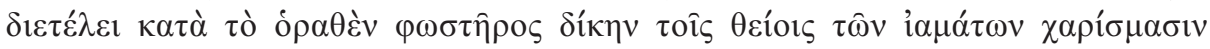
$\dot{\varepsilon} \kappa \lambda \alpha ́ \mu \pi \omega v, \ldots)$.

121. ViThSy 73-74, Bd. 1, p. 60,35-62,21: Theodoros prophezeite den nahenden Tod des Wüstenvaters Antiochos, der ihn auf der Durchreise von Kon-

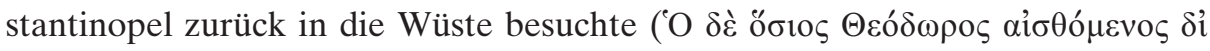

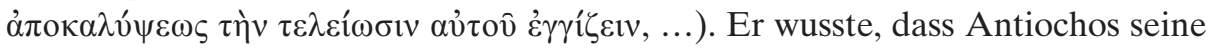

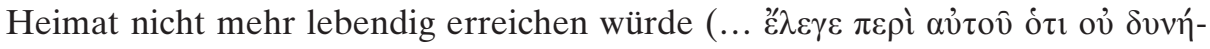

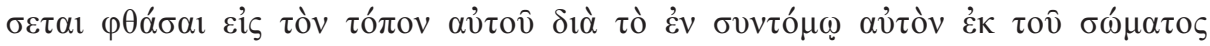

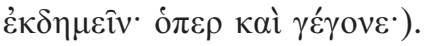

122. ViThSy 78, Bd. 1, p. 66,14-18: Als Theodoros sein Bischofsamt abgeben wollte und deshalb in die Metropole Ankyra ging, sah ein Stadtbewohner im

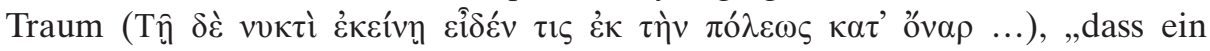
leuchtender Stern seine Strahlen aussandte und die Stadt erleuchtete. Über der Kirche stand er still, setzte sich wieder in Bewegung und entfernte sich von ihnen. Als er schon weit weg war, konnte man ihn kaum noch sehen. Nachdem er dies gesehen hatte, verstand er, dass sich dies im Hinblick auf den Heiligen

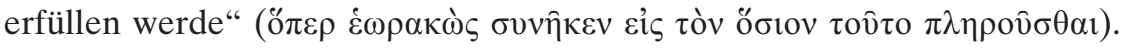

123. ViThSy 134, Bd. 1, p. 106,3-107,7: Als sich Theodoros in Konstantinopel aufhielt, wurde er vom Patriarchen Thomas gebeten, ihm zu sagen, ob sich tatsächlich bei den Prozessionen die Kreuze auf wunderbare Weise bewegten. Als Theodoros dies bestätigte, wollte Thomas von ihm wissen, was dieses Zei-

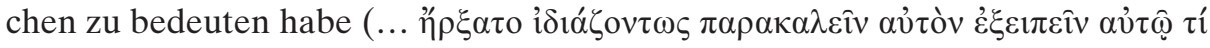

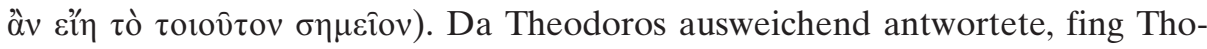
mas an, ihn noch hartnäckiger zu bitten, denn er sei davon überzeugt, dass Theodoros nicht nur dieses Zeichen, sondern auch viele andere kenne („„ઈí $\delta \alpha \alpha \alpha i$

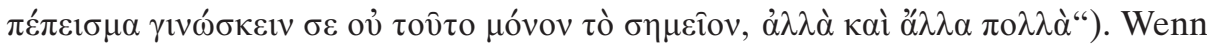
es ihm aber bis jetzt verborgen geblieben sei, und er nicht danach verlangt habe, es zu erfahren, dann werde es Gott ihm nun offenbaren, wenn er ihn darum bitte

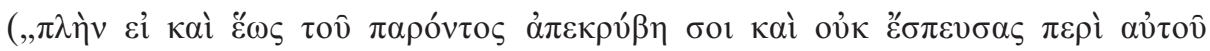

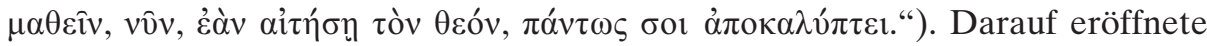
ihm Theodoros unter Tränen, dass er ihn nicht betrüben wollte, da es nicht zu 
seinem Nutzen sei, die zukünftigen Ereignisse zu erfahren. Da der Patriarch aber nicht nachgab, erzählte ihm Theodoros, dass das Beben der Kreuze viel Schlimmes bedeute, so z.B. Zweifel und Apostasie im Glauben, den Einfall barbarischer Völker, Blutvergießen, Zerstörung, Gefangenschaft und Verwüstung der Kirchen. 


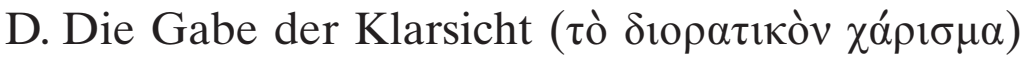

124. ViAn 59,1-6, p. 292,3-294,2: Zwei Brüder, die auf dem Weg zu Antonios waren, gerieten in Not, da sie zu wenig Wasser bei sich hatten. Der eine starb, der andere war kurz davor. Er lag auf dem Boden und wartete auf den nahenden Tod. Antonios aber befand sich zur selben Zeit auf dem Berg (4 Kön 1,9), als er zwei Mönche zu sich rief und ihnen auftrug, sich mit einem Wassergefäß auf den Weg in Richtung Ägypten zu machen. Sie würden auf der Strecke zwei Mönche treffen, der eine sei bereits tot, der andere werde es bald sein, wenn sie sich nicht beeilten. Dies sei ihm nämlich beim Beten offenbart

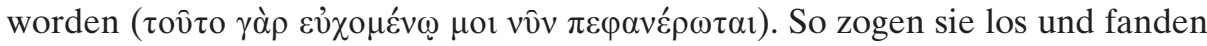
die beiden Brüder auf dem Weg. Den einen bestatteten sie, den anderen richteten sie mit Wasser wieder auf. „Der Grund, warum Antonios dies nicht vor dem Tod des Bruders erzählte war, dass es nicht ihm, sondern nur Gott zustand, über Leben und Tod zu entscheiden. Er war es denn auch, der über den einen

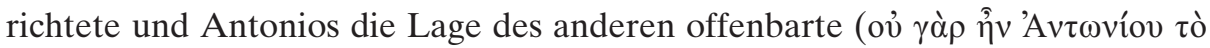

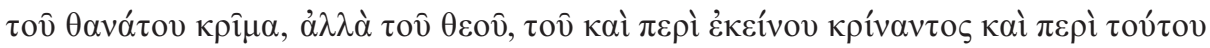

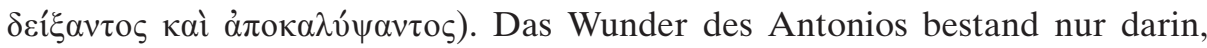
dass ihm der Herr, als er sich auf dem Berg befand und um sein Herz besorgt

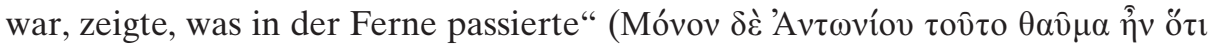

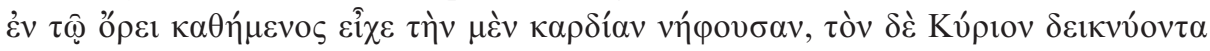
$\alpha u ̛ \tau \hat{~} \tau \grave{\alpha} \mu \alpha \kappa \rho \alpha ́ v)$.

125. ApAl, Makarios der Ägypter 33, PG 65, col. 273D-277B: Abbas Makarios übernachtete bei zwei jungen Brüdern, da er ihre Lebensweise erfahren wollte. Als sie sich alle hingelegt hatten, betete Makarios zu Gott, er möge ihm die Werke der Brüder offenbaren. „Da hob sich das Dach, und es wurde hell wie am Tag. Die beiden Brüder aber nahmen das Licht nicht wahr." Und da sie glaubten, dass Makarios schlafe, stieß der Ältere den Jüngeren in die Seite. Sie standen auf, gürteten sich und strecken die Hände in den Himmel. Und Makarios beobachtete, wie die Dämonen wie Fliegen auf den Jüngeren zuströmten

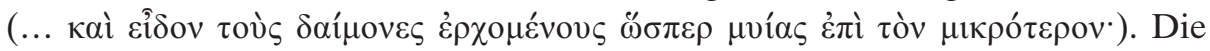
einen setzten sich in seinen Mund, die anderen auf seine Augen. Dann sah er einen Engel des Herrn, der ein Feuerschwert herunterstreckte und einen Kreis um den Bruder zog, um die Dämonen zu vertreiben (vgl. auch 431).

126. ApSy X 110, Bd. 2, p. 86: Über einen Asketen wird gesagt, dass er 25 Jahre

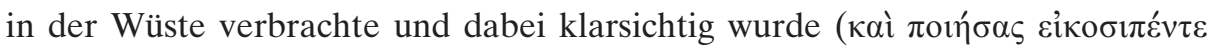

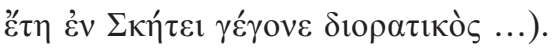


127. ApSy XI 111, Bd. 2, p. 86 f.: Als ein besessener Mönch seine Zelle verlassen wollte, sah ihn ein klarsichtiger Greis in der Nachbarschaft ('Hv $\delta$ '́ $\tau ı \varsigma$

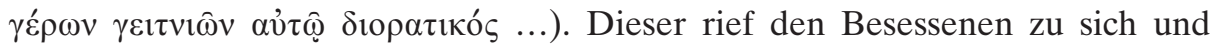
schickte ihn zurück in die Zelle.

128. ApSy XII 14, Bd. 2, p. 218: Ein Bruder besuchte einen klarsichtigen Mönch

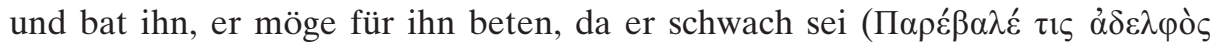

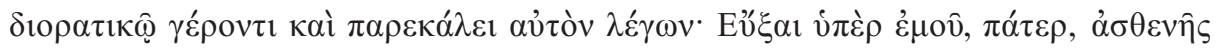

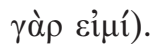

129. ViEu 19, p. 30,6-24: Als sich die Brüder Maron und Klematios eines Nachts davonschleichen wollten, wurde dies dem meditierenden Euthymios auf der Stelle offenbart. „Er sah, wie der Teufel den beiden einen Zügel anlegte und

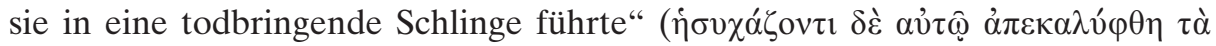

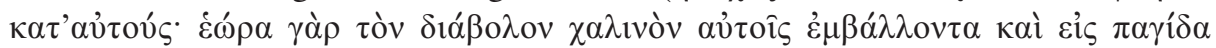

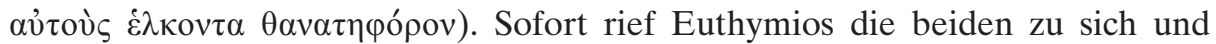
belehrte sie ausführlich. Schließlich sagte er ihnen, dass man sich immer und

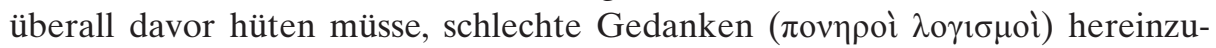
lassen, und dass eine Pflanze, die ständig umgepflanzt werde, keine Früchte tragen könne. Ebenso wenig fruchtbar sei der Mönch, der von einem Ort zum nächsten ziehe.

130. ViEu 21, p. 34,24-30: Als Euthymios anfing, „die Lebensweise des ägyptischen Wüstenvaters Arsenios nachzuahmen, wurde er auch für würdig befunden, sich der charismatischen Gaben, an welchen jener teilhatte, zu erfreuen. So wurde ihm der heilige Geist, das Leuchten des göttlichen Lichts und die Gabe der Klarsicht zuteil. Über die Gaben der Heilung und der Austreibung unreiner Geister zeugen die Wunder, die sich bis heute an seinem Grab ab-

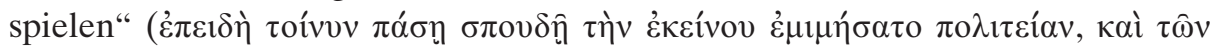

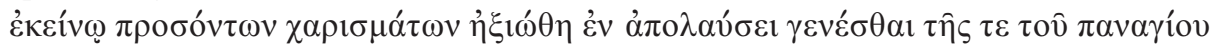

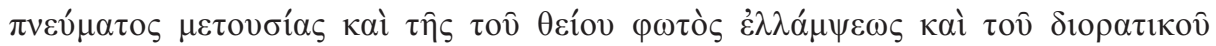

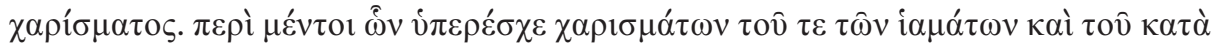

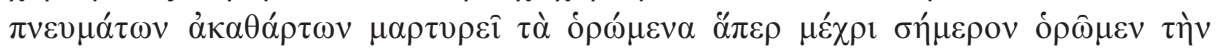

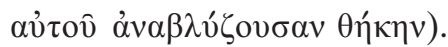

131. ViEu 22, p. 35,1-22: Kyrillos von Skythopolis fängt an, über die Gabe der Klarsicht zu erzählen und setzt da ein, wo Euthymios begann, seine Strahlen

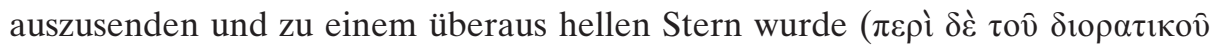

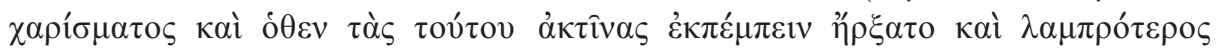

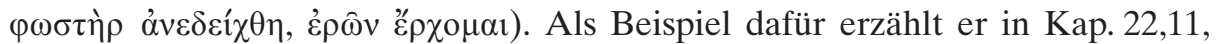
dass Euthymios die Ankunft des Hüters der Heiligen Stätte Anastasios und seiner Gefolgschaft geoffenbart wurde, als diese noch auf dem Weg zu ihm

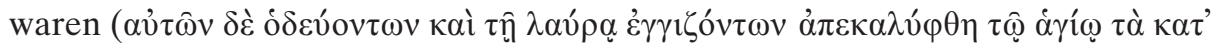
$\alpha$ $\tau$ ov̀s ....).

132. ViEu 24, p. 36,30-37,17: Euthymios erzählt den Brüdern die Geschichte eines Klarsichtigen, der durch die Gabe der Klarsicht einen im Sterben lie- 
genden „Pseudoheiligen“ als solchen entlarvte. Dieser wurde von allen Stadtbewohnern für heilig gehalten, erzürnte aber im Verborgenen seines Herzens Gott durch unreine Gedanken. Als der Klarsichtige in die Stadt des

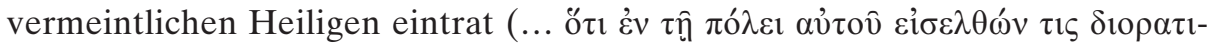
кós), fand er die ganze Bevölkerung des Ortes in Tränen aufgelöst, da sie um das Leben des heiligen Mannes und damit um ihre eigene Rettung fürchteten. „Sofort ging der Klarsichtige zum vermeintlichen Heiligen, um von ihm den Segen zu empfangen. Als er zu ihm kam, traf er auf eine große Menschenmenge von Weltlichen und Klerikern bis hin zum Bischof, die im Begriff

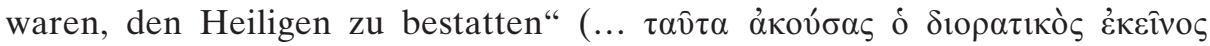

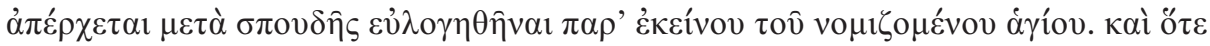

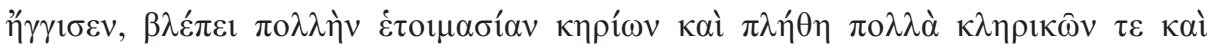

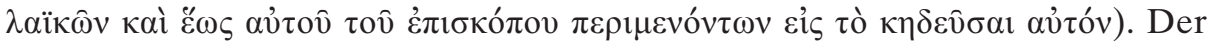
Klarsichtige aber „trat an ihn heran und fand ihn noch lebend. Mit den Augen des Geistes sah er, wie der Tartaros des Hades einen feurigen Dreizack in das Herz des falschen Heiligen hineinrammte und damit unter großen Qualen seine Seele aufspießte. Und er hörte eine aus dem Himmel kommende Stimme, die sagte: ,So wie die Seele dieses Mannes nicht einen Tag aufgehört hat mich zu quälen, so lass du nicht davon ab, seine Seele zu plagen und aufzu-

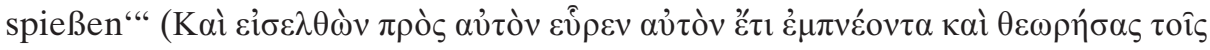

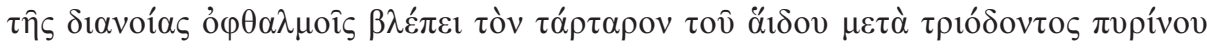

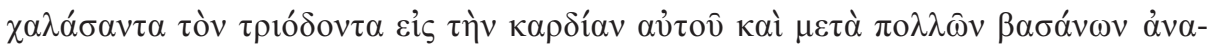

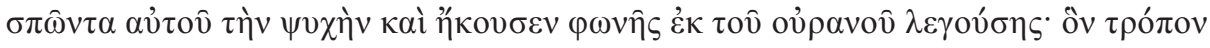

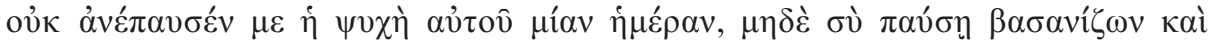

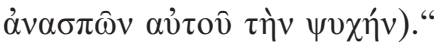

133. ViEu 29, p. 45,27-46,9: Die Väter erzählten, „dass Euthymios auch diese Gabe hatte, dass er durch den Blick des sichtbaren Körpers die Regungen der Seele erblickte und erkannte, gegen welche schlechten Gedanke ein jeder ankämpfte, welche er überwand und von welchen er niedergerungen wurde"

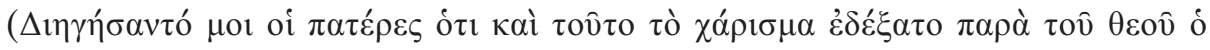

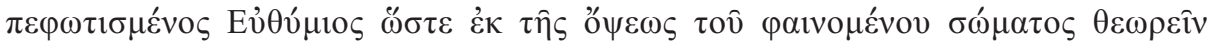
$\alpha$

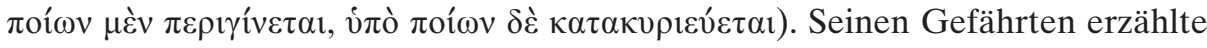
er, dass er bei der Eucharistie unter den aus der Menge Vortretenden häufig Erleuchtete sah. Andere unter ihnen waren jedoch verdammt und in einer ge-

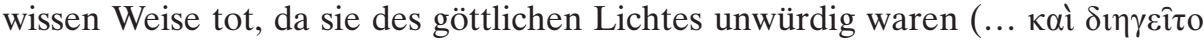

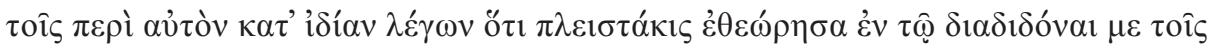

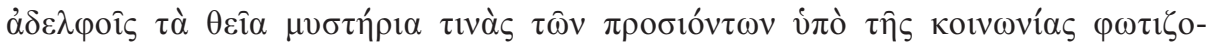

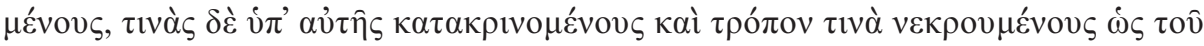

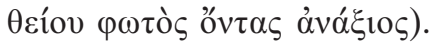

134. HiLa 18, p. 52,1-53,13: Abbas Makarios wanderte durch die Wüste Thebais zum Kloster in Tabennisi, wo er auf den mit der Prophetengabe ausge- 


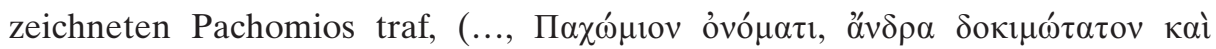

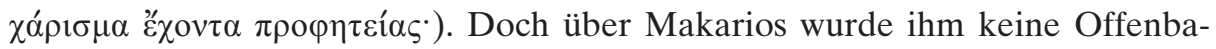

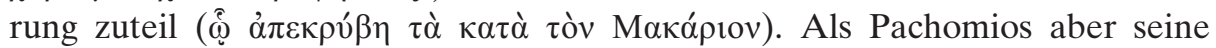
Lebensweise beobachtete, wurde er allmählich neugierig und betete zu Gott, er möge ihm offenbaren, wer Makarios sei. So geschah es [vgl. auch 81].

135. ViIo 9, p. 208,6-19: Sabas betete zu Gott, er möge ihm offenbaren, was es

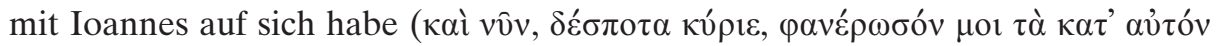
...). Als er unter Tränen solcherlei Worte sprach und die Nacht durchwachte,

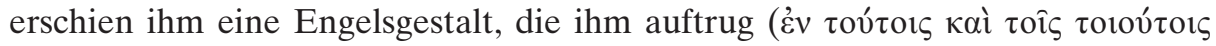

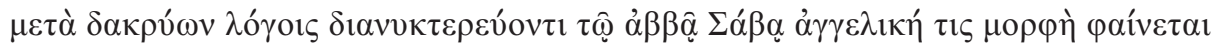

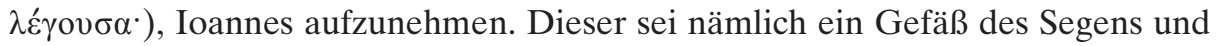
sei bereits zum Bischof geweiht worden, sodass er nicht mehr Presbyter werden

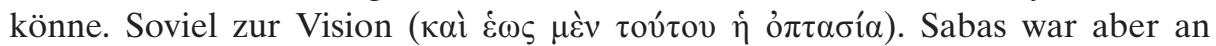
Gotteserscheinungen und Engelsgesichte gewöhnt und fürchtete sich nicht. Vielmehr freute er sich und ging sofort zu Ioannes, um ihm mitzuteilen, dass der Herr ihm offenbart habe, was Ioannes ihm verschwiegen hatte (ó $\delta \grave{\varepsilon} \pi \alpha \tau \dot{\eta} \rho \dot{\eta} \mu \hat{\omega} v$

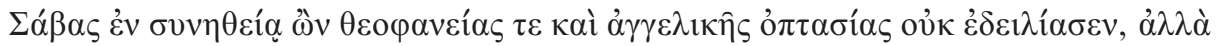

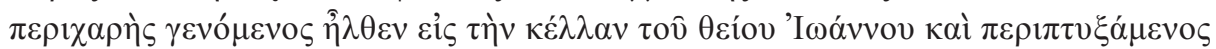

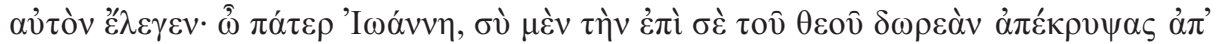

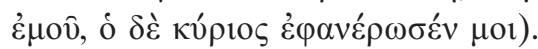

136. ViIo 17, p. 214,21-215,4: Der heilige Ioannes ,hatte das Verlangen zu sehen, wie sich die Seele vom Körper trennt. Als er dabei war, Gott darum zu bitten, wurde er im Geist nach Betlehem entrückt und sah im Narthex der dortigen Kirche einen unbekannten Heiligen liegen. Er war tot, und seine Seele wurde von Engeln emporgehoben und mit Hymnengesang und Wohlgeruch in

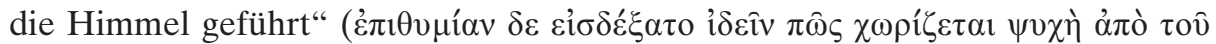

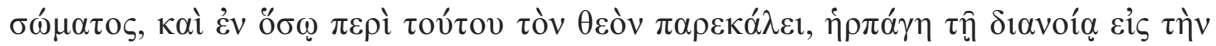

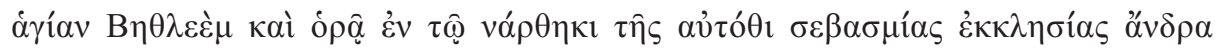

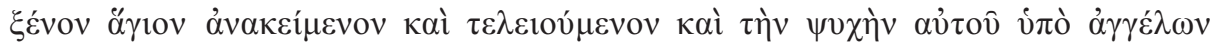

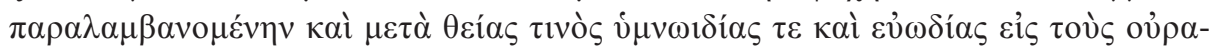

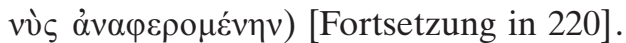

137. ViPa 112, Halkin 1982, p. 54,13-55,11: Über die Angelegenheit, dass Pachomios von vielen für klarsichtig gehalten wurde, brach ein Streit aus, weswegen sich der heilige Mann auf der Synode von Latopolis seinen Gegnern

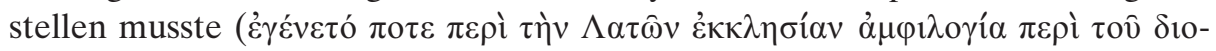

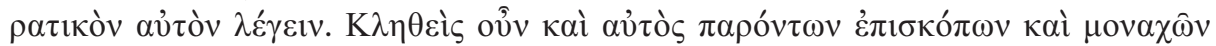

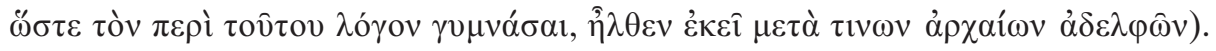
Dort anerkannten die Bischöfe Pachomios zwar als Mann Gottes, da sie wussten, dass er Dämonen gesehen, gegen sie angekämpft und sie aus den Seelen von Menschen vertrieben hatte. Da es sich aber bei der Klarsicht um eine bedeutungsvolle Angelegenheit handelte, verlangten sie, dass er sich noch einmal wegen ihr verteidige, um damit seine Gegner zu überzeugen («O 


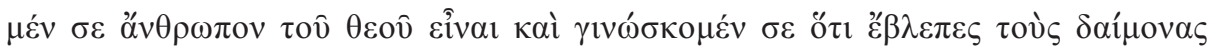

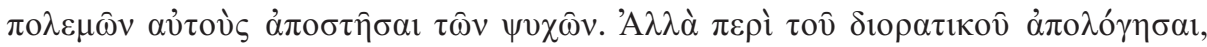

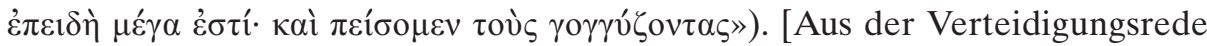
des Pachomios auf der Synode von Latopolis, p. 54,34-55,2]: „,Lass doch das charisma Gottes, denn würde Jesus, wenn er jemanden sähe, der aus ganzem Herzen den Untergang seines Nächsten oder sogar vieler fürchtet, ihn nicht mit der Gabe versehen zu erkennen, wie sie zu retten sind, sei es durch die Unterscheidung des heiligen Geistes, sei es durch ein Gesicht, wann und wie er es

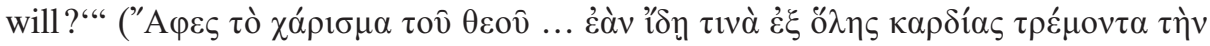

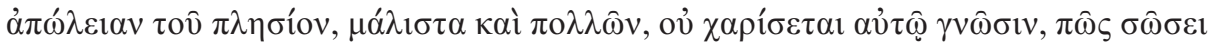
$\alpha$

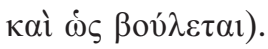

138. ViPa 135, HaLkin 1982, 1-4, p. 64,13-16: Theodoros, der Lieblingsschüler des bereits verstorbenen Pachomios, begann, als er vom Gerede über die Klarsichtigkeit des Pachomios hörte, zu verbergen, wenn er durch den Willen

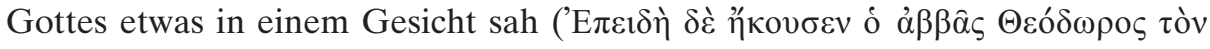

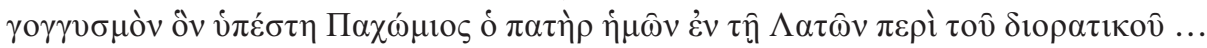

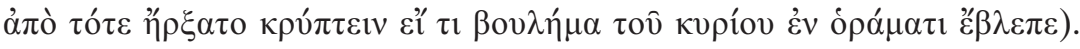

139. PaThII 16, p. 105,1-40: Ammonos bat Ausonios, ihn durch die heiligen Schriften darüber zu belehren, ob es dem Menschen überhaupt möglich sei, das

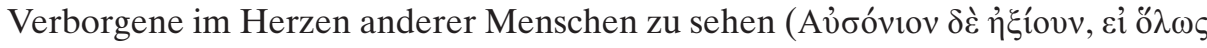

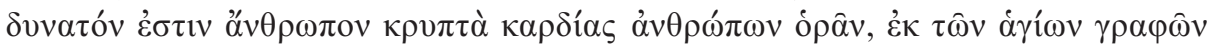

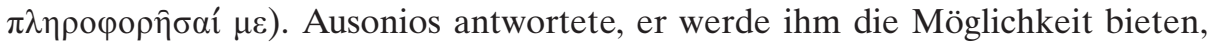
es durch eigene Erfahrung zu verstehen, wenn Gott Theodoros seine Geheimnisse (des Ammonos) offenbare. Denn ohne dass Gott es offenbare, könne kein

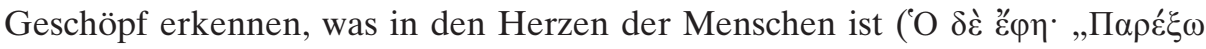

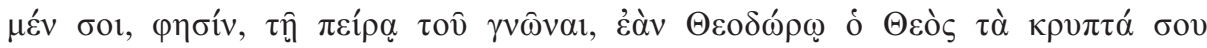

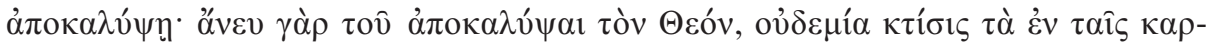

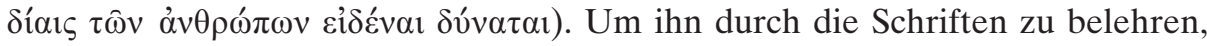
erzählte Ausonios, was der Prophet Samuel zu Saul sagte: „Komm, und ich werde dir alles in deinem Herzen verkünden ... [1 Kön 9,19-20].“ Ammonos solle aber auch lesen, was die Söhne des Jesaia zu Samuel gesagt haben, damit er erkenne, dass die Diener des Herrn sehen, wenn er ihnen Offenbarungen zukommen lässt. Wenn er sich aber nicht offenbare, dann sehen sie in sich nicht

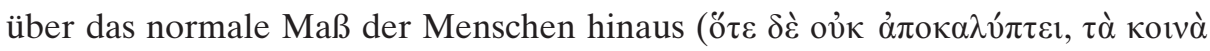

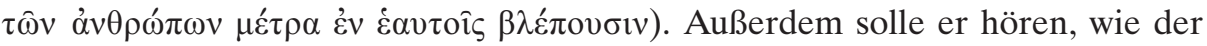
Prophet Elisa seinem eigenen Diener über eine fromme Frau sagte: „Ihre Seele ist betrübt, und der Herr hat es mir nicht offenbart [4 Kön 4,2]“, so wie Gott ihm von vielen Herzen offenbart hat. Und in den Sprüchen stehe ,verständig erkenne die Seelen deiner Hirten, und dein Auge wird bei den Herden weilen"

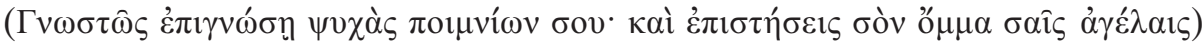
[Spr 27,23; 21,12]. Dann erzählte Ausonios aus den Apostelakten, wie Paulus 
einen Gelähmten heilte (Apg 14,8-10). Dies sei gelungen, da Paulus sah, dass er

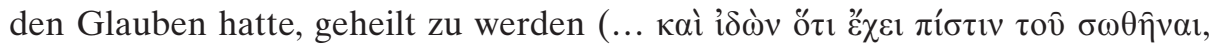
...), denn der Glaube sei im Herzen und nicht physisch im Gesicht zu sehen

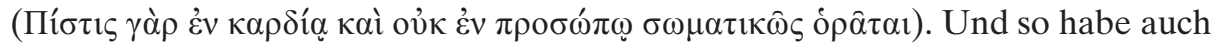
Petrus das Übel in Symon dem Magier nicht im Gesicht des Körpers, sondern im

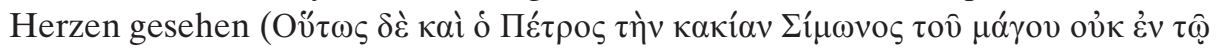

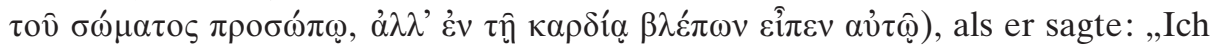
sehe, dass du bittere Galle und eine Fessel von Ungerechtigkeit bist [Apg 8,23].“ Nachdem Ammonos dies von Ausonios vernommen hatte, nahm er die Schriften und begann zu lesen.

140. ViPo 35, p. 29,25-30,16: Markos Diakonos erzählt, dass er mit Porphyrios, dem Bischof von Gaza und Ioannes, dem Erzbischof von Kaisarea, nach Konstantinopel segelte. Als sie auf Rhodos zwischenhielten, besuchten sie Prokopios, einen mit der Prophetengabe ausgezeichneten Mönch (..., है $\sigma \chi \varepsilon v \delta \varepsilon \grave{\varepsilon} \kappa \alpha \grave{\imath}$

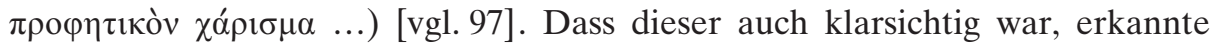
Markos daran, dass er, ohne sie jemals gesehen oder von ihnen gehört zu haben, im Geist erkannte, dass Ioannes und Porphyrios Bischöfe waren und ihnen

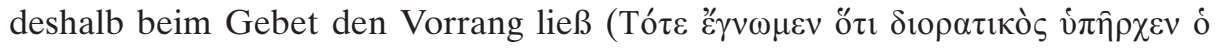

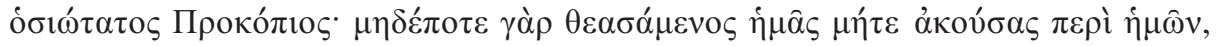

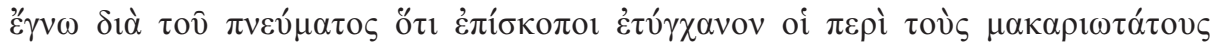

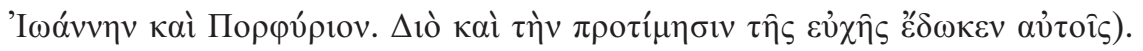

141. ViSa 24, p. 108,1-11: Sabas wanderte mit dem Bruder Agapetos durch die Wüste, als sie zu einem Felsen mit einer Höhle kamen. Zerknirscht und unter Mühen bestiegen sie diesen Ort, da er Sabas von Gott offenbart worden war. Und als sie in die Höhle kamen, fanden sie darin einen klarsichtigen Anacho-

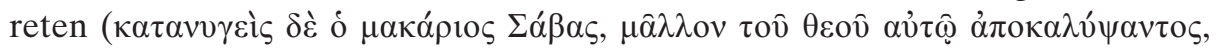

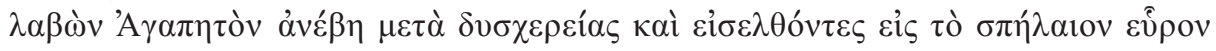

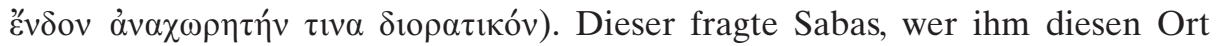
gezeigt habe und wie er hierher gefunden habe, denn er befinde sich seit 38 Jahren in dieser Höhle und habe keinen einzigen Menschen gesehen. Darauf antwortete Sabas, dass ihm Gott, der auch ihm (dem Anachoreten) seinen

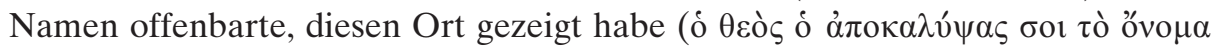

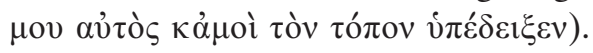

142. ViSa 44, p. 135,13-15: Vom Wüstenvater Aphrodisios wird gesagt, dass er

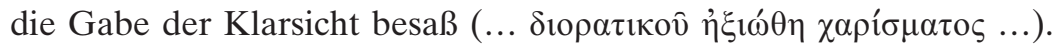

143. ViSyStII 110, Bd. 1, p. 89,17-90,10: Symeon erzählte, er habe heute einen Bauern gesehen, der sich an der Mündung des Flusses zum Meer befunden habe

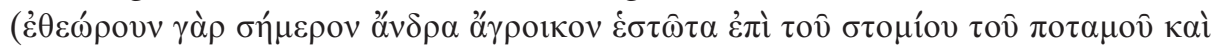

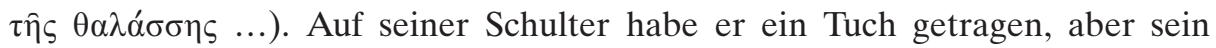
Gesicht habe er nicht sehen können. Dann sei er zu ihm gekommen und habe wegen eines Dämons, der ihn im Bad zu Boden geworfen hatte, vor ihm das Gebet verrichtet. Dies sah Symeon in der Kraft des heiligen Geistes (ő $\pi \varepsilon \rho$ каi 


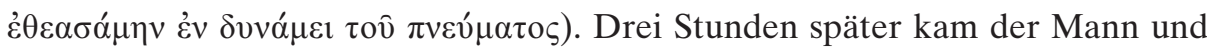
trug als Zeichen das Tuch auf der Schulter. Da trieb Symeon den Dämon aus. 144. ViSyStII 170, Bd.1, p. 152,7-18: Ein Bruder fiel, während er den wunderbaren Berg bestieg, in der Hitze vor Durst in Ohnmacht. Symeon sah dies und beauftragte zwei Brüder, dem Entkräfteten Wasser und Brot zu bringen, um ihn zu retten.

145. ViSyStII 174, Bd. 1, p. 155,4-12: Symeon ermahnte die Brüder, über nichts Weltliches zu reden, sondern bloß Psalmen und ihre Lektionen zu rezitieren. Eines Tages, als die Brüder arbeiteten, ,ungefähr in der vierten Stunde, wurde

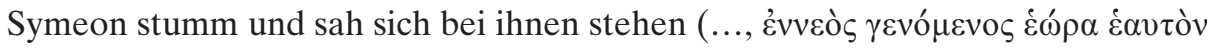
...). Er hörte, dass einer von den Brüdern etwas ihnen Verbotenes erzählte. Sofort rief er sie herbei und erzählte ihnen gemäß der ihm erschienen Schau,

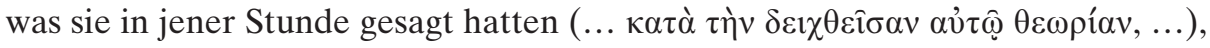
und alle fürchteten sich.“

146. ViSyStII 175, Bd.1, p. 155,13-19: Einer, der gemäß dem Zeugnis der

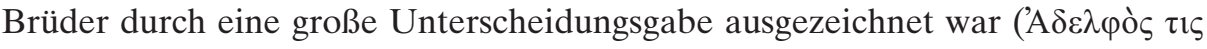

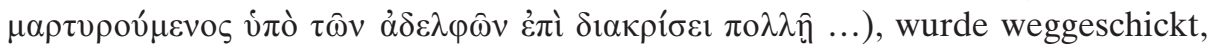
um Salz zu besorgen. Er überging jedoch das Gesetz und legte von dem Geld für die Bezahlung etwas für sich zur Seite. Doch noch bevor er zurückkam, erzählte Symeon dies den anderen. Und als der Bruder ins Kloster zurückkehrte, stellte ihn Symeon zur Rede. Dadurch erkannte er, dass sein Handeln dem Heiligen

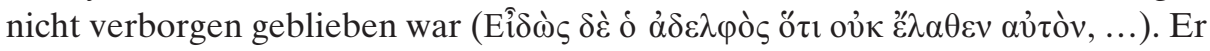
gestand seinen Fehler und bereute ihn vor allen Brüdern.

147. ViSyStII 176, Bd. 1, p. 155,20-156,7: Eines Tages drang ein Bär in den Klostergarten ein. „Als er sich gerade mit der Schnauze einem Kürbis näherte, sah der betende Symeon, wie er durch die Kraft des heiligen Geistes auf einmal vor dem Raubtier stand und es daran hinderte, die Frucht zu fressen" (... عîं $\delta \varepsilon v$

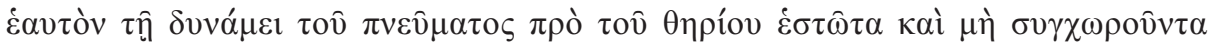

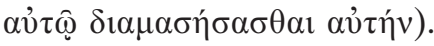

148. ViSyStII 178, Bd. 1, p. 157,23-158,18: Einige der Brüder schliefen auf dem Acker beim Kloster. Auf einmal sah Symeon, wie eine Leopardenfrau aus dem Gehölz kam, sich neben den Kopf eines Bruders setzte und anfing zu brüllen, da sie sein Blut trinken wollte. Doch Symeon hinderte das Raubtier, den Bruder zu berühren. Und als sich die anderen Brüder im Kloster zur nächtlichen Psalmodie versammelten, erzählte Symeon vor allen die Geschichte. Er habe den Namen des Herrn angerufen, worauf das Raubtier den Mund schloss. Jener Bruder aber sah, als er aufwachte, neben seinem Kopf das Raubtier sitzen, erschrak und rief den heiligen Symeon an. „Und auf der Stelle erschien ihm durch die Kraft der Gnade in ihm gleichsam der Morgenstern, der das unter

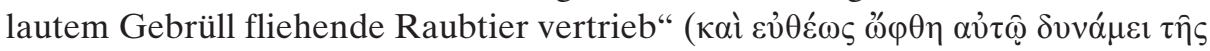

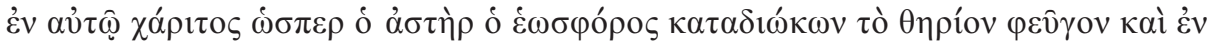

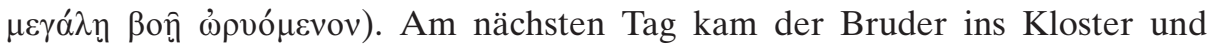


erzählte, was in der Nacht passiert war. Und alles stimmte mit der von Symeon

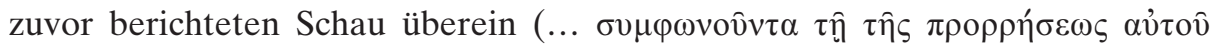
$\theta \varepsilon \omega \rho i ́ \alpha)$ (vgl. auch 330).

149. ViSyStII 215, Bd.1, p. 184,23-185,14: Ein Mann war auf dem Weg zu Symeon. Als er sich auf dem Anstieg zum bewunderungswürdigen Berg befand, setzte er sich ohne Rücksicht auf den Heiligen an den Straßenrand und aß ein wenig vom Abendmahlsbrot, welches er mitgebracht hatte. Er glaubte nämlich,

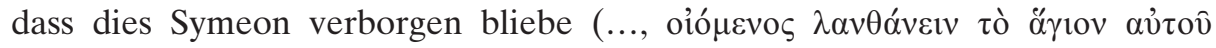
$\pi v \varepsilon \hat{\mu} \mu \alpha)$. Doch als er zu Symeon kam und sein heiliges Gesicht sah, wurde er sofort zu Boden geworfen und blieb stumm liegen, sodass alle glaubten, er sei tot. Symeon zwang den Mann, sein Fehlverhalten zu gestehen und wies ihn zurecht.

150. ViSyStII 216, Bd. 1, p. 185,15-186,2: Als ein gewisser Kyriakos zu Symeon pilgerte, sah er auf dem Weg Maulbeeren und aß davon. Dabei fragte er sich, ob

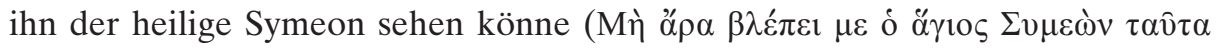

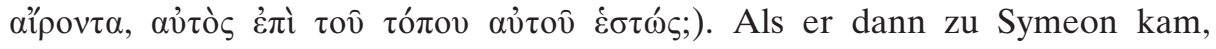
schaute er ihn gebannt an, wurde zu Boden geworfen und blieb wie tot liegen. Symeon zwang ihn, seine Sünde zu gestehen und „,belehrte ihn, dass die Augen Gottes tausendfach heller seien als die Sonne und die ganze Erde überblicken“

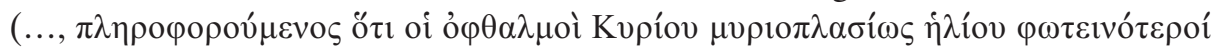

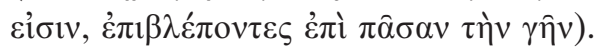

151. ViThSy 42, Bd.1, p. 36,32-38,2: Der heilige Theodoros schickte seinen Archidiakon nach Konstantinopel, um Abendmahlgefäße aus Silber zu besorgen. Als der Archidiakon zurück war, enthüllte er in der Sakristei Kelch und Patene, um sie dem Heiligen zu zeigen und darin das Abendmahl darzubringen. „Doch als Theodoros die Gefäße sah, erkannte er mit seinem klarsichtigen Auge, wofür sie verwendet worden waren und tadelte sie als unbrauchbar und

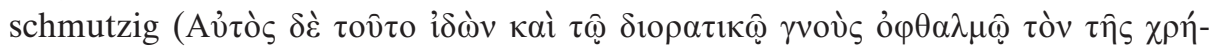

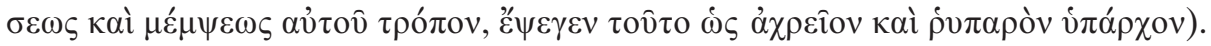
Der andere aber schaute nicht zum Verborgenen, sondern zum Sichtbaren hin“"

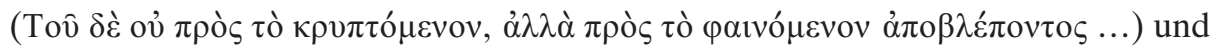
zeigte Theodoros, dass das Silber der beiden Stücke rein und gut gearbeitet war. Theodoros belehrte ihn, dass es einen anderen, verborgenen Grund zum Tadel

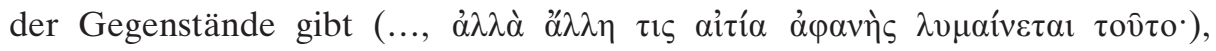
nämlich eine schmutzige Verwendung. Der Archidiakon brachte die Gefäße zurück nach Konstantinopel und fand heraus, dass das Silber vom Eimer ( $\sigma i ́ \tau \lambda \alpha)$ einer Prostituierten stammte.

152. ViThSy 70, Bd. 1, p. 57,26-58,5: Als sich Theodoros einmal nicht im Kloster aufhielt, kam ein Fremder, der um Aufnahme bat. Der Abt des koinobion erlaubte ihm, sich im martryrion des heiligen Georg aufzuhalten. Der Besucher aber trug, als er in der Kirche schlief, in seiner Tasche ein Stück Schweinefleisch. In jener Nacht erschien Theodoros der Heilige Georg (Kà $\tau \hat{\eta}$ 


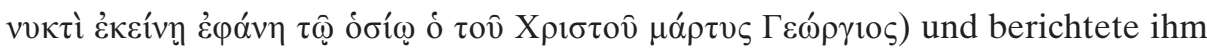
über die Ereignisse im martyrion. Darauf entsandte der Heilige einen Boten in seine Heimat, um den Fremden zurechtzuweisen.

153. ViThSy 73, Bd. 1, p. 26-58,5: Theodoros empfing einmal einen mit der Gabe der Vorausschau ausgezeichneten Wüstenheiligen (... vi $\pi \varepsilon \delta \varepsilon \varepsilon \xi \alpha \tau o \pi \rho \circ o \rho \alpha-$

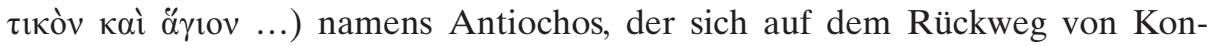
stantinopel in Richtung Osten befand. Ihnen beiden wurde die Lebensweise des

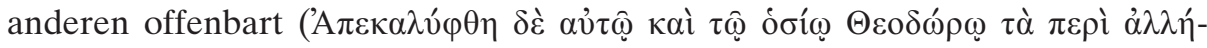
$\lambda \omega v)$. Theodoros erzählte seinen Brüdern, dass er in der ganzen östlichen Wüste noch nie einen so würdevollen Diener Gottes wie Antiochos gesehen oder gehört habe. Jener aber erzählte seinen Schülern, dass es bis zu diesem Zeitpunkt noch keinen so heiligen Mann wie Theodoros gegeben habe. Gott habe ihm

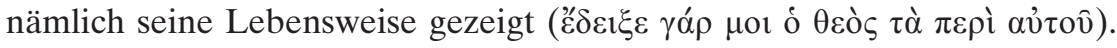




\section{E. Inspirations- und Berufungsoffenbarungen sowie Ermutigung zu Glaube und Askese}

154. ApAl, Ephraim 1, PG 65, col. 168B: „Ephraim war noch ein Kind, als er ein Traumgesicht sah oder auch eine Vision. Aus seiner Zunge spross ein Weinstock empor, wuchs und erfüllte alles, was unter dem Himmel existierte, und war äußerst fruchtbar. Es kamen alle Vögel des Himmels und aßen von der Frucht des Weinstockes, wobei sich die Frucht, die sie wegpickten, verviel-

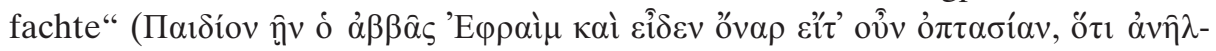

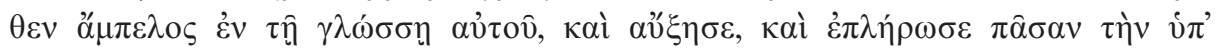

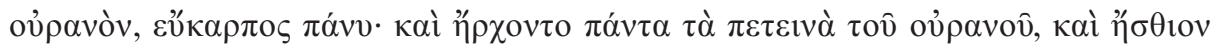

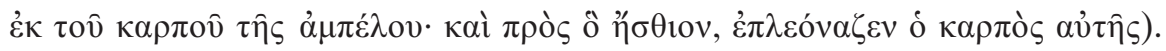

155. ApAl, Ephraim 2, PG 65, col. 168B-C: Ein heiliger Mann sah in einer

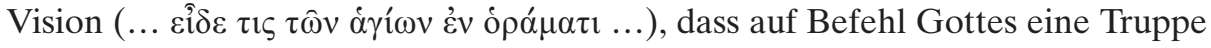
von Engeln vom Himmel herunterkam, die eine Schriftrolle ( $\varepsilon \varphi \alpha \lambda i \delta \alpha)$ in den Händen hielten. Die Engel fragten einander, was es bringe, dies zu überliefern, und die einen sagten dies, die anderen etwas anderes. Sie gaben aber auch Antworten auf die Frage und sagten, dass wahrlich alle heilig und gerecht seien. Und trotzdem könne dies keiner übernehmen, außer Ephraim. Und der heilige Mann sah, wie sie die Rolle Ephraim übergaben. Und als er am Morgen aufstand, hörte er, wie Ephraim sein Werk verfasste, indem aus seinem Mund gleichsam eine Quelle hervorsprudelte, und er erkannte, dass die Worte, die durch die Lippen des Ephraim flossen, vom heiligen Geist kamen.

156. ApSy VII 52, Bd.1, p. 382-386: In der Thebais lebte ein Mönch, der die Gewohnheit hatte, jeden Abend seinen Schüler zu unterrichten und ihn nach einem gemeinsamen Gebet schlafen zu schicken. Einmal schlief er während des Redens selber ein. Der Schüler wartete aber, bis der Mönch wieder erwachte, um danach mit ihm das Gebet zu verrichten. Als er dasaß und wartete, wurde er vom unreinen Gedanken versucht, sich schlafen zu legen, obwohl sein Lehrer ihn noch nicht entlassen hatte. Er strengte sich an, diesen Gedanken zu vertreiben und hielt sich wach. Sieben mal wurde er auf diese Weise versucht, und jedesmal widerstand er dem unreinen Gedanken. Als der Mönch erwachte und seinen Schüler fragte, warum er sich nicht schlafen gelegt oder ihn geweckt habe, gab dieser als Grund an, dass er noch nicht von ihm entlassen worden war und er ihn nicht ärgern wollte. Darauf verrichteten sie gemeinsam das Morgengebet, und der Mönch entließ den Schüler, setzte sich alleine hin und geriet

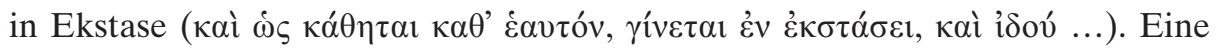


Gestalt zeigte ihm einen strahlenden Ort mit einem Thron, auf welchem sieben Kränze lagen. Als der Mönch fragte, wem dies alles zugedacht sei, antwortete die Gestalt, dies sei für seinen Schüler. Sowohl den Ort als auch den Thron habe Gott ihm geschenkt, als er die Welt verließ. Die sieben Kränze aber habe er in dieser Nacht erhalten.

157. ViDanSt 21, p. 21,18-23,4: Daniel geriet in Ekstase und sah eine überaus

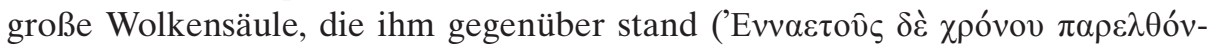

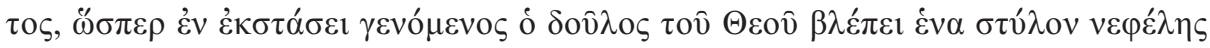

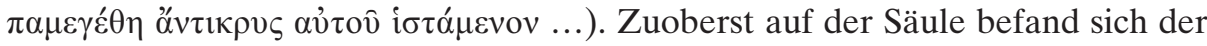
heilige Symeon, und direkt neben ihm standen zwei ehrwürdige, weißgekleidete Jünglinge. Dann hörte er, wie ihn die Stimme des heiligen Symeon zu sich rief. Als Daniel ihn fragte, wie er diese Höhe erklimmen solle, befahl er den beiden Jünglingen, hinunterzusteigen und Daniel auf die Säule zu begleiten. Als Daniel oben ankam, umarmte ihn Symeon und küsste ihn. Dann wurde Symeon von anderen Gestalten herbeigerufen und in die Höhe gehoben. Daniel ließ er mit den beiden Männern auf der Säule zurück und verschwand. Dann hörte Daniel, wie Symeon sagte: „Steh fest und sei tapfer“. Als Daniel wieder zu sich ge-

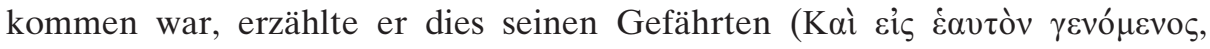

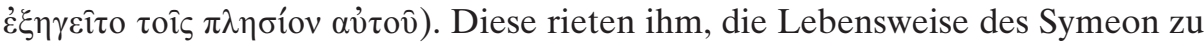
übernehmen und auf die Säule zu steigen. 22, p. 23,5-24,18: Zur gleichen Zeit befand sich Sergios, ein Schüler des Symeon Stylites, auf dem Weg nach Konstantinopel, um Kaiser Leon den Tod des heiligen Mannes mitzuteilen und ihm sein Fellkleid zu überbringen. Als Sergios auf dem Weg mit den anderen Schiffsreisenden Daniel besuchte und vom Tod des Symeon berichtete, erzählte

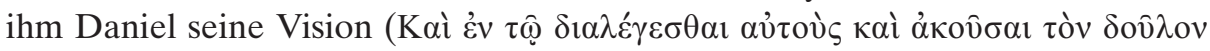

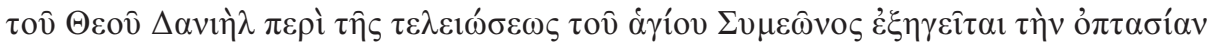

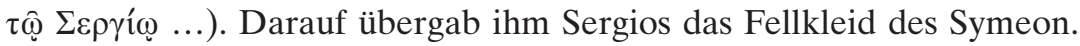

158. ViDanSt 23, p. 25,1-21: Sergios, der nunmehr bei Daniel lebte (s.o. 157),

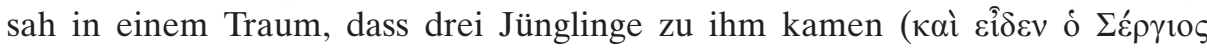

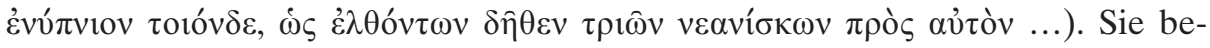
fahlen ihm, aufzustehen und Daniel mitzuteilen, dass die Zeit seiner Askese in der Kirche abgelaufen sei. Er solle nun voranschreiten und seinen Kampf beginnen. Nachdem Sergios aufgewacht war, erzählte er Daniel, was er gesehen

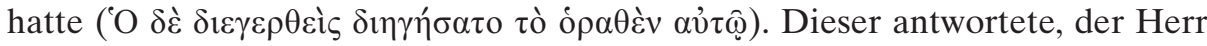
habe ihnen klar offenbart, was nun zu tun sei. Denn der Traum, den er gesehen

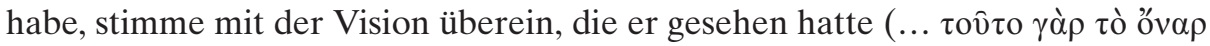

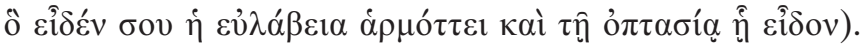

159. HiMo 8,33-34, p. 59,10-60,12: Apollo nahm einen Räuberführer und gefürchteten Mörder mit in die Wüste und versprach ihm, Gott darum zu bitten, all seine Sünden zu vergeben. „Als es aber Nacht wurde, befanden sich beide

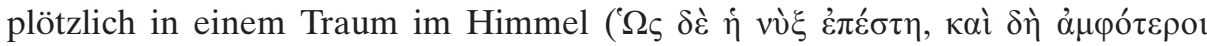

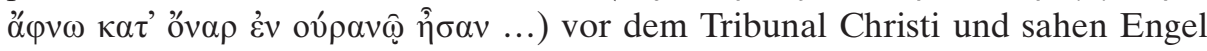


bei den Gläubigen vor Gott niederkniehen. Als auch sie niederfielen und ihr

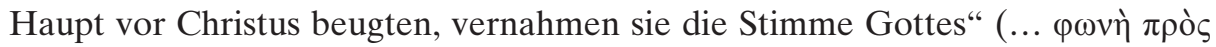

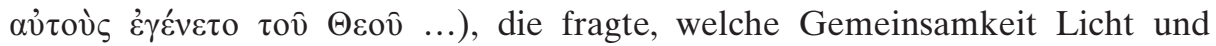
Finsternis haben, was der Gläubige mit dem Ungläubigen teile und warum der Mörder direkt neben dem Gerechten stehe. Er (Apollo) aber solle abtreten, dieser Spätgeborene sei ihm nämlich als Schützling anvertraut worden. „Sie sahen und hörten noch viele andere Wunder, welche Worte nicht auszusprechen

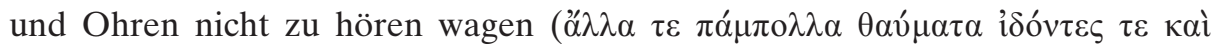

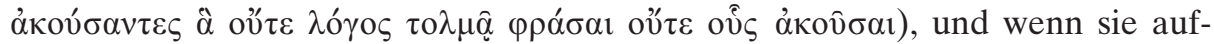
wachten, erzählten sie den Anwesenden davon. Diese aber waren überaus er-

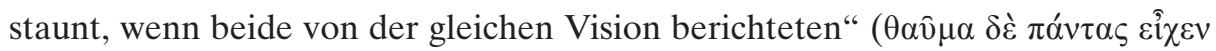

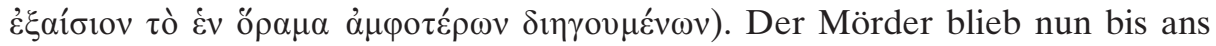
Ende seines Lebens bei den Asketen und führte ein Leben voller Reue.

160. HiMo 10,4, p. 76,10-77,9: Patermuthios war ein Räuber, der heidnische Gräber schändete und berühmt war für seine Übeltaten. Eines Nachts hatte er vor, ein Kloster zu plündern. Er kletterte auf das Dach des Klosters, fand aber von dort aus weder die Möglichkeit, in die Vorratskammer einzudringen, noch sich zurückzuziehen. Aus diesem Grund blieb er bis zum Tagesanbruch auf dem Dach. Als er dabei ein wenig einschlummerte, sah er im Schlaf einen König, der

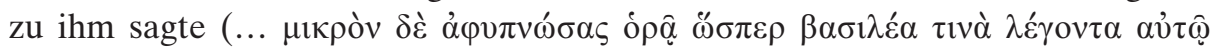

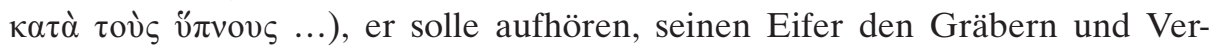
brechen zuzuwenden. Doch wenn er das Gewand der Tugend und ein Heer aus Engeln erhalten möchte, werde er ihm dies gewähren. Mit Freude willigte der Räuber ein. Der König zeigte ihm eine Truppe von Mönchen und forderte ihn auf, diesen vorzustehen. Von diesem Augenblick an war Patermuthios bekehrt. 161. ViIoEl 6,50-94, Bd. 2, p. 351,26-352,24: Ioannes erzählte seinen Gefährten folgende Geschichte: Als er mit ungefähr fünfzehn Jahren noch auf Zypern (und noch nicht in Alexandreia) war, sah er eines Tages im Schlaf eine junge

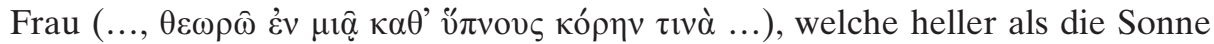
und über das menschliche Verständnis hinaus leuchtete. Sie kam, stellte sich vor sein Bett, und stieß ihn in die Seite. Ioannes wachte auf und sah sie wahrhaftig

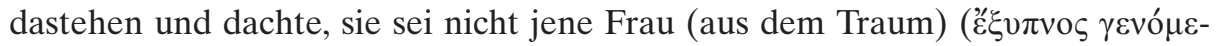

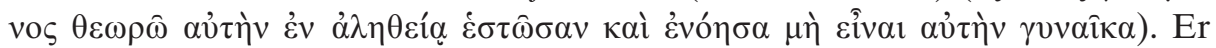
bekreuzigte sich und fragte sie, wer sie sei und warum sie es gewagt habe, bei ihm einzutreten, während er schlief. Sie trug einen Kranz von Ölzweigen auf dem Kopf und sagte mit strahlendem Gesicht und lächelnden Lippen, sie sei die erste Tochter des Königs. Als Ioannes dies hörte, verbeugte er sich sofort vor ihr. Dann versprach sie, ihn vor den König zu führen, vorausgesetzt er erkläre sie zu seiner Freundin. Niemand außer ihr habe nämlich so viele Rechte vor dem König wie sie, denn durch sie sei er in einem Körper auf die Welt gekommen, um die Menschen zu retten. Nachdem sie dies gesagt hatte, ver-

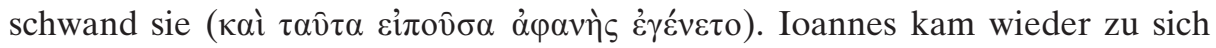




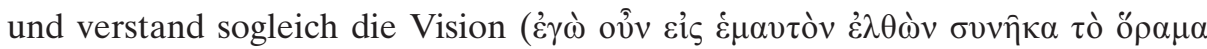
...). $\mathrm{Zu}$ den anderen sagte er, dies sei die Nächstenliebe und Barmherzigkeit, deshalb habe sie auf dem Kopf Ölbaumblätter getragen. Denn wahrhaftig habe das Mitgefühl zu den Menschen und die Barmherzigkeit den Herrn zum Menschen gemacht. Sogleich kleidete er sich an und ging zur Kirche. Auf dem Weg dorthin traf er einen frierenden Mann. Diesem schenkte er sein Ziegenfell und sagte bei sich: „Dadurch werde ich verstehen, ob die Vision, die ich gesehen

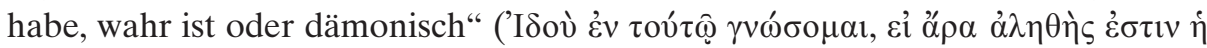

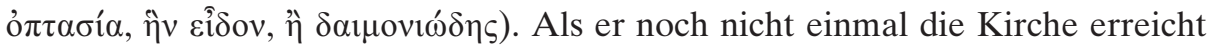
hatte, wurde die Wahrheit der Vision bezeugt. Denn auf einmal stand eine

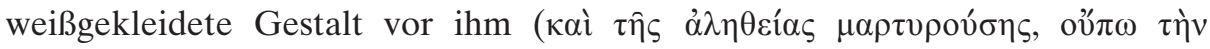

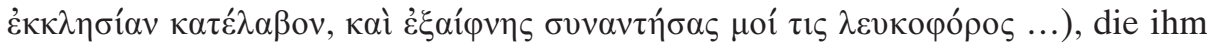
einen Sack mit hundert Goldmünzen reichte und sagte, er solle ihn nehmen und verwenden, wie er wolle. Aus Freude nahm er den Sack, drehte sich aber sogleich wieder um, um ihn der Gestalt zurückzugeben. Dies war allerdings nicht möglich, denn der Weißgekleidete war verschwunden. Darauf sagte Ioannes bei

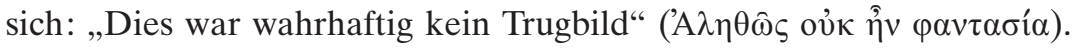

162. ViNi 67,1-9, p. 82,1-9: Nikolaos Sionites erschien im Traum der heilige

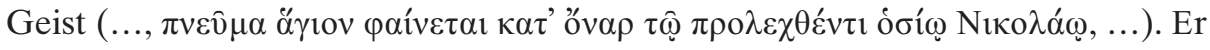
zeigte ihm einen ehrwürdigen Thron und ein Priestergewand und befahl ihm, auf dem Thron Platz zu nehmen. Daraufhin zeigte er ihm den Altar der himmlischen Herrlichkeit. „Und als Nikolaos wieder aufwachte, dachte er nach

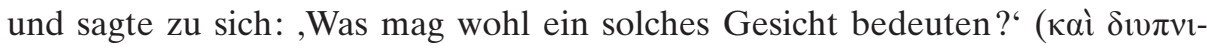

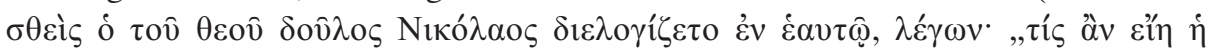

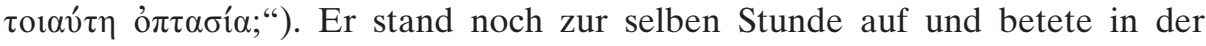
Klosterkapelle. Danach wurde er von noch größerer Unruhe ergriffen wegen der dunklen Vorahnung, die ihm zugetragen wurde, und er beschloss, das Gesicht gänzlich für sich zu behalten und es niemandem zu erzählen, bis der Zeitpunkt seiner Vorsteherschaft und des göttlichen Segens kommen würde“

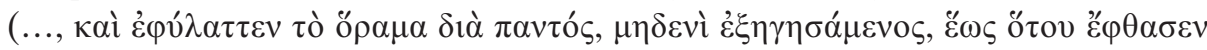

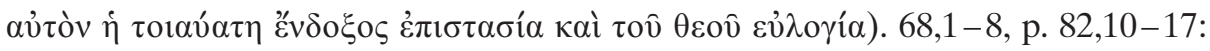
Drei Monate später wurde Nikolaos zum Bischof geweiht.

163. ViPa 5,13-17, Halkin 1982, p. 13,13-17: „In der Nacht, nachdem Pachomios für würdig erachtet wurde, das Mysterium zu empfangen [nachdem er getauft worden war], sah er einen Traum. Er sah sich selbst, wie er durch Tau aus dem Himmel befeuchtet wurde. Und die Tropfen sammelten sich auf seiner rechten Hand und verwandelten sich gleichsam in festen Honig. Dann fiel der Honig zu Boden, und Pachomios hörte jemanden, der zu ihm sagte: ,Das, was

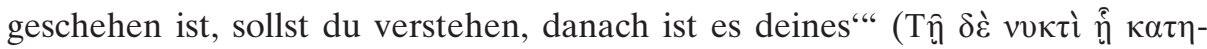

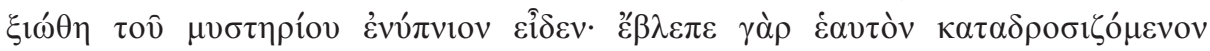

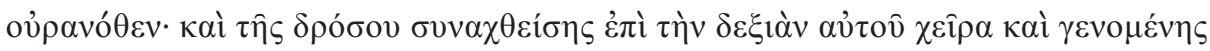




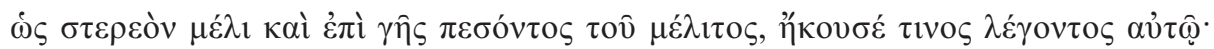

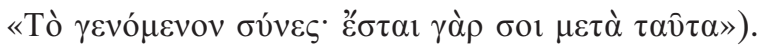

164. ViPa 129, Halkin 1982, p. 61,28-62,9: Orisios, der Nachfolger des Pachomios und Abt seines Klosters, betete $\mathrm{zu}$ Gott, er möge ihm jemanden zeigen, der fähig sei, im Kloster wieder Ordnung herzustellen. Noch in der

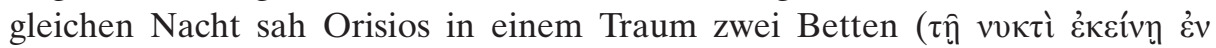

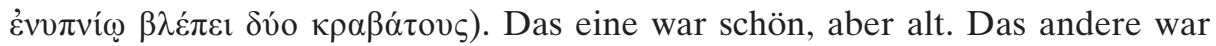

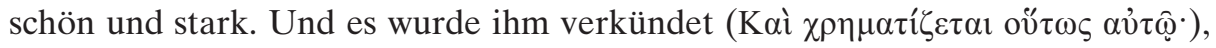
er solle sich auf dem starken Bett ausruhen. „Und in seinem Geist erkannte er, dass dieses Bett Theodoros war, der früher immer ein Herz und eine Seele mit

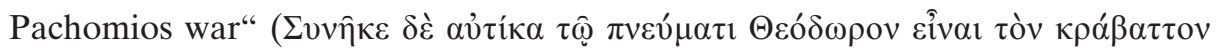

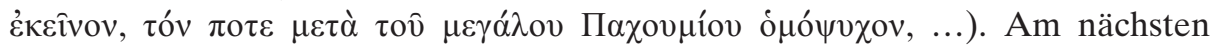
Morgen versammelte Orisios alle Äbte und verkündete, er selber trete zurück und setze Theodoros als seinen Nachfolger ein.

165. PaThII 14, p. 104,19-37: Als der junge Theodoros einmal die nächtlichen Gebete verrichtete, war er noch ganz benommen vom Schlaf und fing an, im Kloster herumzuwandeln. Da es Nacht war und ihn niemand sehen konnte, betete er bloß ein wenig. Dann beschloss er, sich ein bisschen auszuruhen. „Er setzte sich an die Tür der Klosterkirche und schlief, bloß um das natürliche Verlangen seines Körpers zu erfüllen. Da stellte sich ein Engel des Herrn zu

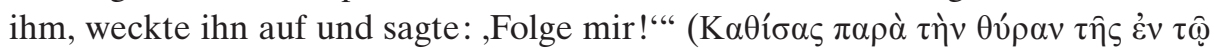

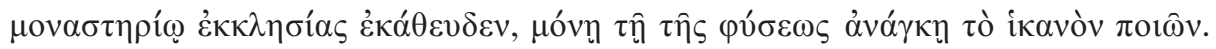

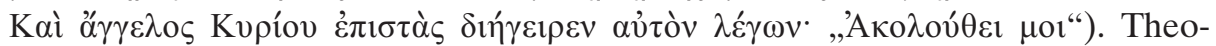
doros stand auf und folgte dem Engel in die lichterfüllte Kirche. Dort, wo die Priester ihre Dienste zu vollbringen pflegten, sah er eine Gruppe versammelter Engel, und er wurde von großer Furcht ergriffen. Einer der Engel rief ihn herbei, und als er herantrat, gab ihm ein anderer, hell erstrahlender Engel, eine unbekannte Speise. Er machte Theodoros Mut und befahl ihm, die Speise im Mund auflösen zu lassen. Theodoros aß die Speise und wurde von einem fremdartigen Geschmack überrascht. Gleichzeitig sah er, wie das Licht und die versammelten Engel hinausgingen. Er aber war drin und strebte danach, mit Pachomios zusammenzusein, erfüllt von Freude und Glück. „Und als er ihm [Pachomios] dies mit einem Lächeln erzählte, sah er aus der Offenbarung sein

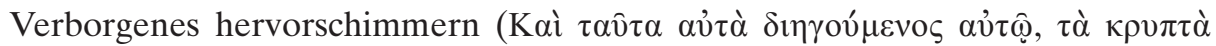

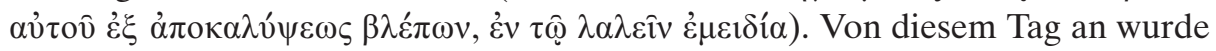

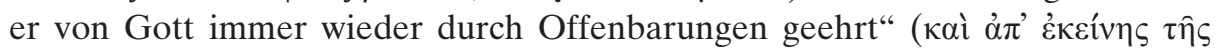

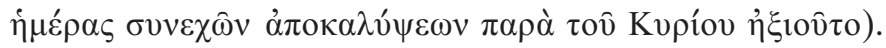

166. ViPo 12, p. 11,15-12,5: Nachdem der Bischof von Gaza gestorben war, kamen die Stadtbewohner zu Ioannes, dem Erzbischof von Kaisarea, und baten ihn, einen würdigen Nachfolger einzusetzen. Ioannes ging auf ihre Bitte ein und verordnete sogleich ein Fasten. Drei Tage später hatte er eine Offenbarung über

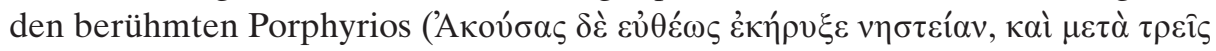




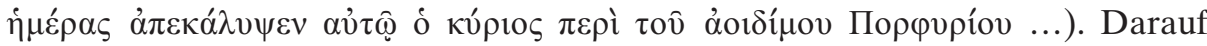
sandte er dem Bischof von Jerusalem einen Brief mit dem Auftrag, Porphyrios nach Kaisarea zu schicken.

167. ViPo 13, p. 12,6-13,2: Als Porphyrios vom Schreiben des Erzbischofs aus Kaisarea hörte (s.o. 166), rief er Markos Diakonos zu sich, um mit ihm beim heiligen Kreuz zu beten, da dies für lange Zeit die letzte Gelegenheit sei. Als Markos ihn nach dem Sinn seiner Worte fragte, antwortete Porphyrios, dass er die vergangene Nacht den Retter gesehen habe, der ihm sagte (Tṇ̂ $\pi \alpha \rho \varepsilon \lambda \theta$ ov́øṇ

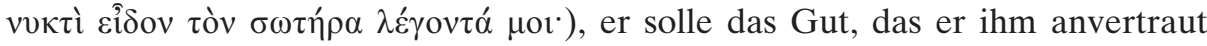
hatte, zurückgeben. Er wolle ihn nämlich mit einer Frau vereinen, die einfach, aber von gutem Charakter sei. Er solle sie aufnehmen und schmücken, damit sie ihre frühere Armut vergesse. Wenn sie auch unbedeutend sei, so sei sie dennoch nicht seine Feindin, sondern seine rechtmässige Schwester. Porphyrios solle sorgfältig damit umgehen, wenn er einmal eine Frau habe und ein Haus bewache, damit er nicht Reichtum durch Ungerechtigkeit, Gewalt oder Gesetzlosigkeit anhäufe. Denn wenn er sie betrübe, würde er auch ihn erzürnen. Er solle zuversichtlich sein, dann werde sich für ihn alles wider Erwarten ereignen. Dies, so sagte Porphyrios, wurde ihm in der vergangenen Nacht von Christus

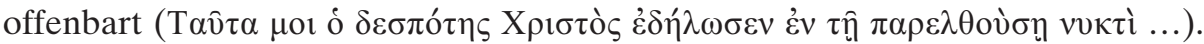
168. PrSp 66, PG 87.3, col. 2917A: Über Abbas Theodosios den Hesychasten wird berichtet, dass er sagte: „Bevor ich Einsiedler wurde, habe ich in einer

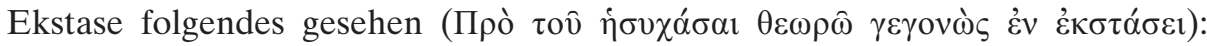
einen Jüngling, dessen Gestalt über die Sonne hinausreichte, der mich an der Hand hielt und sagte: ,Sieh, was du zu bekämpfen hast ${ }^{t}$. Und er führte mich in ein Theater, dessen Größe ich nicht schildern kann. Da sah ich, wie das Theater mit Männern gefüllt war. Der eine Teil von ihnen trug weiße Kleider, der andere bestand aus Äthiopiern. Und als er mich in die Arena des Theaters führte, sah ich einen hässlichen und riesengroßen Äthiopier, dessen Kopf bis zu den Wolken reichte. Dann sagte mir der Jüngling: ,Mit diesem musst du kämpfen'. Als ich aber den Mann sah, fürchtete ich mich und fing vor Schrecken an zu zittern

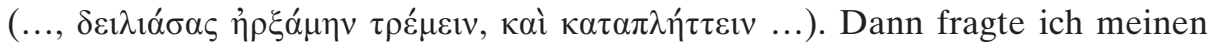
Führer: ,Welcher sterbliche Mensch besitzt die Fähigkeit, mit diesem zu kämpfen?' Er aber antwortete: ,Trete mit deinem ganzem Mut in die Arena ein. Denn während ihr einander gegenübersteht, werde ich siegen und dir den Siegeskranz überreichen'. Als ich nun in die Menge trat und wir anfingen, einander zu bekämpfen, kam der „Gute Sieger“ und gab mir den Siegeskranz. Und das Volk der Äthiopier verschwand schreiend. Die Gruppe der Strahlenden jedoch ließ Lobrufe erklingen und sprach mir den Sieg zu“.

169. PrSp 105, PG 87.3, col. 2964A-B: Abbas Christophoros erzählt aus seiner Jugend: „Als ich die Welt verließ, hatte ich ein starkes Verlangen, in den Mönchsstand zu gehen. Am Tag beschäftigte ich mich mit dem Kanon, in der Nacht ging ich zum Gebet in die Höhle, wo der heilige Theodosios und die 
übrigen Väter waren. Alle beichteten der Reihe nach ihre Sünden. Damals wurde ich in den Kanon eingeführt. Nachdem ich dies während zehn Jahren getan hatte, kam ich eines Tages wie gewohnt in die Höhle. Nachdem ich die Beichte abgelegt hatte und mich hinknien wollte, geriet ich in Ekstase und sah

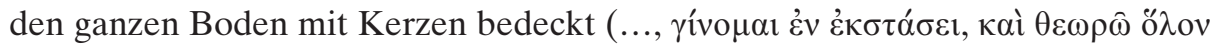

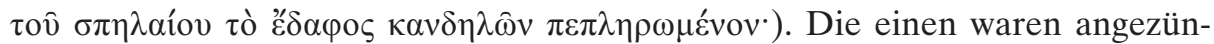
det, die anderen nicht. Ich sah auch zwei Männer, die in Mäntel gehüllt und weiß bekleidet waren und die Kerzen beobachteten. Als ich sie fragte, warum sie diese Kerzen hingestellt haben und uns nicht erlaubten, zum Gebet herunterzukommen, antworteten sie, dass die Kerzen vom Vater seien. Als ich sie fragte, warum manche Kerzen brannten und andere nicht, antworteten sie, dass diejenigen, die es wollten, ihre Kerzen anzündeten. Daraufhin fragte ich sie, ob meine Kerze brenne oder nicht. Sie antworteten, ich solle beten, dann würden sie meine Kerzen anzünden, worauf ich versprach zu beten. Noch während dieses Gesprächs kam ich wieder zu mir und kehrte zurück, doch alle waren weg

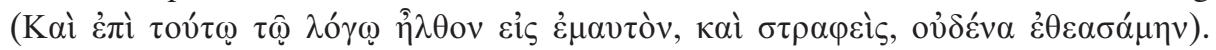
Daraufhin verließ ich das Kloster und wurde Einsiedler“.

170. PrSp 130, PG 87.3, col. 2996A-B: Abbas Athanasios berichtet, dass einmal ein schlechter Gedanke $(\lambda \circ \gamma 1 \sigma \mu o ́ s)$ zu ihm kam und er sich fragte, was eigentlich den Kämpfenden und was den nicht Kämpfenden zugedacht sei. Da geriet er in Ekstase, und es kam eine Gestalt, die ihn aufforderte, ihm zu folgen und ihn an einen von Licht erfüllten Ort führte, wo er ihn zu einer Säule von

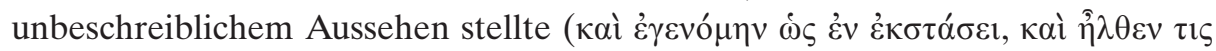

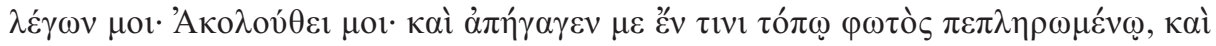

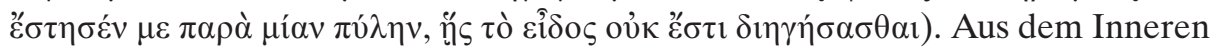
des Ortes vernahmen sie zahllose Stimmen, die Gott priesen. Als sie anklopften, hörte dies jemand, der fragte, was sie wollten, worauf die Gestalt um Einlass bat. Der andere aber antwortete, dass hier keiner hereinkomme, der in Unachtsamkeit lebe. Wenn sie hineinkommen wollten, sollten sie kämpfen, ohne an irgendetwas in der vergänglichen Welt zu denken.

171. ViSyStII 9, Bd. 1, p. 9,21-10,19: Es geschah, dass sich der kleine Symeon (ca. 6 Jahre alt) bei Cherubim aufhielt (die Stadtmauer am südlichen Rand von Antiocheia), ,als der Herr [...] beschloss, ihm seine zukünftigen Güter zu zeigen. Und er sah auf dem alten Mauerwerk von Cherubim augenscheinlich Jesus und das Volk der Gerechten, das ihn begleitete. Wer könnte diese ehrfurcht-

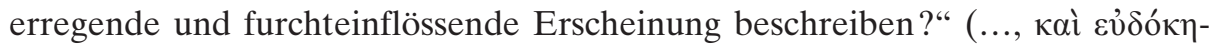

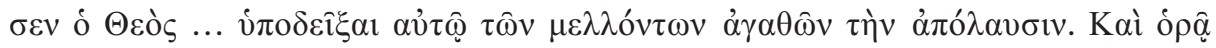

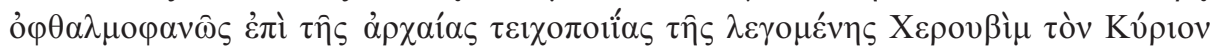

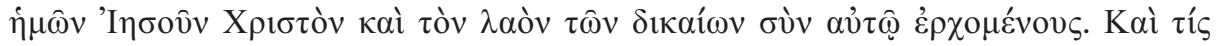

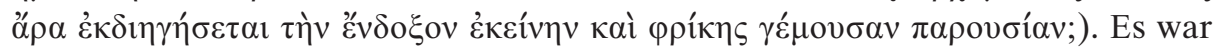
ein unbestechliches Gericht versammelt, und das Buch des Lebens lag geöffnet in der Hand des Herrn. Aus dem Osten erstreckte sich das Paradies bis zu den 
Wolken des Himmels und im Westen brodelte ein Feuersee. Der Geist, der folgte ( $\tau$ ò $\delta \dot{\varepsilon} \dot{\varepsilon} \pi$ ó $\mu \varepsilon v o v \pi v \varepsilon \hat{\varepsilon} \mu \alpha$ ), kam mit dem zeigenden Finger und belehrte den Knaben mit vielen Worten. Er sagte ihm etwa, er solle ein gottesfürchtiges Leben ergreifen und sich durch das, was ihm gezeigt werde, belehren lassen. Die Auferstehung werde wegen der zukünftigen Wahrheit unsichtbar sein; die Freude der Gerechten werde sich einstellen, wenn der Herr regiere, denn die Schrift zeuge vom unvergänglichen Leben und das Paradies bleibe bestehen. Er solle erblicken, wie die Flamme der ewigen Hölle auflodert und deshalb den richtigen Weg wählen. „Nachdem Symeon diese über den menschlichen Verstand hinausgehende Vision gezeigt wurde, war er in das göttliche Wissen und in die Weisheit des Herrn eingeführt, und die Kenntnis der göttlichen Offenba-

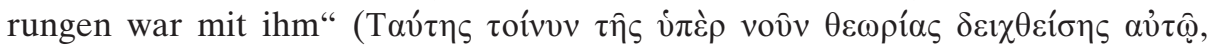

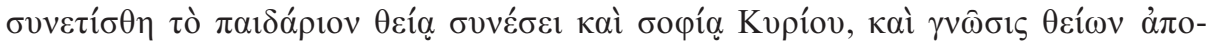
$\kappa \alpha \lambda u ́ \psi \varepsilon \omega v$ ทेv $\sigma u ̀ v ~ \alpha u ̛ \tau(\widehat{)})$.

172. ViSyStII 40, Bd. 1, p. 39,7-40,6: Symeon „sah den Himmel von Osten her geöffnet und Jesus und das elektron ${ }^{742}$ in Licht und Feuer um ihn herum (Kà

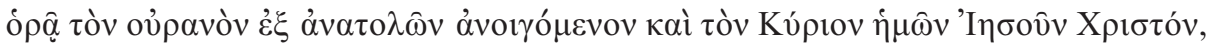

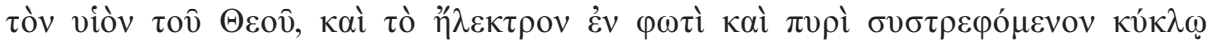

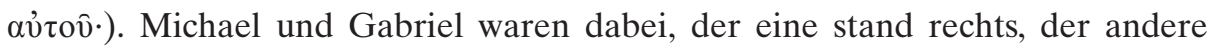
links, und ein Wolkenmeer schwamm zu Symeons Füssen wie ein leuchtender Porphyrteppich." Dadurch erhielt Symeon die Kraft zu heilen. Und alle, die zu ihm kamen, um geheilt zu werden, sahen drei Engel des Herrn (Kaì ø̋ $\varphi \theta \eta \sigma \alpha v$ $\tau \rho \varepsilon i ̄ \varsigma ~ a ̆ \gamma \gamma \varepsilon \lambda$ or Kupíov ...). „Einer stand rechts, einer links und der dritte hinter Symeon. Sie hielten von Silber und Gold glänzende Schreibgeräte in den Händen, und auf den Auftrag des Heiligen schrieben sie jeden, der geheilt werden wollte, auf ein Pergament, das weißer war als Schnee."

173. ViSyStII 47, Bd. 1, p. 44,3-28: Symeon sah Truppen von Engeln und den

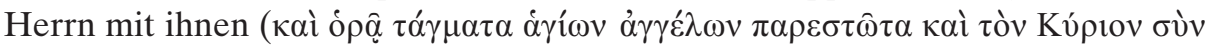

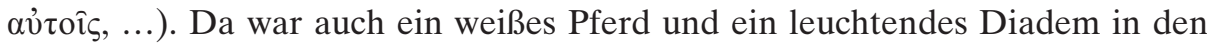
Händen der Erzengel. Damit sollte er bekränzt werden. Er wandte aber ein, das Wort Gottes sei in ihm, und das härene Gewand verlasse ihn nicht, denn es bedeute die Ehre Gottes. Die Engel erwiderten, er solle Christus in dieses Kleid wie in Purpur hüllen und sich selber mit dem heiligen Geist einwickeln wie mit einem Prunkgewand. Symeon erwiderte, dass er wegen der Güte des Herrn keine Speisen des Lebens mehr zu sich nehmen werde, wenn er mit den Heiligen regieren solle. Darauf antwortete Christus, dass er auch darin seinen Willen erfüllen wolle, da er ihn mit der Hoffnung auf die unvergänglichen Güter geheiligt habe. Und die Engel bekleideten ihn über das Asketenkleid mit Glanz und Zauber der Heiligkeit, und sie legten ein Diadem aus Edelstein, entstanden

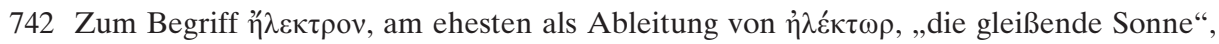
zu verstehen, s. VAN DEN VEN, La vie ancienne II 49, A. 1. 
durch den Geist des Lebens, auf sein Haupt, über dem ein Kreuz und Sterne glitzerten, so hell wie ein Blitz. Dann setzten sie ihn auf das weiße Pferd und sagten einstimmig: „Christus, Gott wird in den Himmeln und auf Erden besungen, und sein Diener Symeon, der unter den Heiligen regiert, wird siegen“. 174. ViSyStII 65, Bd. 1, p. 56,7-57,7: Als der junge Symeon loszog, um sich auf dem nahen Berg niederzulassen, erinnerte er sich an Elias, der im Fellkleid auf den Berg ging, an Ioannes Prodromos in der Einöde und vor allem an den Herrn, der auf dem Ölberg wachte. „Als er über diese Dinge nachdachte, sah er Jesus selber mit einem Heer von unzähligen Engeln von diesem Berg herun-

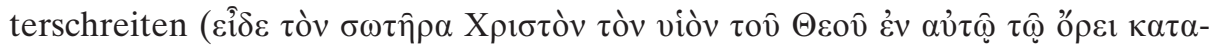
$\beta \varepsilon \beta \eta \kappa o ́ \tau \alpha ~ . .$.$) . Er sah auch eine Wolke aus Licht, welche sich rund um die$ Bergspitze herum verteilte“, und eine Stimme forderte Symeon auf, sich zu beeilen und diesen Berg der Wunder zu erklimmen (So werde er nämlich von nun an genannt werden). Dabei zeigte die Stimme ihm einen Felsen, auf dem der Herr stand und auf den sich jetzt Symeon stellen sollte. Darauf war ein Podest, das wie die Sonne glänzte. Das waren die Geheimnisse dieser Vision

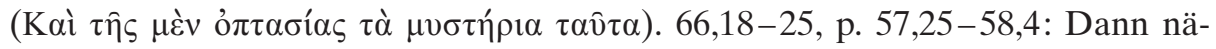
herte sich Symeon der Bergspitze und verrichtete sein Gebet. Als er damit zu Ende war, vernahm er die Stimme eines Engelsheeres (

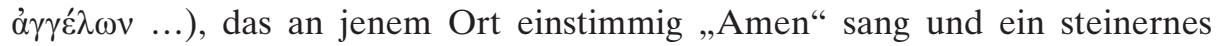
Kreuz aufrichtete. Symeon starrte unverwandt dorthin und sah auf der Spitze

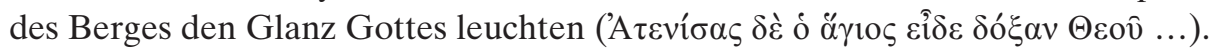
Er erkannte, dass dies der Ort war, der ihm gezeigt wurde, und bestieg ihn eifrig. 175. ViSyStII 133, Bd. 1, p. 125,22-126,11: Eine Stimme aus dem Himmel kam

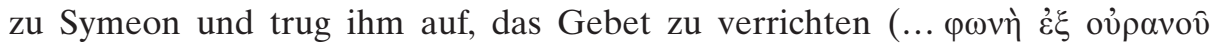
$\gamma \varepsilon v o \mu \varepsilon ́ v \eta$...). Im selben Moment wurde sein Mund durch den heiligen Geist geöffnet, und er antwortete: „Du regierst über uns, Gott, und dein Sohn und der heilige Geist jetzt und immer und in Ewigkeit, Amen“. Von da an wusste er, dass er von Gott als Priester eingesetzt wurde, da er für würdig erachtet wurde, seine Stimme zu hören. Wie Melchisedek auf dem Berg Tabor und wie Petrus, so hörte sie auch Symeon, als er in seinem dreiunddreißigsten Lebensjahr auf dem wunderbaren Berg stand.

176. ViSyStII 135, Bd. 1, p. 127,13-27: Symeon fragte sich, als er die Eucharistie vorbereitete, ob er dies wirklich tun dürfe. Doch auf einmal sah er sich selbst, wie er die Liturgie verrichtete, und Truppen von Engeln, die das Aussehen von

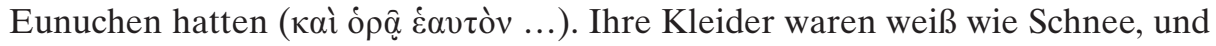
sie standen vor Symeons Säule, klatschten in die Hände und sagten dreimal: „Wenn jemand mit diesem Glaubensbekenntnis nicht übereinstimmt, wird er verdammt“. Über ihnen erschien der Herr und bestätigte die Worte mit folgendem Zusatz: „vom Vater, dem Sohn und dem heiligen Geist.“ Von diesem Augenblick an verrichtete Symeon mit großer Zuversicht das Abendmahl. 
177. ViThSy 10, Bd. 1, p. 9,7-23: Der zwölfjährige Theodoros ging eines Tages in die Kapelle des Heiligen Märtyrers Gemellos und blieb über Nacht dort. „Auf einmal sah er sich gleichsam bei einem König stehen, der von einer großen Leibgarde umgeben war. Eine Purpur tragende Frau stand bei ihm, und der König sagte: ,Kämpfe, Theodoros, damit du im himmlischen Heer den vollkommenen Lohn erhältst und ich dich auf der Erde vor den Menschen ehre'.

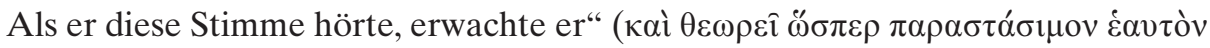

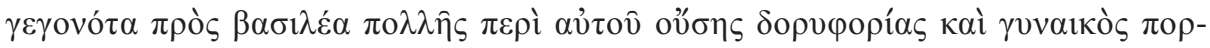

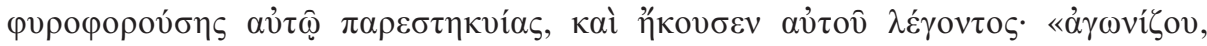

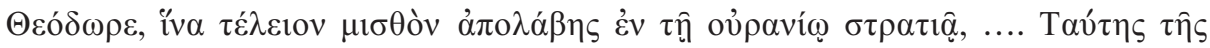

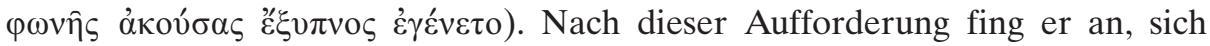
zurückzuziehen.

178. ApSy XV 129, Bd. 2, p. 376-378: Ein Gärtner bat einen Bruder, während seiner Abwesenheit auf seinen Garten aufzupassen. Als er zurückkam, war der Garten verwüstet, da der Bruder Tag und Nacht nichts anderes getan hatte als zu beten. Als der Gärtner ihm Vorwürfe machte, erwiderte der Bruder, es werde alles wieder blühen. Als der Bruder dann sterben sollte, bat er den Gärtner, niemandem etwas von seiner Krankheit zu erzählen und seinen Leichnam in die Wüste zu werfen. Widerwillig tat der Gärtner, was der andere von ihm verlangte. Am dritten Tag nach der Entschlafung des Bruders erschien ihm dieser

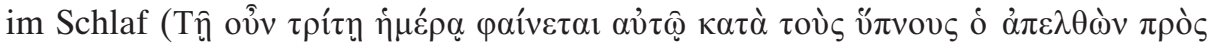
Kúptov ...). Er verkündete, dass sich Gott des Gärtners erbarmen werde, so wie er sich auch seiner erbarmt habe. Ihm sei eine große Gnade erwiesen worden, da sein Körper unbegraben blieb und mit Antonios zusammen sei. Überdies habe er bei Gott für ihn um Einspruch gebeten. Nun solle er gehen, diesen (irdischen) Garten zurücklassen und den anderen Garten bewachen.

179. ViEu 60, p. 83,35-84,21: Als Kyrillos von Skythopolis sich in den Klöstern der ersten palästinischen Mönche Euthymios und Sabas aufhielt, sammelte er Material über deren Leben und Wirken, um später ihre Biographien zu verfassen. Als Kyrillos die beschriebenen Blätter ordnen und die Biographien verfassen sollte, verbrachte er ungefähr zwei Jahre in Hesychase im Kloster (Nea Laura), ohne von der Beschäftigung mit seiner Schrift abzulassen

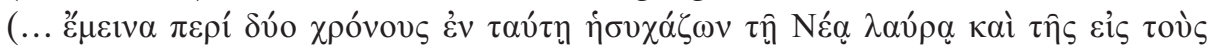

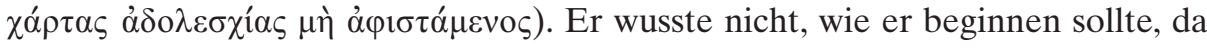
er unerfahren und ungebildet war. Weil ihm die Worte und die angemessene Ausdrucksweise fehlten, beschloss er, die beschriebenen Blätter zu lassen und

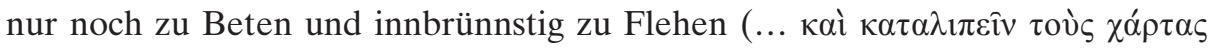

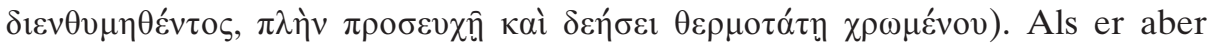
eines Tages auf seinem gewohnten Sitz saß und dabei die beschriebenen Blätter in den Händen hielt, erschienen ihm in der zweiten Stunde des Tages, nachdem er vom Schlaf ergriffen worden war, die heiligen Väter Euthymios und Sabas in

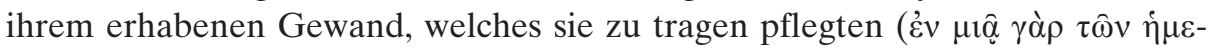




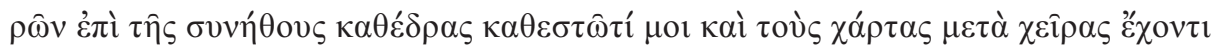

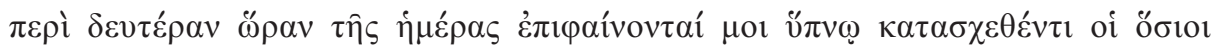

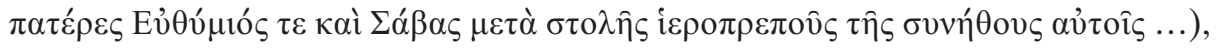
und Kyrillos hörte, wie Sabas zu Euthymios sagte: „Sieh dir Kyrillos an, er hält die Notizen über dich in den Händen. Er zeigt so viel Eifer, und nun, nach so viel Anstrengung, findet er keinen Anfang für sein Werk“. Euthymios antwortete: „Wie könnte er auch das Werk über mich beginnen, wenn er noch nicht die Gnade des angemessenen Ausdrucks empfangen hat, um den Mund zu öffnen und zu sprechen?" Darauf erwiderte Sabas: „Schenk ihm diese Gnade, Vater“. Euthymios stimmte zu, zog aus seiner Brust ein Alabastergefäß aus Silber und eine Sonde, tauchte die Sonde in das Gefäß ein und befeuchtete Kyrillos damit dreimal den Mund. „Die Flüssigkeit sah aus wie Öl, und sein Geschmack war süßer als Honig und wahrlich eine Offenbarung der göttlichen Worte, Wie süß ist deine Rede meinem Gaumen, süßer als Honig meinem Munde“ [Ps 118,103], sodass er, nachdem er durch diese unaussprechliche Süßigkeit aufgewacht war,

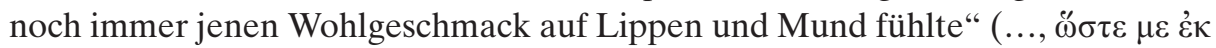

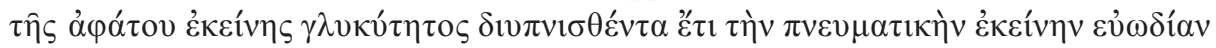

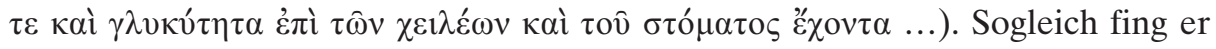
an, das Werk über die beiden Väter zu verfassen.

180. ViIo 16, p. 214,10-20: Nach dem Tod des heiligen Sabas war Ioannes so sehr betrübt, dass er seine Zelle nicht mehr verließ. „Als er sich in solcher Mutlosigkeit befand und das Fehlen des Vaters beweinte, erschien ihm im Schlaf

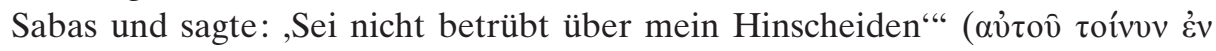

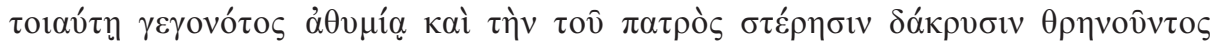

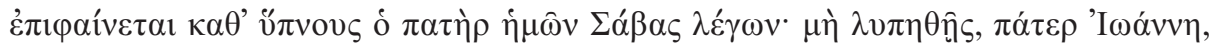
$\pi \varepsilon \rho \grave{~} \tau \hat{\eta} \varsigma \varepsilon \dot{\varepsilon} \mu \hat{\eta} \varsigma \tau \varepsilon \lambda \varepsilon v \tau \hat{\eta} \varsigma)$. Wenn sie auch durch den Körper getrennt seien, so sei er doch im Geist mit ihm. Als Ioannes ihn aufforderte, den Herrn zu bitten, auch ihn bei sich aufzunehmen, sagte Sabas, dies sei nicht möglich. Es werde nämlich eine Prüfung über die Laura kommen, und Gott wolle, dass Ioannes dann noch lebendig sei zum Trost und zur Stärkung von denjenigen, die für den Glauben kämpfen. Als Ioannes dies gesehen und gehört hatte, wurde er wieder fröhlich

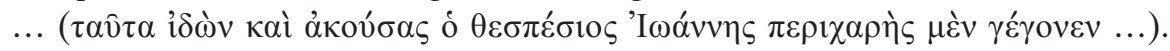

181. ViMa 8, Bd.2, p. 259,5-13: Als Martha den nächtlichen Gottesdienst vollendet hatte, schlief sie ein und wurde durch die Erscheinung des Ioannes

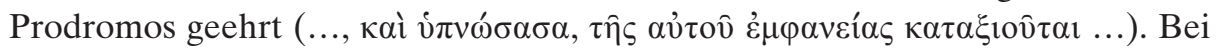
ihm war Timotheus, der Schüler des Paulus, und die beiden unterhielten sich. Dann versprach Ioannes ihr, sie immer im Namen Gottes zu beschützen, ihr vorzustehen und sie nie im Stich zu lassen. Martha erwachte in Furcht und

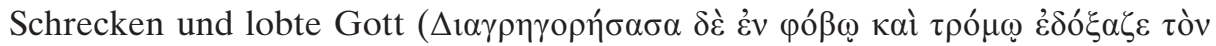
$\Theta \varepsilon o ̀ v)$.

182. ViSa 80, p. 186,4-14: Genarus, eine fromme Frau, wollte zwei Vorhänge weben lassen, den einen für das Kastellion, den anderen für die Höhle des 
Sabas. Als alles zur Herstellung der Vorhänge vorbereitet war, erschienen die Weberinnen nicht wie verabredet. Da Genarus darüber sehr betrübt war, er-

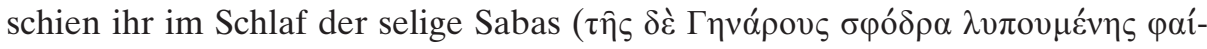

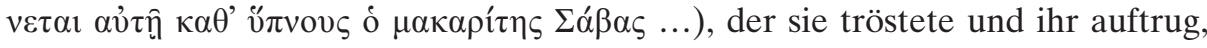
am nächsten Tag nach den Weberinnen schicken zu lassen. Sie würden nämlich kommen und die Arbeit vollbringen. Den Weberinnen erschien das gleiche Gesicht, denn sie hatten durch ihr Wegbleiben Gottes Zorn auf sich gezogen

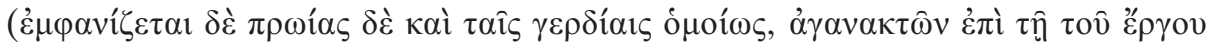

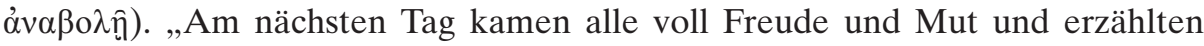

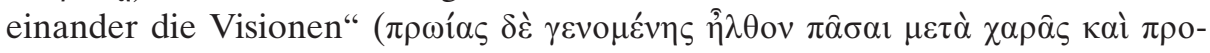

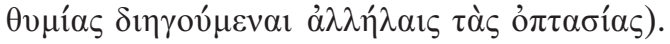

183. ViSySa 1697C-1700A, p. 72,23-73,14: Nachdem Symeon und Ioannes zwei Jahre in der Wüste verbracht hatten, wurde Symeon von Gott darüber unterrichtet, dass seine Mutter nun nicht mehr betrübt sei seinetwegen. Er sei

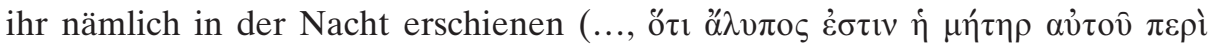

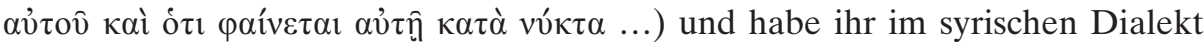
gesagt, sie solle nicht traurig sein, da es ihm und Ioannes gut gehe. Sie seien in den Palast Gottes eingegangen und trügen einen Kranz, den ihnen der König aufgesetzt habe, und wunderbaren Schmuck. Dann habe er seiner Mutter gesagt, sie solle auch die Eltern des Ioannes darüber in Kenntnis setzen, dass ihr Sohn mit ihm zusammen kämpfe. Ioannes indes sah, wie ein Weißgekleideter zu

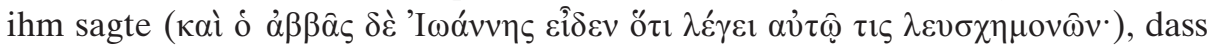
sein Vater unbesorgt und seine Ehefrau in diesen Tagen gestorben sei. Die

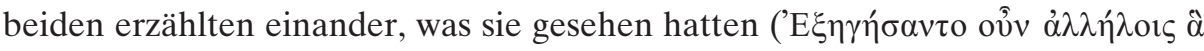

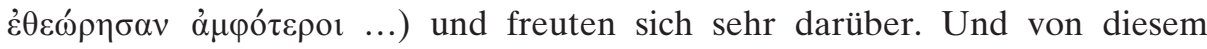
Zeitpunkt an waren sie nicht mehr betrübt wegen ihrer Verwandten und beschritten guten Mutes und entschlossen den Weg der Askese.

184. ViSyStII 16, Bd. 1, p. 14,3-15: ,Symeon erschien an der Stelle, wo er stand,

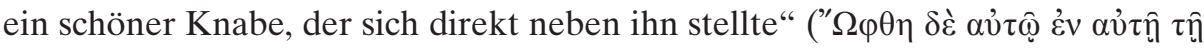

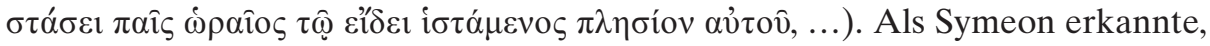
dass es der Herr war, fasste er Mut und fragte den Jüngling, auf welche Art und Weise die Juden ihn gekreuzigt haben. Der Herr zeigte es ihm, indem er die Arme in der Form eines Kreuzes ausstreckte und sagte, die Juden hätten ihn so

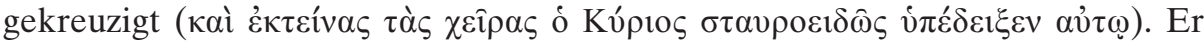
aber solle stark und tapfer sein. Damals verstand Symeon nicht, warum er ihm dies sagte. Erst im Nachhinein wurde ihm klar, dass er ihm das Bild des Kreuzes wegen seines Stehens (auf der Säule) und der dafür erforderlichen Geduld zeigte.

185. ViSyStII 28, Bd. 1, p. 29,3-14: Als alle Brüder über die Bibelkenntnisse des jungen Symeon staunten, sagte ein Priester des Klosters, in dem sich der Knabe aufhielt, er habe im Schlaf eine Kraftgestalt herannahen sehen, die in der rechten Hand einen Honigstab hielt und sagte, sie sei gekommen, um ihre Liebe 


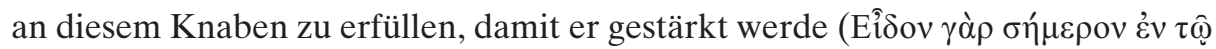

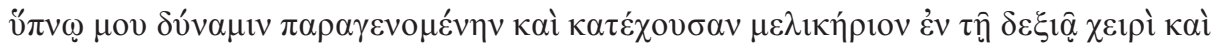

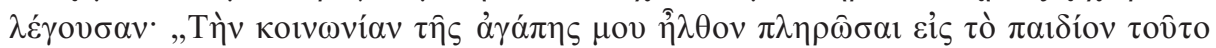

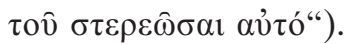

186. ViSyStII 35,11-21, Bd.1, p. 34,10-20: Nachdem Symeon in nächtlichen Träumen von Dämonen angegriffen worden war (vgl. 473), ,,erblickte er einen Priester, ein heiliger Diener der himmlischen Altäre, der in den Händen ein Gefäß mit dem Körper und Blut Jesu hielt. Der Ort wurde von einem wohlriechenden Räucherwerk erfüllt, und Symeon musste dem Priester geloben,

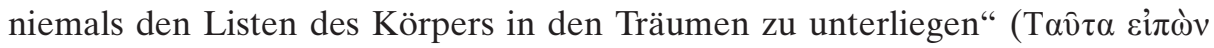

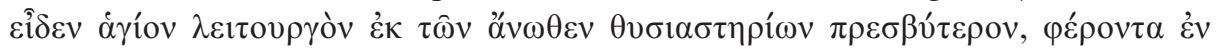

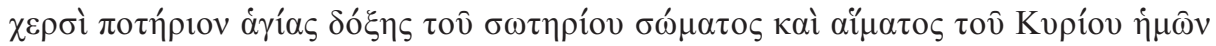

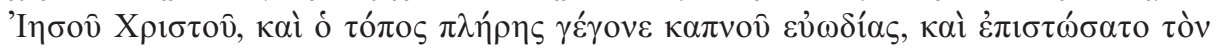

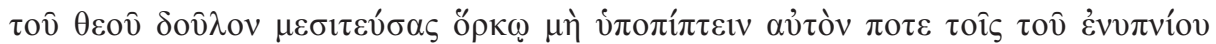
ع́p und Körper die lebensspendende Kraft und sagte: „Sei stark und tapfer [Jos1,18].“

187. ViSyStII 60,22-33, Bd. 1, p. 54,6-17: Als die Perser die Gegend verwüsteten und die anderen Brüder aus Angst das Kloster verlassen hatten, streckte Symeon die Arme zum Himmel und betete zu Gott, er möge die Gottlosen vertreiben. Sein Gebet wurde erhört, und Symeon verharrte drei Tage lang in Gebet und Gesang. Dann kam die göttliche Gnade über ihn und überschüttete ihn mit dem Wohlgeruch, der sein Kleid nie wieder verließ (..,,$\hat{\eta} \lambda \theta \varepsilon v \dot{\eta} \theta \varepsilon i ́ \alpha$

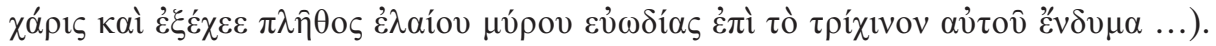
Als Symeon schon glaubte, er werde nun für immer auf diese Weise in Hesychase verbringen, sah er zwei Engel, der eine rechts, der andere links (i் $\sigma 0 \alpha \dot{\zeta} \varepsilon ı v$

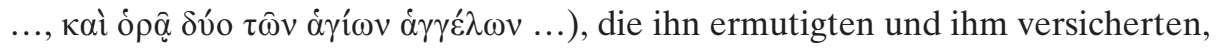
ihm beizustehen. 


\section{F. Mysterienerscheinungen (bei der Eucharistie)}

188. ApSy IX 6, Bd. 1, p. 428-430: Markos, der Ägypter, verließ während 30 Jahren nie seine Zelle, wobei ihm das Abendmahl regelmässig von einem Priester gebracht wurde. Eines Tages führte der Teufel Markos in Versuchung und schickte, unter dem Vorwand des Gebets, einen Besessenen zu ihm (..., каі̀

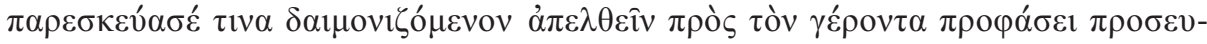
$\chi \bar{\eta} \varsigma)$. Dieser versuchte, Markos zu überreden, den Priester nicht mehr zu empfangen, da dieser ein Sünder sei. Markos aber hörte nicht auf ihn, sondern verrichtete ein Gebet und trieb den Dämon vom Besessenen aus. Als dann der Priester kam, empfing Markos diesen mit Freude, und weil Gott seine Recht-

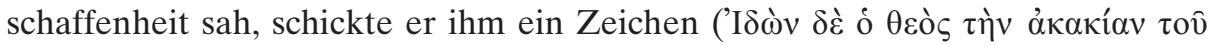

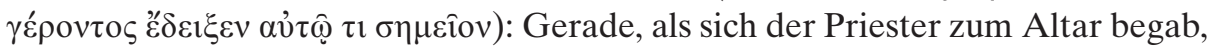
sah Markos, wie ein Engel aus dem Himmel kam und die Hand auf seinen Kopf

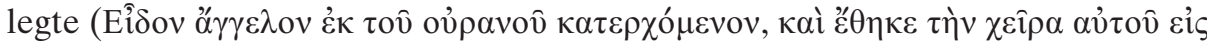

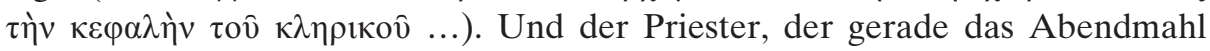

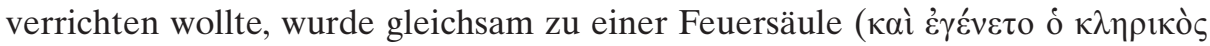

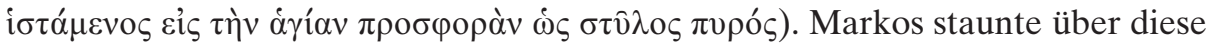
Vision, als ihn eine Stimme fragte, warum ihn dies überrasche ('E $\mu$ ov̂ $\delta \grave{\varepsilon} \theta \alpha v-$

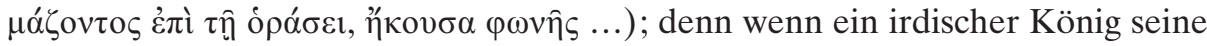
Diener nicht in schmutzigen Kleidern empfange, um wieviel mehr reinige dann die göttliche Macht die Diener der heiligen Mysterien, die im himmlischen Glanz stattfinden.

189. ApSy XVIII 4, Bd. 3, p. 44 (= ApAl, PG 65, col. 156C-157B): Ein Sketiote behauptete, das Brot des Abendmahls sei nicht der Leib Christi, sondern sein Abbild. Zwei Greise hörten davon und gingen zu ihm, um ihn eines Besseren zu belehren. Sie konnten ihn aber nicht gänzlich von der Sache überzeugen. Deshalb luden sie ihn noch in derselben Woche zum Abendmahl ein, bei dem sich, wie sie versprachen, Gott offenbaren werde. Der Sketiote willigte ein und betete zu Gott, er möge ihm offenbaren, wenn er sich irre. Die beiden Greise aber gingen in ihre Zellen und beteten zu Gott, er möge dem Sketioten das Mysterium offenbaren. Und Gott erhörte beide. „Am Sonntag kamen alle drei in die Kirche und stellten sich an einem einzigen Kissen zusammen, in der Mitte der Sketiote. Ihre geistigen Augen öffneten sich, und als das Brot auf den Altar gelegt wurde, erschien ihnen allen gleichsam ein Knabe. Und als der Priester die Hand ausstreckte, um das Brot zu brechen, kam ein Engel aus dem Himmel, der ein Messer hielt und den Knaben opferte. Das Blut ließ er in einen Becher fließen. Als der Priester das Brot in kleine Stücke brach, schnitt der Engel vom 
Knaben kleine Teile ab. Und als er hervortrat, um vom Abendmahl zu nehmen, gab er dem Sketioten vom blutigen Fleisch. Dieser schrie auf und sagte: ,Herr, ich glaube, dass das Brot dein Körper und das Getränk dein Blut ist‘. Und plötzlich wurde das Fleisch in seinen Händen gemäß dem Mysterium zu Brot “

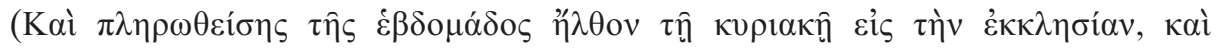

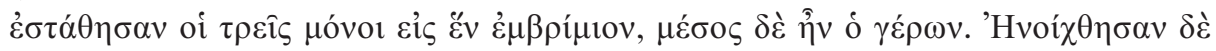

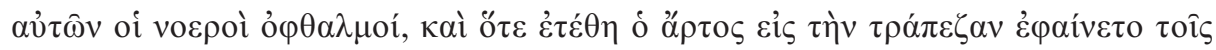

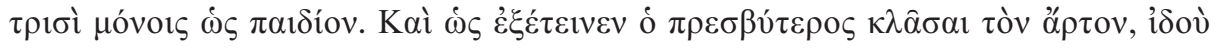

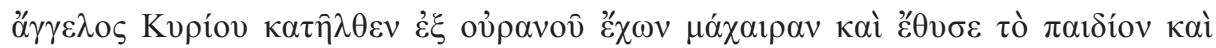

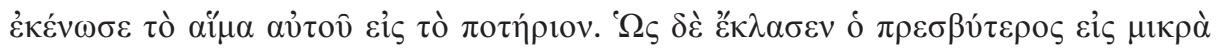

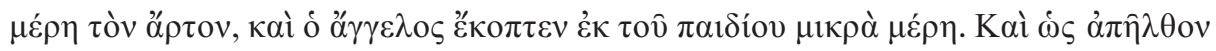

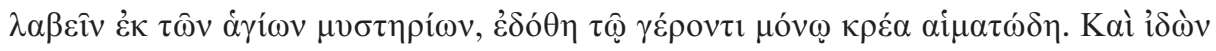

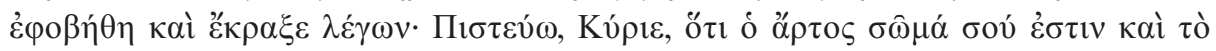

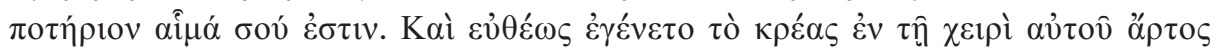

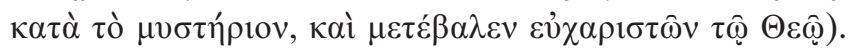

190. ViEu 28, p. 45,7-26: Als Euthymios an einem Sonntag die Liturgie las, „stand Terebon, der Sarazene, bei der Rezitation der anaphora ${ }^{743}$ neben dem Altar und stützte sich auf das Geländer des Altarraums. Plötzlich sah er, wie ein Feuer aus dem Himmel kam und sich gleich einem Schleier über dem Altar ausbreitete, Euthymios und Dometianos bedeckte und vom Anfang bis zum

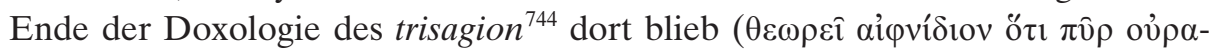

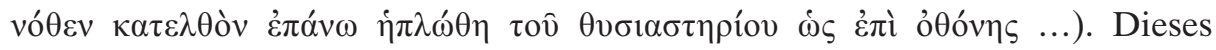
Wunder sah niemand, außer die vom Feuer Bedeckten sowie Terebon und Gabriel, der Bruder des Chrysippos [...] (

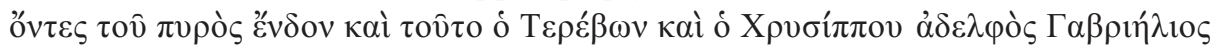
...). Terebon aber wurde von Furcht ergriffen und rannte zum Ausgang. Von nun an stützte er sich während des Gottesdienstes nicht mehr auf das Altargeländer", sondern stand vielmehr in Furcht und Frömmigkeit direkt neben der Kirchentür.

191. ViEu 29, p. 46,3-9: Während der Liturgie sah Euthymios häufig Engel, die

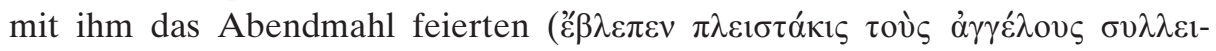

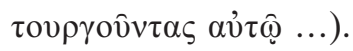

192. PrSp 4, PG 87.3, col. 2856C: Vater Leontios erzählte, dass er sich in der Nea Laura aufhielt und eines Sonntags von dort in die Kirche ging, um das Abendmahl zu feiern. Als er die Kirche betrat, sah er am rechten Flügel des

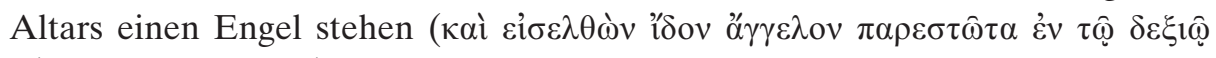

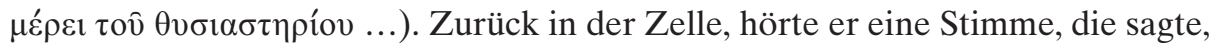

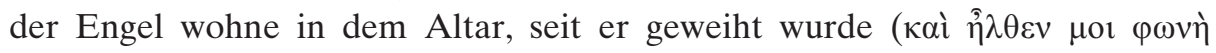

743 Das Gebet während der Eucharistie, s. R. F. TAFt, Art. Anaphora, in: ODB 1, 85.

744 Teil der Anaphora, s. R. F. TAFT, Art. Trisagion, in: ODB 3, 2121. 


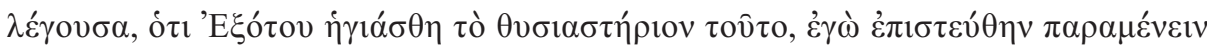
$\dot{\varepsilon} v \alpha \hat{\tau} \tau \hat{\emptyset})$.

193. PrSp 10, PG 87.3, col. 2860C: Ein Anachoret kam in die Höhle des Barnabas am Jordan, wo er einen auf dem Altar stehenden Engel Gottes er-

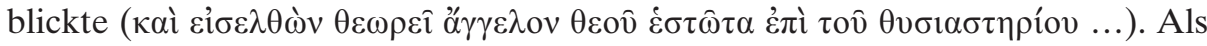
er ihn fragte, was er hier mache, antwortete der Engel, er sei ein Engel Gottes, und der Altar sei ihm seit seiner Weihung von Gott anvertraut. (Kaì $\lambda \varepsilon_{\varepsilon}^{\gamma \varepsilon 1} \delta$

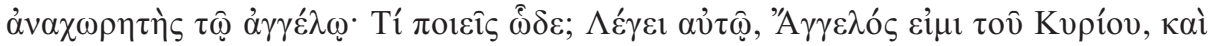

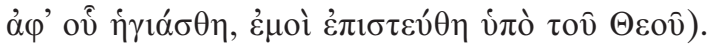

194. PrSp 150, PG 87.3, col. 3013D-3016A: (Fortsetzung der Erzählung in 355): Der Papst Agapet (535-536) entließ den Bischof, der bei ihm verleumdet worden war, nach einer dreimaligen Vision aus dem Gefängnis und ließ ihn am Sonntag das Abendmahl verrichten. Der Bischof eröffnete die anaphora ${ }^{745}$, und als er das Gebet der proskomide ${ }^{746}$ verrichtete, fing er, bevor er damit zu Ende war, von neuem, und ein drittes und viertes mal mit der anaphora an. Da fragte ihn der Papst, warum er das Gebet nicht vollendet, sondern vier mal wieder von vorne angefangen habe. Der Bischof antwortete, der Grund dafür sei, dass er nicht wie gewohnt die Aussendung des heiligen Geistes gesehen habe (... oủ

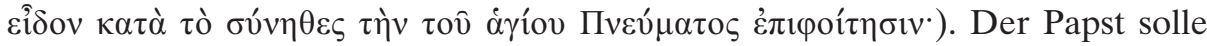
den Diakon, der das rhipidion ${ }^{747}$ hielt, weg vom Altar stellen. „Da befahl der Papst dem Diakon wegzutreten, und auf einmal sahen der Bischof und der Papst

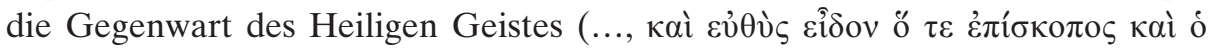

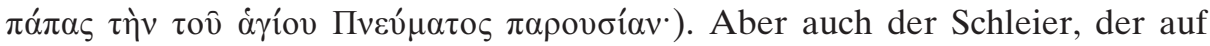
dem Altar lag, wurde von alleine in die Höhe gehoben und bedeckte alle Anwesenden während drei Stunden. Jetzt erkannte der Papst, dass der Bischof verleumdet worden war."

195. ViSyStII 256, Bd. 1, p. 221,20-223,4: Kurz bevor Symeon starb, versammelte er noch einmal alle seine Schüler, um ihnen die Geheimnisse Gottes in

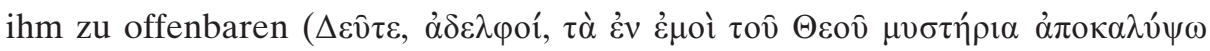
v́uiv ...). Denn derjenige, der die Geheimnisse verkünde, der das Verborgene kenne, der überall anwesend sei und zu allen, die ihn anrufen, komme, der habe auch ihm in sichtbarer Form einen weißgekleideten Mann in einem härenen Gewand und von leuchtender Erscheinung gezeigt (... ó $\varphi \theta \alpha \lambda \mu \circ \varphi \alpha v \omega ิ \varsigma$ vं $\pi \varepsilon \delta \varepsilon \varepsilon \xi \xi$ $\tau$ ติ

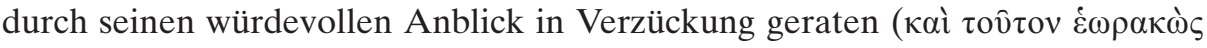

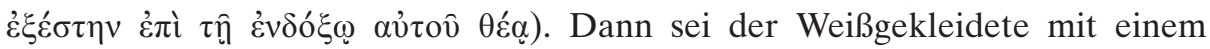

745 S. A. 743.

746 Vorbereitende Handlungen zur Eucharistie, s. K. ONASCH, Art. Prothesis, in: Lexikon Liturgie und Kunst der Ostkirche, Berlin 1993, $321 \mathrm{f}$.

747 Liturgischer Fächer zum Schutz des Abendmahls, s. M. M. Mango, Art. Rhipidion, in: ODB 3, 1790. 
heiligen Gefäß in den Händen durch die Lüfte zu ihm geschwebt. Im Gefäß sei so etwas wie Reis gewesen, der so weiß war, wie er ihn noch nie zuvor gesehen hatte. Dreimal habe der Mann mit einem Löffel davon genommen und in seinen Mund gegeben. Und seither habe er ihn bis heute jeden Sonntag nach der Liturgie gesehen, wie er mit dem heiligen Gefäß zu ihm kam und ihn mit dieser Speise ehrte.

196. ViThSy 80, Bd. 1, p. 67,10-68,11: Als Theodoros eines Tages das Abendmahl verrichtete, beobachtete der Bruder Iulianos, wie sich das Gesicht des Heiligen veränderte und wie nie zuvor leuchtete und erstrahlte. Als er Theodoros nach dem Grund dafür fragte, erzählte ihm dieser unter Schweigepflicht,

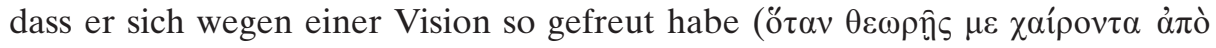

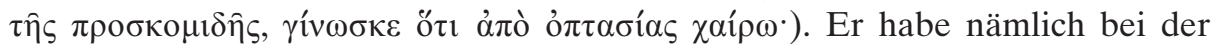
Vorbereitungen zur Eucharistie gleichsam einen wahrhaftigen, überaus leuchtenden Stern auf das Heilige Abendmahl herunterkommen sehen. Wenn er dies

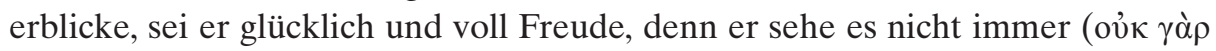

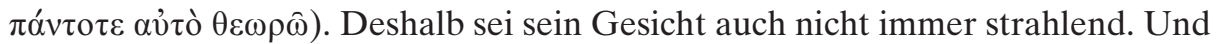
wenn er es nicht sehe, dann dehne er das Gebet der proskomide ${ }^{748}$ aus, um auf

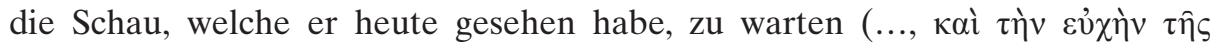

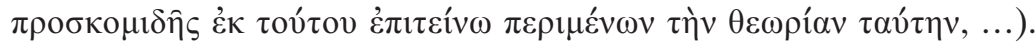

748 S. S. 218 A. 746. 


\section{G. Gnaden- und Lichterscheinungen}

197. ApAl, Arsenios 27, PG 65, col. 96C: „Es ging einmal ein Bruder zur Zelle des Abbas Arsenios in der Skete. Als er dort zum Fenster hineinschaute, sah er

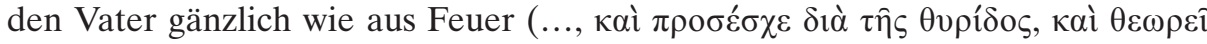

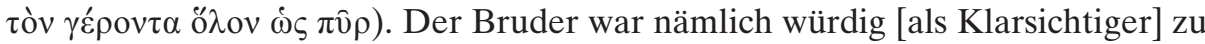

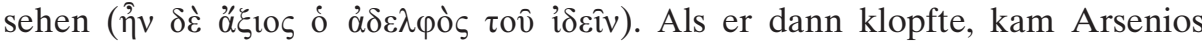
heraus und war erstaunt, als er den Bruder sah." Er fragte ihn, ob er schon lange

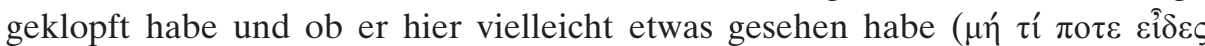
$\hat{\omega} \delta \varepsilon ;$ ). Der andere verneinte.

198. ApAl, Ioannes Kolobos 33, PG 65, col. 216A: „Ein Vater kam in die Zelle des Ioannes und fand ihn schlafend. Ein Engel stand bei ihm und fächelte ihm

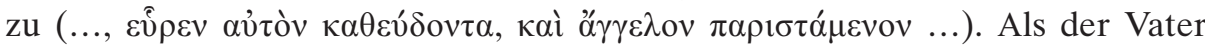
dies sah, ging er weg." Ioannes aber stand auf und fragte seinen Schüler, ob jemand hierher gekommen sei, als er schlief. „Ja“, sagte er, „der berühmte Wüstenvater“. Und Ioannes erkannte, dass der Vater von seinem spirituellen

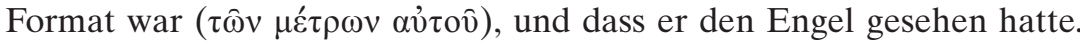

199. ApAl, Ioannes Kolobos 38, PG 65, col. 216D-217A: Ioannes erzählte von einem pneumatikos ${ }^{749}$, der den Tod eines sterbenden Asketen voraussah und sich zu diesem begeben wollte, um sich von ihm $\mathrm{zu}$ verabschieden (s.o. 73). Er beschloss, in der Dunkelheit hinzugehen, damit ihn niemand sehe und ihm dadurch Ruhm entstehen könnte. Als er aber am Abend die Zelle verließ, wurden ihm von Gott zwei Engel mit Laternen gesandt, welche ihm den Weg

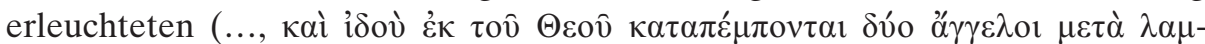
$\pi \alpha ́ \delta \omega v ~ . .$.$) . Daraufhin strömte die ganze Stadt zusammen und sah seinen Ruhm.$ 200. ApSy IX 14, Bd.1, p. 438 [vgl. ApAl, PG 65, col.377C]: Als Abbas Paphnutios einmal unterwegs war, kam er zu einem Dorf und traf auf Leute, die schlecht über andere redeten. Paphnutios drehte sich um, warf sich hin und klagte sich selbst vor Gott an. Da kam ein Engel mit einem Schwert zu ihm (...,

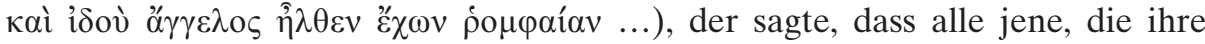
Brüder verurteilen, mit diesem Schwert umgebracht werden. Er aber habe gut daran getan, nicht zu urteilen, sondern sich selber vor Gott zu demütigen, als ob er selber eine Sünde begangen hätte. Deshalb werde sein Name in das Buch des Lebens geschrieben.

201. ViIo 24, p. 219,19-220,3: Basilina, eine Diakonissin aus der Hagia Sophia wollte unbedingt mit eigenen Augen Ioannes, den Hesychasten, sehen. So be-

749 S. S. 77 A. 354. 
schloss sie, Männerkleider anzuziehen und zu ihm in die Laura zu gehen, um ihm ihre Sorgen zu erzählen. Er aber zeigte sich ihr in Engelsgestalt und sagte, sie solle sich gar nicht bemühen, denn wenn sie zu ihm komme, werde sie ihn gar nicht sehen. Vielmehr solle sie geduldig sein, dann erscheine er ihr, wohin auch immer sie gehe, im Schlaf und höre sich ihre Sorgen an. Und was auch immer Gott ihm auftrage, werde er ihr mitteilen. Als sie dies hörte, glaubte sie es und hielt das Gesicht für wahr. Er erschien ihr nämlich abermals im Schlaf und sagte, Gott habe ihn zu ihr gesandt, und sie solle sagen, wenn sie etwas wolle. Darauf erzählte sie ihre Sorgen, erhielt eine angemessene Antwort, stand auf und dankte Gott. Und dem Schüler, der zu ihr kam, teilte sie die Gestalt und das

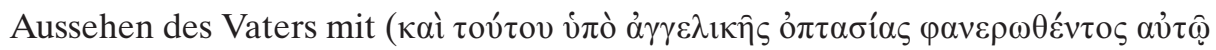

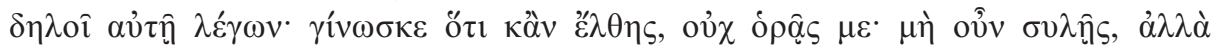

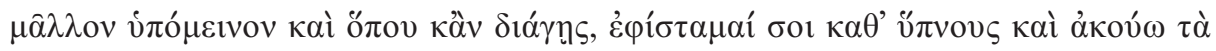

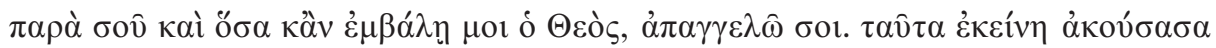

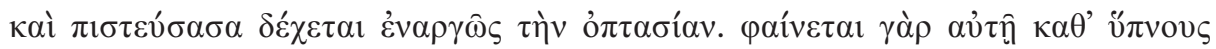

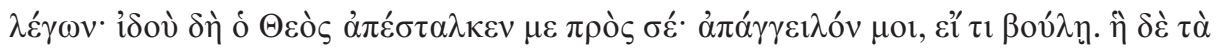

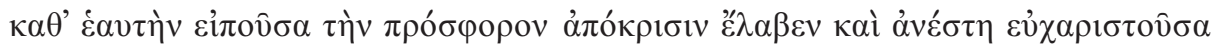

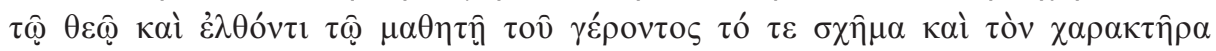

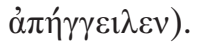

202. ViMa 32, Bd. 2, p. 277,1-12: Der Leichnam der Martha wurde drei Tage nach ihrem Tod zur Säule des Symeon gebracht, an deren rechten Seite sie begraben werden sollte. „In der Nacht, als sie hierhergebracht wurde, erschien aus der Überdachung der Umzäunung der Säule, als ob die Decke aufgerissen würde, die Heilige Martha (..., $ڤ \varphi \theta \eta \dot{\eta} \mu \alpha \kappa \alpha \rho i ́ \alpha . .$.$) . Sie trat stumm heraus und$ stützte sich auf zwei Brüder, durch die sie Symeon die Gebote zukommen ließ. Die beiden Brüder wurden von großer Furcht ergriffen, da sie wussten, dass Martha bereits gestorben war." Sie aber sagte ihnen, sie sollen sich nicht fürchten, denn der Herr habe sie nicht zu den Toten, sondern zu den Lebenden gezählt. Deshalb sei sie auch unbeschädigt bewahrt worden. Nur ihre Kleider seien nass von der Feuchtigkeit der anderen Leichen, zu denen sie hinuntergelegt wurde. Sie sei gekommen, um ihnen das Leben zu verkünden, auf dass sie in Sicherheit leben und die Dämonen besiegen werden. „Nachdem sie dies

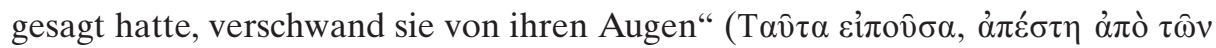
o $\varphi \theta \alpha \lambda \mu \hat{\omega} v \alpha \hat{\tau} \tau \hat{\omega} v)$.

203. ViMa 57, Bd. 2, p. 300,19-25: Sechs Monate nach dem Tod der Martha „erschien die Gnade des Herrn und offenbarte Symeon noch Größeres (...,

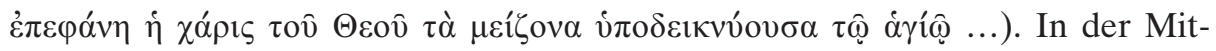
tagszeit sah er von Jerusalem her die Sonne, deren Leuchten über das menschlich Wahrnehmbare hinausging und mit ihren Lichtstrahlen seine mandra [s. A. 752] erfüllte, und sie reichte bis zu den Händen der Seligen und sandte Strahlen aus.“ 
204. ViMa 65, Bd.2, p. 307,22-27: Symeon erzählte, dass er plötzlich eine

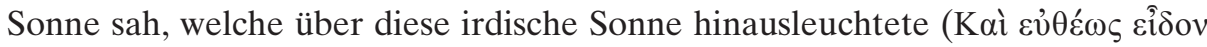

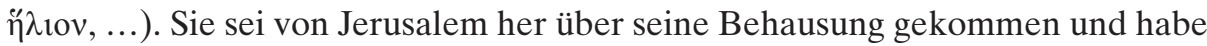
das ganze Haus mit Lichtglanz erfüllt. Und er habe einen Iberer ${ }^{750}$ gesehen, der zusammen mit zwei anderen Mönchen das lebensspendende Kreuz herbeibrachte.

205. PrSp 37, PG 87.3 col. 2885D-2887A: Nachdem die heilige Stadt durch ein Erdbeben zerstört worden war, baute sie der damalige komes Ephraimios wieder auf. $\mathrm{Zu}$ jener Zeit verließ ein Bischof sein Hauptquartier und zog nach Jerusalem, um sich beim Wiederaufbau der Stadt nützlich zu machen. „Eines Tages sah Ephraimios im Schlaf den Bischof. Er schlief, und direkt über ihm

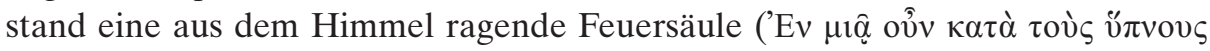

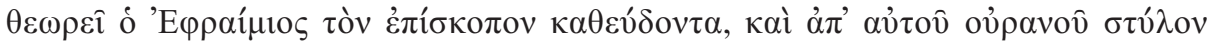

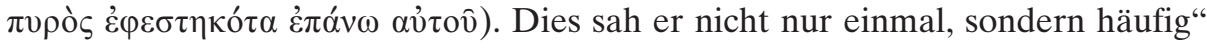

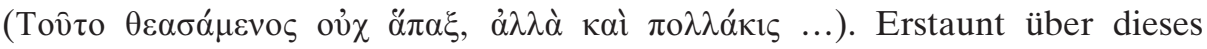
furchteinflössende Wunder ( $\tau$ ò $\theta \alpha \hat{v} \mu \alpha$ ) fragte sich Ephraimios, was dies wohl zu bedeuten habe, denn er wusste nicht, dass der Arbeiter ein Bischof war. Aus diesem Grund ließ er diesen zu sich kommen und erfuhr erst jetzt, wer er eigentlich war.

206. ViSyStII 121, Bd. 1, p. 99,18-100,18: Symeon unterrichtete seine Schüler. „Als sie alle zusammen den großen Psalm ,Selig die unerschütterlich auf dem Weg des Herrn gehen' sangen, erschien dem Heiligen der Herr (..., íovô ó

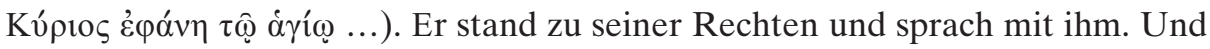

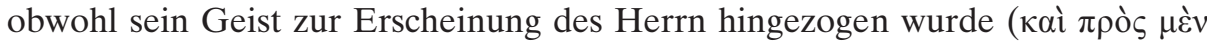

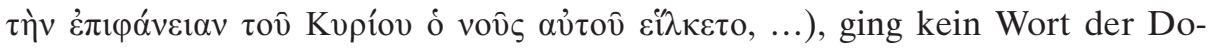
xologie verloren. Über den Köpfen der Brüder sah Symeon jetzt gleichsam einen fliegenden Vogel, der gemeinsam mit der Bewegung ihrer Lippen lieblich

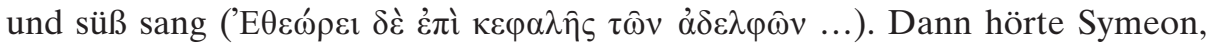
wie der Herr ihn lobte: , Gut tust du daran, die Spatzen schön singen zu lehren““. Als die Brüder dies hörten, erinnerten sie sich an den Satz im Evangelium ,Ihr seid mehr wert als viele Spatzen‘ (Mt 10,31).

750 S. S. 186 A. 741. 


\section{H. Jenseitsoffenbarungen}

\section{Todesvisionen und Seelenwanderungen}

207. ViAn 60,1-2 p. 294,3-9: „Als Antonios einmal auf dem Berg saß und in den Himmel schaute, sah er in der Luft jemanden emporgehen, und die Freude

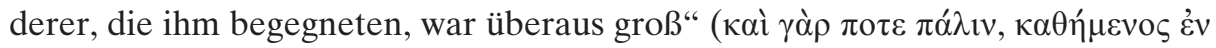

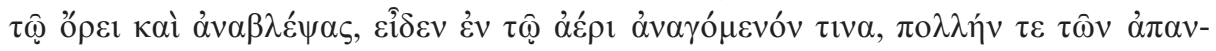

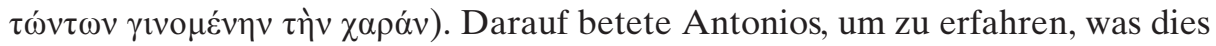
zu bedeuten habe. „Da vernahm er auf einmal eine Stimme, die verkündete, dies

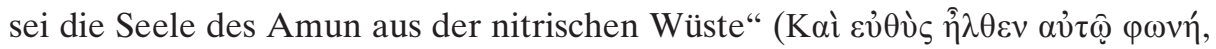

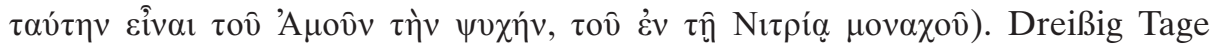
später kamen Brüder aus Nitrien und verkündeten den Tod des Amun. Er war genau zu der Zeit gestorben, als Antonios seine Seele hatte in den Himmel steigen sehen.

208. ViAn 65,1-6, p. 304,4-306,9: Als Antonios einmal beim Essen war, stand er auf, um das Gebet zu verrichten. „Da fühlte er, wie er im Geist entrückt

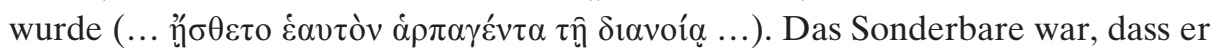
dastand und sich selber wie aus sich herausgehen sah und von einigen in die Luft

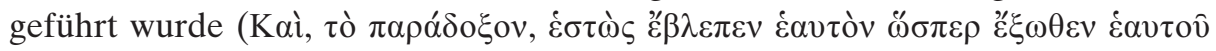

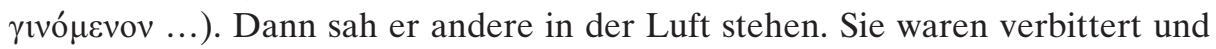
fürchterlich und wollten ihn am Vorbeigehen hindern. Als seine Begleiter ihn verteidigten, fragten die anderen, ob er ihnen nicht Rechenschaft schuldig sei. Als sie Antonios aufforderten, von Geburt an Rechenschaft abzulegen, erwiderten seine Begleiter, dass der Herr auf alles, was mit seiner Geburt zu tun habe, verzichte. Sie könnten ihn erst ab dem Augenblick, wo er Mönch geworden war, verantwortlich machen. Dann wurde der Weg frei für ihn. Und auf einmal sah er sich selbst, wie wenn er zurückkommen und wieder bei sich stehen

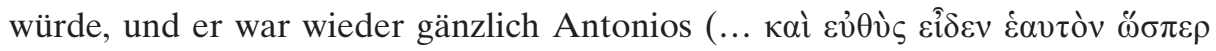

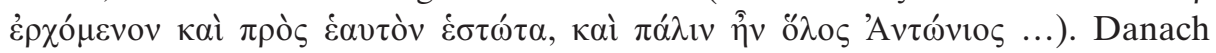
vergaß er zu essen und verbrachte den Rest des Tages und die ganze Nacht beim

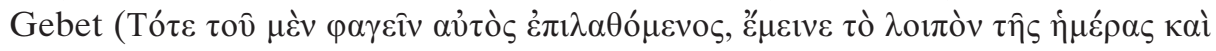

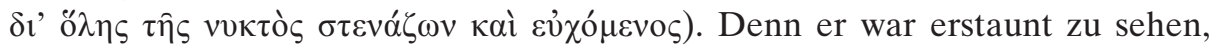
gegen wie viele Feinde der Mensch kämpfen und mit wie vielen Mühen er die Luft durchqueren muss".

209. ApSy XI 9, Bd. 2, p. 140: „Als Agathon sterben sollte, verharrte er wäh-

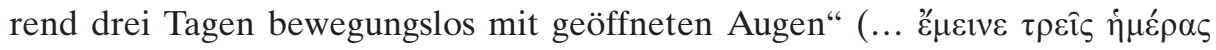

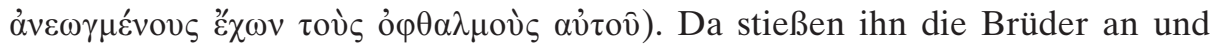
fragten, wo er sich befinde. Er antwortete, dass er vor dem Gericht Gottes stehe 


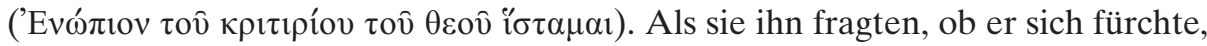
erwiderte Agathon, er hätte sein Möglichstes getan, um die Gebote zu befolgen. Da er aber ein Mensch sei, könne er nicht wissen, ob seine Werke Gott gefallen. Darauf fragten sie ihn, ob er nicht davon überzeugt sei, seine Werke gemäß Gottes Willen vollbracht zu haben. Agathon antwortete, darüber zu urteilen stehe ihm nicht zu, solange er Gott nicht begegnet sei. Das Urteil Gottes sei nämlich etwas anderes als das der Menschen. Als sie ihm noch weitere Fragen stellen wollten, sagte er, sie sollten ihm den Gefallen tun, nicht zu sprechen, denn er sei beschäftigt. Dann starb er.

210. ApSy XV 20, Bd. 2, p. 300: Abbas Moses fragte den Bruder Zacharias, als dieser im Sterben lag, was er sehe (Tí ópậs;). Er fragte zurück, ob es nicht besser sei, zu schweigen. Und Moses antwortete: ,Ja, schweig!‘. „Und Abbas Isidoros $\mathrm{sa}$ in seiner Todesstunde da, schaute in den Himmel und sagte: ,Freu dich, freu dich, Zacharias, die Pforten des himmlischen Königreichs sind geöffnet!““ (Kà̀

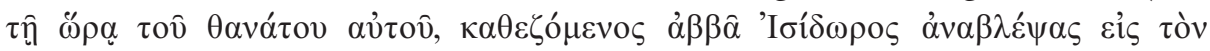

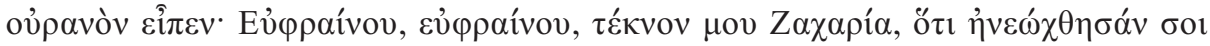

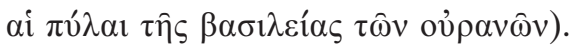

211. ApSy XVI 27, Bd. 2, p. 408 f.: Ein Mönch war ein Trinker. Er flocht jeden Tag eine Binsenmatte, verkaufte sie in der Stadt und vertrank danach seinen Lohn. Irgendwann kam ein Bruder zu ihm und flocht auch täglich eine Binsenmatte. Der Mönch vertrank nunmehr den Lohn von zwei Binsenmatten und brachte dem Bruder am Abend lediglich ein wenig Brot mit. Das geschah während drei Jahren. Dann sagte sich der Bruder, er habe nun genug von dieser Art Leben und gehe dorthin (ins Jenseits). Dann überlegte er es sich noch einmal anders und setzte sich wieder hin, da er ja für Gott im koinobion saß

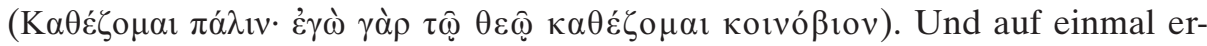

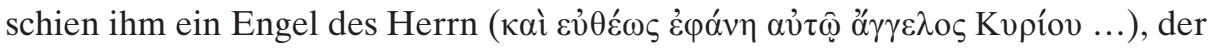
ihm befahl, nicht wegzugehen, da sie (die himmlischen Heerscharen) zu ihm kommen werden. Noch am selben Tag bat der Bruder den trinkenden Mönch, nicht in die Stadt zu gehen, da die Seinigen kommen werden, um ihn abzuholen. Der Mönch aber hörte nicht auf seine Worte, und sagte, sie haben sich bestimmt verspätet und kommen nicht heute. Der andere beharrte aber darauf, dass sie auf jeden Fall kommen werden. Dann starb er. Der trinkende Mönch bereute und führte von nun an ein frommes Leben.

212. ApSy XIII 17, Bd.2, p. 244-248: Ein Mädchen wurde Vollwaise und funktionierte ihr Elternhaus zu einem Hospiz ( $\xi \varepsilon v o \delta o \chi \varepsilon i ̂ o v)$ für die Wüstenväter um, die sie aufnahm und pflegte. Weil irgendwann das Geld knapp wurde, fing sie an, als Prostituierte zu arbeiten. Die Brüder wollten ihr helfen und schickten Ioannes Kolobos zu ihr. Als dieser zu ihr kam, setzte er sich neben sie aufs Bett, rückte nah an sie heran, schaute ihr ins Gesicht und fragte sie, was sie von Jesus erkannt habe, da sie so weit gekommen sei. Da erstarrte sie. „Der Greis senkte

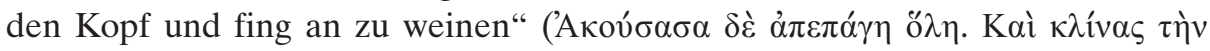




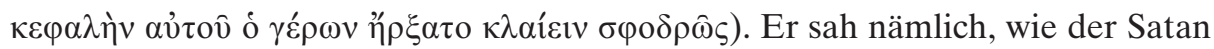

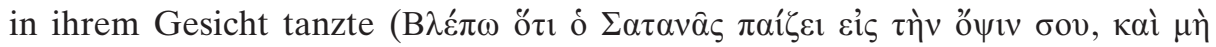
$\left.\kappa \lambda \alpha v^{\sigma} \omega^{\circ}\right)$. Als er ihr dies sagte, erstarrte sie abermals und wollte bereuen. Da nahm Ioannes Kolobos sie mit sich. Als sie die Wüste erreichten, fing es an zu dämmern. Ioannes baute für beide eine Art Kissen aus Sand, und sie legten sich schlafen. „Um Mitternacht wachte er auf und sah, wie sich ein Lichtstraße vom Himmel zu ihr herunter erstreckte und wie die Engel ihre Seele emporhoben

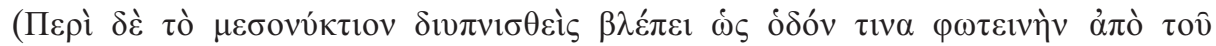

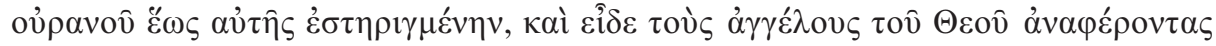

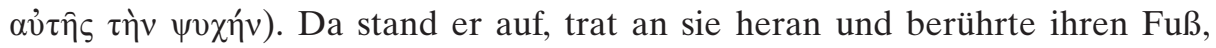
doch sie bewegte sich nicht mehr. Als er verstand, dass sie gestorben war, fing er an, sich ins Gesicht zu schlagen“. Doch auf einmal hörte er eine Stimme, die sagte, ihre einzige Stunde der Reue bewirke mehr als die Reue von vielen, die sich verspäteten und niemals das Werk einer solchen Reue verrichtet haben (...

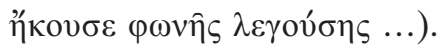

213. Bar 778, Bd. 3, p. 225 f.: Ein weltlicher Gläubiger, der Philosophielehrer war, fragte Ioannes, ob sein kranker Sohn leben oder sterben werde. Nachdem sich Ioannes' Vorhersage, dass der Sohn leben werde, bewahrheitet hatte, erkrankte der andere Sohn des gläubigen Mannes. Als dieser wieder zu Ioannes kam und fragte, ob sein Sohn leben oder sterben werde, ,antwortete er ihm: ,Wir beten, aber nur Gott steht es zu, ihm Barmherzigkeit zu gewähren. Nehme für ihn deinen Willen zurück und sei ihm dankbar für alles'. Er hörte diese Worte, verstand aber nicht ihre Bedeutung, und so glaubte er, dass sein Sohn leben werde. Als er aber zu diesem zurückkam, erhob der Sohn den Blick, sah

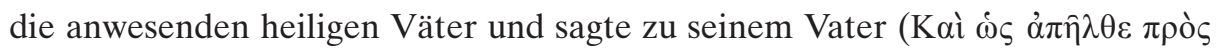

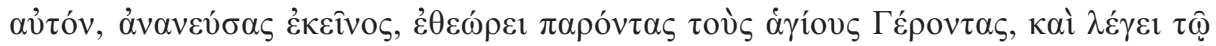

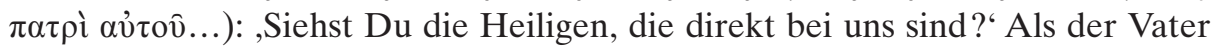
aber antwortete, dass er nichts sehe, sagte der Sohn: ,Hier stehen sie und sagen mir: «Was kommt und geht dein Vater, um uns zu stören, damit du im Fleisch lebst? Siehe, wir beten für dich zu Gott, und er sagte, dass für dich die Zeit gekommen sei, aus dem Körper zu scheiden»'. Nachdem er dies dem Vater erzählt hatte, fuhr er fort: ,Sie haben mich von einem Sarazenen befreit und mich an einen leuchtenden und unaussprechlichen Ort geführt ('I $\delta o v ́, ~ \Pi \alpha ́ \tau \varepsilon \rho$,

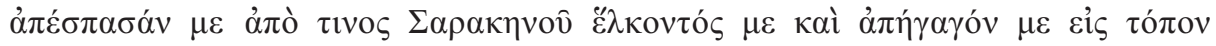

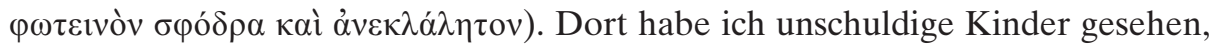
die sagten: «Wegen dem Gebet deines Vaters, haben wir Gott gebeten, dich an diesem Ort aufzunehmen». Und siehe, dort feiern sie die Liturgie und die Eu-

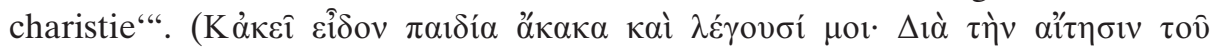

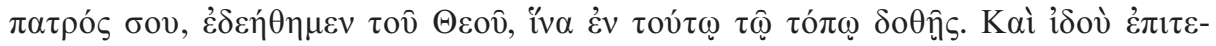

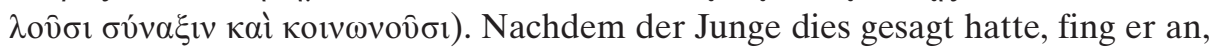
verschiedene Gebete zu sprechen, und der Vater fand Trost, da er nun von der Rettung der Seele seines Sohnes überzeugt war. 
214. ViDanSt 96, p. 90,1-24: „Drei Tage bevor der heilige Daniel starb, wurde er mitten in der Nacht damit geehrt, alle jene zu sehen, die Gott wohlgefällig

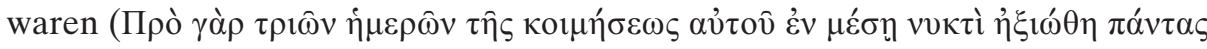

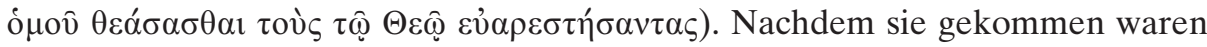
und ihn umarmt hatten, forderten sie ihn auf, die heilige proskomide ${ }^{751} \mathrm{zu}$ vollbringen. Zwei Brüder hatten die Ehre, Zeugen dieser Worte zu werden und in gebührender Weise zu antworten. Sobald Daniel diesen göttlichen Dienst vollendet hatte, erwachte er aus der Ekstase. Und als er wieder zu sich ge-

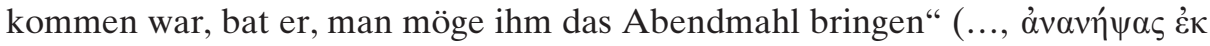

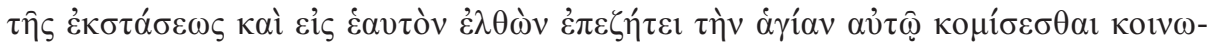
víav).

215. ViDanSt 99,13, p. 92,5-8: „Bevor der tote Daniel bestattet wurde, erschienen der Menge am Himmel über dem Heiligen plötzlich drei Kreuze und

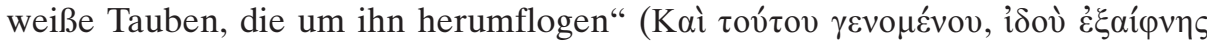

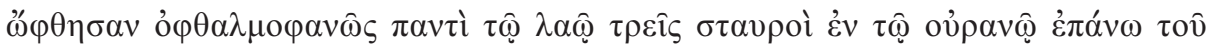

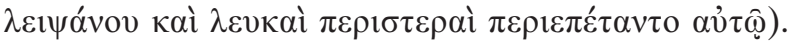

216. ViEu 41, p. 61,11-16: „Nachdem sieben Tage seit dem Tod des Euthymios vergangen waren, erschien der Heilige in der Nacht dem Bruder Dometianos

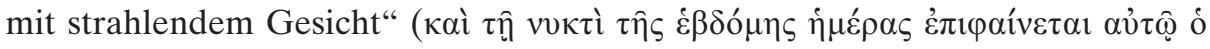

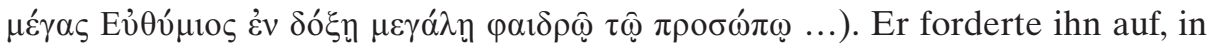
den für ihn vorbereiteten Glanz zu kommen, denn Christus habe ihm den Wunsch erfüllt, dass er, Dometianos, bei ihm sein werde. „Nachdem Dometianos dies gehört hatte, ging er in die Kirche, erzählte die Vision den Brüdern und

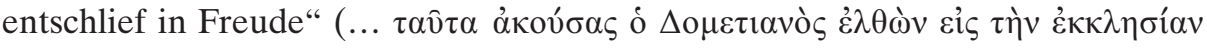

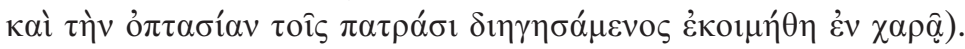

217. HiLa 4, p. 20,16-21,2: Didymos, der blinde Schriftsteller erzählte, dass er einmal so bekümmert über das Leben des Kaisers Iulianos, des Christenverfolgers, war, dass er in seiner Traurigkeit bis zum späten Abend nichts aß. So kam es, dass er auf dem Stuhl saß, vom Schlaf überwältigt wurde und eine

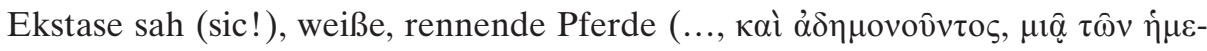

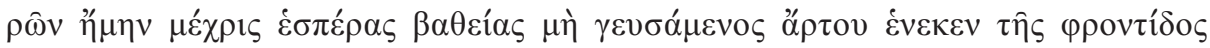

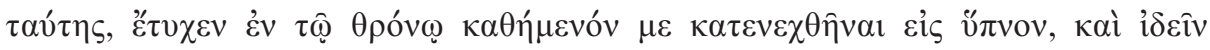

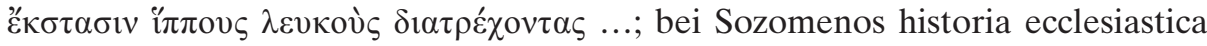

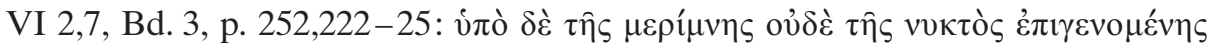

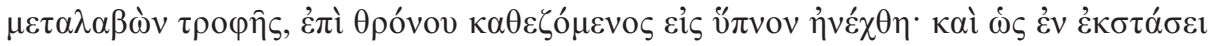

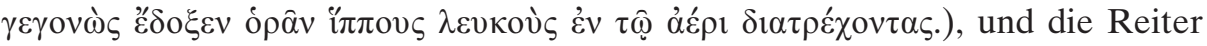
auf ihnen riefen: „Sagt Didymos, dass heute um die siebte Stunde Iulianos gestorben ist“. Zu Didymos sagten sie: „Steh auf und iss, dann teil es dem Bischof Athanasios mit". Dies tat er, und es stellte sich heraus, dass sich alles genau so ereignet hatte.

751 S. S. 218 A. 746. 
218. HiMo 14,2-23, p. 102,5-110,8: Paphnutios erschien ein Engel, der ihn mit

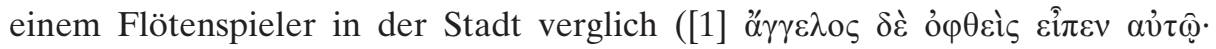

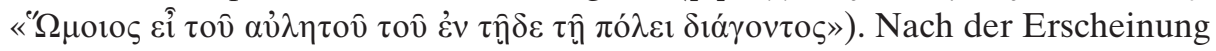
suchte Paphnutios den Flötenspieler auf und erkannte, dass dieser zwar ein Sünder und Trinker war, aber auch gute Werke vollbracht hatte, durch die er dem Asketen in keiner Weise nachstand. Der Flötenspieler folgte Paphnutios in die Wüste und wurde Asket. Dann machte er sich auf die Himmelsreise und

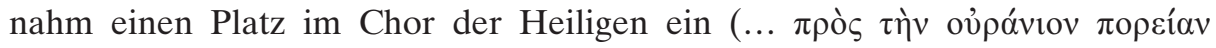
$\dot{\varepsilon} \sigma \tau \varepsilon \dot{\lambda} \lambda \lambda \varepsilon \tau \mathrm{o} . .$.$) . Danach wurde Paphnutios von einer göttlichen Stimme mit$

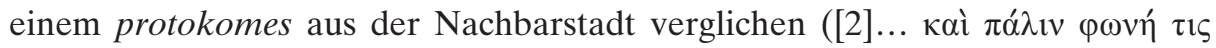

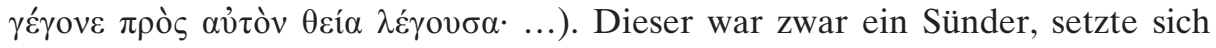
aber für die Armen ein und stand dem Heiligen deshalb in keiner Weise nach. Auch er folgte Paphnutios und führte nunmehr das Leben eines Asketen. Doch auch er starb bald, und Paphnutios sah, wie die Seele des Mannes von Engeln in

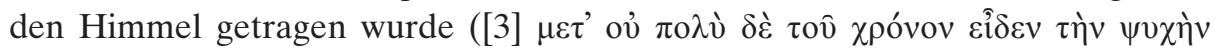

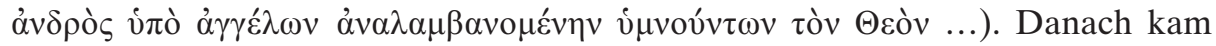
wieder eine göttliche Stimme zu Paphnutios, die ihn mit einem Händler, der sich

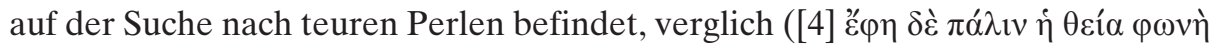

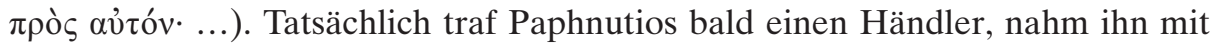
und überredete ihn zum Mönchsleben. Doch auch dieser starb nach kurzer Zeit. Jetzt hatte auch Paphnutios keine Lust mehr zu leben. Da kam ein Engel zu ihm und forderte ihn auf, zu den ewigen Gefilden Gottes mitzukommen ([5] ...

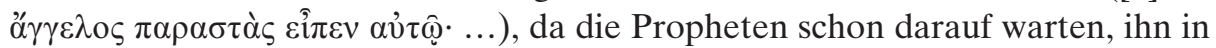
ihren Chören aufzunehmen. Ein Tag später starb Paphnutios.

219. ViHy 51,2-4, p. 286,22-288,5: Hypatios war vor seinem Tod fünf Tage lang krank. Am sechsten Tag, an einem Sonntag, ließ er die Brüder zur Eucharistie zusammenkommen. Als das Abendmahl verteilt wurde, befand er sich

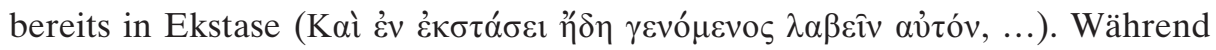
die anderen Brüder psalmodierten und die Kommunion aus seiner Hand entgegennahmen, weinten alle, da sie wussten, dass er sterben würde. „Er hingegen glaubte zu sehen, wie sich ihm Bischöfe und einige enge Freunde näherten, um

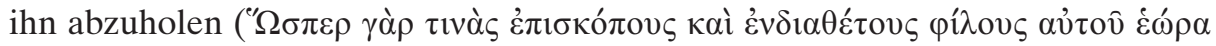

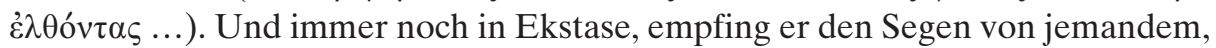
der neben ihm stand und schien ihn weiterzugeben, als ob da jemand gewesen wäre. Doch es erschien niemand, um den Segen entgegenzunehmen, sodass ihn

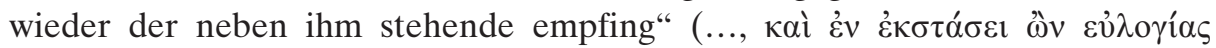

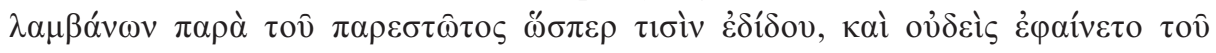

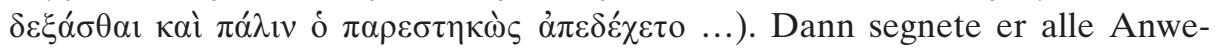
senden und starb.

220. ViIo 17, p. 214,21-215,4: Der heilige Ioannes ,hatte das Verlangen zu sehen, wie sich die Seele vom Körper trennt. Als er dabei war, Gott darum zu bitten, wurde er im Geist nach Betlehem entrückt und sah im Narthex der 
dortigen Kirche einen unbekannten heiligen Mann liegen. Er war tot, und seine Seele wurde von Engeln emporgehoben und mit Hymnengesang und Wohlgeruch in die Himmel geführt [vgl. auch mit gr. Text 136]. Doch Ioannes verlangte danach, mit eigenen Augen zu sehen, ob es tatsächlich so geschehen war. Noch in der gleichen Stunde machte er sich auf den Weg nach Betlehem. Und als er dort angekommen war, stellte sich heraus, dass der heilige Mann tatsächlich in

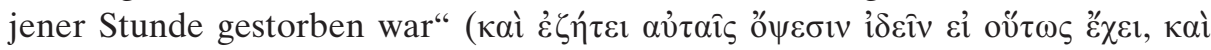

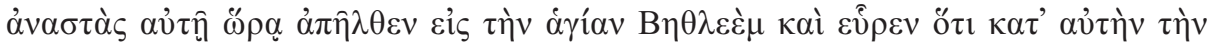

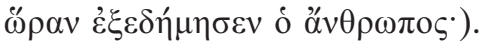

221. ViIoEl 52,27-52, Bd. 2, p. 403,1-21: Als Alexandreia von den Persern überflutet wurde und Ioannes vorhatte, mit dem Schiff in seine Heimat Zypern zu flüchten, bat ihn sein Freund, der patrikios Niketas, einen Abstecher nach Konstantinopel zu machen, um der kaiserlichen Familie die Gunst seines Gebetes zu erweisen. Doch als sie sich auf dem Schiff befanden, gerieten sie in einen heftigen Sturm und drohten unterzugehen. Ioannes flehte zusammen mit den Armen, die sich auf dem Schiff befanden, Gott um Hilfe an. Und als sie gerade bei Rhodos waren, ,sah der noch immer wache Ioannes auf einmal einen Eunuchen von leuchtender Gestalt mit einem goldenen Szepter in der rechten

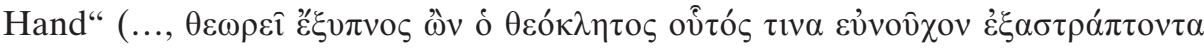

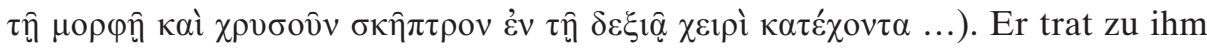
und forderte ihn auf mitzukommen, denn der König der Könige verlange nach ihm. Sofort ließ Ioannes den patrikios Niketas kommen „und sagte ihm unter Tränen: ,Du hast mich gebeten, zum irdischen König zu gehen, der himmlische ist aber zuvorgekommen und hat mich zu sich gerufen'. Dann erzählte er ihm die Vision des Eunuchen, oder vielmehr des Engels, welche ihm in dieser Stunde

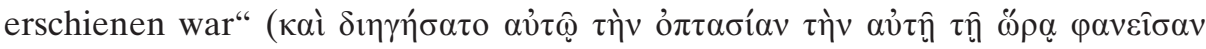

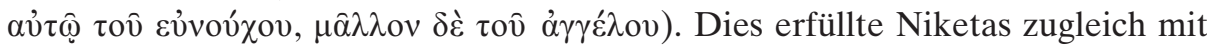
Freude und Trauer. Er versuchte aber nicht, den Heiligen von seinem Vorsatz abzubringen und ließ ihn nach Zypern fahren.

222. ViIoEl 60,1-37, Bd. 2, p. 408,3-30: Am Todestag des Heiligen Ioannes „sah ein gewisser Mönch Sabinos in Alexandreia, als er in eine Art Ekstase

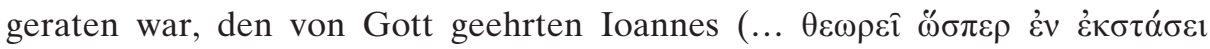

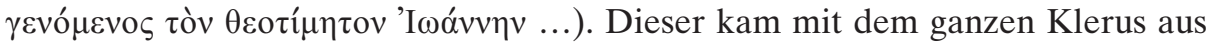

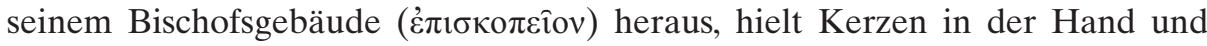
schritt zum Kaiser, während ihn ein Eunuche in der Funktion des kubikularios herbeirief. Er sah auch ein Mädchen, das hell war wie die Sonne. Als Ioannes das Tor des Bischofgebäudes verlassen hatte - was das Hinscheiden aus seinem

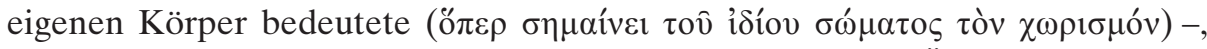
nahm sie ihn an der Hand und legte ihm einen Kranz aus Ölzweigen auf den Kopf. Auf einmal verstand Sabinos, dass das Hinübergehen des Patriarchen zu Gott in dieser Stunde stattgefunden hatte (

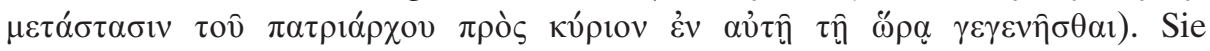


schrieben den Monat und den Tag des Hinscheidens auf (es war der Festtag des heiligen Menas). Und einige Leute, die aus Zypern kamen, wurden von den Schülern des Ioannes befragt, die daraufhin erkannten, dass die Vision wahr war, da sie sich sich exakt zu jenem Zeitpunkt ereignet hatte, als Ioannes starb.

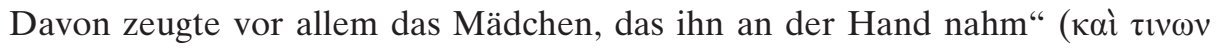

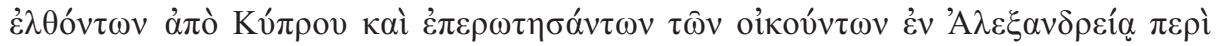

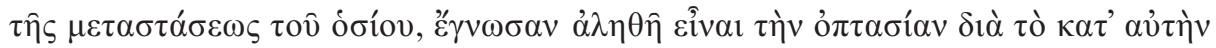

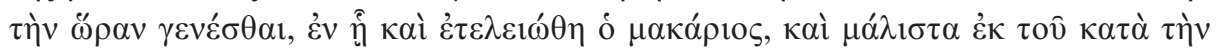

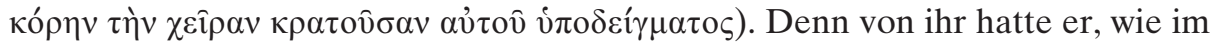
Vorwort der Vita gesagt wurde (vgl. 161), das Versprechen erhalten, dass sie Ioannes ins Königreich führen werde, wenn er sie zu seiner Freundin mache. 223. ViKy 5, p. 225, 13-16: „Kurz nach dem Tod des Euthymios sah der heilige Gerasimos, wie seine Seele von Engeln begleitet in den Himmel gehoben

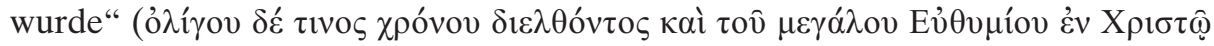

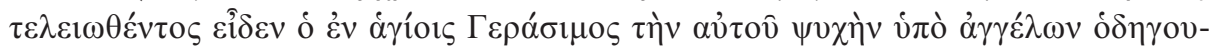

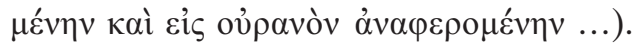

224. ViMa 11, Bd. 2, p. 261,15-262,10: Ein Jahr bevor Martha starb, geriet sie in

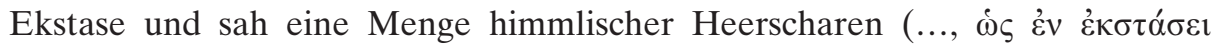

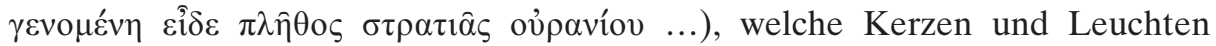
hielten und $\mathrm{zu}$ ihr sagten, dass sie sie im kommenden Jahr von diesem Ort wegführen und in die für sie vorbereitete Ruhe mitnehmen werden. Und so

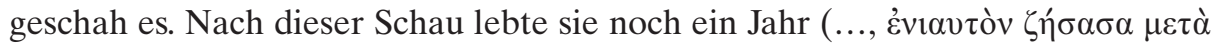

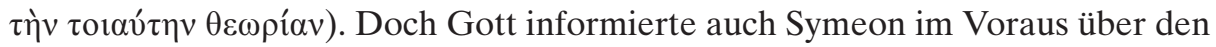

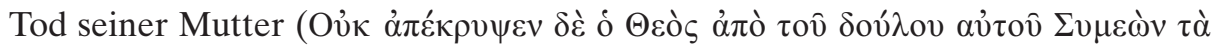

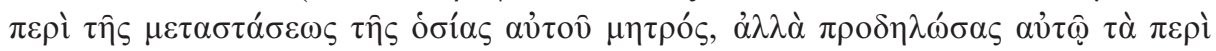
$\alpha \hat{\tau} \tau \hat{\jmath}, \ldots)$.

225. ViMa 12, Bd.2, p. 262,11-263,3: Drei Monate bevor Martha starb

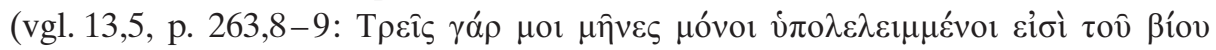

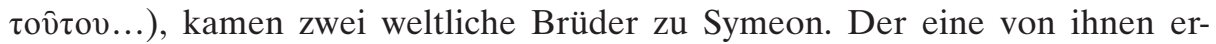
zählte, dass er am selben Tag in einer nächtlichen Vision die Heilige Martha

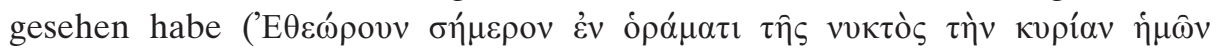

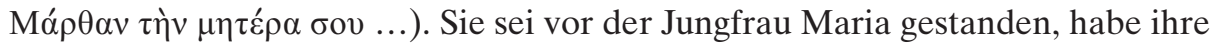
Hände ausgestreckt und sich vollständig in ein Kreuz aus Gold und Silber verwandelt, welches wie die Sonne Lichtstrahlen aussandte. Über dem Kreuz war bloß ihr Gesicht zu erkennen, ihr Körper erschien aber gänzlich in die Gestalt eines Lichtkreuzes verwandelt.

226. ViMa 15, Bd. 2, p. 264,5-16: Symeon rief seine Lieblingsbrüder zu sich und erzählte ihnen, dass Martha auf jeden Fall bald in den Himmel fahren werde. Er habe nämlich in einer nächtlichen Vision gesehen, wie für sie vor ihm ein Thron

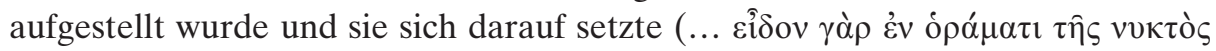
...). Und sie, die Brüder, drängten sich an Martha wie Kinder und wurden von ihr belehrt, dass jener (Symeon) ein seliger Mann sei, der niemals unter den 
Ungläubigen gewandelt oder auf dem sündhaften Weg gestanden habe. Danach habe sie jeden Bruder einzeln geküsst und sich selbst Gott übergeben. Sie sei aufgestanden und sei mit dem Kreuz in der Hand vor Symeon auf die mandra ${ }^{752}$ geschwebt.

227. ViMa 17-21, Bd. 2, p. 265,1-269,8: Martha sah bei Symeon Männer aus dem Dorf Charandama stehen, welche sich in der Kirche des Jason versammelt

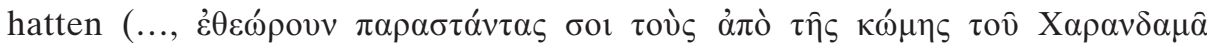

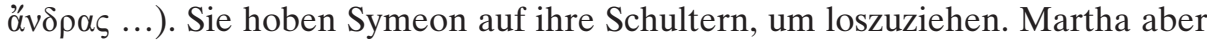
folgte ihnen und fragte Symeon, was es zu bedeuten habe, dass er von Bauern weggetragen werde. Er antwortete, sie solle sich keine Sorgen machen, da diese

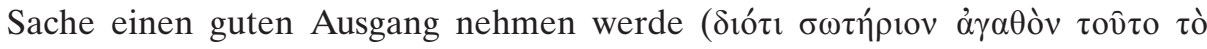

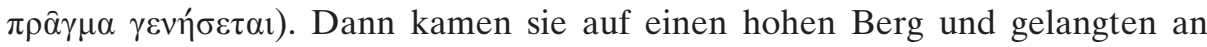
einen Ort, der, wie sie erkannte, die Gestalt der heiligen mandra $^{753}$ hatte. Sie staunte und wurde gleichsam in die himmlischen Lüfte gehoben ([1] ..., кaì

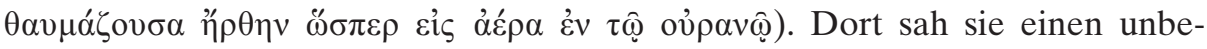

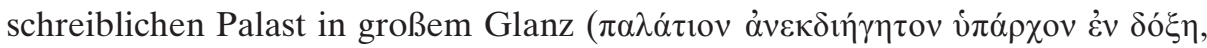
...). Martha ruhte sich aus und staunte über diese nicht von Menschenhand

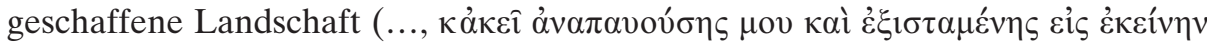

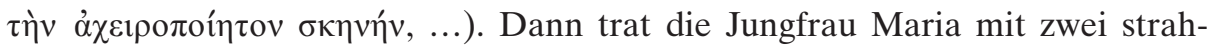
lenden Engeln zu ihr und fragte sie, warum sie staune, worauf Martha antwortete, dass sie auf der Erde niemals einen solchen Glanz gesehen habe. Als sie sagte, sie wisse nicht, wem diese große Gnade zugedacht sei, wurde sie von der Gottesmutter gefragt, ob sie nicht die ihr von vornherein zugewiesene Gunst erkenne, in der sie von nun an bis in alle Ewigkeit bleiben werde. Denn dies sei der Palast, den Marthas Sohn im Himmel erbaut habe. Dann neigte sie sich den beiden Engeln zu, die einen Schleier in die Mitte des Palastes legten. Zu Martha sagte sie, dass ihr diese Gnade geschenkt worden sei, weil sie Gott gefürchtet und seine Kirche geehrt habe. 18, Bd. 2, p. 266,11-267,2: Da die Seele Marthas durch diese Worte gestärkt wurde, sagte die Mutter Gottes zu ihr, sie werde noch mehr davon sehen. Dann wurde sie in die Höhe der Lüfte gerafft wie in

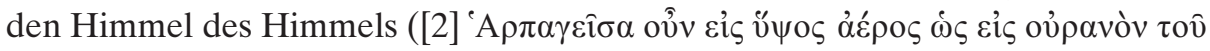
oủpavov̂ ...) und erblickte einen weiteren Palast, der den ersten noch übertraf. Die theotokos aber stärkte sie und sagte ihr, dass dieser Palast von ihrem Sohn, Symeon, erbaut worden sei, der überdies angefangen habe, die Grundsteine für einen dritten Palast zu legen. Und wiederum führte sie Martha in der Kraft des Geistes in Richtung Osten und zeigte ihr aus der Höhe das Paradies und die Wohnstätte jener, die durch Mitleid fromm waren, und der gottesfürchtigen Frauen und Männer. Nun solle Martha aber mit Hilfe der hier stehenden Ma-

752 Eine geschlossene Umzäunung, in der sich Symeons Säule sowie die Behausungen seiner Anhänger und eine Kapelle befand, s. Van den Ven, La vie ancienne, Bd. 1, 189*.

753 S.o. A. 752. 
schine ( $\mu \eta \chi \alpha v \eta ́)$ hinunterfahren und wieder auf die Erde zurückkehren. Und als Martha aufblickte, sah sie vor sich eine Maschine auf der Erde stehen, deren Kopf bis in den Himmel reichte und deren Flanken sie mühelos herunterbe-

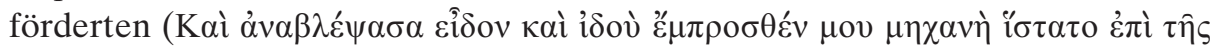

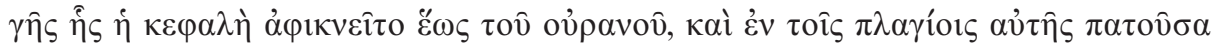

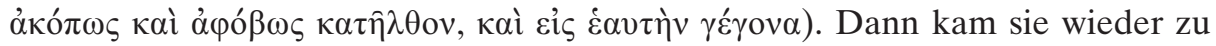

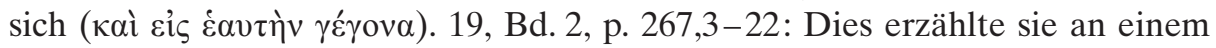
Sonntag. Von nun an tröstete sie Symeon, indem sie ihm erzählte, wie es später, im anderen Leben sein werde. 21, Bd. 2, p. 268,19-269,8: Martha erzählte Symeon, dass ihr Flügel zum himmlischen Aufgang gewachsen seien, so wie sie auch ihn in einer Vision in seiner Kindheit habe hinauffliegen sehen (Ai

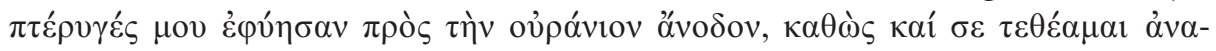

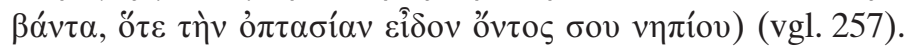

228. ViMa 28, Bd. 2, p. 274,3-20: Nachdem Martha gestorben war, wurde sie auf ihren Wunsch hin an einem Ort namens Elephantos bestattet. Nach drei Tagen sah Symeon, der bisher noch nichts vom Tod seiner Mutter erfahren hatte, in einer nächtlichen Vision auf der rechten Seite in seinem Rocksaum den

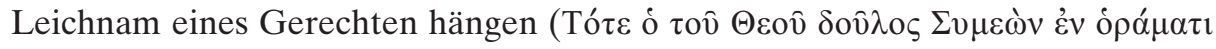

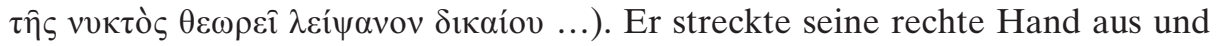
sprach den Segen. Dann rief er einige seiner Brüder herbei und teilte ihnen mit, dass seine große Herrin entschlafen sei. Ein gewisser Paulos bat Symeon, er möge ihm erlauben, für Martha einen Sarg aus Stein zu hauen. In 29, Bd. 2, p. 274,21-22, erscheint ein Bauer, um Symeon mitzuteilen, dass Martha tatsächlich gestorben war.

229. ViMac 15,12-22, p. 192: Als sich Gregor von Nyssa auf dem Weg zum Kloster seiner Schwester Makrina in Annisa im Pontos befand und noch eine Tagesreise von seinem Ziel entfernt war, erschien ihm im Traum ein Gesicht, das in ihm schreckliche Zukunftsahnungen hervorrief. Es schien ihm nämlich, dass er die Reliquien von Märtyrern in den Händen hielt und dass von diesen ein Glanz ausging wie von einem reinen Spiegel, der das Licht der Sonne reflektiert, so dass seine Augen von der Helligkeit dieses Lichtes geblendet wurden. Und obwohl Gregor in derselben Nacht dreimal das gleiche Gesicht hatte, konnte er das Rätsel des Traumes nicht entschlüsseln. Dennoch sah er in seiner Seele ein trauriges Ereignis voraus und wartete den Ausgang der Geschehnisse

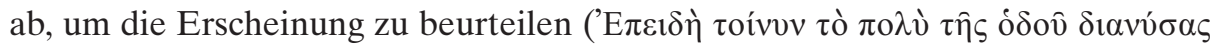

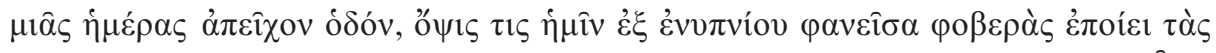

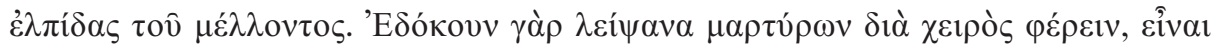

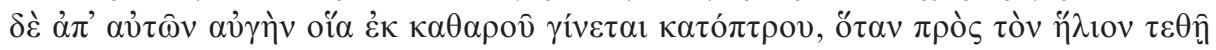

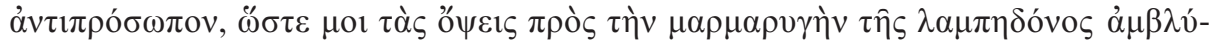

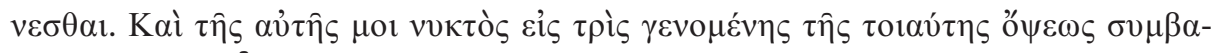

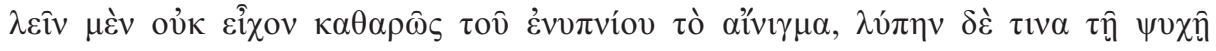

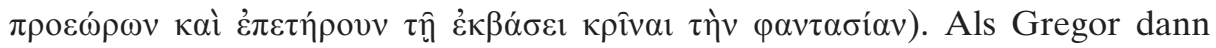


beim Kloster ankam, fand er seine Schwester schwer krank auf dem Sterbebett liegen. 19,11-16, p. 202: Und Gregor war betrübt, denn das Traumgesicht schien ihm durch das, was er erblickte (nämlich die kranke Makrina), das Rätsel zu enthüllen. Was er sah, war nämlich in der Tat die Reliquie eines heiligen Märtyrers, die tot war durch die Sünde, jedoch durch die ihr innewohnende Gnade des Geistes hell leuchtete. Gregor erzählte dies auch einem von denen, die

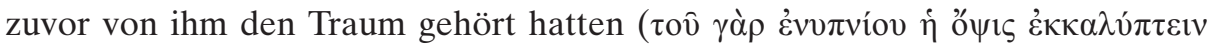

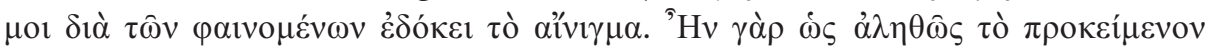

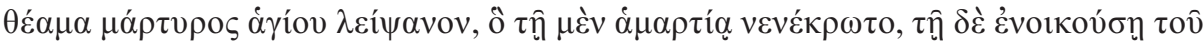

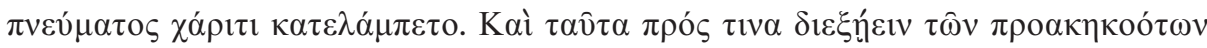

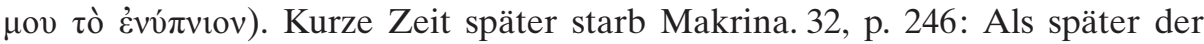
Leichnam von Makrina geschmückt wurde, erstrahlte ihr Körper genau so, wie

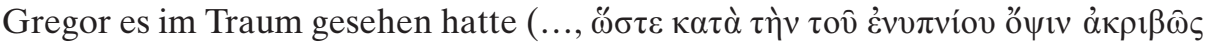

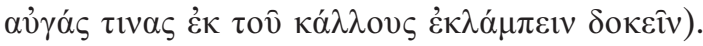

230. PaThI 3,13,1-14, p. 77,26-78,8: Pachomios machte sich auf den Weg, um einem sterbenden Bruder in einem anderen Kloster die letzte Ehre zu erweiesen. „Als er ungefähr zwei Meilen vom Kloster entfernt war, hörte er eine

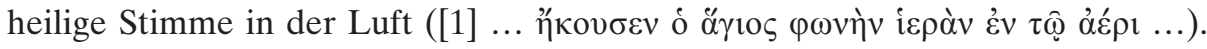
Und als er den Kopf hob, sah er die Seele des kranken Bruders mit den Engeln

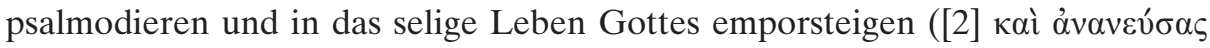

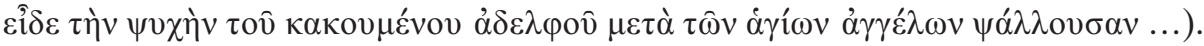
Die anwesenden Brüder aber hörten und sahen nichts davon" (Oi $\delta \grave{\varepsilon} \alpha \dot{\alpha} \kappa o \lambda o v$ -

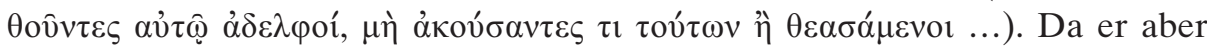
stehen blieb und lange Zeit gebannt in den Osten starrte, fragten ihn die an-

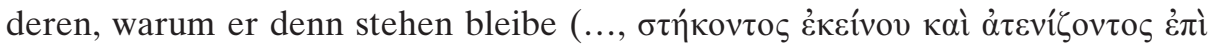
$\pi \mathrm{o} \lambda \dot{v} \kappa \alpha \tau \grave{\alpha} \alpha \dot{\alpha} \alpha \tau o \lambda \grave{\alpha} \varsigma . .$.$) . Wenn sie nämlich den kranken Bruder noch lebend$ antreffen wollten, müssten sie nun schnell weitergehen. Pachomios jedoch erwiderte, dass sie ihn dort nicht mehr antreffen würden. Sein Blick sei nämlich auf ihn gerichtet, und er sei gerade dabei, in das ewige Leben einzugehen ( $\alpha$ v่ $\hat{\emptyset}$

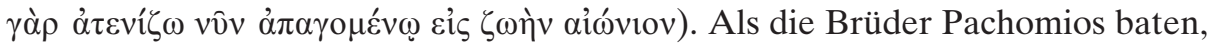
ihnen zu erzählen, wie er die Seele des verstorbenen Bruders gesehen habe, sagte er es ihnen. Und tatsächlich war der Bruder zu eben jener Stunde, als Pachomios seine Seele aufsteigen sah, verstorben.

231. ViSa 41, p. 131,19-132,19: Bruder Iakobos wurde schlimm vom Dämon der Unzucht belästigt. So sehr brannte die körperliche Begierde in ihm, dass er ein Messer nahm und sich die Hoden abschnitt. „Doch er ertrug den Blutfluss und die Schmerzen nicht und rief seine Nachbarn zu Hilfe. Diese holten einen Arzt aus der Laura, der sich um Iakobos kümmern sollte. Da Sabas erkannte, dass Iakobos zum Selbstmörder geworden war, vertrieb er ihn aus der Laura. Darauf nahm ihn Theodosios in seinem Kloster auf. Und nachdem er ihn angehört hatte, ging er mit ihm zur Laura und bat Sabas, Iakobos wieder aufzunehmen. Sabas aber trug ihm auf, in der eigenen Zelle Hesychase zu betreiben 
und weder hinauszugehen, noch irgendjemanden, außer seinen Gehilfen, aufzunehmen. Iakobos befolgte dies und betete während langer Zeit unter Tränen

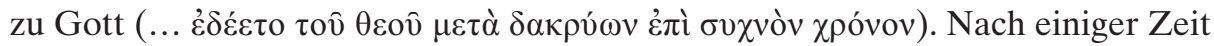

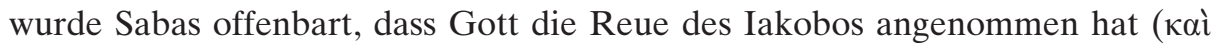

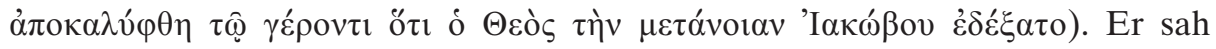
nämlich einen lichtdurchfluteten Mann, der ihm einen Leichnam zeigte, welcher

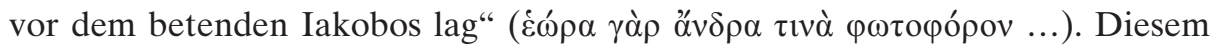
wurde gesagt, dass sein Gebet erhört wurde. Er solle nun seine Hand ausstrecken und den Leichnam aufstellen. Als Iakobos dies getan hatte, sagte der Leuchtende zu Sabas: „Sieh, der Leichnam ist auferstanden“. Er solle nun auch die Kette von dem, der stehe, lösen. Nachdem Sabas wieder zu sich gekommen war und die Vision beurteilt hatte, ließ er Iakobos in die Kirche rufen und allen

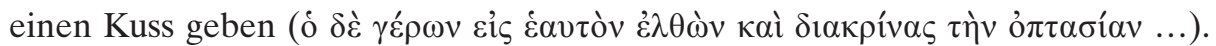

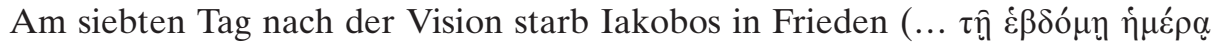

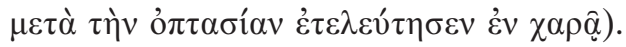

232. ViSa 76, p. 182,12-14: „Unser Vater Sabas sah eine Offenbarung, welche ankündigte, dass er in wenigen Tagen sterben werde“ (... ả

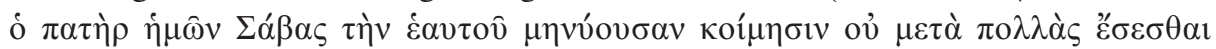
$\dot{\eta} \mu \dot{\varepsilon} \rho \alpha \varsigma)$.

233. ScPa 7, PG 88, col. 812C: Stephanos, der am heiligen Berg des Sinai lebte, wurde im Alter von einer Krankheit befallen, die ihm sein Ende brachte. „Ein Tag vor seinem Hinscheiden wurde er im Geist entrückt. Mit offenen Augen

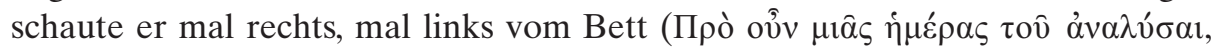

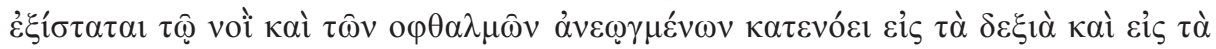

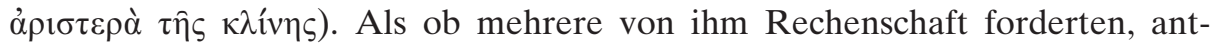
wortete er laut, sodass es alle Anwesenden hörten: ,Ja, wirklich, das ist wahr, doch ich habe so viele Jahre dafür gefastet‘. Dann wieder sagte er: ,Nein, ihr lügt, das habe ich nicht getan'. Und wieder: Ja, fürwahr, dies ja, doch habe ich geweint und Dienst geleistet‘. Dann sagte er: ,Ja, ihr habt recht, mich anzuklagen“ oder ,Ja, dagegen habe ich nichts einzuwenden'. Es war ein wirklich schauerliches und furchterregendes Mitverfolgen eines unsichtbaren und gna-

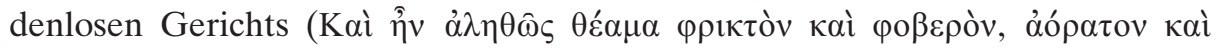

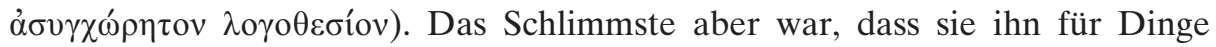
beschuldigten, die er nicht verbrochen hatte".

234. ViSyStI 30, p. 70,16-72,8 (Gruppe 1 der Hss.): Der Autor schildert, dass er fünf, sechs Tage vor dem Tod des Symeon einen Mann in einem furchteinflössenden Gewand sah, das er nicht zu beschreiben in der Lage sei (... غ $\dot{\varepsilon} \theta$ -

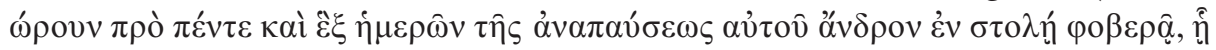

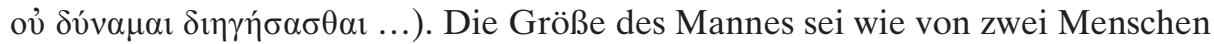

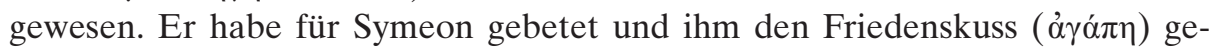
geben. Eigentlich habe er manchen darüber erzählen wollen, doch sein Geist sei entrückt worden, und er sei daran gehindert worden, davon zu erzählen, bevor 


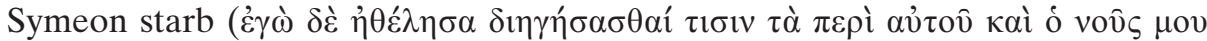

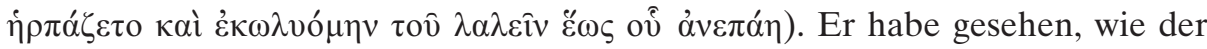
erwähnte Mann zu Symeon kam und wie sie zusammen aßen. Was sie aßen, wusste er jedoch nicht. Dann haben sie Psalmen gesungen, doch welche Psalmen sie sangen, wusste er nicht. Und beim Anblick des Mannes habe ihn Furcht

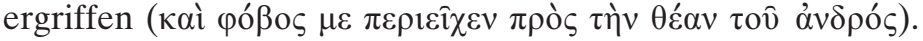

30 (Gruppe 2 der Hss.): Der Autor schildert, wie er während sieben Tagen jeden Tag um die zehnte Stunde einen Engel zu Symeon kommen sah, der mit ihm

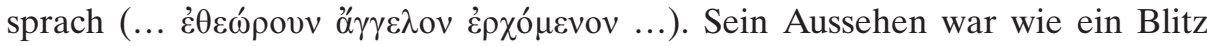
und sein Kleid war weiß wie Schnee, seine Stimme aber war Furcht und Zittern, und er verharrte jeweils bis zum morgendlichen Gebet. Und er sah sie essen, wusste aber nicht, woraus das Abendmahl bestand. Und als der Engel von ihm ging, sprach er mit sich selber, bis er in der Höhe unsichtbar wurde, und hielt dabei das Bildnis des Symeon fest. Er aber sei von Schlaf ergriffen worden und habe nicht mehr reden können.

235. ViSyStII 71, Bd.1, p. 60,25-62,3: Symeon sah sich durch die Kraft des heiligen Geistes am Bett des sterbenden Bischofs Ephraimios stehen ([1] Eî̉ov

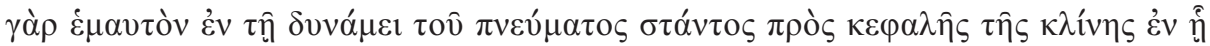

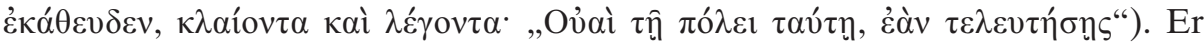
weinte und sagte: „Ohweh auf diese Stadt, wenn du stirbst!“. Und als er wieder zu sich kam, sah er, wie Tränen über seine Wangen rollten (Kaì $\dot{\varepsilon} v \dot{\varepsilon} \mu \alpha v \tau \hat{\emptyset}$

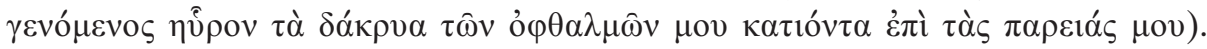

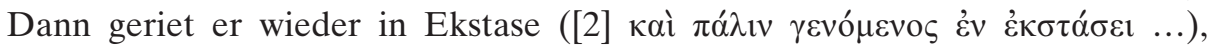
weinte und sagte dieselben Worte noch einmal. Dann sah er dies ein drittes Mal

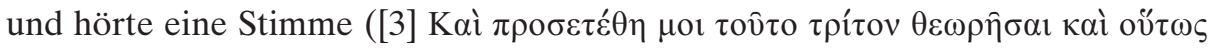

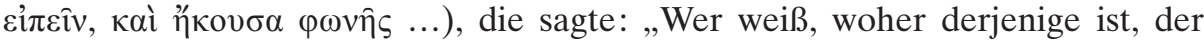
kommen wird“. Kurz darauf erzählte Symeon, Ephraimios sei gestorben. Er habe seine Seele hier gesehen ( raimios habe ihn mit einer Menge von Weißbekleideten begrüßt und ihm aufgetragen, sich in seinen Gebeten an ihn zu erinnern. Er habe auch gesagt, dass er zu Symeon gekommen sei, damit dieser wisse, dass die große Säule der Kirche von Antiocheia zerbrochen sei. Nachdem er dies gesagt habe, sei Eph-

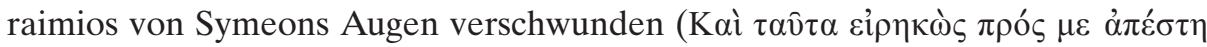
$\tau \hat{\omega} v \dot{o} \varphi \theta \alpha \lambda \mu \hat{\omega} v \mu \mathrm{ov})$.

236. ViThSy 32, Bd.1, p. 29,12-36: Kurz vor ihrem Tod sah Elpidia, die Großmutter des Theodoros, eines Nachts eine Vision, die sie ihrem Enkel er-

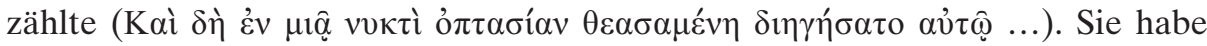
einen wunderschönen Jüngling in einem leuchtenden Kleid und mit gekrausten, goldglänzenden Haaren gesehen, welcher der Darstellung des Heiligen Märtyrers Georgios glich. Er trat an sie heran und verlangte, seine (des Theodoros) Lebensweise und den Kanon der Psalmodie zu erfahren. Als sie es ihm erzählte, übergab er ihr Worte für die Psalmodie und sagte, sie habe ein großes Glück, 
ihren Enkel auf einer so hohen Stufe erblickt zu haben. Von nun an werde sie ohne Sorgen sein, da der Eifer seiner Lebensweise auf sie übertragen werde. Kurz darauf starb Elpidia.

237. ViThSy 90, Bd. 1, p. 74,26-75,7: Theodoros empfing Theodora, die Frau des von ihm geheilten silentiarios (s.u. 286). Sie wollte vom Heiligen wissen, ob zuerst sie oder ihr Mann sterbe. „Nachdem sie ihn mit viel Mühe überredet

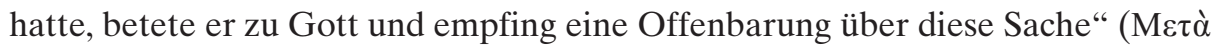

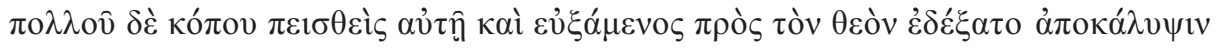

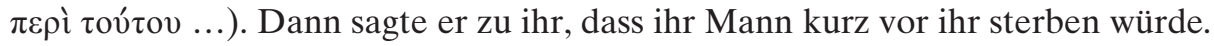
Darauf flehte sie den Heiligen jeden Tag unter Tränen an, er möge zu Gott flehen, dass sie nach dem Tod ihres Mannes schnell ins jenseitige Leben hinübergehen werde. Auch in dieser Sache betete Theodoros dafür, dass das Verlangen der Frau erfüllt werde. Durch eine göttliche Offenbarung unterrichtet

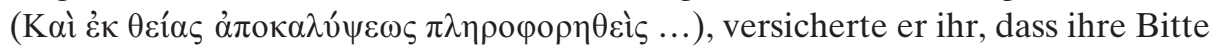
erhört worden sei, und dass sie nunmehr auf sich achtgeben solle, da sie in wenigen Tagen sterben würde.

238. ViThSy 119, Bd. 1, p. 95,24-96,21: Theodoros hatte eine Offenbarung über

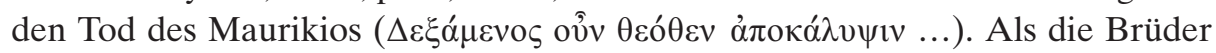

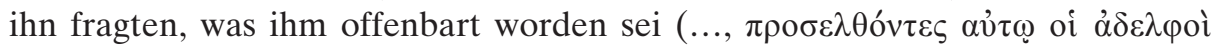

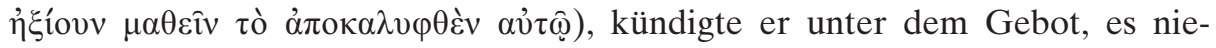
mandem weiterzuerzählen, den Tod des Maurikios an. Wenige Tage später (120, Bd. 1, p. 96,20-21) wurde Maurikios ermordet (602), und Phokas kam auf den Thron.

239. ViThSy 162, Bd. 1, p. 145,33-147,33: Dem Heiligen Theodoros „erschien in einer Nacht, als er sich in der Kirche der theotokos aufhielt, die Heilige

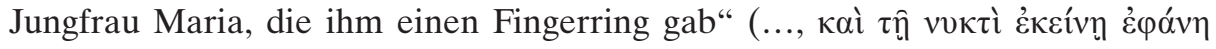

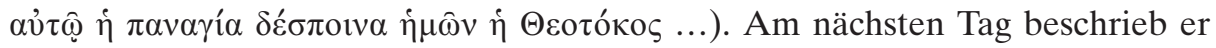
seinen Schülern während des Essens den Ring. Als diese ihn nach seiner Bedeutung fragten, sagte er, dass er die Bedeutung kenne, dass es aber unnütz sei, sie beim Essen zu erzählen, da sie Grund zur Trauer sei. Dann erzählte er schrittweise, mit großer Freude und Strahlen im Gesicht, dass er den Ring für ein gutes und leichtes Voranschreiten bekommen habe. Im selben Monat „legte sich Theodoros, von einer leichten Krankheit heimgesucht, in seiner Zelle hin, sodass man glaubte, dies wiederfahre ihm aus Müdigkeit vom nächtlichen Wa-

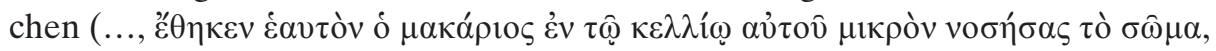

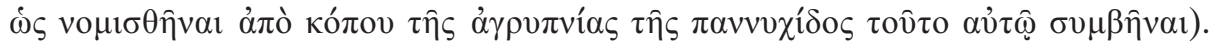
Dreizehn Tage verharrte er ohne zu essen und zu reden, schaute aber wie ge-

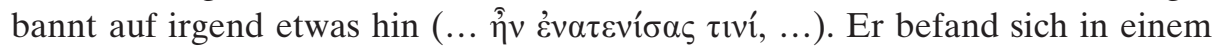
schlafähnlichen Zustand, und es blieb ihm nur noch der Atem, sodass alle weinten, weil sie glaubten, er habe sich schon vom diesseitigen Leben getrennt

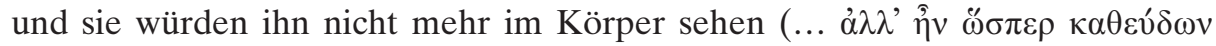

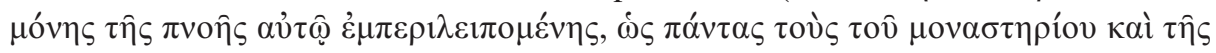




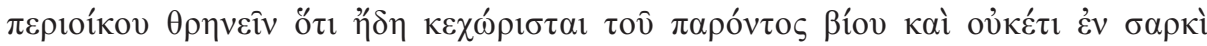

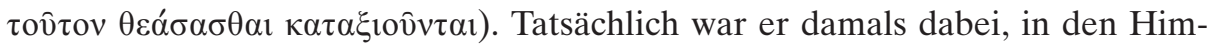
mel einzutreten und sich über seinen Anblick zu freuen, denn der Herr zeigte

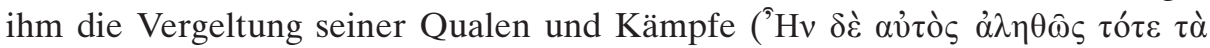

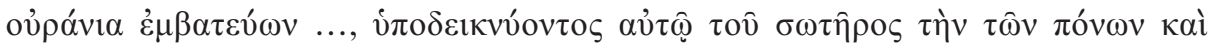

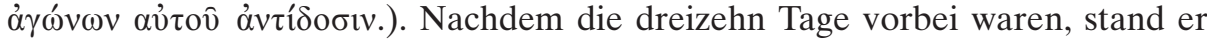
plötzlich von diesem hoffnungslosen Zustand auf, geradeso, wie er die Ge-

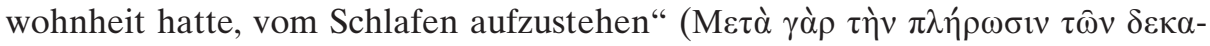

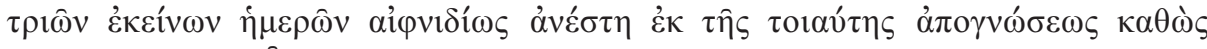

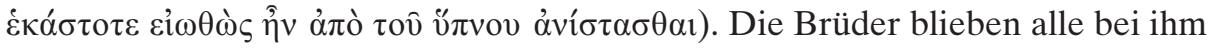
und schliefen in seiner Nähe, als er auf einmal anfing, sie aufzuwecken und anzuschreien. Dabei warf er ihnen vor, bei der Psalmodie unaufmerksam gewesen zu sein und sich der Faulheit und dem Genuss des Schlafes hingegeben zu

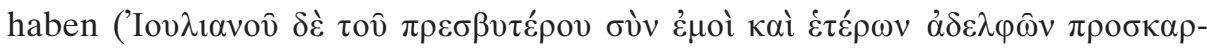

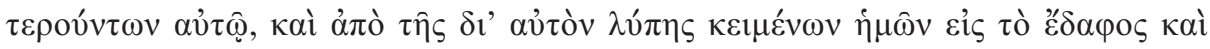

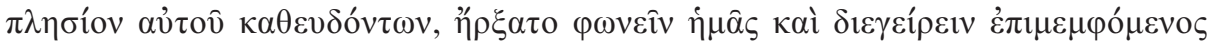

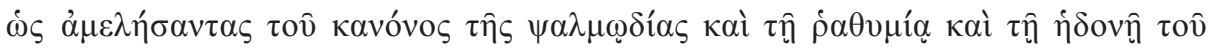

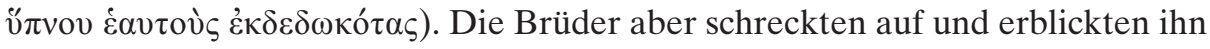
halb in Freude, halb unter Tränen, doch als sie seine Genesung sahen, priesen sie Gott. Sie erzählten ihm, in welch hoffnungslosem Zustand er sich befunden habe und welch unaussprechliche Trauer bei ihnen dadurch ausgelöst worden sei. Er antwortete, dass er all dies wisse. Dann nahmen sie ihn auf wie einen, der

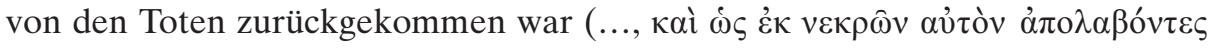

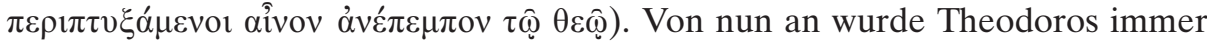
schwächer, denn er aß nichts mehr. „Wie sollte auch, wer schon von den himmlischen und ewigen Gütern gekostet hat, noch Lust auf vergängliche und irdische Speise haben?"Als die Brüder von ihm wissen wollten, wo er in jenen Tagen, als sie ihn als bereits Vestorbenen beweinten, hingegangen sei und was er

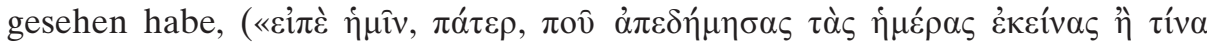

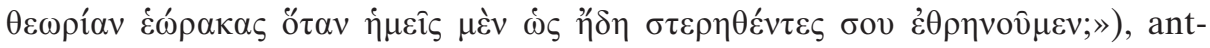
wortete er, er habe in den ganzen dreizehn Tagen, wo er nicht bei ihnen war, nicht von der Schau in den Himmeln abgelassen. „Doch als er anfing, von dieser Schau zu erzählen, wurde er von einem demütigen Gedanken ergriffen. Er fing an zu weinen, schlug sich mit den Fingern auf den Mund, wie wenn er sich Vorwürfe machen würde, bekreuzigte sich über den Lippen und flehte um

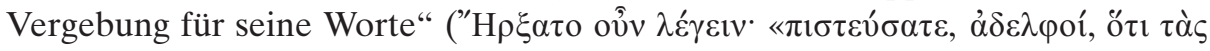

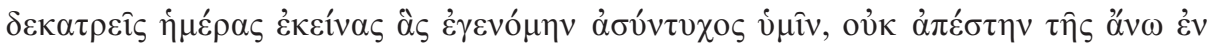

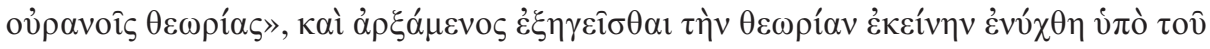

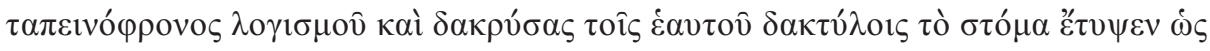

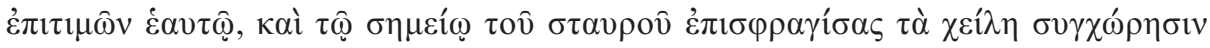

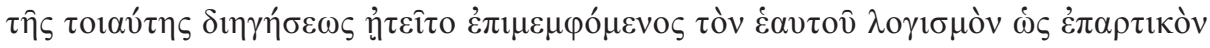

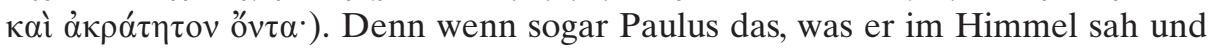


hörte, nicht preisgab, wie könne er Allerniedrigster es wagen, auf diese Weise große Worte zu machen. „Und nachdem er sich dies vorgeworfen hatte, ver-

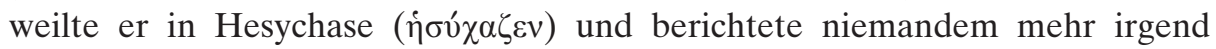
etwas".

240. ViThSy 167, Bd. 1, p. 154,27-155,23: Kurz vor seinem Tod erschien Theodoros eines Nachts im Schlaf der heilige Georgios ('Ev $\mu 1 \alpha \underline{\alpha} \delta \dot{\varepsilon} v v \kappa \tau \grave{~}$

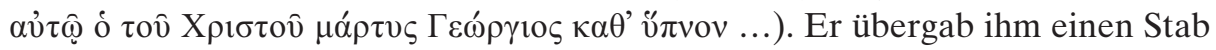
und forderte ihn auf, sich mit ihm auf den Weg zu machen. Dies erzählte Theodoros voller Freude den anderen Brüdern. Als man ihn fragte, was dies zu bedeuten habe, antwortete er, die Vision entspreche den zukünftigen Ereig-

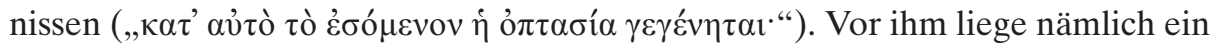
weiter Weg, und der heilige Georgios sei ihm wegen seiner Schwäche zur Unterstützung erschienen, habe ihm den Stab übergeben und ihn aufgefordert, sich zusammen mit ihm auf den Weg zu machen. In einer anderen Nacht erschien

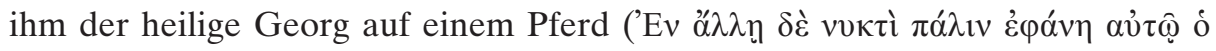

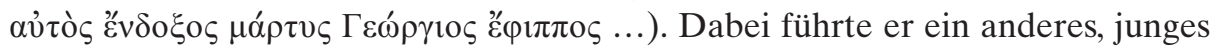
Pferd bei sich und sagte, er habe dies zu Theodoros' Diensten mitgebracht. Er soll es besteigen und ihm folgen. Und als Theodoros dies den Brüdern unter

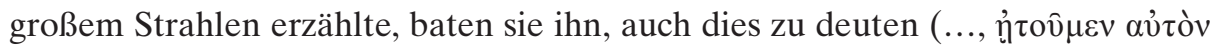

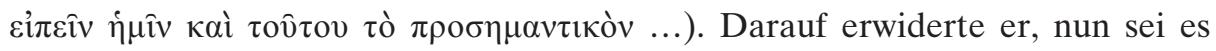

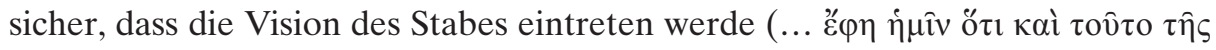

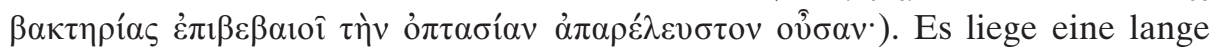
Reise vor ihm, und der heilige Georgios, der ihn seit seiner Kindheit ernährte, habe seine Reise vorbereitet.

\section{Weitere Informationen über Himmel, Hölle, Paradies und das göttliche Gericht}

241. ViAn 66,1-8, p. 308,1-310,13: Wenn Antonios ,alleine auf dem Berg saß und es geschah, dass er im Zweifel war über etwas, dann wurde es ihm während

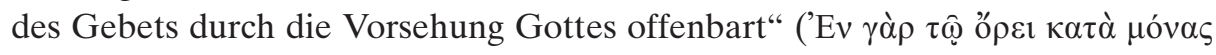

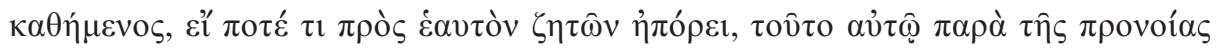
$\varepsilon \cup ̉ \chi 0 \mu \varepsilon ́ v \omega$ ả $\varepsilon \kappa \alpha \lambda u ́ \pi \tau \varepsilon \tau o)$. „[...]. Einmal diskutierte er mit seinen Besuchern über den Zustand der Seele und über den Ort, wo sie sich später aufhalten werde. In der folgenden Nacht rief ihn jemand aus der Höhe an: ,Antonios, steh

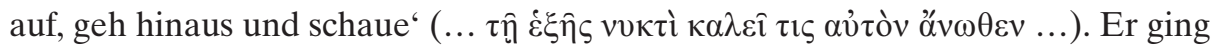
hinaus, denn er wusste, wem er zu gehorchen hatte. Dann erhob er die Augen

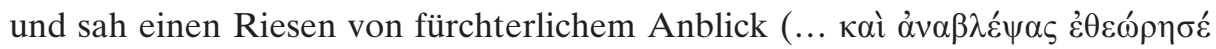

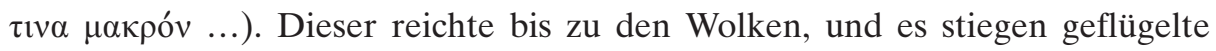
Wesen in die Höhe. Der Riese streckte seine Hände aus und hinderte die einen 
am aufsteigen. Die anderen aber flogen über ihn hinaus, ließen ihn hinter sich und wurden ungestört in die Höhe geführt. Gegen diese knirschte der Riese mit den Zähnen, über die Gefallenen aber freute er sich. Und auf einmal kam eine Stimme zu Antonios, die sagte: ,Versteh, was du siehst!' [Dan 9,23]. Dann wurde sein Geist geöffnet [Lk 24, 31], und er verstand, dass dies der Übergang der Seelen war und dass der Riese der Feind war, der die Frommen beneidet und seine Günstlinge am Vorbeigehen hindert, der aber jene, welche sich von ihm nicht haben überzeugen lassen, nicht zurückhalten kann. Nachdem er dies gesehen hatte, bewahrte es Antonios in seiner Erinnerung und kämpfte jeden

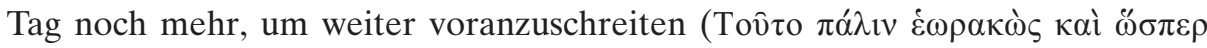

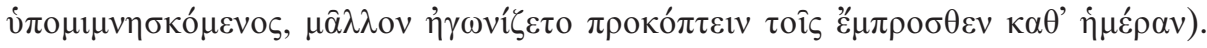

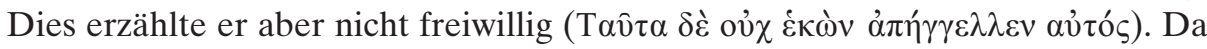
er anfing, sich beim Gebet zu verspäten und sich über sich selber zu wundern, fragten ihn die Anwesenden und zwangen ihn zu reden, so wie ein Vater seinen Kindern nichts verbergen kann. Überdies dachte er, dass sein Gewissen rein sei und dass diese Erzählung nützlich sei, um zu lernen, dass Visionen oft Trost für

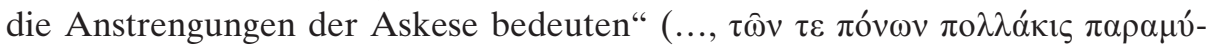

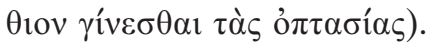

242. ApAl, Jugie 249: Der selige Paulos erzählte über einen seiner Schüler, dass dieser in vielerlei Sünden gefallen sei, ohne dass er davon wusste. Dann geschah es, dass der Schüler starb und Paulos die heilige theotokos anflehte, sie möge ihm zeigen, wo der Schüler seit seinem Hinscheiden weile. Nachdem Paulos zahlreiche Tage betend verbracht hatte, geriet er in Ekstase (Kaì $\pi \rho 0-$

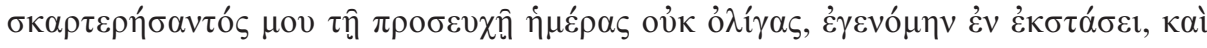
$\theta \varepsilon \omega \rho \hat{\omega} . .$.$) und sah, wie sein Schüler von zwei Unbekannten getragen wurde. Er$ war von Kopf bis Fuß zu einer Muschel (ő блрккоv) geworden und hatte keinerlei Energie mehr, weder seelisch noch körperlich. Er sprach auch nicht, sondern war wie versteinert. Paulos fürchtete sich und wurde gleichsam von

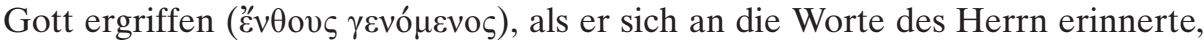
der sagte: „Wer kein Hochzeitskleid trägt, dem bindet die Hände und die Füße und werft ihn in die Dunkelheit, die draußen ist. Dort wird Heulen und Zähneknirschen sein" (Mt 22,12 f.). Das Binden von Händen und Füssen will uns nichts anderes andeuten als das Auslöschen und das Nicht in die Tat Umsetzen von jedem schlechten Gedanken und Einfall, der nicht gemäß dem Willen Gottes in diese Welt gekommen ist. Als Paulos aus der Ekstase erwachte fing er

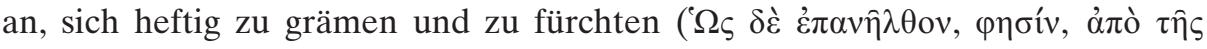

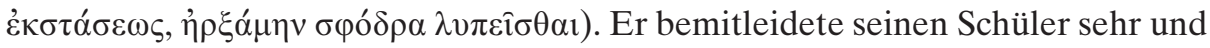
ersuchte die theotokos, diesen zu retten und Gott für ihn zu bitten.

243. ApAl, Poimen 144, PG 65, col. 357B: Abbas Isaak ging einmal zu Poimen

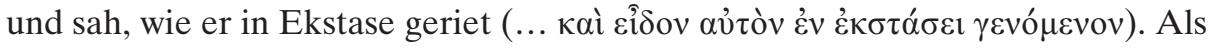
er ihn fragte, wo er war, erwiderte er, dass seine Gedanken da waren, wo die

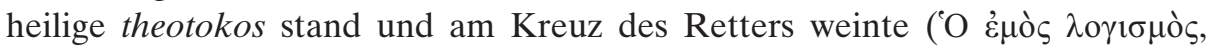




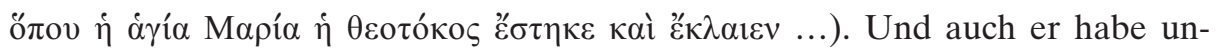

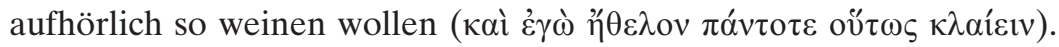

244. ApAl, Siluanos 2, PG 65, 408D: Abbas Siluanos „,saß einmal mit Brüdern zusammen, als er in Ekstase geriet und aufs Gesicht fiel ('O $\alpha$ vò $\varsigma \kappa \alpha \theta \varepsilon \zeta o ́ \mu \varepsilon v o ́ \varsigma$

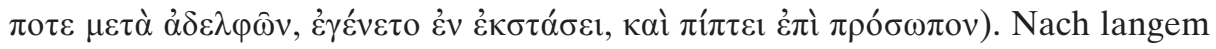

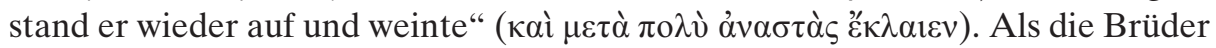
ihn fragten, was mit ihm los sei, antwortete er, er sei vors Gericht gezerrt

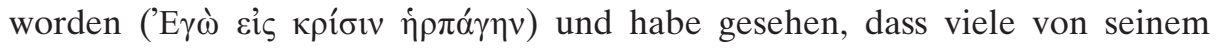
Geschlecht (von den Asketen) in die Hölle heruntergingen und viele von den Weltlichen ins Königreich eintraten. „Deshalb trauerte der Mönch und wollte seine Zelle nicht mehr verlassen“.

245. ApAl, Siluanos 3, PG 65, col. 409A: „Einmal trat der Schüler Zacharias bei Siluanos ein und fand ihn in Ekstase mit zum Himmel erhobenen Armen

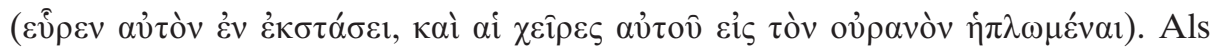
Zacharias dies sah, ging er hinaus und schloss die Tür. In der sechsten und in der siebten Stunde kam er wieder und fand Siluanos noch immer in der gleichen Position. Als er in der zehnten Stunde anklopfte und hineinging, befand sich Siluanos in Hesychase ( $\dot{\sigma} \sigma \chi \chi \alpha ́ \zeta o v \tau \alpha)$. Zacharias fragte ihn:, Was ist heute mit dir los?‘ Siluanos antwortete: ,Ich bin heute krank gewesen, Junge““. Der Schüler aber umklammerte seine Füsse und drohte, ihn solange nicht in Ruhe zu lassen,

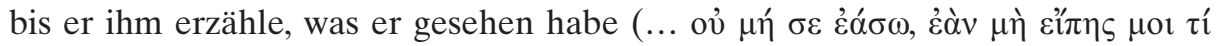
$\varepsilon \hat{\imath} \delta \varepsilon \varsigma . .$.$) . Erst jetzt sagte Siluanos, dass er in den Himmel entrafft worden sei,$ den Glanz Gottes geschaut und sich bis eben gerade dort befunden habe (... عis

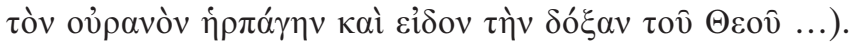

246. ApSy III 48; Bd. 1, p. 176: „Eines Nachts klagte ein Greis, der nicht wusste, dass sein Schüler ihm zuhörte, bitterlich, knirschte mit den Zähnen und weinte“. Auf das Bitten seines Schülers hin erzählte er, dass er in den Hades heruntergeführt worden sei und die Seelen der Sünder und ihre Qualen gesehen habe.

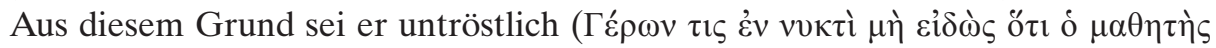

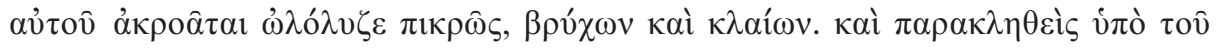

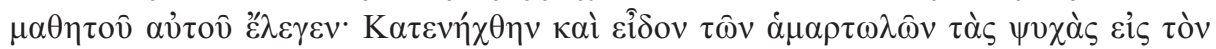

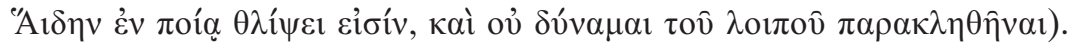

247. HiLa 14, p. 37,12-39,10: Zwei Brüder wurden nach dem Tod ihres Vaters Mönche, aber auf grundverschiedene Weise. Der eine schenkte seinen ganzen Besitz an Kirchen und übte sich in Enthaltsamkeit und Gebet. Der andere gründete ein Kloster und kümmerte sich um Arme und Alte. Nach dem Tod der beiden Brüder wollten einige erfahren, welcher der beiden frommer gewesen sei. Sie gingen zu Abbas Pambo, um ihm das Urteil anheimzustellen. Dieser sagte, beide seien vollkommen, denn der eine habe in seinem Lebenswandel Abraham nachgeahmt, der andere Elias. Als sie sich mit dieser Antwort noch immer nicht zufrieden gaben, sagte Pambo, sie sollen solange warten, bis ihm

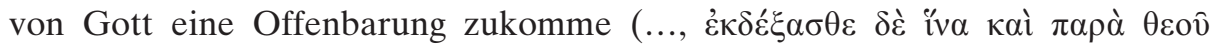




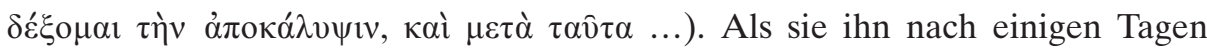
wieder aufsuchten, erzählte er, dass er beide zusammen vor Gottes Angesicht

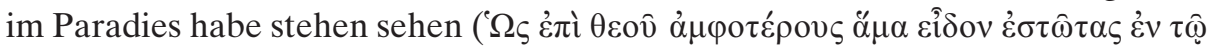
$\pi \alpha \rho \alpha \delta \varepsilon i ́ \sigma()$.

248. HiLa 18, p. 49,9-51,4 (vgl. 252): Von Makarios dem Alexandriner wird erzählt, dass er sich auf den Weg zum Grab im Garten der Zauberer Ianes und Iambre machte, welche zu Zeiten des Pharaos große Macht besessen hatten. Sie hatten damals ihre eigenen Grabkammern vorbereitet und darin viel Gold hinterlassen. Außerdem hatten sie Bäume angepflanzt und einen Brunnen gegraben. Da Makarios den Weg dorthin nicht kannte, richtete er sich nach den Sternen, nahm Schilfrohr mit und steckte nach jeder Meile ein Rohr in den Boden, um dadurch den Heimweg wieder zu finden. Nach neun Tagen näherte er sich dem Garten. Doch als er ungefähr eine Meile vom Grabmal entfernt war und einschlief, sammelte der Teufel das Schilfrohr und legte es neben seinen Kopf. Außerdem griffen ihn siebzig heulende Dämonen aus dem Garten an. Sie schlugen wie Raben mit den Flügeln gegen sein Gesicht und fragten ihn, was er hier suche, denn er könne nicht hier bleiben. Er sagte, er wolle nur eintreten, sich umschauen und wieder hinausgehen. Dies tat er, und als er wieder auf dem Heimweg und schon seit zwanzig Tagen unterwegs war, wurde seine Wegzehrung knapp, sodass er in große Not geriet. „Und als er kurz davor war, zusammenzubrechen, erschien ihm ein Mädchen in schimmernd weißem Gewand

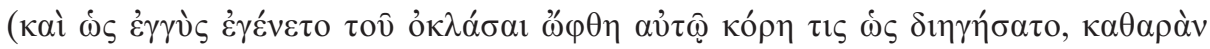

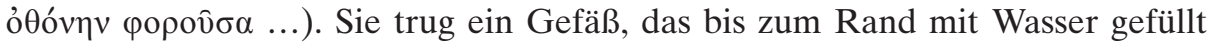
war. Drei Tage lang ging sie etwa ein stadion vor ihm her, und auch wenn es ihm schien, sie bleibe stehen, war es unmöglich, sie einzuholen. Jedoch gab ihm die Hoffnung, trinken zu dürfen, ständig neue Kraft“". Und dann sah er ein Rudel Gazellen. Eine von ihnen führte ein Junges bei sich, und aus ihrem vollen Euter tropfte Milch. Makarios trat an sie heran und trank, bis er satt war.

249. HiLa 21, p. 69,4-16: Der heilige Antonios erzählte eines Nachts, dass er ein volles Jahr betete, damit ihm der Ort der Gerechten und der Sünder gezeigt

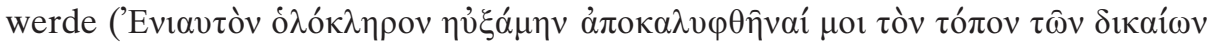

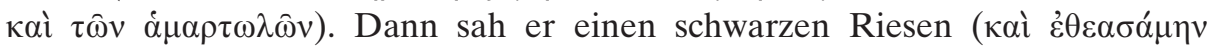
$\mu \alpha \kappa \rho o ́ v \tau \imath v \alpha$...) von so gewaltiger Größe, dass er bis an die Wolken reichte. Die Hände hielt er in den Himmel gestreckt, und unter ihm lag ein See, so groß wie das Meer. Antonios sah die Seelen emporfliegen wie Vögel, und alle, die über Haupt und Hände des Riesen gelangten, waren gerettet. All jene aber, die er mit den Händen ergreifen konnte, fielen in den See. Dann rief der Riese Antonios zu, dass jene, die höher fliegen, die Seelen der Gerechten seien, die ins Paradies gelangen. Die anderen aber werden in die Hölle geworfen, da sie den Gelüsten des Fleisches gefolgt und rachsüchtig gewesen seien.

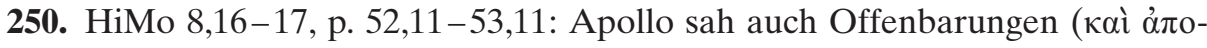

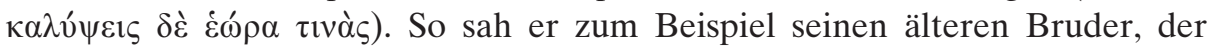


früher ebenfalls in der Wüste lebte und eine noch bessere Lebensweise als er vorzuweisen hatte, inzwischen aber tot war. Dieser Bruder erschien ihm nun im Schlaf, wie er neben den Aposteln auf dem Thron saß und ihm das Erbe seiner

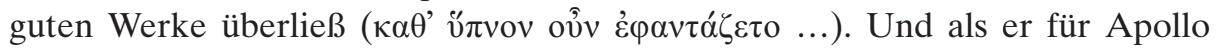
einstand und Gott bat, für ihn schnell den Übergang zu vollziehen, um mit ihm in die Himmel aufzusteigen, sagte der Retter zu ihm, dass sein Bruder noch ein wenig Zeit auf Erden verbringen müsse, nämlich solange, bis viele andere seine

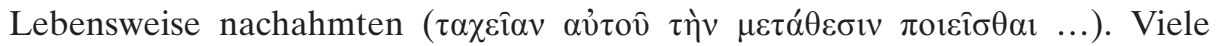
Menschen und ein frommes Heer sollten sich ihm anvertrauen, damit ihm der Wert seiner Mühen vor dem Herrn vergolten werde. Dies sah er, und so geschah

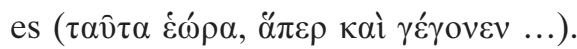

251. HiMo 10, 20, p. 84,1-12: Patermuthios „erzählte seinen Brüdern, dass er, als er aus der Wüste zurückkam, in einer Vision in die Himmel emporgehoben wurde und alles Gute sah, was die Mönche dort an Unaussprechlichem erwarte

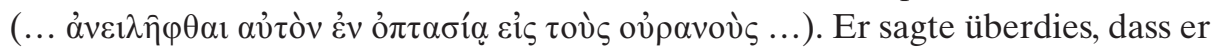
im Körper ins Paradies geführt wurde, wo er eine Schar von Heiligen erblickte

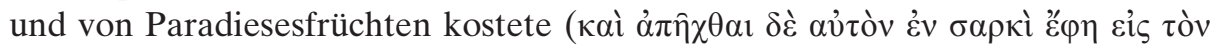

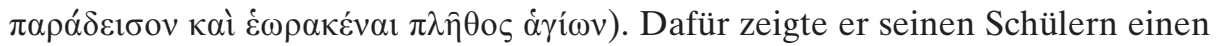
Beweis, denn er brachte ihnen eine große und wohlriechende Feige, um die Wahrheit seiner Erzählung zu beweisen. Diese Feige hielt auch der Priester Kopres, der dies erzählte und damals noch jung war, in den Händen“.

252. HiMo 21,5, p. 125,3-126,8 (S.u. 248): Makarios „fastete intensiv und betete zu Gott, er möge ihm das Paradies zeigen, das Iannes und Iambres in der Wüste angelegt hatten, weil sie ein Abbild des wahren Paradieses schaffen wollten. Nachdem er drei Wochen ohne zu essen in der Wüste umhergeirrt und schon

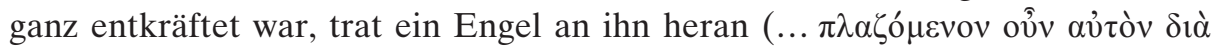

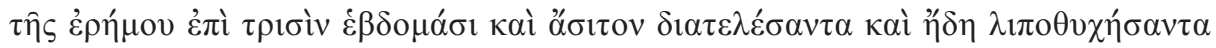

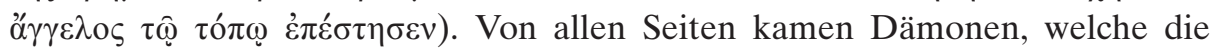

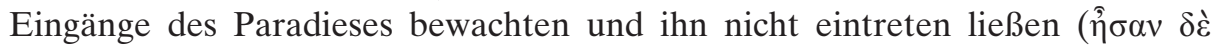

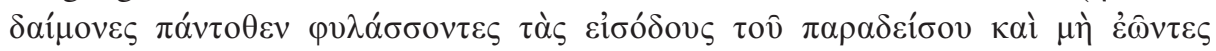

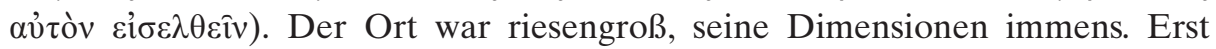
nachdem Makarios gebetet hatte, wagte er einzutreten. Drinnen fand er zwei heilige Männer, die selber schon vor langer Zeit auf die gleiche Weise hier-

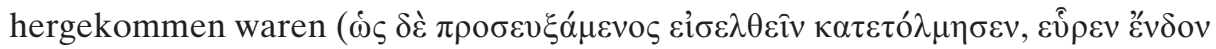

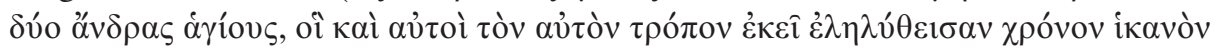
$\eta \nmid \delta \eta \varepsilon ้ \chi 0 \vee \tau \varepsilon \varsigma)$. Sie beteten und umarmten einander. Makarios wuschen sie die Füsse und reichten ihm Paradiesesfrüchte, die er kostete. Voll Staunen über die Größe der Früchte und die Mannigfaltigkeit ihrer Farben dankte er Gott"

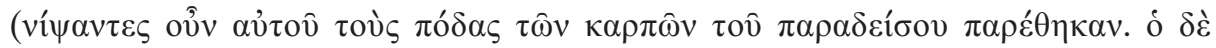

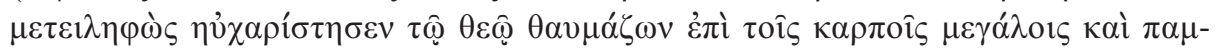

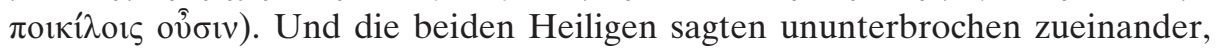
wie schön es wäre, wenn alle Mönche hierher kommen würden. Inmitten des 
Paradieses gab es drei große Quellen, die aus der Tiefe hervorsprudelten und den Garten tränkten, außerdem große Bäume, die jede Sorte von Früchten

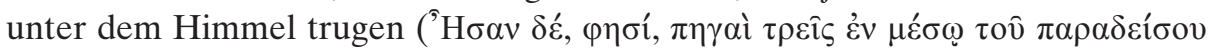

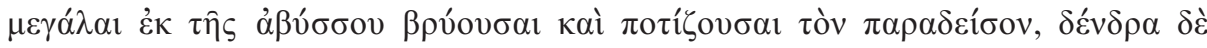

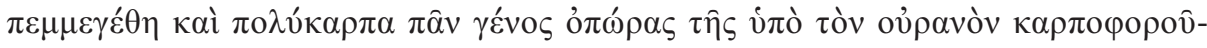
$v \alpha \tau \alpha)$. „Makarios blieb sieben Tage lang dort. Dann wollte er in das bewohnte Land zurückkehren, um die anderen Mönche zu holen und sie ebenfalls zum Paradies zu führen. Die Heiligen sagten aber, dass dies nicht möglich sei, da die Wüste ausgedehnt und groß sei und viele Dämonen beherberge, die die Mönche verführten und töteten. So seien auch schon zahlreiche andere auf dem Weg zum Paradies vernichtet worden. Makarios hielt es aber nicht aus, noch länger dort zu bleiben, denn er wollte unbedingt auch die anderen herbeibringen, um

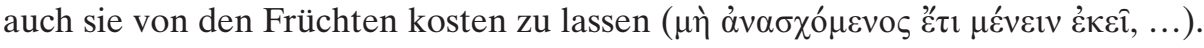
Auf dem Heimweg legte er Palmzweige in den Sand, um später den Weg wieder zu finden. Nachdem er aber ein wenig geschlafen hatte, fand er alle Zweige von den Dämonen neben seinem Kopf gesammelt. Da sagte er zu den Dämonen, dass sie die Mönche nicht daran hindern könnten ins Paradies zu gelangen, wenn dies der Wille Gottes sei. Als er wieder in die bewohnte Welt kam, brachte er den Brüdern als Beweis Früchte mit und versuchte, sie dazu zu bewegen, ihn ins Paradies zu begleiten. Da wurde er von einigen Vätern gefragt, ob sein Vorhaben nicht der Seele schade. Denn wenn sie sich schon jetzt über die Paradiesesfrüchte freuten, gingen die guten Werke auf Erden verloren. Sie fragten ihn, welchen Lohn sie denn noch erhalten und welche Werke ihnen noch vergolten werden könnten, wenn sie einst zu Gott eingehen werden. Auf diese Weise wurde Makarios davon überzeugt, nicht mehr wegzugehen".

253. ViMa 33, Bd.2, p. 278,1-279,3: Nachdem Martha gestorben war, „sah Ioannes, ein frommer anagnostes ${ }^{754}$, in der Reinheit seiner Seele, als er einge-

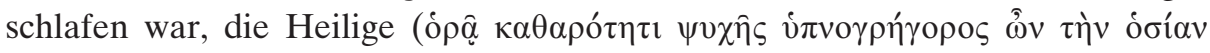
Máp $\theta \alpha v$...), wie sie die Leiter an der Säule des Symeon emporstieg, in der

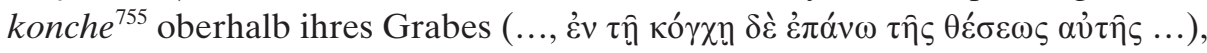
so wie in der Geschichte der Tiere mit sechs Flügeln, auf einem geräderten Wagen [Ez 1, 5-14]. Den darauf Sitzenden sah er jedoch nicht. Er wollte aber die Erscheinung noch klarer begutachten, denn er glaubte, an jenem Ort etwas Geschriebenes wahrzunehmen. Deshalb ging er los, um es zu erfahren, doch auf

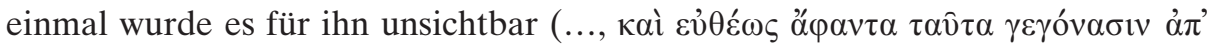

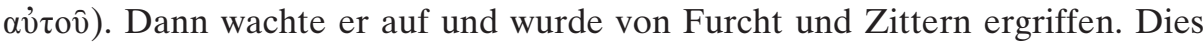
berichtete er Symeon und versicherte unter zahlreichen Schwüren die Wahr-

754 Vorleser der für die Liturgie vorgeschriebenen Bibeltexte s. P. Magdalino, Art. Anagnostes, in: ODB $1,84$.

755 Eine muschelförmige Halbkuppel oberhalb einer Nische oder Apsis, s. M. J. Johnson, Art. Konche, in: ODB, $492 \mathrm{f}$. 


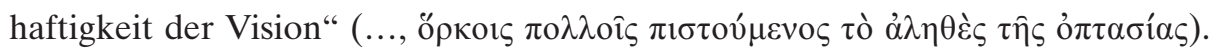
Da sagte Symeon zu ihm, er solle den Herrn ehren, da er die Gnade erhalten habe, im Rahmen seiner Möglichkeiten die heiligen Tiere des Cherubim, der auf einem Wagen hinauffährt, zu erblicken.

254. ViPa 93, Halkin 1982, p. 45,28-46,9 : Als Theodoros einmal vernahm, wie einige im Himmel eine liebliche und schön anzuhörende Melodie sangen, fragte er Pachomios, was dies sei. Pachomios antwortete, eine gute Seele, die in den Himmel gehoben worden war, komme nun von oben zu ihnen, und sie hätten die Gnade, an erster Stelle denjenigen zuzuhören, die psalmodieren und Gott loben. „Ein anderes mal wiederum wurde ihnen der Ausgang der Seele vom

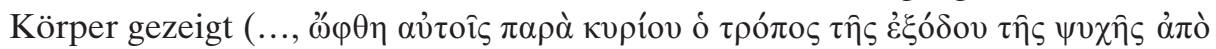

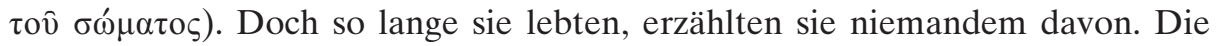
anwesenden Brüder aber fühlten, wie sie gebannt hinschauten, wenn die Seele

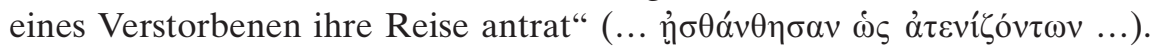

255. PhHi 21,22, Bd. 2, p. 104,17-106,2: Vater Iakobos erzählte, „dass er den

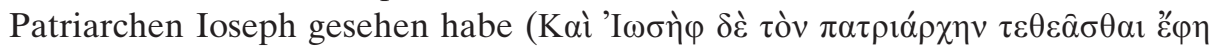
...). Trotz weißem Haupthaar und Bart strahlte der Greis den Glanz des Jugendalters aus“. Und obschon er sich auf der Spitze der Tugend befand, habe er sich selber als den Niedrigsten unter den Heiligen bezeichnet. Als Iakobos erwiderte, er sei der erste von jenen, die mit ihm den Sarg teilen, nannte er sich selber den Letzten.

256. PrSp 44, PG 87.3, 2900A: Ein Mönch, der sich in der Thebais aufhielt, ermahnte einen seiner Schüler, der sich vernachlässigte, wiederholt zur Achtsamkeit. Nachdem der Schüler gestorben war, betete der Mönch zu Gott, er möge ihm alles über die Seele des unachtsamen Bruders offenbaren (Kaì ᄁ̆ $\rho \xi \alpha \tau o$

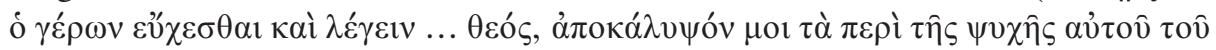
$\alpha \dot{\alpha} \varepsilon \lambda \varphi \circ \hat{)})$. „Da geriet er in Ekstase und sah einen Feuerfluss. Darin befand sich eine Menschenmenge, und in ihrer Mitte der Bruder, eingetaucht bis zum Hals

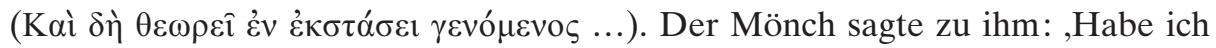
dich nicht wegen eben dieser Strafe ermahnt, deine Seele zu hüten?' Der Bruder antwortete: ,Ich danke Gott, dass mein Kopf Ruhe hat. Wegen deines Gebetes stehe ich über dem Haupt des Bischofs““.

257. ViSyStII 7, Bd.1, p. 9,2-10: Der Autor der Vita bemerkt, dass es notwendig sei, alles für einen frommen Zuhörer Nützliche aufzuschreiben. Da nichts von dem, was gesagt werden muss, verborgen bleiben solle, halte er es für

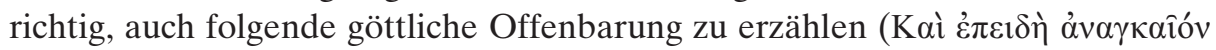

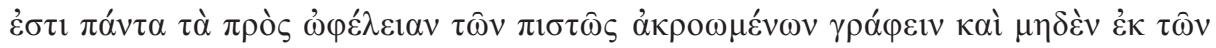

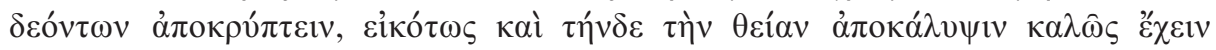

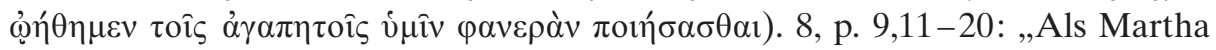
eines Tages über ihren Sohn nachdachte, machte sie sich Sorgen darüber, was mit ihm geschehen werde. Sie schlief ein und sah sich selbst flügeltragend und

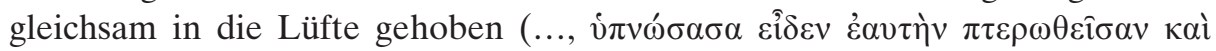




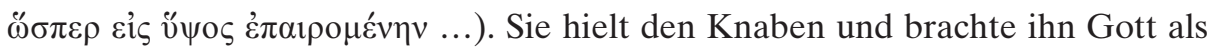
Geschenk dar“. Zu Symeon sagte sie, sie wolle seinen göttlichen Aufstieg sehen, sodass der Herr sie in Frieden gehen lasse (Lk 2,29), denn sie habe unter den Frauen die Gnade erhalten, ihre Geburtsschmerzen dem Höchsten darzubringen. (S. auch 227).

258. ViSyStII 29, Bd. 1, p. 29,15-26: „Der junge Symeon sah sich selbst bis zum Äther ${ }^{756}$ des Himmels emporgehoben, an allen Orten der Erde umherirren und

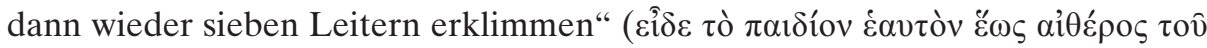

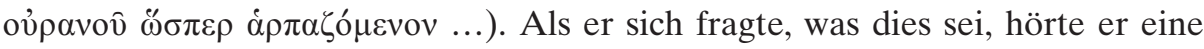
Stimme, die sagte, dass das, wordurch er emporgestiegen sei, die sieben Himmel seien. „Darauf wurde er auch von hier weggerafft und sah das Paradies, Pflanzen, einen Palast aus Licht und eine Quelle von Wohlgerüchen, welche auf ein von Gott gewirktes Gewölbe hervorsprudelte. Außer Adam und dem Räuber sah er keine Menschen. Als er wieder zu sich kam, erzählte er die Vision

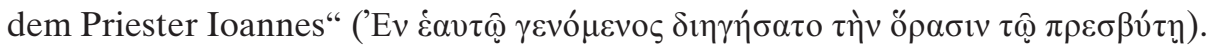
33, Bd. 1, p. 32,22-26: Von diesem Augenblick an waren die anderen Mönche

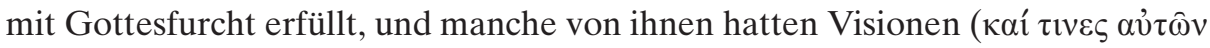
$\dot{\omega} \rho \alpha \mu \alpha \tau i \sigma \theta \eta \sigma \alpha v)$. Sie sahen drei Apsiden, drei Throne und drei Kränze auf den drei Thronen, und als sie fragten, wem diese Ehre beschieden sei, hörten sie eine Stimme, die antwortete: „Dem Knaben Symeon“.

259. ViSyStII 124, Bd. 1, p. 106,1-110,14: Symeon hatte eine Schau, nach der er äußerst betrübt die Brüder zu sich rief und sie lange darüber belehrte, wie sie

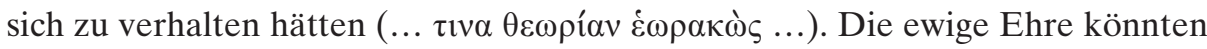
sie nur dann erlangen, wenn sie nicht zum Sichtbaren, sondern zum Unsichtbaren hinschauen. Denn das Sichtbare sei vergänglich, das Unsichtbare aber

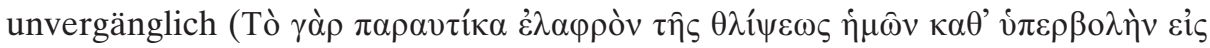

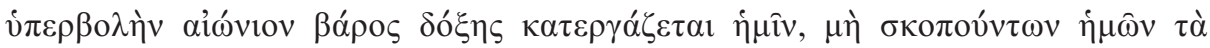

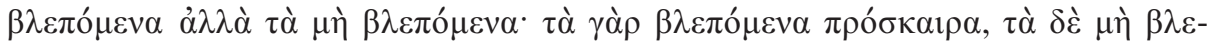
$\pi$ ó $\mu \varepsilon v \alpha \alpha i ́ \omega v \imath \alpha)$. Denjenigen, die gottgefällig gelebt haben, werde durch die Güte des Herrn ein nicht von Menschenhand geschaffenes Zelt in den Himmeln zugewiesen. $\mathrm{Zu}$ diesem habe ihm Gott in der Nacht den Aufstieg gezeigt (...

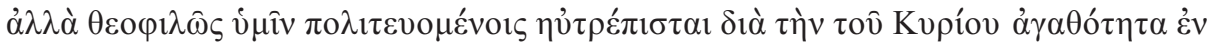

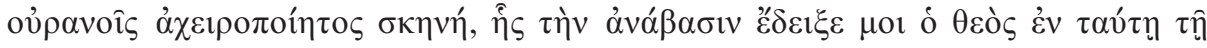

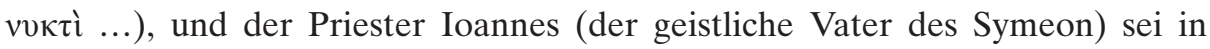
dieses Zelt eingegangen. Die Brüder sollen Mut fassen, denn an seine Säule sei eine Leiter gelehnt, die bis in den Himmel reiche. Und an den Himmelstoren habe er, als sich die Engel dort zur Proskynese vor Gott versammelten, auch den Teufel gesehen. Dieser habe sich als schamloser, riesengroßer Äthiopier mit grimmigem Gesichtsausdruck und blutunterlaufenen Augen gezeigt. Er habe

756 Zurückgehend auf Galen der obere Teil des Himmels oberhalb von Luft und Wolken, s. H. M. Nobis, Art. Äther, LexMa 1, München 1980, Sp. 1165. 
Symeon mit den Zähnen entgegengeknirscht und den Kopf hin und her gewiegt im Verlangen, die Brüder wie das Korn zu sieben. Symeon aber habe gebetet, damit der Glaube der Brüder nicht verloren gehe. Dann ertönte Gottes Stimme und beauftragte den Teufel, die Kinder und die guten Menschen zu versuchen. Der Teufel erwiderte, er wolle mit Symeon beginnen, worauf der Herr ihn vor seiner Gesinnung gegen Symeon warnte. Daraufhin sagte der Teufel irritiert zum Herrn, tatsächlich besitze Symeon die Kraft, ihn zu binden, und er mache sich lustig über ihn wie kein anderer auf dieser Erde. Gott habe ihn zusammen mit zwei seiner Erzengel in ein strahlendes Licht $\left(\dot{\varepsilon} v \dot{\eta} \lambda \varepsilon \dot{\varepsilon} \kappa \tau \rho \varphi \varphi \omega \tau \grave{\text { ò }} \varsigma^{757}\right)$ und in leuchtende und goldglänzende Wolken gestellt und eine Krone auf sein Haupt gesetzt. Und er habe Symeon den Stab der göttlichen Kraft gegeben, um die dämonischen Legionen zu vertreiben, die wie Heuschrecken heruntergeschleudert wurden, damit sie unter seinen Füssen zertrampelt werden. Symeon vertreibe die Dämonen durch den heiligen Geist gleich einem Blitz, denn er sei mit dem Licht und der Ehre Gottes wie mit einem Gewand bekleidet. Nun werde er, der Teufel, aber listige Menschen gegen ihn aufstacheln und in seine Schüler einfahren.

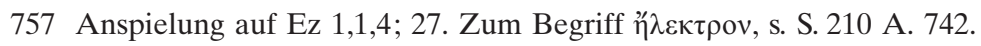




\section{Heilungen}

\section{Dämonenaustreibungen und Heilung

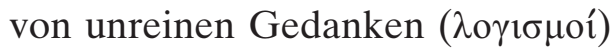

260. ApSy VI 25, Bd. 1, p. 330 f.: Ein Gärtner arbeitete sein Leben lang hart und setzte seine ganze Kraft für die Mönche ein. Für sich selber behielt er nur das Notwendigste. Eines Tages aber gab ihm der unreine Geist ein ( ${ }^{\mathrm{Y}} \mathrm{Y} \pi \dot{\varepsilon} \beta \alpha \lambda \varepsilon \delta \dot{\varepsilon}$

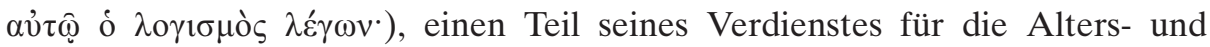
Krankenvorsorge zu sparen, und so fing er an, in einem Tongefäß etwas Geld zurückzulegen. Dann wurde er krank, und sein Bein war gelähmt. Nun gab er das gesammelte Geld für Ärzte aus, jedoch ohne Erfolg. Eines Tages riet ihm ein erfahrener Mediziner, das kranke Bein amputieren zu lassen. Aber noch in der selben Nacht kehrte er nach Hause zurück und besann sich seiner Taten. Er betete zu Gott, er möge sich an die Werke erinnern, die er vollbracht hatte, als

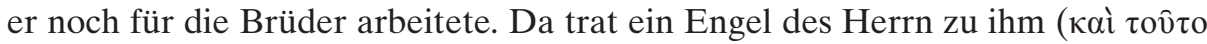

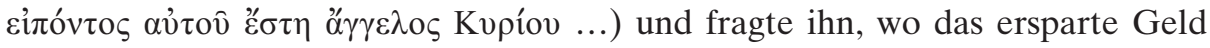
und wo die von ihm angehäufte Hoffnung geblieben sei. Er dachte nach und kam zu der Einsicht, dass er gesündigt hatte. Nachdem er Gott um Vergebung gebeten hatte, berührte der Engel seinen Fuß, und sogleich war er geheilt.

261. ViEu 10, p. 18,12-20,20: Terebon, der Sohn des heidnischen Beduinenfürsten Aspebetos, der ein Verbündeter des persischen Herrschers Isdigerdos ${ }^{758}$ war, wurde in seiner Jugend von einem Dämon geschlagen, sodass er von Kopf bis Fuß gelähmt war. Da Aspebetos die Christenverfolgung des Isdigerdos nicht unterstützte, sondern den Christen vielmehr zur Flucht verhalf, wurde er selber verfolgt und flüchtete in die byzantinische Provinz Arabia, wo er philarchos ${ }^{759}$ über die sarazenischen Untertanen der Byzantiner wurde. Nachdem er sich dort mit seiner Familie niedergelassen hatte, ,sah Terebon ein Traumgesicht, das er

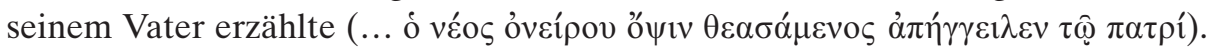
Dieser machte sich sogleich mit seinem Sohn und einem großen Hofstaat auf den Weg, um an den im Traum angekündigten Ort, wo die heiligen Männer

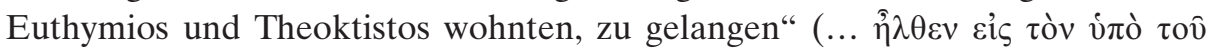

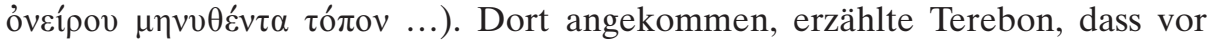
einiger Zeit in Persien dieses Leid über ihn gekommen sei, und dass er jede

758 Jazdegerd I. (399-422), s. S. VRYonis, Art. Sassanians, in: ODB 3, 1845.

759 Zw. dem 4. und 7. Jhd. gebräuchlicher Titel für die Befehlshaber der mit den Byzantinern verbündeten arabischen Hilfstruppen, s. A. J. CAPPEL, Art. Phylarch, ODB 3, 1672. 
ärztliche Kunst und jede magische List an sich erfahren habe. Doch nichts habe ihm geholfen, vielmehr sei sein Leid noch größer geworden. Eines Nachts habe er sich gefragt, wo die ganze ärztliche Kunst bleibe, wo die Phantasien der Magier und die Anrufungen und Märchenerzählungen der Astronomen und Astrologen, wo die Sänger und die geschwätzigen Zauberer. Denn nichts davon besitze Macht, wenn es nicht von Gott gutgeheißen werde. Mit diesen Gedanken habe er angefangen zu beten und beschlossen, zum Christentum zu konvertieren, wenn er geheilt würde. Dann sei er vom Schlaf entrafft worden und

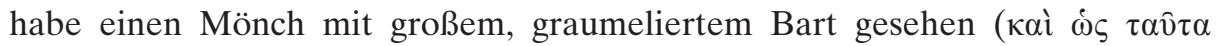

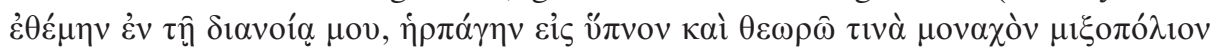

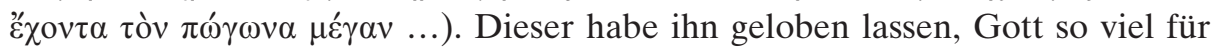
die Heilung zu bezahlen, wie er versprochen hatte (Konversion zum Christentum). Dann habe sich der Mönch als Euthymios zu erkennen gegeben und ihm den Weg zu seinem heiligen Ort beschrieben. Denn, so sagte der heilige Mann, wenn Terebon geheilt werden wolle, müsse er sofort zu ihm kommen. Nachdem der Junge dies erzählt hatte, wurde er von Euthymios geheilt.

262. ViEu 50, p. 72,11-74,27: Ein Mönch namens Paulos aus Kilikien wurde schrecklich von einem unreinen Geist geplagt, ,worauf man ihn in die Be-

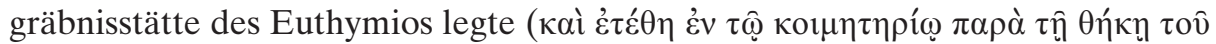

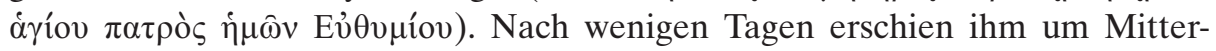
nacht Euthymios, und nachdem dieser den unreinen Geist ausgetrieben hatte, ging Paulos zur Stunde des nächtlichen Psalmengesanges in die Kirche“"

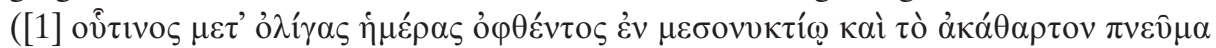

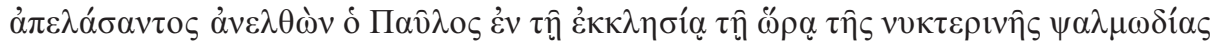
...). Dort berichtete er vor allen Brüdern das Wunder, welches geschehen war

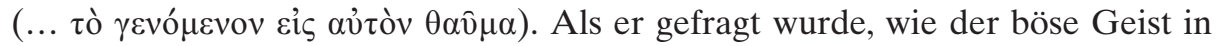
ihn gekommen sei, erzählte er die ganze Geschichte. Er habe in seinem Kloster immer wieder das eine oder andere mitgehen lassen. Und nachdem er eines Abends Wein getrunken hatte, seien seine Gedanken gänzlich durcheinander geraten. Er habe eine Frau gesehen, die ihm beiwohnte, und er sei mehrere Tage auf diese Weise von einem Dämon heimgesucht worden, weshalb er schließlich hierher gebracht wurde. Man legte ihn direkt neben das Grab des Euthymos, wo er flehte und betete. In der besagten Nacht aber, um die fünfte Stunde, als er unter Wehklagen und Tränen betete, fiel er in eine Art Ekstase und erblickte einen lichterfüllten und furchteinflössenden Ort von unbeschreiblichem Glanz

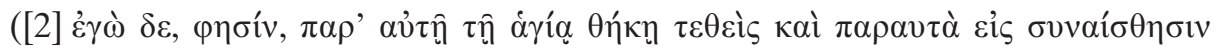

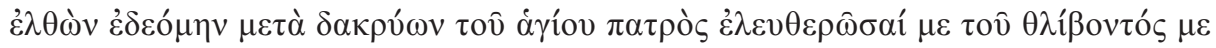

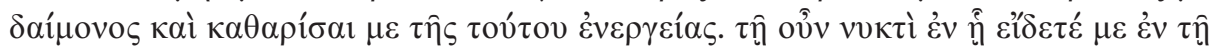

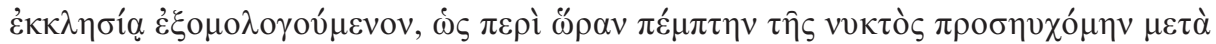

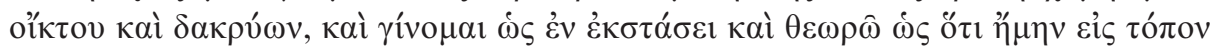

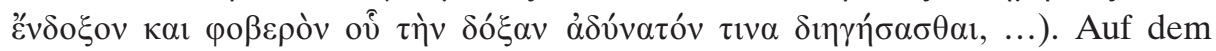
Kopf schien er ein schwarzes kukullion (Wollmütze) zu tragen, das gemäß der 
Schrift (Mk 15,17) ein dorniges Instrument mit spitzigen Rosshaaren war, die ihn fürchterlich stachen und quälten. Dann öffnete sich sein Mund und er flehte den Herrn um Rettung an. Und auf einmal erblickte er den heiligen Mann in gleißendem Glanz, mit weißem Haar, untersetzt vom Alter, mit großem Bart, kugelrundem Gesicht und freudestrahlendem Ausdruck. Der heilige Mann trug einen Umhang, der schwärzer und kürzer war als das kolobion ${ }^{760}$ ([3] кà

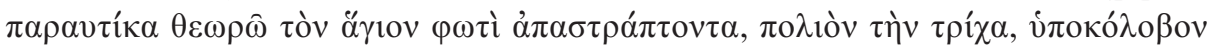

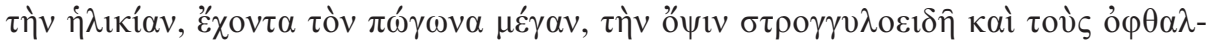

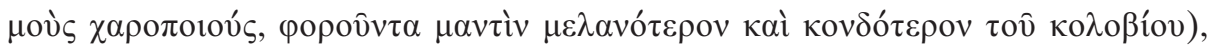
und in der Hand hielt er einen Stab. Dann fragte er Paulos, warum er ihn störe und was er von ihm wolle, worauf dieser furchterfüllt erwiderte, dass er um sein Mitleid flehe. Daraufhin fragte ihn Euthymios, ob er nicht wisse, dass Gott nichts verborgen bleibe. Erst als Paulos versprach, sich von nun an richtig zu verhalten, riss ihm Euthymios das schwarze kukullion vom Kopf. In seinen Händen verwandelte es sich zu einem kleinen Äthiopier, aus dessen Augen Feuer schoss. Und am Boden erblickte Paulos eine tiefe Grube, in die Euthymios den Äthiopier warf. Darauf sagte er ihm, er sei jetzt gesund. Dann sei

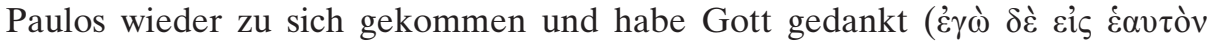
$\dot{\varepsilon} \lambda \theta \grave{\omega} v \varepsilon u ̉ \chi \alpha \rho i ́ \sigma \tau \eta \sigma \alpha \tau \hat{\emptyset} \Theta \varepsilon(\hat{)})$.

263. ViEu 54, p. 76,13-27: Eine Frau wurde von einem Dämon geschlagen und

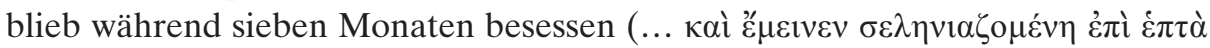

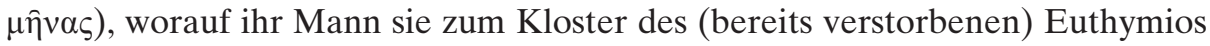
brachte. „Da die Frau nicht ins Kloster eintreten durfte, verharrte sie drei Tage und drei Nächte fastend und betend vor dem Kloster, und am Abend erhielt sie geweihtes Öl vom Sarg des Heiligen und trank von der Flüssigkeit ${ }^{761}$ seiner

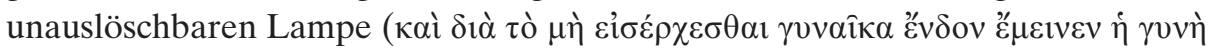

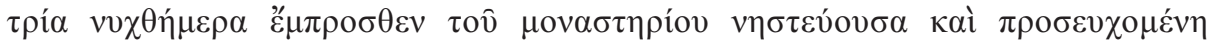

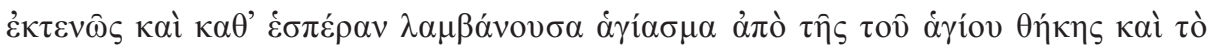

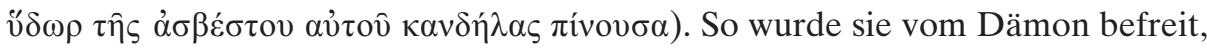
als ihr der Heilige in der dritten Nacht erschien und sagte: ,Sieh, du bist geheilt;

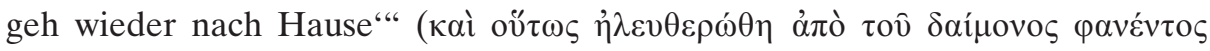

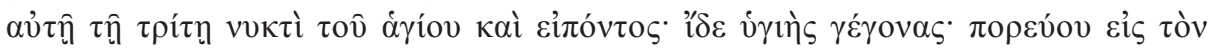
oîKóv $\sigma 0 \mathrm{ov})$.

264. ViEu 57, p. 78,3-79,14: Ein gewisser Romanos wurde durch einen Zauber

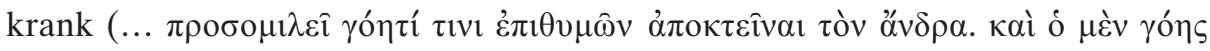

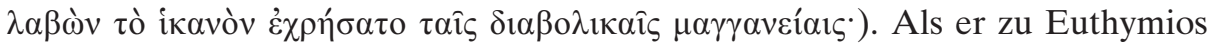
betete, er möge ihm helfen, geriet er in Ekstase und sah einen bärtigen Mönch,

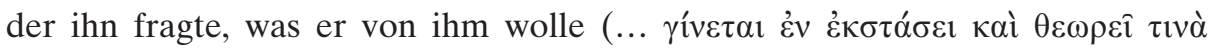

760 Kurzärmlige Tunika.

761 Gemeint ist das geweihte Öl der Grablampe, s. dazu Festugière, Les moines d"' Orient III/1, 132, A. 177. 


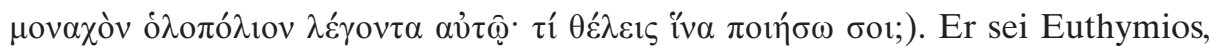
welchen er gerufen habe. Er solle sich nicht vor ihm fürchten, sondern ihm zeigen, worunter er leide. „Darauf zeigte ihm Romanos seinen Bauch. Und

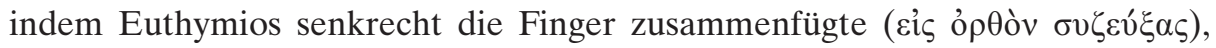
schnitt er wie mit einem Schwert die Stelle auf und entnahm aus dem Bauch ein mit Einritzungen versehenes Plättchen aus Zinn und legte es vor ihm auf einen Tisch. Dann massierte er mit der Hand seinen Bauch, beseitigte den Einschnitt und heilte ihn“. Romanos wies er zurecht und belehrte ihn, dass ihm dies geschehen sei, weil er tagelang nicht in der Kirche und beim Abendmahl gewesen sei. Es sei nämlich jemand in die palästinische Stadt Eleutheropolis gegangen, um Dämonen gegen ihn auszusenden, die im Stande waren, ihn seinem eigenen Heil gegenüber gleichgültig werden zu lassen. Nun habe sich Gott seiner erbarmt, doch in Zukunft solle er nicht wieder die Gebete vernachlässigen. „Und

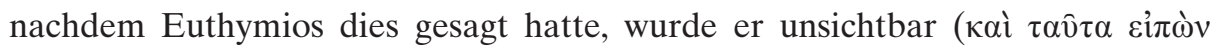

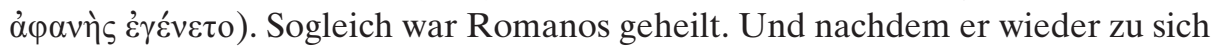
gekommen war, stand er auf und nahm Abstand von allem, was die Ursache für eine solche Krankheit hätte sein können. Seinen Angehörigen aber erzählte er

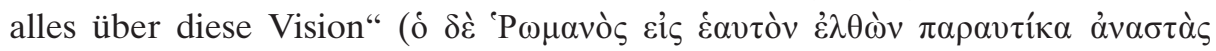

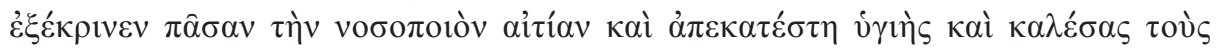

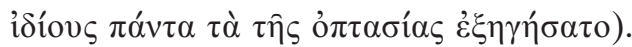

265. HiLa 29, p. 85,3-17: Vom Asketen Elias wird erzählt, dass er ein großes Kloster baute, in welchem er alle Frauen, die keinen festen Wohnsitz hatten, aufnahm und versorgte. Sie kamen aus sehr unterschiedlichen Milieus, sodass sie ständig aneinander gerieten und er die Rolle des Schiedsrichters übernehmen musste. Da er aber noch jung war, wurde er von unreinen Begierden befallen. Deshalb ging er eines Tages in die Wüste und flehte Gott um Hilfe an. „Als es Abend wurde, schlief er ein. Da kamen, wie er selber erzählte, drei Engel auf

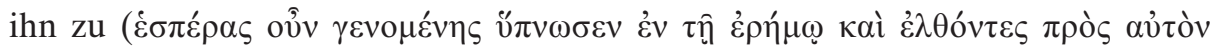

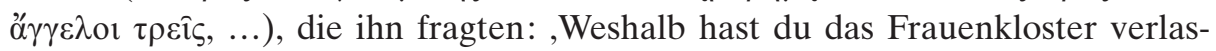
sen?"“ Elias erzählte seine Beweggründe und sagte, er fürchte sich davor, sich selber und die Frauen zu verderben. Darauf schlugen ihm die Engel vor, ihn von seiner Leidenschaft zu befreien, sofern er sich bereit erkläre, umzukehren und weiterhin für die Jungfrauen zu sorgen. Er willigte ein und legte den Schwur „So wahr Gott für mich sorgt, will ich für sie sorgen“ ab. „Danach hielt einer der Engel seine Hände fest, der zweite seine Füsse. Der dritte nahm ein scharfes Messer und schnitt ihm die Hoden ab - nicht in Wirklichkeit, sondern in der

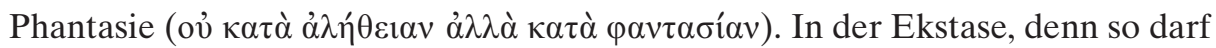

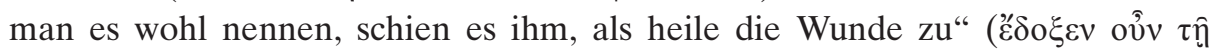

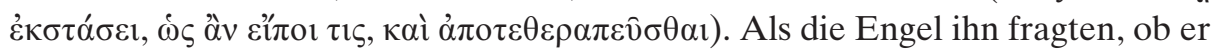
sich besser fühle, sagte er, es sei ihm um vieles leichter und er glaube fest daran, dass er von der Leidenschaft erlöst sei. Danach kehrte er ins Kloster zurück. 
266. ViMa 41, Bd. 2, p. 283,25-284,24: Als sich die Brüder zum nächtlichen Psalmengesang versammelten, wurde ein gewisser Lyakon von zwei Dämonen

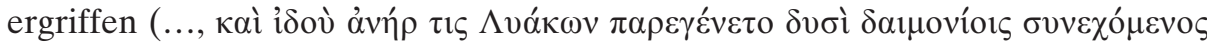
...). Er konnte an dem Ort, wo in der Kirche die Psalmen gesungen wurden, nicht mehr stehen bleiben und war auch außerstande, der Liturgie zu folgen. Vielmehr führten ihn die Dämonen aus der Kirche, warfen ihn zu Boden, ließen

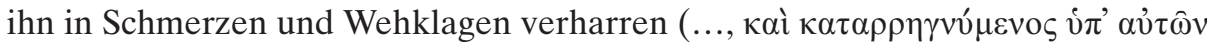

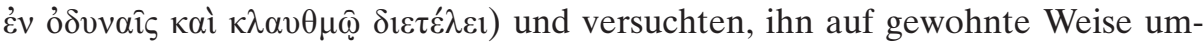

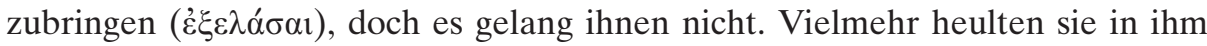
laut auf, „und auf einmal wurde der Kranke durch eine göttliche Kraft zur Ruhestätte der seligen Martha gezogen, ohne dass er wusste, wessen Grab dies war. Und als er sich dicht an den Boden drängte und dabei den Kopf aufschlug, sah er, wie ein Feuer auf ihn kam und sich gleichsam über das Grab ausbreitete, und eine fromme Frau trat heraus, streckte ihre Hand gegen die Mitte der konche $^{762}$ hin aus und traktierte bis zum Sonnenaufgang die Dämonen. Dann fing Lyakon an, Gott zu loben, und sah, wie die beiden Dämonen ausfuhren“. 267. ViMa 42, Bd. 2, p. 284,25-285,8: „Ein Soldat aus Hierapolis in Syrien, der am Fuß von einem Dämon gequält wurde und deshalb zur Säule des Symeon kam, wurde von einer unsichtbaren Kraft zum Grab der Martha gezogen (...

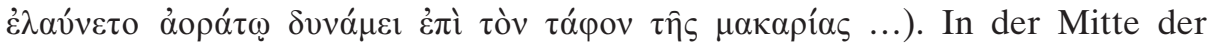
Grabstätte sah er eine ehrwürdige Frau, die den Dämon vertrieb und ihn wie ein

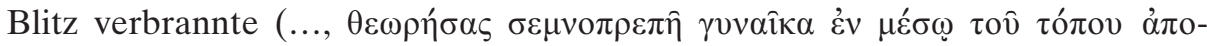

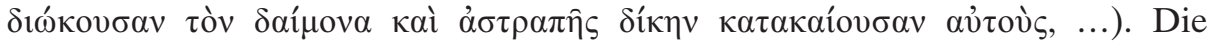
Schüler des Symeon umgaben sie mit brennenden Lichtern. Und über ihr erschien das Herrschaftssymbol ( $\delta \varepsilon \sigma \pi о \tau$ кòv $\chi \alpha \rho \alpha \kappa \tau \hat{\rho} \rho)$ ), das der Gnade der Heilungen seinen Schatten spendete. Nachdem der Soldat dies gesehen und sich unter Tränen dem Grab genähert hatte, war er geheilt [...]“.

268. PhHi 3,22, Bd. 1, p. 286,20-288,12: Von Sabinos wird gesagt, „dass er von Gott so viel Gnade erlangt hatte, dass eine adlige und reiche Frau aus Antiocheia zu ihm kam, um ihn um Hilfe für ihre vom Dämon besessene Tochter

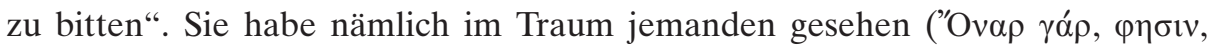
$\dot{\varepsilon} \theta \varepsilon \alpha \sigma \alpha ́ \mu \eta v ~ \tau \imath v \alpha ̀$...), der ihr riet, hierher zu kommen und ihrer Tochter durch die Gebete des Klostervorstehers Hilfe zu verschaffen. „Als aber der Abt vor die Tür trat, sagte die Frau, es sei nicht dieser, der ihr gezeigt wurde ("Е $\varphi \alpha \sigma \kappa \varepsilon \delta \dot{\varepsilon} \dot{\eta}$

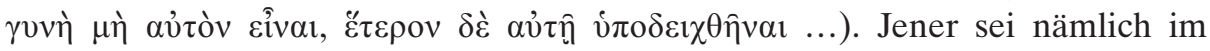
Gesicht gerötet gewesen und habe einen Ausschlag an den Wangen gehabt. Da verstanden sie, dass die Frau den dritten und nicht den ersten des Klosters meinte, und überzeugten Sabinos, vor die Frau zu treten. Sie erkannte ihn auf der Stelle, und der Dämon schrie auf und verließ das Mädchen“.

762 S. S. 242 A. 755. 
269. ViSyStII 49. Bd.1, p. 45,7-20: Ein alter Mann und seine ganze Familie wurden von Dämonen angegriffen, die von einem mit der Verwendung von Zaubermitteln Vertrauten losgesandt wurden. Als im Kloster des Symeon einmal zu wenig Brot für die Armen vorhanden war, erschien jenem vom Alter

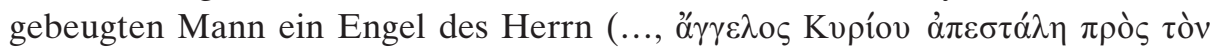

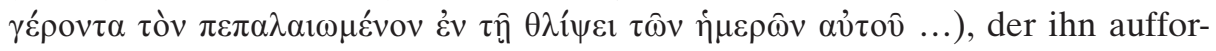
derte, mit Getreide für die Armen zu Symeon zu gehen. Und wenn er dort den Rockzipfel des Heiligen berühre, werden die Ketten, durch welche sein Haus gefesselt sei, in die tiefsten Orte der Erde hinunterstürzen. Als Zeichen solle er dem Heiligen sagen, dass ihm (Symeon) gestern um die neunte Stunde eine Decke zur Segnung für die Verwendung als Schutz vor Krankheiten ins Leder-

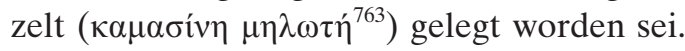

270. ViSyStII 55, Bd. 1, p. 48,28-49,6: „Eine Jungfrau ging zu Symeon, weil sie fürchterlich von einem Dämon geplagt wurde. Sie hatte den heiligen Knaben

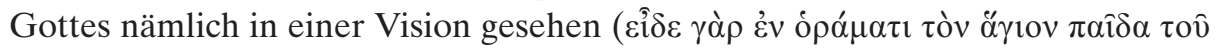
$\Theta \varepsilon \circ \hat{~ . . .) . ~ E r ~ t r u g ~ e i n ~ K l e i d, ~ d a s ~ s o ~ w e i ß ~ w a r ~ w i e ~ L i c h t . ~ I n ~ d e n ~ H a ̈ n d e n ~ h i e l t ~ e r ~}$ eine Lanzette ( $\varphi \lambda \varepsilon \beta$ ó́ $\mu$ ov), mit der er ihr den Fuß aufschnitt“. Tatsächlich wurde die Frau von Symeon geheilt.

271. ViSyStII 73, Bd. 1, p. 63,6-25: Ein Mann an der Grenze zu Persien war von einem Dämon besessen, als ihm ein Engel des Herren gesandt wurde ('A $\pi \varepsilon \sigma \tau \alpha ́ \lambda \eta$

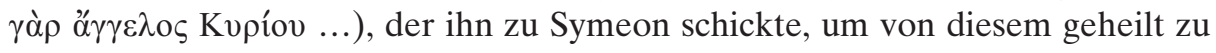
werden. So geschah es. Der Mann machte sich auf den Weg zu Symeon und wurde von ihm geheilt. „Der ausfahrende Dämon erblickte zusammen mit dem kranken Mann einen goldglänzenden Kranz mit Perlen auf dem Kopf des

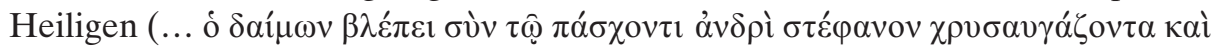

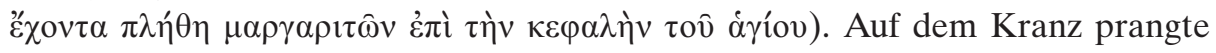
ein Kreuz, das hell wie die Sonne erstrahlte, und Symeon war von einem himmlischen Heer umgeben“.

272. ViSyStII 74, Bd. 1, p. 63,26-64,23: „Ein neunzehnjähriger Jüngling wurde so sehr von einem Dämon geplagt, dass seine Augen aus ihrer normalen Position heraustraten, und er sich in großer Gefahr befand. Da wurde ein Engel des

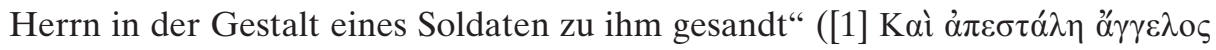

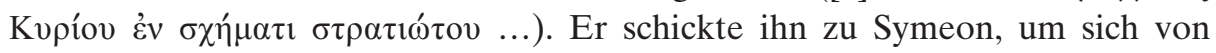
diesem heilen zu lassen. Nachdem der Engel dem Jungen diesen Auftrag ge-

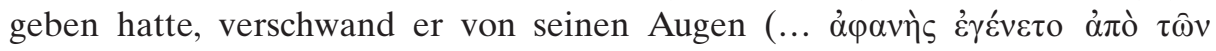
ỏ $\varphi \alpha \lambda \mu \hat{\omega} v \alpha u ̛ \tau o v)$. Sogleich machte sich der Jüngling auf den Weg zu Symeon, der den Dämon austrieb. „Von dieser Stunde an war der Junge geheilt, und er sah mit eigenen Augen einen Engel Gottes im Gewand eines Soldaten vor dem

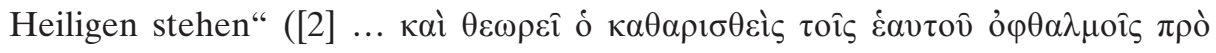

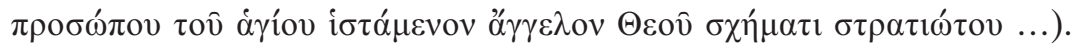

763 Zur Bedeutung dieses Begriffes s. VAN DEN Ven, La vie ancienne, Bd. 1, 144*f. 
273. ViSyStII 75, Bd. 1, p. 64,25-65,6: „Ein Mann hatte ein von einem Dämon entstelltes Gesicht. Als er den Namen des Symeon anrief, sah er diesen im Äther ${ }^{764}$ des Himmels. Er hielt einen Feuerstab in der Hand und kam ihm zu

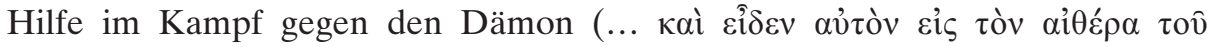

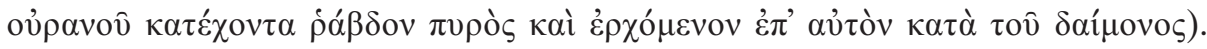
Als der unreine Geist Symeon erblickte, floh er sofort. Von dieser Stunde an war das Gesicht des Mannes geheilt".

274. ViSyStII 82, Bd.1, p. 69,5-9: „Eine Frau wurde fürchterlich von einem Dämon geplagt, der sie häufig ins Wasser warf, um sie zu ertränken. Bevor sie zu Symeon kam und ihn in Fleisch und Blut sah, hatte sie ihn schon häufig geschaut

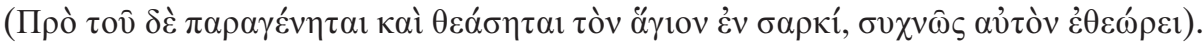
Als sie dann zu ihm kam und Symeon sah, heulte der Dämon auf und fuhr aus ihr aus".

275. ViSyStII 92, Bd. 1, p. 72,10-73,4: Ein Leprakranker kam zu Symeon und flehte ihn an, er möge ihn heilen. Dieser schickte ihn wieder nach Hause, da sich Gott dort seiner annehmen werde. Der Kranke befolgte den Rat, „und noch in der gleichen Nacht sah er einen Jüngling in leuchtendem Gewand, der ihm

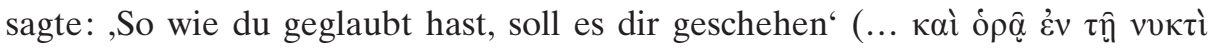

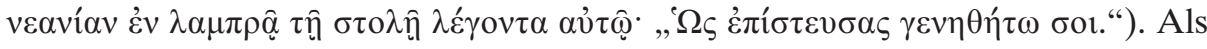

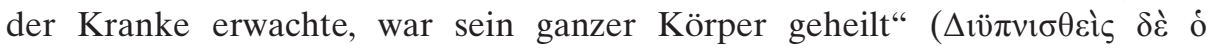

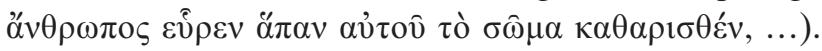

276. ViSyStII 101, Bd.1, p. 78,18-79,26: Der Neid eines Dämons auf die Schönheit eines Mädchens führte dazu, „dass dieses plötzlich anfing zu stöhnen und am ganzen Körper zu zittern, sodass es den Verstand verlor und keinen Augenblick Ruhe hatte, um sich zu erholen“. Erst das Eingreifen des Styliten führte dazu, dass sich die Glieder des Mädchens plötzlich wieder beruhigten ( $\varphi$ óv

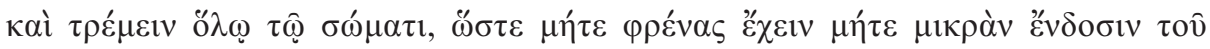

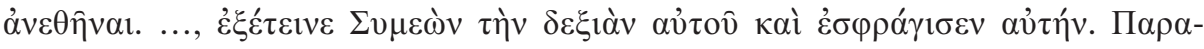

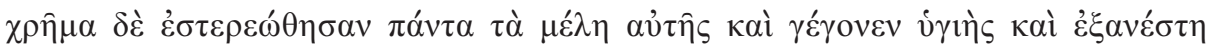

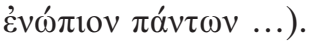

277. ViSyStII 177, Bd. 1, p. 156,16-157,22: Ein gewisser Theodoros aus Antiocheia wurde von einem wilden Dämon besessen. Er kam zu Symeon und bat ihn um Heilung. Dieser schickte ihn wieder nach Hause und versprach, dass er ihm, wenn er sich auf seinem Bett ausruhe, erscheinen und ihn heilen werde (... кai

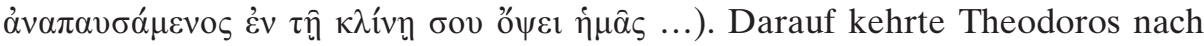
Hause zurück. Als er auf dem Heimweg zum Fluss Melas kam, zog ein heftiges Unwetter auf. Theodoros wollte aber dennoch den Fluss durchqueren und wurde von einer Wasserflut mitgerissen. Dabei ergriff ihn große Furcht, sodass er in der Not ein Gebet an Symeon richtete. Dieser sagte im gleichen Moment

764 S. S. 244 A. 756. 
mit einem sanften Ausdruck im Gesicht zu den Brüdern, er habe soeben gesehen, wie der Mann, der sich auf den Weg gemacht hatte, von einer Flut im Fluss weggerissen worden sei (vgl. „Klarsicht“). Mit der Kraft des heiligen Geistes habe er ihn ergriffen und unversehrt aus dem Wasser gezogen. Und als die Sonne unterging, sagte er zu den Brüdern, dass er denselben Mann auf der Straße einen Kilometer vor der Stadt gesehen habe. „Als Theodoros zu Hause ankam und sich ein wenig auf dem Bett ausruhte, erschien ihm plötzlich Symeon

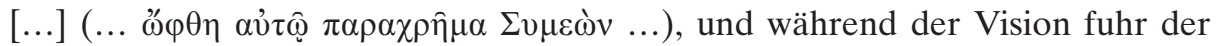
Dämon auf einmal aus ihm aus und wagte nicht wieder, sich ihm zu nähern

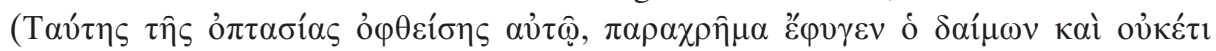

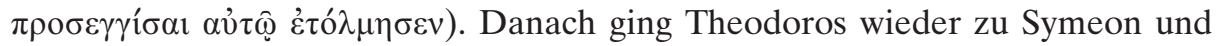
erzählte ihm, wie er vom Wasser mitgerissen wurde und wie er ihm erschienen sei. Symeon habe ihn ergriffen und aus dem Wasser gezogen. Bei Sonnenuntergang habe er ihn dann auf der Straße erblickt, und in der Nacht sei er ihm abermals erschienen und habe ihn geheilt, indem er den schreienden Dämon aus ihm vertrieben habe“. Und die Brüder erinnerten sich an die Schau, von der

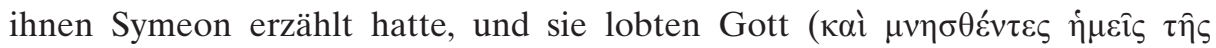

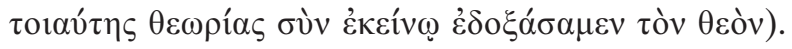

278. ViSyStII 196, Bd. 1, p. 173,7-174,7: Ein junger Mann, der sich mit seinem Vater bei Symeon aufhielt, wurde eines Tages von einem Dämon geschlagen. Dieser ließ ihn von einem Felsen herunterfallen, sodass sein Kopf ganz zerschmettert war. Der Junge ließ einen lauten Schrei fahren, sodass alle Anwesenden bei ihm zusammenliefen. Man stellte fest, dass er tot war und brachte ihn zum heiligen Symeon. Dieser auferweckte ihn und ordnete an, man solle ihn ein wenig schlafen lassen, damit der Herr ihn vollständig wiederherstelle (Nv̂v

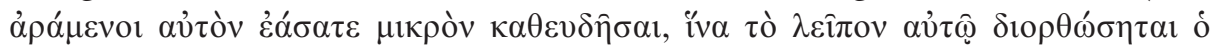
Kúpıs). Symeons Anweisung wurde befolgt, ,und der Junge schlief ein. Da schnitt ihm Symeon in einer unsichtbaren Operation durch die Kraft des Geistes das Ohr auf, sodass eine Menge Blut aus seinem Gehirn floss (..., $\alpha \varphi v ́ \pi v \omega \sigma \varepsilon v$ ó

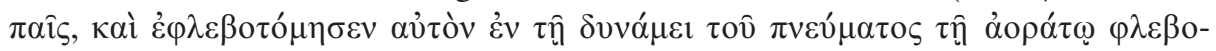

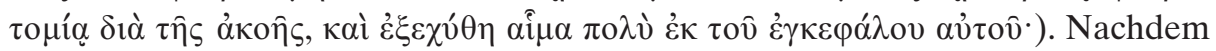

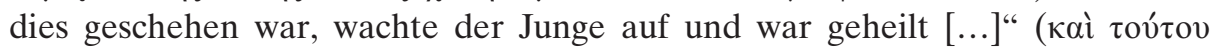

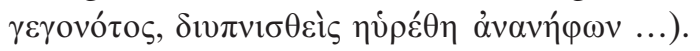

279. ViSyStII 231, Bd. 1, p. 204,20-208,24: Ein Priester brachte seinen kranken Sohn zu Symeon. Dieser heilte den Jungen. Doch als sie wieder zu Hause waren, erkrankte ein anderer Sohn. Auch dieser wurde zu Symeon gebracht, und der Priester bat den Heiligen, auch über ihm die rechte Hand zur Heilung auszustrecken. Symeon streckte zwar die rechte Hand aus, forderte den Priester aber auf, nach Hause zu gehen, damit der Sohn dort geheilt werde. Als der Vater Symeon dennoch bat, länger bei ihm bleiben zu dürfen, damit sich das Heil der Familie dadurch vergrößere, wurde Symeon zornig und sagte, die Kraft Gottes wirke überall. Dann überreichte er ihm vom heiligen Staub und schickte ihn weg 
mit den Worten: „Wenn du den Umriss unseres Bildes siehst, dann siehst du

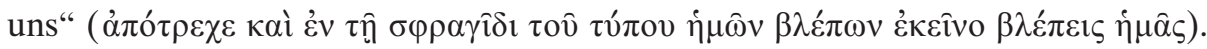
Darauf ging der Priester nach Hause und legte seinen Jungen aufs Bett. Er selber sah, wie sich Symeon in einer anderen Gestalt zu ihm stellte ([1] Kà ó $\rho \hat{\alpha}$

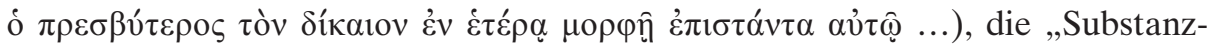

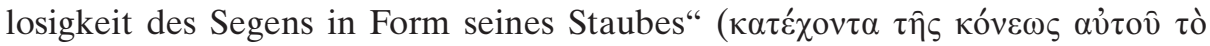

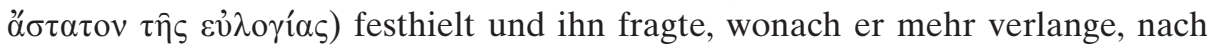
diesem Segen, welchen er schickte, oder nach seiner rechten Hand. Darauf bat der Priester Symeon, nicht mehr zornig zu sein, denn obschon sein Segen groß sei, habe er nach seiner rechten Hand verlangt. Da streckte Symeon seine rechte Hand aus und segnete ihn. Er warf ihm aber auch vor, an seinen Worten gezweifelt zu haben. Nach einigen Tagen erkrankte ein dritter Sohn des Priesters und bat seinen Vater, ihn zum heiligen Symeon zu bringen. Doch der Priester erwiderte, dass Symeon auch die Fähigkeit habe, ihn hier zu besuchen und zu

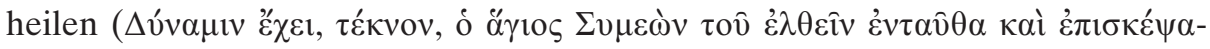

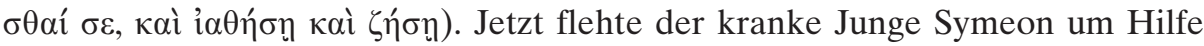
an. Den Vater forderte er auf, Weihrauch zu verbrennen und zu beten. Der heilige Symeon stehe nämlich mit einem eisernen Stab und einer feurig roten

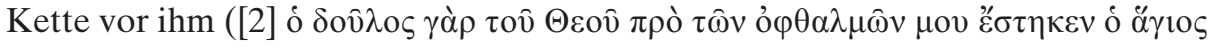

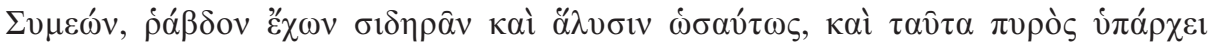
$\pi \lambda \eta \rho^{\circ} \varsigma^{-}$. Er sah auch einen schwarzen und furchterregenden Dämon ohne Kopf. Diesen fesselte Symeon und fragte ihn, ob er nicht den Befehl bekommen

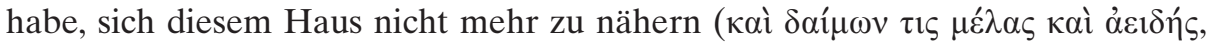

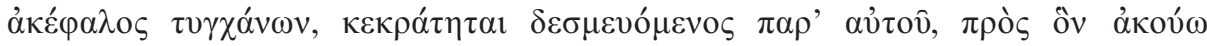

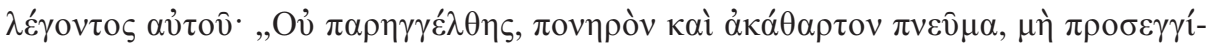

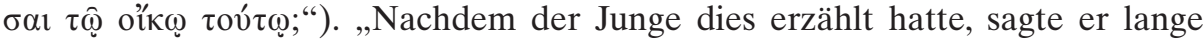

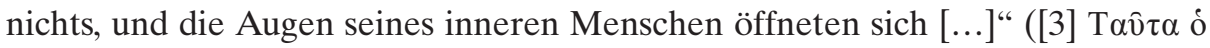

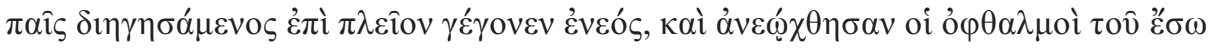
aঠ̉ meon den Dämon mit hinter dem Rücken gefesselten Händen zu seiner Säule führe. Dort werfe er ihn in einen von Symeon entfachten Feuerofen und lasse ihn heulend verbrennen. Nachdem der Junge dies erzählt hatte, war er geheilt

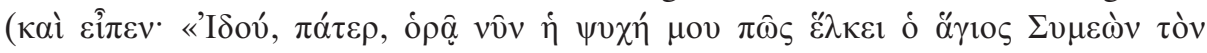

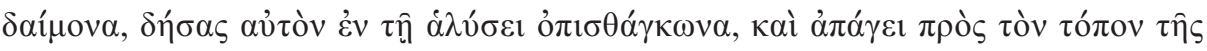

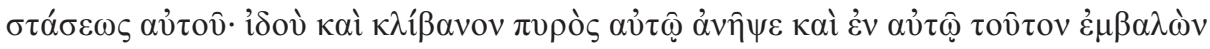

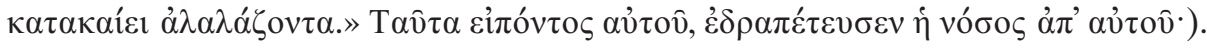
280. ViSyStII 243, Bd. 1, p. 217,21-218,8: „Die Jungfrau Theosebeia war von einem wilden Dämon besessen, der sie häufig ins Wasser warf, um sie zu ertränken. Bevor sie zu Symeon kam, sah sie ihn oft, wie er sie zu sich rief ([1] Прò

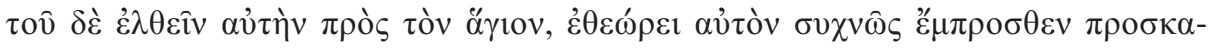

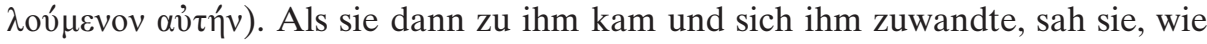

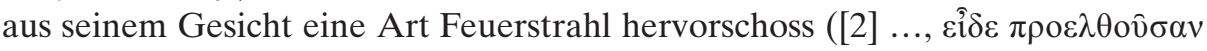




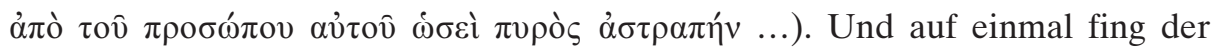
Dämon an zu heulen und bat Symeon, von ihr ausfahren zu dürfen. Jetzt geriet die Jungfrau in Ekstase und sah, wie der heilige Mann den Dämon fesselte (Kaì

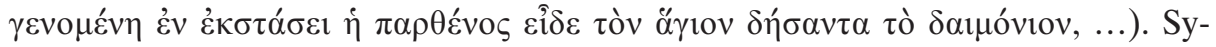
meon war bekleidet mit einem Gewand aus Licht, auf dem Kopf.trug er eine Krone, über der ein Kreuz leuchtete, und auf seiner Stirn prangten Sterne. Der Dämon aber fuhr als dunkler Inder durch die Schulter des Mädchens aus. Nachdem die Jungfrau dies gesehen hatte, wurde sie Nonne und blieb es bis zu

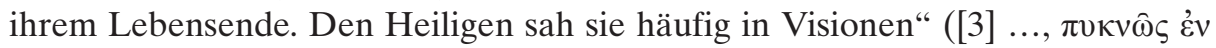

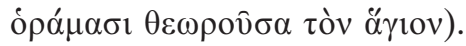

281. ViThSy 17, p. 14,31-15,11: „Eines Tages brachte der Dämon wegen der Kälte eine Krankheit über den kleinen Theodoros, sodass er sich nicht mehr

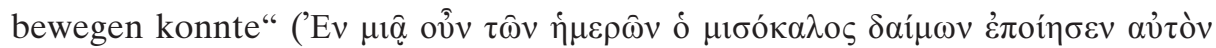

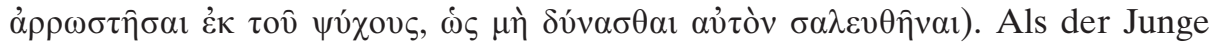
einschlief, trat der heilige Georgios an ihn heran und fragte, wer ihn krank gemacht habe. Theodoros sah jetzt vor sich einen schwarzen Dämon stehen

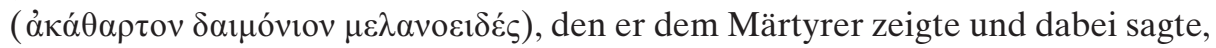
dass ihm dieses verabscheuungswürdige Ding die Krankheit gebracht habe. Darauf folterte Georgios den Dämon heftig und vertrieb ihn vom Jungen, den er an der Hand nahm und wegführte. Dann sagte er zu ihm, er solle von seiner Krankheit aufstehen und gesund sein. In Zukunft werde nämlich kein listiger Dämon mehr vor ihm erscheinen. Sogleich wachte der Junge auf und war gesund.

282. ViThSy 46, p. 41,3-22: Theodoros trieb bei einem Knaben namens Arsinos einen Dämon aus. Als er für den Jungen betete, ,fing dieser durch die Bewegung des Dämons an, Qualen zu erleiden. Er wurde gleichsam von der Erde gehoben, schwebte in der Luft und sagte: ,Ich fahre aus, Eisenesser, löse mich, und ich geh weg'. Und als er dies gesagt hatte, sah er auf einmal den Märtyrer Christophoros kommen, der sich mit Theodoros treffen wollte. Jetzt heulte der Dämon noch mehr und quälte den Knaben. Dann warf er ihn zu Boden und fuhr

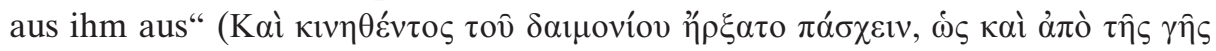

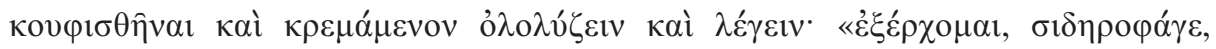

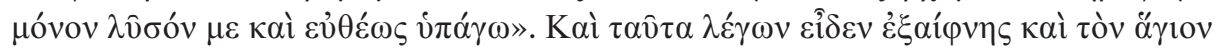

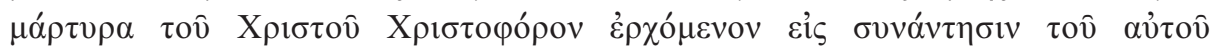

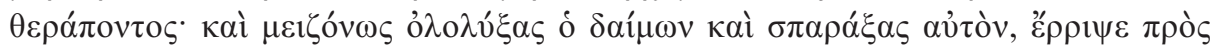

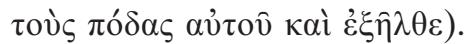

283. ViThSy 77, p. 64,32-65,12: Eines Tages wurde Theodoros von einigen vergiftet. „Drei Tage lang hielt er sich ohne zu reden oder sich zu bewegen in seiner Zelle auf, sodass das Gerücht entstand, er sei gestorben. Nach dem

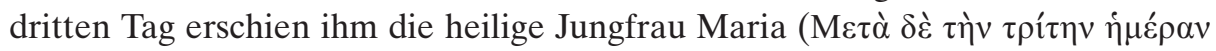

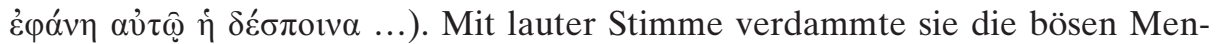
schen als Unglückselige und teilte Theodoros den Grund für seine Krankheit 
mit. Aus ihrem Tuch nahm sie drei Rizinusbeeren, gab sie ihm und sagte: ,Iss dies, dann wird dir in Zukunft kein Übel mehr zustoßen'. Er schien die Beeren

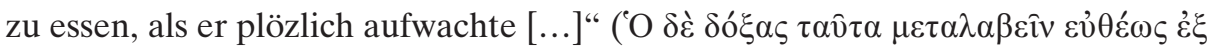

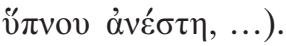

284. ViThSy 86, p. 72,24-27: Ein besessener Junge sah bei der Dämonenaustreibung, wie eine schwarze Frau schreiend und wehklagend aus ihm herausfuhr und von Theodoros aus der Tür gejagt wurde (

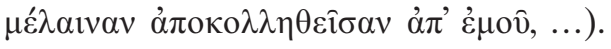

285. ViThSy 88, p. 73,7-25: Ein durch dämonische Besessenheit am ganzen Körper Erkrankter flehte Theodoros um Hilfe an. Dieser verabreichte ihm Wein und Öl und befahl ihm, nach Hause zu gehen. Wenn er sich zum Schlafen aufs Bett lege, solle er sich damit einreiben, und was er danach im Traum sehe,

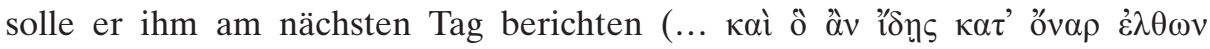
$\dot{\alpha} \pi \alpha \gamma \gamma \varepsilon \lambda \varepsilon \hat{\imath} \zeta \mu \mathrm{o})$. Der Besessene ging und tat, wie ihm der heilige Mann befohlen hatte. Am nächsten Tag erzählte er Theodoros, er habe im Schlaf einen Jüngling mit Umhang gesehen, der von Theodoros zu ihm geschickt worden sei (દî̉ov,

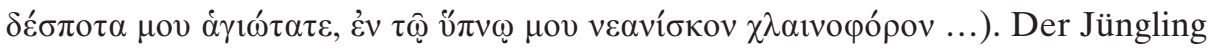
habe ihn am Kopf angefasst und ihn zu Theodoros geführt. Sogleich habe sich der ganze Schmerz in den Gelenken gelöst, und durch die Kopfhaare sei ein heftiger Wind entwichen. Nachdem er dies erzählt hatte, sagte ihm Theodoros, er sei jetzt gesund. Der Jüngling, der ihm im Schlaf erschienen sei, sei der heilige

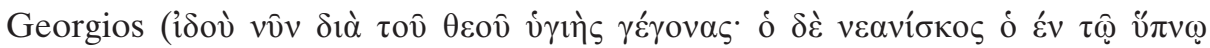

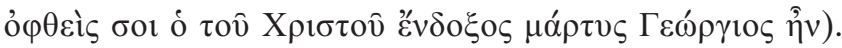

286. ViThSy 89, p. 73, p. 73,26-74,25: „Ein silentiarios ${ }^{765}$ ersten Ranges namens Mannas wurde durch dämonische Kräfte von einem verborgenen Leiden an den inneren Organen befallen". Auf sein Bitten hin besuchte ihn eines Tages der heilige Theodoros, um die Dämonen zu vertreiben und das ganze Haus zu segnen. „In der selben Nacht sah Iulianos, ein Schüler von Theodoros, nachdem er die vorgeschriebene Psalmodie vollendet hatte, im Traum, wie der heilige

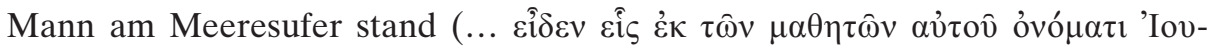

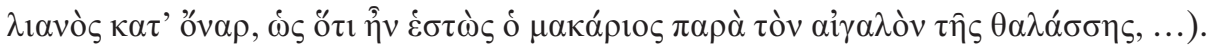
Dann trat Mannas heran und hielt in seinen Armen ein großes, dreiköpfiges und fürchterlich brüllendes Wildschwein, das er Theodoros überbrachte. Als der Heilige es ergriff, verwandelte es sich in eine kleine Katze, die er in die Meeresbrandung warf". Am nächsten Tag sagte Theodoros zu Mannas, dass das Übel von ihm vertrieben worden sei. „Und im selben Augenblick erinnerte sich

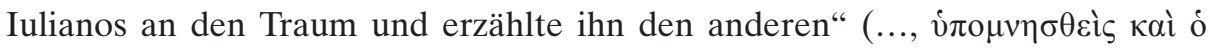

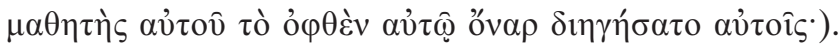

765 Kaiserlicher Hofbeamte, dessen wichtigste Aufgabe die Herstellung von Ordnung und Ruhe im Palast war, s. dazu A. Kazhdan, Art. Silentiarios, in: ODB 3, 1896. 
287. ViThSy 132, p. 105,15-17: Theodoros heilte auf einem Schiff einen Be-

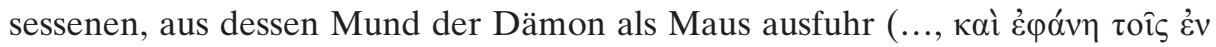

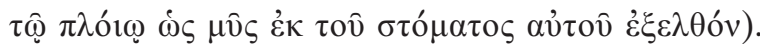

288. ViThSy 162, p. 148,18-22: Theodoros heilte einen Besessenen, der den

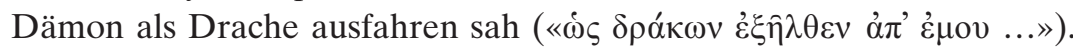

\section{Andere Heilungen}

289. ApSy III 38, Bd.1, p. 107-172: Ein Bruder zog in die Wüste, um seine Seele zu retten, verbrachte aber ein Asketenleben in Unachtsamkeit. „Irgendwann starb seine Mutter. Nach einiger Zeit wurde er schwer krank und geriet in Ekstase. Dabei wurde er vors Gericht gezerrt, wo er seine Mutter inmitten der

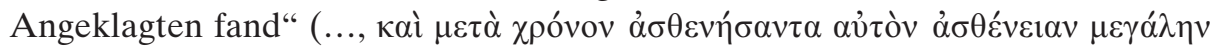

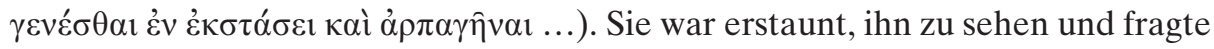
ihn, ob er auch an diesen Ort verdammt sei und was nun mit seinem Vorsatz, seine Seele zu retten, geschehen sei. ,Verwirrt durch diese Worte, stand er unter großen Qualen da und wusste nicht, was er antworten sollte. Gemäß dem Ratschluss Gottes geschah es aber, dass er, nachdem er dies gesehen hatte, von seiner Krankheit geheilt war".

290. ViMa 35, Bd. 2, p. 279,20-27: Als die Pest in der ganzen Umgebung wütete, wurde auch das Dorf Charandrama befallen, und viele erkrankten und flehten den Herrn um Rettung an. „Da sahen einige von ihnen in einer Vision den von brennenden Kerzen umgebenen Leichnam der Martha in ihrem Dorf und auf ihrer Erde. Dieser Schau folgte ein sichtbares Ende, denn von nun an wurde keiner mehr von der Pest ergriffen. Und diejenigen, die schon vorher

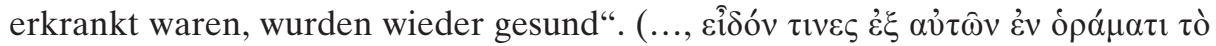

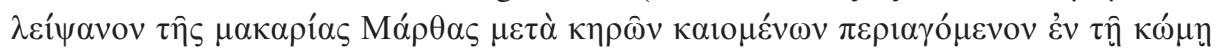

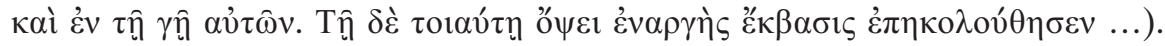

291. ViMa 38, Bd. 2, p. 281,18-282,22: Da Ioannes, der fromme anagnostes (vgl. auch 253), fürchterliche Schmerzen an den Augen hatte, sodass er kaum mehr sehen konnte, verbrachte er mehrere Tage schlaflos und betete ununterbrochen

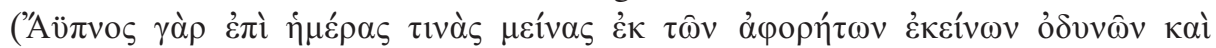

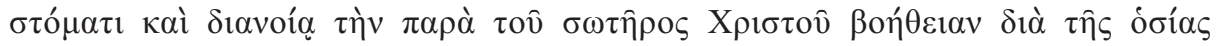

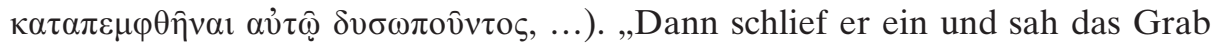

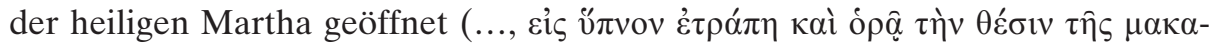

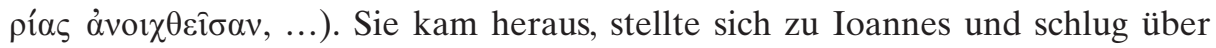
seinen Augen das Kreuz." Dabei sagte sie, er solle gesund werden und sich aufmachen, um ihren Leichnam zu beweihräuchern. Als er aufwachte, machte er sich auf den Weg zum heiligen Symeon ("E

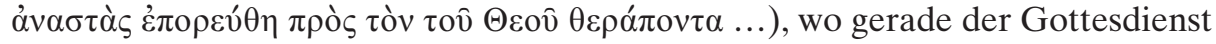
gefeiert wurde. Ioannes nahm das Weihrauchgefäß und fing an zu wedeln. Da 
die anderen erstaunt waren über diese Handlung, erzählte er ihnen die Vision

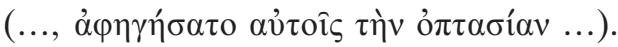

292. ViMa 44, Bd. 2, p. 286,12-287,4: „Bruder Ioannes wurde von einer schlimmen und lebensgefährlichen Krankheit heimgesucht, da er Symeon un-

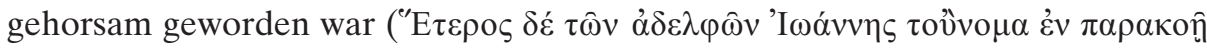

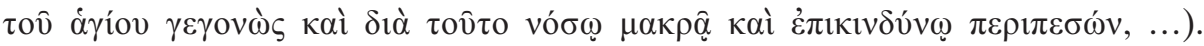
Eines Nachts, als er schon sterben wollte, schlief er tief ein und sah die Brüder,

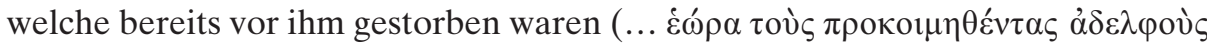
...). Sie freuten sich über sein Kommen, da er in Zukunft mit ihnen zusammen sein würde. Er sah auch den heiligen Engel dastehen und Martha, die über den Zustand des Bruders niedergeschlagen war. Sie flehte die Engel an, sie mögen verhindern, dass Ioannes schon jetzt aufgenommen werde. Dann sah Ioannes eine Leiter, die von der Erde bis in den Himmel reichte. Martha öffnete das Tor zum Himmel und trat in ein unbeschreibliches Licht ein. Dann stand sie vor dem Herrn und bat ihn, Ioannes am Leben zu lassen, und Ihre Bitte wurde erhört. Jetzt spürte sich Ioannes auf einmal wieder, doch er war verzweifelt und fürchtete sich ("H gekommen und seine Seele wieder hergestellt war, blieb er gesund" (... каi દiऽ

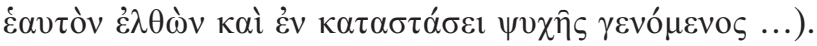

293. ViSyStII 54, Bd. 1, p. 48,21-27: „Ein Mann mit einem gänzlich verkrebsten Bauch rief den heiligen Symeon an. Da sah er ihn in seinem Haus (... عî̉ $\delta \varepsilon v$

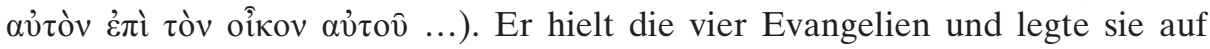
seinen Bauch. Sogleich wurde er geheilt".

294. ViSyStII 81, Bd.1, p. 68,24-69,4: „Ein gläubiger Mann, der schon seit

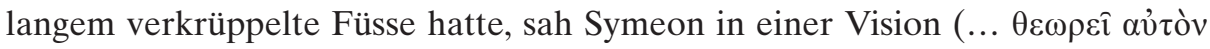
Ėv ópó́ $\mu \alpha \tau 1$...). Symeon hielt seinen Palmstab in der Hand, welchen er auf seine Füsse legte. Von diesem Augenblick an war er geheilt".

295. ViSyStII 129,87-147 Bd.1, p. 119,16-121,19: Nachdem der Lieblingsschüler des Symeon, Konon, gestorben war (vgl. 426), „sah der heilige Mann nach langem Beten in der achten Stunde, wie sich die Himmel öffneten (... عî̉ $\delta \varepsilon v$

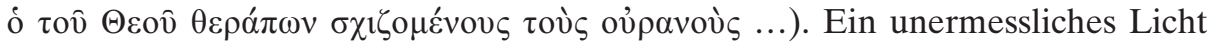
erstrahlte über dem Firmament, es glühte und leuchtete, als ob es die Sonne und das Tageslicht in den Schatten stellen wollte. Aus dem Osten hörte Symeon eine

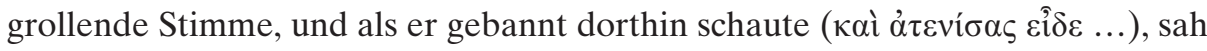
er einen großen Wagen mit vier Rädern und vier Pferden, der Symeon hinter der Säule von links nach rechts umrundete, dann zu ihm gelangte und anhielt. Drei Männer lenkten die Kutsche, ihre Kleider waren weiß wie Schnee, und die Pferde waren wie aus Gold. Der eine der Männer befand sich auf der rechten Seite zwischen zwei Pferden und zwei Rädern, der andere auf der linken Seite zwischen zwei Pferden und zwei Rädern, und der dritte befand sich hinter ihnen. Derjenige auf der rechten Seite befahl, die Kutsche bei Symeon stillstehen zu lassen und sie gegen Osten zu wenden. Die Pferde waren weiß wie Milch, ihre 
Nüstern und Gebisse voller Licht, und die Kutsche leuchtete in gleißendem Licht. Da kam aus dem Osten ein milder Windstoß. Und siehe, da war eine Gestalt des Firmaments, die gleichsam einen Saphir auf dem Rücken trug, und es erschienen die Hände von vier Männern, die gleichsam vor dem Altartuch das Kreuz schlugen und in einer unbeschreiblichen Furcht daherflogen. Über ihnen aber befand sich etwas Rundes, das den Sitzenden [Herrn] gleichzeitig in die Höhe hob und verdeckte. Die Gnade Gottes erschien in der Gestalt eines Menschen, von der Brust an aufwärts. Es waren viele tausende Engel anwesend, und sie umkreisten denjenigen, den man trug, schickten Strahlen los und leuchteten. Die einen waren luftig, die anderen feurig, wieder andere aber waren wie die Sonne. Und sie standen über dem Diener Gottes. Sie wurden aber überragt von Michael, der in seiner Wortgewalt dabeistand. Denn während alle anderen den Kopf senkten, intervenierte er als einziger durch die Stimme Gottes, und man hörte das Gerede über ihn: ,Dies ist Michael, der Symeon, den Heiligen Gottes, liebt‘. Von der Säule bis zu den fürchterlichen Männern, die den Saphir trugen, und dem Wesen in Menschengestalt, stiegen die himmlischen Mächte in einer einzigen Erschütterung gleichsam in den Himmel auf. Mit ihnen

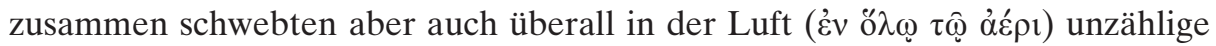
unterschiedliche Engel empor, die in einem immensen, für irdische Geschöpfe unerträglichen Licht erstrahlten. Und sie befanden sich dicht beieinander, sodass ihre Gesichter aussahen, als wären sie miteinander verbunden. Die Stimme des Herrn ertönte wie die eines Machthabers und verkündete die Wiederher-

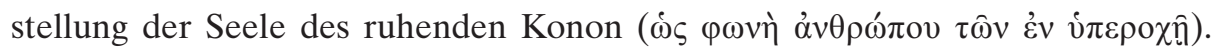
Michael sagte zu Symeon: ,Der Herr fordert noch ein wenig [von Konons Leben]'. Und die vier Männer mit dem Saphirwerk näherten sich. Es waren die Cherubim, wie Symeon durch den heiligen Geist wusste. Mit Furcht und Zittern gaben sie den himmlischen Mächten, mit denen sie zum Firmament schwebten, das Zeichen, ihr Schweigen noch zu vergrößern. Und der zweite Ruf des Herrn kündigte die Wiederherstellung der Seele Konons an. Und erneut sagte Michael: ,Der Schöpfer fordert noch ein wenig‘. Dann sagte der Herr: ,Kommt, jetzt wird er wieder hergestellt‘. Und als er sich versteckte und den Blicken entschwand, beschloss der Schöpfer, dass seinem Diener Symeon eine Truppe seiner fähigsten Engel gegeben werden soll, damit es ihm möglich sei, sich mit einer noch größeren Widerstandskraft gegen jeden schlechten Geist zu wenden. Darauf erschien von jeder Seite der Säule eine himmlische Truppe, und Symeon rief: ,Konon, steh auf, derjenige, der Lazarus am vierten Tag gerufen hat, ruft dich durch meine Stimme'. Tatsächlich wurde Symeon erhört, und Konon öffnete die Augen und stand auf".

296. ViSyStII 156, Bd. 1, p. 137,19-138,5: „Man brachte einen Blinden zu Symeon, der noch in der gleichen Nacht einen leuchtenden Jüngling mit einem Fellkleid und nackten Füssen sah, mit einem Palmstab in der Hand und en-

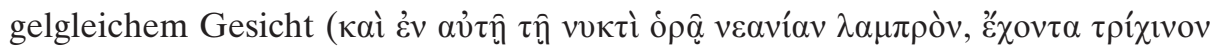




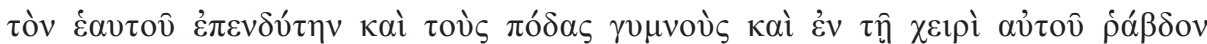

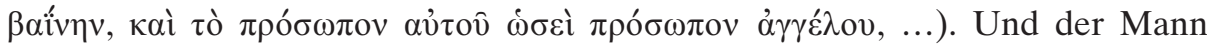
glaubte, schon jetzt in Wirklichkeit seine Hand zu halten und zu küssen (...,

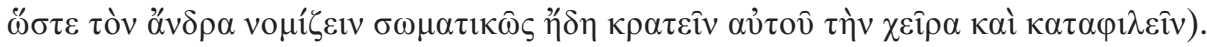
Und der Jüngling sagte zu ihm: ,Erweise Gott Ehre!‘. Doch plötzlich wurde er

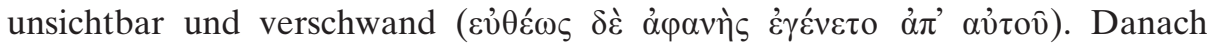
brachte man den Blinden zu Symeon. Als dieser seine Augen mit dem Zeichen des Gottessohnes bekreuzigte, schaute der Blinde sogleich auf, erkannte die Erscheinung des Heiligen wieder und sagte zu allen: ,Das ist derjenige, den ich

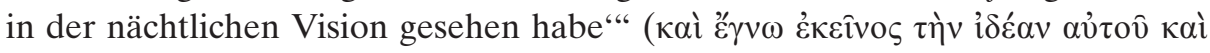

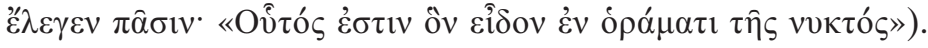

297. ViSyStII 163, Bd.1, p. 145,10-20: Ein kranker Bettler in der Stadt „sah

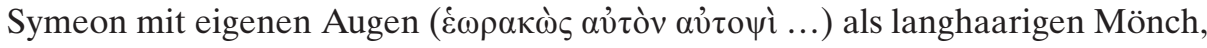
der seine Hand ausstreckte und ihn aufrichtete. Symeon wurde begleitet von der Mutter Gottes und einer Menge von Heiligen, welche sich über die Widerlegung und Verurteilung der Heiden freuten. Dies war nämlich das Paradies Gottes, welches alles überdeckte und von dem Symeon vorher gesagt hatte, es in der

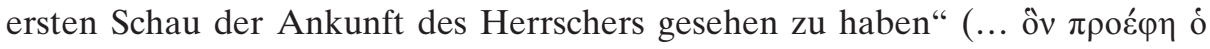

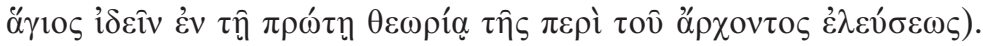

298. ViSyStII 192, Bd. 1, p. 170,12-20: Ein fünfzehnjähriges Mädchen wurde vom Vater zu Symeon gebracht, da es von Geburt an stumm war. Doch Symeon schickte die beiden nach Hause zurück. Denn Gott sei es nicht unmöglich, sie auf dem offenen Meer zu besuchen und die Tochter wieder zum Sprechen zu bringen. „Als sie dann auf dem Meer segelten, stattete ihnen der Herr durch

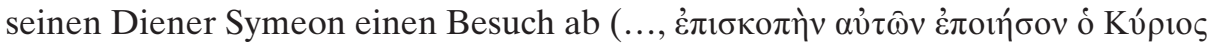

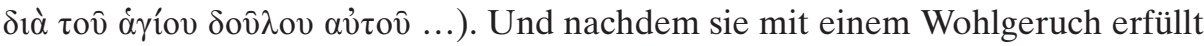
worden waren, fing das Mädchen an zu sprechen ...".

299. ViSyStII 195, Bd. 1, p. 172,12-173,6: Epiphanios, ein Diakon, „sagte aus Unwissenheit schlechte Dinge über den heiligen Symeon und diejenigen, die an

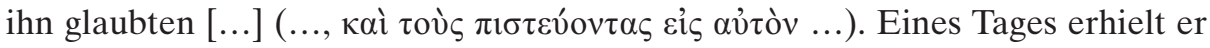
dafür durch die Gnade des heiligen Geistes, die in Symeon wohnte, die gerechte Strafe. Er fiel wie tot zu Boden, die inneren Organe seines Körpers zogen sich

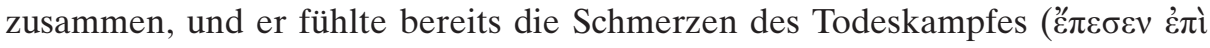

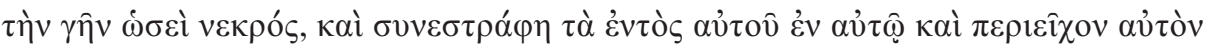

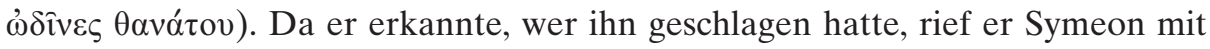
ganzer Kraft an und bat ihn, er möge ihm helfen." Darauf bekam er in einer

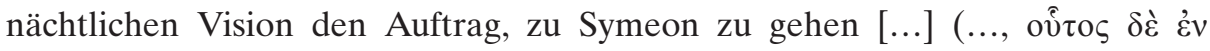

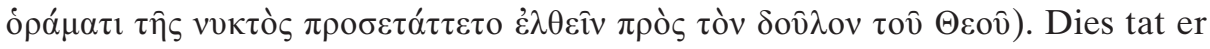
und er wurde geheilt.

300. ViSyStII 213, Bd. 1, p. 182,1-24: Eine Frau brachte ihre Tochter mit einer Krankheit am Geschlechtsteil zu Symeon. Dieser schickte sie nach Hause und

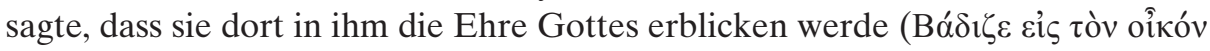




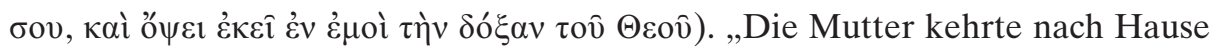
zurück. Als sie einschlief, sah sie den Heiligen in einer anderen Gestalt (..., ช゙ ihr: ,Hol das Mädchen und entblösse es, damit wir sehen können, woran es

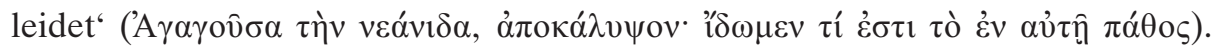
Dies tat sie und sah, wie Symeon mit den Fingern die beiden Tumore des Mädchens aufschnitt, sie wie zwei Eier herausnahm und die Wunden wieder

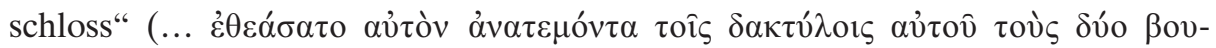

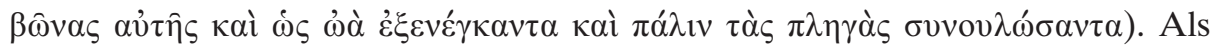
Symeon darauf das Haus verließ, fragte ihn die Mutter des Mädchens, wer er sei. Er fragte sie, ob sie sich nicht an denjenigen erinnere, den sie besucht und der sie wieder nach Hause geschickt hatte, damit sie dort in ihm die Gnade Gottes erblicken werde? „[...] Dann wurde er unsichtbar (..., à

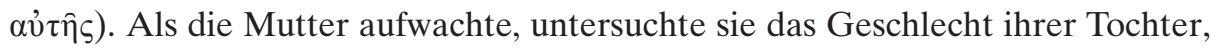
und tatsächlich war ihr Leiden weg“".

301. ViSyStII 230, Bd. 1, p. 203,9-26: Ein gewisser Babylas erblindete an beiden Augen, da in ihnen myokephaloi ${ }^{766}$ wuchsen. Er wurde zu verschiedenen Ärzten gebracht, bei denen er jedoch keine Heilung fand. Dann rief er Symeon um Hilfe an. „Und noch in der selben Nacht sah er den Heiligen ins Kran-

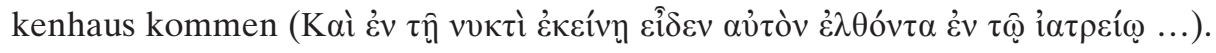
Er saß auf einem weißen Pferd“, gab ihm die Hand und forderte ihn auf, zum wunderbaren Berg hochzublicken. Sogleich stand der Blinde auf, erhob den Kopf zum wunderbaren Berg und betete zu Christus, er möge ihn wieder sehend machen. „Und plötzlich schmolzen die myokephaloi wie Wachs vor dem Feuer, und Babylas sah wieder ansatzweise." Darauf ging er zum Heiligen und erzählte

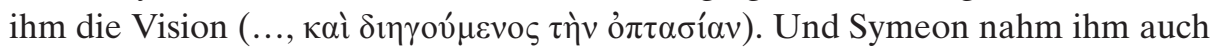
den Rest seiner Blindheit.

302. ViSyStII 242, Bd.1, p. 217,9-20: Ioannes, der seit langem verkrüppelte Beine hatte, betete zu Symeon, er möge ihn heilen. „Eines Tages sah er in der dritten Stunde in einer Vision zwei weißgekleidete Engel, die rechts und links

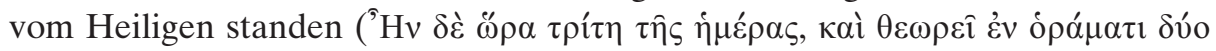

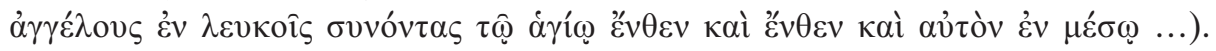
Symeon befand sich in der Mitte und hielt seinen Palmstab, mit welchem er die Füsse des Ioannes bekreuzigte. Dabei sagte er zu ihm: ,Im Namen unseres Herrn Jesus Christus, werde gesund!““. Danach war Ioannes geheilt.

303. ViThSy 39, p. 34,28-35,35: Eines Tages ,wurde der heilige Theodoros von einer schweren Krankheit heimgesucht, sodass er bereits die heiligen Engel zu

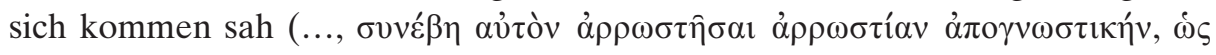

766 Eine tumorartige Augenkrankheit, die sich durch eine Entzündung der Membran zwischen dem äußeren Augenmantel und der Netzhaut äußert, s. VAN DEN VEN, La vie ancienne, Bd. 2, 229, A. 1. 


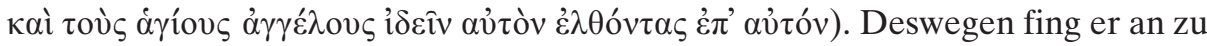
weinen und zu wehklagen. Doch über ihm hing ein Bild der heiligen Kosmas

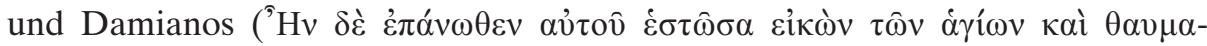

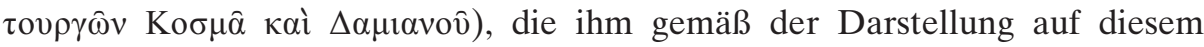

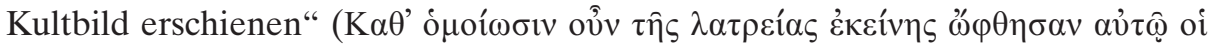

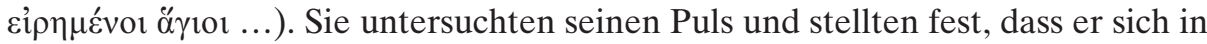
einem hoffnungslosen Zustand befand. Dann fragten sie ihn, warum er weine. Theodoros antwortete, er habe nicht gebüsst und seine kleine Herde benötige ihn noch zur Belehrung und Ordnung. Darauf schlugen die Heiligen vor, sich für die Verlängerung seines Lebens einzusetzen. Nachdem Theodoros diesem Vorschlag zugestimmt hatte, ,wandten sich die Heiligen an die Engel und baten diese solange darum, ihm noch ein wenig Zeit zu gewähren, bis sie losschwebten und den himmlischen König für ihn anflehten. Kosmas und Damianos gaben sie das Zeichen, auf sie zu warten. Als sie wieder zu Theodoros zurückkamen, hielten sie in ihrer Mitte einen überaus großen Jüngling, der aussah wie die anwesenden Engel, sich aber durch einen noch größeren Glanz von diesen unterschied“". Er sagte zu den Engeln, sie sollen weggehen von Theodoros, da es diesem gewährt worden sei, noch ein wenig länger im Fleisch zu leben. Auf der Stelle verschwand der Jüngling zusammen mit den Engeln, die zum Himmel

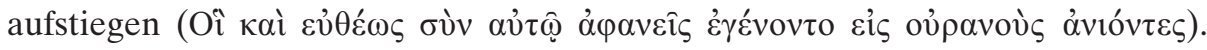
Kosmas und Damianos aber befahlen Theodoros aufzustehen, um auf sich und auf seine Herde achtzugeben, da Gott es ihm gewährt habe, noch länger zu leben. „Nachdem sie ihm dies gesagt hatten, wurden auch sie unsichtbar“ (Kaì

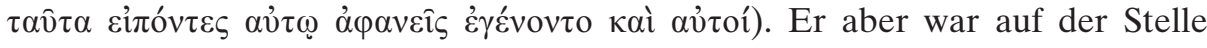
gesund. 


\section{K. Vergebung von Sünden}

304. ApSy V 43, Bd. 1, p. 284-288: Ein Bruder wurde vom Geist der Unzucht heimgesucht, verliebte sich in die Tochter eines Priesters und hielt um ihre Hand an. Der Vater des Mädchens fragte den Dämon, was er tun solle. Dieser antwortete, er solle die Tochter nur unter der Bedingung weggeben, dass der Bruder der Taufe und dem Mönchsleben abschwöre. Der Bruder war bereit, dies zu tun. Nachdem er aber den Schwur abgelegt hatte, sah er eine Taube aus

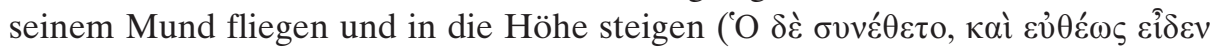

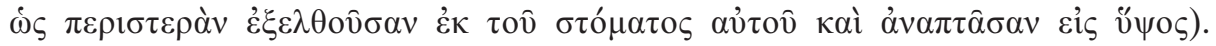
Daraufhin riet der Dämon dem Priester, seine Tochter nicht wegzugeben, da sich Gott noch nicht wirklich vom Bruder getrennt habe. Als der letztere davon erfuhr, kam er zur Besinnung, bat Gott um Hilfe und zog in die Wüste zu einem Mönch, dem er alles erzählte. Dieser forderte ihn auf, drei Wochen bei ihm zu bleiben und fing an, für sein Seelenheil zu beten. Als er den Mönch nach einer

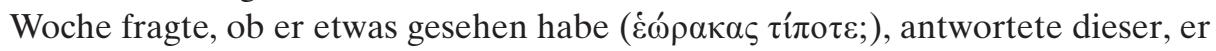
habe eine Taube im Himmel gesehen, die über seinem Kopf stillstand (Naì

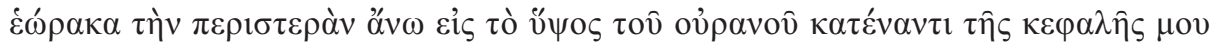
$\dot{\varepsilon} \sigma \tau \hat{\omega} \sigma \alpha v)$. In der zweiten Woche sah er eine Taube, die sich auf seinen Kopf

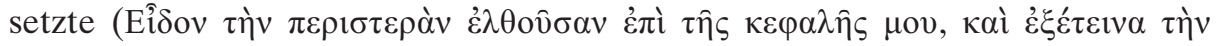

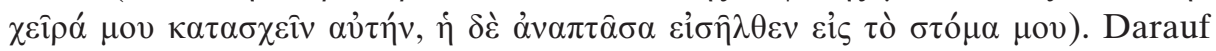
riet ihm der Mönch, zu wachen und zu beten. In der dritten Woche sah der Bruder schließlich, wie die Taube herbeiflog und über seinem Kopf stillstand

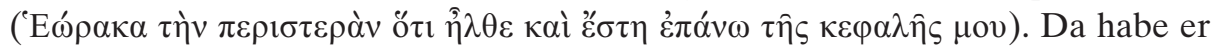
seine Hand ausgestreckt, um sie zu ergreifen; sie aber sei aufgeschreckt und in seinen Mund hineingeflogen. Jetzt dankte der Mönch Gott dafür, dass er die Reue des Bruders angenommen hatte.

305. HiMo 1,58, p. 25,24-30: Ein vom Teufel geprüfter Mönch zog sich in die Wüste zurück und verbrachte den Rest seines Lebens in Kummer. Er sperrte sich in einer Höhle ein, legte sich auf Asche und erhob sich nicht eher vom Boden und hörte nicht auf zu jammern, bis er die Stimme eines Engels vernahm,

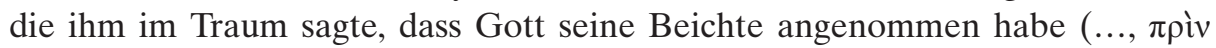

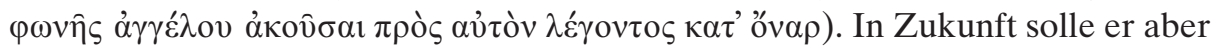
achtgeben, dass er nicht sündige.

306. ViIoEl 59, Bd. 2, p. 405,25-407,33: Eine Frau ging zum heiligen Ioannes, um ihm eine Sünde zu beichten. Sie schämte sich jedoch so sehr über die von ihr begangene Tat, dass sie sie in einem versiegelten Schreiben dem heiligen Mann übergab, damit niemand davon erfahre. Doch fünf Tage später starb der Heilige, 
ohne dass die Frau irgendwelche Anweisungen bezüglich des Schreibens hinterlassen hatte. Am Todestag des Ioannes befand sie sich zufälligerweise nicht in der Stadt und erfuhr deshalb erst einen Tag später von seinem Hinscheiden. Darüber geriet sie außer sich, da sie fürchtete, ihr Schreiben sei im Bischofsgebäude zurückgelassen worden, sodass ihre Sünde inzwischen öffentlich bekannt geworden sei. Sofort ging sie zum Grab des Heiligen und redete mit ihm, als ob er noch lebendig gewesen wäre und verbrachte drei Tage ohne zu essen

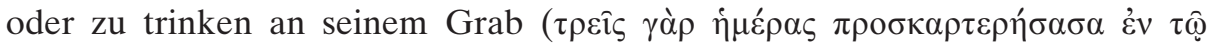

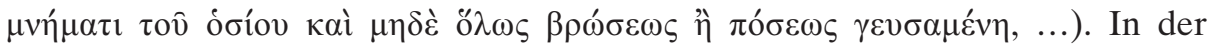
dritten Nacht stieg Ioannes mit den beiden mit ihm begrabenen Bischöfen zu

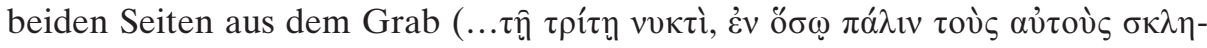

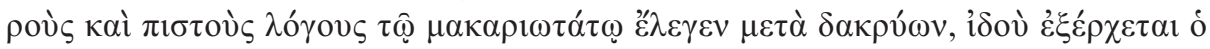

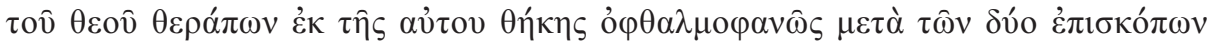

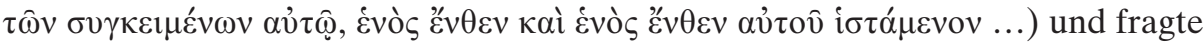
sie, wie lange sie noch die hier Bestatteten stören wolle und ihnen ihre Ruhe nicht gönne. Ihre Gewänder seien schon nass von ihren Tränen. Mit diesen Worten gab ihr Ioannes das versiegelte Schreiben und befahl ihr, es zu öffnen und zu lesen. „Als sie aus ihrer Vision erwachte, sah sie, dass die Heiligen wieder an ihren Platz zurückgekehrt waren und dass sie ihr Schreiben in der

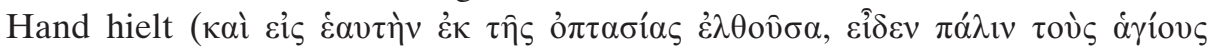

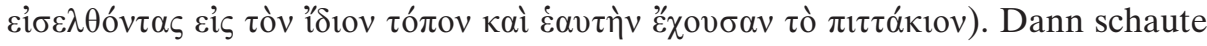
sie sich dieses genauer an und sah, dass das Siegel noch verschlossen war. Als sie es öffnete, stellte sie fest, dass ihr Schreiben ausgelöscht war und stattdessen folgende Worte zu lesen waren: ,Durch meinen Diener Ioannes wurde dir die Sünde vergeben““.

307. ViPa 23, Halkin 1982, p. 17,19-25: Nachdem Pachomios bereits zahlreichen dämonischen Erscheinungen standgehalten hatte, „befand er sich eines Tages mit den anderen Brüdern auf einer Insel, um Binsen zu schneiden. Er war gerade dabei zu wachen und für sich alleine zu beten, um den Willen Gottes zu erfahren, als ihm ein Engel des Herrn erschien, sowie er auch Manoah und

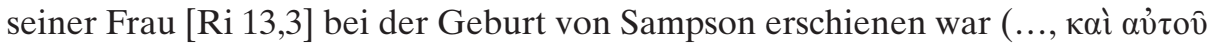

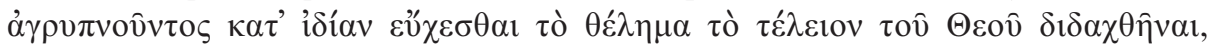

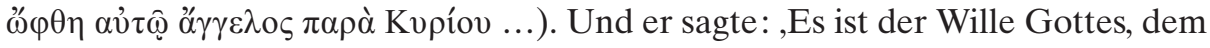
Menschengeschlecht zu dienen, um ihm die Sünden zu vergeben'. Nachdem er dies dreimal gesagt hatte, verschwand er".

308. PrSp 143, 87.3, col. 3005B-D: David, der Dieb, bereute eines Tages all seine Sünden und beschloss, ins Kloster zu gehen und das Mönchsgewand zu nehmen. Er fing an, hart zu kämpfen, und bald übertraf er alle anderen im Kloster an Enthaltsamkeit, Gehorsam und Demut. Als er eines Tages in seiner Zelle saß, trat ein Engel des Herrn zu ihm und verkündete, dass der Herr ihm seine Sünden vergeben habe und dass er von nun an Wunder wirken werde ('Ev

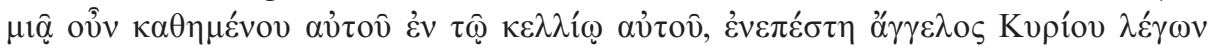




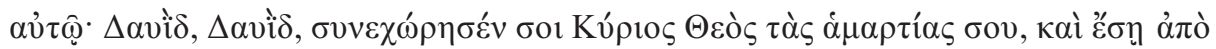

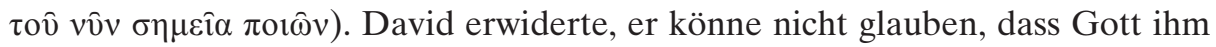
nach so kurzer Zeit all seine Sünden, die so zahlreich seien wie Sand am Meer, vergeben habe. Darauf sagte der Engel, dass er ihn nicht unbestraft lassen könne, da er auch die Zunge des heiligen Zacharias gebunden habe, als er ihm wegen seines Sohnes nicht glauben wollte. Dies habe er getan, um ihn zu belehren, dass dem von ihm Gesagten nicht zu misstrauen sei. Deswegen solle von nun an auch David nicht mehr reden. Dieser aber verstand nicht, warum er, als er in der Welt Frevel- und Mordtaten vollbrachte, reden konnte und jetzt, wo er Gott pries, seine Zunge gebunden werden sollte. Der Engel antwortete ihm, er werde von nun an nur noch beim Kanon reden können, ansonsten werde er aber schweigen [vgl. auch „Bestrafungen"].

309. PrSp 165, PG 87.3, 3032B-D: Kyriakos war der Anführer einer Räuberbande. Seine Leute überfielen eines Tages in seiner Abwesenheit eine aus der heiligen Stadt zurückkehrende Pilgergruppe und metzelten sämtliche Kinder nieder. Die Männer der Pilgergruppe ergriffen die Flucht und trafen auf dem Weg auf Kyriakos. Als dieser erfuhr, was passiert war, eilte er zum Tatort und sah das von den anderen angerichtete Gemetzel. Darüber war er empört und er köpfte all jene, die das Leid vollbracht hatten. Die Leichen der Kinder ließ er auf den Grundstücken, von denen sie kamen, begraben. Kurz darauf wurde Kyriakos gefasst und verbrachte zehn Jahre im Gefängnis. Die Machthaber brachten ihn jedoch nie um, sondern ließen ihn leben. Er selber sagte immer, dass er wegen dieser Kinder dem bitteren Tod entflohen sei. Denn er habe sie im Traum gesehen. Sie hätten zu ihm gesagt, er solle sich nicht fürchten, da sie

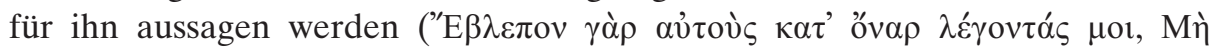


310. ScPa 4, PG 88, col. 721B-D: Ein junger Mönch namens Antiochos ließ sich in einem pontischen Kloster nieder. „In der ersten Nacht nach seiner Ankunft sah er im Schlaf, wie einige von ihm Rechenschaft forderten“ ([1] кà $\tau \hat{n}$

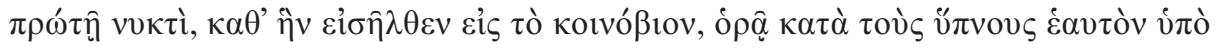
$\tau \iota v \omega v \lambda o \gamma o \theta \varepsilon \tau o v ́ \mu \varepsilon v o v$...). Am Ende der Verhandlung verlangten sie von ihm hundert Pfund Gold. Als er aufgewacht war, beurteilte er das Geschaute und bemitleidete sich selbst wegen der hohen Schulden, die er noch zu begleichen

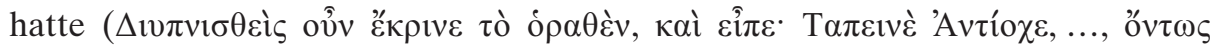

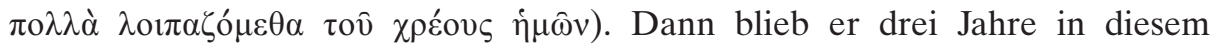
Kloster, als er wiederum jemanden im Schlaf sah, der ihm einen Beleg für zehn

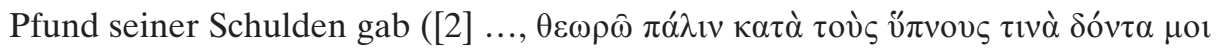

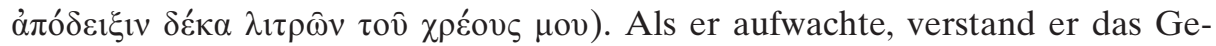

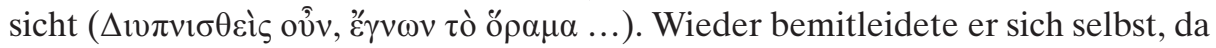
er noch so viele Schulden zu begleichen hatte. Dann sagte er sich, dass er noch mehr Anstrengung und Demütigung zu erleiden habe und fing an, den Verrückten zu spielen, sodass man ihm im Kloster die niedrigsten Aufgaben über- 
gab. Nach dreizehn Jahren sah er wieder die ihm vormals Erschienenen, und sie

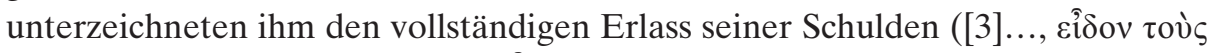

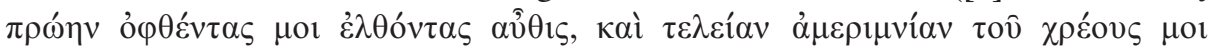

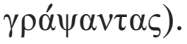




\section{Geburtsankündigungen}

311. ViDanSt 2, p. 2,11-3,13: Da Martha, die Mutter des Daniel Stylites, während langer Zeit kinderlos war und ihr deshalb von ihrem Mann Elias und ihren Verwandten Vorwürfe gemacht wurden, ging sie eines Nachts im Verborgenen hinaus und betete zu Gott, er möge ihr ein Kind schenken. „Dann ging sie wieder hinein, und während sie neben ihrem Mann schlief, sah sie in einer nächtlichen Vision zwei große, diskusförmige Leuchten, die vom Himmel

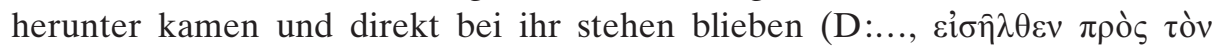

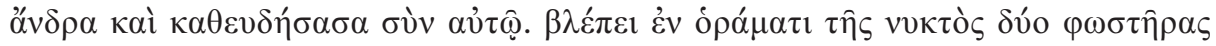

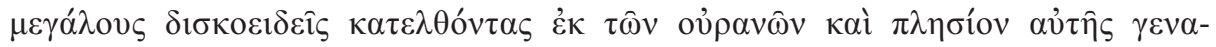

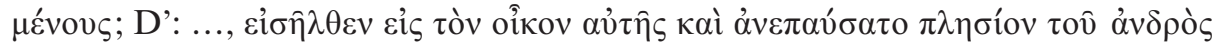

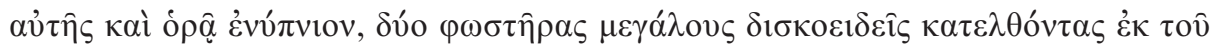

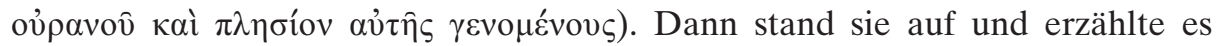
ihrem Mann und ihren Verwandten, und jeder beurteilte ihre Worte unter-

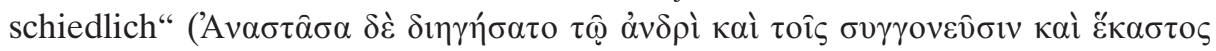

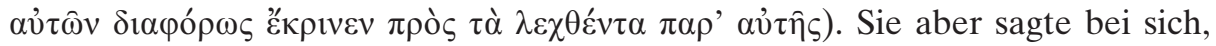
dass Gott am Besten wisse, was das Richtige für sie sei. Und es vergingen nur wenige Tage, bis sie mit Daniel schwanger wurde. (Das Bild der zwei Leuchten wird in 46, p. 44,3-13, wieder aufgenommen. Hier wird es erklärt mit dem Erscheinen des Kaisers Leo und seiner Frau zur Proskynese vor Daniels Säule

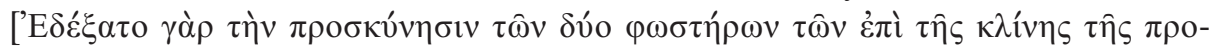

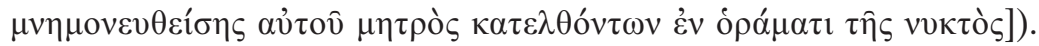

312. ViEu 2-3, p. 8,24-10,16: Dionysia, die Mutter des Euthymios, war schon mehrere Jahre verheiratet, konnte aber keine Kinder kriegen. Während langer Zeit betete sie zu Gott, er möge ihr ein Kind schenken. Eines Tages ging sie mit ihrem Mann zur Kapelle des Märtyrers Polyeuktos in der Nähe der Stadt, wo sich die beiden mehrere Tage aufhielten. Als sie sich eines Nachts beim Gebet befanden, zeigte sich ihnen eine göttliche Erscheinung, die sagte, sie sollen guten Mutes sein, denn Gott habe ihnen ein Kind geschenkt, welches den

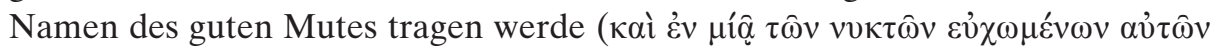

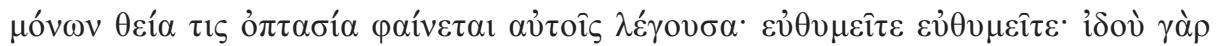

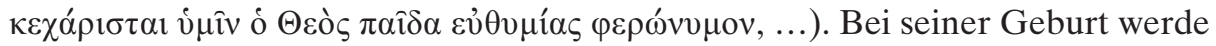
derjenige, der es ihnen schenke, auch seiner eigenen Kirche Mut zusprechen. „Nach dieser Vision kehrten sie nach Hause zurück. Und als Dionysia schwanger wurde, erkannte sie, dass die Verheißung der Vision eingetreten war

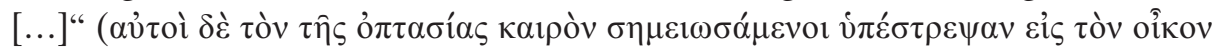

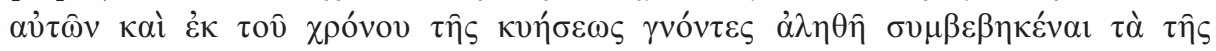


ỏ $\pi \alpha \sigma i ́ \alpha \varsigma$...). Das Kind wurde im August des vierten Konsulats des Gratian $\left(377^{767}\right)$ geboren. „Dass die Vision wahr ist, haben die Leser verstanden, denn die heiligen Kirchen befanden sich während fast vierzig Jahren in Hoffnungslosigkeit $(\dot{\alpha} \theta 0 \mu i ́ \alpha)[\ldots]$ “, als aber Euthymios geboren wurde, wendete sich alles

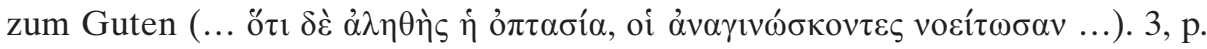
10,5-11,8: Als Euthymios drei Jahre alt war, starb Paulos, sein Vater. Da erfüllte Dionysia ihr Verprechen und brachte den Jungen zu ihrem Bruder Eudoxios, der dem Bischof beistand. Da dieser von der Vision der Eltern gehört

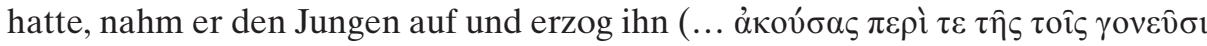

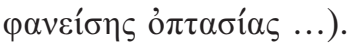

313. ViMac, 2,5-34, p. 144,2-148,4: Neben ihrem offiziellen Namen erhielt Makrina am Tag ihrer Geburt, kurz bevor sie das Licht der Welt erblickte, durch

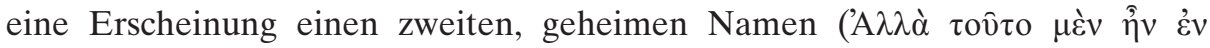


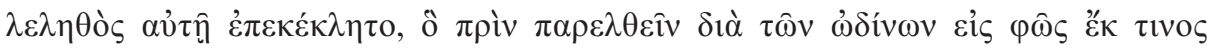

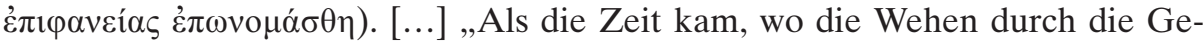
burt ein Ende nehmen sollten, schlief sie [die Mutter der Makrina] ein, und es schien ihr, dass sie in ihren Händen das Kind hielt, das sie noch in sich trug. Und es erschien jemand in übermenschlich prachtvoller Gestalt und Kleidung und sprach das Kind mit dem Namen Thekla an. Gemeint ist der Name von jener unter den Jungfrauen überaus berühmten Thekla. Nachdem die Gestalt dies dreimal getan hatte, verschwand sie aus ihrem Blick und brachte gleichzeitig ihren Schmerzen Erleichterung, so dass sie, als sie aus dem Schlaf erwachte, den Traum als Wirklichkeit erkannte. Dies war also ihr geheimer Name. Es scheint mir aber, dass der Erschienene dies nicht verkündete, um die Mutter bei der Namenswahl zu leiten, sondern vielmehr, um die Lebensweise des Kindes vorherzusagen und durch den gleichen Namen die Ähnlichkeit der Gesinnung

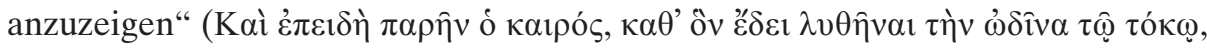

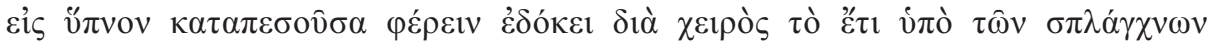

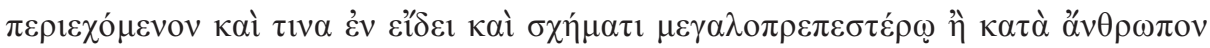

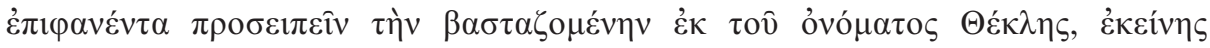

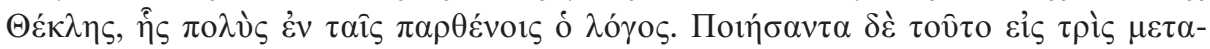

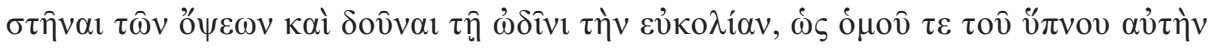

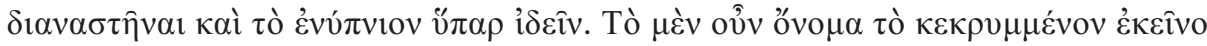

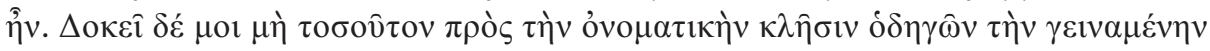

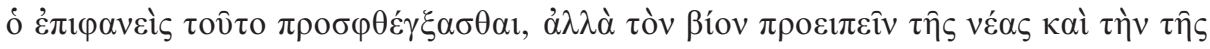

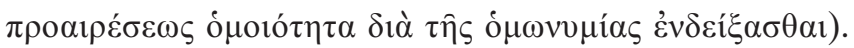

314. PhHi 13,16-17, Bd.1, p. 502,1-506,4: Die Mutter des Theodoret war während dreizehn Jahren ihrer Ehe kinderlos. Eines Tages aber versprach der mit der Prophetengabe ausgezeichnete Mönch Makedonios (13,15, Bd.1, p.

767 S. Festugière, Les moines, III/1, S. 60. 


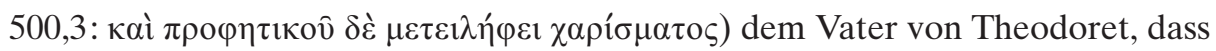
seine Frau schwanger werde und dass ihnen ein Gott geweihter Sohn geschenkt werde. Dieses Versprechen ging nach vier weiteren Jahren in Erfüllung. Doch als die Mutter des Theodoret im fünften Monat schwanger war, unterlag sie der Gefahr einer Frühgeburt. Ihr Zustand ließ es nicht zu, dass sie sich selber auf den Weg machte, weswegen sie einen Boten zu Makedonios schickte, um ihn an sein Versprechen zu erinnern. „Als Makedonios von weitem den Boten sah, erkannte er ihn sofort und wusste, warum er kam. Denn in der Nacht hatte ihm

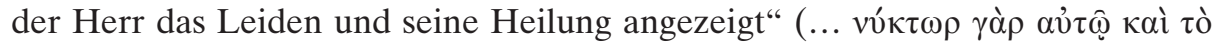

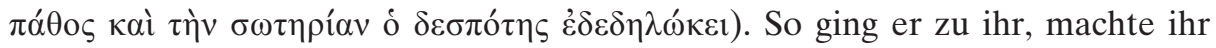
Mut und sagte, derjenige, der ihr die Frucht gegeben habe, werde sie ihr auch nicht wieder wegnehmen, wenn sie das Kind gemäß ihrem Versprechen dem Gottesdienst weihen werde.

315. ViSyStII 2, Bd. 1, p. 3,24-5,19: Nachdem die Heilige Martha (Mutter des Symeon Stylites Jun.) gegen ihren Willen mit Ioannes verheiratet worden war, „ging sie zur Kapelle des Heiligen Ioannes am Stadtrand von Antiocheia und betete dort, es möge ihr ein Sohn zum Dienste Christi geschenkt werden. Sie verharrte lange in der Kapelle und betete unter Tränen ohne zu essen und zu trinken. So saß sie am Boden und vollbrachte den körperlichen Schlaf ([1] ..., غ̇ं

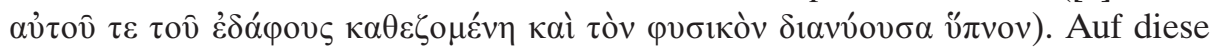
Weise verbrachte sie einige Zeit an jenem Ort, als sie eines Nachts mit eigenen

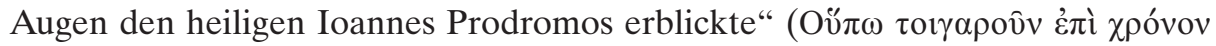

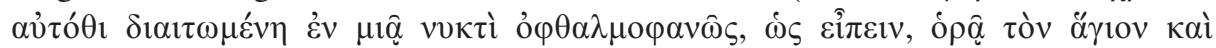

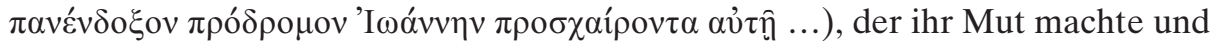
sie zum Beten aufforderte, denn ihr Wunsch werde in Erfüllung gehen. Als Beweis ( $\rceil \mu \varepsilon \hat{\imath} \mathbf{0}$ ) dafür gab er ihr Weihrauch, mit dem sie das Haus beweihräuchern sollte. Voll Furcht wachte Martha auf und fand in ihrer Hand eine große Kugel Weihrauch. „Als einige Zeit vergangen war, erschien ihr eines

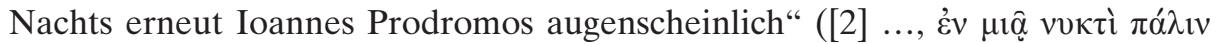

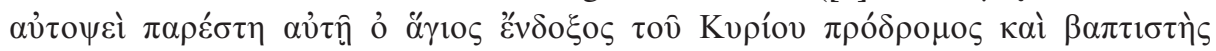

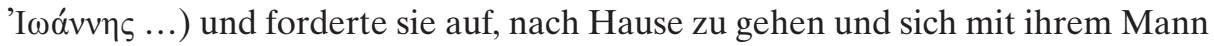
zu vereinigen, dann werde sie einen Sohn empfangen, den sie Symeon nennen solle. Ioannes Prodromos gab Martha eine Reihe von Anweisungen, die sie bei der Erziehung des Ioannes einzuhalten habe, z. B. ihm nur die rechte Brust zu geben und Symeon mit zwei Jahren in der Kapelle des Ioannes taufen zu lassen. „Als Martha aufwachte, war sie furchterfüllt, alle Glieder zogen sich zusammen

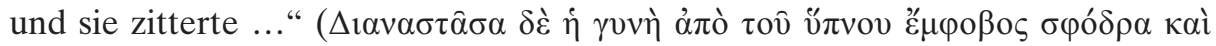

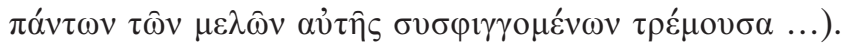

316. ViThSy 3-4, p. 3,9-4,19: Die Mutter des Theodoros von Sykeon, die Prostituierte Maria, sah, nachdem sie mit dem kaiserlichen Gesandten Kosmas geschlafen hatte, ,im Traum einen großen und leuchtenden Stern, der vom

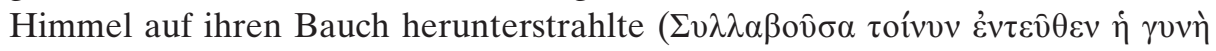




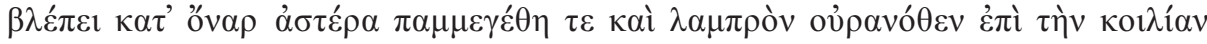

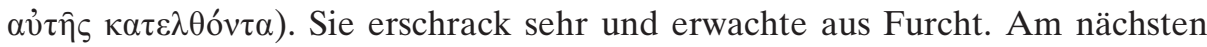

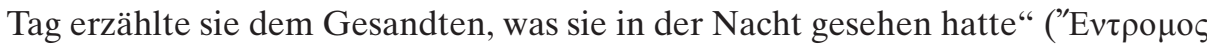

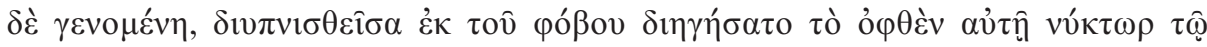
$\lambda \varepsilon \chi \theta \varepsilon \dot{\varepsilon} \tau \imath \mu \alpha \gamma(\sigma \tau \rho \alpha v \imath(\hat{)})$. Dieser erwiderte, sie solle auf sich achtgeben, da ihr Gott womöglich ein Kind schenke, das des Bischofsamtes würdig sei. Dararufhin zog er weiter. Maria ging zu einem mit der Prophetengabe ausgezeichneten Vater, der ihr ankündigte, dass der Sohn, den sie gebären werde, eine große Persönlichkeit sein werde. Zweifellos zeige ein leuchtender Stern bei den Traumdeutern eine kaiserliche Würde an. Über ihre Sache solle man aber nicht auf diese Weise sprechen. Das, was ihr mit einem leuchtenden Stern angezeigt werde, sei die strahlende Schönheit der Tugenden und Gaben Gottes, mit welchen der Herr das Kind in ihrem Bauch ausgezeichnet habe. Auch Theodosios, der Bischof von Anastasiupolis, interpretierte die Vision auf die gleiche Weise

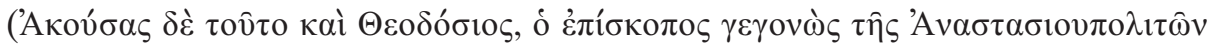

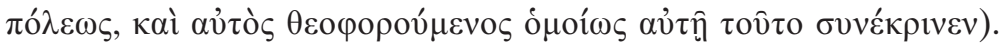




\section{Rettung in Notsituationen}

317. ApAl Zenon 5, PG 65, 177A-B: Zenon hielt sich in der Sketis auf, ,als er eines Nachts die Zelle verließ und sich verirrte. Drei Tage und drei Nächte irrte er herum. Dann war er derart abgekämpft und kraftlos, dass er hinfiel, um zu

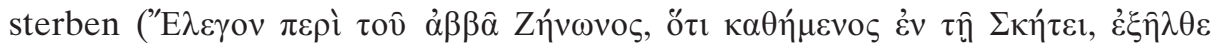

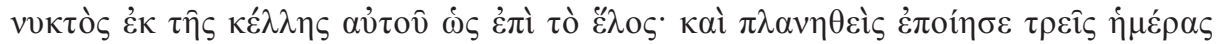

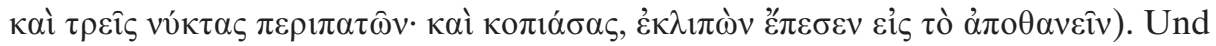
siehe, da trat ein Knabe zu ihm, der Brot und einen Becher Wasser bei sich hatte

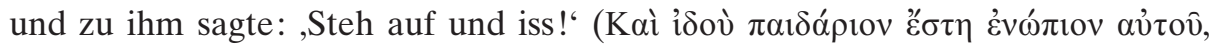

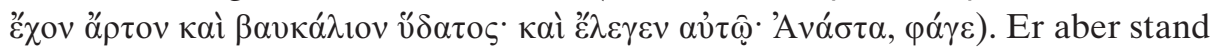

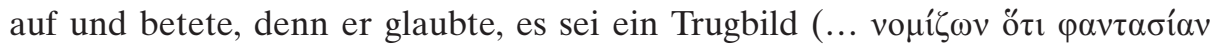

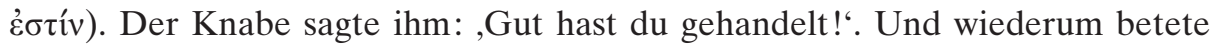
Zenon ein zweites und ein drittes mal. Und wieder sagte der Knabe: ,Gut hast du gehandelt!‘. Da stand Zenon auf, nahm und aß“. Danach sagte ihm der Knabe, er sei gerade so weit von seiner Zelle entfernt, wie er marschiert sei. Nun solle er aufstehen und ihm folgen. Und plötzlich befand sich Zenon wieder bei seiner Zelle. Er forderte den Knaben auf, zum gemeinsamen Gebet einzutreten. Doch dieser war verschwunden.

318. ViEu 43, p. 63,4-64,5: Der Diakon Phidos erlitt auf seiner Reise von Ioppe nach Konstantinopel Schiffbruch. In seiner Not fing er an, zum (bereits verstorbenen) heiligen Euthymios zu beten, er möge ihm helfen und ihn aus dieser Not befreien. „..., da erschien ihm Euthymios auf dem Wasser

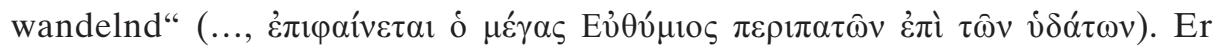
sagte zu Phidos, er solle sich nicht fürchten, denn er sei Euthymios, der Diener Gottes. Er solle erkennen, dass seine Reise nach Konstantinopel Gott nicht genehm sei, da sie seiner Kirche keinerlei Nutzen bringe. Vielmehr solle er in die Laura des Euthymios zurückkehren und dort ein koinobion bauen. „Als Phidos dies hörte, versprach er dem Heiligen, dies zu tun. Er wusste aber nicht, dass das, was geschah, wahr war, sondern glaubte viel-

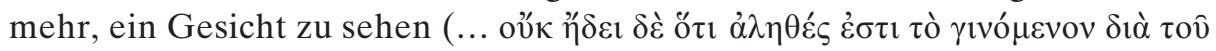

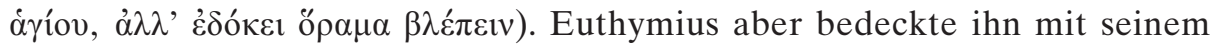
Mantel und verabschiedete sich. Phidos wurde in die Höhe gerafft und schwebte wie Habakuk in der Luft. In Windeseile befand er sich am Strand und in der heiligen Stadt, in einem Zustand der völligen Bewusstlosigkeit (... $\mu \eta \delta \varepsilon v o ̀ \varsigma \tau \hat{\omega} v$ àv $\theta \rho \omega \pi i ́ v \omega v \alpha i \sigma \theta \alpha v o ́ \mu \varepsilon v o \varsigma)$ “.

319. HiLa 63, p. 158,14-159,12: Als Athanasios von Alexandrien von den Arianern verfolgt wurde, erfuhr er durch eine göttliche Offenbarung in der 
Nacht, dass er bloß gerettet werde, wenn er zu einer ganz bestimmten, in

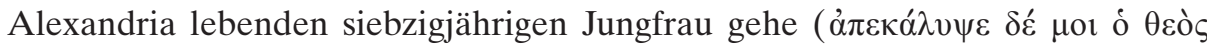

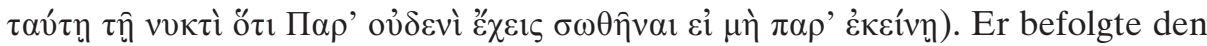
Rat und wurde gerettet.

320. HiMo 12,14, p. 96,18-97,10: „Als den Brüdern in einer Grotte einmal Brot fehlte, kam ein Engel in der Gestalt eines Bruders und brachte ihnen Nahrung (... غ̇ं deres mal suchten zehn Brüder den Vater Helles und verirrten sich. Als sie schon sieben Tage lang nichts gegessen hatten, entdeckte sie der Vater und lud sie zu sich in die Grotte ein. Als sie ihn über ihren Zustand in Kenntnis setzten und er nichts anzubieten hatte, sagte er: ,Gott ist fähig, einen Tisch in der Wüste zu decken' (Ps 77,19). Und plötzlich stand ein schöner, junger Mann vor der Tür und klopfte an, als sie beim Gebet saßen. Als sie öffneten, sahen sie den

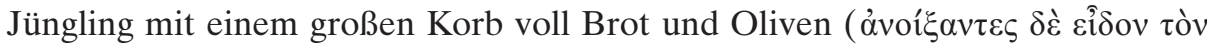

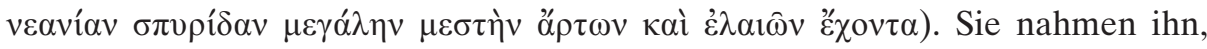
aßen und dankten Gott. Der Jüngling war aber auf einmal verschwunden“ (...,

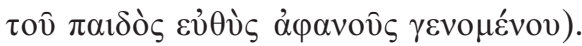

321. ViHy 17,6 f., p. 130,8-14: Als einmal das Brot knapp wurde, saß Hypatios um die Mittagszeit besorgt an der Klosterpforte. Er nickte ein und sah einen strahlenden alten Mann, der ihn in die Seite stieß und sagte, er solle sich keine Sorgen machen, weil er kein Brot habe. Denn von nun an werde es nie mehr an Brot auf dem Tisch fehlen, weder für ihn, noch für seine Gefährten. ('Ev $\mu 1 \hat{\alpha} \delta \grave{\varepsilon}$

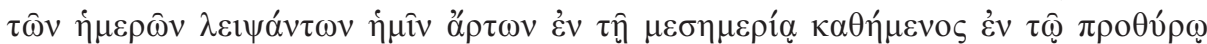

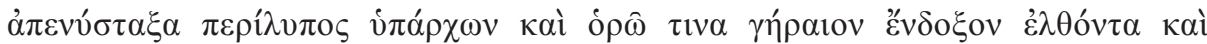

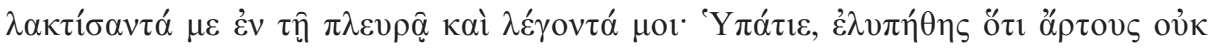

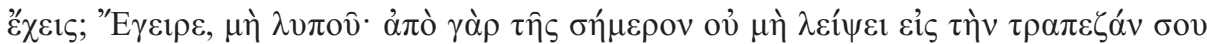

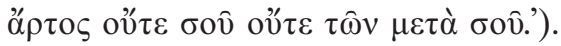

322. ViHy 19,1-6, p. 132,16-134,10: „In der Nähe des Klosters des Heiligen Hypatios gab es einen Fluss, auf dessen Wasser die Brüder angewiesen waren. Irgendwelche Leute aber warfen Unrat in das Wasser - ob aus Unwissenheit oder durch eine dämonische Eingebung, wussten nur sie selbst. Jedenfalls wurden die Brüder krank und erlitten schreckliche Qualen, da die Verantwortlichen ihr Tun fortsetzten. Hypatios war darüber zutiefst betrübt, so wie ein Vater wegen seiner Kinder besorgt ist, und so fing er an zu fasten und den Herrn zu bitten, ihnen entweder Wasser zu schenken oder die feindlichen Machenschaften zu beenden. Und nach drei Tagen sah er drei Männer in leuchtender Kleidung, die zueinander sagten: ,Wo sollen wir Hypatios ein Loch graben

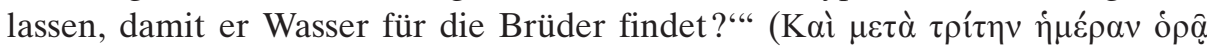

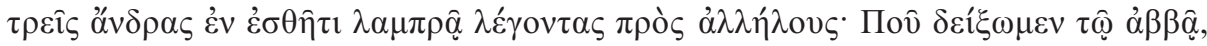

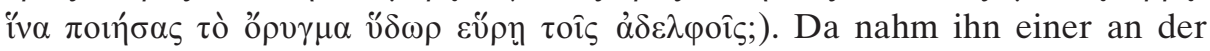
Hand und führte ihn zum Ort, wo er graben sollte. An dieser Stelle fand sich tatsächlich unvergleichlich gutes Wasser. 
323. ViHy 21,1-6, p. 134,21-136,11: „Einmal entflohen dem Konsul Monaxios vier Sklaven. Hypatios nahm sie im Kloster auf und machte sie zu Mönchen“. Monaxios schickte sofort eine Truppe los, um sie zu suchen und erwischte einen der Sklaven namens Paulos. „Er folterte ihn, warf ihn in Ketten, ließ ihn einsperren und von einem Soldaten bewachen. Doch mitten in der Nacht kam ein Engel des Herrn, löste seine Ketten, öffnete die Tür und sagte zu ihm: ,Zieh los

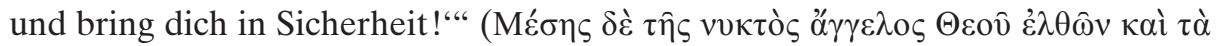

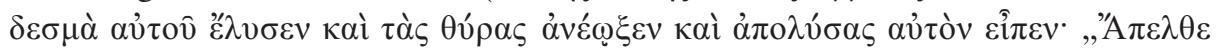

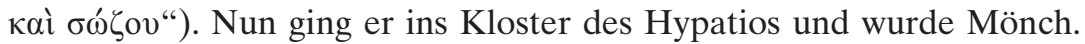

324. ViMa 16, Bd. 2, p. 265,1-12: In jener Nacht sah Martha eine Vision (Kaì عُv

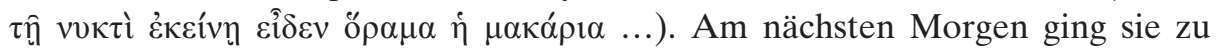
Symeon und erzählte ihm, sie habe ihn in der Kirche Daphne gesehen, als Leute mit Säuglingen aus einem nahen Dorf zu ihm kamen und ihn um ein Gebet anflehten wegen des Fluches, der auf ihnen lag. Unter Tränen und Wehklagen haben sie Symeon zugerufen, er solle sich zeigen und ihnen helfen. Und auf einmal sei ein mit Wasser gefülltes Gefäß in seiner Hand gewesen. Er habe es gesegnet und es ihnen gegeben. Dabei habe er gesagt, sie sollen es wegen des auf ihnen liegenden Fluchs unter sich aufteilen, dann werde ihnen Freude geschenkt, und der Verfluchende werde Ruhe geben.

325. ViNi 24,1-14, p. 42,17-30: Nikolaos wurde von den Dorfbewohnern gebeten, ihnen eine verborgene Quelle auf dem nahegelegenen Berg, von deren Existenz sie wussten, deren genauen Ort sie aber nicht kannten, zu zeigen. Daraufhin zog der heilige Mann mit der gesamten Dorfbevölkerung auf den Berg und flehte zu Gott, er möge ihm den verborgenen Schatz des Wassers zeigen. Danach sagte er zu den Dorfbewohnern, dass ihm Gott an der Stelle, wo er auf die Knie gefallen war, den Segen des Wassers geoffenbart habe ('Ev $\tau \hat{\emptyset}$

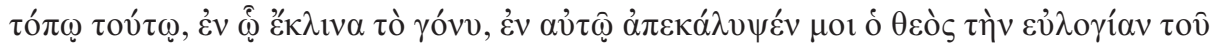

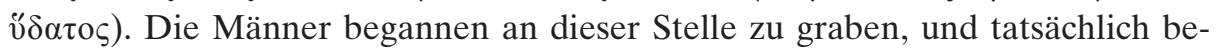
fand sich dort das verborgene Wasser.

326. PhHi 21,21, Bd. 2, p. 104,5-16: Bevor Theodoret eines Tages in ein Dorf unterwegs war, um dort die Aufständischen (die Markioniten) zurechtzuweisen, bat er Iakobos, er möge möglichst eifrig beten. Darauf wachte Iakobos die ganze

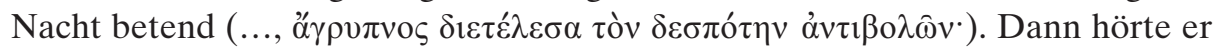
eine Stimme, die sagte, er solle sich nicht fürchten, da Ioannes der Täufer

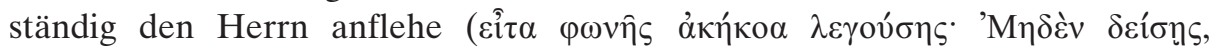

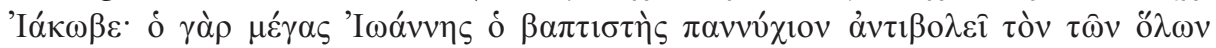
$\theta \varepsilon$ óv$^{*}$ ). Und wenn die Unverschämtheit des Teufels nicht durch sein Eingreifen ausgelöscht worden wäre, hätte es ein großes Gemetzel gegeben.

327. PrSp 16, PG 87.3, col. 2864A-B: Ein Wüstenvater namens Nikolaos erzählt, dass er sich einmal mit zwei anderen Brüdern in der Wüste Thebais verirrte. Als sie vor lauter Durst und Hitze ihre Kraft verloren und nicht mehr gehen konnten, setzten sie sich in den Schatten eines Tamariskenbaums und 


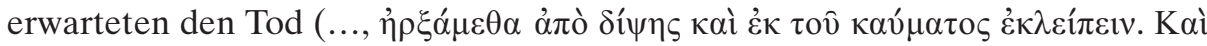

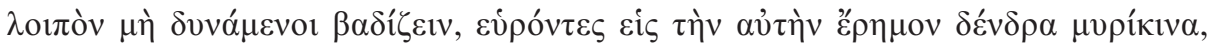

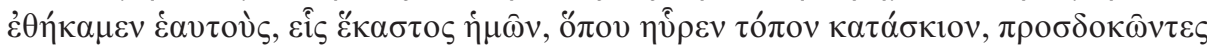

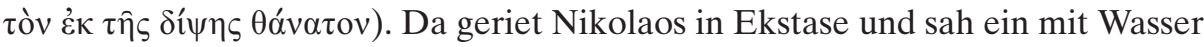
gefülltes Schwimmbecken und zwei Gestalten am Rand des Beckens, welche

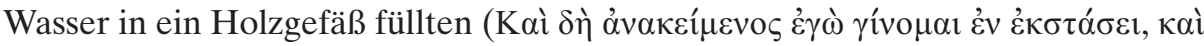

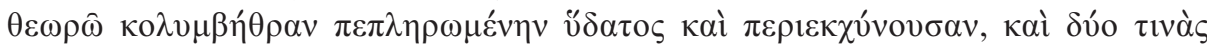

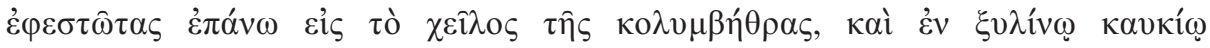

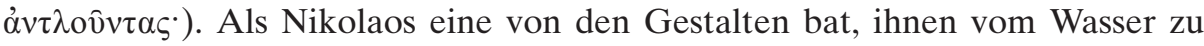
trinken zu geben, weigerte sich diese zunächst mit der Begründung, dass Nikolaos nachlässig sei. Da wandte die andere Gestalt ein, tatsächlich sei Nikolaos nachlässig, sie sollten ihm aber wegen seiner Fremdheit dennoch Wasser geben. So bekamen sie schließlich vom Wasser zu trinken. Dann machten sie sich wieder auf den Weg.

328. ViSa 81, p. 186,15-29: Einem Sarazenen, der mit beladenen Kamelen vom Toten Meer her in Richtung Megiste Laura zog, stürzte ein Kamel ab. Da flehte er den heiligen Sabas um Hilfe an. Auch das umgestürzte Kamel schrie um Hilfe. „Auf einmal sah der Sarazene einen ehrwürdigen Greis auf dem hinge-

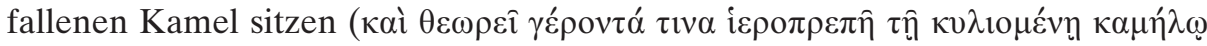
$\dot{\varepsilon} \pi \kappa \alpha \theta \dot{\eta} \mu \varepsilon v o v$...). Er selber lief schnell auf einem anderen Weg hinunter, doch als er beim Kamel angekommen war, fand er den darauf sitzenden Greis nicht

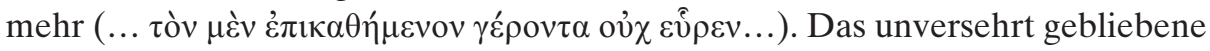
Kamel führte er nun auf dem ebenen Weg zum xenodocheion".

329. ViSyStII 91, Bd. 1, p. 71,10-72,9: Ein gewisser Iakobos stieg auf einen hohen Baum am Straßenrand, um Früchte zu pflücken. „Da sah er, wie zwei Dämonen auf ihn sprangen, ihn an den Füssen packten und vom Baum auf den

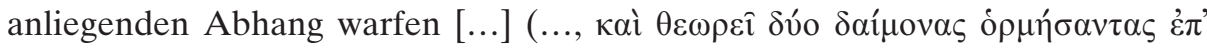

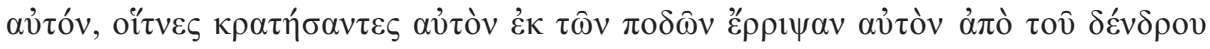

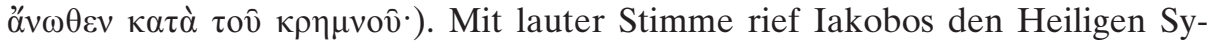
meon an und sah ihn, wie er die Hände ausstreckte, ihn festhielt und gesund und

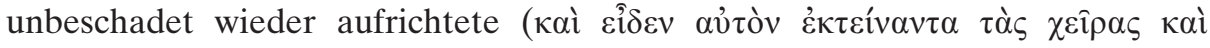

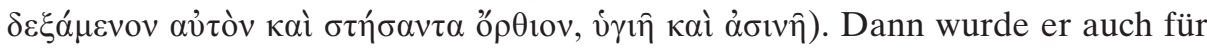
würdig erachtet, durch die im Heiligen sichtbar gewordene Kraft zu erblicken, wie an jenem Ort die Erde aufklaffte, sodass die Beschaffenheit der Wasser zu

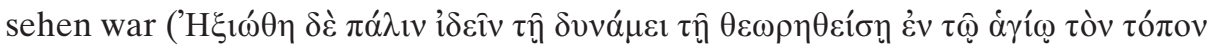

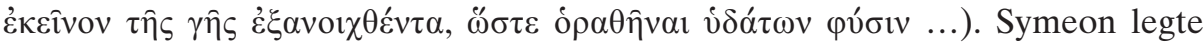
den beiden Dämonen Fesseln um und warf sie in den Abgrund ( $\alpha \beta \beta \sigma \sigma o \varsigma)$. Nachdem Iakobos dies gesehen hatte, schloss sich der Ort wieder. In der Stunde, in der dies geschah, erzählte Symeon den Brüdern das Wunder, welches der

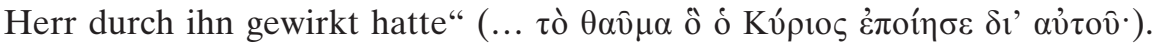

330. ViSyStII 178, Bd. 1, p. 157,23-158,18: Einige der Brüder schliefen auf dem Acker beim Kloster. Da sah Symeon, wie eine Leopardin aus dem Gehölz kam, 
sich neben den Kopf eines der Brüder setzte und anfing zu brüllen, weil sie sein Blut trinken wollte. Doch Symeon hinderte das Raubtier daran, den Bruder anzurühren. Und als sich die anderen Brüder im Kloster zur nächtlichen Psalmodie versammelten, erzählte Symeon vor allen die Geschichte. Er habe den Namen des Herrn angerufen, und das Raubtier habe den Mund geschlossen. Als aber jener Bruder erwachte, sah er das Raubtier neben seinem Kopf sitzen, erschrak und rief den heiligen Symeon an. Und auf einmal erschien ihm durch die Kraft der Gnade in ihm gleichsam der Morgenstern, der das Raubtier ver-

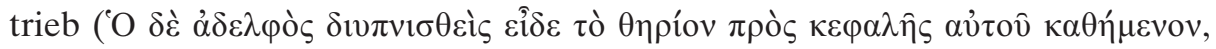

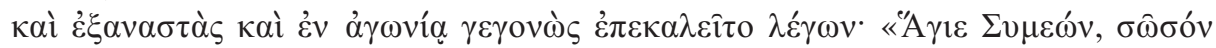

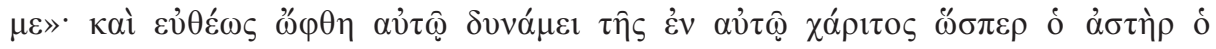

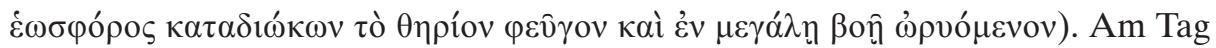
kam der Bruder ins Kloster und erzählte, was in der Nacht passiert war. Und es

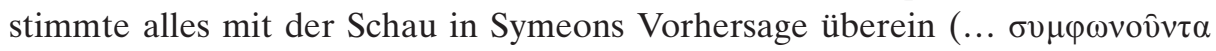

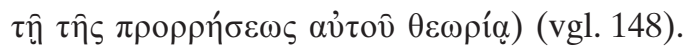

331. ViSyStII 186, Bd.1, p. 164,8-165,3: Alamundaros, ein philarchos (S. A. 759) der Sarazenen ${ }^{768}$, war ein blutrünstiger Heide, der danach trachtete, alle mit Gewalt zu unterwerfen. Seine christlichen Untertanen traktierte er mit tausend Übeln und quälte sie aufs Übelste. Er zwang sie zum Beispiel, an Dä-

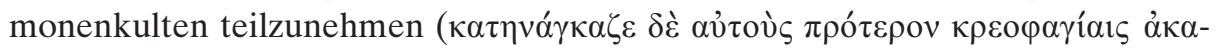

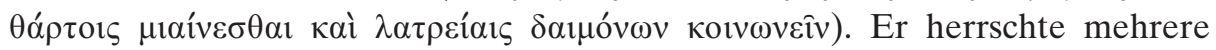
Jahre auf diese Weise, und niemand griff ihn an. Dann kamen byzantinische Gesandte zum persischen König Chosroes $^{769}$, um mit ihm einen Frieden auszuhandeln. Alamundaros aber wich nicht von seiner Feindschaft gegen die Christen ab und versammelte seine Truppen, um an die byzantinische Grenze zu ziehen. „Damals geriet Symeon in Ekstase und sah ein Gesicht ..." (Tó $\tau \varepsilon$

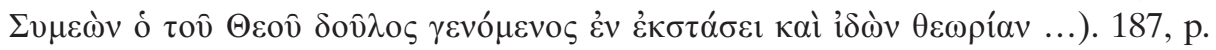
165,4-166,10: Noch am selben Tag erzählte er, dass er im heiligen Geist ent-

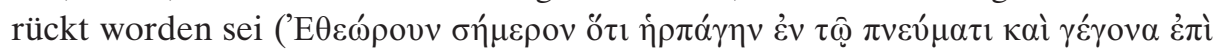

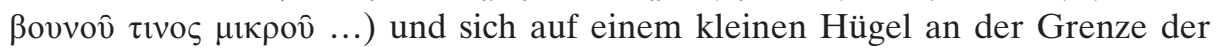
Sarazenen, Perser und Griechen wieder gefunden habe. Er sei inmitten eines Militärlagers der Sarazenen gewesen, die Arethas, der byzantnische philar$\operatorname{chos}^{770}$, befehligte. Vor Symeon habe eine Masse von berittenen Kriegern ge-

768 al-Mundir, der lachmidische König von Hīra, der die byzantinische Grenze als Verbündeter der Perser für ca. 50 Jahre (505-554) verwüstete, s. I. A. ShahīD, Art. Alamundarus, in: ODB 1, 51.

769 Der persische Großkönig Chosroes I. Anūshirwān (531-578/79), der 532 mit den Byzantinern einen „ewigen Frieden“ schloss, s. W. E. Kaegi, Art. Chosroes I, in: ODB 1, 432.

770 al-Ḥāriț, der gassānidische König von Ğabala (529-569), der sich v.a. als Militärkommandant Justinians I. gegen die Perser hervortat und 554 bei Chalkis Alamundaros schlug, s. I. A. SHAhĪD, Art. Arethas, in: ODB 1, 163. 
standen, welche mit Alamundaros, dem Tyrannen, gekommen seien, so zahlreich wie die Sterne am Himmel und die Sandkörner am Meeresstrand. Da seien die Soldaten des Arethas von einer fürchterlichen Angst ergriffen worden, sodass die Muskeln ihrer Arme erschlafft seien. Als Symeon zugeschaut habe, wie alles seinen Lauf nahm, habe vor ihm der Geist der Kraft mit einer Feuerkugel gestanden. Auf sein Gebet hin habe er sie Alamundaros an den Kopf geschleudert und ihn dadurch vernichtet. Eine Woche später kamen griechische Soldaten zu Symeon und berichteten, dass sie mit seiner Hilfe gegen Alamundaros gewonnen hätten. 


\section{N. Wegweisungen und Reiseanordnungen}

332. ApAl Ammonas 7, PG 65, col. 121A: Ammonas machte sich auf den Weg, um Antonios zu besuchen und verirrte sich auf dem Weg. Er setzte sich hin, um

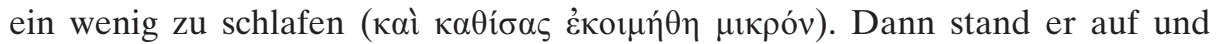
flehte Gott um Hilfe an. Da erschien ihm gleichsam eine menschliche Hand, die aus dem Himmel herunterhing und ihm den Weg zeigte, bis er vor der Höhle des

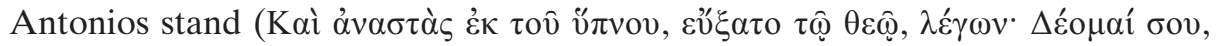

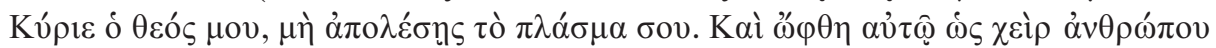

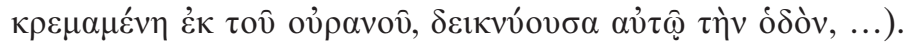

333. ViDanSt 13, p. 13,28-14,10: Als Daniel auf dem Weg von Syrien nach Palästina war, traf er einen alten Mönch, der dem heiligen Symeon ähnlich sah. Dieser hielt Daniel wegen der in Palästina drohenden Gefahren von seiner Reise $\mathrm{ab}$ und riet ihm, stattdessen nach Konstantinopel zu gehen. Noch am gleichen Abend gelangten die beiden zu einem Kloster, doch der alte Mönch war auf einmal verschwunden. Nachdem die Brüder im Kloster gegessen hatten, gingen sie schlafen. Da erschien Daniel der alte Mönch in einer Vision und sagte ihm noch einmal, dass er seinen Ratschlag befolgen solle. Als Daniel aufwachte, fragte er sich, ob jener Ratgeber wohl ein Mann oder ein Engel sei (Kà $\mu \varepsilon \tau \grave{\alpha} \tau$ ò

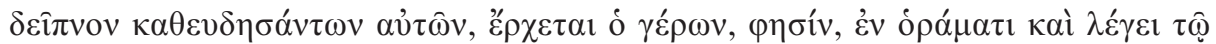

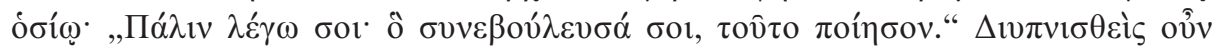

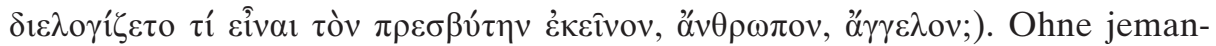
dem davon zu erzählen, machte er sich auf den Weg nach Konstantinopel.

334. ViIo 5, p. 204,14-22: „Der heilige Ioannes hielt sich in einem Altersheim

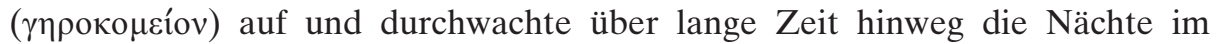
Gebet. Eines Nachts ging er alleine in den Innenhof des Altersheims, und als er in den Himmel blickte, sah er auf einmal einen Stern, der ihn in der Gestalt eines Lichtkreuzes beschien. Dabei hörte er eine Stimme, welche aus dem Licht kam und sagte, wenn er gerettet werden wolle, solle er dem Licht folgen ( $\Omega \varsigma$ ov์ $v$

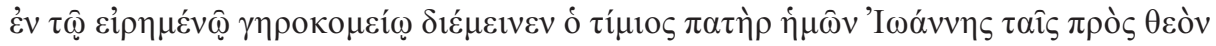

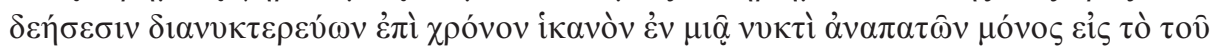

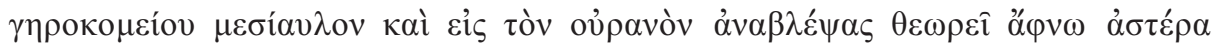

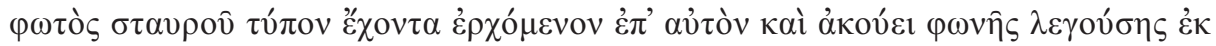

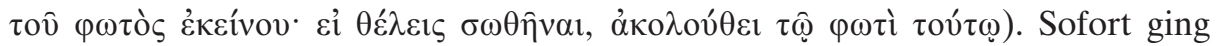
Ioannes heraus, folgte jenem Licht und wurde in die Megiste Laura des heiligen Sabas geführt ...". 
335. ViIo 15, p. 213,3-20: Aitherios, ein Erzbischof aus der Provinz Asia ${ }^{771}$, kam nach Jerusalem, um die heiligen Stätte zu verehren. Als er nach Hause segelte, musste er wegen eines heftigen Sturmes nach Askalon zurückkehren. Nach zwei Tagen wollte er wieder hinaussegeln, doch im Traum erschien ihm ein Engel des Herrn, der sagte, es sei ihm unmöglich zu segeln, wenn er nicht vorher in die heilige Stadt zurückkehre, um in die Laura des heiligen Sabas zu gehen

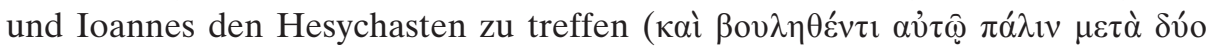

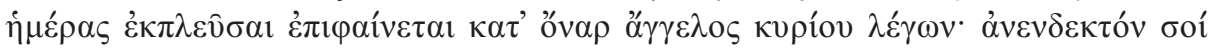

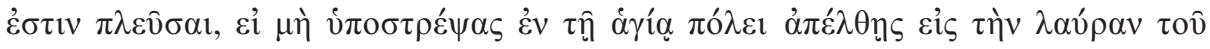

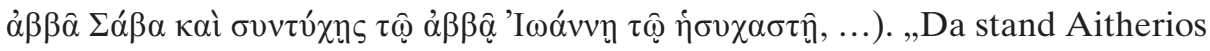
vom Schlafen auf und beurteilte das Gesicht, indem er es mit ganzem Eifer hinterfragte. Dann ging er in die Laura des heiligen Sabas. Und nachdem er den Vätern die Schau erzählt hatte, besuchte er Ioannes den Hesychasten“ ( $\tau$ ó $\tau \varepsilon$

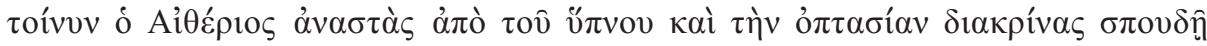

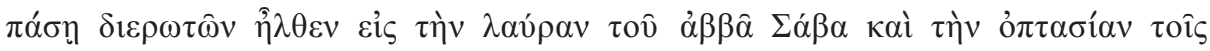

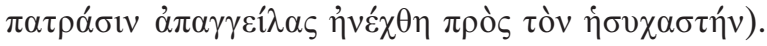

336. ViIo 20, p. 216,24-217,8: Kyrillos von Skythopolis erzählt, wie er in die Laura des heiligen Sabas kam. Nach sechs Monaten wurde er jedoch schwer krank. Er geriet in ein schlimmes Leiden und in große Hoffnungslosigkeit wegen der Fremde, Krankheit und Einsamkeit (..., $\dot{\alpha} \lambda \lambda \dot{\alpha} \kappa \alpha \grave{~} \dot{\varepsilon} \pi \grave{~} \hat{\varepsilon} \xi \mu \eta \hat{\eta} v \alpha \varsigma \dot{\varepsilon} v \tau \hat{n}$

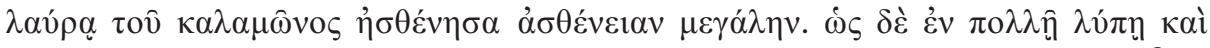

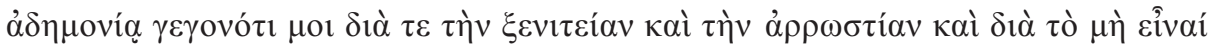

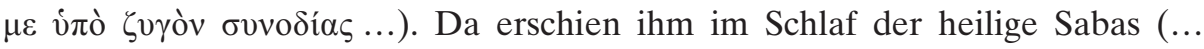

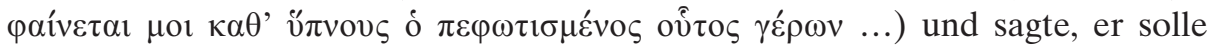
aufstehen und nach Jericho gehen, wo er im xenodocheion des Klosters des Euthymios einen Mönch namens Gerontios finden werde. Er solle diesem ins Kloster folgen, dann werde er gerettet. Als Kyrillos vom Schlafen aufstand, war er wieder voller Kraft und machte sich auf den Weg nach Jericho.

337. ViMa 53, Bd. 2, p. 297,23-298,7: Der heilige Symeon „sah in einer Offenbarung drei iberische Mönche ${ }^{772}$, die von Jerusalem zum Kloster kamen ([1]

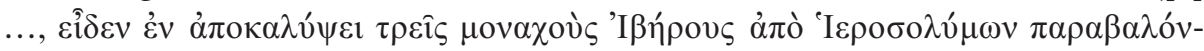
$\tau \alpha \varsigma \mu v \alpha \sigma \tau \eta \rho i ́(. .$.$) . Der eine von ihnen hieß Antonios und war Priester und$ Abt eines Klosters. Er erschien in Form eines goldenen Kreuzes (..., $\dot{\varepsilon} \omega \rho \hat{\tau} \tau o ~ \dot{\varepsilon} v$ $\chi \rho v \sigma \hat{\omega} \sigma \tau \alpha v \rho \hat{\omega} . .$.$) und trug die Kraft des heiligen Holzes in großer Furcht in$ den Händen und übergab es dem Heiligen, wie er es verlangt hatte. Antonios war nämlich ein ehrwürdiger Mann und hatte damals Symeon in einer nächtlichen Vision gesehen und von ihm den Auftrag erhalten, zum wunderbaren

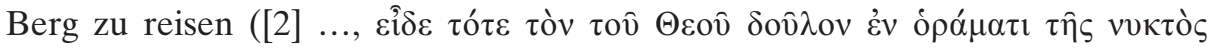

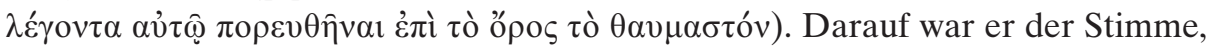

771 Er war Metropolit von Ephesos, s. Festugière, Les moines, III/3, S. 25, A. 50.

772 S. S. 186 A. 741. 


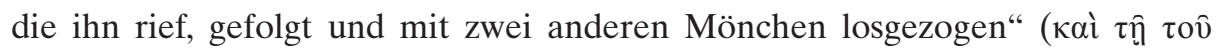

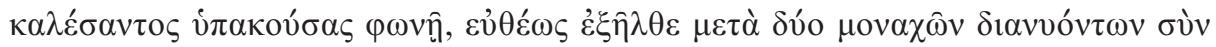

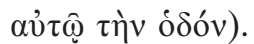

338. ViMa 57, Bd. 2, p. 300,19-301,16: Dem iberischen Mönch Antonios (s.o. 337) erschien in einer nächtlichen Vision ein Engel des Herrn, der ihn aufforderte, schnell loszugehen, einen Weinstock aus dem Garten der heiligen Ana-

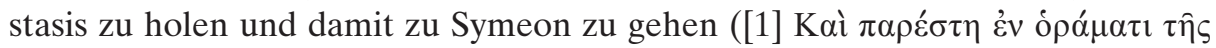

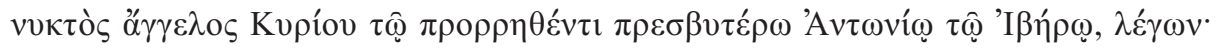

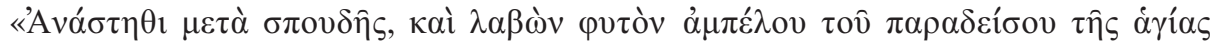

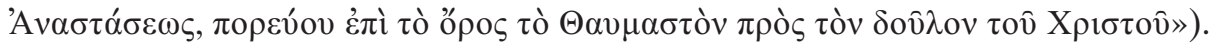
Nachdem Antonios aufgewacht war, ging er furchterfüllt in das Haus Gottes und rollte das heilige Evangelium auf (Lesung von Joh 14,31). „Jetzt wurde

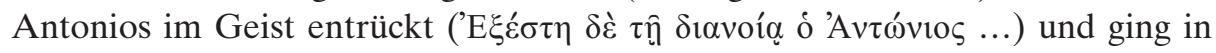
eine andere Kirche, wo er die heiligen Evangelien aufrollte und den Abschnitt fand ,Derjenige, der an mich glaubt, wird meine Werke und noch mehr als dies tun [Joh 14,12]'. Dann stärkte der Herr sein Herz und erfüllte ihn mit einer großen Furcht, sodass alle seine Glieder anfingen zu beben. Da Antonios glaubte, dass die Worte über die Rebe wirklich so gemeint waren, zögerte er nicht länger, sondern machte sich unverzüglich mit einem Weinstock aus dem Garten der heiligen Anastasis auf den Weg zum wunderbaren Berg“ (No $\mu$ í $\sigma \alpha \varsigma$

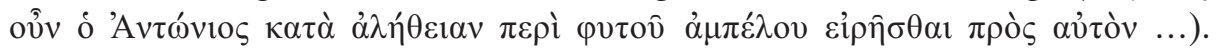
Gleichzeitig wie Antonios kam (58, Bd.2, p. 302,1-21) Paulos, ein Bote des staurophylax aus Jerusalem, auf den wunderbaren Berg und verkündete (61, Bd. 2, p. 304,19-13), dass Symeon ein Stück des heiligen Kreuzes gebracht werden solle. Symeon sagte (in 62, Bd. 2, p. 304,30-305,18) zu Antonios, dies (Paulos) sei der Diener des heiligen Kreuzes, welcher ihm vom Herrn angekündigt worden sei. „Antonios aber zeigte seinen Weinstock und erzählte, was

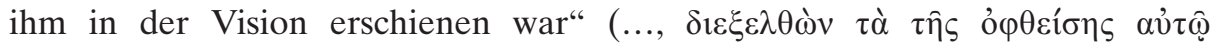
ópá $\sigma \varepsilon \omega \varsigma)$. Am nächsten Tag wurde Paulos losgeschickt, Antonios blieb aber noch länger auf dem wunderbaren Berg. „In einer der darauffolgenden Nächte erschien ihm Martha und forderte ihn auf, sofort loszureisen, um den Segen zu

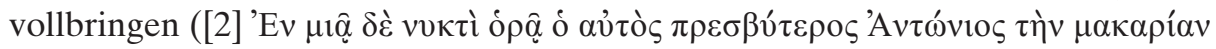

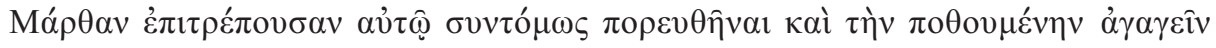
$\varepsilon \cup ̉ \lambda o \gamma i ́ \alpha v)$. Als er dies erzählte und die Zeichen ihrer Erscheinung schilderte", wurde er von Symeon auf der Stelle nach Jerusalem zum staurophylax geschickt

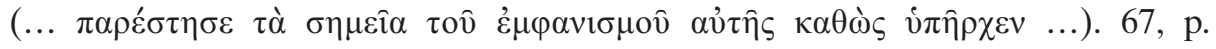
308,17-309,15: Antonios kam zur heiligen Anastasis in Jerusalem und übergab dem staurophylax den Brief des Symeon mit dem Auftrag zur Herstellung einer Kreuzesreliquie. Sofort wurde ein goldenes Kreuz hergestellt, in welchem ein Stück des echten Kreuzes eingefügt wurde. Dann wurde es in einen Behälter gelegt und von Antonios zusammen mit einem Schreiben zum heiligen Symeon gebracht. 
339. ViNi 35,9 f., p. 54,9 f.: Als Nikolaos Sionites acht Tage in Jerusalem verbracht und dort alle heiligen Stätte verehrt hatte, „erschien ihm ein Engel des Herrn, der ihm sagte: ,Beeil dich und geh zurück nach Lykien in deine Heimat ““

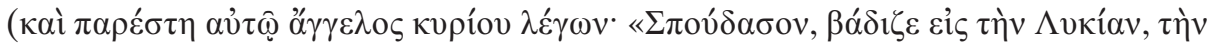

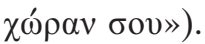

340. PrSp 108, PG 87.3, col. 2969C-2972C: Von einem Priester auf Samos wird erzählt, dass er zu unrecht vor dem Bischof verleumdet wurde, woraufhin man ihn ins Gefängnis sperrte. Als es Sonntag wurde, erschien ihm in der Nacht ein wunderschöner Jüngling, der ihm befahl aufzustehen, um die heilige Eucharistie

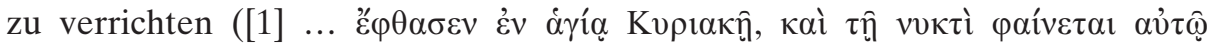

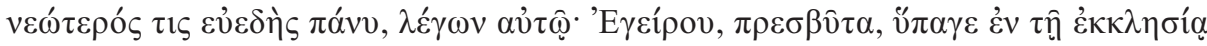

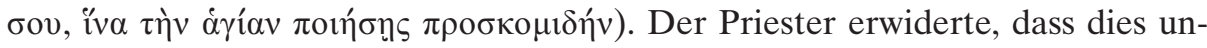
möglich sei, da er im Gefängnis eingesperrt sei. Der Jüngling aber sagte, er werde das Gefängnis öffnen, und er solle ihm folgen. Dann sperrte er die Türe der Zelle auf und ging hinaus. Als sie draussen waren, folgte der Priester dem Jüngling bis eine Meile vor das Gebäude. Am nächsten Tag fand man den Priester nicht mehr im Gefängnis, sondern in der Kirche beim Abendmahl, was den Bischof noch mehr erzürnte. In der Nacht auf den Dienstag erschien dem Priester der gleiche Jüngling und befahl ihm, mit ihm ins Gefängnis zurückzu-

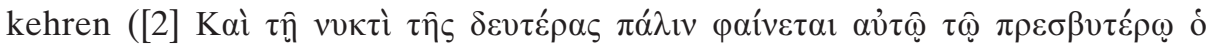

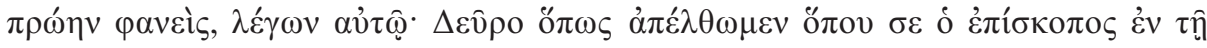
$\pi$ Tó $\lambda \varepsilon 1$ ๕̌ $\beta \alpha \lambda \varepsilon v)$. Dies tat er. Als der Bischof am nächsten Morgen erfuhr, dass der Priester wieder im Gefängnis gefunden wurde, verlangte er von diesem eine Rechtfertigung. Er erzählte, wie er ohne das Wissen der Wachen ausgebrochen und wieder zurückgekommen sei. Ein schöner, gut gekleideter Jüngling aus dem Bischofssitz sei gekommen und habe ihn hinausgeführt. In dieser Nacht sei er ihm wieder erschienen und habe ihn zurückgebracht. Nachdem alle Sklaven des Bischofssitzes versammelt worden waren und der Priester keinen von ihnen wieder erkannte, kam der Bischof zu dem Ergebnis, dass dies das Werk eines Engels Gottes sei, damit die Tugendhaftigkeit des Priesters nicht verborgen bleibe, sondern alle davon erfahren.

341. ViSyStII 7, Bd. 1, p. 8,5-9,10: Als Symeon fünf Jahre alt war, gab es in Antiocheia ein Erdbeben ${ }^{773}$. Die ganze Stadt wurde zerstört und lag in Trümmern. Martha, die Mutter des Symeon, befand sich gerade zum Zeitpunkt des Erdbebens nicht zu Hause, während sich der kleine Symeon im Heiligtum des Protomärtyrers Stephanos aufhielt. „Als das Erdebeben dann vorbei war, streunte Symeon alleine durch die Stadt, und Martha konnte ihn im Durcheinander der Zerstörung nicht finden. Zufälligerweise stieß eine Bekannte der Familie auf Symeon und erkannte ihn, setzte ihn auf die Schultern und brachte

773 Dabei handelt es sich um das Erdbeben, das die Stadt am 29./29. Mai 526 zerstörte, s. VAN DEN Ven, La vie ancienne II 11, A. 1. 
ihn zum Berg, der direkt bei Antiocheia liegt. Nachdem sieben Tage vergangen waren und Martha ihren Sohn noch immer nicht gefunden hatte, glaubte sie, er sei dem Beben zum Opfer gefallen. Da erschien ihr Ioannes der Täufer und

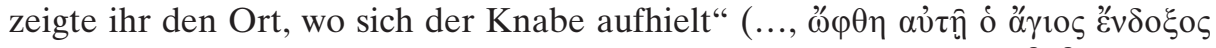

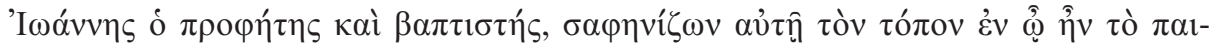
Síov).

342. ViSyStII 10, Bd. 1, p. 10,20-11,5: Nachdem Symeon seine Berufungsvision hatte (vgl. 171), sah er augenscheinlich einen weiß gekleideten Mann, der ihm

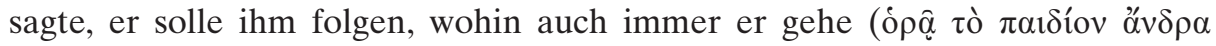

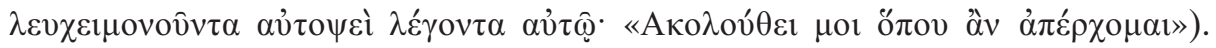
„Auf der Stelle folgte Symeon dem Schatten der Erscheinung. Diese brachte ihn nach Tiberine bei Seleukeia [...]. Hier blieb der Junge alleine in der Einöde des Berges inmitten der wilden Tiere. Tag und Nacht sah er sich von einem unbeschreiblichen Licht umgeben und wurde vom weißtragenden Mann geführt und

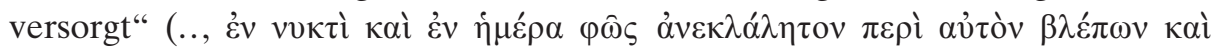

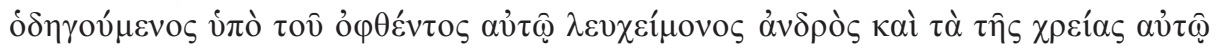

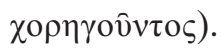

343. ViThSy 7, 6-7, p. 6,25-28: „Als Theodoros eines Tages aus der Schule kam, bestieg er den nahen Berg, auf dem sich das martyrion des heiligen Georg befand. Dieser Heilige führte ihn sichtbar in der Gestalt eines Jünglinges zum

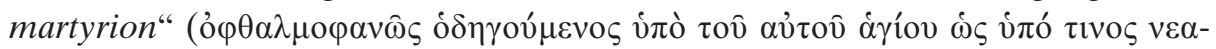
víoкоv).

344. ViThSy 8,7-8, p. 7,24-8,8: Als Theodoros „in der Nacht zusammen mit der Mutter und den anderen Frauen schlief, bekam er Besuch vom heiligen Georg. Dieser weckte ihn, als sich alle im Tiefschlaf befanden“ (K $\alpha \theta \varepsilon v ́ \delta o v \tau o \varsigma \delta \varepsilon$

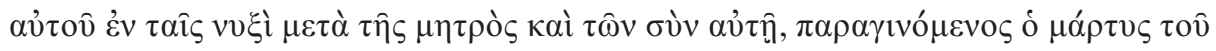
X erst kam er in der Gestalt des Stephanos, dann in der eigenen Erscheinung und befahl ihm aufzustehen, um mit ihm im martyrion des heiligen Georg zu beten

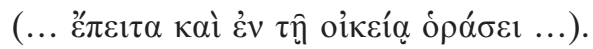

345. ViThSy 63, p. 52,32-53,26: Der heilige Theodoros hielt sich in der Laura des Heiligen Sabas auf, als ihm eines Nachts im Schlaf der Märtyrer Georgios

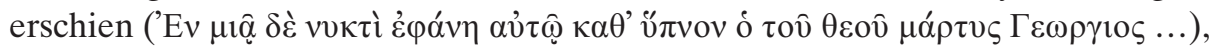
der ihm einen Stab übergab und ihn aufforderte, in seine Heimat zurückzukehren. Er dürfe nämlich nicht die dortigen Angelegenheiten vernachlässigen, um hier zu leben. Als Theodoros dem widersprach mit dem Argument, dass er sein Bischofsamt nicht freiwillig angetreten habe, versprach ihm der heilige Georgios, ihn von dieser Bürde zu befreien, wenn er nur seinen eigenen Palast (des heiligen Georgios), den er mit Mühen erbaut hatte, nicht vernachlässige.

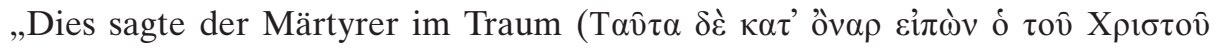
$\mu \alpha ́ \rho \tau v \varsigma \tau \hat{\varrho} \mu \alpha \kappa \alpha \rho i ́ \omega, . .$.$) und empfing mit der rechten Hand Theodoros' Zusi-$ cherung, dies unverzüglich zu tun. Als der heilige Mann aufwachte, rief er so- 
gleich die zwei Brüder, die bei ihm waren, herbei und erzählte ihnen die Vision“

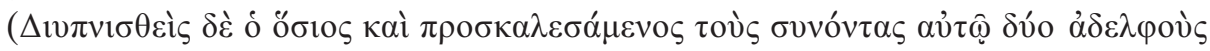

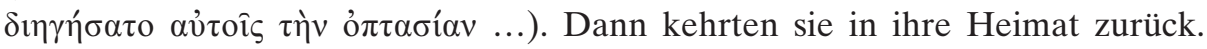




\section{O. Befehle und Anordnungen}

346. ApAl, Bisarion 4, PG 65, col. 140B-C: Ein Bruder berichtet, dass sein geistlicher Vater Bisarion einmal vierzehn Tage lang mit in den Himmel erhobenen Armen im Gebet verharrte. Danach hieß Bisarion seinen Schüler, mit ihm in die Wüste zu ziehen. Auf dem Weg besuchten sie einen Bruder namens Ioannes, mit dem sich Bisarion zusammensetzte, um sich über die Schau, die er

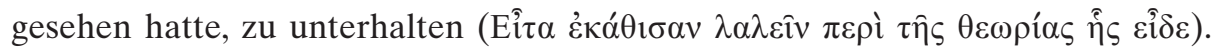
„Danach sagte Bisarion, dass die Entscheidung gefallen sei, die Tempel zu

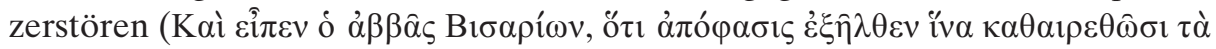

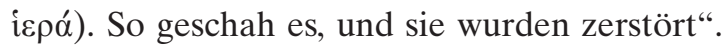

347. ApSy VII 1, Bd.1, p. 336 [vgl. ApAl, PG 65, col. 76A-B]: „Der heilige Antonios saß einmal in der Wüste, als er von Gleichgültigkeit und einer großen Umnachtung der Gedanken heimgesucht wurde“ ('O år

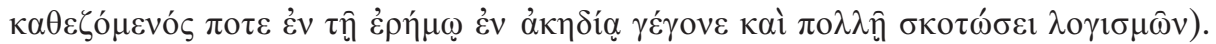
In seinem Kummer betete er zu Gott, er möge ihm zeigen, wie er gerettet

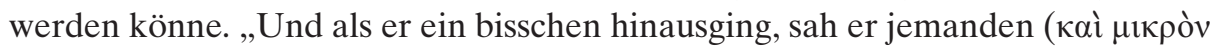

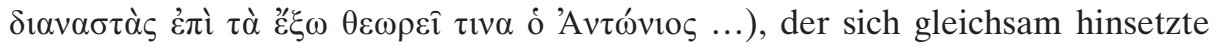
und arbeitete, wieder von der Arbeit aufstand und betete, um sich erneut zu setzen und Seil herzustellen. Dann stand er wieder zum Gebet auf. Es war aber ein Engel des Herrn, der zur Zurechtweisung und Rettung des Antonios ge-

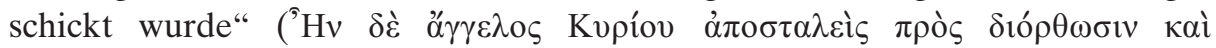

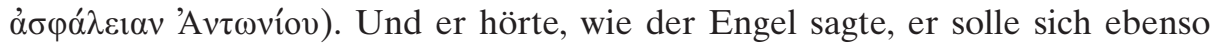
verhalten, wenn er gerettet werden wolle.

348. ApSy XV 33, Bd, 2, p. 308: „Von Abbas Theodoros erzählte man, dass er sich, als er in der Sketis zum Diakon geweiht wurde, weigerte, sein Amt auszuüben und an verschiedene Orte floh“. Die anderen Greise holten ihn zurück und machten ihm Vorwürfe. Er aber sagte ihnen, sie sollen ihn in Ruhe lassen. Er werde Gott bitten, ihm zu zeigen, ob er am Ort seines Amtes bleiben solle oder nicht. „Und es zeigte sich ihm eine feurige Säule von der Erde bis zum Himmel. Dabei erklang eine Stimme, die sagte: ,Wenn du wie die Feuersäule

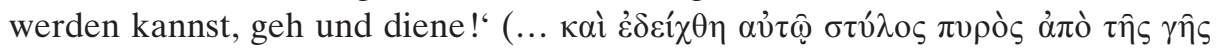

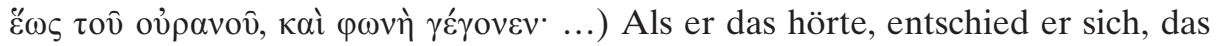
Amt nicht anzunehmen“. Die anderen Brüder entschuldigten sich bei ihm und ließen ihn gehen.

349. ViEu 16, p. 25,13-15: Noch bevor Euthymios seine Laura gründete, kamen drei Brüder aus Kappadokien zu ihm, um bei ihm zu leben. Euthymios wollte sie jedoch nicht bei sich aufnehmen, da er die Einsamkeit liebte. Überdies hielt er 
die Brüder für zu jung und störte sich daran, dass einer von ihnen Eunuche war. In der Nacht aber sah er jemanden, der ihm befahl, die Brüder aufzunehmen

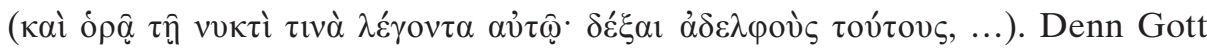
habe sie gesandt, und er solle niemanden abweisen, der gerettet werden wolle. Daraufhin nahm Euthymios die Brüder auf.

350. HiMo 11,3, p. 93,5-11: „Nachdem Helles eine Woche gefastet hatte, nickte

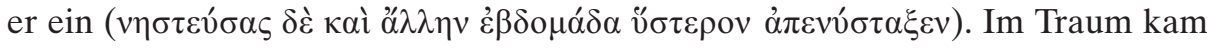

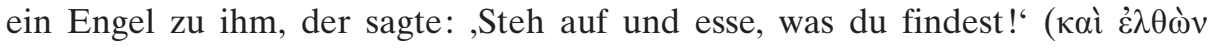

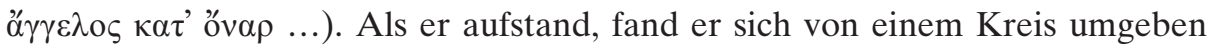
und sah eine Quelle, die innerhalb des Kreises frische Pflanzen sprießen ließ. Da nahm er vom Trank und vom Gemüse zu sich und versicherte, niemals etwas Köstlicheres gegessen zu haben“.

351. ViPo 56, p. 45,20-46,14: Als die Bischöfe Porphyrios und Ioannes von Konstantinopel nach Palästina segelten, gerieten sie in ein heftiges Unwetter. In der Not flehten sie den Anachoreten Prokopios von Rhodos um Hilfe an. Der Sturm ließ nicht nach, sodass sie die ganze Nacht schlaflos verbrachten. Erst in der Morgendämmerung schliefen sie aus Erschöpfung durch ihre Bedrängnis ein wenig ein. Da sah Porphyrios den Einsiedler Prokopios, der ihnen auftrug, den

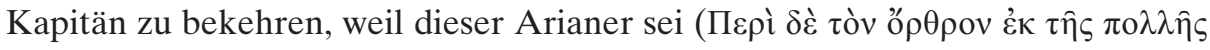

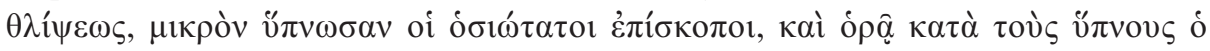

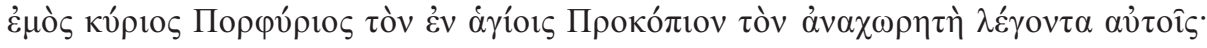
...). Sobald er durch Porphyrios den wahren Glauben angenommen habe, werde der Sturm nachlassen. 57, p. 46,15-47,10: Nachdem Porphyrios dies gehört hatte, wachte er auf, rief die anderen zu sich und erzählte ihnen, was er gesehen

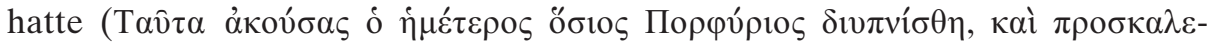

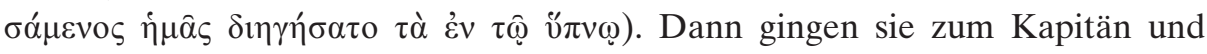
stellten ihn zur Rede. Dieser ließ sich sofort bekehren, weil er sah, dass sie die Gabe des Vorherwissens besaßen und verstanden hatten, was in seinem Herzen

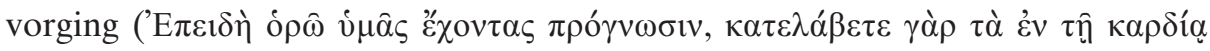

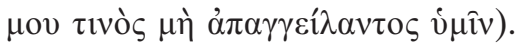

352. PrSp 81, PG 87.3, 2940A-B: Die heiligen Väter erzählen, dass in jenen Tagen eine fromme Frau einen Brunnen grub. Obwohl sie viel dafür aufwandte und tief hinunter grub, fand sie kein Wasser. Als sie sich deshalb in großer Mutlosigkeit befand, sah sie eines Tages jemanden, der ihr sagte, sie solle sich

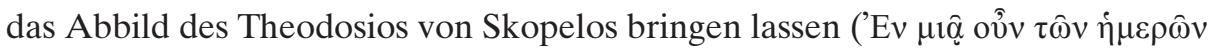

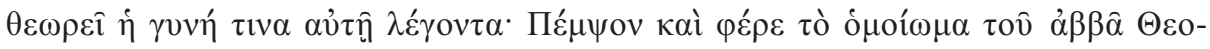

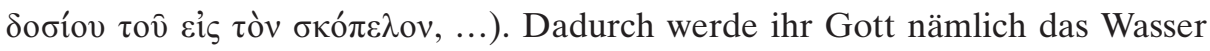
gewähren. Dementsprechend handelte die Frau. Als sie die Ikone des Heiligen

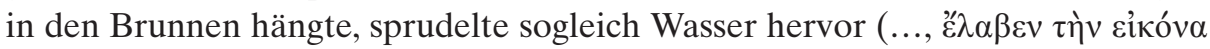

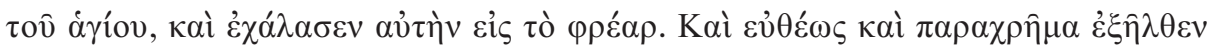

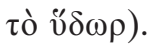


353. PrSp 84, PG 87.3, col. 2941A-B: Ein Einsiedler, der über mehrere Jahre hinweg als Hirte in den Bergen lebte, starb in einer Höhle, ohne dass jemand

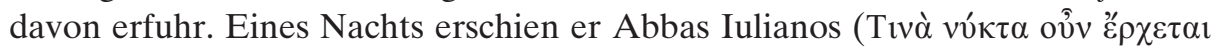

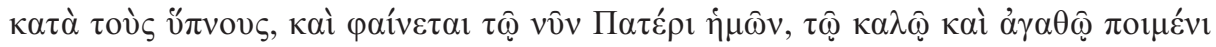
$\dot{\alpha} \beta \beta \hat{\alpha}$ 'Iov $\lambda_{1} \alpha v \hat{\text { ) }}$ ) und trug ihm auf, ihn mit anderen zusammen vom Berg, welcher „der Hirsch“ ( $\dot{\eta}$ ”E $\lambda \alpha \varphi \varsigma)$ genannt werde und wo er liege, herunterzuholen. Der Auftrag wurde ausgeführt und der Einsiedler im Kloster bestattet.

354. PrSp 92, PG 87.3, col. 2949C-2952A: Vater Georgios erzählt, dass man die Kirche des Heiligen Kerykos in Phasilaidi erbauen wollte und anfing, die Fundamente dafür zu graben, als ihm im Schlaf ein Mönch erschien, der

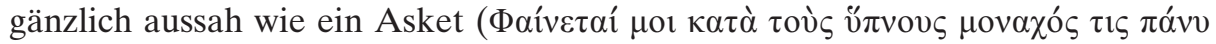

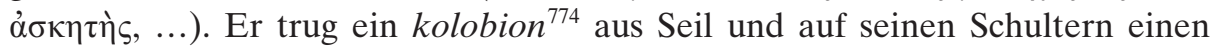

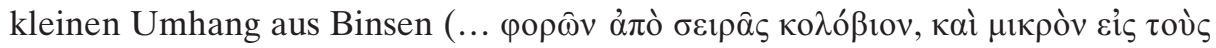

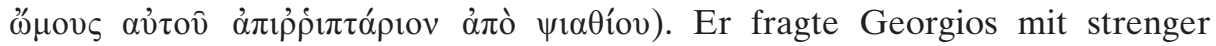
Stimme, ob es ihm leicht falle, ihn nach so viel Mühe und Askese außerhalb des Tempels zu lassen, den er baue. Da jenem die Ehrwürdigkeit des Mönchs Respekt einflösste, fragte er ihn, wer er sei. Darauf antwortete dieser, er sei Petros der Hirte vom Heiligen Jordan. Am nächsten Tag fand Georgios beim Graben dessen Körper, so wie er ihn im Schlaf gesehen hatte, und bestattete ihn im

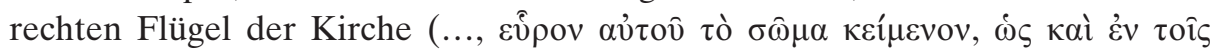

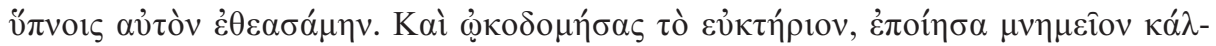

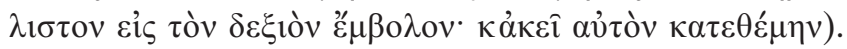

355. PrSp 150, PG 87.3, col. 3013D-3016A: In Romilla, einer Stadt in der Nähe von Rom, lebte ein großer und tugendhafter Bischof. Dieser wurde vor dem Papst (Agapet, 535-536) angeklagt, vom heiligen Brot auf der Patene gegessen zu haben. Deshalb wurde er nach Rom ins Gefängnis gebracht. Der Bischof brachte drei Tage im Gefängnis zu, als es Sonntag wurde und der Papst im Schlaf eine Gestalt erblickte, die ihm sagte, er solle nicht selber das Abendmahl

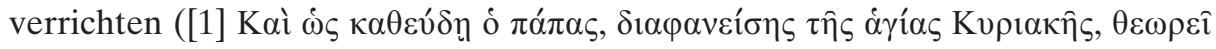

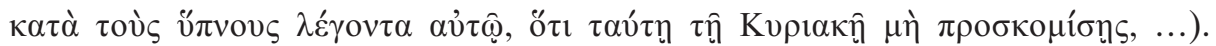
Weder er noch ein anderer von den Klerikern, die sich in der Stadt befinden, sondern alleine der im Gefängnis eingesperrte Bischof solle dies tun. „Als der Papst aufwachte, sagte er sich wegen des Gesichtes, das er gesehen hatte: ,Eine solche Anklage habe ich gegen ihn akzeptiert, und jetzt soll er das Abendmahl

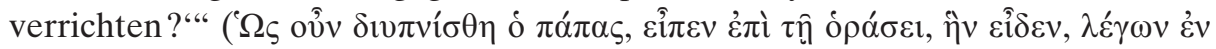

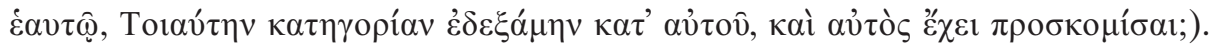
Da kam ein zweites Mal eine Stimme in einer Vision zu ihm, die ihm noch

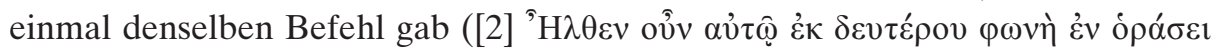

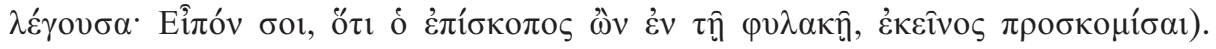
„Und da er noch immer zweifelte, erschien ihm ein drittes mal dasselbe Gesicht

774 S. S. 248 A. 760. 


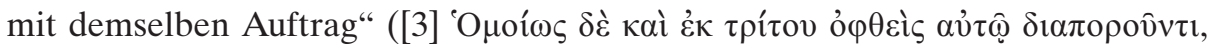

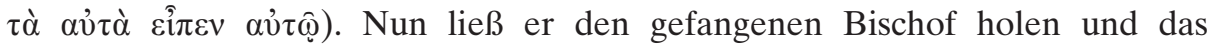
Abendmahl verrichten (Fortsetzung in 194).

356. PrSp 195, PG 87.3, col.3077A-D: Synesios von Kyrene war mit dem Philosophen Euagrios befreundet. Erst nach langer Zeit und vielen Versuchen gelang es Synesios, Euagrios zum Christentum zu bekehren. Dieser ließ sich und seine ganze Familie taufen. Einige Jahre danach gab er dem Bischof Synesios Geld für die Armen und verlangte im Gegenzug ein Garantieschreiben dafür, dass ihm diese Tat im zukünftigen Leben vergolten werde. Synesios tat ihm diesen Gefallen. Einige Jahre später wurde Euagrios schwer krank und sagte zu seinen Kindern, sie sollen, wenn er sterbe, den Papyrus, den er ihnen gebe, in seine Hand legen und ihn so begraben. So geschah es. Drei Tage nach dem Begräbnis erschien Euagrios in der Nacht dem schlafenden Bischof Synesios und sagte ihm, er solle in seine Grabstätte kommen und sich sein Schreiben

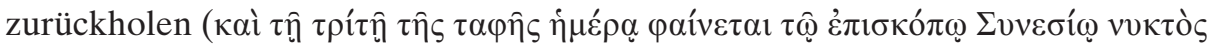

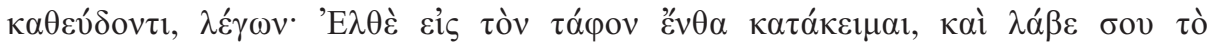

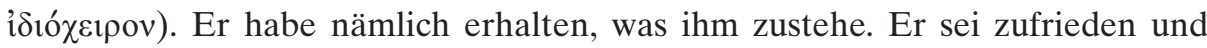
habe ihm nichts vorzuwerfen, und um ihn davon zu überzeugen, habe er seine Unterschrift auf seinem Schreiben hinterlassen. Synesios aber wusste nicht, dass Euagrios mit seinem Schreiben bestattet worden war. So erzählte er am nächsten Tag den Kindern des Euagrios den Traum, den er in der Nacht gesehen

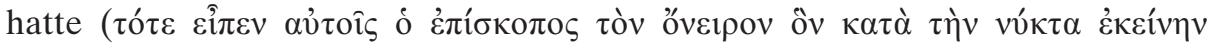

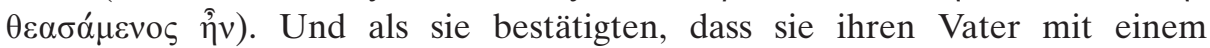
Schreiben in der Hand bestattet hatten, ging Synesios zum Grab des Philosophen und grub seinen Leichnam aus. „In seiner Hand fand er einen Papyrus mit einem an ihn gerichteten Schreiben: ,Ich, Euagrios, grüße dich, den Bischof Synesios. Ich nahm das Schreiben von dir und mein Anliegen wurde erfüllt und habe kein Wort mehr gegen dich zu richten, und deshalb habe ich dir, und durch dich Christus, unserem Gott und Retter, das Geld gegeben“".

357. ViSa 78, p. 185,1-16: In der heiligen Stadt gab es einen Silberschmied, dem zur Zeit der Entschlafung des Sabas die Werkstatt ausgeraubt wurde. Sofort ging er ins martyrion des heiligen Theodoros, ließ während fünf Tagen Kerzen brennen und verharrte Tag und Nacht am Geländer des Altars. Am fünften Tag wurde er um Mitternacht vom Schlaf übermannt und sah den heiligen Theo-

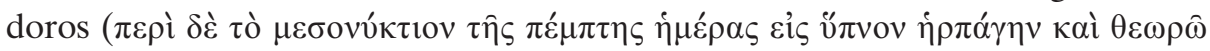

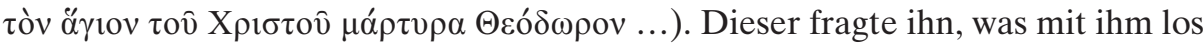
sei, warum er so verwirrt sei und weine. Als der Silberschmied ihm sein Schicksal schilderte, erwiderte Theodoros, dass er sich zur Zeit, als das Silber gestohlen wurde, nicht an diesem Ort aufgehalten habe. Es sei ihnen (den Heiligen) nämlich befohlen worden, sich zu versammeln, bei der Seele des heiligen Sabas zusammenzukommen und sie an den Ort der letzten Ruhe zu begleiten. Er solle nun zu jenem Ort gehen, dann werde er die Räuber und das 
Silber finden. Sogleich stand der Silberschmied auf und ging zusammen mit

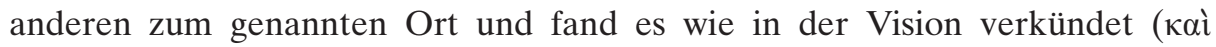

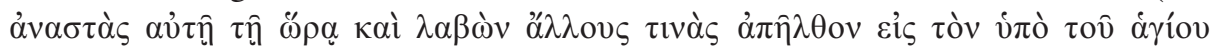

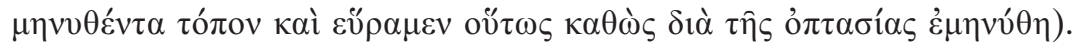

358. ViThSy 5, p. 4,26-5,14: Maria, die Mutter des Theodoros, wollte ihren sechsjährigen Sohn in den kaiserlichen Dienst nach Konstantinopel schicken. „In der Nacht vor der Abreise erschien ihr der heilige Georgios, der sie fragte:

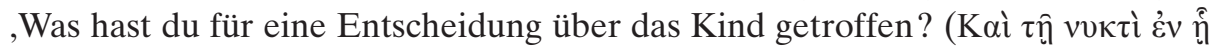

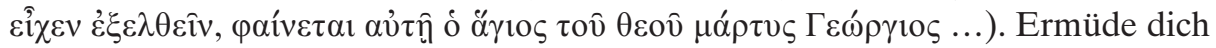
nicht umsonst. Der Herrscher der Himmel braucht ihn'. Am nächsten Morgen

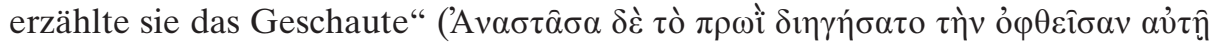
ő $\rho \sigma ı v, . .$.$) . Sie fürchtete, dass ihr Junge sterben werde und schickte ihn nicht$ nach Konstantinopel.

359. ViThSy 157, p. 130,24-36: Theodoros befand sich mit anderen Mönchen auf der Reise. In der Nähe des Hafens von Herakleion kam der paramonarios der dortigen Kapelle des heiligen Georgios zu ihm. Er beweihräucherte den heiligen Mann und pries Gott dafür, dass er seine Vision erfüllt hatte (... каџ̀

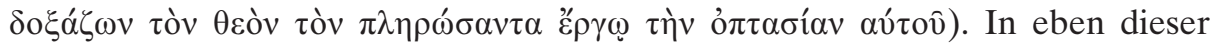
Nacht sei ihm nämlich der heilige Märtyrer Georgios erschienen, habe ihn aufgeweckt und gesagt, er solle aufstehen, das Haus ehren und Kerzen anzün-

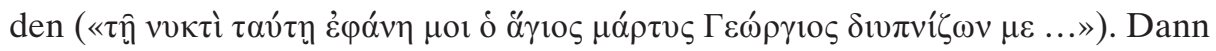
solle er hinausgehen und den Herrn Sykeon treffen, denn dieser werde sogleich hier vorbeikommen. 


\section{P. Befehle zur Gründung und Errichtung von Kirchen und Klöstern}

360. HiLa 32, p. 88,4-9: Als Pachomios einmal in der Höhle saß, erschien ihm ein Engel und sagte ihm, jetzt wo er für sich selber gesorgt habe, sitze er

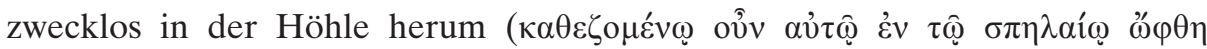

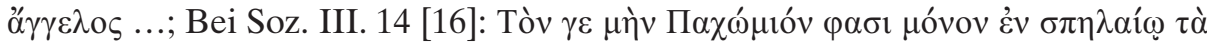

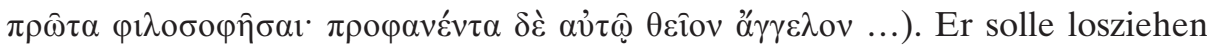
und alle jungen Mönche vereinigen. Er solle sich mit ihnen zusammen niederlassen und ihnen eine Regel nach dem Muster, wie er es ihm übergeben werde, überreichen. Und er gab ihm eine eherne Tafel, auf der die sogenannten Mönchsregeln des Pachomios festgehalten waren.

361. ViMa 45, Bd.2, p. 287,5-19: Symeon „sah den Leichnam der heiligen Martha zusammen mit der konche ${ }^{775}$, in der sich der Leichnam befand. Dann wurde sie vor ihm zum südlichen Flügel seiner erstgebauten Kirche entrückt

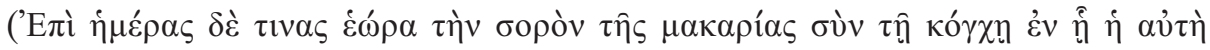

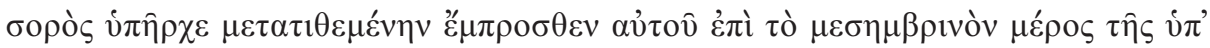

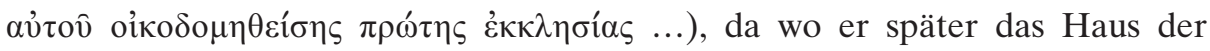
heiligen Theophanie baute. Als der Leichnam entrückt wurde, umgaben ihn schöne Jünglinge, die Hymnen sangen und einander das Halleluja zuriefen“. 362. ViMa 46-50, Bd. 2, p. 287,20-295,2: „Ein Bruder, dem vier Monate vor dem Hinscheiden der Martha die erste Offenbarung zukam, berichtete, wie bereits erzählt wurde [vgl. 225], dass die Heilige ihre Hände ausbreitete und sich in die Form eines strahlenden Kreuzes verwandelte, über dem ihr Gesicht zu

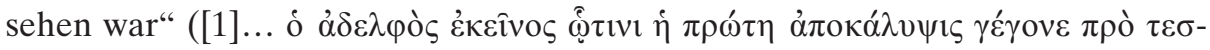

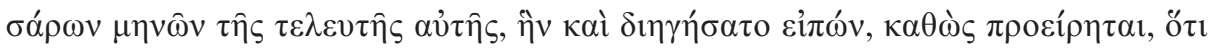

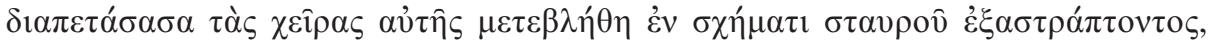

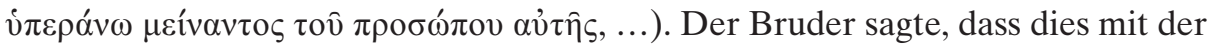
Herrin drei oder viermal geschehen sei. Und sie zeigte ihm den Bau eines Gebäudes mit drei Schreinen, einer im Osten, einer rechts und einer links. Überdies zeigte sie ihm den Plan des ganzen Gebäudes und legte ihm nahe, dies allen anderen zu berichten. Sie kündigte an, sich gegen ihn zu erzürnen, wenn er es nicht ganz genau so weitererzähle. Deshalb sei der Herr Zeuge, dass sich das Erzählte in Wahrheit so verhalte, wie der Bruder es gesehen und gehört habe

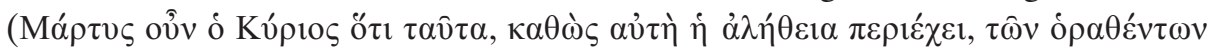

775 S. S. 242 A. 755. 


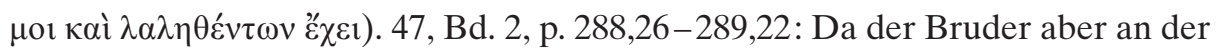
Größe ihres Wirkens zweifelte, sah er auf einmal rund um ihren Sitz herum Kandelaber und feuerlodernde Leuchten, die die Flamme des Blitzes wider-

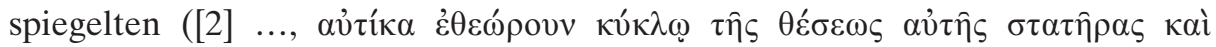

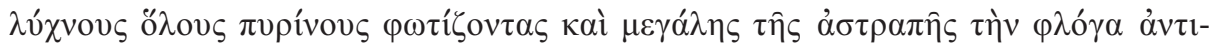
$\varphi \varepsilon ́ \gamma \gamma o v \tau \alpha \varsigma . .$.$) . Da standen auch einige, die eine liebliche Melodie psalmodierten$ und andere, die einander das Halleluja zusangen. Überdies sah er den heiligen Symeon, der sein Gesicht auf der Öffnung seiner Bedachung ( $\left.\kappa \mu \mu \alpha \sigma^{\prime} v \eta \mu \eta \lambda \omega \tau \eta ́\right)$ abstützte und zu ihm sagte, dass Martha ihm den Weg der Gebote gezeigt habe. Und als er dies sagte, sah der Bruder, wie Martha vor ihrer Grabstätte stand, die Hände in den Himmel streckte und betete. Da wurde er furchterfüllt und warf sich ihr zu Füssen. Auf diese Weise kam er wieder zu sich und pries Gott (... каi

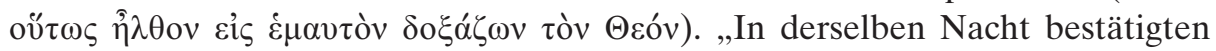

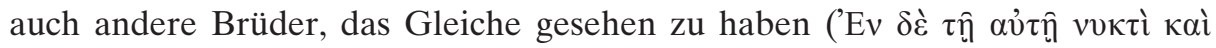

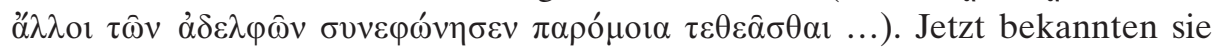
alle ihre Sünden und baten den Heiligen, er möge für sie beten. Und so fingen sie an, das Gebäude zu bauen, so wie es Martha angewiesen hatte“. 48, Bd. 2, p. 289,23-290,17: Und nachdem Symeon die Brüder an die Arbeit geschickt hatte, wandte er sich um Mitternacht zum Grab seiner Mutter und sah sie in ihrer geheiligten Gestalt dastehen, in der Mitte der konche ${ }^{776}$, in die sie hingelegt

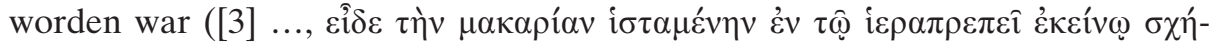
$\mu \alpha \tau 1 .$.$) . Voll Furcht blickte sie in den Himmel und sandte eine engelhafte$ Stimme in die Höhe, mit der sie dreimal das Halleluja erschallen ließ. „Die ganze mandra ${ }^{777}$ hallte wider, wie wenn sie selbst die Stimme erklingen lassen würde, und der Leichnam der heiligen Frau erbebte durch diesen Lobpreis Gottes im Grab“. 49,10, Bd.2, p. 291,4: Beim Bau des martyrions erschien

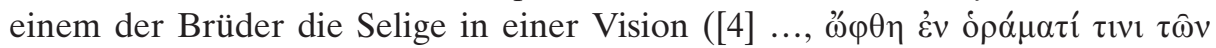
$\grave{\alpha} \delta \varepsilon \lambda \varphi \hat{\omega} v \dot{\eta} \mu \alpha \kappa \alpha \rho i ́ \alpha . .$.$) . Sie stand der Arbeit bei und befahl, die zwei kleinen$ Schiffe mit einer Bedachung zu überwölben. 50, Bd. 2, p. 293,1-295,2: Als der Bruder dies den anderen erzählte, war ein gewisser Angulas anwesend, der mit allen Mitteln verhindern wollte, dass der Plan der Martha durchgeführt wurde. Deshalb befahl er Theodoros, dem Vorsteher des Bauwerks, seinen eigenen Plan durchzusetzen. Doch Angulas konnte seine Intrige nicht lange weitertreiben. Denn Neon, einem Bauarbeiter, erschien die Selige in einer nächtlichen Vision

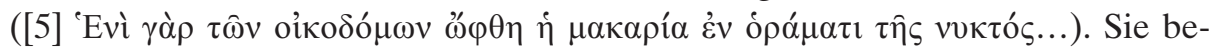
schimpfte Angulas als schlechten Architekten und sagte über Theodoros, dass er aufgrund seiner Ungläubigkeit sein Werk nicht vollenden werde. Nachdem Neon dies erzählt hatte, dauerte es nur einen Tag, bis Theodoros von einem unreinen Geist besessen wurde und starb.

776 S. S. 242 A. 755.

777 S. S. 230 A. 752. 
363. ViNi 1,7-12, p. 26,7-12: Als Nikolaos (Nikolaos von Akalissos, der Onkel des Nikolaos Sionites) „mit seinem geistlichen Vater Sabbatios im Kloster Akalissos zusammenlebte, beschloss er nach einer Erscheinung durch Christus,

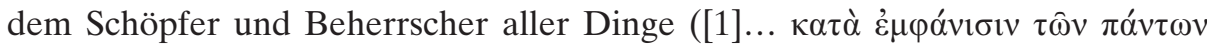

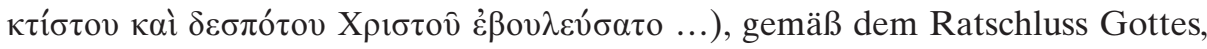
das Kloster der heiligen Sion zu errichten“. 10,6 f., p. 32,20 f.: Nikolaos begann das Gebetshaus zu errichten, „da ihm ein Engel des Herrn erschienen war, der

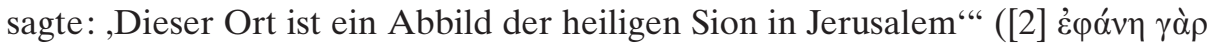

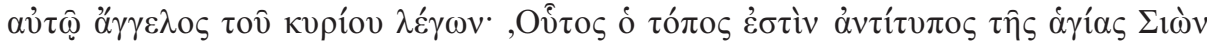

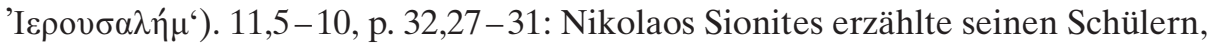
dass in Akalissos einst ein gewisser Sabbatios lebte, dem Gott als erstem das Licht dieses Ortes (Sion) gezeigt habe. Sabbatios habe allen Menschen erzählt, was ihm an diesem Ort erschienen war, doch niemand habe ihm geglaubt. Er habe ihnen gesagt: „Ich sah etwas, das aussah wie eine brennende Fackel und das Gebäude aus einem einzigen Stein, und der ganze Berg leuchtete wie die

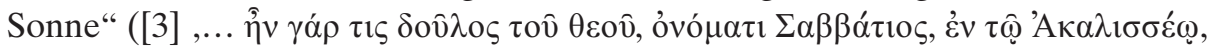

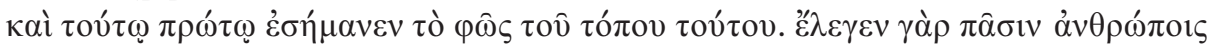

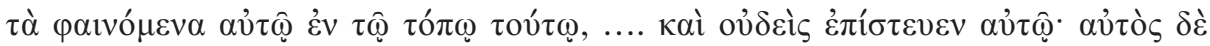

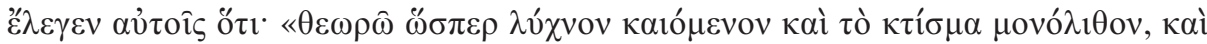

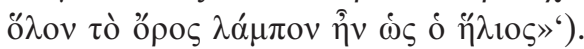

364. ViNi 69,1-13, p. 82,18-84,1: „Drei Jahre nachdem Nikolaos Sionites zum Bischof geweiht wurde, erschien ihm die Mutter Gottes und zeigte ihm den Ort und die Maße eines Gebäudes, das ihren Namen trug, damit er eine Marien-

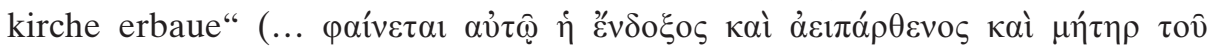

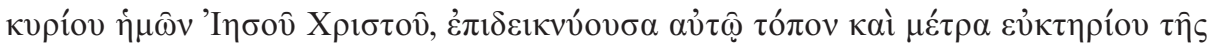

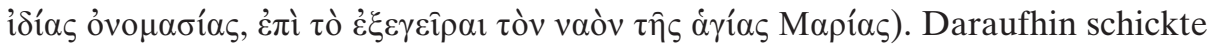
sich Nikolaos an, an dem ihm offenbarten Ort eine Kirche zu errichten, „doch die Kleriker der Stadt hinderten ihn daran, das göttliche Gesicht zu erfüllen“

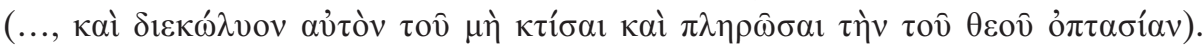
Doch Nikolaos gelang es schließlich, den ihm entgegen gebrachten Widerstand zu bekämpfen und an dem Ort eine Marienkirche zu errichten.

365. ViPa 12, Halkin 1932, p. 7,24-8,17: Als Pachomios einmal in die Wüste ging, kam er zu einem verlassenen Dorf namens Tabennese. Als er das Gebet verrichtete, kam eine Stimme zu ihm - bis jetzt hatte er nämlich noch keine Vision gehabt -, die ihm auftrug, hier zu bleiben und ein Kloster zu gründen (...

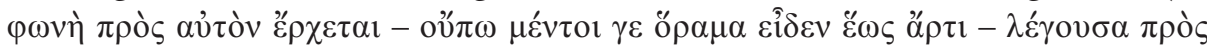

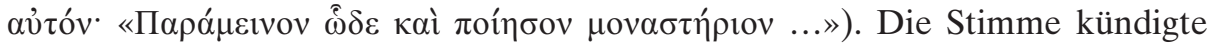
auch an, dass viele zu ihm kommen werden, um in den Mönchsstand einzutreten. „Und als er dies gehört hatte und in der Reinheit seines Geistes gemäß den Schriften beurteilt hatte, dass die Stimme heilig war, kehrte er zu seinem

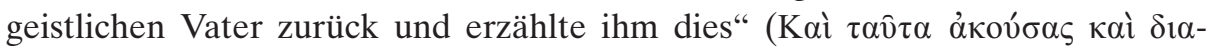

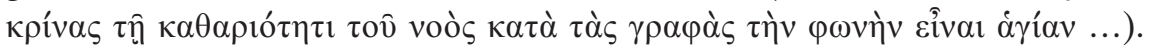


366. ViPa 81,6-12, Halkin 1982, p. 41,6-12: Als die Mönche des Pachomios das Kloster von Panopolis bauten, näherten sich in der Nacht Neider, um die Mauern zu zerstören. „Einige von ihnen glaubten einen Engel zu sehen, der gleichsam mit dem Finger in einem göttlichen Feuer die Mauer rundherum

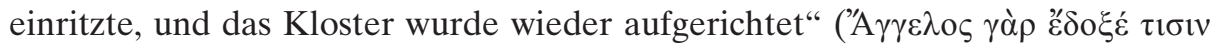

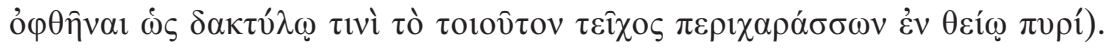

367. PrSp1, PG 87.3, 2852D-2853B: Ein Wüstenvater befand sich auf dem Weg von Palästina zum Berg Sinai. Beim Überqueren des Jordan wurde er krank

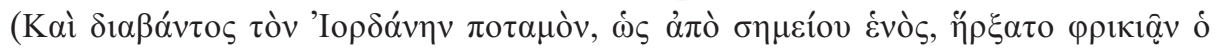

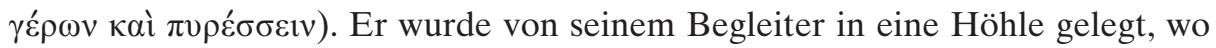

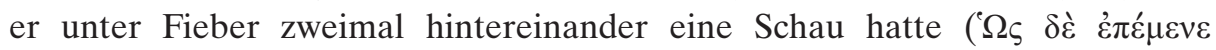

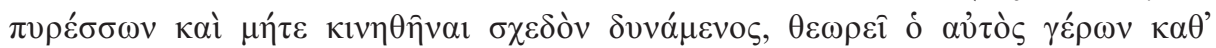

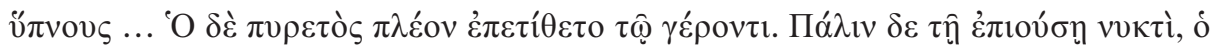
$\alpha$ đò $\pi \alpha \rho i ́ \sigma \tau \alpha \tau \alpha \iota \alpha u ̛$....). Es erschien ihm Ioannes der Täufer und befahl ihm, in der Höhle zu bleiben und dort eine Kirche einzurichten.

368. PrSp 146, PG 87.3, col. 3012A: Vom Patriarchen von Alexandreia Eulogios (580-607) erzählte man, „dass er eines Nachts, als er im Bischofsgebäude alleine den Kanon vollendete, Iulianos, den Archidiakon, neben sich stehen sah

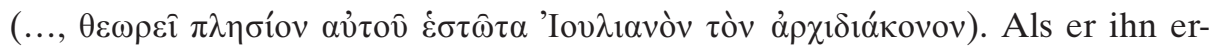
blickte, erschrak er darüber, dass dieser es wagte, ohne Ankündigung einzutreten. Außerdem schwieg er. Als Eulogios den Psalm vollendet hatte und die Buße ablegte, warf sich die im Gewand des Archidiakon erschienene Gestalt

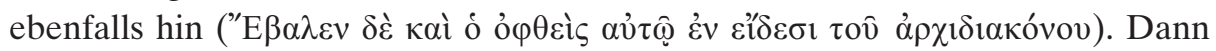
stand der Patriarch auf und verrichtete die Proskynese. Der andere aber blieb auf dem Boden liegen. Da ging Eulogios zurück zu ihm“ und fragte ihn, wie lange er noch liegen bleiben wolle. Dieser antwortete, dass er nicht aufstehen könne, wenn nicht er selber die Hand ausstrecke und ihm aufzustehen helfe. Darauf half ihm der Patriarch beim Aufstehen. „Dann fing er wieder an zu psalmodieren. Als er sich aber umwandte, sah er niemanden mehr“. Sogleich warf er dem kubikularios, dann dem Türsteher vor, sie hätten den Archidiakon ohne Ankündigung in das Bischofsgebäude eintreten lassen. Beide verstanden aber nicht, wovon der Patriarch redete. Als am nächsten Morgen der Archidiakon Iulianos zur Proskynese erschien, fragte ihn Eulogios, warum er nicht die Regel eingehalten habe und mitten in der Nacht unangekündigt bei ihm eingetreten sei. Darauf versicherte Iulianos unter Schwüren, in der Nacht ganz bestimmt nicht in das Bischofsgebäude eingetreten zu sein. „Daraus schloss Eulogios, Iulianos, den Märtyrer, gesehen zu haben, der ihn zur Restaurierung

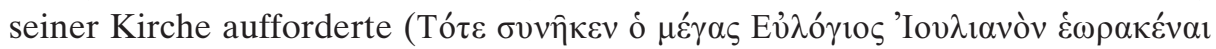

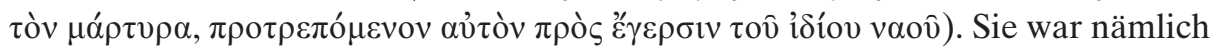
durch die Zeit hindurch alt und brüchig geworden und drohte zusammenzufallen“. 
369. ViSa 15, p. 97,21-98,10: Nachdem Sabas vier Jahre in der Wüste verbracht hatte, erschien ihm, ,als er im Gebet eine Nacht durchwachte, eine Engelsgestalt in strahlendem Kleid, die ihm südlich jenes Berges einen Bach zeigte [...]“

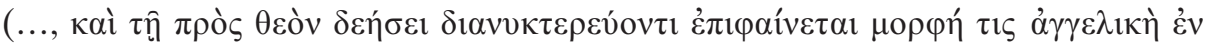

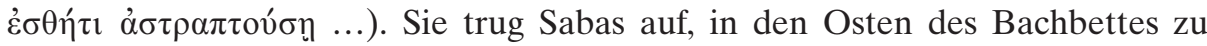
gehen. Auf der anderen Seite werde er eine Höhle finden, in der er sich nie-

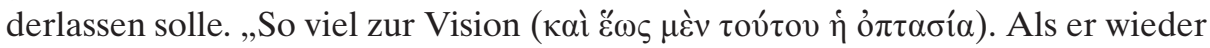

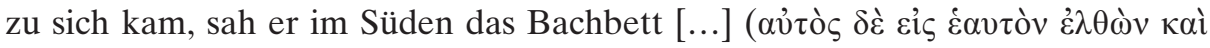

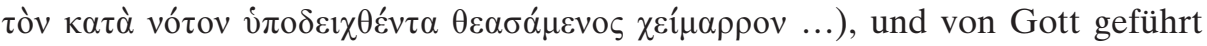

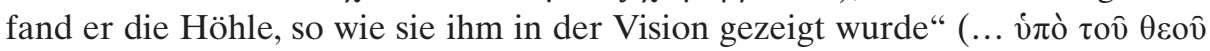

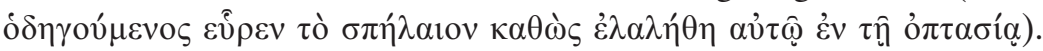

370. ViSyStII 95, Bd. 1, p. 74,5-15,: Symeon „sah einen Engel des Herrn, der ein Maßband hielt und die Spur eines Klosters und darin den Plan einer Kirche

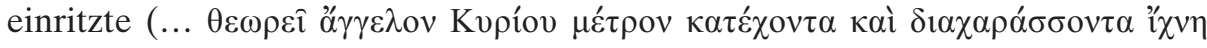

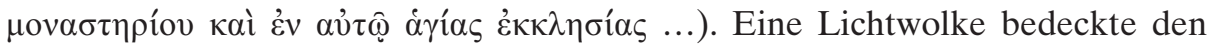

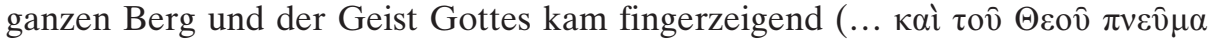

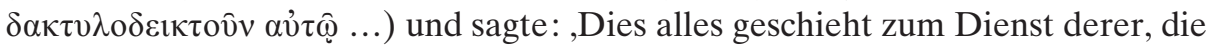
hier wohnen und unterkommen werden“". 


\section{Q. Dogmatische, exegetische und ethische Belehrungen}

371. PaThII 11, p. 102,30-103,2: Theodoros, der Schüler des Pachomios, betete einmal zu Gott, er möge das Menschengeschlecht von der Verirrung der Arianer befreien. „Während des Betens sah er drei vollständig identische Säulen aus

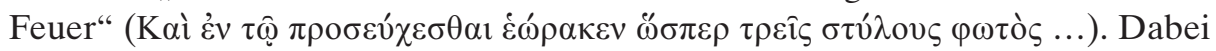
hörte er eine Stimme, die sagte, er solle nicht auf das Abweichende des Beispiels

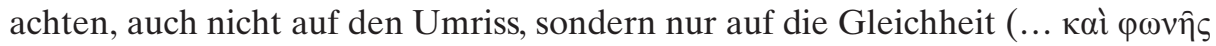

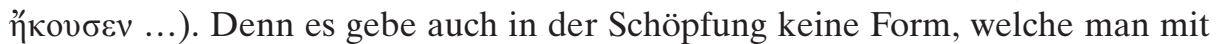
dem Vater, dem Sohn und dem heiligen Geist vergleichen könne.12,1, p. 103,3 f.: Als Pachomios dies hörte, belehrte er Theodoros, dass es ihm so gezeigt und gesagt worden sei, wie er imstande sei, es zu sehen und zu hören (' $\Omega \varsigma$ i $\delta \varepsilon i ̂ v$

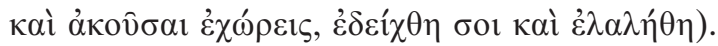

372. PaThII 12, p. 103,28-104,11 (vgl. 380): Pachomios erzählte seinem Schüler Theodoros aus seiner Jugend, dass er durch all die unterschiedlichen Häresien, welche behaupteten, die Wahrheit zu kennen, verwirrt worden sei. Da habe er unter Tränen Gott angefleht, er möge ihm zeigen, bei welcher der Glaubensrichtungen die Wahrheit liege. Und noch während er betete, geriet er in Ekstase

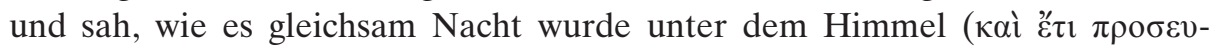

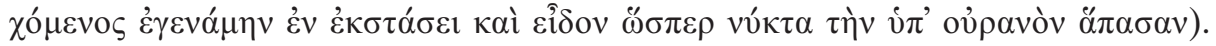
Aus verschiedenen Richtungen vernahm er eine Stimme, die sagte: „Hier ist die

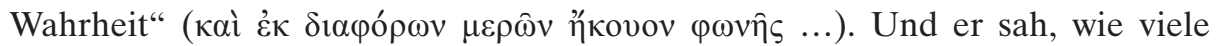
Menschen diesen Stimmen folgten und sich in der Dunkelheit gegenseitig den

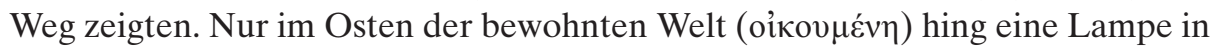
der Höhe, und die Morgenröte erstrahlte. Dann vernahm er von dort eine Stimme, die sagte, er solle sich nicht täuschen lassen von denen, die in die Dunkelheit ziehen, sondern diesem Licht folgen, denn in ihm sei die Wahrheit

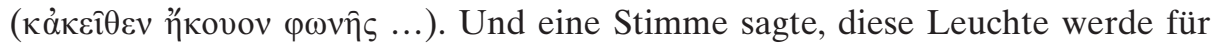

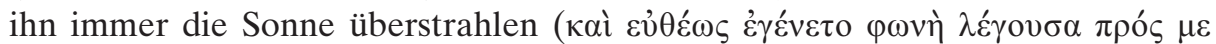
...). Dies sei nämlich die Predigt des Evangeliums Christi, das in seiner heiligen Kirche gepredigt werde, in der er getauft wurde. Christus wohne im Bischof Alexandros in der Kirche von Alexandria. Die anderen Stimmen in der Dunkelheit seien diejenigen der Häresien. Im Führer jeder Häresie sitze nämlich ein Dämon, der rufe und für Zerrüttung sorge. Dann erblickte Pachomios viele Gestalten mit strahlenden Gewändern, die zur Leuchte eilten. Er lobte Gott und verachtete jene, die ihn täuschen wollten.

373. ApAl, Arsenios 33, PG 65, col. 100C-101A: „Arsenios erzählte gleichsam über einen anderen, obwohl es sich wahrscheinlich um ihn selbst handelte, daß 
er in der Zelle saß, als er eine Stimme vernahm, die ihn aufforderte: ,Komm mit,

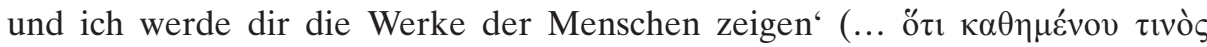

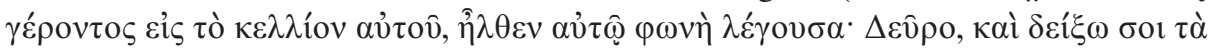

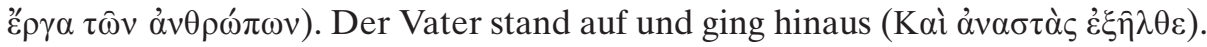
Der andere führte ihn zu einem Ort und zeigte ihm einen Äthiopier, der Holz

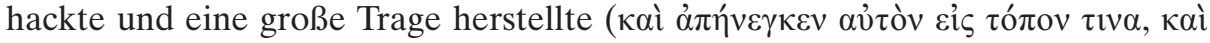

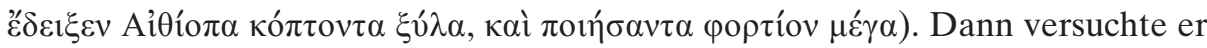
sie hochzuheben, was ihm aber nicht gelang. Anstatt Holz von der Trage herunterzunehmen, hackte er jetzt neue Stücke und legte sie auf die Trage. Dies tat er während langer Zeit. Dann wurde Arsenios ein Mensch gezeigt, der bei einer Grube stand und Wasser daraus schöpfte. Dann schüttete er es in ein Wassergefäß um, welches durchlöchert war und das Wasser zurück in die Grube fließen ließ. Die Stimme sagte jetzt: ,Komm, ich werde dir etwas anderes zeigen'. Jetzt sah er einen Tempel und zwei Männer, die auf Pferden saßen und seitlich Holz schleppten, einer neben dem anderen. Sie wollten durch das Tor in den Tempel eintreten, was ihnen aber nicht gelang, da das Holz seitlich herausragte. Keiner von den beiden erniedrigte sich, das Holz hinter dem anderen hineinzutragen. Deshalb blieben sie außerhalb des Tores stehen. ,So sind die', sagte die Stimme, ,die das Joch der Gerechtigkeit mit Überheblichkeit tragen und sich nicht dazu erniedrigen, sich selber zu korrigieren und den demütigen Weg Christi zu gehen. Deshalb bleiben sie außerhalb des Königreichs Gottes. Der Mann aber, der Holz hackt, befindet sich in vielen Sünden. Anstatt zu bereuen, fügt er noch weitere Gesetzlosigkeiten auf seinen Sündenberg. Und der wasserschöpfende Mann tut gute Werke. Weil er aber Übel in sie hineingemischt hat, zerstört er dabei auch seine guten Werke. Es ist notwendig, dass jeder Mensch nüchtern bleibt bei dem, was er wirkt, damit er sich nicht umsonst anstrengt', sagte die Stimme".

374. ApAl, Ioannes Kolobos 14, PG 65, col. 208C-D: „Abbas Ioannes erzählte, dass ein geron in einer Ekstase sah, wie drei Mönche am Meeresufer standen

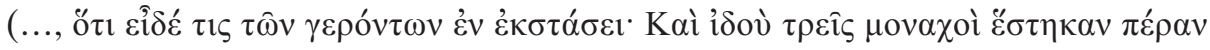

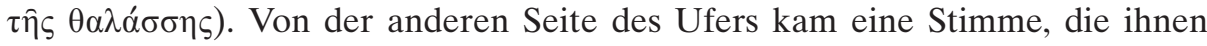
zurief: ,Nehmt Flügel aus Feuer und macht euch auf zu mir'. Zwei der Mönche taten dies und machten sich daran, auf die andere Seite zu gelangen. Der dritte aber blieb, weinte heftig und schrie. Später gab man auch ihm Flügel, jedoch nicht aus Feuer, sondern schwache und kraftlose. Unter großen Schmerzen wurde er niedergeworfen und stand wieder auf und nur mit großem Kummer kam er auf der anderen Seite an. So ist es mit diesem Geschlecht. Wenn es auch Flügel zu Hilfe nimmt, so nicht aus Feuer, sondern kranke und schwache".

375. ApSy XV 91, Bd. 2, p. 342 f.: Ein Greis fastete während 70 Wochen. Und obwohl er Gott um die Auslegung eines bestimmten Bibelwortes bat, offenbarte

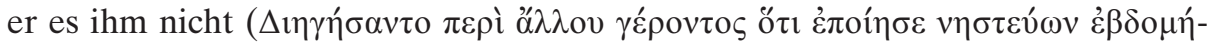

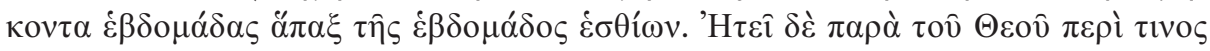




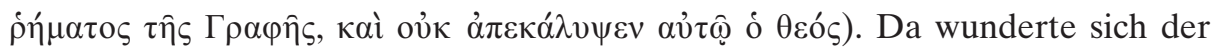
Greis, dass er nach so vielen Mühen keine Vergeltung erhielt. Deshalb beschloss er, zu einem Bruder zu gehen und ihn über die Angelegenheit zu befragen. Doch als er die Türe seiner Zelle zumachte, wurde ein Engel des Herrn zu ihm gesandt, der sagte, die 70 Wochen Fasten hätten ihn Gott nicht näher gebracht

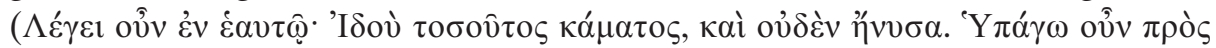

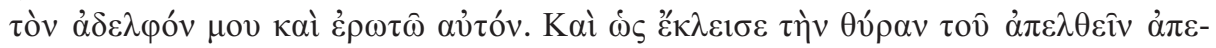

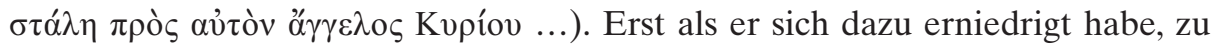
seinem Bruder zu gehen, sei er ausgesandt worden, um ihm das Bibelwort zu verkünden. Dann belehrte er ihn in seiner Frage zum Bibelwort und verschwand.

376. HiMo 13,7, p. 100,1-7: Ioannes stand während drei Jahren in ständigem Gebet aufrecht auf einem Felsen, ohne sich jemals zu setzen oder zu schlafen. Als Nahrung nahm er bloß am Sonntag das Abendmahl zu sich, welches ihm ein Priester brachte. „Als seine Füße durch die lange Bewegungslosigkeit schon wund waren und Gestank und Fäulnis erzeugten, trat ein Engel an ihn heran, berührte seinen Mund und sagte“, Christus solle seine wahre Nahrung und der

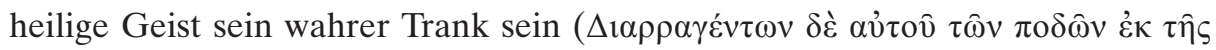

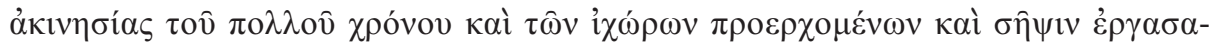

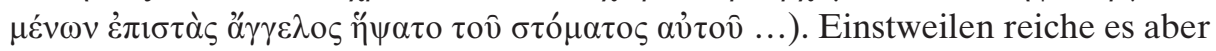
mit der geistigen Nahrung, sonst fange er noch an, aus Übersättigung zu erbrechen. „Der Engel stellte seine Gesundheit wieder her und brachte ihn weg von dem Ort. Von nun an zog Ioannes durch die Wüste und aß Kräuter, [...]“. 377. ViIoEl 20, Bd. 2, p. 368,1-369,10: Petros, ein geiziger Zöllner in Alexandreia, schenkte niemals etwas den Armen. Eines Tages schlossen mehrere Bettler eine Wette $a b$, ob es gelingen würde, von Petros ein Almosen zu bekommen. Einer von den Bettlern ging vor seine Tür und wartete, bis er nach Hause kam. Erzürnt über den Anblick des Bettlers, warf ihm Petros, da er keinen Stein zur Hand hatte, widerwillig einen Silbertaler zu. „Zwei Tage später wurde der Zöllner todkrank und sah im Schlaf, wie er zur Rechenschaft gezogen wurde und wie alle seine Taten auf eine Waage gelegt wurden ([1] $\mu \varepsilon \tau \dot{\alpha}$ ov̂v $\delta$ o

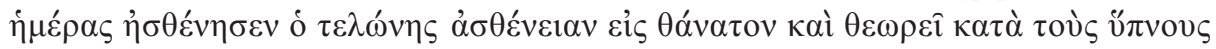

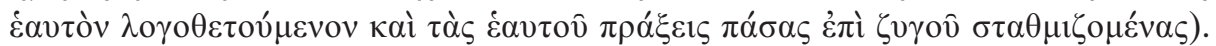
Auf der einen Waagschale waren schwarze, hässliche Gestalten versammelt. Auf der anderen Waagschale befanden sich Weißgekleidete von furchteinflößendem Anblick. Diese fanden aber nichts Gutes, was sie den von den Schwarzen versammelten Werken hätten entgegensetzen können“. Deshalb waren sie zutiefst betrübt, stöhnten und sagten zueinander, dass sie nichts hätten, außer dem Silbertaler, welchen Petros vor zwei Tagen widerwillig Christus geschenkt habe. Dann warfen sie den Silbertaler auf die Waagschale, und die Waage glich sich aus. Petros trugen sie auf, noch mehr als diesen Silbertaler zu spenden, damit er nicht von den Schwarzen mitgenommen werde. „Und als er erwachte, erkannte 


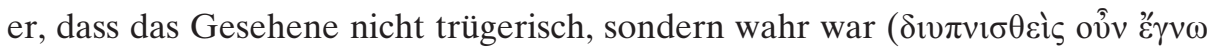

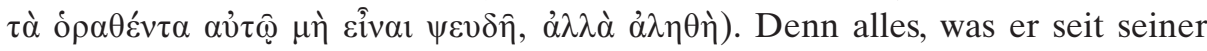
Jugend getan und selber schon wieder vergessen hatte, sah er nun von diesen Äthiopiern zusammengetragen auf der Waage liegen“. Da sagte er zu sich selbst, dass er, wenn schon dieser eine Silbertaler, den er aus Wut hingeworfen hatte, derart nützlich sei, in Zukunft seine Güter an diejenigen geben werde, die sie benötigten, um sich von den Übeln zu reinigen. „Als er später eines Tages aufs Zollamt ging, kam ein Schiffsherr zu ihm, der ganz nackt vor ihn trat, da er bei einem Schiffbruch alles verloren hatte. Er warf sich zu seinen Füssen und bat ihn um Hilfe. Da Petros dachte, dass der Nackte arm sei, gab er ihm seinen Mantel". Doch dem anderen war es peinlich, ihn zu tragen, und so ließ er ihn verkaufen. Als Petros eines Tages Dienstschluss hatte, sah er den Mantel dahängen und wurde derart betrübt, dass er in sein Haus ging und nichts essen konnte. Er verriegelte die Tür und saß weinend da. In seiner Verzweiflung schlief er ein und sah eine Gestalt, die so schön leuchtete wie die Sonne ([2]...,

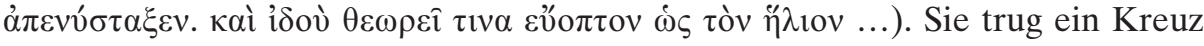
an der Stirne und den Mantel, den Petros dem Nackten geschenkt hatte. Sie zeigte ihm den Mantel und sagte, sie trage ihn jetzt und danke ihm für die gute Absicht, mit der er ihn weggegeben habe. Als Petros wieder zu sich kam, staunte er und fing an, die Armen zu rühmen und beschloss, einer der ihren zu werden

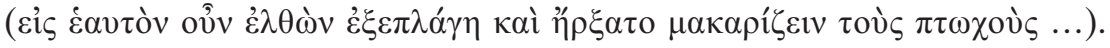

378. ViIoEl 25, Bd. 2, p. 376,18-378.3: Eines Tages kam ein Reeder zum Patriarchen Ioannes. Er gab ihm siebeneinhalb Pfund Gold, damit Ioannes dafür bete, dass sein fünfzehnjähriger Sohn heil aus Afrika zurückkehre. Doch noch bevor dreißig Tage vergangen waren, starb der Sohn in Afrika, und nur drei Tage nach seinem Tod lief das Schiff mit dem Bruder des Reeders in Richtung Alexandreia aus und kenterte. Dabei ging das Schiff mit der gesamten Fracht unter, alleine die Besatzung überlebte. Als Ioannes davon erfuhr, ließ er dem Reeder eine Nachricht schicken, in der er sein Beileid ausdrückte. Damit dieser aber verstand, dass er die Vergeltung für die siebeneinhalb Pfund und für das Vertrauen, das er dem Patriarchen geschenkt hatte, nicht verlieren würde - und auch, um die Leser zu belehren, dass man immer an Gott festhalten soll, auch wenn man nach guten Taten in Schwierigkeiten gerate - sah der Reeder in der folgenden Nacht im Schlaf einen Mann mit dem Aussehen des Patriarchen (iv $v$

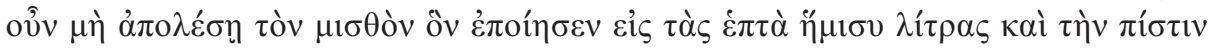

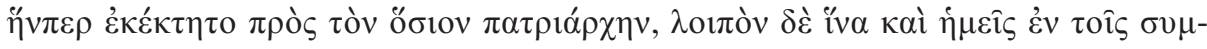

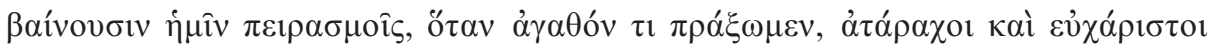

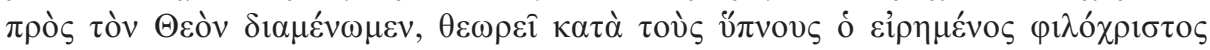

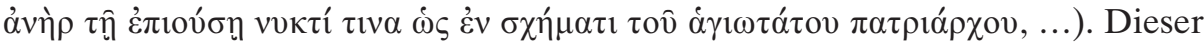
fragte ihn, warum er so hoffnungslos sei, und ob er ihn nicht gebeten habe, für seinen Sohn zu beten, der jetzt tatsächlich gerettet worden sei. Hätte er nämlich weitergelebt, so hätte er ein lasterhaftes Leben geführt. Und wenn nicht Gott 
durch seine gute Tat zu Hilfe gerufen worden wäre, dann hätte er zusammen mit der Schiffsfracht auch seinen Bruder verloren. „Als der Reeder aufwachte, fühlte er, wie seine Seele gestärkt und von allen Sorgen befreit war [...]“ ( $\delta$ w-

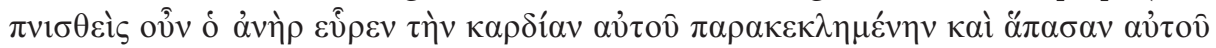

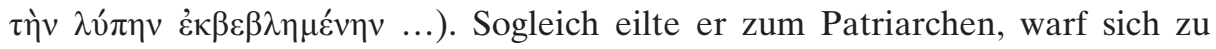
seinen Füssen, dankte Gott und erzählte die Vision, die er gesehen hatte (... каì $\alpha$ น’

379. ViIoEl 30 u. 32, Bd. 2, p. 381,18-382,3; 382,14-383,6 Ein Mann wurde von Steuereintreibern verfolgt, da er seine Schulden nicht bezahlen konnte. Aus diesem Grund ging er zu einem Offizier und verlangte von ihm 50 Pfund. Dieser versprach ihm das Geld, verschob aber die Auszahlung auf einen späteren Zeitpunkt. Da die Steuereintreiber den Mann nicht in Ruhe ließen, ging er zum Patriarchen Ioannes und schilderte ihm seine Situation. Dieser lieh ihm ohne zu zögern das Geld. „In der folgenden Nacht sah der Offizier, wie er selbst an

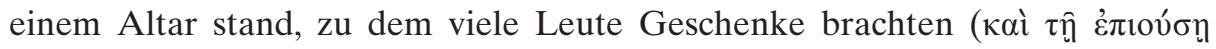

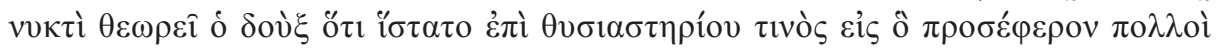
$\pi \rho о \sigma \varphi о \rho \alpha ́ \varsigma)$. Für jede Gabe, die sie brachten, bekamen sie vom Altar das Hundertfache zurück. Auch der Patriarch war da und stand direkt hinter dem Offizier". Auf einem Stuhl vor ihnen lag ein Geschenk, und jemand sagte zum Offizier, er solle es nehmen und zum Altar bringen, damit er dafür das Hundertfache zurückbekomme. Da der Offizier zögerte, rannte der Patriarch nach vorne und nahm die Gabe, bevor der andere es tun konnte. Er trug es zum Altar und erhielt dafür, wie die anderen auch, das Hundertfache. Als der Offizier

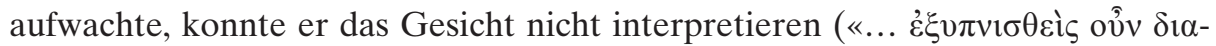

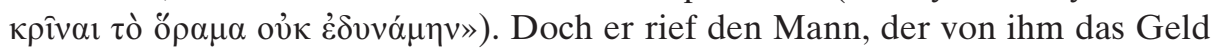
verlangt hatte, um es ihm jetzt zu geben. Dieser sagte dem Offizier, dass ihm der Patriarch in seinem guten Wirken an ihm zuvorgekommen sei. Da er es aufgeschoben habe, ihm das Geld zu geben, habe er in seiner Not den Patriarchen um Hilfe bitten müssen. Als der Offizier dies hörte, erinnerte er sich unverzüglich an seinen Traum und antwortete, dass ihm der Patriarch tatsächlich

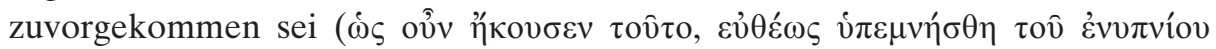
...,). „Dann erzählte er ihm und vielen anderen das Traumgesicht, das er ge-

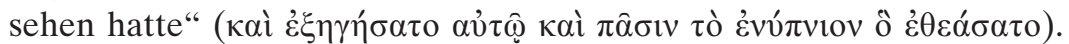

380. ViPa 102, Halkin 1932, p. 67,23-68,3: Einmal erzählte Pachomios den

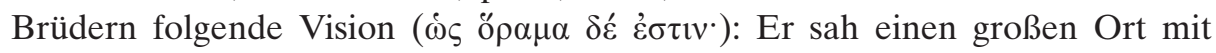
vielen Säulen und Menschen, die nicht erkannten, wohin sie gingen (Eî́óv $\pi$ o $\tau \varepsilon$

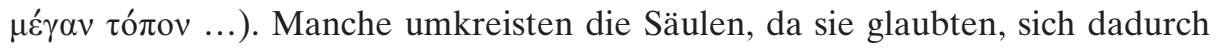
ein großes Stück Weg zu ersparen. Sie gelangten aber ins Feuer. Überall war eine Stimme zu vernehmen, die sagte: „Sieh, das Licht ist hier“. Und die Menschen wandten sich um, um es zu finden. Dann erklang wieder eine Stimme, die dasselbe sagte, und sie drehten sich abermals um. Und es gab viel Elend an jenem Ort. Dann sah Pachomios eine Leuchte, die zahlreichen Menschen vor- 
ausging, aber nur vier von ihnen sahen sie. Alle anderen folgten ihnen, indem sich jeder an der Schulter des Nächsten festhielt, um sich nicht in der Dunkelheit zu verirren. Hätte einer den Vorausgehenden losgelassen, hätte er sich mit dem ihm Folgenden in der Dunkelheit verloren. Und weil Pachomios sah, dass zwei sich nicht mehr festhielten, schrie er ihnen zu, sie sollten sich festhalten, um sich und die anderen nicht zu vernichten. Die Leuchte zeigte den Weg an, und die Folgenden gingen durch eine Tür ins Licht. Einigen erzählte Pachomios in

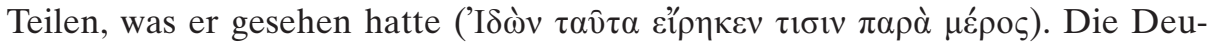
tung davon erzählte er den Brüdern jedoch erst nach langer Zeit (Kà $\mu \varepsilon \tau \grave{\alpha}$

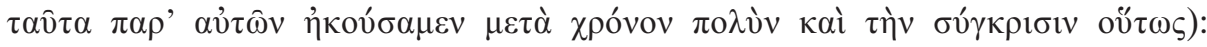
„Diese Welt ist dunkel wegen der Verirrung jeder einzelnen Häresie, die sich einbildet, den richtigen Weg zu kennen. Die Leuchte aber bedeutet Glaube an Christus, der die Rechtgläubigen rettet und ins Königreich Gottes führt".

381. PaThI 2,7,13-15, p. 80,4-6: Als einige Brüder zu Pachomios kamen, nahm er einen fürchterlichen Gestank wahr, wusste aber nicht, woher dieser kam. „Um den Grund dafür zu erfahren, ging er in seine Zelle. Er betete zu Gott und erkannte sofort, dass es die Lehren des Unglaubens waren, die einen solchen

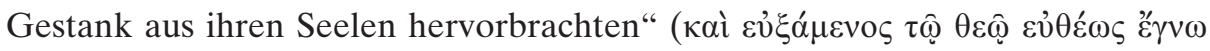

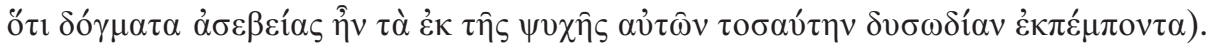
382. PrSp 25, PG 87.3, col. 2869D-2872A: „[...] Es war einmal ein Bruder im Kloster Chuziba, der die proskomide ${ }^{778}$ der anaphora ${ }^{779}$ lernte. Eines Tages schickte man ihn los, um die Eulogie ${ }^{780}$ zu holen. Als er zurückkam, rezitierte er die Worte der proskomide, wie es in den Versen festgeschrieben war, und die Diakone legten die Eulogie auf der Patene auf den Altar. Und als der Priester Ioannes, ,der Chuzibit', der später Bischof von Kaisarea in Palästina wurde, die proskomide verrichtete, sah er nicht wie gewohnt die Erleuchtung des heiligen

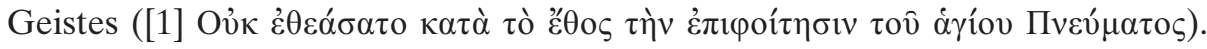
Da er glaubte, seine eigene Sündhaftigkeit sei der Grund dafür, ging er ins

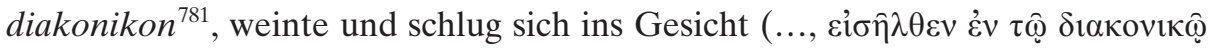

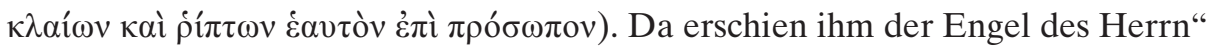

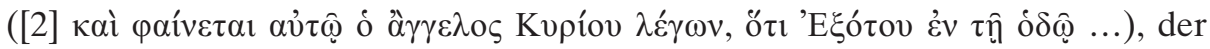
ihm sagte, dass die Eulogie geheiligt und bereit sei, da der Bruder sie auf dem Weg vorbereitet und die heilige anaphora rezitiert habe. Und von diesem Zeitpunkt an ordnete der Mönch an, dass niemand die heilige anaphora lernen

778 S. S. 218 A. 746.

779 S. S. 217 A. 743.

780 Gemeint ist hier das Brot für das Abendmahl. S. G. Vikan, Art. Eulogia, in: ODB 2, 745.

781 Ein südlich der Zentralapsis gelegener Raum zur Aufbewahrung von kirchlichen Geräten und Gewändern, s. K. ONASCH, Art. Prothesis, in: Lexikon Liturgie und Kunst der Ostkirche, Berlin 1993, $85 \mathrm{f}$. 
dürfe, der nicht geweiht ist, und dass sie niemand zu jeder beliebigen Zeit und ohne geweihten Ort rezitieren dürfe.

383. PrSp 31, PG 87.3, col. 2872B-2873A: Ein nestorianischer Bruder kam zu Kyriakos, um sich von ihm über die schlechten Gedanken belehren zu lassen. Dieser wollte ihn von der Richtigkeit der Orthodoxie überzeugen. Darauf ließ sich aber der nestorianische Bruder nicht ein, da jede Glaubensgemeinschaft behaupte, dass nur gerettet werden könne, wer zu ihr gehöre ('O $\delta \dot{\varepsilon} \alpha \dot{\alpha} \delta \varepsilon \lambda \varphi$ ò $^{\circ}$

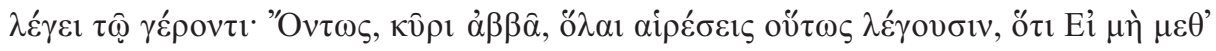

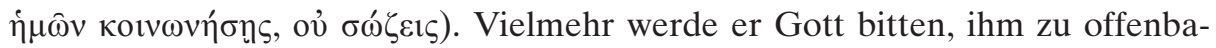

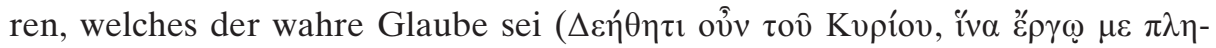

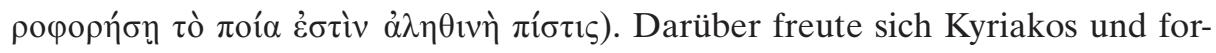
derte ihn auf, sich in seine Zelle zu setzen, damit ihm Gott die Wahrheit seiner

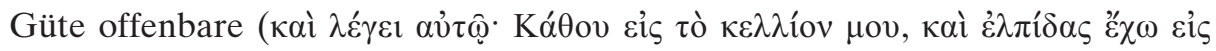

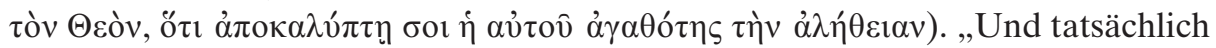
sah der Bruder in der neunten Stunde des zweiten Tages jemanden von fürch-

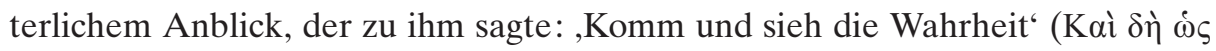

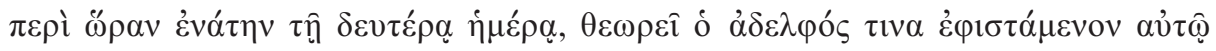
 ihn an einen düsteren, stinkenden und feurigen Ort, wo alle Häretiker ver-

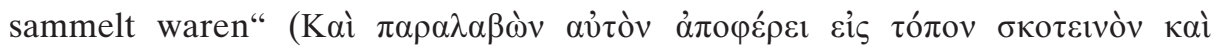

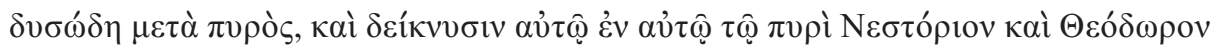
$\kappa . \tau . \lambda$.$) . Als er wieder zu sich kam, war er vom wahren Glauben überzeugt und$ trat der rechtgläubigen Kirche bei.

384. PrSp 30, PG 87.3, col. 2877B-2880A: Bruder Isidoros von Melitene war ständig am Weinen wegen der vielen Sünden, die er begangen hatte, als er noch

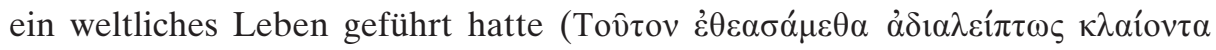
$\mu \varepsilon \tau \grave{\alpha}$ oi $\mu \omega \gamma \eta \hat{\varsigma})$. Er erzählte, dass er und seine Frau früher der severianischen Kirche angehört hatten. Eines Tages habe er festgestellt, dass seine Frau im Nachbarhaus an einem Gottesdienst der rechtgläubigen Kirche teilnahm. Als er in das Haus des Nachbarn kam, wollte seine Frau gerade das heilige Abendmahl zu sich nehmen. Auf der Stelle packte er sie am Hals und brachte sie dazu, das heilige Stück auszuspucken. Überdies verdrosch er sie von oben bis unten. Doch auf einmal sah er, wie ein Blitz über jenem Ort die heilige Gemeinde ergriff

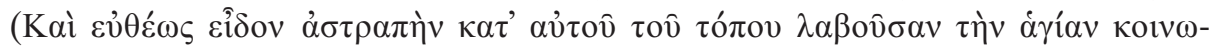
víav). Und nach zwei Tagen sah er einen Äthiopier. Dieser war in ein Tuch gehüllt und sagte zu ihm, er und Isidoros seien gleichermaßen dazu verdammt,

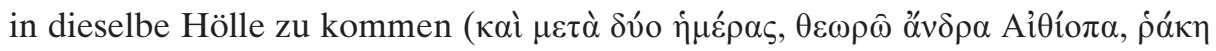

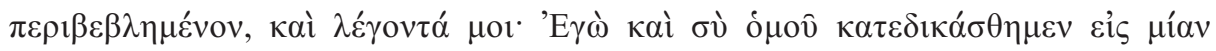
$\kappa o ́ \lambda \alpha \sigma \iota v)$. Und als er den Äthiopier fragte, wer er sei, antwortete dieser, er sei derjenige, der Jesus Christus in der Zeit des Leidens auf die Wange geschlagen habe. 
385. PrSp 46, PG 87.3, col. 2900D-2901C: Der Presbyter Kyriakos erzählt, dass er im Schlaf eine Purpur tragende Frau mit zwei heiligen Männern gesehen habe

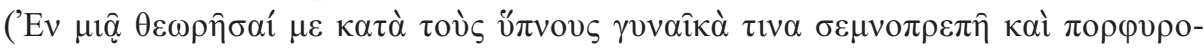

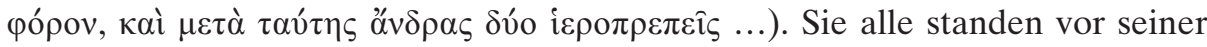
Zelle, und er vermutete, dass es sich bei der Frau um die theotokos, bei den beiden Männern um Ioannes den Theologen und Ioannes den Täufer handelte

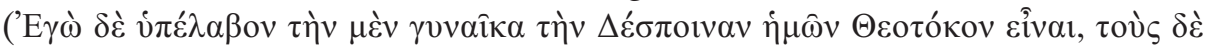

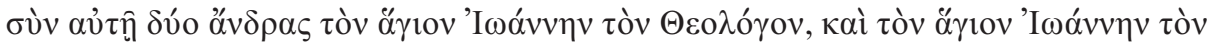

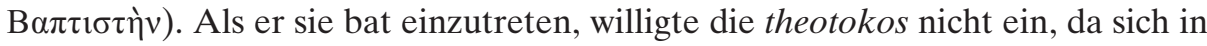

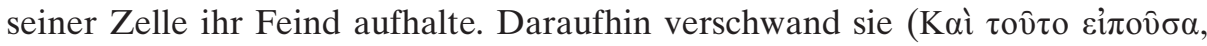
$\dot{\alpha} \pi \hat{\eta} \lambda \theta \varepsilon v)$. Als Kyriakos aufwachte, fing er an, sich Sorgen zu machen ('E $\gamma \grave{\omega} \delta \grave{\varepsilon}$

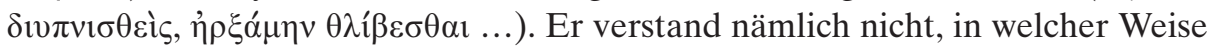
er gegen die heilige Jungfrau gesündigt hatte. Als er aber zur Lektüre ein Buch öffnete, das er von Hesychios, dem Presbyter von Jerusalem, bekommen hatte, stellte er fest, dass darin am Ende zwei nestorianische Reden standen. In diesem Augenblick erkannte er, dass dies der Feind der theotokos war und brachte das Buch an seinen Herkunftsort zurück, wo die beiden Reden des Nestorios herausgerissen und vernichtet wurden.

386. PrSp 48, PG 87.3, col. 2904A-B: „Anastasios, Priester und Schatzmeister

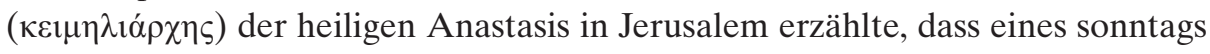
nachts Kosmiane, die Frau des patrikios Germanos, alleine dem heiligen Grab Christi in der Auferstehungskirche die Proskynese erweisen wollte. Als sie sich dem Allerheiligsten näherte, trat die theotokos mit anderen Frauen zusammen

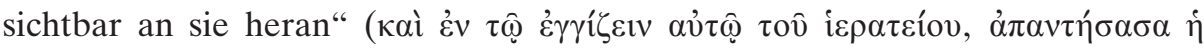

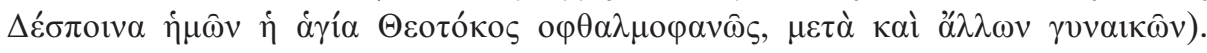
Dabei sagte sie zu Kosmiane, dass sie nicht eintreten dürfe, da sie nicht eine von ihnen sei, sondern der Häresie der Severianer angehöre. Als Kosmiane dennoch darum bat, hineingelassen zu werden, antwortete die theotokos, dass sie solange nicht hereingelassen werde, bis sie mit ihnen das Abendmahl einnehme. Daraufhin empfing Kosmiane das Abendmahl und durfte in das Allerheiligste der Auferstehungskirche eintreten.

387. PrSp 49, PG 87.3, col.2904C-2905A: Als Gabemer dux von Palästina wurde, wollte er als erstes der heiligen Anastasis die Proskynese erweisen. Als er aber die Kirche betrat, „erblickte er einen ihm entgegenstürzenden Widder,

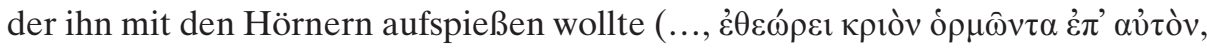

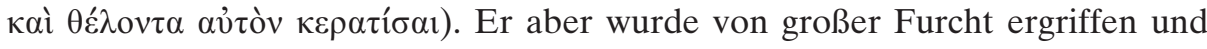
wandte sich um". Als der staurophylax Azarias und seine Diener ihn fragten, warum er nicht eintrete, fragte er sie zurück, warum sie diesen Widder hier hereingebracht hätten. Diese sahen jedoch nichts und wollten ihn eintreten lassen. „Doch wiederum sah Gabemer denselben Widder, der auf ihn losstürzte

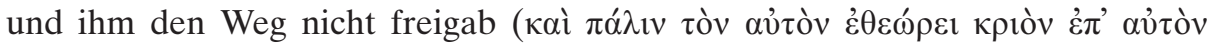

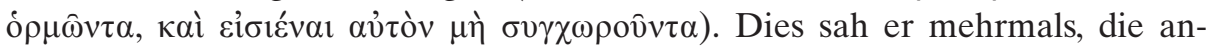




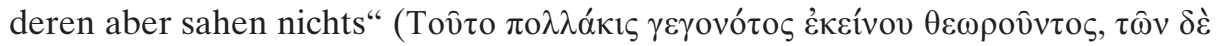
$\pi \alpha \rho \varepsilon \sigma \tau \omega \dot{v} \tau \omega \nu, \mu \eta \delta \varepsilon \grave{\varepsilon} v$ ó$\lambda \omega \varsigma \beta \lambda \varepsilon \pi o ́ v \tau \omega v, \ldots)$. Darauf sagte der staurophylax zu ihm, es müsse etwas in seiner Seele sein und er solle beichten. Jetzt gestand Gabemer unter Tränen, dass er viele Sünden begangen hatte, dann beichtete er vor Gott. Trotzdem versperrte ihm der Widder noch immer den Eintritt zum Allerhei-

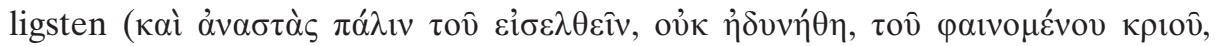

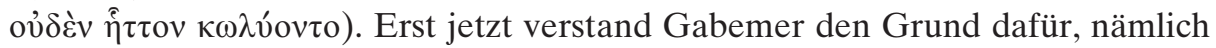
seine Zugehörigkeit zur Kirche des Severus. Darauf empfing er das heilige Abendmahl und durfte in das Allerheiligste eintreten.

388. PrSp 128, PG 87.3, col. 2992D-2993A: Iannia, die Schwester des Bischofs Adelphios, berichtete, dass Ioannes Chrysostomos, der Bischof von Konstantinopel, als er nach Kukuson verbannt wurde, in ihrem Haus gewohnt habe. Als sie später vom Tod des Ioannes erfahren habe, sei sie in große Sorgen geraten, da dieser außerhalb des Patriarchensitzes gestorben sei. Darauf habe sie unter Tränen zu Gott gebetet, er möge ihr zeigen, in welchem Zustand sich Ioannes befinde und ob er unter den Patriarchen aufgereiht sei. Lange habe sie gebetet, dann sei sie in eine Ekstase geraten und habe einen wunderschönen Mann

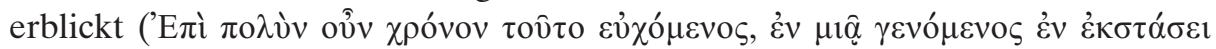

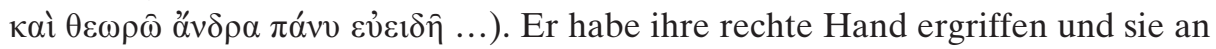

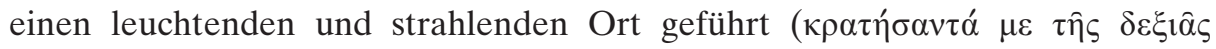

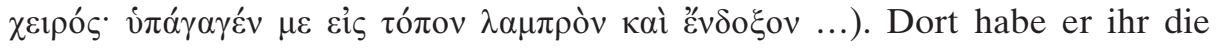
Prediger der Frömmigkeit und die Kirchenlehrer gezeigt. Sie habe sich umgeschaut, um zu sehen, welches ihr geliebter Ioannes sei. Der Mann habe alle vorgeführt und den Namen von jedem einzelnen genannt. Dann habe er sie an der Hand hinausgeführt. Sie aber sei zutiefst betrübt gewesen, da sie Ioannes nicht unter den Vätern erblickt habe. Doch als sie dies dem Erschienenen erzählte, erwiderte jener, dass es unmöglich sei, Ioannes im Fleisch zu sehen, da er dort sei, wo der Thron Gottes stehe.

389. PrSp 148, PG 87.3, col. 3012C-3014A: Theodoros, der Bischof von Daphne in Libyen, erzählte, dass er, als er noch synkellos ${ }^{782}$ des Patriarchen Eulogios (580-608) von Alexandreia war, im Schlaf einen frommen und großen Mann gesehen habe, der ihm aufgetragen habe, ihn beim Patriarchen anzu-

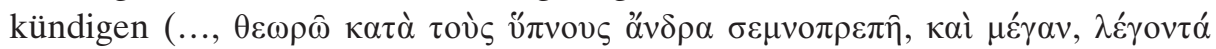

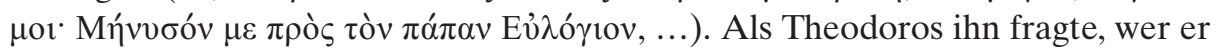
sei und warum er befehle, angekündigt zu werden, antwortete dieser, er sei Leon, der Papst von Rom. Darauf kündigte ihn Theodoros bei Eulogios an, der ihn empfing. Sie küssten einander und knieten nieder, um das Gebet zu verrichten. Dann erzählte Leon dem Patriarchen, dass er gekommen sei, um ihm zu danken, dass er für seinen Brief eingestanden sei, welchen er für Flavios, den

782 Berater und Vertrauter des Patriarchen oder Bischofs, dessen Amtsnachfolger er häufig wurde, s. A. Papadakis, Art. Synkellos, in: ODB 3, 1993 f. 
Patriarchen von Konstantinopel geschrieben habe. Der Patriarch habe Leons Meinung verbreitet und die Münder der Häretiker als unheilvoll verkündet. Er solle wissen, dass er damit nicht nur ihm, sondern auch der Spitze der Apostel, nämlich Petrus, und der von ihm gepredigten Wahrheit einen Gefallen getan habe. Dies sah Theodoros nicht nur einmal, sondern dreimal. Doch erst nach

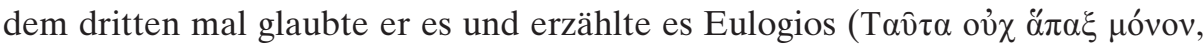

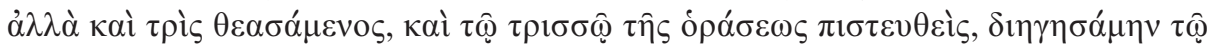

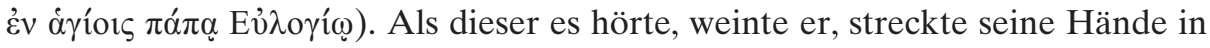
den Himmel und dankte Gott dafür, dass er ihn zum Boten seiner Wahrheit gemacht habe.

390. PrSp 178, PG 87.3, col. 3048C-3049A: Einem sehr frommen Wüstenvater

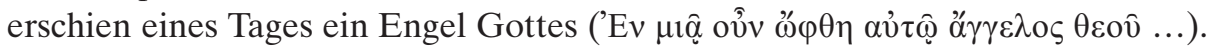
Er fragte ihn, ob er wie die ägyptischen Väter oder wie die Mönche von Jerusalem bestattet werden wolle. Der Vater antwortete, er wisse es nicht. Da sagte ihm der Engel, er solle darüber nachdenken. In drei Wochen werde er wieder zu ihm kommen, dann solle er es ihm sagen. Darauf ging der Wüstenvater zu einem anderen Bruder und erzählte diesem, was ihm der Engel gesagt hatte. Als dieser das hörte, wurde er stumm, starrte ihn lange an und fragte ihn dann, wo er die heilige Eucharistie zu sich nehme. Wo auch immer er sie finde, antwortete der Vater. Darauf belehrte ihn der Bruder, dass es ihm nicht zustehe außerhalb der katholischen und apostolischen Kirche, wo die vier heiligen Synoden genannt werden (Nikaia, Konstantinopel, Ephesos und Chalkedon), an der Eucharistie teilzunehmen. Wenn der Engel wieder komme, solle er ihm sagen, dass er wie die Mönche von Jerusalem begraben werden wolle. Nach drei Wochen kam der Engel und fragte den Wüstenvater, ob er über die Angelegenheit nachgedacht

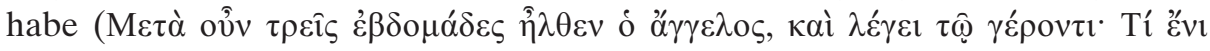

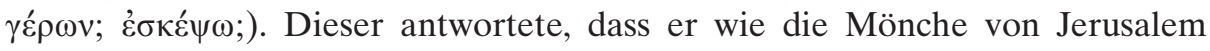
begraben werden möchte.

391. PrSp 188, PG 87.3, col. 3065C: Es waren einmal zwei syrische Brüder in Konstantinopel, die ein Juweliergeschäft besaßen. Eines Tages sagte der ältere zum jüngeren Bruder: „Lass uns nach Syrien gehen und uns auf dem Gut der Eltern niederlassen“. Der jüngere Bruder erwiderte, wegen des Juweliergeschäfts sei es besser, wenn nur einer nach Syrien ginge, der andere aber in Konstantinopel bleibe. Schließlich ging der jüngere, der ältere aber blieb in Konstantinopel. Nach kurzer Zeit sah der Zurückgebliebene im Schlaf einen heiligen Mann, der ihn fragte, ob er wisse, dass sein Bruder der Frau des Wirtes

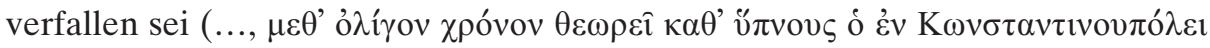

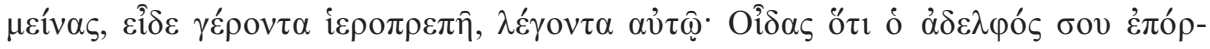

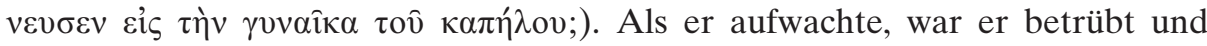
machte sich Vorwürfe, dass er seinen kleinen Bruder alleine hatte gehen lassen. Und nach einiger Zeit sah er wieder denselben, der ihn fragte, ob er wisse, dass

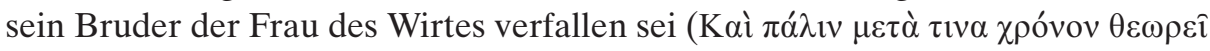




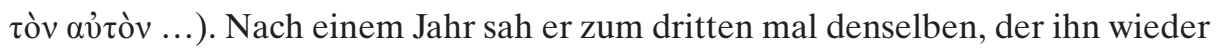
fragte, ob er nicht wisse, dass sein Bruder die Freiheit zerstört habe und der Frau

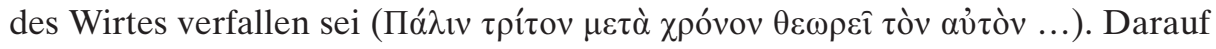
forderte er seinen jüngeren Bruder in einem Brief auf, sofort nach Konstantinopel zurückzukehren. Dieser befolgte seine Anweisung und schwor, nicht getan zu haben, was ihm vorgeworfen wurde. Er habe nichts auf dem Gewissen, außer dass er in seinem Dorf auf Mönche der severianischen Sekte getroffen sei. Und da er nicht wusste, dass dies schlecht sei, feierte er mit ihnen Gottesdienst. In diesem Augenblick verstand der ältere Bruder, dass dies seine Hurerei war. 392. ViSa 38, p. 127,24-128,10: Der heilige Sabas grämte sich darüber, dass sich im Turm der Eudokia am höchsten Punkt in der Wüste, der über seinen drei Klöstern gelegen war, Nestorianer niedergelassen hatten. „In jenen Tagen ge-

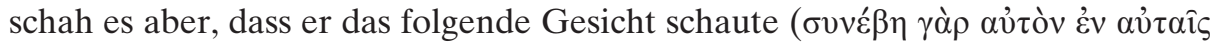

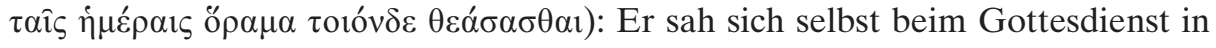
der heiligen Anastasis, und jene Mönche [die Nestorianer] wurden unter hef-

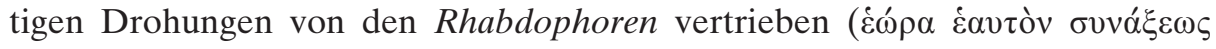

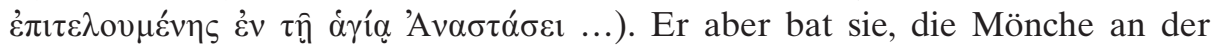
Eucharistie teilnehmen zu lassen“. Doch die Rhabdophoren antworteten mit strenger Stimme, dass es ihnen nicht erlaubt sei, daran teilzunehmen. Sie seien nämlich Juden ${ }^{783}$, die leugneten, dass Christus wahrhaftig Gott sei und dass die heilige Maria die Mutter Gottes sei. Von da an versuchte Sabas mit allen Mitteln, jene Mönche von der Irrlehre des Nestorios wegzubringen.

393. ViSySa 1697B, p. 72,14-17: „Als sich Symeon und Ioannes in der Wüste aufhielten, erschien ihnen zuweilen im Traum Nikon ${ }^{784}$, der sie warnte, für sie betete oder sie Psalmen lehrte. Und wenn sie aufwachten, wiederholten sie alles,

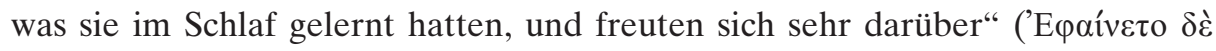

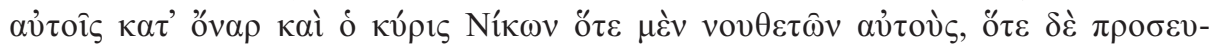

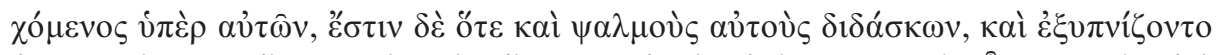

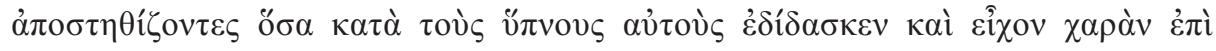

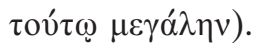

783 Nestorianer; S. Festugière, Les moines, III/2, S. 53, A. 81.

784 Der Abt des koinobion, in dem sich die beiden aufhielten, bevor sie in die Wüste zogen. 


\section{R. Zurechtweisungen, Strafandrohungen und Bestrafungen}

394. PaThII 19, p. 107,35-109,7: Nachdem der Mönch Siluanos bei der Arbeit in einer Grube beinahe erstickt wäre, trug man ihn bewusstlos auf einer Bahre

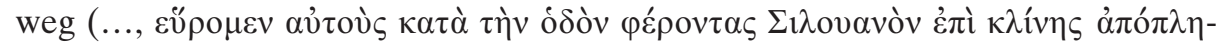
$\kappa \tau o \nu$...). Weder hörte noch redete er, und es vergingen sechs Tage seit dem Unfall, ohne dass er aß oder trank. Dann fingen die Mönche an zu beten, so lange, bis Siluanos wieder redete und Gott lobte. In der Morgenröte versammelte Siluanos alle Mönche bei sich. Er saß auf dem Bett, während Elurionos seine Worte mit lauter Stimme der Menschenmenge verkündete. Sie alle sollten hören, was mit Siluanos geschehen war. Am Samstag sei er auf der Insel gewesen, zusammen mit Theodoros, der gerade dabei war, seine Schüler zu unterrichten. Er schwieg und stand etwas entfernt, als er zwei kleine Vipern erblickte und sich sagte, einer der anderen werde sie bestimmt töten. Im selben Augenblick aber schlängelten sich die Vipern um seine Füsse. Und damit keiner der Brüder erschrecke, baute er ihnen mit seinen Füssen eine Art Gehäuse als Versteck. Und als er sie dann aufhob, erschien ihm ein Engel und sagte, dass sich manche von den mit ihm lebenden Mönchen nicht um ihre Rettung kümmern

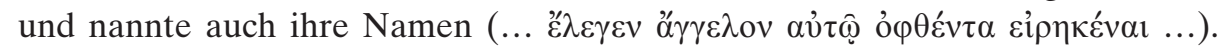
Gegen einen aus dem Kloster Bau, so sagte der Engel, habe Gott das Urteil gefällt und befohlen, ihn rauszuwerfen. Als Siluanos daraufhin anfing, in seinem

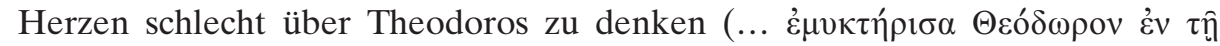
$\kappa \alpha \rho \delta i ́ \alpha \mu$ ov ...), stellte sich einer in menschlicher Gestalt, leuchtendem Gewand

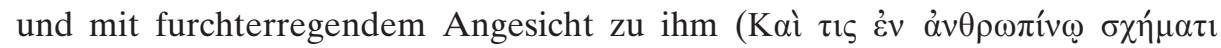

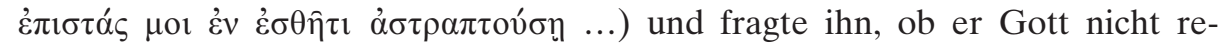
spektiere, wenn er solche Gedanken gegen seinen Diener hege. Dann fühlte Siluanos, wie die Gestalt ihm einen Schlag ins Gesicht gab, und er wusste nicht mehr, wo er sich befand und wo er herkam, bis Gott ihn heilte.

395. ApAl, Sisoes 33, PG 65, col. 404A: Abbas Sisoes ,wollte den Schlaf bekämpfen und hängte sich an den Steilhang von Petra. Da kam ein Engel und band ihn wieder los. Und er befahl ihm, dies nie wieder zu tun und diesen

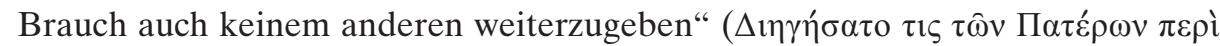

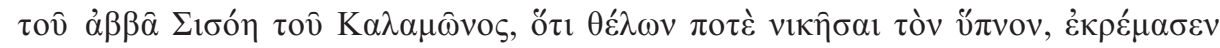

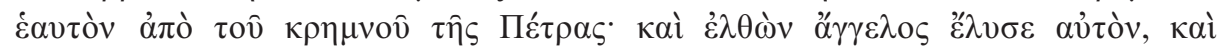

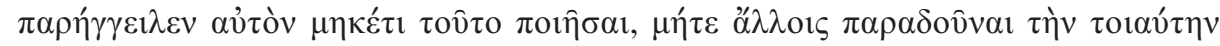
$\pi \alpha \rho \alpha ́ \delta o \sigma v)$.

396. ApSy IX 5, Bd. 1, p. 428: „Abbas Isaak in der Thebais kam eines Tages zu einem koinobion, wo er einen sündigen Bruder antraf und diesen zurechtwies. 
Als er zurück in die Wüste ging, kam ein Engel des Herrn, stellte sich vor die

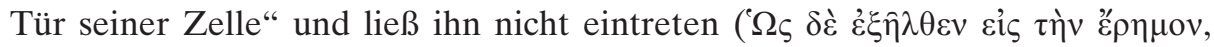

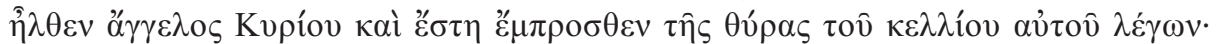
...). Gott habe ihn hierher geschickt, um ihn zu fragen, wohin er den sündigen Bruder hinzuwerfen befehle. Da bereute Isaak sofort, gestand seine Sünde und bat um Vergebung. Der Engel ließ ihn aufstehen, denn Gott habe ihm vergeben. In Zukunft solle er aber aufpassen, dass er niemanden mehr richte, bevor dieser von Gott gerichtet wurde.

397. ApSy IX 16, Bd. 1, p. 438-440: „Ein Priester brachte einem Anachoreten regelmäßig das heilige Abendmahl. Eines Tages kam aber jemand zu ihm, der den Priester als Sünder verleumdete. Als dieser wieder kam, um das Abendmahl zu spenden, öffnete ihm der Anachoret nicht. So ging der Priester wieder weg. Jetzt kam eine Stimme von Gott, die zum Anachoreten sagte: ,Die Menschen

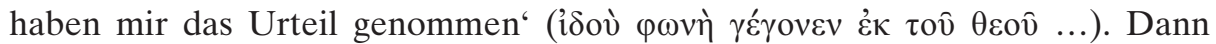
geriet er gleichsam in Ekstase und sah eine goldene Grube, einen goldenen

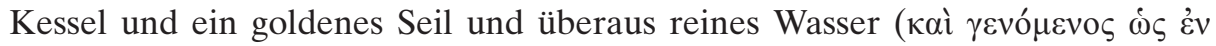

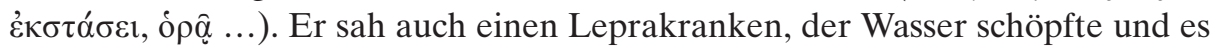
wegbrachte. Und obwohl er davon trinken wollte, unterließ er es, da es vom Leprakranken geschöpft wurde“. Da erklang wieder die Stimme, die ihn fragte, warum er nicht von diesem Wasser trinke, denn der Leprakranke schöpfe bloß das Wasser und bringe es weg. ,Als der Anachoret wieder zu sich kam, wägte er

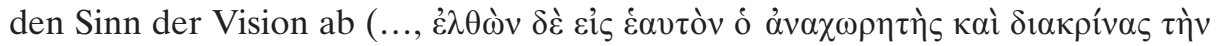

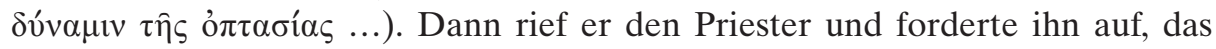
heilige Abendmahl zu spenden“.

398. ApSy IX 24, Bd. 1, p. 446: „Es war einmal ein Wüstenvater, der die Gewohnheit hatte, jeden Tag drei Pfannkuchen zu essen“. Als ihn ein anderer Bruder besuchte und mehr als drei Pfannkuchen aß, wies er diesen zurecht. Es sei schlecht, dem Fleisch zu dienen. Der Bruder büsste und ging weg. Von nun an hatte der Wüstenvater nach drei Pfannkuchen noch immer Hunger, weswegen er zu Gott betete, er möge ihn nicht verderben. Da sah er einen Engel, der ihn belehrte, dass ihm dies geschehen sei, weil er seinen Bruder verdammt

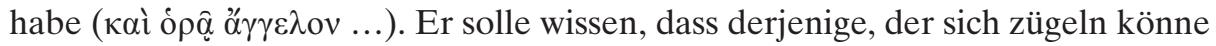
oder eine andere gute Tat verrichte, dies nicht aus eigener Kraft, sondern durch die Gnade Gottes vermöge.

399. ApSy X 137, Bd. 2, p. 104: Ein Bruder hatte eine arme Mutter, der er bei einer Hungersnot Brot bringen wollte. Als er sich auf den Weg machte, hörte er eine Stimme, die ihn fragte, wer sich um seine Mutter zu kümmern habe, er oder

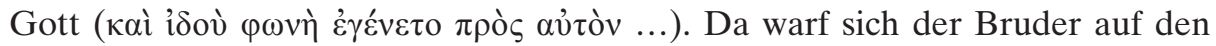
Boden, betete und sagte: „Du, Herr, sorgst für uns“.

400. ApSy XV 1, Bd. 2, p. 284: Antonios konzentrierte sich auf die Tiefe der Urteile Gottes und verlangte danach zu wissen, wie es geschehe, dass manche jung sterben, andere aber alt werden, warum manche hungern, während andere 
zu Reichtum kommen, warum Ungerechte reich sind und Gerechte hungern. Da kam eine Stimme zu ihm, die ihm sagte, er solle sich auf sich selbst konzen-

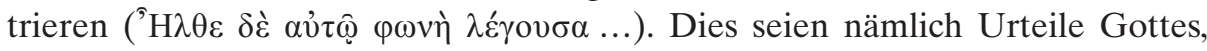
und es stehe ihm nicht zu, Antworten auf seine Fragen zu bekommen.

401. ViEu 44, p. 65,18-66,7: Elias, der Abt des koinobion des Euthymios, ordnete wegen Wassermangels an, Pferde nach Pharan zu schicken, um die beiden Zisternen des Klosters zu füllen. In derselben Nacht erschien ihm aber

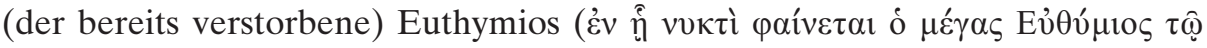

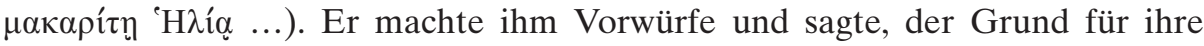
Notsituation sei, dass sie Gott nicht um Wasser gebeten haben. Wenn sie, anstatt Pferde nach Pharan zu schicken, zu Gott beteten, werden die beiden großen Zisternen noch am selben Tag vor der dritten Stunde angefüllt sein. „Als Elias aufgestanden war, erzählte er Phidos und den anderen die Vision und schickte

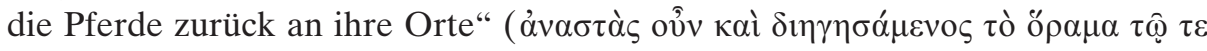

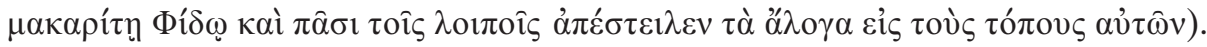
402. ViEu 48, p. 69,15-70,12: Theodotos von Gaza raubte 600 Goldstücke aus dem koinobion des Euthymios und versteckte sie in Jerusalem unter einem Stein. Als er sie wieder holen wollte, wurde er von einer unkörperlichen Macht halbtot zu Boden geschlagen. Daraufhin wurde er in Jerusalem in ein Hospital gebracht. Doch als er sich dort befand, nahmen die Schmerzen noch zu, und er sah im Traum einen Heiligen, der wutentbrannt $\mathrm{zu}$ ihm sagte, er werde nicht mehr von diesem Bett aufstehen, wenn er das gestohlene Geld nicht zum

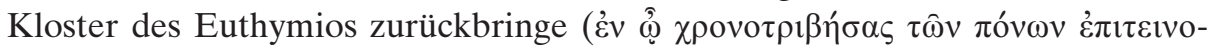

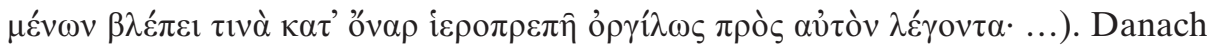
ließ Theodotos den Verwalter des Klosters kommen und gestand den Diebstahl. Das Geld wurde aus dem Versteck geholt und zurück ins Kloster gebracht.

403. ViEu 58, p. 79,24-81,26: Kyriakos aus Pharan betrog einen armen Hirten in der Gegend um zwei Schafe. Aus diesem Grund entbrannte zwischen den beiden ein Streit, der dadurch gelöst werden sollte, dass Kyriakos und der Hirte in der Gegenwart einer Mittlerperson im Kloster des heiligen Euthymios einen Schwur ablegten. So kam es, dass der unglückselige Kyriakos bei den Reliquien des Euthymios einen Meineid ablegte. „Er glaubte nämlich, dass dies Gott verborgen bliebe. Vielmehr noch, er hatte Gott vergessen und sagte in seinem Herzen zu sich selbst ,Gott gibt es nicht' [Ps 13,1]. Nachdem ein Tag vergangen war, und die zweite Nacht hereinbrach, und er alleine zu Hause im Bett lag, wachte er in der sechsten Stunde auf und hing müssigen Gedanken nach, als er plötzlich sah, wie sich von alleine die Türe öffnete und ein alter Mönch eintrat

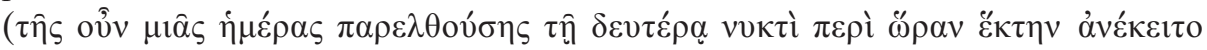

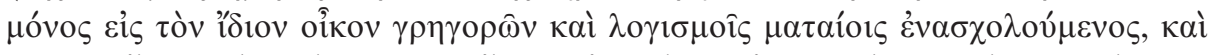

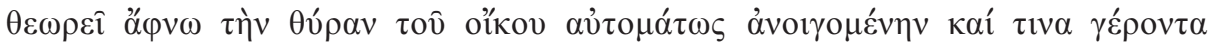

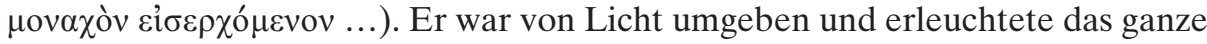
Gebäude. Er hatte fünf Jünglinge bei sich, einen Stock in der Hand und sagte 
mit strenger Stimme und ernstem Blick zu Kyriakos“, er solle ihm sagen, warum er ins Kloster des Euthmyios gegangen sei. Als Kyriakos keine Rechtfertigung fand, befahl der Mönch den Jünglingen, ihn festzuhalten. Diese ergriffen ihn sofort, indem sie ihn an allen vier Seiten festhielten. Dem Fünften gab Euthymios den Stock. Er solle ihn schlagen und von ihm verlangen, keinen Meineid mehr zu begehen und die Geduld Gottes nicht länger zu strapazieren. Als Kyriakos reichlich geschlagen worden war und Qualen erlitten hatte, sagte der Mönch zum Schläger, nun sei es genug. Dann packte er Kyriakos an den Haaren und belehrte ihn, dass Gott jedem das gebe, was ihm gebühre. Und noch in derselben Nacht würden sie seine Seele fordern. Kyriakos selbst habe diesen Zorn gegen sich herbeigeführt. Aus seinem Beispiel sollten alle lernen, keinen

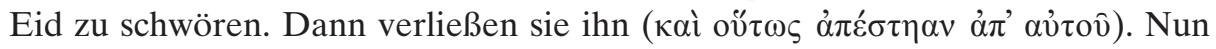
wurde Kyriakos von Furcht ergriffen und flehte um Erbarmen. Seine Nachbarn versammelten sich bei ihm, und als sie sahen, dass sein Rücken von Schlägen gezeichnet war, wurden auch sie von einer großen Furcht ergriffen. Kyriakos verlangte, ins Kloster gebracht $\mathrm{zu}$ werden, da er gegen diesen heiligen Ort gefrevelt hatte. Doch zum Beweis, was mit denen, die Meineid leisten, geschieht, starb er.

404. HiLa 34, p. 98,16-99,2: Im Frauenkloster von Tabennese wohnte eine Nonne, die sich als verrückt ausgab. Sie hielt sich ständig in der Küche auf und

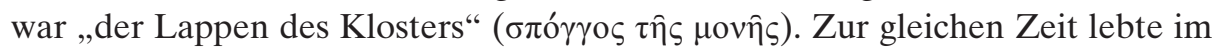
Porphyrgebirge der heilige Piterum. An diesen trat ein Engel heran, der ihm vorwarf, stolz auf seine Frömmigkeit und sein weltfernes Leben zu sein

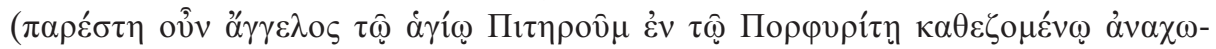

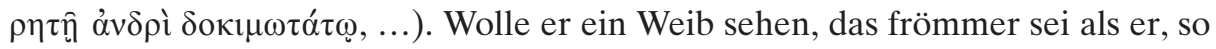
solle er in das Frauenkloster der Mönche von Tabennese gehen. Dort werde er eine Jungfrau mit einem Lumpen um den Kopf finden, die besser sei als er. Denn obschon sie von allen Seiten gehänselt werde, habe sie niemals ihr Herz von Gott entfernt. Er dagegen sitze hier und lasse seine Gedanken in den Städten herumschweifen. Darauf verließ Piterum seine Zelle und ging in das Frauenkloster von Tabennese.

405. HiLa 38, p. 116,6-119,9: Euagrios aus dem Pontos, der von Basileios dem Großen zum Lektor und von Gregorios von Nazianz zum Diakon geweiht worden war, weilte in Konstantinopel, um sich für den richtigen Glauben einzusetzen. Dabei wurde er von der Leidenschaft zu einer verheirateten Frau gefesselt. So sehr zog ihn ihre Lockung an, dass es ihm nicht gelang, ihr aus dem Weg zu gehen. Aus Angst, der Versuchung zu erliegen, betete er und flehte Gott an, er möge ihm helfen. „Da erschien ihm ein engelhaftes Gesicht, dessen

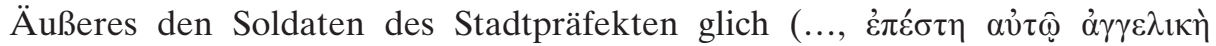

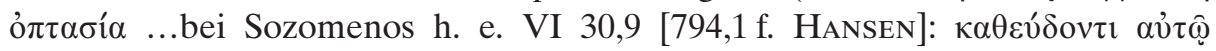

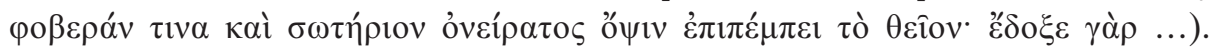
Diese nahm ihn fest, führte ihn weg, allem Anschein nach vor Gericht, und warf 
ihn ins Gefängnis, wo man ihm eiserne Ketten an Hals und Hände legte. Keiner von denen, die hereinkamen, verriet ihm den Grund für seine Verhaftung. Sein Gewissen sagte ihm aber, dass er dies wegen jenes Weibes erleide, und er glaubte, ihr Ehemann würde nun kommen“. Während ihn ein entsetzlicher Schrecken peinigte und man ihn alleine seiner Angst überließ, wurden vierzig andere verhört. Da verwandelte sich der Engel, der ihm erschienen war, in eine Freundesgestalt und fragte ihn, warum er hier im Gefängnis sei $(\mu \varepsilon \tau \alpha \sigma \chi \eta \mu \alpha \tau i ́-$

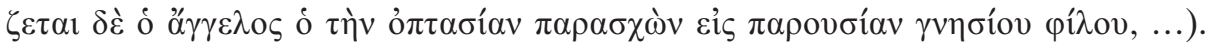
Dieser antwortete, er wisse es nicht sicher, vermute aber, dass ihn jener Befehlshaber aus grundloser Eifersucht angeklagt habe. Er fürchte, man habe den Richter bestochen, sodass dieser ein hartes Urteil gegen ihn fällen werde. Darauf riet ihm die Freundesgestalt, die Stadt zu verlassen, da er sonst eine schlimme Strafe erleiden müsse. Nun schwor Euagrios auf das Evangelium, dass er die Stadt verlassen und nunmehr für sein Seelenheil sorgen werde. Sobald der Schwur vollbracht war, erwachte er aus der Ekstase ( $\tau$ ov ö

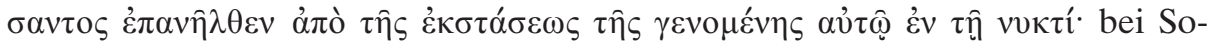
zomenos, historia ecclesiastica VI 30,11, Bd. 3, p. 412,16f.: $\delta 1 \alpha \varphi \varepsilon \theta \varepsilon i \varsigma \tau \varepsilon \tau \hat{\omega} v$

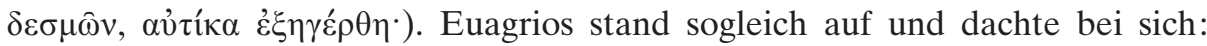
„Und habe ich in der Ekstase geschworen - geschworen habe ich doch“ (каì

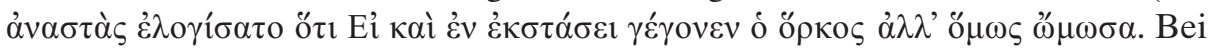

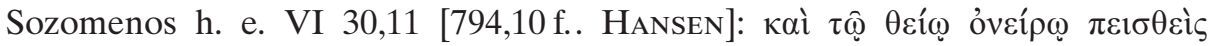

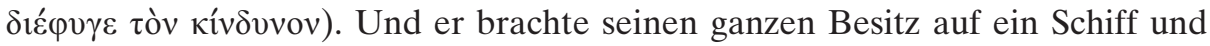
reiste nach Jerusalem.

406. ViHy 10,1-5, p. 108,1-20: Der heilige Hypatios führte mit seinen zwei Gefährten Timotheos und Moschion ein Einsiedlerleben im Kloster von Ruphinianai, als der Teufel Hypatios und Timotheos gegeneinander aufbrachte. Aus diesem Grund ging Hypatios zurück nach Thrakien und führte dort sein spirituelles Leben fort. Timotheos machte sich jedoch auf die Suche nach Hypatios und bat Abbas Ionas in der Stadt nahe beim Aufenthaltsort des Hypatios, er möge diesen zu ihnen zurückschicken. Daraufhin wurde Abbas Ionas krank und sah in der Nacht eine Gestalt, die ihm sagte, er werde nur gesund, wenn Hypatios ins Kloster von Ruphinianai zurückkomme. Sogleich befahl er den

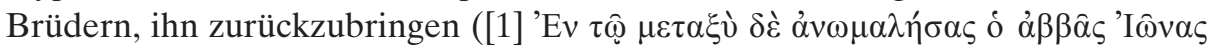

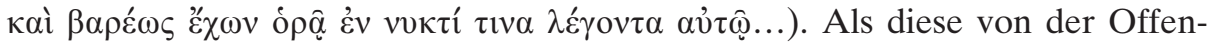

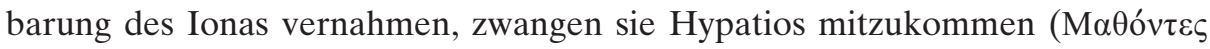

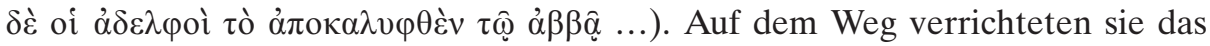
Gebet und hörten auf einmal eine Stimme aus dem Himmel, die Hypatios aufforderte, zurück nach Ruphinianai zu gehen, da Gott ihn eingesetzt habe, ein

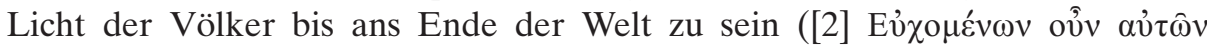

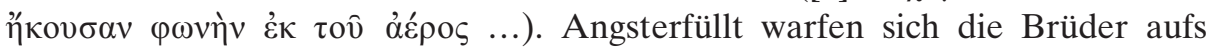
Gesicht und beteten lange. Als sie wieder aufgestanden waren, fing Hypatios an zu murmeln, so als ob er widersprechen möchte. Aber sein Gefährte zitterte am 
ganzen Körper und fragte ihn, was er da rede, und er treibe es noch soweit, dass sie von der Erde verschlungen werden (vgl. 1 Petr 5, 8.).

407. ViIoEl 23, Bd. 2, p. 373,7-375,14: Einmal wurde ein Mönch, der in Begleitung eines jungen Mädchens durch die Stadt wanderte und bettelte, vor dem Patriarchen Ioannes angeklagt, da man dachte, das Mädchen sei seine Frau. Sofort ließ Ioannes den Mönch einsperren. Doch in der Nacht erschien dieser dem Patriarchen im Schlaf und zeigte ihm seinen Rücken, der voll von Striemen

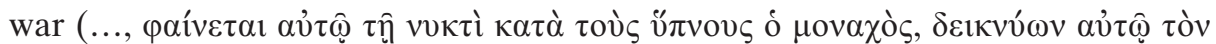

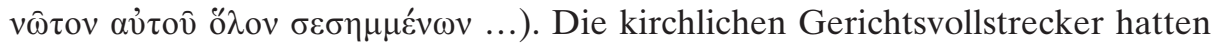
ihn nämlich gnadenlos ausgepeitscht. Der Mönch warf Ioannes vor, sich dieses

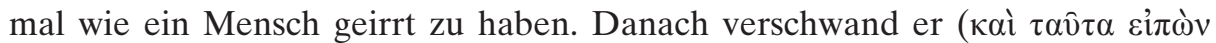

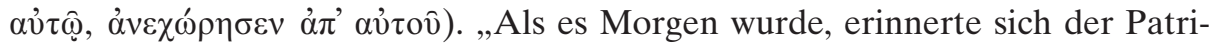
arch an den nächtlichen Traum und setzte sich gedankenverloren auf sein Bett"“

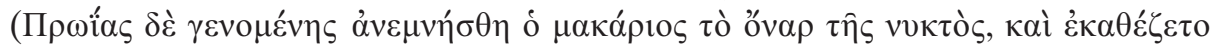

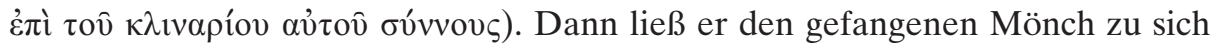
kommen. Er fragte sich nämlich, ob er demjenigen, der ihm in der Nacht er-

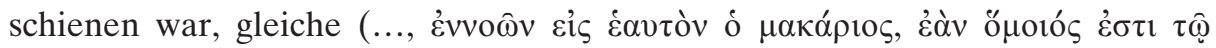

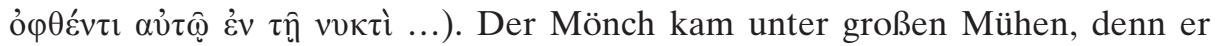
konnte sich wegen der unerträglichen Schmerzen kaum bewegen. Als Ioannes sein Gesicht sah, ,verharrte er sprachlos, bewegungslos, gedankenverloren und ohne irgend etwas von sich zu geben. Er bedeutete ihm bloß mit der Hand, sich hinzusetzen. Als er wieder zu sich gekommen war, bekreuzigte er sich und bat den Mönch, sich auszuziehen, damit er sehe, ob sein Rücken in dem Zustand sei,

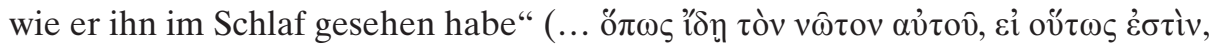

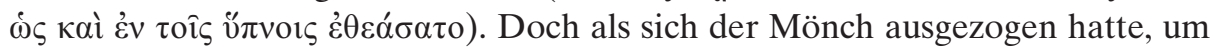
dem Patriarchen den Rücken zu zeigen, fiel versehentlich sein Lendentuch zu Boden, sodass alle sahen, dass er Eunuch war. Darauf entschuldigte sich Ioannes sofort für die falsche Verleumdung und forderte ihn auf, seine Geschichte zu erzählen. Der Mönch sagte, er sei von Gaza nach Alexandreia gekommen, um den heiligen Kyros zu verehren, als ihm außerhalb der Stadt das Mädchen begegnete. Er habe es nicht weggeschickt, da es behauptete, es sei Jüdin und wolle zum Christentum konvertieren. Als der Patriarch dies hörte, staunte er darüber, wie viele verborgene Diener Gott habe, ohne dass die Niedrigen davon erfahren. Den Anwesenden erzählte er das Traumgesicht, das er in der Nacht gesehen

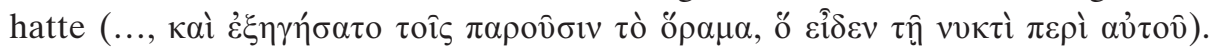
408. ViMa 39, Bd. 2, p. 282,23-283,24: Da die Brüder unachtsam waren und häufig vergaßen, die Grabeskerze $(\lambda \alpha ́ \rho v \alpha \kappa o \varsigma \kappa \alpha ́ v \delta \eta \lambda \alpha)$ der heiligen Martha anzuzünden, ,wurde der Haushälter des Klosters auf einmal von einem uner-

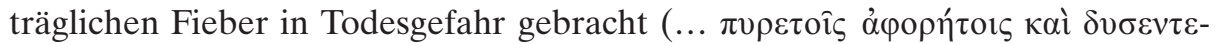

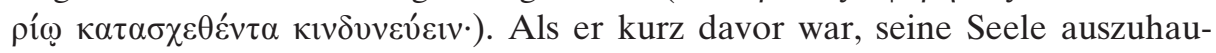
chen, erschien ihm im Traum die heilige Martha, die ihn stellvertretend für alle Brüder zurechtwies“ und fragte, warum sie ihre Kerze nicht angezündet haben 


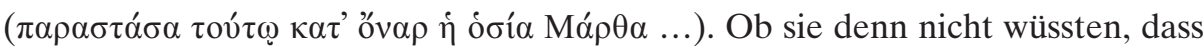
sie dem himmlischen Licht teilhaftig sei. Dann übergab sie ihm ein Brot, das den rettenden Körper des Herrn enthielt und sagte dabei, dass darin sein Leben und

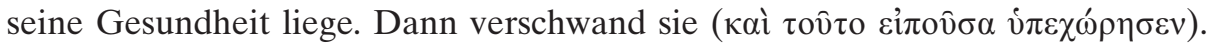
40, Bd. 2, p. 283,12-24: „Als der Haushälter wieder zu sich gekommen war, ging er unter Tränen zum Grab der heiligen Martha und wurde sofort gesund [...]

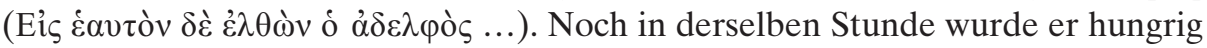
und fing an zu essen und zu trinken und kam wieder zu Kräften“. Am Abend zündete er ihre Kerze an und versprach, dies von nun an immer zu tun. „Danach schlief er ein und sah sie wieder mit leuchtendem Gesicht, umgeben von den

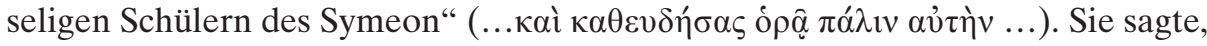
dass nicht die Brüder oder Symeon sie geehrt hätten. Vielmehr komme die Gnade und Ehre von dort, wo sie hingegangen sei.

409. ViMa 43, Bd. 2, p. 285,9-286,11: Ein Bruder ging zum Grab der seligen Martha und blies die Kerze aus, ohne zu bedenken, dass dies eine Sünde war. Auf der Stelle kam ein fürchterliches Fieber über ihn, und er erlitt schlimme Qualen. Obwohl er mehrmals gefragt wurde, welche Sünde Grund für seinen elenden Zustand sei, hielt er seine Freveltat verborgen. „Erst als es ihm noch schlechter ging, gestand er vor allen Brüdern den Grund für sein Leiden. Dann schlief er ein und sah die heilige Martha mit leuchtendem Gesicht inmitten von

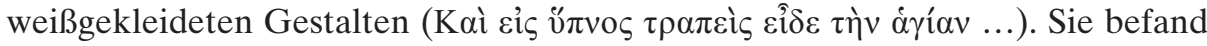
sich auf der konche ${ }^{785}$ des Altars der Kirche der heiligen Trinität und betete. Dann wandte sie sich zu ihm und zeigte ihm vor ihrem Grab zwei Wege, der eine war derjenige der Ungläubigen, der andere derjenige der Gläubigen. Sie forderte den Bruder auf, ein Bekenntnis abzulegen. Als er aber genauer hinsah,

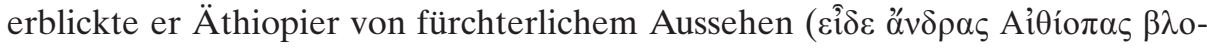

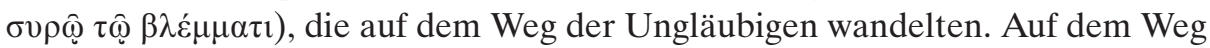
der Gläubigen befanden sich Männer, die vor Glück strahlten und zum Grab der heiligen Frau schritten, wo sie die heilende Erde fanden. Durch diese Vision belehrte ihn Martha, den rechtschaffenen Weg zu beschreiten und sich in Zu-

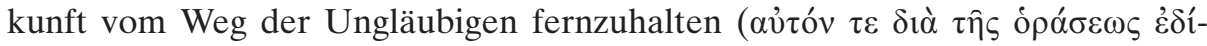
$\delta \alpha \xi \varepsilon v . .$.$) . Furchterfüllt erwachte der Bruder, und von nun an war er gesund“.$ 410. ViNi 22,7-15, p. 40,32-42,7: Einem Ungläubigen erschien in der Nacht ein Fluss, der voll von Schlamm war und ihn wegen seines Unglaubens zu ersticken

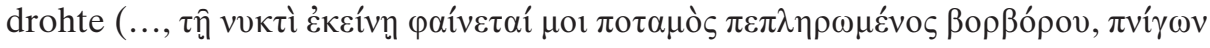

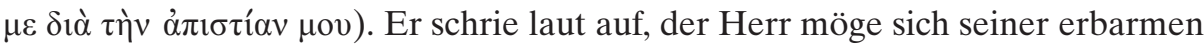
und ihn aus dem Schlamm herausführen. Sogleich erschien ihm Nikolaos Sionites und streckte seine Hand aus, ergriff ihn und zog ihn aus dem Schlamm. Dann sagte er zu ihm, er solle nicht ungläubig sein, sondern glauben, da den Ungläubigen dieses Urteil bestimmt sei.

785 S. S. 242 A. 755. 
411. ViNi 43,1-12, p. 62,1-12: „Eines Tages kam ein Dämon in die Zelle des Nikolaos, stellte sich in die Mitte des Raumes und verwandelte sich in einen

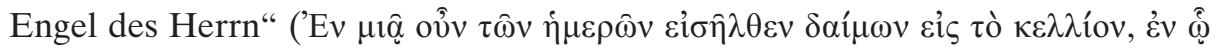

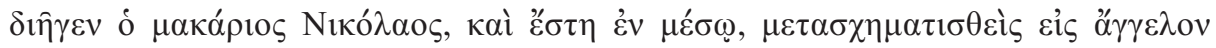
$\theta \varepsilon o v \hat{)}$. Als Nikolaos ihn fragte, wer er sei, antwortete er, er sei ein Engel des Herrn. Dieser habe ihn ausgesandt, damit er nachsehe, was Nikolaos mache. Doch Nikolaos erkannte die List, bekreuzigte sich und verscheuchte den

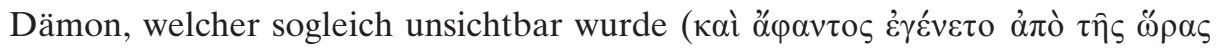

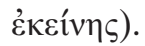

412. ViNi 46,1-10, p. 64,12-21: Als Nikolaos einmal nach dem Mitternachtsgebet zusammen mit seinem Bruder Artemas in die Zelle zurückkehrte, ,erschien ein böser Geist, welcher meinte, den Dienern Gottes etwas vorspielen zu

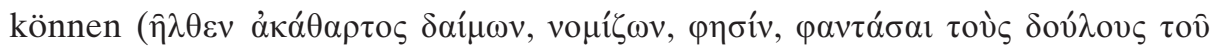
$\theta \varepsilon \circ \hat{)})$. Er verwandelte sich in einen furchterregenden Menschen und fing an, die Treppe vom Obergeschoss herunterzusteigen“. Nikolaos beruhigte den erschreckten Artemas, in dem er ihm sagte, dass es kein Mensch, sondern der

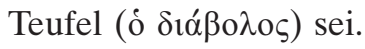

413. ViPa 70, Halkin 1982, p. 37,1-10: Pachomios ging mit den Brüdern zu

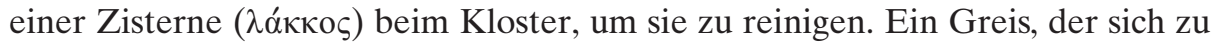
jener Zeit noch als Weltlicher im Kloster aufhielt, aber Mönch werden wollte, sah die Brüder zur Grube gehen. Er fing an zu murren, da er Pachomios für unbarmherzig hielt, weil er die Brüder in der Nacht in die Grube schickte. „Doch in jener Nacht sah sich der weltliche Bruder im Schlaf selbst über der

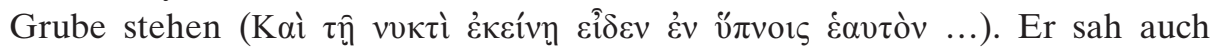
diejenigen, die unten arbeiteten, und in ihrer Mitte einen Mann, der sich von den anderen durch seinen Glanz unterschied" und zu den Brüdern sagte, sie sollen den Geist des Gehorsams und der Kraft ergreifen. Zu ihm aber sagte er, er sei würdig, den Geist des Unglaubens zu erhalten. Und da er durch den Traum verwirrt war, ging er noch in jener Nacht zu den Brüdern, die gerade

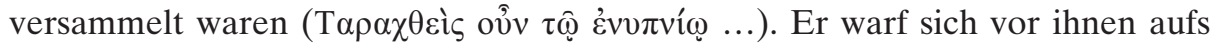
Gesicht, um zu beichten.

414. ViPa 138, Halkin 1982, p. 65,32-66,17: Artemios, ein arianischer dux, suchte im Kloster des Pachomios nach dem vom Kaiser verfolgten Bischof Athanasios. Artemios wurde zwar im Kloster aufgenommen, bekam aber Theodoros, Schüler des Pachomios und damaliger Abt, der sich in der Wüste versteckt hatte, nicht zu Gesicht. Außerdem weigerten sich die Mönche, weil er Arianer war, mit ihm zusammen zu beten. „Als er am folgenden Tag in der

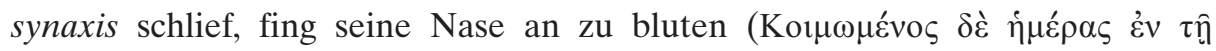

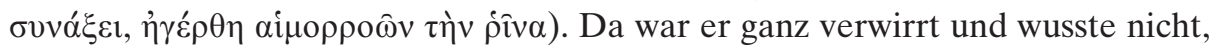
wie ihm geschah“. Ganz eingeschüchtert sagte er, dass er in der Vision, die er gerade gesehen hatte, durch Gottes Erbarmen dem Tod entflohen sei ('Ev 


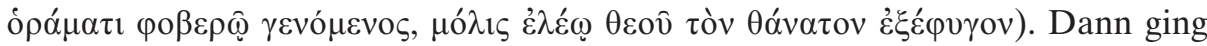
er.

415. PhHi 21,20, Bd. 2, p. 102,5-104,4: Der Asket Iakobos erzählte, dass er an der Echtheit der Reliquien Ioannes' des Täufers gezweifelt habe, als diese von Phönizien und Palästina nach Syrien gebracht wurden. Als er am folgenden Tag zum nächtlichen Hymnengesang aufgestanden sei, habe er eine weißgekleidete Gestalt gesehen, die ihn fragte, warum er sie nicht begrüßt habe, als sie anka-

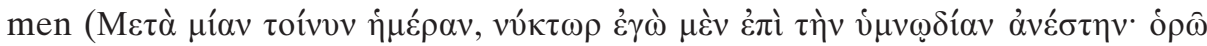

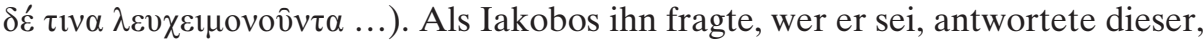
er verkörpere diejenigen, die gestern aus Phönizien und Palästina angekommen seien. Alle haben sie wärmstens empfangen, nur Iakobos habe nicht an dieser Ehrerbietung teilgenommen. Offensichtlich spielte er auf Iakobos' Zweifel an. Da erwiderte dieser, dass er ihn auch in seiner Abwesenheit verehre. Am nächsten Tag erschien ihm wieder zur gleichen Zeit der gleiche Mann (Пá $\lambda_{\imath} v \delta \grave{\varepsilon}$ $\tau \hat{~}$ Iakobos auf, jene Gestalt dort anzusehen, die in einem schneeweißen Kleid dastand und vor der ein brennender Ofen zu sehen war. Iakobos wandte den Blick dorthin und vermutete, dass es Ioannes der Täufer war. Er trug nämlich dessen Gewand und streckte die Hand wie zur Taufe aus. Der andere bestätigte, dass es tatsächlich jener sei, den Iakobos zu sehen vermutete.

416. PrSp 3, PG 87.3, col. 2853C-2856B: Ein gewisser Kilix wurde bei der Salbung einer Frau von lasterhaften Gedanken heimgesucht. Als er deswegen sein Kloster verlassen und in die Berge gehen wollte, erschien ihm zweimal

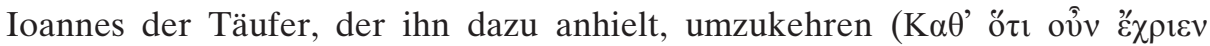

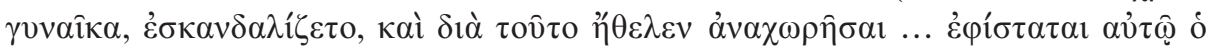

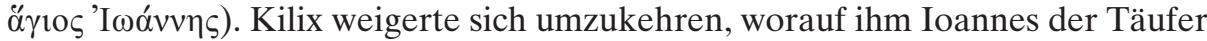

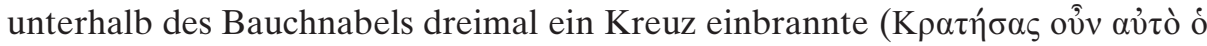

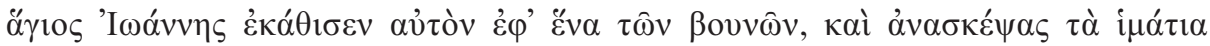

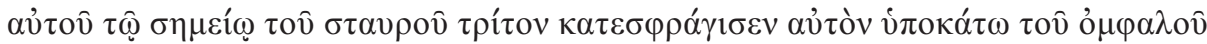
....). Dies führte dazu, dass Kilix von nun an beim Anblick von Frauen unbe-

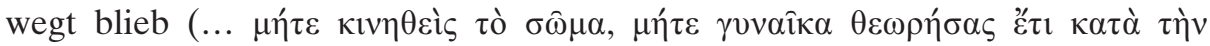

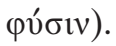

417. PrSp 38, PG 87.3, col. 2888D-2889A: Kaiser Anastasios hatte die zwei Patriarchen Euphemios und Makedonios abgesetzt und verbannt. Danach sah er im Schlaf einen weiß gekleideten Mann, der einen beschrifteten Kodex hielt

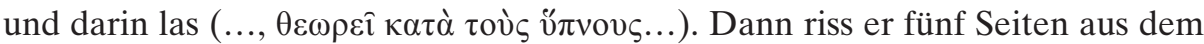
Kodex, las den Namen des Kaisers und sagte zu ihm, dass er wegen seines Unglaubens vierzehn ausgelöscht habe. Und mit dem eigenen Finger löschte er auch ihn aus. Kurz danach starb Anastasios in Kummer darüber, dass er ungläubig gegen die Kirche gehandelt und ihre Hirten verbannt hatte.

418. PrSp 47, PG 87.3, 47, col. 2901C-D: In Heliupolis, einer Stadt in Phoinike Libanensis, lästerte ein Schauspieler namens Gaianos beim Theaterspielen 


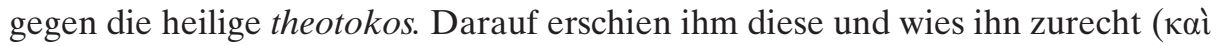

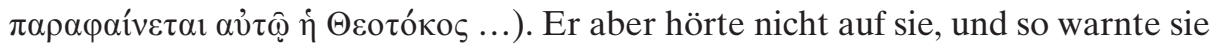

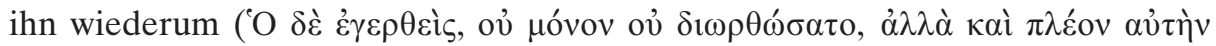

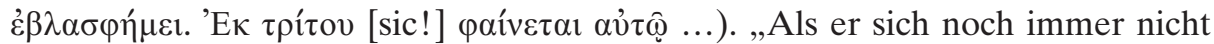
besserte, sondern die theotokos noch mehr entwürdigte, erschien ihm diese abermals, als er eines Nachmittags schlief. Sie sagte nichts, trennte aber mit

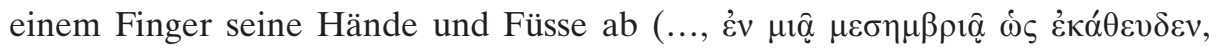

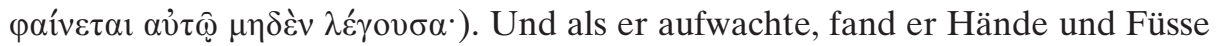
abgeschnitten, und er bestand nur noch aus einem auf dem Boden liegenden

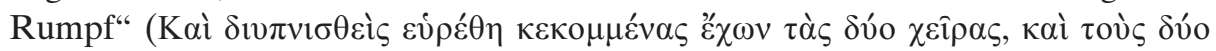

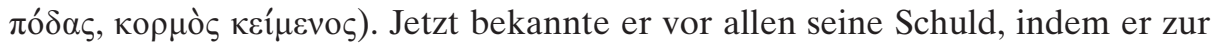
Schau trug, welchen Lohn er für seine Blasphemie erhalten hatte.

419. PrSp 65, PG 87.3, col. 2916: Vom Priestermönch Stephanos wird erzählt, „dass er unter einer starken Schwäche und Krankheit litt, sodass ihm die Ärzte anordneten, das Opferbrot $(\theta v ́ \mu \alpha)$ zu sich zu nehmen. Als dies geschah, war sein Bruder zugegen, der ein weltliches Leben führte, aber fromm und rechtschaffen war“. Dieser war zutiefst bekümmert darüber, dass Stephanos am Ende von soviel Fasten und Askese das Opferbrot zu sich nahm. Doch auf einmal geriet er in Ekstase und sah eine Gestalt, die ihn fragte, warum er sich am Priester

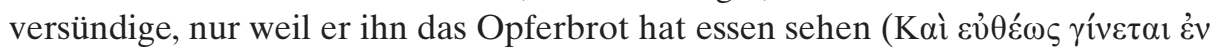

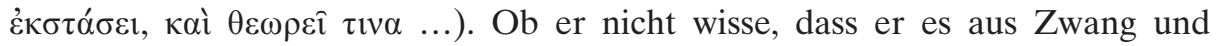
Gehorsam zu sich nehme. Es nütze ihm nichts, sich zu versündigen. Und wenn er sehen wolle, in welcher Ehre sich sein Bruder befinde, dann solle er sich umdrehen und es sich anschauen. Und er drehte sich um und sah Stephanos gleichsam über Christus gekreuzigt. Jetzt sagte die Gestalt zu ihm, er solle sehen, in welchem Glanz sich Stephanos befinde.

420. ViSa 6, p. 90,5-15: Nachdem der heilige Sabas zehn Jahre als Mönch im Kloster verbracht hatte, wollte er in die Wüste bei Jerusalem gehen. Als er aber den Archimandriten bat, er möge ihn gehen lassen, wollte dieser ihn zurückhalten. Da wurde dem Archimandriten eine göttliche Vision offenbart, die ihm befahl, Sabas ziehen zu lassen, „damit er mir in der Wüste diene“ ( $\tau \hat{\emptyset} \delta \grave{\varepsilon} \mu \grave{\eta}$

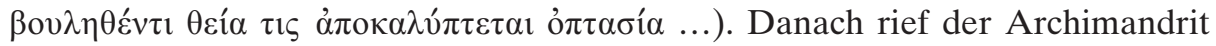
Sabas beim Abendmahl zu sich und teilte ihm mit, er sei durch eine göttliche

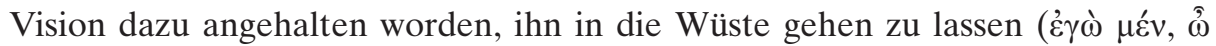

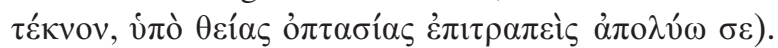

421. ViSc, PG 88, col. 601B-C: Als Moses, der Schüler des Ioannes Klimakos, eines Tages einen Gemüsegarten anlegen sollte, legte er sich in der Mittagszeit unter einen großen Stein und schlief ein. Zur gleichen Zeit befand sich Ioannes in seiner Zelle und hielt wie gewohnt Zwiesprache mit Gott, als er von einem leichten Schlaf ergriffen wurde und einen ehrwürdigen Mann sah, der ihn auf-

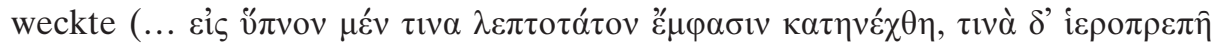

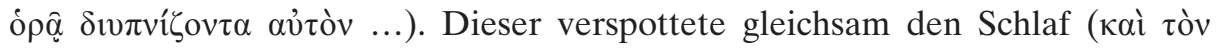




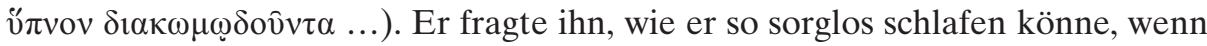
sich sein Schüler Moses in Gefahr befinde. Sofort fing Ioannes an, für Moses zu beten. Und als dieser am Abend zurückkam, fragte er ihn, ob ihm vielleicht ein Unglück zugestoßen sei. Darauf erzählte Moses, dass er in der Mittagszeit beim Schlafen von einem großen Stein zermalmt worden wäre, wenn er sich nicht mit einem Sprung von jenem Ort entfernt hätte, da er glaubte, die Stimme des

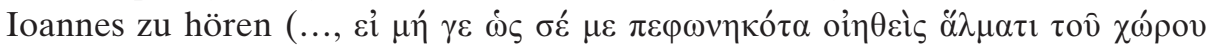
$\dot{\varepsilon} \kappa \pi \varepsilon \pi \hat{\jmath} \delta \eta \kappa \alpha)$. Noch im selben Augenblick habe er gesehen, wie ein Stein herunterstürzte. Ioannes aber erzählte ihm nichts von seiner Vision und dankte

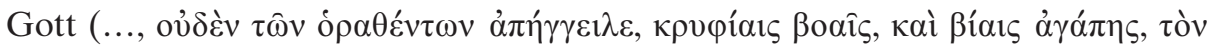

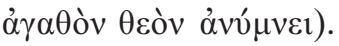

422. ViSySa 1724B-C, p. 88,12-27: Ein Arbeiter aus Emesa hatte gesehen, wie sich Symeon in seiner Reinheit mit zwei Engeln unterhielt. Da er selber Jude war und Christus schmähte, wollte er Symeon zum öffentlichen Gerede machen. Darauf erschien ihm der heilige Mann im Schlaf und befahl ihm, niemandem zu

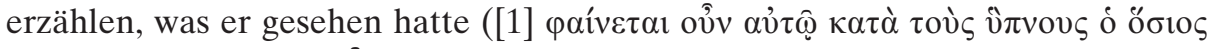

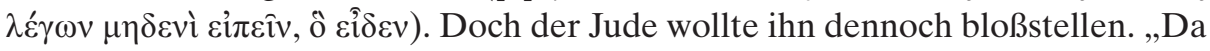
stand auf einmal Symeon bei ihm, berührte seine Lippen und brachte ihn zum

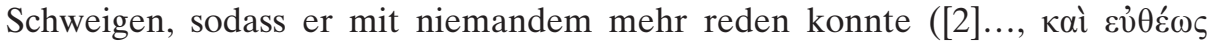

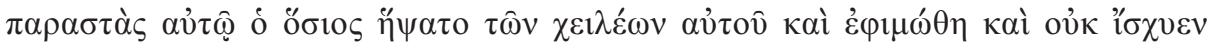
$\lambda \alpha \lambda \eta \bar{\sigma} \sigma \mathrm{\imath} \tau \mathrm{ivt})$. Jetzt kam der mit Stummheit Geschlagene zu Symeon und bedeutete ihm mit dem Finger, er solle ihn wieder zum Sprechen bringen“. Symeon aber antwortete ebenfalls durch Gesten, er solle sich bekreuzigen. Danach erschien er dem Juden wieder im Traum und riet ihm, er solle sich taufen

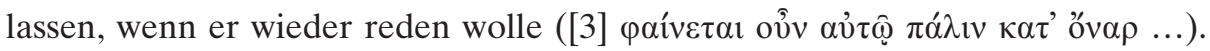
Damals konnte er ihn aber nicht überzeugen. Als Symeon dann starb, sah der Jude, wie der heilige Mann beim Begräbnis bekränzt wurde ([4] ..., ö $\tau \varepsilon \delta \grave{\varepsilon}$

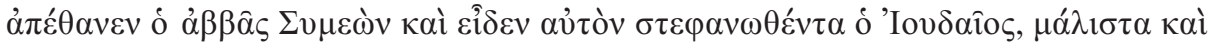

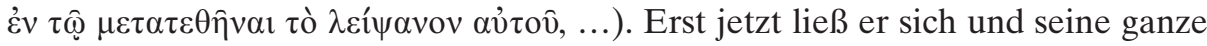
Familie taufen. Und als er aus dem Taufbecken herausstieg, konnte er auf einmal wieder sprechen.

423. ViSySa 1740C-1741A, p. 99,15-100,4: Eines Tages erkrankte ein Vornehmer aus Emesa, in dessen Haus Symeon öfters erschien, um seine Späße zu treiben. „Als der Kranke kurz davor war zu sterben, sah er sich im Schlaf mit

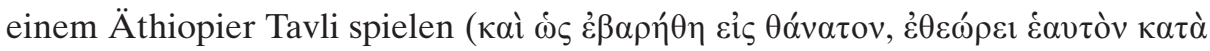

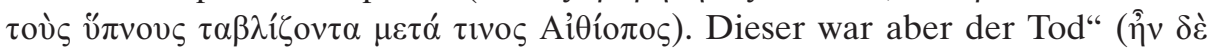
ỡ würfeln, um nicht zu verlieren. Dann erschien ihm im Schlaf der heilige Symeon

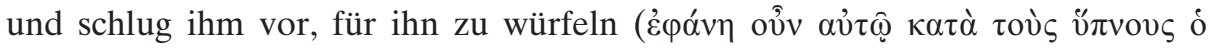
$\dot{\alpha} \beta \beta \hat{\alpha} \varsigma \Sigma v \mu \varepsilon \dot{\omega} v$...). Er müsse ihm aber als Gegenleistung geloben, von nun an nie mehr seine Frau zu betrügen. Der Kranke schwor, worauf Symeon die Würfel ergriff und dreimal sechs würfelte. Als der Kranke wieder erwachte, kam so- 
gleich Symeon herbei und drohte ihm, der Schwarze werde ihn ersticken, wenn

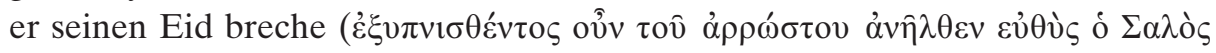
...).

424. ViSyStI 10, p. 32,7-22: „Zehn Tage nachdem der junge Symeon das Kloster verlassen hatte, sah der Archimandrit in der Nacht in einem Traum eine unermessliche Menge von weißgekleideten Männern mit Fackeln, die das

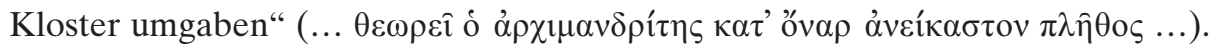
Sie drohten ihm an, ihn auf der Stelle zu verbrennen, wenn er ihnen nicht Symeon, den Diener Gottes übergebe. Dann wollten sie von ihm wissen, warum er Symeon vertrieben habe, da dieser ihm doch nichts getan habe. Am jüngsten Tag aber werde es Symeon besser ergehen als ihm. Als der Archimandrit wieder aufgewacht war, sagte er furchterfüllt zu den anderen Brüdern, dass Symeon ein echter Diener Gottes sei, denn er habe in dieser Nacht im Traum viel

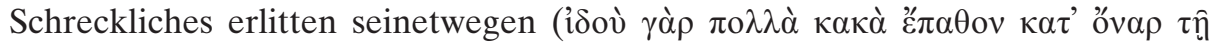

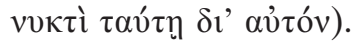

425. ViSyStII 123,30-48, Bd.1, p. 104,17-105,9: Der vom Dämon zerrüttete Isaurier Angulas brachte die Mönchsgemeinschaft gegen Symeon auf. Deshalb fingen die Brüder an, die Werke des Heiligen als nichtig hinzustellen. Aufgrund dieser dämonischen Machenschaften wurde die Kornkammer des Klosters immer leerer und die Brüder litten Hunger. Besorgt über diese Situation ,geriet Symeon gleichsam in Ekstase und sah durch den heiligen Geist im Speicher auf

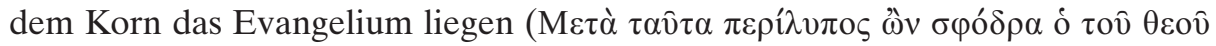

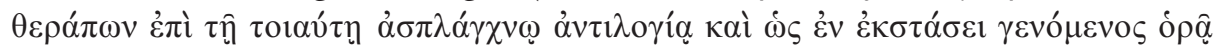

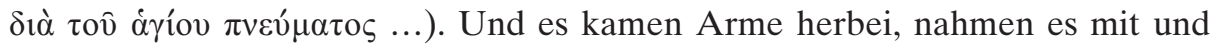
gingen davon. Und der Diener Gottes verfolgte sie auf der kaiserlichen Straße, doch weil er sie nicht einholen konnte, kehrte er auf halbem Weg um“. Und weil Symeon jeden Tag nicht mehr als drei Brote fand, ergriff er sie, schaute in den Himmel und sagte, dass er es so wie Jesus mache. Gott möge das Brot segnen. „Und indem er das Vaterunser betete, brach er das Brot und verteilte es unter den Armen. Und während er es brach, verwandelten sich die Stücke zu großen Broten. Und als er wieder zu sich kam, betete er ('Ev $\dot{\varepsilon} \alpha v \tau \hat{\jmath} \delta \dot{\varepsilon} \gamma \varepsilon v o ́ \mu \varepsilon v o \varsigma . .$.$) . Er$ hatte nämlich verstanden, dass sich durch diesen dämonischen Widerstand die Gnade des Herrn vom Speicher zurückgezogen hatte, und dass die Brüder nur durch den Hunger die Versuchung erkennen würden und entweder sterben oder fliehen würden“.

426. ViSyStII 129, Bd. 1, p. 116,11-118,28: Bruder Konon, ein Lieblingsschüler des Symeon, war sehr betrübt über die dämonische Heimsuchung des Klosters (s. 128, Bd. 1. P. 116,1-11). Er geriet in Ekstase und sah den heiligen Symeon ([1] ..., ǐ

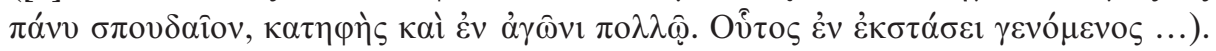
Dieser fragte ihn, wie groß die Redefreiheit eines Menschen vor Gott sei, der heute die Hilfe und Rettung der Welt sei, von der Welt aber nicht erkannt 
werde. Als Konon wissen wollte, wer dieser Mensch sei, sagte ihm der Heilige, er sei derjenige, der mit ihm rede. „Als Konon wieder zu sich gekommen war,

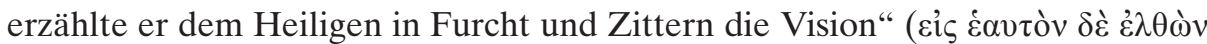

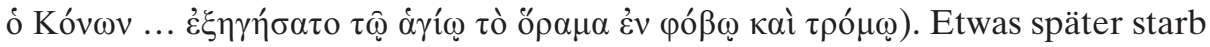

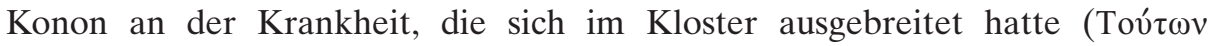

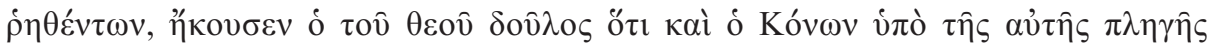
$\tau \rho \omega \theta \varepsilon \grave{s} \varsigma \dot{\varepsilon} \tau \varepsilon \lambda \varepsilon v ́ \tau \eta \sigma \varepsilon v)$. Als Symeon davon erfuhr, fing er an, heftig zu trauern. Er schlug immer wieder den Kopf gegen die Säule und rief Konon an, doch dieser antwortete nicht. „Als Martha das Klagen ihres Sohnes hörte, fiel sie in Ekstase

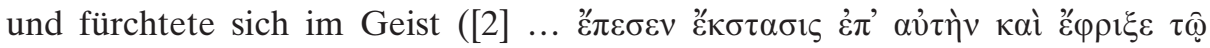
$\pi v \varepsilon v ́ \mu \alpha \tau \imath$...). Sie verstand, dass auf den Ruf des Gerechten eine göttliche Gnade aus dem Himmel herunterkam, sodass der ganze Ort anfing zu beben. Danach geriet ihre Seele und ihr Körper durch die Kraft, die sie beschützte, in eine große Ruhe. Dann kam sie wieder zu sich, und noch bevor sie die Vision er-

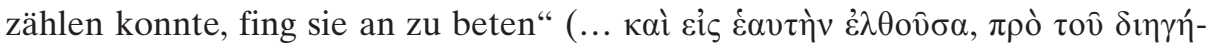

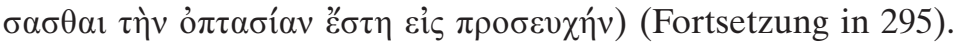

427. ViSyStII 214, Bd. 1, p. 182,25-184,22: Ein rauher und lügnerischer Mann, der die Wunder des Heiligen Symeon in Frage stellte, wurde fürchterlich von einem Dämon besessen. Deshalb wurde er zu Symeon gebracht und von ihm geheilt. „Obwohl er dieser guten Tat gewürdigt worden war, ließ er nicht von seiner Roheit ab. Deshalb erschien ihm in einer nächtlichen Vision der wutentbrannte Symeon und entfernte ihm die rechte Hand ([1] $\Delta$ iò $\kappa \alpha \grave{~} \omega \varphi \varphi \theta \eta \alpha \hat{\tau} \tau \hat{\omega}$ ó

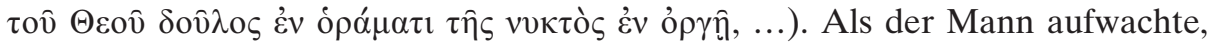

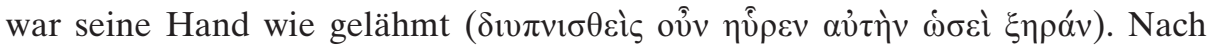
einigen Tagen löste sich das Fleisch an den Fingern und Fäusten bis zur Handwurzel und fiel ab. Jetzt waren die nackten, bloß noch an den Knochen befestigten Nerven zu sehen, manche von ihnen eiterten. Die Knochen waren schwarz wie Kohle und eine Menge von Würmern kroch auf der ganzen Hand herum, und der Gestank war unerträglich“. Nun bereute der Mann und ging wieder zu Symeon. Dieser schickte ihn nach Hause und befahl ihm, vom heiligen Staub, den er ihm gab, auf die Wunde zu streuen, dann werde er von Gott geheilt. Als in jener Nacht Symeon gerade dabei war, seinen Schülern das Wort Gottes zu verkünden, hielt er auf einmal inne und ,sah sich selbst bei jenem Mann stehen und die schreckliche Wunde heilen ([2] ... Ėveò

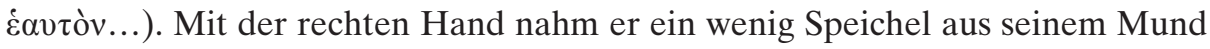
und verteilte ihn auf der ganzen Wunde. Da bildete sich Fleisch um die Knochen, und die ganze Hand bedeckte sich wieder mit Haut". Doch als er zum Gelenk des Mittelfingers kam, sagte Symeon, er werde dieses Glied wegen der ungebührlichen Gesinnung des Mannes abfallen lassen. Und als Symeon wieder zu sich kam, baten ihn die Brüder, er möge ihnen den Inhalt der Schau erzählen

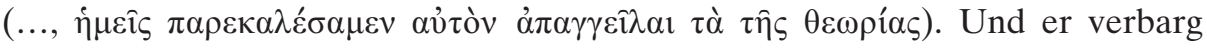
nichts von dem, was er sich selbst an jenem Mann hatte wirken sehen. „Das 
Seltsame war, dass jener Mann in der selben Nacht Symeon zu sich kommen sah ([3] П $\alpha \rho \alpha ́ \delta$ o

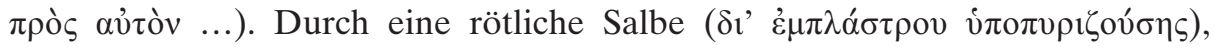
welche aus seinem heiligen Staub bestand, bildete er wieder Fleisch um die Knochen an der Hand. Als er aber zum Gelenk des Mittelfingers kam, ließ er das Glied mit dem Nagel abfallen. Dann geschah Folgendes: Sogleich fielen alle Würmer herunter, und an den Knochen der Hand bildete sich wieder Fleisch, so als ob es aus einem flüssigen in einen festen Zustand übergehen würde (ఝ̋ $\sigma \pi \varepsilon \rho$

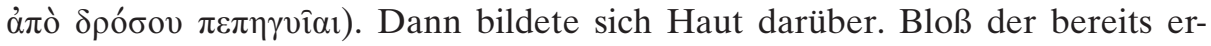
wähnte Mittelfinger fiel samt dem Nagel ab, und entgegen der Natur bildete sich auf dem Gelenk in der Mitte dieses Fingers ein neuer Nagel“. Nachdem dies geschehen war, kehrte der Mann zu Symeon zurück und erzählte, wie er ihm in

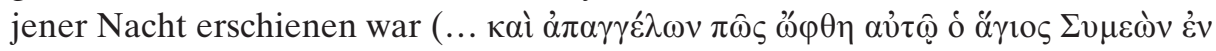

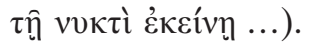

428. ViThSy 9, p. 8,9-9,6: Theodoros ging jede Nacht zum martyrion des heiligen Georgios. Als die Mutter und die anderen Frauen ihn eines morgens nicht finden konnten, verboten sie ihm wegzugehen. Als er dies trotzdem wieder tat, wurden die Frauen wütend und schickten Sklaven los, welche Theodoros an den Haaren nach Hause zerrten. „Dort wurde er von der Mutter ausgepeitscht und mit den Händen hinter dem Rücken ans Bett gebunden. Doch in der folgenden Nacht erschien der Mutter und den anderen Frauen der heilige Georgios mit

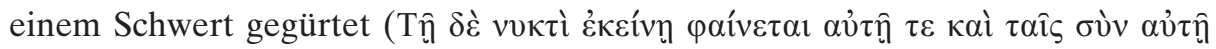

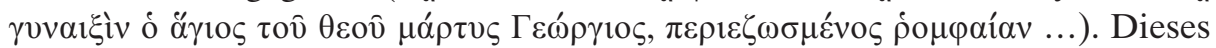
zog er aus der Scheide und fing an, die Frauen zu bedrohen. Dabei sagte er: ,Ich werde euch den Kopf abschlagen, da ihr das Kind bestraft, geschlagen und daran gehindert habt, zu mir zu kommen'. Sie schworen ihm, dies nicht wieder zu tun, worauf Georgios von seinen Drohungen abließ und verschwand. Die Frauen erwachten aus Furcht und banden das Kind los“. Als sie den Jungen fragten, wohin er vor dem Sonnenaufgang jeweils gehe, antwortete er, die ersten Male sei er mit Stephanos zum martyrion gegangen, dann mit einem wunderbar strahlenden und schönen Mann. „Da erkannten sie, dass es der Märtyrer war,

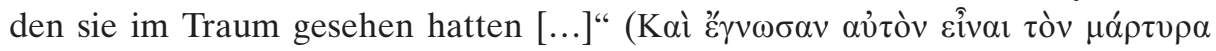

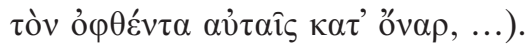

429. ViThSy 76, p. 63,8-64,31: Theodosios, der Vorsteher der umliegenden Dörfer, schädigte seine Bauern, indem er mehr von ihnen verlangte, als ihm zustand. Als Theodoros ihn zurechtwies, stritt er sein Tun ab und beschimpfte den Heiligen. Eines Tages kam er wieder zu ihm, um ihn wegen einer unrechten Sache zu behelligen. Doch als man ihn bei Theodoros ankündigte, wurde er plötzlich von einer großen Angst ergriffen, und es erschien ihm ein Jüngling von

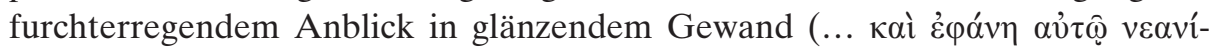

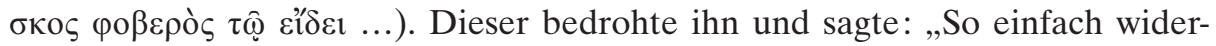
sprichst du dem Heiligen und hörst nicht auf, ihm Schmerzen und Kummer zu 
bringen? Ich kündige dir an, dass ein großer Zorn über dich kommen wird und dein Leben auf furchtbare Weise zu Ende geht, wenn du ihm nicht gehorchst“"

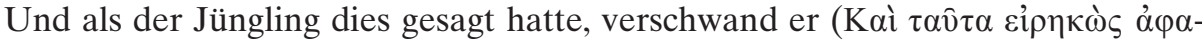

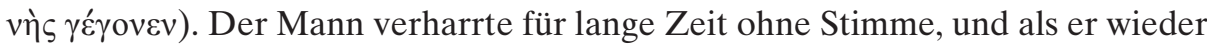
ein wenig zu sich kam, wurde er vom Heiligen zu sich gerufen. Jetzt gestand er

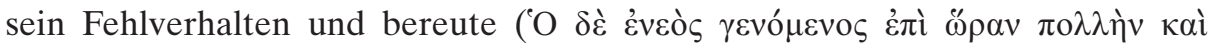

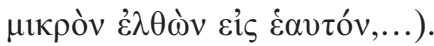




\section{S. Dämonenanschläge}

430. ViAn 5,5, p. 144,8 f.: „Der Teufel erschien dem heiligen Antonios in der

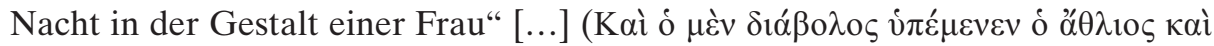

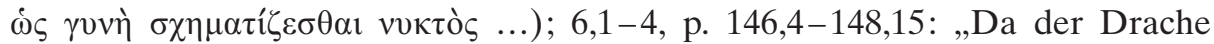

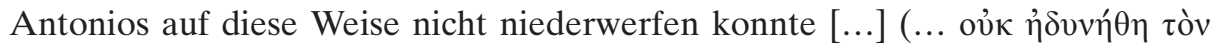

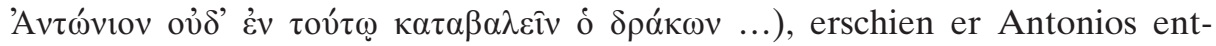
sprechend seiner Gesinnung, nämlich im Trugbild eines schwarzen Knaben (...,

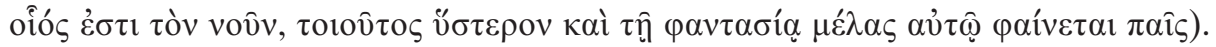
[...], dann wieder machte er Gebrauch von einer menschlichen Stimme [...]“

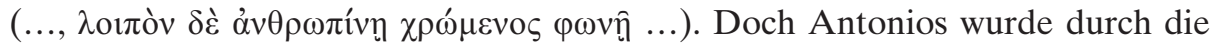
Kraft des Herrn gestärkt und fürchtete sich nicht vor dem schwarzen Knaben, da er sich sagte, dass er, ganz seinem Aussehen entsprechend, im Geist schwarz

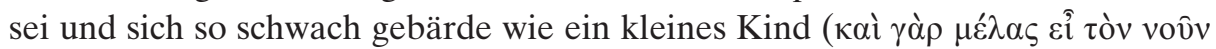

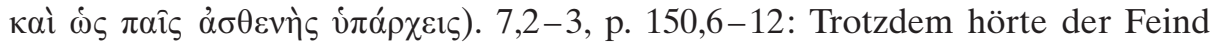
nicht auf, ihm zu erscheinen. „Doch Antonios wusste aus der Bibel, dass die Listen des Feindes vielgestaltig sind [Eph 6.11] und rüstete sich durch noch

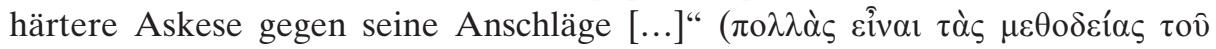

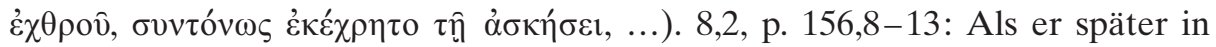
einem Grab lebte, wurde er eines Nachts von einem Schwarm Dämonen angegriffen. „Dabei wurde er so stark verwundet, dass er vor Schmerz bewusstlos

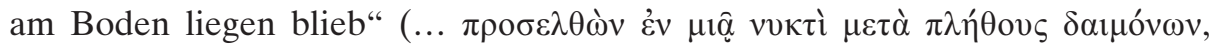

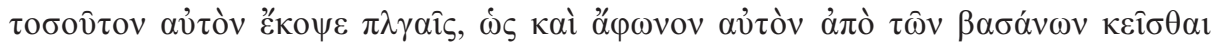

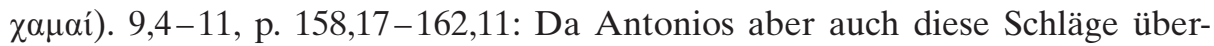
lebte, versammelte der Teufel seine Hunde, die eines Nachts einen solchen Lärm machten, dass der ganze Ort zu beben schien. Die Dämonen rissen die Wände der Behausung nieder , und verwandelten sich in Trugbilder als wilde

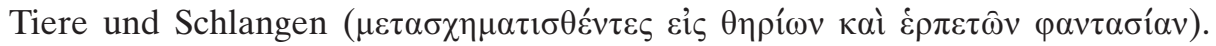

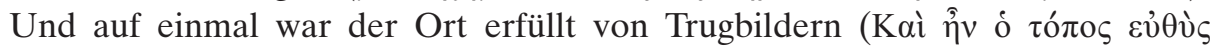

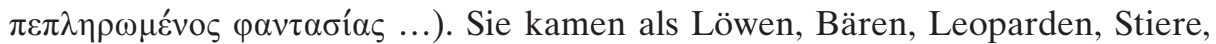
Schlangen, Skorpione und Wölfe. Und jedes Tier bewegte sich entsprechend seiner Gestalt. Der Löwe brüllte und wollte ihn überfallen, der Stier wollte ihn mit den Hörnern aufspießen, die Schlange schlich sich an ihn heran, und der Wolf stürzte sich auf ihn“. Unter fürchterlichen körperlichen Schmerzen gelang es Antonios schließlich, durch seinen Glauben die Dämonen zu vertreiben. 11,2-4, p. 164,16-166,9: Ein anderes mal wandte sich der Feind gegen Antonios, indem er ,vor ihm das Trugbild einer großen Silberschale auf den

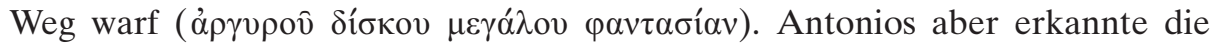


Ränke des Übeltäters“. Da er den Dämon im Diskus erkannte und ihn als List

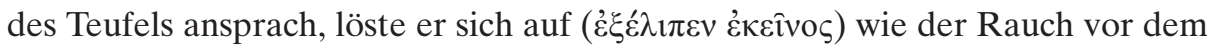
Feuer (Ps 67,2). 12,1, p. 166,10-13: „Ein anderes mal wiederum war es kein Trugbild, sondern echtes Gold, das Antonios auf dem Weg erblickte (Eî̀ $\alpha$ á́ $\lambda \iota v$

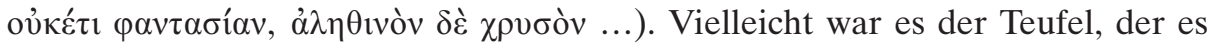
zeigte, vielleicht auch eine höhere Macht, die ihn prüfen wollte (Eı̌ $\tau \varepsilon \delta \dot{\varepsilon} \tau$

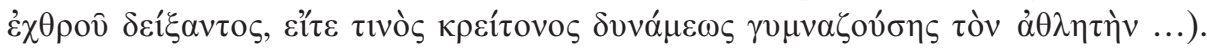
Antonios ließ sich aber auch davon nicht beeindrucken.13,1-7, p. 168,16170,19: Auch, als sich Antonios in der inneren Wüste zurückgezogen hatte, wurde er von Dämonen angegriffen. „Doch der Reichtum an Visionen, die er im Geist hatte, und die Schwäche des bösen Geistes gewährten ihm große Erholung

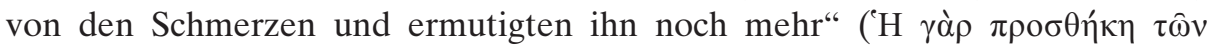

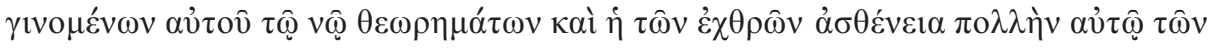

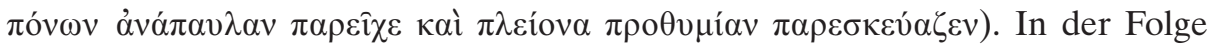
versuchte der Teufel, Antonios durch viele andere Trugbilder zu überlisten. So wird etwa in 53,1-3, p. 276,12-278,6 geschildert, wie jemand vor seiner Tür stand und anklopfte. Als Antonios öffnete, ,sah er ein Tier, das bis zu den Hüften von menschlicher Gestalt war, aber Beine und Füsse wie ein Esel hatte"

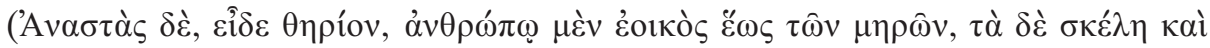

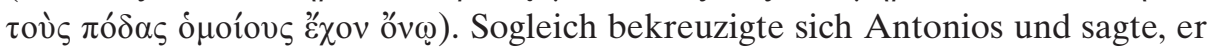
sei ein Diener Christi. Sollte er gegen ihn geschickt worden sein, so stehe er nun vor ihm. „Darauf floh das Tier mit seinen Dämonen so schnell, dass es umstürzte und starb".

431. ApAl, Makarios der Ägypter 33, PG 65, col.276D-277A: Abbas Makarios berichtet, wie er einmal bei zwei jungen Brüdern übernachtete, da er ihre Lebensweise erfahren wollte. Als sie sich alle hingelegt hatten, betete er zu Gott, er möge ihm die Werke der Brüder offenbaren. Da hob sich das Dach, und es wurde hell wie am Tag. Die beiden Brüder aber nahmen das Licht nicht wahr. Und da sie glaubten, dass Makarios sie nicht sehe, stieß der Ältere den Jüngeren in die Seite. Sie standen auf, gürteten sich und streckten die Hände in den Himmel. Und Makarios beobachtete, wie die Dämonen wie Fliegen auf den

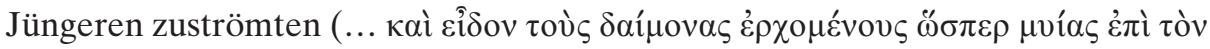

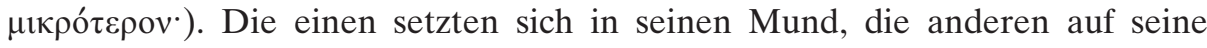
Augen. Dann sah er einen Engel des Herrn, der ein Feuerschwert herunterstreckte und einen Kreis um den Bruder einritzte, um die Dämonen zu vertreiben [vgl. auch 125].

432. ApAl Niketas, PG 65, col.312B-C: Niketas erzählte, dass zwei Brüder gute Freunde waren und über Jahre hinweg gemeinsam in Frieden und Eintracht lebten. „Als dies der Feind sah, wollte er die beiden trennen. Er stellte sich vor die Türe und erschien dem einen als Taube, dem anderen als Krähe“ (...,

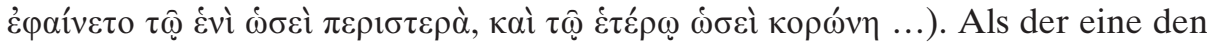
anderen fragte, ob er die Taube sehe, behauptete der andere, es sei eine Krähe. 
Da fingen sie an zu streiten und trennten sich. „Nach drei Tagen kamen sie aber wieder zur Besinnung und kehrten zurück. Sie bekannten ihre Sünden und stimmten überein, dass sich beide den Vogel eingebildet hatten“ (..., $\dot{\omega} \mu \mathrm{o} \lambda$ ó

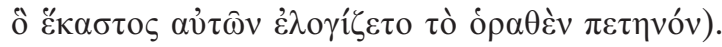

433. ApSy V 4, Bd. 1, p. 242-244: Abbas Apollo betete zu Gott, er möge jenen geron in Versuchung führen, der einem jungen, von schlechten Gedanken heimgesuchten Bruder sagte, er sei des Mönchslebens nicht würdig. Als Apollo das Gebet beendet hatte, „sah er einen Äthiopier in der Nähe der Zelle des

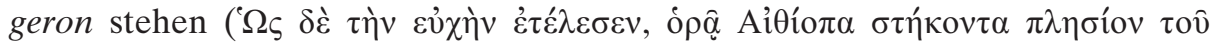
$\kappa \varepsilon \lambda \lambda$ íov ...). Er schoss Pfeile gegen ihn, sodass er auf der Stelle wie betrunken hin und her torkelte“. Da er sich aber nicht wieder fassen konnte, verließ er die Zelle und ging in die Welt.

434. ApSy X 138, Bd. 2, p. 104: „Ein Mönch, der in Versenkung saß, wurde von Dämonen verwirrt. Sie gaben sich als Engel aus und weckten ihn unter dem

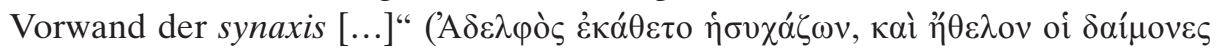

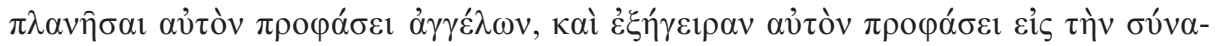
$\xi ı$, ...). Da suchte er einen Bruder auf und erzählte ihm, dass die Engel mit Licht zu ihm kämen und ihn zur synaxis weckten. Der Bruder erwiderte ihm, er

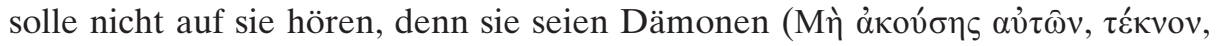

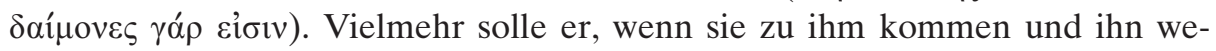
cken, sagen: „Ich stehe auf, wann ich will, und ich höre nicht auf euch“.

435. ApSy XIV 30, Bd.2, p. 280: Ein Mönchsschüler ließ sich von einem Wüstenvater belehren. Dabei wunderte er sich, dass dieser nichts über das Beten sagte, stand auf und sang mehrere Psalmen. „Dann stand er auf, um schlafen zu gehen, doch auf seiner Binsenmatte saß ein Äthiopier, der ihm mit

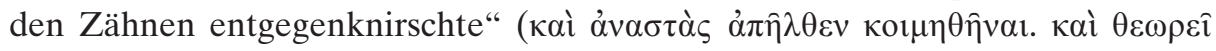

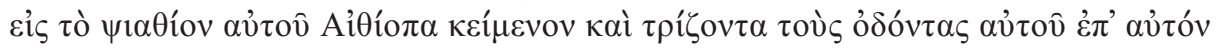
...). Sofort rannte er zum Wüstenvater, der sogleich erkannte, dass der junge Bruder seinen Befehl nicht befolgt hatte.

436. ApSy XV 87, Bd. 2, p. 342: Einem Bruder erschien der Teufel als Engel des Lichts und behauptete, der Erzengel Gabriel zu sein, der zu ihm gesandt wurde

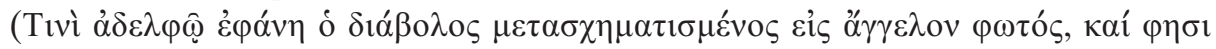

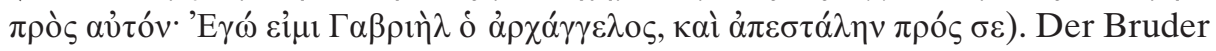
erwiderte, er solle sehen, ob er nicht zu einem anderen gesandt wurde, denn er sei unwürdig, einen Engel zu schauen. Sogleich wurde er unsichtbar.

437. ApSy XV 89, Bd.2, p. 342: Ein Wüstenvater saß in seiner Zelle. Er er-

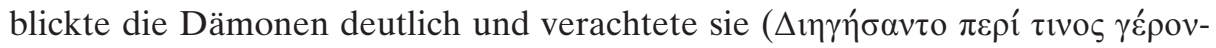

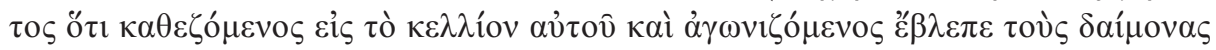
 erschien er ihm selber und gab sich als Christus aus (.. каi દ̇ $\lambda \theta \omega े v ~ \varepsilon ́ v \varepsilon \varphi \alpha ́ v \eta \sigma \varepsilon v$

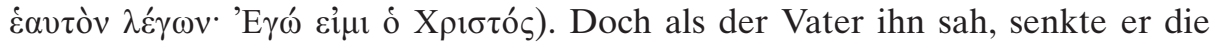
Augen. Jetzt fragte ihn der Teufel, warum er die Augen senke, er sei nämlich 
Christus. Darauf antwortete der Vater, er wolle Christus hier nicht sehen. Sogleich verschwand der Teufel.

438. ApSy XV 118, Bd. 2, p. 362 f.: Ein Bruder verfiel durch das Wirken des Teufels häufig der Unzucht, war aber dennoch nicht bereit, die Askese aufzugeben und hoffte auf die Hilfe Gottes. Als er eines Nachts wieder sündigte, stand er plötzlich auf und fing an, einen Kanon zu singen. „Da wunderte sich der Teufel über die Hoffnung und die Unverschämtheit des Bruders gegenüber Gott. Deshalb erschien er ihm augenscheinlich" und fragte ihn, ob er sich nicht

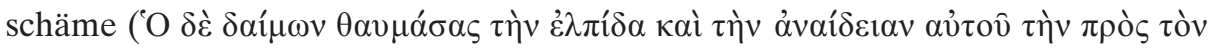

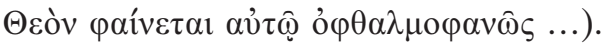

439. Bar 46, Bd. 1,1, p. 252-255: „Der Widersacher suchte einen Bruder mit schlechten Träumen heim und zeigte ihm ein Kloster und eine Kirche, wo sich

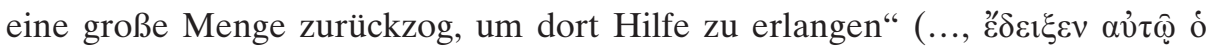

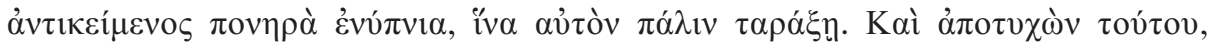

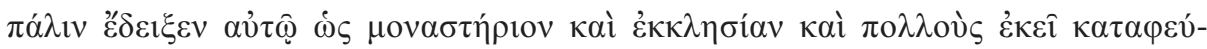

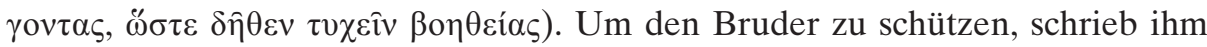
daraufhin Barsanuphios, dass der Herr den Teufel daran gehindert habe, ihn zu vernichten. Da der Teufel aber gemerkt habe, dass ihm nicht erlaubt wurde, zu tun, was er vorhatte, habe er sich daran gemacht, den Geist des Bruders durcheinanderzubringen, und habe ihm in seinen schändlichen Träumen gewisse

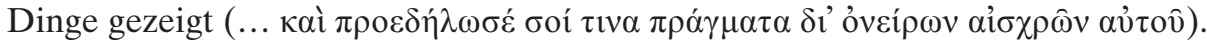
Und weil der Teufel gesehen habe, dass der Herr nicht zuließ, dass der Bruder versucht wurde, habe er gemacht, dass er ein Kloster und eine Kirche sehe,

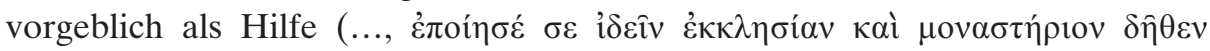

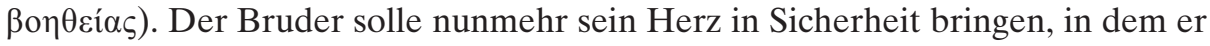
sich unerschütterlich bekreuzige im Namen des Vaters, des Sohnes und des Heiligen Geistes, dann werde er nicht mehr heimgesucht werden. Der Grund für den Dämonenanschlag sei nämlich seine Unachtsamkeit gewesen ( $\Sigma \grave{v} \gamma \grave{\alpha} \rho$ àmò

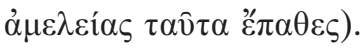

440. Bar 78,6; 31-33, Bd. 1,2, p. 362-364: Ein geron, der an den Füssen und Händen Rheuma hatte, fragte Barsanuphios, was es zu bedeuten habe, dass er

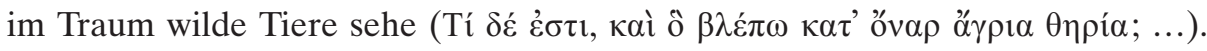
Die Antwort des Barsanuphios lautete, dass die wilden Tiere im Traum dämonische Trugbilder seien, die ihn täuschen und ihn glauben lassen wollten, dass seine Krankheit von ihnen komme ('A

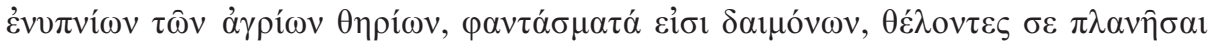

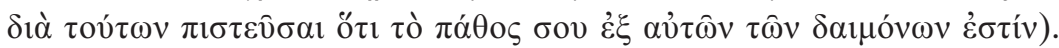

441. Bar 347b,1-3; 20, Bd. 2,1, p. 364-366: „Ein Bruder verriegelte seine Tür für eine gewisse Zeit und wurde von verborgenen Gedanken und von Träumen

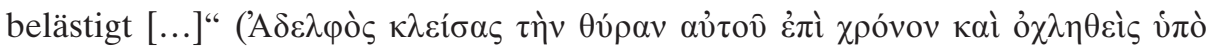

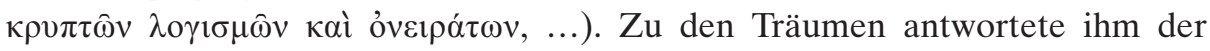


Greis, er solle sie nicht beachten, da sie dämonisch und trügerisch seien ('Evv-

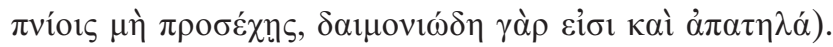

442. Bar 416, Bd. 2,2, p. 488-490: Ein gläubiger Christ fragte Barsanuphios, wie es möglich sei, dass der Teufel es wage, sei es durch eine Vision oder durch eine Traumerscheinung, Christus oder die heilige Eucharistie zu zeigen ('E

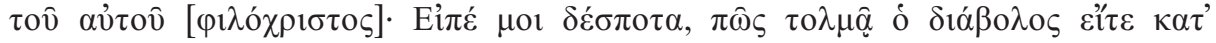

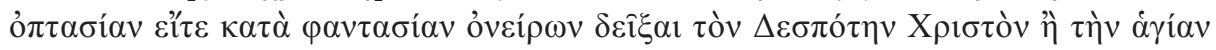

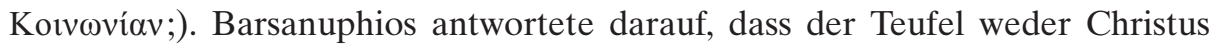
noch die Eucharistie zu zeigen vermöge. Vielmehr täusche er vor und forme irgendeinen Menschen und einfaches Brot. Das heilige Kreuz könne er nicht zeigen, da er es nicht in einer anderen Form abbilden könne. Da sie sein wahres Bild und seine Form kennen, wage er nicht, sich des Kreuzes zu bedienen

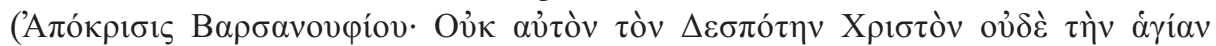

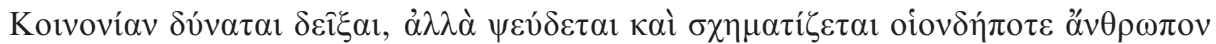

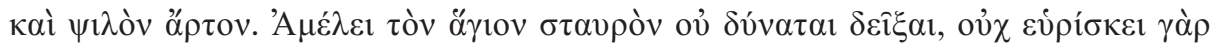

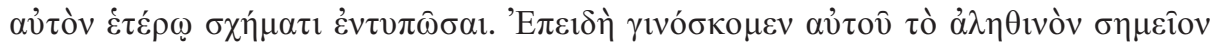

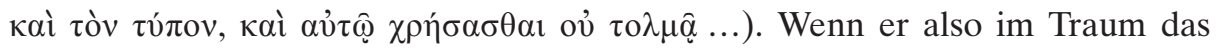
Kreuzeszeichen sehe, dann solle er wissen, dass es wahr sei und der Traum von

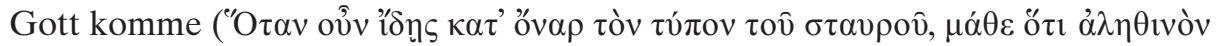

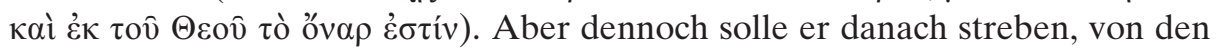
heiligen Vätern die Unterscheidung davon zu erhalten, und er solle sich nicht auf die eigene Vernunft verlassen. Der Herr möge die Augen seines Geistes erleuchten, damit er jeder Täuschung des Feindes entgehe ('A $\lambda \lambda \dot{\alpha} \sigma \pi \circ v ́ \delta \alpha \sigma o v$

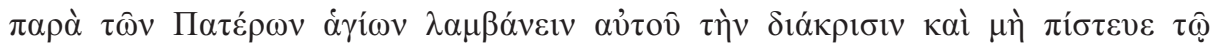

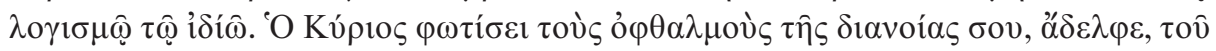

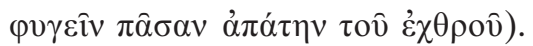

443. Bar 691,54-62, Bd.3, p. 132-135: Einer der heiligen Väter wurde von einem Bruder gefragt, was es zu bedeuten habe, dass er jedes mal, wenn er vor dem Schlafengehen bete und sich bekreuzige, unreine Träume habe, dass er aber, wenn er dies nicht tue, nicht träume. Der Greis antwortete, dass dies die List der Dämonen sei, die ihn gerade vom Beten und Bekreuzigen abhalten wollen, da sie wissen, dass aus diesen beiden Dingen Hilfe für den Menschen

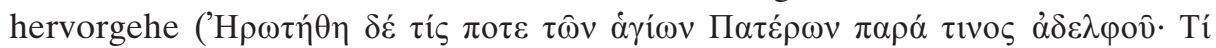

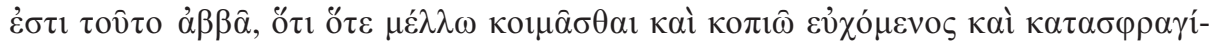

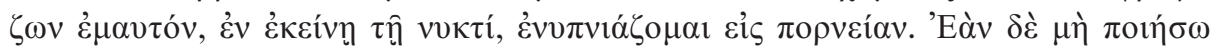

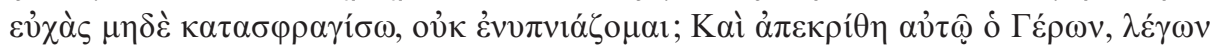

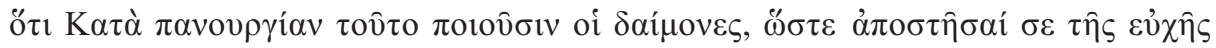

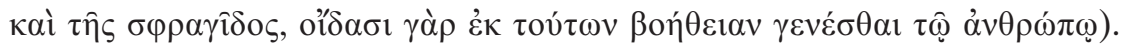

444. ViDanSt 15, p. 15,11-16,10: Daniel Stylites kam in Syrien zu einer Kirche, wo Dämonen wohnten. In der Nacht wurden Steine gegen ihn geworfen, und er hörte Geräusche von einer polternden und lärmenden Menge. Daniel aber verharrte im Gebet, und erst in der dritten Nacht wurde er vom Schlaf über- 
wältigt. Jetzt näherten sich ihm viele Trugbider von Riesen, die ihn verjagen

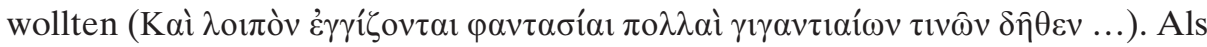
Daniel aufwachte, ging er betend und singend in alle Ecken der Kirche und vertrieb die Dämonen.

445. DeMa 23,14-22, p. 234,10-18: Wenn ein Anachoret von den bösen Gedanken der Überheblichkeit heimgesucht wird, „dann sieht er zuerst, wie die Luft der Zelle feurig wird und wie in der Nacht an den Wänden Blitze aufleuchten. Dann vernimmt er Stimmen von Verfolgern und Verfolgten und Pferdewagen in der Luft, und das ganze Haus füllt sich mit Äthiopiern und

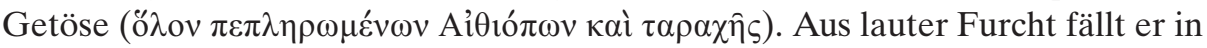

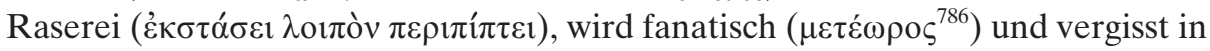
seiner Angst, dass er ein Mensch ist."

446. HiLa 19, p. 58,14-62,15: Der äthiopische Räuber Moses bekehrte sich nach langen Jahren des frevelhaften Lebens, ging ins Kloster und legte Buße ab. Hier wurde er aber von Dämonen heimgesucht, weswegen er zu Abbas Isidoros ging. Dieser beruhigte ihn. Danach führte Moses ein noch strengeres Leben. Doch obwohl er seinen Leib hart kasteite, plagten ihn unreine Begierden, sogar im Schlaf. Deshalb suchte er einen anderen heiligen Mann auf und fragte diesen,

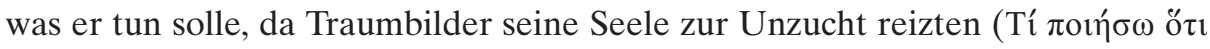

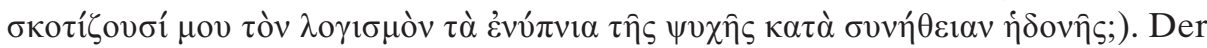
andere antwortete, da Moses in dieser Sache bis jetzt die Phantasie nicht ge-

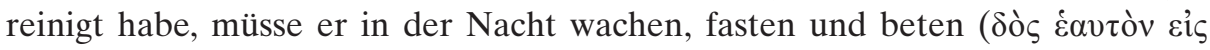

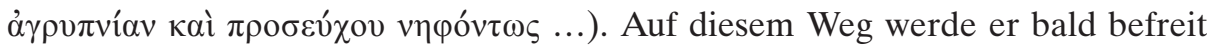
sein. „Darauf ging er in seine Zelle und nahm sich vor, die ganze Nacht zu

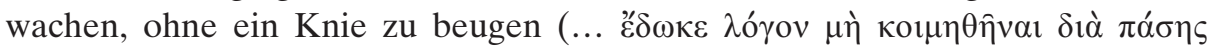

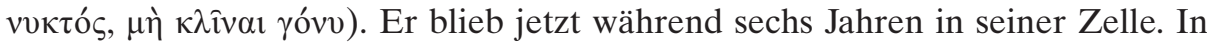
den Nächten stand er betend inmitten des Raumes, ohne ein Auge zu schließen

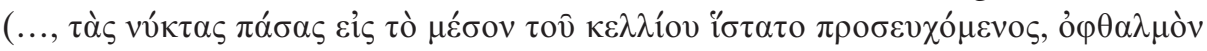

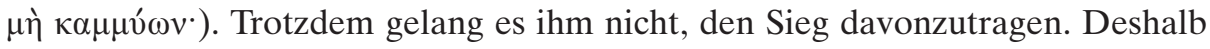
dachte er sich ein anderes Mittel aus. Er holte sich in der Nacht bei den Ältesten des Klosters die Wasserkrüge und ging Wasser schöpfen“. Darüber wurde der Teufel wütend und lauerte ihm auf. Als sich Moses zum Brunnen bückte, schlug er ihn mit der Keule so heftig um die Lenden, dass er wie tot liegen blieb und nicht mehr wusste, wie ihm geschah. Am nächsten Tag wurde Moses gefunden und in die Kirche getragen. Nun lag er ein Jahr darnieder und wurde an Leib und Geist nur langsam wieder gesund. Da sagte Isidoros der Große zu ihm, er solle aufhören, sich mit dem Teufel zu messen, denn auch in der Askese gebe es

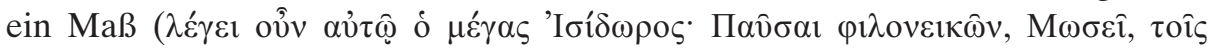

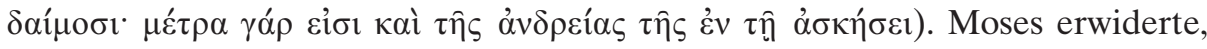
dass er solange nicht davon ablassen werde, bis ihn die Dämonen mit ihren

786 S. dazu Évagre le Pontique, Sur les penśees (Hg. GéHIN), 235, A. 6. 


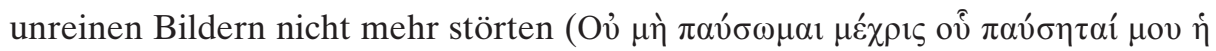
$\varphi \alpha v \tau \alpha \sigma i ́ \alpha \tau \hat{\omega} \nu \delta \alpha \iota \mu o ́ v \omega v)$. Darauf sagte Isidor: „Im Namen Christi sollen deine

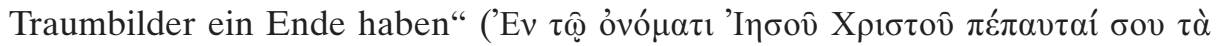

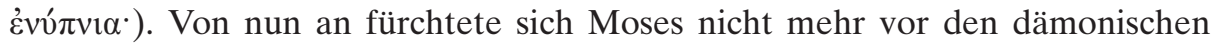
Trugbildern.

447. HiLa 25, p. 79,4-80,15: Ein Asket namens Valens wurde vom Dämon versucht. „Da dieser wusste, dass Valens sich in großer Verwirrung befand, verwandelte er sich in den Erlöser und kam als nächtliches Trugbild (..., $\alpha$ á $\rho$ -

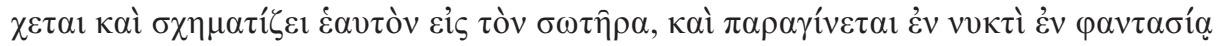
...). Er war von tausend Engeln umgeben, die tausende Leuchten und ein brennendes Rad hielten, indem der Dämon sich als Erlöser ausgab und einen hervorschickte“, der zu ihm sagte, Christus habe ihn, Valens, wegen seines Lebenswandels und Wesens liebgewonnen und komme nun, um ihn zu sehen. Er solle vor seine Zelle treten und sich, sobald er ihn sehe, niederwerfen und ihn anbeten. „So ging Valens hinaus und sah das strahlende Gefolge und in der Entfernung von einem Stadion den Antichristen. Jetzt fiel Valens nieder und

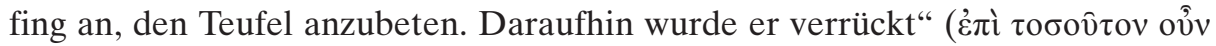

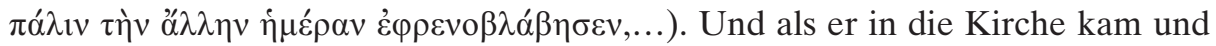
sich mit den anderen Brüdern traf, sagte er, er benötige das gemeinschaftliche Leben nicht mehr, da er heute Christus gesehen habe.

448. HiMo 2,9, p. 37,19-38,16: Ein in der Wüste lebender Asket nahm während drei Jahren keine irdische Speise zu sich. „Ein Engel brachte ihm jeden dritten Tag Nahrung aus dem Himmel, welche er ihm in den Mund warf. Dies war ihm Ersatz für Speis und Trank. [...], in der Einbildung kamen aber Dämonen zu

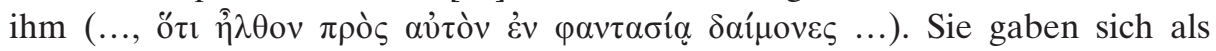
engelhafte Soldaten aus und waren mit Feuerwaffen und viel Rüstung ausgestattet, als ob ein König ankommen würde“, der vom Asketen verehrt werden wollte. Jener aber durchschaute die List des Dämons und anerkannte ihn nicht als seinen König. Da wurde er auf der Stelle unsichtbar.

449. HiMo 9,11, p. 74,16-75,2: Es war einmal ein Ungeheuer in der Gegend des Amun. Als es noch lebte, ,wurde es von einem Hirtenknaben gesehen, welcher

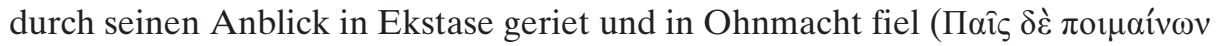

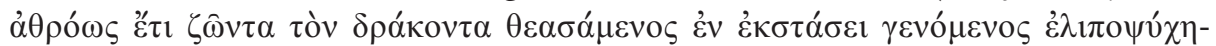
$\sigma \varepsilon v)$. Der Junge blieb den ganzen Tag bewusstlos in der Wüste liegen. Erst am Abend wurde er von seinen Eltern gefunden. Er atmete kaum mehr und war

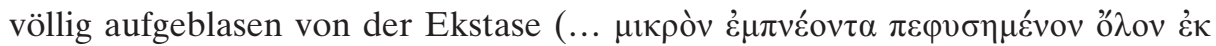
$\tau \eta ি \varsigma ~ \varepsilon ̇ \kappa \sigma \tau \alpha ́ \sigma \varepsilon \omega \varsigma . .$.$) . Man brachte ihn zu Amun, ohne den Grund für den Vorfall$ zu kennen. Dieser aber betete und salbte den Jungen. Jetzt stand er auf und erzählte, was er gesehen hatte“. Darauf beschloss man, das Ungeheuer zu töten. 450. ViHy 8,12, p. 102,3-6: Als der heilige Hypatios mit zwei Gefährten in Ruphinianai ein Einsiedlerleben führte, ,gingen sie regelmässig in die Kapelle, um zu beten oder Psalmen zu lesen. Und immer wieder sahen sie einen Feu- 
erball, der im ganzen Gebäude herumrollte und mit Tosen auf sie zukam $(\dot{\varepsilon} \theta \varepsilon-$

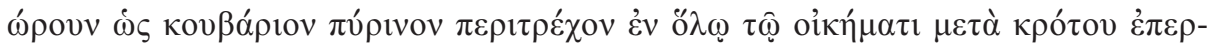

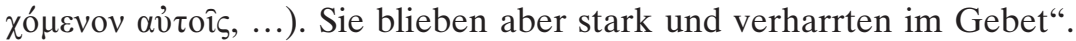

451. ViHy 28,14-23, p. 188,9-190,13: Hypatios traf in einem Kloster auf einen Magier ( $\pi \varepsilon \rho i ́ \varepsilon \rho \gamma o ́ \varsigma \tau \iota \varsigma)$, der die anderen Brüder und den Abt dauernd schikanierte. Vergeblich wies Hypatios ihn zurecht. Als er sich wieder in seinem eigenen Kloster befand, ,sah er nach fünf Tagen vier Dämonen in der Gestalt von

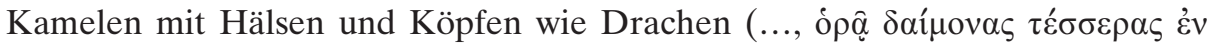

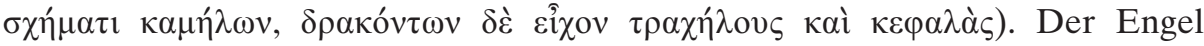
Gottes aber, welcher Hypatios beschützte, hob ihn in die Höhe. Die Dämonen streckten die Hälse, um ihn zu erreichen. Dies gelang aber nicht, denn Hypatios stieg immer höher hinauf“. Schließlich zeigte ihm der Engel jenen Magier, wie er in der Gestalt eines Sklaven auf dem Bett saß. Er sei es, welcher die Dämonen geschickt habe. Darauf befahl Hypatios den Dämonen, sie sollen das, was jener Magier ihm Schlechtes habe tun wollen, zu diesem zurückbringen. So geschah es, und der Magier wurde von den Dämonen besessen.

452. ViHy 42,13-16, p. 250,10-25: Makarios, ein Schüler des Hypatios verbrachte 18 Jahre im Kloster, ohne dass es dem Teufel gelang, ihn zu Fall zu bringen. Deshalb wollte er ihn nun an seinem schwächsten Punkt, der Demut ( $\tau \alpha \pi \varepsilon เ v о \varphi \rho о \sigma u ́ v \eta)$, bekämpfen. Er ließ ihn mit Genugtuung an seine Anstren-

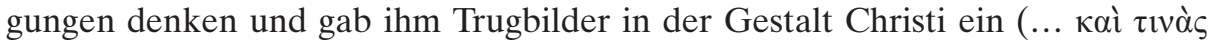

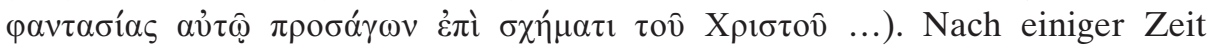
merkten Hypatios und die anderen Brüder, dass Makarios zum Opfer der Verwirrung geworden war. Sie versuchten ihn zu belehren, doch Makarios hörte nicht auf sie, sondern machte sich lustig über ihre Worte. Seine Verwirrung wurde immer größer, und er fing an Dinge zu behaupten, so z.B., die rechte Hand Gottes liege auf seinem Haupt, oder Jesus spreche durch ihn und habe

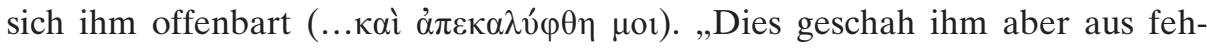

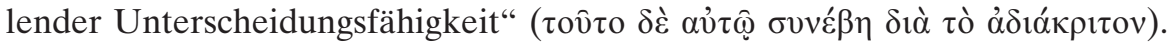

453. ViHy 43,9-13, p. 258,17-260,9: Hypatios ließ eines Tages einen Mann zu sich kommen, von dem er gehört hatte, dass er divinatorisch tätig war, und sagte zu ihm: „,Ich habe von dir gehört, dass du die Zukunft voraussagst, und wenn jemand etwas verloren hat, sagst du ihm, wer es gestohlen hat. Ich bitte dich, sag auch mir, wie du das machst, damit auch ich erfahre, ob ich dich zu recht ehren soll‘. Da fing der andere mit Begeisterung an zu erzählen: ,Wenn mir jemand über irgend eine Angelegenheit berichtet, wird es mir sogleich in der Nacht offenbart, und ich erzähle es ihnen, damit sie in den Tempel opfern gehen. Und so sage ich es jedesmal, wenn der Engel mir etwas offenbart'“.

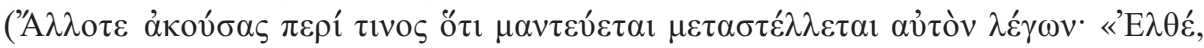

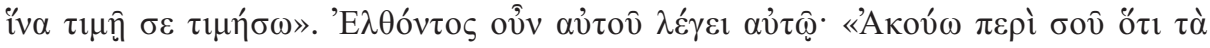

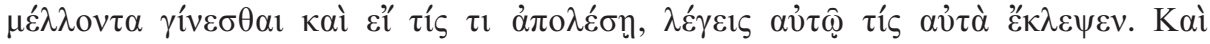

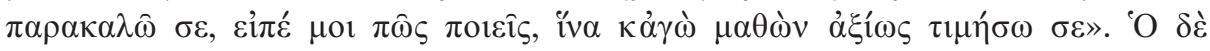




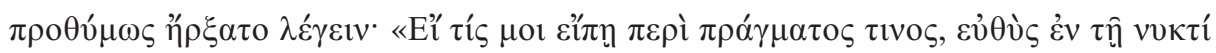

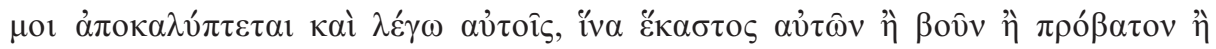

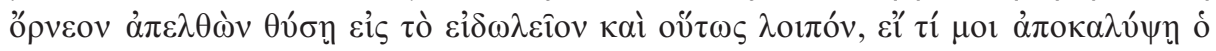

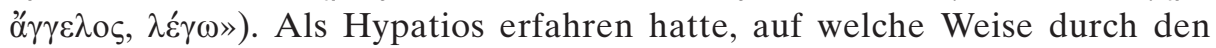
Mann Dämonen in die Menschen kommen, ließ er ihn fesseln und einsperren.

454. ViIoEl 38,102, Bd.2, p. 389,29-390,30: Nachdem der heilige Bitalios (vgl. 30) gestorben war, ohne dass irgend jemand davon wusste, erschien einem Freier, der eben diesen beschimpft und geohrfeigt hatte (vgl. 38,88, Bd. 2, p. 389,18-28), ein Dämon in Gestalt eines hässlichen Äthiopiers und gab ihm eine

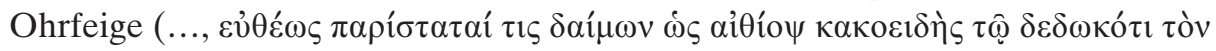

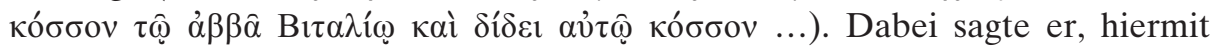
erhalte er die Ohrfeige, die er Bitalios gegeben hatte, zurück. "Sogleich fiel der Freier um und fing an zu schäumen". Ganz Alexandreia versammelte sich, um zu sehen, was geschehen war. „Erst nach mehreren Stunden kam der Freier wieder zu sich, riss sich die Kleider von der Brust und rannte schreiend zur Zelle

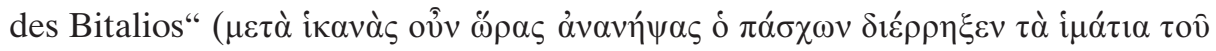

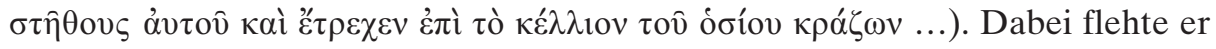
ihn an, er möge ihn erlösen. „Die ganze Menschenmenge strömte mit, und als sie die Zelle des Bitalios erreichte, kam der Dämon heraus und warf den Freier vor allen um. Und als sie in die Zelle kamen, sahen sie, wie der heilige Bitalios betend auf dem Boden kniete und seine Seele bereits ausgehaucht hatte. Auf dem Boden fand man die Inschrift: ,Männer Alexandreias, urteilt nicht, bevor der Herr kommt“". Darauf gestand der vom Dämon Besessene, was er getan hatte.

455. ViNi 28,1-12, p. 46,17-28: Als sich Nikolaos Sionites auf dem Weg ins heilige Land auf hoher See befand, forderte er seine Reisegefährten auf zu beten, da in Kürze ein heftiger Sturm heranziehen würde. Als die Reisegefährten Nikolaos fragten, woher er denn vom herannahenden Sturm wisse, antwortete dieser, dass er den Teufel gesehen habe, wie er das Schiff umzingelte

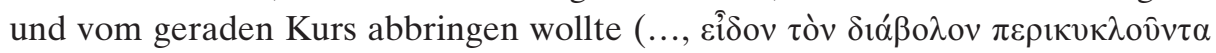

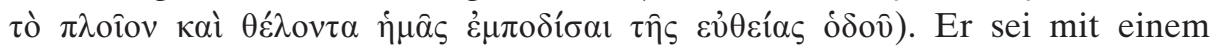
zweischneidigen Schwert beim Schiff gestanden, um alle Ruderstricke vom Schiff herunterzureißen und sie (Nikolaos und seine Reisegefährten) ins Meer zu werfen, damit sie sterben.

456. ViPa 8, Halkin 1982, p. 14,27-15,6: Bei einem vom Teufel überlisteten Bruder klopfte der Dämon als schöne Frau an die Tür und bat ihn, sie aufzunehmen, da sie verfolgt werde. „Er aber konnte in der Blindheit seines Verstandes nicht unterscheiden, was das zu bedeuten hatte, und nahm sie auf ('O $\delta \grave{\varepsilon}$,

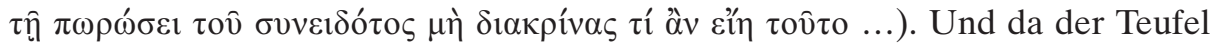
darauf abzielte, ihn in eine üble Leidenschaft zu bringen, war der Bruder kurz davor, zu sündigen. Deshalb wurde er vom Dämon in eine Ekstase gerissen, 


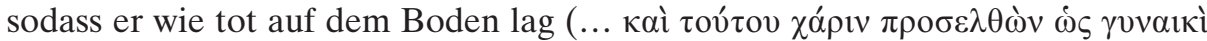

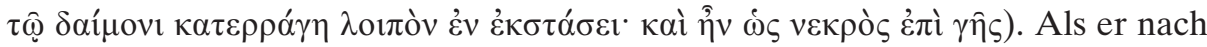
Tagen wieder ein wenig zu sich kam, sagte er unter Weinen und Zittern“, er

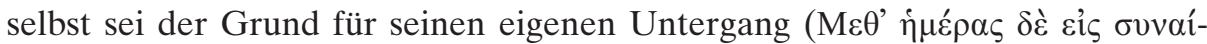

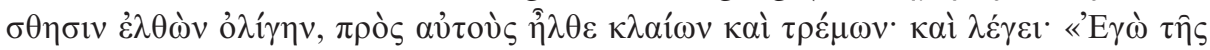

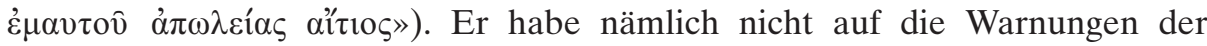
Brüder gehört. Trotzdem sollten sie ihm helfen, denn er sei in Gefahr, vom Dämon zerstört zu werden. „Und noch während er dies sagte, wurde er so vom

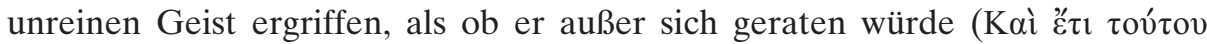

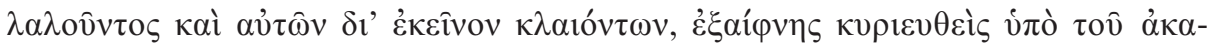

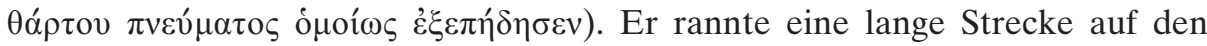
Berg und kam in eine Stadt namens Panos. Dort warf sich der außer sich Ge-

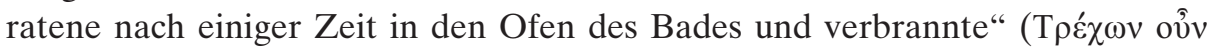

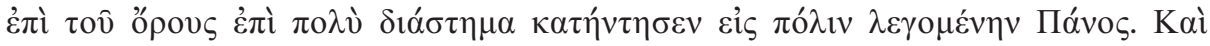

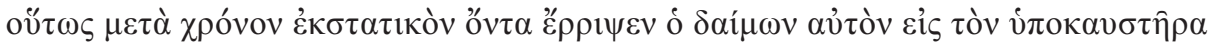

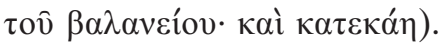

457. ViPa 19, Halkin 1982, p. 16,20-32: Als Pachomios „einmal beim Arbeiten $\mathrm{sa}$, kamen die Dämonen, um ihn auf andere Weise niederzuringen. Sie nahmen

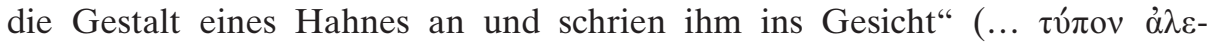
$\kappa \tau \rho v o ́ v o \zeta ~ \lambda \alpha \beta \omega ̀ v ~ . .$.$) . Und sie erschienen in vielerlei anderen Gestalten. „Als er$ beim Essen saß, kamen sie als nackte Frauen. Doch er schloss das Auge seines

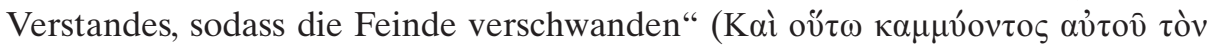

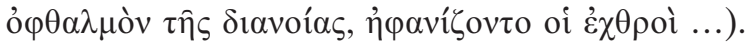

458. ViPa 87, Halkin 1982, p. 43,15-24: „Einmal erschien Pachomios, als er gerade dabei war, eine Binsenmatte zu flechten, ein Dämon, der von sich be-

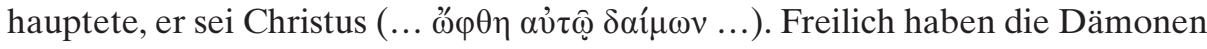
ohne die Erlaubnis Gottes keine Macht, jemandem zu erscheinen oder einen schlechten Gedanken über jemanden zu bringen. Und da Pachomios die Unterscheidungsgabe des Geistes besaß, sodass er die schlechten von den heiligen Gedanken unterscheiden konnte", dachte er sofort daran, dass in der Vision der heiligen Dinge die schlechten Gedanken die Schau des Sehenden gänzlich

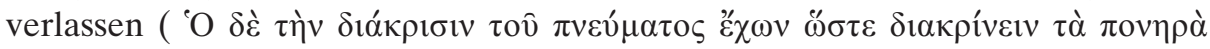

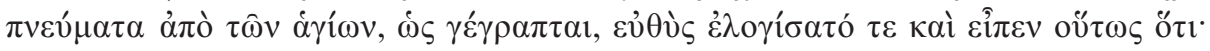

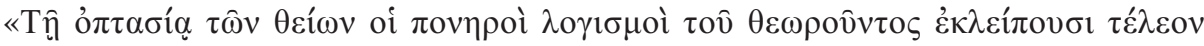
...»). Und dass sie (die Sehenden) sich auf nichts, außer auf die Heiligkeit der

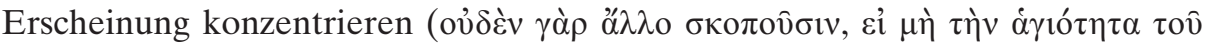
ó $\pi \tau \alpha \mu \varepsilon ́ v o v)$. Er aber sah dies und fing an, nachzusinnen und abzuwägen ('A $\lambda \lambda \lambda^{\prime}$

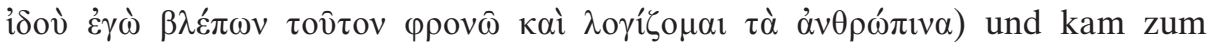
Schluss, dass es offensichtlich sei, dass es eine Lüge und nichts von den heiligen

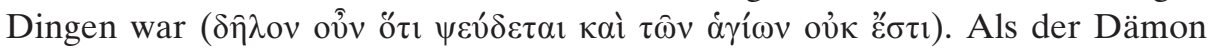
sah, welche Gedanken sich Pachomios machte, fing er an, seine schlechten Geister zurückzuziehen. 
459. PaThI 7,24, p. 87,6-27: „Als Pachomios und Theodoros einmal in der Nacht zusammen herumspazierten, sahen beide auf einmal von weitem ein

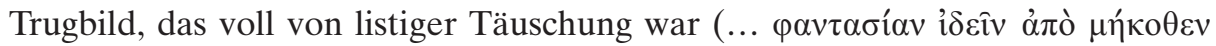

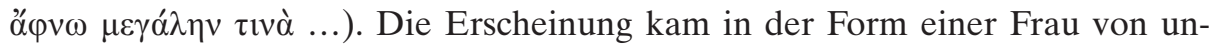
aussprechlicher Schönheit. Theodoros wurde derart verwirrt, dass sich sein Gesichtsausdruck vollständig veränderte“. Als Pachomios ihn so verzückt sah, sprach er ihm Mut zu, und sie fingen an, zusammen zu beten, damit das Trugbild

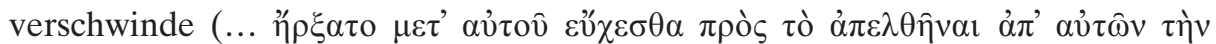

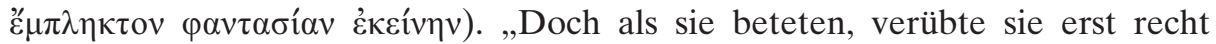
einen Anschlag gegen sie und näherte sich mit einer ganzen Truppe von Dä-

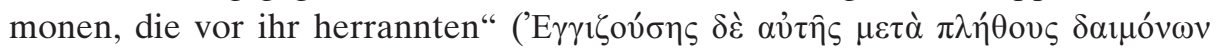

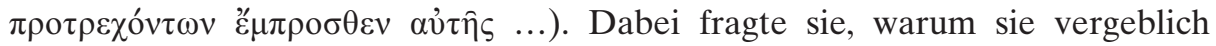
gegen sie ankämpften. Denn sie habe von Gott schon vor langer Zeit die Kraft bekommen zu versuchen, wen auch immer sie wolle. Sie sei die Tochter des Teufels, von der man sage, sie besitze all seine Kraft, denn ihr diene die ganze Phalanx der Dämonen. Doch Gott habe Pachomios und den Seinigen die Macht gegeben, ihre ganze Kraft mit Füssen zu treten und sie zu überlisten. 7,25, p. 87,22-88,16: Wenn sie gegen ihn und Theodoros ankämpfe, gereiche sie ihnen mehr zum Nutzen als zum Schaden, und vor allem gegen Pachomios könne sie nichts ausrichten, da er mit den körperlichen Augen ausgezeichnet

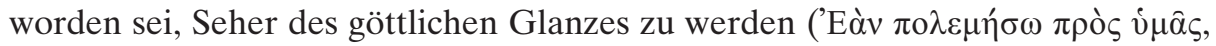

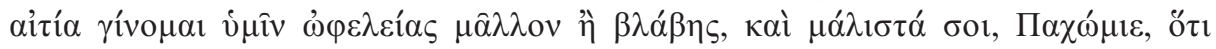

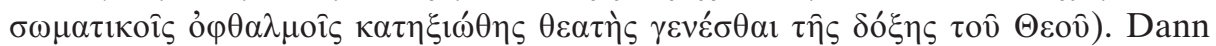
kündigte sie an, dass sie nach dem Tod der beiden die nachfolgenden Brüder auf schreckliche Weise heimsuchen werde. Jetzt widersprach Pachomios. Sie habe nämlich überhaupt nichts Prophetisches an sich. Nur Gott sei der Blick in die

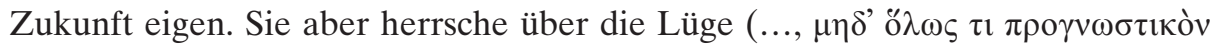

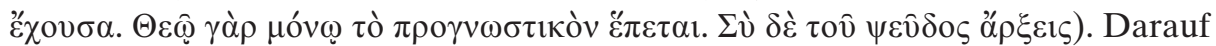
gab sie zu, nichts über die Vorhersage zu wissen. Tatsächlich könne nur Gott zukünftige Dinge voraussagen. Sie kenne sich besser mit Spekulationen aus. Aus den bereits vorhergesagten Dingen vermute sie das noch nicht Geschehene. Sie habe verstanden, dass der Ursprung von jeder Sache eine Kraft besitze, die im Verlangen nach den zu erforschenden Dingen liege, besonders wenn es um die göttliche Schöpfung und das himmlische Gericht gehe. Er (der Ursprung der Dinge) werde durch den Willen Gottes bestätigt, indem er durch Wunder,

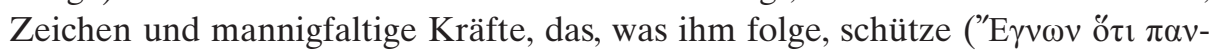

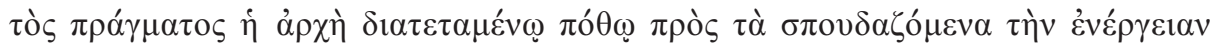

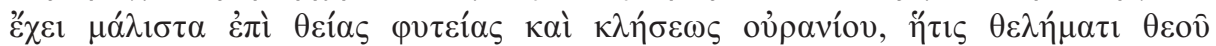

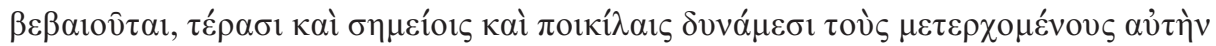

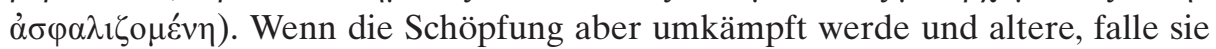
vom Aufstieg ab. Und wenn sie vom Aufstieg abfalle, löse sie sich entweder mit

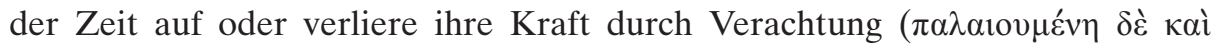




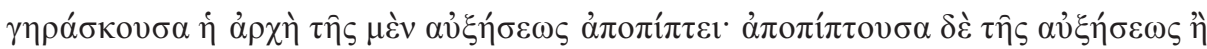

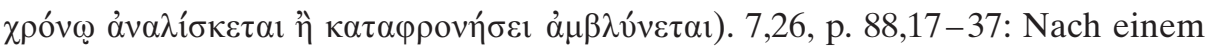
langen Dialog befahl Pachomios der Dämonin, zurückzugehen, woher sie gekommen war, und sich dem Kloster nicht mehr zu nähern. Am nächsten Morgen versammelte er die Brüder und erzählte ihnen, was er vom unglückseligen Dämon gesehen und gehört hatte. Er ließ aber auch in den anderen Klöstern die

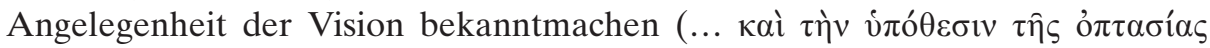

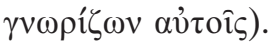

460. PhHi 21,23, Bd. 2, p. 106,3-17: Vater Iakobos erzählte, dass er am Anfang dieser Lebensweise (der asketischen) auf einmal ein gänzlich nacktes Wesen mit dem Aussehen eines Äthiopiers sah, aus dessen Augen Feuer hervorschoss (...

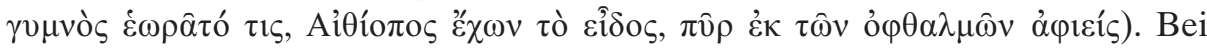
diesem Anblick wurde er von Furcht ergriffen und fing an zu beten. Er konnte aber nichts mehr zu sich nehmen, da der Schwarze immer beim Essen erschien. Nachdem Iakobos zehn Tage lang nichts gegessen und trotzdem die Geduld nicht verloren hatte, kam der Schwarze mit einem Stock, um ihn zu schlagen. Iakobos jedoch verspottete ihn und sagte, er solle dies ruhig tun, wenn er dafür die Erlaubnis vom Herrn bekommen habe. Als der Teufel dies hörte, eilte er

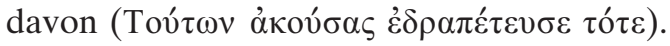

461. PhHi 21,27, Bd. 2, p. 110,22-112,18: In der Zeit, als isaurische Räuberbanden den Osten verwüsteten, fürchtete sich Bruder Iakobos davor, gefangen genommen zu werden. Der Teufel aber nützte diese Angst aus. So hörte Iakobos eines Nachts Geräusche, als ob die Feinde ankommen und die Dörfer nieder-

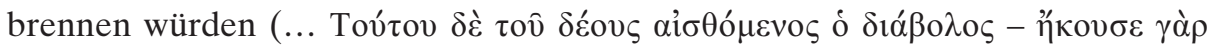

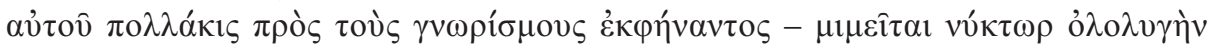

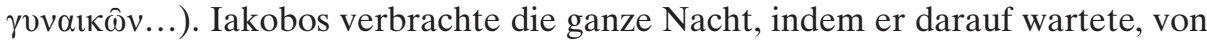
den Räubern ergriffen zu werden. Am nächsten Tag kamen Leute vorbei, die er fragte, ob sie etwas über die Sache der Isaurier gehört hätten. Erst als sie sagten, dass sie nichts dergleichen gehört hatten, verstand Iakobos, dass es sich auch

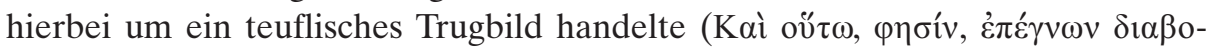

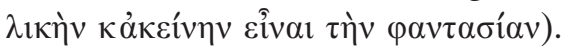

462. PhHi 21,28, Bd. 2, p. 112,19-22: Einmal nahm der Dämon das Äußere eines ungestümen Jünglings an, der mit leuchtendem Gesicht und blonden Haaren geschmückt war und neckisch lächelnd auf Iakobos zuging ('A $\lambda \lambda \mathrm{o} \tau \varepsilon \delta \varepsilon$,

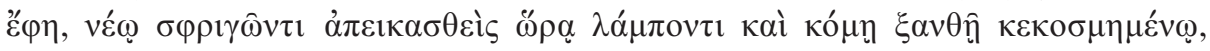

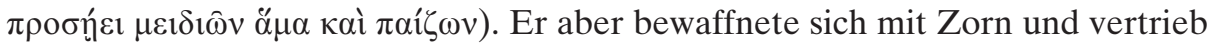
ihn mit Beschimpfungen.

463. ViPo 90,2-6, p. 70,7-22 : Die von einem Dämon besessene Manichäerin Iulia fing in der Gegenwart des Porphyrios ,an zu zittern, ihr Gesicht veränderte sich, und sie verharrte während geraumer Zeit in Ekstase und sprach nicht, sondern starrte stumm und regungslos mit geöffneten Augen auf den

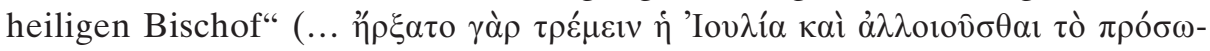




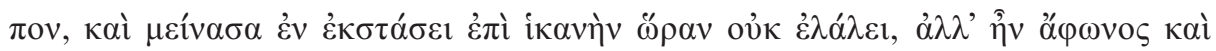

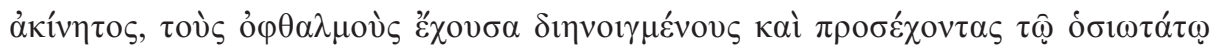
$\dot{\varepsilon} \pi$ $1 \sigma \kappa o ́ \pi \omega)$.

464. PrSp 19, PG 87.3, col. 2865C: Beim Hirten Elias, der in einer Höhle des Jordan wohnte, kam eine schöne Frau vorbei und bat um ein wenig Wasser. Nachdem sie weitergezogen war, gab der Teufel dem Bruder schlechte Ge-

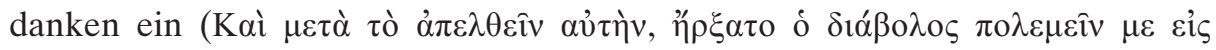

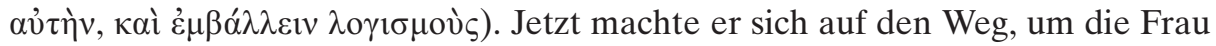

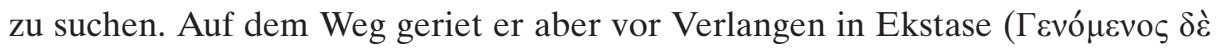

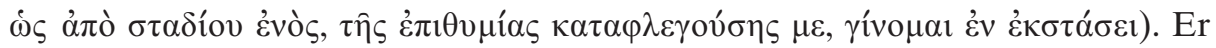

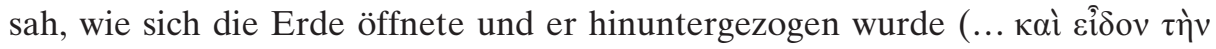

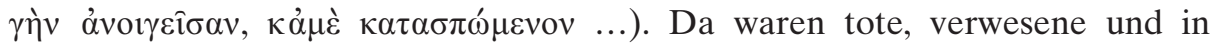
Stücke gerissene Körper, und ein Heiliger sagte: „Sieh, dies ist eine Frau, und dies ist ein Mann. Erfreue dich an so vielen du willst". Schließlich fiel Elias vom Gestank zu Boden. Der Heilige kam und richtete ihn auf.

465. PrSp 45, PG 87.3, col. 2900B: Ein Einsiedler auf dem Ölberg wurde vom Dämon der Unzucht bekämpft. Eines Tages erschien ihm der Dämon auf

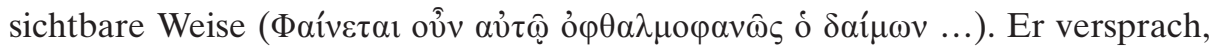
ihn nicht mehr zu bekämpfen, wenn er seine Worte geheimhalte. Dann sagte er ihm, er solle in Zukunft nicht mehr vor der Ikone der theotokos niederknien. Obwohl der Bruder schwor, niemandem etwas davon zu erzählen, fragte er am nächsten Tag Abbas Theodoros um Rat. Dieser belehrte ihn, dass er vom Dämon getäuscht worden sei und unterstützte ihn mit erbauenden Worten. Als der Einsiedler zurück zu seinem Ort kam, erschien ihm der Dämon abermals

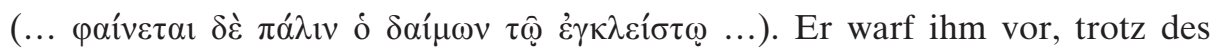
Schwurs seine Worte ausgeplaudert zu haben und Meineid begangen zu haben. Doch der Einsiedler erkannte die List des Dämons und wies ihn mit einer Gegenanklage zurecht.

466. PrSp 55, PG 87.3, col. 2909A-B: „Ein in der Sketis sitzender Wüstenvater sah eines Nachts, wie der Teufel den Brüdern einen Spaten brachte“ (.. r $\gamma \dot{\varepsilon} \rho \omega v$

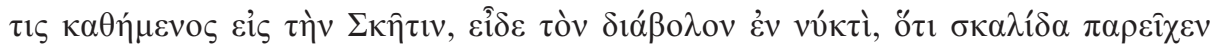

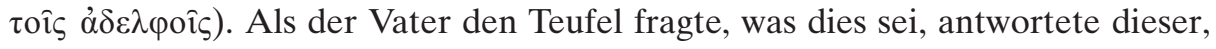
er bringe Zerstreuung für die Brüder und mache sie unaufmerksam für die Verehrung Gottes (s. auch „Klarsicht“).

467. PrSp 63, PG 87.3, col.2916A-B: Über einen Wüstenvater wird erzählt, „dass er in der Zelle saß und las, als der Dämon auf sichtbare Weise zu ihm

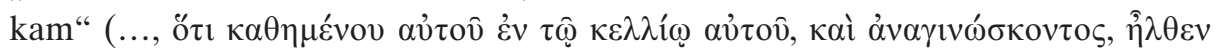
$\pi \alpha ́ \lambda ı v$ o $\delta \alpha i ́ \mu \omega v o ̉ \varphi \theta \alpha \lambda \mu о \varphi \alpha v \hat{\omega} \varsigma)$. Dabei sagte dieser zu ihm, er solle weggehen, da er von hier keinen Nutzen habe. Der Wüstenvater antwortete, wenn er wolle, dass er weiche, dann solle er dafür sorgen, dass der Sessel, auf dem er sitze, herumwandle. Darauf brachte der Dämon nicht nur den Sessel, sondern die 
ganze Zelle in Bewegung. Trotzdem ließ sich der Wüstenvater nicht vertreiben, sondern betete und vertrieb damit den Dämon.

468. PrSp 160, PG 87.3, col. 3028B-C: Ein Asket erzählte, dass er eines Tages in seiner Zelle saß und seine Handarbeit verrichtete, Körbe flocht und Gebete rezitierte, als durch die Tür ein sarazenischer Knabe mit einem Korb kam (...,

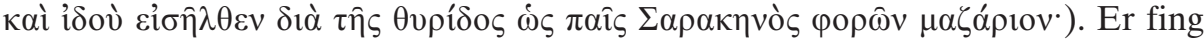
an, vor ihm herumzutanzen und fragte den Vater, ob es ihm gefalle. Da jener nicht antwortete, fragte ihn der Knabe ein zweites mal, ob er gut tanze. Als der Vater wieder nicht antwortete, sagte der Sarazene: „Warum, Vater, glaubst du, dass du gute Arbeit verrichtest? Ich sage dir, das fünfte, sechste und siebte von sechzig Malen wirst du fehlen“. Da stand der Wüstenvater auf und beichtete vor

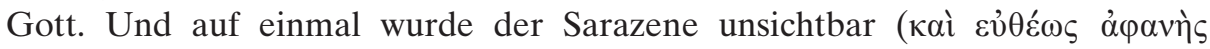

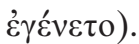

469. ViSa 12, p. 95,6-96,9: Als der heilige Sabas mit 35 Jahren in der Wüste lebte, ein Asketenleben führte und sich in hesychia, Fasten und ständigem Gebet übte, „wurde der Teufel neidisch und dachte sich mancherlei Listen aus, um ihn von seiner Lebenweise wegzubringen. Einmal, als Sabas sich um Mitternacht auf die Binsenmatte legte, verwandelte er sich in Schlangen und

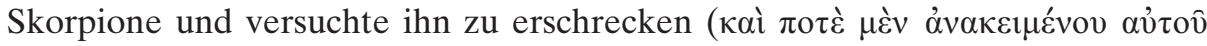

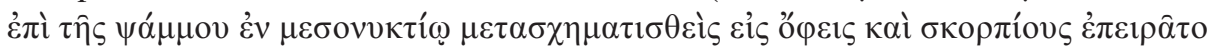

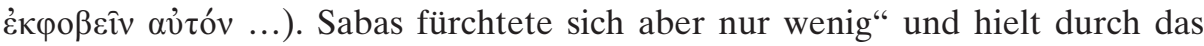
Kreuzeszeichen die Angst von sich. Er stand auf, fasste Mut und sagte, dass Gott ihm die Macht gegeben habe, Schlangen, Skorpione und alle Kraft des Feindes mit Füssen zu treten (Lk 10,19). „Als er dies sagte, verschwanden die giftigen

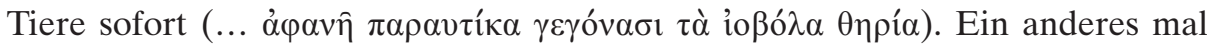
erschien ihm der Satan im Ebenbild eines fürchterlichen und bedrohlichen

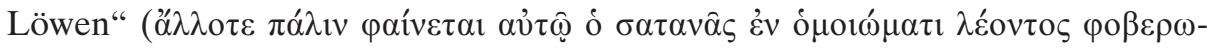

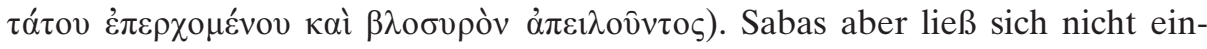
schüchtern und vertrieb den Löwen mit den Worten, dass ihm Gott aufgetragen habe, Schlangen und Basilisken mit Füssen zu treten (Ps 90,13). Als er dies

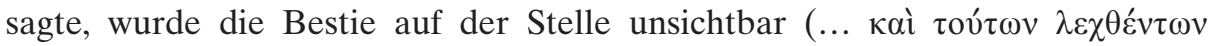

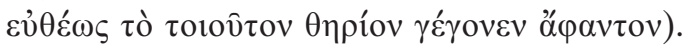

470. ViSa 27, p. 110,22-111,14: Die Dämonen „fingen an, anzuklopfen und Trugbilder zu zeigen, manchmal von Schlangen oder von wilden Tieren. Dann wieder zeigten sie das Ebenbild von Raben, denn sie wollten Sabas durch diese

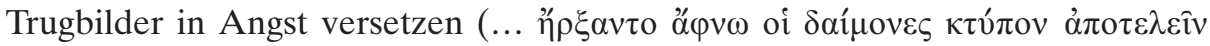

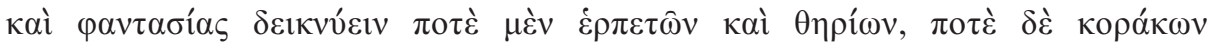

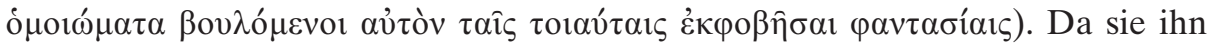
aber nicht vom Gebet abhalten konnten, kamen sie als Menschenstimme" und machten ihm den Vorwurf, er vertreibe sie von ihrem Ort. ,[...] um Mitternacht verließen sie in einer großen Gruppe den Berg und kamen gleich einer Horde

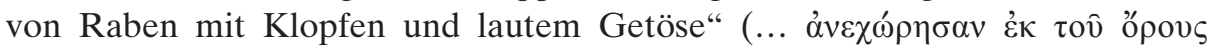




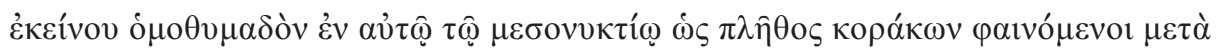

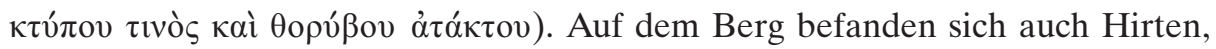
„die das Durcheinander der Raben sahen und die Stimmen hörten. Sie fürchteten sich sehr und sagten zueinander, dass sich wahrscheinlich heilige Männer im kastellion ${ }^{787}$ aufhielten und die dort wohnenden Dämonen vertrieben“. Und tatsächlich fanden sie den Einsiedler und erzählten ihm, was sie in der Nacht

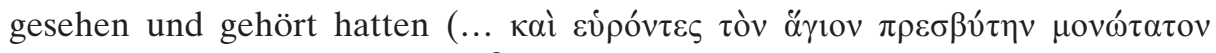

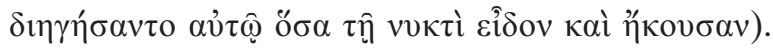

471. ViSySa 1721B-1724A, p. 87,18-88,11: „Als Symeon eines Tages in der

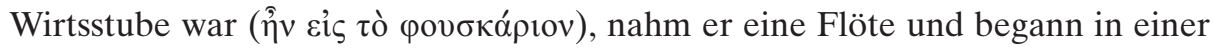
Gasse, wo sich ein unreiner Geist befand, zu spielen. Dabei sprach er das Gebet des großen Nikon, um den Geist von jenem Ort zu vertreiben, denn er quälte viele. Als der Dämon floh, raste er in Gestalt eines Äthiopiers durch die

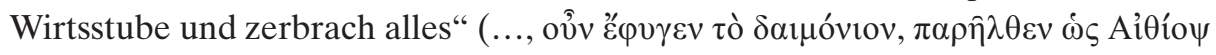

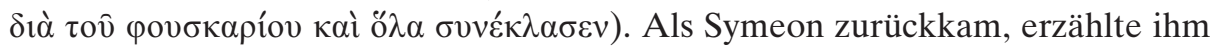
die Wirtin, dass ein verfluchter Schwarzer gekommen sei und alles zerschlagen

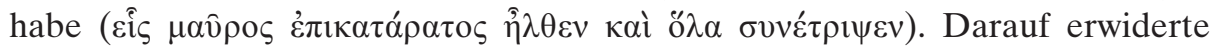
Symeon, dass er den Schwarzen geschickt habe. „Als die Wirtin dies hörte, wollte sie Symeon schlagen. Doch der heilige Mann bewarf sie mit Erde, sodass sich ihre Augen verfinsterten". Dann drohte er ihr, dass der Schwarze nunmehr täglich alles zerbrechen werde, wenn sie nicht seiner Kirche beitreten würden (Sie gehörten nämlich zu den Monophysiten). Darauf machte sich Symeon auf. „[...] doch am nächsten Tag erschien der Schwarze wieder und schlug auf

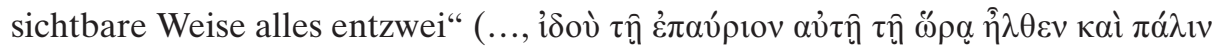

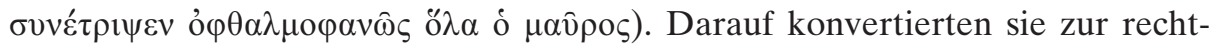
gläubigen Kirche und verehrten Symeon als Diener Gottes.

472. ViSyStII 18,10-21 Bd. 1, p. 15,23-16,6: Symeon ,sah Dämonentruppen neben sich, die Gold, Edelsteine, Perlen und Musikinstrumente bei sich trugen. Als Tochter führten sie die Sünde mit sich, die sich mit den Getäuschten vereinigte. Er sah den Geist der Unzucht, des Vergessens und der Gleichgültigkeit und den Geist der Liebe zum Geld, welcher den Mund aufklaffte, um die Welt zu verschlingen“. Doch Symeon zerschlug die Bilder durch das Zeichen des Kreuzes.

473. ViSyStII 35,1-5, Bd. 1, p. 34,1-5: ,[...], der Satan rüstete sich, um Symeon

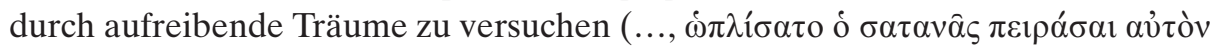

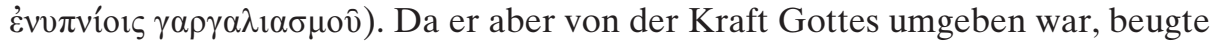
er sich dem Traum nicht. Als er aufwachte, schlug er sich ins Gesicht" und

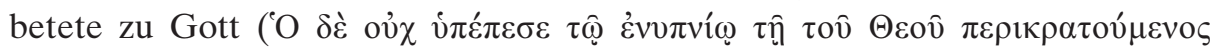

787 Im Nord-Osten der Sabas-Laura gelegen, s. Festugière, Les moines d"' Orient III/2, 37, A. 45 . 


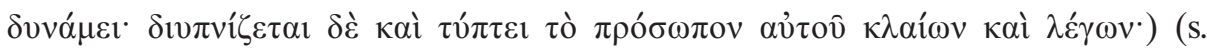
Fortsetzung in 186).

474. ViSyStII 39, Bd.1, p. 37,24-38,24: Der Satan näherte sich Symeon in unterschiedlichen Erscheinungsformen. „Einmal versammelte er eine Truppe von Dämonen, welche die Säule umkreisten, da sie Symeon herunterzerren wollten. Die Gnade Gottes leuchtete aber wie ein Blitz auf und zerstreute sie

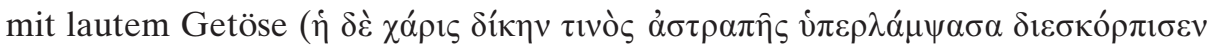

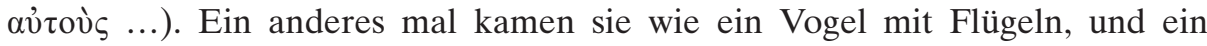
Knabengesicht stürmte gegen sein Haupt. Doch als er sich bekreuzigte, löste es sich in Rauch auf. [...] Die göttliche Gnade erschien nun in Form einer Taube, vernichtete die Gefahr und richtete die Säule wieder gerade“. Doch wiederum erschien der Satan, dieses mal in Form von Schlangen, und schließlich wie ein

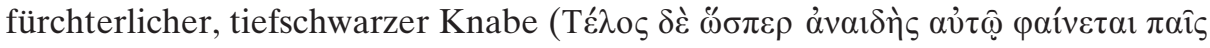
$\mu \varepsilon \dot{\lambda} \alpha_{\varsigma}$ ő $\left.\lambda \circ \varsigma_{,}, \ldots\right)$.

475. ViSyStII 127, Bd. 1, p. 113,25-115,29 Als der Teufel Antiocheia heimsuchte (vgl. 109), ,wurde Symeon im Morgengrauen des Sonntags durch die

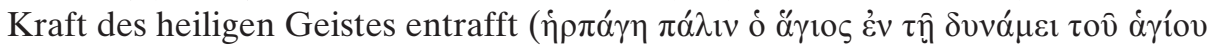
$\pi v \varepsilon v ́ \mu \alpha \tau o \zeta . .$.$) . Er sah sich selbst am Südtor in Richtung Seleukeia stehen,$ während der Teufel einen Angriff auf den bei diesem Tor gelegenen Ort startete. Dann wandte er sich aber von hier ab und machte sich wutentbrannt auf, um die ganze Stadt heimzusuchen, wurde aber von Symeon daran gehindert“. Dieser sagte ihm, es werde so geschehen, wie es Gott gefällt. „Dann entfernte sich der Teufel, um zu sehen, welches Zeichen er bezüglich des Klosters bekommen habe. [...]. Nun wurde ein Teil des Klosters vom Teufel besetzt, der andere von Symeon“. Der Teufel hörte vom Himmel eine Stimme, die ihm vorschrieb, er dürfe nur einen bestimmten Teil des Klosters (der Kassioten) angreifen. Dies alles erzählte Symeon seiner Mutter Martha. Am Sonntag versammelte er die Brüder, und er wurde im Geist verwirrt und sehr betrübt, was er bis zu seinem Tod blieb. Als sie gegessen hatten und sich ausruhten, rief er alle zu sich. Er betete für sie, auf dass sie nicht vom Übeltäter versucht werden. Gerade, als er über ihnen das Kreuz geschlagen hatte, ,wurde er von einer Schau entrafft und

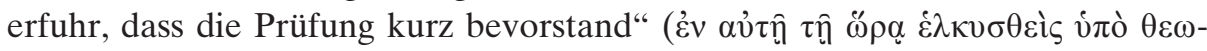

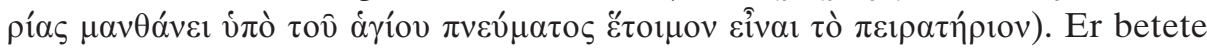
zu Gott, „, und seine Gnade erschien ihm in Form einer Jungfrau, die ihn tröstete und sagte, dass nur ein Gottesfreund fähig sei, den Krieg zu verhindern und zu bannen, was in der Zukunft geschehe“. 128, Bd. 1, p. 116,1-11: Dann wiederum sagte der Teufel in einer Vision zu Symeon, dass er seinen Diener, Bruder Angulas besonders schlimm heimsuche und von ihm nicht ablassen werde (...,

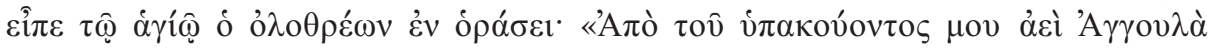

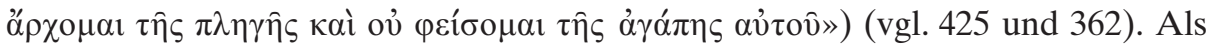
Symeon dies den Brüdern erzählte, erwiderte Angulas: „Pass auf dich selber auf!“ Direkt danach wurde er schrecklich heimgesucht. Alle Brüder wurden 
attackiert und von einer todbringenden Krankheit befallen. Die Unaufmerksamsten unter ihnen starben.

476. ViSyStII 167,1-5, Bd.1, p. 148,29-149,2: „Ein alter Mann, der in den Reben arbeitete, glaubte, dass er von seiner Frau gerufen werde. Da er dachte, sie sei es, drehte er sich um und antwortete, doch da wurde sie unsichtbar

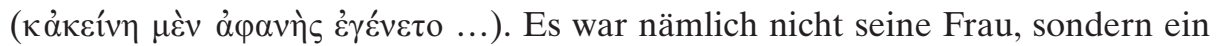
perverser Dämon, der sich über ihn lustig machte“.

477. ViThSy 8,19, p. 7,24-8,8: Als der heilige Georgios Theodoros weckte (vgl. 344) und ihn zu seinem Heiligtum brachte, , war es noch dunkel, sodass der Junge auch die Ränke der Dämonen sehen konnte, die ihm in der Gestalt von

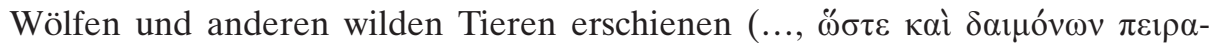

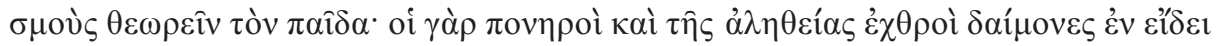

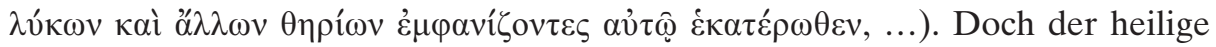
Georgios beschützte ihn und vertrieb die Dämonen mit seinem Schwert, [...]“. 478. ViThSy 11, p. 9,24-10,19: Der Teufel sah die Tugendhaftigkeit des jungen Theodoros und wollte ihn zu Fall bringen. „Er verwandelte sich in einen Mitschüler namens Gerontios und brachte ihn zu den Felsen von Tzidrama (...

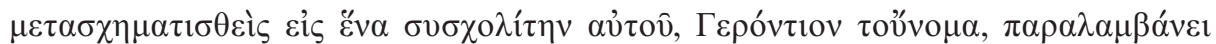

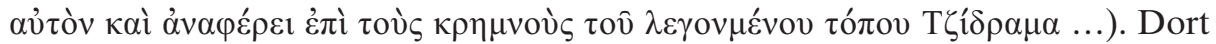
stellte er ihn auf einen hohen Stein" und forderte ihn auf, sich in die Tiefe zu stürzen. Da sich der Knabe fürchtete, freute sich der Teufel darüber, Theodoros endlich überlegen zu sein und sprang hinunter. Doch als der Teufel noch dabei war, den Jungen zum Herunterspringen zu überreden, ,kam der heilige Georgios, nahm Theodoros an der Hand und führte ihn weg. Dabei sagte er ihm: ,Komm, folge mir und höre nicht auf die Versuchung, die nach deiner Seele verlangt. Es ist nämlich nicht Gerontios, sondern der Feind unseres Geschlechts"“.

479. ViThSy 106, p. 84,22-85,14: Der Besitzer eines Gasthauses bat Theodoros, in seiner Herberge einzukehren und das Haus zu segnen. Er war nämlich schon seit langem todkrank, und sein Gesicht war nach hinten verdreht. Als Theodoros ihn fragte, wie das geschehen sei, sagte er, dass er sich eines Tages vor der

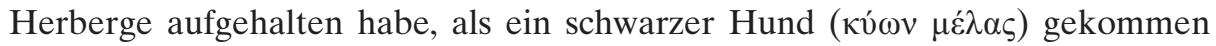
sei, der sich vor ihn hingestellt und gegähnt habe. Da habe auch er auf dieselbe Weise gegähnt, worauf der Hund verschwand. Doch sogleich sei er von einem Fieber ergriffen worden und sein Gesicht habe sich nach hinten verdreht. Seine Pferde seien damals alle gestorben. Nachdem er dies erzählt hatte, heilte Theodoros den Kranken.

480. ViThSy 155, p. 126,3-13: „[...], man zeigte dem Heiligen Theodoros einen Baum, der am Straßenrand stand und an dem nach Sonnenuntergang niemand vorbeigehen konnte. Es schien nämlich ein schwarzer Hund aus ihm hervor-

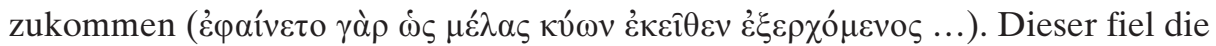
Vorübergehenden an und fügte ihnen Schaden zu. Die Pferde erschreckte er 
und streckte sie nieder. Als Theodoros an der Stelle das Gebet verrichtete und das Kreuz Christi in den Baum ritzte, wiederholte sich der vom Trugbild aus-

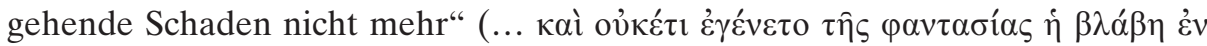
$\alpha \hat{\tau} \tau \hat{)}$.

481. ViThSy 159,40-43, p. 134,28-33: Ein gewisser Theodoros „wurde von einem Dämon ergriffen und lief Tag und Nacht außer sich herum und ergriff ein Stück Holz, um sich damit grundlos zu verletzen. Was auch immer er fand, zerstörte er, und er tat unschickliche und strafbare Dinge, schrie mit lauter

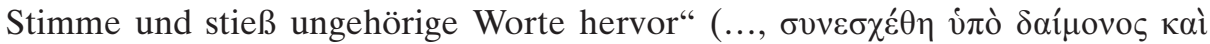

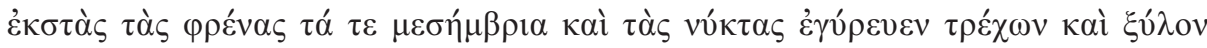

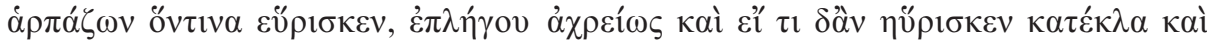

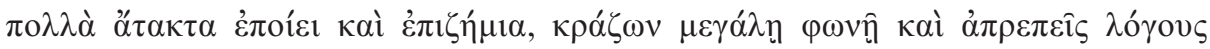

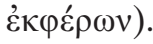




\title{
Siglen und allgemeine Abkürzungen
}

\author{
ABzF Acta Byzantina Fennica \\ AnBoll Analecta Bollandiana \\ ANRW Aufstieg und Niedergang der römischen Welt \\ $\mathrm{AuC} \quad$ Antike und Christentum \\ BaBesch Bulletin antieke Beschaving \\ BGAM Beiträge zur Geschichte des alten Mönchtums und des Benedikti- \\ nerordens \\ BHG Bibliotheca Hagiographica Graeca \\ Bib. Biblica \\ BICS Bulletin of the Institute of Classical Studies \\ BMGS Byzantine and Modern Greek Studies \\ BSGRT Bibliotheca scriptorum Graecorum et Romanorum Teubneriana \\ Byz Byzantion \\ BZ Byzantinische Zeitschrift \\ BZAW Beihefte zur Zeitschrift für die alttestamentliche Wissenschaft \\ DNP Der Neue Pauly \\ Er. Eranos \\ GLCP Graecitas et latinitas christianorum primaeva \\ CSEL Corpus scriptorum ecclesiasticorum latinorum \\ CSHB Corpus scriptorum historiae byzantinae \\ DOP Dumbarton Oaks Papers \\ EnAC Entretiens sur l' antiquité classique \\ GCS Die griechischen christlichen Schriftsteller \\ HKG[J] Handbuch der Kirchengeschichte \\ JAC Jahrbuch für Antike und Christentum \\ JÖB Jahrbuch der Österreichischen Byzantinistik \\ JRS Journal of Roman Studies \\ JudUm Judentum und Umwelt \\ KIG Die Kirche in ihrer Geschichte \\ LCL The Loeb classical library \\ LexMa Lexikon des Mittelalters \\ LThK Lexikon für Theologie und Kirche \\ Mn. Mnemosyne \\ ODB The Oxford Dictionary of Byzantium \\ OCP Orientalia Christiana Periodica \\ OrChrA Orientalia Christiana Analecta
}


PG Patrologia Graeca

PZJ Die Psychologie des 20. Jahrhunderts

RAC Reallexikon für Antike und Christentum

RGG Religion in Geschichte und Gegenwart

RHR Revue de l'histoire des religions

SC Sources chrétiennes

StAns Studia Anselmiana

StH Studia Humaniora

Subs. hag. Subsidia hagiographica

ThWNT Theologisches Wörterbuch zum Neuen Testament

TM Travaux et Mémoires

Tr. Traditio

TRE Theologische Realenzyklopädie

TSMÂO Typologie des sources du Moyen Âge occidental

TU Texte und Untersuchungen zur Geschichte der altchristlichen Literatur. Archiv für die griechisch-christlichen Schriftsteller der ersten drei Jahrhunderte

WO Die Welt des Orients

WSt Wiener Studien

ZAC Zeitschrift für antikes Christentum 


\section{Quellen und Literaturverzeichnis}

\section{Quellen}

Antonios Hagiographikos, Vita Symeon stylitae senioris: Das Leben des heiligen Symeon Stylites, bearbeitet von Hans LiETzmann. Mit einer deutschen Übersetzung der syrischen Lebensbeschreibung und der Briefe von Heinrich Hilgenfeld, Leipzig 1908.

Apophthegmata Patrum: Alphabetische Sammlung, PG 65, col. 71-440.

- M. Jugie, Un apophthegme des pères inédit sur le purgatoire, in: Mémorial Luis Petrt. Mélanges d'histoire et d'archéologie Byzanthines, Bukarest 1948, 245-253.

- Les apophtègmes des Pères, Collection Systématique, t. I-III, Introduction, texte critique, traduction et notes par J.-C. GuY (SC 387/474/498), Paris 1993, 2003 und 2005.

Artemidor von Daldis: Artemidori Daldiani, Onirocriticon Libri V, ed. R. A. Pack (BSGRT), Leipzig 1963.

Athanasios von Alexandreia, Vita Antonii: Athanase d'Alexandrie, Vie d' Antoine, Introduction, texte critique, traduction, notes et index par G. J. M. BARTELINK (SC 400), Paris 1994.

Augustinus, De genesi ad litteram: Sancti Aureli Augustini De genesi ad litteram libri duodecim, ed. I. Zycha, Wien u. a. 1894.

Barlaam und Ioasaph: Die Schriften des Johannes von Damaskos. Historia animae utilis de Barlaam et Ioasaph (spuria), Bd. VI/1: Einführung; Bd. VI/2: Text und zehn Appendices, ed. R. Volk, (Patristische Texte und Studien 60, 61), Berlin u.a. 2006-2009.

Barsanuphios und Johannes: Barsanuphe et Jean de Gaza, Correspondence, t. I-III, ed. F. Neyt, P. De Angelis-Noah, L. Regnault (SC 426, 427, 450, 451), Paris 1997-2001.

Basileios von Kaisarea, Enarratio in prophetam Isaiam, PG 30, col. 118-668.

Cassianus: Cassiani Opera, Collationes XXIIII, ed. M. Petschenig, EditioAltera supplementis aucta curante G. KREUZ (CSEL 13), Wien 2004 (Neudruck der 1. Auflage Wien 1886).

Codex Justinianus: Codex Justinianus, in Corpus juris civilis II, ed. P. Krueger, Hildesheim 1989 (Nachdruck der 1. Auflage Berlin 1954).

De SS. Pachomio et Theodoro: Paralipomena de SS. Pachomio et Theodoro (BHG 1399a), ed. Halkin, Genève 1982, 73 -98 (s. unter Vita Pachomii). Epistula Ammonis Episcopi, de SS. Pachomio et Theodoro (BHG 1397), ed. HalkIn, Genève 1932, 99-115 (s. unter Vita Pachomii).

Euagrios Pontikos, Praktike: Évagre le Pontique, Traité Pratique ou le Moine, 2 Bde, Introduction, traduction, commentaire et tables par A. et C. Guillaumont (SC 170, 171), Paris 1971.

- Gnostikos: Évagre le Pontique, Le Gnostique, éd. A. et C. Guillaumont (SC 356), Paris 1989.

- Ad Monachos: The „ad monachos“ of Evagrius Ponticus, ed. J. Driscoll (StAns 104), Rom 1991. 45-70. 
- De malignis cogitationibus: Évagre le Pontique, Sur les penśees. Édition du texte grec, introduction, traduction, notes et index de P. Géhin, A. et C. Guillaumont, (SC 438), Paris 1998.

- Capitula xxxiii. Per gradus quosdam disposita consequentiae, PG 40, col. 1264 1268.

- Capita cognoscitiva, in: J. Muyldermans (ed.), Evagriana. Extrait de la revue Le Muséon t. 44, augmenté de Nouveaux fragments grecs inédits, Paris 1931, p. 57-68 $(21-32)$.

- De octo spiritibus malititiae, PG 79, col. 1145-1164.

- De oratione, PG 79, col. 1165-1200.

- Dialogus de contemplatione: Un entretien monastique sur la contemplation, Recherches de Science Réligieuse 50 (1962), 230-241.

Euripides, Bakchen: Euripides, Bacchae, Iphigenia at Aulis [u.a.]. Edited and translated by D. Kovacs (LCL 495), Cambridge, Mass. 2002.

Eusebios von Kaisarea, Historia Ecclesiastica: Eusèbe de Césarée, Histoire ecclésiastique II, Livres V-VII. Texte grec, traduction et notes par G. BARDY (SC 41), Paris 1955.

- Vita Constantini: Eusebius Caesariensis, Werke, Band 1, Teil 1: Über das Leben des Kaisers Konstantin, ed. F. Winkelmann (GCS Eusebius 1,1), Berlin, New York ${ }^{2} 1991$.

Eustathios Makrembolites: Eustathius Macrembolites, De Hysmines et Hysminiae Amoribus Libri XI, ed. M. Marcovich (BSGRT), Leipzig 2001.

- Eustathios Makrembolites, Hysmine und Hysminias, eingeleitet, übersetzt und erläutert von K. PlePELITS (Bibliothek der griechischen Literatur 29), Stuttgart 1989.

Gregor von Nyssa, De hominis opificio, PG 44, col. 123-256.

- De vita Moysis: Grégoire de Nysse, La vie de Moïse ou traité de la perfection en matière de vertu. Introduction, texte critique et traduction par J. DANIÉLOU (SC 1), Paris ${ }^{3} 2007$.

- Vita Macrinae: Grégoire de Nysse, La Vie de Sainte Macrine. Introduction, texte critique, traduction, notes et index par P. Maraval (SC 178), Paris 1971.

Heraklit, Fragmenta: Héraclite d'Éphèse, Les vestiges. 3. Les fragments du livre d'Héraclite, B. Les textes pertinents. Extraits des sources (II.A et II.B), établis, traduits et annotés par S. Mouraviev, Sankt Augustin 2006.

Herodot: Hérodote, Histoires, livre I, Clio. Texte établi et traduit par. Ph.-E. Legrand, Paris ${ }^{5} 1970$.

Hesiod: Hesiod, Theogony, ed. M. L. West, Oxford 1966, 111-149.

Historia Monachorum in Aegypto: Historia Monachorum in Aegypto, ed. P. FestUGIÈRE, Bruxelles 1961.

Hippokrates: Oeuvres complètes d'Hippocrate: traduction nouvelle avec le texte grec en regard, accompagnées d'une introduction (...) et de notes philologiques par É. LitTRÉ, vol. VII, Paris 1851.

- De morbo sacro: Ippocrate, La malattia sacra, a cura di A. Roselli, con testo a fronte, Venezia 1996.

Hippolyt von Rom, Traditio Apostolica: Hippolyte de Rome, La tradition apostolique d'après les anciennes versions. Introduction, traduction et notes par B. Botte (SC 11), Paris ${ }^{2} 1968$.

Homer, Odyssee: Homer, Odysse. Griechisch und Deutsch. Übertragen von A. WeIHer, mit Urtext, Anhang und Registern, Einführung von A. Heubeck, Zürich ${ }^{10} 1994$. 
Ioannes Chrysostomos, Commentarius in Acta Apostolorum, PG 60, col. 13-390.

Ioannes Klimakos, Scala Paradisi, PG 88, col. 632-1209.

Ioannes Moschos, Pratum Spirituale, PG 87.3, col. 2851-3112.

Kallinikos, Vita Hypatii: Callinicios, Vie de Hypatios, ed. G. J. M. Bartelink (SC 177), Paris 1971.

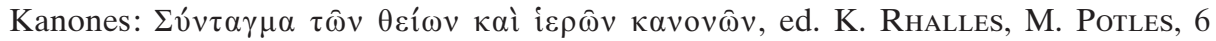
Bde., Athen 1852-1890.

- G. D. MANSI, Sacrorum conciliorum nova et amplissima collectio, Florenz u.a., 1757-1798.

Kyrillos von Skythopolis: Kyrill von Skythopolis, ed. E. SchwarTz (TU 49, 2), Leipzig 1939.

Leges: Corpus Iuris Civilis, Bd.2, Codex Iustinianus. Regognovit et retractavit P. Krueger, Dublin 1967.

- Basilika: Basilicorum Libri LX, Series a volumen VIII, textus libri LX, ediderunt H. J. Scheltema u. a., Groningen 1988.

Leon Diakonos, Historia: Leonis Diaconi Caloënsis Historiae Libri Decem et Liber de Velitatione Bellica Nicephori Augusti, e recensione Benedictii HAsII, addita eiusdem versione atque annotationibus ab ipso recognitis, Bonn 1828, 1-178.

Leontios von Neapolis, Vita Symeonis Stulti, Vita Johannis Aeemosynarii: Léontios de Néapolis, Vie de Syméon le fou et vie de Jean de Chypre, 2 Bde, ed. A. J. FestUGIÈRE et L. RYdÉn (Bibliothèque archéologique et historique 90), Paris 1974.

Markos Diakonos, Vita Porphyrii: Marc le Diacre, vie de Porphyre, ed. H. GréGoIre et M. A. Kruger (Collection Byzantine), Paris 1930.

Miracula S. Artemii: A. Papadopoulos - Kerameus (ed.), Varia graeca sacra, St. Petersburg 1909 (repr. Leipzig 1975), 1-75.

Origenes, Contra Celsum: Origène, Contre Celse, t. 4 (livres VII et VIII), Introduction, texte critique, traduction et notes par M. Borret (SC 150), Paris 1969.

Pachomios, Praecepta: H. BACHT (ed.), Das Vermächtnis des Ursprungs. Studien zum frühen Mönchtum, Bd. 2: Pachomius - Der Mann und sein Werk, Würzburg 1983, $82-225$.

Palladios, Historia Lausiaca: Palladius, The Lausiac History of Palladius. A critical discussion together with notes on early Egyptian monasticism, ed. C. ButLER (Texts and studies 6, 1.2), Hildesheim 1967.

Passio Perpetuae: The passion of S. Perpetua: together with an appendix containing the original Latin text of the Scillitan martyrdom, newly ed. from the mss. with an introduction and notes by J. A. Robinson (Texts and Studies. Contributions to Biblical and Patristic Literature 1.2), Cambridge 1891, 61-95 (repr. Nendeln/ Liechtenstein 1967).

Philon von Alexandreia: Philonis Alexandrini opera quae supersunt, Bde. III, IV und V, ed. P. Wendland, L. Cohn, Berlin 1896 (repr. 1962) und 1902 (repr. 1962).

Philostratos, Vita Apollonii: Philostratus, The Live of Apollonius of Tyana, 2 Bde, with an Engl. translation, ed. F. C. Conybeare (LCL 34), Cambridge u.a. 1912.

Platon, Phaidros: Platon, Werke in acht Bänden, griechisch und deutsch, Bd. 5: Phaidros [u.a.], bearb. von D. KuRz, Darmstadt 1983.

Plotin, Enneaden: Plotini opera, 2 Bde., ed. P. Henry and H.-R. Schwyzer, Leiden u. a. 1951 u. 1959.

Prokopios von Kaisarea, Anekdota: Geheimgeschichte des Kaiserhofs von Byzanz, griechisch-deutsch, ed. O. VEH (Tusculum-Bücherei), Düsseldorf u.a. 2005.

Prokopios von Gaza, Comentarii in Genesim, PG 87,1, col. 129-178.

- Comentarii in Isaïam, PG 87,2, col. 1801-2718. 
Pseudo-Dionysius Aeropagita, De Ecclesiastica Hierarchia: Corpus Dionysacum II: Pseudo-Dionysius Aeropagita, De Coelesti Hierarchia - De Ecclesiastica Hierarchia - De Mystica Theologia - Epistulae, ed. G. HeIL, A. M. RitTer (Patristische Texte und Studien 36), Berlin, New York 1991.

Sophronios von Jerusalem, Miracula der Heiligen Kyrhos und Johannes: Los thaumata de Sofroni: contributión al estudio de la incubatio Christiana por N. Fernandes MARCos, Madrid 1975.

Sozomenos, Historia Ecclesiastica: Sozomène, Histoire Ecclésiastique, 4 bde. Texte grec de l' édition J. Bidez, Introduction par B. Grillet et G. C. Hansen (SC 306, 418, 495, 516), Paris 1983-2008.

Synesios von Kyrene: Sinesio di Cirene, I sogni. Introduzione, traduzione e commento di D. Susanetri (Studi e commenti 10), Bari 1992.

Tertullian, De Anima: Tertulliani, De anima, ed. with introduction and commentary by J. H. Waszink, in: Tertullianus, Opera, Pars II, Opera Montanistica, Turnholt 1954.

Theodoret von Kyrrhos, Philotheos Historia: Théodoret de Cyr, Histoire des Moines de Syrie, t. I-II, Introduction, texte critique, traduction, notes et index par P. CANIVET, A. Leroy-Molinghen (SC 234, 257), Paris 1977 und 1979.

- Historia Ecclesiastica: Theodoret, Kirchengeschichte, ed. L. Parmentier, Dritte, durchgesehene Auflage von G. Ch. Hansen, Berlin 1998.

Theophanes Confessor: Theophanis Chronographia, ed. C. de Boor, Bd.1, Leipzig 1883 und 1885.

Theophanes Continuatus: Theophanes Continuatus, Ioannes Cameniata, Symeon magister, Georgius monachus, ed. I. BeKKer (CSHB 31), Bonn 1838.

Traumbuch des Achmet: Achmetis Oneirocriticon, ed. F. DreXL, Leipzig 1925.

Traumbuch des Patriarchen Germanos, ed. F. DreXL, Laogr. 7 (1923), 433-448.

Traumbuch des Propheten Daniel, ed. F. Drexl, BZ 26 (1926), 290-314.

Traumbuch des Pseudo-Nikephoros, Libro dei sogni, testo critico, introduzione, traduzione e commento a cura di G. GuIdorizzi (KOINSNIA 5), Neapel 1980.

Vita Danielis Stylitae: Les Saints Stylites, ed. H. Delehaye, Bruxelles 1923, (Neudruck 1989), 1-94.

Vita Nicolai Sionitae: Die Vita Nicolai Sionitae: griechischer Text. Übersetzt und kommentiert von H. BLum, Bonn 1997.

Vita Pachomii: Sancti Pachomii, Vitae Greacae, ed. Hagiographi Bollandiani ex recensione F. Halkin (Subs. hag. 19), Bruxelles 1932.

- Le Corpus athénien de saint Pachome, ed. F. Halkin, avec une traduction française par A.-J. Festugière, Genève 1982.

Vita Symeon Stylitae iun. und Vita Marthae: La vie ancienne de S. Syméon Stylite le jeune, t. I: Introduction et texte grec, Bruxelles; t. II: Traduction et Commentaire, Vie grecque de sainte Marthe, mère de S. Syméon, ed. P. VAn den Ven (Subs. hag. 32), Bruxelles 1962 und 1970.

Vita et miracula S. Theclae: Vie et miracles de Sainte Thècle. Texte grec, traduction et commentaire par D. DAGRon (Subs. hag. 62), Bruxelles 1978.

Vita Theodori Syceotae: Vie de Théodore de Sykéôn, t. I: Texte grec, t. II: Traduction, commentaire et appendice, ed. A.-J. Festugière (Subs. hag. 48), Bruxelles 1970. 


\section{Sekundärliteratur}

Abrahamse, D., Introduction, in: Alexander, The byzantine Apocalyptic Tradition, Berkeley u. a. 1985, 1-9.

Alexander, P. J., The Byzantine Apocalyptic Tradition. Edited with an introduction by D. de F. Abrahamse, Berkeley u.a. 1985.

Allen, P., R. Canning, L. Cross (Hg.), Prayer and Spirituality in the Early Church, 3 Bde., Everton Park 1998-2003.

Alt, K., Plotin, Stuttgart 2005.

Anderson, G., Sage, Saint and Sophist. Holy Men and their Associates in the Early Roman Empire, London u. a. 1994.

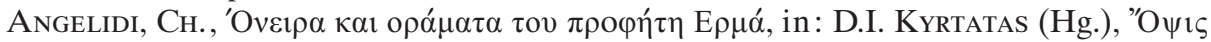

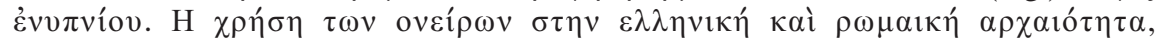
Herakleion 1993, 209-229.

Arbman, E., Ecstasy or Religious Trance. In the Experience of the Ecstatics and from Psychological Point of View, Bd. I: Vision and Ecstasy, Uppsala 1967; Bd. II: Essence and Forms of Ecstasy, Uppsala 1968; Bd. III: Ecstasy and Psychopathological States, Uppsala 1970.

Ariantzi, D., Kindheit in Byzanz. Emotionale, geistige und materielle Entwicklung im familiären Umfeld vom 6. bis zum 11. Jahrhundert, Berlin u. a. 2012.

BAcht, H., Art. Akoimeten, in: LThK 1, Freiburg i. Br. u. a. ${ }^{3} 1957$, Sp. 244-245.

- Ders., „Meditatio“, in den ältesten Mönchsquellen, in: Ders., Das Vermächtnis des Ursprungs I, Würzburg 1972, 244-264.

Baldwin, B., Art. Ephrem the Syrian, in: ODB 1, Oxford 1991, 708-709.

BARTELINK, G. J. M., Quelques observations sur ПАРPHऽIA dans la litterature paleochretienne, GLCP Suppl. 3 (1970), 7-57.

BAun, J., Tales from Another Byzantium. Celestical Journey and Local Community in the Medieval Greek Apocrypha, Cambridge 2007.

Baus K., E. Ewig, Die Reichskirche nach Konstantin dem Grossen. Erster Halbband: Die Kirche von Nikaia bis Chalkedon (HKG[J] 2), Freiburg i. Br. u.a. 1973.

Beatrice, P. F., Ascetical Fasting and Original Sin in the Early Christian Writers, in: Allen u.a., Prayer and Spirituality I (1998), 211-228.

Behr, C. A., Aelius Aristides and the Sacred Tales, Amsterdam 1968.

Benz, E., Die Vision. Erfahrungsformen und Bildwelt, Stuttgart 1969.

Berger, K., Formgeschichte des Neuen Testaments, Heidelberg 1984.

- Ders., Historische Psychologie des Neuen Testaments (Stuttgarter Bibel-Studien 146/147), Stuttgart 1991.

- Ders., Visionsberichte, Formgeschichtliche Bemerkungen über pagane hellenistische Texte und ihre frühchristlichen Analogien, in: Ders. (Hg.), Studien und Texte zur Formgeschichte, Tübingen 1992, 177-233.

- Ders., Darf man an Wunder Glauben?, Stuttgart 1996.

- Ders., Der Wundertäter. Die Wahrheit über Jesus, Freiburg i. Br. 2010.

Betz, O., Art. $\varphi \omega v \eta ́$, in: ThWNT 9, Stuttgart 1973, 272-302 (Unver. Nachdr. der 1933 erschien. Erstauflage).

Biedermann, H. M., Art. Mystik. A. Christentum. II. Ostkirchlicher Bereich, in: LexMa 6, München 1993, Sp. 989-991.

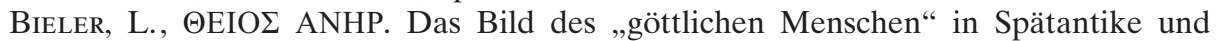
Frühchristentum. Darmstadt 1967 (Unver. Nachdr. der Ausgaben Wien 1935 und 1936). 
Binns, J., Ascetics and Ambassadors of Christ. The Monasteries of Palestine, 314-631, Oxford 1994.

BJÖRcK, G., ONAP I $\triangle$ EIN. De la perception de rêve chez les anciens, Er. 44 (1946), 306-314.

Blum, G. G., Byzantinische Mystik. Ihre Praxis und Theologie vom 7. Jahrhundert bis zum Beginn der Turkokratie, ihre Fortdauer in der Neuzeit, Berlin 2009.

Bolton, W. F., Parable, Allegorie and Romance in the Legend of Barlaam and Josaphat, Tr. 14 (1958), 359-66.

Bourguignon, E., Religion, Altered State of Consciousness, and Social change, Columbus 1973.

Bovon, F., These Christians Who Dream: The Authority of Dreams in the First Centuries of Christianity, in: Ders. (Hg.), Studies in Early Christianity, Tübingen 2003, 144-162.

Brakke, D., Demons and the Making of the Monk. Spiritual Combat in Early Christianity, Cambridge, Massachusetts u. a. 2006.

Braet, H., Rêve, réalité, écriture. Du référentiel à la sui-référence, in: T. Gregory (Hg.), I sogni nel medioevo, Seminario Internazionale Roma, 2-4 ottobre 1983 (Lessico Intellettuale Europeo 35), Rom 1985, 11-23.

Brandes, W., Apokalyptische Literatur, in: F. Winkelmann, W. Brandes (Hg.), Quellen zur Geschichte des frühen Byzanz (4.-9. Jahrhundert). Bestand und Probleme, Amsterdam 1990, 305-322.

- Ders., Anastasios ó díkopos. Endzeiterwartung und Kaiserkritik in Byzanz um 500 n. Chr., BZ 90 (1997), 24-63.

- Ders., Liudprand von Cremona (Legatio cap. 39-41) und eine bisher unbeachtete west-östliche Korrespondenz über die Bedeutung des Jahres 1000 a. D., BZ 93 (2000), 435-463.

- Ders., Endzeiterwartung im Jahre 1009 a.D.?, in: T. Pratsch (Hg.), Konflikt und Bewältigung. Die Zerstörung der Grabeskirche zu Jerusalem im Jahre 1009, Berlin u. a. 2011, 301-320.

Bravo García, A., La interpretación de los sueños en Bizancio, Erytheya 5 (1984), 63 82.

- Ders., Fisiología y filosofia en Aristóteles: el problema de los sueños, Cuadernos de Filología (Colegio Universitario de Ciudad Real) 4 (1985), 15-65.

- Ders., Sueño y ensueño en la literatura ascético-mística del siglo IV: Evagrio Póntico, in: M. Morfakidis (Hg.), La religion en el mundo griego: de la antigüedad a la Grecia moderna, Granada 1997, 183-193.

Brown, P., The Rise and Function of the Holy Man in Late Antiquity, JRS 61 (1971), 80-101.

- Ders., Society and the holy in late antiquity, New York 1982.

- Ders., Die Keuschheit der Engel. Sexuelle Entsagung, Askese und Körperlichkeit im frühen Christentum, München 1991 [Originaltitel: The body and society. Men, woman and sexual renunciation in early Christianity, New York 1988].

- Ders.: Die Gesellschaft und das Übernatürliche, Berlin 1993.

- Ders.: Autorität und Heiligkeit. Aspekte der Christianisierung des römischen Reiches, Stuttgart 1998 [Originaltitel: Authority and the Sacred. Aspects of the Christianisation of the Roman world, Cambridge u.a. 1995].

Brown Tkacz, C., Art. Prophet book, in: ODB 3, Oxford 1991, 1736-1737.

Browning, R., The ,Low Level' Saint's Life in the Early Byzantine World, in: S. Hackel (Hg.), The Byzantine Saint, University of Birmingham Fourteenth Spring 
Symposium of Byzantine Studies (Studies supplementary to Sobornost 5), London 1981, 117-127.

Calofonos, G., Dream Interpretation: A Byzantinist Superstition?, BMGS 9 (1984/ 85), 215-220.

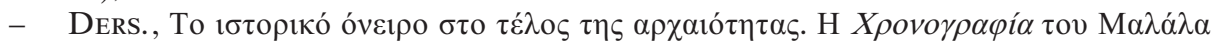

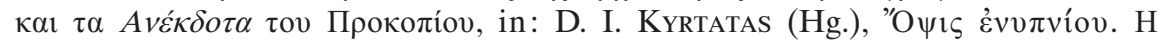

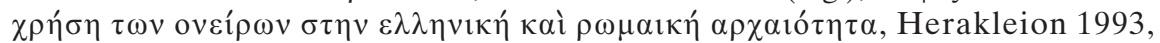
$283-322$.

Cameron, Al., Oracles and Earthquakes. A Note on the Theodosian Sibyl, in: C. Sode, S. A. TAKács (Hg.), Novum Millenium. Studies on Byzantine History and Culture Dedicated to Paul Speck, Aldershot 2001, 45-52.

Cameron, Av., Christianity and the Rhetoric of Empire. The Development of Christian Discourse (Sather Classical Lectures 55), Berkeley u.a. 1991.

- Dies., On defining the holy man, in: J. Howard-Johnston, P. A. Hayward (Hg.), The Cult of Saints in Late Antiquity and the Middle Ages. Essays on the Contribution of Peter Brown, Oxford 1999, 27-43.

Canivet, P., Le Monachisme syrien selon Théodoret de Cyr, Paris 1977.

Chadwick, H., Pachomios and the Idea of Sanctity, in: S. Hackel (Hg.), The Byzantine Saint, University of Birmingham Fourteenth Spring Symposium of Byzantine Studies (Studies supplementary to Sobornost 5), London 1981, 11-24.

Chitty, D. J., The Desert A City. An Introduction to the Study of Egyptian and Palestinian Monasticism under the Christian Empire, Oxford 1966.

Ciccarese, M. P., La genesi letteraria della visione dell'aldila: Gregorio Magno e le sue fonti, in: Sogni, Visioni e Profezie nell'antico cristianesimo, Roma, 5-7 Maggio 1987 (Aug. 29), Rom 1989, 435-449.

Clark, E. A., ,Spiritual Reading“: The Profit and Peril of Figurative Exegesis in Early Christian Asceticism, in: Allen u.a., Prayer and Spirituality I (1998), 251-274.

Colpe, C., Art. Himmelfahrt, in: RAC 15, Stuttgart 1991, 212-219.

- Ders., Archetyp und Prototyp. Zur Klärung des Verhältnisses zwischen Tiefenpsychologie und Geschichtswissenschaft, in: J. Assmann, (Hg.), Die Erfindung des inneren Menschen. Studien zur religiösen Anthropologie (Studien zum Verstehen fremder Religionen 6), Gütersloh 1993, 51-73.

- Ders., P. Habermehl, Art. Jenseitsreise, in: RAC 17, Stuttgart 1996, 490-543.

- Ders., E. Dassmann, J. Engemann, P. Habermehl, Art. Jenseitsfahrt I (Himmelfahrt), in: RAC 17, Stuttgart 1996, 407-466.

Consolino, F. E., Sogni e visioni nell' agiografia tardoantica: modelli e variazioni sul tema, in: Sogni, Visioni e Profezie nell'antico cristianesimo, Roma, 5-7 Maggio 1987 (Aug. 29), Rom 1989, 238-256.

Cox Miller, P., Dreams in Late Antiquity, Princeton 1994.

- Dies., The Poetry of Thought in Late Antiquity. Essays in Imagination and Religion, Aldershot u.a. 2001.

- Dies., The Corporeal Imagination. Signifying the Holy in Late Ancient Christianity, Philadelphia 2009.

Coyle, J. K, Early Monks, Prayer, and the Devil, in: Allen u. a., Prayer and Spirituality I (1998), 229-249.

- Ders., What Was „Prayer“ for Early Christians?, in: Allen u.a., Prayer and Spirituality II (1999), 25-41.

Csepregi, I., The miracles of saints Cosmas and Damian: characteristics of dream healing, Annual of Medieval Studies 8 (2002), 89-137. 
Cupane, C., Metamorphosen des Eros. Liebesdarstellung und Liebesdiskurs in der byzantinischen Literatur der Komnenenzeit, in: P. Agapitos, D. R. ReInsch (Hg.), Der Roman im Byzanz der Komnenenzeit, Referate des Internationalen Symposiums an der Freien Universität Berlin, 3. bis 6. April 1998 (Meletemata 8), Frankfurt 2000, 25-54.

Dagron, G., Idées byzantines, 2 Bde., Paris 2012.

- Ders., Quand la terre tremble ..., in: Ders., Idées byzantines I (2012), 3-22.

- Ders., L'hagiographie en question. Le saint, le savant, l'astrologue à travers les recueils de „Questions et réponses“ (Ve-VIIe s.) (Version remaniée de: Le saint, le savant, l'astrologue. Étude de thèmes hagiographiques à travers quelques recueils de Questions et Réponses des Ve-VIIe siècles, dans Hagiographie, cultures et Sociétés $\left[4^{\mathrm{e}}-12^{\mathrm{e}}\right.$ Siècles], Paris 1981, 143-156), in: Ders., Idées byzantines I (2012), 53-78.

- Ders., G., Le culte des images dans le monde byzantin, in: J. Delumeau (Hg.), Histoire vécue du peuple chrétien, Toulouse 1979, 133-160.

- Ders., Rêver de Dieu et parler de soi: le rêve et son interprétation d'après les sources byzantines, in: T. Gregory (Hg.), I sogni nel medioevo, Seminario Internazionale Roma, 2-4 ottobre 1983 (Lessico Intellettuale Europeo 35), Rom 1985, $37-55$.

DaniÉlou, J., Platonisme et théologie mystique: Doctrine spirituelle de Saint Grégoire de Nysse, Paris 1944.

Davis, S. T., The Cult of Saint Thecla: A Tradition of Women's Piety in Late Antiquity, Oxford 1995.

Dean-Otting, M., Heavenly Journeys. A Study of the Motif in Hellenistic Jewish Literature (JudUm 8), Frankfurt 1984.

Del Corno, D. (Hg.), Graecorum de re onirocritica scriptorum reliquiae, Mailand 1969.

- Ders., I sogni e la loro interpretazione dell' età dell' imperio, in: ANRW 16.2 (1978), 1605-1618.

- Ders., Dreams and their Interpretation in Ancient Greece, BICS 29 (1982), 55-62.

Delehaye, H., Les saints Stylites, Bruxelles 1923.

Delierneux, N., L'exploitation des topoi hagiographiques: du cliché figé à la réalité codée, Byz 70 (2000), 57-90.

Deubner, L., Kosmas und Damian. Texte und Einleitung, Leipzig u.a. 1907.

Dickie, M. W., Magic and Magicians in the Graeco-Roman World, London u. a. 2001.

Dihle, A., Art. Demut, in: RAC 3, Stuttgart 1957, 738-778.

Dinzelbacher, P., Die Jenseitsbrücke im Mittelalter, Wien 1973.

- Ders., Vision und Visionsliteratur im Mittelalter, Stuttgart 1981.

- Ders., Körperliche und seelische Vorbedingungen religiöser Träume und Visionen, in: T. Gregory, (Hg.), I sogni nel medioevo, Seminario Internazionale Roma, 2-4 ottobre 1983 (Lessico Intellettuale Europeo 35), Rom 1985, 57-86.

- Ders., Mittelalterliche Vision und moderne Sterbeforschung, in: J. KüHNEL, H.-D. Mück (Hg.) u.a., Psychologie in der Mediävistik, Gesammelte Beiträge des Steinheimer Symposions (1985), Göppingen 1985, 9-49.

- Ders., Mittelalterliche Visionsliteratur. Eine Anthologie, Darmstadt 1989.

- Ders., Revelationes (TSMÂO 57), Turnhout 1991.

- Ders., Nova visionaria et eschatologia, Mediaevistik 6 (1993), 45-84.

- Ders., Himmel, Hölle, Heilige. Visionen und Kunst im Mittelalter, Darmstadt 2002.

- Ders., Art. Mystik. A. Christentum. I. Westliches Mittelalter, in: LexMa 6, München 1993, Sp. 982-988. 
- Ders., Art., Visio(n), -sliteratur. A. I. Allgemein, in: LexMa 8, München 1997, Sp. $1734 \mathrm{f}$.

Dodds, E. R., The Greeks and the Irrational, Berkeley u.a. 1951.

- Ders., Pagan and Christian in an Age of Anxiety, Cambridge 1965.

Dodel, F., Das Sitzen der Wüstenväter: eine Untersuchung anhand der Apophthegmata Patrum (Paradosis 42), Freiburg 1997.

Dölger, F. J., Der Einfluß des Origenes auf die Beurteilung der Epilepsie und Mondsucht im christlichen Altertum, AuC 4 (1934), 95-109.

- Ders., Die Sonne der Gerechtigkeit und der Schwarze. Eine religionsgeschichtliche Studie zum Taufgelöbnis (Liturgische Forschungen 2), Münster 1918.

Draguet, M. R., Les Pères du Désert, Paris 1949.

Dronke, P., Imagination in the Late Pagan and Early Christian World. The First Nine Centuries A.D. (Millennio Medievale 42), Florenz 2003.

Duffy, J., Byzantine Medicine in the sixth and seventh centuries, DOP 38 (1984), 21 27.

Dummer, J., Zum Reflex des Bilderstreites in der byzantinischen Hagiographie, in: J. Irmscher, J., Der byzantinische Bilderstreit. Sozialökonomische Voraussetzungen, ideologische Grundlagen, geschichtliche Wirkungen, Leipzig 1980, 91-103.

- Ders., Griechische Hagiographie, in: F. Winkelmann, W. Brandes (Hg.), Quellen zur Geschichte des frühen Byzanz (4. -9. Jahrhundert). Bestand und Probleme, Amsterdam 1990, 284-296.

Edelstein, E. J., L., Asclepius, A Collection and Interpretation of the Testimonies, 2 Bde., Baltimore 1945.

Efthymiadis, S., V. Déroche, Greek Hagiography in Late Antiquity (Fourth-Seventh Centuries), in: Ders. (Hg.), The Ashgate Research Companion to Byzantine Hagiography, I: Periods and Places, Farnham u. a. 2011, 35-94.

- Ders., Hagiography from the 'Dark Age' to the Age of Symeon Metaphrastes (Eigth-Tenth Centuries), in: Ders. (Hg.), The Ashgate Research Companion to Byzantine Hagiography, I: Periods and Places, Farnham u. a. 2011, 95-142.

EhrLich, E. L., Der Traum im Alten Testament (BZAW 73), Berlin 1953.

Festugiere, A.-J., Lieux communs littéraires et thèmes de folk-lore dans l'Hagiographie primitive, WSt 73 (1960), 123-152.

- Ders., A.-J., Les moines d'Orient I-IV, Paris 1961.

Flusin, B., Miracle et histoire dans l'oeuvre de Cyrille de Scythopolis, Paris 1983.

FögEN, M. T., Die Enteignung der Wahrsager. Studien zum kaiserlichen Wissensmonopol in der Spätantike, Frankfurt 1993.

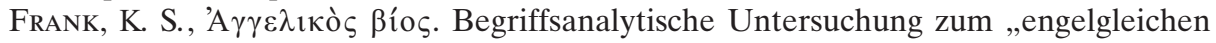
Leben“ im frühen Mönchtum (BGAM 26), Frankfurt 1964.

Frenschkowski, M., Traum und Traumdeutung im Matthäusevangelium, JAC 41 (1998), 5-47.

- Ders., C. Morgenthaler, Art. Traum, in: TRE 34, Berlin u.a. 2002, 28-50.

Gascou, J., Les origines du culte des saints Cyr et Jean, AnBoll 125 (2007), 241-284.

Gaston, R. W., Attention and Decorum in Early Christian Prayer, in: Allen u.a., Prayer and Spirituality I (1998), 81-96.

Gerok-Reiter, A., Einleitung: Zwischen den Welten, in: A. Gerok-Reiter, C. Walde (Hg.), Traum und Vision in der Vormoderne. Traditionen, Diskussionen, Perspektiven, Berlin 2012, 7-17.

Goodman, F. D., Trance. Der uralte Weg zum religiösen Erleben. Rituelle Körperhaltungen und ekstatische Erlebnisse, 1992. 
- Dies., Ekstase, Besessenheit, Dämonen. Die geheimnisvolle Seite der Religion. Gütersloh 1991 [Originaltitel: How about Demons? Bloomington 1988].

- Dies., Die andere Wirklichkeit: Über das Religiöse in den Kulturen der Welt, München 1994 [Originaltitel: Ecstasy, Ritual, and Alternate Reality. Religion in a Pluralistic World, Bloomington u.a. 1988].

Gould, G., The Desert Fathers on Monastic Community, Oxford 1993.

Grabar, A., Martyrium. Recherches sur le culte des reliques et l'art chrétien antique. Iconographie, Bd. II, Paris 1946.

Graf, F., Heiligtum und Ritual. Das Beispiel der griechisch-römischen Asklepieia, in: Le sanctuaire grec (EnAC 37), Genf-Vandoeuvres 1992, 159-199.

- Ders., Art. Ekstase, in: DNP, Stuttgart u. a. 1997, 950-952.

Guidorizzi, G., L'interpretazione dei sogni nel mondo tardoantico: oralità e scrittura, in: T. Gregory (Hg.), I sogni nel medioevo, Seminario Internazionale Roma, 2-4 ottobre 1983 (Lessico Intellettuale Europeo 35), Rom 1985, 149-170.

- Ders., La letteratura dell' irrazionale, in: G. Cambiano, D. Lanza (Hg.), Lo spazzio letterario della grecia Antica II, La ricezione e l'attualizzazione del testo, Rom 1995, 591-627.

Guillaumont, A., C. Guillaumont, Art. Démon: III. Dans la plus ancienne littérature monastique, in: Dictionnaire de spiritualité ascétique et mystique: Doctrine et histoire 3, Paris 1957, 189-212.

- Ders., Un philosophe au désert: Evagre le Pontique, RHR 181 (1972), 29-56.

- Ders., La vision de l'intellect par lui-même dans la mystique évagrienne, Melanges de l'Université Saint-Joseph L (vol. I-II), Beyrouth 1984, 255-262 (Nachdr. in: Études sur la spiritualité de l'Orient chrétien [Spiritualité Orientale 66], Abbaye de Bellefontaine 1996, 144-150).

Habermehl, P., Perpetua und der Ägypter oder Bilder des Bösen im frühen afrikanischen Christentum. Ein Versuch zur Passio Perpetuae et Felicitatis (TU 140), Berlin ${ }^{2} 1992$.

HäGG, T., The life of St. Antony between Biography and Hagiography, in: S. EFTHYMIADIS (Hg.), The Ashgate Research Companion to Byzantine Hagiography, I: Periods and Places, Farnham u. a. 2011, 18-34.

Hahn, I., Traumdeutung und gesellschaftliche Wirklichkeit: Artemidorus Daldiensis als sozialgeschichtliche Quelle (Xenia 27), Konstanz 1992.

Halfwassen, J., Plotin und der Neuplatonismus, München 2004.

Hammerstaedt, J., Geister im Zeugenstand. Die früheste lateinische Dämonologie in Tertullians Apologeticum, in: H.-J. HoRn (Hg.), Jakobs Traum. Zur Bedeutung der Zwischenwelt in der Tradition des Platonismus (Itinera Classica 1), St. Katherinen 2002, 25-41.

Hanson, J. S., Dreams and Visions in the Graeco-Roman World and Early Christianity, in: ANRW II 23.2 (1980), 1395-1427.

Harmless, W., Desert Christians: An Introduction to the Literature of Early Monasticism, Oxford u. a. 2004.

Hartmann, G., Selbstsigmatisierung und Charisma christlicher Heiliger der Spätantike, (Studien und Texte zu Antike und Christentum 38), Tübingen 2006.

Hausherr, I., Penthos. La doctrine de componction dans l'Orient Chrétien, (OrChrA 132), Rom 1944.

- Ders., L'Hésychasme. Étude de spiritualité, OCP 22 (1956), 5-40, 247-285.

Hehl, E.-D., Politische Träume und Visionen im Mittelalter, in: A. GeroK-Reiter, C. Walde (Hg.), Traum und Vision in der Vormoderne. Traditionen, Diskussionen, Perspektiven, Berlin 2012, 197-215. 
Heinemann, K., Die Ärzteheiligen Kosmas und Damian, Medizinhistorisches Journal 9 (1974), 255-317.

Hevelone-Harper, J., Disciples of the Desert: Monks, Laity, and Spiritual Authority in Sixth-Century Gaza, Baltimore 2005.

Hiestand, R. (Hg.), Traum und Träumen. Inhalt, Darstellung, Funktion einer Lebenserfahrung in Mittelalter und Renaissance (StH 24), Düsseldorf 1994.

Hinterberger, M., Autobiographische Traditionen in Byzanz (Wiener Byzantinistische Studien 22), Wien 1999.

Hoffman, K., Zur Aktualität der Besessenheit, in: Goodman, Ekstase (1997), 9-19.

Hoheisel, K., Art. Vision/Visionsbericht, in: RGG ${ }^{4}$ 8, Tübingen 2005, Sp. 1126 f.

Holl, K., Der Anteil der Styliten am Aufkommen der Bilderverehrung, in: Ders., Gesammelte Aufsätze zur Kirchengeschichte II, Der Osten, Tübingen 1928, 388 398.

Horn, J., Art. Esnē, in: LThK 3, Freiburg i. Br. u. a. ${ }^{3} 1995$, Sp. 883 f.

Hunger, H., Prooimion. Elemente der byzantinischen Kaiseridee in den Arengen der Urkunden (Wiener Byzantinische Studien 1), Wien 1964.

Irmscher, J., A. Kazhdan, A. Cutler, Art. Visions, in: ODB 3, Oxford 1991, 2179 f.

Ivanov, S. A., Holy Fools in Byzantium and Beyond, Oxford 2006.

Johanek, P., Die Wahrheit der mittelalterlichen Historiographen, in: F. P. Knapp, M. Niesner (Hg.), Historisches und fiktionales Erzählen im Mittelalter, Berlin 2002, $9-26$.

Johnson, S. F., The life and Miracles of Thekla, Cambridge Mass. u.a. 2006.

Kablitz, A., Art. Allegorische Interpretation, in: Metzler Lexikon Literatur- und Kulturtheorie, Stuttgart ${ }^{2} 2001,8-10$.

Kapelle, van De, R. P., Prophets and Mantics. A Response to E. R. Dodds, in: R. E. Smith, J. Lounibos (Hg.), Pagan and Christian Anxiety, Lanham u. a. 1984, 87-111.

Kazhdan, A., Art. Anargyroi, in: ODB 1, Oxford 1991, 85.

- Ders., A. Cutler, Art. Ecstasy, in: ODB 1, Oxford 1991, 675.

- Ders. u. a., Art. Dionysios the Aeropagite, Pseudo-, in: ODB 1, Oxford 1991, 629 f.

- Ders. u.a., Art. Gregory of Nyssa, in: ODB 2, Oxford 1991, 882.

- Ders., Holy and Unholy Miracle Workers, in: H. Maguire (Hg.), Byzantine Magic, Dumbarton Oaks 1995, 73-82.

- Ders., A History of Byzantine Literature (650-850), in Collaboration with L. F. Sherry, C. Angelidi, Athen 1999.

Kelsey, M. T., Trance, Ekstase und Dämonen, München 1994 [Originaltitel: How about Demons?, Bloomington 1988].

Klitenic Wear, S., u.a., Dionysius the Areopagite and the Neoplatonist Tradition, Aldershot 2007.

Kessels, A. H. M., Ancient Systems of Dream-classification, Mn. 22 (1969), 389-424.

- Ders., Studies on the Dream in Greek Literature, Utrecht 1978.

Kitzinger, E., The Cult of the Images in the Age before Iconoclasm, DOP 8 (1954), $83-150$.

Konstantinovsky, J., Evagrius Ponticus. The Making of a Gnostic, Farnham 2009.

Kreuzer, A., Art. Visio, in: Historisches Wörterbuch der Philosophie 11, Darmstadt 2001, Sp. $1068-1071$.

KRÖNUNG, B., Ekstasen und andere Formen von Visionserfahrungen in der frühbyzantinischen monastischen Literatur, in: A. Gerok-Reiter, C. Walde (Hg.), Traum und Vision in der Vormoderne. Traditionen, Diskussionen, Perspektiven, Berlin 2012, 65-90. 
Krovoza, A., Die Stellung Freuds zur Vorgeschichte der Traumdeutung. Nachwort, in: WALDE, Antike Traumdeutung und moderne Traumforschung (2001), 223-233.

Kunz, C. E., Schweigen und Geist. Biblische und patristische Studien zu einer Spiritualität des Schweigens, Freiburg i. Br. u. a. 1996.

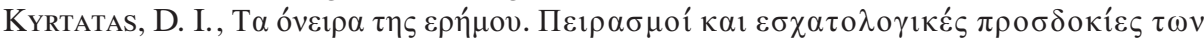

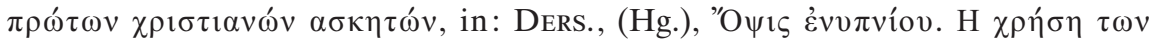

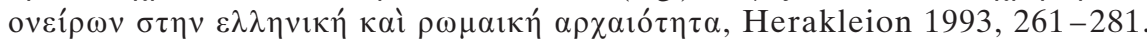

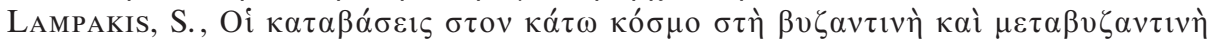

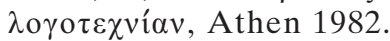

LANZONI, F., Il sogno presago della madre incinta nella letteratura medievale e antica, AnBoll 45 (1927), 225-261.

Latacz, J., Die Lesersteuerung durch Träume. Der Traum der Penelope im 19. Gesang der Odyssee, in: H. Froning u.a. (Hg.), Kotinos, Festschrift für E. Simon, Mainz 1992, 76-87.

Lauer, H., Art. Schlaf, in: LexMa 7, München 1995, Sp. 1470-1472.

Le Goff, J., Le christianisme et les rêves ( $\mathrm{II}^{\mathrm{e}}-\mathrm{VII}^{\mathrm{e}}$ siècles), in: T. Gregory, (Hg.), I sogni nel medioevo, Seminario Internazionale Roma, 2-4 ottobre 1983 (Lessico Intellettuale Europeo 35), Rom 1985, 171-218.

LewIS, I. M., Art. Ekstase, in: RGG ${ }^{4}$ 2, Tübingen 2005, Sp. 1186-1188.

Lesky, E., J. H. Waszink, Art. Epilepsie, in: RAC 5, Stuttgart 1962, 819-831.

LiEnHARD, B., Vom arabischen Buch Bilawhar wa- Būdāsf zum byzantinischen Barlaam und Ioasaph. Textumformungen am Beispiel der Sämannsparabel, in: G. CARbonaro, E. Creazzo (Hg.) u.a., Medioevo romanzo e orientale. Macrotesti fra Oriente e Occidente, IV Colloquio Internazionale, Vico Equense, 26-29 ottobre 2000, Soveria Mannelli 2003, 495-507.

Lifshitz, F., Beyond Positivism and Genre: „Hagiographical“ Texts as historical narrative, Viator 25 (1994), 96-113.

Lorenz, R., Das vierte Jahrhundert, Der Osten (KIG 1, Lfg C, 2), Göttingen 1992.

LuCK, G., Magie und andere Geheimlehren in der Antike (KTA 489), Stuttgart 1990.

LutzKa, C., Die Kleinen Horen des byzantinischen Stundengebetes und ihre geschichtliche Entwicklung, Berlin ${ }^{2} 2010$.

MacAlister, S., Dreams and Suicides. The Greek Novel from Antiquity to the Byzantine Empire. The Novel, the Dream and Suicide in the interim Period, New York 1996.

Magdalino, P., The History of the Future and its Uses: Prophecy, Policy and Propaganda, in: R. Beaton, C. Rouché (Hg.), The Making of Byzantine History. Studies Dedicated to Donald M. Nicol, Aldershot 1993, 3-43.

- Ders., Une prophétie inédite des environs de l'an 965 attribuée à Léon le Philosophe (Ms. Karakallou 14, f. 253 -254 ), TM 14 (2002), 391-402.

- Ders., The Year 1000 in Byzantium, in: P. Magdalino (Hg.), Byzantium in the Year 1000, Leiden-Boston 2003, 233-270.

- Ders., The End of Time in Byzantium, in: Brandes u.a. (Hg.), Endzeiten. Eschatologie in den monotheistischen Weltreligionen, Berlin u.a. 2008, 119-133.

Maguire, H., A. Kazhdan, Byzantine Hagiographical Texts as Sources on Art, DOP 45 (1991), 1-22.

- Ders., Magic and the Christian Image, in: Ders. (Hg.), Byzantine Magic, Dumbarton Oaks 1995, 51-71.

Mainberger, G. K., Art. Imagination, in: PZJ 15, Zürich 1979, 25 -43.

MaKris, G., Zur Epilepsie in Byzanz, BZ 88 (1995), 363-404. 
Maltese, E. V., Il Libro di Sindbad. Novelle persiane medievali dalla versione bizantina di Michele Andreopoulos, Turin 1993.

- Ders., Dimensione bizantine. Donne angeli e demoni nel Medioevo greco, Turin 1995, 49-92. 139-156.

Manuwald, B., Traum und Traumdeutung in der griechischen Antike, in: R. Hiestand (Hg.), Traum und Träumen. Inhalt, Darstellung, Funktion einer Lebenserfahrung in Mittelalter und Renaissance (StH 24), Düsseldorf 1994, 15-42.

Mavroudi, M., A Byzantine Book on Dream Interpretation. The Oneirocriticon of Achmet and Its Arabic Sources (The Medieval Mediterranean 36), Leiden u.a. 2002.

McGuckin, J. A., The Prayer of the Heart in Patristic and Early Byzantine Tradition, in: Prayer and Spirituality II (1999), 69-108.

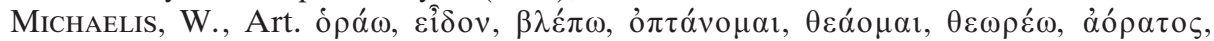

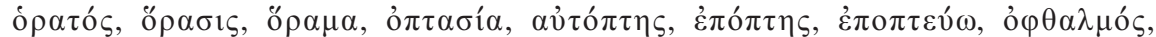

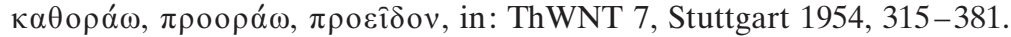

Michl, J., Art. Engel IV (christliche), in: RAC 5, Stuttgart 1962, 109-200.

Müller, A., Die Vita des Sinaiten von Daniel von Raithu. Ein Beitrag zur byzantinischen Hagiographie, BZ 95/2 (2002), 585-601.

Müller, B., Der Weg des Weinens. Die Tradition des „Penthos“ in den Apophthegmata Patrum (FKDG 77), Göttingen 2000.

Müller, C. D. G., Von Teufel, Mittagsdämon und Amuletten, JAC 17 (1974), 91-102.

Mullet, M., Dancing with Deconstructionists in the Gardens of the Muses: New Literary History vs?, Byzantine and Modern Greek Studies 14 (1990), 258-275.

- Dies., The Madness of Genre, DOP 46 (1992), 233-243.

NäF, B., Traum und Traumdeutung im Altertum, Darmstadt 2004.

Oberhelman, S. M., The Oneirocriticon of Achmet. A Medieval Greek and Arabic Treatise on the Interpretation of Dreams, Texas 1991.

- Ders., Dreambooks in Byzantium. Six Oneirocritica in translation, with commentary and introduction, Aldershot 2008.

Overwien, O., Neues zu den Quellen der Vita Antonii des Athanasius, Millenium 3 (2006), 159-184.

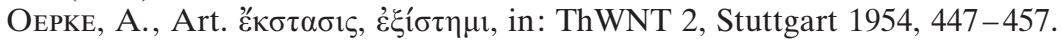

- Ders., Art. ővap, in: ThWNT 7, Stuttgart 1954, 220-238.

Patlagean, É, Sainteté et pouvoir, in: S. Hackel (Hg.), The Byzantine Saint, University of Birmingham Fourteenth Spring Symposium of Byzantine Studies (Studies supplementary to Sobornost 5), London 1981, 88-105.

PeIL, D., Art. Allegorie, in: Metzler Lexikon Literatur- und Kulturtheorie, Stuttgart ${ }^{2} 2001,8$.

Pfister, F., Art. Ekstase, RAC 4, Stuttgart 1959, $944-987$.

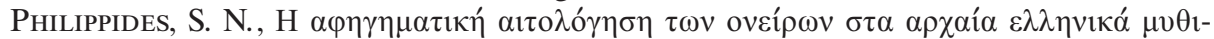

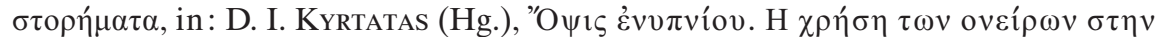

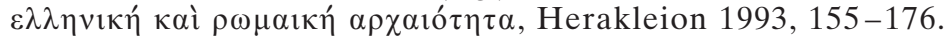

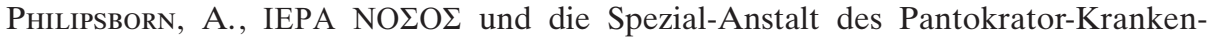
hauses, Byz 33 (1963), 223-230.

Podkalsky, G., Byzantinische Reichseschatologie. Die Periodisierung der Weltgeschichte in den vier Grossreichen (Daniel 2 und 7) und dem tausendjährigen Friedensreiche (Apok. 20). Eine Motivgeschichtliche Untersuchung, München 1972. 
Pratsch, T., Exploring the Jungle - Hagiographical Literature between Fact and Fiction, in: A. Cameron (Hg.), Fifty Years of Prosopography (Proceedings of the British Academy 118), London 2003, 59-72.

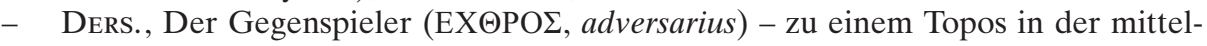
byzantinischen Heiligenliteratur, ABzF N. S. (2003-2004), 72-89.

- Ders., Der hagiographische Topos. Griechische Heiligenviten in mittelbyzantinischer Zeit, Berlin u. a. 2005.

- Ders., „... erwachte und war geheilt“ - Inkubationsdarstellungen in byzantinischen Heiligenviten, ZAC (im Druck).

RAPP C., „For next to God, you are my salvation“. Reflections on the Rise of the Holy Man in Late Antiquity, in: J. Howard-Johnston, P. A. Hayward (Hg.), The Cult of Saints in Late Antiquity and the Middle Ages. Essays on the Contribution of Peter Brown, Oxford 1999, 63-81.

- Dies., Holy Bishops in Late Antiquity: The Nature of Christian Leadership in an Age of Transition, Berkeley u.a. 2005.

- Dies., The Origins of hagiography and the literature of early monasticism: purpose and genre between tradition and innovation, in: Ch. Kelly, R. Flower, M. S. Williams (Hg.), Unclassical Traditions. Volume I: Alternatives to the classical past in Late Antiquity, Cambridge 2010, 119-130.

Refoulé, F., Rêves et vie spirituelle d'après Evagre le Pontique, in: Supplément de la vie spirituelle 59 (1961), 470-516.

Reinsch, D. R., Autor und Leser in frühbyzantinischen hagiographischen Texten und historiographischen Werken, in: 18. International Congress of Byzantine Studies. Major Papers, Moskau 1991, 400-414.

Rousseau, P., Pachomius. The Making of a Community in Fourth-Century Egypt, Berkeley u.a. 1985.

- Ders., Ascetics as mediators and as teachers, in: J. Howard-Johnston, P. A. Hayward (Hg.), The Cult of Saints in Late Antiquity and the Middle Ages. Essays on the Contribution of Peter Brown, Oxford 1999, 45-62.

Rubenson, R., Anthony and Pythagoras: A Reappraisal of the Appropriation of Classical Biography in Athanasius' Vita Antonii, in: D. Brakke, A.-C. Jacobsen, J. Ulrich (Hg.), Beyond Reception - Mutual Influences between Antique Religion, Judaism, and Early Christianity, Frankfurt 2006, 191-208.

- Ders., The Transformation of the Ascetic in Early Egyptian Monasticism, in: T. K. Seim, J. ØKland (Hg.), Metamorphoses. Resurrection, Body and Transformative Practices in Early Christianity (Ekstasis. Religious Experience from Antiquity to the Middle Ages 1), Berlin u. a. 2009, 271-289.

Scarborough, J., Art. Insanity, in: ODB 2, Oxford 1991, 998.

Scharfetter, C., Allgemeine Psychopathologie. Eine Einführung, Stuttgart u. a. ${ }^{5} 2002$.

Schiffer, E., Art. Hagiographie, in: Historisches Wörterbuch der Rhetorik 3, Tübingen 1996, 1277-1280.

- DiEs., Zur Bewertung des Schweigens in byzantinisch-monastischer Tradition, JÖB 52 (2002), 1-22.

Schimmel, A., Art. Ekstase, in: RGG 2, Tübingen 1958, 410-412.

- Dies., Mystische Dimensionen des Islam: Die Geschichte des Sufismus, Köln ${ }^{2} 1992$.

- Dies., Sufismus. Eine Einführung in die islamische Mystik, München 2000.

Schröder, H. O., Publius Aelius Aristides. Heilige Berichte. Einleitung, deutsche Übersetzung und Kommentar, Heidelberg 1986. 
Schulz, G., J. ZIEMER, Mit Wüstenvätern und Wüstenmüttern im Gespräch, Göttingen 2010.

Seprälä, S., In speechless Ecstasy. Expression and Interpretation of Mystical Experience in Classical Syriac and Sufi Literature, Helsinki 2003.

Ševčenko, I., Hagiography of the Iconoclast Period, in: A. Bryer, Herrin J. (Hg.), Iconoclasm, Birmingham 1977, 113-131.

Severus, E., Art. Gebet I, RAC 8, Stuttgart 1972, 1134-1258.

SöDER, Rosa, Die apokryphen Apostelgeschichten und die romanhafte Literatur der Antike, Stuttgart 1932.

SPECK, P., Weitere Überlegungen und Untersuchungen über die Ursprünge der byzantinischen Renaissance, in: Varia II (ПOIKI^A BYZANTINA 6), Bonn 1987, $255-283$.

- Ders., Byzantium: cultural suicide?, in: L. Brubacker (Hg.), Byzantium in the ninth century: dead or alive?, Papers from the Thirtieth Spring Symposium of Byzantine Studies, Birmingham, March 1996 (Society for the Promotion of Byzantine Studies 5), Aldershot u. a. 1998, 74-84.

SpeYer, W., Zum Bild des Apollonios von Tyana bei Heiden und Christen, JAC 17 (1974), 47-63.

- Ders., Der christliche Heilige der Spätantike. Wesen, Bedeutung, Leitbild, in: J. Dummer, M. Vielberg (Hg.), Leitbilder in der Diskussion (Altertumswissenschaftliches Kolloquium 3), Stuttgart 2001, 79-92.

Stathakopoulos, D., Rain Miracles in Late Antiquity. An Essay in Typology, JÖB 52 (2002), 73-87.

Stichel, R., Studien zum Verhältnis von Text und Bild spät- und nachbyzantinischer Vergänglichkeitsdarstellungen (Byzantina Vindobonensia 5), Wien u.a. 1971.

van Straten, F. T., Diakrates' Dream. A Votive Relief from Kos, and Some Other kat' onar Dedications, BaBesch 15 (1976), 1-38.

Strathmann, H., P. Keseling, Art. Askese II (christlich), in: RAC 1, Stuttgart 1950, $749-795$.

Strobl, P., Die Macht des Schlafes in der griechisch-römischen Welt (Studien zur Geschichtsforschung des Altertums 11), Hamburg 2002.

TAFT, R. F., Art. Vigil ( $\pi \alpha v v v \chi i ́ \varsigma, \pi \alpha \rho \alpha \mu o v \eta ́, ~ \alpha ُ \gamma \rho v \pi v i ́ \alpha)$, in: ODB 3, Oxford 1991, 2166.

Talbot, A.-M., R. F. Taft, Art. Akoimetoi, Monastery of, in: ODB 1, Oxford 1991, 46.

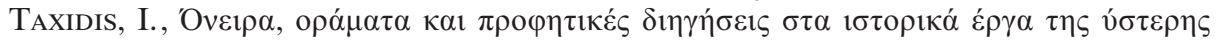

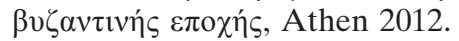

Temkin, O., The falling sickness. A history of epilepsy from the Greeks to the beginnings of modern neurology, Baltimore ${ }^{2} 1994$.

Timotin, A., Visions, prophéties et pouvoir à Byzance. Étude sur l'hagiographie mésobyzantine (IX-XI siècles), Paris 2010.

TworuschKa, U., Sucher, Pilger, Himmelsstürmer. Reisen im Diesseits und Jenseits, Stuttgart 1991.

Uthemann, K.-H., Art. Mysticism, in: ODB 2, Oxford 1991, 1431.

Van Uytfanghe, M., Art., Heiligenverehrung II (Hagiographie), in: RAC 14 Stuttgart 1988, 150-183.

- Ders., Art. Biographie II (spirituelle). C Christlich, in: RAC Supplement I, Stuttgart 2001, 1153-1336.

- Ders., La biographie classique et hagiographie chrétienne, Hagiographica 12 (2005), 223-248.

Vinagre, M. A., Die griechische Terminologie der Traumdeutung, Mn. 49 (1996), 257 282. 
Vincent-Bernardi, A.-M., La didascalie onirique. Ambivalence du rêve, dans l'Antiquité tardive et l'empire byzantin, in: G. Filoramo ( $\mathrm{Hg}$.), Maestro e discepolo. Temi e problemi della direzione spirituale tra VI secolo a.C. e VII secolo d.C., Brescia 2002, 127-139.

VIRT, G., Art. Wachsamkeit, in: LThK 10, Freiburg i. Br. u. a. ${ }^{3} 1965$, Sp. 916.

Volk, R., Die Schriften des Johannes von Damaskos, Bd. VI/1: Historia animae utilis de Barlaam et Joasaph (spuria). Einführung, Berlin u.a. 2009.

VölKer, W., Kontemplation und Ekstase bei Pseudo-Dionysius Areopagita, Wiesbaden 1958.

Vollmann, K., Erlaubte Fiktionalität: Die Heiligenlegende, in: F. P. KnapP, M. Niesner (Hg.), Historisches und fiktionales Erzählen im Mittelalter, Berlin 2002, $63-72$.

Vööвus, A., History of Asceticism in the Syrian Orient. A contribution to the History of Culture in the near East. I. The Origin of Ascetism. Early Monasticism in Persia, II. Early Monasticism in Mesopotamia and Syria, III. A Contribution to the History of Culture In the Near East, Louvain 1958-1988.

WaChT, M., Art. Inkubation, in: RAC 18, Stuttgart 1998, 179-265.

Walde, C., Art. Traum, in: Metzler Lexikon Religion, Stuttgart u. a. 2000, 530-532.

- Dies., Die Traumdarstellungen in der griechisch- römischen Dichtung. München u. a. 2001.

- Dies., Antike Traumdeutung und moderne Traumforschung, Zürich 2001.

- Dies., Traum und Traumdeutung in der griechisch-römischen Antike oder vom Zwang, Träume zu deuten, in: A. GeroK-Reiter, C. Walde (Hg.), Traum und Vision in der Vormoderne. Traditionen, Diskussionen, Perspektiven, Berlin 2012, $65-$ 90.

Weber, G., Herrscher und Traum in hellenistischer Zeit, Archiv für Kulturgeschichte 81 (1999), 1-33.

- Ders., Kaiser, Träume und Visionen in Prinzipat und Spätantike (Historia, Einzelschriften 243), Stuttgart 2000.

- Ders., Träume in der römischen Kaiserzeit. Normalität, Exzeptionalität und Signifikanz, in: K. Brodersen (Hg.), Gebet und Fluch, Zeichen und Traum. Aspekte religiöser Kommunikation in der Antike (Antike Kultur und Geschichte 1), Münster 2001, 89-109.

Weinstock, F., De somniorum visionumque in amatoriis graecorum fabulis vi atque usu, Eos 35 (1934), 29-72.

Welte, F. M., Art. Trance (-techniken), in: Metzler Lexikon Religion 3, Stuttgart u.a., 2000, 521-525.

Wikenhauser, A., Doppelträume, Bib. 29 (1948), 100-111.

Wissmann, H., Art. Ekstase, in: TRE 9, Berlin u.a. 1982, 488-491.

WitTmer- Butsch, M. E., Zur Bedeutung von Schlaf und Traum im Mittelalter (Medium aevum quotidianum 1), Krems 1990.

WöHrle, G., Hypnos, der Allbezwinger (Palingenesia 53), Stuttgart 1995.

Zeller, D., Geburtsankündigung und Geburtsverkündigung. Formgeschichtliche Untersuchung im Blick auf Mt $1 \mathrm{f}, \mathrm{Lk} 1 \mathrm{f}$., in: K. Berger (Hg.), Studien und Texte zur Formgeschichte, Tübingen 1992, 59-134.

ZGoll, A., Die Welt im Schlaf sehen - Inkubation von Träumen im antiken Mesopotamien, WO 32 (2002), 74-101. 


\section{Namens- und Ortsindex}

Aelius Aristides 30 A 111, 97 A. 469 Agapet, Papst (535-536) 218 (194), 285 f. (355)

Agapetos, Mönchsbruder des Sabas 199 (141)

Agathon, ägyptischer Wüstenvater 81, 223 (209)

Ägypten 60, 157 f. (8), 175 (82), 183 (100), 194 (124)

Aitherios (Metropolit von Ephesos) 117 A, 573, 278 (335)

Akalissos (Lykien) 290 (363 [3])

Alexandreia 162 (30), 228 f. (221, 222), 271 f. (319), 295 f. (377), 296 f. (378), 327 (454)

Alamundaros (sarazenischer philarchos) 275 f. (331)

Amantios (kubikularios) 182 (97)

Amantios (Befehlshaber) $188(113$ [1])

Ammianus Marcellinus (Geschichtsschreiber) 138 A. 673 u. 674

Ammonas (Wüstenvater) 5, 24, 78, 152, 277 (332)

Ammonos (pachomianischer Mönch) 198 f. (139)

Amun (ägyptischer Wüstenvater) 223 (207), 325 (449)

Anastasios, Kaiser (491-518) 312 (417)

Anastasios I., Patriarch von Jerusalem (458-478) (staurophylax) 174 (77), 195 (131)

Anastasios I., Patriarch von Antiocheia (559-570) 190 (117)

Anastasios (Schatzmeister der Grabeskirche) $300(386)$

Anastasios von Skythopolis (kanonarchos) 182 f. (99)

Anastasiskirche (Jerusalem) 83, 130, 279 (338), 300 f. (386, 387), 303 (392)

Anastasiupolis (Galatia) 192 (120)
Angulas (Mönch, Architekt) 289 (362 [4]), 315 (425), 334 f. (475)

Ankyra (Galatia) $192(120,122)$

Annisa (Pontos) $231 \mathrm{f}$. (229)

Antiocheia 32, 33, 184 f. $(106,107)$, 186 f. (109), 188 (113[1]), 190 (117), 209 f. (171), 250 (268), 269 (315), 280 f. (341), 334 f. (475)

Antiochos (Wüstenvater) 192 (121), 202 (153)

Antiochos (junger Mönch) $265 \mathrm{f}$. (310)

Antonios der Große (Asket, heiliger Mann) 5, 20, 23, 24, 45, 54, 64 81, 83, 84 f., 89, 106, 117, 118, 127, 131, 132 A. 643,157 f. $(8,9), 168$ (60), 172 (71), 194 (124), 223 (207, 208), 247 f. (241), 240 (249), 277 (332), 283 (347), 305 f. (400), 319 f. (430)

Antonios Hagiographikos (Autor) 12, 108-112, $233 \mathrm{f}$. (234)

Antonios (georgischer Mönch) $130 \mathrm{f} ., 278 \mathrm{f} .(337,338)$

Aphrodisios (palästinischer Wüstenvater) 147,199 (142)

Apollo (Wüstenvater) 21, 161 (27), 204 f. (159), 240 f. (250), 321 (433)

Apollonios von Tyana 1 A. 2, 2 A. 3, 106, 134

Arabia (Provinz) 246f. (261)

Arethas (philarchos) 275 f. (331)

Arkadios (Kaisersohn) 126

Arsenios (Wüstenvater) 24, 125, 126, 147, 158 (13), 195 (130), 220 (197), 293 f. (373)

Arsinos (Junge) 255 (282)

Artemas (Mönchsbruder des Nikolaos Sionites) 311 (412)

Artemios (arianischer $d u x$ ) $\quad 65,311 \mathrm{f}$. (414)

Artemidor von Daldis 97 A. 469, 101, 121, 122, 125, 144 A. 705, 152

Asia, Provinz 278 (335) 
Askalon (Palästina) 278 (335)

Aspebetos (Beduinenfürst, philarchos) 135, $246 \mathrm{f}$. (261)

Athanasios von Alexandreia (Autor, Bischof) 11, 64, 81, 83, 84 A. 396, 92 A. 446, 108-112, 271 f. (319), $311 \mathrm{f} .(414)$

Athanasios (Anachoret) 209 (170)

Augustinus 4, 47, 123, 151

Ausonios (pachomianischer Mönch) 198 f. (139)

Azarias (staurophylax) 300 f. (387)

Babylas (Erblindeter) $261(301)$

Barnabas (Anachoret) 218 (193)

Barsanuphios und Ioannes (heilige Männer) $7,11,24,39,53,62,73$, $100,102,106,115,120,159(16,18)$, 169 f. (62-64), 173 (74), 225 (213), 322 f. $(439-443)$

Basileios I., Kaiser (867-886) 42 A. 174,129 A. 635

Basileios von Kaisarea (Kirchenvater) 88

Basilina (Diakonissin) $220 \mathrm{f}$. (201)

Bis(s)arion (Wüstenvater) 158 (14), 283 (346)

Bitalios (heiliger Mann) 162 (30), 327 (454)

Cassianus, Johannes (Wüstenvater, Autor) 74

Cassius Dio (Geschichtsschreiber) 138 A. 675

Charandrama (syrisches Dorf) 257 (290)

Chorebitos (Einsiedler) 166 (52),

Chosroes I., persischer Großkönig (531-578/79) 184 (106), $275 \mathrm{f}$. (331)

Christophoros (Anachoret) $208 \mathrm{f}$. (169)

Chrysippos (Mönch, staurophylax) 174 (76, 77), 217 (190)

Clemens von Alexandreia 24 A. 70, 148

Daniel Stylites (heiliger Mann) 40, 41, 50, 79, 102, 132, $144 \mathrm{f} ., 173 \mathrm{f}$.
(75), 204 (157, 158), $226(214,215)$, 267 (311), 277 (333), 323 f. (444)

David (Dieb) 264 f. (308)

Didymos der Blinde (Autor) 226 (217)

Diokletian, Kaiser (284-305)

121 A. 598

Dionysia (Mutter des Euthymios) 32, $267 \mathrm{f}$. (312)

Dionysios Aeropagites 2 A. 3, 5 A. 12,76

Dioskoros (Wüstenvater) 58

Dometianos (Mönchsbruder des Euthymios) 217 (190), 226 (216)

Dominos III., Patriarch von Antiocheia (546-561) 190 (117)

Elephantos (Syrien) 231 (228)

Eleutheropolis (Palästina) 135, 249 (264)

Elias (Abt) 306 (401)

Elias (Asket) 80, 249 f. (265)

Elias (Hirtenasket) 331 (464)

Elias (Vater des Daniel Stylites) 267 (311)

Elpidia (Großmutter des Theodoros von Sykeon) 234 f. (236)

Emesa 314 f. (422, 423)

Ephraim der Syrer (Autor) $128 \mathrm{f}$., $203(154,155)$

Ephraimios (komes) 222 (205)

Epiphanios (Vater des Nikolaos Sionites) $177(89)$

Epiphanios (Diakon) 260 (299)

Euagrios Pontikos (Asket, Autor) 5 A. $12,7,10,11$ f., 13, 27, 50, 5559, 61 f., 63, 77 A. 353, 80 f., 89, 102 A. 506, 105, 114 A. 554, 118, 151, 152, 307 f. (405)

Euagrios Scholastikos (Kirchenhistoriker) $286(356)$

Eudokia, Augusta (400-404) 174 (79), $182(97,98)$

Eudoxios (Onkel des Euthymios) $267 \mathrm{f}$. (312)

Eulogios I., Patriarch von Alexandreia (581-607) 291 (368), 301 f. (389)

Euphemios, Patriarch von Konstantinopel (489-495) 312 (417) 
Euripides 87

Eusebios von Kaisarea (Kirchenvater) $\quad 42$ A. 174, 88

Eustathios Makrembolites (Autor) 116 A. 567

Euthymios der Große (heiliger Mann) 31, 32, 33 A. 129, 44 f., 73, 84 A. $396,128,131,132$ A. 643 , 135, 147 f., 174 f. (76-80), 195 f. (129-133), 212 (179), 217 (190, 191), 226 (216), 229 (223), 246-249 (261-264), 267 f. (312), 283 f. (349)

Gabemer (dux von Palästina) $300 \mathrm{f}$. (387)

Gabriel (Mönch) 217 (190)

Gaianos (Schauspieler) 312 (418)

Galatien 191 (119)

Galen (Arzt) 54, 59 A. 252, 61

Gaza 134, 135, 164 (41), $182(97,98)$, 207 f. (166), 309 (407)

Genarus (fromme Christin) $213 \mathrm{f}$. (182)

Georgios (Mönch) 23, 182 f. (99)

Georgios (Wüstenvater) 285 (354)

Gerasimos (heiliger Mann) 229 (223)

Germanos (patrikios) 300 (386)

Gerontios (Mönch) 278 (336)

Gregor von Nyssa (Autor, Kirchenvater) 5 A. 12, 11, 42, 52 A. 222, 54, 76, 100 A. 495, 105, 106, 129 A. 635,140 f., 148,231 f. (229)

Heliupolis 312 (418)

Helles (Wüstenvater) 28, 272 (320), 284 (350)

Herakleion (Kreta) 287 (359)

Heraklit 98 A. 487

Herodot 98 A. 487,129 A. 635,142

Hesiod 68 A. 308

Hierapolis (Syrien) 250 (267)

Hippokrates (Arzt, Autor) 54, 59, 92

Homer 52, 67 A. 302, 100 A. 495, 101

Honorios (Kaisersohn) 126

Hypatios (heiliger Mann) 23, 26, 37, $38,52,82,119,131,132$ A. 643,134 , 136, 161 (28), 175 f. (85-87), 227
(219), 272 (321, 322), 273 (323), 308 f. (406), 325 f. (450), 326 f. (451453)

Iakobos (Asket) 37, 119, 164 (39), 180 (93), 243 (255), 273 (326), 312 (415), 330 (460-462)

Iakobos (Mönchsbruder) $232 \mathrm{f}$. (231)

Iakobos (vom Baum Stürzender) 36, 274 (329)

Iannes und Iambres (Magier) 240 (248), 241 (252)

Iannia (Schwester des Bischofs Adelphios) 301 (388)

Jericho (Palästina) 278 (336)

Jerusalem 130, 181 (96), 186 (109 [1]), 221 (203), 222 (205), 278 (335), 279 (338), 280 (339), 286 f. (357), 300 (386), 306 (402), 307 f. (405), 327 (455)

Ioannes Chrysostomos (Kirchenvater, Autor) $\quad 75,84,92$ A. 446, 301 (388)

Ioannes der Chuzibit (Bischof von Kaisarea) 298 f. (382)

Ioannes von Edessa (Asket) 52, 165 f. (51), 184 (102), 214 (183), 303 (393)

Ioannes Eleemon, Patriarch von Alexandreia (610-619) 67, 114, 129 f., 205 f. (161), 228 f. (221, 222), 263 f. (306), 296 f. (378), 297 (379), 309 (407)

Ioannes Hesychastes (heiliger Mann) 161 f. (29), $197(135,136)$, 213 (180), $220 \mathrm{f}$. (201), $227 \mathrm{f}$. (220), 277 (334), 278 (335)

Ioannes Klimakos (Asket, Autor) 7, 10, 12, 13, 24 f., 29, 59-62, 67 A. $300,69,93,108-111,118,151$, $313 \mathrm{f}$. (421)

Ioannes Kolobos (Wüstenvater)

$172 \mathrm{f}$. (73), 220 (198, 199), $224 \mathrm{f}$. (212), 294 (374)

Ioannes Lykopolis (Anachoret) 132, 175 (84)

Ioannes Moschos (Mönch, Autor) $12,40,108-112$ 
Ioannes (Erzbischof von Kaisarea) 182 (97), 199 (140), 207 f. (166), 284 (351)

Ioannes (pneumatikos pater des Symeon Stylites jun.) 184 (103-105), 187 (111), 244 (258)

Ioannes (anagnostes) 242 (253), $257 \mathrm{f}$. (291)

Ioannes (Mönchsbruder) 258 (292)

Ioannes III., Patriarch von Konstantinopel (565-577) $137 \mathrm{f}, 190 \mathrm{f}$. (118)

Ioannes (Vater des Symeon Stylites jun.) $269(315)$

Ioannes (Verkrüppelter) 261 (302)

Ioannes (Asket) 295 (376)

Ioannes (Wüstenvater) 283 (346)

Ionas (Mönchsbruder des Hypatios) 308 f. (406)

Ioppe (Palästina) 44, 271 (318)

Isaak (Wüstenvater) $238 \mathrm{f}$. (243), 304 f. (396)

Isdigerdos/Jazdegerd I., persischer Herrscher (399-422) 135, $246 \mathrm{f}$. (261)

Isidoros (Wüstenvater) 28, 40, 77, 80, 93 A. 499, 160 (22), 224 (210), 299 (384), 324 f. (446)

Iulia (Mänichäerin) 90 f., 330 f. (463)

Iulianos, Kaiser (361-363) 226 (217)

Iulianos (Archidiakon) 291 (368)

Iulianos von Osrhoene (Eremit) $163 \mathrm{f}$. (37)

Iulianos (Schüler des Theodoros von Sykeon) 219 (196), 256 (286)

Iulianos (Wüstenvater) 285 (353)

Iustianos I., Kaiser (507-565) 190 (116)

Iustinos I., Kaiser (518-527) 42 A. 174

Iustinos II., Kaiser (565-578) 137 f., 190 (116), 190 f. (118)

Jordan (Fluss) 218 (193), 291 (367), 331 (464)

Joseph (alttestamentlicher Traumdeuter) 54 A. 229, 132

Josephus, Flavius (Historiker) 101 A. 500,123 A. 607
Kallinikos (Mönch und Autor) 11, $108-112$

Karion (Anachoret) 105, 168 f. (61)

Kastellion (Palästina) 213 f. (182)

Kilix (Mönch) 312 (416)

Klematios (Mönchsbruder des Euthymios) 195 (129)

Konon (Lieblingsschüler des Symeon Stylites jun.) $258 \mathrm{f}$. (295), $315 \mathrm{f}$. (426)

Konstans II., Kaiser (641-668) 145

Konstantinos I., Kaiser (306-337) 42 A. 174

Konstantinopel 42 A. 174, 44, 52, 73 f. (75), 137 f., 175 f. (85), 182 (97), 187 (110), 190 (116), 191 (119), 192 (121), 192 f. (123), 199 (140), 201 (151), 202 (153), 204 (157), 228 (221), 271 (318), 277 (332), 284 (351), 287 (358), 302 f. (391), $307 \mathrm{f}$. (405)

- Hagia Sophia 175 f. (85), 220 f. (201)

Konstantios II., Kaiser (337-361) 121 A. 598, 138 A. 673

Kosmas und Damianos $\quad 34,261 \mathrm{f}$. (303)

Kosmas (kaiserlicher Gesandter, Vater des Theodoros von Sykeon) 269 f. (316)

Kosmiane (Ehefrau des patrikios Germanos) 40, 300 (386)

Kukuson (Armenien) 301 (388)

Kyriakos (Asket) 299 (383), 300 (385)

Kyriakos (Pilger zu Symeon Stylites jun.) 201 (150)

Kyriakos (Räuberführer) 265 (309)

Kyriakos (Gutsherr) 306 f. (403)

Kyrillos von Skythopolis 11 f., 20, 73, $84,86,92,108-112,128,135,195$ (131), 212 f. (179), 278 (336)

Laodikeia (Syrien) 187 (109 [3])

Latopolis (Oberägypten) 148 A. 728, 171 (68), 197 f. (137)

Leon I., Kaiser (457-474) $173 \mathrm{f}$. (75), 204 (157)

Leon VI., Kaiser (886-912) 145 
Leontios von Neapolis, Autor 94 A. 454, 108-113, 114

Leontios (Wüstenvater) $217 \mathrm{f}$. (192)

Lyakon (Mönchsbruder) 250 (266)

Lykien 178 (90 [3]), 280 (339)

Makarios der Ägypter (Makarios der Große, Wüstenvater) 194 (125), 320 (431)

Makarios der Alexandriner (Makarios der Jüngere, Asket) $45 \mathrm{f}$, 93 A. 450, 175 (81), 196 f. (134), 240 (248), $241 \mathrm{f}$. (252)

Makarios (Schüler des Hypatios) 119, 326 (452)

Makedonios II., Patriarch von Konstantinopel (495-511) 312 (417)

Makedonios (Mönch) $268 \mathrm{f}$. (314)

Makrina (Schwester des Gregor von Nyssa) 42, 140 f., 231 f. (229), 268 (313)

Mannas (silentiarios) 256 (286)

Maria (Mutter des Theodoros von Sykeon) $\quad 31$ A. 119, 143-145, $269 \mathrm{f}$. (316), 287 (358), 317 (428)

Markos der Ägypter (Einsiedler) 216 (188)

Markos Diakonos (Autor) 12, 108113, 181 (96), 199 (140), 208 (167)

Maron (Mönchsbruder des Euthymios) 195 (129)

Martha (Mutter des Symeon Stylites jun., heilige Frau) 32, 39 A. 164, 68 A. 307, 84, 97, 130, 140, 144 f., 213 (181), 221 f. (202-204), 229231 (224-228), 242 f. (253), $243 \mathrm{f}$. (257), 257 f. (290, 292), 269 (315), 273 (324), 280 f. (341), 315 f. (426 [2]), $334 \mathrm{f} .(475)$

Martha (Mutter des Daniel Stylites) 144 f., 267 (311)

Maurikios, Kaiser (582-602) 191 (119), 235 (238)

Melas (Fluss in Syrien) $252 \mathrm{f}$. (277)

Monaxios (Konsul) 273 (323)

Montanos (Prophet) 14, 88

Moschion (Gefährte des Hypatios) 308 f. (406)
Moses der Äthiopier (Räuber, Wüstenvater) $23,28,64,120,224$ (210), $324 \mathrm{f}$. (446)

Moses (Schüler des Ioannes Klimakos) $\quad 67$ A. 300,313 f. (421)

Neon (Mönch, Bauführer) 289 (362 [5])

Nestorios, Patriarch von Konstantinopel (428-431) 52, 175 f. (85)

Nikephoros II. Phokas, Kaiser (363369) 63 A. 265

Niketas (patrikios) 228 (221)

Niketas (Wüstenvater) $320 \mathrm{f}$. (432)

Nikolaos von Akalissos, Onkel des Nikolaos Sionites 176 f. $(89,90)$, 290 (363)

Nikolaos Sionites (heiliger Mann) 20, 38, 177 f. (89, 90), 206 (162), 273 (325), 280 (339), 290 (363 [3], 364), 311 (411, 412), 327 (455)

Nikolaos (Wüstenvater) 28, $273 \mathrm{f}$. (327)

Nikon (Abt) 184 (102)

Nonna (Mutter des Nikolaos Sionites) $177(89)$

Oreibasios (Arzt) 59 A. 252, 61

Origenes (Theologe, Autor) 14, 24 A. 70, 88, 92, 114 A. 554, 123 A. $607,148,152$ A. 736

Orisios (Abt und Nachfolger des Pachomios) 207 (164)

Pabaus/Pbow (Oberägypten) 162 (32)

Pachomios, der Ältere (heiliger Mann) 11, 21, 22 f., 41, 50 f., 65, $84,89,98,107,117,127,133,147$, 148 f., 160 (23), 162 f. (31-36), 170 (66), 175 (81), 179 f. (91, 92), $196 \mathrm{f}$. (134), 197 f. (137), 198 (138), 206 f. (163-165), 232 (230), 243 (254), 264 (307), 289 (360), $290 \mathrm{f} .(365,366)$, 293 (371, 372), 297 f. $(380,381), 311$ (413), 328-330 (457-459)

Pachomios (Abt der Klöster von Tabennese) $157(7), 171$ (68) 
Palästina 164 (38), 190 (117), 277 (333), 284 (351), 291 (367), 312 (415)

- Euthymioskloster 135, 306 f. (401403)

- Megiste Laura (Sabas-Laura) 35, 161 f. (29), 274 (328), 277 (334), 278 $(335,336), 281 \mathrm{f} .(345)$

- Nea Laura 212 f. (179), 217 f. (192)

- Phasilaidi (Kirche des heiligen Kerykos) 285 (354)

- Totes Meer 35, 274 (328)

- Turm der Eudokia (judäische Wüste) 303 (392)

Palladios von Helenopolis (Mönch, Bischof, Autor) 11, 80 f., 93, 108112

Pambo (Wüstenvater) 239 f. (247)

Panopolis (Oberägypten) 291 (366)

Panos (Oberägypten) 90, 327 f. (456)

Paphnutios (Wüstenvater) 220 (200), 227 (218)

Patermuthios (Räuber, Asket) 205 (160), 241 (251)

Paulos (Erzbischof von Ankyra) 192 (120)

Paulos (Anachoret) 238 (242)

Paulos (Bote) 279 (338 [1])

Paulos (besessener Mönch) 31, 86, $247 \mathrm{f}$. (262)

Paulos (Sklave) 273 (323)

Paulos (Steinmetz) 231 (228)

Paulos (Vater des Euthymios) $267 \mathrm{f}$. (312)

Pekyssios (pachomianischer Mönch) $171(68)$

Petros der Galater (Asket) 164 (38)

Petros (Zöllner) $40 \mathrm{f}$, $115 \mathrm{f}$., $295 \mathrm{f}$. (377)

Pharan (Palästina) $306(401,403)$

Phidos (Diakon) 44 f., 46, 84 A. 396, 271 (318), 306 (401)

Philon von Alexandreia (Philosoph, Autor) 1 A. 2, 2 A. 3, 59 A. 252, 101 A. 500, 106, 123

Phönikien 183 (99)

Phokas, Kaiser (602-610) 235 (238)

Piamun (ägyptische Jungfrau) 132, $175(82)$

Piterum (heiliger Mann) 307 (404)
Platon (Philosoph) $56 \mathrm{f} ., 76,87$

Plotin (Philosoph) 1 A. 2, 4 A. 10, 76

Poimen (Wüstenvater) $105 \mathrm{f}$., 158 (10), 169 (61), 238 f. (243)

Polychronios (Mönch) $176(88)$

Pontos (Provinz) 265 f. (310)

Porphyrios (Bischof von Gaza, heiliger Mann) 90 f., 181 f. (96-98), 199 (140), 207 f. (166, 167), 284 (351), $330 \mathrm{f}$. (463)

Prokopios von Gaza (Autor) 75, 79, 81

Prokopios (heiliger Mann auf Rhodos) 147, $182(97,98), 199$ (140), $284(351)$

Pseudo Dionysios Aeropagites s. Dionysios

Rhodos 182 (97), 199 (140), 228 (221)

Romanos (durch Zauber Erkrankter) $73,86,135,248 \mathrm{f}$. (264)

Romilla (Stadt in Italien) 285 f. (355)

Rufinus von Aquileia (Mönch, Übersetzer) 59 A. 250

Ruphinianai (Bithynien) 308 f. (406), 325 f. (450)

Sabas (heiliger Mann) 35, 83, 117, 174 (78), 197 (135), 199 (141), 213 (180), 213 f. (182), 232 f. (231, 232), 292 (369), 303 (392), 313 (420), 332 f. $(469,470)$

Sabbatios (Abt) 176 f. (89), 290 (363)

Sabinos (Mönch) 129 f., 228 f. (222)

Sabinos (heiliger Mann) 33, 250 (268)

Samos $280(340)$

Serapion (Bischof von Thmuis) $157 \mathrm{f}$. (8)

Sergios (Schüler des Symeon Stylites sen.) 50, $204(157,158)$

Seridon (Abt) 173 (74)

Siluanos (Wüstenvater) 83, 239 (244, 245)

Siluanos (pachomianischer Mönch) 304 (394)

Simon Magus 134, 149, 199 (139)

Sinai 183 (100), 233 (233), 291 (367) 
Sisoes (Asket) $\quad 65,304$ (395)

Sketis (Asketensiedlung in Ägypten) 28, $168 \mathrm{f}$. (61), 283 (348), 331 (466)

Sozomenos (Kirchenhistoriker) 63 A. $265,80 \mathrm{f}$.

Stephanos, der Lyber (Asket) 81, 117 A, 573, 170 (65), 233 (233)

Stephanos (Priestermnöch) 313 (419)

Symeon Salos $\quad 52,165$ f. (51), 184 (102), 214 (183), 303 (393), $314 \mathrm{f}$. (422, 423), 333 (471)

Symeon Stylites der Ältere 22, 23, 35, 180 f. $(94,95), 233$ f. (234), 277 (332), 315 (324)

Symeon Stylites der Jüngere 20, 26, $31 \mathrm{f},, 32 \mathrm{f}$, , 34, 35, 36, $37 \mathrm{f}$, 39 A. 164, 47, 52, 64, 69, 74, 83, 84, 85, 97, 115 A. 561,130 f., 131 f., 136, 140, 184-191 (103-119), $200 \mathrm{f}$. (143-150), 209-211(171-176), 214 f. (184-187), 218 f. (195), 222 (206), 229-231 (226-228), 234 (235), 244 f. (258, 259), 251-255 (269-280), 258-260 (295, 296), 260 (298, 299), 261 (301), 273 (324), 274 f. (330), 279 (338), 280 f. (341, 342), 288 f. (361, 362), 292 (370), 315 (425), 333 f. (472, 473), 334 f. (475)

Synesios von Kyrene (Philosoph, Autor) 145 f., 286 (356)

Syrien 277 (332), 302 f. (391), 323 f. (444)

Tabennese (Oberägypten) $162(32)$, 175 (81), 196 f. (134), 290 (365), 307 (404)

Terebon (Sarazene) 135, 217 (190), 246 f. (261)

Tertullian 68 A. $309,76,114$ A. 554

Thebais (Wüstengebiet in Oberägypten) $28,53,64,161$ (124), 175 (81), 196 f. (134), 203 f. (156), 243 (256), 273 f. (327), 304 f. (396)

Thekla (heilige Frau) 141, 268 (313)

Theodora (Frau eines silentiarios) 36,235 (237)
Theodoret von Kyrrhos (Bischof, Theologe, Autor) 12, 35, 37, 50, 52, 66 A. 291, 67 A. 302, 93, 99, 100, 108-112, 119, 142, $164(39,40), 180$ (93), 268 f. (314), 273 (326)

Theodoros (Schüler des Pachomios) 21, 22 f., 149, 157, 162 f. $(32,33)$, 198 f. (138, 139), 207 (164, 165), 243 (254), 293 (371, 372), 304 (394), 311 f. (414), 329 f. (459)

Theodoros von Sykeon (heiliger Mann) 23, 31 A. 119, 34, 36, 39 A. 164, $41 \mathrm{f},, 67 \mathrm{f}$, , 79, 90, 131, 136, 140, 141, $143,145,147,191-193$ (119-123), 201 f. (151-153), 212 (177), 219 (196), 234-237 (236-240), 255-257 (281-288), 261 f. (303), 281 f. (343345), 287 (358, 359), 317 f. (428, 429), 335 f. (477-481)

Theodoros (Bischof von Daphne) $301 \mathrm{f}$. (389)

Theodoros (Mönch, Bauführer) 289 $(362[4,5])$

Theodoros (Wüstenvater) 283 (348)

Theodoros (Besessener) $252 \mathrm{f}$. (277)

Theodoros (Besessener) 90, 336 (481)

Theodosios I., Kaiser (379-395) 126

Theodosios II., Kaiser (408-450) 63 A. $265,182(97)$

Theodosios (Bischof von Anastasiupolis) $\quad 269 \mathrm{f}$. (316)

Theodosios der Hesychast (Einsiedler) 208 (168), $232 \mathrm{f}$. (231)

Theodosios (Dorfvorsteher) $317 \mathrm{f}$. (429)

Theodotos von Gaza (Dieb) 306 (402)

Theoktistos (heiliger Mann) 174 (78), $246 \mathrm{f}$. (261)

Theosebeia (besessene Jungfrau) 86 f., 254 f. (280 [2])

Thomas I., Patriarch von Konstantinopel (607-610) 141, $192 \mathrm{f}$. (123)

Thrakien (Provinz) $308 \mathrm{f}$. (406)

Tiberine (Syrien) 281 (342)

Tiberios I., Kaiser (578-582) 191 (119)

Timotheos (jüdischer Arzt) 137, $190 \mathrm{f}$. (118) 
Timotheos (Bischof von Anastasiupolis) $192(120)$

Timotheos (Gefährte des Hypatios) 308 f. (406)

Tithoes (Wüstenvater) 158 (11)

Valens (Asket) 325 (447)
Zacharias (Anachoret) 23, 83, $105 \mathrm{f}$., 168 f. (61), 224 (210), 239 (245)

Zenon (Wüstenvater der Sketis) 28, 119, 132, 271 (317)

Zenon (Anachoret beim Roten Meer) $176(87)$

Zosimos (Wüstenvater) 183 (100)

Zypern 67, 205 f. (161), 228 f. (221, 222) 


\section{Sach- und Begriffsindex}

Abbild (antitypos, homoioma) 1, 34, arretos, s. unbeschreibbar 51, 217 (189), 241 (252), 290 (363), Ärzte, Mediziner 30, 61, 92 A. 444, 284 (352). S. auch Imitation 93 A. 447, 135, 232 f. (231), 246 Abendmahl, s. Liturgie agrypnia, s. Wachen adiakriton, s. Gabe akedeia, s. Untugenden akoe, s. Ohr, Stimme

Akoimeten 63

Allegorie, Allegorese 15, 26, 63, $123-131,138,140,141,143,144,153$ Altersheim (gerokomeion) 277 (334) ameleia, s. Untugenden

Anachorese, Anachoreten, anachoretisch 53, 58, 85, 89, 102, $159 \mathrm{f}$. $(20,21), 161(24,25), 166(52), 175$ (83), 199 (141), 324 (445)

anaphora, s. Liturgie

anargyros, s. Ärzte

Angesicht, Gesicht $\quad 82,84,90$, opsis 224 f. (212), 228 (220), 231 (229), prosopon 173 (75), 186 (109), 199 (139, 143), 201 (149), 219 (196), 221 (201), 225 (212), 235 (239), 239 (244), 250 (268), 252 (273), 252 (277), 298 (382), 308 (406), $330 \mathrm{f}$. (463), 333 f. (473)

aoratos, aorata, s. unsichtbar apatheia, s. Tugenden aperigraphos, s. unbeschreibbar aphrastos, s. unbeschreibbar apokalypsis, s. Offenbarung Apokalyptik, Apokalypse, Endzeit 4 f., 10, 97, 115, 124, 138, 139 A. 677, 140, 141, 142, 178 f. (90)

Apophthegmata Patrum (Vätersprüche) 7,11, 24 A. 72, 25 A. 73, 29, 54, 55, 57, 58, 60, 81, 89 f., 105 f., $108-112,118,120,125,126,128$, $129,132,151,152$

Archidiakon 201 (151), 291 (368)

Archimandrit $175(81), 313$ (420), 315 (424)

arete, $\mathrm{s}$. Tugenden 
- Auge der Seele (tes psyches ommata) 71, $166(53)$

- inneres Auge 26, 48, 74, 82, $85 \mathrm{f}$, 98, 151, ophthalmoi tu eso autu anthropu 254 (279)

- augenscheinlich, mit eigenen Augen sehend, auf sichtbare Weise (autoptikos, autops (e)i) 32, 35, $96 \mathrm{f}$, 99, 176 (89), 188 (13), 260 (297), 269 (315), 281 (342), ophthalmophanos 209 (171), 269 (315), 322 (438), 331 (465), 332 (467), 333 (471), tois eautu ophthalmois 251 (272)

- Augenzeuge, Augenzeugenschaft 10, 96 f., 99

Bad 90, 199 f. (143), 328 (456)

Barlaam und Ioasaph 126

Barmherzigkeit, Erbarmen, Mitleid (eleemosyne, eleos) 114, 135, 165 (46),173 (74), 180 (92), 187 (109), 206 (161), 212 (178), 225 (213), 249 (264), 307 (403), 310 (410), $311 \mathrm{f.} \mathrm{(414)}$

Bauern 189 (114), 199 f. (143), $230 \mathrm{f}$. (227, 228), 317 (429)

Besessenheit, dämonische 14, 31, 33, $37,86,87$ A. $420,88,89,90-94,135$, 136 f., 152, 195 (127), 216 (188), 240 (248), 248 (263), 250 (268), 251 (271), 252 f. (277), 254 f. (280), 256 (284, 285), $257(287,288), 289(362$ [5]), 316 (427), 326 (451), 327 (454), 328 (456), 330 f. (463). S. auch Ekstase, Krankheit

Bestattung, Begräbnis 147,183

(100), 194 (124), 196 (132), 212

(178), 221 (202), 226 (215), 231

(228), 247 (262), 264 (306), 265

(309), 285 (353, 354), 286 (356), 302 (390), 314 (422)

Beten, s. Gebet

Bettler, Bedürftige $171(68), 188$ (113[3]), 206 (161), 260 (297), 395 f. (377)

Bewegung (des Körpers) (kinesis) 54-62, 118, 164 f. (43)

- Unbewegtheit (akineton) 60, 165 (50), 312 (416)
Bewusstseinszustand 13, 14, Kap. II (44-94), 95, 101 A. 497, 151

- Bewusstseinserweiterung 76, 77, 85

- Bewusstseinsverslust 75,89

- Tagesbewusstsein 70 A. 315, 115

- Überbewusstsein 32 A. 123, 70, $73,74,89$

- Unterbewusstsein 70 A. 315, 89

Bischöfe 143 A. 697, 148, 197 (137), 218 (194), 222 (205), 280 (340), 285 f. (355)

Brunnen 34, 240 (248), 284 (352), $324(446)$

charisma, s. Gabe

Charismatiker (allg.) 9 A. 29, 20-23, 26 A. 86,28 A. 97,30 A. 109 , 39 A. 164, 47, 64, 68 f., 73, 86, 98, $105,114-150,153$

Christenverfolgung 226 (217), $246 \mathrm{f}$. (261), 275 f. (331)

dakrya, s. Emotionen

Dämon (daimon) (allg.), dämonisch 6 A. 19, 159, 31, 32, 33, 36, 37, 41, 44 A. $181,45,48,50,53-62,69,85$, 86, 89, 90, 91, 92, 93, 102, 106, 107. 114 A. $554,116-120,129$ A. 637 , 131, 132, 133, 134, 136-138, 148, 151, 152, 159 f. (21), 162 (31), 163 $(34,36), 164$ (42), 165 (46), 167 f. (57 [5], 60), 169 (63), 171 f. $(69,70), 183$ (101), 190 f. (118), 197 (137), 199 f. (143), 215 (186), 216 (188), 221 (202), 232 f. (231), 246-257 (261288), 263 (304), 272 (322), 293 (372), 315-317 (425-427), 319-336 (430481). S. auch Besessenheit, Geist, Ekstase, Erscheinung, Gesicht, Schau, Traum, Trugbild, Vision

- Dämonenkult 137,190 f. (118), 275 (331)

- Neid der Dämonen (phthonos daimonon) 55, 61, 91, 252 (276), 332 (469)

- pneumatische Beschaffenheit, pneumatisch 114 A. 554, 133, 136, 183 (101) 


\author{
De Sanctis Pachomio et Theodoro \\ 11, 133 \\ diakrisis, s. Gabe \\ diakritikos 120, 121 \\ dianoia, s. Geist \\ dioratikon, s. Gabe
}

Diebstahl, Räuberei $\quad 118,119,167$ (57), 171 (69), 204 f. (159, 160), 264 f. (308, 309), 286 (357), 306 (402), 324 (446), 330 (461)

Dissoziation 83

Divination, s. Mantik

Durst, s. Hunger

ekkrisis, s. Erguss

ekstasis, s. Ekstase, Verrücktheit

Ekstase 2, 19, 28, 31, 46 f., 48, 50, 64, 67-70, 72 f., 74-84, 96, 102-104, $109 \mathrm{f.}, 152$

- dämonische/trügerische Ekstase 87-94, 104, 120, 149, 152, ekstasis, ekstatikos $159(19,20), 163(34,35)$, 325 (449), 328 (456), 330 (463), 331 (464), ekstasis frenon 87, 158 (9), 164 (42), 336 (481). S. auch Epilepsie, Verrücktheit

- falsche Ekstase, Pseudoekstase ( $p a$ rekstasis) 88, A. 423

- Heilungsekstase (ekstasis) 73, 8587, 248 (264), 255 (280 [2]), 328 (456). S. auch Traumheilung und Inkubation

- mystische Ekstase (ekstasis) 7485, 102 f., 129, 137, 152, 158 (11), 159 (19), 160 (22), 163 (35), 166 (52), 172 (71), 179 (91), 181 (96), 185 (106, 108), 187 (112), 191 (118 [2]), 203 (156), 204 (157), 208 (168), $209(169,170), 226$ (214), 226 (217), 227 (219), 228 (222), 229 (224), 234 (235 [2]), 238 (242, 243), 239 (244), 239 (245), 243 (256), 247 (262), 249 (265), 257 (289), 274 (327), 275 (331), 293 (372), 294 (374), 301 (388), 305 (397), 308 (405), 313 (419), 315 (425, 426), 316 (426), existemi 165 (48)
- ekstatische Schau, Vision, Erfahrung $70,72,76$ A. 345,77 A. 351, 79, 82, 85, 87 A. 420, 123, 152

- Entrückung/Entraffung, entrückt/entrafft werden (existamai, harpazomai) $22,74,76,77,78,79,81-85$, $89,103,115$ A. 561, 140, 152, 160 (22), 187 (110), 188 (113), 197 (136), 223 (208), 227 f. (220), 233 f. (233, 234), 239 (245), 247 (261), 275 (331), 279 (338), 288 (361), 334 (475)

Emotionen, Affekte, Leidenschaften

- Freude (chara etc.) 82, 118, 119, 160 (21), 167 (57), 173 f. (75), 205 (160), 206 (161), 207 (165), 210 (171), 214 (182), 216 (188), 219 (196), 223 (207), 226 (216), 228 (221), 235 f. (239), 237 (240), 247 f. (262), 273 (324)

- Furcht, Angst, Schrecken Zittern, Stöhnen, Weinen (aus Furcht) (phobos, deilia etc.) 6 A. 19, 82, 84, 85, 86, 90, 91, 118, 119, 136, 147. 158 (12), 159 (18), 162 (32), 167 (57), 162 (32), 167 (57), 172 (71), 177 f. (90), 179 (91), 183 (99), 185 (107), 186 (109), 198 (137), 200 (145), 207 (165), 208 (168), 213 (181), 215 (187), 217 (190), 221 (202), 233 f. (233, 234), 238 (242), 242 (253), 244 (258), 248 (262), 252 (276, 277), 258 (292), 259 (295), 269 f. $(315,316), 276$ (331), 278 (337), 279 (338 [1]), $289(362$ [2, 3]), 300 (387), 307-309 (403, 405, 406), 310 (409), $315 \mathrm{f} .(424,426), 317 \mathrm{f}$. (428, 429), 324 (445), 427 f. (456), 330 f. (460, 461, 463), 332 f. (469, 470), 335 (478)

- Hass (misos) 118, 165 (46), 167 (57)

- Kummer, Leid (lype) 159 (20), 164 (42), 167 (57), 190 (118), 283 (347)

- Trauer, Weinen, Tränen (penthos, threnos, dakrya) 23, 24, A. 72, 25 , A. $81,31,32,64,74$, A. 334,82 , $84,85,90,138,142,160,166(52,55)$, 178 (90 [1]), 182 f. (99), 186 (109), 191 (118), 192 (123), 197 (135), 224 (212), 228 (221), 233 (231), 234 
(235), 235 (237), 235 f. (239), 239

(243, 244), 247 (262), 250 (267), 262

(303), 264 (306), 269 (315 [1]), 173

(324), 293 (372), 296 (377), 299

(384), 301 (387, 388), 310 (408), 316 (426), 328 (456)

- Zorn, zornig, Wut, wütend (orge)

57, 89, 135, 137, 158 (12), 159 f. (20,

21), 164 (42), 165 (46), 172 (71),

184 f. (106, 107), 186 (109), 191 (118

[1]), 214 (182), 253 f. (279 [1]), 296

(377), 307 (403), 317 f. (428, 429),

324 (446), 330 (462). S. auch Gott

emphaneia, emphanisis, s. Erscheinung

Endzeit, s. Apokalyptik

Engel (allg.), engelhaft 2 A. 3,

5 A. 13, 20, 25, 26, 29, 34, 107,

114 A. 554, 116, 118, 124, 134, 153,

157 (6), 158 (15), 165 (46), 166 (56), engelhaft 50, 57, 78, 97 f., 118, 152, 157 (6), 160 (21). S. auch Gesicht,

Traum, Stimme, Vision

- angelus interpres 126

- engelgleiches Leben (angelikos bios) 24, 53

engkrateia, s. Fasten u. Tugenden

Entraffung, Entrückung, s. Ekstase enypnion, enypniazo, s. Traum

Epilepsie (epilepsia), s. Krankheit

epiphaneia, s. Erscheinung

Erguss, Pollution (ekkrisis) 57-63

Erscheinung, göttliche, wahre (epiphaneia, emphaneia, emphanisis

etc.) 2, 13, $33 \mathrm{f}$., 42, A. 174, 47, 52, A. $221,96,98,107,114,117-$

119, 121, A. 599, 130, 141, 147, 151, 180 (93), 192 (120), 209 (171), 213

(181), 218 (195), 227 (218), 231

(229), 242 (253), 260 (296), 268

(313), 279 (338 [2]), 281 (342, 344),

290 (363 [1]), 328 (458). S. auch

Vision, Schau, Gesicht

- dämonische Erscheinung 29, 44 A. 181, 53, 106, 120, 153, 264 (307). S. auch Trugbild

- Engelserscheinung (optasia ton angelon) 178 (90 [2])

- Gotteserscheinung 107, (theophaneia) 197 (135), (theia optasia) 267
(312), (epiphaneia tu kyriu) 222

(206)

- Traumerscheinung, s. Traum

Eucharistie, s. Liturgie

euche, proseuche, s. Gebet

Eunuchen 283 f. (349), 309 (407)

Evangelium, Evangelien 50, 91, 97, 100 A. 493, 101, 123 f., 279 (338)

Exemplum 2, 7, 10, 15, 16, 45, 53, $105,116,153$

Fasten (engkrateia, nesteia, nepsis) 25, 27-31, 38, 61, 64, 71, 73 f., 118, 166 (56), 207 (166), 233 (233), 241 (252), 249 (363, 264), 272 (322), 284 (350), 294 f. (375), 313 (419), 324 (466), 332 (469)

Fellkleid 33, 204 (157), 206 (161), 211 (174), 259 (296)

Feuer, Flamme $\quad 91,129,157(1,4)$, 176 f. (89), 188 (113 [1]), 261 (301)

Flötenspieler 227 (218 [1])

Fluss, Bach, Strom 38, 252 (277), 272 (322), 291 (367), 292 (369)

Gabe, Gaben (charisma)(allg.) 157 (7), 174 (80)

- Gabe der Unterscheidung, Unterscheidung (der Geister) (charisma tes diakriseos [ton pneumaton], diakrisis) 20, 26, 52, 55, 57, 102, 105, 114-122, 123, 130, 131, 148 f., 153 f., 167-170 (57-67), 198 (137), 200 (146), 323 (442), fehlende Unterscheidung (adiakriton) 119, 326 (452), 328 (458)

- Gabe der Prophezeiung, Prophetengabe (charisma tes propheteias) 20, 52, 131-148, 153, 171-193 (68123), 284 (351). S. auch Prophezeiung

- Gabe der Klarsicht, Klarsicht, klarsichtig (dioratikon charisma, dioratikon) 15 f., 37, 68, 143 A. 703, 147-150, 154, 170 (66), 194-202 (124-153), 220 (197), 331 (466)

Garten, Gärtner $\quad 45,130,189$ (115), 200 (147), 212 (178), 240 (248), 
241 f. (252), 246 (260), 279 (338), 313 (421)

Gasthaus (pandocheion) 335 (479) gastrimargia, s. Untugenden

Gebet, Beten (euche, proseuche, aitesis) 25, $27 \mathrm{f},, 31 \mathrm{f} ., 36-39,46$, 56, 62, 63, 64, 66 f., 68 f., 71, 73 f., 83, 117, 118 f., 135, 137, 154, 159 (18), 160 (21), 161 (25), $162(30,32), 166$ (56), 167 (57), 172 (71), 174 (79), 175 (82, 83), 178 f. $(90,91,92), 180$ (93, 94), 186 f. (109), 190 (117, 118), 191 (119), 195 (124, 128), 199 (140, 143), 200 (147), 204 (156), 207 (165), 208 f. (167, 169), 211 (174, 175), 212 (178, 179), 215 (187), 216 (188), 217 (190), 218 (194), 219 (196), 223 (208), 225 (213), 228 (221), $233 \mathrm{f}$. (231-235), 237 f. (241, 242), 239 (247), 241 (252), 243 (256), 245 (259), 247 (262), 248 (263), 249 (264), 250 (268), 252 (277), 254 (279), 258 (295), 263 (304), 264 (307), 267 (312), 269 (315), 271 (317, 318), 272 (320), 273 (324, 326), 276 (331), 278 (334), 281 (344), 283 (346, 347), 289 (362 [2]), 290 (365), 292 (369), 293 (371), 295 (376), 301 (388, 389), 304 (394), 308 (406), 311 (412, 414), 314 (421), 316 (426), 321 (433, 435), 323-325 (443-447), 326 (450), 327 (454, 455), 329 (459), 330 (460), 332 (468-470), 333 (471), 336 (480)

Geburt 268 (313)

- Frühgeburt 268 f. (314)

- Geburtsankündigung 30, 31, 41 A. 107, 74, 144, 145, 267-270 (311-316)

- Geburtsschmerzen, Wehen 244 (257), 268 (313)

Gedanke (schlechter, unlauterer) (logismos) 57, 59, 60, 64, 89, 116, $117,118,120,147,157(4,5), 159 \mathrm{f}$. (20, 21), 163 (33), 167 (57), 168 (59), 183 (101), 195 f. (129, 232, 133), 203 (156), 209 (170), 238 (242), 247 (262 [1]), 283 (347), 299 (383), 304 (394), 307 (404), 312 (416), 321 (433),
322 f. (441), 324 (445), 328 (458), 331 (464)

- heiliger, demütiger, lauterer Gedanke $\quad 23,57,79,117,165(44,48)$, 168 f. (61), 236 (239), 238 f. (243), 247 (261)

Gefängnis 218 (194), 265 (309), 280 (340), 285 f. (355), 309 (407)

Geheimnis, Mysterium, verborgene Dinge (mysterion, krypta) $21-$ 23, 23, 26, 107, 152 A. 736, 153, 159 $(16,17), 161(26,28), 162(32), 170$ (66), 198 (139), 206 (163), 211 (174), 216-219 (188-196)

Geist, Intellekt 44, 54 A. 229, 56, 63, 71 A. $325,73,74,75,77,81,83,84$, 99, 103, 107, 117, 119, 127, 147, 154, 213 (180), 324 (446), dianoia 157 (2), 160 (22), 164 (40), 167 f. (57), 174 (77), 196 (132), 197 (136), 223 (208), 227 f. (220), 279 (338), 323 (442), logismos 159 (18), nus 1, 159 (18), 165 (45), 222 (206), 233 f. (233, 234), 290 (365), 319 f. (430), pneuma 199 (140), 207 (164), 316 (426 [2])

- dämonischer, unreiner, böser Geist (pneuma akatharton, akathartos daimon etc.) $88,91,117,118$, 136, 167 (57), 195 (130), 246 (260), 247 (262), 252 (273), 259 (295), 263 (304), 289 (362 [5]), 311 (412), 320 (430), 328 (456), $328 \mathrm{f}$ (458), 333 $(471,472)$

- geistige Kraft (noera dynamis) 71, 166 (53)

- heiliger Geist, Geist Gottes (pneuma [hagion]) 28, 88, 117, 120, 128, $131,132,137,141,143,148,149,159$ (16), 167 (57), 171 (68), 177 (89), 185-187 (106-110), 188 f. (113), 190 f. (117, 118 [1]), 195 (130), 198 (137), 199 f. (143), 200 (147), 203 (155), 206 (162), 210 f. (271, 173, 175, 176), 218 (194), 230 (227), 232 (229), 234 (235), 245 (259), 253 (277, 278), 259 (295), 260 (299), 263 (304), 275 f. (331), 292 (370), 293 (371), 295 (376), 298 (382), 315 (425), 322 (439), 328 (458), 334 (475) 
Gesandtschaft, Botendienst $\quad 52,175$ (85), 202 (152), 268 (314), $269 \mathrm{f}$. (316), 275 f. (331), 279 (338)

Gesetze, Gesetzestexte $121 \mathrm{f} ., 134$, $139,145 \mathrm{f}$.

Gesicht 23, 25, 44, 52, 57, 80, 98, $104 \mathrm{f} ., 110-113,118,120,123,126$, $127,131,143,144,145,149,150$, horama 182 (98), 198 (138), 265 (310), 271 (318), 297 (379), 303 (392), horasis 285 (355), optasia 162 (32). 177 (90), 198 (137), 206 (162), 221 (201), 278 (335), opsis 231 (229), prosopon 165 (43), theama 158 (10), theoria 275 (331), theorema 165 (49). S. auch Schau, Vision

- dämonisches Gesicht 118

- ekstatisches Gesicht, Gesicht in Ekstase 81,123

- engelhaftes Gesicht, Engelsgesicht (angelike optasia) 20,57,81, 104, 118, 197 (135), 221 (201), 307 (405)

- göttliches Gesicht (theu optasia) 21, 32, 104, 106, 117, 290 (364)

- Traumgesicht 42,81,115,131, 135, 143, enypnion 297 (379), onar 203 (154), oneiru opsis 246 (260), opsis enypniu $231 \mathrm{f}$. (229), orama 309 (407)

Getränke, s. Lebensmittel

Gnosis, gnostisch 124, A. 613, $138 \mathrm{f}$. gnostikos, gnose 27 A. 89

Gott. S. auch Geist

- Augen Gottes (ophthalmoi kyriu) 201 (150)

- Vorsehung, Ratschluss Gottes (pronoia) 172 (72), 182 (98), 237 (241), 257 (289), 290 (363)

- Zorn Gottes 176 (86), 185 (106, 107), 186 (109 [1]), 191 (118)

Gottesschau, s. Gesicht, Erscheinung, Schau, Vision

Gute Taten (katorthoma) $161 \mathrm{f}$. (29, 30), 188 (113 [1]). S. auch Tugend

Halluzination 3, 28

Händler 227 (218 [4])

Häresie, häretisch, Irrglaube, Unglaube $14,40,52,65,75,77,88,90$,
188 (113 [1]), 204 f. (159), 229 f. (226), 289 (362 [5]), 293 (372), 298 (380, 381), 299 (383), 300 (386), 301 f. (389), 310 (409, 410), 311 (413)

- Arianer 65, 81, 172 (71), $271 \mathrm{f}$. (319), 284 (351), 293 (371), $311 \mathrm{f}$. (414)

- Manichäer 139 A. 677, 330 f. (463)

- Markioniten 36 f., 180 (93), 273 (326)

- Monophysiten $333(471)$

- Montanisten 14, 88, 117 A. 574, 139 A. 677

- Nestorianer 52, 175 f. (85), 299 (383), 303 (392), 300 (385), 303 (392)

- Severianer 40, 299 (384), $300 \mathrm{f}$. (386, 387), 302 f. (391), 284 (351), 293 (371), 311 (414)

Heidentum, Götzenanbetung 90, 94, 134, 136, 138 A. 672, 164 (41), 184 f. (106, 107), 188 (113[2,3]), 260 (297), 275 f. (331)

Heiligenbild, s. Ikone

Herz (kardia) 157 (7), 159 (18), 162 (31), 165 (46), 166 (55), 169 (64),181 (96), 183 (99), 185 (106),194 (124), 196 (132), 198 (137, 139), 179 (338), 284 (351), 304 (394), 306 (403), 307 (404), 312 (417), 322 (439)

hesychia, s. Meditation

Himmel, Himmelsreise (allg.) 2, A. $3,5,21,23,25$ f., $45,68,75,78$, 84,114 A. 554,123 A. $607,127,128$, $138,140,142,143$ f., 148,152 A. 736 , $179(92)$

Hirte $\quad 57,90,160(21), 285(353,354)$, 306 f. (403), 325 (449), 331 (464), $333(470)$

Hirt des Hermas 124 A. 613, Historia Lausiaca $\quad 11,65,80 \mathrm{f}$. Historia Monachorum in Aegypto 11, 21, 26, 45, 58 f., 90, 108-112, 152 Hölle, Höllennreise (allg.) 5, 10, 40, 78 A. 358

horama, horasis, s. Gesicht, Vision

Hören 14, 21, 132, 149, 161 (27), 171 (69), 198 (139), 205 (159), 211 (175), 243 (254), 293 (371), 304 (394), 314 
(421), 321 (434). S. auch Ohr, Stimme

Hospiz (xenodocheion) 224 f. (212), 274 (328), 278 (336)

Hunger, Durst 28, 38 A. 155, 58, 157 (1), 194 (124), 200 (144), 251 (269), 272 (321), 273 f. (327), 305 f. (398400), 310 (408), 315 (425)

Hymnen(gesang) 25 A. 81, 26, 46, 71, 161 (25), 180 (93), 197 (136), 228 (220), 288 (361), 312 (415)

hypar, s. Traum

hyperefaneia, s. Untugenden

hypnos, s. Schlaf

iatreion, s. Krankenhaus

Ikone, Heiligenbild, Ikonographie, ikonographisch 2, 8, 34, 35, 99, 29 A. $637,154,261$ f. (303), 284 (352), 331 (465)

Imagination 1 A. 1, 2, 31, 32, 36, 4448, 76, 86, 99, 106-107, 124, 141, $151-152$

Imitation (mimesis) 1 A. 2, 2 A. 3, 106. S. auch Abbild

Inkubation $10,14,30-34,74,86 \mathrm{f}$, 154

Jenseits (allg.) 24, 26, 45, 82

- Früchte aus dem Jenseits/Paradies $45 \mathrm{f} ., 115$

- Jenseitsoffenbarung, Jenseitsschau, Jenseitsvision $\quad 68,140,223-245$ (207-259)

- Jenseitssehnsucht 76

- Jenseitsreise 46, 140

Juden, jüdisch $30 \mathrm{f}$. A. 111, 93 A. $452,137,138$ A. 672,152 , 190 f. (118), 214 (184), 309 (407), $314(422)$

kardia, s. Herz

katorthoma, s. Gute Taten

kathizo, s. Meditation

kat' onar, s. Traum

Kinderlosigkeit $\quad 267-269(311,312$, 314)
Kirche, Kapelle, martyrion $180 \mathrm{f}$. (94)

- Kapelle des Ioannes Prodromos 32, 269 (315)

- Kapelle des Märtyrers Gemellos 41, 212 (177)

- Kapelle des Märtyrers Polyeuktos 32, 267 f. (312)

- Kirche des Märtyrers Iulianos 291 (368)

- Kirche des heiligen Kerykos 285 (354)

- Kirche der theotokos 235 (239)

- martyrion des heiligen Georg 67, $201 \mathrm{f}$. (152), 281 f. (343-345), 287 (359), 317 (428), 335 (477)

- martyrion des Märtyrers Kolluthos 175 (83)

- martyrion der heiligen Martha 288 f. (362 [2])

- martyrion des Protomärtyrers Stephanos $280 \mathrm{f}$. (341)

- martyrion des heiligen Theodoros 286 f. (357)

Kirchenväter $13,14,75,77,88$, 139 A. 677

Klarsicht/klarsichtig, s. Gabe

koimesis (Entschlafung) 68, $174 \mathrm{f}$. (80), 187 (111), 212 (178), 226 (216), 231 (228), 286 f. (357). S. auch Tod

koimeterion $247 \mathrm{f}$. (262)

koinobion, koinobitisch, Koinobiten $20 \mathrm{f}$, , 89, 201 (152), 224 (211), 271 (318), 303 (393) A. 784, 304 (396), 306 (401, 402), 307 (404)

Konversion, Bekehrung 28, 161 (27), 205 (160), 246 f. (261), 284 (351), 286 (356), 309 (407), 324 (446), 333 (471), 286 (356), 299 (383), 309 (407), 314 (422), 324 f. (446), 333 (471)

Korrespondenz des Barsanuphios und Ioannes $7,11,39,53,62,73$, 100 A. 494, 102, 106, 116, 140

Krankenhaus (iatreion, nosokomeion) 261 (301), 306 (402)

Krankheit und körperliche Schwäche 3 A. 7, 13, 28, 33 f., 38, 41, 48, 57, 58, 61, 67, 70 f., 73, 74 A. 334 , 85, 86, 89 f., 92, 93, 94, 129, 131, 134, 
135, 137, 140 f., 152, 154, 159 f. (21), 164 f. (43), 166 (52), 172 (70), 190 f. (118), 212 (178), 225 (213), 227 (219), 231 f. (229, 230), 233 (233), 235 (239), 239 (245), 246 (260), 248 f. (264), 250 (266), 251 (269, 271), 252 (275), 253 f. (279), 255 f. (281, 283, 285), 257 (289, 290), 258 (292), 260-262 (297, 300, 301, 303), 272 (322), 278 (336), 286 (356), 291 (367), 294 (374), 295 (377), 305 (397), 308 (406), 313 (419), 314 (423), 316 (426), 322 (440), $334 \mathrm{f}$. $(475,479)$

- Augenschmerzen $257 \mathrm{f} .(291)$

- Blindheit 33, 226 (217), $259 \mathrm{f}$. (296), 261 (301)

- Epilepsie (epilepsia, epileptiazo) 14, 79, A. 361, 91-94, 152, 165 (48)

- Fieber, fiebern (pyretos, pyresso) 28, 291 (367), 309 (408), 310 (409), 335 (479)

- Geschlechtskrankheit 260 f. (300)

- Krebs 258 (293)

- Lähmung 37, 135, 188 (113 [2]), 198 f. (139), 246 (260, 261), 316 (427 [1])

- Lepra 92 A. 443, 252 (275), 305 (397)

- Mondsucht (seleniasmos, seleniazomai) $91 \mathrm{f}, 248$ (263)

- myokephaloi (Augenkrankheit) 261 (301)

- Ohnmacht 90,200 (144), 325 (444)

- Pest 178 (90 [3]), 257 (290)

- Rheuma 322 (440)

- Stummheit 260 (298)

- Vergiftung 255 f. (283), 272 (322)

Kreuz, Kreuzeszeichen 23, 42 A. 174, 62, 86, 116, 119, $130 \mathrm{f}$, $141 \mathrm{f},, 185$ (106), 192 f., (123), 205 (161), 208 (167), 214 (184), 236 (239), 260 (296), 279 (338), 309 (407), 311 (411), 314 (422), 320 (430), 322 (439), 323 (442, 443), 332 (469), 333 (472), 334 f. (474, 475), $336(480)$

Kriegsgefangene $\quad 42$ A. 147,185 (106)
Lebensmittel

- Alkohol 224 (211)

- Brot 200 (144), 224 (211), 251 (269), 272 (320, 321), 305 (399), 315 (425)

- Früchte 274 (329)

- Korn $315(425)$

- Kräuter 295 (376)

- Pfannkuchen 305 (398)

- Salz 200 (146)

- Schweinefleisch $201 \mathrm{f}$. (152)

- Wasser 45, 59, 194 (124), 200 (144)

- Wein 247 f. (262), 256 (285)

Liber Syntipas 126

Liebe (agape, philtros) 165 (46), 214 f. (185)

- Liebe zu Gott 163 f. (37), 164 (39), 167 (57)

Liturgie, Gottesdienst $\quad 40,63,83,190$ (117), 211 (176), 213 (181), 217 (190, 191), 219 (195), 225 (213), 250 (266), 257 (291), 269 (314), 299 (384), 303 $(391,392)$

- Abendmahl, Eucharistie 28, 40, 82, 120, 196 (133), $201(149,151)$, 211 (176), 216-219 (188-196), 225 (213), 226 (214), 227 (219), 280 (340), 285 f. (355), 295 (376), 299 (384), 300 f. (386, 387), 302 (390), 303 (392), 305 (397), 313 (420), 323 (442)

- Abendmahlgeschirr 201 (151), 285 f. (355), 297-299 (380, 382)

- anaphora 217 (190), 218 (194), 298 (382)

- Doxologie $185(108), 217$ (190), 222 (206)

- nächtlicher Gottesdienst 213 (181)

- proskomide 218 (194), 219 (196), 226 (214), 298 (382)

- rhipidion $218(194)$

- trisagion 217 (190)

logismos, s. Gedanke und Geist

Magie, Zauberei (mageia, goeteia), Magier (magos), Zauberer (goes, periergos) 30, 86, 131-139, 144, 149, 190 (118), 199 (139), 240 (248), 247 
(261), 248 (264), 251 (269), 326 (451)

Mantik, Mantiker, Divination 121 , 131 f., 136, 138 f., 142, 146

- Astrologie, Astrologe (astrologia, astrologos) 30, 92, 121, $135 \mathrm{f}$., 141, 185 (107), 88 (113), 246 (261)

- Gastromantie 137 A. 670

- Geomantie, Pyromantie 141

- Hydromantie 137 A. 670

- Oneiromantie 54 A. 229, 145

- Rhabdomantie 142

- Weissagerin (gynaika engastrimythos) 191 (118)

Märtyrerakten 124 A. 613, 140

martyrion, s. Kirche

Meditation, Meditieren, spirituelle Versenkung/Kontemplation 25, 26, 28, 46, 56 A 236, 63, 71, 73, 79, 82, $105,106,148$

- Hesychase, Ruhen, Versenkung (hesychia, hesychazo) 25 A. 77, 83, 161 (25), 177 (90), 195 (129), 208 (168), 212 (179), 215 (187), 220 (201), 232 (231), 237 (239), 239 (245), 278 (335), 321 (434), 332 (469)

- kontemplative Erfahrung, spirituelle Kontemplation, Meditation (theoria, pneumatike theoria, melete) 159 (18), 161 (25), 164 (40), 165 (46)

- unverwandtes Hinschauen (atenizo) $\quad 25,26,67,211$ (174), 232 (230), 235 (239), 243 (254), 258 (295)

- Sitzen, in der Wüste (kathizo) 25 A. 78 u. 81, 72, 125, 158 (11), 166 (52), 168 f. (61), 171 (68), 172 (71), 203 (156), 212 f. (179), 223 (207), 224 (210, 211), 226 (217), 237 (241), 239 (244), 264 f. (308), 277 (332), 283 (347), 288 (360), 293 f. (373), 299 (383), 321 f. (437), 331 (466)

Mediziner, s. Ärzte

mimesis, s. Imitation

Mönchsregeln 21 A. 45, 65, 288 (360)

Mönchsschüler, Novizen 53, $203 \mathrm{f}$. (156), 220 (198), 235 f. (239), 238 (242), 239 (246), 243 (256) mysterion, s. Geheimnis

Mystik, mystisch 4 f., 21, 26, 47, 72, 74-85, 105 f., 140 f., 148, 152, 153, 154

Nacht, nachts, s. auch Psalmen, Vision u. Wachen 28, 31, 32, 33, 37, 38, 40, 41, 52, 53, 57-64, 66, 67, 69, 71, 73, $95,101,118,119,127,130,131,134$, 135, 144, 151, $159(21), 162(30,32)$, 163 f. (37, 39), 165 (44), 168 f. (61), 175 (83), 177 (90), 179 (92), 180 (93), 182 f. $(98,99), 189$ (115), 194 (125), 195 (129), 193 (135), 200-202 (148, 152), 203-205 (156, 159, 160), 206 f. $(163-165), 208$ f. $(167,169)$, 212 (177, 178), 213 (181), 214 (183), 215 (186), 221 (202), 224 (208), 224 f. (212), 226 (214, 216), 229 f. (225, 226), 231 f. $(228,229), 234$ (236), 235 f. (239), 237 f. (240, 241), 239 (246), 240 (249), 244 (259), 246248 (260-263), 250 (266), $252 \mathrm{f}$. (272, 277), 256 (286), 258 (292), 259 f. $(296,299), 261$ (301), 264 (306), 265 (310), 267-273 (311, 312, $314,315,317,319,323,324,326)$, 274 f. (330), 277 (334), 278 f. (337, 338), 280 (340), 281 f. $(344,345)$, 283 f. (347, 349, 351), 285 (353), 286 f. (356-359), 288 f. (362), 291 (366, 368), 292 (369), 293 (372), 296 f. $(378,379), 300$ (386), $306 \mathrm{f}$. (401, 403), 308 (406), 309 (407), 310 (410), 311 f. (412, 413, 415), 315 (424), 316 f. (427, 428), 319 f. (430, 431), 322 (438), 323-325 (444-447), 326 f. (453), 329 (459), 330 (461), 331 (466), 332 f. (469, 470), 336 (481)

nesteia, s. Fasten

Neues Testament, neutestamentlich 4 A. 10,42 A. $175,49,50,62,63,69$, 75, 86, 91 f., 98, 100, 102, 103, 104, 122, 124 A. $611,126,144,149$

Neuplatonismus, neuplatonisch 4 A. 10, 27, 76, 105, 148, 152

Offenbarung, offenbaren (apokalypsis, apokalypto) 19, 20-23, 24, 26, 
$29,30,35,36,41,46,47,49-51,52$, 53, 69, 72 A. 327, 75, 79 f., 97 f., 102, 104, 106, 112 f., 114, 116, 117, 123 f., 126 f., 128, 131, 138, 145, 149, 151, 152 A. 736, 153, 157 (7), 158 (12), 159 (16), 161 (26, 28), 170 (66), 173 (74), 175 (82), 176 (85), 177 (89), 178 (90 [3]), 182 (97, 98), 184 (103, 106), 188 (113), 190 (117), 194 (124), 195 (129, 131), 198 (139), 199 (141), 202 (153), 204 (158), 233 (231, 232), 235 (237, 238), 237 (241), 239 (247), 240 (250), 243 (257), 271 (319), 273 (325), 278 (337), 288 (362 [1]), 294 (375), 308 (406), 313 (420), 326 (452), 327 (453), chresmos 176 (87)

- Berufungsoffenbarung, Inspirationsoffenbarung $\quad 41,127 \mathrm{f}$., 203-215 (154-187)

- Jenseitsoffenbarung 223-270 (207-316)

- göttliche Offenbarung (theia apokalypsis, theike optasia) 170 (64), 191 (118, 119), 235 (237), 243 (257)

- Offenbarungstraum, s. Traum

- Offenbarungsvision, s. Vision

Ohr, Ohren (akoe, us) 21, 32, 55, 253 (278), 161 (27), 205 (159). S. auch Hören

Öl, heiliges (hagiasma) 248 (263), $256(285)$

onar, s. Traum

oneirokritika, s. Traumhandbücher oneiros, oneiropoleo, s. Traum ophthalmos, ophthalmophanos, s. Auge opsis, s. Angesicht, Auge, Gesicht, Schau optasia, s. Gesicht, Schau, Vision orge, s. Emotionen

Origenismus 27

Parabel 126

Paradies (allg.) 45 f., 115. S. auch Jenseits

Paralipomena Pachomio et Theodoro, s. De Sanctis Pachomio et Theodoro paramonarios 287 (359) parekstasis, s. Ekstase
Passio Perpetuae et Felicitatis 68, 124 A. 613,140 A. 687

pathos, s. Untugenden

peirasmos, s. Versuchung

penthos, s. Emotionen

Pflanzen

- Baum 274 (329), 335 f. (480)

- Binsen $179(91)$

- Kürbis 200 (147)

- Maulbeeren 201 (150)

- Reben, Weinstock 176 (86), 279 f. (338)

- Tamariskenbaum $273 \mathrm{f} .(327)$

phantasia, phantasma, phasma, s. Trugbild

Philosophielehrer 225 (213)

Philotheos Historia 12, 33, 36 f., 93, 142

phone, s. Stimme

phthonos, s. Dämon

Platonismus, platonisch 56 f., 76, 87

pneuma, s. Geist

pneumatikos 77 A. 354, 172 f. (73), 220 (198)

pneumatikos pater, s. Verwandte

Pollution, s. Erguss

praktikos, praktike (asketische Methode) 27 A. 89, 56, 57, 59, 105 A. 533, 168 f. (61)

Pratum Spirituale 12, 23, 34, 40, 51

Priesterschaft, Priester 160 (21), 176 (87), 216 (188), 253 f. (279), 263 (304), 280 (340)

Prophet, Propheten (prophetes) (allg.), Prophezeiung 20,75, 78, 79, 131-133, 138 f., 144, 146, 161 f. (29), 176 (87), 183 (101), 198 (139), 227 (218). S. auch Gabe (charisma)

- falscher Prophet, falsche Prophezeiung, Scheinprophezeiung 14, 75, 88 f., 133, 136

- Prophetenbücher 146

- Todesprophezeiung 85, 140 pronoia, s. Gott

prooratikos 143,147 A. 721

propheteia, s. Gabe proskomide, s. Liturgie prosopon, s. Angesicht, Gesicht 
Prostitution, Prostituierte 162 (30), 201 (151), 224 f. (212), 269 f. (316), 327 (454)

protokomes $227(218[1])$

Prozession 141, 192 f. (123)

Psalmen Psalmodie, Pslamengesang, -gebet 25 A. 80 u. 81, 63 A. 265 , 68, 71, 170 (66), 177 (90), 200 (145), 222 (206), 227 (219), 232 (230 [1]), 234 (234, 236), 236 (239), 243 (253), 289 (362 [2]), 291 (368), 303 (393), 321 (435), 325 f. (450)

- nächtliche Psalmodie 66, 69, 200 (148), 247 (262), 250 (266), 256 (286), 275 (330)

psyche, s. Seele

Psychoanalyse 6

Psychopathologie/psychopathologisch 3, 8, 70 A. 315

pyretos, s. Krankheit

Quelle 38, 45, 128, 203 (154), $241 \mathrm{f}$. (252), 273 (325)

Raserei s. Verrücktheit, Ekstase

Reliquien 35 A. 140, 37 A. 151, 39, 121 A. 599, 130, 141, 231 f. (229), 279 (338), 306 (403), 312 (415)

Scala Paradisi $\quad$ 12, 51, 59-62, 79, 81, 118, 133

Schatten 28, 51, 52, 165 (47), 185 (108), 250 (267), 258 (295), 273 (327), 281 (342)

Schau 2, 23, 24-26, 29, 46, 53, 76, 77, 79, 80, 84, 104, 105, 115, $117 \mathrm{f} ., 126$, 129, 130, 131, 153, opsis 257 (290), optasia 278 (335), theoria 75, A. 343, 160 (22), 161 (25), $164(38,39), 166$ (54), 168 f. (61), 172 (71), 184 (106 [2]), 185 (107), 186 (108, 109), $188 \mathrm{f}$. (113 [2]), 200 (145), 201 (148), 219 (196), 229 (224), 236 (239), 244 (259), 253 (277), 260 (297), 275 (330), 283 (346), 316 (427 [2]), 334 (475). S. auch Gesicht, Vision, Meditation

- dämonische Schau 105
- Gottesschau, göttliche Schau 5, 26 f., 63, 105 f., 148, 151, 153. S. auch Gesicht, Erscheinung, Vision

- spirituelle, intellektuelle Schau (pneumatike theoria) 27,30,75, A. 342, 87, 164 (40). S. auch Meditation

- unkritische Schau (adiakritos theoria) 119, 170 (67)

- Zukunftsschau 132, 134, 141

Schiff, Schifffahrt 179 (91), 204 (157), 228 (221), 278 (335), $307 \mathrm{f}$. (405), 327 (455)

- Kapitän 284 (351)

- Reeder 296 f. (378)

- Schiffbruch 44, 271 (318)

Schlaf, Schlafen (hypnos, hypnoo, katheudo) 28, 32, 34 A. 134, 41, 42 A. $174,46-48,49-69,62-69$, 70 A. $315,74,75,76$ A. $374,79-81$, 93 A. $450,95,118,129,133$, 135 A. $663,151,157(1,2,3,5), 161$ (25), 162 (30), 164 (43), 165 (45, 50), 166 (56), 173 (75), 178 (90), $180 \mathrm{f}$. (94), 183 (101), 184 (102), 194 (125), 200 (148), 203 (156), 205 (160, 161), 207 (165), 212 (178, 179), 213 (180, 181), 214 (182, 185), 220 (198), 221 (201), 222 (205), 225 (212), 226 (217), 234 (234), 235 f. (239), 237 (240), 241 (250), 242 (252, 253), 243 (257), 247 (261), 249 (265), 253 (278), 256 (285), 257 (291), 258 (292), 261 (300), 265 (310), 267 (311), 268 (313), 269 (315 [1]), 274 (330), $277(332,333), 278(335,336)$, 281 (344, 345), 284 (351), 285 (354, 355), $286(356,357), 295(376,377$ [1]), 296 (378), 300 (385), 301 (389), 302 (391), 303 (393), 304 (395), 309 (407), 310 (408, 409), 311 (413, 414), 312 (417), 313 f. (318, 421), 314 (422, 423), 321 (435), 323 f. (444), 324 (446)

- schläfrig (hypnodes) 157 (1)

Schlechte, das, Übel (kakia, kakon) 89, 119, 125, 136, 149, 157 (1), 159 (19), 164 (42), 165 (46), 199 (139), 256 (283, 286), 275 (331), 294 (373), 296 (377) 
Schmerz, schmerzhaft $\quad 77,129,181$ (96), 232 (231), 250 (286), 256 (285), 257 (291), 260 (299), 268 (313), 294 (374), 306 (402), 309 (407), $317 \mathrm{f}$. (429), 319 (430). S. auch Geburt

Schweigen (siope, siopao, sigao) 21 23, 24 f., 29, 72 A. 327, 84, 157 (8), 165 (49), 186 (109), 224 (210), 265 (308)

Sehen, Schauen (imaginär, geistig) 1, 14, 20, 21, 22, 25 f., 28, 29, 32, 33, 35, $36,38,40,41,44,45,46,49,52,53$, $56,64,66,67,69,73,75,76$ А. 345 , 77 A. $355,80-86,89,95,96,97,102$, 103, 104, 106, 114, 117 A. 574, 123, $125,127,128,129,131,135,136,137$, $140,141,142,143,144,147,148,149$, 153, 154, 157 f. (8), 158 (12), 159 (18), 161 (25, 27), 162 f. (31-33), 163 35, 36), 164 (38), 165 (45), 166 (52), 168 (60), 170 (66), 172 (71), 173 (75), 174 (77), 175 f. (85), $176-$ 181 (89-96), 184-187 (102-110), 187-189 (112, 113, 115), 190 f. (117, 118), 192 (120, 122), 194 (125), $195 \mathrm{f}$. (127, 129, 132), 197 (136), 198-201 $(138,139,143-145,147,148,151)$, 203 (154, 155), 204-207 (157-161, 163-165), 208-212 (167-169, 171 174, 176, 177), 213-219 (180, 183, $185,187,188,190-192,194-196)$, 220-223 (197-199, 203-208), 224 (210), 225-233 (213, 214, 217-232), 233-241 (234-236, 239, 241, 242, 244-247, 249-251), 242-249 (253, 255-262, 264), 250 (266-268), 251 (270), 252-255 (273-275, 277, 279282), 256 (284-286), 257-263 (288297, 300-304), 265-367 (309-311), 269 f. (316), 271 (318), 272 (320322), 273 (324), 273-276 (327-331), 277 (334), 278 (337), 281 (342),

283 f. $(346,347,349,351,352), 285-$ 287 (354-357), 288 f. (361, 362), 291 (366, 368), 292 (370), 293 f. (371, $373,374), 295-301$ (377-380, 382385, 387-389), 302 f. $(391,392), 305$ $(397,398), 306$ f. $(402,403), 308-$ 310 (406-409), 311 f. (413, 414, 415, 417), 313 (419), 313-317 (421-428),
320 (431), 321 (433, 436), 325 f. (447, 449-451), 327 (455), 328-330 (458, 459), 331 (464, 466), 333 (470), 334 (475), 335 (477)

- Sehen ist zuverlässiger als Hören 95-100

Seele (psyche) 2 A. 3, 16, 21, 47, 48, 54, 57, 58, 60, 64, 69, 71, 75, 84, 118, 120, 127, 137, 140, 147, 148, 154, 158 (12), 162 (32), 164 f. (43), 165 (46), 166 (52, 53), 167 (57), 169 (63), 170 (66), 177 f. (90), 190 f. (118 [1]), 196 (132, 133), 197 f. $(136,137), 198 \mathrm{f}$. (139), 215 (186), 223-238 (207241), 239 (246), 240 (249), $242 \mathrm{f}$. (252-254, 256), 254 (279 [3]), 257 (289), 258 f. (292, 295), 286 (357), 297 (378), 298 (381), 301 (387), 307 (403), 309 f. (408), 316 (427), 324 (446), 327 (454), 335 (478)

- begehrender Teil der Seele (epithymikon) 57, $159 \mathrm{f}$. (21)

- Hauptteil der Seele (hegemonikon) 56

- sehender Teil der Seele (tes psyches optikon) 164 (38)

- verständiger Teil der Seele (logike psyche) 89, 159 (19)

- zorniger Teil der Seele (thymikon) $57,159 \mathrm{f}$.

- Seelenruhe (galene) 118, 160 (21)

Selbstmord, Selbsttötung 163 (34), 232 (231)

seleniasmos, s. Krankheit

semantron $182(99)$

semeion, s. Zeichen, Wunder

Septuaginta, Altes Testament

42 A. $174,49,51$ A. $215,75,79,81$, $88,98,101,124$ A. 613,132 A. 645 , 149

Silberschmied $286 \mathrm{f}$. (357)

siope, s. Schweigen

Sitzen, s. Meditation

Sklaven 273 (323), 280 (340), 317 (428)

Soldaten 191 (119), 250 (267), 273 (323), 276 (331)

Speisen, s. Lebensmittel

Spiegel, Spiegelbild $\quad 51,162(31), 231$ (229) 
Staub, heiliger $\quad 34,38,253$ f. (279), 316 (427)

Stimme (akoe, phone, phonein) 21, 23, 36, 37, 42, 47, 90, 98, 104 f., 107, $110-113,125,126,127,129,137$, 148, 158 (10), 172 (71), 175 (85), 179 (92 [2]), 181 (94, 96), 187 (109), 196 (132), 204 (157), 205 (259), 209 (170), 211 (174, 175), 212 (177), 216 (188), 217 (192), 223 (207), 225 (212), 227 (218), 232 (230), 234 (235 [3]), 238 (241), 244 (258), 245 (259), 255 (283), 258 f. (295), 263 (305), 273 (326), 277 (334), 278 f. (337), 283 (348), 285 (354, 355 [2]), 290 (365), 293 f. (371-374), 297 f. (380), 303 (392), 305 f. $(397,399,400), 308$ (406 [2]), 314 (421), 319 (430), 336 (481). S. auch Audition und Hören

- heilige Stimme (phone hiera) 21, 232 (230 [1]), phone ... hagia 290 (365)

- Stimme Gottes, göttliche Stimme (phone theu) 205 (159), 245 (259), 305 (397), phone tis ... theia 227 (218 [2]), theia phone 227 (218 [4]), phone tu kyriu 259 (295)

Stoizismus, stoisch 56,76

Strafe, Bestrafung 19,38, 39, 65, 115, 137, 166 (55), 189 (113), 243 (256), 260 (299), 265 (308), 308 (405), 317 (428)

Sufismus 3 f., 19 A. 39, 72

Synoden, Konzilien 302 (390)

- Ankyra 121 A. 599

- Karthago 121 A. 599

- Laodikeia 121 A. 599

- Latopolis 148 f., 197 f. (137)

tapeinophrosyne, s. Tugenden

Tempel $182(97,98), 283(346), 326 \mathrm{f}$. (453)

Teufel (diabolos) (allg.) 28, 44 A. 181, 116, 119 f.,133, 188 (113), 216 (188), 240 (248), 263 (305), 273 (326), 308 (406), 311 (412), $321 \mathrm{f}$. (436, 437), 323 (442), 324 (446), 325 (447), 327 f. (456), 329 f. (459-461), 331 (464) thauma, s. Wunder

theama, s. Gesicht

Theater, Schauspielerei $\quad 65,312$ (418)

theophaneia, s. Erscheinung

theorema, s. Gesicht, Vision

theoria, s. Gesicht, Meditation, Schau, und Vision

theotokos, Muttergottes 65,

68 A. 307, 238 (242), 300 (385),

312 f. (418), 331 (465)

threnos, s. Emotionen

Tiere

- Bär $200(147)$

- Esel 168 (60)

- Kamele 274 (328)

- Leopardin 200 f. (148)

- Löwe 189 (115)

- Maultier 189 (114)

- wilde Tiere $281(342)$

- Wildschwein 189 (114)

Tod, tot, Sterben $\quad 21,22,23,26 \mathrm{f}$, , 28, $32,36,41,42,68,69,79,81,82,85$, 90 f., 118, 119, 120, 129, 133, 135, 137, 138, 140 f., 147, $158(12,14)$, 162 (30), 165 (48), 166 (52), 167 (57), 168 (60), 172-174 (72, 73, 75, 79), 175 (83), $176(86,87), 179$ (91), 183 (100, 101), 184 (104, 105), 189 (113), 190 f. (117, 118), 192 (121), 194 (124), 195 f. (132, 133), 201 (149, 150), 204 (157), 212 (178), 213 (180), 218 (195), 220 (199), 221 (202, 203), 223-237 (207-240), 238 (242), 239 (247), 241 (250), 253 (278), 257 (289), 258 (292), 260 (299), $263 \mathrm{f}$. (306), 265 (309), 267 f. (312), 271 (317), 273 f. (327), 285 (353), 289 f. (362 [5]), 296 (378), 301 (388), 305 (400), 306 f. (403), 311 f. (414, 417), 314 (422, 423), 315 f. (425, 426), 320 (430), 324 (446), 327 f. (456), 329 (459), 334 f. (475). S. auch koimesis, Prophezeiung, Vision, Begräbnis

Topos $6 \mathrm{f},, 31,42,43$ A. 178

Traditio Apostolica 121 A. 599

Trance (religiöse) 3, 13, 14, 46, 69, 70-74, 77, 79, 82, 83, 100, 103, 151, 152,154

Traum, Träume 2, 8, 33, 41 f., 42, 47, 49-69, 73 f., 79, 81, 84, 87, 95-97, 
100-102, 105, 108, 115 f., 118, 120, 133 f., 135, 139, 140 f., 143, 151 f., enypnion 100-102, 108, 160 (21), 165 (44), 166 (55), 169 (62), 176 (85), 181 (101), 204 (158), 206 (163), 207 (164), 215 (186), 231 f. (229), 268 (313), 297 (379), 311 (413), 322 (440), 324 f. (446), 333 (473), hypar 100 A. 495, 108, 180 (93), 268 (313), kat' onar 50 A. 211, 100, 102, 108, 164 (41), 192 (122), 204 (159), 206 (162), 256 (285, 286), 263 (305), 265 (309), 269 (316), 278 (335), 281 (345), 284 (350), 303 (393), 306 (402), 309 (408), 314 (422 [3]), 315 (424), 317 (428), 322 (440, 441), 323 (442), onar 100 f., 108, 166 (51), 180 (93), 181 (94), 203 (154), 204 (158), 250 (268), 256 (286), 309 (407), oneiros 100-102, 108, 159 (18), 161 (24), 165 (47), 247 (261), 286 (356), 422 (439)

- träumen (enypniazo) 108, 323 (443), oneiropoleo 100, $164(37,39)$

- Träumer (enypniastes) 175 (85)

- Berufungstraum 102

- Belehrungstraum 115

- Traumbild 53, 54, 56, 62, 64, 102, 122

- Doppeltraum, Wiederholungstraum 115, 169 (62), $301 \mathrm{f}$. (389)

- dämonischer Traum (enypnion daimoniodes) 53,157 (6)

- Engelstraum, engelhafter Traum 118, 152, enypnion angelikon 157 (6), ta hypnia ton angelon 160 (21)

- Traumerscheinung (phantasia oneiron) $\quad 51,120,323$ (442)

- Offenbarungstraum 13, 51, 102

- Privilegierungstraum 42 A. 174, 139

- Träume der Ruhmsucht (kenodoxias enypnia) $159 \mathrm{f}$. (21)

- schlechte Träume (ponera enypnia) 118, 166 (56), 322 (439)

Traumdeutung, Traumdeuter 3, 15, 101, 116, 121 f., 131 f., 138, 143-146, $152,153,270$ (316)

Traumhandbücher (oneirokritika) 4, $121 \mathrm{f.}, 144,146$
Traumheilung 73, 86 f., 154. S. auch Inkubation

Trugbild, Täuschung, dämonische Erscheinung (phantasia, phantasma, phasma) 1, A. 2, 29, 44, A. 181, 46, 49, 51, 53, 55-60, $63 \mathrm{f} ., 73,104$, A. $524,105 \mathrm{f},, 114$, A. 554, $118 \mathrm{f}$, 136, 151, 153, 157 (1), 159 (18), 160 (21), 165 (45, 46, 50), 167 (57), 169 (64), 206 (161), 271, 168 (60), (317), 319-320 (430), 322 (440), 323 (442), 325 (446, 447), 326 (452), 329 (459), 330 (461), 332 (470), 336 (480)

- nächtliches Trugbild 53, 325 (447)

Tugenden, asketische

- Demut, demütig (tapeinophroyne, tapeinosis) 23, 29, 37, 125, 142, 159 (17), 166 (54), 170 (66), 220 (200), 236 (239), 264 (308), 265 (310 [3]), 294 (373), 326 (452)

- Enthaltsamkeit, enthaltsam (engkrateia) $\quad 76$ A. 347, 239 (247), 264 (308)

- Hoffnung (euthymia) 118, 167 (57), 169 (64), 210 (173), 240 (248), 246 (260)

- Keuschheit (agneia) 59 f., 165 (50)

- Leidenschaftslosigkeit (apatheia) $27,54,56,57,58,61,118,119,165$ $(44,45), 167$ f. (57)

- Mäßigung (sophrosyne) 59

- Mut, mutig, Furchtlosigkeit 118, 119, 136, 167 (57), 197 (135), 207 (165), 208 (168), 214 (182-184), 244 (259), 267 (312), 269 (314, 315), 319 (430), 325 (446), 329 (459), 332 (469)

- Tugend, Tugendhaftigkeit (allg.) (arete) 63, 89, 118, 132, 159 (19), 165 (46), 167 (57), 171 (69), 205 (160), 243 (255), 270 (316), 335 (478)

- Wachsamkeit 52,62 A. 263, 65, 68, 69

unbeschreibbar, unbeschreiblich (aperigraphos, aphrastos, arretos etc.) 21 f., 164 (38), 180 (92 [3]), 186 (109 
[1, 2]), 209 (170), 230 (227), 247 (262 [2]), 258 (292), 281 (342)

unsichtbar, das Unsichtbare (aoratos, ta me blepomena) 22, 26, 32, 98, 114 A. 554, 153, 162 (31), 163 (33), 170 (66), 210 (171), 233 (233), 244 (259), 250 (267), 253 (278)

Unterscheidung Geister, Unterscheidungsgabe s. Gabe (charisma)

Untugenden, asketische

- Gleichgültigkeit, Nachlässigkeit, Unachtsamkeit (akedeia, ameleia) 118, 166 (52), 167 (57), 209 (170), 243 (256), 249 (264), 257 (289), 283 (347), 309 (408), 322 (439), 333 (472)

- Hoffnungslosigkeit, Verzweiflung (apognosis, athymia) $\quad 68,120,168$ (59), 236 (239), 268 (312), 278 (336), $296(377,378)$

- Hurerei, Unzucht (porneia) 59, 60, 64, 90, 232 (231), 263 (304), 303 (391), 322 (438), 324 f. (446), 331 (465), 333 (472)

- Kummer, s. Emotionen

- Leidenschaft (pathos) 56, 58, 63, 89, 159 (20), 160 (21), 249 (265), 307 (405), 327 f. (456). S. auch Emotionen

- Liebe zum Geld 333 (472)

- Überheblichkeit, Stolz (hyperefaneia) 29, 89, 125, 159 (20), 164 (42), 294 (373), 307 (404), 324 (445)

- Völlerei, Maßlosigkeit, Gefräßigkeit (gastrimargia) $\quad 55,59,60,166$ (55)

- Zerstreuung $\quad 73,159$ (18), 331 (466)

- Zorn, s. Emotionen

Verrücktheit, Wahnsinn, verrückt/ wahnsinnig sein, Raserei, rasen 76, 87-94, 120, 135, 137, 138, 307 (404), ekphron 191 (118), ekstasis 159 (20), 163 (34), 324 (445), ekstasis elauno 93, A. 450, ekstasis phrenon 158 (9), 164 (42), existamai dianoias 88, A. 422-425, mania 164 (42), phrenoblabeo 325 (447)
Versuchung (peirasmos) 53, 61, 63, 157 (3), 216 (188), 307 (405), 315 (425), 321 (433), 335 (478)

Verwandte 92 A. 442, 118, 129 A. 635, 144 f., 167 (57), 214 (183), 267 (311)

- Ehemann, Ehefrau 144 f., 214 (183), 307 f. (405)

- Eltern, Vater, Mutter $31 \mathrm{f}$, 42 A. $174,52,68$ A. $307,90,91,97$, 129 A. $635,141,143,150,165$ f. (51), 177 (89), 187 (111), 214 (183), 224 f. (212, 213), 229 (224), 231 (228), 238 (241), 239 (247), 246 (261), 250 (268), 253 f. (278, 279), 257 (289), 260 f. (298, 300), 263 (304), 267-270 (311-316), 272 (322), 280 (341), 281 (344), 286 (356), 287 (258), 302 (391), 305 (399), 317 (428), 325 (449), 334 (475)

- geistlicher Vater (pneumatikos pater) 64, 145, 187 (111), 244 (259), 283 (346), $290(363,365)$

- Geschwister, Schwester, Bruder 42, 93 A. 450, 140 f., 208 (167), $231 \mathrm{f}$. (229), 239 (247), 301 (388), $302 \mathrm{f}$. (391), 313 (419)

- Großmutter 234 (236)

- Kind, Sohn, Tochter 32, 42 A. 174, 90, 91, 126, 129 A. $635,135,140$, 143, 182 (97), 214 (183), 225 (213), 230 (227), 243 (257), 246 (261), 253 f. (279), 260 (298), 263 (304), 265 (308), 268-270 (314-316), 272 (322), $280 \mathrm{f}$. (341), 287 (358), $296 \mathrm{f}$. (378), 316 (426)

Verzückung, in Verzückung geraten (eneazein, existemi) $\quad 77,103,160$ (22), 218 (195)

visio corporalis, visio spiritalis, visio intellectualis (Augustinus) 47

Vision 2, 3, 5, 13, 19-21, 23, 27, 29, 41 f., 45-48, 49 f., 52, 66, 69, 70 f., $85,95,97,104,107,110-113,114$, 119 f., 123, 126, 127 f., 130, 137, 139, 149, 151-153, horama 161 (27), 163 (35), 170 (66), 176 (89), 179 (91), 189 (115), 203 (155), 205 (159), 206 (161), 251 (270), 255 (280 [3]), 257 (290), 258 (294), 261 (302), 273 
(324), 277 (333), 289 (362 44]), 290 (365), 297 (378, 380), 306 (401),

$311 \mathrm{f}$. (414), 316 (426), horasis 185 (106, 107), 189 (113), 190 (117), 216 (188), 244 (258), 279 (338), 285 (355), 310 (409), 334 (475), optasia 158 (8), 163 (36), 169 (63), 174 (75), 179 (92), 187 (110), 192 (120), 197 (135), 203 (154), 204 (157), 206 (161), 211 (174), 214 (182), 219 (196), 226 (216), 228 (221), 229 (222), 231 (227), 233 (231), 234 (234), 237 (240), 238 (241), 241 (251), 243 (253), 249 (264), 253 (277), 258 (291), 261 (301), 264 (306), 267 (312), 282 (345), 287 (357, 359), 292 (369), 305 (397), 313 (420), 316 (426), 323 (442), 330 (459), theorema 320 (430), theoria 157 (8), 188 (113), 191 (118 [1]), 210 (171). S. auch Gesicht, Schau

- Bestrafungsvision 65

- eine Vision haben (horamatizomai) 244 (258)

- Engelsvision (optasia angelike) 80, 160 (23)

- göttliche Vision 22, 46 (horaseis tines theioterai) 161 (25), theia optasia 185 (106 [3]), 313 (420)

- Vision der Heiligen, Heiligenvision (hagion optasia) 167 (57)

- Vision der göttlichen/heiligen Dinge (optasia ton theion) 117,328 (458)

- in einer nächtliche Vision (en oramati tes nyktos) 33, 37, 66, 144, 229 (225, 226), 231 (228), 234 (236), 260 (296, 299), 267 (311), 278 (337 [2]), 279 (338), 289 (362 [5]), 316 (427)

- Inspirationsvision $127 \mathrm{f}$.

- Prophezeiungsvision 42, 81, 83, 141

- Todesvision 23, 41, 81, $140 \mathrm{f}$.

- Traumvision, Visionstraum 49, 54, 108,140

- Visionserzählung, Visionsbericht 81, 83, 95 f., 97, 126, 153

Vita Antonii $\quad 11,81,82,93,118,132$, 152

Vita Danielis Stylitae $\quad 11,51,102-112$
Vita Euthymii

Vita Hypatii

$11,31 \mathrm{f}$, , 44, 73, 86

Vita Macrinae

$11,38,52,53,92$ 140

Vita Marthae 11, 130

Vita Nicolai Sionitae 11

Vita Pachomii $\quad 11,50,89,90,119,127$, 148, 153

Vita Porphyrii $\quad$ 12, 90, 98 A. 487, 134

Vita Symeonis Stulti (Symeon Salos) 52, 129

Vita Symeonis Stylitae junioris 11 A. 36, 12, 23, 32, 37, 48, 91, 103, 135,137

Vita Symeonis Stylitae senioris $\quad 12,22$, 35

Vita Theodori Syceota 12, 90, 136,

Vollendung (spirituell), vollendet 26, 46, 56, 73, 117, 159 (18)

Völker

- Hunnen $176(86)$

- Iberer (Georgier) 185 f. (108), 222 (204), 278 (337)

- Perser 135, 181 (95), 184 f. (106), 191 (119), 215 (187), 228 (221), 246 f. (261), 275 f. (331)

- Sarazenen (Araber) 35, $246 \mathrm{f}$. (261), 274 (328), 275 f. (331)

- Skythen 181 (95)

Wachen, wachend, schlaflos (agrypnia, pannychis, aypnos) 13,25 A. 76 u. $81,27,56,62-69,71,73,74,80$, 151, $157(1,2,3,4,5), 181(96), 197$ (135), 211 (174), 235 f. (239), 257 (291), 263 (304), 264 (407), 273 (326), 277 (334), 284 (351), 292 (369), 324 (446)

Wachs $157(1,4), 261(301)$

Wahnsinn, s. Verrücktheit

Wasser $\quad 34,79,91,137$ A. 670, 173 (75), 175 (82), 252 (274), $254 \mathrm{f}$. (280), 272 (322), 273 (325), 284 (352), 331 (464)

- Wasserflut $252 \mathrm{f}$. (277)

- Wasserkrug 324 f. (446)

- Wassermangel 306 (401)

- Wasserschöpfen 324 f. (446)

Weberinnen $213 \mathrm{f}$. (182) 
Wetterbedingungen, Naturgewalten

- Erdbeben 136, 143, 176 (86), 183 (99), 185 (107), 186 f. (109, 110), 222 (205), $280 \mathrm{f.}$ (341)

- Hagel $176(86)$

- Hitze 28, 93 A. 450, 200 (144), 273 f. (327)

- Kälte 79, 93 A. 450, 173 (75), 255 (281)

- Sturm 228 (221), 278 (335), 284 (351), 327 (425), 327 (455)

- Unwetter 252f. (277), 284 (351)

- Wind 173 (75)

Wirtsstube (phuskarion) $33(471)$

Wunder (thauma, semeion) 33, 34, 36-39, 107, 161 (27), 163 (33), 188 (113 [2]), 195 (124), 205 (159), 217 (190), 222 (205), 247 (262) , 274 (329)

- Wunderheilung 31,33 A.130, 86,
- Wundererzählung 86

- Wundertäter 33, 34, 136 A. 667

xenodocheion, s. Hospiz

Zauberei, s. Magie

Zeichen, Vorzeichen 15, 26, 34, 57, $60,61 \mathrm{f}, \mathrm{6}, 65,107,115$, A. 560, 116, $118,123,130,132,135,141-143$, 144 f., 153, 181 (95), 251 (269), semeion 176 (89), 178 (90), 192 (123), 216 (188), 279 (338 [2]), 329 (459), symbolon 164 (43), sphrangis 260 (269), 333 (472), tekmerion 165 (45), teras 329 (459)

- Zeichendeutung 15,141-143, $145 \mathrm{f}$.

Zunge (glosse) 73, 88, 128, 159 (18), 203 (154), 265 (308) 154 


\section{Index der Motive imaginärer Erfahrungen}

\author{
Abgrund (abyssos) 274 (329) \\ Adam 244 (258) \\ Altar $172(71), 178$ (90), 190 (117), \\ 206 (162), 297 (379) \\ - Altartuch $258 \mathrm{f}$. (295) \\ Angeklagte, vierzig $307 \mathrm{f}$. (405) \\ Apostel $240 \mathrm{f}$. (250) \\ Apsis (drei Apsiden) 244 (258) \\ Arena 208 (168) \\ Armer, gelähmt 188 (113[2]) \\ Äther (des Himmels) 244 (258), 252 \\ (273) \\ Äthiopier 208 (168), (mit Augen, aus \\ denen Feuer schießt) 247 f. (262 \\ [3]), 293 f. (373), 299 (384), (von \\ fürchterlichem Aussehen) 310 \\ (409), 314 (422), (Pfeile schießend) \\ 321 (433), (mit den Zähnen knir- \\ schend) 321 (435), 324 (445)
}

Bauer, Bauern 199 f. (143), 230 (227 [1])

Becher 216 f. (189)

Berg 177 (89), 230 (227 [1])

Besessener (Theodoros) $252 \mathrm{f}$. (277)

Bett (leuchtendes) $173 \mathrm{f}$. (75)

- zwei Betten 207 (164)

Bild, Ikone (des Symeon Stylites sen.) 234 (234)

Bischöfe, Patriarchen, Päpste 227 (219), (zwei Bischöfe) 263 f. (306)

- Dionysios, Bischof von Seleukeia $187 \mathrm{f}$. (112)

- Dominos III., Patriarch von Antiocheia 190 (117)

- Ephraimios, Bischof von Antiocheia 234 (235)

- Eulogios, Patriarch von Alexandreia $301 \mathrm{f}$. (389)

- Ioseph, Patriarch 243 (255)

- Leon I., Papst von Rom (400-461) (als frommer und großer Mann) 301 f. (389)
Bischofsgebäude (episkopeion)

$228 \mathrm{f}$. (222)

Blitz 288 f. (362 [1]), 299 (384), 324

(445)

Blut $216 \mathrm{f}$. (189)

Brüder (Mönchs-) 179 f. $(91,92)$, 229 f. (226), 258 (292)

- leiblicher Bruder $240 \mathrm{f}$. (250)

- zwei (leibliche) Brüder $239 \mathrm{f}$. (247)

Buch (des Lebens) 209 f. (170)

Cherubim (Gestalt des Firmaments mit Händen von vier Männern, die einen Saphir auf dem Rücken tragen) $258 \mathrm{f}$. (295)

Dämon, Dämonen (allg.) 160, $241 \mathrm{f}$. (252), (zwei Dämonen) 250 (266), 250 (268), (schwarz, furchterregend, ohne Kopf) 253 f. (279 [2]), (gefesselter Dämon) $254 \mathrm{f}$. (280), (schwarzer Dämon) 255 (281), 255 (282), (zwei Dämonen mit Fesseln) 274 (329), 331 f. $(465,467)$

- als Äthiopier (hässlicher) 327 (454), 333 (471)

- der Brot zeigt 323 (442)

- als Christus 169 f. (64), 323 (442), (von tausend Engeln umgeben, die tausend Leuchten und ein brennendes Rad halten) 325 (447), $328 \mathrm{f}$. (458)

- als Bären $319(430)$

- als Drache 257 (288)

- als dunkler Inder $254 \mathrm{f}$. (280)

- als Engel (des Herrn) 311 (411), 321 (434)

- die Eucharistie zeigend 323 (442)

- als Fliegen 194 (125), 320 (431)

- als Frau 247 f. (262), (schreiende, wehklagende schwarze Frau) 256 (284), (als schöne Frau) 327 f. 
(456), (als nackte Frauen) 328 (457), 335 (476)

- als Hahn 328 (457)

- als schwarzer Hund 335 f. (480)

- als Jüngling (ungestüm, mit leuchtendem Gesicht, blondem Haar, neckisch lächelnd) 330 (460)

- als Kamele mit Drachenköpfen 326 (451)

- als Knabengesicht 334 (474)

- als Leoparden 319 (430)

- als Löwen 319 (430)

- als Maus 257 (287)

- als furchterregender Mensch 311 (412)

- als Raben 240 (248), 332 f. (470)

- als Riesen 323 f. (444)

- als Schlangen 319 (430), $332 \mathrm{f}$. (470)

- ein Schwarm von Dämonen 319 (430)

- als Skorpione 319 (430)

- als engelhafte Soldaten mit Feuerwaffen und Rüstung 325 (448)

- als Stiere $319(430)$

- als Vögel 203 (154)

- als wilde Tiere $319(430), 322$ (440), 332 f. (470), 335 (477)

- als Wölfe 319 (430), 335 (477)

- Dämonentruppe (mit Gold, Edelsteinen, Perlen, Musikinstrumenten) 333 (472), $333 \mathrm{f}$. (473)

Diadem aus Edelstein mit Kreuz und Sternen $210 \mathrm{f}$. (173)

Dunkelheit $179(92[1]), 189(113[3])$, 293 (372), 297 f. (380)

\section{elektron $210(172)$}

Engel 175 (82), (als Soldat auf Pferd) 177 (90 [1]), 184 (103), 197 (135), 204 f. (159), 216 (188), (mit Messer) 216 f. (189), 217 f. (191, 192), (mit Fächer) 220 (198), (mit Schwert) 220 (200), 224 f. (212), 227 (218 [1-5]), 227 f. (220), (als Eunuch) 228 (221), 229 (223), 232 (230 [2]), (gleich einem Blitz, mit schneeweißem Kleid) 234 (234), 241 f. (252), 244 (259), 249 f. (265),
258 (292), 261 f. (303), (als

Mönchsbruder) 272 (320), 284

(350), 289 (360), 291 (366), (in

strahlendem Kleid) 292 (369), 295

(376), 304 (394, 395), 305 (398), 307

(404), (als Soldat des Stadtpräfek-

ten) $307 \mathrm{f}$. (405), 325 (448)

- Engel des Herrn (mit Feuerschwert) 194 (125), 207 (164), 218 (193), 224 (211), 246 (260), 251 $(269,271)$, (in Gestalt eines Soldaten) 251 (272 [1, 2]), $264 \mathrm{f}$. (307, 308), 273 (323), 278 (335), 279 (338 [1]), 280 (339), 283 (347), 290 (363), 292 (370), 294 f. (375), 297 f. (380), 302 (390), 304 f. (396), (mit

Feuerschwert) 320 (431), 326 (451)

- zwei Engel 180 (92 [3]), (in Leinen gekleidet, Pfeile und Bögen in der Hand) 185 (106 [3]), 215 (187), (mit Laternen) 220 (199), 230 (227 [1]), (weißgekleidet) 261 (302), 314 (422)

- drei Engel 210 (172), 249 f. (265)

- Gruppe von Engeln 207 (165)

- viele tausend luftige, feurige und sonnenähnliche Engel $258 \mathrm{f}$. (295)

- Armeen, Truppen von Engeln 158, 186 f. (109 [1, 2]), 203 (155), $210 \mathrm{f}$. (173), (als Eunuchen) 211 (176)

Ernte 178 (90 [3])

Erzengel $210 \mathrm{f}$. (173)

- Gabriel $210(172)$

- Michael 177 (89), (als Soldat) 178 (90 [3]), 210 (172), 258 f. (295)

Eunuch (kubikularios) $228 \mathrm{f.} \mathrm{(222)}$

Evangelium 182 (97), 186 f. (109), $315(425)$

- die vier Evangelien 258 (293)

Fackel, brennende $290(363$ [3])

Fels mit Podest 211 (174)

Feuer 220 (197), 250 (266), (göttlich) 291 (366), 297 f. (380)

- Feuerfluss 243 (256)

- Feuerkreis 179 (91)

- Feuerkugel, Feuerball 275 f. (331), 325 f. (450) 
- Feuersäule 216 (188), 222 (205), (von der Erde bis zum Himmel) 283 (348)

- Feuerschleier 217 (190)

- Feuersee 209 f. (170)

- Feuerstrahl 254 f. (280)

Fingerring 235 (239)

Firmament, mit Sonne, Mond, Sterne $189(113[3])$

Flügel 243 f. (257)

- Flügel aus Feuer 294 (374)

- schwache und kraftlose Flügel (374)

Fluss 179 (91), (voll Schlamm) 310 (410)

- Flussmündung ins Meer $199 \mathrm{f}$. (143)

- Jordan 188 (113[1])

Flüssigkeit, süß wie Honig, aussehend wie Öl $212 \mathrm{f}$. (179)

Freundesgestalt 307 f. (405)

Fundamente $180 \mathrm{f}$. (94)

Gebäudeplan 288 f. (362), 292 (370)

Gefängnis 189 (113[3]), 307 f. (405)

Gefäß

- Alabastergefäß, versilbert $212 \mathrm{f}$. (179)

- heiliges Gefäß 218 f. (195)

- mit Körper und Blut Christi 215 (186)

- mit Wasser gefüllt 240 (248), 273 (324)

- Holzgefäß 273 f. (327)

Geist, heiliger Geist (mit Messer in der Hand) 184 (106), (mit dem Finger zeigend) 189 (113[3]), 206 (162), (mit dem Finger zeigend) $209 \mathrm{f}$. (170), (die Hand wiegend) 187 (109 [3], 110), 218 (194), 275 f. (331)

Gericht 189 (113[3]), 209 f. (170), 233 (233), 239 (244), 257 (289), 307 f. (405)

- Gericht Christi 204 f. (159)

- Gericht Gottes 223 (209)

Geschenke 297 (379)

Gestalt, Gestalten 183 (100), 184 (102), 203 f. (156), 204 (157), 209 (170), 223 (207, 208), 226 (215),
265 f. (310), 267 f. (312), (in übermenschlich prachtvoller Kleidung) 268 (313), 283 f. (349), 284 (352), 285 f. (355), 288 f. (362 [2]), (mit leuchtenden Kleidern) 293 (372), (leuchtend wie die Sonne, mit Kreuz an der Stirn und Mantel tragend) 395 f. (377), 299 (383), (mit leuchtendem Gewand und furchterregenden Augen) 304 (394), 308 f. (406), (weißgekleidet) 312 (415), 313 (419)

- Gestalt des Firmaments mit Saphir auf dem Rücken $258 \mathrm{f}$. (295)

- zwei Unbekannte, Gestalten 238 (242), 273 f. (327)

- weißgekleidete Gestalt(en) 206 (161), 208 (168), 214 (183), 234 (235 [3])

Gewölbe, von Gott gewirkt 244 (258)

Glanz (der Heiligkeit) 210 f. (173), (Gottes) 239 (245)

Gnade Gottes

- als aufleuchtender Blitz 334 (474)

- als Jungfrau 334 f. (475)

- als Mensch von der Brust an aufwärts $259(295)$

- als Taube 334 (474)

Gott, Herr (allg.) 204 f. (159), 210 f. (173), 222 (206), 243 f. (257), 258 (292)

- Gottes Angesicht 239 f. (247)

- auf Thron sitzend $183 \mathrm{f}$. (99)

- Kraft Gottes 186 (109 [1]), 191 (118 [2])

- unsichtbarer Gott (aoratos theos) 162 (31)

Grab der heiligen Martha $257 \mathrm{f}$. (291), 310 (409)

Grube (dreckige) 179 (92 [1]), (graben)181 (94), (tiefe Grube) $247 \mathrm{f}$. (262 [3]), 293 f. (373), (goldene Grube) 305 (397), 311 (413), (geöffnete Erde) 331 (464)

- Grubenarbeiter 311 (413)

Hades 239 (246)

Hand (menschliche) 277 (332) 
Häretiker 299 (383)

Haus Gottes 177 (89)

Heerscharen, himmlische

Heiliger, heiliger Mann 302 f. (391), (wutentbrandt) 306 (402)

- Christophoros 255 (282)

- Euthymios 212 f. (179), 226 (216), (mit großem, graumeliertem Bart) 246 f. (261), (in gleißendem Glanz, weißhaarig, untersetzt vom Alter, mit großem Bart, kugelrundem Gesicht, schwarzem Umhang, mit Stab in der Hand) 247 f. (262 [3]), 248 (263), (bärtiger Mönch) $248 \mathrm{f}$. (264), 271 (318), 306 (401), (als von Licht umgebener, alter Mönch) $306 \mathrm{f}$. (403)

- Georgios 201 f. (152), (als wunderschöner Jüngling in leuchtendem Kleid, mit gekraustem, goldglänzendem Haar) 234 f. (236), (auf Pferd) 237 (240), 255 (281), (als Jüngling mit Umhang) 256 (285), (als Jüngling) 281 (343), (in der Gestalt des Märtyrers Stephanos, dann in der eigenen Gestalt) $281 \mathrm{f}$. (344, 345), 287 (358), 287 (359), (mit Schwert gegürtet) 317 (428), (mit Schwert) 335 (477, 478)

- Gruppe, Menge, Schar von Heiligen $188(113[3]), 225$ (213), 241 (251), 260 (297)

- Ioannes Eleemon $228 \mathrm{f}$. (222), 263 f. (306), 296 f. (378), 297 (379)

- Ioannes Hesychastes, in Engelsgestalt $220 \mathrm{f}$. (201)

- Ioannes der Täufer 213 (181), 269 (315), 280 f. (341), 291 (367), 300 (385), (in schneeweißem Kleid) 312 $(415,416)$

- Ioannes der Theologe 300 (385)

- Iulianos, Märtyrer 291 (368)

- Kosmas und Damianos $261 \mathrm{f}$. (303)

- Martha 221 (202), 229 (225), $242 \mathrm{f}$. (253), (als fromme Frau) 250 (266), (ehrwürdige Frau) 250 (267), $257 \mathrm{f}$. (291), 258 (292), 279 (338 [2]), (als strahlendes Kreuz) $288 \mathrm{f}$. (362 [1-5]), (mit leuchtendem Gesicht, inmitten von weißgekleideten Gestalten) $309 \mathrm{f}$. (408, 409)

- Nikolaos Sionites 310 (410)

- Nikon 303 (393)

- Petros, Hirte vom Jordan (als Asket mit kolobion und Binsenumhang über den Schultern) 285 (354)

- Prokopios von Rhodos 284 (351)

- Sabas 212 f. (179, 180), $213 \mathrm{f}$. (182), (als ehrwürdiger Greis) 274 (328), 278 (336)

- Sabinos (gerötetes Gesicht, Ausschlag auf den Wangen) 250 (268)

- Sion $176 \mathrm{f}$. (89)

- Stephanos 317 (428)

- Syemeon Salos 214 (183), $314 \mathrm{f}$. (422, 423)

- Symeon Stylites sen. 173 f. (75), 204 (157), 233 f. (234), (als alter Mann) 277 (332)

- Symeon Stylites iun. 189 (115), (als weißgekleideter Junge auf Wagen; herumfliegend; mit feuriger Säule in der Luft umherwandelnd) 184 (103), 188 f. (als langhaariger Mönch) (113 [3]), (als Knabe) $243 \mathrm{f}$. (257), (mit weißem Kleid; mit Feuerstab; als Jüngling mit leuchtendem Gewand; mit eisernem Stab und feurig roter Kette; mit Krone, über der ein Kreuz prangte, mit Sternen an der Stirn) 251-254 (270-280), (mit Palmstab) 258 (293-295), (als Jüngling mit Fellkleid und nackten Füssen; mit Palmstab und engelgleichem Gesicht; als langhaariger Mönch) $259 \mathrm{f}$. $(296,297)$, (in einer anderen Gestalt; auf weißem Pferd) 260 f. (300302), 274 (329), 288 f. (362 [2]), $315 \mathrm{f}$. (326), (wutentbrannt) $316 \mathrm{f}$. $(427[1,3])$

- Theodoros von Sykeon 256 (284, 285, 286)

- Theodoros (Palästina) $286 \mathrm{f}$. (357)

- Timotheos, Schüler des Paulus 213 (181)

- Prediger der Frömmigkeit und Kirchenlehrer 301 (388)

- Einsiedler, Hirte 285 (353) 
- toter Heiliger 197 (136), $227 \mathrm{f}$. (220)

Herrschaftssymbol 250 (267)

Himmel 204 f. (159), 236 (239), 239 (245), 241 (251), 244 (259), 258 (292)

- aufgerissen, geöffnet 158 (12), 180 (92 [3]), 185 (107), 186 (109 [2]), 191 (118 [2]), 210 (172), 258 f. (295)

- Himmel der Himmel 230 (227 [2])

- sieben Himmel 244 (258)

- Himmelstore 244 (259), 258 (292)

Hölle (allg.) 187 (109 [3]), 239 (244)

Holz

- dornige, splittrige Hölzer 179 (91)

- Holz des heiligen Kreuzes 181 (96)

- Holzhacken 293 f. (373)

- Holzschleppen 293 f. (373)

Honig $206 \mathrm{f}$. (163)

- Honigstab 214 f. (185)

Iberer (Georgier) 222 (204)

Ich (sich selbst sehen) $186 \mathrm{f}$. (109), 188 f. (113), 190 f. (118), 200 (147), 206 f. (163), 223 (208), 234 (235), 243 f. $(257,258), 247$ f. (262 [3]), 303 (392), 311 (413), 314 (422), $316 \mathrm{f}$. (427 [2]), 334 (475)

- ein Hirtengewand tragend und Herde weiden lassend; Krankheiten heilend, als Priester 159 f. (21)

- von Leitern herunterstürzend; erblindend und Mauern entlang tastend; Schiffbruch erleidend (bzgl. des monastischen Lebens) $\quad 160$ (21)

Jesus Christus 208 (167), 209 f. (170), 210 (172), 211 (174), 290 (363 [1])

- als Knabe 214 (184), 216 f. (189)

- am Kreuz 181 (96)

- zornig, auf Thron sitzend $186(109$ [2])

Junge Frau, heller als die Sonne leuchtend 205 (106)

Junge, Knabe (paidarion)
(sarazenischer, tanzender Knabe mit Korb) 332 (468)
Jungfrau Maria, theotokos 188 (113 [3]), 229 (225), 230 (227 [1]), 235 (239), 255 f. (283), 260 (297), 290 (364), (mit anderen Frauen) 300 (386), 312 (418)

- in Purpur gehüllte Frau 183 (99), 212 (177), 300 (385)

Jüngling (neoteros, neanias) (engelgleich, überaus groß, mit Dornenkrone) 180 (92 [3]), (über die Sonne hinausreichend) 208 (168), 261 f. (303), 272 (320), (wunderschön) 280 (340 [1, 2]), (von furchterregendem Anblick, in glänzendem Gewand) 317 f. (429)

- zwei Jünglinge (weißgekleidet) 204 (157)

- drei Jünglinge 204 (158), (schöne Jünglinge) 288 (361)

- fünf Jünglinge $306 \mathrm{f}$. (403)

Kandelaber 288 f. (362 [2])

Kerzen (einige angezündet, andere nicht) 208 f. (169), $228 \mathrm{f}$. (222), 229 (224), (angezündete) 257 (290)

Kessel, golden 305 (397)

Ketten 307 f. (405)

Kinder 225 (213), 265 (309)

Kirche 178 (90 [2]), 190 (117), 207 (165), 290 (363 [3], 364)

- Apsis 178 (90 [2])

- Kirche des Jason 230 (227 [1])

- Grabeskirche 303 (392)

Kloster $315(324)$

Kodex 312 (417)

König 205 (160), (von Leibgarde umgeben) 212 (177), 214 (183)

- himmlischer König 261 f. (303)

Königreich 239 (244)

Körper (tote, verwesene, in Stücke gerissene) $331(464)$

Kraftgestalt 214 f. (185)

Kranz 214 (183)

- Kranz aus Ölzweigen 205 f. (161), $228 \mathrm{f}$. (222)

- Siegeskranz 208 (168)

- goldglänzender Kranz mit Perlen 251 (271)

- drei Kränze $244(258)$ 
- sieben Kränze 203 f. (156)

Kreis $284(350)$

Kreuz 222 (204), 229 f. (226)

- Kreuz aus Gold und Silber 229 (225)

- steinernes Kreuz 211 (174)

- drei Kreuze $226(215)$

kukullion 247 f. (262 [3])

Lanzette (phlebotomon) $251(270)$

Lebensmittel

- Milch $240(248)$

- Brot 177 (90[1]), 271 (317)

- Gemüse 284 (350)

- Korn $315(425)$

- Oliven $272(320)$

- Reis $218 \mathrm{f}$. (195), 272 (320)

- Rizinusbeeren 256 (283)

- Trank 284 (350)

- unbekannte Speise, Nahrung 207 (165), 233 f. (234), 325 (448)

- Wasser 271 (317)

Leichnam 232 f. (231)

- eines Gerechten 231 (228), 288 (361)

- der heiligen Martha 257 (290)

Leiter 258 (292)

- an der Säule des Symeon $242 \mathrm{f}$. (253), 244 (259)

- sieben Leitern 244 (258)

Leprakranker 305 (397)

Leuchte, Lampe 229 (224), (zwei diskusförmige Leuchten) 267 (311), (feuerlodernde Leuchte) 288 f. (362 [2]), 293 (372), 297 f. (380)

Licht $177(89), 179(92[1,3]), 185$ (107), 194 (125), 210 (172), 258 (292), 258 f. (295), 281 (342), 297 f. (380), 320 (431)

- Lichtstraße 224 f. (212)

- von Licht erfüllter Ort 209 (170), 225 (213), 247 f. (262)

Löffel 218 f. (195)

Luft

- Lüfte $243 \mathrm{f}$. (257)

- himmlische Lüfte 230 (227 [1])

- Luft hinter dem Himmel 186 (109 [2])
Luftschiff mit wutentbrannten Engeln $187(109[3])$

Mädchen (hell wie die Sonne) $228 \mathrm{f}$. (222), (in weißem Gewand) 240 (248)

mandra 229 f. $(226,227$ [1])

Mann (in furchteinflößendem Gewand, so groß wie zwei Menschen) 233 f. (234), (in würdevollen Kleidern, Herrscher) 188 f. $(113[1,3])$, (weißgekleideter Mann, in härenem Gewand) 210 f. (173), 281 (342), (lichtdurchfluteter Mann) $232 \mathrm{f}$. (231), (strahlender alter Mann) 272 (321), (wunderschöner Mann) 301 (388), (weißgekleideter Mann) 312 (417), (ehrwürdiger Mann) $313 \mathrm{f}$. (421)

- zwei Männer (zwei weißgekleidete Männer) 208 f. (169), (Iannes und Iambre) $241 \mathrm{f}$. (252), (zwei Männer auf Pferden) 293 f. (373)

- drei Männer in leuchtender Kleidung $272(322)$

- vor Glück strahlende Männer 310 (409)

- unermessliche Menge von weißgekleideten Männern mit Fackeln 315 (324)

Maschine (mechane) mit Kopf und Flanken $230(227$ [2])

Maßband 292 (370)

Meeresufer, Meeresbrandung 156 (186), 256 (286), 294 (374)

Melodie 243 (254)

Mensch 293 f. (373), (arme Menschen) 315 (425)

Menschheit 158 (12)

Menschenmenge, Menschschar 243 (256), 273 (324), 293 (372), $297 \mathrm{f}$. (380)

- von Flehenden 183 (99)

- Iberer (Georgier) in Prozession 185 f. (107)

Mönch 309 (407)

- Mönche aus Palästina 190 (117)

- drei Mönche 294 (374)

- Gruppe von Mönchen 205 (160) 
Morgenröte 293 (372)

Muschel 238 (242)

Nestorianer 303 (392)

Ofen (Feuer-) 253 f. (279), (brennender Ofen) 312 (415)

Orte (unbekannt) 293 f. (373), 297 f. (380), (düsterer, stinkender und feuriger Ort) 299 (383), (leuchtender und strahlender Ort) 301 (388)

- Antiocheia 186 (109 [1]), 188 (113 [1]), (südliches Stadttor Richtung Seleukeia) 334 f. (475)

- Betlehem 197 (136), 227 f. (220)

- Jerusalem 186 (109[1]), $221 \mathrm{f}$. $(203,204)$

- Konstantinopel (Palast) 188 (113 [1]), $191(118[1,2])$

- Laodikeia 186 (109 [1])

- Seleukeia 187 (109 [3])

- Tyros 186 (109 [1])

Palast $230(227[1,2])$, (aus Licht) 244 (258)

Paradies $188 \mathrm{f} .(113[1,3]), 209 \mathrm{f}$. (170), 230 f. (227 [2]), 239 f. (247), 241 (251, [mit drei Quellen, großen Bäumen, allen Sorten von Früchten] 252), 244 (258), 260 (297)

Paradiesesfrüchte $241 \mathrm{f} .(251,252)$

Pergament, weißer als Schnee 210 (172)

Personen

- Euagrios Scholastikos 286 (356)

- Iakobos (Mönch) 232 f. (231)

- Mannas (silentiarios) 256 (286)

- Mönchsschüler 243 (256)

- Mutter eines Mönchsbruders (289)

Pflanzen 244 (258), 284 (350)

- Weinstock 203 (154)

Priester 215 (186)

- Ioannes (pneumatikos pater des Symeon Stylites jun.) 244 (259)

- Stephanos (Priestermönch) 313 (419)

Priestergewand $206(162)$
Quelle (von Wohlgerüchen) 244 (258), 284 (350)

Räuber am Kreuz 181 (96)

Rauch $180(93)$

Reiter 226 (217)

Reliquien von Märtyrern 231 f. (229)

Rhabdophoren 303 (392)

Richter 189 (113[3])

Riese (von fürchterlichem Anblick, bis zu den Wolken reichend) $247 \mathrm{f}$. (241), 240 (249)

Sarazene $225(213)$

Säugling 273 (324)

Säule, Säulen 173 f. (75), 209 (170), 297 f. (380)

- Säule des Symeon Stylites jun. 253 f. (279)

- Wolkensäule $204(157)$

- drei Säulen aus Licht 293 (371)

Schatten

- des heiligen Geistes 185 f. (108)

- einer Erscheinung 281 (342)

Schlagstock 306 f. (403)

Schleier $230(227[1])$

Schreiben 263 f. (306)

Schreibgeräte aus Silber und Gold $210(172)$

Schriftrolle 203 (155)

Schüler des Symeon Stylites jun. 250 (267)

Schwimmbecken 273 f. (327)

See $240(249)$

Seele $232(230[2]), 234(235[3]), 243$ (254)

- Seelen der Sünder 239 (246)

Seil, golden 305 (397)

Sichel 177 (90 [1])

Silbertaler 395 f. (377)

Sklave $326(451)$

Sonde 212 f. (179)

Sonne $221 \mathrm{f} .(203,204)$

Speisen, s. Lebensmittel

Stab 237 (240), 281 f. (345)

Staub, heiliger 253 f. (279) 
Stern $192(120,122), 219(196), 269$ f. Thron 173 f. (75), 183 (99), 186 (109 (316)

- Morgenstern $200 \mathrm{f}$. (148), $274 \mathrm{f}$. (330)

- in Form eines Lichtkreuzes 277 (334)

Stöcke, zwei 181 (95)

Szepter (goldenes) 228 (221)

[2]), 189 (113[3]), 203 f. (156), 206 (162), 229 f. (226), 240 f. (250)

- drei Throne 208 (168)

Tiere

- Adler(nest) 173 f. (75)

- Falke 173 f. (75)

- Gazelle 240 (248)

- Hund, schwarzer 335 (479)

Tartaros des Hades mit Dreizack (132)

Tautropfen 206 f. (163)

Tavli 314 (422)

Tempel 293 f. (373)

- des Marneion 182 (98)

Teufel, Satan, der Feind, Widersacher 195 (129), $224 \mathrm{f} .(212), 322$ (438), (zeigt Kloster und Kirche) 322 (439), (mit zweischneidigem Schwert) 327 (455), (mit Spaten) 331 (466), 333 f. (473, 474), 334 f. (475)

- als Äthiopier (als schamlos, mit grimmigem Gesichtsausdruck und blutunterlaufenen Augen) $244 \mathrm{f}$. (259), (nackt, Feuer aus den Augen schießend, mit Schlagstock) 330 (460)

- als Christus $321 \mathrm{f}$. (437), zeigt Christus 326 (452)

- als Engel des Lichts 170 (67), (Erzengel Gabriel) 321 (436)

- als Gerontios (Mitschüler des jungen Theodoros von Sykeon) 335 (478)

- in Gestalt einer Frau 319 (430)

- als schwarzer Knabe 319 (430), 334 (474)

- als Krähe 320 f. (431)

- als Löwe 319 (430), (fürchterlich, bedrohlich) 332 (369)

- als Mischwesen (halb Mensch, halb Esel) 320 (430)

- als Schlangen 332 (469), 334 (474)

- als Skorpione $332(469)$

- als Taube $320 \mathrm{f}$. (431)

Theater 208 (168)

theotokos, s. Jungfrau

196 - Katze $156(186)$

- Krokodil $179(91)$

- Leopardin 200 f. (148), 274 f. (330)

- Löwe 189 (115)

- Maultiere $172(71)$

- Pferd (weiß) 210 f. (173), 226 (217), (junges Pferd) 237 (240)

- Raubtier 188 (113[1])

- Schlange (feurig) 180 (93)

- Taube 177 (90 [1]), (weiße Tauben) 226 (215), 263 (304)

- Vogel 203 (154), 222 (206), 240 (249)

- Widder 300 f. (387)

- Wildschwein 189 (115), (groß, dreiköpfig und fürchterlich brüllend) 156 (186)

Tochter des Teufels (als unaussprechlich schöne Frau mit einer Schar von Dämonen) 329 f. (459)

Tor, Tür 293 f. (373)

Trage aus Holz 293 f. (373)

Triumphzug $188(113[1])$

Uferböschung $179(91)$

Verwandte, Angehörige (kranke bzw. Gefahren ausgesetzte) 160 (21)

Volk der Gerechten 209 f. (170)

Waage (eine Waagschale mit schwarzen, hässlichen Äthiopiern, die andere Waagschale mit Weißgekleideten) 395 f. (377 [1])

Wagen (mit den Tieren des Cherubim) 242 f. (253), (mit vier Rädern und vier weißen Pferden, gelenkt von drei schneeweiß gekleideten Männern) 258 f. (295) 
Wasser 178 (90 [2]), (überaus reines

Wasser) 305 (397)

- Wassergefäß, durchlöchert (373)

- Wasserschöpfen 293 f. (373)

Weg 293 (372), 297 f. (380), 315 (425)

- zwei Wege $310(409)$

Weihrauch 269 (315)

Wesen, geflügelte $247 \mathrm{f.}$ (241),

Wolke 211 (174)

- Lichtwolke 211 (174), 292 (370)
- Wolkenmeer, wie leuchtender Porphyrteppich 210 (172)

293 f. Würfel 314 (422)

Zelt in den Himmeln, nicht von Menschenhand geschaffen (acheiropoietos skene) 208 (168)

Zinnplättchen mit Einritzungen 248 f. (264) 


\section{Bibelstellenindex}

\section{Altes Testament}

\begin{tabular}{|c|c|c|c|}
\hline Gen 2,21 & 79 & Ps 53,5 & 170 \\
\hline Gen 3,14 & 133 & Ps 77,19 & $272(320)$ \\
\hline Gen 41,32 & 115 A. 562 & Ps 90,13 & $332(469)$ \\
\hline Gen 41,38 & 132 & Ps 118,103 & 128 \\
\hline Ex 3,4 ff.; 19; 20 & 98 A. 482 & Spr 27,$23 ; 21,12$ & 198 (139) \\
\hline Dtn 6,16 & $163(36)$ & Ez 1, 5-14 & $242(253)$ \\
\hline Dtn 28,28 & 88 & Ez 38 & 142 \\
\hline \multirow[t]{2}{*}{$\operatorname{Ri} 13,3$} & $264(307)$ & Dan, 4,19 & $157(8)$ \\
\hline & & Dan 9,23 & $238(241)$ \\
\hline \multirow[t]{2}{*}{1 Sam $3,1-8$} & 115 A. 562 & Dan 9,25 & 127 \\
\hline & & Dan 13,42 & $171(69)$ \\
\hline 1 Kön 9,19-20 & 198 (139) & & \\
\hline 2 Kön 5,27 & 147 & Joel 3,1 & 49 \\
\hline 4 Kön 1,9 & $194(124)$ & & \\
\hline 4 Kön 4,2; & 198 (139) & Sach 4,1 , & 66 \\
\hline Ps 13,1 & 306 f. (403) & Sir $34,1-6$ & 51 \\
\hline
\end{tabular}

Neues Testament

\begin{tabular}{|c|c|c|c|}
\hline Mt $2,1-2$ & 144 & Lk 1,22 & 104 A. 523 \\
\hline Mt 10,31 & 222 & Lk 2,10 & 118 A. 584 \\
\hline Mt $13,1-20$ & 125 & Lk 2,29 & $244(257)$ \\
\hline Mt 16,18 & $182(98)$ & Lk 8,9 & 26 \\
\hline Mt 17,15 & 91 & Lk 9,35 & 98 A. 482 \\
\hline Mt 17,22 & $172(71)$ & Lk 10,19 & $332(469)$ \\
\hline Mt 18,10 & $25 \mathrm{f}$ & Lk 21,34 & 55 \\
\hline Mt 22,12 f. & $238(242)$ & Lk 24,23 & 104 A. 523 \\
\hline Mt 22.21 & 139 & Lk 24,31 & $127,238(241)$ \\
\hline Mt 28,3 & 124 A. 611 & & \\
\hline \multirow[t]{2}{*}{ Mt $28,16-20$} & 115 A. 562 & Joh. 14,12 & 279 (338 [1]) \\
\hline & & Joh 14,31 & 279 (338 [1]) \\
\hline Mk 6,49 & 97 & Joh 15,1 & 131 \\
\hline Mk 9,2 ff & 124 A. 611 & Joh 20,15 & 97 \\
\hline Mk 9,14-29 & 91 & & \\
\hline $\mathrm{Mk} 15,17$ & 247 f. (262 [3]) & Apg 2,17 & 49 \\
\hline
\end{tabular}




$\begin{array}{llll}\text { Apg } 7,31 & 98 \text { A. } 482 & \text { II Kor 5,6 } & 77 \text { A. } 355 \\ \text { Apg 8,9-24 } & 134 & & \\ \text { Apg 8,23 } & 199(139) & \text { Gal 4,24, } & 123 \text { A. } 607 \\ \text { Apg 9,10; } 10,3 & 104,115 \text { A. } 562 & & \\ \text { Apg 10,10 f., } & 75 & \text { Eph 5,18 } & 55 \\ \text { Apg 12,9 } & 44,97 & \text { Eph 6.11 } & 319(430) \\ \text { Apg 14,8-10 } & 199 & \text { Eph 6,17 } & 184(106) \\ \text { Apg 16,9 } & 66 & & \\ \text { Apg 18,9 } & 66 & \text { I Thess. 5,17 } & 63 \\ \text { Apg 23,11 } & 66 & & \\ \text { Apg 26,19 } & 104 \text { A. 523 } & \text { I Tim 6,14 } & 132,171(69) \\ \text { Apg 27,23 } & 66 & \text { II Tim 4,7 } & 132,171(69) \\ \text { I Kor 2,12 } & 77 \text { A. 354 } & & \\ \text { I Kor 12,4 } & 20 & \text { I Petr 5, } 8 & 308 \text { f. (406) } \\ \text { I Kor 12,8-10 } & 170 \text { A. 570 } & & \\ \text { I Kor 12,10 } & 148 & \text { Offb 9,17 } & 104 \text { A. 522 } \\ \text { I Kor 14,24 } & 148 & & \end{array}$

